Changing by Degrees: Steps To Reduce Greenhouse Gases

February 1991

OTA-O-482

NTIS order \#PB91-163428

\section{Changing BY DEGREDS}

\section{STEPS TO REDUCE GREENHOUSE GASES}

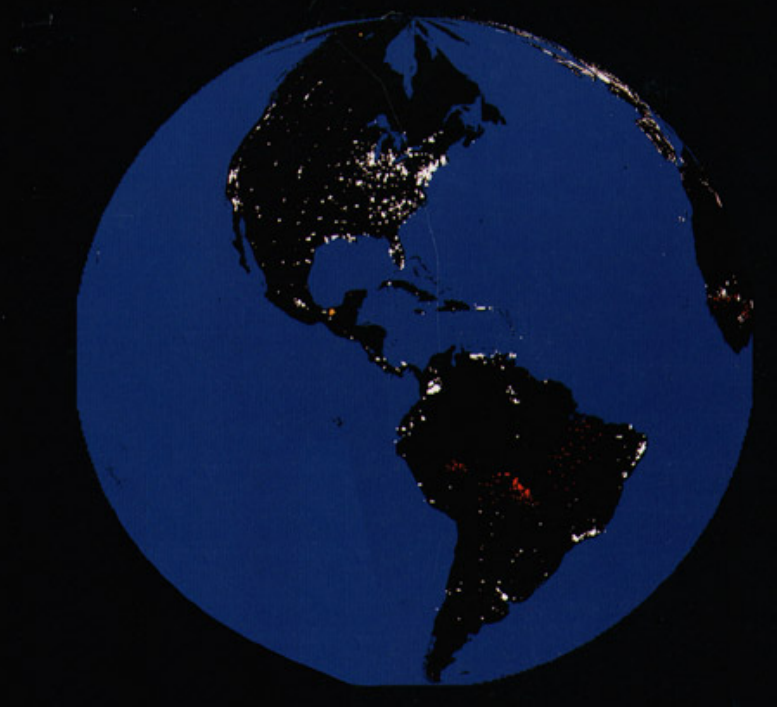

CONGRESS OF THE UNITED STATES OFFICE OF TECHNOLOGY ASSESSMENT 


\section{Recommended Citation:}

U.S. Congress, Office of Technology Assessment, Changing by Degrees: Steps To Reduce Greenhouse Gases, OTA-O-482 (Washington, DC: U.S. Government Printing Office, February 1991).

For sale by the Superintendent of Documents

U.S. Government Printing Office, Washington, DC 20402-9325

(order form can be found in the back of this report) 


\section{Foreword}

Our Nation has a history of people working towards common goals. It has demonstrated this in time of war, in landing a man on the moon, and in reducing energy use during the oil crises of the 1970s. However, in each case, the effort was sustained less than a decade; the desired goals were achieved or the crises passed.

The United States is the world's leading industrial society and largest single emitter of carbon dioxide. Climate change therefore presents a unique challenge to this Nation. It is a threat that will require major prudent political actions even before all the scientific certainties are resolved. The analysis, prevention, and remediation of global warming will require unprecedented international cooperation and action - an effort requiring actions sustained over decades, not just a few years.

Carbon dioxide and chlorofluorocarbon (CFC) emissions are responsible for 80 percent of the "global warming commitment" caused by human activities over the last decade. A landmark international agreement to totally phase out the use of CFCs by the year 2000 is already in effect. Many of the nations involved in that accord are now seeking ways to reduce the carbon dioxide emissions. This task is clearly more daunting since most industrialized nations currently depend so heavily on fossil fuels - the major source of carbon dioxide-for their economic well-being.

For this reason, this assessment focuses principally on ways to cut carbon dioxide emissions both in the United States and in other countries as well, although it does examine all greenhouse gases. The report responds to the concerns of six Committees of Congress who requested in 1988 that OTA undertake this study. The Senate requesting Committees are: Commerce, Science, and Transportation; Energy and Natural Resources; Environment and Public Works; and Governmental Affairs. The House requesters are: Committee on Science, Space, and Technology; and the Committee on Foreign Affairs.

This assessment shows that major reductions of carbon dioxide and other greenhouse gases will require significant new initiatives by the Federal Government, by the private sector, and by individual citizens. Many of these initiatives will pay for themselves; for others, the economic cost may be considerable. And many of these efforts must be sustained over decades.

Although many ancillary environmental benefits will accrue from the actions necessary to effect a major reduction of U.S. carbon dioxide emissions, such a decrease will not, in itself, significantly decrease the greenhouse effect. Other nations will have to take similar actions and, even then, those actions will only slow any warming trend. An Intergovernmental Panel on Climate Change and the U.S. Environmental Protection Agency estimated that at least a 50- to 80-percent worldwide reduction in carbon dioxide emissions is needed to keep the atmosphere at today's already altered level.

That level of reduction requires the world to wean itself from fossil fuels if it hopes to keep emissions from growing steeply under the combined pressure of economic and population growth. Steps taken now to use more efficient energy technologies would reduce emissions while buying time required for the transition to nonfossil fuels.

OTA appreciates the support this effort received from hundreds of contributors both from the United States and abroad. Workshop participants, reviewers, contractors, and informal advisers provided OTA invaluable support as it attempted to sift through the voluminous material on this subject. OTA, however, remains solely responsible for the contents of this report.

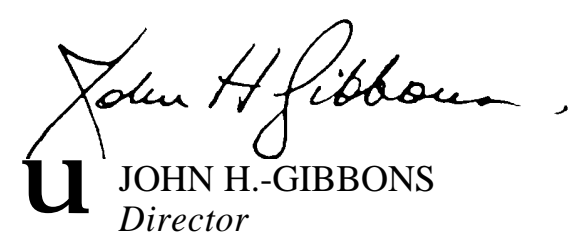




\title{
Changing By Degrees: Steps To Reduce Greenhouse Gases OTA Project Staff
}

John Andelin, Assistant Director, OTA

Science, Information, and Natural Resources Division

Robert Niblock, Oceans and Environment Program Manager

\author{
Rosina M. Bierbaum, Project Director \\ Robert M. Friedman, Senior Associate \\ Howard Levenson, Senior Associate \\ Richard D. Rapoport, Analyst \\ Nick Sundt, Analyst
}

\section{Research Assistants}

Jennifer H. Cohen

Stanislav F. Kolar

Other Contributors

David Festa

Susan Kulakowski

Mark Pastore

Dan Schechter

Eric Washburn

Fred Wood

\author{
Gretchen Kolsrud \\ Jana Milford \\ Linda Sawyer \\ Rhodri Walters \\ Frances Wood \\ Andrew Wyckoff
}

\section{Contractors}

Susan Wintsch, Editor

Battelle, Pacific Northwest Laboratories

Enterprise Development International, Inc.

Murray Feshbach

International Resources Group, Ltd.

Don Kash

Vicki Norberg-Bohm

Pacific Institute (SIDES)

Edward A. Parson

Princeton University

University of Washington

Michael P. Walsh

\section{Administrative Staff}

Kathleen A. Beil

Sally W. Van Aller 


\section{Assessment Advisory Groups}

\section{Advisory Group on Buildings}

Fred Abel

Senior Economist

Office of Building Technologies

U.S. Department of Energy

Edward Baily

Vice President

Government and Industry Relations

Carrier Corp.

Douglas C. Bauer

Senior Vice President

ERC Environmental \& Energy Services Co.

G.Z. Brown

Professor of Architecture

Department of Architecture

University of Oregon

William Chandler

Director, Advanced International Studies Unit

Battelle, Pacific Northwest Laboratories

Armond Cohen

Senior Attorney

Conservation Law Foundation

Drury Crawley

Senior Research Scientist

Pacific Northwest Laboratories

Daniel Dreyfus

Strategic Analysis/Energy Forecasting

Gas Research Institute

Ezra Ehrenkrantz

President

The Ehrenkrantz Group

Dave Engel

Deputy Division Director

Technology and Research Division

U.S. Department of Housing and

Urban Development

Charles Field

Staff Vice President

National Association of Home Builders

Howard Geller

Associate Director

American Council for an Energy-Efficient Economy

Jim Gross

Deputy Director

Center for Building Technology

National Institute of Standards and Technology
Erik Haites

Principal

Barakat \& Chamberlain

Cheryl Barrington

Commissioner

Maine Public Utilities Commission

Michael Joroff

Director, Laboratory of Architecture and Planning

Massachusetts Institute of Technology

Henry Kelly

Senior Associate

Office of Technology Assessment

David MacFadyen

President

NAHB National Research Center

Alan Miller

Director

Center for Global Change

University of Maryland

John P. Millhone

Deputy Assistant Secretary

Office of Building Technologies

U.S. Department of Energy

Ronald Morony

Director, Innovative Technology and Research

U.S. Department of Housing and

Urban Development

Brad W. Oberg

Program Manager

New Systems Laboratory

USG Corp.

Bill Prindle

Senior Program Manager

Alliance to Save Energy

Art Rosenfeld

Director, Center for Building Science

Lawrence Berkeley Laboratory

John Scalzi

Program Director, Structures and Building Systems

National Science Foundation

John Slayter

Director of Research and Engineering

The Ryland Group

NOTE OTA appreciates and is grateful for the valuable assistance and thoughtful critiques provided by the advisory group members. The groups do not, however, necessarily approve, disapprove, or endorse this report OTA assumes full responsibility for the report and the accuracy of its contents 
Peter Smeallia

Director, Geotechnical Board

National Research Council

Bill Staubitz

Manager Marketing Development

Sylvania Corp./GTE

Mary Tucker

Acting Manager, Energy Program

City of San Jose, CA
Steven Winter

President

Steven Winter Associates, Inc.

Richard Wright

Director

Center for Building Technology

National Institute of Standards and Technology

\section{Advisory Group on Industry}

John Barker

Vice President, Energy Affairs

ARMCO Inc.

Deborah Bleviss

Executive Director

International Institute for Energy Conservation

Kenneth Burgess

Vice President

Dow Chemical Co.

William Chandler

Director, Advanced International Studies Unit

Battelle, Pacific Northwest Laboratories

Thomas J. Gross

Director, Improved Energy Productivity

U.S. Department of Energy

Hillard G. Huntington

Senior Research Associate

Energy Modeling Forum

Stanford University

Martin Klepper, Esq.

Partner

Skadden Arps

Paul Leiby

Economist

Oak Ridge National Laboratory

Alastair McKechnie

Chief, Energy Efficiency and Strategy Unit

Industry and Energy Department

World Bank

Jeremy Metz

Director, Energy, Materials, and Technology

American Paper Institute
Steve Rayner

Coordinator, Policy, Energy and

Human Systems Analysis

Center for Global Environmental Studies

Oak Ridge National Laboratory

Joe Roop

Staff Scientist

International Energy Agency

Organization for Economic Cooperation

\& Development

Marc Ross

Professor

Physics Department

University of Michigan

Irv Snyder

Director, Research and Development

Dow Chemical Co.

Jack Vanderryn

Agency Director for Energy and Natural Resources

Bureau for Science and Technology

U.S. Agency for International Development

Ronald Wishart

Vice President for Public Affairs

Union Carbide Corp.

James Wolf

Executive Director

Alliance to Save Energy

Erie Young (retired)

Vice President of Environment and Energy

Environmental and Energy Department

American Iron and Steel Institute 


\section{Advisory Group on Energy Supply}

Stanley R. Bull

Director, Solar Fuels Research Division

Solar Energy Research Institute

William Chandler

Director, Advanced International Studies Unit

Battelle, Pacific Northwest Laboratories

David Choengold

Bureau Director, Systems Planning

Wisconsin Public Service Commission

Joel Darmstadter

Senior Associate

Resources for the Future

William Fulkerson

Director, Energy Division

Oak Ridge National Laboratory

Michael German

Senior Vice President

American Gas Association

Connie Holmes

Senior Vice President for Policy Analysis

National Coal Association

Don Kash

Director

Science and Public Policy Program

University of Oklahoma, Norman

Daniel Lashof

Environmental Scientist

Natural Resources Defense Council

Doug McDonald

Economist

American Petroleum Institute
Joan Ogden

Research Professor

Center for Environmental and Energy Studies

Princeton University

Rajat Sen

Professional Senior Scientist

Battelle, Pacific Northwest Laboratories

Fred Sissine

Analyst, Science and Technology

Congressional Research Service

The Library of Congress

Angelo Skalafuris

President

Modular Cogeneration Corp.

Jim Sullivan

Director, Office of Energy

Bureau for Science and Technology

U.S. Agency for International Development

Alvin M. Weinberg

Distinguished Fellow

Institute for Energy Analysis

Chris Whipple

Manager, Risk Communication

Electric Power Research Institute

Robert H. Williams

Research Professor

Center for Environmental and Energy Studies

Princeton University

NOTE: OTA appreciates and is grateful for the valuable assistance and thoughtful critiques provided by the advisory group members. The groups do not, however, necessarily approve, disapprove, or endorse this report, OTA assumes full responsibility for the report and the accuracy of its contents. 


\section{Advisory Group on Developing Countries}

Robert H. Annan

Staff Director

Committee on Renewable Energy, Commerce and Trade

U.S. Department of Energy

Mark Bernstein

Director

Center for Energy and the Environment

University of Pennsylvania

James H. Caldwell

Independent Consultant

David Curry

Acting Director

Office of Regional and Resources Policy

U.S. Department of the Treasury

Ghazi Darkazalli

Vice President of Photovoltaics

Spire Corp.

Robert Ford

Foreign Affairs Officer

Office of Global Change

U.S. Department of State

Les Garden

International Trade Specialist for Renewable Energy

U.S. Department of Commerce

Michael Greene

Associate Director

Board on Science and Technology in Development

National Academy of Sciences

Erik Helland-Hansen

Principal Technical Advisor

Bureau of Program Policy and Evaluation

United Nations Development Programme

David Jhirad

Senior Energy Advisor

Office of Energy

U.S. Agency for International Development

Linda Ladis

Director of Programs

U.S. Export Council for Renewable Energy

Mark Levine

Program Leader

International Energy Studies

Lawrence Berkeley Laboratory

Frances Li

Acting Director

Office of Global Change

U.S. Department of State
Janice Mazer

Major Projects Officer

U.S. Department of Commerce

Mohan Munasinghe

Division Chief

Brazil Energy and Infrastructure Operations Division

World Bank

D. Lou Peoples

Vice President \& Manager of Marketing and Strategy

Bechtel Power Corp.

Paul Schwengels

Senior Analyst

Air Economics Branch

U.S. Environmental Protection Agency

Joseph Sedlak

Director of Domestic Programs

Volunteers in Technical Assistance

James Sullivan

Director, Office of Energy

Bureau for Science and Technology

U.S. Agency for International Development

Franklin Tugwell

Project Director, Biomass Energy

Winrock International Institute for Agricultural

Development

Jack Vanderryn

Director, Energy and Natural Resources

Bureau for Science and Technology

U.S. Agency for International Development

Frank Vukmanic

Director, Office of Multilateral Development Banks

U.S. Department of the Treasury

Timothy Weiskel

Warren Weaver Fellow

Rockefeller Foundation

Gerald T. West

Vice President for Development

Overseas Private Investment Corporation

Thomas Wilbanks

Corporate Fellow and Senior Planner

Oak Ridge National Laboratory

John W. Wisniewski

Vice President for Engineering

Export-Import Bank 


\section{Advisory Group on Transportation}

Alvin Alm

Vice President

Science Applications International Cm-p.

Clark Bullard

Director, Office of Energy Research

University of Illinois, Urbana

Roger Carlsmith

Director

Conservation and Renewable Energy Program

Oak Ridge National Laboratory

William Chandler

Director, Advanced International Studies Unit

Battelle, Pacific Northwest Laboratories

Robert Dewey

Associate

Center for Auto Safety

Carmen Difiglio

Deputy Director

Office of Policy Integration

U.S. Department of Energy

Nick Fedoruk

Director

Energy Conservation Coalition

Helen Kahn (retired)

Formerly with Automotive News

Richard L. Klimisch

Executive Director, Environmental Activities Staff

General Motors Technical Center
David Kulp

Manager

Fuel Economy Planning and Compliance

Ford Motor Co.

Robert Maxwell

Director, Certification Division

U.S. Environmental Protection Agency

Barry McNutt

Policy Analyst

U.S. Department of Energy

Harriet Parcells

Transportation Associate

National Association of Railroad Passengers

Marc Ross

Professor

Physics Department

University of Michigan

Maxine Savitz

Director

Garrett Ceramic Components

Jim Scott

Director, 2020 Project

National Academy of Sciences

NOTE: OTA appreciates and is grateful for the valuable assistance and thoughtful critiques provided by the advisory group members. The groups do not, however, necessarily approve, disapprove, or endorse this repor. OTA assumes full responsibility for the report and the accuracy of its contents. 


\section{Contents}

Chapter Page

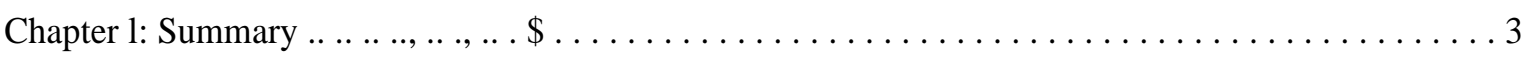

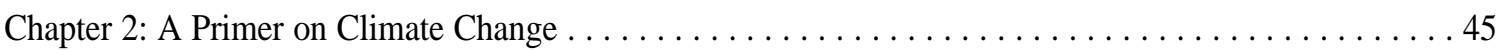

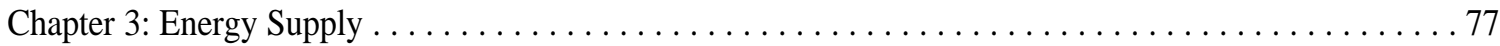

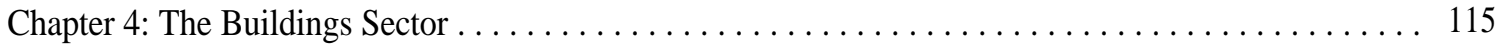

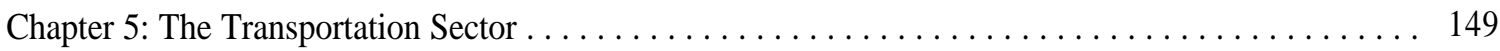

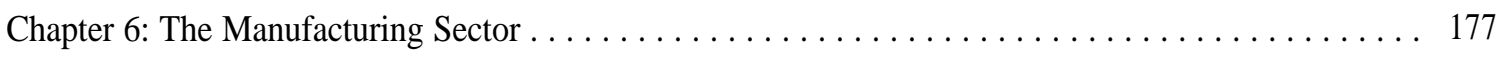

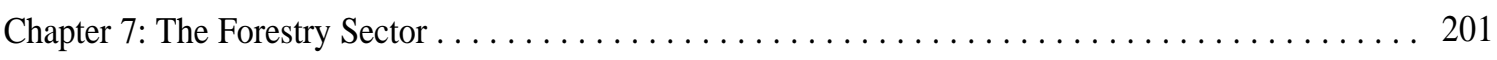

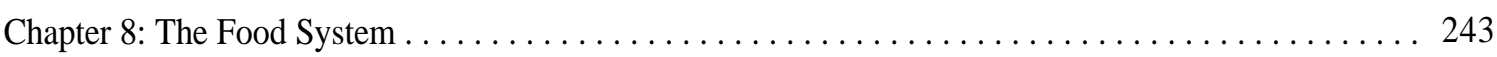

Chapter 9: International Dimensions: U.S. Influence and Regional Trends . . . . . . . . . 273

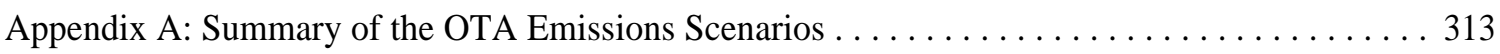

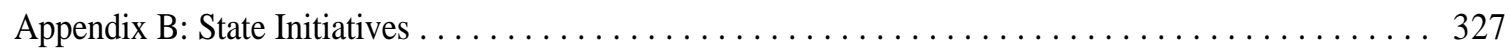

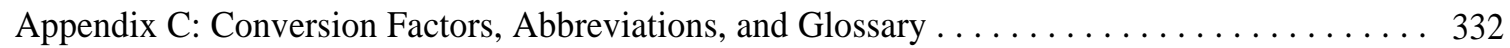

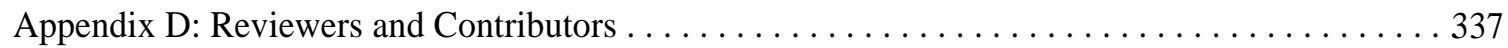

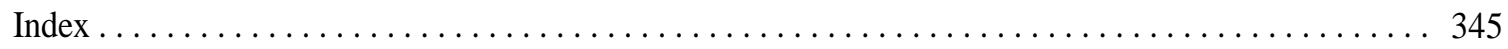




\section{Chapter 1}

\section{Summary}
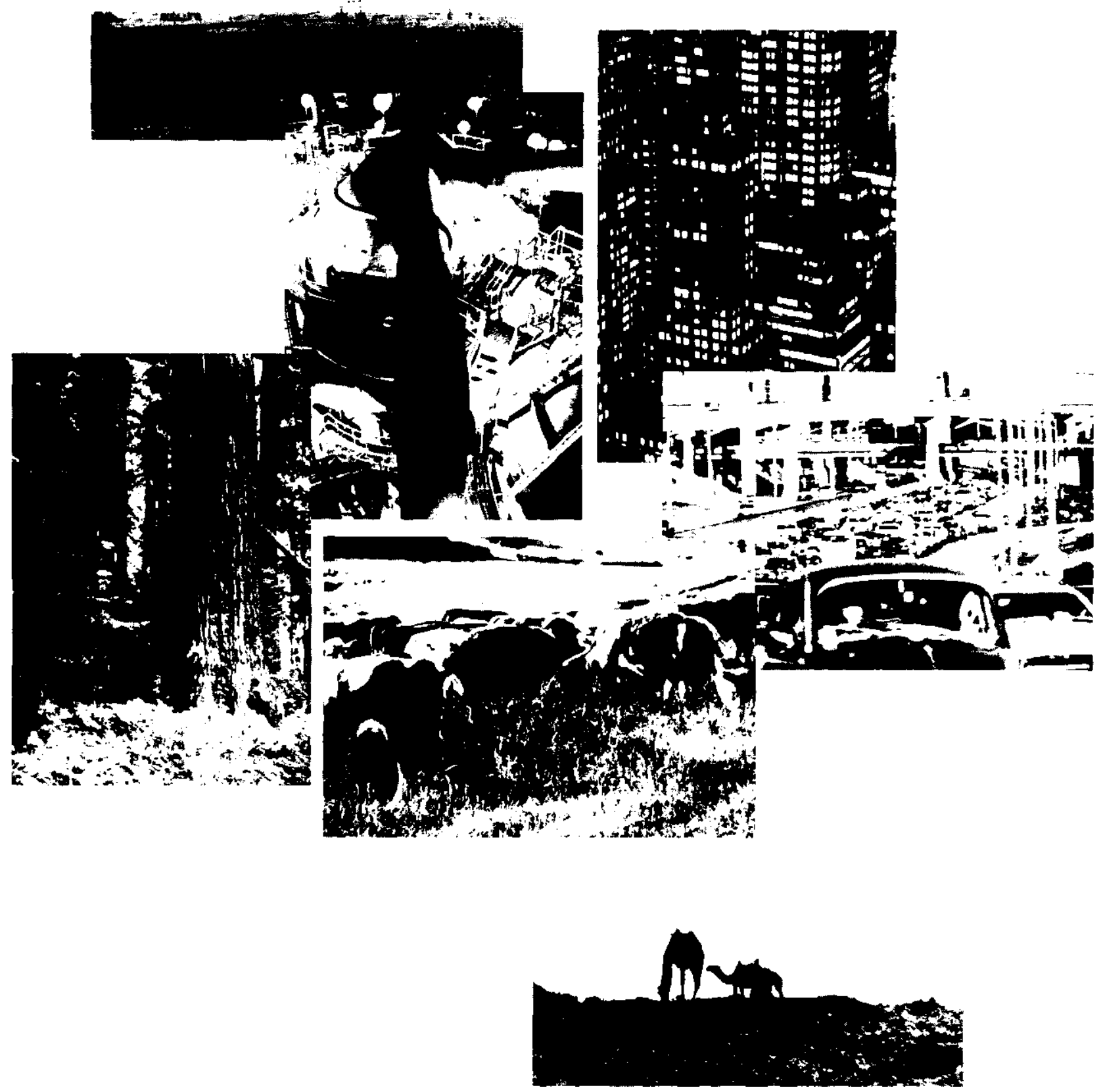


\section{CONTENTS}

Page

CLIMATE CHANGE AND GREENHOUSE GASES . . . . . . . . . . . . . . . 3

U.S. SECTORAL ANALYSES AND PROJECTIONS OF C0 ${ }_{2}$ EMISSIONS $\ldots \ldots \ldots \ldots 7$

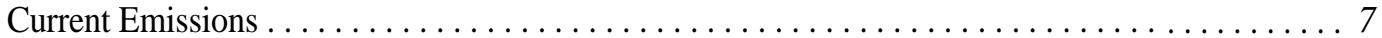

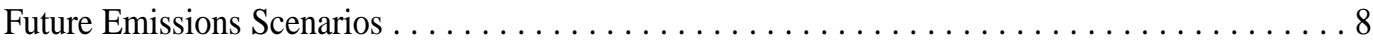

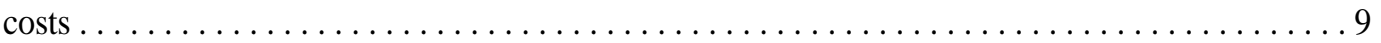

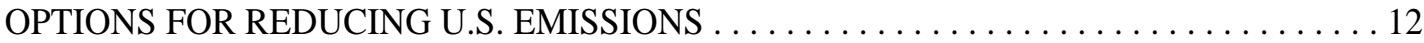

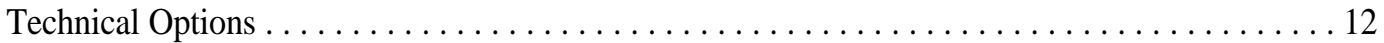

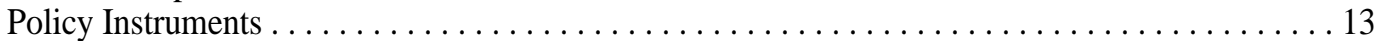

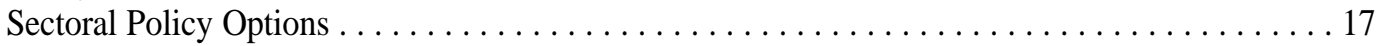

U.S. INFLUENCE ON THE REST OF THE WORLD . . . . . . . . . . . . . . 31

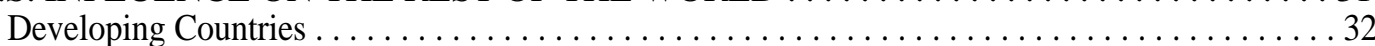

U.S.S.R. and Eastern Europe . . . . . . . . . . . . . . . . . . . . . . . . . . . . . . . . 33

U.S. Policy Options To Help Limit Greenhouse Gas Emissions Abroad . . . . . . . . . . . 33

CONCLUDING REMARKS . . . . . . . . . . . . . . . . . . . . . . . . . 40

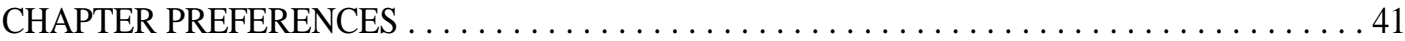

\section{Boxes}

Box Page

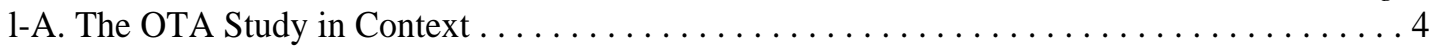

l-B. The OTA $\mathrm{CO}_{2}$ Emissions Reduction Model ..................... 10

1-C. Agencies and Organizations That Can Influence Greenhouse Emissions Abroad . . 35

Figures

Figure

Page

1-1. Greenhouse Gas Emissions in 1985, by Region, and the Contribution of Each Greenhouse Gas to Global Warmingin the 1980s . . . . . . . . . . . . . . . . 5

1-2. Summary of OTA's Analysis of Carbon Emissions With and Without

"Moderate" and "Tough" Controls ........................... 6

1-3. U.S. Energy Consumption and Associated Carbon Emissions in 1989 . . . . . . . . . 7

1-4, 1987 U.S. Co Emissions by Sector . . . . . . . . . . . . . . . . . . . . . . . . . . 8

1-5. Carbon Emissions Under the Base Case, Moderate, and Tough Scenarios . . . . . . . 9

1-6. Federal Government Funding for Energy Supply R\&D, 1980 to 1990 . . . . . . . . . . 16

1-7. Demand-Side Measures . . . . . . . . . . . . . . . . . . . . . . . . . . . . . . . . . . . . 17

1-8. Electric Utility Supply-Side Measures . . . . . . . . . . . . . . . . . . . . . . . . . . . 25

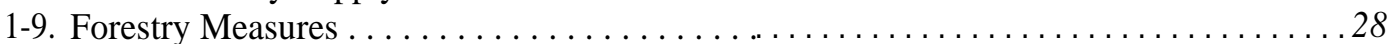

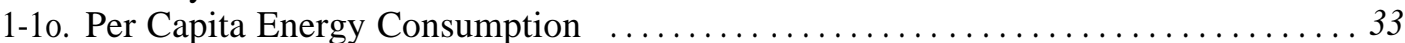

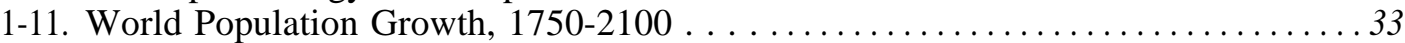

Tables

Table

Page

1-1. Measures To Lower U.S. Carbon Emissions $\ldots \ldots \ldots \ldots \ldots \ldots \ldots \ldots \ldots \ldots \ldots \ldots \ldots$

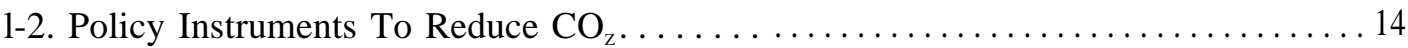




\section{CLIMATE CHANGE AND GREENHOUSE GASES}

The first photographs from space brought home the fact that Earth is an integrated and isolated system. Concern that human impacts could be changing the equilibrium of this system grew in the 1970s as theories about ozone depletion and the ' greenhouse effect developed. The concept of the Earth changing over various time scales was not new: solar and astronomical cycles, the waxing and waning of ice ages, and seasonal changes have long been recognized. What was new was the realization that humans can have a lasting and far-reaching impact on Earth's natural fluctuations and cycles.

Potential human impacts on climate are linked to the globally increasing emission of "greenhouse gases' "through activities such as burning fossil fuels (coal, oil, natural gas); deforestation; fertilizing croplands; and heating, air-conditioning, and lighting buildings. Greenhouse gases, like other atmospheric gases, allow sunlight to reach and warm the Earth's surface; unlike other atmospheric gases, however, they trap much of the heat and keep it from escaping back into space. Such gases, therefore, aid in warming the surface of the Earth. Some of them-the chlorofluorocarbons (CFCs) and halonsalso react with sunlight in the upper atmosphere to destroy the ozone layer around the Earth. In industrialized countries, greenhouse gas emissions are primarily related to energy use; with only 20 percent of the world population, these countries account for 75 percent of annual energy use, In developing countries, current greenhouse gas emissions are tied primarily to changes in land use practices (e.g., deforestation).

We cannot yet predict the magnitude of climatic effects from greenhouse gas emissions with accuracy. But it is clear that the decision to limit emissions cannot await the time when the full impacts are evident. The lag time between emission of the gases and their full impact is on the order of decades to centuries; ${ }^{2}$ so too is the time needed to reverse any effects. Today's emissions thus commit the planet to changes well into the 21 st century. And the lag times between identification of policy options, legislation of controls, and actual implementation can also be considerable. For example, the recent reauthorization of the Clean Air Act took 10 years; implementation of the Act will begin now and continue over the next 10 to 20 years.

Among individual countries, the United States is the leading contributor of greenhouse gases. With 5 percent of the world's population, the United States accounts for about 20 percent of the worlds warming commitment (ref. 56; see figure 1-la). U.S. $\mathrm{CO}_{2}$ emissions (20 percent of the global total) originate almost exclusively from fossil fuel combustion. Anthropogenic sources of methane in the United States account for about 6 percent of global emissions from all sources; among the anthropogenic sources, landfills, coal mining, and domestic animals account for most of the U.S. total $(2,24)$. The United States also consumes between 20 and 30 percent of the world'sCFC-11 and CFC-12, the two most damaging chlorofluorocarbons in terms of global warming. Roughly 60 to 70 percent of these CFCs are used in air-conditioning or in the production of thermal insulation; these gases are scheduled to be phased out by the year 2000 under the revised Montreal Protocol. U.S. nitrous oxide emissions (roughly 15 to 20 percent of the manmade global total; refs. 6,24 ) originate primarily from fertilizer breakdown and high-temperature fossil-fuel combustion. Greenhouse gas emissions are closely entwined in the United States with energy use; currently, America uses about 15 times more energy per person than does the typical developing country.

The warming commitment or "radiative forcing caused by the different greenhouse gases is not equal. It depends on the absorbing characteristics, concentration in the atmosphere, and the lifetime of each gas. Although the other gases are more potent on a per molecule basis, currently $\mathrm{CO}_{2}$ accounts for

\footnotetext{
${ }^{2}$ The atmospheric lifetime of $\mathrm{CO}_{2}$ is 50 to 200 years; $\mathrm{N}_{2} 0$, about 150 years; $\mathrm{CFCs}$ and halons, from 60 to 400 years; and $\mathrm{CH}_{4}, 10$ years. $\mathrm{CFC}$ replacements allowed under the Montreal Protocol for the next several decades have lifetimes of less than 40 years,

${ }^{3}$ The U.S. Department of Energy (DOE) found that of an 18-percent reduction in residential energy use between 1972 and 1984, one-third was due to behavioral changes (53).
} 


\section{Box l-A-The OTA Study in Context}

The six congressional committees requesting this assessment asked OTA to focus on a very specific question: "Can the United States reduce carbon dioxide emissions in the near term?"

Changing by Degrees does not examine in depth many equally difficult questions such as the science of climate change, the uncertainties and state of atmospheric modeling, or the projected ecological effects of global warming. Rather, most of OTA's resources have been devoted to analyzing technical options to decrease $\mathrm{CO}_{2}$, although methane, nitrous oxide, and chlorofluorocarbon (CFC) emissions are addressed wherever possible. At the time of their request, the congressional committees were well aware of ongoing international efforts to phase out CFCs and halons; since OTA's study began, successful negotiations have been completed.

To answer the question Congress posed, OTA focuses specifically on potential emissions reductions in the next 25 years. The analysis is structured around six key sectors of the U.S. economy: Buildings, Transportation, Manufacturing, Energy Supply, Forestry, and Food. To the extent possible, the report quantifies the potential for emissions reduction within each sector-areas where gains in efficiency, product substitution, conservation, or other technical options can ameliorate increases in $\mathrm{CO}_{2}$ and other greenhouse gases. A selection of policy options that appear to offer the most promise for achieving these reductions in the United States is presented. OTA was charged to look abroad as well, so the special needs of Eastern Europe, the U. S. S. R,, and developing countries-with respect to both energy and natural resource issues-are also addressed.

In our detailed analysis of potential emissions reductions for the United States, we consider an extensive suite of technical options. For example, we estimate the potential increments of $\mathrm{CO}_{2}$ reduction from electric utility fuel switching, possible improvements in automobile efficiency, changes in commercial building construction, more efficient manufacturing processes, etc. Most of the options relate to decreasing emissions, although some, such as reforestation, involve recapturing gases already emitted to the atmosphere.

The assessment lays out three paths: a Base case ("business as usual"), a Moderate (essentially "no-cost") case, and a Tough case. Only the last fulfills the congressional request and reduces future $\mathrm{C}_{2}$ emissions - to a level in 2015 that is 20 to 35 percent lower than today. Some will argue that our estimates of emissions reductions are both politically unattainable and costly. Others will decry a 20-to 35-percent reduction as not being nearly enough; the Intergovernmental Panel on Climate Change and the U.S. Environmental Protection Agency recently estimated that the world must reduce $\mathrm{CO}_{2}$ emissions by at least 50 to 80 percent to stabilize the atmosphere. Congress' request that we work within a 25-year timeframe in the study proved to be a two-edged analytic sword. It forced OTA to take a close look at where U.S. $\mathrm{C}_{2}$ emissions were heading without policy intervention. But, 25 years also is too short a period to include a scenario in which fossil fuels are supplanted with such nonfossil fuel sources as renewable and improved nuclear energy sources.

Indeed, the United States described 25 years hence in this report does not sound fundamentally different from what we know today. However, an underlying theme in OTA's report is that a strong R\&D effort is pivotal to bringing non- $\mathrm{CO}_{2}$ (i.e., nonfossil fuel) sources to commercialization as quickly as possible, even as all sectors of the economy move to use more efficient equipment and decrease energy consumption. If long-term R\&D is geared to that purpose, then new nonfossil supply technologies can start to replace existing powerplants and equipment early in the next century.

Many of the technical options evaluated here are worth pursuing for other reasons in addition to climate change, because they address other important U.S. goals such as energy security, local environmental quality, and economic competitiveness. They can reduce emissions in the short-term, reduce total energy demand, and serve to bridge the U.S. economy from a fossil-fuel age to a nonfossil future.

The warming commitment or " radiative forcing' caused by the different greenhouse gases is not equal. It depends on the absorbing characteristics, concentration in the atmosphere, and the lifetime of each gas. Although the other gases are more potent on a per molecule basis, currently $\mathrm{CO}_{2}$ accounts for an estimated 55 percent of the commitment to global warming. This is largely due to the fact that so much $\mathrm{CO}_{2}$ has been emitted worldwide (6 billion metric tons of carbon in 1988) as to swamp the higher radiative forcings per unit of the other gases (24). Still, CFCs are responsible for 24 percent of the current commitment to global warming; $\mathrm{CH}_{4}$ is responsible for 15 percent and $\mathrm{N}_{2} \mathrm{O}$ for 6 percent (see figure $1-1 b)$.

Recently, public interest and concern over global changes intensified with the discovery of the annual ozone hole over Antarctica, thinning ozone over the 
Figure I-I-Greenhouse Gas Emissions in 1985, by Region, and the Contribution of Each Greenhouse Gas to Global Warming in the 1980s

a.

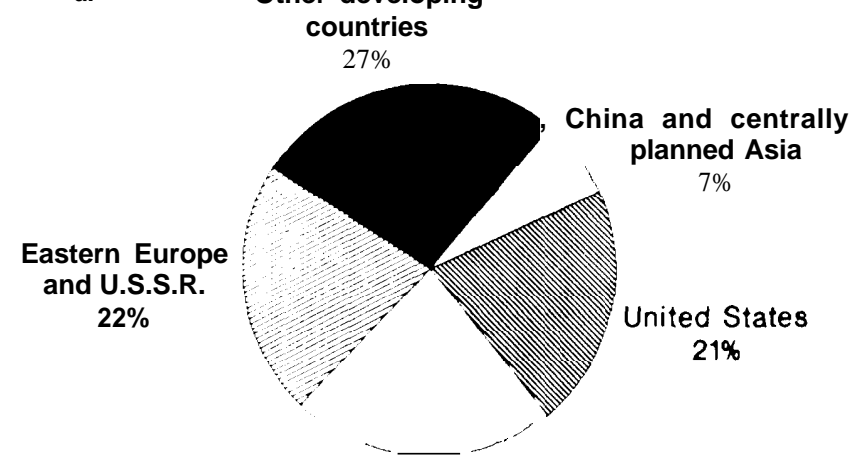

b.

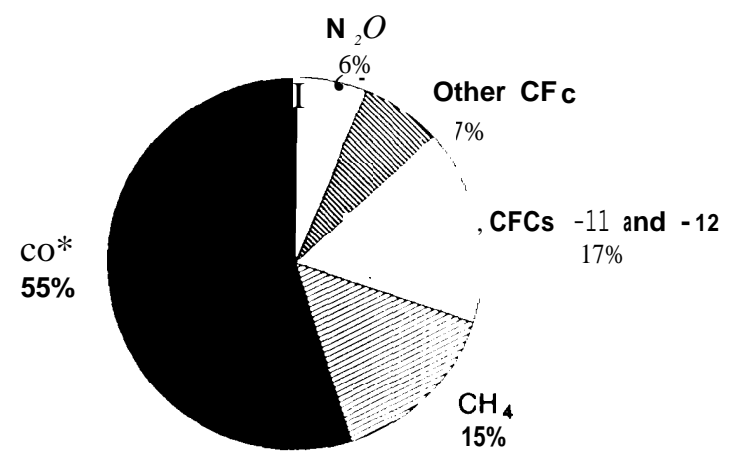

Rest of OECD

$23 \%$

NOTE: Figure at left shows the share of greenhouse gas emissions by region, weighted by their contribution to radiative forcing between 1980 and 1990 . It includes all greenhouse gases and $\mathrm{CO}_{2}$ from deforestation and fossil fuel use. Estimates for $\mathrm{CO}_{2}$ emissions from deforestation range from less than 10 to about 30 percent of total $\mathrm{CO}_{2}$. If the upper range proves to be correct, developing countries' shares would be larger. Figure at right shows the contribution of each of the manmade greenhouse gases to the change in radiative forcing from 1980 to 1990 . The contribution from urban ozone may also be significant, but cannot be quantified at present.

SOURCES: Figure at left: adapted from U.S. Environmental Protection Agency, 1990. Figure at right: Intergovernmental Panel on Climate Change, Scientific Assessment of Climate Change, Summary and Report, World Meteorological Organization/U.N. Environment Program (Cambridge, MA: C a m b r i d g e University Press, 1990).

Arctic, the severe drought of 1988, and recent abnormal weather patterns in Europe. International concern was demonstrated by the recent rapid renegotiation of the Montreal Protocol to completely phase out CFCs and assist developing countries in achieving that goal. Many industrialized countries, principally in Europe, have further called for a 20-percent reduction in $\mathrm{CO}_{2}$ emissions from the developed world by 2000 or shortly thereafter; several have pledged to freeze or reduce emissions whether or not the rest of the world participates.

Meanwhile, there is debate here as to whether and when a freeze or a 20-percent reduction in U.S. greenhouse gas emissions could be achieved in the near-term. A 20-percent reduction in U.S. $\mathrm{CO}_{2}$ emissions would represent a 3-percent decline in current worldwide emissions of $\mathrm{CO}_{2}$ and less than a 2-percent decline in current worldwide emissions of all greenhouse gases. More importantly, however, even if a 20-percent cut by all developed Nations could be achieved, it would not be enough to stabilize the atmosphere at today's level, let alone to reduce greenhouse gases to pre-industrial levels. To stabilize the atmosphere, the Intergovernmental Panel on Climate Change (24) and the Environmental Protection Agency (EPA) (56) suggest, would require much more-up to an 80-percent global reduction in $\mathrm{CO}_{2}$ emissions from current levels as well as significant reductions in the other greenhouse gases. To achieve this under the combined pressures of economic and population growth, nonfossil fuel technologies such as solar or nuclear power would be needed to replace much of today's fossil fuel use.

Energy conservation is the logical first step for the United States if it wishes to reduce its own $\mathrm{CO}_{2}$ emissions below present levels over the next 25 years. For comparison, if no actions are taken, emissions of $\mathrm{CO}_{2}$ will likely rise 50 percent during the next quarter century. Under a set of modest policies designed to encourage people to choose technologies that are cost-effective, emissions of $\mathrm{CO}_{2}$ probably will rise about 15 percent over the next 25 years. This policy package is labeled OTA's 'Moderate' scenario.

OTA also identified an energy conservation, energy-supply, and forest-management package that can achieve a 20- to 35-percent emissions reduction. This package is labeled OTA's “Tough" scenario. While difficult to achieve, major technological breakthroughs are not needed. Existing equipment would not have to be instantly scrapped and replaced with untested prototypes. The requisite energyrelated technologies are either already available or are demonstrated and close to commercialization 
today. Most of the forestry-related practices also are proven and already commercialized. OTA's Tough scenario thus does not represent "maximum technical potential.' Although it could be argued, for example, that there is a 'technical potential' for a massive return to nuclear power by 2015 , we assume that this is not feasible for the United States, given lead times and current public concerns. Likewise, we assume that a massive penetration of solar-based electricity generation will not take place by then. Nor will most people be driving 80 mile per gallon (mpg) cars, although prototypes are available today. In each of these cases, though, increased research, development, and demonstration (RD\&D) could bring substantial benefits within a half-century.

In the OTA analysis of' energy-related activities, only those technical options that would result in $\mathrm{CO}_{2}$ emissions reductions without loss of comfort or convenience were examined. If implemented, the energy conservation options discussed in our Moderate scenario would likely save consumers money over the lifetime of, for example, an energy-using appliance, given today energy costs. Greater reductions are quite feasible, as our Tough scenario shows, with technologies that are either technically challenging or more expensive. Even greater reductions are possible if consumers can be persuaded to forego some amenity or comfort ${ }^{3}$ however, because many such actions are reversible, they may not continue if energy prices drop and so are not considered here.

U.S. carbon dioxide emissions in 1987 expressed as carbon equivalents were about 1.3 billion metric tons per year (see figure 1-2). OTA projects that under "business-as-usual"" conditions (i.e., our Base case) emissions in 2015 will rise to 1.9 billion metric tons per year. In order to reduce emission levels 20 percent below 1987 levels by 2015 (i.e., to about 1.0 billion metric tons), we must not only attain zero growth over the 1987 level, but must also trim that level by an additional 0.3 billion metric tons. As figure 1-2 shows, a 20-percent emissions reduction is much more than OTA's Moderate scenario but less than its Tough scenario.
Figure 1-2-Summary of OTA's Analysis of Carbon Emissions With and Without "Moderate" and "Tough" Controls

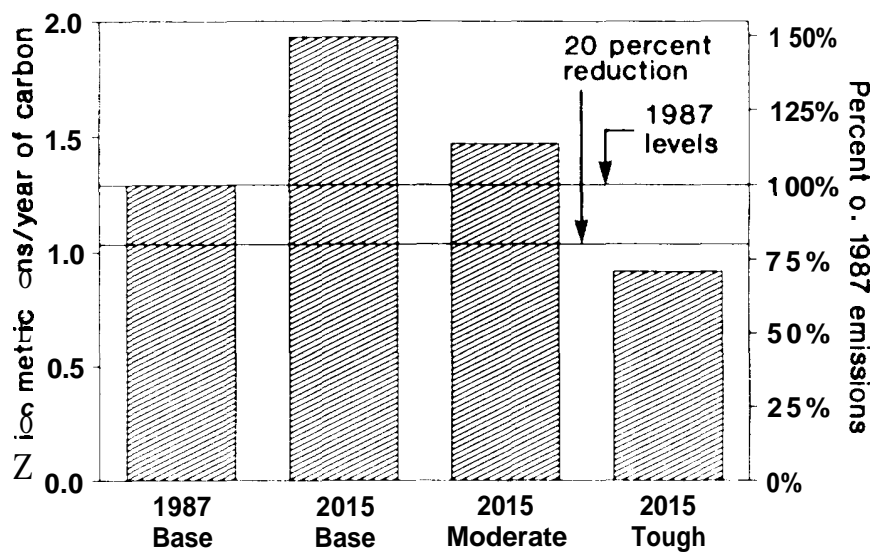

SOURCE: Office of Technology Assessment, 1991.

During the 1970s the extraordinary freeze in energy consumption-while the Gross National Product (GNP) grew 35 percent-was about twothirds due to increases in energy efficiency and one-third due to structural change $e^{5}$ in the economy. Investments in more efficient technologies were facilitated by higher energy prices and the regulatory climate. We already have shown our ability as a Nation to change our energy consumption patterns.

The Nation's track record gives us confidence that such improvements could continue to be achieved, especially if energy prices were to significantly rise again. To achieve lasting reductions in energy consumption, government signals (e.g., pricing and regulatory policies) need to be consistent and reinforcing. Otherwise we are likely to see reversalsas in the 1980s, when energy prices decreased and U.S. fossil fuel consumption started climbing again. For example, higher gasoline prices in the 1970s and early 1980s led to increased purchases of fuelefficient automobiles. As gasoline prices fell and long-term energy problems were discounted by national leaders, car buyers shifted their attention away from efficiency toward higher luxury and power. Similarly, Federal R\&D funding for renewable technology plummeted 90 percent (in constant dollars), from $\$ 1.3$ billion in 1980 to $\$ 0.14$ billion in

\footnotetext{
${ }^{3}$ The US Department of Energy (DOE) found that of an 18-percent reduction in residential energy use between 1972 and 1984, one-third was due to behavioral changes (53).

${ }^{4} \mathrm{U} \mathrm{SCO}_{2}$ emissions were 4.7 billion metric tons. $\mathrm{Fo}_{\mathrm{r}}$ the purposes of this report, all emissions are shown as weight of carbon. To convert to $\mathrm{CO}_{2}$ equivalent, multiply the weight of carbon by 3.67.

${ }^{5} \mathrm{I}$.doclines in $\mathrm{e}_{\text {ner }}=\mathrm{i}_{\mathrm{n}} \mathrm{t}_{\mathrm{en}} \mathrm{s}_{\mathrm{ive}}$ industry and increases in the service sector. For further details see ref. 47.
} 
Figure 1-3-U.S. Energy Consumption and Associated Carbon Emissions in 1989
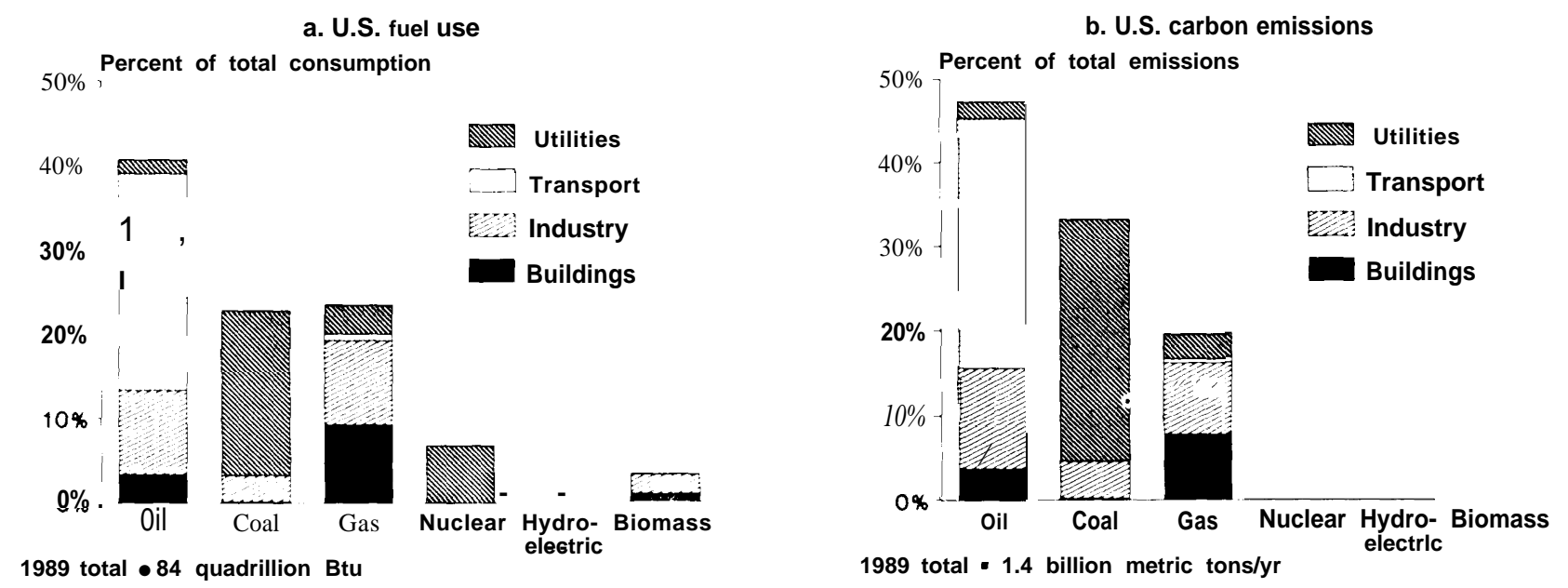

NOTE: Emission estimates in the right-hand figure calculated by multiplying fuel use (from left-hand figure) by fossil-fuel carbon emission factors. Coal, 55 to $60 \mathrm{lbsC} / \mathrm{mmBtu} ; 011,45 \mathrm{lbs} \mathrm{C} / \mathrm{mmBtu}$; gas, $32 \mathrm{lbs} \mathrm{C} / \mathrm{mm}$ Btu. Wood emissions are similar to coal; however in the United States, wood is currently regrown, so we show no net emissions for biomass.

SOURCES: Off Ice of Technology Assessment, 1991, using DOE, ‘1990.

1990 (see figure 1-6 below), The United States has recently become a net importer of solar thermal and wind systems after dominating the market in the mid- 1980s.

A variety of policy interventions will be required to reduce $\mathrm{CO}_{2}$ emissions 20 to 35 percent below current levels by the year 2015. These could include regulatory ' 'push' and market ' pull' mechanisms to provide maximum encouragement and flexibility. They could affect both energy supply and demand and forestry and agricultural practices. Without an increase in and refocusing of current Federal initiatives-including performance standards, incentive programs, energy taxes, and RD\&D activities - the use of greenhouse gas reducing technologies is unlikely to increase greatly in the next few decades.

Many of the measures discussed in this study will have ancillary environmental benefits, including abating acid rain, urban smog, ozone depletion in the stratosphere, and groundwater contamination. Decreasing oil use-primarily affecting the transportation sector-will reduce our dependence on foreign oil. Developing and producing renewable energy technologies with worldwide applicability may strengthen U.S. trade markets and our competi- tiveness abroad. Given that about a dozen industrialized countries have officially pledged to stabilize or reduce $\mathrm{CO}_{2}$ emissions by 2005 , and that energy demand in rapidly growing, developing countries must increase, burgeoning markets for efficient and lower $\mathrm{CO}_{2}$-emitting technologies are likely. The United States, as the world's largest producer of greenhouse gases, has an opportunity both to set a good example and be in the forefront of developing new markets for the associated technologies and products.

\section{U.S. SECTORAL ANALYSES AND PROJECTIONS OF $\mathrm{CO}_{2}$ EMISSIONS}

\section{Current Emissions}

Total U.S. energy use has risen since 1987, the year OTA's modeling effort begins. In 1989, energy use was about 84 quads (quadrillion British thermal units). As shown in figure 1-3a, in 1989 oil accounted for about 40 percent, coal and gas each provided about 23 percent, nuclear power provided 7 percent, and hydroelectric power and biomass each contributed about 3 to 4 percent of energy use.?

\footnotetext{
${ }^{6}$ As of January 1991, Austria, Australia, Canada, Denmark, France, Germany, Italy, Japan, The Netherlands, New Zealand, Norway, Sweden, United Kingdom, Some of these countries' policies are still subject to change.

${ }^{7}$ Data for 1989 energy consumption are from ref. 54.
} 
Figure 1-4-1987 U.S. CO2 Emissions by Sector

Buildings:

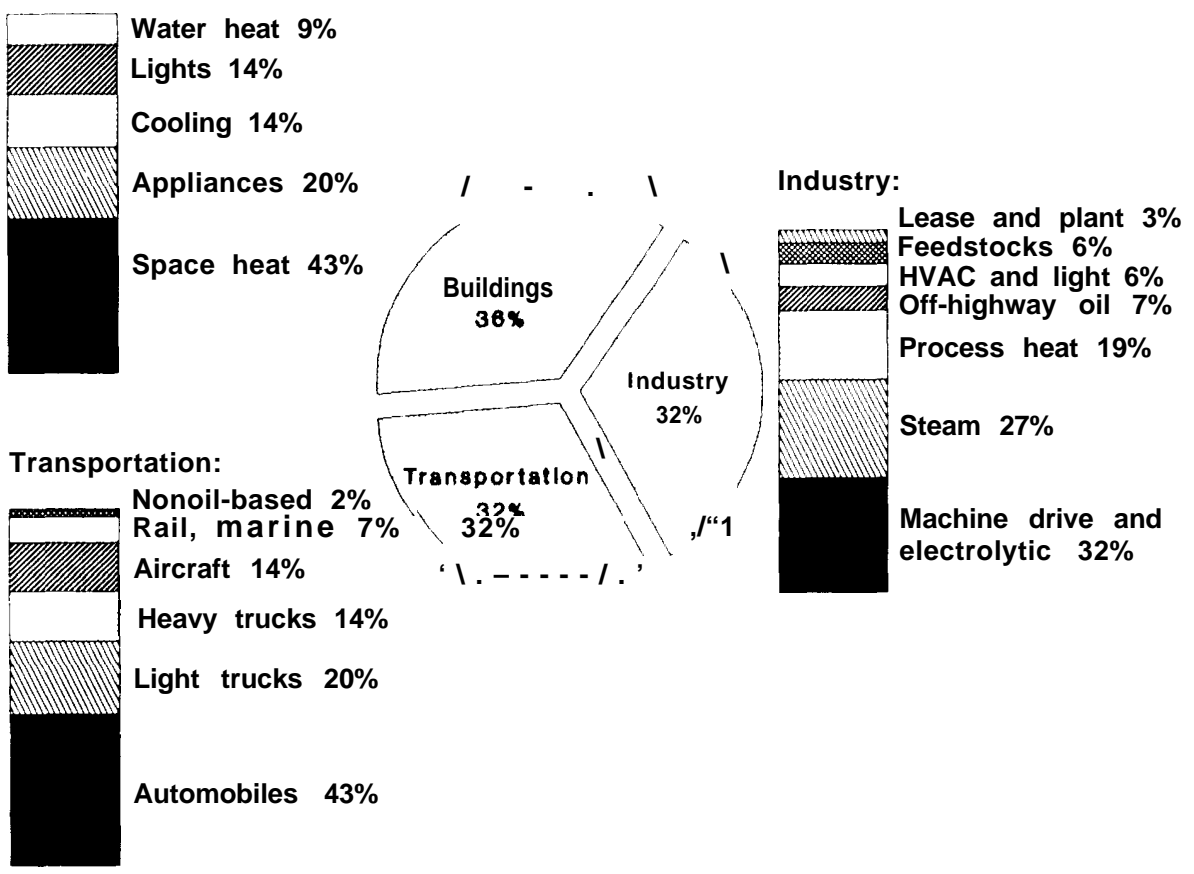

NOTE: Total carbon emissions from all three sectors equaled about 1.3 billion metric tons in 1987. Emissions have continued to increase since then.

SOURCE: Office ol Technology Assessment, 1991.

About two-thirds of the total energy was used directly as fuel in "end uses," for example as gasoline to run our cars and natural gas to heat our homes. Another 35 percent was used to generate electricity; well over half of that electricity was generated from coal.

Carbon dioxide emissions (as carbon) from energy use in the United States in 1989 totaled about 1.4 billion metric tons (this is up from 1,3 billion metric tons in 1987), about 20 percent of the world total. As shown in figure 1-3b, oil accounted for about 48 percent of carbon emissions, coal about 34 percent, and natural gas about 18 percent. One-third of the energy was used to generate electricity. Oil dominates direct uses; coal dominates electricity generation. Coal and wood contain the highest concentrations of carbon per unit energy--commonly about 55 to 60 pounds of carbon per million Btu (lbs C/mmBtu). Natural gas has the lowest concentrations (32 $\mathrm{lbs} \mathrm{C} / \mathrm{mmBtu}$ ) and petroleum is intermediate (45 lbs $\mathrm{C} / \mathrm{mmBtu}$ ).
When the emissions from the generation of electricity are allocated to the sector in which the electricity is used, total emissions from energy use are roughly equal in the buildings, transportation, and industrial sectors. Figure 1-4 displays emissions by sector, as well as the major components within each sector. We have detailed estimates of how energy was used in 1987, the reference year for our model. For that year, 36 percent of carbon emissions were from the buildings sector-about 20 percent from activities within our homes and apartments and 16 percent from energy use in commercial buildings. ${ }^{8}$ Another 32 percent of emissions are transportation related and 32 percent come from industry.

\section{Future Emissions Scenarios}

For the energy-related sectors, OTA projected future $\mathrm{CO}_{2}$ emissions under a "business as usual" scenario--our baseline or "Base' case. Two scenarios were then modeled, based on "Moderate' and "Tough" technical measures respectively (see

@ f the 36 percent of total $\mathrm{CO}_{2}$ emissions coming from the buildings sector, one-third is from fossil fuels (i.e., oil and gas) burned directly within residential and commercial buildings; two-thirds come indirectly as a result of the generation of electricity used in buildings. 
box 1-B for a description of the model). Moderate measures typically require some initial capital investment but later save money through future fuel savings; in most cases savings more than compensate for initial costs. None of the measures are difficult to achieve technically, though inducing consumers to use them may not be easy.

The 'Tough' measures would lower energy demand even further, but in many cases at a higher cost for the same level of convenience and comfort All of the Tough measures analyzed are technically feasible, but most are not based on the best available prototypes or practices; OTA made judgments about what will be feasible for widespread use. Fully implementing the Tough measures would be challenging-politically, logistically, and perhaps economically.

The model only included energy-related sectors. For the forestry sector, OTA independently evaluated Moderate and Tough measures; these were chosen by the same criteria as measures in the model (i.e., difficulty and cost) and estimates of $\mathrm{CO}_{2}$ uptake over time were calculated. Data were not sufficient to calculate potential emissions reductions from the food sector.

\section{Overall Modeling Results}

Based on the OTA energy modeling analysis, under current trends and regulations carbon emissions by 2015 will be close to 50 percent greater than today's level-almost 1.9 billion metric tons per year (see figure 1-5). This Base case projection assumes that some efficiency improvements will occur even in the absence of new legislation. For example, by then we assume new homes will require 15 percent less heating, recently adopted appliance standards will have taken effect, and new cars will average close to $37 \mathrm{mpg}$.

By adopting all Moderate measures that lower energy demand, $\mathrm{CO}_{2}$ emissions in 2015 could be held to about a 22-percent increase over 1987 levels. The emissions savings achieved by the Moderate measures are shown for each demand sector (buildings, transportation, industry) as well as for electricity supply in figure 1-5. Changes in the fuel mix used to generate electricity can lower emissions an additional 6 to 7 percent, The Moderate forestry

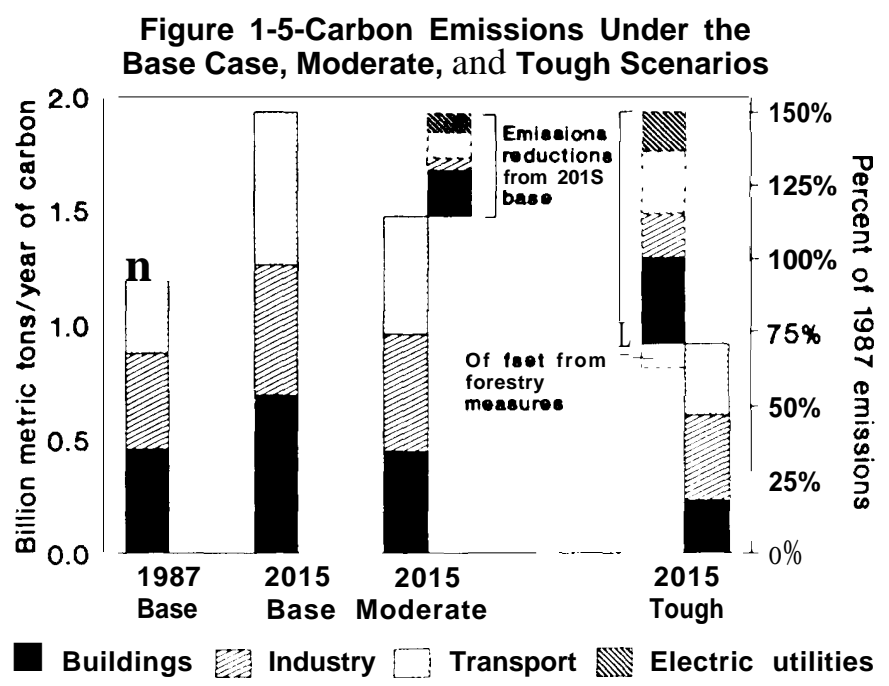

NOTE: The boxes outlined with dashed lines represent the reductions in carbon emissions associated with control measures applied in each of the three demand-side sectors (i.e., buildings, industry, and transportation) and electricity supply (electric utilities); additional carbon offsets afforded by forestry measures are also shown. The boxes outlined with solid lines represent total emissions from each demand-side sector. Emissions associated with electricity generation have been allocated to the three demand-side sectors.

SOURCE: Office of Technology Assessment, 1991.

measures provide about a 0.2 -percent offset in carbon emissions by 2015. All Moderate measures together hold emissions to 15 percent above 1987 levels.

Finally, OTA's Tough scenario could lower net emissions by 2015 (excluding offsets from forestry measures) to 29 percent below 1987 levels-i.e., to about 0.9 billion metric tons per year. This is about half of our Base case forecast for 2015. Tough forestry measures could reduce emissions another 7 percent. The detailed emissions reductions estimated for the Tough scenario analysis are shown in table 1-1, by individual measures within sectors.

\section{costs}

While we think the Moderate scenario is achievable at a net savings, "nonetheless substantial shifts in the economy would have to occur. For example, energy expenditures would be 15 percent lower than they would be otherwise, but the cost of appliances, cars, and houses would be higher.

\footnotetext{
9We believe that overall savings are possible because, on balance, fuel savings (assuming projected 2015 prices) will exceed annual capital and operating costs.
} 


\section{Box l-B-The OTA CO Emissions Reduction Model}

OTA developed a simple energy accounting model to estimate the effectiveness of various technical options for lowering $\mathrm{CO}_{2}$ emissions. The model is based on a larger system of energy and economic models used by the Gas Research Institute (GRI) to forecast energy use through 2010 (23) ${ }^{1}$. Of all the integrated energy/economic forecasting models available, the GRI approach includes the greatest detail on the demand side for specific technologies. (Other models may contain, for example, estimates of total residential electricity demand, but do not include breakdowns of heating, cooling, refrigerators, freezers, clothes dryers, etc.) With such information, changes in $\mathrm{CO}_{2}$ emissions can be simulated in detail based on changes in technology.

GRI provided OTA with detailed output from its model simulations of energy use through 2010. We, in turn, built a very much simplified set of models by "modeling" GRITS detailed output. For example, to estimate the energy demand for heating homes, GRI's residential sector model starts with the number of existing furnaces, heat pumps, and electric heaters. It then forecasts the number that must be replaced through time (with more efficient technology) based on typical equipment lifetimes. The number of new homes (which, of course, must also be heated) is forecast based on economic conditions. Whether consumers buy gas, oil, or electric heaters is forecast in part based on economics and in part on historical buying habits,

OTA took the GRI forecasts of energy use by each technology category (e.g., gas furnaces) and built a series of simple models that simulate the number and energy efficiency of each technology type through time, based only on the GRI detailed output data, rather than the economic decisions that influence the forecast. Note that for two categories-highway vehicles and electric utilities-we felt that the GRI model did not have adequate detail for our needs. For highway vehicles, we used Oak Ridge National Laboratory's "Alternative Motor Fuel Use Model" (but used GRI's oil price assumptions for consistency). For electric utilities, we built our own model using detailed data from the U.S. Department of Energy's Energy Information Administration.

We total all the energy use and $\mathrm{C}_{2}$ emissions from each technology and sector. This forms the basis for our Base case forecast that emissions will be approximately 50 percent above today's level by 2015 . In the Base case (business as usual), OTA implicitly assumes GRI's economic forecast of GNP growth averaging 2.3 percent per year and energy price increases averaging 1.7 percent per year for coal, 3.7 percent per year for oil, and 4.8 percent per year for natural gas over the next two decades. This represents a reasonable future picture barring major changes in energy supply, economic, or regulatory conditions.

Then we estimate the effect of changes in technology (e.g., more efficient gas furnaces than included in the GRI forecast) or policy (e.g., forcing coal-fired plants to retire after 40 years of operation) in two alternative scenarios: "Moderate" and "Tough." Our model, for the most part, assumes the same level of "services" as the GRI base case. In the alternative scenarios, $\mathrm{CO}_{2}$ emissions are reduced, for example, by using more efficient furnaces, switching fuel, or insulating houses, but not by assuming people keep their homes at lower temperatures in the winter or warmer in the summer like they currently do. In a few cases, most notably the transportation options, all "services" are not identical. For example, one of the measures that we include is to reinstate a $55 \mathrm{mph}$ speed limit. Under our most aggressive scenario, we assume that cars will be somewhat smaller than they are today (for either economic or regulatory reasons). Both of these include some loss of convenience to consumers.

${ }^{1}$ The GRI modeling system has as its core the U.S. Energy Model, developed by Data Resources, Inc. (DRI). The model includes four submodels: the industrial sector, residential sector, commercial sector, and electric utilities. Economic projections, which drive the Energy Model, come from the DRI Macrocionomic Model of the U.S. economy. Additional inputs are generated from the Industrial Sector Technology Use Model, developed by Energy and Environmental Analysis, Inc.; the GRI Hydrocarbon Supply Model; and the RDI Coal Model, developed by Resource Data International.

Many of the Tough scenario measures entail costs in excess of projected fuel savings; others are cost effective over their lifetime but are difficult to implement. A rough estimate of the cost range for the Tough scenario is a savings of $\$ 20$ billion to a cost of about $\$ 150$ billion per year (in 1987 dollars) by 2015 , after subtracting fuel savings (assuming forecasted 2015 fuel prices). ${ }^{10}$ This range is equal to savings of a few tenths of a percent to a cost up to 1.8 percent of the Gross National Product (GNP) projected for 2015. For comparison, all environmental compliance costs today are about 1.5 percent of

\footnotetext{
${ }^{10}$ For example, $\mathrm{W}_{\mathrm{c}}$ assume that oil prices by 2015 will be about $\$ 50$ per barrel.
} 
Table I-I-Measures To Lower U.S. Carbon Emissions (expressed as percentage of 1987 total emissions)'

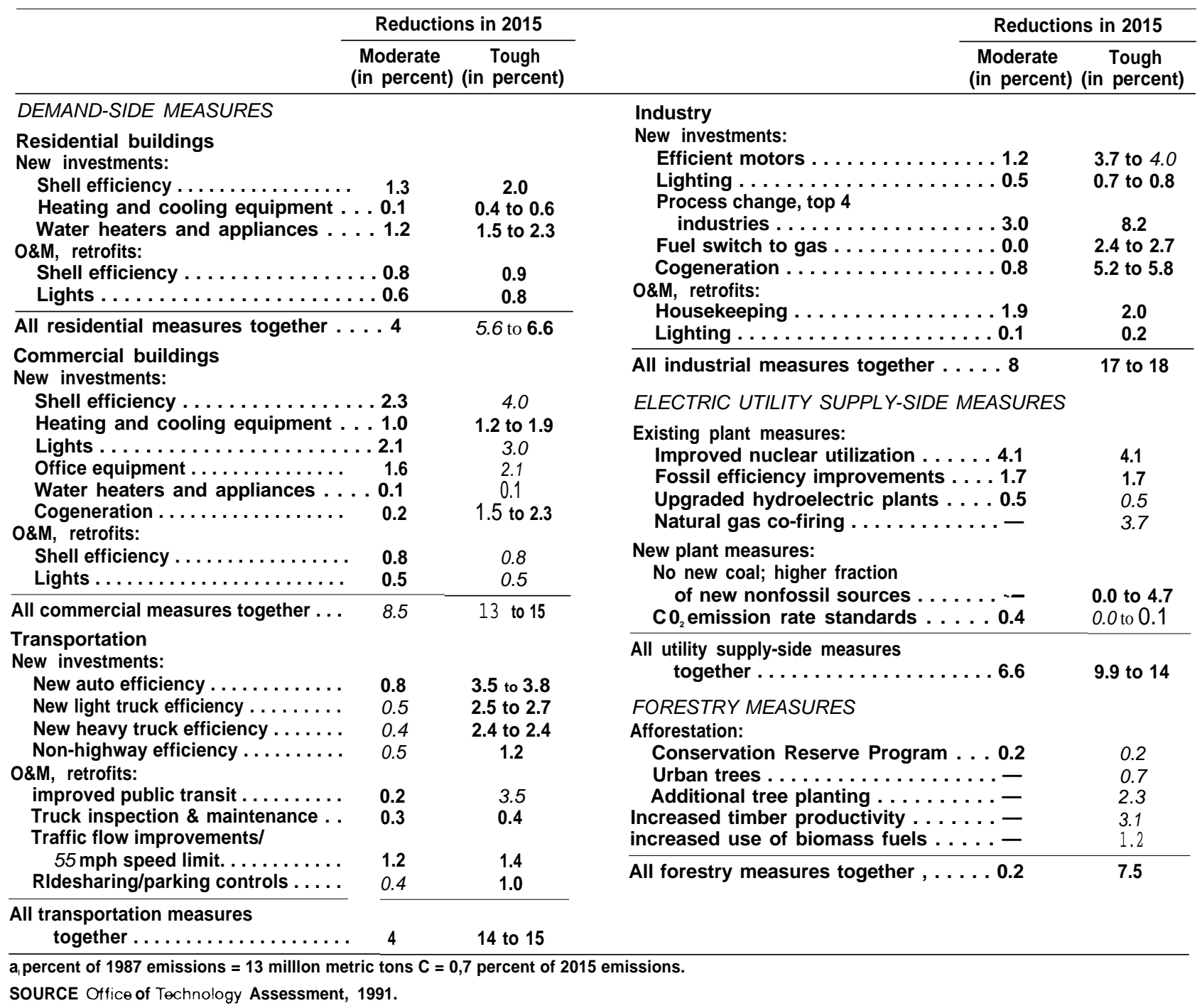

GNP; direct fossil fuel and electricity consumption purchases account for about 9 percent of GNP.

Other groups have tried to estimate the costs of $\mathrm{CO}_{2}$ reductions, but with different control scenarios, often a carbon tax. For example, using several short-term econometric models (i.e., analyses that extend only to the year 2000), the Congressional Budget Office (CBO) estimated that a $\$ 100$ per ton carbon tax phased in by the year 2000 would hold $\mathrm{CO}_{2}$ emissions at just about current levels or reduce them to 25 percent below current levels by 2000 (45). By the end of the first decade, GNP would be lowered by about 0.5 to 2.0 percent (about $\$ 40$ to $\$ 130$ billion per year in 1987 dollars). However,
GNP effects over the first few years of a suddenly instituted policy could be 5 percent or more.

CBO also looked at two longer term econometric models that forecast energy use past 2000, one constructed by the Environmental Protection Agency (EPA) and the other by the Electric Power Research Institute (EPRI). These models' projections for Base case energy use in 2015 are reasonably close to each other and to OTA's Base case and thus offer useful comparisons of reductions and costs. The model used by EPA forecasts that holding emissions to 10 to 15 percent below current levels would lower GNP by about 1 to 1.3 percent by the year 2015. The EPRI model forecasts that holding emissions to 20 percent 
below current levels would lower GNP about 3 percent by that year.

The costs associated with any scenario depend on many factors - including the price of fuel projected under Base case conditions. For example, we are assuming the price of crude oil will be $\$ 42$ per barrel (in 1987 dollars) by the year 2010(23) and about $\$ 50$ per barrel by 2015. ${ }^{11}$ Net costs for an emissions reduction scenario would be higher if 2015 fuel prices are lower than projected; for example, if oil prices are \$5 per barrel lower in 2015 than we forecast (and other energy prices remain the same as forecast), costs will be about $\$ 15$ billion higher. Similarly, net costs would be lower if energy prices rise more than projected. No quantitative estimates have been made of the ancillary air, water, soil, health, economic, and energy security benefits that result from reducing energy use and associated pollutants.

\section{OPTIONS FOR REDUCING U.S. EMISSIONS}

The major options available or likely to be available for reducing $\mathrm{CO}_{2}$ emissions in the nearterm fall into three categories:

1. increasing energy conversion and efficiency in end-use technologies,

2. changing use patterns to conserve energy, and

3. shifting energy supply away from high $\mathrm{CO}_{2}-$ emitting fuels.

Additional options to offset $\mathrm{CO}_{2}$ emissions are primarily forestry-related or agricultural. If Congress chooses to pursue any of these options, it obviously will also seek: to assure continuous economic progress.

When choosing policy options Congress must consider two interdependent components: the universe of possible technical (or in some cases, behavioral) changes and the policy instruments (e.g., taxes, regulations, financial incentives) available to require or encourage the technical change. One policy option, for example, would be to reduce $\mathrm{CO}_{2}$ emissions through regulations (i.e., a policy instrument) to require more fuel-efficient autos (i.e., a technical option). An alternative or perhaps complementary policy option would be to use a high

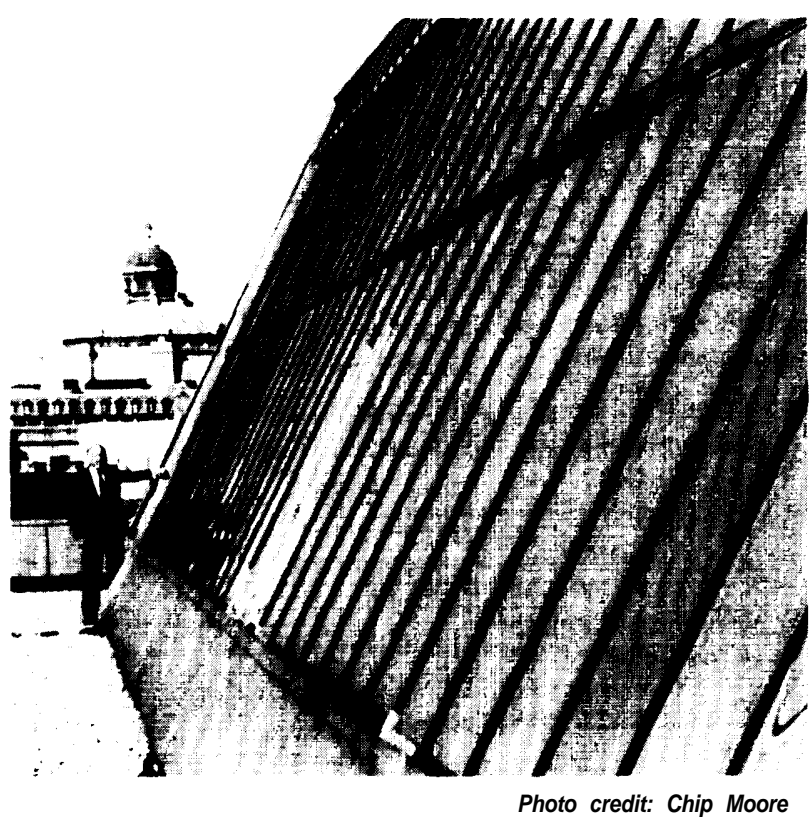

Solar panels supply all of the hot water and up to 70 percent of the space heating needed for the 80,000-square-foot building in which OTA is housed.

"gas guzzler' tax (i.e., policy instrument) to stimulate purchase of fuel-efficient autos.

\section{Technical Options}

This report identifies a range of $\mathrm{CO}_{2}$-reducing technical options available or likely to be available to the Nation over the next 25 years, and what their contribution might be. There are a large number of technical options to pick from and many targets of opportunity within each sector, as figure 1-4 shows. Significant progress in reducing U.S. $\mathrm{CO}_{2}$ emissions will require that most of these options be pursued simultaneously.

Presently available energy "supply" options for achieving major $\mathrm{CO}_{2}$ reductions over the 25-year timeframe of this assessment include: replacing high carbon-emitting fuels (e.g., coal) with lower carbonemitting fuels (e.g., natural gas); using highefficiency, electricity-generating technologies (e.g., high-efficiency gas turbines or cogeneration); and using nonfossil fuels.

While nonfossil energy offers the greatest longterm potential for achieving deep cuts in $\mathrm{CO}_{2}$ emissions, we cannot count on large-scale use of

\footnotetext{
$1 /$ For comparison, DOE's Energy Information Administration estimated the price of oil to be $\$ 28$ to $\$ 46$ per barrel by 2010 ; the American Gas Association projected \$48 per barrel in 2015.
} 
nonfossil energy sources to replace fossil fuels within 25 years. These sources do not yet offer the performance, costs, or social acceptance needed to fully displace fossil fuels in such a relatively short period of time (42). Only three nonfossil sources are presently being used on a significant scale in the United States: hydroelectric power, biomass, and nuclear light-water reactors (LWRs). Because of a combination of low baseload demand growth, cost, and environmental and social problems, no orders for new LWRs have been initiated in over a decade and there are no plans underway to build new reactors in the United States. Environmental factors set an upper limit on the number of potential new dam sites for hydroelectric facilities and on biomass production.

On the energy "end use" side, the technical options available today are primarily more efficient technologies or changes in energy use patterns. The first requires time and investment, whether for old equipment to be replaced or new equipment to be purchased. Changing energy use can include immediate (but reversible) changes such as fewer miles driven, lights dimmed, etc. In addition to the currently available technical options there is a large menu of additional options that could be developed over time. A diverse suite of energy $R \& D$ is ongoing, but what it will make available in the next quarter century depends greatly on Federal funding for demonstration.

Several technical options are available in the forestry sector to provide some offsets of $\mathrm{CO}_{2}$ emissions. Increasing forest productivity and planting new trees can result in increased carbon storage that offsets fossil-fuel related emissions. Planting short-rotation tree crops for use as biomass fuels can partially replace the use of fossil fuels in some situations. These and other forestry options have attendant uncertainties and difficulties. For example, attempts to increase productivity focus on the timber component of forests (i.e., the commercially valuable portion). However, it is unclear whether increases in timber productivity actually indicate whether or not productivity in the entire forest has increased,

\section{Policy Instruments}

Policy instruments are the means government uses to require or encourage a desired technical or behavioral response. Many potential targets exist within each sector to achieve $\mathrm{CO}_{2}$ emissions reductions (see figure 1-4). Whatever the $\mathrm{CO}_{2}$ reduction goal, Congress will have to use a variety of policy instruments to stimulate a diverse set of decisionmakers to use the appropriate fuels, technologies, and forestry and agricultural practices and to adopt energy use patterns that conserve energy.

Identifying the relevant decisionmakers will be critical to selection of appropriate policy instruments. Within the energy system, for example, appliance and lighting use patterns represent the collective decisions of nearly all Americans. In contrast, utility fuel choices are made within a relatively small community of decisionmakers (e.g., utility executives, State regulators, and segments of the financial community).

Certain generalizations nonetheless can provide guidance:

- Decisionmakers generally prefer lower cost options and many individuals prefer low firstcost options over low life-cycle cost options.

- Highly efficient "cutting edge" technologies often have relatively lower life-cycle costs but higher front-end costs.

- Historically, fragmented decisionmaking reinforces the preference for low first costs, especially in the buildings sector-decisions relevant to efficiency are made by developers and builders, not by the occupants who will be paying the energy bills.

A wide range of possible policy instruments could be used to influence decisionmakers. Table 1-2 groups them into six generic categories:

1. taxes;

2. financial incentives;

3. marketable permits;

4. regulations;

5. research, development, and demonstration (RD\&D); and

6. information and public education.

Just as there is no single technical option that is a cure-all, many policy instruments will be needed. The synergisms possible among taxation, regulation, incentives, information, and RD\&D programs are key to significantly reducing emissions. Taxes, if properly set, can be used to adjust prices to tilt purchase decisions. Regulation (codes and standards) can be used to remove the least efficient equipment, appliances, and buildings from the 


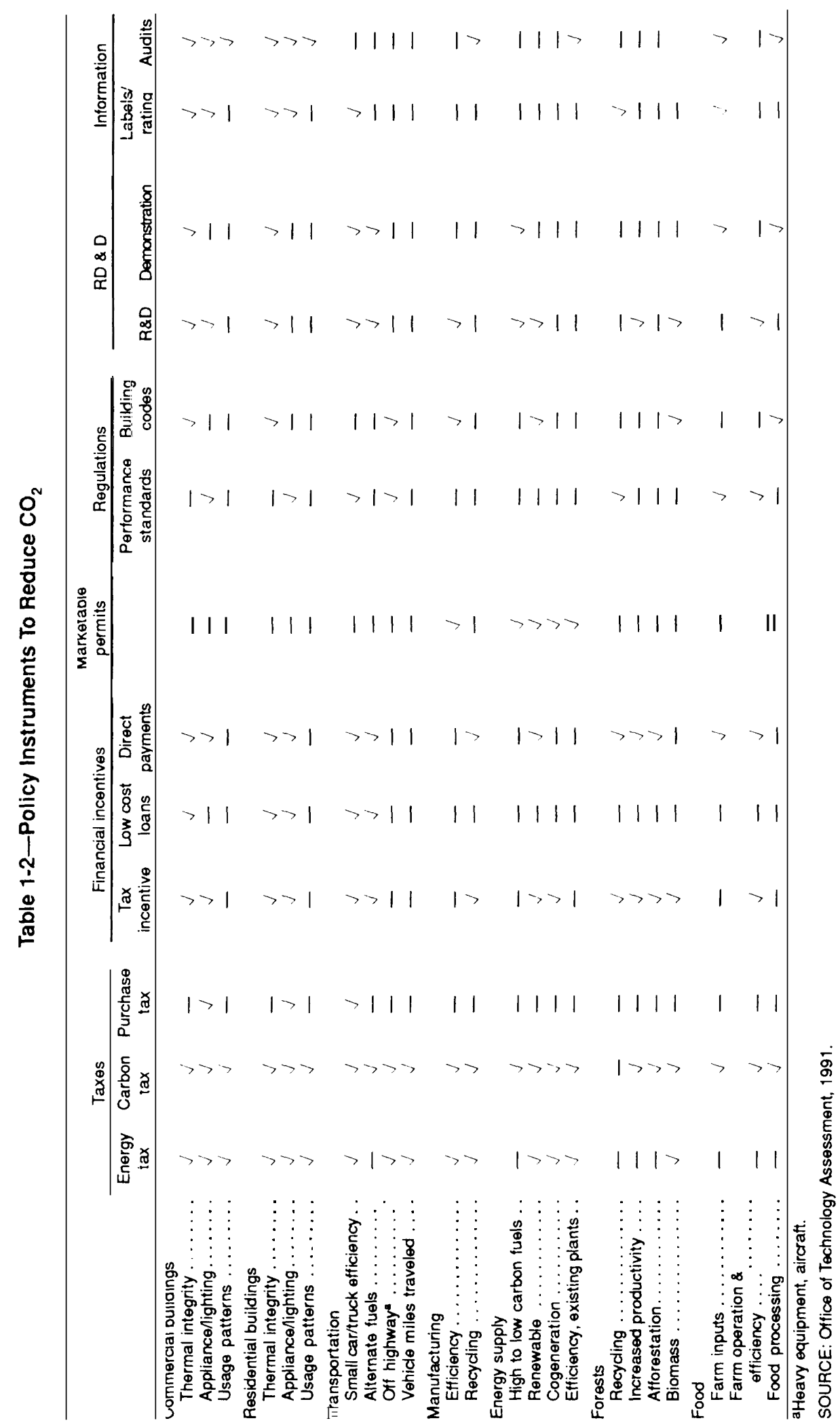


market. Incentive and information programs can be used to clarify cost information and help create a market for improved energy performance. Education programs also provide consumers with the knowledge and information needed to make wiser energy choices. Government-sponsored RD\&D can help provide producers and consumers with new technical options that can be used to reach national goals, as well as reduce, by cost-sharing, the risk to industry of developing these new options.

\section{Taxes}

Taxes offer a way to make high $\mathrm{CO}_{2}$-emitting technical options more expensive than lower $\mathrm{CO}_{2}-$ emitting options. If Congress so desires, new tax monies could help fund incentive programs, offset the budget deficit, or replace other existing taxes.

Three possibilities include: 1) a general energy tax, 2) a carbon tax, and 3) initial purchase taxes. A general energy tax is levied on the energy (i.e., Btu) content of fuels. A carbon tax is set to reflect the fact that some fuels emit more carbon per unit of energy than do others. Both of these are thus "fuel" taxes. An initial purchase tax is levied on energyconsuming technologies, rather than fuels; the tax would be based on estimates of lifetime energy use or carbon emissions.

The first-a general energy tax-would stimulate greater energy efficiency, regardless of whether energy is derived from fossil or nonfossil fuels. By making all energy more expensive, it would apply pressure to reduce total energy use. On the other hand, a carbon tax would not only stimulate energy efficiency, but also shift the energy system from high carbon-emitting fossil fuels to nonfossil fuels or lower carbon-emitting fuels (e.g., natural gas).

Initial purchase taxes could have effects broadly similar to either an energy or carbon tax, depending on whether they were based on lifetime energy use or carbon emissions. Because consumers are often more concerned with the initial cost of a technology than with 'life-cycle' costs (i.e., including fuel costs), purchase taxes can be more effective than either type of fuel tax in many situations, An example of an initial purchase tax is the current "gas guzzler' tax on autos, which was increased in the 1990 Omnibus Budget Reconciliation Act (Public Law $101-508$ ). In a similar fashion, a tax on less efficient appliances or houses could serve to reduce

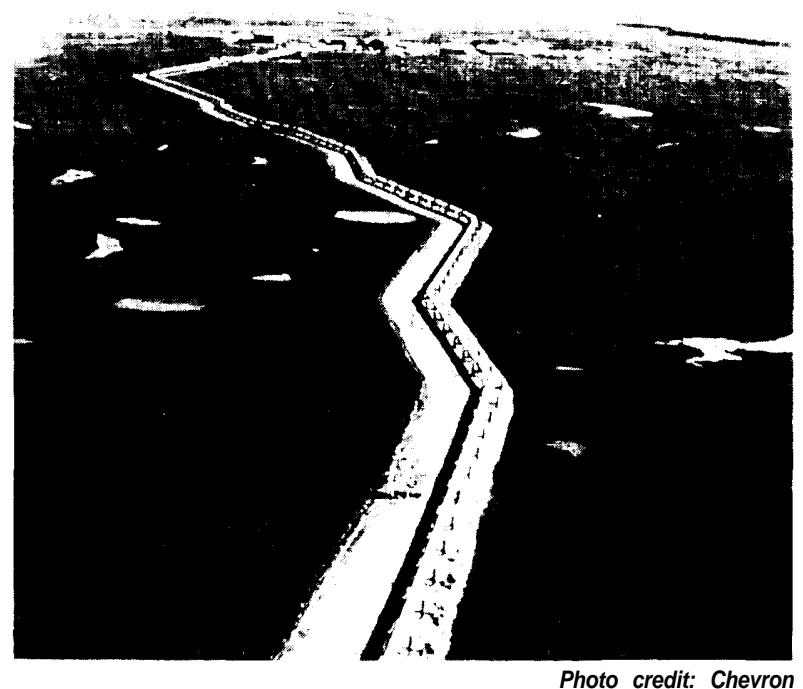

The Trans-Alaska pipeline has been in operation since 1977. North Slope oil production is currently declining, and a little less than 2 million barrels of crude oil per day now flow through the 800-mile pipeline. The United States currently uses 17 million barrels of oil each day.

consumer preferences for lower initial costs rather than life-cycle costs.

Energy and carbon taxes have the advantage of affecting all emitters simultaneously, rather than focusing on a few selected technologies. A carbon tax is a particularly effective way of targeting the heaviest economic sanctions against the worst emitters of $\mathrm{CO}_{2}$. A carbon tax would stimulate greater demand for natural gas relative to other fossil fuels. This, in turn, could drive natural gas prospecting and resource recovery technology development. Over the longer term, it could also motivate development of noncarbon energy sources whereas a straight energy tax would probably not.

Financial Incentives

Through financial incentives (e.g., tax incentives, low cost loans, and direct payment subsidies), the government pays part of the costs of utilizing desirable fuels, technologies, or practices. Tax incentives can be powerful instruments for stimulating desired actions by corporations and individual taxpayers looking for ways to reduce tax liabilities; however, tax incentives have little effect on those who pay low or no taxes. 
Low-cost loans either defray some portion of loan interest or eliminate lender risk by insuring against loss. Low-cost loans can be effective policy instruments to stimulate utilization of $\mathrm{CO}_{2}$-reducing technical options by both individuals and corporations. Direct payments for utilization of $\mathrm{CO}_{2}$ reducing options (e.g., cash bonus for scrapping an old, fuel-inefficient car) are especially effective in stimulating the use of desired options by lowincome or financially strapped decisionmakers.

\section{Marketable Permits}

Marketable permits and carbon taxes are closely related. Under a marketable permit system, policymakers fix the amount of carbon that can be emitted. The government then issues the allowed number of permits to emit a given amount of carbon. Permits can be bought and sold by energy users just like fuels. For example, for every 1 million Btu's of coal purchased, the user must also own (or purchase) permits to emit 57 pounds of carbon. To burn 1 million Btu's of natural gas, the user must own or purchase permits to emit 32 pounds of carbon. If demand for energy rises, the price of a carbon permit will rise to reflect the cost of lowering emissions. Some holders of permits will find ways to lower emissions (e.g., purchase more efficient equipment, switch from coal to natural gas) so that they can sell their permits (at a profit) to others. Theoretically, the effective price of fossil fuels will rise just high enough to meet the allowed carbon emission target. Just how high prices will rise, however, is difficult to forecast.

Marketable emission permits is the current U.S. method for enforcing the Montreal Protocol and controlling CFC emissions. A marketable permit system also is the regulatory mechanism for limiting emissions of sulfur dioxide to control acid rain under the new Clean Air Act Amendments (Public Law 101-549).

Marketable permits could be required for all fossil fuel users or only for large users such as electric utilities, factories, and even large commercial installations. Permits could be required for wholesalers who sell gasoline, rather than for individual drivers.

\section{Regulations}

Regulations are policy instruments that can eliminate inefficient and/or high $\mathrm{CO}_{2}$-emitting activities from the market. They can take the form, for example, of performance standards and building
Figure 1-6-Federal Government Funding for Energy Supply R\&D, 1980 to 1990

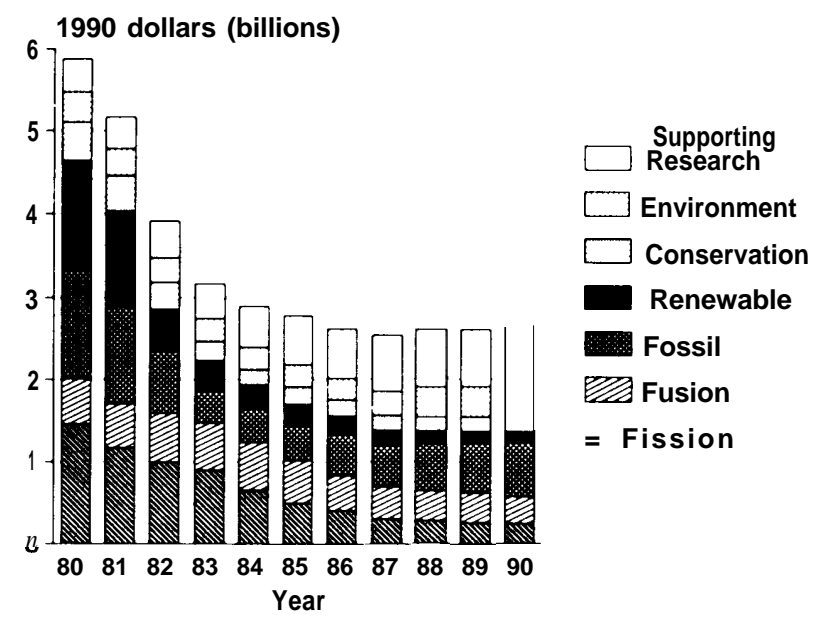

NOTE: The bars represent Federal budget authority for research, development, and technology demonstrations, in 1990 dollars. "Supporting" refers to research in basic energy sciences.

SOURCES: J.P.Holdren, "Energy in Transition," Scientific American 263(3):156-163, September 1990, original data compiled from the Office of Management and Budget, Budget of the United States Government, Fiscal Years 1990 Through 1991 (Washington, DC: U.S. Government Printing Office, 1980 through 1990); Inter-society Working Group/American Association for the Advancement of Science, Research and Development FY 1980-1997 (Washington, DC: 1980 through 1990); and Environmental and Energy Study Conference, Weokly Bulletin(s) and Special Report(s) (Washington, DC: several years).

codes. Performance standards can be established for many diverse types of technologies (e.g., lighting standards) and applied nationwide; they are currently used for automobile efficiency and appliance efficiency. Building codes traditionally have been the province of local governments and their effective use depends on enforcement at that level.

\section{Research, Development, and Demonstration (RD\&D)}

Through RD\&D, government can search for and free-tune technological frees to the greenhouse gas emissions problem. In fact, climate change can only be effectively addressed over the long-term with the development and worldwide use of better nonfossil energy sources. Government can speed the process of testing and commercializing many energy-supply and end-use technologies. However, only about 5 percent of the $\$ 2.7$ billion national budget for energy technology R\&D in 1990 was devoted to renewable (including biomass energy) and only 7 percent to energy conservation. Fossil fuels had 25 percent of the research budget, nuclear fusion 12 percent, and nuclear fission 9 percent (see figure 1-6). 


\section{Information}

Information as a policy instrument has the potential to change the awareness level and perceptions of decisionmakers. Information programs rest on the assumption that if decisionmakers are better informed they will make better decisions. The most common goal of information programs is to stimulate decisionmakers to opt for least cost (life-cycle) savings, as opposed to initial-purchase savings, in their energy decisions. For example, although the most efficient model of an appliance usually costs more initially, energy savings accrue over its useful life. Information can be supplied by Federal, State, or local governments, utility programs (see 'DemandSide Management' below), manufacturers, or nongovernmental organizations (NGOs).

Information can be delivered to all decisionmakers in many ways, for example via label and rating systems and audits. Label and rating systems serve to provide purchasers with a basis for comparing front-end versus life-cycle costs at the time of purchase. Energy audits provide building owners and occupants with information they need when considering whether to purchase, rent, or retrofit alternatives. Energy audits can be effectively coupled with financial incentives to carry out retrofits that provide greater efficiency, and thus reduced $\mathrm{CO}_{2}$ emissions.

\section{Sectoral Policy Options}

\section{Buildings Sector}

Figure 1-7 summarizes the emissions reductions possible for each " "demand-side" option modeled by OTA under both the Moderate and Tough scenarios. For buildings, improving shell efficiency and lighting are the two technical options with the greatest potential for lowering $\mathrm{CO}_{2}$ emissions. Under the Base case, OTA assumes that by 2015 new homes and apartments will be designed such that they need about 15 percent less heating and 8 percent less cooling than current new homes. By adopting Moderate shell efficiency measures, such as thicker insulation and better windows, new homes will require an estimated 50 percent less heat and 25 percent less air-conditioning than today's average new home (27). With Tough measures, homes can be built to require an estimated 85 percent less heat and 45 percent less air-conditioning (20).
Figure 1 -7-Demand-Side Measures

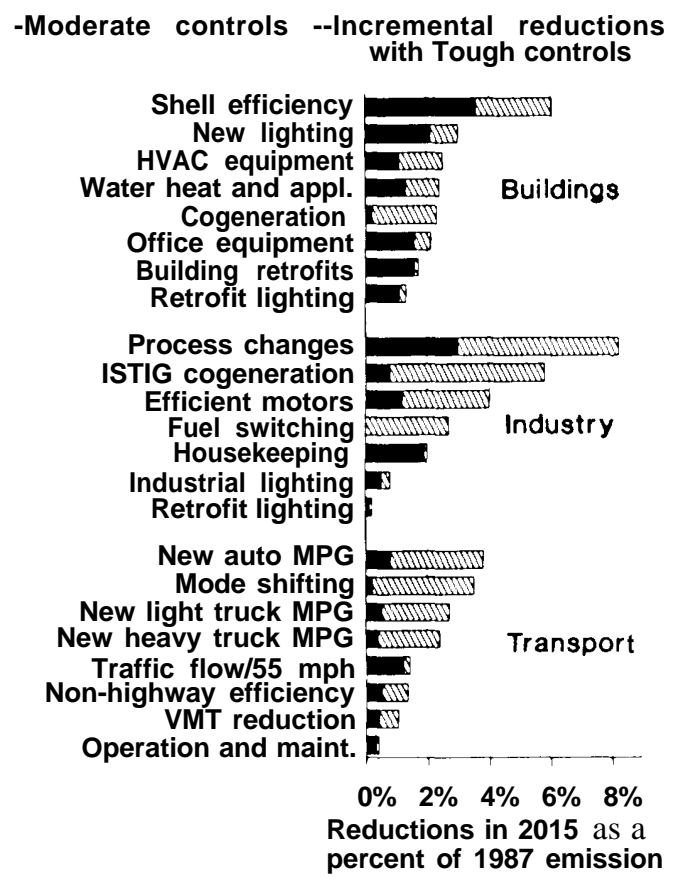

NOTE: Reductions presented as a percentage of total U.S. carbon emissions in 1987.

SOURCE: Office of Technology Assessment, 1991.

As shown in table 1-1, Moderate shell improvements in new residential buildings can reduce U.S. carbon emissions by 1.3 percent of current levels by 2015. By implementing Tough improvements in the North and Moderate ones in the South, reductions of 2 percent in new residential buildings might be achieved. Tough measures for new commercial building shells can achieve reductions equal to 4 percent of 1987 levels by 2015 .

Existing homes can also be made more efficient by installing more efficient heating and cooling equipment, insulation, windows, etc. The Base case assumes that existing homes will require 6 percent less heating by 2015 because of replacements and improvements that will happen anyway. Moderate measures boost this to 25 percent by 2015 and Tough measures boost it to 40 percent by 2015 (20). Tough measures in the North and Moderate ones in the South would reduce carbon emissions from existing buildings by 4 percent by 2000 , but would have a declining effect thereafter as many of the older homes are replaced by new ones.

Improving the efficiency of lighting in new commercial buildings is another technical option that can yield substantial reductions. The Tough 
scenario measures together-a combination of highefficiency fluorescent bulbs and ballasts, improved reflectors, and better use of daylight-would lower lighting energy needs by 60 percent in these buildings (18). This achieves reductions equal to 3 percent of 1987 emissions by 2015 .

Gains in commercial buildings can also be made by simply replacing existing bulbs with highefficiency ones-without replacing fixturesas shown under the "Operation and Maintenance' heading of table 1-1. Replacing the most heavily used incandescent bulbs in homes with compact fluorescent and using high-efficiency fluorescent in commercial buildings can lower emissions by 1.3 percent under our Tough scenario.

The instruments listed in table 1-2 and the policies described below appear to offer the most promise to achieve these reductions. While a carbon tax will certainly help, because there are so many different decisionmakers-some of whom may not be that responsive to price changes-a larger arsenal of policy instruments is needed. These include demandside management (with the utilities as partners) as well as a series of targeted financial sanctions, incentives, and regulations.

Demand-Side Management (DSM)-DSM refers to electric utility programs designed to encourage customers to modify their patterns of energy use. Particularly promising-from a global warming perspective-are those situations where utilities allow energy conservation to compete with traditional supply technologies (e.g., powerplants) to balance energy supply and demand. DSM can be an effective approach to reduce energy consumption by improving building shells as well as the equipment inside buildings. In some cases, utilities pay for rebate programs, give out high-efficiency light bulbs, or otherwise stimulate end-use efficiency improvements, and save energy at a fraction of the cost of new power supplies.

Demand-side management can result in greater investments in energy efficiency than customers would otherwise make. Utility programs have long time horizons and can capture the potential in both the new and retrofit markets, for both equipment efficiency and building shell improvements. There is already considerable support for DSM by many
State energy offices, State legislatures, and public utility commissions. ${ }^{12}$

However, in order for DSM to stimulate significant investment in conservation, incentive structures must be changed so that utilities can profit from demand-side investments. Any Federal legislation concerning DSM would need to be general enough to allow States flexibility in implementation and specific enough to have a genuine impact on conservation. Congress could provide funding to evaluate various incentive structures currently being examined by States and utilities. Should Congress wish to pursue more direct action, it could require States to formally consider demand-side resources in their planning, with oversight by the Federal Energy Regulatory Commission (FERC).

The Federal and State Governments share the regulation of electric utilities, and there is a history of tension over this sharing of jurisdiction (48). Congress can play a powerful leadership role in the direction of utility planning through legislation that guides FERC (which has jurisdiction over wholesale electricity transactions). An example of such legislation is the Public Utility Regulatory Policies Act of 1978 (PURPA), which required utilities to purchase electricity from qualifying facilities at avoided cost. Recently Congress addressed some aspects of this; for example, the Omnibus Budget Reconciliation Act amended PURPA to eliminate the 80-megawatt capacity limitation for qualifying facilities fueled by wind, geothermal, solar, or waste energy.

Further, the Federal Government could mandate that environmental externalities be considered in evaluating supply-side options (as New York State has done-i. e., penalizing polluting options based on estimates of the costs of environmental damage that would accrue; ref. 33). Congress has already mandated, in the 1980 Pacific Northwest Electric Power Planning and Conservation Act (Public Law 96-501 ), that the Northwest Power Planning Council adopt rate structures that give conservation measures a cost break over other, more traditional supply-side measures.

Technology-Specific ReguZations--Congress can directly mandate efficiency improvements through appliance standards and building energy codes. 
Appliance Standards-Appliance standards, by fiat, remove inefficient appliances from the market. The National Appliance Energy Conservation Act (Public Law 100-12), passed in 1987, are expected to lower residential energy use by up to 10 percent by the year 2000 (17), However, even stricter standards are possible. ${ }^{13}$ The law requires review of appliance standards twice during the 1990s, which provides an opportunity to obtain additional energy reductions through more stringent standards. Congress could also consider extending standards to other equipment such as commercial heating, ventilation, and air-conditioning equipment; lightbulbs; and building components such as windows.

Standards could be even more effective if used in conjunction with other incentives. Policies such as utility programs, appliance labeling, and tax schemes provide incentives to do more than standards require.

Building Energy Codes-Building energy codes serve a function analogous to that of appliance standards by preventing the least efficient buildings from being constructed. Building codes have traditionally been under the jurisdiction of States and localities. Currently, there is little support from the States or the construction industry for a mandatory national building code. In 1976, Congress enacted legislation that required the development of the Building Energy Performance Standards (BEPS), a mandatory national code based on performance standards. In 1983, the law was modified to be a mandator-y code only for Federal buildings.

Greater energy savings could be achieved by:

1. mandating compliance with a uniform code or creating incentives for States to adopt the national code;

2. developing a more stringent national code; and

3. increasing funding for implementation and enforcement.

The National Affordable Housing Act of 1990 (Public Law 101-922) requires the Department of Housing and Urban Development (HUD) to develop energy efficiency standards for new public housing and for housing subject to mortgages under the National Housing Act. ${ }^{14}$

Financial Measures-congress can choose from among several sector-specific financial mechanisms, including building tax credits and subsidies and initial purchasetaxes for appliances and other equipment.

Building Tax Credits and Subsidies--Tax credits and subsidies for using more efficient technologies can promote retrofitting of existing residential and commercial buildings. The Federal Government, for example, passed legislation that provided solar and conservation tax credits for the years 1978 through 1984. By 1983, 24 million households claimed a residential tax credit of up to $\$ 700$ each for investments in energy conservation; however, no evaluation or monitoring of energy saved by this program was ever conducted. The 1986 Tax Reform Act allowed the energy conservation tax credits for residential use to expire but extended residential solar tax credits and some commercial energy conservation Credits.

The Federal Government currently funds several subsidy programs. The Institutional Conservation Program, the Weatherization Assistance Program, and the Low Income Home Energy Assistance Program all pay for some energy conservation measures in low-income housing. The recently expired Solar Energy and Energy Conservation Bank helped finance energy conservation and costeffective solar energy in low- and moderate-income housing and in commercial buildings owned by nonprofit organizations. Under these programs, the Federal Government provides funding to States, who in turn provide matching grants and loan subsidies. Such programs could be reinstated or expanded.

Initial Purchase Taxes and Rebates for Appliances and Other Equipment-An initial purchase tax scaled to penalize inefficient equipment could accelerate the market penetration of efficient equipment, Examples include a lump-sum tax on appliances and equipment at the time of purchase. Taxes collected on the most polluting items could be used

\footnotetext{
I3. The amendments define all energy-efficiency improvements with a payback of 3 years or less as economically justified. Any paybacks longer than 3 years must be shown to be economically justified.

${ }_{14} \mathrm{Ie}$, mortgages that include ${ }_{\mathrm{a}}$ loan, under the National Housing Act, for financing energy.conse 1 lng improvements or adding solar energy systems.

${ }^{15}$ The omnibus Budget Reconciliation Act of 1990 extended the ()-percent business energy tax credit for solar and geothermal property through Dec. 31, 1991
} 
to provide a rebate on the least polluting items. However, although an initial purchase tax sends appropriate signals regarding consumer purchasing decisions, it would not-unlike an energy or carbon tax--change use of an appliance once it is purchased.

Consumer Information and Marketing Programs-Lack of information and uncertainty have been identified as key barriers to greater investment in energy conservation in the buildings sector. The large number of highly cost-effective investments in energy efficiency that are not chosen by consumers indicates that price alone does not stimulate optimal investment decisions. Therefore, information dissemination is a key element of several of the policy options discussed above, including the sectorspecific financial measures and general energy and carbon taxes.

Home Energy Rating Systems-The Federal Government has been involved in home energy rating systems-which tell buyers how efficient their prospective homes or offices are-through its role in the mortgage market. In addition, the National Affordable Housing Act of 1990 requires HUD to develop a plan to make housing more affordable through mortgage financing incentives for energy efficiency. The Federal Government could play a further role by developing a uniform energy rating system for all residential and commercial buildings, making it easier and less expensive for lenders to include energy costs in their mortgage evaluations.

State Information Programs-The State Energy Conservation Program (SECP) provides financial assistance to the State energy offices to promote energy efficiency and conservation in commercial and residential buildings. The Energy Extension Service (EES) is a Federal/State effort to provide small-scale energy users with individually tailored technical assistance for energy conservation and increased use of renewable. The SECP and the EES were consolidated under the 1990 State Energy Conservation Programs Improvement Act (Public Law 101-440).

Energy Audits-The Federal Residential Conservation Service, created in 1978, mandated that gas and electric utilities provide their customers with onsite energy audits. The program was implemented in 1981 and recently expired. There has been little evaluation of the program, and little reliable information has been kept on its success in reducing energy consumption. However, while it is unclear whether information from audits alone is enough to encourage conservation, it would certainly seem to be useful when combined with other measures.

Building Research, Development, and Demonstration--Major barriers to private investment in RD\&D in the buildings sector include the fragmented structure of this sector and the short-term perspective of many of the decisionmakers (e.g., builders, renters). In addition, the U.S. Government currently spends a negligible amount on housing research. In contrast, in countries such as Sweden and Japan, RD\&D spending has been part of a trend toward energy-efficient prefabricated housing. This spending has contributed to the energy efficiency of homes through standardization of energy-saving features and quality control in the design and manufacture of building components.

As a step, Congress has required HUD, in the National Affordable Housing Act of 1990, to develop a plan to encourage and improve energy efficiency in newly constructed, rehabilitated, and existing housing; and demonstrate various methods of improving the energy efficiency of existing housing. Such projects should encourage the development of "energy efficiency businesses' that can bridge the gap between owners, builders and occupants of buildings. Congress also required HUD to encourage the use of private energy service companies in public housing projects.

The Federal Energy Management Program (FEMP), administered by the Department of Energy, works with government agencies to implement cost-effective, energy-efficiency improvements. Congress could authorize FEMP to test and demonstrate performance, acceptance, and cost-effectiveness of new technologies in Federal buildings.

\section{Transportation Sector}

Urban passenger travel in cars and light trucks (i.e., light vehicles) in the United States requires the largest share of transport energy, consuming 15 percent of the world's oil production. The two main opportunities for reducing transportation's contribution to global warming are measures to increase the energy efficiency of light vehicles and measures to encourage urban passengers to drive less. Thus, under OTA's modeling exercise, the major reductions come from higher auto and truck efficiency, 
better control of traffic, and, under the Tough scenario, more use of public transit (see figure 1-7).

With respect to auto efficiency, our Base case assumes that new cars will average about $32 \mathrm{mpg}$ by 2000 and about $37 \mathrm{mpg}$ by 2010. Under the Moderate scenario, new car efficiency averages 35 mpg by 2000 (9) and $39 \mathrm{mpg}$ by 2010 (1 O). Under the Tough scenario, we assume a range of new car efficiencies. For example, efficiencies of $39 \mathrm{mpg}$ by 2000 and $55 \mathrm{mpg}$ by 2010 might be possible even if consumers maintain their current preferences for car size and performance (10). If consumers are willing to buy smaller cars, new car fleet average efficiencies of $42 \mathrm{mpg}$ by 2000 and $58 \mathrm{mpg}$ by $2010 \mathrm{might}$ be achievable, Given this range of assumptions, reductions amount to about 3.5 to 3.8 percent of current emissions by 2015 (see table 1-1).

Reductions of about 2.5 to 2.7 percent from light trucks and another 2.4 percent from medium- and heavy-duty trucks are achievable under our Tough scenario, as well.

Traffic speed affects fuel consumption, too. By reinstating the 55 mile-per-hour speed limit and by reducing traffic congestion in urban areas in order to speed up travel, reductions of 1.4 percent by 2015 are possible under our Tough scenario. ${ }^{*} \mathrm{G}$

Measures to move people out of their cars and into mass transit under the Tough scenario would yield reductions of about 3.5 percent by 2015 . To achieve this, however, urban auto traffic would have to be reduced by 10 percent through urban light rail, busways, and improved urban design. Additionally, 5 percent of car travel between cities would have to shift to high-speed intercity rail.

The following four policy instruments will promote new car efficiency: gasoline taxes, vehicle taxes and rebates, fuel economy standards, and incentives for vehicle manufacturers. In addition, improved operation and maintenance practices will reduce energy use in existing cars. Two other measures, transportation control measures (TCMs) and controlling settlement patterns, can help reduce $\mathrm{CO}_{2}$ by reducing vehicle miles traveled.
Gasoline Taxes-A gasoline tax would create incentives for both increased efficiency and reduced travel. Taxes would induce consumers to use less fuel while leaving them free to choose how they adjust their behavior. In concert with increasing fuel economy standards (see below), a long-term impact on the efficiency of the vehicle fleet could be achieved.

Although the effectiveness of taxes is hard to predict from studies of past responses to price changes, one might expect a 10-percent hike in gasoline prices to yield a 1- to 6-percent drop in gas consumption. ${ }^{17} \mathrm{~A} 50$-percent increase in price might reduce consumption 5 to 20 percent over the near term, even more over the longer term. A doubling or tripling in price (approaching the costs in Europe and Japan) might yield an immediate decrease of 13 to 20 percent and a longer term response of a 35- to 40-percent reduction in gasoline consumption. About half of this longer term adjustment to high price is expected from driving less, and the other half from more efficient vehicles. For example, consumers might choose to spend money on fuel-efficient technologies or to use mass transit, carpool, or simply travel less.

A gasoline tax, however, is regressive and thus affects the poor proportionately more than the rich. ${ }^{18}$ To ameliorate this, Congress could provide rebates to low-income households. It could also phase in the tax to give consumers time to adjust their purchasing decisions and operation and management practices.

Vehicle Taxes and Rebates-Taxes on inefficient vehicles can create incentives to choose better fuel economy and forego large size and extra power. Such a program would be most effective if accompanied by rebates for highly efficient cars. In a "revenue neutral" program, the money taken in from the taxes would be redistributed through the rebates. The Federal Gas Guzzler Tax ${ }^{19}$ already applies to cars with fuel economies below certain thresholds; the Omnibus Budget Reconciliation Act of 1990 recently doubled the tax for cars getting less than $22.5 \mathrm{mpg}$.

\footnotetext{
${ }^{16} \mathrm{Cars}$ use gasoline most efficiently in the range of 35 to $45 \mathrm{mph}$; slower travel (due to congestion) and faster travel lead to losses in efficiency.

${ }^{17}$ Two recent studies $(4,8)$ review the "elasticity' of gasoline use relative to price (i.e., the ratio of the percentage change in use to the percentage change in price).

[8 $\mathrm{F}_{\text {or }}$ example, in 1985 , households with earnings exceeding \$35,)()() spent 4 percent of income on gasoline whereas households earning $\$ 5,()() 0$ to $\$ 10,000$ spent 11 percent.

${ }^{19}$ The Energy Tax Act of 1978 (Public Law 95-618).
} 


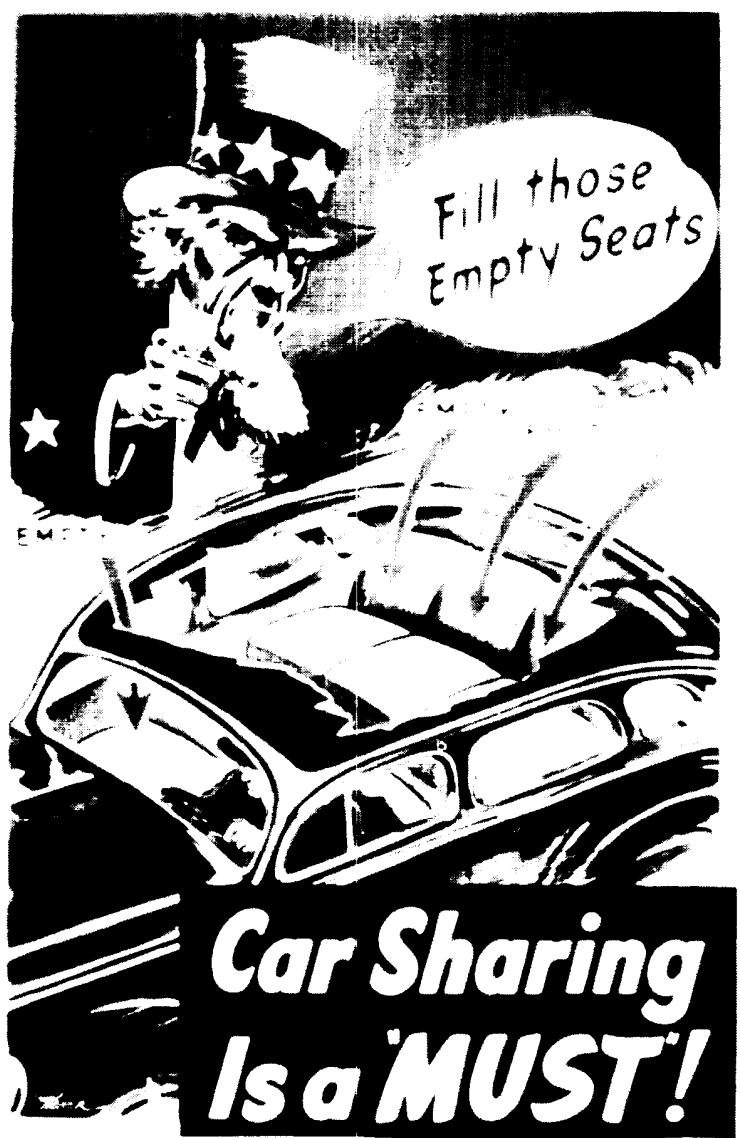

Photo credit: Bressler Editorial Cartoons, New York, Artist: Packer

A World War II poster encouraging car pooling. Urban commuters average $\mathbf{1 . 2}$ passengers per vehicle to and from work.

An expanded program of auto purchase taxes and rebates could complement fuel economy standards and taxes, but it could also pose serious trade difficulties as long as the high-efficiency end of the auto market is dominated by imports. If implemented suddenly, such measures would put domestic manufacturers at a disadvantage; on the other hand, measures designed to protect domestic manufacturers might conflict with General Agreement on Tariffs and Trade (GATT) rules.

Fuel Economy Standards-Standards influence the tradeoffs among cost, performance, size, and efficiency that underlie the development and introduction of new models. The current fuel economy standards for cars, in place since 1978, have helped to increase auto fuel economy (21), More stringent standards can both lower $\mathrm{C}_{2}$ emissions and reduce our dependence on imported oil. Redesigned stand- ards that vary with vehicle volume can help minimize the burden on U.S. manufacturers that offer a full range of car sizes $(31,49)$.

Incentives for Vehicle Manufacturers-One incentive, aimed at producers instead of consumers, is the use of government-sponsored competitions to induce manufacturers to develop high-efficiency or alternate-fueled cars. A variant of the incentive scheme injects competitive elements into a highefficiency rebate program. For example, the government could identify a few classes of vehicles most in need of fuel economy improvement and offer a competitive reward in the form of consumer rebates on a large (e.g., 200,000 units) production run of a new vehicle achieving the best fuel economy above a specified threshold.

Efficient Vehicle Operating Practices----Changes in vehicle operating practices offer small potential reductions individually but often have short startup times and do not require large, upfront capital investment. They include reimposing (and enforcing) the 55-mph speed limit; requiring efficiency inspections for trucks; and charging efficiencypromoting parking fees at Federal offices.

Transportation Control Measures (TCMs)TCMs include a wide variety of measures to reduce the number of vehicle miles traveled (VMT) and lower congestion. They are attractive because they typically have short startup times and low capital costs, and can reduce energy use and greenhouse emissions even within existing settlement and employment patterns. In aggregate, TCMs appear to hold modest promise for reducing VMT. They include:

- ridesharing (promotion and matching services);

- employer-based transportation management (high parking charges, transit or vanpool subsidies, and expedited transactions-e. g., bus passes, van leasing, and insurance made available at work);

- High-Occupancy Vehicle (HOV) lanes (restricting lanes on freeways to cars with three or four occupants and to buses);

- parking management (parking taxes or development surcharges, restricting street parking, and mandating high parking charges at workplaces);

- Park and Ride (intercept drivers near their origins); 
- mass transit improvements (bus service expansion, operational changes, and fare changes);

- travel substitution (telecommunications, workat-home, 4-day work weeks);

- traffic flow improvements (sophisticated signals, ramp metering, intersection improvement); and

- bicycling promotion.

Under the Energy Tax Act of 1978, employerprovided vanpools between an employee's residence and place of work were excludable from the employee's income if the vehicle was capable of carrying nine people. Congress could consider reinstating this provision or a variation of it.

Under present law, employer-provided transit passes, tokens, fare cards, and employer reimbursements for travel over $\$ 15$ per month are considered taxable income. However, under current Federal tax law the value of parking provided to an employee is excludable from the gross income as a fringe benefit. Congress could consider making reimbursements for public transportation nontaxable or making parking taxable.

Controlling Settlement Patterns-Long-term reductions in emissions can be achieved by changing patterns of settlement to reduce the need for travel. This can be accomplished through higher densities, or through mixing uses so that residences, jobs, and services are roughly balanced at a local scale. When more destinations are close to home, more trips can be made by foot; when densities are higher, public transit can serve more people effectively.

In the United States, except possibly for some high-growth areas in the South and West, efforts to change the shape of settlement in major cities may meet local resistance. Nevertheless, some changes are feasible in suburban areas nationwide, Stringent suburban restrictions on development-sometimes only on commercial and industrial development, sometimes on new residential development as wellhave been attempted in some regions of the United States (12).

Transportation RD\&D-American automakers lag behind their Japanese, and to a lesser extent their European, counterparts in moving research results to the market (3). In the 1980s, a program to support more aggressive research and development in the American auto industry-the Cooperative Automotive Research Program-was briefly attempted by the Department of Transportation. A revived, combined government/industry program could be successful if domestic automakers, their suppliers, and innovative research companies all are key players. The program could target important efficiency areas such as continuously variable transmissions, energystorage systems, new engine designs for heavy trucks, improved safety for lighter vehicles, and innovations to permit increased intermodal freight.

An area of longer term research that deserves special attention is development of truly clean, economically acceptable, alternative fuels and a supporting infrastructure. Fuels with the greatest potential-electricity or hydrogen from noncarbon energy sources (e.g., solar and nuclear) and woody biomass fuels grown on a sustainable basis-are the furthest from large-scale technical viability. Research in these areas could be expanded, with parallel programs to assess and demonstrate the actual performance of a variety of fuels.

\section{Manufacturing Sector}

For manufacturing, as shown in figure 1-7, three types of technical improvements offer the greatest promise. The first area is ' 'process changes.' The top four manufacturing energy consumers (paper, chemicals, petroleum, and primary metals)--which account for more than 75 percent of energy use in this sector-improved their energy efficiency by between 2.3 and 4.3 percent per year between 1980 and 1985 (52). If this pace can be maintained, as we assume in our Tough scenario, reductions equal to about 8 percent of current emissions (by 2015) will result.

Cogenerating electricity and steam for industrial processes is a second promising option. When utilities generate electricity, about two-thirds of the energy from burning the fuel is released as heat. If electricity is generated at industrial sites where the heat can be used, the efficiency of fossil fuel use can be increased dramatically. Under our Tough scenario, we assume that 90 percent of new and replacement industrial steam boilers will cogenerate electricity. Such measures can lead to reductions equivalent to about 5.8 percent of current total U.S. emissions.

More efficient motors are a third technical improvement that can lead to substantial improvements. Moderate and Tough measures might improve motor efficiencies by 10 percent and 30 
percent (1), respectively, yielding reductions of about 1.2 percent by 2015 under the Moderate scenario and 4 percent under the Tough one.

The following policy instruments could encourage these technical measures: carbon taxes, DSM, efficiency standards, marketable permits, tax incentives, informational policies, and RD\&D.

Carbon Tax-A carbon tax would levy economic penalties against the highest industrial emitters of $\mathrm{CO}_{2}$. Under such an approach, the tax would be highest on coal, low for natural gas, and zero for noncarbon sources (e.g., wind, solar, geothermal, or nuclear). For industries where the cost of energy is particularly important, carbon taxes should encourage energy efficiency, fuel switching and cogeneration.

Using several econometric models, the Congressional Budget Office estimated that a carbon tax of $\$ 100$ per ton would lower $\mathrm{CO}_{2}$ emissions from industry by between 10 and 35 percent by the year 2000. The higher reduction estimate reflects a 70 -percent reduction in coal use,

Demand-Side Management-DSM programsjoint programs between electric utilities and their customers discussed previously-can help lower electricity use in the industrial sector. The major programs are:

1. rebates to customers who install approved equipment;

2. low-interest loans to customers for conservation installations; and

3. installation of conservation equipment at utility cost (37).

Many large industrial customers of electric utilities receive special lower rates because they supply the utility with a large, dependable portion of electricity demand. Utility programs could facilitate reductions in greenhouse gas emissions if these special rates were contingent on efficient use of electricity. This differs from demand-side management in that the financial burden of improving energy efficiency is placed on the manufacturer, not the utility.

Standards $-\boldsymbol{A}$ more traditional regulatory policy is to require efficiency standards for common energy-using equipment, similar to those existing for automobiles and some appliances. Motors would be the most likely candidate for this approach.

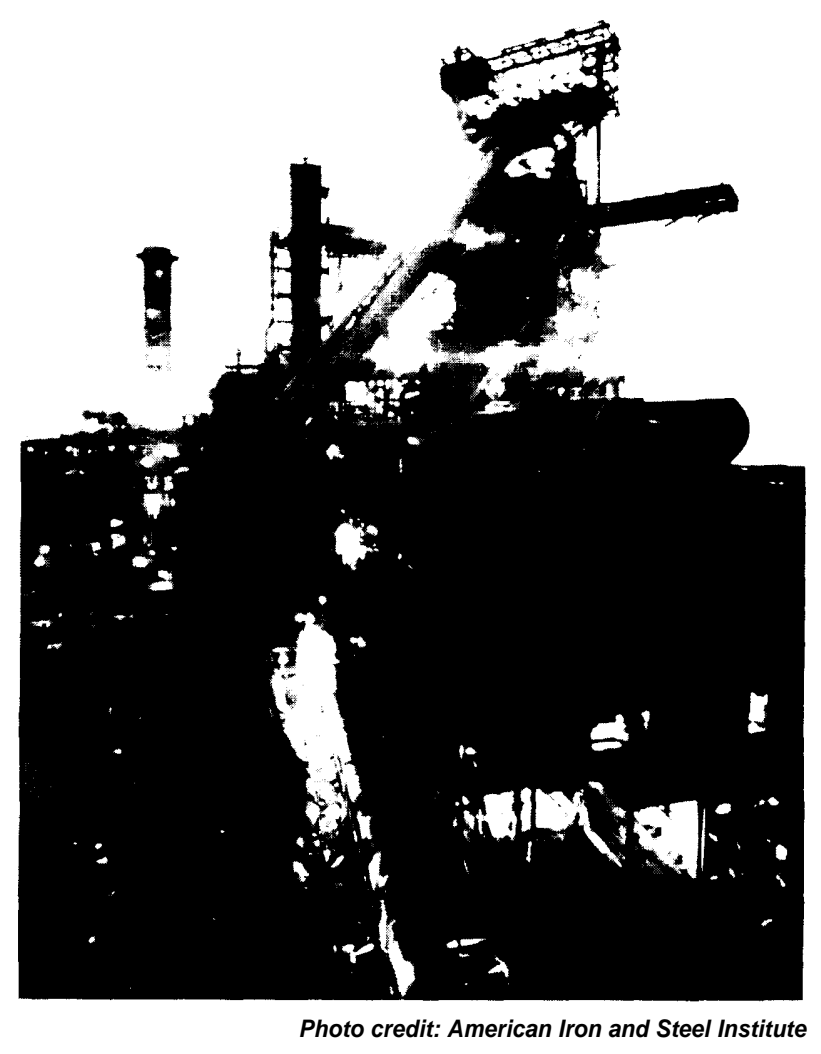

About 60 percent of the fossil fuels and electricity used by
industry provides process heat, steam, and cogenerated
heat and steam. Energy in manufacturing is also used
for feedstocks, mechanical drive, electrolysis,
lighting, and space heat.

Marketable Permits-- $\mathrm{CO}_{2}$ emissions can be regulated by requiring permits for emissions; manufacturers could be issued permits based, for example, on some percentage of their 1990 emissions. Reductions might be accomplished by installing energyefficient technologies and fuel switching; offsets could result from approved reforestation/afforestation projects. It would be up to the manufacturer to choose the most cost-effective strategy. Marketable permits would allow firms to trade their unused carbon rights to a firm that is exceeding its budget.

Manufacturing Tax Incentives-Much industrial equipment is old and energy-inefficient compared to the best available technology. In many cases, replacing old equipment improves energy efficiency by 10 to 50 percent. Financial policies, such as tax credits or accelerated tax depreciation schedules, aimed at stimulating rapid replacement of older equipment have the potential to stimulate 
improvements in energy use, Such policies have a precedent: the Energy Tax Act of 1978 provided a 10-percent added "energy investment tax credit" for certain energy-conservation investments (as well as tax credits for some energy-supply investments). The tax credits were available until 1985 and applied to a specific list of technologies. However, rather than specify which technologies qualify, Congress could foster innovation by offering similar-or greater-tax breaks for company-chosen conservation technologies.

Informational Policies-A barrier to reducing emissions in the manufacturing sector is lack of information about how to improve energy useespecially for smaller, less energy-intensive industries. Informational policies can include performance goals, the collection of performance data, labeling of the energy performance of equipment, training, and performance audits.

Renewed support for cooperative government/ industry information-sharing programs could help. For example, DOE's Energy Analysis and Diagnostic Center program funds faculty and students at several universities to perform free energy audits for small and medium-sized manufacturers in more than 30 States. Because costs saved by manufacturers translate to increased taxable income, the program can provide additional tax revenues to the Federal Government. The biggest cost savings have come from efficiency improvements associated with cogeneration, space heating, lighting, and process equipment maintenance and replacement (in descending order of savings; ref. 25). This program could be expanded or new programs could be modeled after it.

Manufacturing R\&D-Research and development sponsored by DOE's Office of Industrial Programs in waste energy reduction and industrial process efficiency, if funded, are projected to save more than 3 to 4 percent of energy used by industry per year over the next decade. Research areas identified by Oak Ridge National Laboratory as particularly promising are: improved use of catalysts in chemical production; intelligent sensors and controls; and heat recovery and cogeneration (16). R\&D in nonenergy areas, such as materials science, also holds promise for partial replacement of energyintensive materials like steel and aluminum. Likewise, research and development to improve the quality of products made with recycled materials could help reduce energy use by increasing the
Figure I-8--Electric Utility Supply-Side Measures

Moderate controls* ${ }^{\star}$ Tough controls ${ }^{\star *}$

Existing plant measures:

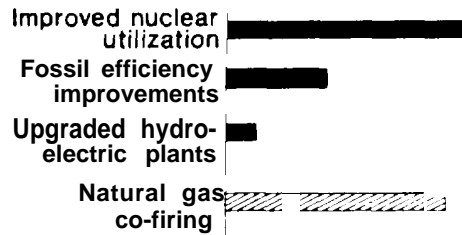

New plant measures:

No new coal; higher

fraction of new

nonfossil sources

$\mathrm{CO}_{2}$ emission rate

standards

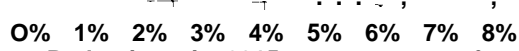

Reductions in 2015 as a percent of of 1987 emissions

- assureing Moderate demand-side measures

- assuming Tough demand-side measures

NOTE: Reductions presented as a percentage of total U.S. carbon emissions in 1987.

SOURCE: Office of Technology Assessment, 1991.

demand for recycled materials such as paper, steel, and aluminum.

\section{Electricity Generation}

About one-third of U.S. carbon emissions come from generating electricity (see figure 1-3); by 2015 under our Base case this may be as high as 45 percent. Thus measures that lower the rate of carbon emissions per kilowatt-hour $(\mathrm{kWh})$ of electricity generated would translate into substantial reductions.

Figure 1-8 shows OTA's estimate of the technical potential for emissions reductions in the electric utility sector depending on the demand for electricity and the stringency of policies. Moderate utility supply-side measures can lower emissions by about 6.6 percent (see table 1-1). The two with the greatest reduction potential are: 1) increasing the efficiency of fossil fuel-fired plants (by about 5 percent) through improved maintenance (14); and 2) operating existing nuclear powerplants 70 percent of the time (similar to Western Europe and Japan (16) and extending their useful life to 45 years.

Our Tough measures eliminate coal use wherever possible. A combination of renewable energy sources, nuclear plants with improved designs that may be available after 2005, and high-efficiency gas turbines are the only new utility plants built under the 
Tough scenario. However, if all the Tough demandside measures in the buildings and industrial sectors are implemented, growth in demand for electricity is so low that very few new plants are needed through 2015 . Thus, the only way to lower emissions under this scenario is to either cofire existing coal plants (e.g., with 50 percent natural gas), or retire existing coal plants after 40 years of operation (rather than the typical 60 years) and replace them with renewable or nuclear fuels or natural gas. The former measure would reduce emissions by about 3.7 percent by 2015; the latter, by about 4.7 percent of current levels by 2015 .

The following policy options could be used to encourage these technical measures: carbon taxes, marketable permits, subsidizing noncarbon sources, emissions limits and standards, and RD\&D.

Carbon Taxes- $\boldsymbol{A}$ carbon tax, if set high enough, would encourage fuel switching and conservation. A carbon tax in the range of $\$ 75$ to $\$ 150$ per ton would make natural gas a more economic choice than coal at many facilities. A carbon tax would also provide added motivation to develop more noncarbon energy sources.

Marketable Permits---Utilities could be issued marketable permits for $\mathrm{CO}_{2}$ emissions allowed from their coal-fired units, based on their generation in a historic year (e.g., 1990) multiplied by an allowed emission rate. Under this approach some utilities could curtail coal use more than necessary to meet their limits and sell permits to others exceeding their limits.

A variant on the above approach is to simply issue permits for a limited amount of coal use in existing facilities. Such an approach would be simpler to administer than emission permits, but it does not give credit to more efficient coal plants or to those plants that use lower $\mathrm{CO}_{2}$-emitting coals.

To hold new coal plant construction between now and 2015 to a predetermined level, a limited number of coal permits (or carbon permits specific to coal plants) could be auctioned each year to the highest bidder. If such a policy were adopted in combination with marketable permits for existing coal plants, utilities could be allowed to freely trade among new and existing facilities.
Subsidize Noncarbon Sources-Any of the general financial instruments, such as a carbon tax or fossil fuel energy tax, will serve to encourage use of nonfossil sources for electricity generation. According to one estimate (42), a 2 cent-per-kWh subsidy or its equivalent ${ }^{20}$ for only renewable sources of electricity might double the contribution of renewable sources of electricity by $2010-i$. e., allow them to supply 40 percent of new demand under a Base case growth scenario. Under our Tough scenario, we assume nonfossil sources can provide between 30 and 45 percent of new demand (depending on the success of other demand-side measures).

$\mathrm{CO}_{2}$ Emission Limits and Efficiency StandardsCongress could mandate reductions by setting $\mathrm{CO}_{2}$ emission limits or efficiency standards. For example, an emission rate limit of 0.55 pounds carbon per $\mathrm{kWh}(\mathrm{lbs} \mathrm{C} / \mathrm{kWh})$ would require a typical Midwestern plant burning Illinois coal to burn between about 10 and 30 percent gas, depending on its efficiency. At $0.55 \mathrm{lbs} \mathrm{C} / \mathrm{kWh}$, the most efficient new coal burning technologies (e.g., integrated coal gasification combined cycle, or IGCC) would just qualify burning coal alone.

Two somewhat different strategies could be pursued to set $\mathrm{CO}_{2}$ emission limits for new plants. If the intent is to force development of ultra-efficient coal technologies, then a standard in the range of 0.35 to $0.40 \mathrm{lbs} \mathrm{C} / \mathrm{kWh}$ would be appropriate. Molten carbonate fuel cells, if successful, might be able to achieve such emission rates using bituminous coals. If the intent is to limit new fossil fuel-fired generation to the cleanest sources only-advanced combined cycle turbines burning gas- then a new source performance standard of about $0.25 \mathrm{lbs}$ $\mathrm{C} / \mathrm{kWh}$ would be more appropriate. To speed up replacement of old plants with new, lower emitting ones, Congress could mandate the retirement of existing fossil-fuel-fired plants earlier than their expected lifetime of 60 years.

In addition, powerplant efficiencies are not routinely monitored and industry attention to methods for improving efficiencies is only fairly recent (15). To demonstrate how better monitoring affects energy efficiency, Congress could require TVA and the Federal power agencies (e.g., Bonneville Power Authority) to undertake improvement at their own facilities. About 4 percent of the electricity gener-

${ }^{20} \mathrm{~A} 2$ cent-per-kWh subsidy is equivalent to a carbon tax of $\$ 75$ per ton of carbon for coal and about $\$ 150$ per ton of carbon fOr naturalgas 


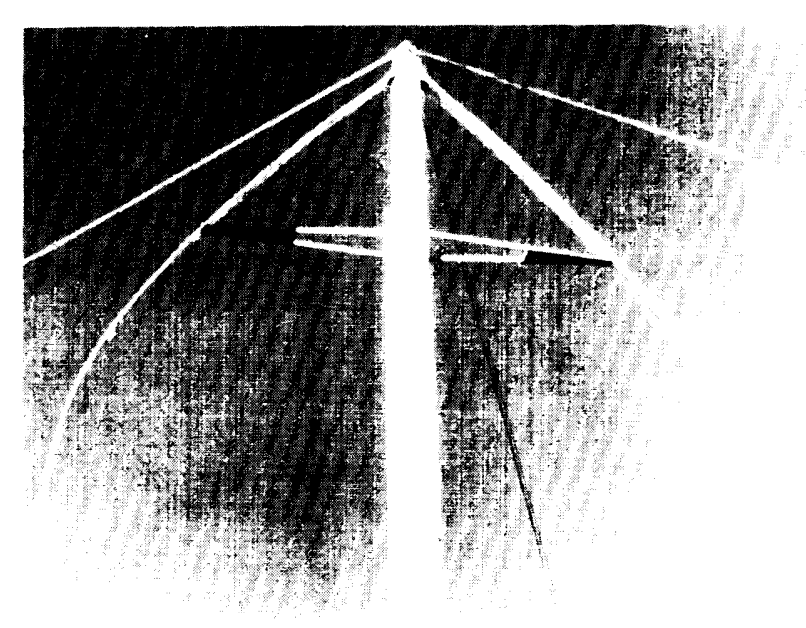

budgets (in 1990 dollars) for these three categories were 82 percent lower than they were in 1980 . To reinstate the funding levels of 10 years ago would require adding about $\$ 2.6$ billion. By doing so, the Federal Government could hasten the development and demonstration of supply technologies that would reduce greenhouse gas emissions. The most promising of these technologies include: commercial fuel cells; storage technologies for solar electricity; biomass-driven turbines; variable-speed wind turbines; and better designs for nuclear powerplants. Many experts estimate that these technologies could be commercially available within the next few decades.

The government could also play a role in reducing the perceived risk of new technologies and integrating renewable energy sources in existing energy systems by conducting demonstration projects or, perhaps, providing government-backed loans. To encourage new nuclear energy sources, a two-track process appears best: the Department of Energy could help fund full-scale demonstrations of both new "evolutionary' light water reactors and "revolutionary' design changes such as a modular high-temperature gas reactor.

For existing nuclear powerplants, the goal should be to increase the number of hours of operation, rather than to increase efficiency of fuel use, A Department of Energy demonstration program (coordinated with the Nuclear Regulatory Commission) might bring U.S. hours of nuclear plant operation from well below to above the average for Western Europe and Japan. Key elements of such a program would include improving preventive maintenance; installing automated controls to improve reactor operation; and speeding up time spent refueling.

ated from fossil fuels comes from Federal power agency facilities (13).

The Federal Government, through the Federal Energy Regulatory Commission (FERC), also has indirect ability to influence private utility operations through its authority over the prices and conditions of interstate wholesale power sales. If Congress feels that the State Public Utility Commissions are not identifying and enforcing efficiency improvements, it could direct FERC to consider these issues when regulating interstate wholesale power sales.

Energy RD\&D Funding-Over the last decade, Federal funding for renewable energy, conservation, and nuclear (fission) R\&D fell rapidly (see figure 1-6). The 1990 combined energy technology R\&D

\section{Forests}

Forestry-related measures with the greatest potential to offset carbon emissions include increasing the productivity of existing forests, planting trees in new areas, and growing tree crops for biomass energy; we consider these to be Tough measures, with the exception of ongoing tree planting in the Conservation Reserve program. As shown in figure 1-9, OTA estimates that the increased carbon uptake from increasing productivity on about 60 million hectares of timberland might be equivalent to annual emissions reductions of about 3 percent of current levels by 2015 . Planting new trees (i.e., afforestation) on farmland and other nonforested areas and in cities 
might result in carbon storage equivalent to emissions reductions of about 12 percent of current levels by 2015 . Planting trees for biomass energy might result in an additional reduction of about 1 percent by 2015 .

There are several caveats to this potential for offsetting emissions. Trees planted today can continue to store carbon beyond this report's 25-year timeframe. But this carbon eventually will be released to the atmosphere, either when trees die and decompose naturally, when they are harvested and burned, or when products made from wood eventually decompose. Unless the wood is used to displace fossil fuel use or is permanently stored under conditions that do not allow decomposition, carbon offsets in later years will dwindle, These estimates also assume that increasing the productivity of a forest's commercial timber component is equivalent to increasing the productivity of the entire forest ecosystem, but this assumption needs to be tested. Finally, forests - and the feasibility of using forestry practices to offset emissions-are likely to be affected by future climate changes. Therefore, forestry options in industrialized countries such as the United States cannot be considered a substitute for reducing total energy use, but rather as a way of "buying' time while developing alternative nonfossil fuel sources and improving the efficiency of energy use in general.

Congress could promote management practices that increase carbon storage or offset $\mathrm{CO}_{2}$ emissions by augmenting existing forest management and tree planting programs of the U.S. Forest Service (USFS) and the Agricultural Stabilization and Conservation Service, and by enhancing the biomass energy research program of the Department of Energy. In addition to direct support for such programs, Congress also could consider using financial mechanisms (e.g., changing income tax policies to encourage more investments in forest management; imposing a tax on fossil fuels to make biomass fuels more competitive).

Incentives To Increase Carbon Storage on Forest Lands-Incentives to increase productivityi.e., net carbon storage-will differ for publicly and privately owned forests. On public lands, which are located mostly in the West, management objectives
Figure 1-9--Forestry Measures

Forestry measures

g Moderate controls EZZ Tough controls

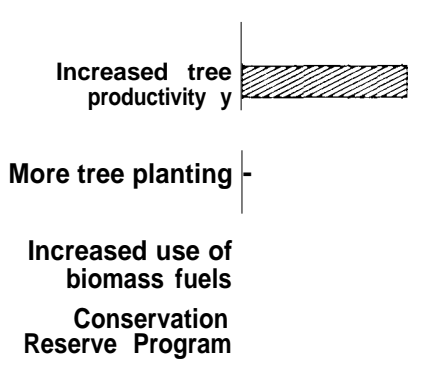

Urban trees

O\% $1 \%$ 2\% 3\% 4\% 5\% 6\% 7\% 8\%

Reductions in 2015 as a percent of 1987 emissions

NOTE: Offsets presented as a percentage of total U.S. carbon emissions in 1987.

SOURCE: Office of Technology Assessment, 1991.

are determined by planning processes legislated by Congress. ${ }^{21}$ Government investments in these lands are likely to focus on reforestation and timber stand management. Congress could direct the USFS and Bureau of Land Management to, for example, increase reforestation activities and to conduct research on the ability of "new forestry' practices that proponents contend might help to both maintain higher levels of diversity and allow commodity production.

Privately owned forests are most extensive in the East and South. For nonindustry private forests, Congress could continue to increase assistance to States and private landowners under programs such as the Forestry Incentives Program and the Agricultural Conservation Program. These programs currently reach only about 2 percent of nonindustry private owners (32), even though these owners undertake over 40 percent of all reforestation. The Interior and Related Agencies Appropriations Act for fiscal year 1991 almost doubled funding for the USFS's State and private forestry programs, which include tree planting and management. The 1990 Food, Agriculture, Conservation, and Trade Act (Public Law 101-624), known as the 1990 Farm Bill,

\footnotetext{
${ }^{21}$ E.g., for National Forests in the Renewable Resources Planning Act (Public Law 93-378) and National Forest Management Act (Public Law 94-585), within the framework set forth in the Multiple-Use and Sustained-Yield Act of 1960 (Public Law 86-5 17).
} 


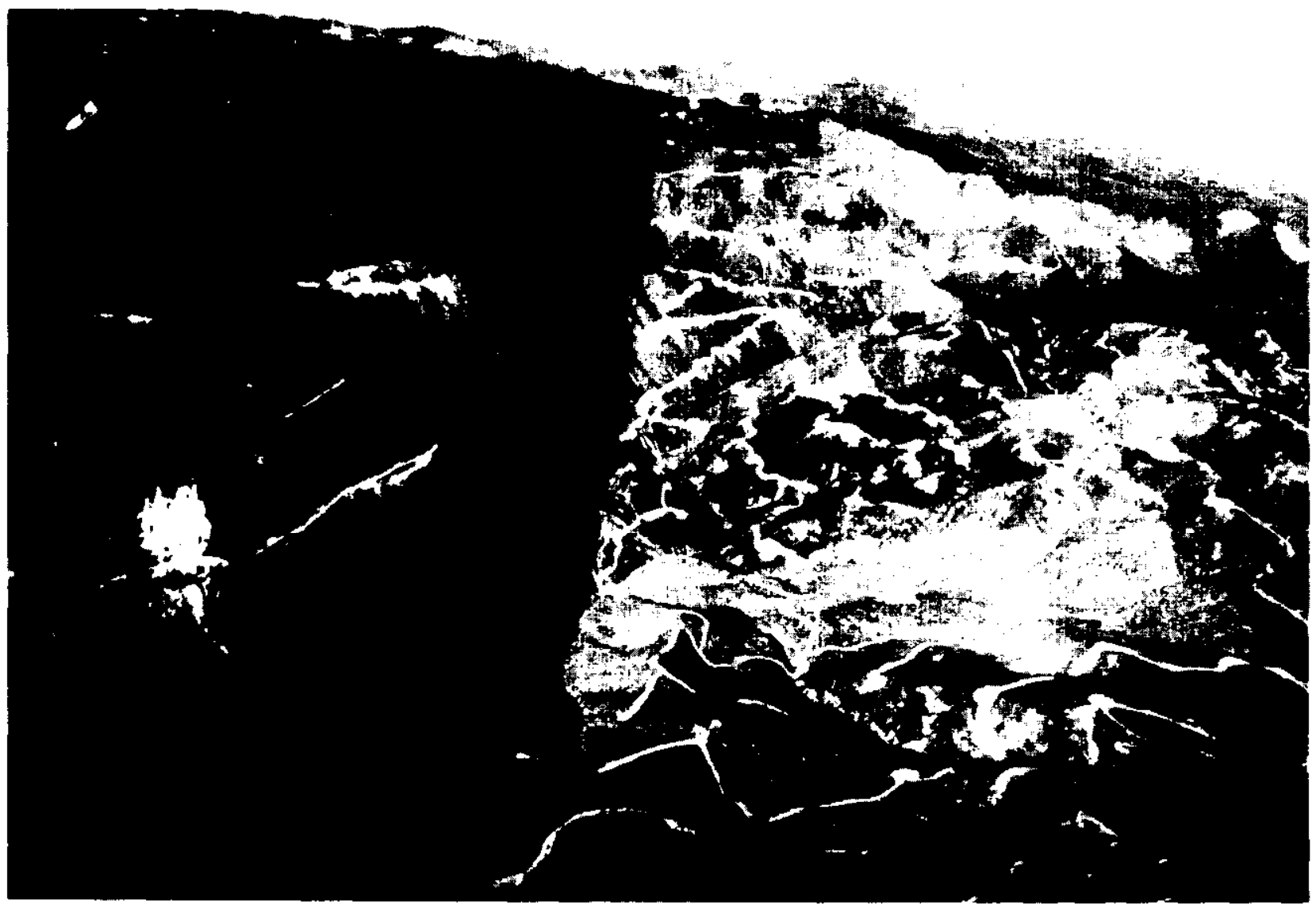

Photo credit: James P. Blair (c) 1990 National Geographic Society

The effects of clearcutting U.S. forests can be seen on the steep slopes of the Mount Baker-Snoqualmie National Forest below the Clearwater Wilderness.

also authorized a forestry stewardship program in which the USFS would work with State and local governments, land grant universities, and the private sector to improve resource management on privately owned forest land.

For industry-owned timberland, investments might be stimulated through changes in capital gains provisions (e.g., restoring preferential tax rates or providing a partial exclusion from taxable income for timber held longer than 20 years) or allowing full annual deductions for expenses, as well as by increasing funding for Federal assistance programs. One possibility for increasing support of such programs is to use funds that would accrue if below-cost timber sales in National Forests were eliminated.
Incentives for Growing New Trees on Unforested and Urban Lands-Mechanisms to promote afforestation include the Conservation Reserve Program (CRP), the President's proposed America the Beautiful program, and financial incentives such as tax credits for carbon storage. In general, any tree-planting program needs to consider the costs of maintaining trees in a healthy state once planted; this will be even more critical as climate changes occur.

Congress could expand the CRP by increasing its tree-planting goals and its incentives for enrolling land for tree planting (e.g., higher rentals, greater share of reforestation costs, longer contracts) .22 The 1990 Farm Bill expanded CRP eligibility criteria to include, for example, marginal pasture lands previously converted to wetlands or wildlife habitat,

\footnotetext{
${ }^{22}$ Under the CRP, farmers whotakclands out of production for 10 years receive annual rental payments from the Federal Government and ${ }^{\mathrm{a}}$ one-lime payment for one-half the cost of establishing protective vegetation.
} 
marginal pasture lands to be converted to trees in or near riparian areas, and croplands that contribute to water quality degradation. 23 Another option would be to, encourage new shelterbelts, perhaps through tax credits or by conservation compliance requirements tied to commodity support programs.

The 1990 Farm Bill authorized startup funds for the America the Beautiful tree-planting program, as well as funds for urban and community tree planting and maintenance. The Interior and Related Agencies Appropriations Act for fiscal year 1991 did not fired the program, although, as noted above, tree planting was included in funding for the USFS's State and private forestry programs. Infrastructure for increased planting also may need to be developed, since current planting is near the historical peak, and funding for long-term maintenance also will be needed.

Congress also could consider providing tax incentives (similar to those once more widely available for energy conservation) for properly planting and maintaining urban trees, especially near homes and buildings to save energy used for cooling.

Incentives for Biomass Energy To Offset $\mathrm{CO}_{2}$ Emissions--Growing short-rotation woody crops on nonforested land for use as an energy source shows some promise. Congress could increase funding for Department of Energy research on uncertainties regarding long-term productivity, including effects on nutrient availability, and costs. Increasing fossil fuel taxes would make biomass fuels more competitive. Even then, farmers wishing to invest in biomass crops maybe limited by loss of base acreage in commodity support programs and by lack of revenues for several years. Thus, changes in support programs or provision of some subsidy may be needed to stimulate investments in biomass crops on current cropland.

\section{Food Sector}

In the other U.S. sectors, $\mathrm{CO}_{2}$ is the primary focus of OTA's analysis, although both CFCs (e.g., in buildings and transportation) and methane (e.g., from natural gas production and distribution) also are assessed. The food sector, though, differs in two important aspects. First, the relative importance of methane $\left(\mathrm{CH}_{4}\right)$ and $\mathrm{N}_{2} \mathrm{O}$ emissions is greater than in other sectors. Although estimates are uncertain, the food sector may account for one-third of global $\mathrm{CH}_{4}$ emissions and anywhere from one-tenth to one-fifth of current global $\mathrm{N}_{2} \mathrm{O}$ emissions. Its contribution to total U.S. $\mathrm{CH}_{4}$ emissions is roughly 9 percent (its contribution to U.S. $\mathrm{N}_{2} \mathrm{O}$ emissions is uncertain, though).

Second, fossil fuel-related $\mathrm{CO}_{2}$ emissions (i.e., from farm machinery, irrigation equipment, fertilizer manufacturing, food transport, processing and packaging, and cooking) and CFC emissions (primarily from refrigeration) are subsumed in the transportation, industry, and buildings analyses summarized earlier. Further, $\mathrm{CO}_{2}$ emissions from agricultural-related deforestation in the United States are very small (although they are very important in developing countries). To place the food sector in perspective, though, we estimate that it accounts for at least 8 percent of total U.S. $\mathrm{CO}_{2}$ emissions and about 5 percent of U.S. CFC-11 and CFC-12 emissions (worldwide, it may account for one-fifth of global $\mathrm{CO}_{2}$ emissions and up to 15 percent of globalCFC-11 and CFC-12 emissions). ${ }^{24}$

In the past, congressional concern about agriculture largely has focused on farm production, promotion, and income. With the passage of the 1985 Food Security Act, Congress began dealing with some of the environmental impacts of U.S. agriculture. Although the 1990 Farm Bill expanded these efforts, including extending the CRP until 1995, additional steps can still be taken, as discussed below for methane and nitrous oxide emissions,

Some of the opportunities discussed earlier for the buildings, industry, and transportation sectors also can affect food sector activities (e.g., more efficient cooking, processing and packaging, etc.). In addition, fossil fuel-related $\mathrm{CO}_{2}$ emissions from the U.S. food system could be reduced by making fertilizer manufacture, farm machinery, and irrigation more energy efficient.

\footnotetext{
${ }^{23}$ This will enhance the chances of achieving the CRP's goal of reducing soil erosion problems; some of these lands could be devoted to tree planting.

${ }^{24} \mathrm{About} 70$ percent of the U.S. food sector's $\mathrm{CO}_{2}$ emissions (i.e., about 5 percent of total U.S. $\mathrm{CO}_{2}$ emissions) comes from fossilfuel combustion for food refrigeration, residential cooking, and food processing and packaging; the remainder comes from farm machinery, fertilizer manufacturing, and onfarm electricity use. These $\mathrm{CO}_{2}$ emissions do not represent a complete accounting of emissions from the U.S. food sector, for example, $\mathrm{CO}_{2} \mathrm{emissions}$ associated with food transport are not included.
} 
Reducing Methane Emissions-U.S. methane emissions from the food sector are primarily from ruminant anumals (e.g., cattle, sheep). Congress could direct the U.S. Department of Agriculture (USDA) to determine the potential for techniques such as improved nutrient management, feed additives, and manure management to reduce methane emissions. To limit future growth in, or even reduce, livestock populations in the United States, Congress could consider reducing or removing price supports for feed grains, which might make beef and dairy products more expensive (although it is unclear if the costs would rise or fall over the long term). Such a policy could cause large near-term economic disruptions for some farmers and portions of the food industry, however,

Reducing $\mathrm{N}_{2} \mathrm{O}$ Emissions-To reduce nitrous oxide emissions, Congress could modify commodity program policies, which now encourage monocropping and heavy fertilizer use, to give farmers more control over the types of crops they plant without losing program crop base acreage and support payments. ${ }^{2}$ Congress Could provide cropping flexi bility only to those farmers who adopt environmentally sound cropping patterns. Congress also could make implementation of best management practices (BMPs) a prerequisite for receiving Federal price and income supports. BMPs, designed by the Soil Conservation Service (SCS) to reduce soil degradation and water contamination from agricultural activities, include more efficient fertilizer use, water impoundments, permanent vegetative cover, and manure storage. ${ }^{26}$ At present, however, the SCS does not have statutory authority to promulgate enforceable regulations. Such a cross-compliance policy also would not apply to the one-third of U.S. croplands that are not enrolled in Federal farm support programs. In addition, enrolling more farm land in the CRP would help reduce $\mathrm{N}_{2} \mathrm{O}$ emissions from fertilizer use (as well as $\mathrm{CO}_{2}$ emissions from onfarm fossil fuel use and offsite fertilizer manufacturing).

Food RD\&D--The development of an accurate emissions database for the food sector is perhaps the most critical research priority. Increased research is needed to quantify $\mathrm{CO}_{2}$ emissions from agricultural land-clearing activities, $\mathrm{CH}_{4}$ emissions from ruminant animals (and from rice cultivation, particularly in the developing world), and $\mathrm{N}_{2} \mathrm{O}$ emissions from nitrogenous fertilizers. The emissions reduction potential of different alternative practices must also be investigated; for example, support is needed for research on methane-reducing techniques, especially for livestock in confined and rangemanagement systems. Congress also could increase funding for RD\&D efforts to develop new alternative practices, especially those that simultaneously increase crop yields and reduce greenhouse gas emissions per unit of food output.

\section{U.S. INFLUENCE ON THE REST OF THE WORLD}

There are many reasons why the U.S. Congress should seek to promote the reduction of greenhouse gas emissions abroad. First, climate change is a global problem. Solutions must come from all emitters, as reductions made by one country will only make a small dent in total greenhouse gas emissions.

Second, emissions of greenhouse gases will rise in the developing countries. Because the developing countries have higher growth rates for energy use, population, and Gross National Product (GNP) than do industrialized countries, and because their current energy use per person is so low, their emissions of greenhouse gases will continue to rise signnificantly, Stabilizing or even reducing greenhouse gas emissions from developing countries will be next to impossible to achieve (at least until nonfossil energy sources are widely available), given their need to increase energy consumption for supplying basic services. However, the United States could influence emissions growth rates in developing countries and also assist these countries to achieve economic progress by helping them to increase energy production based on nonfossil fuels (e.g., solar or nuclear) and to make both their energy production and consumption more efficient.

Third, energy-related improvements may be cheaper and relatively greater-at least in the short term-in developing countries, Eastern

\footnotetext{
${ }^{25}$ The 1990 Farm Bill now allows farmers to plant a limited amount of selected crops on land designated for other commodity program crops without losing program benefits.

${ }^{26}$ This idea also could be extended to other energy-intensive inputs such as pesticides and irrigation water. For example, the SCS could establish guidelines on how, and in what quantities, various inputs should be applied to crops in specific regions of the country.
} 
Europe, and the U.S.S.R. than in the United States. For example, because energy use in all the sectors of the U.S.S.R. and Eastern Europe is relatively inefficient, significant efficiency gains may be achieved at modest expense. In developing countries, much of the energy infrastructure is yet to be built; these countries can take advantage, for example, of new technologies that may be costeffective for new construction but expensive for retrofits.

Fourth, tropical deforestation contributes between 7 and about 30 percent of worldwide $\mathrm{CO}_{2}$ emissions; these forests are being lost at an estimated rate of over 17 million hectares per year-an area exceeding that of Virginia and West Virginia combined. In addition, much more than $\mathrm{CO}_{2}$ emissions is at stake. Tropical forests harbor at least half of the world's species, are the source of many products used by people living in the forests and elsewhere in the world (e.g. , medicines, nuts, fibers, fruits), and serve many critical functions such as watershed protection.

\section{Developing Countries}

The OECD countries (which include the United States), U. S. S. R., and Eastern Europe currently contribute about one-half to two-thirds of all greenhouse gas emissions, mostly from combustion of fossil fuels to power their economies (see figure 1-1; note the caveat on the figure regarding how the wide range of estimates of $\mathrm{CO}_{2}$ emissions from deforestation affects estimates of the relative contribution from each region). In contrast, developing countries contribute about one-third to one-half of emissions, mostly from land use changes and practices (e.g., deforestation of tropical forests, cultivation of rice, and raising of livestock).

Most current forest-related greenhouse emissions come from tropical forests, which are located almost exclusively in developing countries and which are being felled, burned, and degraded on an unprecedented scale. ${ }^{27}$ In contrast, loss of temperate zone forests, located mostly in developed countries, currently contributes little to $\mathrm{C}_{2}$ emissions, although many of these forests were cleared in the past.
The major causes of tropical deforestation and degradation are the conversion of forests to temporary agriculture (e.g., 'shifting' cultivation) and permanent agriculture (including cattle ranching), and poor timber harvesting practices. However, these are driven by underlying social, economic, and political factors-poverty and lack of land tenure for most people, national development policies, and foreign debts - that are exacerbated by rapid population growth (60). These factors encourage rapid exploitation of natural resources, for example to expand development and obtain foreign currency for servicing debts.

Emissions from fossil fuel use in developing countries are relatively less important now but will increase significantly in the future. Decisions that these countries make within the next 5 to 10 years about how to pursue economic growth and expand energy services and infrastructure (e.g., industrial bases, electric generation) will influence their share of emissions for decades to come. The ongoing OTA assessment, "Fueling Development: Energy and Technology in Developing Countries, "will continue to examine this issue. A background report (51) discusses linkages between energy use, economic development, and environmental quality.

Figure 1-10 shows the great disparity in per-capita energy use in different parts of the world. Although a person in a developing country uses about onefifteenth the amount of energy as does the average U.S. citizen, ${ }^{28}$ even modest gains in per-capita and total economic growth in these countries translates into emissions that will exceed those from the developed world within a few decades. And such growth is likely to be more than moderate. Developing countries have been increasing their total energy use by approximately 6 percent per year, in contrast to 1 percent in OECD countries, and they increased their electrical power consumption by an average of 8 percent per year between 1971 and 1987; most of the added electrical capacity was provided by conventional power-plants (which are high $\mathrm{CO}_{2}$ emitters) and was used for manufacturing and in buildings (43). Further increases will be needed since many countries are continuing to fully electrify cities and beginning or continuing rural electrifica-

\footnotetext{
27**Deforestation" means converting forest land to other vegetation or uses (e.g., pasture, cropland, darns). "Degradation" involves practices that leave trees as the predominant vegetation but degrade overall forest quality (e.g., soil erosion; damages to trees and streams from selective logging).

${ }^{28}$ The average American uses about 260 million Btu's. The average for the entire developing world (defined by the World Bank as " $l$ lower and middle income' countries) is about 20 million Btu's. The average for the selected developing countries shown in figure 1-10 is 25 million Btu's.
} 
Figure I-I O-Per Capita Energy Consumption

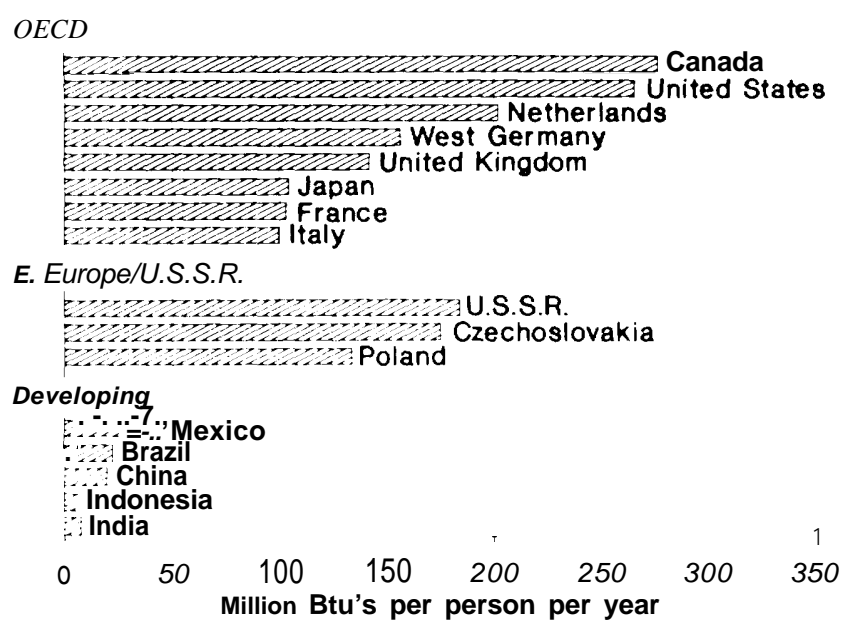

SOURCES: U.S. Congress, Office of Technology Assessment, Energy in Developing Countries, OTA-E-486 (Washington, DC: U.S. Government Printing Office, January 1991),

tion programs, and since refrigeration and airconditioning are becoming more widely available. Moreover, rapid population growth, in combination with economic growth, will continue to fuel increased demands for energy and land resources long beyond the time frame of this study; the world population now grows by over 10,000 people per hour (figure 1-11), with virtually all of that growth occurring in developing countries.

\section{U.S.S.R. and Eastern Europe}

The economies of the U.S.S.R. and of Eastern European countries have been centrally planned for decades but now are changing, rapidly in some cases. ${ }^{29}$ These countries account for about one-fifth of current global greenhouse gas emissions, mostly from the combustion of fossil fuels to provide energy. In 1988, the U.S.S.R. accounted for 18 percent of global primary energy consumption, Eastern Europe for 6 percent. The energy infrastructure in place in these countries is generally old and inefficient.

Efforts to promote energy conservation and efficiency in Eastern Europe and the U. S. S. R., and thereby reduce future growth in carbon emissions, face major obstacles. First, energy is highly subsi-
Figure I-I I-World Population Growth, 1750-2100

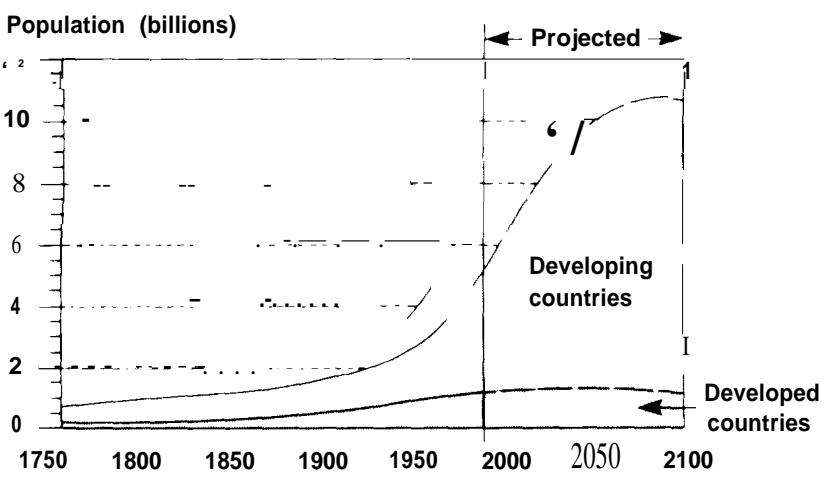

SOURCE: Population Reference Bureau, 1990 World Population Data Sheot (Washington, DC: 1990).

dized, so consumers (particularly industries) bear only a small portion of its real costs. ${ }^{30}$ Second, the central economic planning systems set rigid quotas for production (i.e., gross output) of goods and services. Enterprises must consume virtually all of the supplies allocated to them by central planners, even when not all are needed, in order to receive the same amount next year. Third, the production quotas require investments in heavy industries (e.g., steel, aluminum, chemicals) at the expense of services and consumer goods. Finally, implementation of plans for alternative energy sources is hindered by a fragmentation of responsibilities among multiple government agencies.

Thus, even when opportunities exist, there are strong disincentives to save energy and raw materials or to invest in energy efficiency. These obstacles have led to high industrial demand for energy, energy-inefficient production of goods and services, less availability of electricity for nonindustrial consumers, low standards of living, and severe environmental problems in many areas.

\section{U.S. Policy Options To Help Limit Greenhouse Gas Emissions Abroad}

Earlier sections in this summary set forth specific policy options that the United States could pursue to reduce or offset its own greenhouse gas emissions. By taking such actions to reduce its own emissions, the United States can provide leadership through

\footnotetext{
${ }^{29}$ Eastern Europe as defined here includes Bulgaria, Czechoslovakia, East Germany (prior to unification with West Germany), Hungary, Poland, and Romania.

${ }^{3}$ In Poland, for example, subsidies accounted for 49 percent of the delivered price of coal and 83 percent of the delivered Price of natural gas in $9^{8} 7$ (ref. 4 1).
} 
example. In the broader context, the United States also can work towards the adoption of international conventions and protocols regarding climate change, similar to those developed for phasing out CFCs and halons.

The United States also can attempt to help developing countries, Eastern Europe, and the U.S.S.R. to minimize their greenhouse gas emissions, without hindering the prospects for needed economic development. Indeed, strategies to lower greenhouse emissions can simultaneously help these nations become more economically efficient. Numerous existing programs and organizations in the United States and on the international scene directly influence development and indirectly can affect greenhouse gas emissions (see box 1-C). The United States, for example, provides direct bilateral assistance through the U.S. Agency for International Development (A. I,D.). Numerous other U.S. agencies-such as the State Department, the Commerce Department, the U.S. Trade Representative, the Treasury Department, the Agriculture Department, and the Environmental Protection Agency - support technology transfer and development assistance in certain areas. Through these U.S. and international organizations, the United States currently contributes about $\$ 9$ billion annually in foreign aid assistance (including bilateral aid, food aid, securityrelated economic support funds, and multilateral aid) to developing countries. ${ }^{31}$

The United States can continue to work through its own bilateral assistance programs and international organizations, as well as through NGOs, to increase the development and transfer of technologies and policies related to energy, family planning, and land use and management practices that provide sustainable alternatives to deforestation and dependence on fossil fuels. General congressional issues regarding developing countries, the U. S. S. R, and Eastern Europe fall into five categories:

. technology transfer and trade;

. building local institutional capacities;

-redirecting energy policies;

. redirecting natural resource policies; and

. redirecting family planning assistance policies.
Technology Transfer and Trade With Other Countries

The opportunity seems ripe for U.S. businesses to increase exports of energy-efficient and renewable energy technologies (as well as CFC-free technologies) to developing countries, since much of the energy infrastructure needed to fulfill development aspirations has yet to be built. For example, a market of $\$ 370$ to $\$ 900$ billion for electric power equipment is expected over the next 20 years (43). In addition, the U.S.S.R. and Eastern Europe have antiquated infrastructures in place; in these countries, the United States could provide modern equipment, as well as engineering and management services.

The U.S. Government promotes private sector technology transfer to non-OECD countries through government departmental programs (e.g., the Committee on Renewable Energy Commerce and Trade, or CORECT, led by the Department of Energy) and through independent government agencies and corporations (e.g., Eximbank, Overseas Private Investment Corp.). Some programs focus directly on energy technologies, while others are more general in nature.

Options-Congress could attempt to facilitate U.S. trade in renewable and efficient energy technologies in several ways. First, it could expand the financial resources of agencies that fund feasibility studies and project preparation (e.g., A. I.D., U.S. Trade and Development Program) or that provide financing for exports (e.g., Eximbank, Overseas Private Investment Corp.), as well as direct them to focus some resources on specific technology areas. For example, the fiscal year 1990 Foreign Operations Appropriations Act (Public Law 101-167) directs Eximbank to set aside 5 percent of its energy industry export funds for renewable energy projects. The Act also directed A.I.D. to focus on energy efficiency, renewable energy resources, and leastcost energy planning in the development of national energy plans, but additional funds were not appropriated. The Overseas Private Investment Corp. is planning a $\$ 100$ million Environmental Investment Fund.

\footnotetext{
${ }^{31}$ Compared to other countries, U.S. foreign aid and assistance is a relatively smaller percentage of its GNP. The U.S. portion was 0.19 percent in 1987 and 0.21 percent in 1988. In 1987, the larger Western European countries provided an average of 0.42 percent and Japan provided 0.31 percent; Notway topped the list at 1.1 percent.
} 


\section{Box l-C-Agencies and Organizations That Can Influence Greenhouse Emissions Abroad}

This box briefly describes major U.S. and international "players" looking at climate change. While no organization seems to place a premium on discouraging climate-modifying emissions for that reason alone, most are exploring the ways in which their policies and programs may affect climate change. In addition to those listed below, there are also many regional organizations, industry-sponsored consortia, non-governmental organizations, and philanthropic foundations that influence energy and environment policy internationally.

\section{U.S. Government Agencies}

The Agency for International Development is the lead agency for administering foreign economic assistance, through training, education and research, policy advice, technical assistance, and technology transfer. It is the second largest bilateral aid donor in the world (following Japan), spending over \$2 billion in 1989 on nonmilitary Overseas Development Assistance. Of that sum, about 1 percent (between $\$ 100$ to $\$ 2(\mathrm{X})$ million) is spent on energy projects. A.I.D. is presently undertaking an inventory of its activities and their related effect on climate change.

The Department of Agriculture promotes U.S. agricultural products and coordinates agricultural trade policy with other U.S. agencies. The Forest Service administers timber sales and other activities in national forests and is involved in international forestry issues. The Agricultural Stabilization and Conservation Service administers programs that provide cost-sharing for tree planting and forest management.

The Department of Commerce supports U.S. manufacturers and businesses in pursuing overseas export opportunities, collects and disseminates commercial information, and supports other U.S. overseas programs, including the Eximbank and the Overseas Private Investment Corp.

The Department of Energy is exploring, as a part of the forthcoming National Energy Strategy, how the U.S. energy program contributes to climate change problems and what technologies may be best suited to mitigate the problems. Among other programs, the department leads the multi-agency Committee on Renewable Energy Commerce and Trade, which promotes trade of U.S. renewable energy technologies.

The Department of State has responsibility for overall conduct of U.S. foreign policy. It is the lead agency in negotiating any international agreements and heads U.S. participation in the IPCC! process.

The Department of Treasury has primary responsibility for U.S. financial policies affecting other countries and for international financial institutions. The department's Office of Multilateral Development Banks directs the U.S. Executive Directors that sit on the boards of the multilateral development banks (e.g., the World Bank); through the directors, the United States has been active in scrutinizing the banks' environmental policies. The department examines approximately 400 bank projects per year that might have adverse environmental effects.

The Environmental Protection Agency is examining climate change issues (including energy use, deforestation, sea-level rise, CFCs, and methane) in developed and developing counties; it provided technical support for U.S. involvement in the IPCC.

The U.S. Trade Representative is charged with formulating overall trade policy and with bilateral and multilateral trade negotiations.

\section{Independent U.S. Agencies/Corporations}

The Export-import Bank (Eximbank) is an independent government agency that facilitates exports of U.S. goods and services, particularly in developing countries. Its main programs include direct loans to foreign borrowers, export credit guarantees and insurance, and discount loans. Since it is not a development assistance agency, it must have a reasonable assurance of repayment.

The Overseas Private Investment Corp. (OPIC) is a public/private corporation created by Congress that directly finances projects sponsored by U.S. private investors in developing countries and provides insurance against political risks for U.S. private investments in those countries. In 1987, OPIC accounted for over $\$ 8$ billion in insurance and \$230 million in directly financed projects.

The U.S. Trade and Development Program, housed in the U.S. International Development Cooperation Agency, funds feasibility and planning studies for projects involving export markets for U.S. goods and services; its focus is primarily on large public sector projects. 


\section{Box l-C--Agencies and Organizations That Can Influence Greenhouse Emissions Abroad- Continued}

Multilateral Development Banks (MDBs)

The World Bank, the largest multilateral development bank, spent approximately $\$ 15$ billion in 1989, including \$3.3 billion in the energy sector. Bank funding for free-standing environmental projects from 1990 through 1992 is expected to be about $\$ 1.3$ billion. The Bank recently issued an operational directive outlining procedures for assessing the environmental consequences of proposed projects; it is too early to ascertain its effects. In 1990, the United States lost its position as the largest international aid donor to Japan This change will reduce the U.S. voting share in the Bank.

The three regional MDBs--the Asian Development Bank, African Development Bank, and Inter-American Development Bank-are also major sources of assistance and have a larger role than the World Bank in many countries, for example in Central America. The latter two banks have provided about $\$ 1$ billion for energy sector projects since 1988. The Inter-American Development Bank, like the World Bank, has established procedures for evaluating environmental impacts.

\section{United Nations Agencies}

The UN Development Program (UNDP) provides funding and advisory services to developing countries dealing with trade in development technology. It spent approximately \$122 million in 1988 for natural resource, energy, and environment projects.

The UN Food and Agriculture Organization (FAO) is active in rural and agricultural research and development, fuelwood and charcoal projects, and forestry issues (including coordinating the Tropical Forestry Action Plan).

The UN Population Fund (UNFPA) provides technical and monetary assistance to developing countries on population issues. It provided about $\$ 169$ million in 1988 for programs in 141 developing countries.

The UN Environment Program (UNEP) coordinates environmental activities within the United Nations and led the development of the Montreal Protocol to Protect the Ozone Layer. Along with the World Meteorological Organization, UNEP coordinated the Intergovernmental Panel on Climate Change (IPCC), and is one of the managers of the World Climate program.

The UN Industrial Development Organization (UNIDO) promotes industrialization in developing countries and provides assistance to improve industrial use of energy.

The World Meteorological Organization (WMO) monitors climate trends, provides a framework for research on global climate models, and facilitates the exchange of meteorological information between countries, Along with UNEP, it plays an important role in many activities involving climate change issues (see UNEP above).

\section{International Science and Natural Resource Organizations}

The International Council of Scientific Unions coordinates scientific research projects worldwide and works with non-governmental organizations and intergovernmental agencies. It runs the International GeosphereBiosphere Program and is a joint manager of the World Climate Program with UNEP and WMO.

The Intergovernmental Panel on Climate Change (WCC), setup in 1988 under the auspices of UNEP and WMO, has been the primary international forum for addressing climate change. Its three working groups were charged with: 1) assessing scientific evidence on climate change; 2) assessing likely impacts resulting from such change; and 3) considering possible response strategies for limiting or adapting to climate change. The groups were chaired by the United Kingdom, U. S. S.R., and United States, respectively. The IPCC's final report was presented to the UN General Assembly in the fall of 1990.

Other organizations focus on agriculture and forestry. The International Fund for Agricultural Development, funded by OPEC and OECD members, makes financial resources available on confessional terms for agricultural development in developing countries. The Consultative Group on International Agricultural Research is a network of organizations that conducts agricultural research in developing countries. The International Tropical Timber Organization provides a framework for coordination between tropical timber producing and consuming countries, and the Tropical Forestry Action Plan attempts to enhance donor coopemtion and funding in sustainable forestry management.

11111984, the United States had 19.5 percent of the voting power in the World Bank. This was larger than the combined voting power of the next three highest donors. 
On December 26, 1990, the United States announced that it will double the number of joint trade-promotion programs in 1991; top priority will be given to helping the U.S.S.R. increase its oil and gas exploration and production capabilities-a means of obtaining needed hard currency, In December 1990, the President also approved credit guarantees for Soviet purchases of up to $\$ 1$ billion in American commodities, making the U.S.S.R. eligible for some Eximbank credits and guarantees. However, the continuing upheaval in the U.S.S.R. suggests that the Soviets may be unable to take full advantage of these programs for some time. In addition, the June 1990 trade agreement signed by President Bush will not be submitted to Congress for approval until Soviet emigration laws are revised, so "Most Favored Nation" status cannot yet be conferred on the U.S.S.R.

Second, Congress could continue the process of streamlining restrictions on technology exports to Eastern Europe and the U.S.S.R. This could be done as part of the reauthorization of the Export Administration Act and/or by providing new directions on U.S. participation in the Coordinating Committee on Multilateral Export Controls (COCOM), a nontreaty agreement among 17 Western countries established to harmonize export control policies.

Third, Congress could provide further direction regarding "'tied-aid' financing (i.e., linking foreign aid to financing of foreign purchases of U.S products); such financing runs counter to free market policies but is used by other OECD countries. Congress already appropriated some resources for tied-aid financing to Eximbank, which decided to join with A.I.D. in creating a $\$ 500$ million tied-aid pool to leverage financing for exports of U.S. products.

Congress also could consider supporting-with the cooperation of the host countries and perhaps in conjunction with other donor countries-technology research and/or assistance centers in Eastern Europe and developing countries. EPA already is coordinating the establishment of the Budapest Center in Hungary, and A.I.D. has proposed that a Global Energy Efficiency Initiative be developed to promote pricing reform, end-use energy efficiency, cogeneration, and private-sector activities.

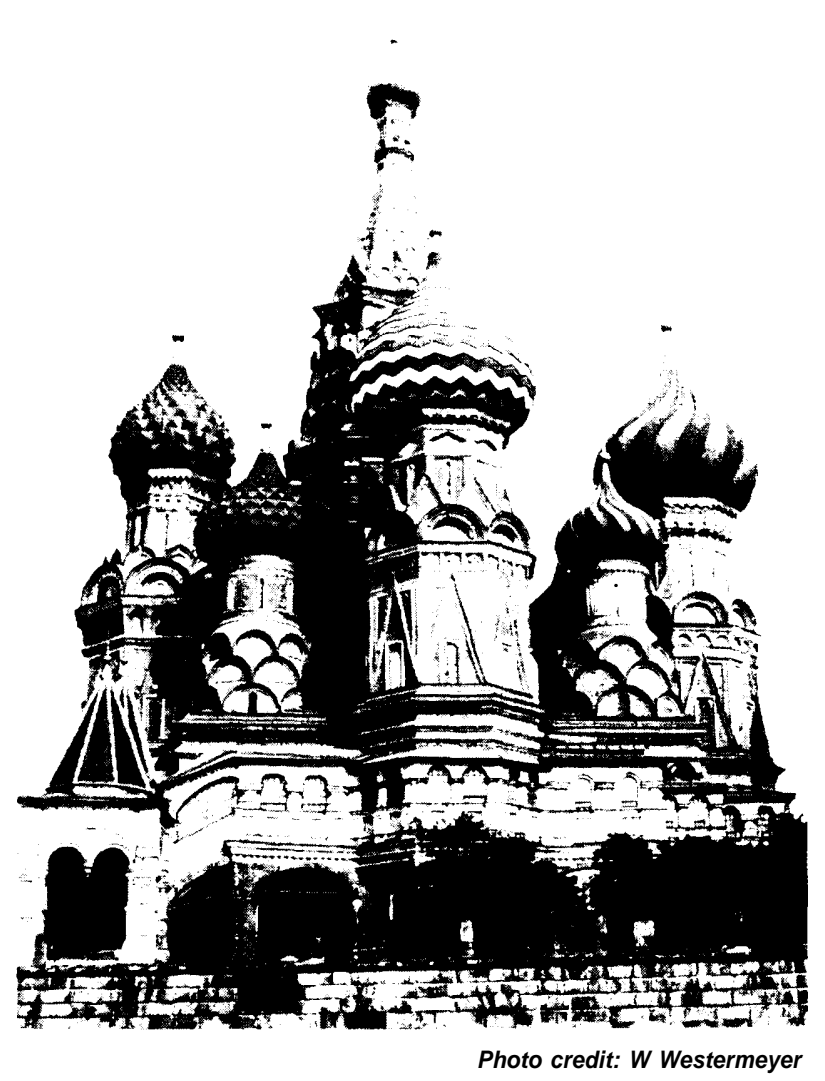

St. Basil's Cathedral, located on the edge of Red Square in Moscow, U.S.S.R. The Soviet infrastructure is both massive and inefficient; investments are needed both in new, more efficient facilities and in retrofitting existing facilities for better energy use.

\section{Building Local Institutional Capacities}

Many developing country and Eastern European governmental agencies and NGOS lack the resources and experience needed to plan and implement projects, meet requirements of international donors, and assess the impact of policies and budgets on resources $(29,61)$. Building the institutional capacities of these governmental agencies and NGOs is critical to the success of energy and natural resource policies and programs. Bilateral agencies such as A.I.D. and multilateral assistance agencies such as the World Bank, United Nations Development Program (UNDP), and United Nations Environment Program (UNEP) already provide some assistance to help build these institutional capabilities. ${ }^{32}$

\footnotetext{
${ }^{32}$ The 1989 International Development and Finance Act (Public Law 101-24.0) requires the U.S. Executive Directors to the multilateral development banks to promote increased assistance and support for non-U.S. NGOs.
} 
Options--Congress could direct A.I.D. to evaluate the effectiveness of its activities in this area. If found lacking, Congress could direct A.I.D. to increase its emphasis on this component, This would likely require increased funding for education and training; environmental information gathering and analysis; conservation planning and policy analysis; and coordination of regional authorities and communitybased organizations.

\section{Redirecting Natural Resources Policy}

Most developing country economies are based on natural resources $(29,61)$, many of which have been exploited rapidly during the past few decades. However, short-term revenue gains have come at the expense of the underlying resource base and the long-term economic outlook for some countries. During the 1980s, for example, some countries that once were net exporters of tropical hardwood products found that their forests could no longer maintain a positive export flow. Resource depletion in one area also can have unintended consequences elsewhere----e. g., upland deforestation has increased silting of reservoirs and flooding in many downstream areas.

Many national and multilateral development policies foster resource exploitation, including subsidies for cattle ranching and short-term, low-rent licenses for timber harvesting. Fortunately, direct bilateral and multilateral assistance is beginning to be restructured to promote more environmentally sensitive economic development, although much more needs to be done. A. I.D., the World Bank, the Inter-American Development Bank, and UNDP, among others, are all developing or have recently adopted environmental assessment guidelines.

In addition, the food sector in developing countries is a major direct source of greenhouse gas emissions, particularly methane from cultivating rice and raising livestock. Most people in developing countries also rely on biomass fuels to meet their cooking and heating needs,, in some cases, this has led to localized deforestation (from cutting fuelwood) or loss of soil nutrients (when dung and agricultural residues are used as fuels).

Options--Congress could influence what happens in tropical forests through several means:

1. encourage continued change in multilateral development bank (MDB) policies. For example, Congress should continue to review MDB progress in implementing environmental impact assessment procedures, and in making loans contingent on host country development policies (e.g., eliminating subsidies that encourage inappropriate cattle ranching and poor logging);

2 increase funding for A.I.D. projects on agroforestry, sustainable agriculture, natural forest management, and nontimber forest products;

3. direct A.I.D. and the State Department to help make the Tropical Forestry Action Plan and the International Tropical Timber Organization, both of which have been severely criticized lately, more effective vehicles for promoting forest conservation and improved commercial forest management;

4. support development of a global forestry conservation protocol;

5. address family planning, land reform, and debt reduction issues; and

6. provide directions for U.S. participation as a donor in the new Global Environmental Facility, established in November 1990 (and coordinated by UNEP, UNDP, and the World Bank) to provide funding for projects on greenhouse gases (e.g., non- $\mathrm{CO}_{2}$-emitting energy sources, energy efficiency, reforestation, CFC substitutes), biological diversity, and marine pollution.

The United States also can have some influence on emissions directly emanating from the food sectors of developing countries. Some of the policies described above for tropical forests, for example, would specifically involve agricultural projects. U.S. bilateral aid programs could attempt to introduce more efficient (in terms of greenhouse gas emissions) agricultural practices; this must, however, be carefully tailored to fit existing social traditions and economic conditions. At the same time, Congress could help fund, through U.S. bilateral aid programs and through multilateral lending organizations, various research organizations (e.g., the Consultative Group on International Agricultural Research centers) so that they could expand existing programs in developing countries to include methane reductions from livestock.

\section{Redirecting Energy Policies}

A. I.D., United Nations agencies, and the World Bank's Energy Sector Management Assistance Program provided over $\$ 200$ million in fiscal year 1988 
for energy-related grants and assistance; in addition, over $\$ 6$ billion was provided for energy-related loans. Including technical assistance from other countries and technical support derived from portions of the loans, total technical assistance for energy may be on the order of $\$ 500$ million per year-less than 1 percent of total annual energy expenditures by developing countries (28).

Until recently, much of this assistance, particularly that from bank loans, focused on conventional energy supply projects such as large hydroelectric dams and coal plants. In 1989, for example, World Bank lending for solar, geothermal, and wood-based energy projects amounted to less than 1 percent of its energy sector funding. Similarly, energy efficiency has not been a significant focus (57).

Options-Congress could redirect U.S. (and attempt to redirect multilateral) energy policies away from large-scale energy projects, such as oil- and coal-fired powerplants, and toward energy efficiency, renewable technologies, and least-cost planning. Congress could ensure that A,I.D. and the Department of Treasury have sufficient resources allocated to comply with the provisions of the fiscal year 1990 Foreign Operations Appropriations Act (Public Law 101-167), which is a step in this direction .33

Congress also could consider expanding A.I.D.'s Office of Energy program, which provides assistance to developing countries in formulating strategies for price reform. Similarly, it could encourage A.I.D. and the MDBs to work with the Eastern European and Soviet governments to initiate reforms in pricing policies.

To overcome agency reluctance to fund small projects, Congress could promote "bundling"combining several small energy projects into one large project that supplies a substantial amount of energy and involves financial scales customarily handled by large development banks (e.g., \$5 million or more). Public Law 101-167 instructs the Secretary of Treasury to work with borrowing countries to develop loans for bundled projects on end-use energy efficiency and renewable energy,

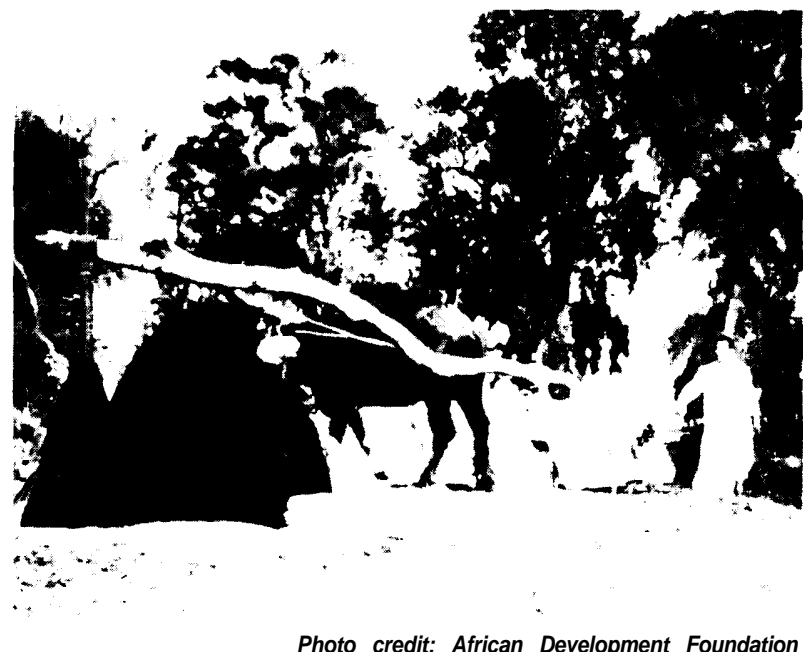

The juxtaposition of old and new technology: Guide leads oxen around solar cells at water pump, part of the Basaisa Project, Egypt.

Congress also could promote greater funding by smaller development organizations. ${ }^{34}$ For example, the Inter-American Foundation (IAF) and the African Development Foundation (ADF) work closely with the larger Inter-American and African Development Banks to find or implement community-scale, grassroots development programs. These smaller foundations generally have a greater ability to examine smaller scale, modular programs than do their parent organizations, but to date they have rarely been involved in energy projects.

\section{Population Policy Issues}

The U.S. Government supported the right of couples worldwide to control the number and spacing of their children beginning in the mid1960s; under the Foreign Assistance Act as amended in 1965, family planning is considered an important contributor to economic development and improved health and nutrition $(11,46)$. Most nations now firmly support family planning assistance.

However, at the world population conference held in Mexico City in 1984, the United States reversed its historic position by declaring that population growth was a 'neutral' factor and that economic

\footnotetext{
${ }^{33}$ Public Law 101-] 67 directed A.I.D. to identify key middle- and low-income countries in which energy and forestry policies could significantly reduce greenhouse gas emissions, Four countries-China, Brazil, Indonesia, India-appear to emit as much greenhouse gases as the other developing countries combined. Other countries considered strong candidates for attention include Poland, Egypt, Mexico, Thailand, Colombia, the Philippines, Bangladesh, Nigeria, and Zaire. A.I.D. currently does not provide direct assistance to China, Poland, or Mexico.

${ }^{34}$ Other mechanisms to facilitate private-sector trade $\mathrm{i}_{\mathrm{n}} \mathrm{e}_{\mathrm{ner}=\mathrm{e}} \cdot \mathrm{ff}_{\mathrm{ic}} \mathrm{i}_{\mathrm{en}} \mathrm{t}$ and renewable energy technologies were discussed above (see ' 'Technology Transfer and Trade With Other Countries" above).
} 
development could compensate for any population level. Associated with this change were new restrictions on A.I.D. Thus, two important international population assistance programs lost U.S. funds-the International Planned Parenthood Federation at the end of 1984, and the United Nations Population Fund (UNFPA) in early 1986. Moreover, U.S. funding earmarked specifically for A. I.D. 's main population account has declined in recent years, from \$290 million in fiscal year 1985 to an estimated $\$ 218$ million in fiscal year 1990 (44). ${ }^{35}$

Some people argue that family planning assistance should be reduced or eliminated as a part of international aid (1 1). However, the UNFPA (38) concluded that more assistance is needed if the world's population is to stabilize--sometime early in the $22 \mathrm{~d}$ century-at a level of 10 or 11 billion people (this is the UN's ' "mid-range' projection). In particular, more assistance is needed to eliminate the large ' "unmet need' for family planning services; the UNFPA estimates that the additional direct cost of providing contraceptive services would likely be less than $\$ 1$ billion per year, but that several billion dollars per year also are needed for a range of backup activities (e.g., education and communication, women's programs, research and evaluation).

Any global warming policies thus must include decisions on the U.S. role in international family planning. As indicated above, this issue has been and still is highly contentious. Nevertheless, Congress could reconsider the appropriate level of funding, how funds should be distributed, and under what restrictions or sanctions they should be distributed.

\section{CONCLUDING REMARKS}

Currently, the United States and other industrialized countries (including the U.S.S.R. and Eastern Europe) contribute up to two-thirds of all greenhouse gas emissions, mostly from fossil fuels used to power these highly energy-consumptive societies. There are opportunities for industrialized countries to stabilize or decrease their annual emissions of greenhouse gases. However, some sectors in Eastern Europe and the U.S.S.R. are; also likely to increase $\mathrm{CO}_{2}$ emissions still further. In the U. S. S. R., for example, there is only 1 car for every 25 people. In Poland and Hungary, living areas average 10 to 15 square meters per person as opposed to the U.S. average of 60 .

Developing countries currently contribute at least one-third of greenhouse gases, mostly from land use changes and practices (e.g., tropical deforestation, rice cultivation, and livestock). But, $\mathrm{CO}_{2}$ emissions will surely rise for developing nations still building an industrial base, just beginning to supply electricity to their people, and increasing the use of modern methods for cooking, heating, and transportation. Efficiency investments, while crucial to growth, can only decrease the need for new power; they can not eliminate it. Thus, if current trends continue, the greenhouse gas contribution from developing countries will grow quickly within a few decades to equal or exceed those from the developed world.

Social, cultural, and economic differences will be of paramount importance in any international negotiations that take place regarding climate change, For example, reductions in per-capita living standards (which reflect many of the above factors) are not a desirable policy goal, especially for countries that are well below the average. A goal for these countries is to decouple greenhouse gas emissions from desired economic growth. Conceptually, there are several ways to achieve this-switching to nonfossil fuels (e.g., solar, nuclear), increasing the efficiency of energy and materials use, reversing tropical deforestation, and implementing sustainable use of forest and agricultural resources. Moreover, no examination of the nature and dynamics of development, natural resource and energy use, and environmental protection can omit consideration of population growth nor, for that matter, issues such as foreign debt.

Options for the U.S. Congress are limited when dealing with the actions of other sovereign nations. However, Congress could directly encourage reductions in greenhouse gas emissions by adjusting aid policies and processes to take greenhouse gases into account. It could also encourage development and transfer of appropriate technology, encourage corporate ventures into nongreenhouse gas emitting technologies, and work towards adoption of international protocols.

\footnotetext{
${ }^{35}$ These are actualor estimated expenditures and vary slightly from official authorizations. Total funding for population-related projects was slightly higher, because some family planning projects also are funded under other accounts.
} 
The United States is the world's leading industrial society and largest single producer of $\mathrm{CO}_{2}$. Major reductions of $\mathrm{CO}_{2}$ and other greenhouse gases will require significant new initiatives by the Federal Government, the private sector, and individual citizens. The economic cost of these initiatives could be considerable. And many of these efforts must be sustained over decades.

OTA's analyses suggest that if the United States enacts a "Moderate set of low-cost technical options, $\mathrm{CO}_{2}$ emissions in 2015 will be about 15 percent higher than 1987 levels. If the United States enacts a 'Tbugh' package, $\mathrm{CO}_{2}$ emissions in 2015 could be as much as 35 percent below 1987 levels.

But, if the United States takes no action, emissions could increase by 50 percent in the next 25 years. This would continue the trend seen in the 1980s. Since the last two oil crises in the 1970s, concerted efforts to conserve energy have dwindled on all fronts-from government research and development to personal purchasing decisions. Many other goals diluted these efforts as energy prices dropped in the 1980s.

Now, as we begin the 1990s, several overarching issues loom on the horizon-energy insecurity, m demonstrated by the events in the Persian Gulf; domestic environmental problems as evidenced by numerous oiI spills and persistent air pollution; global environmental degradation such as the Antarctic ozone hole, and tropical deforestation; and sustainablc development as the Third World struggles to bring burgeoning populations into the industrial age and compete in world markets.

All of these concerns are difficult to control unilaterally, yet the changes they could induce in the average (J. S. citizen's lifc over the next few decades may be profound. However, a common thread runs through these issues and can serve as an overall national $\mathrm{g}(\sim$ al-efficient energy use and conservation of' natural resources. Ultimately, achieving this goal can help to sustain industrial output, competitiveness, and our overall quality of life. However, getting there will not be easy. Many of the options identified in this report can help move us in this direction while simultaneously reducing greenhouse gases.

\section{CHAPTER 1 REFERENCES}

1. Baldwin, S., "Energy-efficient Electric Motor Drive Systems," in T.B. Johansson et al. (eds.), Efficient End Use and New Generation Technologies ${ }_{p}$ and Their Planning Implications (Lund, Sweden: Lund University Pros, 1989).

2. Barns, D. W., W.U. Chandler, and J.A. Edmonds, "Atmospheric Methane Emissions: A Summary of Sources and Policy Issues," contract prepared for U.S. Congress, Office of Technology Assessment (Washington, DC: Battelle, Pacific Northwest Laboratories, October 1989).

3. Bleviss, D. L., The New Oil Crisis and Fuel Economy Technologies (Quorum Books, New York: 1988).

4. Bohi, D.R. and M.B. Zimmerman, "An Update on Econometric Studies of Energy Demand Behavior, 'Annual Review' of Energy 9:105-154, 1984.

5. Cantor, R.A. and D.A. Trumble, Gas Furnace Purchases. A Study of Consumer Decisionmaking and Conservation Investments, ORNL/ TM- 10727 (Oak Ridge, TN: Oak Ridge National Laboratory, 1988).

6. Cristafaro, A., "The Cost of Reducing Greenhouse Gas Emissions in the United States" (Washington, DC: U.S. Environmental Protection Agency, Air and Energy Policy Division, 1990).

7. Crutzen, P.J., I. Aselmann, and W. Seiler, "Methane Production by Domestic Animals, Wild Ruminants, Other Herbivorous Fauna, and Humans,' Tellus 38:271-284, 1986.

8. Dahl, C. A., "Gasoline Demand Survey," The Energy Journal 7(1):67-82, 1986 .

9. DiFiglio, C., K.G. DuLeep, and D.L Greene, ' 'Cost Effectiveness of Future Fuel Economy Improvements, submitted to Energy Journal, 1989.

10. DiFiglio, C., presentation at OTA workshop on transport and global warming, Apr. 6, 1989.

11. Donaldson, P.J. and C.B.Kcely, 'Population and Family Planning: An International Perspective, " Family Planning Perspectives 20(6) :307-3 11,320, November/December 1988.

12. Downs, A., "The Real Problem With Suburban Anti-Growth Policies, "Brookings Review', pp. 23-29, Spring 1988.

13 Edison Electric Institute, Statistical Yearbook of the Electric Utility Industry/1987. No 55 (Washington, DC: December 1988).

14. Electric Power Rescarch Institute, Power Plant Performance Monitoring and Improvement, EPRI report CS/EL-4415, vol.3 (Palo Alto, CA: February 1986).

15, Electric Power Research Institute, Power Plant Performance Monitoring and Improvement, EPRI report CS/EL-4415, May 1989

16. Fulkerson, W. et at., Energy Technology R\&D What Can Make A Difference?, Volume 2, Supply Technology, ORNL-6541/V2/P2 (Oak Ridge, TN: Oak Ridge Nationat Laboratory, 1989).

17. Geller, H. S., ' 'Residential Equipment Efficiency: A State of the Art Review, ' contract prepared for U.S. Congress, Office of Technology Assessment (Washington DC: American Council for an Energy-Efficient Economy, 1988).

18. Geller, H. S., "Commercial Building Equipment Efficiency: A State-of-the-Art Review," contract prepared for U. S Congress, Office of Technology Assessment (Washington, DC: American Council for an Energy-Efficient Economy, February 1988).

19, Goldemberg, J et al, Energy for a Sustainable World (New Delhi, India: Wiley Eastern Ltd, 1988).

20 Goldman, C.A, "Measured Results of Energy Conservation Retrofits in Residential Buildings, paper presented at 1986 ,4 SHRAE Winter Meeting, LBL-20950 (San Francisco, CA: Jan. 19-22, 1986).

21. Greene, D.L, 'CAFE or Price'? An Analysis of the Effects of Federal Fuel Economy Regulations and Gasoline Prices on New Car MPG, 1978 -89," Energy Journal, 11(3):37-57,1990.

22. Holdren, J. P., ' 'Energy in Transition,' Scientific American,pp. 1 S7-163, September 1990. 
23. Holtberg, P.D. et al., 1988 GRI Baseline Projection of U.S. Energy Supply and Demand to 2010 (Chicago, IL: Gas Research Institute, 1988).

24. Intergovernmental Panel on Climate Change, Scientific Assessment of Climate Change, Summary and Report, World Meteorological Organization/U.N. Environment Program (Cambridge, MA: Cambridge University Press, 1990).

25. Kirsch, F. W., Energy Conserved and Costs Saved by Small and Medium-Sized Manufacturers: 1987-88 EADC Program Period (Philadelphia, PA: University City Science Center, March, 1988).

26. Kolar, S. and W.U. Chandler, "Energy and Energy Conservation in Eastern Europe, " report prepared for U.S. Agency for International Development (Washington, DC: Battelle Memorial Institute, Pacific Northwest Laboratories, 1990).

27. Lawrence Berkeley Laboratory, "Buildings Energy Use Compilation and Analysis Project" (Berkeley, CA: Mar. 6, 1986).

28. Lawrence Berkeley Laboratory, Argonne National Laboratory, Oak Ridge National Laboratory, Sandia National Laboratory, Solar Energy Research Institute, Los Alamos National Laboratory, Pacific Northwest Laboratory, Energy Technology for Developing Countries: Issues for the U.S. National Energy Strategy, prepared for U.S. Department of Energy (Berkeley, CA: Lawrence Berkeley Laboratory, December 1989).

29. MacNeill, J., P, Winsemius, and T. Yakushiji, Beyond Interdependence, The Meshing of the World's Economy and the Earth's Ecology, A Report to the Trilateral Commission(Halifax, Canada: Institute for Research on Public Policy, 1990).

30. Mazurski, K. R., "Industrial Pollution: The Threat to Polish Forests," Ambio 19(2):70-74, April 1990.

31. McNutt, B. and P. Patterson, "CAFE Standards-Is a Change of Form Needed?" SAE Technical Paper Series, \#861424 (Warrendale, PA: Society of Automotive Engineers, 1986).

32. National Association of State Foresters, 'Global Warming and Forestry in the United States, ' background paper (Washington, DC: April 1990).

33. Ottinger, R.L. et al, "Environmental Costs of Electricity, "Oceana Publications, 1990

34. Piddington, K. W., "Sovereignty and the Environment, Part of the Solution or Part of the Problem?" Environment 31(7):18-20,35-39, September 1989.

35. Population Reference Bureau, 1990 World Population Data Sheet (Washington DC: 1990).

36. Ramanathan, V., "The Greenhouse Theory of Climate Change: A Test By an Inadvertent Global Experiment,' Science 240:293-299, Apr. 15, 1988.

37. Ross, M., "Improving the Energy Efficiency of Electricity Use in Manufacturing," Science 244:31 1-317, Apr. 21, 1989.

38. Sadik, N., "The State of World Population, 1990" (New York, NY: UN Population Fund, 1990).

39. Savinskaya, I., "Threat to the Biosphere, "Sovietskaya Kultura Mar. 25,1989 , p. 2 (reprinted in Joint Publications Research Service-USSR Economic Affairs, May 22, 1989).

40. Shapiro, L., P. Markowitz and N. Hirsh, A Brighter Future: State Actions In Least Cost Electrical Planning (Washington, DC: The Energy Conservation Coalition, December 1987).

41. Sitnicki, S. et al., Poland: Opportunities for Carbon Emissions Control, prepared for U.S. Environmental Protection Agency (Richland, WA: Battelle Pacific Northwest Laboratories, May 1990).

42. Solar Energy Research Institute, Idaho National Engineering Laboratory, Los Alamos National Laboratory, Oak Ridge National Laboratory, and Sandia National Laboratories, The Potential of Renewable Energy, An Interlaboratory White Paper, prepared for
U.S. Department of Energy, Office of Policy, Planning and Analysis, SERI/TP-260-3674 (Golden, CO: Solar Energy Research Institute, March 1990).

43. U.S. Agency for International Development, Power Shortages in Developing Countries: Magnitude, Impacts, Solutions, and the Role of the Private Sector (Washington, DC: 1988).

44. U.S. Agency for International Development, Congressional Presentation, FY 1991, Main Volume (Washington, DC: U.S. Government Printing Office, February 1990).

45. U.S. Congress, Congressional Budget Office, Carbon Charges as a Response to Global Warming: The Effects of Taxing Fossil Fuels (Washington DC: U.S. Government Printing Office, August 1990).

46. U.S. Congress, The Library of Congress, Congressional Research Service, "Library of Congress, Congressional Research Service, International Population and Family Plarming Programs: Issues for Congress," IB85187 (Washington, DC: Mar. 30, 1990).

47. U.S. Congress, Office of Technology Assessment Energy Use and the U.S. Economy, OTA-BP-E-57 (Washington, DC: U.S. Government Printing Office, June 1990).

48. U.S. Congress, Office of Technology Assessment, Electric PowerWheeling and Dealing: Technological Considerations for Increasing Competition, OTA-E-409 (Washington DC: U.S. Government Printing Office, May 1989).

49. U.S. Congress, Office of Technology Assessment, S. Plotkin, testimony before the Senate Committee on Commerce, Science and Transportation, May 2, 1989, "Increasing the Efficiency of Automobile and Light Trucks-A Component of a Strategy to Combat Global Warming and Growing U.S. Oil Dependence.'

50. U.S. Congress, Office of Technology Assessment, Replacing Gasoline: Alternative Fuels for Light-Duty Vehicles, OTA-E-364 (Washington, DC: U.S. Government Printing Office, September 1990).

51. U.S. Congress, Office of Technology Assessment, Energy in Developing Countries, OTA-E-486 (Washington DC: Us. Government Printing Office, January 1991).

52. U.S. Department of Energy, Energy Information Administration, Indicators of Energy Efficiency: An International Comparison, EIA Service Report, SR/EMEU/90-02 (Washington, DC: July 1990).

53. U.S. Departrnentof Energy, Energy Use Trendsin the UnitedStates, 1972-1984 (Washington, DC: May 1985).

54. U.S. Department of Energy, Energy Information Administration, Annual Energy Review, 1989, DOE/EIA-0384(88) (Washington, DC: May 1990).

55. U.S. Environmental Protection Agency, Office of Solid Waste and Emergency Response, Characterization of Municipal Solid Waste in the United States: 1990 Update, EPA/530-SW-90-042 (Washington, DC: June 1990).

56. U.S. Environmental Protection Agency, Office of Policy, Planning and Evaluation, Policy Options for Stabilizing Global Climate, draft report to Congress (Washington DC: June 1990).

57. U.S. Export Council for Renewable Energy, Energy Lending at The World Bank and Inter-American Development Bank (Arlington, VA: January 1990).

58. World Bank, World Development Report 1987 (Washington DC: 1987).

59. World Bank, "World Bank Support for the Environment: A Progress Report," Development Committee Pamphlet No. 22 (Washington, DC: September 1989).

60. World Commission on Environment and Development, Our Common Future (Oxford: Oxford University Press, 1987).

61. World Resources Institute, Natural Endowments: Financing Resource Conservation for Development (Washington DC: September 1989). 


\section{Chapter 2}

\section{A Primer on Climate Change}

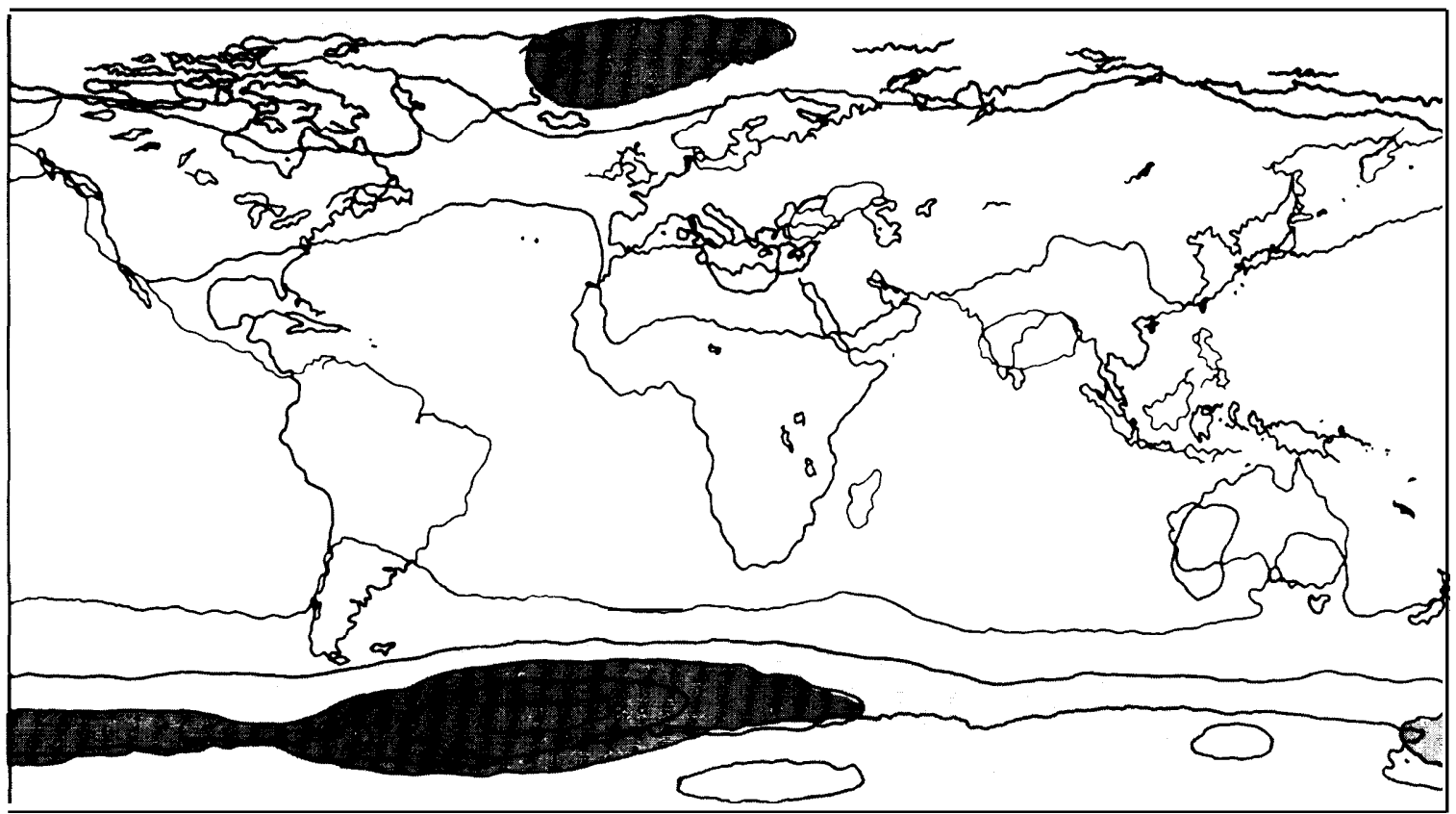

8 to $12^{\circ} \mathrm{C}$

$\square 4$ to $6^{\circ} \mathrm{C}$

6 to $8^{\circ} \mathrm{C}$

2 to $4^{\circ} \mathrm{C}$

Photo credit: IPCC, 1990 from atmosphere-mixed layer ocean model of S. Manage.

Projected surface temperature increases due to a doubling of $\mathrm{CO}_{2}$ 


\section{CONTENTS}

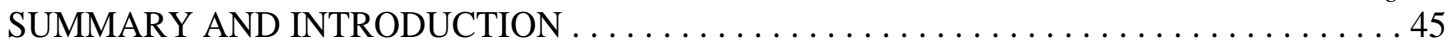

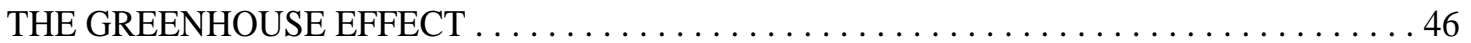

What Is Climate and Climate Change? . . . . . . . . . . . . . . . . . . . . 46

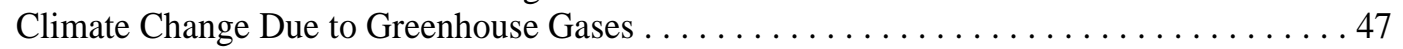

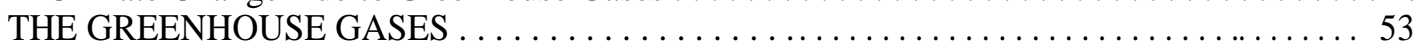

Carbon Dioxide ................................................. 56

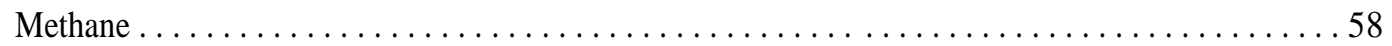

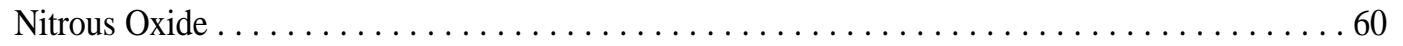

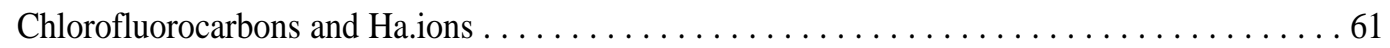

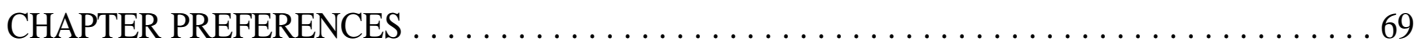

APPENDIX 2A: FERTILIZING THE OCEANS WITH IRON $\ldots \ldots \ldots \ldots \ldots \ldots \ldots \ldots 72$

Boxes

Box Page

2-A. Models of Climate Change .................................. 49

2-B. Stratospheric Ozone Depletion . . . . . . . . . . . . . . . . . . . . 65

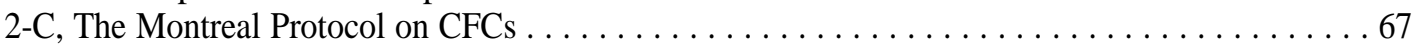

2-1. U.S. Annual Temperature and Precipitation, 1895-1989 . .

2-2. The Greenhouse Effect . ........................ 47

2-3. Global Temperature Anomalies by Hemisphere, $1861-1989$................ 51

2-4. Decline in Radiative Forcing Through Time From a Pulse of Greenhouse Gas

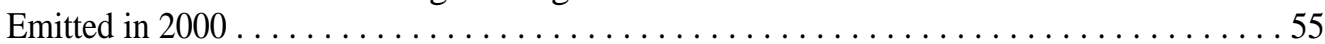

2-5. Carbon Dioxide Concentrations at Mauna Loa, Hawaii . . . . . . . . . . . . . . 56

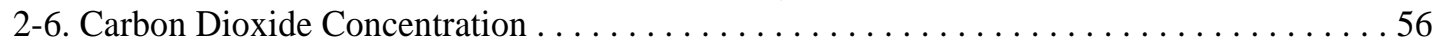

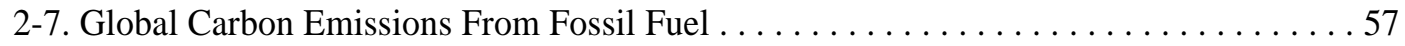

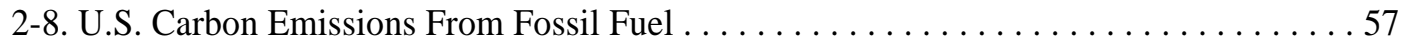

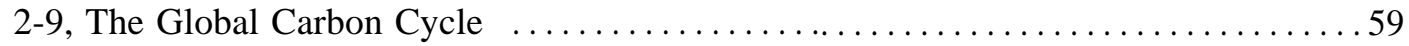

2-10. Atmospheric Methane Concentration ........................... 60

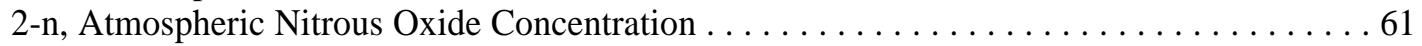

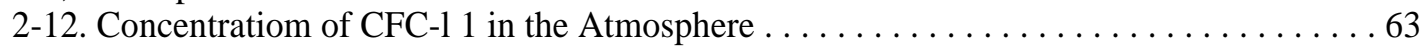

2-13. Estimated CMA Reporting Country and U.S. Use of CFC-11 and

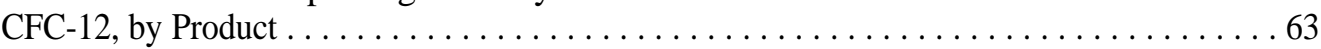

2-14. Ozone Depletion Potential and Global Warming Potential of CFCs and

Replacement Compounds (HFCs and HCFCs) . . . . . . . . . . . . . . 63

\section{Tables}

Table

2-1. Highlights of the IPCC 1990 Scientific Assessment of Climate Change . . . . . . . . 46

2-2. Major Greenhouse Gases . . . . . . . . . . . . . . . . . . . . . . . . . . . 54

2-3. Alternative Estimates of Global Warming Potential of Selected

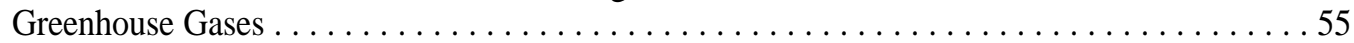

2-4. Estimated Annual Global Methane Emissions and U.S. Contribution

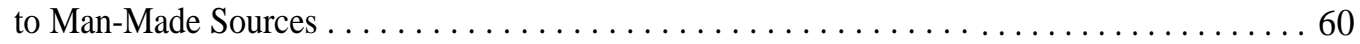

2-5. Estimated Sources and Sinks of Nitrous Oxide .................... 61

2-6. Chlorinated and Brorninated Compounds $\ldots \ldots \ldots \ldots \ldots \ldots \ldots \ldots \ldots \ldots \ldots \ldots \ldots \ldots \ldots \ldots \ldots$ 


\section{SUMMARY AND INTRODUCTION}

Scientists are confident that human activity is dramatically changing the chemical makeup of the Earth's atmosphere. Atmospheric concentrations of several "greenhouse gases," ${ }^{11}$ which trap heat in the atmosphere, have risen rapidly over the last 100 years. Some of these gases (carbon dioxide, methane, and nitrous oxide) occur naturally, but their rapid increase is generally a consequence of human activity. For example, the atmospheric concentration of carbon dioxide is currently increasing about 30 to 100 times faster than the rate of natural fluctuations indicated in the paleoclimatic record (7, 53 ); concentrations are already 25 percent above average interglacial levels and 75 percent above the level during the last glacial maximum (37). Likewise, the atmospheric concentration of methane is increasing more than 400 times natural rates of variability $(13 \mathrm{a}, 37)$. Other greenhouse gaseschlorofluorocarbons (CFCs) and halons--are synthetic chemicals that have been introduced into the atmosphere only during the last 50 years. The United States currently accounts for about 20 to 25 percent of all greenhouse gas emissions associated with human activity.

Many climate models used to predict global average surface temperatures suggest an increase of 0.5 to 2 ' $F\left(0.3\right.$ to $\left.1.1^{\circ} \mathrm{C}\right)$ should have occurred over the past 100 years due to increased atmospheric concentrations of greenhouse gases. Natural climate variability and other factors (measurement errors, urban heat island effects, etc.) confound detection of the expected change. The Intergovernmental Panel on Climate Change, or IPCC (37),---(a group of several hundred scientists from 25 countries)-concluded that the global temperature record over this period indicates that the Earth actually has warmed by about $0.8{ }^{\circ} \mathrm{F}\left(0.45^{\circ} \mathrm{C}\right),{ }^{2}$ which is within (but at the low end) of the range of estimates. ${ }^{3}$ See table 2-1 for a summary of the IPCC findings.

Although there are many uncertainties about climate change, the IPCC (37) concluded that if present emission trends continue, global average temperatures could rise by roughly an additional $2.2^{\circ} \mathrm{F}\left(1.0^{\circ} \mathrm{C}\right)$ by the year 2030 .

Unfortunately, scientists have much less confidence in predictions for specific regions than for global averages, in that regional climate change is heavily affected by shifting and difficult-to-predict atmospheric and oceanic circulation patterns. Greater warming is likely to occur in some geographic areas compared to others; negligible change or even cooling is expected in some places. Some regions may experience more drought, others more precipitation and perhaps changes in the frequency and

${ }^{\prime}$ Greenhouse gases trap heat in the atmosphere instead of letting it radiate out into space. Much of the increase in these gases over natural levels is due to actions of humankind. The key greenhouse gases and their primary anthropogenic sources are:

- Carbon dioxide $\left(\mathrm{CO}_{2}\right)$-which is responsible for an estimated 55 percent of the enhanced greenhouse effect from 1980 to 1990 (37), primarily from fossil fuel burning in industrialized counties and deforestation in less developed countries. $\mathrm{CO}_{2}$ is increasing in the atmosphere at 0.5 percent/year.

- Methane $\left(\mathrm{CH}_{4}-15\right.$ percent of the effect; emitted from nce paddies, ruminant animals, coal mining, natural gas leakage, landfills, and biomass burning. $\mathrm{CH}_{4}$ is increasing at 0.9 percent/year.

- Nitrous oxide $\left(\mathrm{N}_{2} \mathrm{O}\right)-6$ percent of the effect; sources are nitrogenous fertilizers, fossil fuel combustion, and biomass burning. $\mathrm{N}_{2} \mathrm{O}$ is increasing at 0.25 percent/year,

- Chlorofluorocarbons(CFCs)- -24 percent of the effect; these are manmade chemicals used primarily for refrigeration and insulation. CFCs are increasing in the atmosphere at the rate of 4 percent/year. The revised Montreal Protocol (see box 2-C) will phase out these chemicals over the next two decades in participating counties.

${ }^{2}$ This estimate is based on a weighted average of measurements from sites around the globe, corrected to remove warming due to urban growth. The IPCC estimate did not include data for 1990, which is reported to be the warmest year of the instrumental record. Temperature data for the global land surface, total global surface (land and oceans), and troposphere indicate that 1990 was about $0.1{ }^{\circ} \mathrm{C}, 0.05^{\circ} \mathrm{C}$, and 0.02 ' $\mathrm{C}$ warmer, respectively, than any prior year $\mathrm{m}$ the 1980s or $\mathrm{m}$ the entire record; satellite data suggest that 1990 was the fourth warmest year since observations began (3a, 10a,13b, 30a),

+ Several hundred scientists from 25 countries participated in this multi-year effort sponsored by the World Meteorological Organization and the United Nations Environment Program, 
Table 2-I —Highlights of the IPCC 1990 Scientific Assessment of Climate Change

The IPCC is certain that:

. There is a natural greenhouse effect that already keeps the Earth warmer than it would otherwise be.

. Emissions resulting from human activities are substantially increasing the atmospheric concentrations of the greenhouse gases.

The IPCC calculates with confidence that:

- Atmospheric concentrations of the long-lived gases $\left(\mathrm{CO}_{2}, \mathrm{~N}_{2} \mathrm{O}\right.$, and the CFCs) adjust only slowly to changes in emissions. continued emissions of these gases at present rates would commit us to increased concentrations for centuries ahead.

. The longer emissions continue to increase at present-day rates, the greater reductions would have to be for concentrations to stabilize at a given level.

. immediate reductions (on the order of $60 \%$ ) in emissions of long-lived gases $\left(\mathrm{CO}_{2}, \mathrm{~N}_{2} \mathrm{O}\right.$, and the $\mathrm{CFCs}$ ) from human activities would be required to stabilize their concentrations at today's levels; methane would require a 15 to $200 /$. reduction.

Based on current model results, the IPCC predicts that:

- Under the I PCC Business-As-Usual Scenario, ${ }^{2}$ global mean temperature will increase about 0.3 ' $C$ per decade (with an uncertainty range of 0.2 to 0.5 ' $\mathrm{C}$ per decade), reaching about 1 ' $\mathrm{C}$ above the present value by 2025 and $3^{\prime} \mathrm{C}$ before the end of the 21 st century.

. Land surfaces will warm more rapidly than the ocean, and high northern latitudes will warm more than the global mean in winter.

- Global mean sea level will rise about $6 \mathrm{~cm}$ per decade over the next century, rising about $20 \mathrm{~cm}$ by 2030 and $65 \mathrm{~cm}$ by the end of the 21st century.

All pred ictlons are subject to many uncertalnties wit $\mathrm{h}$ regard to the timing, magnitude, and regional patterns of climate change, due to incomplete understanding of:

. sources and sinks of greenhouse gases,

. clouds,

. oceans, and

- polar ice sheets.

The IPCC judgment is that:

. Global mean surface air temperature has increased by about 0.45 ' $C$ (with an uncertainty range of 0.3 to 0.6 ' $C$ ) over the last 100 years, with the five globally averaged warmest years occurring in the $1980 \mathrm{~s}$.

. The size of this warming is broadly consistent with predictions of climate models, but it is also of the same magnitude as natural climate variability. Thus, the observed temperature increase could be largely due to natural variability; alternatively, this variability y and other human factors could have offset a still larger human-induced greenhouse warming. The unequivocal detection of the enhanced greenhouse effect from observations is not likely for a decade or more.

${ }^{a}$ Assumes that emissions of all greenhouse gases continue at 1990 levels. See note 7 in text and ref. 37.

SOURCE: Intergovernmental Panel on Climate Change, Scientific Assessment of Climate Change, Summary and Report, World Meteorological Organization/U.N. Environment Program (Cambridge, MA: Cambridge University Press, 1990).

intensity of storms.$^{4}$ At this stage it is impossible to confidently project the magnitude of the impacts of global warming, the speed with which they will develop, or where they will manifest themselves most severely.

We appear to be pushing the climate system beyond the limits of natural rates of change experienced by the Earth for hundreds of thousands and probably millions of years $(9,37,53)$. The projected rate of climate change may outpace the ability of natural and human systems to adapt in some areas $(37,81)$. While it maybe many years before climate monitoring proves global warming is statistically significant, each year that passes increases the severity of the policy actions that would be needed to slow or reverse these climate trends. The IPCC (37) estimates that stabilizing trace gas concentrations at current (perturbed) levels would require an immediate 60-percent reduction in carbon dioxide emissions, 15 percent in methane emissions, and 70 percent in nitrous oxide and CFC emissions.

\section{THE GREENHOUSE EFFECT}

\section{What Is Climate and Climate Change?}

The Earth's climate is driven by many factors. The primary force is radiant energy from the Sun, and the reflection or absorption and reradiation of this energy by atmospheric gas molecules, clouds, and the surface of the Earth itself (including, for

\footnotetext{
${ }^{4}$ General circulation models (GCMs) predict that warming could exacerbate summer drought over land at mid-latitudes primarily through a combination of earlier spring snowmelt and enhanced evaporation of soil water (30, 56). In Hansen et al. 's (30) model, both extremes are intensified; wet areas tend to get wetter, dry areas tend to get dryer. However, predictions of regional drought occurrence and intensity are uncertain because they are sensitive to uncertain components of GCMs, particularly soil moisture content, clouds, and ocean circulation patterns (30, 59). Precipitation data for land suggest some broad consistency with model projections, but with many unexplained discrepancies (17). Warming could also result in more intense or frequent storms of some types, including hurricanes and thunderstorms $(20,55,30)$. Some studies indicate that maximum sustainable hurricane intensity should increase with global warming (20). Moreover, the region where hurricanes are viable may expand (30). However, present modeling results provide no consistent, convincing evidence that storms and related climate extremes will increase or decrease in frequency or intensity. Better understanding of regional climate change must await higher resolution climate models $(37,85)$.
} 
Figure 2-1-U.S. Annual Temperature and Precipitation, 1895-1989
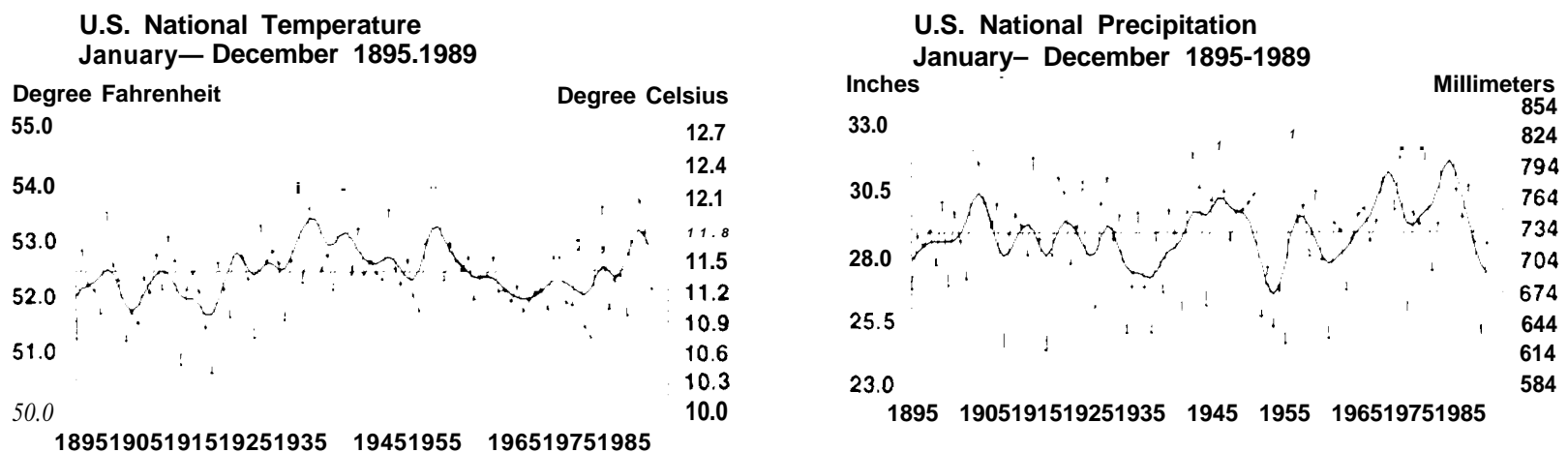

Fluctuation in temperature and rainfall can be dramatic from year to year even over an area as large as the United States (6 percent of the global land area and 2 percent of total global surface area). No trend can be interpreted from these data.

SOURCE: National Climatic Data Center, NOAA.

example, forests, mountains, ice sheets, and urbanized areas), A portion of the reradiated energy leaves the atmosphere. Over the long-term, balance is maintained between the solar energy entering the atmosphere and energy leaving it. Within the bounds of this balance, variations in global and local climate are caused by interactions among the atmosphere, snow and ice, oceans, biomass, and land. An example is El Niño, a large-scale warming of the tropical Pacific that occurs periodically, apparently due to complex interactions between the ocean and atmosphere (60).

A region's general climate is defined by aggregate weather patterns-e. g., snowfall, predominant wind direction, summertime high temperature, precipitation-averaged over several decades or longer. These patterns can vary substantially from one year to another in a given area. The mean annual temperature of the United States, for example, can differ by 2 to 3 ' $F$ from one year to the next and annual rainfall can differ by 4 or more inches (see figures 2-la and 2-lb).

When scientists talk about climate change, they are generally talking about trends that persist for decades or even centuries, over and above natural seasonal and annual fluctuations. One type of change arises from forces that are external to the Earth's climate system. The ice ages and glacialinterglacial cycles, for example, are thought to have been triggered in large part by changes in the seasonal and geographical distributions of solar energy entering the Earth's atmosphere associated with asymmetries in the Earth's orbit around the
Sun. Also, major volcanic eruptions can pour aerosols (e.g., sulfur particles) into the stratosphere, partially blocking or screening sunlight from reaching the surface of the Earth and thus temporarily cooling the Earth's surface. Variations in volcanic activity, ice sheets, forest cover, marine phytoplankton populations, and/or ocean circulation, among other factors, may have interacted with solar variability (including changes in the Sun's brightness) to determin e the Earth's past temperature record (4a, 11, 12, 24, 46a, 76, 108, 114). Scientific research continues to improve our understanding of climate as a very complex system $(37,38,99,102,103)$.

Emissions of greenhouse gases due to human activity constitute a new force for climate change, acting in addition to the natural climatic phenomena. Because of natural variability in climate, the IPCC (37) concluded that the observed 20th century warming trend will have to continue for one to two more decades before it can be unambiguously attributed to enhanced greenhouse gases $(18,52,62$, $86,87)$. However, given the potentially severe consequences of climate change, policymakers are faced with the challenge of making decisions under conditions of considerable scientific uncertainty.

\section{Climate Change Due to Greenhouse Gases}

\section{Overview}

About 30 percent of the solar radiation reaching the Earth is reflected by the atmosphere and Earth back to space, and the remainder is absorbed by the atmosphere, ice, oceans, land, and biomass of Earth (see figure 2-2). The Earth then emits long-wave 
Figure 2-2-The Greenhouse Effect (radiation flows expressed as a percent of total Incoming or outgoing energy)

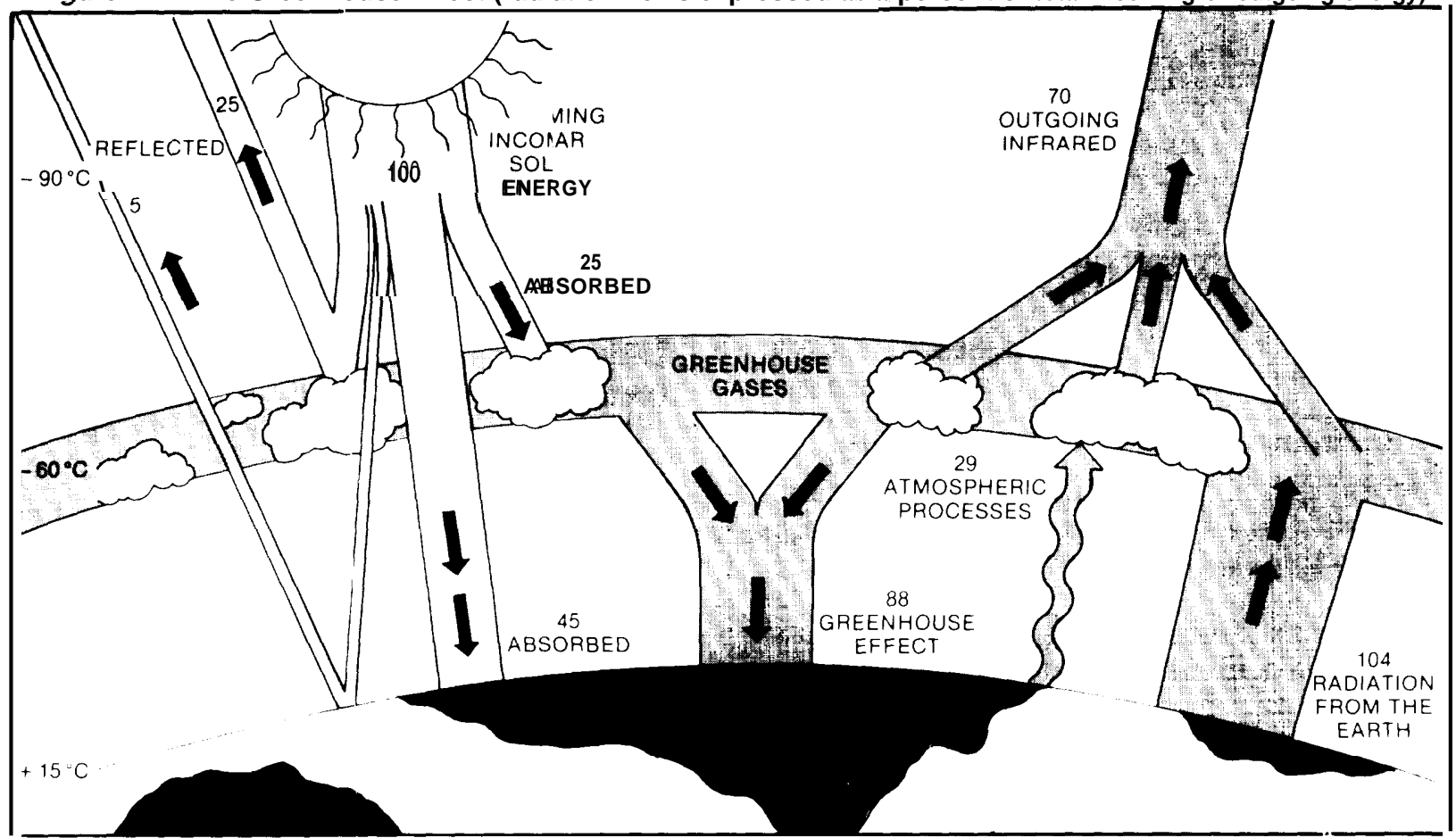

Incoming solar radiation is partially reflected back into space (30 percent) and partially absorbed by the atmosphere, ice, oceans, land, and biomass-of the Earth (70 percent). The Earth then emits radiant energy back into space. The "Greenhouse Effect" refers to the trapping of some of the radiant energy the Earth emits by atmospheric gases, both natural and anthropogenic. As a result of this effect, the Earth's surface and lower atmosphere warms.

SOURCE: Office of Technology Assessment, 1991.

radiation, which is partially absorbed and 'trapped' by atmospheric gases. The net result of these natural processes is the ' the Earth's atmosphere and surface. Without the natural heat trap of these atmospheric gases, Earth's surface temperatures would be about $60{ }^{\circ} \mathrm{F}\left(33^{\circ} \mathrm{C}\right)$ cooler than at present, and life as we know it today on Earth would not be possible. ${ }^{6}$ Water vapor (in the form of clouds) and carbon dioxide $\left(\mathrm{CO}_{2}\right)$ are the major contributors to this effect, with smaller but still significant contributions, from other trace gases, such as methane $\left(\mathrm{CH}_{4}\right)$, nitrous oxide $\left(\mathrm{N}_{2} \mathrm{O}\right)$, and ozone $\left(\mathrm{O}_{3}\right)$.

Human activities during the last century have resulted in substantial increases in the atmospheric concentrations of $\mathrm{CO}_{2}, \mathrm{CH}_{4}$, and $\mathrm{N}_{2} \mathrm{O}$, as well as the introduction and rapid increase of the synthetic chlorofluorocarbons (CFCs). All other things being equal, as concentrations of these gases increase, more radiation should be trapped to further warm the Earth's surface and atmosphere. However, as more heat is trapped and the Earth and atmosphere warm, more thermal radiation should be emitted back to space, eventually restoring the energy balance or equilibrium, but with a warmer climate.

The basic "heat trapping" property of greenhouse gases is essentially undisputed. However, there is still considerable scientific uncertainty about how and when Earth's climate will respond to enhanced greenhouse gases. The more uncertain aspects of climate response include: climate feedbacks that will help determine the ultimate magnitude of temperature change (i.e., " equilibrium" warming); the role of the oceans in setting the pace of Warming; and other climate changes that might accompany warming and how specific regions of the world might be affected.

\footnotetext{
${ }^{5}$ Greenhouse gases both emit and absorb radiation. The net effect is absorption because they absorb relatively intense radiation from the warmer Earth and emit relatively weak radiation at cooler atmospheric temperatures. Thermal radiation declines as the temperature of the emitting object declines.

${ }^{6}$ Thisalsoexplains differences among surface temperatures on Venus, Mars, and Earth.
} 


\section{"Benchmark" Warming-The Effect of Doubled $\mathrm{CO}_{2}$ Concentrations}

Predictions of future warming due to greenhouse gases are highly uncertain, largely because of the uncertainties inherent in both the climate models themselves and in the projection of future greenhouse gas emissions levels (box 2-A discusses climate change models). Future emissions will be tied to population and economic growth, technological developments, and government policies, all of which are difficult to project.

To avoid the pitfalls and complexity of estimating future emissions, and to provide a common basis for comparing different models or assumptions, climate modelers typically examine climates associated with preindustrial levels of atmospheric $\mathrm{CO}_{2}$ concentration. These are compared to "equilibrium" climates-i.e., when the climate system has fully responded and is in equilibrium with a given level of radiative forcing associated with double those levels. Although such 'sensitivity analyses' provide useful benchmarks, they are unrealistic in that they instantaneously double $\mathrm{CO}_{2}$ concentrations, rather than increase them gradually over time. In the last few years, scientists have intensified research using more realistic ' 'transient' climate models where $\mathrm{CO}_{2}$ increases incrementally over time $(28,37,90$, 105).

Many models indicate that a rangeof3to8 " $\mathrm{F}$ ( 1.5 to $4.5{ }^{\circ} \mathrm{C}$ ) bounds the anticipated equilibrium warming in response to a doubling of $\mathrm{CO}_{2}$ from preindustrial levels $(37,54,84,101)$. Uncertainty as to the actual figure is primarily due to uncertainty about feedbacks-processes that occur in response to initial warming and act either to amplify or dampen the ultimate equilibrium response. The lower end of the range $\left(3{ }^{\circ} \mathrm{F}\right.$ change) roughly corresponds to the direct impact of heat trapping

\section{Box 2-A-Models of Climate Change}

Climate models consist of sets of mathematical expressions that describe the physical processes associated with climate-e. g., seasonal changes in sunlight, large-scale movement of air masses, evaporation and condensation of water vapor, absorption of heat from the atmosphere into the oceans, etc. In the most detailed models, known as general circulation models (GCMs), the atmosphere is sectioned off into "cells" roughly 300-miles square at the Earth's surface, and the cells are stacked several layers deep. The vertical layers reach about 20 miles into the atmosphere. For each cell and period of time (e.g., an hour), the sets of mathematical expressions are solved to predict such variables as temperature, humidity, air pressure, and wind speed. In simulating a century's worth of climate, the process is repeated billions of times,

At the core of climate models are expressions of physical principles such as the conservation of energy or mass (e.g., of air or water vapor). Such "laws" govern interactions among the atmosphere, oceans, sea ice, land, and vegetation. However, using fundamental principles is too cumbersome to model some processes--because the real scale involved is much smaller than the dimensions of a GCM cell. In these cases, modelers are forced to rely on observed (i.e., empirical) relationships. For example, statistics on how cloud occurrence (i.e., types, altitudes) depend on temperature and humidity levels could be used to predict when clouds should be "created" during a model simulation. A potentially critical problem with using empirical relationships, rather than fundamental physical principles, is the possibility that observed relationships may not hold for conditions other than those under which the observations were made.

In climate models developed to date, atmospheric conditions have been treated more comprehensively than oceanic or biosphere (i.e., land and vegetation) conditions. Atmospheric conditions are the first to adjust to changes in radiative forcing such as increased greenhouse gas concentrations, and the seasonal cycle of climate provides a good test of the ability of models to simulate the short-time-scale processes involved. Although they are not treated in as much detail, some changes in the oceans and in the extent of sea ice are also predicted and fed back into further predictions. Efforts to improve oceanic components of models are a major focus of current research. Finally, conditions of land and vegetation are usually fixed before a simulation is run and are not changed during it. The rationale for holding these conditions fixed is that they are expected to respond to climate change comparatively slowly. However, these simplifications could mean that some important processes or feedbacks are ignored (15, 51, $55)$.

State-of-the-art climate modeling is focusing on: higher spatial resolution of models; coupled models that link atmosphere, ocean, land, and ice models; and more realistic model representations of key climate processes such as cloud formation and atmosphere-oceans-biomass interactions (37). 
associated with doubled $\mathrm{CO}_{2}$, with little amplification from feedbacks. The upper end of the range $(8$ ${ }^{\circ} \mathrm{F}$ ) accounts for feedback processes that roughly triple the direct heat-trapping effect. Hypothesized feedbacks that could release extra $\mathrm{CH}_{4}$ and $\mathrm{CO}_{2}$ into the atmosphere are not included in present models $(37,51)$, so warming could be even more severe. On the other hand, clouds may block much more solar radiation than models presently assume and thereby reduce the warming (see 'Climate Feedbacks' below).

It is important to realize that a 3 to 8 ' $\mathrm{F}$ warming only bounds model predictions of warming in response to this reference or benchmark $\mathrm{CO}_{2}$ level. Higher $\mathrm{CO}_{2}$ concentrations, or a combination of greenhouse gas levels equivalent to more than a doubling of $\mathrm{CO}_{2}$, could lead to greater warming. Likewise, lower greenhouse gas concentrations lower the eventual warming. EPA (98) projected that in the absence of a slowdown in emissions growth, an "effective $\mathrm{CO}_{2}$ doubling (i.e., accounting for increases in other trace gases as well as $\mathrm{CO}_{2}$ ) could occur as early as 2030 assuming high rates of population and economic growth, or be delayed for about a decade if lower growth prevails. The IPCC "business as usual" emissions scenario projects a global mean temperature increase above today's level of about 0.54 ' $\mathrm{F}\left(0.3{ }^{\prime} \mathrm{C}\right)$ per decade, or an increase of roughly $2.2^{\circ} \mathrm{F}\left(1.0^{\circ} \mathrm{C}\right)$ by 2030 and 6.6 ${ }^{\circ} \mathrm{F}\left(3.0{ }^{\circ} \mathrm{C}\right)$ by $2100(37)$.

\section{Detecting Climate Change-Warming Over the Past Century}

Change in global average surface air temperature is the most common measure of climate change. There has been much debate over whether warming consistent with greenhouse theory predictions actually has been observed in the global temperature record of the past century. High regional variability of both the "natural' climate and of "enhanced greenhouse' effects make detection of climate change difficult (37). Nonetheless, the six warmest years of the past century occurred since 1980 (37, 40) and, overall, global warming appears to have occurred over the last century (see figure 2-3) (30). ${ }^{8}$ Based on a review of all major global temperature series, for both land and ocean, the IPCC (37) concluded that global mean temperature has increased by 0.54 to $1.08{ }^{\circ} \mathrm{F}\left(0.3\right.$ to $\left.0.6^{\circ} \mathrm{C}\right)$ over the last 100 years. ${ }^{9}$ However, the IPCC noted that " "the size of the observed warming is also of the same magnitude as natural climate variability.

The midpoint of the IPCC range is at the low end of most estimates from models of the warming that should have occurred to date, ${ }^{10}$ even when the delaying effect of the oceans is taken into account. For example, Wigley and Schlesinger (1 10) estimated that between 1850 and 1980, a global temperature increase of about 0.7 to $2.0{ }^{\circ} \mathrm{F}(0,4$ to 1.1 ' $\mathrm{C}$ ) should have been caused by emissions of $\mathrm{CO}_{2}$ and other greenhouse gases. ${ }^{11}$ Dickinson and Cicerone (18) analyzed the effects of increased greenhouse gases and estimated a similar expected warming trend of 0.5 to $1.8{ }^{\circ} \mathrm{F}\left(0.3\right.$ to $\left.1.0{ }^{\circ} \mathrm{C}\right)$ for the period 1900 to 1985 . In general, models that use historical increases in greenhouse gas concentrations as inputs (as opposed to instantaneous doubling calculations) show a warming of about 0.4 to $1.1{ }^{~} \mathrm{C}$ (depending on model assumptions) through the year $1990(26,37,83,110,111)$.

Nonetheless, given uncertainties in the models, the magnitudes of observed and predicted warming are considered ' 'broadly consistent' $(37,86,87)$, Most puzzling, however, is the interruption in the warming trend that occurred during the middle of

\footnotetext{
${ }^{7}$ The IPCC " business as usual" scenario assumes that emissions of selected greenhouse gases $\left(\mathrm{CO}_{2}, \mathrm{CH}_{4}, \mathrm{~N}_{2} \mathrm{O}\right)$ continue at 1990 levels from 1990 to 2100 . For CFCs, the scenario assumes that the Montreal Protocol is implemented, albeit with only partial participation (see box 2-C). The atmospheric concentration of $\mathrm{CO}_{2}$ would double (over preindustrial levels) by about 2060, but the "effective' $\mathrm{CO}_{2}$ concentration (the cumulative effect of all trace gases) would double by 2025 . The IPCC temperature projections cited here assume a "best estimate" climate sensitivity of 2.5 'C for equilibrium warming.

${ }^{8}$ The Hansen estimates (29) were compiled using data from land-based sites; no da@ fromships were included, Comparison with the trend estimated by Jones et al. (38\& 39), who used data taken aboard ships as well as on land, suggests that this omission had only a small effect on the overall trend. The method used to combine individual station data attempted to minimize errors due to uneven coverage. Preliminary surface temperature data indicate that 1990 was the warmest year of the past century (3a, 1Oa, 30a).

${ }^{9}$ Urban heat island effects can be large in specific areas $(42,112 \mathrm{a})$ but are estimated to account for no more than 0.05 to $0.1{ }^{\circ} \mathrm{C}$ in the global averages $(40,41,43)$.

${ }^{10}$ Some scientists believe the actual warming has been closer to the low end of this range due to errors from uncorrected urban heat island effects (5) (but see footnote 9), ocean temperature measurement problems (1 16), and various discontinuities or inconsistencies in the temperature data (2 1, 62).

${ }^{1}$ Based on model predictions that a temperature increase in the range of 3 to $8{ }^{\circ} \mathrm{F}\left(1.5\right.$ to $\left.4.5^{\circ} \mathrm{C}\right)$ would ultimately result from instantaneously doubling atmospheric $\mathrm{CO}_{2}$ concentrations; and including a range of time lags due to the uncertain effect of the oceans in delaying warming.
} 
this century (see figure 2-3), when the Northern Hemisphere cooled and the Southern Hemisphere temperature was " flat.' This underscores the possibility that other "natural " influences-e. g., changes in volcanic dust, solar radiation, or ocean circulationhave affected 20th century climate, The IPCC (37) concluded that "the observed [temperature] increase could be largely due to this natural variability; alternatively this variability and other human factors could have offset a still larger human-induced greenhouse warming.' The IPCC (37) further concluded that " [t]he fact that we are unable to reliably detect the predicted [enhanced greenhouse] signals today does not mean that the [enhanced] greenhouse theory is wrong, or that it will not be a serious problem for mankind in the decades ahead."

Hansen and Lebedeff (29) examined the observed changes in average temperatures at different latitudes and found that the past century's warming was especially enhanced at high northern latitudes, which is consistent with model results. However, the trend is not smooth. Cooling actually occurred in the high northern latitudes between 1940 and 1965. And the 1980s' warming was driven by changes in the low latitudes, with relatively level temperatures or cooling in much of the mid- to high-northern and southern latitudes $(3,29)$. A significant reduction in summer/winter temperature differentials (over the past century is also consistent with model calculations (29).

Finally, oxygen isotope data recovered from air trapped in Greenland and Antarctic ice allow scientists to place the temperature record of the past century in geologic perspective $(50,100)$. The IPCC midpoint estimate of global warming over the past century $\left(0.8 \mathrm{O}_{\mathrm{F}}\right.$ or $\left.0.45^{\circ} \mathrm{C}\right)$ is about one-fourth as large as temperature variations $\left(3.6{ }^{\circ} \mathrm{F}\right.$ or $2{ }^{\circ} \mathrm{C}$ minimum to maximum) estimated to have occurred during the past 10,000 years. Thus, attributing some part of the warming since the late 1800s to natural variations would be consistent with the longer term record. The IPCC (37) concluded that "[a] global warming of larger size has almost certainly occurred at least once since the end of the last glaciation without any appreciable increase in greenhouse gases. Because we do not understand the reasons for
Figure 2-3-Global Temperature Anomalies by Hemisphere, 1861-1989
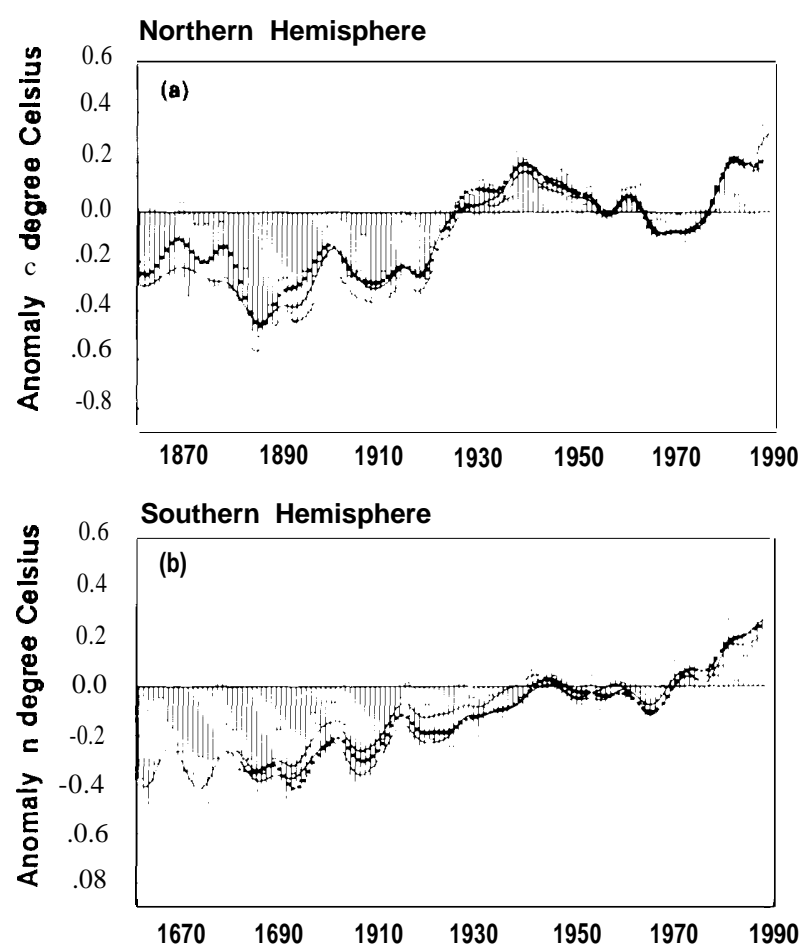

Temperatures over land expressed as differences relative to 1951-1 980: Northern Hemisphere, Southern Hemisphere. Three research groups have produced similar analyses of hemispheric land surface air temperature variations. All three analyses indicate that during the last decade globally averaged land temperatures have been higher than in any decade in the past 100 to 140 years. SOURCE: IPCC, 1990: annual values from P.D. Jones (bars); smoothed curves of values from P.D. Jones (1861-1989) (solid lines) Hansen and Lebedeff (1860-1987) (dashed lines), and Vinnikov et al, (1861-1987 Northern Hemisphere and 1881-1987 Southern Hemisphere) (dots).

these past warming events, it is not yet possible to attribute a specific proportion of the recent, smaller warming to an increase of greenhouse gases.

\section{Climate Feedbacks}

"Direct' heat trapping, or "radiative forcing" refers to the expected warming due to greenhouse gas emissions if potential climate feedbacks-processes that occur in response to warming either augmenting or diminishing the effect-are ignored. The radiative forcing effect of greenhouse gases

\footnotetext{
${ }^{12}$ Radiative forcing or heat trapping is calculated with models of the energy balance Of the Earth/atmosphere system. These models calculate surface temperature adjustments to increased greenhouse gas concentrations from information about the radiative absorption characteristics of the gas molecules, and globally averaged profiles of gas concentration versus height in the atmosphere. The models also require information about preexisting conditions - c.g., atmospheric temperature profiles; the amount of solar energy entering the atmosphere and the amount reflected from the Earth's surface and from atmospheric aerosols and gases; and the rate at which heat is redistributed through mechanical mixing processes.
} 
added to the atmosphere since the late $1800 \mathrm{~s}$ is equivalent to about a $1.4{ }^{\prime} \mathrm{F}\left(0.8{ }^{\circ} \mathrm{C}\right)$ equilibrium increase in global average surface temperatures (18, $70,71)$.

However, scientists expect that some climate feedbacks will operate. Enhanced radiative forcing is expected to lead to changes in oceanic and atmospheric circulation patterns, the hydrologic cycle of precipitation and evaporation, vegetation cover, and snow and ice clover, all of which could, in turn, stimulate further, complex climate change. ${ }^{13}$

Most climate models suggest that, overall, feedback will amplify warming by a factor of up to 3 (26, $31,37)$. Two fairly well understood feedbacks result from increases in atmospheric water vapor and the melting of snow and ice. As temperatures increase, air can hold more water vapor (itself a greenhouse gas). This can more than double the effect of radiative forcing $(25,37,72) .{ }^{14}$

Melting of snow and ice due to warmer temperatures enhances warming in two ways:

1. reducing the reflectivity of the Earth's surface (land or ocean), so less solar radiation is reflected and more is absorbed; and

2. reducing the insulating effect that sea ice has on the ocean, so heat escapes from high-latitude oceans more readily.

Snow and ice feedbacks result in only a 10 to 20 percent increase in warming on a global scale, but they can increase local warning at high latitudes by up to a factor of 4 , particularly in winter $(19,72,78)$.

Indeed, the greatest warming due to increasing greenhouse gas concentrations is predicted to occur in winter, at high latitudes. In particular, General Circulation Models' (GCMs) highest estimates of 8 ' $\mathrm{F}$ global warming in response to doubled $\mathrm{CO}_{2}$ rest on predictions that wintertime warming in high latitudes will exceed 15 ' $\mathrm{F}$, with lesser changes occurring during other seasons and at lower latitudes $(82,84)$.

Twentieth century warming has not been large enough to cause widespread, detectable melting of high latitude snow and ice, with the notable excep- tion of the retreat of some alpine glaciers (although with periods of readvance [113]). Sea ice, snow cover, and ice sheet data either indicate no clear overall trends or are too limited or unreliable for identifying trends (37). There is recent evidence that at least parts of the Antarctic and Greenland ice sheets are actually thickening $(37,67 \mathrm{a}, 118)$, possibly because of increased snowfall due to warming in those areas (1 19). (This somewhat counterintuitive result can be explained if: a) warmer surface temperatures increase evaporation from the oceans, which would increase absolute humidity and precipitation; and b) the precipitation falls as snow, not rain, so long as temperatures are still below freezing [37]). Recent modeling results from coupled atmosphere-ocean GCMs suggest that amplified high latitude warming may not occur at least in the Southern Hemisphere around Antarctica (37, 57,90, $105)$, with the implication that temperatures in this region will remain below freezing.

Finally, how climate will respond to greenhouse forcing depends, in part, on what will happen to clouds (37). Clouds play a dual role in Earth's energy balance: depending on their shape, altitude, and location, their dominant effect can either be to reflect solar radiation or to absorb or trap thermal radiation (from Earth). Recent satellite data demonstrate that the dominant effect of clouds at present is to reflect solar radiation and hence help cool the Earth, and that the magnitude of this cooling is about three to five times the expected warming effect of doubled $\mathrm{CO}_{2}$ (73). However, as conditions change, the cooling effects of clouds may increase or decrease. If all types of clouds simply increase in area, or if lower, broader stratus clouds increase, they will reflect more sunlight back into space and cool the Earth. If taller, narrower clouds or cirrus clouds form, they will actually exacerbate the warming effect. Overall, GCMs are extremely sensitive to assumptions about cloud cover; a recent model intercomparison concluded that clouds can be either a strong positive or negative feedback on global warming $(13,49)$. Depending on the model, clouds can halve the warming expected from doubled $\mathrm{CO}_{2}(64)$ or double it $(72,73)$.

\footnotetext{
${ }^{13}$ The complexity and viability of climate change suggests that simultaneously monitoring a large number of relevant $\mathrm{p}$ arameters will increase the chances of detecting significant change $(6,37,43,115)$.

${ }^{14}$ Some $(52,66)$ believe that the water vapor feedback will actually diminish rather than amplify $\mathrm{CO}_{2}{ }^{w}$ arming, due to drying of the air at high altitudes and increased intensity of convection These are topics of continuing scientific research and debate.
} 
Several feedbacks involving emissions of greenhouse gases are so speculative that they have not been incorporated into most climate models. These potential feedbacks are discussed below, in the sections on $\mathrm{CO}_{2}$ and $\mathrm{CH}_{4}$. If worst case conditions hold, they could greatly increase atmospheric $\mathrm{CO}_{2}$ and $\mathrm{CH}_{2}$ concentrations, resulting in twice as much warming as current GCMs predict (98).

\section{Delays in Climatic Response}

Based on the 1.4 ' $\mathrm{F}$ increase in radiative forcing estimated to have occurred from 1880 to 1980, and assuming that positive feedbacks could amplify warming by a factor of up to three, a global average warming of about 1.4 to 4 ' $\mathrm{F}$ is eventually expected as a result of the greenhouse gas concentration increases of the past century. (This estimate does not include any warming from current and future emissions. ) As noted, this degree of warming has not yet been seen. In fact, scientists do not yet expect to see it, primarily because: 1) the natural variability of climate would mask or could even offset some of the change due to greenhouse gases; and 2) heat uptake by the oceans would delay the warming of the air.

The oceans have an enormous capacity to absorb and store heat. However, it takes several years for the ocean's rapidly mixed surface layer (i.e., the top 100 meters) to equilibrate, on average, with warmer air temperatures, and it takes decades to centuries for the deep oceans to reach full equilibrium(31). Thus, global average surface temperatures would continue to increase for decades after greenhouse gas concentrations were stabilized. For example, scientists estimate that only about half the 1.4 to $4^{\circ} \mathrm{F}$ warming expected from emissions over the last century should have been realized by now because of this ocean effect $(18,26,31,110)$. The actual observed warming has been at the low end of this range, suggesting one or more of the following:

. the "enhanced greenhouse effect is considerably weaker than models predict, due perhaps to stronger negative feedbacks;

- natural variability is offsetting a large part of the enhanced greenhouse;
- other anthropogenic factors (e.g., sulfur aerosols) are offsetting some of the enhanced greenhouse; ${ }^{15}$

- ocean thermal lag is longer than thought.

\section{Sea Level}

Sea level, averaged globally, is estimated to have risen 4 to 8 inches $(10$ to $20 \mathrm{~cm}$ ) over the past century $(22,37,61)$. Scientists express high confidence that sea level will rise as a result of warming, but questions of how much and how rapidly are controversial $(37,61)$. The IPCC (37) has attributed 20th century sea level rise primarily to thermal expansion of ocean water as it warms and to partial melting of alpine glaciers. Hoffman et al. (32) predicted that sea water expansion and glacial melting could cause sea level to rise about 4 to 8 inches $(10$ to $20 \mathrm{~cm})$ by 2025 , and 16 to 80 inches ( 40 to $200 \mathrm{~cm}$ ) by 2075 . The IPCC reviewed all available evidence and estimated about the same sea level rise by $2030(3.2$ to 11.6 inches, or 8 to $29 \mathrm{~cm}$ with a best estimate of $18 \mathrm{~cm})$ but a considerably smaller rise by $2070(8.4$ to 28,4 inches, or 27 to71 $\mathrm{cm}$ with a best estimate of $44 \mathrm{~cm}$ ). This lower estimate includes the counteracting sea level drop due to (warming-induced) increased snow accumulation in Antarctica (37).16 The possibility that a polar ice sheet (such as the West Antarctic ice sheet) could slide into the ocean and raise sea level is very speculative. The IPCC (37) concluded that "[a] rapid disintegration of the West Antarctic ice sheet due to global warming is unlikely within the next century, and cautioned that sea level projections more than a few decades into the future " are fraught with many uncertainties. .."

\section{THE GREENHOUSE GASES}

Historical and current growth rates in greenhouse gas concentrations (see table 2-2) fuel concerns about the possibility that human activity has been and will go on altering climate. Increases in CFC concentrations are unambiguously due to human activity, as they are synthetic chemicals that do not occur naturally. Human activity also is thought to be largely responsible for raising concentrations of $\mathrm{N}_{2} \mathrm{O}, \mathrm{CH}_{4}$, and $\mathrm{CO}_{2}$ above preindustrial levels,

${ }^{15}$ TheIPCC $(37$, concluded that the climatic effects of manmade sulfur emissions are "highly uncertain, " but that " it is conceivable that this radiative forcing has been of a comparable magnitude, but of opposite sign, to (he greenhouse forcing earlier in this century. "Over the longer term, the IPCC concluded that greenhouse forcing is likely to be larger on a global basis, but that forcing from sulfur emissions could be significant on a regional basis. Predictions are difficult due to uncertainties about the direct and indirect radiative effects of sulfur aerosols (including their impact on clouds) as well as future levels of sulfur emissions,

${ }^{16}$ Recent research (63) suggests a sea level rise toward the lower end of the IPCC range of estimates for 2030. 
Table 2-2-Major Greenhouse Gases

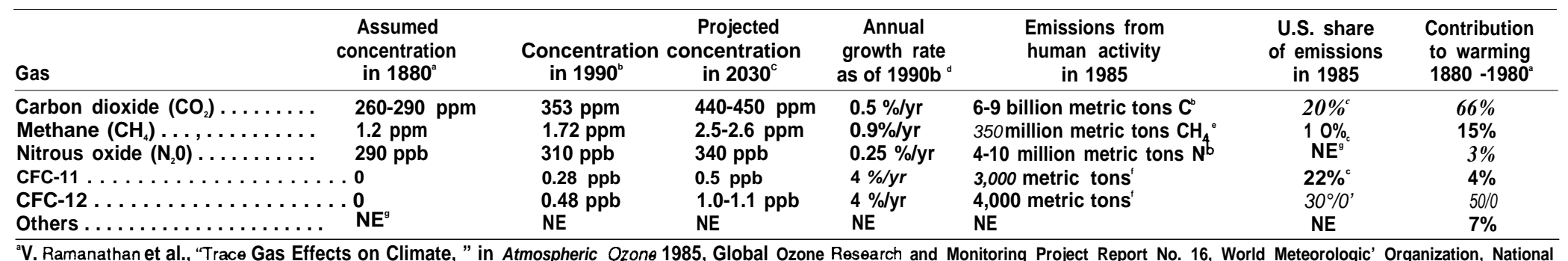

'V. Ramanathan et al., 'Trace Gas Effects on Climate, ” in Atmospheric Ozone 1985, Global Ozone Research and Monitoring Project Report No. 16, World Meteorologic' Organization, National Aeronautics and Space Administration (Washington, DC: 1985).

bIntergovernmental Panel on Climate Change, Scientific Assessment of Climate Change, Summary and Report, World Meteorological OrganizationU.N. Environment Program (Cambridge, MA: Cambridge University Press, 1990).

CU.S. Environmental Protection Agency, Office of Policy Planning and Evaluation, Policy Options for Stabilizing Global Climate, Draft Report to Congress (Washington, DC: June 1990).

Impact on warming over the next three decades of reducingU.S. EPA's (1990) projected annualemissions of each gas by an amount equal to 20 percent of 1985 levels. Expressed as a f raction of the impact of reducing projected annual carbon dioxide emissions by 20 percent of 1985 levels.

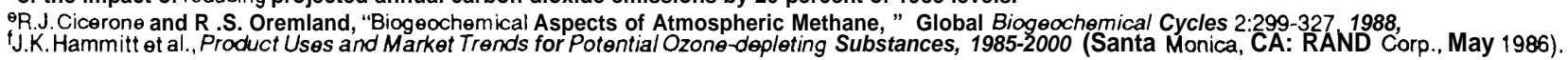

SNE = no estimate. 
Table 2-3--Alternative Estimates of Global Warming Potential (GWP) of Selected Greenhouse Gases

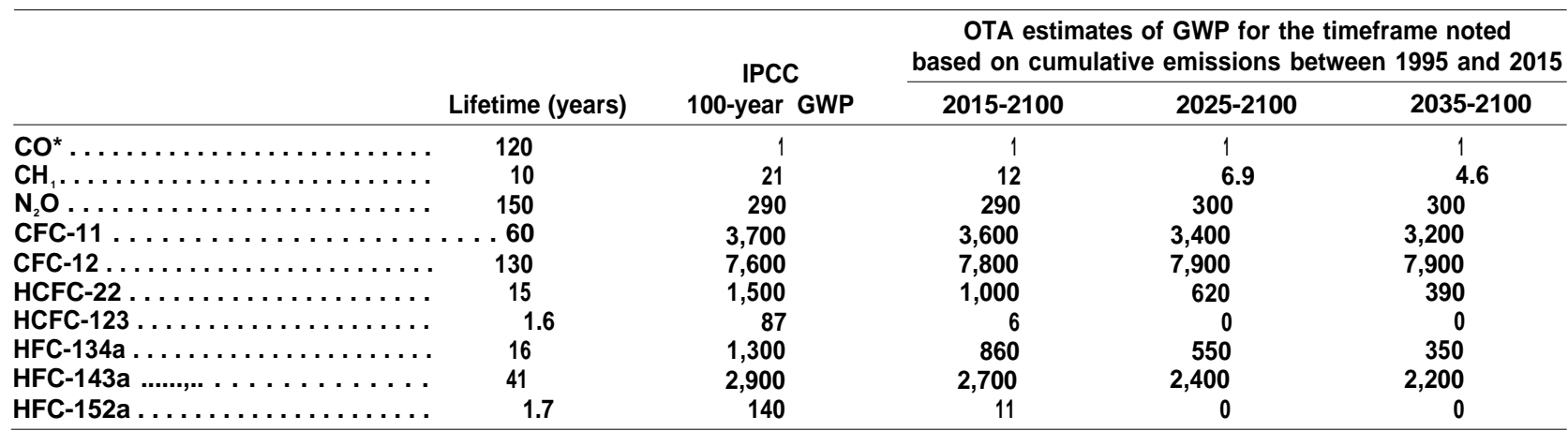

NOTE: The 100-year GWP estimateis slightly different than the IPCCIOO-yearestimatedue to slight differences in modeling the lifetime of $\mathrm{CO}_{2}$. The 120 year lifetime for $\mathrm{CO}_{2}$ is approximate.

SOURCE. Of fice of Technology Assessment, 1991, using data from IPCC, 1990,

although natural sources of these gases also exist $(14,47,74,88,107)$. U.S. emissions (see table 2-2) are disproportionate to its 5 percent share of the world's population; in particular, U.S. emissions of $\mathrm{CO}_{2}$ and CFCs account for about one-fifth and one-fourth of the world's estimated totals, respectively.

The warming effect of a greenhouse gas depends on several factors, including its concentration, radiative absorption and emission characteristics, and, in some cases, radiative interferences with other gases. 17 Radiative forcing calculations (see table 2-2) suggest that increased $\mathrm{CO}_{2}$ accounts for about two-thirds of the equilibrium warming ultimately expected to result from growth in greenhouse gas concentrations over the past century. Growth in $\mathrm{CH}_{4}$ concentrations has contributed an additional 15 percent, CFC-11 and CFC-12 together about 10 percent, and $\mathrm{N}_{2} \mathrm{O}$ about 3 percent (70).

Reducing greenhouse gas emissions can reduce the level of equilibrium warming projected for 2030 . However, the effects of reducing different greenhouse gases vary (see table 2-3 and figure 2-4). The IPCC has proposed a method for comparing the warming from equal quantities of greenhouse gases. It defines Global Warming Potential (GWP) as the ratio of the amount of warming from a pound of a greenhouse gas to the warming from a pound of $\mathrm{CO}_{2}$, over a period of 20,100 , and 500 years. It prefers to use the 100-year- timeframe for its policy analysis,
Figure 2-4-Decline in Radiative Forcing Through Time From a Pulse of Greenhouse Gas Emitted in $\mathbf{2 0 0 0}$

Radiative forcing

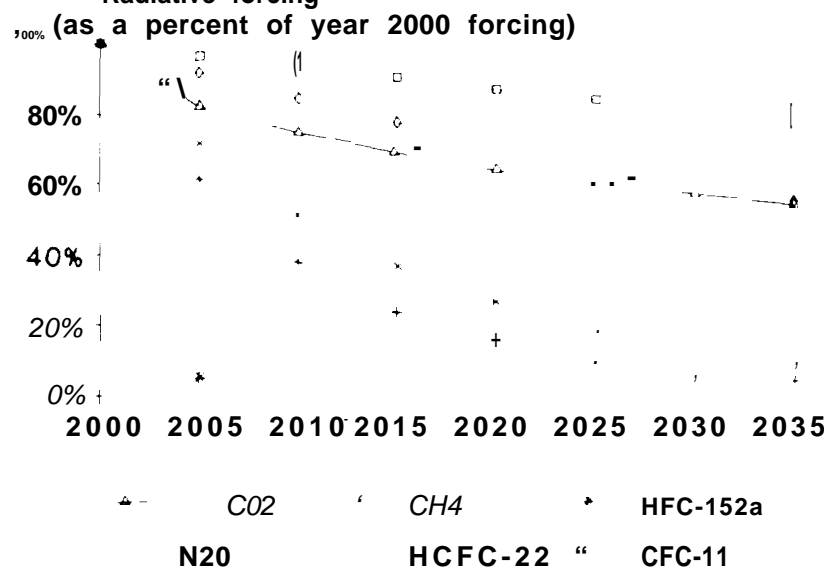

The radiative forcing from each gas is considered equal to 100 percent when it is emitted in the year 2000 . The graph illustrates the decline in radiative forcing over the next 35 years as the greenhouse gases decompose in the atmosphere.

SOURCE: Office of Technology Assessment, 1991, using data from IPCC, 1990.

which is shown in the second column of table 2-3. However, while GWP may be a good way for comparing the effects of different gases emitted well into the next century-when the effects from warming are likely to be greater-it may not be the appropriate choice for comparing the merits of alternative near- term policy measures (i. e., with in the 25-year timeframe of this assessment).

\footnotetext{
$17 \mathrm{CH}_{4}$ : $\mathrm{nd} \mathrm{N}_{2}$ ) interfere with each other, so that the impact of moreasing the concentration of one depends on how much the concentration of the other gas is increased at the same tme For the other gases, interferences are insignificant when incremental inceases in concentration are considered
} 
Figure 2-5-Carbon Dioxide Concentrations at Mauna Loa, Hawaii

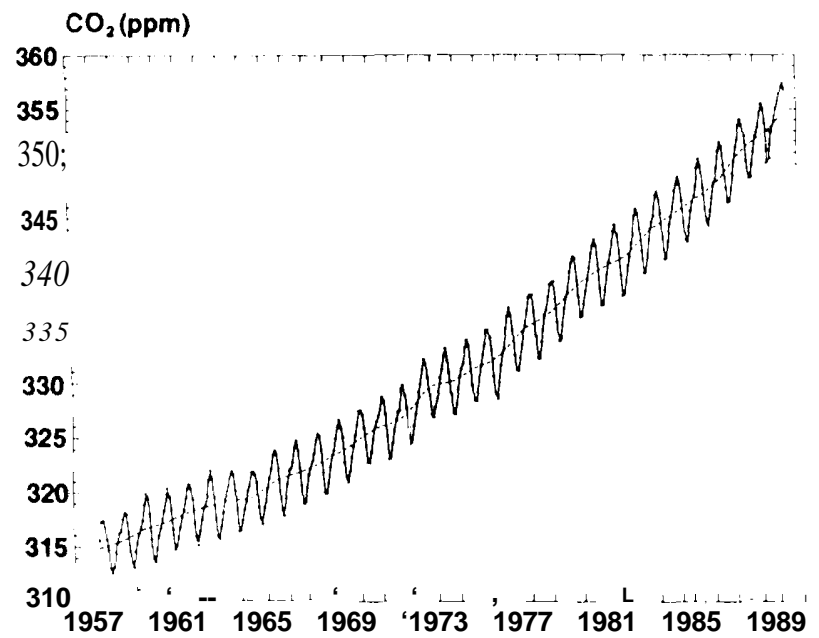

The solid line depicts monthly concentrations of atmospheric $\mathrm{CO}_{2}$ at Mauna Loa Observatory, Hawaii. The yearly oscillation is explained mainly by the annual cycle of photosynthesis and respiration of plants in the Northern Hemisphere. The increasing concentration of atmospheric $\mathrm{CO}_{2}$ at Mauna Loa since the 1950s (dashed line) is caused primarily by the $\mathrm{CO}_{2}$ inputs from fossil fuel combustion.

SOURCE: P. Tans, National Climatic Data Center, GMCC, 1990.

Some gases decay much more rapidly than others (see figure 2-4). For example, if we define the radiative forcing from a pound of $\mathrm{CO}_{2}$ emitted in 2000 to be equal to 100 percent, by 2010 the amount left in the atmosphere will have radiative forcing equal to 75 percent. Similarly, by 2025 the radiative forcing from $\mathrm{N}_{2} \mathrm{O}$ is about 85 percent of its original value 25 years earlier and CFC- 11 is about 65 percent of its original value. But note that the shorter lived gases, such as HFC-152a (a replacement for CFCs) and $\mathrm{CH}_{4}$, behave differently. By 2010 HFC152a will have almost completely decomposed. By 2025 , the radiative forcing from $\mathrm{CH}_{4}$ will be about 10 percent of the amount 25 years earlier.

The IPCC measure assumes that an increment of warming today is equal to an increment of warming in the future. We have constructed our own formulation of GWP that we feel is more appropriate for evaluating the near-term policies presented in this report. Our measure focuses on the amount of warming that would be prevented during a specified period of concern during the 21st century, by elimin ating a pound of greenhouse gas emissions
Figure 2-6-Carbon Dioxide Concentration (parts per million by volume)

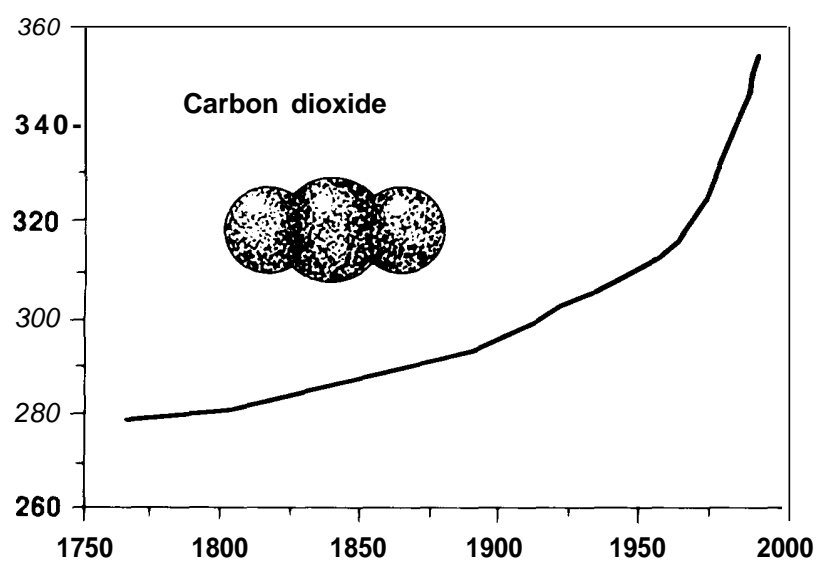

The history of atmospheric $\mathrm{CO}_{2}$ presented here is based on ice core and atmospheric measurements. The data show that $\mathrm{CO}_{2}$ increased slowly in the 1800 s and more rapidly in the 1900 s when temperate forests were converted to agricultural land. The rapid rise since the 1950s is due primarily to fossil fuel combustion and tropical deforestation. The current rate of increase is unprecedented in the ice core records.

SOURCE: Office of Technology Assessment, 1991, from IPCC, 1990.

each year between 1995 and 2015. Because it is not possible to pick one particular year when one might begin to be concerned about global warming effects, table 2-3 presents three versions of our measure, starting at either 2015,2025, or 2035. Again note the differences in the shorter lived gases. Methane is less than half the IPCC's 100-year estimate and the effects of several of the short-lived CFC substitutes drop considerably. Thus, over the near-term, Congress may wish to focus efforts on the longer lived greenhouse gases- $\mathrm{CO}_{2}, \mathrm{~N}_{2} \mathrm{O}$, and CFCs.

\section{Carbon Dioxide}

Along with water vapor and clouds, $\mathrm{CO}_{2}$ is a major natural greenhouse agent, without which Earth would be uninhabitable. However, $\mathrm{CO}_{2}$ concentrations are estimated to have increased by about 25 percent since the mid-1800s, from around 280 ppm to about $350 \mathrm{ppm}$ now (see figures 2-5 and 2-6). The continuous record of $\mathrm{CO}_{2}$ concentrations measured at Mauna Loa since 1958 shows a steady year-to-year increase superimposed on a clear sea- 
Figure 2-7-Global Carbon Emissions From Fossil Fuel

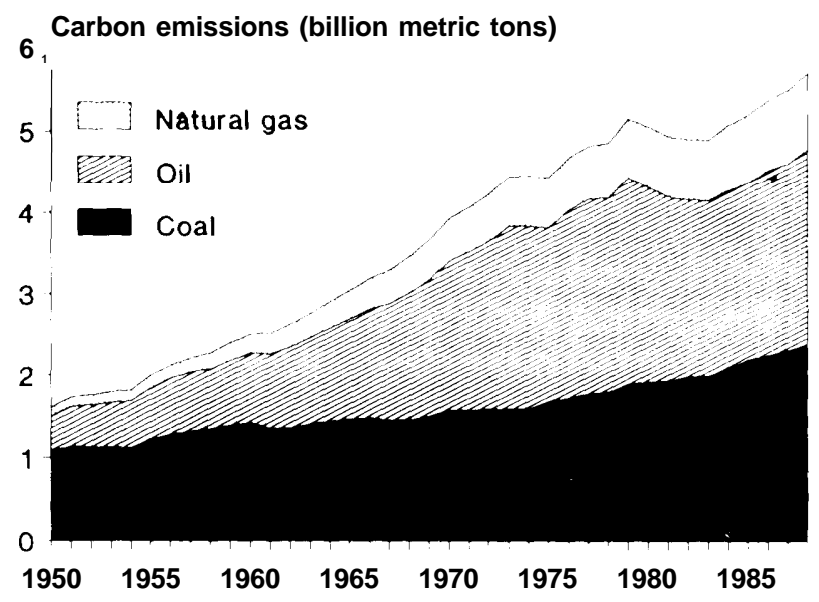

$\mathrm{CO}_{2}$ emissions from fossil fuel combustion alone have grown from less than 0.1 billion metric tons $C$ in the mid-1850s to approximately 6 billion metric tons $C$ in 1989 . Emissions have more than tripled in the last $\mathbf{4 0}$ years.

SOURCE: Oak Ridge National Laboratory, Carbon Dioxide Information Analysis Center, "Trends ' 90 A Compendium of Data on Global Change" (Oak Ridge, TN:1990).

sonal cycle. ${ }^{18}$ Most of the increase occurred in the 20 th century $(37,45,80,88)$ and is attributed largely to fossil fuel consumption (see figure 2-7).

$\mathrm{CO}_{2}$ concentrations in air bubbles trapped in Antarctic ice indicate that present $\mathrm{CO}_{2}$ levels are already higher than at any time in the past 160,000 years. Past $\mathrm{CO}_{2}$ concentrations ranged from roughly $200 \mathrm{ppm}$ during glacial episodes to $280 \mathrm{ppm}$ during interglacial periods and were roughly correlated with temperature $(7,37,53)$. Unless steps are taken to reduce emissions, $\mathrm{CO}_{2}$ concentrations in 2030 are projected to be about $450 \mathrm{ppm}$, up more than 60 percent from preindustrial levels and 30 percent from 1985 levels $(28,37,70,98)$.

$\mathrm{CO}_{2}$ accounted for an estimated two-thirds of the enhanced radiative forcing that occurred from 1880 to 1980 , with the share declining to about 50 percent during the last decade as CFCs grew in importance $(29,70)$. With anticipated controls on CFC emissions, however, $\mathrm{CO}_{2}$ 's comparative contribution is expected to rebound in the future (98). Assuming feedbacks amplify the direct radiative forcing effect by a factor of 1 to 3 , climate models suggest that the
Figure 2-8--U.S. Carbon Emissions From Fossil Fuel

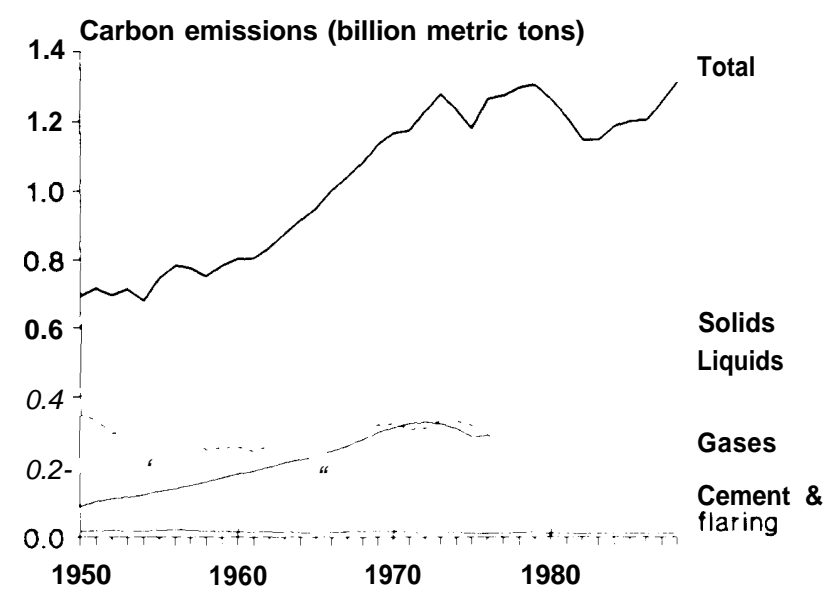

U.S. emissions of carbon from fossil fuels are currently about 1.3 billion metric tons $\mathrm{C}$. Emissions have doubled since the industrial revolution.

SOURCE: Oak Ridge National Laboratory, Carbon Dioxide Information Analysis Center, "Trends '90: A Compendium of Data on Global Change" (Oak Ridge, TN: 1990).

30 percent increase in $\mathrm{CO}_{2}$ concentration projected for the period from 1985 to 2030 would add 0.45 to $1.3{ }^{\prime} \mathrm{C}$ to the equilibrium warming already expected from current greenhouse gas levels (98).

Of the total (estimated) cur-rent $\mathrm{CO}_{2}$ emissions due to human activity ( 5.8 to 8.7 billion metric tons of carbon), 5.2 to 6.2 billion metric tons is due to fossil fuel burning, and 0.6 to 2.5 billion metric tons is due to deforestation (37).19 Fossil fuel emissions are estimated to have increased more than 50-fold since the middle of the last century and are expected to reach 9 to 12 billion metric tons of carbon in 2025 without deliberate action to reduce them (98).

The United States, with less than 5 percent of the world's population, is responsible for almost 25 percent of fossil fuel $\mathrm{CO}_{2}$ emissions, more than any other nation (58). U.S. emissions dropped during the two energy crises but have recently increased (see figure 2-8). Current emissions from deforestation in the United States are considered negligible (see ch. 7). Electricity production (for industrial, residential, and commercial use) dominates U.S. $\mathrm{CO}_{2}$ emissions, followed by transportation, and then by direct

\footnotetext{
${ }^{18}$ The seasonal variation reflects winter-to-s $\sim$ mer changes in photosynthesis $\left(\mathrm{CO}_{2}\right.$ storage $)$ and respiration $\left(\mathrm{CO}_{2}\right.$ release $)$ in live plants.

${ }^{19}$ Others $(35,36)$ estimate that deforestation could contribute up to 2.8 billion metric tons of carbon (see ch. 7). Note that 1 billion metric tons of carbon is equivalent to 3.7 billion metric tons of $\mathrm{CO}_{2}(37)$.
} 
fossil fuel use in industrial and buildings applications. Oil and coal combustion each account for roughly 40 percent of U.S. emissions, natural gas the other 20 percent (see ch. 3 ). ${ }^{20}$

The United States is projected to contribute about 2 billion metric tons of carbon in 2025, slightly more than its current contribution in absolute terms, but a smaller fraction of the world's total than at present (98; also see ch. 3). China and other developing countries, the U. S. S. R., and centrally planned European countries are projected to be major emitters in 2025 (98; see ch. 9).

Calculating atmospheric concentrations of $\mathrm{CO}_{2}$ from anthropogenic emission levels is complicated; annual emissions from human activity are small compared with natural exchanges of carbon among the atmosphere, oceans, and biosphere (see figure 2-9). These natural exchanges are substantial, yet not very well understood $(16,37,68)$. For example, about 100 billion metric tons of carbon in the atmosphere is stored annually in living vegetation through the process of photosynthesis; an approximately equal amount of carbon is put back into the atmosphere through plant respiration and decay of dead vegetation (34). (The seasonal variation in the Mauna Loa $\mathrm{CO}_{2}$ data (see figure 2-5) is caused by the seasonal imbalance between these processes, which roughly even out on an annual basis.)

An estimated 90 billion metric tons of carbon is exchanged between the oceans and the atmosphere each year (4). Over the past 30 years, the net effect of this exchange has been uptake and absorption by the oceans of roughly 2 to 3 billion metric tons of carbon from the atmosphere per year. If biosphere/ atmosphere exchanges are ignored, this means that effectively about 45 percent of each year's $\mathrm{CO}_{2}$ emissions from fossil fuel combustion have been offset by absorption by the oceans (4). However, the fraction of fossil fuel $\mathrm{CO}_{2}$ that is absorbed by the ocean appears to be declining (46). One partial explanation may be that the surface layer of the ocean has warmed, and warmer water absorbs less $\mathrm{C} \mathrm{O}_{2}$

Recent analyses suggest that the oceans are not the only major sink for $\mathrm{CO}_{2}$ and that terrestrial ecosystems may absorb a larger amount of $\mathrm{CO}_{2}$ than previously thought (91). The IPCC (37) estimated that about 30 percent of today's $\mathrm{CO}_{2}$ emissions is absorbed by the oceans and 23 percent by the land biota, and that 47 percent remains in the atmosphere. However, sequestering by the land biota is not well understood, and the biota could become saturated at some point in the future. In this event, the atmospheric accumulation would increase even faster, unless the oceans could somehow make up the difference (or $\mathrm{CO}_{2}$ emissions declined). Appendix 2-A discusses the idea of fertilizing areas in the Antarctic Ocean with iron, in order to stimulate phytoplankton productivity and increase carbon sequestration in the ocean.

Greenhouse gas/global warming feedbacks may affect the natural balance between $\mathrm{CO}_{2}$ storage and release. For example, some plants respond to increased atmospheric $\mathrm{CO}_{2}$ by storing more carbon, at least under laboratory and horticultural greenhouse conditions; at the same time, warmer temperatures can speed up respiration and decay and hence accelerate the release of $\mathrm{CO}_{2}$ to the atmosphere (see ch. 7). Some scientists hypothesize that feedback mechanisms are already operating and that they may explain: 1 ) the increase over the past three decades in the difference between wintertime peak and summertime low $\mathrm{CO}_{2}$ concentrations (46); and 2) the recent acceleration of annual growth in $\mathrm{CO}_{2}$ concentrations, despite leveling off of fossil fuel emission rates (35).

Because of the long atmospheric lifetime for $\mathrm{CO}_{2}$ (50 to 200 years), the IPCC (37) estimated that anthropogenic $\mathrm{CO}_{2}$ emissions would have to be reduced to 50 percent of their present level by the year 2050 in order to limit the atmospheric $\mathrm{CO}_{2}$ concentration in 2050 to "only" $420 \mathrm{ppm}$ (50 percent above the preindustrial level). The IPCC (37) estimated that an immediate 60 to 80 percent reduction in anthropogenic $\mathrm{CO}_{2}$ emissions would be necessary to stabilize atmospheric $\mathrm{CO}_{2}$ concentrations at 1990 levels (353 ppm).

\section{Methane}

Methane concentrations have steadily risen at about 1 percent per year, from about $1.52 \mathrm{ppm}$ in 1978 to about $1.68 \mathrm{ppm}$ in 1987 (see figure 2- 10). Ice core data show that $\mathrm{CH}_{4}$ concentrations have approximately doubled over the past two centuries and are currently higher than at any time during the past 160,000 years. Like $\mathrm{CO}_{2}$ concentrations, they have 
Figure 2-9--The Global Carbon Cycle

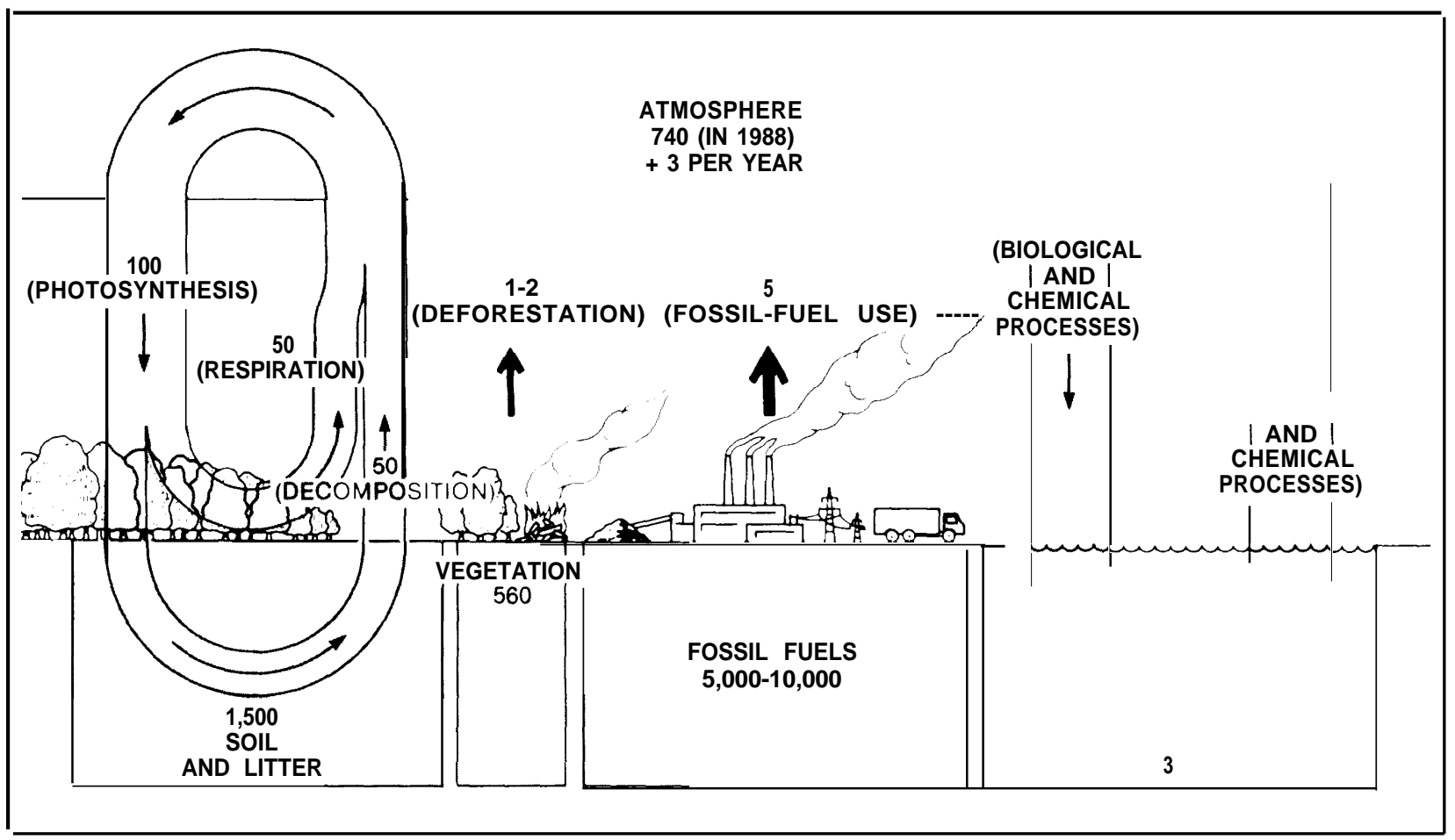

The carbon fluxes and reservoirs are shown in billions of metric tons $C$.

SOURCE: Office of Technology Assessment, 1991.

been roughly correlated with temperature over this period $(37,75,89)$.

Per molecule, $\mathrm{CH}_{4}$ is about 25 times more effective in trapping heat than $\mathrm{CO}_{2}(98)$. Increases in $\mathrm{CH}_{4}$ over preindustrial levels contributed about 15 percent of the total greenhouse gas forcing estimated to have occurred from 1880 to $1980(70,71)$. In the absence of steps to reduce $\mathrm{CH}_{4}$ emissions, average $\mathrm{CH}_{4}$ concentrations in the year 2030 are projected to reach about $2.5 \mathrm{ppm}(28,70,71,98)$. This nearly 50 -percent rise above current atmospheric concentrations would increase expected equilibrium warming by about 0.2 to $0.5{ }^{\prime} \mathrm{F}$ above currently projected levels.

Current $\mathrm{CH}_{4}$ emissions are estimated to range between 290 and 965 million metric tons per year (8, 14, 37, 98). Rice paddies and domestic animals (mainly cattle and sheep) are thought to be the largest sources related to human activity (see ch. 8), although natural gas production and delivery, coal production, and landfills also contribute substantially (see table 2-4). The United States apparently contributes about 6 percent of the $\mathrm{CH}_{\mathrm{d}}$ emissions due to human activity, mostly from landfills, natural gas and coal production, and domestic animals. Without action to reduce emissions, EPA (98) projects that annual worldwide $\mathrm{CH}_{4}$ emissions will increase by about 10 to 30 percent by 2025, with a slight decline in the relative U.S. share. The largest increases axe projected from landfills and production and distribution of fossil fuels; smaller increases are projected from domestic animals and rice production.

Methane molecules emitted today will remain in the atmosphere for an average of 10 years. Methane removal occurs primarily via a chemical reaction with a hydroxyl radical (OH-), which is a short-lived fragment of a water vapor molecule (69). However, the average lifetime of $\mathrm{CH}_{4}$ molecules may be increasing, due to reductions in hydroxyl radical levels (69). Hydroxyl radicals can be lost due to reactions with $\mathrm{CH}_{4}$ or carbon monoxide $(\mathrm{CO})$, and emissions of both gases are thought to be increasing. Currently, $\mathrm{OH}^{-}$depletion is estimated to have an effect equivalent to emitting a few additional million 
Figure 2-10-Atmospheric: Methane Concentration (parts per billion by volume)

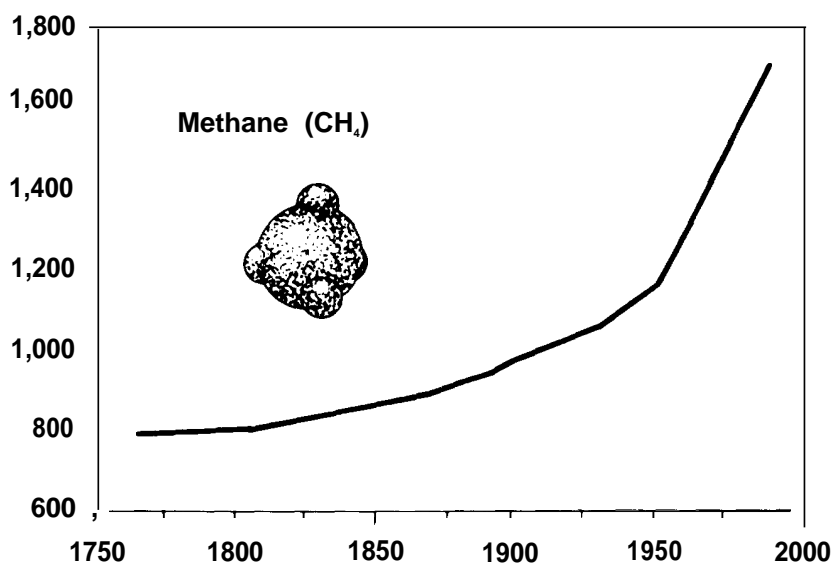

SOURCE: Office of Technology Assessment, 1991, from IPCC, 1990

Table 2-4-Estimated Annual Global Methane Emissions and U.S. Contribution to Man-Made Sources

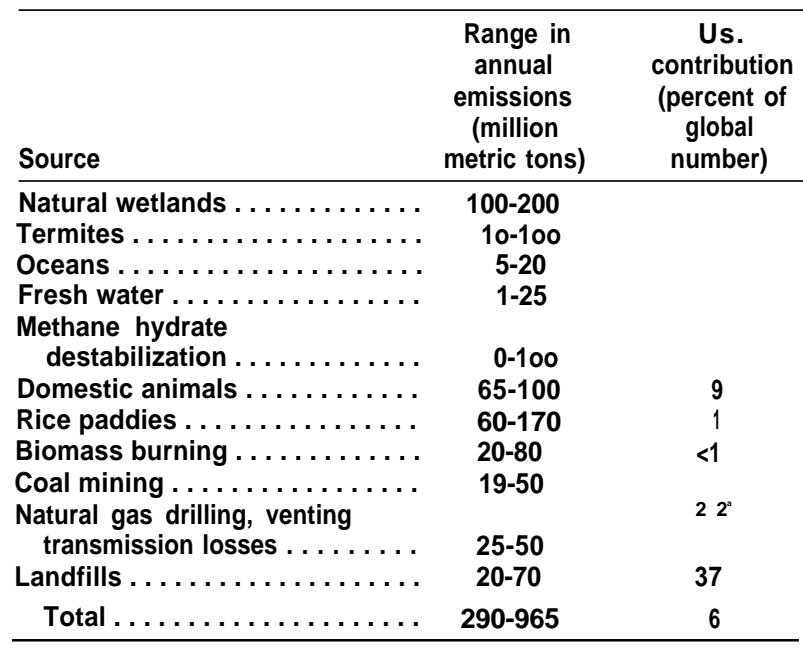

alncludes both coal mining and natural gas sources.

SOURCES: R.J. Cicerone and R.S. Oremland, 1988; D.W. Barns et al., 1989; Intergovernmental Panel on Climate Change, 1990.

metric tons of $\mathrm{CH}_{4}$ per year, but this could increase in the future (14).

Climate change feedbacks could also potentially increase $\mathrm{CH}_{4}$ emissions levels. Warmer temperatures could increase emissions from wetlands and rice paddies, because the rate at which organic matter is decomposed in these environments increases with temperature (15). However, warming and a drier climate could decrease emissions from high-latitude tundra soils, as a result of lowered water tables (109). Warmer temperatures could also release $\mathrm{CH}_{4}$ from permafrost where it is stored as " "methane-hydrates (37). With a global average temperature increase of $5{ }^{\circ} \mathrm{F}(3 * \mathrm{C})$, as much as 100 million metric tons of $\mathrm{CH}_{4}$ per year (48) to several times this amount (76) could be released from methane-hydrate deposits. In order to stabilize atmospheric $\mathrm{CH}_{4}$ concentrations at current levels, the IPCC (37) estimated that an immediate 15 to 20 percent reduction in global anthropogenic $\mathrm{CH}_{4}$ emissions would be necessary.

\section{Nitrous Oxide}

Nitrous oxide concentrations apparently began to rise rapidly in the $1940 \mathrm{~s}$, and increased about 0.2 to 0.3 percent per year during the mid-1980s. Current concentrations are about $310 \mathrm{ppb}$, compared to about $285 \mathrm{ppb}$ during the late $1800 \mathrm{~s}$ (see figure $2-11$ ). Ice core measurements indicate that the preindustrial $\mathrm{N}_{2} \mathrm{O}$ level was relatively stable at about $285 * 5 \mathrm{ppb}$ for at least the past 2,000 years (37). Thus, today's $\mathrm{N}_{2} \mathrm{O}$ atmospheric concentration appears to be without historical precedent. Unless $\mathrm{N}_{2} \mathrm{O}$ emissions are reduced, concentrations are projected to rise to between 340 and 380 ppb by $2030(28,70,71,98)$.

Per molecule, the radiative forcing effect of $\mathrm{N}_{2} \mathrm{O}$ is about 200 times greater than that of $\mathrm{CO}_{2}(98)$. The almost 10 percent increase in $\mathrm{N}_{2} 0$ concentration that has occurred over the past century contributed about 2.5 percent of the total greenhouse gas forcing during that period $(70,71)$. Adding $35 \mathrm{ppb}$ to the atmospheric $\mathrm{N}_{2} \mathrm{O}$ burden by 2030 would increase the projected equilibrium warming by about 0.1 to 0.2 *F $\left(() .() 55\right.$ to $\left.0.11^{\circ} \mathrm{C}\right)$.

$\mathrm{N}_{2} \mathrm{O}$ emissions levels are extremely uncertain; EPA (98) estimated the total to be 11 to 17 million metric tons per year, primarily from microbial soil vitrification and denitrification. Several kinds of human activity also result in $\mathrm{N}_{2} \mathrm{O}$ emissions. Both the use of nitrogenous fertilizers for agriculture (ch. 8 ) and microbial activity in groundwater aquifers contaminated by nitrogenous compounds are sources associated with human activity (79). $\mathrm{N}_{2} \mathrm{O}$ is also produced during fossil fuel combustion, although the magnitude of emissions from this source is highly uncertain (65). Biomass burning releases $\mathrm{N}_{2} \mathrm{O}$ as well, but clearing of primary tropical forests could lower subsequent $\mathrm{N}_{2} \mathrm{O}$ emissions if the soils then emit $\mathrm{N}_{2} \mathrm{O}$ at a slower rate (77). In fact, 
Figure 2-1 I-Atmospheric Nitrous Oxide concentration (parts per billion by volume)

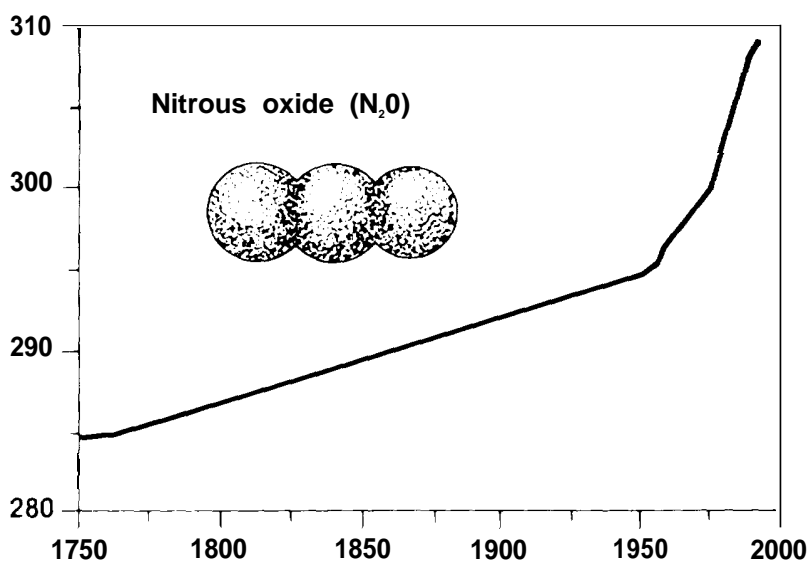

SOURCE: Office of Technology Assessment, 1991, from IPCC, 1990.

emissions from fossil fuel and biomass combustion appear to be considerably less than once thought.

The IPCC (37) concluded that $\mathrm{N}_{2} \mathrm{O}$ emissions of 10 to 17.5 million metric tons $\mathrm{N}$ per year are needed to account for the observed increase in atmospheric $\mathrm{N}_{2} \mathrm{O}$ concentration. Yet the IPCC could identify only 4.4 to 10.5 million metric tons $\mathrm{N}$ per year from known sources (see table 2-5). The IPCC (37) concluded that the data suggest the likelihood of unaccounted for or underestimated sources of $\mathrm{N}_{2} \mathrm{O}$. Despite uncertainties as to what these are, the IPCC concluded that "the observed increase in $\mathrm{N}_{2} \mathrm{O}$ concentrations is caused by human activities.

$\mathrm{N}_{2} \mathrm{O}$ has an atmospheric lifetime of about 150 year; $(37,117)$. It is destroyed via reactions that occur in the stratosphere $(70,71)$ and possibly via removal by soils (37). The IPCC (37) estimates that to stabilize $\mathrm{N}_{2} \mathrm{O}$ concentrations at current levels, an immediate 70 to 80 percent reduction in anthropogenic $\mathrm{N}_{2} \mathrm{O}$ emissions would be needed.

\section{Chlorofluorocarbons and Halons}

Chlorofluorocarbons (CFCs) and halons are longIived synthetic chemicals containing chlorine, fluorine (and in the case of halons, bromine), and carbon. They are released to the atmosphere from many sources: venting during servicing of appliances such as refrigerators or air-conditioners; leaks from such appliances (while in use or after disposal); production of 'open-cell' foams; deterioration of 'closed-
Table 2-5-Estimated Sources and Sinks of Nitrous Oxide

\begin{tabular}{|c|c|}
\hline Source/sinks & $\begin{array}{c}\text { Annual emissions } \\
\text { (million metric tons } \\
\text { per year) }\end{array}$ \\
\hline $\begin{array}{l}\text { Sources: } \\
\text { Coal and oil combustion } \ldots \ldots \ldots \ldots \\
\text { Biomass burning } \ldots \ldots \ldots \ldots \ldots \ldots \\
\text { Fertilized croplands } \ldots \ldots \ldots \ldots \ldots \\
\text { Forest soils } \ldots \ldots \ldots \ldots \ldots \ldots \ldots \ldots \\
\text { Oceans } \ldots \ldots \ldots \ldots \ldots \ldots \ldots\end{array}$ & $\begin{array}{r}0.10-0.3 \\
0.02-0.2 \\
0.01-2.2 \\
2.9-5.2 \\
1.4-2.6\end{array}$ \\
\hline Total $\ldots \ldots \ldots \ldots \ldots \ldots \ldots$ & 4.4-10.5 \\
\hline $\begin{array}{l}\text { Sinks: } \\
\text { Removal by soils } \ldots \ldots \ldots \ldots \ldots \ldots \\
\text { Photolysis in the stratosphere } \ldots \ldots \\
\text { Atmospheric increase } \ldots \ldots \ldots \ldots\end{array}$ & $\begin{array}{c}\text { No estimate } \\
7-13 \\
3-4.5\end{array}$ \\
\hline Total $\ldots \ldots \ldots \ldots \ldots \ldots \ldots$ & $10-17.5$ \\
\hline
\end{tabular}

cell' foams; and during use as aerosol propellants, solvents, and fire extinguishers. Emissions could be avoided from many of these applications, for example, through recapture and recycling or through incineration rather than disposal. Such measures are seldom taken.

CFCs and halons were first introduced in the 1930s, and worldwide production increased steadily until the mid-1970s (see table 2-6 and figures 2-12 and 2-13), when the use of CFCs in nonessential aerosols was banned in the United States and a few other counties. Largely because of this ban, which was enacted in response to concerns about the destruction of stratospheric ozone, growth rates in atmospheric concentrations of CFCs have slowed, from an average of about 10 percent per year (between 1975 and 1985) to about 4 percent per year now. Atmospheric concentrations of the most widely used CFCs (CFC-11 and CFC-12) were 230 and 400 ppt, respectively in 1986, and 280 and 484 ppt in 1990 (37).

Outside the United States, however, both CFC- 11 and CFC-12 are still commonly used in aerosol sprays. CFC- 11 use in the United States is dominated by production of synthetic rigid foams for cushioning and insulation, while the largest use of CFC- 12 is for motor vehicle air-conditioning.

CFCs and halons have extremely long lifetimes, typically on the order of 65 to over 100 years (see table 2-6), before they are eventually destroyed in 
Table 2-6--Chlorinated and Brominated Compounds

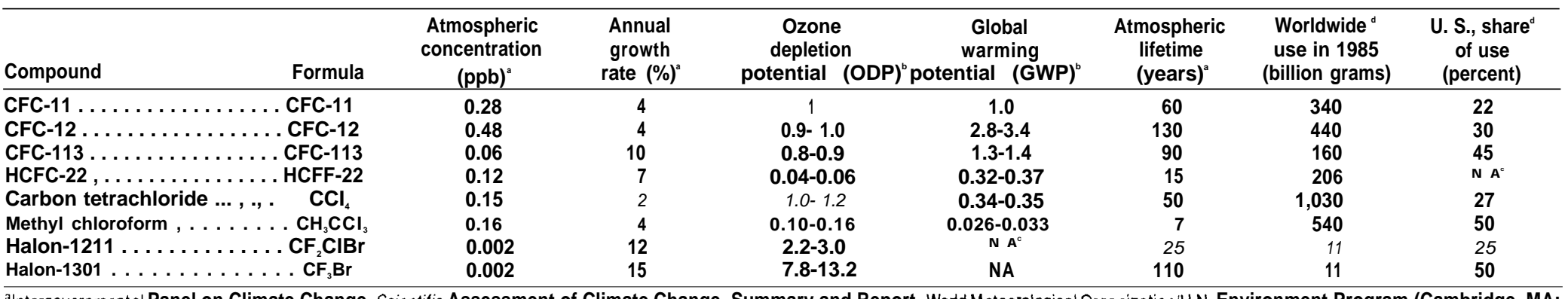
antergovernmental Panel on Climate Change, Scientific Assessment of Climate Change, Summary and Report, World Meteorological Organization/U.N. Environment Program (Cambridge, MA: Cambridge University Press, 1990).

bNASA, Present State of Knowledge of the Upper Atmosphere 1990.' An Assessment Report (Washington, DC: 1990). Ozone depletion potential and global warming potential per unit mass emitted, relative to that of CFC- 11 .

'NA = not available.
dJ.K. Hammitt et. al., Product Uses and Market Trends for Potential Ozone-depleting Substances, 1985-2000(Santa Monica, CA:RAND Corp., May 1986); data for HCFC-22 for 1984, from U.S. Environmental Protectlon Agency, Office of Policy Planning and Evaluation, Policy Options for Stabilizing Global Climate, Draft Report to Congress (Washington, DC: February 1989). 
Figure 2-1 2-Concentration of CFC-11 in the Atmosphere (parts per billion by volume)

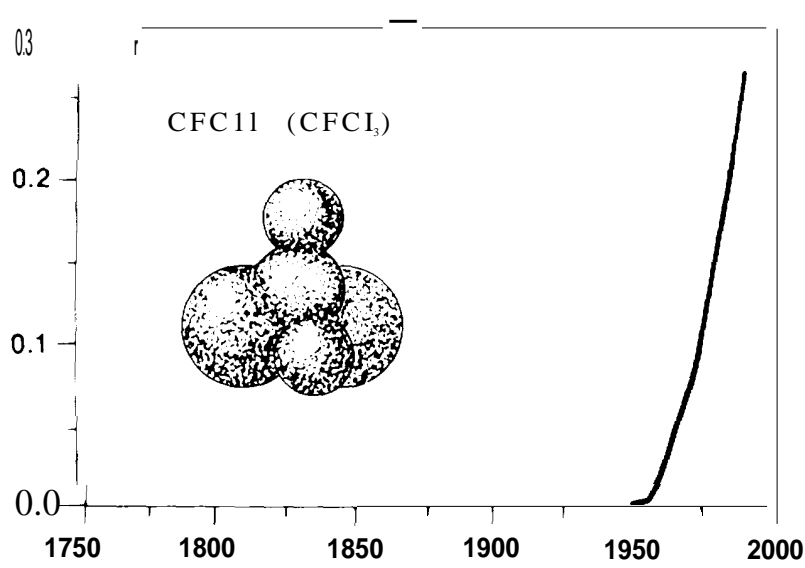

Total reported production of CFC-11 and CFC-12 increased rapidly throughout the 1960 s and 1970 s, reaching a maximum of 813,000 metric tons in 1974 . Aerosol applications declined since the mid-1970s, while nonaerosol applications continued to increase.

SOURCE: Off Ice of Technology Assessment, 1991, from IPCC, 1990.
Figure 2-14-Ozone Depletion Potential and Global Warming Potential of CFCs and Replacement Compounds (HFCs and HCFCs)

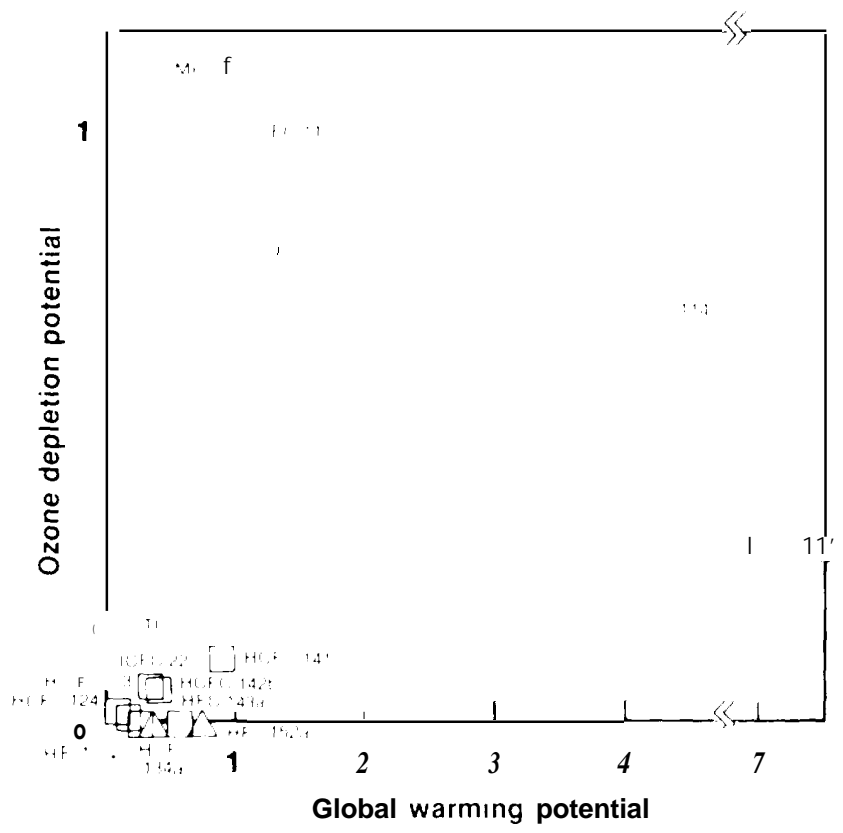

Note that there is a strong correlation between ozone depletion effect and global warming potential; this relates to the lifetime of the compound in the atmosphere. Those with few chlorine and/or bromine atoms decompose more quickly (therefore causing less environmental damage) than fully chlorinated or brominated compounds.

SOURCE: Intergovernmental Panel on Climate Change, 1990; and Office of Technology Assessment, 1991.

Figure 2-13-Estimated CMA Reporting Country and U.S. Use of CFC-11 and CFC-12, by Product

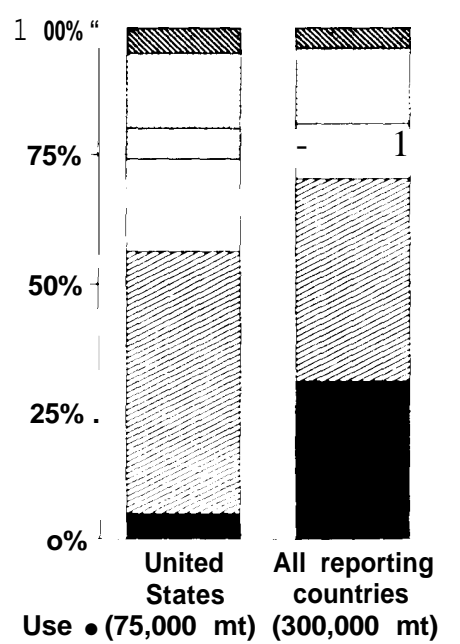

CFC-11 uses:

m Flexible molded

C Flexible slabstock

$\square$ Chillers

Unallocated

福 Rigid foam

Aerosol

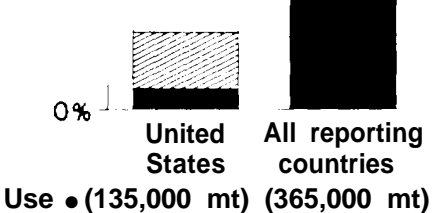

$25 \%+$

$100 \% 7$
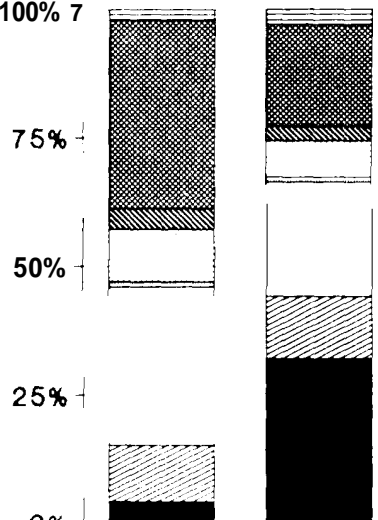

$(365,000 \mathrm{mt})$
CFC-12 uses;

Home refrigeration

Mobile air conditioning

Retail food refrigeration

Miscellaneous

Chillers

Unallocated

㲘 Rigid foam

Aerosol

SOURCE: J K. Hammitt et al Product Uses and MarketTrendsfor Potential Ozone-depleting Substances, 1985-2000 (Santa Monica, CA: RAND Corp., May 1986). 
the stratospheric reactions that also deplete stratospheric ozone (see box 2-B). Evidence regarding ozone destruction mounted steadily in the 1980s (see box 2-B). In response, 47 countries negotiated the Montreal Protocol on Substances that Deplete the Ozone Layer, which was signed in September 1987 and strengthened in 1990 (see box 2-C).

The radiative forcing effect of CFCs is on the order of 10,000 times greater, per molecule, than that of $\mathrm{CO}^{2}(70)$. CFC-11 and CFC- 12 contributed about 9 percent of the total radiative forcing increase that occurred over the last hundred years (70). Recently, however, their contribution has been much higherapproximately 25 percent over the last decade (30). Based on EPA projections conducted before the Montreal Protocol was strengthened in 1990, the added contribution of CFCs from the late 1980s through 2030 was projected to be an equilibrium warming increment of about 0.2 to 0.5 ' $\mathrm{F}(0.1$ to 0.3 $\left.{ }^{\circ} \mathrm{C}\right)$ (98). Other chlorinated and brominated com- pounds have had less impact to date because their concentrations in the atmosphere are low, but molecule-for-molecule they can contribute as much to ozone depletion and global warming as CFC-11 and CFC- 12. Concentrations of some of these compounds are growing rapidly (see table 2-6).

The hydrofluorocarbons (HFCs) and hydrochlorofluorocarbons (HCFCs) being considered as CFC replacements have shorter atmospheric lifetimes, generally 1 to 40 years for HFCs and HCFCs, compared to 65 to 130 years for CFCs (37) (see figure 2-14 and table 2-6). Thus, a rapid phaseout of CFCs coupled with aggressive substitution of HFCs and HCFCs (especially those with the shortest atmospheric lifetimes) would be expected to significantly lower net atmospheric concentrations of radiatively active gases, with a commensurate reduction in ozone depletion and global warming potential (37).

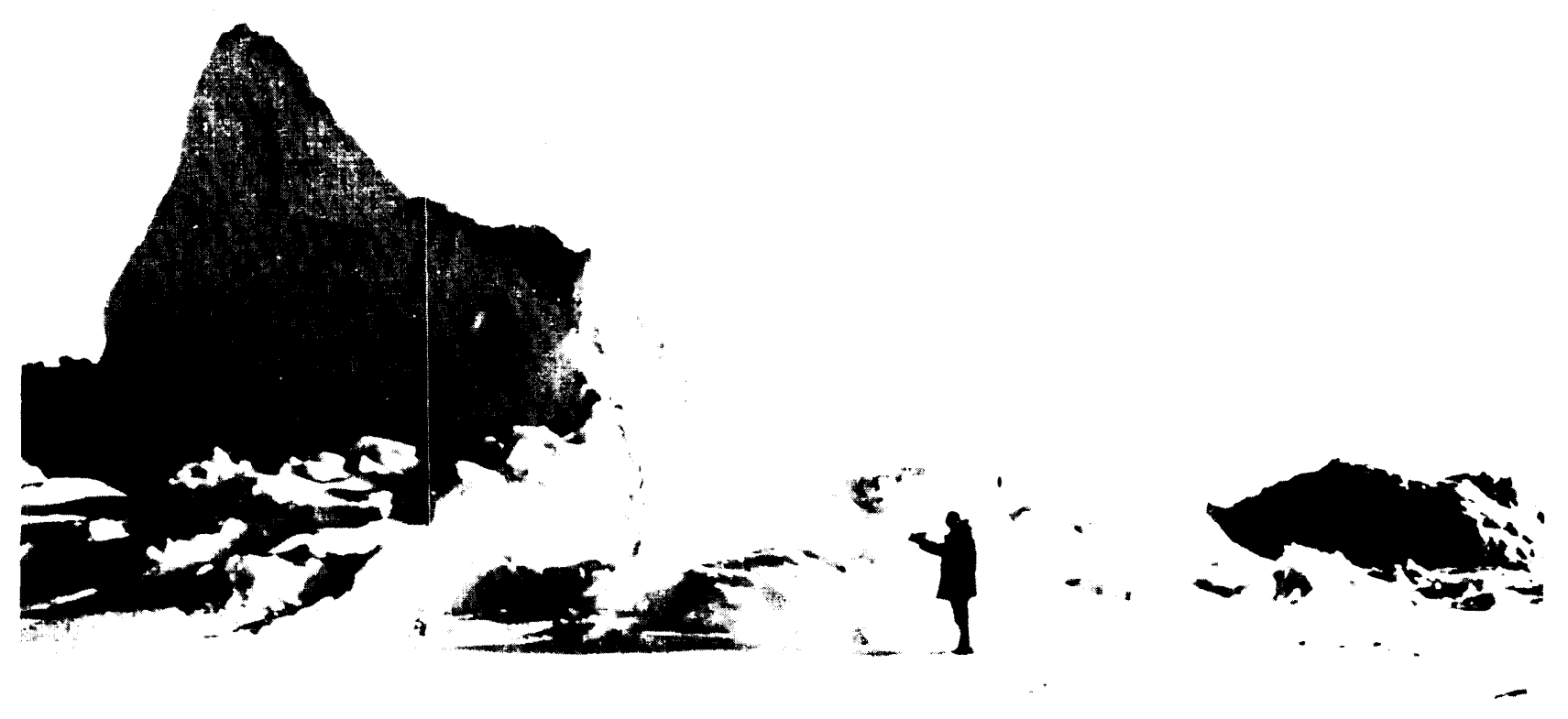

Photo credit: A, Kovacs

Carbon dioxide trapped in air bubbles in Antarctic ice indicates that present $\mathrm{CO}_{2}$ concentrations are higher than at any time in the past 160,000 years. Ice core data also show that $\mathrm{CH}_{4}$ concentrations have approximately doubled over the past two centuries; measurements for $\mathrm{N}_{2} \mathrm{O}$ suggest that atmospheric concentrations remained stable for 2,000 years and started to climb during the industrial revolution. 


\section{Box 2-B-Stratospheric Ozone Depletion}

Stratospheric ozone $\left(0_{3}\right)$ shields the Earth from solar radiation in the biologically harmful range of ultraviolet wavelengths known as W-B (the wavelength band extending from about 280 to $320 \mathrm{rim}$ ). In humans, the harmful effects of exposure to W-B radiation include sunburn; premature aging of the skin; nonmelanoma skin cancer; occular disorders, including cataracts; and suppression of immune system responses. Though uncertain, malignant melanoma skin cancer may also be linked to W-B exposure. Excessive W-B exposure can also damage plants and animals in terrestrial and aquatic ecosystems.

Ninety percent of the protective ozone is contained in the stratosphere. The natural balance of stratospheric ozone is maintained through a continuous cycle of production and destruction involving solar radiation, molecular oxygen (02), and naturally produced molecules containing hydrogen, nitrogen, chlorine, and bromine atoms. CFCs, halons, methyl chloroform, and carbon tetrachloride-all of which are synthetically produced chlorinated or brominated compounds-an severely alter this balance by speeding up ozone destruction. Because they are catalysts (i.e., they are not destroyed by the reactions in which they participate), one chlorine or bromine molecule can destroy thousands of molecules of ozone. ${ }^{2}$

The amount of UV-B radiation that reaches Earth's surface depends on season, time of day, latitude, and altitude. At present, on a clear day at the equator, only about 30 percent of the UV-B that enters Earth's atmosphere reaches its surface. Fractions as low as 10 percent reach the surface at higher latitudes or when clouds are present. However, for each 1-percent reduction in ozone concentrations, the penetration of biologically active UV-B is predicted to increase by roughly 2 percent. In turn, the Environmental Protection Agency (33) estimates that with a 2-percent increase in W-B radiation, the incidence of nonmelanoma skin cancer in the United States would increase by about 2 to 6 percent over the current rate of roughly 400,000 new cases per year; and that the incidence of malignant melanoma in the United States would increase by 1 to 2 percent over the current rate of about 26,000 new cases and 6,000 fatalities per year.

In October 1987, the amount of ozone over Antarctica fell to the lowest levels ever observed. Averaged over 100 latitude bands extending south from $60^{\circ}, 70^{\circ}$, and $80^{\circ} \mathrm{S}$, respectively, total column ozone (i.e., the amount of ozone directly overhead at a given site) had dropped by 24,40, and 50 percent compared to October 1979. At some locations and heights, the depletion reached 95 percent. observational evidence very strongly suggests that chemical mechanisms involving chlorine from human-made sources are the primary cause of this rapid decline (106). In particular, chlorine and bromine released from CFCs and halons are primed for ozone destruction by chemical interactions with cloud particles. With the extremely cold temperatures of the Antarctic winter, clouds form readily in the polar stratosphere. The greatest ozone depletion occurs during the austral spring, when the air above the Antarctic is chemically primed and isolated from air at lower latitudes, and sunlight is available to participate in ozone-destroying reactions. More normaI ozone levels were observed in 1988, indicating that meteorological conditions have to be "right" for severe ozone depletion to occur. The Antarctic ozone hole appeared in both 1989 and 1990, the first time such depletion was observed in two consecutive years. The 1990 hole was nearly as severe as the record levels found in 1987 and persisted longer.

Observations in the Arctic in December 1988 and February 1989 indicated that Arctic stratospheric ozone also had fallen, although on a much smaller scale than in the Antarctic. Observers found increased amounts of potential ozone-destroying compounds $(\mathrm{C} 1 \mathrm{O}$ and $\mathrm{OC} 1 \mathrm{O})$, suggesting that the potential exists for significant destruction of ozone in the Arctic (106).

${ }^{1}$ The stratosphere is the region of the atmosphere that extends from about 8 to $17 \mathrm{~km}$ (depending on latitude) and up to about $50 \mathrm{~km}$ above the Earth's surface. The remaining 10 percent of the ozone is found in the troposphere, the region of the atmosphere extending from Earth's surface up to the base of the stratosphere.

${ }^{2}$ The "greenhouse" gases $\mathrm{CO}_{2}, \mathrm{CH}_{4}$, and $\mathrm{N}_{2} \mathrm{O}$ also affect stratospheric ozone. Increasing $\mathrm{CO}_{2}$ or $\mathrm{CH}_{4}$ would tend to increase rather than reduce stratospheric ozone. $\mathrm{CO}_{2}$ Cools the stratosphere, which generally slows the rates of ozone-destroying reactions. $\mathrm{CH}_{4}$ helps tie-up chlorine in "inactive" molecules that do not react with ozone. Increasing $\mathrm{N}_{2} \mathrm{O}$ can either increase or reduce stratospheric ozone, depending on the relative amounts of chlorine and nitrogen oxides present.

${ }^{3}$ People with light skin, red or blond hair, and blue or green eyes are most susceptible to developing nonmelanoma skin cancer. ${ }^{\mathrm{A}} \mathbf{1}^{\circ 0}$ 2 percent mortality rate is associated with the disease. 


\section{Box 2-B-Statospheric Ozone Depletion-Continued}

Measurements of total column ozone show that ozone has declined at mid-latitudes in the Northern Hemisphere, with the reduction being especially pronounced in winter (see figure $2 \mathrm{~B}-1$ ). While computer models of stratospheric ozone have predicted an ozone decrease due to CFC emissions, the observed wintertime depletion is up to three times greater than has been predicted (106). The IPCC (37) concluded that, after allowing for natural variability, the Northern Hemisphere (300 to $64^{\circ} \mathrm{N}$ latitude) mean winter ozone level decreased by about 3.4 to 5.1 percent between $1 \% 9$ and 1988 (with no statistically significant trends during the summer).

The compounds implicated in stratospheric ozone depletion have two characteristics: they contain chlorine or bromine, and they are not broken down before they reach the stratosphere. Table 2-6 presents estimates of the "ozone depletion potential" (ODP) per molecule, relative to that ofCFC-11, of eight widely used compounds. ODP depends on the number of chlorine or bromine atoms in the molecule, its atmospheric lifetime (i.e., how long it takes before it is broken down or removed from the atmosphere), and the mechanisms involved in breaking it down. The compounds of greatest concern are extremely long-lived, with lifetimes on the order of 100 years, and are only broken down by reaction with intense solar radiation in the stratosphere. Thus, even though the Montreal Protocol has been strengthened to accelerate elimination of long-lived CFCs (see box 2-C), it will take a century for prior emissions to dissipate from the atmosphere.

Figure 2B-1—Estimated Percentage Changes in Total Column Ozone at Northern Mid-Latitudes, 1969-66 DECLINE IN THE OZONE SHIELD

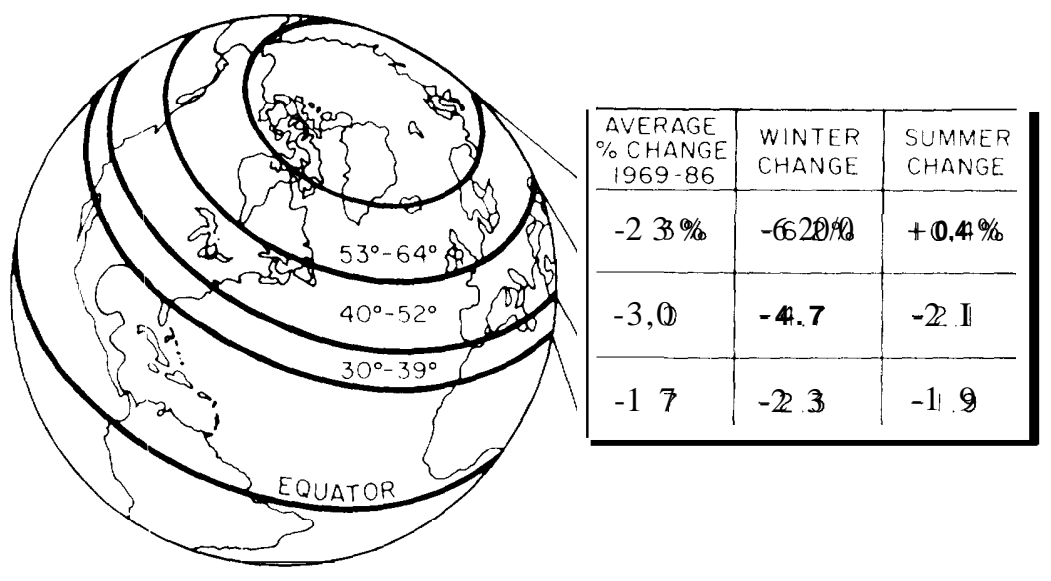

Changes in total ozone concentration, 1969-66, by latitude bands in Northern Hemisphere. Winter months: December, January, February, March. Summer months: June, July, August.

SOURCE: R.T. Watson et al., Present State of Knowledge of the Upper Atmosphere 1988: An Assessment Report (Washington, DC: National Aeronautics and Space Administration, 19SS), figure supplied byF.S. Rowland, 1990. 


\section{Box 2-C-The Montreal Protocol on CFCs}

In response to growing international concern about the role of chlorofluorocarbons (CFCs) in destroying stratospheric ozone, 47 nations reached agreement on a set of CFC control measures in September 1987. Entitled the Montreal Protocol on Substances that Deplete the Ozone Layer, the control measures laid out a schedule of production and consumption reductions for many CFCs (95). Nations with high CFC use, such as the United States, were to reduce production and consumption of certain CFCs and halons to 50 percent of 1986 levels by 1998. 'Those developing nations with low per-capita use were allowed to increase their use through 1999 and then were to cut back to 50 percent of 1995-97 levels over the following 10 years.

While the agreement represented a milestone in international environmental cooperation, many observers felt that the scope and time frame of the reduction schedule was insufficient to protect the ozone layer from further damage. For example, EPA estimated that even under the best participation scenario, future concentrations of CFCs 11 and 12 would double and triple, respectively, by 2030 without additional action (see figure 2C-1) (98). OTA concluded that the uncertainties of the agreement were such that under the most optimistic conditions the consumption of CFCs 11 and 12 could range from a 20-percent increase to a 45-percent decrease from 1986 levels (95). Finally, IPCC (37) has estimated that "[t]o stabilize, and then reduce, the current atmospheric concentrations of the fully halogenated CFCs (e.g., 11, 12, and 113) would require approximate reductions in emissions of 70 to 75 percent, 75 to 85 percent, and 85 to 95 percent respectively. $^{\prime}$

\footnotetext{
${ }^{1}$ Substances controlled under Annex A are:CFCs -11, -12,-113, -114,-115 and halons 1211, 1301, 2402.
}

(Continued on next page)

\section{Figure 2C-1-Atmospheric Concentrations of Chlorocarbon Molecules PPBV \\ 7,0 $\mathrm{Cl}$}

60.

50

4.0

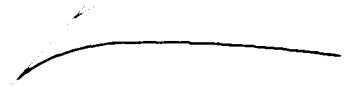

3.0

2.0

1.0

0.0

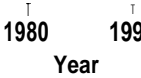

Actual observations to 1990; calculated future concentrations if emissions remain constant at 1986 levels.

Calculated future concentrations with cutbacks in CFC emissions specified in Montreal Protocol in 1987 $\left(20^{\circ} 0\right.$ in 1994 ; future $30 \%$ in 1999$)$

- Calculated future concentrations with complete phaseout of CFCs by year 2000. 


\section{Box 2-C-The Montreal Protocol on CFCs-Continued}

With these concerns in mind, delegates met in June 1990 to finalize a significantly stronger version of the Montreal Protocol $(2,93,94)$. The new agreement regulates 10 additional CFCs and requires participating countries with high use per capita (greater than 0.3 kilograms) to reduce production and consumption by 20 percent of 1986 levels in the next 3 years, achieve a So-percent reduction by 1997, and a 100-percent phaseout by the year 2000. ${ }^{2}$ HaIon production and consumption are to be frozen at 1986 levels by 1992 and steadily phased out by 2000, except for certain "essential uses," to be determined. Methyl chloroform (an industrial solvent that destroys stratospheric ozone) and carbon tetrachloride have been included in the Protocol for the first time; they will be phased out by 2000 and 2005, respectively. Parties to the Protocol are also required to declare their intent to phase out hydrochlorofluo rocarbons (HCFCs), which are less damaging, shorter lived substitutes for CFCs, no later than 2040.

Countries with low per-capita consumption of CFCs (i.e., developing nations) are given a lo-year grace period on all 1990 Montreal Protocol deadlines to allow them to meet their "basic domestic needs" (i.e., they are not to build up an export industry, but may produce CFCs for internal consumption). Such countries will also be assisted in their transition to CFC substitutes by a Multilateral Fund, financed by industrialized nations and designed to facilitate technology transfer and ease the financial burden of compliance with the control measures. This fired is meant to encourage key nations such as China and India to join the 65 signatories to the agreement. ${ }^{3}$ For the first 3 years the fund is expected to total $\$ 160$ million, but it could increase to \$240 million if China and India decide to participate (94). ${ }^{4}$ Their cooperation is considered vital if the Montreal Protocol is to achieve its long-term objectives of stabilizing global CFC emissions and allowing the stratospheric ozone layer to fully recover.

Trade with nonparties (those nations which have not signed or acceded to the agreement) is also restricted by the Protocol. Imports from and exports to nonparties of controlled substances is prohibited as of January 1990, and a list of products containing such substances is to be developed and their import banned by 1993. The feasibility of listing and banning products produced with $\mathrm{CFCs}$ and halons (e.g., computer chips) will be under consideration until 1994.5

In the new Clean Air Act Amendments, the U.S. Congress included provisions to control ozone-depleting substances that are slightly more stringent than those in the revised Montreal Protocol. First, the reduction schedule calls for specific reductions in each year until production ends. Second methyl chloroform is to be phased out 3 years earlier than required by the international agreement (i.e., by 2002 instead of 2005). Finally, a reduction schedule is laid out for HCFCs, with a freeze in 2015 and production prohibited in 2030 (10 years earlier than the Montreal Protocol's suggested but not binding deadline). Congress has also authorized $\$ 30$ million over the next 3 years to support the Multilateral Fund; the amount will be raised to $\$ 60$ million if India and China officially join. The House so far has appropriated \$10 million for fiscal year 1991. Public Law 101-513 (Sec. 534) states that "not less than $\$ 10$ million" of the funds appropriated to fund the Foreign Assistance Act shall be used to fund activities related to the Montreal Protocol.

\footnotetext{
2Substances controlled under Annex B are: CFCs -13,-111,-112,-211,-212, -213,-214,-215,-216, -217, carbon tetrachloride, and $1,1,1$-trichloroethane (methyl chloroform).

${ }^{3}$ Current parties include the U.S.S.R., Polar@ Hungary, and Germany, as well as large developing nations such as Argentina, Bangladesh, Brazil, Egypt, Indonesia, Mexico, and the Philippines. Notably absent, as of December 1990, are Turkey (the only OECD non-signatory), China, and India.

${ }^{4}$ These totals are based on estimates extrapolated from case studies conducted by EPA and agreed on by the conferees. On the basis of the United Nations assessmentscale, the United States would be responsible for a quarter of the voluntary contribution(R.J.Smith, U.S. Department Of State, personal cornmunication, Aug. 23, 1990).

${ }^{5}$ This timeschedule is for Annex A substances only (see footnote 1). Trade restrictions on Annex B substances will be implemented according to a slower schedule (generally a 2-year lag) to accommodate their recent inclusion and relatively rare use.
} 


\section{CHAPTER 2 REFERENCES}

1. Albritton, D. L., "Stratospheric Ozone Depletion: Global Processes, ' in National Research Council, Ozone Depletion, Greenhouse Gases, and Climate Change (Washington, DC: National Academy Press, 1989)

2. Alliance for Responsible CFC Policy, "Statement of Kevin J. Fay, Executive Director, Alliance for Responsible CFC Policy, Before the House Committee on Science, Space and Technology, Subcommittee on International Scientific Cooperation Subcommittee on Natural Resources, Agricultural Research, and Environment, on the Montreal Protocol on Substances that Deplete the Ozone Layer" (Washington DC: July 11, 1990).

3. Angell, J. K., "Variations and Trends in Tropospheric and Stratospheric Global Temperatures, 1958-1987, ”J. Climate 1: 1296-1313, 1988.

3a. Angell, J. K., NOAA Air Resources Laboratory, personal communication, Jan. 16, 1991

4. Baes, C. F., Jr., A. Bjorkstrom, and P.J. Mulholland, "Uptake of Carbon Dioxide by the Oceans, ' J.R.Trabalka (cd.), Atmospheric Carbon Dioxide and the Global Carbon Cycle, DOE/ER-0239 (Washington, DC: U.S. Department of Energy, December 1985).

4a. Baliunas, $\mathrm{S}$ and Jastrow, R., "Evidence for L.nng-Term Brightness Changes of Solar-Type Stars, " Nature 348:520-522, 1990.

5. Balling, R. C., Jr. and S.B. Idso, ' 'Historical Temperature Trends in the United States and the Effect of Urban Population Growth,' Journal of Geophysical Research 94:3359-3363, 1989.

6. Barnett, T.P. and M.E. Schlesinger, ' 'Detecting Changes in Global Climate Induced By Greenhouse Gases,' Journal of Geophysical Research 92:14722-14780, 1987.

7. Barnola, J.M. et al., ' 'Vostok Icc Core Provides 160,000-year Record of Atmospheric $\mathrm{CO}_{2}$," Nature 329:408-414, 1987.

8. Barns, D, W., W.U. Chandler, and J.A.Edmonds, "Atmospheric Methane Emissions: A Summary of Sources and Policy Issues," contract report prepared for U.S. Congress, Office of Technology Assessment (Washington DC: Battelle, Pacific Northwest Laboratories, October 1989).

9. Berner, R. A., ' "Atmospheric Carbon Dioxide Levels Over Phanerozoic Time," Science 249: 1382-1386, 1990.

10, Blake, D.R. and S.F. Rowland, "Continuing Worldwide Increase m Tropospheric Methane, 1978 to 1987, 'Science 239: 1129-1131, 1988.

10a. Booth, W., "Global Warming Continues, But Cause Is Uncertain," The Washington Post, Jan. 10, 1991, p. A3.

11 Broecker, W. S., "Unpleasant Surprises in the Greenhouse?' Nature 328123-126, 1987

12. Bryson, R. A., "Late Quarternary Volcanic Modulation of Milankovitch Climate Forcing," Theoretical and Applied Climatology 39: 1 i 5-125, 1989.

13. Cess, R. et al., "Interpretation of Cloud-Climate Feedback as Produced by 14 Atmospheric General Circulation Models," Science 245:513-5 16, 1989.

13a. Chappellez, J. et al., "Ice-core Record of Atmospheric Metbane Over (he Past 160,000 Years," Nature 345: 127-131, 1990.

13b Christy, J.R, satellite-derived global and hemispheric temperature data, Atmospheric Science and Remote Sensing Laboratory, University of Alabama, Huntsville, Jan. 11, 1991.

14. Cicerone, R.J. and R S. Oremland, "Biogcochemical Aspects of Atmospheric Methane,' Global Biogeochemical Cycles 2:299327, 1988 .

15. Cicerone, R. J., testimony before the U.S. Senate Subcommittee on Science, Technology, and Space of the Committee on Commerce, Science, and Transportation, May 8, 1989.

16. Detwiler, R.P and C.A.S. Hall, "Tropical Forests and the Global Carbon Cycle, ' Science 239:42-47, 1988.

17. Diaz, H. F., R.S. Bradley, and J.K.Eischied, "Precipita[lon Fluctuations Over Global Land Areas Since the Late 1800' s," Journal of Geophysical Research 94: 1195-1210, 1989
18. Dickinson, R.E. and R.J.Cicerone, "Future Global Warming From Atmospheric Trace Gases, " Nature 319:109-1 15, 1986.

19. Dickinson, R.E., G.A.Meehl, and W.M. Washington "IceAlbedo Feedback in a $\mathrm{CO}_{2}$-Doubling Simulation, ' Climatic Change 10:241-248, 1987.

20. Emanuel, K. A., "The Dependence of Hurricane Intensity on Climate," Nature 326:483-485, 1987.

21. Ellsaesser, H.W. et al., "Global Climatic Trends As Revealed in the Recorded Data," Review of Geophysics and Space Physics 24:745-802, 1986.

22. Gornitz, V., S. Lebedeff, and J. Hansen, "Global Sea Level Trend in the Past Century,' Science 215:161 1-1614, 1982.

23. Hammitt, J.K. et al., Product Uses and Market Trends for Potential Ozone-depleting Substances, 19/35-20(?0 (Santa Monica, CA: RANDCorp., May 1986).

24. Handler, P., "Volcanoes, Stratospheric Aerosols, and Global Climate,' Journal of Volcanic and Geothermal Processes 37:233ff, 1989.

25. Hansen, J. et al., "Climate Sensitivity: Analysis of Feedback Mechanisms,' J. Hansen and T. Takahashi (eds.), Climate Processes and Climate Sensitivity (Washington. DC: American Geophysical Union, 1984).

26. Hansen, J. et al., "Climate Response Times: Dependence on Climate Sensitivity and Ocean Mixing, "Science 229:857-859, 1985.

27. Hansen, J. and S. Lebedeff, "'Global Trends of Measured Surface Air Temperature, ' J. Geophysical Research 92: 13345-13372, 1987.

28. Hansen, J. et al., "Global Climate Changes as Forecast by the Goddard Institute for Space Studies Three-Dimensional Model, ' J. Geophysical Research, 93:9341-9364,1988.

29, Hansen, J. and S. Lebedeff, "Global Surface Air Temperature: Update Through 1987," Geophysical Research Letters 15:323326, 1988.

30. Hansen, J. et al., "Regional Greenhouse Climate Effects," in Preparing for Climate Change, proceedings of the Second North American Conference on Preparing for Climate Change, Dec. 6-8, 1988 (Washington, DC: Climate Institute, 1989).

30a, Hansen, J. et al., "GISS Analysis of Global Air Temperature," NASA Goddard Institute of Space Studies, 2880 Broadway, New York, NY 1(2025, Jan. 9, 1991.

31. Hoffert, M.I. and B.P. Flannery, "Model Projections of the Time-Dependent Response to Increasing Carbon Dioxide, in Projecting the Climatic Effects of Increasing Carbon Dioxide, M.C. McCracken and F.M. Luther (eds.), DOE/ER-0237(Washington, DC: U.S. Department of Energy, December 1985).

32, Hoffman, J. S., J.B. Wells, and J.G. Titus, "Future Global Warming and Sea Level Rise,' Iceland Coastal and River Symposium, F. Sigbjarnarson (cd.) (Rekjavik, Iceland: National Energy Authority, 1986), as cited in U.S. Environmental Protection Agency, Greenhouse Effect, Sea Level Rise and Coastal Wetlands,J.G. Titus (cd.),EPA-23@05-86-013 (Washington, DC: July 1988).

33. Hoffman, J. S., An Assessment of the Risks of Stratospheric Modification (Washington, DC: U.S. Environmental Protection Agency, December 1987).

34. Houghton, R.A. et al., "Carbon Dioxide Exchange Between the Atmosphere and Terrestrial Ecosystems, "J.R. Trabalka (cd,), Atmospheric Carbon Dioxide and the Global Carbon Cycle, DOE/ER-0239 (Washington, DC: U.S, Department of Energy, December 1985)

35. Houghton, R.A. and G.M. Woodwell, ' 'Global Climatic Change,' Scientific American 260:36-44, 1989

36. Houghton, R. A., "The Global Effects of Tropical Deformation, Environmental Science and Technology 24:414-422, 1990.

37. Intergovernmental Panel on Climate Change, Scientific Assessment of Climate Change, Summary and Report, World Meteorological Organization/U.N. Environment Program (Cambridge, MA: Cambridge University Press, 1990) 
38. International Council of Scientific Unions, The International Geosphere-Biosphere Programme: A Study of Global ChangeThe Initial Core Projects (Stockholm, Sweden: 1990).

38a. Jones, P.D. et al., "Global Temperature Variations Between 1981 and 1984,' Nature 322:430-434, 1986.

39. Jones, P.D. et al., "Evidence for Global Warming in the Past Decade, "Nature 332:790, 1988

40. Jones, P.D., personal communication, as cited in S.H. Schneider, P.H. Gleick and L.O. Mearns, "Prospects for Climate Change," Climate and Water: Climate Change, Climatic Variability and the Planning and Management of U.S. Water Resources (New York, NY: Wiley, 1989).

41. Jones, P.D. et al., "Assessment of Urbanization Effects in Time Series of Surface Air Temperature Over Land,' Nature 347: 169172, 1990.

42. Karl, T. R., H.F. Diaz and G. Kukia, "Urbanization: Its Detection and Effect in the United States, "Journal of Climate $1: 1099-1123$, 1988.

43. Karl, T.R. and P.D. Jones, "Urban Bias in Area-Averaged Surface Air Temperature Trends, 'Bulletin of the American Meteorological Society 70:265-270, 1989.

44. Karl, T.R. et al., "The Recent Climate Record: What It Can and Cannot Tell Us," Review of Geophysics 27:405-430,1989.

45. Keeling, C.D., "Industrial Production of Carbon Dioxide From Fossil Fuels and Limestone," Tellus 28:174-198, 1973.

46. Keeling, C. D., "Overview of Scripps Program to Observe Atmospheric Carbon Dioxide, unpublished, January 1989.

46a. Kelly, P.M. and Wigley, T. M.L,., "The Influence of Solar Forcing Trends on Global Mean Temperature Since 1861," Nature 347:460-462, 1990

47. Khalil, M.A.K. and R.A. Rasmussen, "Sources, Sinks and Seasonal Cycles of Atmospheric Methane,' Journal of Geophysical Research 88:5 131-5144, 1983.

48, Kvenvolden, K., "Methane Hydrates and Global Climate," Global Biogeochemical Cycles 2:221-229, 1988. (As cited in Cicerone and Oremland, 1988. )

49. LaBrecque, M., "Clouds and Climate: A Critical Unknown in the Global Equations," Mosaic 21:2-1 1, 1990,

50. Lamb, H.H., Climatic History and the Future (Princeton, NJ: Princeton University Press, 1977).

51. Lashof, D., "The Dynamic Greenhouse: Feedback processes that May Influence Future Concentrations of Atmospheric Trace Gases and Climatic Change, "Climatic Change 14:213-242, 1989.

52. Lindzen, R. S., "Some Coolness Concerning Global Warming," Bulletin of the American Meteorological Society 71:288-290, 1990

53. Lorius, C. et al., "The Ice-Core Record: Climate Sensitivity and Future Greenhouse Warming, " Nature 347: 139-145, 1990.

54. MacCracken, M.C. and F.M. Luther, Projecting the Climatic Effects of Increasing Carbon Dioxide, DOE/ER-0237 (Washington, DC: 1985).

55. Mahlman, J. D., testimony before the Subcommittee on Science, Technology, and Space of the Committee on Commerce, Science and Transportation U.S. Senate May 8, 1989.

56. Manabe, S. and R.T.Wetherald, "Reduction in Summer Soil Wetness Induced By an Increase in Atmospheric Carbon Dioxide," Science 232:626-627,1986.

57. Manabe, S., K. Bryan, and M.J.Spelman, "Transient Response of a Global Ocean-Atmosphere Model to a Doubling of Atmospheric Carbon Dioxide," paper abstract, DOE Workshop on Greenhouse-Gas-Induced Climatic Change: A Critical Appraisal of Simulations and Observations (Amherst, MA: May 8-12, 1989).

58. Marland, G. et al., Es timates of $\mathrm{CO}_{2}$ Emissions From Fossil Fuel Burning and Cement Manufacturing Using the United Nations Energy Statistics and the U.S. Burt'au of Mines Cement Manufacturing Data, ORNL/CDIAC-25 NDP-030 (Oak Ridge, TN: Oak Ridge National Laboratory, October 1989).
59. Meehl, G.A. and W.M. Washington "A Comparison of SoilMoisture Sensitivity in Two Global Climate Models, Journal of the Atmospheric Sciences 45:1476-1492, 1988.

60. Meehl, G. A., "Seasonal Cycle Forcing of El Nino-Southern Oscillation in a Global Coupled Ocean-Atmosphere GCM," Journal of Climate 3:72-98, 1990.

61. Meier, M.F. et al., Glaciers, Ice Sheets, and Sea Level: Effect of a $\mathrm{CO}_{2}$-induced Climatic Change, DOE/EV/60235-1 (Washington DC: U.S. Department of Energy, September 1985).

62. Michaels, P.J., "The Greenhouse Effect and Global Change: Review and Appraisal, ' International Journal of Environmental Studies 36:55-71, 1990.

63. Mikolajewicz, U., B.D.Santer, and E. Maier-Reimer, "Ocean Response to Greenhouse Warming," Nature 345:589-593, 1990.

64. Mitchell, J.F.B., C.A. Senior, and W.J. Ingram, "C 02 and Climate: A Missing Feedback?" Nature 341:132-134, 1989.

65. Muzio, L.J. and J.C. Kramlich, "An Artifact in the Measurement of $\mathrm{N}_{2} \mathrm{O}$ From Combustion Sources, Geophysical Research Letters 15:1369-1372, 1988 .

66. Newell, R.E. and T.G.Dopplick, "Questions Concerning the Possible Influence of Anthropogenic $\mathrm{CO}_{2}$ on Atmospheric Temperature, "Journal of Applied Meteorology 18:822-825, 1979.

67. Newell, N.E. et al., "Global Marine Temperature Variation and the Solar Magnetic Cycle," Geophysical Research Letters 16:31 1314, 1989.

67a. Peel, D.A. and Mulvaney, R., "Air Temperature and Snow Accumulation in the Antarctic Peninsula During the Past 50 Years," Annals of Glaciology 11:206-207, 1988.

68. Post, W.M. et al., "The Global Carbon Cycle, American Scientist 78:310-326, 1990.

69. Prinn, R. et al,, 'Atmospheric Trends in Methylchloroform and the Global Average for the Hydroxyl Radical, Science 238:945-949, 1987.

70. Ramanathan, V. et al., "Trace Gas Effects on Climate," in Atmospheric Ozone 1985, Global Ozone Research and Monitoring Project Report No. 16, World Meteorological organization (Washington, DC: National Aeronautics and Space Administration, 1985).

71, Ramanathan, V. et al., "Trace Gas Trends and Their Potential Role in Climate Change,' Journal of Geophysical Research 90:5547$5566,1985 \mathrm{~b}$

72. Ramanathan, V., "The Greenhouse Theory of Climate Change: A Test by an Inadvertent Global Experiment' Science 240:293-299, 1988.

73. Ramanathan, V. et al., "Cloud-Radiative Forcing and Climate: Results From the Earth Radiation Budget Experiment," Science 243:57-63, 1989.

74. Rasmussen, R.A. and M. AX. Khalil "Atmospheric Trace Gases: Trends and Distributions Over the Last Decade,' Science 232: 16231624,1986

75. Raynaud, D. et al., "Climatic and $\mathbf{C H}_{4}$ Cycle Implications of Glacial-Interglacial $\mathbf{C H}_{4}$ Change in the Vostok Ice Core,' Nature 333:655-657, 1988.

76. Revelle, R.R., "Methane Hydrates in Continental Slope Sediments and Increasing Atmospheric Carbon Dioxide, ' Changing Climate (Washington, DC: National Academy Press, 1983).

77. Robertson, G.P. and J.M. Tiedje, 'Deforestation Alters Denitrification in a Lowland Tropical Rain Forest+' Nature 336:756-759, 1988.

78. Robock, A., "Ice and Snow Feedbacks and the Latitudinal and Seasonal Distribution of climate Sensitivity," Journal of Atmospheric Science 40:986-997, 1983.

79. Ronen, D., M. Magaritz, and E. Almon, "Contaminated Aquifers Are a Forgotten Component of the Global $\mathrm{N}_{2} \mathrm{O}$ Budget+' Nature 335:57-59, 1988.

80. Rotty, R.M. and C.D. Masters, "Carbon Dioxide From Fossil Fuel Combustion: Trends, Resources, and Technological Implications, “ in J.R. Trabalka (cd.), Atmospheric Carbon Dioxide and 
the Global CarbonCycle, DOE/ER-0239 (Washington, DC: U.S. Department of Energy, December 1985).

80a Rowland, F S., "Stratosiltwric Ozone Depletion by Chlorofluorocarbons.' 'Ambio 19:281-292, 1990.

81. Schindler, D. W. et al., "Effects of Climatic Warming on Lakes of the Central Boreal Forest," Science 250:967-970, 1990.

82. Schlesinger, M.E. and J.F.B. Mitchell, "Model Projections of the Equilibrium Climatic Response to Increased Carbon Dioxide,' in Projecting the Climatic Effects of Increasing Carbon Dioxide, DOE/ER-0237 (Washington, DC: U.S. Department of Energy. December 1985).

83 Schlesinger, M.E, "Equilibrium and Transient Climatic Warming Induced by Increased Atmospheric $\mathrm{CO}_{2}$ ' Climate Dynamics $1: 35-51,1986$

84. Schlesinger, M.E., "Model Projections of the Climate Changes Induced by Increasing Atmospheric $\mathrm{CO}_{2}$,' A. Berger, S. Schneider, and J.C Duplessy (eds.), Climate and the Geo-Sciences .4 Challenge for Science and Society in the 21st Century (Dordrecht: Kluwer Academic Publishers, 1989), pp. 375-415.

85. Schlesinger, M. E., 'Statement on H.R. 3131, the National High Performance Computing Technology Act, " testimony before the Subcommittee on Science, Research, and Technology of the House Committee cm Science, Space, and Technology, Mar. 14, 1990.

86. Schneider, S. H., "The Greenhouse Effect: Science and Policy." Science 243"771-781, 1989

87. Schneider, S. H., "Predicting Future Climate Can It Be Done Reliably?" testimony before tbc Subcommittee on Science, Technology, and Space of the Committee on Commerce, Science, and Transportation, US. Senate, May 8, 1989.

88. Solomon, A.M. etal, "The Global Cycle of Carbon," in J.R Trabalka(ed.), Atmospheric Carbon Dioxide and the GloIxz1 Carbon Cycle, DOWER-0239 (Washington, DC: U.S. Department of Energy, December 1985)

89. Stauffer, B. et al., 'Increases in Atmospheric Methane Recorded m Antarctic Ice Core, Science 229: 1386-1388, 1985.

90. Stouffer, R J., S Manabe, and J. Bryan, "Interhemispheric Asymmetry in Climate Response to a Gradual Increase of Atmospheric Carbon Dioxide, 'Nature 342:660-662, 1989.

91. Tans, P P., I.Y. Fung, and T. Takahashi, "Observational Constraints on the Global Atmospheric $\mathrm{CO}_{2}$ Budget,' Science 247,1431-1438, 1990

92 U.N. Environment Programme, Scientific Assessment of Stratospheric Ozone, 1989.

93. U.N. Environment Programme, " Annex II, Amendment to the Montreal Protocol on Substances That Deplete the Orone Layer,' June 1990

94 U N. Environment Programme, "Most of the World's Nations Have Agreed to Halt Production of Chemicals, 'UNEP North America New's 5,1, August 1990.

95. U S. Congress, Office of Technology Assessment, ' 'An Analysis of the Montreal Protocol on Substances that Deplete the Ozone Layer,' staff paper (Washington, DC: Dee, 10, 1987, revised Feb. 1. 1988)

96 U.SDepartment of Commerce, National Meteorological Center, WeeklyClimate Bulletin no, 89/02 (Washington, DC: Jan 14 1989).

97 U s Environmental protection Agency, Office of Air and Radiaton, Assessing the Risks of Trace Gases that Can Modify the Stratosphere, EPA 400/1 -87-001B (Washington DC: December 1987 ) and supplementary information provided with the Proposed Rule on Protection of Stratospheric Ozone, December 1987.

98 U S. Environmental Protection Agency, Office of Policy, Planning and Evaluation, Policy Options for Stabilizing Global Climate. Draft Report to Congress (Washington, DC: June 1990).
99. U.S. National Aeronautics and Space Administration, NASA Advisory Council, Earth Systems Science Committee, Earth Systems Science: A Closer View (Washington, DC: 1988).

99a. U.S. National Aeronautics and Space Administration, Present State of Knowledge of the Upper Atmosphere 1990: An Assessment Report, Reference Publication 1242, Report to Congress (Washington, DC: 1990)

100, U.S. National Research Council, Understanding Climate Change (Washington, DC: National Academy Press, 1975).

101, U.S. National Research Council, Changing Climate (Washington, DC: National Academy Press, 1983).

102. U.S. National Research Council, Committee for an International Geosphere-Biosphere Program, Global Change in the Geosphere Biosphere: Initial Priorities for an IGBP (Washington, DC National Academy Press, 1986).

103, U.S. National Research Council, The U.S.Global Change Research Program An Assessment of the FY 1991 Plans (Washington, DC: National Academy Press, 1990).

104. Vinnikov, K. Ya. et al., ' 'The Empirical Data on Modem Global Climate Changes (Temperature and Precipitation),' Journal of Climate, in press.

105, Washington, W.M. and G.A.Mechl, "Climate Sensitivity Due to Increased $\mathrm{C}_{2}$ : Experiments With A Coupled Atmosphere and Ocean General Circulation Model, " Climate Dynamics 4: 1-38, 1989.

106. Watson, R. T., M.J. Prather and M.J. Kurylo, Present State of Knowledge of the Upper Atmosphere 1988: An Assessment Report, NASA reference publication 1208 (Washington, DC: National Aeronautics and Space Administration, August 1988).

107, Weiss, R.F., ' 'The Temporal and Spatial Distribution of Tropospheric Nitrous Oxide, “ Journal of Geophysical Research86:7 1857195,1981

108. Weller, G. et al., "Detwlion and Monitoring of $\mathrm{CO}_{2}$-Induced Climate Changes, ' Changing Climate (Washington, DC: National Academy Press, 1983).

109. Whalen, S.C. and W.S.Reeburgh, "Consumption of Atmospheric Methane By Tundra Soils," Nature .346: 166162, 1990.

110. Wigley, T.M.L. and M.E. Schlesinger, "Analytical Solution for the Effect of Increasing $\mathrm{CO}_{2}$ on Global Mean Temperature," Nature 315:649-652, 1985.

111. Wigley, T.M.L. and S.C.B. Raper, " "Thermal Expansion of Sca Water Associated With Global Warming," Nature 330: 127-131, 1987.

112. Wood, F. B., ' 'Comment: On the Need for Validation of the Jones et al. Temperature Trends With Respect to Urban Warming, " Climatic Change 12:297-312,1988.

113. Wood, F. B., "Global Alpine Glacier Trends, 1960)s to 1980s, ' Arctic and Alpine Research 20:404-413,1988.

114. Wood, F. B., "The Need for Systems Research on Global Climate Change," Systems Research 5:225-240,1988

115, Wood, F, B., "Monitoring Global Climate Change: The Case of Greenhouse Warming, 'Bulletin of the American Meteorological Society 71:42-52, 1990.

116. Wu, Z., R.E. Newell, and J. Hsiung, "Possible Factors Controlling Global Marine Temperature Variations Over the Past Century," Journal of Geophysical Research 95:1 1799-11810, 1990.

117. Wuebbles, D.J. and J. Edmonds, A Primer on Greenhouse Gases, DOE/NBB-0083 (Washington, DC: U.S. Department of Energy, March 1988).

118. Zwally, H.J. et. al., "Growth of Greenland Ice Sheet: Measurement, Science 246: 1587-1589, 1989.

119. Zwally, H.J., "Growth of Greenland Ice Sheet: Interpretation,' Science 246: 1589-1591, 1989 


\section{APPENDIX 2-A: FERTILIZING THE OCEANS WITH IRON}

The idea of "fertilizing" some Antarctic oceanic areas with iron to increase phytoplankton productivity and $\mathrm{CO}_{2}$ uptake has recently attracted scientific and popular attention. The purpose of such an undertaking would be to offset anthropogenic emissions of carbon into the atmosphere. 'Some opponents view this idea as an untested but tempting "tech-fro" that might delay policies to reduce fossil fuel use in industrialized countries (e.g., 4, 5). Proponents contend that ocean fertilization experiments to address emission offsets should begin now (3), because global carbon emissions might increase even if greenhouse policies are enacted.

\section{Phytoplankton and Nutrients}

The relationship between phytoplankton and the availability of such nutrients as iron, nitrogen, and phosphate is the key to the fertilization hypothesis. ${ }^{2}$ Nearshore Antarctic waters, for example, tend to have relatively high concentrations of dissolved iron (apparently from upwell ing of iron-rich sediments from the shallow bottom), as well as nitrogen and phosphorus, so high phytoplankton productivity is both possible and common $(7,10)$. In turn, this supports an enormous amount of marine life, including krill, whales, seals, and penguins.

In contrast, many offshore ocean waters lack sufficient nutrients to sustain high productivity. However, some offshore waters-notably in the Antarctic and Gulf of Alaska-while low in iron, have relatively high concentrations of nitrogen and phosphorus. But, they still exhibit low productivity. Martin et al. (8) conducted some short-term laboratory bottle experiments using water collected from the Gulf of Alaska and concluded that lack of iron was limiting phytoplankton growth, Martin et al. (10) also hypothesized that low levels of iron in offshore Antarctic waters prevent phytoplankton from using more than a small portion of available nutrients,

\section{Fertilizing the Antarctic-The Proposal and the Uncertainties}

Hence the idea to stimulate phytoplankton growth in offshore Antarctic waters by slowly releasing iron and "fertilizing' the water. In theory, this could allow phytoplankton to use a greater share of other nutrients, and permit both phytoplankton populations and carbon uptake from the water to increase substantially.
However, uncertainties about the effects of a largescale operational program exist from many perspectives. For example:

- Experimental--Is iron really the limiting factor? The data demonstrating iron limitation are from small, short-term laboratory experiments from one region and may not be generalizable (2, but see 9 ). Whether other factors might limit productivity over large areas even when sufficient iron is available is unknown. Increasing the scale from small lab studies to large field studies also poses problems, not least of which is conducting well-designed "control' experiments. And, even if iron is the limiting factor, a recent National Research Council (NRC) workshop noted the uncertainties in estimating how much iron might be needed and how much carbon would be taken up in a large-scale operation (1, also see 5 a, 1la).

- Practical-Can the iron be made available? Since iron is not readily soluble, one constraint is a mechanism for retaining iron in a biologically available form and for keeping it on or near frequently rough surface waters long enough to be used by phytoplankton (hours to several days). Another constraint could be economics (e.g., costs of iron and of transporting it to appropriate areas) (1).

- Environmental-What changes might occur in the ecosystem? Whether iron might preferentially enhance growth of some phytoplankton species over others and/or change the composition of existing marine food chains is unknown. Little is known about ecological relationships among phytoplankton populations, Some participants at the NRC workshop noted that the effect of rapidly increasing phytoplankton populations on organisms such as krill, a major component of antarctic food chains, cannot be predicted at this time $(1,4)$.

- Geochemical--Will carbon be sequester in sufficient amounts for sufficient periods? Removal of large amounts of carbon for decades to centuries would be desirable. A recent study (1 la; also see 5a), however, points out that Antarctic surface waters have a limited capacity to take up atmospheric $\mathrm{CO}_{2}$ and that sequestration of carbon in deeper portions of the Antarctic depends on the rate at which surface and deeper waters mix (i.e., the rate of vertical mixing). It concludes that this rate is too slow to have a significant effect on atmospheric $\mathrm{CO}_{2}$ concentrations. In addition, whether carbonaceous compounds

\footnotetext{
'Phytoplankton arc short-lived, microsCopiC marine plants that use $\mathrm{CO}_{2}$ during photosynthesis. Their remains, which retain some of the carbon, can fall to the ocean's bottom, thus serving as a "sink" for carbon.

${ }^{2}$ Phytoplankton live near the ocean's surface, where conditions are conducive to photosynthesis (e.g., proper temperate, sufficient light, $\mathrm{CO}_{2}$ dissolved in the water, and nutrients, which often control their rate of growth).

${ }^{3}$ The workshop was held in October 1990 in h-vine, California. Two NRC committees (the Committee on Global Change and the Panel on Policy Implications of Global Warming) have been involved during the past year or so in examining the idea, but the NRC has not yet released any public reports.
} 
will accumulate on the ocean floor and serve as a long-term carbon "sink" depends in part on the concentration of dissolved $\mathrm{CO}_{2}$ in the water column (11). Moreover, if upwelling brings other nutrients to the surface, it might also bring up carbon-rich sediments and release $\mathrm{CO}_{2}$ back to the atmosphere,

\section{Policy Implications}

Marine phytoplankton form the basis of most oceanic food chains, from which much of the world's commercial fisheries are derived. Fertilizing the oceans to increase carbon storage might be justified if it was relatively certain that only " minimal environmental impacts would occur. But uncertainties about the probability and magnitude of potential impacts are great. The costeffectiveness of large-scale fertilization is unknown, because widely accepted estimates of its effects on $\mathrm{CO}_{2}$ uptake (and on marine ecosystems) and of its implementation costs are not available today.

Participants at the NRC workshop suggested that a " 'transient iron experiment,"” with a suggested area of about 400 square kilometers, be under-taken to gather morc informatation and data on the iron 1 imitation hypothesis. They did not envision detrimental environmental impacts from such an experiment but noted that the impacts of a large-scale treatment cannot be evaluated at this time given our current lack of knowledge ( 12). The American Society of Limnology and Oceanography is planning a symposiurn in early 1991 to focus on the issue of what controls phytoplankton production in nutrientrich areas of the open ocean.

Field studies of a few years duration would probably yield useful information about the effects of iron enrichment on the short-term] productivity of phytoplankton In otherwise nutrient-rich waters: this would be an appropri- ate topic for biological and oceanographic research. [Linger studies would probably be needed to ascertain longer-term impacts on phytoplankton and marine ecosystems in general. The relative utility of a large operation at that time would depend in part on how successfully we develop energy-efficient and renewable energy technologies and practices and better land use management practices-choices that clearly can be implemented today (see ch. 1).

\section{Appendix 2-A References}

1. Anderson, C., “ Iron Solution No Solution, ' Nature 348: 188 , Nov. $15,1990$.

2. Banse, K., "Does Iron Really Limit Phytoplankton Production in the Offshore Subarctic Pacific?' Limnol Oceanogr. 35(3):772-775, 1990.

3. Baum, R., "Adding Iron to Ocean Makes Waves As Way To Cut Greenhouse $\mathrm{CO}_{2}$,' Chemic al \& Engineering New: 68(27):21-24, July 2, 1990.

4, Blakeslee, S., " ideas for Making Ocean Trap Carbon Dioxide Arouse Hope and Fear, New YorkTimes, p. C4, Nov, 20, 1990

5. Bown, W., "Flipp]ng Oceans Could Turn Up the Heat, New Scientist 127:21, Aug. 25,1990

5a. Keir, R. S., "Ironing Out Greenhouse Efects," Nature 349: 198-199, Jan.17, 1991.

6. Martin, J.H. and S.E. Fitzwater, 'Iron Deficiency Limits Phytoplankton Growth in the North-east Pacific Subarctic, Nature 331:341-343, Jan. 28, 1988.

7 Martin,J.H. and R.M. Cordon, "Nmthe\&st Pacific Iron Distributions m Relation to Phytoplankton Productivity, ' Deep-SeaResearch 35(2):1 77-19(5, 1988.

8. Martin, J.H. et al.. 'VERTEX: Phytoplankton/IronStudies in the Gulf of Alaska," Deep-Sea Research 36:(249 680, 1989

9. Martin, J.H. et al., ' 'Yes, It Does: A Reply tothe Comment by Banse,' Limnol.Oceanogr 35(3):775-777, 19(X).

1o. Mar-tin, J.H. et al., "'Iron in Antarctic Waters, ' Nature 345: 156-158, May 10, 1990

11. Mlot, C'., 'Whit'-Water Bounty, BioScience 39(4):222224, April 1989

11a. Peng, T. H. and W. Broeker, "Dynamical Limitations on the Antarctic Ionization Strategy," Nature 349:227-229, Jan. 17, 1991.

12. Zaborsky, O. R., National Research Council, review comments to OTA, Dec. 18, 1990 


\section{Chapter 3}

\section{Energy Supply}

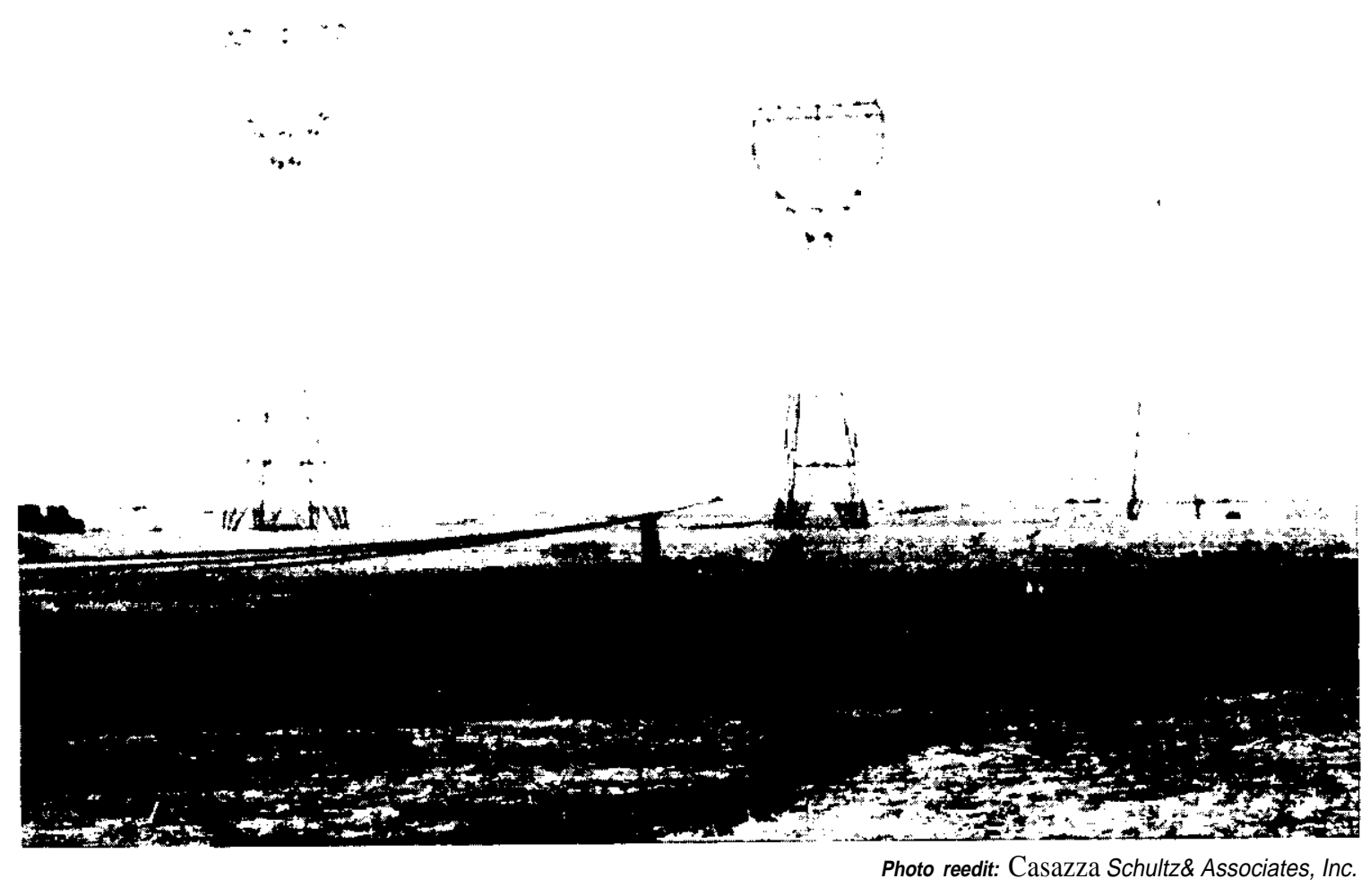

A high-voltage transmission corridor 


\section{CONTENTS}

INTRODUCTION ....................... Page

Fuels and Their Carbon Emissions . . . . . . . . . . . . 77

Electricity Generation ..................... 80

CARBON-BEARING ENERGY SOURCES . . . . . . 81

Fossil Fuels . . . . . . . . . . . . . . . . . . 8 81

Biomass Fuels . . . . . . . . . . . . . . . . . . . . . 8 85

CARBON-FREE ENERGY SOURCES . . . . . . . . . 87

Renewable Energy Sources . . . . . . . . . . . . . . . . . 87

Nuclear ..................................91

REDUCING $\mathrm{CO}_{2}$ EMISSIONS FROM

ELECTRICITY GENERATION . . . . . . . . . . 92

Introduction to Technical Options . . . . . . . . . 92

Fuel Switching and More Efficient

Generating Technologies . . . . . . . . . . . . . . 92

Electricity Transmission and Distribution

Improvements . . . . . . . . . . . . . . . . . . . . . . . . 94

OTA EMISSION REDUCTION SCENARIOS . . . . . 94

Alternative Scenarios of Demand for Electricity . 95

Technical Options for Lowering $\mathrm{CO}_{2}$ Emissions

From Electricity Generation . . . . . . . . . . . . . . 96

POLICY OPTIONS ...................... 103

Energy Taxes and Tax Incentives . . . . . . . . . 103

Marketable Permits ...................... 104

Increase Research Development and

Demonstration Efforts . . . . . . . . . . . . . . . 105

Plugging the Leaksin the Existing System . . . . 106

Improving Electricity Supply: Meeting Demand

With Lower CO Emissions . . . . . . . . . . . . . . 106

CHAPTER PREFERENCES . . . . . . . . . . . . . . . . . . 110

\section{Boxes}

Box

Page

3-A. Energy From Biomass $\ldots . \ldots \ldots \ldots \ldots \ldots . \ldots 8$

3-B. Carbon Dioxide Scrubbing . . . . . . . . . . . . . 95

3-C. Electric Utility Demand-Side Management

Programs ............................. 107

\section{Figures}

Figure

Page

3-1. World and U.S. Energy Consumption,

By Fuel, 1988-89 .78
3-2. World and U.S. Carbon Emissions From Energy Use, By Fuel 1988-89 .. ... ... ......79

3-3. World Carbon Emissions From Fossil Fuels, By Region, 1988 .................. 80

3-4. Carbon Emissions From Electric Generating Technologies as Compared to Emissions From the Average Existing Coal-Fired Power Plant . 92

3-5. OTA Electricity Demand Scenarios ........ 96

3-6. $\mathrm{CO}_{2}$ Emissions From Electricity Generation Under the OTA Demand and Supply Scenarios ..................97

3-7. $\mathrm{CO}_{2}$ Emissions Reductions From Moderate Supply-side Measures, Expressed as a Percentage of 1987 Electricity Emissions, Under the Moderate Demand Scenario . . . . . . . . . . . . 100

3-8. $\mathrm{CO}_{2}$ Emissions Reductions From Tough Supply-side Measures, Expressed as a Percentage of 1987 Electricity Emissions, Under the Moderate and Tough Demand Scenarios . . . . 101

3-9. $\mathrm{CO}_{2}$ Emissions From Electricity Generation Under the Base Case and Selected Control Scenarios, By Year ................... 102

3-10. Fuel Use By Electric Utilities In 2015 Under the Base Case and Selected Control Scenarios, By Year . . . . . . . . . . . . . . . . . . 103

3-11. U.S. Energy Technology Research and Development Budgets, 1978-88 . . . . . . . 105

\section{Tables}

Table Page

3-1. Commercial Fuel Consumption in 1988 by Region, Selected Countries, and Fuel Type . . . . 78

3-2. Coal Resources, Consumption, and Trade . . . . 82

3-3. Petroleum Resources, Consumption, and Trade ........................8 82

3-4. Natural Gas Resources, Consumption, and Trade ........................ 83

3-5. $\mathrm{CO}_{2}$ Emission Rates From Fossil-Fuel-Fired Electric Generating Technologies .......... 93

3-6. Electricity Generation Measures $\ldots . \ldots . \ldots . .98$

\section{Page} 9

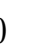




\section{INTRODUCTION}

This chapter examines carbon dioxide and methane emissions from world and U.S. energy production and distribution and looks at technical alternatives for reducing those emissions during the next 25 years.

At the broadest level, four options exist for reducing carbon dioxide $\left(\mathrm{CO}_{2}\right)$ emissions in the energy supply sector:

- switch from high-carbon sources (i.e., coal) to low-carbon sources (i.e., natural gas);

- switch from carbon-based fuels to noncarbonbased fuels;

* convert fossil fuels to usable heat and electricity more efficiently; and

- remove carbon from fossil fuels before the fuel is burned, or capture $\mathrm{CO}_{2}$ from combustion exhaust gas for deep-well or ocean disposal.

This chapter focuses on the first three approaches; we do not consider the fourth a near-term, proven technical option, though it is certainly worthy of further research and development effort.

Primary energy sources include nonrenewable fossil fuels (coal, petroleum, natural gas), nuclear power, potentially renewable biomass, and renewable such as solar, geothermal, and hydropower. Electricity is a secondary energy source produced from the primary energy sources. From the standpoint of greenhouse gas emissions, primary sources can be divided into two categories--carbon-bearing (coal, oil, gas, biomass) and carbon-free (wind, solar, hydropower, geothermal, nuclear).

The four carbon-bearing fuels are discussed in terms of their impact on global warming; their availability (location, production, and consumption); and the technical alternatives and policy options that exist for reducing $\mathrm{CO}_{2}$ and methane emissions during their production and transport. We also discuss carbon-free energy sources and their potential for substituting for fossil fuels; the conversion of carbon and noncarbon energy sources into electricity; and key issues associated with implementing or changing technologies.

Assuming current trends and regulations, U.S. carbon emissions from electricity generation might double by 2015, as compared to 1987 levels. We estimate that stringent measures to lower the demand for electricity (discussed in chs. 4 through 6) have the potential to lower emissions to 10 percent below 1987 levels by 2015. Further measures applied to utilities - in particular, increased use of natural gas and nonfossil sources-have the potential to lower emissions further, to about 50 percent below 1987 emissions by 2015 .

However, it will be increasingly difficult to hold emissions at this low level past the 25-year time horizon of this assessment. Ultimately demand for electricity will begin to rise again. Moreover, much of the potential for lowering emissions comes from switching from coal to natural gas, which will become increasingly difficult to obtain in quantities sufficient to meet the increasing demand. If emissions are to remain low, intensive research, development, and demonstration activities will be needed so that abundant and acceptable nonfossil sources of energy will be available by 2015 .

\section{Fuels and Their Carbon Emissions}

Total world energy consumption in 1988 was between 350 and 400 quadrillion Btu's (quads). Fossil fuels provided 78 percent of energy consumed (35 percent from oil, 25 percent from coal, 18 percent from natural gas), biomass roughly 13 percent, and noncarbon emitting sources (mainly hydropower and nuclear) the remainder (see figure 3-1). In the United States, the percentages are 87 (fossil fuels), 3 (biomass), and 10 (noncarbon), respectively. Total U.S. energy consumption in 1989 was about 84 quads, with oil accounting for 40 percent, coal and gas about 23 percent each, nuclear power 7 percent, and hydropower and biomass about 3 percent each. ${ }^{1}$ Table 3-1 shows commercial fuel consumption in 1988 by region, country, and fuel.

'Data for 1988 energy consumption is from Energy Information Administration (80), The 28 quads of biomass fuels is an estimate for 1987. 
Figure 3-I-World and U.S. Energy Consumption, By Fuel, 1988-89
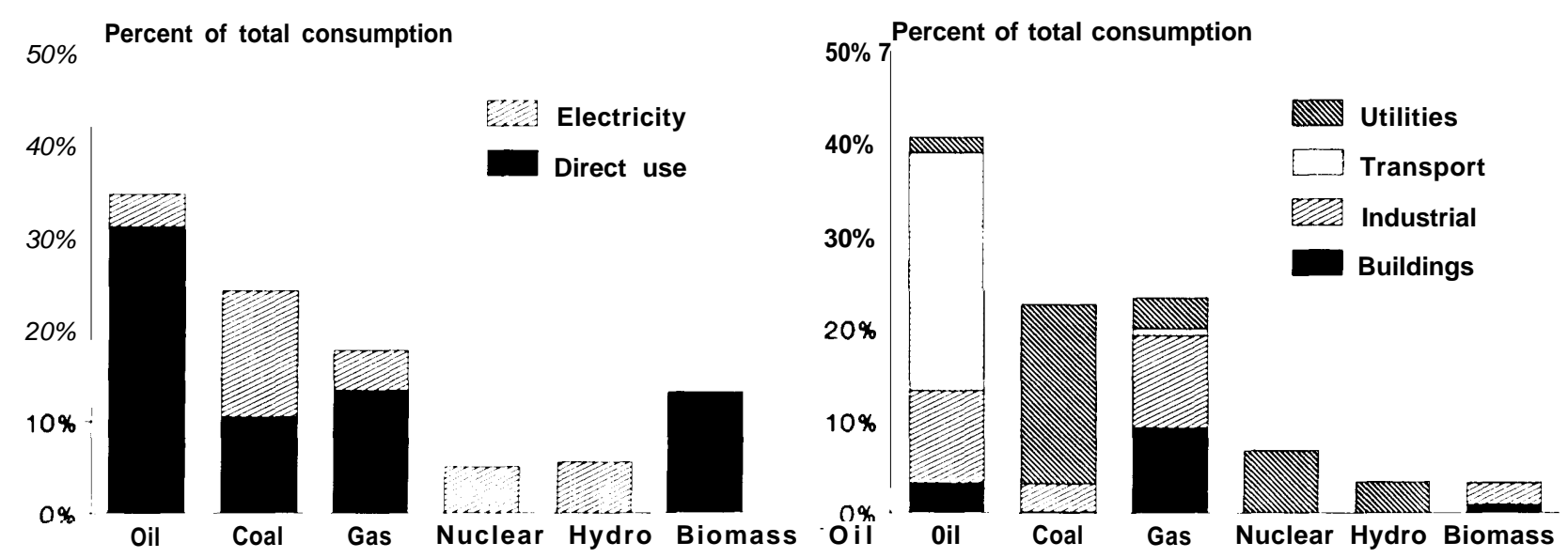

1989 total $\mathbf{~} 385$ quadrillion Btu

1989 total $=84$ quadrillion Btu

SOURCES: U.S. Department of Energy, International Energy Annual, 1988, DOEJEIA-021 9(88) (Washington, DC: Energy Information Administration, November 1989) and U.S. Department of Energy, Annual Energy Review, 1989,DOE/EIA-0384(89) (Washington, DC: Energy Information Administration, May 1990).

Table 3-I-Commercial Fuel Consumption in 1988 (quads) by Region, Selected Countries, and Fuel Type

\begin{tabular}{|c|c|c|c|c|c|}
\hline Region/country & Natural gas & Coal & Hydroelectric & Nuclear & Total \\
\hline $\begin{array}{c}\text { OECD }^{\mathrm{a}} \text { Total } \ldots \ldots \ldots \ldots \ldots \ldots \ldots \ldots \\
(44.64 / .) \\
\end{array}$ & $\begin{array}{l}32.08 \\
(19.0 \%)\end{array}$ & $\begin{array}{l}35.07 \\
(20.80 / 0)\end{array}$ & $\begin{array}{l}11.81 \\
(7.0 \% 0)\end{array}$ & $\begin{array}{l}15.13 \\
(9.0 \%)\end{array}$ & 168.73 \\
\hline 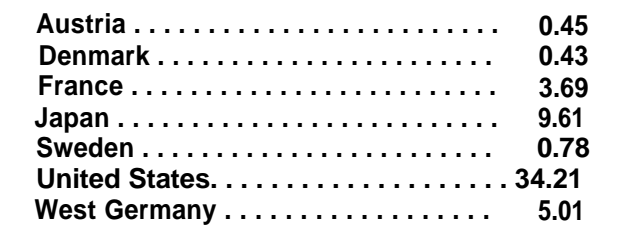 & $\begin{array}{c}0.17 \\
- \\
1.01 \\
1.68 \\
- \\
18.49 \\
2.01\end{array}$ & $\begin{array}{c}0.16 \\
0.29 \\
0.74 \\
2.90 \\
- \\
18.84 \\
3.51\end{array}$ & $\begin{array}{l}0.31 \\
- \\
0.73 \\
0.90 \\
0.71 \\
2.64 \\
0.39\end{array}$ & $\begin{array}{l}\mp \\
2.24 \\
1.75 \\
0.65 \\
5.68 \\
1.46\end{array}$ & $\begin{array}{r}>1.09 \\
>0.72 \\
8.41 \\
16.83 \\
>2.27 \\
79.86 \\
12.39\end{array}$ \\
\hline $\begin{array}{r}\text { U.S.S.R./Eastern Europe-Total } \ldots \ldots \ldots .22 .77 \\
(28.8 \%)\end{array}$ & $\begin{array}{l}25.25 \\
(31.9 \%)\end{array}$ & $\begin{array}{c}25.52 \\
(32.30 / .)\end{array}$ & $\begin{array}{c}2.62 \\
(3.3 \%)\end{array}$ & $\begin{array}{l}2.95 \\
(3.7 \%)\end{array}$ & 79.11 \\
\hline 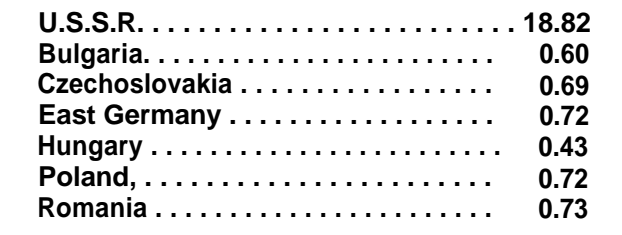 & $\begin{array}{r}21.78 \\
0.21 \\
0.39 \\
0.39 \\
0.41 \\
0.47 \\
1.59\end{array}$ & $\begin{array}{r}14.00 \\
0.52 \\
1.88 \\
2.76 \\
0.19 \\
5.28 \\
0.85\end{array}$ & $\begin{array}{l}2.27 \\
\overline{0.07} \\
\overline{-} \\
0.04 \\
0.12\end{array}$ & $\begin{array}{l}2.26 \\
0.13 \\
0.23 \\
0.11 \\
0.13 \\
-\end{array}$ & $\begin{array}{r}59.13 \\
>1.46 \\
3.26 \\
>4.00 \\
>1.16 \\
>6.57 \\
>3.30\end{array}$ \\
\hline $\begin{array}{r}\text { Developing-Total }^{\circ} \ldots \ldots \ldots \ldots \ldots \ldots \ldots \ldots \\
(40.9 \%)\end{array}$ & $\begin{array}{c}10.07 \\
(11.9 \%)\end{array}$ & $\begin{array}{l}32.35 \\
(38.3 \%)\end{array}$ & $\begin{array}{l}6.62 \\
(7.8 \%)\end{array}$ & $\begin{array}{l}0.82 \\
(1.0 \%)\end{array}$ & 84.36 \\
\hline $\begin{array}{ll}\text { China } \ldots \ldots \ldots \ldots \ldots \ldots \ldots \ldots \ldots & 4.54 \\
\text { India } \ldots \ldots \ldots \ldots \ldots \ldots \ldots \ldots & 2.24 \\
\text { Other Asia and Oceania } \ldots \ldots \ldots \ldots & 7.02 \\
\text { Brazil } \ldots \ldots \ldots \ldots \ldots \ldots \ldots \ldots & 2.74 \\
\text { Other Latin America } \ldots \ldots \ldots \ldots \ldots & 7.90 \\
\text { Middle East } \ldots \ldots \ldots \ldots \ldots \ldots \ldots & 6.11 \\
\text { Africa } \ldots \ldots \ldots \ldots \ldots \ldots \ldots \ldots & 3.96\end{array}$ & $\begin{array}{l}0.54 \\
0.26 \\
1.84 \\
- \\
2.82 \\
3.23 \\
1.38\end{array}$ & $\begin{array}{r}19.51 \\
3.83 \\
3.59 \\
0.41 \\
0.45 \\
0.12 \\
3.46\end{array}$ & $\begin{array}{l}1.08 \\
0.63 \\
0.93 \\
1.96 \\
1.48 \\
0.09 \\
0.45\end{array}$ & $\begin{array}{c}0 \\
0.07 \\
0.69 \\
<0.01 \\
0.06 \\
0 \\
0.11\end{array}$ & $\begin{array}{r}25.67 \\
7.04 \\
14.07 \\
5.23 \\
12.71 \\
9.56 \\
9.37\end{array}$ \\
\hline 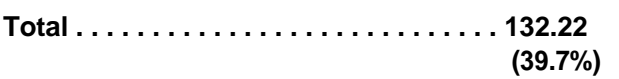 & $\begin{array}{l}67.64 \\
(20.3 \%)\end{array}$ & $\begin{array}{l}92.97 \\
(27.9 \%)\end{array}$ & $\begin{array}{l}21.31 \\
(6.40 / 0)\end{array}$ & $\begin{array}{l}19.06 \\
(5.7 \%)\end{array}$ & 333.21 \\
\hline
\end{tabular}

arganization for Economic Cooperation and Development.

b-means included in "Other" category in U.S. Department of Energy (1989) database.

'Excluding U.S.S.R. and Eastern Europe.

SOURCE: U.S. Department of Energy (1989), 
Figure 3-2-World and U.S. Carbon Emissions From Energy Use, By Fuel, 1988-89

50\% Percent of total emissions

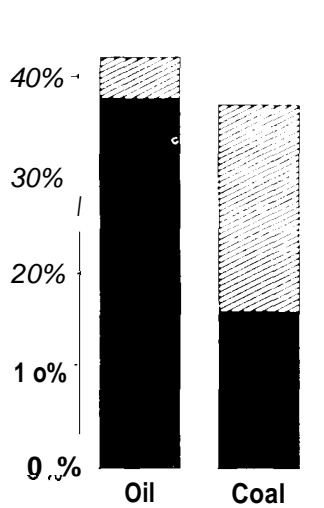

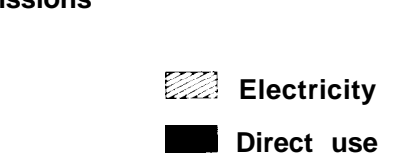

1988 total $=63$ million metric tons $/$ year

SOURCE: Office of Technology Asses Energy Roviow (1989).

About two-thirds of the total world energy was used directly to fuel end uses; for example, gasoline is used to run cars and natural gas to heat homes. One-third of the energy was used to generate electricity, Oil dominates direct uses; coal dominates electricity generation.

U.S. energy consumption mirrors the world pattern: about two-thirds of the energy was used directly in end uses (60 percent of that was provided by oil), and one-third to generate electricity. Well over half the electricity in the United States is generated from coal.

Carbon dioxide emissions from fossil and biomass fuels are estimated to be responsible for half the greenhouse warming that occurred during the 1980s (83). Coal and wood contain the highest concentration of carbon per unit energy--commonly about 55 to 60 pounds of carbon per million Btu (lbs C/mmBtu). Natural gas has the lowest concentrations (32 lbs C/mmBtu) and petroleum is intermediate (45 lbs $\mathrm{C} / \mathrm{mmBtu}$ ),

World $\mathrm{CO}_{2}$ emissions from energy use total about 6.3 billion metric tons of carbon per year. ${ }^{2}$ Of that, about 6.0 billion metric tons derive from fossil fuels either burned directly for end uses or to generate electricity. Included in this estimate are the relatively small but significant emissions of $\mathrm{C}_{2}$ associatcd with making carbon-bearing fuels available to

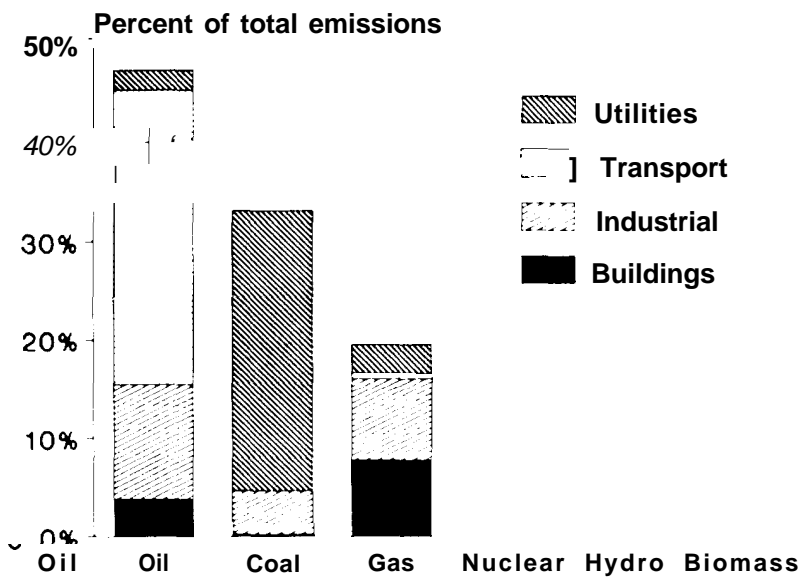

1989 total 1.4 million metric tons/year

consumers, primarily during fuel processing (e.g., to refine petroleum).

Oil accounts for about 42 percent of carbon emissions, coal follows closely with 38 percent, natural gas emits about 15 percent, and biomass between a few and 10 percent (see figure 3-2). The range of estimates for biomass emissions is wide because it is not known how much of biomass fuel burned in developing countries is harvested on a sustainable basis (see ch. 7). Although actual burning of such fuels releases 1.1 billion tons of carbon per year, we estimate that net emissions from biomass fuels are about 0.3 billion tons per year. This estimate assumes that about half of the wood used for fuel is not being regrown on a sustainable basis. Figure 3-3 shows emissions from fossil fuel only, by region.

U.S. carbon emissions from energy use are about 20 percent of the world total, or about 1.4 billion metric tons each year. Oil is the largest source, followed by coal, and then natural gas. ${ }^{\text {s}} \mathrm{The}$ percentages of U.S. emissions from oil and gas are both somewhat higher than the world average; coal emissions somewhat lower (see figure 3-2),

Fossil fuels also are a major source of methane, accounting for perhaps 15 percent of all methane emissions throughout the world each year. Because, molecule for molecule. methane is far more effectivc

\footnotetext{
2To convert to metric tons of $\mathrm{CO}_{2}$, multiply by 3.67 . To convert to short tons of $\mathrm{CO}_{2}$, multiply by 4.03.

In figure 3-2, biomass fuch in the United States are shown contributing no net emissions, which assumes that all harvested fuel wood is replanted. If, for example, only half of the fuel wood is used on a sustamable basis, bionass emissions would account for 2 percent of the total.
} 


\section{Figure 3-3-World Carbon Emissions From Fossil Fuels, By Region, 1988}

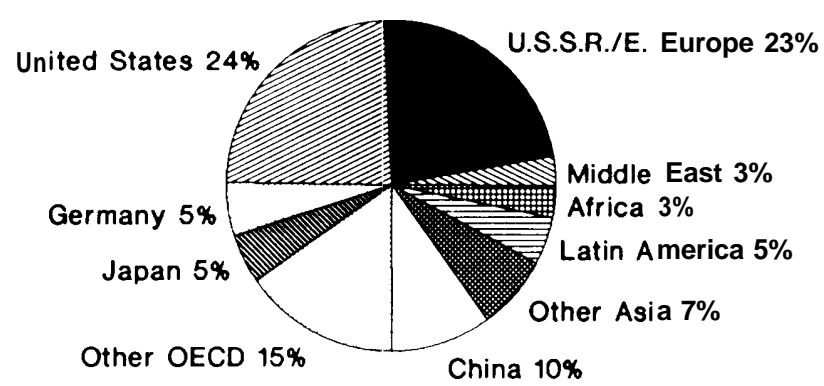

Total 1988 emissions:

6 billion metric tons/year

SOURCE: Office of Technology Assessment, 1991, calculated using data from U.S. Departmen: of Energy, International Energy Annual (1988)

than $\mathrm{C}_{2}$ in trapping energy in the atmosphere, smaller emissions of methane can have as powerful an impact as larger emissions of $\mathrm{CO}_{2}$. Methane, however, is converted in the atmosphere to $\mathrm{CO}_{2}$ after 10 to 20 years (see ch. 2).

Fossil-fuel-related methane emissions occur primarily through leakage from natural gas production and transport, oil production, and coal seams. Methane emissions from all sources are estimated to be responsible for about 15 to 20 percent of the greenhouse warming that occurred during the $1980 \mathrm{~s}$ (83).

While carbon-free energy sources themselves do not release climate-modifying gases to the atmosphere, the steps required to exploit them may nevertheless entail some emissions. For example, the uranium required to run most nuclear powerplants must be extracted, processed, enriched, and manufactured into fuel rods prior to use. The energy this requires typically is provided by fossil fuels. The resulting emissions, however, are still quite low compared to those that would result from using carbon-bearing fuels in place of noncarbon fuels. The latter therefore are gaining attention as lowemission alternatives to fossil fuels.

\section{Electricity Generation}

In 1987, nearly two-thirds of the approximately 2,500 gigawatts (Gw) of" electric generating capacity in the world ran on carbon-bearing fossil fuels; this accounted for nearly all of the $\mathrm{CO}_{2}$ emissions associated with generating electricity. Most of the balance (over one-third) of world generating capacity operates on carbon-free energy sources and does not routinely emit comparable quantities of climatemodifying gases. These low-emission options are dominated by hydropower (about one-quarter of the total world electric capacity) and nuclear power.

Over three-quarters of the world's generating capacity is concentrated in the developed countries of Europe, the U. S. S. R., North America, and Japan. The largest electricity generator is the United States, which in 1987 accounted for about 30 percent of world capacity.

About 30 percent of U.S. electric power in 1987 came from carbon-free energy sources; nuclear power dominated, followed closely by hydropower. All other carbon-free energy-sources (e.g., wind, geothermal, and solar) accounted for less than 0.5 percent of the electric power generated in the United States in 1987. For the United States to supply a large portion of its current electric power from solar, wind, and geothermal energy, enormous growth in those industries would have to occur.

The average efficiency of a U.S. powerplant is 33 percent (14) - that is, only one-third of the energy in the fossil fuel leaves the plants as electric power. The rest is discharged as waste heat. Conversion efficiencies in most industrialized countries are comparable, but they often are quite low (around 25 percent) in developing countries and regions such as China, the Middle East, and Africa (66, 83).

Worldwide growth in capacity has been extremely rapid over the last quarter century. Growth was fastest in the developing world, though this occurred from a much smaller base than in the industrialized countries. In 1987, developing countries accounted for only about a quarter of all the electricity used in the world (see ch. 9). China, India, and Brazil together accounted for nearly a third of the capacity in the developing countries in 1987. Demand for electric power has increased at an annual rate of over 8 percent for the last 20 years (ch. 9; also see refs. 1, 87). The developing countries are expected to continue to increase their share of world capacity during the next quarter century. 


\section{CARBON-BEARING ENERGY SOURCES}

\section{Fossil Fuels}

\section{Introduction}

Important international variations exist in the magnitude of fossil fuel reserves, production and consumption, imports and exports, and prices (see tables 3-2 through 3-4), These variations are key considerations in any U.S. effort to limit production, consumption, or trade of fossil fuels.

Reserves--Globally, the most plentiful fossil fuel is coal. Proven reserves of both petroleum and natural gas are far smaller. The largest proven reserves of fossil fuels are within the U.S.S.R. and Eastern Europe; very large amounts are also found in the United States.

Production and C'onstimption-in 1988, petroleum accounted for over 40 percent of the world's fossil fuel production, coal for nearly a third, and natural gas for the rest. ${ }^{4}$ The U.S.S.R. and the United States account for between 40 and 45 percent of the world's fossil fuel production and also for a very large portion of consumption.

Trade-The extent to which each country's production meets its demand varies widely. Some countries, such as Japan, are heavily dependent on imports of all three fossil fuels. Others, such as the U. S. S. R., are large exporters of all three fuels. The most commonly traded fossil fuel is petroleum; nearly 40 percent of crude oil production and 20 percent of refined products were traded internationally, World trade is far less important for natural gas and coal, largely because they are more difficult to handle. The industrial market economies are the largest importers of fossil fuels. The Middle East region is the most important exporter of fossil fuels.

Prices-Typically, coal prices are considerably lower than those of other fossil fuels. U.S. coal prices (per Btu) in 1988 were about one-third lower than natural gas prices. Fossil-fuel prices have gone up considerably since 1970, but declined between 1980 and 1988. Coal prices have been less volatile than gas and oil prices. The relatively low and stable price of coal has much to do with its popularity. U.S. energy prices, in general, are lower than those of most other developed countries. This is particularly true for petroleum products, and to some extent reflects much higher tax rates outside the United States (76).

\section{Coal}

Emissions-Coal combustion produces approximately 40 percent of the global $\mathrm{CO}_{2}$ emissions from fossil fuels and 35 percent of U.S. $\mathrm{CO}_{2}$ emissions. Electricity generation accounts for about 50 percent of coal use globally, and 80 percent of U.S. coal use. Coal also accounts for a significant portion of the world's methane emissions, mostly from newly opened mines. Preliminary estimates suggest coal production may contribute around 5 to 10 percent of methane emissions directly attributable to human activities worldwide (35a). In the United States, coal may contribute between 10 and 20 percent of total anthropogenic methane emissions.

Resources and Their Use---Coal is the most abundant fossil fuel and is available in many parts of the world. Nevertheless, three countries-the United States, China, and the U.S.S.R.- together account for roughly two-thirds of world reserves. These three countries also were the world's largest producers and consumers of coal in 1988. In recent years, increases in coal production and consumption have been most rapid in China and in India. Very large increases in production also have occurred in Australia, largely to meet rapidly growing export markets, Far smaller, though important, increases occurred in the United States, Canada, and the U.S.S.R. (76).

China, already the world's largest consumer of coal, might triple its consumption of coal to over 3 billion tons by the year 2030, which would increase total world coal production by 50 percent (10). Coal use in India (currently fifth worldwide) also is likely to rise in the future. Many development organizations have encouraged coal use in developing countries because of the availability of domestic supplies.

Over 10 percent of world coal production is traded, at a total value of about $\$ 16$ billion per year. The United States and Australia are the world's largest coal exporters. Several other countries export

${ }^{4}$ Including natural gas plant liquids.

${ }^{5}$ Bituminous and subbituminous coal, and lignite. 
Table 3-2-Coal Resources, Consumption, and Trade (percentage share of worldwide total)

\begin{tabular}{|c|c|c|c|c|}
\hline es, 1989 & Production, 1989 & consumption, 1989 & Imports, 1987 & Exports, 1987 \\
\hline 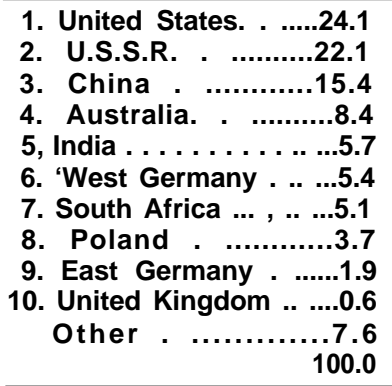 & 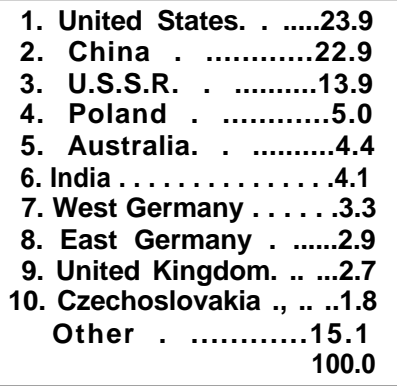 & 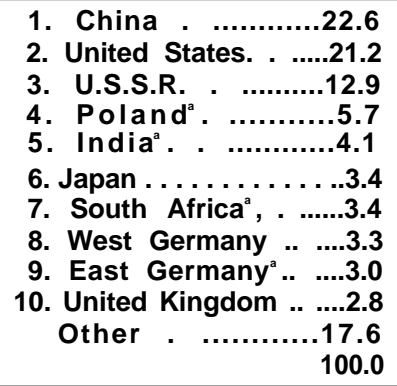 & 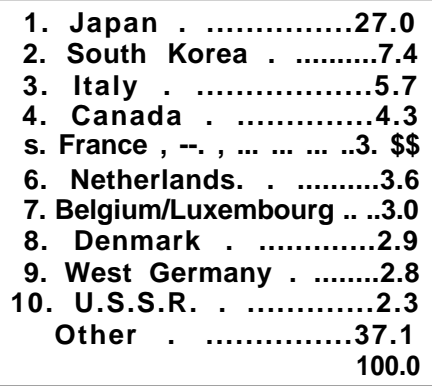 & 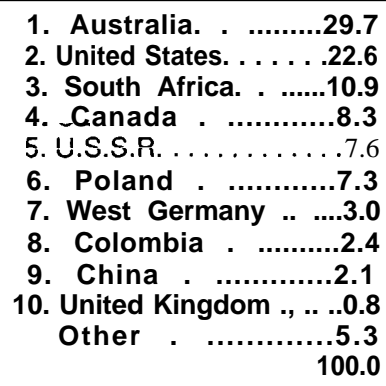 \\
\hline
\end{tabular}
aApparent consumption for Poland, India, South Africa, and East Germany is obtained from U.S. Department of Energy (1989). It represents their share of world apparent consumption in 1987 (not NOTE: Approximately 10 percent of coal production/consumption is traded internationally.

SOURCES: Unless otherwisespecified, data for resources/reserves/production and consumption are from the British Petroleum Company, BPStatistical Review of WorldEnergy (London, UK: British Petroleum, June 1990). Data on imports and exports are derived from U.S. Department of Energy, Energy Information Administration, International Energy Annual, 1988 DOE/EIA-0219(88) (Washington, DC: November 1989).

Table 3-3-Petroleum Resources, Consumption, and Trade (percentage share of worldwide total)

\begin{tabular}{|c|c|c|c|c|}
\hline Reserves, 1989 & Production, 1989 & Consumption, 1989 & Imports, 1987 & Exports, 1987 \\
\hline 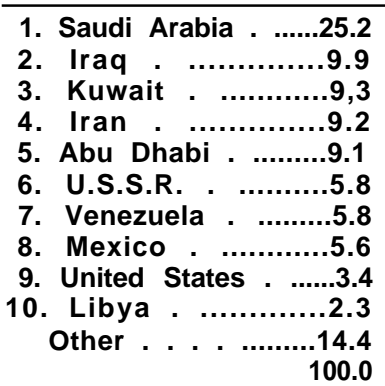 & 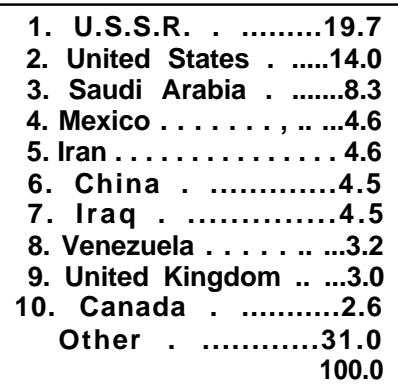 & 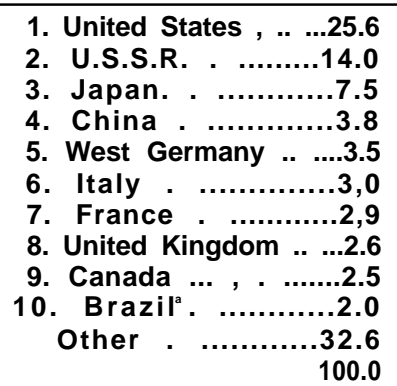 & 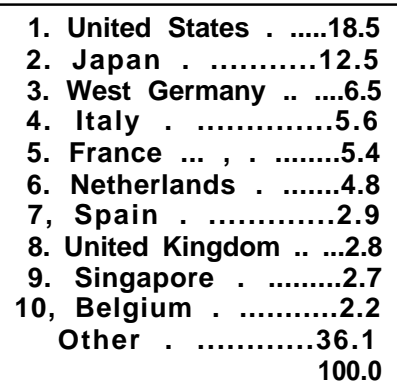 & 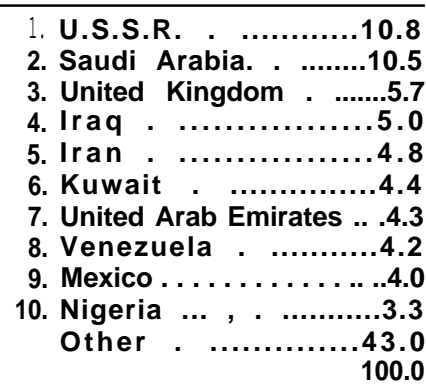 \\
\hline
\end{tabular}

aBrazil's apparent consumption is obtained from U.S. Department of Energy (1989). It represents Brazil's share of world apparent consumption in 1987 (not 1989 ).

NOTE: Imports and Exports, as listed above, include both crude oil and refined petroleum products. Nearly 40 percent of crude oil production was traded internationally in 1987 nearty 20 percent of production was traded internationalty in the form of refined products.

SOURCES: Unless otherwise specified, data for resources/reserves/production and consumption are from the British Petroleum Company, BP Statistic/ Review of World Energy (London, UK: British Petroleum, June 1990). Data on imports and exports are derived from U.S. Department of Energy, Energy Information Administration, International Energy Annual, 1988 DOE-EIA-0219(88) (Washington, DC: November 1989). 
Table 3-4--Natural Gas Resources, Consumption, and Trade (percentage share of worldwide total)

\begin{tabular}{|c|c|c|c|c|}
\hline Reserves, 1989 & Production, 1989 & Consumption, 1989 & Imports, 1987 & Exports, 1987 \\
\hline 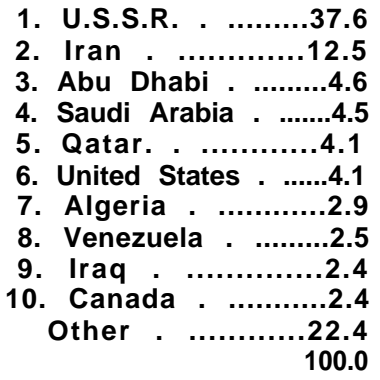 & 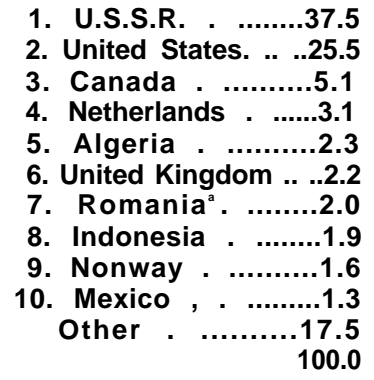 & 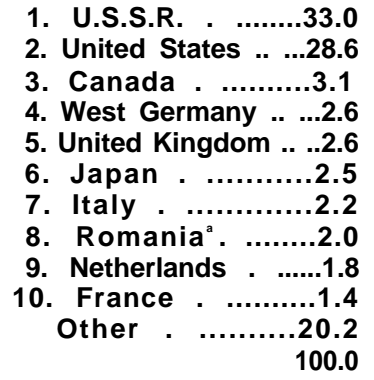 & 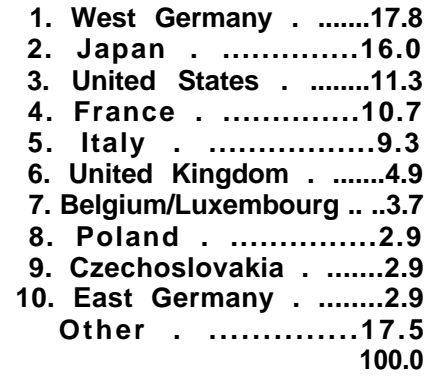 & 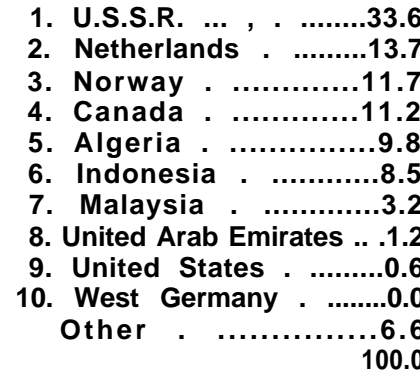 \\
\hline
\end{tabular}

'Romania's production and consumption are obtained from U.S. Department of Energy (1989)

NOTE: Approximately 13 percent of world natural gas production/consum ption is traded internationally.

SOURCES: Unless otherwise specified, data for resources/reserves/production and consumption are from the British Petroleum Company, BP Statistic/ Review of World Energy (London, UK: British Petroleum, June 1990). Data on imports and exports are derived from U.S. Department of Energy, Energy Information Administration, International Energy Annual,
1988DOE/EIA-0219(88) (Washington, DC: November, 1989). 
large quantities of coal, and still others intend to become major traders. By far the largest importer of coal is Japan, accounting for 25 percent of world imports (76).

Issues--several technical options exist to reduce coal-related emissions without abandoning coal as a fuel. For example, methane emissions from coal mines can be relatively quickly reduced with available technology, Coal can be used to simultaneously provide heat and electricity through cogeneration. The efficiency of coal use can be markedly improved in other ways as well, as detailed later in this chapter.

The fact remains, however, that coal emits more carbon per unit of energy than any other fuel. There is no cheap and otherwise acceptable way of removing and disposing of the large amounts of $\mathrm{CO}_{2}$ generated through coal combustion (see box 3-B below). Consequently, beyond the limited options just mentioned, the only other near-term alternative to reduce emissions by large amounts is to switch to lower carbon-emitting fuels.

Unfortunately, even limited actions will be difficult to implement because coal is an important and low-priced source of energy for many countries of the world, including the United States. Aggressive attempts to limit its production, consumption, and trade will have profound social and economic impacts. Both at home and abroad, great resistance may develop from entities heavily dependent on coal; these range from unions of coal miners to countries, such as China, whose ambitious plans for development rest squarely on the greatly expanded use of coal.

\section{Petroleum and Natural Gas}

Emissions-Petroleum combustion contributes about 40 percent of worldwide $\mathrm{CO}_{2}$ emissions and 45 percent of U.S. emissions. End uses account for about 90 percent of world and 95 percent of U.S. petroleum consumption. Natural gas combustion is the source of about 15 percent of worldwide $\mathrm{CO}_{2}$ emissions and about 18 percent of U.S. emissions. About 75 percent of the world's natural gas consumption directly fuels end uses and 25 percent is used to produce electric power. For the United States, these figures are 85 and 15 percent, respectively.

${ }^{6}$ For a discussion of natural gas resources, see refs. 40,45 , and 53 .

${ }^{7}$ Also see refs. 22, 32.
Methane is also released to the atmosphere when oil and gas are produced and when natural gas is transported and stored; two of the more important sources include venting of methane at the well-site and leaks from pipelines. The global magnitude and distribution of methane emissions from these sources remain largely undefined and are matters of contention. However, evidence suggests that emissions are greatest at the extreme ends of natural gas systemsthe production end and in low-pressure distribution systems. Also, anecdotal evidence suggests that the Soviet Union's emissions may be extremely high; the U.S.S.R. accounted for nearly 40 percent of world natural gas production in 1989 and its transmission and distribution system is notoriously leaky. One estimate places transmission losses and direct losses during extraction at 8 percent of total U.S.S.R. production (22a).

Resources and Their Use-Proven natural gas reserves are heavily concentrated in two regions: the U.S.S.R. and the Middle East. Large additional resources, including probable reserves, exist, though estimates of their precise magnitudes are highly disputed and vary widely. ${ }^{6}$

The world's largest gas producer is the U.S.S.R. (about 40 percent of world production). Overall world production increased by over a third between 1977 and 1987, though production in the United States has declined by 25 percent from a peak in the early 1970s. Global production during the next quarter century will continue to increase, particularly in the U.S.S.R. and in developing countries (42). ${ }^{7}$ The U.S.S.R. was also the largest exporter of natural gas in 1986, accounting for over a third of world exports. The major importers were the European countries, with West Germany far in the lead (27).

While natural gas is important in developing countries such as Mexico, Argentina, Venezuela, China, and Algeria, many developing countries have not exploited their natural gas reserves because of the large infrastructure required for a natural gas distribution system. In addition, most of the market for gas is local, making it difficult for foreign oil and gas companies to recoup investments through hard currency earnings (39). 
Petroleum reserves are concentrated in the Middle East and, to a lesser extent, Latin America. The United States produced about 14 percent of the world's petroleum in 1989, ranking it second behind the U.S.S.R. (which produced 20 percent). About a dozen other countries, concentrated in the Middle East, accounted for most remaining production. Unlike coal and natural gas, which tend to be consumed by the countries that produce them, petroleum is heavily traded; indeed, 40 percent of crude oil and 20 percent of refined products are transferred internationally. Exports are dominated by the huge quantities of oil that flow from the Middle East. The largest world importer is the United States, followed by the European nations (both East and West) and Japan.

Excluding China, oil accounted for over half of the commercial fuel use in developing countries. Compared with the United States, the developing countries use relatively more oil for electricity generation and for industry than for transportation (35). While some countries have large oil supplies, many others must use hard currency to purchase oil on the international market. Even so, while oil consumption decreased in the OECD during the price shocks of the mid-1970s and early 1980s, it steadily increased in the developing countries. Its relative share of commercial fuel use in developing countries, however, has been declining since 1979 .

Issues-As with coal, options exist for ' 'tightening' the petroleum and natural gas systems to make them less emissive without necessarily affecting the relative attractiveness of the fuels. One of these is to limit emissions of unburned natural gas, especially in the U.S.S.R. and Eastern Europe. Another is to place greater emphasis on the efficient use of petroleum and natural gas, through cogeneration and by more efficient end-use technologies in general.

Beyond these steps, further measures can be taken to make petroleum less attractive as a fuel. Aside from reduced emissions, the advantages of reduced petroleum use include reduced petroleum imports, trade deficits, and vulnerability to oil-supply cutoffs. Of the many alternatives, the most commonly discussed supply-side alternative is increasing the tax on gasoline (see ch. 5).
Policies affecting the relative attractiveness of natural gas must balance two needs:

I. the need to limit natural gas use because of its methane and $\mathrm{CO}_{2}$ emissions, and

2. the need to promote its use as a near-term alternative to higher emission alternatives such as coal or coal-based electric power.

Policies will have to improve the position of natural gas relative to coal, while simultaneously reducing its appeal relative to options with still lower atmospheric impacts.

A carbon tax could provide an incentive to switch to lower carbon-content fuels such as natural gas. However, care must be taken to structure the tax such that it reflects the methane emissions associated with supplying natural gas. For imports, this will require detailed information on methane emissions in the exporting country as well as leakage in transit.

\section{Biomass Fuels}

\section{Emissions}

During photosynthesis, plants transform solar energy into chemical energy as they convert atmospheric carbon and water from the soil into carbonbased compounds. The resulting plant tissues are known as "biomass." wastes are used as energy sources around the world. "Biomass fuel' is burned for cooking and space heating in developing countries, and for industrial processes and electricity generation.

When biomass fuels are burned for energy (or when residues from harvesting and processing of plants into fuel decompose), the carbon in them is released to the atmosphere. Unlike fossil-fuel carbon, however, the carbon released from biomass fuels was taken from the atmosphere over the past few decades. If biomass fuels are used on a sustainable basis (e.g., if harvested trees are always replanted), the carbon emitted will be resequestered over the next few decades as the plants grow and become available once again for use.

\footnotetext{
8. 'Biomass' in general refers to any living material, including animals and their wastes.

${ }^{9}$ Burning biomass fuels should be distinguished from burning vegetation to clear forests for crop and range land or to remove crop residues from harvested areas; in these latter cases, use of biomass for fuel does not occur. Biomass burning and natural decomposition of biomass are major sources of $\mathrm{CO}_{2}$, methane, and other greenhouse gases (see chs. 7 and 8).
} 
In contrast, the carbon emitted from fossil fuels was taken from the atmosphere millions of years ago. Essentially no carbon is recycled back to fossil fuel (in timeframes of interest to the next several generations) when fossil fuels are burned, since coal and other fossil fuel feedstocks form only very slowly over geologic time.

The net carbon emissions from biomass fuels depends on how they are managed and on the timeframe considered. Dung and agricultural waste used as fuel are typically not considered net emitters because they would rapidly decompose anyway. Twigs and branches will regrow, taking carbon from the atmosphere, over a few years. Carbon emitted by burning harvested trees can be reclaimed in decades, assuming that replacement trees are replanted (see box 7-A in ch. 7).

\section{Resources and Their Use}

Data on biomass fuel use are sketchy. By one rough estimate, about 15 percent of the world's energy was obtained from biomass fuels in 1987 (57), considerably more than was provided by nuclear and hydroelectric power combined. Wood accounted for about 60 percent of the biomass fuels, dung and agricultural residue for most of the remainder (55).

The importance of these fuels varies among different countries, largely according to economic conditions, Developing countries may derive up to one-third of their energy needs from biomass (55), but even among these counties, the percentage varies greatly. For example, biomass energy in China, India, and Kenya accounts for about 25, 40, and 80 percent of the total energy use in each country, respectively (74). In rural areas in many of these countries the energy contribution of biomass is often much higher. Traditional biomass fuels (wood, crop residues, animal dung) are relied on for household cooking and heating, particularly in rural areas and in the poorer developing countries in general (21; also see chs. B and 9). While logs and charcoal are often traded in commercial markets, most biomass use is not reflected in statistics on primary commercial energy consumption.

In industrialized countries, biomass fuels account for only about 3 percent of energy supplies, although in a few cases--particularly in the forest products industry-wood is a significant part of the fuel mix. In Finland, wood accounted for about 15 percent of total energy use in the early 1980 s $(58,62)$. In the United States, forest residues and wood wastes supplied about 2 percent of energy use during the late 1980s, with one-third used at residences and two-thirds by industry (59).

Today, biomass fuels are most commonly used in their unprocessed forms (e.g., wood logs) and are burned directly in residential stoves or industrial boilers or combustors. However, biomass can also be processed into liquid or gaseous fuels for use in boilers, gas turbines, or highway vehicles. Municipal solid waste can be a biomass fuel source in some situations-through combustion in incinerators, with subsequent use of steam (either directly or to drive turbines), or from collection of methane produced when biomass (e.g, paper, food wastes) decomposes in landfills. (See box 3-A for a discussion of how biomass can be used for energy.)

\section{Issues}

The Department of Energy (DOE) estimated (86) that using fast-growing, short-rotation woody crops as biomass fuels could offset 3 to 5 percent of current annual U.S. $\mathrm{CO}_{2}$ emissions, assuming current production and conversion technologies, and up to 35 percent, assuming technology advances and using a high estimate of land availability. OTA's more moderate estimate indicates that planting 0.5 million ha/year in short-rotation woody crops might offset about 1,2 percent of current U.S. $\mathrm{CO}_{2}$ emissions (see ch. 7).

The major constraint on production and use of biomass fuels as an energy source in the United States is their general lack of economic competitiveness with fossil-fuel energy sources. A recent report by several national laboratories, though, projected that biomass fuels might account for 7 to 13 percent of energy use- - two to three times current levels-by the year 2030, depending on the level of Federal support for R\&D of different conversion technologies (59) and on whether vigorous measures are taken to promote them. However, developing a sustainable and balanced biomass energy industry also depends on how several questions are resolved, including whether: productivity of short-rotation crops can be maintained over long periods, sufficient infrastructure to support a biomass fuel industry can be developed, market conditions will be conducive to investments in such an industry, and alternative land uses are more desirable. 


\section{CARBON-FREE ENERGY SOURCES}

\section{Renewable Energy Sources}

The use of renewable, carbon-free energy sources results in no or relatively low emissions of climatemodifying gases. "”

\section{Water}

Hydroelectric power is the largest worldwide nonfossil source of electricity. Most installed capacity is located in the United States, Canada, and the U.S.S.R. From 1977 through 1987, worldwide hydroelectric power production expanded by about 40 percent, though by less than 15 percent in the United States.

Worldwide hydropower capacity could ultimately triple (19). Among the developed countries, the U.S.S.R. has by far the largest resources, followed by the United States and Canada. In the developing countries, the largest potential is in Zaire, China, India, Indonesia, Colombia, and Brazil. ${ }^{11}$ Hydropower does not directly contribute greenhouse gas emissions, but its high capital costs, associated flooding and deforestation, and impacts on indigenous peoples make it controversial in many developing countries. As a result, U.S. Agency for International Development policy is to no longer fund large hydropower projects. Some governments (e.g., China, Brazil) also have scaled down some large projects because of environmental concerns or the realization that end-use energy efficiency could reduce the need for some new generating capacity.

\section{Geothermal Energy}

Geothermal energy is heat, hot water, or steam obtained from the Earth's crust. ${ }^{12}$ In some cases, the hot water comes from wells. In others, cold water (or other working fluid) is pumped down to the hot rock, heated, and returned to the surface to drive a turbine. This heat has many possible applications, but the most common is the generation of electricity. The technology to convert geothermal energy to electricity is relatively well developed for some types of sources (i.e., geysers) but not for all (9).

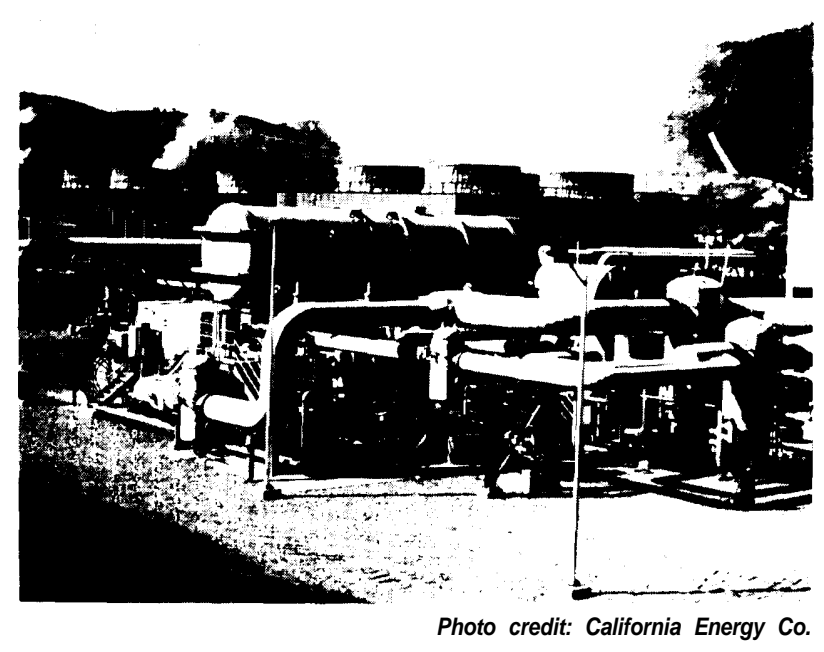

Coso Geothermal project in California.

In 1989, worldwide geothermal capacity totaled over 5,400 megawatts of electricity (MWe). Fortyseven percent of this capacity was in the United States (about 0.4 percent of U.S. generating capacity). Other countries with some geothermal electric capacity were the Philippines, Mexico, Italy, Japan, New Zealand, and Indonesia.

Despite the low absolute use of geothermal energy, growth over the last decade has been extremely rapid; from 1970 to 1988 , total geothermal generating capacity in the United States increased from 78 to 2,409 MW of electricity. An additional 7,325 MW were planned worldwide as of April 1989 (20). By the year 2000, U.S. geothermal capacity could reach 6,800 MW. Most will be located in California, Hawaii, Arizona, New Mexico, Nevada, and Utah (52). Rough estimates indicate substantial reserves. The U.S. Geological Survey estimates that on the order of 23,000 MW might be recoverable from high-temperature geothermal resources in the United States (59).

Wind

Wind power is widely used for pumping water. The technology used to turn wind into electricity is well developed, though advanced wind turbine designs (e.g., variable speed rotors) are just begin-

\footnotetext{
${ }^{10}$ Note that there are hybrid technologies that Supplement noncarbon sources of energy with carbon fuels. Most existing solar thermal electric powerplants, for example, are supplemented with natural gas.

1 I For a detailed listing, see ref. 85.

${ }^{12}$ For more on the technology of geothermal power, see ref. 69.
} 


\section{Box 3-A-Energy From Biomass}

Biomass is a renewable energy resource obtained from organic, nonfossil materials such as wood and wood byproducts, agricultural crops and their residues, animal wastes, municipal solid waste (MSW), and sewage sludge (see figure 3A-1). Most biomass energy currently comes from direct combustion of solid biomass (e.g., wood, plant herbage, MSW) for space and process heating, cooking, and a small amount of electric generation. Biomass also can be converted to various gaseous and liquid fuels (often called biofuels) which can be easily stored and transported

In the United States, biomass sources currently supply about 2.8 quadrillion Btu's (quads), or about 3 percent of the Nation's energy needs (81), an amount typical of industrialized countries. About 87 percent of this energy comes from wood and its byproducts; wastes and alcohol fuels made from biomass account for about 10 and 3 percent, respectively. If fully developed, biomass energy might eventually contribute about 14 quads, or about 17 percent of current U.S. energy consumption (59); Oak Ridge National Lab $(47,48)$ estimates a potential 14 quads from biomass-based liquid fuels alone.

Direct Combustion of Wood and Wood Wastes-In the United States, the largest amounts of energy from biomass come from the direct combustion of wood and wood wastes. (See ch. 7 for a discussion of forest product resources.) The lumber, pulp, and paper industries account for about 65 percent of all wood consumed for energy, and the residential sector about 35 percent (79). In industry, about 95 percent of this energy is used to produce process heat or steam, while the remaining 5 percent is converted to electricity using onsite cogeneration systems.

Direct Combustion of Municipal Solid Waste-Today, about 14 percent (by weight) of the MSW generated in the United States is incinerated (84). ${ }^{1}$ About 120 facilities out of the 160 in the United States that incinerated MSW also produced energy in the form of steam (45 perent of the plants), electricity (26 percent), cogenerated electricity ( 20 percent), and refuse-derived fuel burned elsewhere ( 8 percent) $(25,70)$. These "waste-to-energy" plants account for about 4 percent of the biomass energy consumed in the United States (59). Expansion of this capacity in the United States is uncertain because of public concern over air pollution and possible health impacts of incinerator emissions and ash.

Methane Gas From Landfills-Municipal solid waste (MSW) landfills produce methane gas due to the anaerobic decomposition of organic wastes, which makeup approximately three-quarters of all MSW (70). While current estimates of methane emissions from landfills and other sources are highly uncertaîn, waste disposal in landfills around the world might account for 5 to 18 percent of all methane emissions (8). ${ }^{2}$ Since methane is a more potent short-term greenhouse gas than $\mathrm{CO}_{2}$ (ch. 2), from a climate perspective it would be most desirable to recover and process it for energy. Out of the approximately 6,000 active U.S. landfills in operation in 1986, only 123 collected methane for energy recovery (70). Methane emissions are drawn, sometimes with vacuum pumps, through a series of trenches and/or collection pipes running throughout the landfill. The gas is later purified and can be used to generate steam for heating or electric generation. Today, landfill gas accounts for only 0.3 percent of energy from all biomass sources (36), but if fully developed this resource could supply between 0.2 to 1.0 quads of energy -between 1 and 5 percent of all natural gas consumption, or 0.2 to 1 percent of total U.S. energy demand $(59,82)$.

Methane Gas From Anaerobic Digesters-The decomposition of organic material inside devices called anaerobic digesters essentially mimics similar processes in oxygen-poor environments such as landfills and rice paddy muds, but methane is produced more efficiently because the process can be carefully controlled Ideal biomass feedstocks include sewage sludge, fresh animal manure, aquatic plants, and wet food-processing wastes. The amount of energy that could be recovered from these sources in the United States is about 1 quad (59).

Syngas From Wood, Crops, and Waste--Solid biomass can be converted, through a process called "gasification, "into gas suitable for fuels or chemical synthesis. Lower Btu gas produced using air-blown gasifiers is used as boiler fuels or furthered processed into liquid fuels (e.g., methanol, see below), whereas higher Btu gas from oxygen-blown gasifiers can be added to the natural gas distribution system

1 About 83 percent by weight of MSW consists of combustible materials such as paper and paperboard, plastics, rubber, leather, WOod, and food and yard wastes; the remaininl 7 percent, consists of noncombustibles, such as glass, metals, and miscellaneous inorganic wastes (81).

2The Clean Air Act Amendments of 1990 directed EPA to study methane emissions associated with natural gas and coal extraction, transportation, distribution, storage, and use; solid waste management (which includes landfills); agriculture; and biomass burning. 
Ethanol From Grains and Sugar Crops-In 1987, about 3.2 billion liters of ethanol were sold in the United States, mainly as a transportation fuel, making it the world's second largest consumer after Brazil (see chs. 5 and 8) (61). Over 80 percent of U.S. ethanol plant capacity in 1986 was dedicated to fermentation of corn feedstocks (78). Other grain and sugar crops, such as grain sorghum, molasses, and food-processing wastes, also can be used for feedstock; in Brazil, sugarcane is used. More than 8 percent of the gasoline sold in the United States is a 10 percent ethanol blend (i.e., "gasohol").

Methanol From Wood, Crop Residues, and Grass Crops-Methanol is used primarily as a feedstock in chemical manufacturing, but also as a transportation fuel. In 1986, 1.1 billion liters of methanol were consumed in the United States for transportation, accounting for about 0.09 percent of this sector's energy demand (78). Methanol has traditionally been produced using natural gas feedstocks, but it can also be produced from biomass through pyrolysis or oxygen-blown gasification (as described above) and then converted to methanol using catalysts (67). Significant improvements in both conversion technology and all aspects of the growing and harvesting cycle for biomass-to-methanol production are necessary for biomass-based methanol to become competitive with natural gas feedstocks (73).

Certain plant seeds, such as rape seed, sunflowers, or oil palms can be pyrolyzed to form intermediate biocrude liquids, and then catalytically converted to gasoline, diesel, or jet fuel. Oil seeds maybe able to supply as much as 0.4 quads (47).

Figure 3A-I-Alternative Methods of Using Biomass Energy

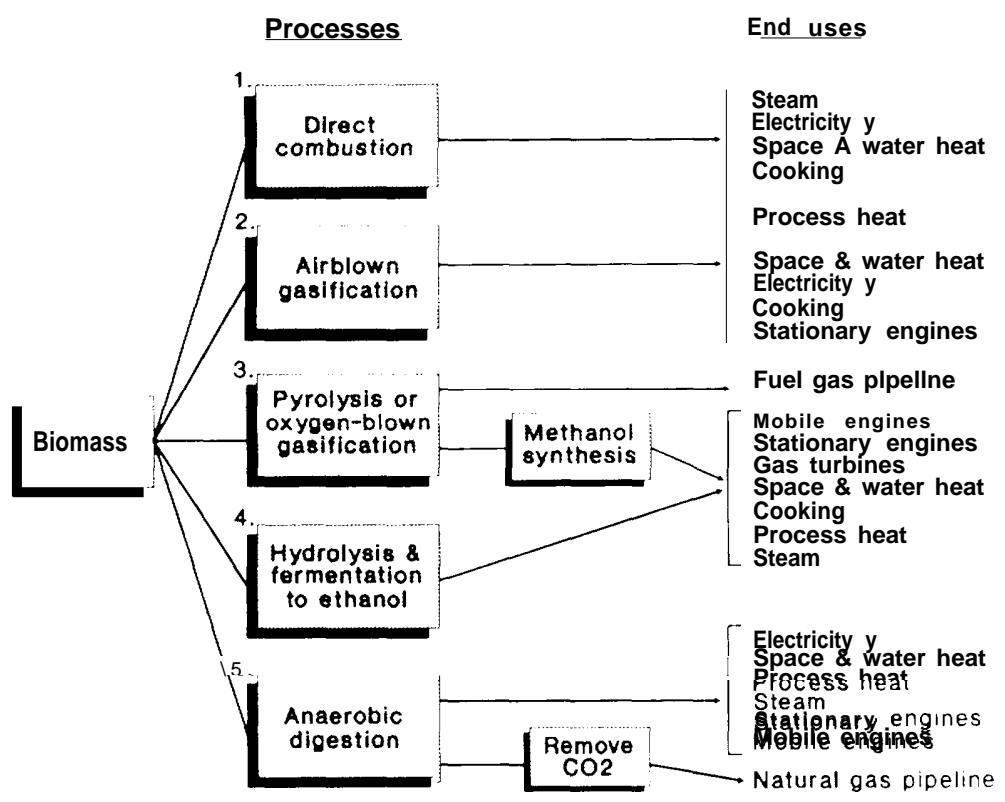

Examples of how biomass can be processed

$\begin{aligned} \text { Process number: } & \text { (see boxes above) } \\ 1,2,3,4 & \text { Wood \& wood wastes } \\ 2,3,4 & \text { Agricultural crops } \\ 1,2,3,4 & \text { Crop residues } \\ 1,2,3,5 & \text { Municipal solid waste } \\ 5 & \text { Sewage sludge } \\ 5 & \text { Animal wastes } \\ 5 & \text { Aquatic plants }\end{aligned}$

SOURCE: Adapted from U.S. Congress, Office of Technology Assessment, Energy From Biological Processes, Volume I/--T\& nical and Environmental Analysis, OTA-E-1 28 (Springfield, VA: National Technical Information Service, September 1980). 
ning to emerge. ${ }^{13}$ In areas with good winds, wind turbines can be a cost-effective method for meeting a portion of power needs. 'Generally, the wind energy flux is greatest in coastal areas in the mid and northern latitudes and along exposed mountain ridges throughout the world. In the United States, good wind resources are widely dispersed, from coastal New England to the mountain passes of southern California (17).

In mid-1989, installed wind turbine electric capacity was roughly $1,760 \mathrm{MW}$ worldwide. In the United States, capacity amounted to roughly 1,520 $\mathrm{MW}^{14}$, triple the capacity 5 years earlier but still only a fraction of a percent of total U.S. electric generating capacity (26). However, a study sponsored several years ago by the Electric Power Research Institute indicated that the market potential by the end of the century could be as high as 21,000 MW (54). Worldwide, the magnitude of the usable wind energy resource cannot be accurately determined because of the current lack of data. Though the annual theoretical potential is quite large, only a small portion of this could be exploited during the next quarter century (19). India reportedly has plans for 5,000 MW of wind power by the year 2000(1 1).

\section{Solar Energy}

The amount of solar energy reaching the Earth's surface in a year is thousands of times that of worldwide annual fossil fuel use (28). Of course, many factors limit the usefulness of this energy, Much of the solar energy shines onto oceans or other locations where it is not easy to capture. Furthermore, insolation (exposure to sunlight) varies geographically, seasonally, daily, and over other periods of time. Despite these limitations, the amount of available energy is enormous. Solar energy can be used to provide light, heat, steam, and even air conditioning for buildings and industry.

Solar Thermal Energy-The sun can provide power for diverse applications in buildings and industry either in passive or active solar energy systems. Passive systems usually use building structures (e.g., windows, walls, floors) for collection and storage. Active systems rely on pumps and fans for heat distribution from solar collectors to areas of use,
Passive solar techniques have been used since at least the days of ancient Greece, and are used to varying degrees in virtually all buildings today. They include many conceptually simple methods, such as orienting buildings north-south, planting trees to block the sun in the summer and let it through in the winter, installing skylights to provide light, and using building materials that absorb or reflect heat (also see ch. 4).

Active solar technologies are much more common than expressly designed passive systems. They are also better suited to the needs of the retrofit market. The central feature of an active solar energy system is the collector, which captures the solar radiation and turns it into heat to warm buildings and provides steam to drive machinery. Solar air-conditioning is developed, but has yet to be widely commercialized.

The outlook for active and passive solar technology is mixed. The field could experience rapid growth over the next 25 years (59). However, even optimistic market forecasts see this technology contributing 1 percent or less of U.S. energy needs over the next 25 years $(59,47)$.

Solar Electricity Generation-Currently, solar power supplies only a minuscule amount of the world's electricity and only 0.07 percent of U.S. electricity. Few expect solar power to provide a significant fraction of electricity world-wide within the timeframe considered in this report (i.e., by 2015)--at most, only a few percent of projected U.S. electricity supply will be solar-based in 2015 . On the other hand, this does represent tremendous growth in the relative share of solar energy in the United States, and this could set the stage for even more dramatic increases in the ability of solar power to meet U.S. and world energy demands after 2015. In the optimistic scenario of one study, solar energy (not just solar electricity) could meet roughly 15 percent of U.S. energy needs by 2030 (59).

While growth in the use of solar and wind power in developing countries is expected, it is unclear whether this will represent much of an increase in the share of the power generation market. Solar and wind power may be most competitive in rural areas where fuel supplies and maintenance services are expensive and energy infrastructure (e.g., power lines) is minimal (see ch. 9).

\footnotetext{
${ }^{13}$ For a description of the technology, see ref. 59.

${ }^{14} \mathrm{California}$ alone accounts for 80 percent of the world total, with most of that capacity located in three mountain passes.
} 


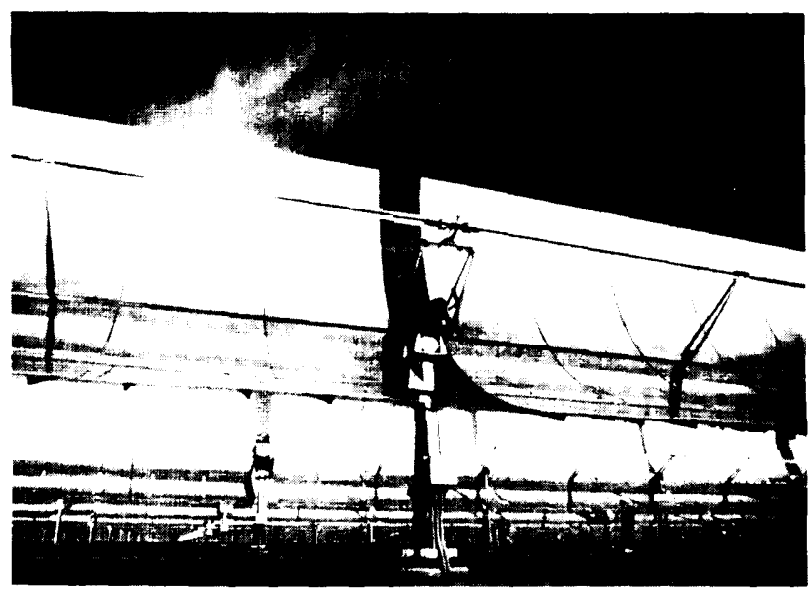

Photo credit: Solar Energy Industries Association

Parabolic trough collector at the Luz solar thermal plant in California.

Issues

Renewable, carbon-free energy sources collectively are now a major source of energy around the world, and they have the potential to meet a sizable h-action of future electric and nonelectric energy needs. These sources cannot, however, fully displace fossil fuels in the near term. The greatest near-term potential lies in hydropower and the radiant energy of the sun; a large but substantially smaller potential also exists for wind and geothermal energy. All are economically competitive to some degree today, but their competitiveness varies widely depending on location, application, and other variables. Hydroelectric and wind power are the least expensive; photovoltaics are currently expensive and therefore competitive only in remote or specialized applications.

Each alternative possesses some advantages over fossil fuels, ranging from photovoltaics' remarkable modularity to the short lead-times of small geothermal units. But the technologies also suffer from serious disadvantages relative to the fossil fuels. Among these are the difficulty of access to transmission capacity, the intermittent nature of photovoltaics, lack of information about the quality and distribution of the resources, high capital costs relative to fossil-fuel competitors, and various regulatory constraints. Rapid and favorable changes must occur in many of these areas if the technologies are to realize their full potential during the next quarter century.

\section{Nuclear}

The emissions of $\mathrm{CO}_{2}$ from the use of nuclear powerplants are small compared to those from use of fossil-fuel-fired plants.

\section{Resources and Their Use}

Worldwide, nuclear power provided about 15 percent of electricity in 1988. The United States possessed the largest amount of nuclear capacity, with about 30 percent of the total; other countries with large amounts of nuclear generating capacity were France, the U. S. S. R., Japan, and West Germany (34). A few countries, such as France, draw more than 50 percent of their electric power from nuclear plants (64). Despite the strong presence of nuclear power in many countries, and in contrast to the rapid increase in nuclear capacity over the last two decades, the immediate future suggests relatively slow growth in capacity. Some countries, such as France and Japan, are continuing to press ahead with ambitious nuclear programs (46), but in many countries growing concern over the safety and long-term appropriateness of nuclear energy has led to a virtual halt in development,

Though several developing countries have operating nuclear power capacity (Argentina, Brazil, India, Mexico, Pakistan, South Africa, South Korea, Taiwan) (64), it plays a minimal role in most. Nuclear power is unlikely to increase substantially in developing countries in the near future, even though some are planning on building facilities by the end of the century (e.g., Bangladesh, China, Cuba, Egypt, Israel, Morocco, Turkey) (64). Most developing countries have not signed the nuclear weapons Non-Proliferation Treaty, which makes it difficult for nuclear nations to assist these countries in further developing their nuclear energy industry.

\section{Issues}

Nuclear power's strong point is that its emissions of $\mathrm{CO}_{2}$, methane, and other pollutants are quite low compared to those of its fossil-fuel competitors. Moreover, if the public is willing to accept nuclear power, it could once again become a viable alternative to fossil-fuel-fired generation in the United States. However, several key issues cloud the future of nuclear power and restrict its near-term potential:

Lead Times-Many of the steps required to commercially deploy additional nuclear power, ranging from the development and demonstration of 
new designs to the licensing and construction of commercial plants and reactors, require long periods of time. This limits the near-term contribution of nuclear power.

Safety and Environmental Issues-These range from concerns about the possibility of catastrophic failure of nuclear plants to questions about waste disposal and decommissioning.

Costs-The cost of nuclear powerplants has been high compared to electricity from fossil fuels. Considerable uncertainty exists over what the future costs-including decommissioning and waste disposal-might be.

Proliferation - Increased dependence on nuclear power will aggravate nuclear proliferation problems. This raises a host of domestic and international issues. Promotion by the United States of nuclear power in key developing countries will be limited by these considerations and related legal obligations.

Some of these concerns are being addressed by efforts to develop improved reactor designs and to change government regulations; however, they are certain to remain important in the near term. For a more complete discussion of these issues, see ref. 68 .

\section{REDUCING $\mathrm{CO}_{2}$ EMISSIONS FROM ELECTRICITY GENERATION}

\section{Introduction to Technical Options}

There are four basic ways to reduce emissions from electricity generation:

1. reduce demand for electricity (see chs. 4 and 6),

2. use more nonfossil energy sources (see previous section),

3. switch to fossil fuels with a lower carbon content per unit energy, and

4. lower the rate of $\mathrm{CO}_{2}$ emissions from fossil fuels through improvements in combustion efficiency and electricity manumission and distribution.

The third and fourth strategies-lowering the rate of emissions from fossil fuels by switching to lower carbon fuels and by using more efficient electric generating and transmission technology-are discussed below.
Figure 3-4-Carbon Emissions From Electric Generating Technologies as Compared to Emissions From the Average Existing Coal-Fired Powerplant

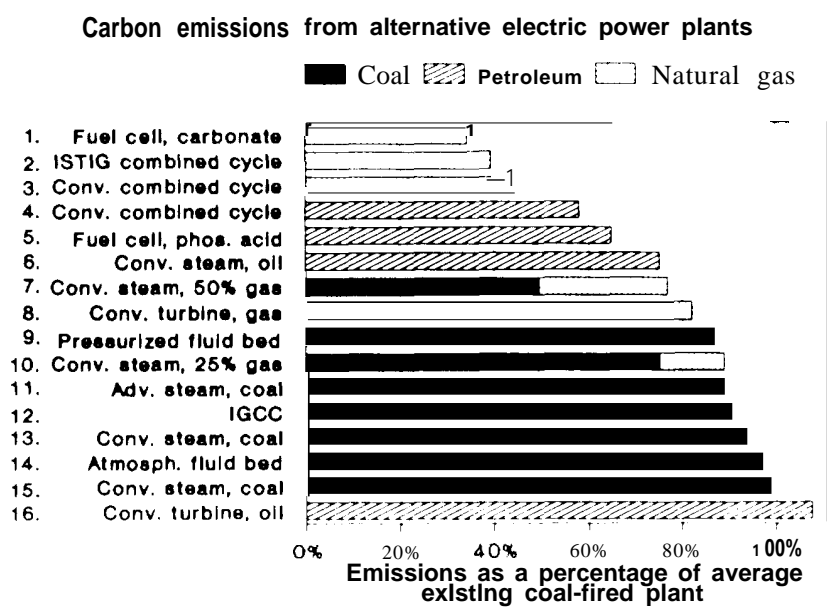

NOTE: The numbers of the technologies on this figure are the same as those presented in table 3-5. Additional details on the technologies are presented in the table.

SOURCE: Office of Technology Assessment, 1991, calculated using data from EPRI, Technical Assessment Guide (1989).

\section{Fuel Switching and More Efficient Generating Technologies}

The amount of $\mathrm{CO}_{2}$ that fossil fuels release when burned depends, in part, on their carbon content, which varies from fuel to fuel. Therefore, even if the total quantity of fossil fuels in the energy supply remains the same, $\mathrm{CO}_{2}$ emission levels can be affected by changing the ratios of coal, oil, and natural gas we burn-a $\mathrm{CO}_{2}$ abatement strategy called fuel switching. Fuel switching can bring large reductions in emissions, since 85 percent of U.S. utility $\mathbf{C O}_{2}$ emissions now come from coal-burning plants.

Emission levels also depend on the efficiency of the plants that burn those fuels. Another way to reduce $\mathrm{CO}_{2}$ emissions from this sector, therefore, is to make powerplants more efficient. Small gains (less than 5 percent per plant) are possible with relatively minor "tune-ups" (49). Similar measures may well have bigger impacts-on the order of 10 percent-in developing countries (66). Larger gains are possible through "repowering' "- the replacement of the basic combustion components of existing powerplants with new technologies. 
Table 3-5-- $\mathrm{CO}_{2}$ Emission Rates From Fossil-Fuel-Fired Electric Generating Technologies

\begin{tabular}{|c|c|c|c|c|c|}
\hline \multicolumn{2}{|c|}{ Technology } & \multirow[b]{2}{*}{ Natural gas } & \multirow{2}{*}{$\begin{array}{c}\begin{array}{c}\text { Net heat rate } \\
\text { full load }\end{array} \\
6,450\end{array}$} & \multirow{2}{*}{$\begin{array}{c}\begin{array}{c}\mathrm{lb} \mathrm{C} / \mathrm{kWh} \\
\text { (from fuel only) }^{\mathrm{a}}\end{array} \\
0.20\end{array}$} & \multirow{2}{*}{$\begin{array}{l}\begin{array}{l}\text { Technology development } \\
\text { rating }\end{array} \\
\text { Laboratory }\end{array}$} \\
\hline 1. & $\begin{array}{l}\text { Dispersed fuel cell, advanced } \\
\text { molten carbonate }\end{array}$ & & & & \\
\hline 2. & $\begin{array}{l}\text { Intercooled steam-injected gas } \\
\text { turbine (ISTIG) }\end{array}$ & Natural gas & $7,260^{b}$ & 0.23 & Pilot \\
\hline 3. & Combined cycle, conventional & Natural gas & 8,230 & 0.26 & Mature \\
\hline 4. & $\begin{array}{l}\text { Combined cycle, advanced, } \\
\text { reheat steam cycle }\end{array}$ & Distillate & 7,580 & 0.34 & Demonstration \\
\hline 5. & $\begin{array}{l}\text { Dispersed fuel cells, phosphoric } \\
\text { acid, first generation }\end{array}$ & Distillate & 8,550 & 0.38 & Demonstration \\
\hline 6. & Steam powerplant & Distillate & 9,680 & 0.45 & Mature \\
\hline 7. & $\begin{array}{l}\text { Conventional subcritical, w/wet } \\
\text { lime flue gas desulfurization, } 200 \\
\text { MW unit }\end{array}$ & $\begin{array}{l}50 \% \text { pulverized } \\
\text { bituminous coal, } \\
50 \% \text { natural gas }\end{array}$ & 10,210 & 0.46 & Mature \\
\hline 8. & $\begin{array}{l}\text { Conventional combustion } \\
\text { turbine }\end{array}$ & Natural gas & 15,040 & 0.49 & Mature \\
\hline 9. & $\begin{array}{l}\text { Pressurized fluid bed combustion- } \\
\text { combined cycle }\end{array}$ & Bituminous coal & 8,980 & 0.51 & Pilot \\
\hline 10. & $\begin{array}{l}\text { Conventional subcritical, w/wet } \\
\text { lime flue gas desulfurization, } 200 \\
\text { MW unit }\end{array}$ & $\begin{array}{l}75 \% \text { pulverized } \\
\text { bituminous coal } \\
250 / \sim \text { natural gas }\end{array}$ & 10,210 & 0.53 & Mature \\
\hline 11. & $\begin{array}{l}\text { Supercritical, demonstration state } \\
\text { of the art, advanced limestone } \\
\text { flue gas scrubber }\end{array}$ & Pulverized bituminous coal & 9,080 & 0.52 & Demonstration \\
\hline 12. & $\begin{array}{l}\text { Integrated gasification- } \\
\text { combined cycle (IGCC), } 200 \text { MW } \\
\text { unit }\end{array}$ & Bituminous coal & 9,320 & 0.53 & Demonstration \\
\hline 13. & $\begin{array}{l}\text { Conventional supercritical w/wet } \\
\text { lime flue gas desulfurization, }\end{array}$ & Pulverized bituminous coal & 9,640 & 0.56 & Mature \\
\hline & $\begin{array}{l}\text { Atmospheric fluidized bed } \\
\text { combustion (circulating bed)) }\end{array}$ & Bituminous coal & 10,060 & 0.57 & Demonstration \\
\hline 15. & $\begin{array}{l}\text { Conventional subcritical, w/wet } \\
\text { lime flue gas desulfurization, } 200 \\
\text { MW unit }\end{array}$ & Pulverized bituminous coal & 10,210 & 0.59 & Mature \\
\hline & $\begin{array}{l}\text { Combustion turbine, } \\
\text { conventional }\end{array}$ & Distillate & 14,020 & 0.64 & Mature \\
\hline
\end{tabular}

aThis does not include other $\mathrm{CO}_{2}$ emissions that maybe associated with use oft he technology. For example, the figure for the fluidized bed technologies does not include the $\mathrm{CO}_{3}$ emissinns released by the limestone used.

SOURCES: All heat rates are average annual heat rates. Heat rate values, with the exception of that for the ISTIG and liquid-fuel-fired steam plants, are from Electric Power Research Institute, TAG-Technical Assessment Guide, Vol.1Rev.6 Electricity Supply-1989 (Palo Alto, CA: November 1989), EPRI P-6587-L.

Liquid-fuel-fired steam values from Electric Power Research Institute, TAG-Tectnical Assessment Guide, Vol.1: Eloctricity Supply-i986 (Palo Alto, CA: December 1986), EPRIP-4436-SR.

Heat rate for ISTIG f rom R. H. Williams and E. D. Larson, Aircraft-Derivative Turbines for Stationary Power (Princeton, NJ: Center for Energy and Environmental Studies, Princeton University, 1988), review draft.

Alternatives to the average existing coal-fired powerplants vary by emission rate (see figure 3-4). Far greater gains are possible by switching away from coal to other fossil fuels (shown as lighter bars) than by switching among coal technologies (the black bars).

Technology options also vary by heat rate-the amount of fuel needed to generate 1 kilowatt-hour $(\mathrm{kWh})$ of electricity - and by $\mathrm{CO}_{2}$ emissions per $\mathrm{kWh}$ for the particular combination of technology and fuel (see table 3-5).
Burning conventional pulverized coal with a sulfur dioxide scrubber (technologies 13 and 15 in figure 3-4 and table 3-5), yields emission rates typical of coal boilers installed during the 1980s. With the most efficient coal technologies, $\mathrm{CO}_{2}$ emissions are about 10 percent lower. These include: 1) pressurized fluid bed combustion; 2) state-of-theart pulverized coal boiler; and 3) integrated coal gasification, combined cycle (IGCC) (technologies 9, 11, and 12, respectively, in figure 3-4 and table 3-5). By replacing conventional coal plants with high-efficiency turbines burning natural gas, the 
same amount of electricity can be generated with about a 60-percent reduction in $\mathrm{CO}_{2}$ emissions (technologies 2 and 3). This is, in part, because gas releases far less $\mathrm{CO}_{2}$ per unit energy than does coal.

However, coal plants need not be completely repowered to achieve some of the benefits of fuel switching. One option is to change coal-fired plants to natural gas co-fired or intermittently fired plants, that is, plants that use both coal and natural gas simultaneously or sequentially to heat the boilers (technologies 7 and 10). Since the boiler technology remains essentially unchanged, a co-firing boiler is about as efficient as a purely coal-fired one, though efficiency may drop a few percent when burning gas (18). The $\mathrm{CO}_{2}$ reductions result mostly from the fact that natural gas has less carbon. A co-firing plant burning 25 percent gas and 75 percent coal would emit about 10 to 15 percent less $\mathrm{CO}_{2}$ than a pure coal-burning plant. Burning 50 percent natural gas would lower emissions by 20 to 25 percent.

Fuel switching, however, is not without its problems. The major one is that it can deplete gas reserves and strain the gas pipeline distribution network. This fact is especially germane since several other strategies discussed in this report rely on increased gas use. Just how much natural gas exists is poorly quantified, If natural gas does become a "lynch pin" of domestic or global $\mathrm{CO}_{2}$ reduction strategy, demand and prices could rise to very high levels. Increased use of natural gas also carries with it the risk of increased leakages of methane.

One additional control option is theoretically possible-the removal of $\mathrm{CO}_{2}$ from combustion exhaust gases for disposal in the deep oceans or wells. Box 3-B discusses this concept, which we do not consider to be a feasible near-term alternative.

\section{Electricity Transmission and Distribution Improvements}

The electricity transmission and distribution (T\&D) system connects the producer of electricity with consumers. During T\&D, a certain amount of electricity is lost due to resistance as well as inefficient operation and maintenance of the distribution network. This loss averages 5 to 10 percent in the developed countries (83). The United States loses roughly 8 percent of its electricity in T\&D (14).

In developing countries, Eastern Europe, and the U.S. S. R., T\&D losses can be much higher. Losses in developing countries commonly exceed 20 percent (India, for example, loses 21 percent (66) and some countries report losses as high as 30 percent between generation and delivery (83; also see ch 9)). Less is known about the T\&D losses in Eastern Europe. Still, a large number of cost-effective opportunities exist to reduce losses. ${ }^{15}$ The one limitation is that in some countries up to half the T\&D loss maybe from theft (66). Eliminating theft could be more difficult than eliminating other losses (and might not lower overall demand very much).

Transmission and distribution systems also affect the ability of low-emission generators to fill the need for electric power. Many of the opportunities for relatively low emission power generation are remote from existing transmission facilities. Geothermal and wind resources, for example, are often located far from existing lines. Similarly, one region may have excess hydroelectric or nuclear capacity at the same time another region is experiencing a power shortfall and being forced to burn more fossil fuels. ${ }^{16}$

\section{OTA EMISSION REDUCTION SCENARIOS}

OTA developed a simple energy accounting model that allows us to estimate the effectiveness of various technical options for lowering $\mathrm{CO}_{2}$ emissions (see app. A). The model is based on a much larger system of energy and economic models used by the Gas Research Institute (GRI) to forecast energy use through 2010 (29).

About 35 percent of total U.S. $\mathrm{CO}_{2}$ emissions comes from fossil fuels burned to generate electricity. By 2015, this might increase to 45 percent. In this section we examine how changes in supply-side characteristics can lower $\mathrm{C}_{2}$ emissions from electricity generation. We class@ supply-side options into two categories-' 'Moderate' measures and more aggressive and costly 'Tough' measures. Because supply-side options will have different effects depending on the demand for electricity, however, we frost review our estimates of electricity

\footnotetext{
${ }^{15}$ One World Bank study, for example, notes that "Witi realistic limits, for many distribution systems, ]0sS reduction is a far cheaper alternative than adding new generating and bulk transmission capacity" (44,66). For examples with rapid paybacks in the United States, see ref. 43.

${ }^{16}$ Options relating to these issues are discussed in a recent OTA report (71).
} 


\section{Box 3-B-Carbon Dioxide Scrubbing}

In addition to reducing $\mathrm{CO}_{2}$ emissions from fossil-fuel-fired plants by using more efficient combustion technologies and fuel switching, it is also possible to remove $\mathrm{CO}_{2}$ from flue gases and liquefy--through a process known as "scrubbing." Theoretically one could pump the liquefied $\mathrm{C}_{2}$ through pipelines to disposal sites, for example, the deep ocean, where it is hoped it will remain rather than entering the atmosphere. While each individual component appears technically feasible, the entire system has never been tried. We do not consider $\mathrm{CO}_{2}$ scrubbing as one of our near-term technical options, but the concept merits further research.

Carbon dioxide scrubbing basically involves:

. compressing and cooling the stack gases;

-removing $\mathrm{C}_{2}$ from the gases via $\boldsymbol{a}$ reaction with a solvent solution;

. heating and steam-stripping the $\mathrm{CO}_{2}$-enriched solution to reverse the reaction, yielding uncondensed steam and $\mathrm{CO}_{2}$;

. condensing and removing water vapor, leaving the recovered $\mathrm{CO}_{2}$; and

. compressing and liquefying the recovered $\mathrm{CO}_{2}$.

The Department of Energy (DOE) examined the feasibility of using scrubber systems at all fossil-fuel-fired powerplants operating as of 1980 (74a). To remove 90 percent of $\mathrm{CO}_{2}$ emissions would require about 11 to 16 percent of total electrical power capacity in gas- and coal-burning regions, respectively. Electricity production costs would increase between 50 and 120 percent, depending on the region, averaging 75 percent nationwide. About 85 to 90 percent of the cost was for removal, recovery, and liquefaction; the remainder was for pumping liquefied $\mathrm{CO}_{2}$ through pipelines for disposal.

DOE suggested three possible disposal methods for liquefied $\left.\mathrm{CO}_{2}-\mathbf{1}\right)$ injection in the deep ocean (i.e., at least 500 meters deep, 100 miles offshore); 2) storage in depleted oil and gas wells; and 3) storage in excavated salt caverns. Some concern has been expressed over whether 500 meters is deep enough for permanent ocean disposal; injection to 3,000 meters would require a 200-mile pipeline. For any of these methods, DOE envisioned carrying the recovered liquefied $\mathrm{CO}_{2}$ in small (6-inch diameter) pipelines from each powerplant to collection centers, and then carrying it from the centers to ultimate disposal sites in larger (36-inch diameter) pipelines. DOE concluded that most of the $\mathrm{CO}_{2}$ would have to be disposed of in the ocean.

A recent study in the Netherlands (27a), however, suggests that the increased electricity costs might be less-perhaps half as much per kWh--if an intermediate gas product from an Integrated Gasification, Combined Cycle (IGCC) powerplant is used (technology 12 in table 3-5). This process involves:

. using a gasifier to convert coal into heat and a gas composed primarily of hydrogen $\left(\mathrm{H}_{2}\right)$ and carbon monoxide $(\mathrm{CO})$;

- converting the $\mathrm{CO}$ to $\mathrm{CO}_{2}$ using an iron-chromium or nickel-chromium catalyst (the $\mathrm{H}_{2}$ would subsequently be used as fuel in the combined cycle process);

. recovering $\mathrm{CO}_{2}$ from the gas mixture by using a physical absorption process, with a solvent known as selexol; and

- drying and compressing the $\mathrm{CO}_{2}$.

To remove 88 percent of the $\mathrm{CO}_{2}$ from the exhaust gas, about 13 percent of the plant's electrical production would be needed to run the system. Electricity production costs would rise about 25 percent for recovery and compression and an additional 5 to 10 percent for pumping to final disposal sites. (For the Netherlands, exhausted natural gas fields were proposed as disposal sites.)

demand over the next 25 years under our model's alternative demand-side scenarios.

\section{Alternative Scenarios of Demand for Electicity}

Under OTA's Base case scenario, electricity demand grows from about 2.7 trillion $\mathrm{kWh}$ in 1990 to 4.6 trillion $\mathrm{kWh}$ by 2015 , an average increase of about 2.2 percent per year. In this and later chapters, we present two other scenarios of energy demand: one lowers demand by imposing a series of Moderate demand-side measures; a second lowers demand even further through an ambitious set of Tough demand-side measures. Under the Moderate scenario, demand for electricity is held to 3,4 trillion $\mathrm{kWh}$ by 2015 , an average increase of 1.0 percent per year over the next two decades (see figure 3-5), The 
Figure 3-5-OTA Electricity Demand Scenarios

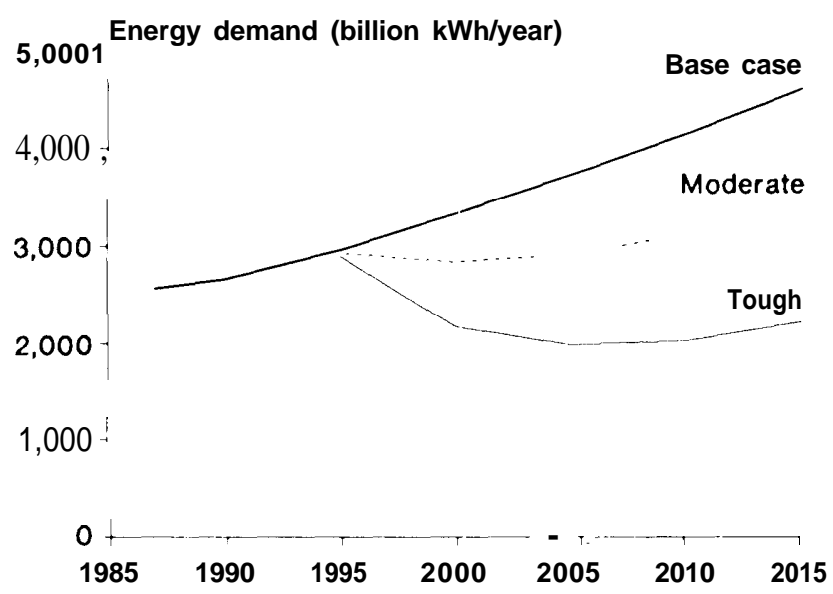

NOTE: Scenarios of electricity demand are discussed in detail in chs. 4 through 6 (Buildings, Transportation, and Manufacturing). For the analysis of electricity supply-side measures discussed in this chapter, we have summed demand from each of these sectors.

SOURCE: Office of Technology Assessment, 1991.

measures used initially require some capital investment, but result in lower fuel costs in the future. Over the life of the investment, these measures cost little or even save money.

The Tough measures lower energy demand even further, but only at a higher cost for the same or similar service. In this scenario, demand for electricity in 2015 is 2.2 trillion $\mathrm{kWh}$-somewhat lower than demand in 1990 (see figure 3-5). Demand drops fairly sharply until about 2005 and then begins to rise again. Existing generating capacity is adequate to meet demand until sometime between 2015 and 2020. Descriptions of the sector-specific technical options that lower demand from the Base case in each of the two scenarios are included in chapters 4 through 6 .

Emissions generally reflect electricity demand, with some variation due to the changing mix of fossil and nonfossil sources through time. The changing mix is especially important in the Tough demand scenario. Because demand for electricity in this scenario is less than potential supply from existing plants, fossil sources can be idled and hydropower and nuclear sources can supply a larger fraction of total supply. Thus, $\mathrm{CO}_{2}$ emissions decline in the Tough demand scenario because both electricity demand and $\mathrm{CO}_{2}$ emission rates (pounds of carbon per $\mathrm{kWh}$ ) are lower than they are today.

\section{Technical Options for Lowering $\mathrm{CO}_{2}$} Emissions From Electricity Generation

As mentioned, we also categorize methods for lowering $\mathrm{CO}_{2}$ emissions from the supply side (i.e., from utilities) as Moderate or Tough, thus creating two alternatives to the Base case or business-asusua1 supply-side scenario. We evaluate Base case, Moderate and Tough supply-side options for each of the three demand-side scenarios to create nine possible approaches to emission reductions (see figure 3-6). The highest $\mathrm{CO}_{2}$ emissions (twice 1987 levels by 2015) will occur under the combined business-as-usual scenarios-demand for electricity follows Base case projections with no supply-side changes. Still assuming the base case demand for electricity, Moderate supply-side measures will limit the growth of emissions somewhat, to about a 75 percent increase above 1987 levels by 2015; Tough supply-side measures can hold emissions to about a 45 percent increase by 2015 .

Supply-side measures have somewhat greater impacts under the Moderate demand scenario. With no supply-side changes (i.e., only lowered demand), emissions will increase by about 45 percent by 2015 . By adopting Moderate supply-side measures as well, emissions will increase by only about 25 percent. Tough electricity supply-side measures in combination with Moderate demand for electricity can lower emissions to about 20 percent below 1987 levels by 2015.

Supply-side measures have slightly lower effects under the Tough electricity demand scenario. The Tough demand scenario alone (i.e., with no change in supply-side technologies) will lower emissions to about 20 percent below 1987 emissions by 2015. By adopting Moderate supply-side measures in addition, emissions can be lowered to 30 percent below 1987 levels by 2015. Tough supply-side measures can cut emissions to about half of 1987 levels by 2015.

In each of the supply-side scenarios, we examine measures that apply to existing sources, measures that apply to new sources, and measures that require early retirement of existing sources with more stringent requirements for the replacement sources (see table 3-6).

Technical options for lowering emissions from existing plants include: 


\section{Figure 3-6-- $\mathrm{CO}_{2}$ Emissions From Electricity Generation Under the OTA Demand and Supply Scenarios}

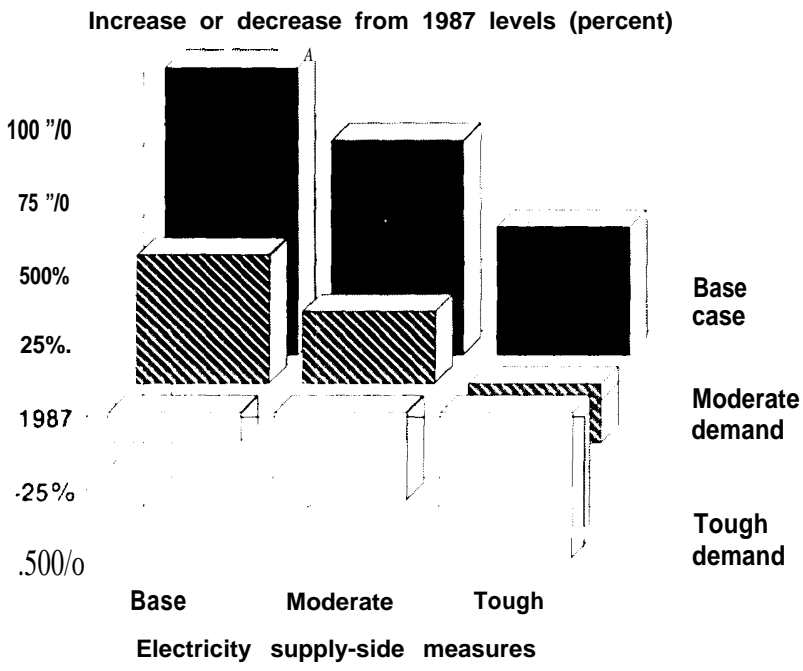

SOURCE: Office of Technology Assessment, 1991,

1. increased utilization of nuclear powerplants,

2. increased efficiency of fossil-fuel-fired plants through improved maintenance practices,

3. substituting natural gas for some fraction of the fuel burned in coal-fired powerplants, and

4. increasing the output from hydroelectric plants.

For lowering emissions from new plants, the options that we consider include:

1. increased reliance on such renewable energy sources as hydropower, geothermal, biomass, and solar energy;

2. revitalizing the nuclear industry so that the next generation of nuclear power technology is ready for use by 2005; and

3 . limiting the number of new coal-fired powerplants in the base case demand scenario and declaring a moratorium on coal-fired powerplants in both lower demand scenarios, with natural gas being the fossil fuel of choice until 2015.

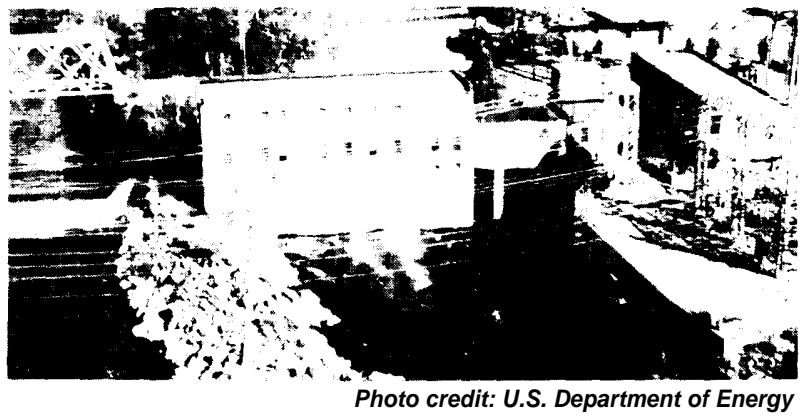

This demonstration project at Idaho Falls, Idaho, consists of redeveloping the city's three existing hydroelectric powerplant sites. The three sites will receive new turbines that are economical for small-scale, low-head hydroelectric power generation. The technology can be used immediately; it does not need extensive research and development.

We classify four of the technical options above as Moderate, that is, able to reduce emissions at little or no cost over the life of the investment. These include:

1. modestly improving the efficiency of existing fossil-fuel-fried plants (about a 5-percent improvement from better maintenance and dispatching procedures), ${ }^{17}$

2. increasing the output of existing hydroelectric plants (by about 11 percent, primarily by adding additional generating units to capture energy from water currently bypassing the plants $),{ }^{18}$

3. increasing utilization of existing nuclear powerplants (from 60 percent of the time, on average, to 70 percent $)^{19}$ as well as lengthening their useful life to 45 years, and

4. using the most efficient generating technologies for new fossil-fuel-fired poweplants. ${ }^{20}$

We classify three of the supply-side options as Tough, that is, technically feasible but not without extra cost. The first is to regulate the mix of new plants being built with the goal of using nonfossil electricity sources whenever possible, or using natural gas rather than coal when it is not feasible or

\footnotetext{
${ }^{17}$ An Electric power Research Institute(EPRI) survey estimated that cost-effective improvements of about 4 percent were achievable (16).

${ }^{18}$ The U.S. Army Corps of Engineers (12) estimated that by adding, replacing, or modifying generating units at between 165 and 300 of the approximately 1,300 existing hydroelectric plants in the United States, output could be increased by 10 to 12 percent in a cost-effective manner.

${ }^{19}$ Nuclear plants in both Japan and Western Europe operate about 75 percent of the time (23).

${ }^{20} \mathrm{~A}$ state-of-the-art pulverized coal plant will emit 10 per-cent less $\mathrm{CO}_{2}$ than a conventional new plant. US@ cost data from EPRI (15),generating electricity from a state-of-the-art coal plant may actually be a few percent cheaper than generation costs from a new conventional plant, after fuel savings are included. A combined cycle gas turbine emits about 45 percent less $\mathrm{CO}_{2}$ than a conventional one. If used for more than infrequent peaking power, the higher capital costs are justifed by lower fuel costs.
} 


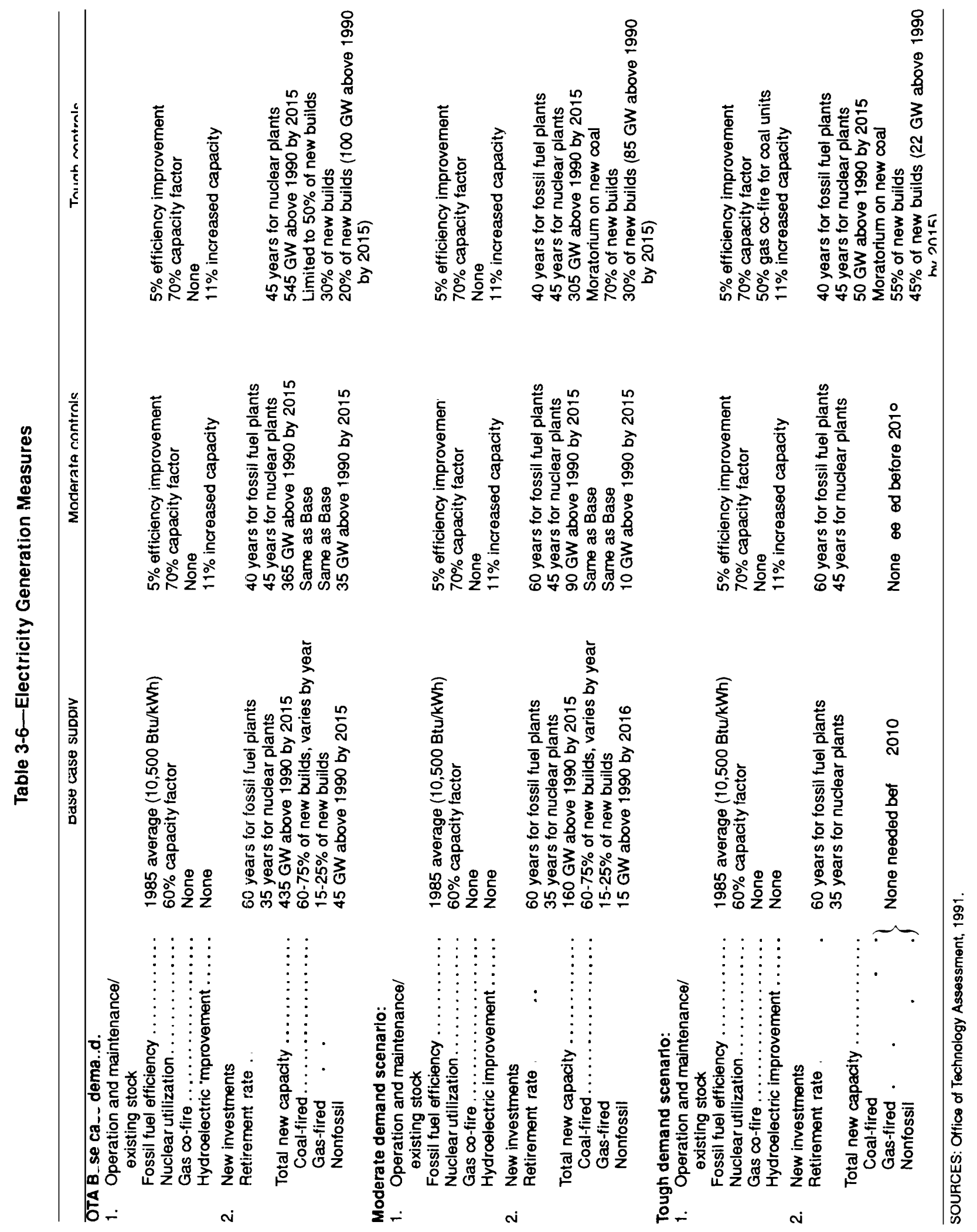


extremely costly. We assume that between 20 and 45 percent of new powerplants will use nonfossil energy sources (depending on the demand for new construction), as compared to about 10 percent in the Base case. Most utilities would likely choose renewable energy sources-primarily wind power, hydroelectric power, and biomass-rather than nuclear powerplants, However, we also assume that by 2000 new and safer designs for nuclear powerplants will be available and able to meet some of this demand within the next decade.

As a second Tough option, we force existing fossil-fuel-fired plants to retire after 40 years of operation. In the absence of new regulations, existing utility boilers will probably last between 55 and 65 years before they are retired (83). Early retirement, combined with a moratorium on replacement with coal, will remove inefficient plants and open up additional opportunities for nonfossil energy sources as well as additional gas-fired generation. Public utility commissions typically allow a utility to recover capital costs of building a new plant over a 30 -year period, Thus, if a utility is forced to retire the plant at any time after 30 years, it will have already paid off the stockholders and bondholders who paid for the plant. The additional costs incurred by early retirement and rebuilding will be paid by the ratepayers.

We assume that there are limits on the amount of electricity that can be generated from both nonfossil energy sources and natural gas. After reviewing projections by the national laboratories for DOE (47, 59) and others, we believe that $100 \mathrm{GW}$ is a reasonable estimate of the potential for nonfossil sources between 2000 and 2015 under a high demand scenario. This is equal to about half of today's total nuclear and hydroelectric capacity. We assume that under slower growth, fewer nonfossil plants are likely to be built, though the percentage of new plants using nonfossil sources will be higher. Natural gas is limited to an increase of 3 quads above the Base case-about twice today's consumption of natural gas by utilities (and about 15 percent of forecasted total gas use by 2015). Under the Moderate and Tough demand scenarios, the need for new plants is low enough that a moratorium on construction of new coal plants is possible through 2015. Under the Base case demand scenario, some new coal plants must be built.

A third Tough alternative is to use some of the additional 3 quads of natural gas to lower emissions from existing coal-fired powerplants. This can be accomplished by either gas co-firing, (i.e., simultaneously burning both gas and coal) or by switching back and forth between gas and coal intermittently (e.g., gas could be used in the summer when demand from other uses is low). Under the Base case demand scenario, we allow natural gas to substitute for up to 20 percent of coal use in existing plants. Under the Tough demand scenario, we allow natural gas to substitute for 50 percent of coal use.

\section{The Effects of Supply Changes Under the OTA Base Case Demand Scenario}

Under the OTA Base case supply and demand scenarios $\mathrm{CO}_{2}$ emissions from electricity generation are 35 percent higher than 1987 levels by 2000 and almost 100 percent higher than 1987 levels by 2015 . By 2015, $435 \mathrm{GW}$ of new electric generating capacity must be built to meet demand that is increasing at an average rate of 2.2 percent per year. ${ }^{21}$ (Current U.S. generating capacity is about $680 \mathrm{GW}$.) About 10 percent $(43 \mathrm{GW})$ of this new capacity uses nonfossil sources and thus would lead to little or no increase in $\mathrm{CO}_{2}$ emissions. About 60 to 75 percent of each year's new construction is coal-fired and 15 to 25 percent uses natural gas. The relative shares of each of the generating technologies for new construction in this Base case scenario closely follows the projections developed by GRI (29).

The Moderate supply-side measures discussed above achieve $\mathrm{CO}_{2}$ reductions of about 11 percent of 1987 levels by 2000, assuming all existing plant improvements are made by that time. By 2015, the combination of efficiency performance standards in plants built after 2000 and the effects of the nuclear

\footnotetext{
${ }^{21}$ Note that the Gas Research Institute (GRI) model used as a basis for the OTA analysis forecasts that electricity demand will increase at about 1.5 percent per year through 2010. This is about 0.5 to 1.0 percent lower than most other forecasts. The primary reason is that the GRI model uses a "bottom up' approach, that is, it forecasts the demand for electricity from current goods and services-the televisions and electric water heaters in our homes, lights in our offices, and the energy to manufacture electricity-intensive goods and materials such as chemicals and aluminum. However, just as 10 years ago a bottom up forecast would have missed the demand for electricity from personal computers and FAX machines, so too is the GRI forecast likely to miss demand from new products by 2000 . OTA has added an extra increment of demand -0.75 percent per year--on top of the GRI forecast in our base case. This results in electricity demand growing at about 2.2 percent per year, an estimate much closer in line with those forecasts that use a statistical “top down' approach to forecast demand using recent economic and energy use trends.
} 


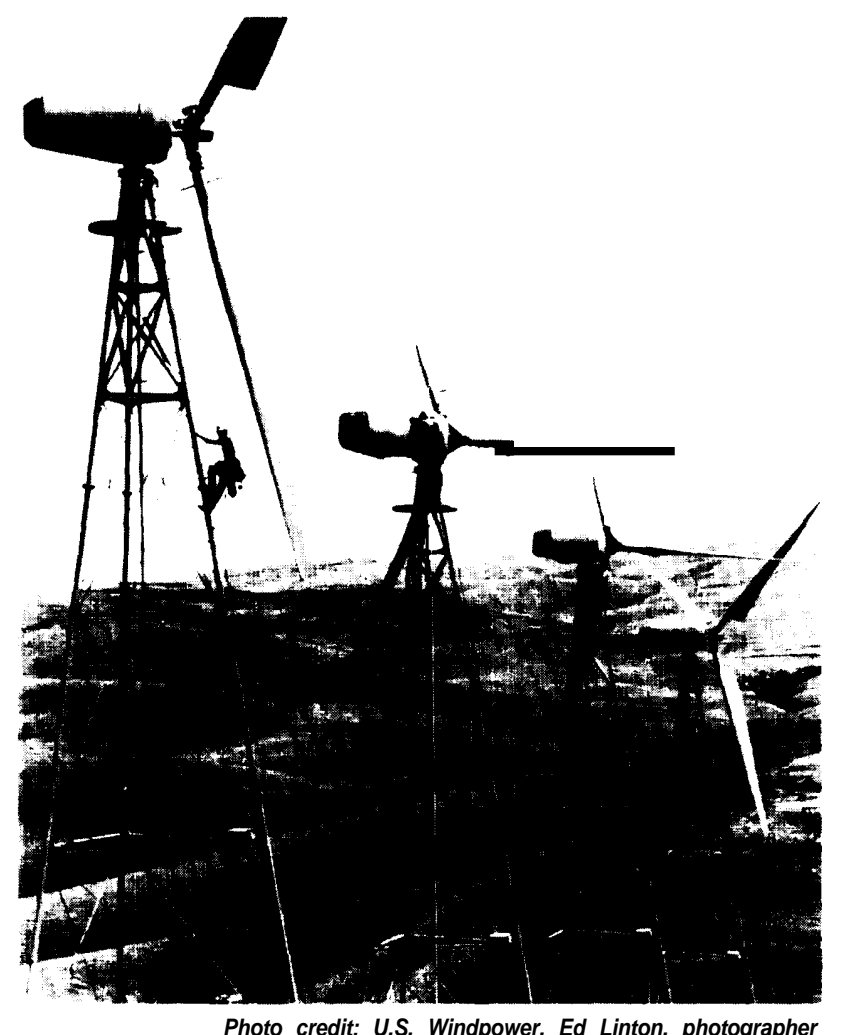

Maintenance crews performing a routine inspection of a small wind turbine.

plant life extension boost reductions to about 21 percent of 1987 levels. Thus, the Moderate measures lower emissions from about a 100 percent increase above 1987 levels in the Base case to about a 77-percent increase above 1987 levels by 2015 .

In our Tough scenario, we require all fossil fuel plants to retire after 40 years and limit the amount of construction of new coal plants to 50 percent of total new builds. About $100 \mathrm{GW}$ of nonfossil sources are built between 2000 and 2015. This amounts to about 20 percent of the new plants needed to replace retired facilities and to meet increasing demand for electricity. The Tough measures yield reductions of about 31 percent of 1987 levels by 2015. Combined with the Moderate measures, utility emissions are held to a 45-percent increase above 1987 levels by 2015 .

The Effects of Supply Changes Under the OTA Moderate Demand Scenario

Under the OTA Moderate demand case, $\mathrm{CO}_{2}$ emissions from electricity generation are about 10 percent higher than 1987 levels by 2000 and 45
Figure 3-7-- $\mathrm{CO}_{2}$ Emissions Reductions From Moderate Supply-side Measures, Expressed as a Percentage of 1987 Electricity y Emissions, Under the Moderate Demand Scenario

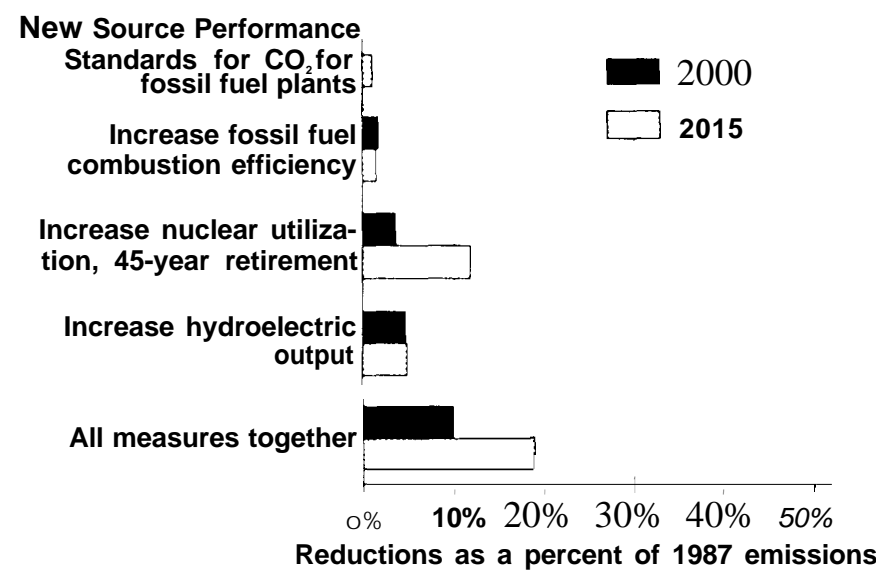

NOTE: The data presented above are the emissions reductions achievable in some future year expressed as a percentage of 1987 electricity emissions, not as a percentage dacrease in emissions below 1987 levels.

SOURCE: Office of Technology Asessment, 1991.

percent higher than 1987 levels by 2015. Emissions are lower than under the Base case demand scenario, reflecting a relatively lower consumption of electricity and a greatly reduced need for new generating capacity ( 35 percent of requirements under the base case demand scenario). Nevertheless, by 2015,160 GW of new electric generating capacity must be built to meet increasing demand. Similar to the Base case demand scenario, we assume that most of the new capacity would be fossil-fuel-fired, with about 60 to 75 percent of each year's new construction using coal and 15 to 25 percent using natural gas. About 10 percent of new plants use nonfossil energy sources.

By implementing our Moderate supply-side measures, additional reductions equal to about 10 percent of 1987 levels can be achieved by 2000. Almost half of the additional reductions comes from improving the efficiency of existing fossil-fuel-fired plants, one-third from increased utilization at nuclear powerplants and the remainder from improvements at existing hydroelectric facilities (see figure 3-7).

By 2015, the Moderate supply-side measures achieve reductions equal to about 19 percent of 1987 levels. Most of the additional improvement comes from extending the lifetimes of nuclear powerplants 


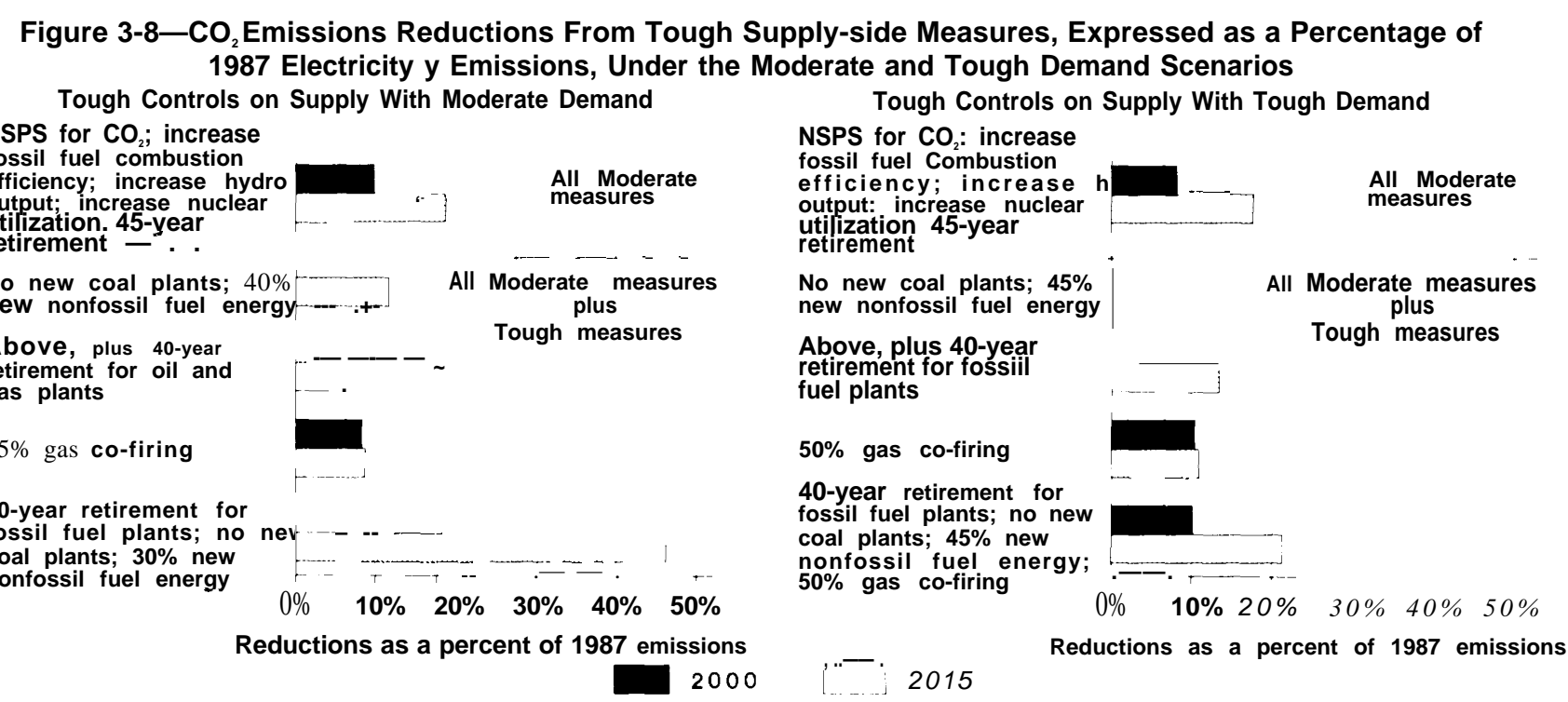

NOTE: The data presented above are the emissions reductions achievable in some future year expressed as a percentage of 1987 electricity emissions, not as a percentage decrease in emissions below 1987 levels.

SOURCE: Office of Technology Assessment, 1991,

thereby avoiding replacement with coal-fired ones. Efficiency performance standards for new coal- and gas-fired powerplants have only a modest effect (see figure 3-7), in part because the need for new construction is already much reduced under this scenario. The combination of Moderate demand measures and Moderate supply-side measures holds utility emissions to about a 25-percent increase above 1987 levels by 2015 (as compared to a 100 percent increase under Base case supply and demand).

Again, we considered Tough supply-side options that are technically feasible but not without extra cost. A series of Tough options together can achieve reductions equal to about 45 percent of 1987 emissions by 2015 (see figure 3-8). These measures include, first, accelerating the replacement of older, higher emitting facilities by requiring all fossil fuel plants to retire after 40 years of operation. Next, we regulate the mix of new plants being built with the goal of building nonfossil sources whenever possible. When it is not feasible or extremely costly, natural gas is chosen for fuel (i.e., we impose a moratorium on the construction of new coal-fired power-plants from 2000 through 2015). About 30 percent of new electricity demand is met by nonfossil sources ( $85 \mathrm{GW}$ between 2000 and 2015).
Figure 3-8 also illustrates the relative importance of each of these and other Tough measures one at a time. Changing the mix of new plants (i.e., no coal, 40 percent nonfossil sources, and the remainder natural gas) achieves reductions equal to about 12 percent of 1987 levels by 2015. Forcing oil and natural gas plants to retire after 40 years (and replacing them with the mix of new plants listed above) achieves another 9 percent reduction. Cofiring existing coal plants with 25 percent natural gas can achieve another 8 to 9 percent reduction. Note that this last option is the only one of the Tough supply-side measures that can achieve significant reductions by 2000 .

The combination of Moderate demand, Moderate supply-side measures, and all Tough supply-side measures except natural gas co-firing lowers utility $\mathrm{CO}_{2}$ emissions to about 20 percent below 1987 levels by 2015. Demand for electricity under this scenario is too great to allow both natural gas co-firing and 40-year retirement of all fossil fuel sources, and hold the increased demand for natural gas to below 3 quads.

The Effects of Supply Changes Under the OTA Tough Demand Scenario

Under the Tough demand scenario, with no additional supply-side measures, emissions drop to 10 percent below 1987 levels due to lowered demand alone. No new plants are needed before 2010. Thus, 
supply-side measures that apply to existing facilities (i.e., efficiency improvements and gas co-firing) can still lower emissions, but measures relevant to new plants have no effect unless existing plants are retired early. The effect of' the Moderate supply-side measures is about the same under this scenario as under the other two. All Moderate measures together achieve reductions equal to about 8 percent of 1987 levels by 2000 and 18 percent by 2015 (see figure 3-8).

By adopting a package of Tough supply-side measures, additional reductions of 10 percent of 1987 levels by 2000 and 21 percent by 2015 are possible. These measures include: co-fining of all existing coal-fired plants with 50 percent natural gas, forced retirement of all fossil fuel plants after 40 years of operation, and altering the mix of new plants to 45 percent nonfossil sources and the remainder gas-fired. All of the reductions in 2000 come from co-firing existing units (see figure 3-8). By 2015, somewhat over half of the Tough measure reductions come from the combination of early retirement of fossil sources and their replacement with new nonfossil and natural gas-fried plants.

The combination of Tough demand measures and all Moderate and Tough supply-side measures lowers utility $\mathrm{CO}_{2}$ emissions to about 50 percent below 1987 levels by 2015 .

Summary of Emissions Reductions From the OTA Electricity Supply Scenarios

Figure 3-9 summarizes the aggregated effects of the Moderate supply-side measures (under the Base case and Moderate demand scenarios) and Tough supply-side measures (under the Moderate and Tough demand scenarios) through 2015. Note that under the two scenarios with Moderate supply-side measures, emissions continue to rise after 2000, though at a slower rate than under the Base case. Under the scenarios with Tough supply-side measures, emissions drop to 1987 levels or below by 2000 and continue to decline through 2015.

Figure 3-10 displays fuel consumed by electric utilities under the Base case and several scenarios by 2015. Under the Base case, coal use grows from about 55 percent of total fuel use to about 65 percent. Under the scenario of Moderate supply-side measures and Moderate demand for electricity, the mix of
Figure 3-9-- $\mathrm{CO}_{2}$ Emissions From Electricity Generation Under the Base Case and Selected Control Scenarios, By Year

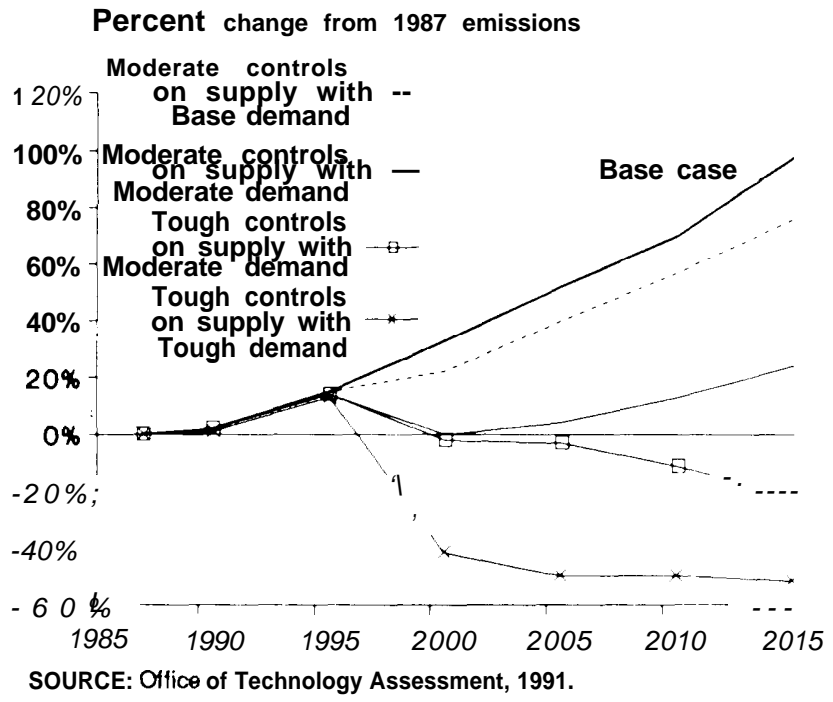

fuels remains quite similar to today's mix, but the total increases about 25 percent above 1987 levels. Under both scenarios with Tough supply-side controls, coal use falls to about 25 percent of the total and the share of nonfossil sources rises to about 50 percent.

\section{Costs of the Tough Electricity Supply Scenario}

We estimate that the Tough electricity supply-side scenario will cost about $\$ 35$ billion per year (1987 dollars) by the year 2015, assuming it is implemented along with all Tough demand measures. This is the cost of the Tough supply-side measures alone and does not include the costs of lowering electricity demand. (These are presented in chs. 4 through 6.)

About half of the costs come from co-firing existing coal plants with natural gas. By 2015, natural gas is forecasted to cost over three times more than coal on an energy equivalent basis. The remaining costs come from forcing existing fossil-fuelfired plants to retire after 40 years of operation and replacing them with natural gas and nonfossil sources. Forcing the coal plants to retire early and replacing them with highly efficient natural gasfired combined cycle turbines could increase electricity costs at affected plants by $\$ 0.04$ to $\$ 0.05$ per 
Figure 3-10-Fuel Use By Electric Utilities In 2015 Under the Base-Case and Selected Control Scenarios, By Year

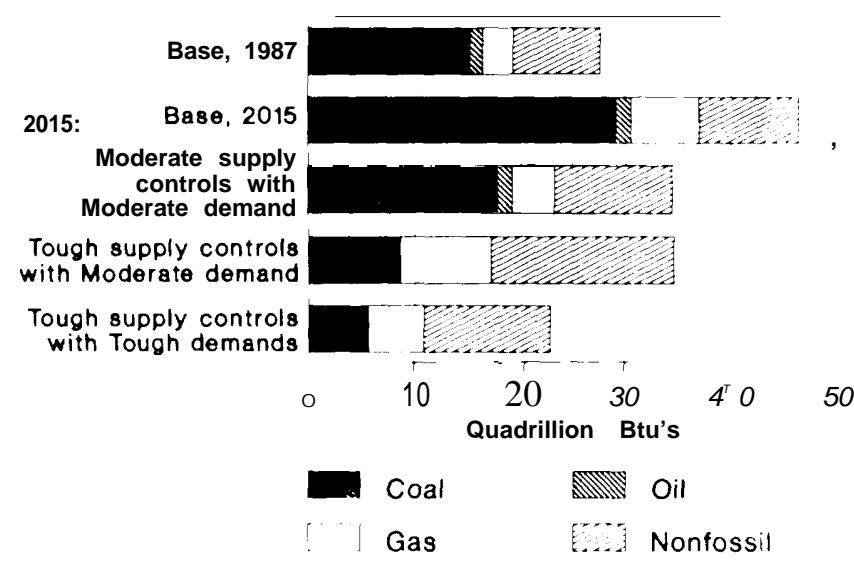

SOURCE: Office of Technology Assessment, 1991

$\mathrm{kWh} .{ }^{22}$ However, forcing existing oil and natural gas plants to retire early saves money-about $\$ 0.01$ to $\$ 0.02$ per kwh-because the replacement facilities are so much more efficient. We have assumed that the cost of electricity from nonfossil sources (either renewable sources or nuclear power) will be comparable to natural gas-fired combined cycle turbines.

The cost effectiveness of early retirement of existing fossil-fuel-fired sources and replacement with natural gas and nonfossil sources is about $\$ 280$ per ton of carbon eliminated. The cost effectiveness of co-firing existing coal plants with natural gas is about $\$ 510$ per ton of carbon.

\section{POLICY OPTIONS}

A variety of policy options can be used to implement the technical options to lower greenhouse gas emissions. Overarching approaches include: 1) energy and emissions taxes and tax incentives, 2) marketable emission permits, and 3) research and development on lower emitting technologies. Many of these themes will be addressed again in chapters on individual emission sources (see chs. 4 through 6). Broad approaches such as energy and carbon taxes or marketable emission permits have the advantage of affecting all emitters simultaneously, but their effects are extremely difficult to predict. They can be adopted alone or in concert with source-specific options (e.g., appliance or automobile efficiency standards).

Options specific to the energy industries include: 1) ways to lower emissions associated with the extraction and delivery of fossils fuels, and 2) options for controlling the amount of $\mathrm{CO}_{2}$ emitted per kilowatt-hour of electricity generated. Sectorspecific options for lowering the demand for energy are discussed in chapters 4 through 6 .

\section{Energy Taxes and Tax Incentives}

Congress could impose direct financial burdens (or benefits) on energy to curtail the use of energy sources that are major contributors of greenhouse gases. Two options that have been proposed are a general energy tax and a carbon tax. Whereas a general energy tax might be based on, say, the Btu content of energy sources, a carbon tax would be calculated on carbon emissions. Under such a formula, the tax would be highest on coal, low for natural gas, and zero for noncarbon sources. ${ }^{23}$ The carbon tax is a particularly effective way of levying the heaviest economic sanctions against the worst emitters of $\mathrm{CO}_{2}$. Either type of tax would lower energy users' overall demand. A carbon tax would also change the mix of energy sources in the economy. It would stimulate greater demand for natural gas relative to other fossil fuels. That, in turn, most certainly would drive natural gas prospecting and resource recovery technology development. It could also provide added motivation to develop more noncarbon energy sources and more quickly bring on line existing low-carbon technologies such as natural gas-fired combined cycle turbines.

Using several econometric models, the Congresssional Budget Office (CBO) estimated that a carbon tax of $\$ 100$ per ton would, at minimum, hold $\mathrm{CO}_{2}$ emissions to just about current levels and might lower them as much as 25 percent below current

\footnotetext{
${ }^{22}$ Note, however, that this estimate is very sensitive to forecasted natural gas prices. The increase would be about $\$ 0.03$ to $\$ 0.04$ per $\mathbf{k W h}$ assuming 2010 prices. Note also, that once these existing facilities retire, costsınust be compared to replacement coal plants. Electricity costs from ncw coal-find powerplants would be about $\$ 0,02$ per $\mathbf{k W h}$ less than electricity from natural gas-fired combined cycle turbines assuming our 2015 prices and about $\$ 0.01$ per kWh less assuming 2010 prices,

${ }^{23}$ Congress would have to decide whether to tax biomass fuels. Though biomass fuels emit carbon, if fuels are used on a sustainable basis, the carbon emitted will be recaptured over the next few decades, Ideally, fuels grown sustainably would be exempt from a tax but those harvested with no provisions for replanting would be taxed at a rate similar to coal, In practice, this would be extremely difficult.
} 
levels by 2000 (66a). By the end of the first decade, the Gross National Product (GNP) would be lowered by about 0.5 to 2.0 percent (about $\$ 40$ to $\$ 130$ billion per year), though the GNP effects over the first few years of a suddenly instituted policy could be 5 percent or more.

CBO looked at two different economic models that forecast energy use past 2000, one used by the Environmental Protection Agency (EPA) and the other by the Electric Power Research Institute (EPRI). Although they widely diverge by 2100 , primarily due to assumptions about Base case growth, at 2015 they are reasonably similar to each other and to our own base case and thus offer a useful comparison of reductions and costs. The EPA model forecasts that holding emissions to 10 to 15 percent below current levels would lower GNP by about 1 to 1.3 percent by the year 2015. The EPRI model forecasts that holding emissions to 20 percent below current levels would lower GNP by about 3 percent by that year.

Congress might also choose to adopt a modified carbon tax that reflects methane emissions in addition to emissions of $\mathrm{CO}_{2}$. Such a tax would still favor natural gas, but not quite as much as when methane emissions are ignored.

Oil and gas producers presently benefit from tax incentives (e.g., through write-offs of intangible drilling costs and a depletion allowance for small producers). During the 1970s the depletion allowance was eliminated for large producers and significantly reduced for small producers. New tax incentives could be structured such that taxes decrease as carbon content decreases. This would help make natural gas (the lowest carbon-emitting fossil fuel) more economically competitive, stimulate the search for new sources, and spur development of techniques for producing unconventional gas. Thus, an appropriately crafted package of tax incentives focused on natural gas would increase its role in the U.S. energy system. If gas replaced some coal and oil, $\mathrm{CO}_{2}$ emissions would also be reduced. The primary difficulty with tax incentives is that as the price of natural gas is reduced, the incentives for its efficient use also decrease.

Tax incentives could also be used to encourage electric utilities to use high-efficiency gas turbines. Turbines historically have had shorter life spans than conventional plants. A tax incentive program based on efficiency could reduce the overall cost of using the most efficient turbines. Similarly, cogeneration activities could be made more attractive with tax incentives.

\section{Marketable Permits}

Another market mechanism that can be used to control $\mathrm{CO}_{2}$ emissions is the marketable emission permit, an approach recently applied to control use of CFCs and to limit emissions of sulfur dioxide to control acid rain.

This regulatory mechanism, like carbon taxes, is simple in theory. The government issues a limited number of permits to energy users allowing a certain level of carbon emissions. More permits would be needed to burn coal than natural gas to produce the same amount of energy, Permits can be bought and sold on the open market.

As the economy expands and the demand for energy rises, the price of a carbon permit will rise to reflect the cost of holding emissions at a level fixed by policymakers. Holders of permits will find ways to lower emissions (e.g., purchase more efficient equipment, switch from coal to natural gas, etc.) so that they can sell their permits (at a profit) to others. In theory, the effective price of fossil fuels (the cost of the fuel plus the cost of the emission permit) will rise just high enough to meet the allowed carbon emission target. Just how high prices will rise, however, is difficult to forecast.

With a carbon tax, the increased cost of fossil fuels brings about similar results (more efficient equipment and fuel switching), but the exact level of emissions is difficult to predict. Theoretically, the two approaches should yield the same result. If a carbon tax of $\$ 100$ per ton can lower emissions to 10 percent below current levels by the year 2000, issuing marketable permits equivalent to emissions 10 percent below current levels should result in the price of permits rising to $\$ 100$ per ton. Taxes allow more certain control over price. Permits offer more certain control over emissions.

Marketable permits can be required for all fossil fuel users or only large users such as utilities, factories, and even large commercial installations. For some uses (e.g., gasoline) regulations can be written so that permits are required for wholesalers, rather than individual end users (i.e., drivers). 
A marketable permit system that applies to utilities is discussed below (see "Improving Electricity Supply").

\section{Increase Research Development and Demonstration Efforts}

Over the last decade, Federal funding for renewable energy research development and demonstration (RD\&D) has fallen rapidly (see figure 3-1 1). Expressed in constant dollars, the 1990 combined energy technology RD\&D budgets were less than half of what they were in 1980. Several recent studies have suggested that for a comparatively small increase in investment, the Federal Government could significantly hasten the development and deployment of technologies that would reduce greenhouse gas emissions. A study by the Oak Ridge National Laboratory (ORNL) (47) recommends that the government and major energy industry research groups-namely the Electric Power Research Institute and the Gas Research Institute-increase spending levels by about a third over 1988 combined RD\&D budgets (to a level that is still below the 1980 combined budgets). Improved energy efficiency and nuclear power are considered the two most promising $\mathrm{RD} \& \mathrm{D}$ approaches to achieving major reductions in $\mathrm{CO}_{2}$ emissions.

The Solar Energy Research Institute (SERI) reached somewhat different conclusions about where to spend the money. In a 1990 report (59), SERI focused strictly on nonnuclear, nonfossil energy sources. Nevertheless, it came to many of the same conclusions as ORNL about how much energy nonfossil-fuel sources could be contributing to the U.S. economy over the next 20 to 40 years. In the SERI Business-as-Usual scenario, nonfossil sources contribute 15 percent of U.S. energy supply in 2030. ORNL's "Base Case" projected a 5 percent contribution by 2020. In SERI's "Intensified R\&D" scenario, the nonfossil contribution in 2030 is about 30 percent. In the "High Efficiency' scenario for ORNL, that figure is about 35 percent.

At the very least, increased governmental RD\&D activity could result in some reduction in greenhouse gas emissions if some of the fossil fuel conversion technologies now in testing phases could be brought on line sooner. The development of a commercial fuel cell, could for example, lower $\mathrm{CO}_{2}$ emissions per unit of energy from electricity generation. In addition, even if the role of nuclear power in the
Figure 3-1 1-US. Energy Technology Research and Development Budgets, 1978-88

71

1990 dollars (billions)

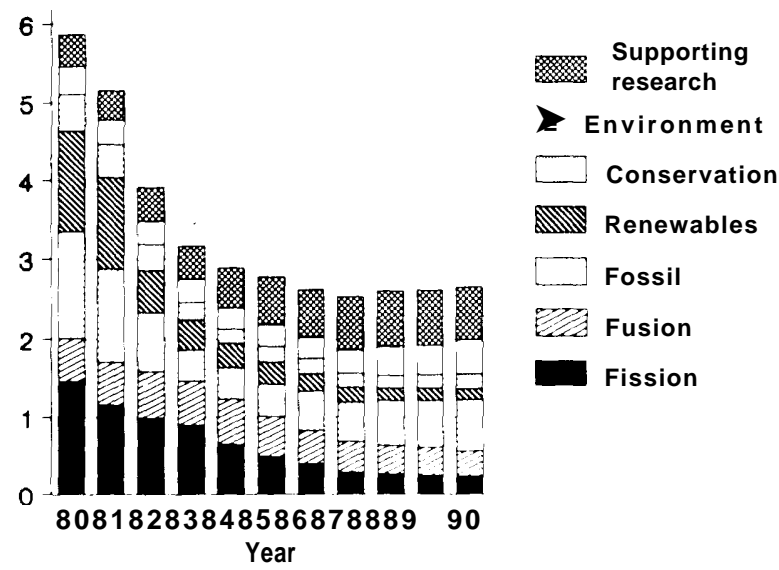

Funding for energy research in the United States has declined sharply since 1980 . The bars represent Federal budget authority for research, development and technology demonstrations, in 1990 dollars. "Supporting" refers to research in basic energy sciences.

SOURCE: J.P. Holdren, "Energy in Transition," Scientific American, September 1990, pp. 157-163.

energy supply system is to continue at a modest level, research into better designs, waste disposal, and related issues will have to continue. Of particular interest is the development and prototyping of advanced reactors with 'passively safe' features.

Renewable energy sources face a host of technical and institutional barriers that increased R\&D support could help overcome. In addition to supporting efforts to develop some of the more promising technologies (e.g., storage technologies for solarelectricity, biomass-driven turbines, and variablespeed wind turbines), government actions could reduce the risk of new technologies and help integrate renewable in existing energy systems. The former could be achieved with demonstration projects or, perhaps, government-backed loans. Both SERI and ORNL concluded that the Federal budget in this area was only about half of what it should be.

Increased resource characterization could also help reduce $\mathrm{CO}_{2}$ emissions. For wind, geothermal, solar, and natural gas to play a bigger role in meeting global energy needs, it is vital to improve prospecting techniques and expand what is known about these resources' potential. In some instances, increased demand for an energy source or a properly 


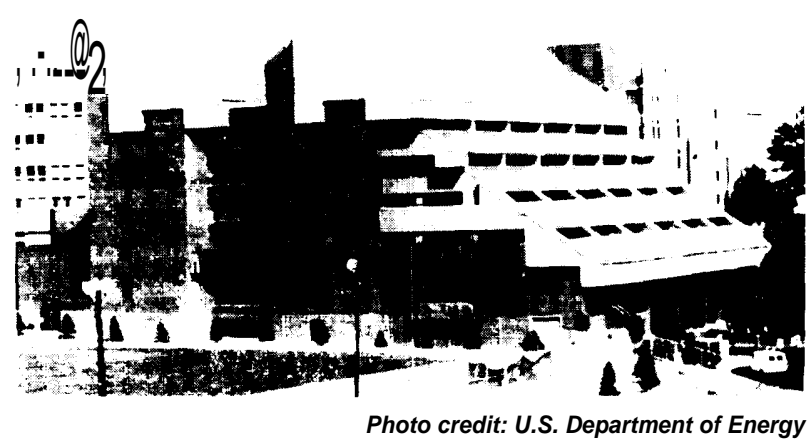

The south-facing roof of Georgetown University's Intercultural Center supports a $\mathbf{3 0 0}$ kilowatt photovoltaic power system, the largest roof-mounted photovoltaic system in the world consisting of over 4,400 PV modules. Electricity generated by the roof is channeled into the local power grid.

designed tax structure will provide an adequate incentive for the private sector to undertake prospecting on its own. In other cases, however, market forces alone may not provide enough incentive. It could be difflcult to keep information on, for example, wind or geothermal resources proprietary. The financial commitment necessary for extensive exploration might be prohibitive. The government could perform, subsidize, and provide regulatory incentives for resource assessment.

If natural gas is to play a significant role in $\mathrm{CO}_{2}$ emission reductions, it is important to find ways of retrieving " unconventional' gas reserves, geologic reservoirs that hold significant amounts of the resource but are difficult to exploit for one reason or another. Accelerated development of leak-resistant transportation systems could also be encouraged.

\section{Plugging the Leaks in the Existing System}

The present energy supply system could be tightened to reduce energy and methane losses. As noted earlier, significant electricity losses occur during transmission and distribution. Better information is needed on the extent and nature of these losses worldwide, particularly in non-OECD countries. Assistance in the form of money, equipment, or expertise could help reduce losses in these countries.

Some fossil fuel is lost during geologic extraction and transport to the end user. Leaked gas is of particular concern because of its contribution (of methane) to the greenhouse effect. Several actions could help reduce the amount of emissions from natural gas extraction and delivery, oil extraction, and coal mining. Regulations against venting gas in the United States have effectively limited the release of' methane to the atmosphere in this country. The U.S. rate is about 0.5 percent of annual production of natural gas (83). The United States could encourage other nations to follow suit. The United States also has a well-developed infrastructure to transport and sell gas with little leakage. Development aid to other nations (see ch. 9) could support their construction of the requisite infrastructure. The United States could also export the technology and 'know-how' to deal with unwanted gas without releasing it to the atmosphere. Such techniques, like the reinfection of gas into oil wells, have been developed here in association with production in remote locations, most notably Alaska (83).

Improved data is needed on methane emissions through leakage, particularly in non-OECD countries. Better and more meters to track gas distribution, along with improved monitoring practices, could provide information crucial to formulating response strategies for all sectors using natural gas in these countries. Finally, incentives are needed (both financial and regulatory) for the development of technology to capture coal seam methane.

\section{Improving Electricity Supply: Meeting Demand With Lower CO,Emissions}

Emissions of $\mathrm{CO}_{2}$ from utilities can be lowered in two ways: by reducing demand for electricity, and by changing supply characteristics to lower the rate of emissions (i.e., pounds of $\mathrm{CO}_{2}$ per kilowatt of electricity generated). This section focuses exclusively on the latter approach, presenting policy options for encouraging more efficient use of current powerplants, use of fuels with inherently lower $\mathrm{CO}_{2}$ emissions, and use of nonfossil energy sources. Demand-side management programs are discussed briefly in box 3-C and in greater detail in chapter 4 .

We present options designed for existing plants and for those not yet built, as well as a set of overall policies that affect all plants.

\section{Measures That Apply to Existing Plants}

Earlier we presented three "Moderate" technical options that can lower $\mathrm{CO}_{2}$ emissions from existing plants at little or no additional cost when averaged over the life of the program. These include: 


\section{Box 3-C--Electric Utility Demand-Side Management Programs}

Utility planners are already beginning to look at ways to encourage the adoption of energy conservation measures among residential, commercial, and industrial ratepayers as a way to reduce the need to build expensive new powerplants. Conservation and other measures are part of a larger concept known as demand-side management (DSM). In addition to encouraging energy conservation, DSM programs also include "load management" options such as alternative rate structures to change the timing of eletricity use and measures to reduce excessive demand during peak hours (e.g., hot summertime afternoons).

Electric utilities conduct DSM programs in various ways (27b):

. information dissemination (e.g., mass media attachments to electric bills);

- onsite energy audits and technical assistance;

- financial incentives (e.g., rebates, low-interest loans, and rate discounts);

- direct installation (e.g., low-flow showerheads, water heater wraps); and

- cooperation with trade allies (e.g., manufacturers and dealers, architects, engineers, builders).

\section{Utility Conservation Case Study: The Northwest Power Planning Council 1990 Power Plan}

The Northwest Power Planning Council' (NPPC) is an interstate compact agency approved by Congress that reviews the activities of the Bonneville Power Administration, the Federal power marketing agency in the Pacific Northwest. Recently the NPCC proposed a series of cost-effective conservation measures to reduce electricity demand by 8 percent in the region by 2010, compared to forecasted levels (46a). These measures will eliminate the need for six new coal-fired powerplants, at roughly half the cost.

Residential measures include those that lower space heating demands in new and existing homes (e.g., improved insulation, storm windows, reduced air leakage); more efficient water heating (e.g., insulated water heaters, pipe wraps); and more efficient refrigerators, freezers and other appliances. The measures proposed by the NPCC can reduce electricity demand in the residential sector by about 10 percent by 2010 . Well over half is from measures to lower space heating demands.

In the commercial building sector, the NPCC has proposed conservation memsures targeting lighting, space heating, and cooling that can reduce commercial electricity use by about 13 percent by 2010 . Measures that can be retrofit in existing buildings are responsible for the majority of these reductions.

For the industrial sector, the NPCC has identified such conservation measures as improved motors, motor controls, and lighting that can lower electricity demand in this sector by 3 percent by 2010. The NPCC has proposed conservation measures that apply to agricultural irrigation that can reduce electricity use by about 12 percent (46a).

1 In accordance with the Pacific Northwest Electric Power Planning and Conservation Act (Public Law 9\&501), the four Northwest States of Idaho, Montana, Oregon, and Washington entered into an interstate compact in 1981. The Act required the NPPC to develop and adopt a $2 \& y e a r$ electrical power plan and a program to protect, mitigate, and enhance f@ and wildlife resources in the region.

1. improving the efficiency of fossil-fuel-freed plants through improved maintenance,

2 . increasing the use of existing nuclear powerplants not currently operating at full capacity, and

3. renovating existing hydroelectric generating facilities to increase their output.

A fourth "Tough" option is to change the fuel mix at existing plants.

Improved Operation--Overseeing the operation of utilities is, in general, the responsibility of the States. Theoretically, utilities should already be operating their powerplants at optimal efficiency so as to provide electricity to their consumers at the lowest cost. State public utility commissions (PUCs) have the authority to regulate retail electricity rates, and thus have considerable influence over utility operations. In practice, however, a few percent gain in efficiency is not a top priority for many utilities or States, nor are efficiencies routinely monitored.

Recently, however, some industry attention has been given to methods for improving efficiencies (15). The Electric Power Research Institute (EPRI) has a multi-year research program underway on methods to lower electricity costs through efficiency improvements. The Federal Government could participate in this effort as well. In addition to DOEfunded research, TVA and the Federal power agencies (e.g., Bonneville Power Authority) could undertake improvements at their own facilities. About 4 
percent of the electricity generated from fossil fuels comes from these Federal facilities (14).

The Federal Government, through the Federal Energy Regulatory Commission (FERC) has some, albeit indirect, ability to influence private utility operations through its authority over prices and conditions of wholesale power sales. Virtually all generating utilities sell power to other utilities at some point. If Congress feels that State PUCs are not identifying and enforcing efficiency improvements, it could direct FERC to include such considerations when regulating wholesale power sales.

For nuclear powerplants, the relevant goal is to increase the number of hours of operation, rather than efficiency of fuel use. The most promising option here is to establish a demonstration program to increase utilization from the current 65 percent $(5,700$ hours per year) to 75 percent $(6,600$ hours per year). In 1975, Japanese nuclear plants operated about 50 percent of the time. A 7-year improvement and upgrade program increased utilization to 75 percent (23), Western Europe averages 75 percent, as well. A coordinated demonstration program by DOE and the Nuclear Regulatory Commission might foster improvements to boost U.S. hours of operation above the average in a timely fashion. Key improvements would include preventive maintenance; installation of automated controls to improve reactor operation, thereby reducing the number of unscheduled shutdowns; and speedier refueling.

Switching to Lower Emitting Fuels-in addition to efficiency improvements, $\mathrm{CO}_{2}$ emission rates from existing fossil-fuel-fired utilities can be lowered by switching to lower emitting fuels, For example, a typical Midwestern powerplant burning Illinois coal emits about 0.60 pounds of carbon per $\mathrm{kWh}$ of electricity generated (lbs $\mathrm{C} / \mathrm{kWh}$ ). By burning a mixture of 75 percent coal and 25 percent natural gas (or burning coal 9 months and gas 3 months per year) emissions will be lowered by 10 to 15 percent.

Such a goal can be achieved in several ways. A high enough carbon tax (discussed above) would encourage natural gas use by utilities. However, the effect of such a policy would depend on the relative price of coal and gas at each location. A carbon tax in the range of $\$ 75$ to $\$ 150$ per ton would make gas a more economic choice at many facilities, at least over the next decade. ${ }^{24}$ If the tax were much lower, few utilities would find natural gas attractive; if it were much higher, demand for gas could be so great that prices would rise sharply.

A much more certain outcome would result from setting $\mathrm{Co}_{2}$ emission limits. An emission rate limit of $0.55 \mathrm{lbs} \mathrm{C} / \mathrm{kWh}$ would require atypical Midwestern coal plant burning Illinois coal to burn about 10 to 30 percent natural gas, depending on its efficiency. Plants burning western coals, for example from the Powder River basin, or Texas lignite might have to burn between 25 and 45 percent gas to meet this limit. Some efficient plants burning high-heatvalue eastern and western coals might meet the standard with only a few to 10 percent natural gas, but almost all existing facilities would need to burn some gas to continue operation. At $0.55 \mathrm{lbs} \mathrm{C} / \mathrm{kWh}$, the most efficient new coal-burning technologies would just qualify (e.g., integrated coal gasification, combined cycle, or IGCC) by burning coal alone.

Because some facilities will have difficulty getting natural gas or converting their boilers to use gas, a marketable permit approach might be preferable. Utilities would receive permits for the amount of $\mathrm{CO}_{2}$ that they are allowed to emit from their coal-fired units; permits could be traded on the open market. Utilities would receive such permits based on their generation in an historic year (e.g., 1990) multiplied by an allowed emission rate $(0.55 \mathrm{lbs}$ $\mathrm{C} / \mathrm{kWh}$, using the example above). Some utilities would curtail coal use more than necessary to meet their limits and others less, but the overall impact on $\mathrm{CO}_{2}$ emissions would be the same as setting uniform emission limits.

A variant on the above approach is to simply issue permits for a limited amount of coal use in existing facilities. Such an approach would be simpler to administer than emission permits, but does not give credit to more efficient coal plants or to lower $\mathrm{CO}_{2}$-emmitting coals.

\section{Measures That Apply to New Plants}

Controlling Emission Rates FromNewFossil-FuelFired Plants-Many of the policy options available to control emission rates from new fossil-fuel-fired plants are similar to those for existing plants, but greater opportunity exists for more stringent control. Earlier, we discussed three electricity demand sce-

'A carbon tax of $\$ 75$ to $\$ 150$ per ton would approximately double or triple coal prices and increase natural gas prices by over 50 percent. 
narios, a Base case and two lower demand scenarios, that assume "Moderate" and "Tough" conservation measures, respectively. Under the Base case scenario, we estimated that at least some new coal plants would have to be built (between 25 and 50 percent of all new plants) to meet demand. Under the two lower demand scenarios, we estimate that natural gas and renewable sources of energy are plentiful enough to meet demand through 2015, without the need for new coal plants. The choice of appropriate policy options will depend on whether the goal is to slow the rate of growth of new coal plant construction or to impose a temporary moratorium on new coal plants through 2015 to allow time to develop more efficient technologies. Under all of our scenarios, however, some fossil fuel sources will be needed to meet demand.

To limit construction of new coal plants a predetermined number of coal permits (or carbon permits specific to coal plants) could be auctioned each year to the highest bidder. If such a policy were adopted in combination with marketable permits for existing coal plants, permits could be freely traded among new and existing facilities.

Adoption of stringent $\mathrm{CO}_{2}$ emission limits for new plants is one way of imposing a temporary moratorium on new coal plants. Two somewhat different strategies could be pursued. If the intent is to force development of ultra-efficient coal technologies, then a standard in the range of 0.35 to $0.40 \mathrm{lb}$ $\mathrm{C} / \mathrm{kWh}$ would be appropriate. Molten carbonate fuel cells, if successful, might be able to meet such emission rates using bituminous coals.

However, such a new source performance standard would do little to encourage improvement of other fuel technologies. Current combined cycle turbines burning distillate oil can meet such a standard, and similar technologies burning natural gas emit about $0.26 \mathrm{lb} \mathrm{C} / \mathrm{kWh}$. If the intent is to limit new fossil-fuel-fired generation to the cleanest sources only-advanced combined cycle turbines burning gas - then setting a new source performance standard at about $0.25 \mathrm{lb} \mathrm{C} / \mathrm{kWh}$ would be more appropriate.

Measures To Encourage Use of Nonfossil Fuel Sources-Any of the general financial options discussed above, such as a carbon tax or fossil fuel energy tax, will serve to encourage use of nonfossil sources for electricity generation. The Solar Energy Research Institute and the National Laboratories

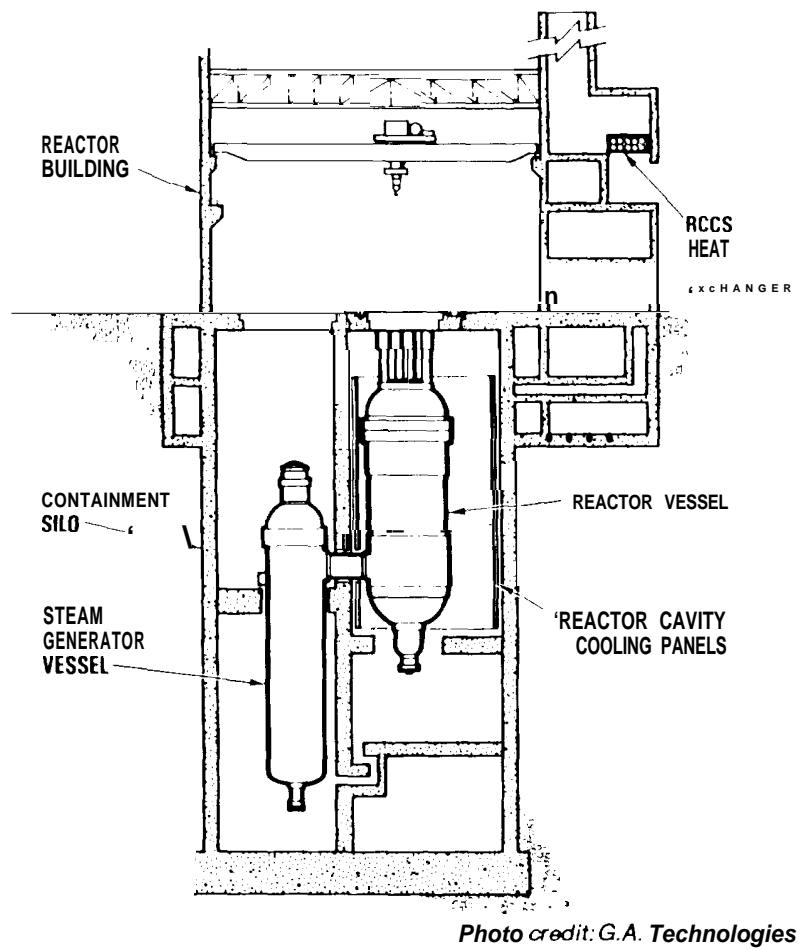

Diagram of the Modular High Temperature Gas Reactor (MHTGR), one of several new nuclear reactors designed to be "passively safe." In the event of loss of coolant, fuel temperatures increase slowly enough to allow heat to be conducted to the surrounding earth, thereby avoiding massive failure and release of radiation.

recently evaluated the effect of a 2 -cent/kWh subsidy for renewable sources of electricity (an increase of 25 to 30 percent over the base case cost for electricity) (59). They concluded that such a subsidy (or, conversely, a tax on fossil fuel) would double the penetration of renewable sources of electricity by 2010 as compared to a business-as-usual case and allow these sources to cost-effectively meet 40 percent of the new demand for electricity. Hydroelectric power, wind power, and biomass provide the bulk of the energy. A 2 -cent $/ \mathrm{kWh}$ subsidy is equivalent to a carbon tax of $\$ 75$ per ton of carbon for coal and about $\$ 150$ per ton of carbon for natural gas.

Although nuclear power might benefit somewhat from a carbon tax, the utility industry is unwilling to undertake construction under the current social and regulatory climate. New technologies are needed for a revival of nuclear power in this country, but utilities are not likely to order these technologies until they have been demonstrated in full-scale operation. Given the shape that the nuclear industry 
is currently in, the pace of such demonstrations is likely to be slow (if they happen at all). Appropriating funds to demonstrate new technologies is a promising way of giving nuclear power another chance at success.

A two-track program would offer the greatest flexibility. DOE could help fund full-scale demonstrations of both new ' "evolutionary' light water reactors (LWR) and 'revolutionary design changes such as a modular high temperature gas reactor (MHTGR). Demonstrations of the new technologies that started operation by 2000 , if successful, might conceivably result in additional units on line by 2010. Evolutionary designs might be able to come on line more quickly than revolutionary ones, especially if one of the goals of the program is to develop standardized designs to minimize licensing time (68).

As noted earlier, research, development, and demonstration funds are needed to increase the role of renewable sources as well. SERI has estimated that if current funding for renewable research were increased to about \$270 million per year (about two and a half times current levels), the penetration of renewable sources of electricity might double by the 2010-to-2020 timeframe (59). This has about the same effect as a 2-cent/kWh subsidy. The SERI forecast may overestimate the effectiveness of accelerated research in lowering the cost of renewable technologies, but it is clear that research and demonstration will help, particularly with respect to geothermal and wind sources.

Measures To Hasten the Rate of Retirement of Existing Facilities-Under the Base case demand scenario, about 7 percent of the utility capacity operating in 1990 will retire by 2015 . One final option for lowering emissions is to force older fossil-fuel-fried plants to retire earlier than their expected lifetime of 60 years. If all fossil-fuel-fired plants were forced to retire after 40 years of operation, about 35 percent of the existing capacity will be eliminated by 2010 and 50 percent by 2015 . When combined with the measures discussed above for new plants, considerable reductions are possible. The 40-year time is arbitrary; it could be 30 or 35 years if desired, or longer if the costs for 40-year retirement are thought to be excessive.

\section{CHAPTER 3 REFERENCES}

1. Alternative Sources of Energy, "The Private Sector's Role in Third World Power," Alternative Sources of Energy, pp. 22-25, September 1988.

2. Batenin, V., "Alternative Power Sources in Use in the USSR," Ambio 19(4):220-224, July 1990.

3. British Petroleum Company, BP Statistical Review of World Energy 1988 (London: June 1988).

4. British Petroleum Company, BP Statistical Review of World Energy 1989 (London: 1989).

5. Brown, L., et al., State of the World, 1988 (Washington DC: Worldwatch Institute, 1988).

6. Central Intelligence Agency, USSR Energy Atlas (Washington DC: January 1985).

7. Central Intelligence Agency, Handbook of Economic Statistics, 1988, CP AS 88-10001 (Washington DC: September 1988).

8. Cicerone, R. J., and Oremland, R. S., "Biogeochemical Aspects of Atmospheric Methane,' Global Biogeochemical Cycles 2(4):299327, December 1988.

9. Commission of the European Communities, Energy Technology Status Report, October 1988.

10. Crane, A., China 's Nuclear Power Program: Implications for U.S. Policy (Washington, DC: Washington Institute for Values in Public Policy, 1988).

11. Cruver, P.C., "Greenhouse Effect Prods Global Legislative Initiatives, "IEEE Technology and Society Magazine 9(l): 10-16, March/April 1990.

12. Davis, D.W. and J.J. Buckley, National Hydroelectric Power Resources Study, Volume IX: Potential for Increasing the Output of Existing Hydroelectric Plants (Fort Belvoir, VA: Institute for Water Resources, 1981)

13. Davison, A., Fossil Fuel Consumption and the Environment (Oxford: Oxford Institute for Energy Studies, April 1989).

14. Edison Electric Institute, Statistical Yearbook of the Electric Utility Industry/1987 (Washington DC: 1988).

15. Electric Power Research Institute, TAG Technical Assessment Guide. Volume 1: Electricity Supply-1989, EPRI report P-6587. L, vol. 1 (Palo Alto, CA: September 1989).

16. Electric Power Research Institute, Power Plant Performance Monitoring and Improvement, EPRI report CS/EL-4415, vol. 3 (Palo Alto, CA: February 1986).

17. Elliott, D.L. et al., Wind Energy Resource Atlas of the United States, DOE/CH 10093-4 (Golden, CO: Solar Energy Research Institute, 1986).

18. Pay, J.A., D. Golomb, and S.C. Zachariades, Feasibility and Cost of Converting Oil- and Coal-Fired Utility Boilers to Intermittent Use of Natural Gas, MIT Energy Laboratory report F00784 (Cambridge, MA: December 1986).

19. Federal Institute for Geosciences and Natural Resour zes, Federal $\mathbb{R}$ Republic of Germany, Survey ofEnergy Resources, 1980, prepared for the 1 1th World Energy Conference, Munich, Sept. 8-12, 1980 (London, England: World Energy Conference, 1980).

20. Finn, D.X., Managing Director, Geothermal Energy Institute, personal communication Apr. 21, 1989.

21. Food and Agriculture Organization Fuelwood Supplies in the Developing Countries, FAO Forestry Paper No. 42 (Rome: 1983).

22. Freudmann, A., "Natural Gas: A Key Role to Play in Third World Development, Panel Says,” The Energy Daily (June 10, 1988).

22a. Pritsche, U., OEKO-Institute Buro Darmstadt, Darmstadt, FRG, personal communication, May 21, 1990; citing data obtained from A.A. Arbatov, Deputy Chairman, U.S.S.R. Academy of Sciences Commission for the Study of Production Forces and Natural Resources.

23. Fulkerson, W. et al., Energy Technology R\&D: What Can Make A Idifference? Volume 2, Supply Technology, ORNL-6541/V2/P2 (Oak Ridge, TN: Oak Ridge National Laboratory, 1989). 
24. Goldemberg, J., T.B. Johansson, A.K.N. Reddy, and R.H. Williams, Energy for Development (Washington, DC: World Resources Institute, September 1987).

25. Government Affairs Association, Inc., Robert Gould (cd.), The 1988-1989 Resource Recovery Yearbook (New York, NY: 1988).

26. Gray, T., American Wind Energy Association, personal communication, May 10, 1989.

27. Hedley, D., World Energy: The Facts and the Future (New York: Facts on File Publications, 1986).

27a. Hendriks, C.A. et al., "Technology and Cost of Recovery and Storage of Carbon Dioxide From an Integrated Gasifier Combined Cycle Plant, ' draft manuscript (Utrecht, The Netherlands: University of Utrecht, Department of Science, Technology and Society, manuscript dated Apr. 18, 1990

27b. Hirst, Eric, Electric-Utility Energy Efficiency and LoadManagement Programs: Resources for the 1990s, ORNL/CON285 (Oak Ridge, TN: Oak Ridge National Laboratory, June 1989).

28. Holdren, J., Dimensions of the Physical World: Part 2 (Berkeley, CA: University of California, 1979).

29. Holtberg, P. D., Woods, T.J., Ashby, A. B., and Lyre, M.L., 1988 GRI Baseline Projection of U. S. Energy Supply and Demand to 2010 (Chicago, IL: Gas Research Institute, 1988).

30. ICF Resources, Inc., 1989 EPA Base Case Forecasts, prepared for the U.S. Environmental Protection Agency, May 1989.

31. Institute of Gas Technology, "New Study Says the Soviets Could Produce 35 TCF/Year of Gas by 2000," Institute of Gas Technology Highlights, 1987.

32. Institute of Gas Technology, "Soviets Debate Advantages of Increased Gas Production vs. Conservation," Institute of Gas Technology Highlights, 1988.

33, Institute of Gas Technology, "New Era for Natural Gas in Asia Heralded at IGT Seminar in Singapore, "International Gas Technology Highlights, XIX(6), 1989.

34. International Atomic Energy Agency, "International Data File," IAEA Bulletin 4:52-53, 1988 .

35. International Energy Agency, World Energy Statistics and Balances (Paris: 1989).

35a. Intergovernmental Panel on Climate Change, Climate Change: The IPCC Scientific Assessment, World Meteorological Organization/ U.N. Environmental program (Cambridge, MA: Cambridge University Press, 1990).

36. Klass, D. L., "The U.S. Biofuels industry," Proceedings of the International Renewable Energy Conference, September 1988.

37. Korchemkin, M. B., "Energy Aspects of Perestroika, " Center for International Energy Studies, Erasmus University (Rotterdam, Netherlands: April 1989).

38. Larson, ED., "Biomass Gasification for Gas Turbine Power Generation, " in Johansson, T. B., B. Bodlund, and R.H. Williams (eds.),Electricity deficient End-Use andNew Generation Technologies, and Their Planning Implications (Sweden: Lund University Press, 1989).

39. Lawrence Berkeley Laboratory, Argonne National Laboratory, Oak Ridge National Laboratory, Sandia National Laboratory, Solar Energy Research Institute, Los Alamos National Laboratory, and Pacific Northwest Laboratory, Energy Technology for Developing Countries: Issues for the U.S. National Energy Strategy, prepared for U.S. Department of Energy (Berkeley, CA: Lawrence Berkeley Laboratory, December 1989).

40. Library of Congress, Congressional Research Service, The Enigma of Natural Gas, 88-561 SPR (Washington, DC: 1988).

41. Makarov, A. A., and I.A. Bashrnakov, The Sow'et Union: A Strategy of Energy Development With Minimum Emission of Greenhouse Gases, prepared for U.S. Environmental Protection Agency (Richland, WA: Battelle Pacific Northwest Laboratories, April 1990).

42. Mashayekhi, A., ' Natural Gas Supply and Demand in Less Developed Counties, " Annual Review of Energy 13:1 19-129, 1988.
43 Moore, J., “Reducing Distribution System Losses,' Public Power 47(2):16-19, 1989.

44. Munasinghe, M., and W. Scott, Energy Efficiency: Optimization of Electric Power Distribution System Losses (Washington DC: The World Bank, 1982).

45, Nederlof, M.H., "The Scope for Natural Gas Supplies From Unconventional Sources," Annual Review of Energy 13:95-1 17, 1988.

46. New York Times, "France Stands by Nuclear Power," New York Times, p. D4, May 8, 1989.

46a. Northwest Power Planning Council, 1989 Supplement to the 1986 Northwest Conservation and Electric Power Plan, Volume 1,89-1 (Portland, OR: Northwest Power Planning Council, 1989).

47. Oak Ridge National Laboratory, Energy Technology R\&D: What Could Make a Difference? Volume 2, Pars 2 of 3, Supply Technology, ORNL-6541/V2/P2 (Oak Ridge, TN: December 1989).

48. Oak Ridge National Laboratory, Energy Technology R\&D: What Can Make a Difference? Part 1: Synthesis Report, ORNL-6541/ V1 (Oak Ridge, TN: 1989).

49. PEI Associates, Inc., SupplySide Conservation Techniques for Tennessee Valley Authority and American Electric Power CoalFired Boilers, draft report (Cincinnati, OH: 1988).

50. Pryde, P. R., "Soviet Development of Solar Energy," Soviet Geography 25 (1):24-33, 1984.

51. Pryde, P.R., 'Environmental Management in the Soviet Union+' Chapter 4 in Renewable Energy Resources (Cambridge, United Kingdom: Cambridge University Press, 1990).

52. Roberts, V., and P. Kruger, "Utility Industry Estimates of Geothermal Energy,' Proceedings: Eighth Annual Geothermal Conference and Workshop (Palo Alto, CA: Electric Power Research Institute, 1984).

53. Riva, J.P., Jr., Domestic Natural Gas Production, IB89009 (Washington, DC: Congressional Research Service, 1989).

54. Science Applications International Corp., Early Market Potential for Utility Application; of Wind Turbines, AP-4077 (Palo Alto, CA: Electric Power Research Institute, 1985).

55. Scurlock, J. M.O., and D.O. Hall, "The Contribution of Biomass to Global Energy Use (1987), "Biomass 23: 39-53, 1990.

56. Skog, K., and High, C., "Current and Projected Wood Energy consumption in the United States,' Biologue 6(2): 16-17 (1989).

57. Smith, K. R., 'The Biofuel Transition' Pacific and Asian Journal of Energy, 1(1):13-32 (1987),

58. Smith, N., "Wood: An Ancient Fuel With a New Future," Worldwatch Paper 42 (Washington DC: Worldwatch Institute, 1981).

59. Solar Energy Research Institute, Idaho National Engineering Laboratory, Los Alamos National Laboratory, Oak Ridge National Laboratory, and Sandia National Laboratories, The Potential of Renewable Energy, An Interlaboratory White Paper, prepared for U.S. Department of Energy, Office of Policy, Planning and Analysis, SERI/TP-260-3674 (Golden, CO: Solar Energy Research Institute, March 1990).

60. Solar Energy Research Institute, The Potential of Renewable Energy SERIITP-260-3674 (Golden, CO: March 1990).

61. Sperling, D., New Transportation Fuels (Berkeley, CA: University of California Press, 1988).

62. Sweden National Energy Administration An Introduction to Biofuel (Sweden: 1984).

63. The Economist, "Electricity in the Third World," The Economist 307(7549):82, 1988.

64. The Energy Daily, "Nuclear Power Reactors in Operation at the End of 1988," The Energy Daily 17(75):4, Apr. 21, 1989.

65. The Energy Daily, "Nuclear Generating Capacity Outside of the United States," The Energy Daily, June 2, 1989, p. 6.

66. U.S. Agency for International Development Power Shortages in Developing Countries: Magnitude, Impacts, Solutions, and the Role of the Private Sector (Washington, DC: 1988). 
66 U.S. Congress, Congressional Budget Office, Carbon Charges as a Response to Global Warming: The Effects of Taxing Fossil Fuels (Washington, DC: U.S. Government Printing Office, August 1990).

67 U.S. Congress, Office of Technology Assessment, Energy From Biological Processes, Volume Ii-Technical and Environmental Analysis, OTA-E-128 (Washington DC: U.S. Government Printing Office, September 1980).

68. U.S. Congress, Office of Technology Assessment, Nuclear Power in an Age of Uncertainty, OTA-E-216 (Washington DC: U.S. Government Printing Office, 1984).

69. U.S. Congress, Office of Technology Assessment, New Electric Power Technologies, OTA-E-246 (Washington, DC: U.S. Government Printing Office, 1985).

70. U.S. Congress, Office of Technology Assessment, Facing America's Trash: What Next for Municipal Solid Waste? OTA-O-424 (Washington, DC: U.S. Government Printing Office, October 1989).

71, U.S. Congress, Office of Technology Assessment, Electric Power Wheeling and Dealing, OTA-E-4(39 (Washington, DC: U.S. Government Printing Office, 1989).

72. U.S. Congress, Office of Technology Assessment, Facing America's Trash: What Next for Municipal Solid Waste? OTA-O-424 (Washington, DC: U.S. Government Printing Office, 1989).

73. U.S. Congress, Office of Technology Assessment, Replacing Gasoline: Alternative Fuels for Light-Duty Vehicles, OTA-E-364 (Washington, DC: U.S. Government Printing Office, September 1990).

74. U.S. Congress, Office of Technology Assessment, Energy in Developing Countries, OTA-E-486 (Washington DC: U.S. Government Printing Office, January 1991).

74a. U.S. Department of Energy, A Systems Study For the Removal, Recovery and Disposal of Carbon Dioxide From Fosssil Fuel Power Plants in the U. S., DOE/C-16-2, prepared by M. Steinberg et al., Brookhaven National Laboratory (Washington, DC: Office of Energy Research, December 1984).

75. U.S. Department of Energy, United States Geothermal Technology, DOE/ID 10130 (Washington, DC: U.S. Department of Energy, 1987).
76. U.S. Department of Energy, International Energy Annual 1987, DOE/ELA-02 19(87) (Washington, DC: Energy Information Administration, 1987).

77. U.S. Department of Energy, Five Year Research Plan 1988-1992, Biofuels: Renewable Fuels for the Future, DOE/CH10093-25 (Washington, DC: July 1988).

78. U.S. Department of Energy, Assessment of Costs and Benefits of Flexible and Alternative Fuel Use in the U.S. Transportation Sector, DOE/PE-0080 (Washington DC: January 1988).

79. U.S. Department of Energy, International Energy Annual, 1988, DOE/EIA-0219(88)(Washington, DC: Energy Information Administration, November 1989).

80. U.S. Department of Energy, Annual Energy Review, 1988, DOE/EIA-0384(88) (Washington, DC: Energy Information Administration, May 1989).

81. U.S. Department of Energy, Annual Energy Review, 1989, DOE/ELA-0384(89) (Washington DC: Energy Information Administration, May 1990).

82. U.S. Environmental Protection Agency, Office of Solid Waste, Operating Criteria (Subpart C), Criteria for Municipal Solid Waste Landfills (40 CFR Part 2S8), EPA/530-SW-88-038 (Washington, DC: July 1988).

83. U.S. Environmental Protection Agency, Office of Policy, Planning and Evaluation, Policy Options for Stabilizing Global Climate, Draft Report to Congress (Washington DC: 1990).

84. U.S. Environmental Protection Agency, Office of Solid Waste and Emergency Response, Characterization of Municipal Solid Waste in the UnitedStates: 1990 Update, EPA/530-SW-90-042(Washington DC: June 1990).

85. World Resources Institute and International Institute of Environment and Development World Resources 1988-89 (New York: Basic Books, 1988).

86. Wright, L. L., Graham, R. L., and Turhollow, A. F., "ShortRotation Woody Crop Opportunities to Mitigate Carbon Dioxide Buildup, " paper presented at North American Conference on Forestry Responses to Climate Change, May 15-17, 1990 (Washington, DC: Climate Institute, 1990).

87. Xi, Xiao-lin and M.G. Morgan, "Energizing China: First Itself, Next the World," IEEE Spectrum, 26(3), 1989. 
Chapter 4

\section{The Buildings Sector}

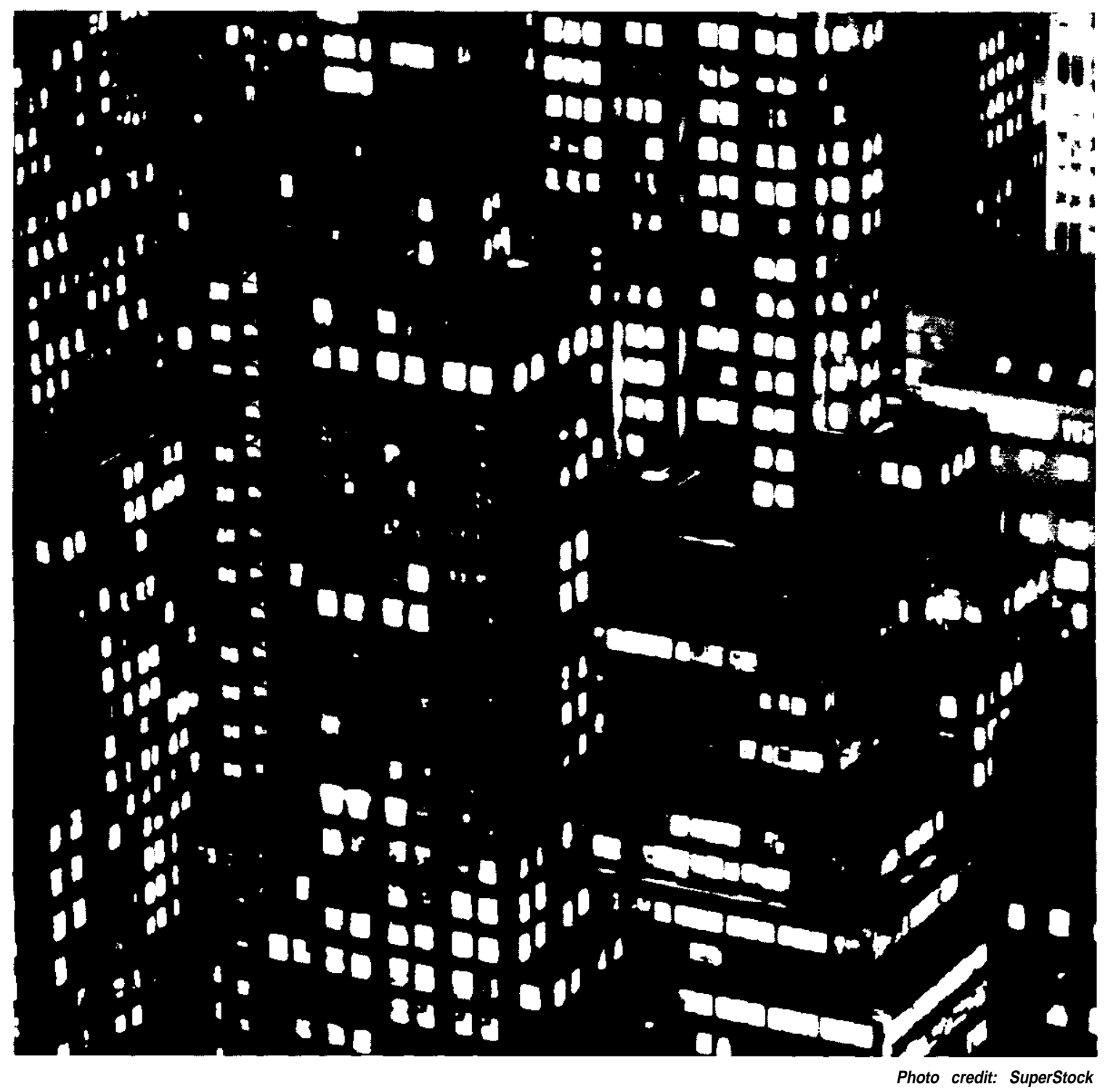




\section{CONTENTS}

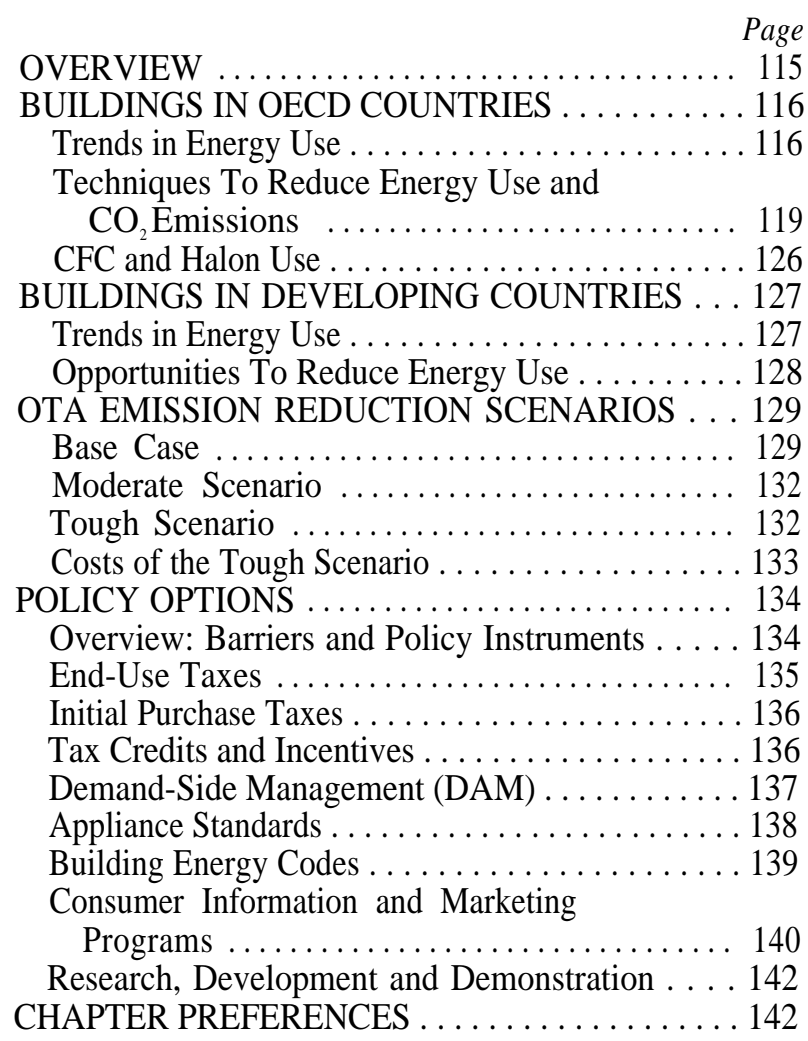

\section{Boxes}

Box
4-A. Swe

4-B. Energy Use in Soviet and Eastern European Buildings ........................ 121

4-C. Insulation and R-Values . . . . . . . . . . . . . . 123

4-D. Energy Management Systems and "Smart" Homes ... . . . . . . . . . . . . . . . . . . . . . . . . 125

4-E. CFCs and Halons in Buildings... . . . . . . . . 127

\section{Figures}

Figure Page

4-1. Contribution of the U.S. Buildings Sector to U.S. CO Emissions From Fossil Fuels . . . . 116

4-2. $\mathrm{CO}_{2}$ Emissions From the U.S. Buildings Sector in 2015, Under the Base Case, Moderate, and Tough Scenarios . . . . . . . . . . 117

4-3. Annual Expenditures for Energy in Average U.S. Households, 1987 . . . . . . . . . . . . . . . . 117

4-4. Components of Change in Fossil Fuel Energy Use in Residential and Commercial Buildings ........................ 118

4-5. Energy Efficiency of Various Light Sources . 122

4-6. Space Heat Requirements in Single-Family Dwellings in the United States and Sweden.. 124

4-7. Energy Efficiency Potential of U.S. Residential Appliances

4-8. Summary of $\mathrm{CO}_{2}$ Emissions From the U.S. Buildings Sector by Year, Under the Base Case, Moderate, and Tough Scenarios

4-9. Fuel Use Under the Base Case, Moderate, and Tough Scenarios, by Fuel Type . . . . . . . 132

4-10. $\mathrm{CO}_{2}$ Emissions Reductions in 2000 and 2015 Expressed as a Percentage of 1987 Building Sector Emissions, by Control Method, Under the Moderate Scenario .

4-11. $\mathrm{CO}_{2}$ Emissions Reductions in 2000 and 2015 Expressed as a Percentage of 1987 Building Sector Emissions, by Control Method, Under the Tough Scenario

\section{Tables}

Table

4-1. Residential Buildings: Measures in the OT.A Model ... . . . . . . . . . . . . . . . . . . . . . . . 130

4-2. Commercial Buildings: Measures in the OTA Model ...................... 131 


\section{OVERVIEW}

The buildings sector includes all activities related to residential and commercial buildings. ${ }^{1}$ Two greenhouse gases are of primary importance in this sector-carbon dioxide $\left(\mathrm{CO}_{2}\right)$ and chlorofluorocarbons (CFCs). $\mathrm{CO}_{2}$ is emitted when fossil fuels and biomass are burned (either directly onsite, or at electric powerplants) to provide services such as space conditioning, water heating, lighting, cooking, refrigeration, and entertainment. CFCs are emitted from foam insulation, air conditioners, and refrigerators.

Worldwide, the buildings sector accounts for about 30 percent of $\mathrm{CO}_{2}$ emissions (108):

- direct, onsite burning of fossil fuels (coal, oil, gas) accounted for an estimated 14 percent of global $\mathrm{CO}_{2}$ emissions in 1985 (108);

- electricity use in buildings accounted for 13 percent (i.e., over one-half of all $\mathrm{CO}_{2}$ emissions from electricity generation) (108); and

- burning fuelwood for domestic heating and cooking accounted for an additional few percent.

In the United States, the buildings sector accounts for an estimated 36 percent of $\mathrm{CO}_{2}$ emissions (see figure 4-1 ) and roughly 20 percent of CFC emissions (35).

Activities in the buildings sector are directly linked to other environmental and social concerns as well. Burning fuelwood and coal, for example, results in emissions of air pollutants such as particulate matter and acid gases. Building new residential and commercial developments can involve clearing forests and paving agricultural land. The spatial pattern of such developments greatly affects subsequent transportation requirements (see ch. 5). Construction materials are supplied through activities such as timber harvesting and processing, and sand and gravel dredging which can also have environmental impacts.
There is no single formula for reducing emissions in the buildings sector. To do so, many technical options will have to be implemented for both residential and commercial buildings. Otherwise, the effect of emission reductions in one area could easily be negated by growth in another.

OTA modeled potential $\mathrm{CO}_{2}$ emissions in the U.S. buildings sector for three scenarios (Base case, Moderate, Tough). In the Moderate scenario, currently available technologies that pay for themselves over the life of the equipment are adopted; these include high-efficiency appliances and equipment, increased insulation, and more efficient lighting devices and designs. In this case, OTA estimates that U.S. $\mathrm{CO}_{2}$ emissions in 2015 from buildings can be reduced by about 5 percent relative to 1987 levels (see figure 4-2). In the Tough scenario, technologies that are expected to be commercially available in the next decade could reduce U.S. building sector emissions in 2015 by about one-third relative to 1987 levels (see figure 4-2). These projected reductions are achievable without major changes in the mix of fossil fuels used for generating electricity for buildings. Because a large portion of the energy used in buildings is supplied by electricity which is produced primarily by coal, the most $\mathrm{CO}_{2}$-intensive of the fuels, further reductions could be achieved by changing how electricity is generated (see ch. 3).

In the United States, available policy levers to implement these technical options include: energyuse taxes, initial purchase taxes, electric utility ' 'Demand-Side Management, ' appliance standards, building codes, consumer information and marketing, and research and development. These options can act synergistically to influence decisions regarding the design and operation of buildings and building services.

In developing countries, the demand for energy services in buildings will grow rapidly during the next 25 years: per-capita growth in energy consumption in this sector is about 10 times that of counties in the Organization for Economic Cooperation and Development $(\mathrm{OECD})^{2}(72)$. While developing coun-

\footnotetext{
'The commercial sector encompasses many enterprises, including offices, warehouses, schools, health care, food sales and services, and lodging.

${ }^{2}$ The 24-member OECD includes Australia, Austria, Belgium, Canada, Denmark, Finland, France, Germany, Greece, Iceland, h-eland, Italy, Japan, Luxembourg, The Netherlands, New Zealand, Norway, Portugal, Spain, Sweden, Switzerland, Turkey, U. K., and U.S.
} 
Figure 4-I--Contribution of the U.S. Buildings Sector to U.S. $\mathrm{CO}_{2}$ Emissions From Fossil Fuels

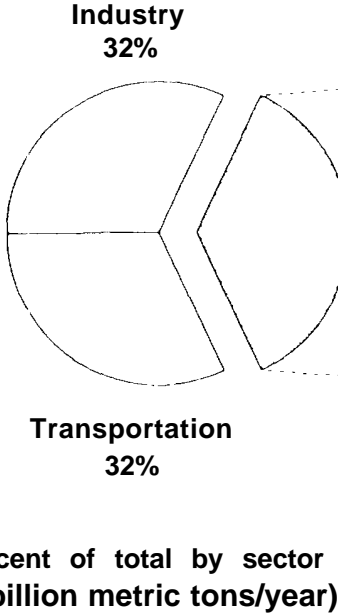

(1.3 billion metric tons/year)

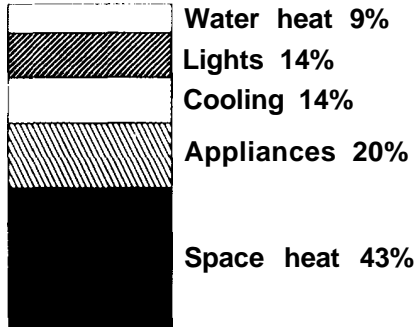

Percent of

emissions from buildings

( 0.47 billion metric tons/year)

SOURCE: Office of Technology Assessment, 1991.

tries currently meet a large share of their energy needs in buildings by using biomass, much of their growth in energy demand (and hence greenhouse gas emissions) in the buildings sector is associated with the spread of electrical services throughout their economies, The use of energy-efficient technologies and practices can slow the rate of increase of $\mathrm{CO}_{2}$ emissions without compromising economic development. However, net reductions below current levels are unlikely.

\section{BUILDINGS IN OECD COUNTRIES}

\section{Trends in Energy Use}

In OECD countries, the buildings sector accounted for 38 percent of primary energy use in $1985^{3}-23$ percent in the residential portion and 15 percent in the commercial portion (67). Space conditioning (heating or cooling) dominates energy use, accounting for 60 to 80 percent of final energy demand in residential buildings and 60 to 65 percent in commercial buildings $(30,67){ }^{4}$ Most of this is for heating; air-conditioning, for example, accounted for only 3 percent, on average, of residential energy use in 1980 throughout the OECD. Water heating and lighting generally are the other major uses in commercial buildings; water heating, electric appliances, and cooking are the other major uses in residential buildings.

In the United States, space heating is the dominant energy user in buildings, accounting for 43 percent of $\mathrm{CO}_{2}$ emissions from the entire sector (figure 4-1). In the residential portion, space heating accounted for 30 percent of the annual energy expenditures in average U.S. households in 1987 (see figure 4-3). Other important end uses in both types of buildings are lighting, water heating, and air-conditioning, along with refrigeration and cooking in residences and ventilation in commercial buildings $(10,75,76)$. More than 20 percent of all electricity generated in the United States is used for lighting, primarily in buildings (other uses include, for example, street lighting) (97). In contrast with the OECD as a whole, air-conditioning is a significant end-use in the United States (78), accounting for 22 percent of the $\mathrm{CO}_{2}$ emissions in the commercial sector, for example.

\footnotetext{
${ }_{3}^{3}$ Primary energy sources include nonrenewable fossil fuels (coat, petroleum, natural gas), potentially renewable biomass, and renewable such as solar, geothermal, and hydroelectric power. Electricity is a secondary energy source produced from primary energy sources.

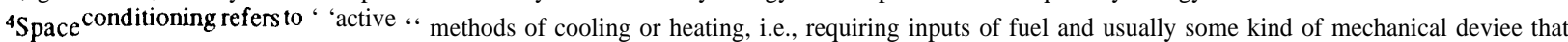
must be deliberately activated or deactivated according to needs. Passive meihods operate with relatively little deliberate intervention depend on natural flows of energy (e.g., solar energy), and are mediated by building design.

${ }^{5}$ Energy use during construction is not covered here; studies in the 1970s indicated that it is a relatively small portion Of total energy USe in the buildings sector, equal to about 5 yearn of operational energy use $(36,84)$.
} 
Figure 4-2- $\mathrm{CO}_{2}$ Emissions From the U.S. Buildings Sector in 2015, Under the Base Case, Moderate, and Tough Scenarios

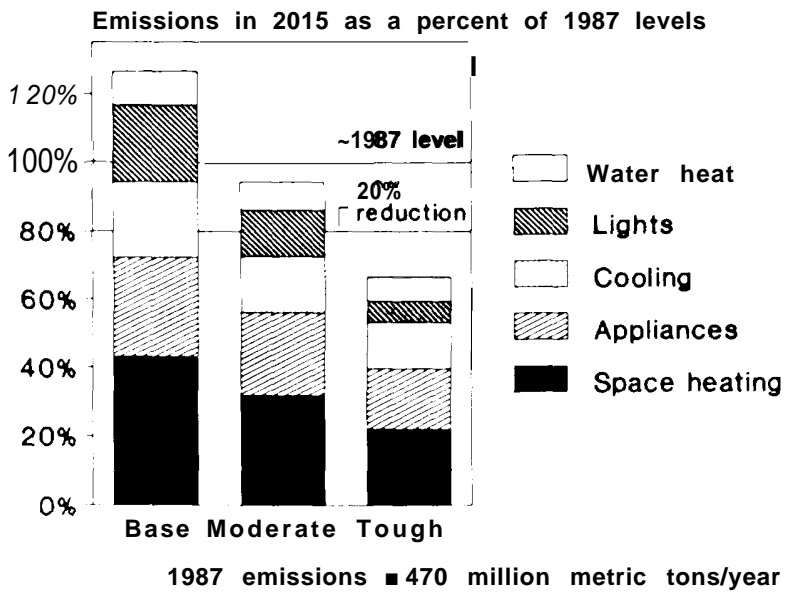

For comparison, lines representing the 1987 baseline and 20 percent below that level are indicated. Emissions from biomass fuels are not included here.

SOURCE: Off Ice of Technology Assessment, 1991,

\section{Figure 4-3--Annual Expenditures for Energy in Average U.S. Households, 1987}

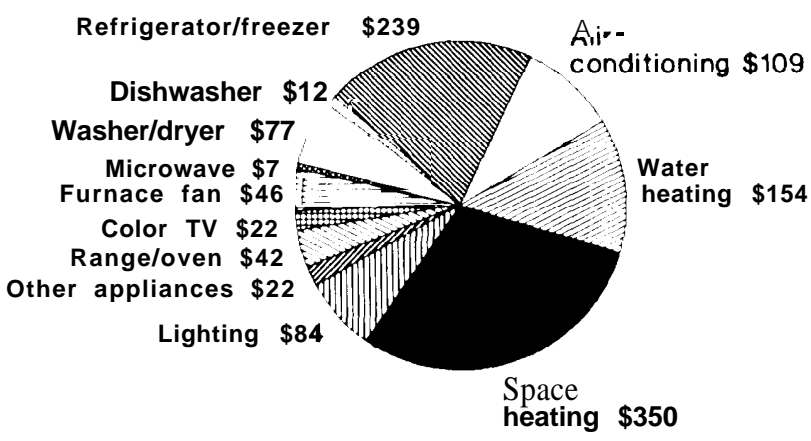

Total annual expenditure $=\$ 1,164$

Five major end-uses---space heating, refrigerating, water heating, air-conditioning, and lighting-account for 80 percent of average household expenditures. (This chart shows electric appliances only and assumes average cost of 7 cents per kWh.)

SOURCE: Office of Technology Assessment, 1991, adapted from U.S. Department of Energy, Energy Information Administration, Household Energy Consumption andExpenditure (Washington, DC: 1989), figure 9 and table 3 . Lighting data provided by $A$. Meier, Lawrence Berkeley Laboratory.

Energy use in U.S. residences, on a per-squarefoot basis, is higher than in Japan, Italy, and Sweden, but lower than in France, the United Kingdom, and West Germany $(77,105)$. Energy use for heating and electricity in commercial buildings in Canada and the United States, after accounting for differences in climate, is 20 to 30 percent higher per unit area than in Europe (78).

Most OECD countries have undertaken considerable efforts since 1973 to conserve energy (see ch. 9). These efforts have significantly slowed the growth in energy demand in residential and commercial buildings. Figure 4-4 shows how U.S. residential energy use dropped due to a combination of technical efficiency improvements, conservation (using less), and demographic changes (decreasing household size and migrating to warmer climates).

A countervailing trend, though, has been an increase in electrification, due to increases in the use of electricity for space and water heating and for electric appliances, and, in the United States, for air-conditioning. Of new U.S. homes built in 1986, 44 percent were electrically heated, compared to only 15 percent in 1983; 70 percent were built with central air-conditioning in 1986, compared with 34 percent in 1970. As a result, primary energy use in the United States between 1979 and 1985 increased by 9.1 percent in the commercial sector and 0.7 percent in the residential sector (62).

The net effect of electrification on $\mathrm{CO}_{2}$ emissions depends partly on the mix of fuels used to generate electricity. If electricity is generated from nuclear power or renewable sources (i.e., solar, wind, geothermal, nuclear, biomass), more electrification will not increase $\mathrm{CO}_{2}$ emissions, all other things being equal. The net effect also depends on the relative efficiencies of fuel- and electric-driven equipment. For example, electric resistance heat (e.g., electric baseboard radiators, or portable or wall-mounted coil heaters) uses about three times as much primary energy per delivered unit of final energy (the average efficiency of a U.S. powerplant) as the most efficient gas or oil furnaces and the most efficient electric heat pumps. When gas heat pumps reach the market, they will use even less primary energy per unit of delivered energy than today's electric heat pumps (see table 4-1).

Over the next 25 years, slow growth in the demand for energy services is expected in the residential sector of OECD countries. This is because population and household growth are expected to be low, and because there is a saturation of major appliances in these countries. Most homes in OECD countries already have hot water, refrigera- 
Figure 4-4-Components of Change in Fossil Fuel Energy Use in Residential and Commercial Buildings

\section{Residential}

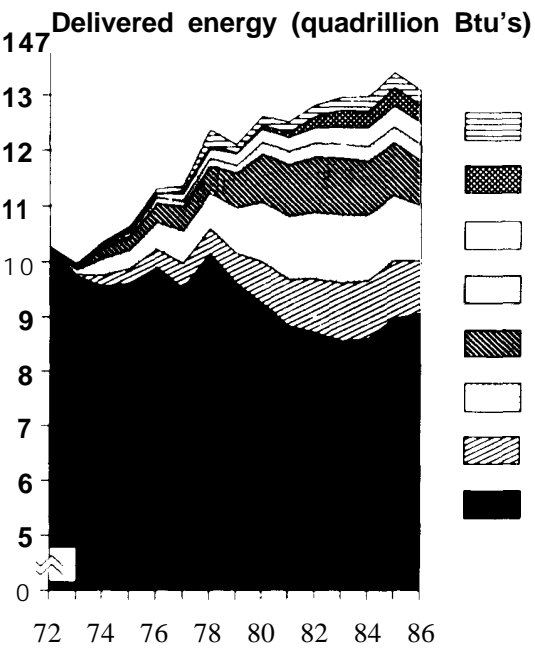

A number of factors contributed to the 4 quads of delivered energy savings in the residential sector in 1986":

- Appliance Use and Efficiency: 1.0 quad. This reflects both the increase in more efficient household appliances and wiser use of appliances in general.

- Space Heating Behavior: 1.0 quad. This includes short-term reversible actions, such as adjustments to thermostat settings and closing off unused living areas. These savings are less than in 1982, suggesting a return of thermostat settings to higher levels.

- Shell Retrofits: 0.8 quad due to weatherstripping, insulation, and caulking. This component has decreased in recent years partly due to lower fuel prices and the end of energyconservation tax credits.

- New Home Shell Efficiency: 0.4 quad. New homes and the equipment in them are more energy efficient.

- Wood Use: 0.3 quad, reflecting consumer use of wood in place of conventional heating fuel.

Household Size: 0.3 quad. The number of persons per household has decreased steadily from 1972 to 1986, resulting in less energy use per household.

- Migration: 0.3 quad. This includes the population shift to the South and West regions of the United States, where households use less energy for heating but more for cooling.

SOURCE: U.S. Department of Energy, Office of Policy, Planning and Analysis, Energy Conservation Trends: Understanding the Factors That Affect Conservation Gains in the U.S. Economy, DOE/PE-0092 (Washington, DC: September 1989).
Commercial

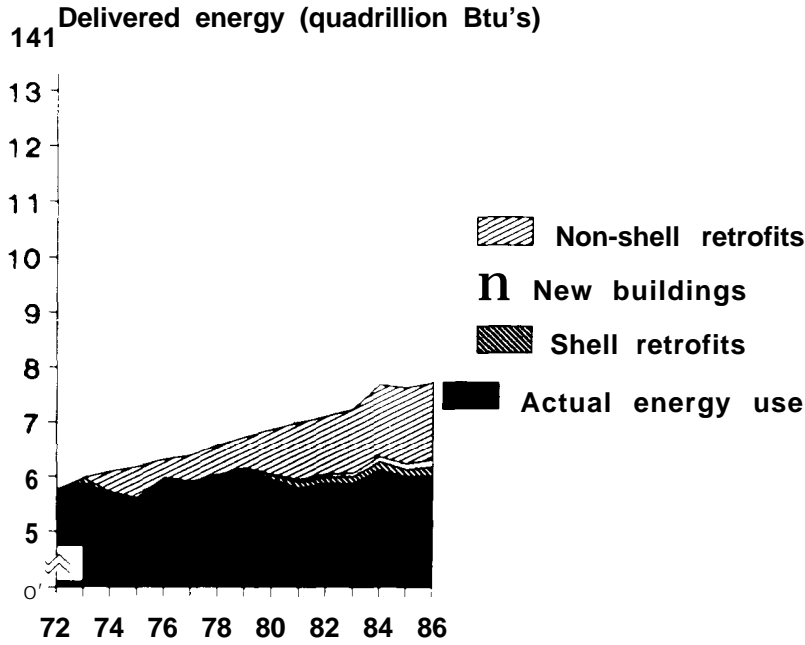

Three major factors contributed to the 1.7 quads of delivered energy savings realized by the commercial sector in 1986:

- Non-Shell Retrofits: about 1.4 quads. These include more energy-efficient maintenance procedures, use of computerized energy-management systems, replacement of heating and cooling equipment, and more energy-efficient lighting.

- New Buildlngs: about 0.1 quad. The savings are attributable to the addition of new, more energy-efficient building designs with energy efficient equipment.

- Shell Retrofits: about $\mathbf{0 . 2}$ quads. These include increased insulation, weatherstripping, and installation of special windows. tors, electric lights, and central heating (which are kept at comfortable temperatures) $(57,32)$. On the other hand, increased domestic use of airconditioning could occur.

However, energy demand in commercial buildings could grow rapidly if OECD economies continue to expand. Use of computers and other electronic equipment in offices, for example, is projected to increase. In the United States, the demographic shift to the South and West also will enhance the trend toward electrification-buildings in these regions are likely to be electrically heated, while buildings in the Northeast are generally heated by oil or gas (78). 


\section{Techniques To Reduce Energy Use and $\mathrm{CO}_{2}$ Emissions}

Energy use will vary with the type of building, In commercial buildings, for example, key determinants include the mix of activities (e.g., manufacturing v. office space v. living area), amount of floor space, thermal characteristics of the building, and types of fuel used. These factors in turn are influenced by the density, design, and distribution of surrounding buildings-e. g., demographic characteristics; climate; availability of land, materials, capital, and labor; energy costs; cultural and individual preferences; and the capabilities of the architects. ${ }^{6}$

Cost-effective reductions in energy use (and associated $\mathrm{CO}_{2}$ emissions) can be achieved through greater use of energy-efficient equipment (lights, heaters, air conditioners), insulation, and improved windows; fuel switching; better operation and maintenance $(\mathrm{O} \& \mathrm{M})$ practices; and changes in how families and businesses occupy buildings and use energy within them $(30,43,50,60)$. Reductions in CFC emissions also are possible (see below),

Because the average lifetime is about 100 years for a home and 50 years for a commercial building in the United States, initial reductions in greenhouse gas emissions will come primarily from retrofitting existing buildings with energy-efficient equipment and better insulation, windows, and other energyconserving structural features $(27,28,39)$. Existing commercial buildings, for example, can be retrofitted with lighting, insulation, and windows that use 20 to 25 percent less energy, with typical payback periods of 2 to 3 years (50). Since appliances and other equipment wear out significantly faster than buildings (lifetimes of about 10 to 25 years), replacement with more efficient equipment can bring about reductions in $\mathrm{CO}_{2}$ and $\mathrm{CFC}$ emissions relatively quickly.

By 2010, however, about one-third of residences and over one-half of commercial buildings in the United States will have been built after 1990, so changes in building codes for new construction could also have an important effect over the next 25 years. Installing better insulation and efficient equipment during construction of new buildings is less expensive and more effective than retrofitting them later. New commercial buildings designed to be energy efficient use about one-half the energy on average of existing buildings (54).

In all buildings, more efficient operation and proper maintenance can significantly reduce energy use, generally at a relatively small cost compared to the cost of providing additional energy. A wide, available array of electronic systems, for example, can be installed to automatically control heating, lights, air conditioners, and other energy-using devices (for example, see box 4-D below).

Because the structure of energy use in the buildings sector is comparable throughout the OECD (67), these technical options should generally be applicable in most other OECD nations, despite variations in energy prices and weather conditions. ${ }^{7}$ Even in countries like Sweden that have long promoted energy efficiency in buildings, reductions in $\mathrm{CO}_{2}$ emissions still are possible (see box 4-A). The potential for improved energy efficiency and reduced $\mathrm{CO}_{2}$ emissions is even greater in Eastern Europe and the U.S.S.R. (see box 4-B).

\section{Lighting}

The amount of energy used for lighting can be reduced by using more efficient bulbs, automatic lighting controls (such as occupancy sensors and individual controls), and design improvements such as task lighting. Lighting accounts for over 25 percent of $\mathrm{CO}_{2}$ emissions in the commercial sector; it offers perhaps the single largest, and certainly the most cost-effective, method for reducing fossil fuel use in the commercial sector. Many of the options for reducing energy use in lighting offer paybacks in less than 2 years, depending on how intensively they are pursued.

The common incandescent bulb uses electricity to heat a filament until it glows, but approximately 90 percent of the electricity is converted to heat, not light. Replacing incandescent with fluorescent bulbs can reduce energy use by up to 75 percent (figure 4-5). Further gains of up to 50 percent are possible with the use of high-efficiency lamps and ballasts. ${ }^{8}$ In addition to reducing the electricity needed for lighting, more efficient lighting gives off less heat to

${ }^{6}$ For discussions of the historical role of climate in determining the quality and location of buildings, S\& refs.19.20.

${ }^{7}$ However, policies to implement these measures are nol necessarily the same throughout the OECD (see ch.9).

${ }^{8}$ A ballast is a device that Provides a voltage high enough to ionize vapor in the tube and then limits the current for stable operation 


\section{Box 4-A-Sweden: Surprising Room for Improvement}

Sweden is often viewed as a model energy-conserving society. For example, it is noted for having the most demanding construction standards in the world for new buildiings and, hence, the world's most energy-efficient buildings. Approximately 40 percent of buildings in Sweden are heated with district heat. Further, much of the heat comes from variety of unconventional sources including urban 'waste-to-energy' plants, large (up to $20 \mathrm{MW}$ ) heat pumps using sewage water as a heat source, wood waste, industrial waste heat, agricultural waste, and even solar energy (supplying housing developments at a scale of up to about 300 to 400 units per system). Despite this, there may still be room for improvement.

\section{Building Standards and Policies}

As early as 1975, thermal requirements for windows were set at levels that could only be satisfied by triple glazing, a practice not common in new homes at the time. The 1976 standards also required heat recovery systems for commercial and large apartment buildings, and insulation of heat distribution pipes. Sweden has tightened its standards several times since then $(77,112)$. To help meet these standards, Sweden also provided various incentives (1 12). For example, grants to promote energy conservation in existing buildings, available since 1984, have been given if adequate energy conservation measures are included in retrofit projects. "Soft loans" have been available for improvements in residential buildings more than 30 years old, and subsidies that cover about 50 percent of interest costs have been offered for multifamily houses. Some of these mechanisms, however, were suspended between 1987 and 1989 (100).

Other policies contributed to construction innovations. In the 1970s, for example, by promising to cancel loan payments for projects that did not produce expected energy savings, the government eliminated economic risks involved in testing experimental designs and technologies. National R\&D funds for technology development helped bring new products, such as residential heat pumps, onto the market. These programs were implemented during a period of rising oil prices and low electricity prices $(112)$.

\section{A Scenario for Future Improvements}

Potential for reducing energy use in buildings still may exist. One study estimated future energy use in Sweden based on implementing the best currently available technologies and advanced technologies expected to be commercialized between now and the year $2020(31,32)$. It projected dramatic reductions in $\mathrm{CO}_{2}$ emissions, ranging from 78 to 90 percent, primarily as a result of: 1) major efficiency improvements; and 2) a shift away from direct use of fossil fuels toward electrification based on nonfossil fuel generating capacity. As a result, the building sector's share of total energy use was projected to drop from 35 to 20 percent.

This scenario also demonstrates how reducing demand can create more flexibility on the supply side. As demand is reduced, the most costly supply technologies, from an environmental and national security standpoint, do not have to be pursued, or at least their use can be minimized. For example, Sweden's program to reduce energy use in buildings is part of its strategy for eliminating nuclear power and reducing dependence on foreign oil over the next few decades.

the room, thus reducing air-conditioning requirements.

Excess use of light can be avoided by: placing light switches in convenient locations; installing individual switches for each light; and using automatic controls to turn lights off or to adjust their intensity. This can be done with simple timers, or sensors that measure light levels or detect whether or not an area is occupied. Excess energy use also occurs when individual lights generate more light than is needed. This can be avoided by using lower-wattage bulbs, task lighting, and using con- trols that permit light levels to be dimmed when less light is required.

\section{Space Conditioning}

The amount of energy used for heating and cooling can be decreased through improved thermal integrity, improved equipment energy efficiency, and siting and landscaping decisions.

Thermal integrity can be improved by insulating buildings to reduce infiltration of outside air. To retrofit buildings ${ }^{9}$ - with typical savings of 20 to 25 percent and paybacks in 2 to 9 years (50), the most

"Building retrofits are modifications t. existing equipment or the building shell to reduce energy use (e.g., adding insulation, upgrading ventilation exuipment in commercial buildings, adding storm windows, etc). 


\section{U.S.S.R.}

\section{Box 4-B-Energy Use in Soviet and Eastern European Buildings}

The Soviet building sector accounts for approximately 20 percent of final energy use, including 49 percent of all heat and 14 percent of all electricity (71). Within the sector, energy is used predominantly for heat (77 percent), followed by electricity (17 percent) and direct fuel use (6 percent). 'As of 1985, per-capita energy consumption in Soviet buildings was less than one-half that in the United States (7), at least partly because of smaller per-capita living area and less use of appliances (74).

Several opportunities exist for conserving energy in buildings. First, the thermal integrity of buildings could be greatly improved, as over one-third of all energy used in buildings is wasted (71). Housing shortages and lack of capital allocated to the sector have resulted in hastily erected apartment buildings with poor thermal integrity. Building energy efficiency codes are very low; for example, recommended wall insulation for Moscow is the same as in California, which has a much warmer climate (74).

Second, heat losses from district heating distribution systems (due to poor insulation of pipelines, long distances between sources of heat and end use, lack of antirust materials, and frequent power outages) could be reduced (71). A large portion of urban Soviet buildings are heated by district heating, up to half of which may be cogenerated.

Third, the energy efficiency of appliances could be irnproved this is particularly important in light of expected growth in appliance use. Current Soviet appliances are less efficient than western ones; for example, Soviet refrigerators use an estimated 30 to 40 percent more electricity than larger sized models in western countries (71).

Fourth, natural gas, which the U.S.S.R. has in abundance, could be used in place of, for example, coal. ${ }^{2}$ The building sector is the only branch of the Soviet economy where coal is the most prevalent fuel; in 1980, coal supplied over 40 percent of all heat for housing and municipal buildings. This accounted for one-third of total fuel use. Electricity is projected to supply only 13 percent of the sector's energy needs by 2000 (7).

One major obstacle to achieving these opportunities is government subsidization of energy costs to consumers-for example, occupants in Soviet buildings pay a fixed fee for heating based on the square footage of their apartments, regardless of how much energy they use (also see ch. 9). Metering systems are almost nonexistent. And, gains made in improved thermal integrity of buildings and in production of more efficient appliances could be more than offset by per-capita increases in living area and use of appliances, depending on the overall rate of economic growth.

\section{Eastern Europe}

Buildings accounted for 28 percent of primary energy demand in Eastern Europe in 1985 (46). As incomes grow, so will other attributes such as air-conditioning, living area per capita, and, consequently, overall energy demand. One study projected that without major policy changes encouraging energy efficiency, total energy consumption in the buildings sectors would double between 1985 and 2025; even with the implementation of energy-efficiency policy measures, energy consumption was still projected to increase by nearly 50 percent.

Not surprisingly, potential changes vary considerably among countries. In the residential sector, for example, no decline in energy use per square foot should be expected in Romania, because energy consumption in Romanian residences already is very low. In contrast, improvements could occur in Poland, because high-quality coal or natural gas could replace low-quality coal, which currently provides the vast majority of heat in residences.

'Direct fuel usc includes fuels not used to produce thermal power for space heating. However, many dual-purpose stoves used for cooking and heating, and fueled mostty by coat and wood, are considered indirect fuel consumers. Here, direct fuel use includes only natural gas, liquefied petroleum gas, and kerosene used for stoves, small boilers, hot water in laundries and bathrooms, etc. (71).

Whether this would reduce greenhouse gas emissions depends partly on whether the U.S.S.R. can reduce its rate of methane leakage from natural gas production and distribution.

feasible options generally are to: 1) caulk and weatherstrip cracks around doors and windows; 2) add more insulation in roofs and walls; 3 ) install draperies and/or shades; and 4) improve windows, e.g., through installing double- and triple-paned windows with higher insulating values (see box 4-C). Just adding attic insulation alone in homes with little or none can reduce space heating require- 
Figure 4-5-Energy Efficiency of Various Light Sources

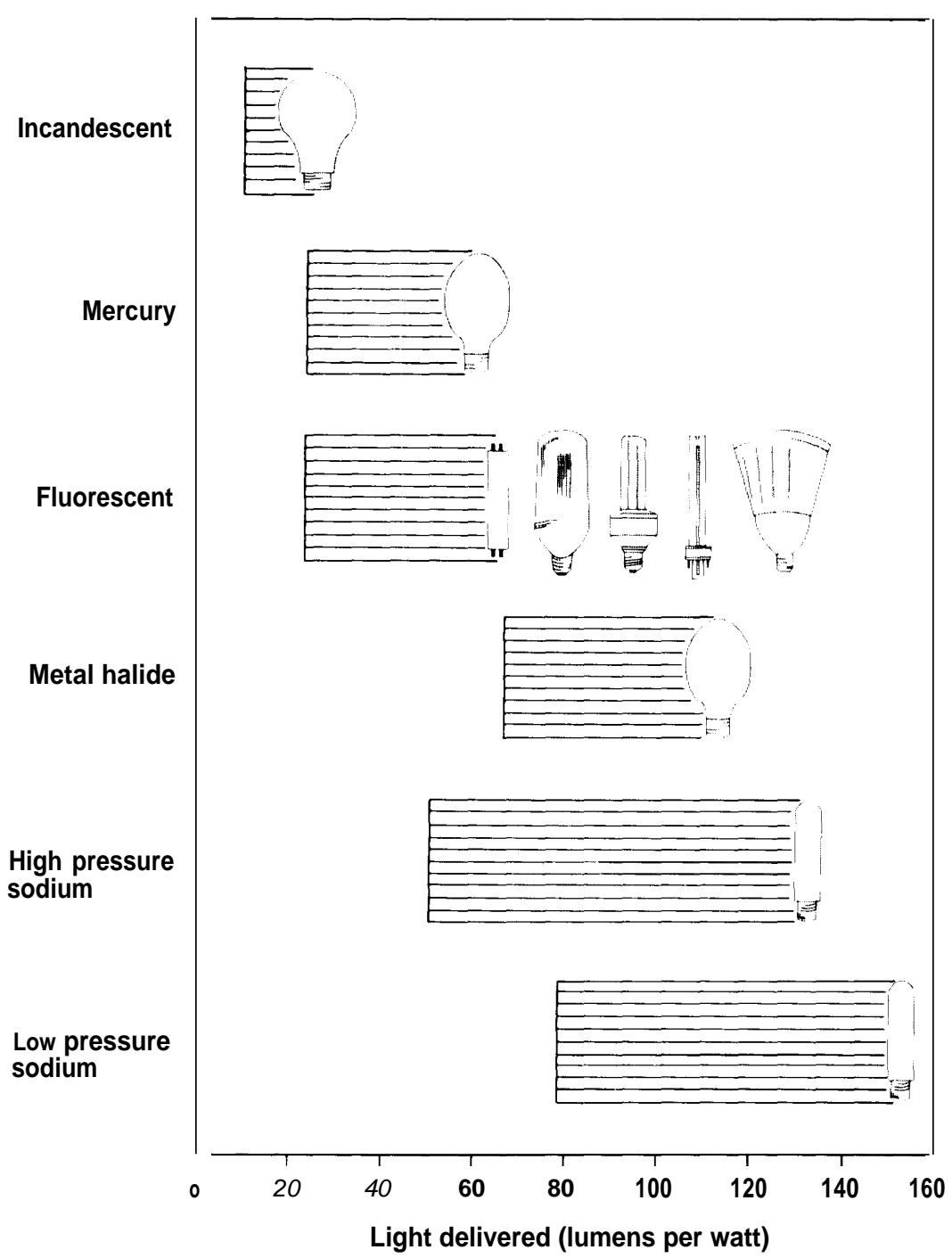

fluorescent includes ballast losses.

SOURCE: U.S. Department of Energy, Energy Efficient Lighting, DOE/CE-0162 (Washington, DC: 1986).

ments by 15 to 33 percent with simple paybacks in 2 to 6 years $(33){ }^{10}$

New buildings can be constructed with more compact forms, oriented to take advantage of sunlight, and designed with less and/or different glazing. 'Passive' solar-heating systems can be used to exploit the Sun's energy during cold periods. The most energy-efficient new houses use one-third to one-half of the energy required by the average new house (see figure 4-6).

Improved equipment for heating, ventilating, and air-conditioning (HVAC) will be important to decrease energy use in commercial buildings (39). The best new HVAC equipment uses 30 to 90 percent less energy than existing stock (39). Automatic controls play an increasingly important role; these

\footnotetext{
${ }^{10}$ Earth-sheltered homes, which use the surrounding earth itself as insulation and for protection from winds, can be cost-effective in colder climates
} with low humidities and proper soil and siting conditions $(37,48)$. 


\section{Box 4-C--Insulation and R-Values}

Keeping buildings warm in winter and cool in summer requires a considerable amount of energy. This energy use can be cut by reducing the amount of heat (or "coolness") lost through the ceiling, walls, and floor of a building.

All materials conduct heat to some extent, but some conduct more than others. A material's resistance to heat flow is measured in units called "R". A ceiling with an R-value of 20, for example, will lose only half as much heat as a ceiling with an R-value of 10 . Some typical R-values for ceilings, walls, and floors in several locations in the United States are shown below. In general, homes in colder climates have higher R-values. Uninsulated homes have very low R-values.

Representative R-values

\begin{tabular}{lccc}
\hline & Ceilings & walls & Floors \\
\cline { 2 - 4 } Uninsulated home ........ & $1-3$ & $2-5$ & $1-5$ \\
New homes: & & $11-12$ & 0 \\
Louisiana ............ & $19-22$ & $12-17$ & $11-19$ \\
Washington, DC ....... & 30 & 17 & 19 \\
Maine ............. & 38 &
\end{tabular}

Almost half the heat in an uninsulated building is lost through the ceiling, about one-fourth through windows and air flow, 20 percent through the floor, and 12 percent through the walls. Increasing R-values can reduce these losses. Adding about 3.5 inches of wall insulation, for example, will increase wall R-value by about R-12. Achieving R-38 requires 9 to 18 inches of insulation. Increasing ceiling insulation in Washington, DC, from none to R-19 can reduce heating bills by about 40 percent and cooling bills by about 20 percent.

A normal single-glazed window is rated at about R-1, whereas a standard insulated wall is rated at R-n or better. Heat lost through windows can be cut in half by adding a second pane of glass (largely due to the insulating space between the two panes); such storm windows are rated R-2. Coating one of the inner surfaces with a thin film of a transparent low-emissivity material (such as tin oxide) reflects infrared heat back into the house-this will raise the rating to R-3. Replacing the air between the two panes of glass with better insulators (such as xenon or argon) will yield a R-4.5 to R-6 window.

Figure 4C-1 below depicts some of the newest insulation technologies for homes and windows. Superinsulated walls and windows can reduce home heating needs by more than 75 percent compared with homes built before 1973. This wall (built in Sweden) prevents heat seepage by using I-beam studs of masonite held between two pine flanges. The heavily insulated walls are sealed on the inside with a plastic membrane to prevent indoor moisture from condensing on the cold insulation in the wall. Heat loss through windows is cut by coating one of the double-glazed windows with tin oxide and filling the air space with argon or xenon gas.

SOURCES: Refs. 17,70,80,86.

\section{Figure 4C-1-Superinsulated Wall and Window}

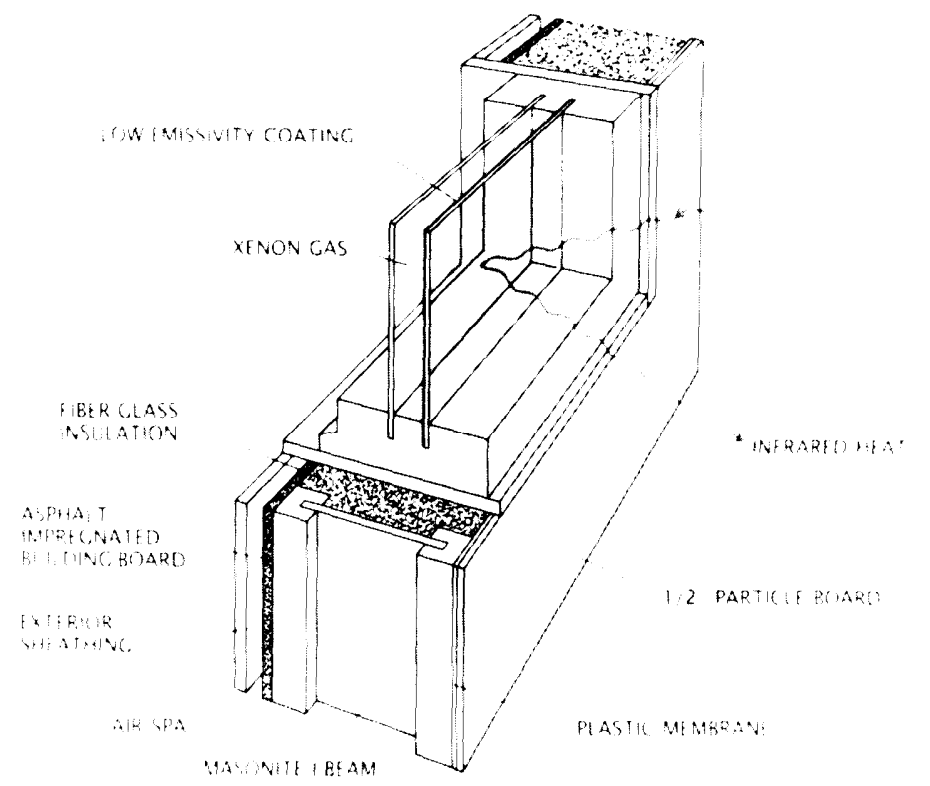

SOURCE: A.H. Rosenfeld and D. Hefemeister,' Energy-Efficient Building," Scientific American 258(4):78-85, April 1988. 
Figure 4-6-Space Heat Requirements in SingleFamily Dwellings in the United States and Sweden

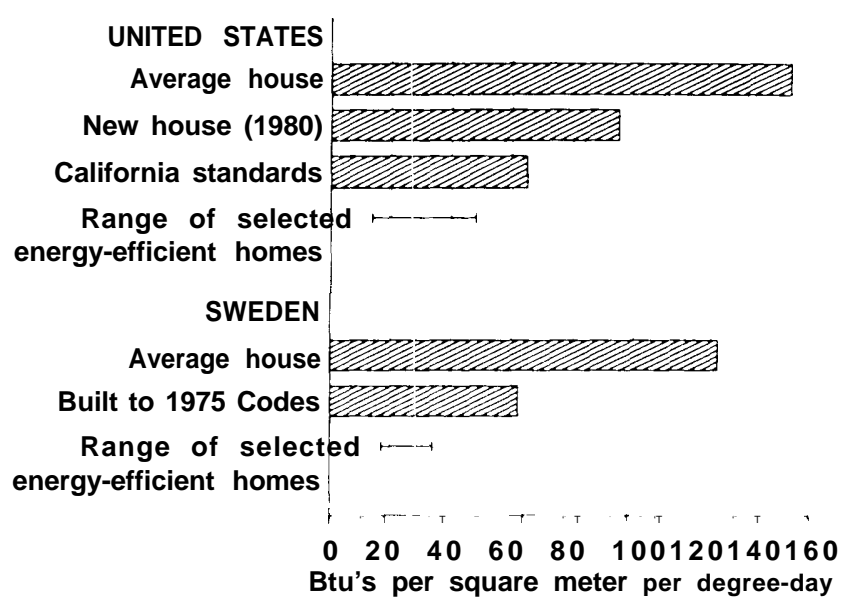

The most energy-efficient new homes in Sweden and the United States use one-third the energy of the average new home and even less than the average home in general (including older homes).

SOURCES: Office of Technology Assessment, 1991, adapted from Goldemberg et al., 1988.

range from common household programmable thermostats to electronic devices that are capable of responding to ambient conditions (e.g., outside and inside temperature and humidity, as well as information from local utilities). Some designers and builders have attempted to develop "smart' homes, in which energy management is electronically integrated with other household services (see box 4-D).

The efficiency of HVAC systems also can be improved through proper maintenance. Air conditioners, for example, contain heat exchangers that absorb heat from the building's air and discharge heat outside the building. The efficiency of these heat exchangers is compromised if dirt, dust, and debris reduce the flow of air over the exchangers and the rate of heat flow from the exchanger.

Building designs can be improved to make more use of natural ventilation and rely less on fans or air-conditioning. Planting trees and shrubs near buildings can reduce the use of energy through direct shading effects in the summer and wind protection in the winter (1; also see ch. 7). Large numbers of trees and light building surfaces may lessen the "heat island' effect associated with large cities and thereby reduce energy use $(1,42)$.

Changes in how buildings and energy are used by occupants also can contribute to energy savings. One option is to heat and cool only some rooms of a home and to conserve hot water. Another possibility is to minimize the conditioned space used per person, for example by purchasing smaller housing or by having more occupants in existing housing (e.g., children living at home for longer periods, renting rooms to borders). Multifamily dwellings share outside walls, thereby reducing wall area exposed to the elements and reducing space conditioning requirements.

\section{Water Heating, Appliances, Cooking}

The efficiency of other major end-uses also can be improved (28). The best 1988-model refrigerators, freezers, gas space heaters, air conditioners, electric water heaters, and lights are all at least 30 percent more efficient than typical models in use today (see figure 4-7). Several studies indicate potential lifecycle savings for a range of efficiency improvements in refrigerators, freezers, and water heaters $(53,101)$. Equipment expected to become available in the 1990s shows additional promise for efficiency gains.

The National Appliance Energy Conservation Act of 1987 (NAECA, Public Law 100-12), which set minimum-efficiency standards for many appliances, "will result in the least efficient appliances being taken off the market. One study estimated that this will lower residential energy use by about 0.9 quads (about 5 to 10 percent of current residential energy use) by the year 2000 (28). The American Council for an Energy-Efficient Economy estimated that appliances sold through the year 2000 in the United States could be operated at peak periods with 25 fewer large powerplants than would have been required had efficiency improvements not been made (2). However, NAECA does not set standards as high as can be achieved by the best currently available models, ${ }^{12}$ nor is it specifically technologyforcing (28). The Act does require that standards be

${ }^{1} 1$ Thirteen Product types are included:1) refrigerators, refrigerator-freezers and freezers; 2) room air conditioners; 3) central air conditioners and central air-conditioning heat pumps; 4) water heaters; 5) furnaces; 6) dishwashers; 7) clothes washers; 8) clothes dryers; 9) direct heating equipment; 10) kitchen ranges and ovens; 11) pool heaters; 12) television sets; and 13) fluorescent lamp ballasts.

${ }^{12}$ From a cost-effectiveness persfrective, this may be reasonable for heating and cooling equipment--e. g., a high-efficiency furnace may be a reasonable investment in Maine, but it would not save enough energy to recover first costs in Florida. 


\section{Box 4-D-Energy Management Systems and "Smart" Homes}

Large reductions in energy use (and hence emissions) are possible with energy management systems. These systems basically allow energy demand in a building to be managed to meet a variety of objectives, including greater convenience, improved security, lower operating costs, and energy conservation. They range from relatively simple programmable thermostats for homes to expensive, sophisticated microprocessor systems for large commercial buildings.

One ambitious project in the United States involves designing, building, and operating a home that integrates energy management and other household functions in an electronic system that is linked to outside information sources. This "Smart House Project" is a cooperative effort headed by the Research Foundation of the National Association of Home Builders. As typically conceived, a house might use as many as 150 microcontrollers, all capable of being individually controlled and monitored but all integrated into a single system that permits control of any individual component from many locations within the building. Occupants could program the operation of appliances in advance. Appliance energy use and performance could be monitored, providing information that could be used to cut energy use and maintenance costs. The linkage with outside entities could allow inputs such as price-signals from the local utility or remote commands from absent occupants. This type of approach to automation is seen by some as being potentially revolutionary $(9,29,47)$. Figure 4D-1 below is a diagram of a Smart House.

The Smart House Project is one of many whole-house automation efforts, including programs in Europe and Japan. These projects represent one area of a broader movement to increase the automation of buildings for a variety of reasons, ranging from load management (91) to improved building security. A small but rapidly expanding number of commercial buildings presently are automated with energy management systems $(27,59)$. Barriers to further penetration include a lack of familiarity with such systems, high costs, and lack of standardization.

Figure 4D-1-A "Smart House"

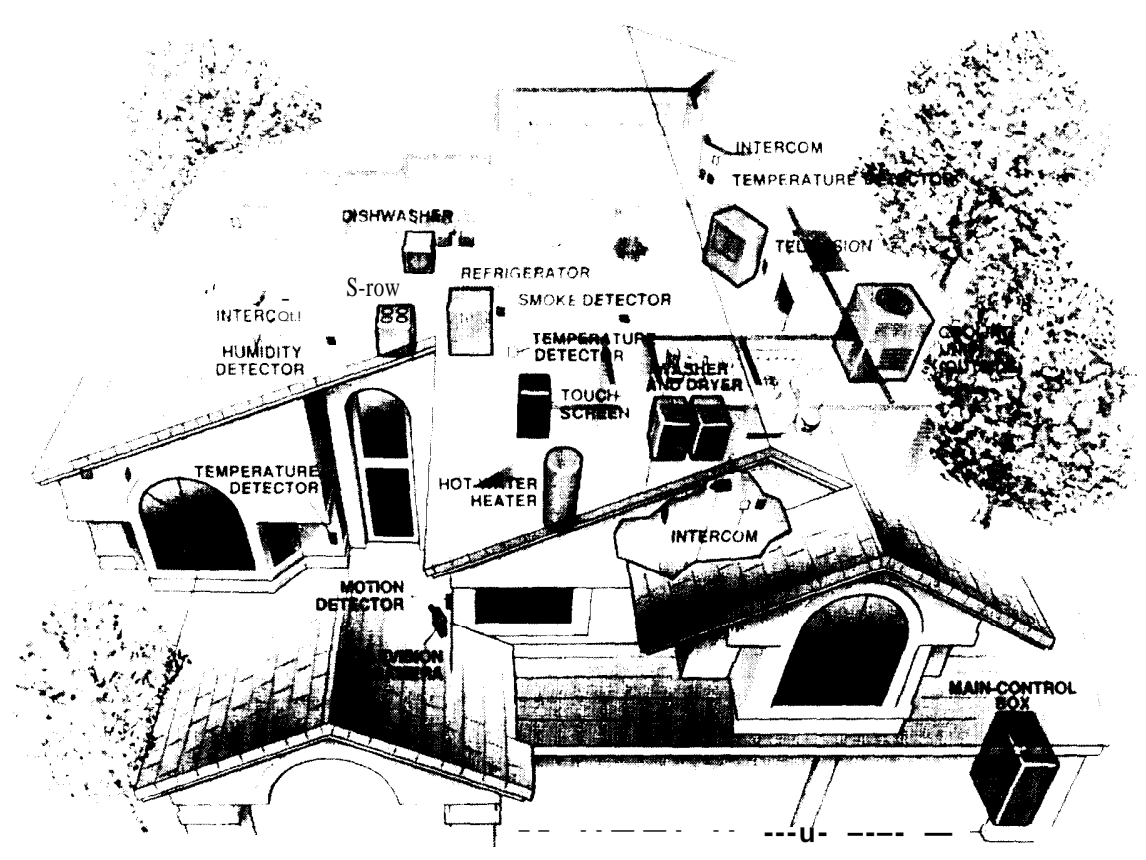

"Smart Houses" offer increased comfort at a reasonable price and are far more energy-efficient than the average home. At the hear of each house is an automated-control box that monitors heating, air-conditioning, lighting, and security systems. In more advanced homes, the owner can adjust the temperature and humidity and turn appliances on and off by touching a wail-mounted screen. Passive measures, including well insulated walls, roofs that reflect solar radiation, and shade trees (particularly on the south and west sides of the building to mitigate the Sun's heat), can also save energy.

SOURCE: R. Bevington and A.H. Rosenteld, "Energy for Buildings and Homes," Scientific American 263(3):76-86, September 1990. 
Figure 4-7-Energy Efficiency Potential of U.S. Residential Appliances

Thousands of $\mathrm{kWh} / \mathrm{year}$

5

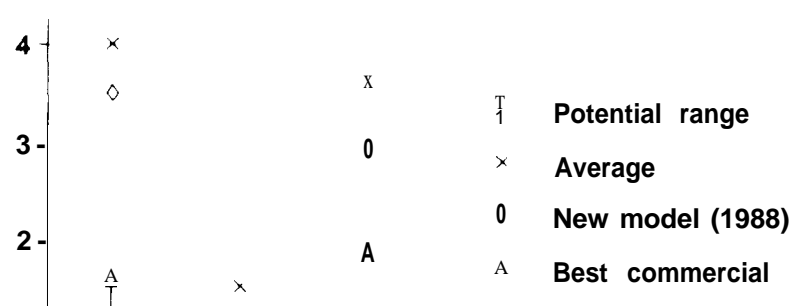

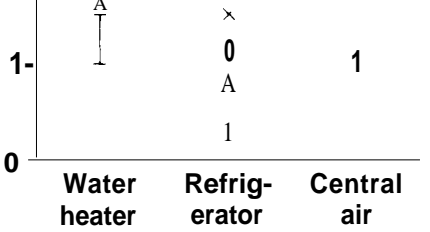

SOURCE: H.S. Geller, "Residential Equipment Efficiency: A State-of-theArt Review," contract prepared for the U.S. Congress, Office of Technology Assessment (Washington, DC: American Council for an Energy-Efficient Economy, 1988).

reviewed twice in the 1990s and allows for raising them. To date, 1993 standards for refrigerators, freezers, and small gas furnaces have been promulgated; ${ }^{13}$ standards are currently being developed for dishwashers, clothes washers, and dryers (87).

\section{Direct Energy Use in Buildings}

In addition to changing how buildings use energy, as described in the preceding sections, energy savings also are possible by changing how buildings get energy. This can involve, for example, renewable fuels, cogeneration, and district heating.

Renewable energy sources such as wind, biomass, and solar power can be used directly at building sites. In 1981, the Solar Energy Research Institute estimated that renewable energy sources applied directly at buildings might replace 4 to 5 quads of energy by the year 2000(81), equivalent to about 15 to 20 percent of energy consumption in U.S. buildings in 1985 . Nearly a decade has passed without major progress toward this goal, however.
Cogeneration is the production of electricity and useful heat at the same time, which improves the overall efficiency of fuel use. ${ }^{14}$ Energy savings then can be achieved in buildings by using cogenerated heat to heat space and water, and to drive cooling devices. One obstacle to cogeneration is that buildings often are distant from their source of heat. This can be overcome by situating cogeneration facilities near or inside buildings. 'District' heating systems, which supply heat (commonly in the form of steam) to a network of buildings, also can be developed. ${ }^{15}$ Cogeneration thus is particularly appropriate in medium- and large-sized commercial buildings (including shopping centers; see ref. 85), multifamily buildings, and densely settled residential communities.

To date, however, cogeneration has barely penetrated the buildings sector in the United Statesonly about 50 megawatts of cogenerating capacity were installed as of $1987(5) .{ }^{16}$ While heat can be used in many ways in industrial settings, its primary use in commercial buildings is for space heating, which is only needed during part of the year. In some buildings where heat build-up from people and office equipment is a problem, additional heat often is not needed. One possibility is to use cooling systems run with heat (i.e., "thermally activated refrigeration' '); some air conditioners that use waste heat are available on the market $(4,11,22,56)$. Additional R\&D is needed on computer monitoring and control technologies for integrating cogeneration into utility grids and reducing maintenance costs. Also needed are institutional arrangements to manage interconnected cogeneration facilities.

\section{CFC and Halon Use}

Chlorofluorocarbons (CFCs) and halons are major agents of the destruction of stratospheric ozone and also are important greenhouse gases (see ch. 2). CFCs are used in large quantities in buildings, principally in insulation and air-conditioning; they also are used in refrigeration (see ch. 8). Halons are used in fire extinguishers because they possess

\footnotetext{
${ }^{13}$ Of all classes of refrigerators, refrigerator-freezers, and freezers, only 7 models out of 2,114 listed in the directory Published by the Association of Home Appliance Manufacturers (6) meet the 1993 standards. Most models must therefore be improved or redesigned over the next 3 years (87).

${ }^{14}$ While a typical fossil fuel powerplant achieves fuel use efficiency of around $\mathbf{3 0}$ to $\mathbf{3 5}$ percent, by capturing waste heat cogeneration facilities can achieve efficiencies of 45 to 80 percent or more (see ch. 3).

${ }^{15}$ District heating already is used extensively in many European countries. It is relatively rare in the United States, although it is used in portions Of some major cities (e.g., New York and St. Paul) and in several entire small towns in the Midwest.

${ }^{16}$ Estimates of the technical potential for cogeneration in commercial buildings range between 3 and 40 gigawatts (i.e., several hundred times what is currently installed) $(5,62)$.
} 


\section{Box 4-E--CFCs and Halons in Buildings}

In the buildings sector, the main sources of CFCs are in insulation and air-conditioning; halons are a principal component of fire extinguishers. Because the United States and other signatories to the Montreal Protocol (see ch. 2) have agreed to rapidly reduce and eliminate production of CFCs, intensive efforts are being made to limit emissions from current sources and to deploy alternatives. Additional information on alternatives discussed in this box can be found in refs. 88, 106, and 107.

Insulation-some $\boldsymbol{C F C S}$ used in insulating foams are released during the manufacturing process, but most remain in the foam and slowly leak out over time. A large reservoir of CFCs therefore exists within existing buildings. Opportunities to change this situation are limited. For new buildings, though, some emissions can be reduced during foam manufacturing and, more significantly, alternatives to CFC-based insulation exist and others are being developed. In addition, building designs and construction techniques can reduce the need for supplemental insulation.

Air-conditioning--CFCs are released during the manufacturing, servicing, and disposal of air-conditioning units. Some emissions can be reduced at each one of these steps, for example, through recycling. Over the long term, the use of CFCs can be reduced by exploiting alternative ways to maintain comfortable temperatures in buildings. These range from using other refrigerants (such as HCFC-123 or -134a), using air-conditioning technologies based on waste heat or solar energy, and designing and constructing buildings in ways which reduce the need for air-conditioning in the first place.

Fire-extinguishers-Halons can be released from fire extinguishers as a result of leaks, testing, or actual use to suppress fires. For existing equipment, halon emissions can be reduced by using effective leak detection technologies and methods for testing fire-extinguishing systems without releasing the halon components. Use of existing halon-based extinguishers also can be limited to applications where their advantages are most critical-for example, fires in sensitive electronic equipment or aircraft. In the longer term, alternative fire extinguishing substances can be developed and deployed.

excellent flame-extinguishing properties and are nontoxic to humans.

CFCs are used to produce rigid foams, which are used primarily for insulation in buildings. In 1985 , roughly one-third of $\mathrm{CFC}-11$ production in the United States was for this purpose (83). Globally, approximately 39 percent of CFC-11 and 12 percent of CFC-12 consumption in 1985 were for rigid foams (35). ${ }^{17} \mathrm{CFC}-11$ and CFC-12 also are used in large, high-volume air conditioners, although most air conditioners use CFC-22, which is somewhat less damaging to stratospheric ozone (see ch. 2). Methods for reducing the use of CFCs and halons in buildings are described in box 4-E.

\section{BUILDINGS IN DEVELOPING COUNTRIES}

\section{Trends in Energy Use}

About 40 percent of total energy use in developing countries currently is derived from noncommercial sources (e.g., firewood, crop residues, char- coal) .18 This percentage varies widely from country to country (e.g., from nearly 100 percent in Nepal, to less than 10 percent in Libya) (72). Much of this noncommercial energy use occurs in the buildings sector, particularly in rural areas and residences. One study, for example, estimated that households accounted for 35 to 60 percent of total energy use in four low-income countries and 15 to 35 percent of total energy use in four transitional developing countries (52). Lower income households tend to use noncommercial fuels mainly for cooking; thus cooking is the largest end-use of household energy in developing countries.

The use of commercial fuels (i.e., coal, oil, gas, and electricity) is growing, however. Between 1978 and 1984, for example, growth in per-capita commercial energy use was about 18 percent in Asia, 21 percent in Latin America, and 36 percent in West Africa (72). In comparison, OECD growth rates for this period were 2 to 3 percent. Although developed countries are currently responsible for the largest share of $\mathrm{CO}_{2}$ emissions in the buildings sector, the

\footnotetext{
${ }^{17}$ I.e., in countries reporting their production to the Chemical Manufacturers Association; countries with centrally planned economies are not included.
}

${ }^{18}$ The distinction between commercial and noncommercial fuels, though, is blurry (see ch. 9 and ref. 94). 
developing countries' share of energy use and associated $\mathrm{CO}_{2}$ emissions in the sector should increase over the next 25 years.

There are many reasons why energy use will increase in these countries, including their continuing urbanization and adoption of modern cooking technologies ${ }^{19}$ and appliances. Greater urbanization and wealth tend to lead to the construction of western-style buildings, both residential and commercial, which generally require commercial energy sources for space conditioning. The number of commercial buildings will continue to grow. Ownership of electric appliance s--+. g., refrigerators, televisions, washing machines-is also growing rapidly in some countries $(72,94)$. These factors and population growth are causing electricity demand to climb sharply, yet current electric power generating infrastructures often are already short of capacity $(89) .^{20}$

Lighting currently accounts for only a small fraction of total energy use in developing countries (94). In rural areas, people often are limited to light from wood fires or perhaps kerosene wick lampsthe primary sources of light for more than 2 billion people. As rural incomes increase, or as people move to urban areas, though, lighting services (e.g., butane or pressurized kerosene mantle lamps, electric lighting) and the energy used to provide them increase dramatically.

Using energy to heat buildings is not an important end-use in the majority of developing countries, since most have tropical climates, although it is important in mountainous, and mid- and highlatitude areas (e.g., northern China) (94). Similarly, little energy currently is used for space cooling, despite typically hot climates. Traditional building designs (e.g., natural ventilation and other techniques that do not require additional energy inputs) and careful siting have long been used to moderate temperatures and keep indoor environments as comfortable as possible $(18,20,21,114)$. However, urbanization and increasing use of commercial building materials, mechanical ventilation, electric fans, and air-conditioning are making traditional designs less common and increasing energy requirements. ${ }^{21}$

\section{Opportunities To Reduce Energy Use}

As the economies of developing countries grow, demands for energy will continue to increase. As this happens, developing countries will have many opportunities to employ technologies and practices that allow for the most efficient generation and use of this energy. Given the critical needs for economic development in many countries, this will not reduce energy demand below current levels, but it can allow overall energy use (and associated $\mathrm{CO}_{2}$ emissions) to grow more slowly without hindering overall economic development.

In the residential sector, more efficient cooking practices are the most pressing need. This can be accomplished by switching to modern fuels such as natural gas, liquefied petroleum gas, kerosene, or electricity, or using more efficient wood stoves (see ch. 7). Significant opportunities also exist for using electricity more efficiently; the technologies for reducing appliance and lighting energy use are basically the same as those discussed above for the OECD countries.

Commercial buildings now being built in developing countries will last well into the next century. Opportunities for more efficient energy use in commercial buildings are similar to those available in industrialized nations, with similar levels of potential savings $(12,23,24,32)$. Nonetheless, because of the anticipated growth of demand for energy services in the buildings sector over the next 25 years, there is likely to be an aggregate growth in energy consumption, despite increased efficiency. Energy conservation can slow this growth and also reduce foreign debt accumulation by minimizing the importation of fossil fuels and equipment for building electricity-generating installations.

\footnotetext{
${ }^{19}$ The use of modern cooking fuels (i.e., natural gas, propane, fuel oil, kerosene, biogas) and cooking technologies makes a substantial difference in energy efficiency. The average consumption level for cooking with biomass is 9.5 to 14 million Btu's per year compared to 1,9 to 2.8 million Btu's per year for fossil fuels. Thus, a switch to more modem fuels, per se, is not necessarily associated with an increase in total residential energy use, but it is associated with the increase in ancillary energy uses that goes along with higher income levels.

${ }^{20}$ The exact effect on $\mathrm{CO}_{2}$ emissions will depend on the mix of fuels (including electricity); the relative efficiencies of commercial versus noncommercial fuels; and whether the use of noncommercial fuels was causing deforestation or forest degradation (see ch. 7).

${ }^{21}$ Air-conditioning currently is rare in residential buildings in developing countries, but it isused in many commercial buildings (73).
} 


\section{OTA EMISSION REDUCTION SCENARIOS}

Tables 4-1 and 4-2 show the assumptions that we used to model potential $\mathrm{CO}_{2}$ reductions in U.S. residential and commercial buildings, respectively, for three scenarios-business as usual (Base case), and after the adoption of Moderate and Tough controls (app. A describes the model in detail). There are three major strategies for controlling emissions (see table row headings). The Operation \& Maintenance/Existing Stock category involves measures that are possible with existing stock; these can be implemented quickly and require no new investment. New Investment incentives would encourage a consumer to buy, for example, a more efficient heater when the existing one needs to be replaced. In the Accelerated Turnover and New Technology category, retirement of old equipment and use of new technologies would occur 5 years sooner than now anticipated.

The model's projections of $\mathrm{CO}_{2}$ emissions in the year 2015 for the three scenarios are given as a percentage of 1987 emissions, with a breakdown by end-use (see figure 4-2). The model's overall results from 1987 to 2015 are shown in figure $4-8$ as a percentage change from 1987 emissions. ${ }^{22}$ Under the Base case, we estimate that U.S. $\mathrm{CO}_{2}$ emissions in 2015 from the buildings sector will be almost 30 percent higher than emissions in 1987. In the Moderate case, if technologies that are currently available and that pay for themselves over the life of the equipment are adopted, $\mathrm{CO}_{2}$ emissions in 2015 from the U.S. buildings sector can be reduced by about 5 percent relative to 1987 levels. In the Tough case, technologies that are expected to be commercially available in the next decade could reduce buildings sector emissions by about one-third relative to 1987 levels by 2015 ,

Other analyses of future energy use in the U.S. buildings sector yield results ranging from an increase of 11 percent by $2010(27,28)$ to a net reduction of 41 percent (based on total penetration of cost-effective, energy-saving technologies) by 2020 , relative to 1985 emissions (3 1). Our scenarios generally fall within the midrange of these estimates.

These projected reductions do not assume major changes in the fuel mix used to produce energy for buildings (figure 4-9 shows this mix for each scenario). Note that a large portion of the energy used in buildings is electricity. Since electricity in the United States is produced primarily from coal, which is the most $\mathrm{CO}_{2}$-intensive fuel, additional emissions reductions could be achieved by changing how electricity is generated. Dramatic changes in the fuel mix used by utilities (see ch. 3) to generate electricity would affect potential $\mathrm{CO}_{2}$ reductions in the buildings sector. A major shift to nonfossil fuels might even change the attractiveness of some technical options; for example, cogeneration could become less attractive. ${ }^{24}$

How the use of wood would change in response to shifts in demand for other energy sources is not modeled. Most residences burning wood also have a second fuel source. As energy prices for these secondary sources increase, wood will be used more. Conversely, as oil and gas energy bills drop as a result of falling prices or conservation investments, wood may be partially replaced with these purchased fuels. The effect of different levels of wood use on $\mathrm{CO}_{2}$ emissions depends on how quickly wood is being grown. If wood is grown at least as fast as it is burnt, then wood use effectively has zero $\mathrm{CO}_{2}$ emissions. However, since wood is often burned inefficiently, the emissions from wood burning (especially when deforestation is factored in) may exceed even coal emissions (per unit of useful energy).

\section{Base Case}

For residential buildings, the base case shows a 6 percent increase in $\mathrm{CO}_{2}$ emissions by 2015 , relative to 1987 levels. This projected increase is lower than other studies $(16,105)$ and even GRI's base case (41) because we include the effects of the new NAECA standards. We assume slower growth

\footnotetext{
${ }^{22}$ Note that the results presented in this figure show emissions as a percentage change from 1987 levels; this should not be confused with the format presented in figures 4-2, 4-10, and 4-11, which present results as a percentage of 1987 emissions.

${ }^{23}$ In the United States, the average emission factor per quadrillion Btu's of delivered electricity currently is 57 million metric tons of carbon, based on a fuel mix of 55 percent coal, 11 percent gas, 5 percent oil, and 30 percent nonfossil sources (including hydroelectric power, nuclear, and renewables) (44).

${ }^{24}$ Changes in the level of demand for electricit also might affect supply choices by utilities (e.g., very low demand would retie it mom. difficult for utilities to justify investments in new, less carbon-intensive generating technologies).
} 
Table 4-I-Residential Buildings: Measures in the OTA Model

\begin{tabular}{|c|c|c|c|}
\hline & Base case & Moderate controls & Tough controls \\
\hline \multicolumn{4}{|l|}{$\begin{array}{l}\text { Operation and maintenance/ } \\
\text { existing stock: }\end{array}$} \\
\hline Housing shell retrofits & $10 \%$ savings by 2015 & $20 \%$ savings by 2015 & $\begin{array}{l}\text { Northern homes } 30^{\circ} / 0 \text { savings by } 2000 \text {. } \\
\text { Southern homes same as Moderate. }\end{array}$ \\
\hline Compact fluorescent & None & $\begin{array}{l}\text { Replace heavily used bulbs, net } 35^{\circ} / 0 \\
\text { savings }\end{array}$ & $\begin{array}{l}\text { Replace more bulbs, net } 50 \% \text { savings } \\
\text { (technical maximum about } 650 \mathrm{~A} \text { ) }\end{array}$ \\
\hline \multicolumn{4}{|l|}{ New Investments: } \\
\hline Shell efficiency of new homes & $\begin{array}{l}\text { New homes } 15^{\circ} \mathrm{A} \text { more efficient } \\
\text { than existing average }\end{array}$ & $\begin{array}{l}\text { New homes space heat } 50^{\circ} \mathrm{A} \text { more } \\
\text { efficient than existing average, AC } \\
25 \% \text { more efficient }\end{array}$ & $\begin{array}{l}\text { Northern new homes space heat } 8570 \text { more } \\
\text { efficient than existing average, AC } 45 \% 0 \\
\text { more efficient. Southern new homes same } \\
\text { as Moderate. }\end{array}$ \\
\hline \multicolumn{4}{|l|}{ HVAC equipment } \\
\hline Gas space heat & $\begin{array}{l}82 \% \text { efficient by } 2005 \\
\text { Gas heat pump introduced in } 1995 \text {, } \\
10 \% \text { new share by } 2015\end{array}$ & $\begin{array}{l}\text { Mix of } 84 \% \text { and } 92 \% \text { (pulse combustion) } \\
\text { Same as Base case }\end{array}$ & $\begin{array}{l}\text { All gas pulse combustion } \\
\text { Move market share of gas heat pump forward } \\
\text { by } 5-10 \text { years and reduce other gas heat }\end{array}$ \\
\hline Oil space heat & $81 \%$ efficient by 2005 & Same as Base case & Same as Base case \\
\hline Electric space heat & Heat pump COP of 2.5 by 2015 & $\begin{array}{l}\text { Replace } 20 \$ 40 \text { of new electric resistance } \\
\text { space heat with heat pump }\end{array}$ & $\begin{array}{l}\text { Replace } 5070 \text { of new electric resistance } \\
\text { space heat with heat pump }\end{array}$ \\
\hline Wood space heat & None & None & Improved efficiency of wood use \\
\hline Appliances & National appliance standards & Most efficient on market today & Most efficient on market today \\
\hline \multicolumn{4}{|l|}{ Water heaters } \\
\hline $\begin{array}{l}\text { Gas water heaters } \\
\text { Heat pump water heaters }\end{array}$ & $\begin{array}{l}\text { National appliance standards } \\
\text { None }\end{array}$ & $\begin{array}{l}\text { Same as Base case } \\
\text { Replace } 80 \% \text { of new electric water } \\
\text { heaters with heat pump water heater }\end{array}$ & $\begin{array}{l}\text { Same as Base case } \\
\text { Replace } 100 \% \text { of new electric and oil water } \\
\text { heaters with heat pump water heater }\end{array}$ \\
\hline $\begin{array}{l}\text { Accelerated turnover and new } \\
\text { technology: }\end{array}$ & & & $\begin{array}{l}\text { Existing equipment lifetimes } 5 \text { years } \\
\text { shorter }\end{array}$ \\
\hline HVAC equipment & Not applicable & Not applicable & $\begin{array}{l}\text { Gas heat pump heating COP of } 1.7 \text { by } 2015 \text {; } \\
\text { electric heat pump heating COP of } 2.8 \text { by } \\
2015 \text {; improved AC efficiency }\end{array}$ \\
\hline Appliances & Not applicable & Not applicable & $\begin{array}{l}\text { New prototype appliances (for example, heat } \\
\text { pump dryer) }\end{array}$ \\
\hline Water heaters & Not applicable & Not applicable & $\begin{array}{l}\text { Replace gas water heat with } 80 \% \text { efficient } \\
\text { prototype }\end{array}$ \\
\hline
\end{tabular}

SOURCE: Office of Technology Assessment, 1991. 
Table 4-2-Commercial Buildings: Measures in the OTA Model

\begin{tabular}{|c|c|c|c|}
\hline & Base case & Moderate controls & Tough controls \\
\hline \multicolumn{4}{|l|}{$\begin{array}{l}\text { Operation and maintenance/ } \\
\text { existing stock: }\end{array}$} \\
\hline Building retrofits & $60 \%$ savings by 2015 & $150 / 0$ savings by $2005,25 \%$ by 2015 & $40 \%$ savings by 2000 \\
\hline Lighting & None & $\begin{array}{l}\text { High efficiency bulbs, net } 120 / . \text { savings } \\
\text { ( } 80 \% \text { of } 15 \% \text {--assume } 20 \% \text { market } \\
\text { already) }\end{array}$ & $\begin{array}{l}\text { High efficiency bulbs, net } 120 / \text {. savings } \\
\left(80^{\circ} / 0 \text { of } 150 / \text { assume } 200 / ' \text { market }\right. \\
\text { already) }\end{array}$ \\
\hline \multicolumn{4}{|l|}{ New investments: } \\
\hline Shell efficiency of new buildings & $\begin{array}{l}\text { New buildings } 150 / \text {. to } 22 \% 0 \text { more } \\
\text { efficient than existing } 1987 \text { average }\end{array}$ & $\begin{array}{l}\text { New buildings } 500 / \text {. more efficient than } \\
\text { average ( } 42 \% \text { above new Base case } \\
\text { buildings) }\end{array}$ & $\begin{array}{l}\text { New buildings } 75 \% \text { more efficient than } \\
\text { average ( } 71 \% \text { above new Base case } \\
\text { buildings) }\end{array}$ \\
\hline \multicolumn{4}{|l|}{ HVAC equipment } \\
\hline Gas space heat & $\begin{array}{l}84 \% \text { efficiency by } 2010 \\
\text { Gas heat pump introduced in } 1995, \\
2 \% \text { new share by } 2015\end{array}$ & $\begin{array}{l}\text { Mix of } 640 / . \text { and } 920 / . \text { efficient } \\
\text { Same as Base case }\end{array}$ & $\begin{array}{l}\text { All } 92 \% \text { efficient } \\
\text { Move market share of gas heat pump } \\
\text { forward by } 5-10 \text { years and reduce } \\
\text { other gas heat }\end{array}$ \\
\hline Electric space heat & Heat pump COP of 1.95 by 2015 & $\begin{array}{l}\text { Replace } 20 \% \text { of new electric resistance } \\
\text { space heat with heat pump }\end{array}$ & $\begin{array}{l}\text { Replace } 50 \% \text { of new electric resistance } \\
\text { space heat with heat pump }\end{array}$ \\
\hline Air-conditioning & None & $\begin{array}{l}\text { Adjust variable speed drives and } \\
\text { economics, net } 200 / 0 \text { savings }\end{array}$ & Same as Moderate case \\
\hline Cogeneration & $\begin{array}{l}0.13 \text { quad by } 2005,0.20 \text { quad } \\
\text { by } 2015\end{array}$ & $\begin{array}{l}0.18 \text { quad by } 2005,0.26 \text { quad } \\
\text { by } 2015\end{array}$ & 0.64 quad by 2015 \\
\hline Water heaters & None & $\begin{array}{l}\text { Replace } 80 \% \text { of new electric water } \\
\text { heaters with heat pump water heater }\end{array}$ & $\begin{array}{l}\text { Replace } 100 \% \text { of new electric water } \\
\text { heaters with heat pump water heater }\end{array}$ \\
\hline Lighting & None & $\begin{array}{l}\text { Combination of high efficiency bulbs, } \\
\text { ballasts, reflectors, and daylight; } \\
\text { net } 50 \% \text { savings in new, } 40 \% \text { in } \\
\text { replacements }\end{array}$ & $\begin{array}{l}\text { Combination of high efficiency bulbs, } \\
\text { ballasts, reflect, and daylight; net } 60 \% \\
\text { savings in new, } 50 \% \text { in replacements }\end{array}$ \\
\hline Electronic office equipment & Increased usage & $\begin{array}{l}50 \% \text { savings from improved technology } \\
\text { and } 20 \% \text { in reduced idle time: total } \\
600 / 0 \text { savings by } 2015\end{array}$ & $\begin{array}{l}65 \% \text { savings from improved technology } \\
\text { and } 40 \% \text { in reduced idle time: total } \\
80 \% \text { savings by } 2015\end{array}$ \\
\hline $\begin{array}{l}\text { Accelerated turnover and new } \\
\text { technology: }\end{array}$ & & & $\begin{array}{l}\text { Existing equipment lifetimes } 5 \text { years } \\
\text { shorter }\end{array}$ \\
\hline HVAC equipment & Not applicable & Not applicable & $\begin{array}{l}\text { Gas heat pump COP of } 1.4 \text { by } 2015 \text {, } \\
\text { electric heat pump COP of } 2.4 \text { by } 2015 \text {. } \\
\text { Heat exchangers yielding } 28 \% \text { AC } \\
\text { savings }\end{array}$ \\
\hline Cogeneration & Not applicable & Not applicable & $\begin{array}{l}0.96 \text { quad by } 2015 \text { including fuel cells } \\
\text { and improved chillers }\end{array}$ \\
\hline Water heaters & Not applicable & Not applicable & $\begin{array}{l}\text { Replace gas water heater with } 80 \% \\
\text { efficient prototype }\end{array}$ \\
\hline
\end{tabular}

Abbreviations: AC-air-conditioning; COP-coefficient of performance; HVAC-Heating, ventilating, and air-conditioning equipment.

SOURCE: Office of Technology Assessment, 1991. 
Figure 4-8-Summary of $\mathrm{CO}_{2}$ Emissions From the U.S. Buildings Sector by Year, Under the Base Case, Moderate, and Tough Scenarios

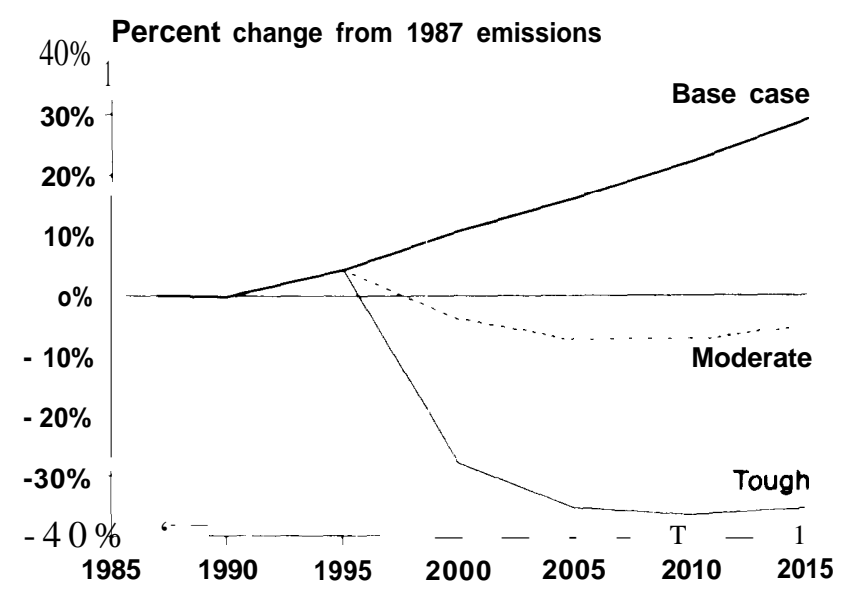

SOURCE: Office of Technology Assessment, 1991.

in electricity use than do other models; of the major commercial energy sources electricity is still the fastest growing energy source in the sector. However, in OTA's base case, residential electricity use increases by 0.5 percent per year, whereas other models assume it increases by 2 to 2.5 percent per year, at least until the year 2000.

For commercial buildings, $\mathrm{CO}_{2}$ emissions in the base case grow about 50 percent between 1987 and 2015. While total delivered energy use in commercial buildings increases by about 40 percent between 1987 and 2015, the increase in $\mathrm{CO}_{2}$ emissions is greater because we assume that electricity use grows by about 68 percent, primarily because of growing demand by commercial users for air-conditioning and office equipment. This corresponds to an electricity growth rate of 1.9 percent per year. Since electricity generated by U.S. utilities currently exhibits relatively high $\mathrm{CO}_{2}$ emissions per unit of delivered energy, increasing electricity consumption increases $\mathrm{CO}_{2}$ emissions disproportionally faster than does increasing use of other energy sources in this sector.

\section{Moderate Scenario}

In the Moderate scenario, improving the shell efficiency (or thermal integrity) of new (residential and commercial) buildings can reduce emissions by about 10 percent of 1987 levels by 2015; similar improvements in existing buildings can achieve a 4 percent reduction by 2015 (see figure 4-10). installing new, more efficient lights and electronic office
Figure 4-9--Fuel Use Under the Base Case, Moderate, and Tough Scenarios, by Fuel Type

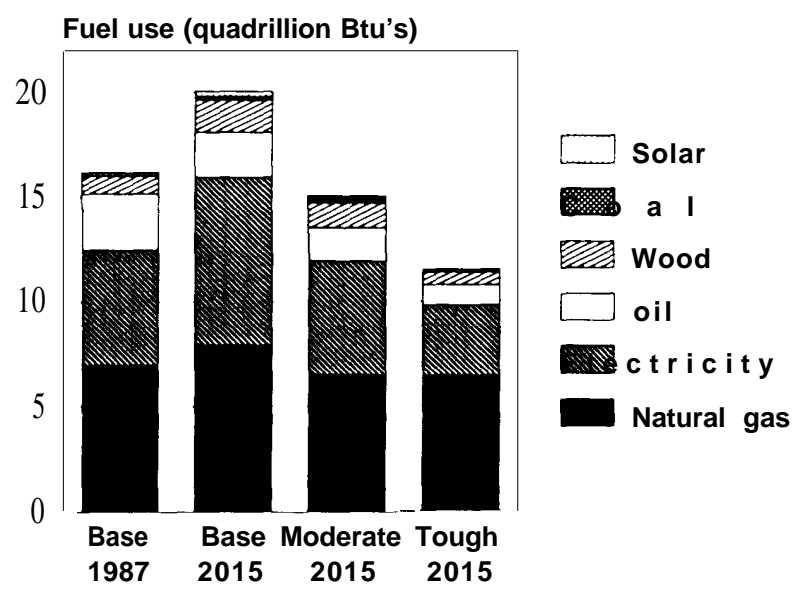

SOURCE: Office of Technology Assessment, 1991.

equipment will reduce emissions in 2015 by about 6 and 5 percent of 1987 levels, respectively; these two options, along with cogeneration, were applied only to commercial buildings in the model. Installing more efficient water heaters and appliances will reduce emissions in 2015 by about 4 percent, primarily in residential buildings.

After accounting for growth in energy use between now and 2015, together these Moderate residential and commercial options can reduce $\mathrm{CO}_{2}$ emissions by about 5 percent in 2000 and 2015, compared to 1987 levels (see figures 4-2 and 4-8). Controls in the commercial sector account for over two-thirds of the reductions. In 2000, New Investment options for both residential and commercial buildings contribute over 70 percent of the total reductions, but by 2015 , when a greater proportion of old buildings has been replaced, this percentage increases to over 80 percent. In both residential and commercial buildings, improvements in building shells yield the highest reductions of any individual option.

\section{Tough Scenanio}

In the Tough scenario, more ambitious investment in increasing the shell efficiency of new residential and commercial building can reduce emissions by about 18 percent relative to 1987 levels by 2015 , while similar improvements in existing buildings (i.e., "building retrofits") can reduce emissions by 4 percent (see figure 4-1 1). Retrofits provide the 
Figure 4-10-- $\mathrm{CO}_{2}$ Emissions Reductions in 2000 and 2015 Expressed as a Percentage of 1987 Building Sector Emissions, by Control Method, Under the Moderate Scenario

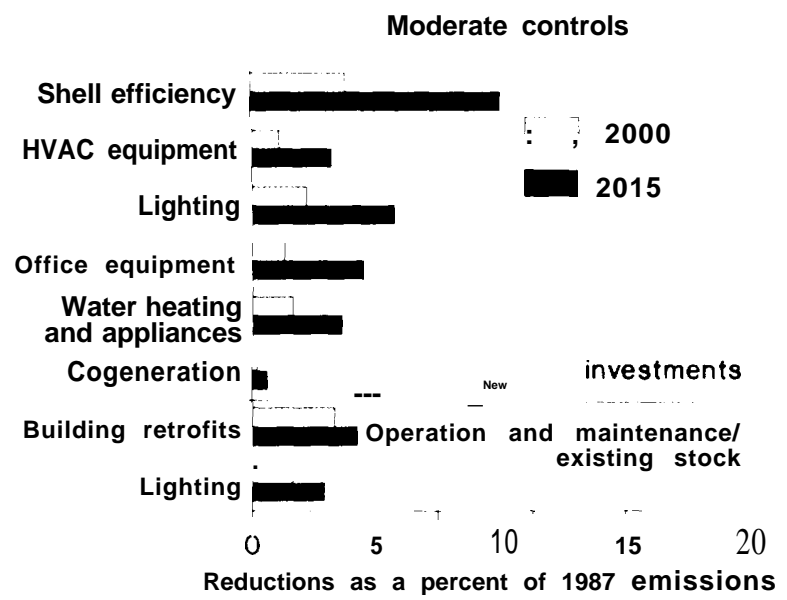

Note that emissions reductions are expressed as a percentage of 1987 emissions. This format should not be confused with the format in figure 4-8, which presents emissions, by year, as a percentage change from 1987 emissions.

SOURCE: Off Ice of Technology Assessment, 1991.

largest reductions of any individual option in the short term (i.e., around 10 years), but this option becomes less effective over time since fewer older buildings remain in which to install retrofit technologies. Installing new, more efficient lights and electronic office equipment will reduce emissions in 2015 by about 8 and 6 percent of 1987 levels, respectively. As in the Moderate scenario, these last two options, along with cogeneration, were applied only to commercial buildings.

More reductions could be achieved if existing equipment is replaced 5 years sooner than normal with new technologies that could become available within the next 20 years (see thin bars in figure 4-1 1). This accelerated schedule can augment total emissions reductions from each of the above three options by another 2 percent in 2015 compared to 1987 levels. About half of these additional reductions come from increasing the rate of turnover and half come from the new technologies themselves. ${ }^{25}$

Together, these Tough options can reduce $\mathrm{CO}^{2}$ emissions in 2000 by about 28 percent below 1987 levels and about one-third below 1987 levels by
Figure 4-1 1-CO Emissions Reductions in 2000 and 2015 Expressed as a Percentage of 1987 Building Sector Emissions, by Control Method, Under the Tough Scenario

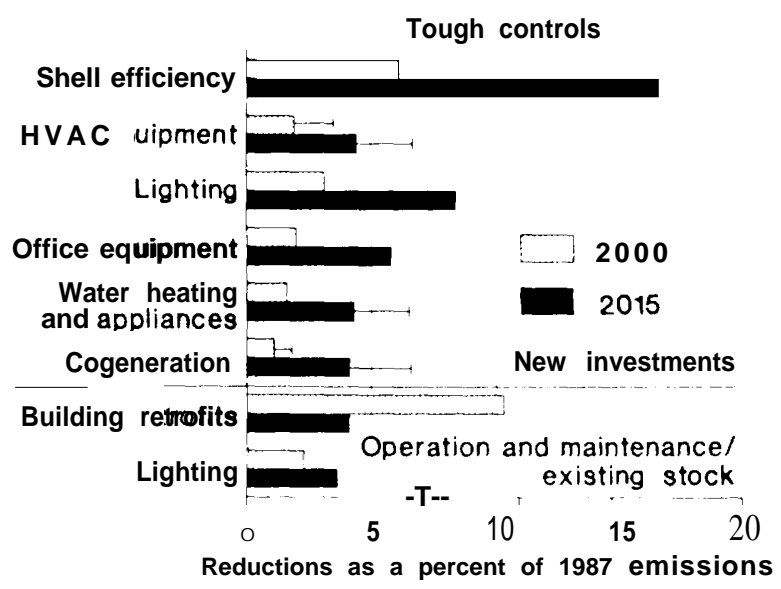

Note that emissions reductions are expressed as a percentage of 1987 emissions. This format should not be confused with the format in figure $4-8$, which presents emissions, by year, as a percentage change from 1987 emissions.

SOURCE: Office of Technology Assessment, 1991.

2015 (see figure 4-8). Controls in the commercial sector alone account for about 60 percent of these reductions. In 2000, New Investment options for both residential and commercial buildings contribute about 55 percent of the total reductions from the buildings sector, but by 2015 , when a greater proportion of old stock has been replaced, this percentage increases to about 70 percent.

\section{Costs of the Tough Scenario}

Costs for all Tough measures that are applicable to buildings in both the residential and commercial sectors fall in a range between net savings (i.e., equipment costs minus fuel savings) of $\$ 53$ billion per year to net costs of $\$ 7$ billion per year (1987 dollars). The costs of the individual measures are summarized below and presented in greater detail in appendix A.

Costs for the residential sector are best estimated by household. By 2015, there will be about 115 million households, 35 million built after 1995 and 80 million built before. We estimate that shell improvements to pre-1995 houses under our Tough

\footnotetext{
${ }^{25}$ The effect of increasing the turnover rate is greatest in space heating, where furnaces have a long lifetime, and in appliances, where the difference between new and average efficiencies is large; increased R\&D has the biggest impact on appliances because numerous promising developments exist in this area $(25,27)$.
} 
scenario will cost about $\$ 2,300$ per single family house in northern climates and $\$ 1,000$ per single family houses in southern ones. ${ }^{26}$ The cost of shell improvements in post- 1995 houses under our Tough scenario are somewhat higher. In northern climates, costs might be in the range of $\$ 6,000$ to $\$ 8,000$ per house and about $\$ 2,500$ per house in the South. For the 25 percent of households that live in multifamily dwellings, shell improvements will cost about half of the single-family home estimates given above. More efficient furnaces, air conditioners, water heaters, and appliances might total about $\$ 1,000$ to $\$ 1,500$ per household.

Assuming the shell improvements have a 30-year life and the more efficient appliances average a 15 -year life, total costs for the residential sector will be in the range of $\$ 30$ to $\$ 40$ billion per year. However, fuel savings from these appliances are about $\$ 55$ billion per year assuming 2015 fuel prices. Thus, the net costs for the residential sector fall in the range of savings of $\$ 15$ to $\$ 25$ billion per year. The cost effectiveness of these reductions is in the range of $-\$ 175$ to $-\$ 300$ per ton of carbon (i.e., savings of $\$ 175$ to $\$ 300$ per ton of carbon avoided).

By 2015, we anticipate about 72 billion square feet of commercial building space (up from about 45 billion today). Though costs of energy efficiency improvements vary by budding type, they appear to cluster in the range of $\$ 5$ to $\$ 11$ per square foot (65a) for a package of measures similar to our Tough lighting, shell, and heating and cooling equipment efficiencies. Costs for these improvements are in the range of $\$ 30$ to $\$ 65$ billion per year but fuel savings are approximately $\$ 55$ billion per year at 2015 fuel prices. Thus net costs for these measures fall between savings of $\$ 25$ billion per year and costs of $\$ 10$ billion per year. The cost effectiveness of these reductions ranges between -- $\$ 190$ per ton and $\$ 75$ per ton of carbon avoided.

The remaining reductions from installing cogeneration equipment and more efficient office equipment might yield net costs in the range of savings of $\$ 3$ billion per year to costs of $\$ 12$ billion per year, Thus total costs for the commercial measures fall between savings of $\$ 28$ billion to costs of $\$ 22$ billion per year.

\section{POLICY OPTIONS}

Reducing $\mathrm{CO}_{2}$ emissions from the buildings sector will require implementing numerous technical options, as well as individual behavioral changes, and removing a variety of barriers to investment in energy conservation. For example, translating our 'Moderate' residential emission reductions into practice means that all existing homes are retrofitted to achieve an average shell improvement of 20 percent; new home shells must be, on average, 50 percent more energy efficient than today's homes. In our 'Tough' scenario, existing homes are improved by 30 percent in northern (cold) parts of the country and 20 percent elsewhere; new home shells are 85 percent more efficient than the existing average in the same five areas of the country. ${ }^{28} \mathrm{To}$ accomplish such changes on a broad scale will require a combination of policies and consistent fiscal and regulatory signals.

This section discusses a wide range of ways to implement the various tactics available to control greenhouse gas emissions from buildings. In many cases, there is not a clear distinction between policy instruments that change, say, maintenance and those that accelerate actual turnover of equipment. Congress could combine several options to achieve modest or aggressive reductions from this sector depending on its goals.

\section{Overview: Barriers and Policy Instruments}

In both residential and commercial construction, minimization of upfront costs often takes precedence over total life-cycle costs because of the overriding concerns about cash flow and the cost of capital at the time of purchase. This creates a barrier to greater investment in energy conservation. In addition, most consumers lack expertise in evaluating energy information and prefer products similar to those they are replacing. An additional barrier is that those who make purchase decisions (e.g., builders) are often not those who pay utility bills. Policies for reducing emissions must address these obstacles.

${ }^{26}$ See ref. 65a for the primary data source from which the costs of our Tough scenario are estimated

27 Using the Census regions, this includes West and East North Central, New England, Mid-Atlantic, and Mountain region \# 2

${ }^{28}$ This efficiency level is between that of the Minnesota Energy Efficient Housing Demonstration Project Home (a well-insulated home; see ref. 32) and the Northern Energy Home (a superinsulated home with triple-glazed windows and night shutters; see ref. 61). 


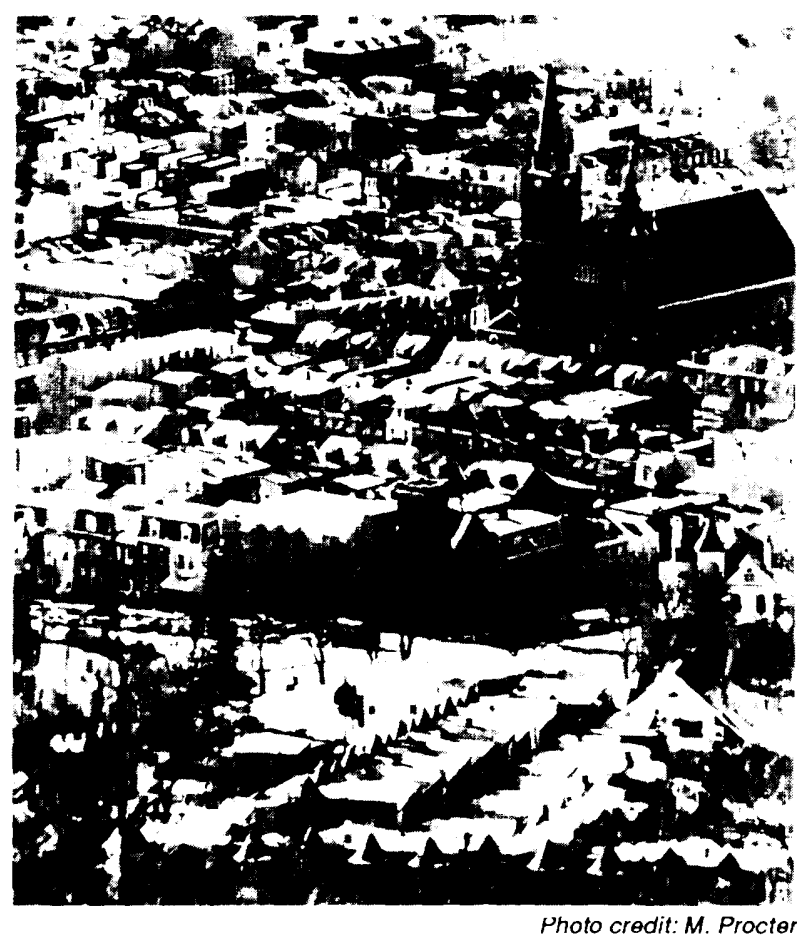

Rowhouses, churches, warehouses, and factories densely packed in Reading, Pennsylvania.

Policies for reducing $\mathrm{CO}_{2}$ emissions in the building sector include: end-use taxes, initial purchase taxes, utility least-cost planning, appliance standards, building codes, consumer information and marketing, zoning ordinances, and research and development. The synergisms possible among these policies are vital to reducing emissions. Taxation sends the price signals to reduce energy consumption. Regulation (codes and standards) can be used to remove the least efficient equipment, appliances, and buildings from the market. Incentive and information programs can be used to create a market for exceeding the standards, as well as to provide consumers with the information needed to make energy-conserving choices in response to price signals from taxation. There is also a role for government-sponsored $\mathrm{R} \& \mathrm{D}$ in the construction industry, the fragmented nature of which discour- ages the private sector from making capitalintensive and risky investments.

Congress could also mandate increased energy conservation in government procurement and in buildings the Federal Government owns or operates. ${ }^{29}$ Such steps would reduce perceptions of risk and provide an example for the rest of the country (98). Also, demonstration projects can provide data to improve our ability to predict savings from conservation measures. The Federal Government is the single largest consumer of energy in the Nation; Federal buildings consume 2 percent of the energy used in this sector-about 2 quads at a cost of $\$ 8.7$ billion (105a). Congress has directed Federal agencies to reduce their energy use by 10 percent (per square foot of floor space) from 1985 to 1995 (Public Law 1,00-615). The DOE Federal Energy Management Program (FEMP) is responsible for reporting to Congress on the progress toward this goal. ${ }^{30}$

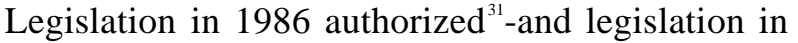
1988 required $^{32}$-Federal agencies to establish a program of 'Shared Energy Savings' (SES). Agencies were to contract with private energy-service companies (for up to 25 years) who would supply the capital for improvements to Federal facilities in exchange for a portion of cost savings. By the end of 1990 only four contracts were in place. Congress could try to streamline the contract process or provide further incentives for compliance.

\section{End-Use Taxes}

Energy end-use taxes would increase the price of energy, thereby encouraging lower energy consumption. Thus, they affect all levels of our model: O\&M, new investment decisions, the rate of turnover, and the intensity of private sector R\&D. End-use taxes can stimulate conservation in both new and existing buildings, and can send signals regarding energy use and purchases. However, end-use taxes can often be less effective in influencing consumer purchase decisions than other policy measures such as appliance standards, building codes, and initial purchase taxes or rebates set at similar levels of stringency. Taxes do not address issues such as the lack of

\footnotetext{
${ }^{29}$ OTA is completing a study in this area "Energy Use in The Federal Government' which will be released in summer 1991.

${ }^{30}$ Executive Order 12003, issued in 1977, mandated a 20 percent reduction in Federal energy use below 1975 levels by 1985. When the order expired in 1985, the executive agencies had not reached the goal, During the following 3 years, energy use rose 6 percent (98a).

${ }^{31}$ Consolidated Omnibus Budget Reconciliation Act (COBRA) Public Law 99-272.

${ }^{32}$ The Federal Energy Management Improvement Act (FEMIA) Public Law 100-615.

${ }^{33}$ Ref. 108 a discusses several impediments that exist under the current SES structure.
} 
information about life-cycle costs, uncertainty, and divergent incentives between purchaser and user. The large number of highly cost-effective energyefficient investments currently not chosen by consumers indicates that price alone does not stimulate optimal investment decisions (61).

If fuel taxes reflected " "externalities" (or nonmonetary costs of a good or service) fuel choice could be influenced. We did not model taxes, but other organizations have. Their results are not necessarily consistent with one another $(45,55,63$, $90)$. From these studies, price and income elasticities $^{34}$ appear to be such that a high tax rate would be needed to achieve substantial reductions in energy consumption over the 25-year timeframe of this study.

High end-use taxes based on $\mathrm{CO}_{2}$ emissions would generate a larger amount of government revenue. For economic (and political) reasons it may be necessary to reduce other taxes. Assuming that the cuts are applied to expenditure taxes and that the net impact is revenue neutral (i.e., as much is given out as is taken in), end-use taxes raise equity issues and might impose hardships on lower income households.

\section{Initial Purchase Taxes}

An initial purchase tax would place a lump-sum tax on energy inefficient appliances and equipment (and possibly buildings and homes) at the time of purchase. ${ }^{35}$ It could be applied to all equipment and appliances, to only the most polluting, or on a revenue neutral basis (i.e., fees on the most polluting items, and rebates for the least polluting that are equal in sum to the amount collected for the most polluting). The major advantage of an initial purchase tax is that it will send the appropriate signals regarding consumer purchasing decisions, which are often based largely on first cost. This type of tax would not affect usage decisions.

\section{Tax Credits and Incentives}

The combination of financial incentives to pursue efficiency coupled with disincentives for high energy use--the "carrot and stick' approach-can be particularly effective. For example, investment tax credits can be aimed at changing both the level of investment as well as investment targets (e.g., commercialization of high-efficiency heat pumps, installation of energy-efficient equipment). Generally speaking, however, this country has not experimented extensively with financial carrots expressly to induce conservation, although it has experimented with regulatory/statutory energy-related carrots such as tax credits for powerplant investment and the Price-Anderson oil depletion allowances. One problem with the experience to date is that there has been little effort made to evaluate the strengths and weaknesses of different approaches.

The Federal Government passed legislation that provided solar and conservation tax credits for the years 1978 through 1984. The 1986 tax reform act allowed the energy conservation tax credits for residential use to expire but extended residential solar tax credits and some commercial energy conservation credits. The Omnibus Budget Reconciliation Act of 1990 extended the 10-percent business energy tax credit for solar and geothermal property through December 31, 1991. Studies on the impact of these credits are inconclusive. Some say they were too low to affect homeowners' behavior. However, one study indicates that the level of the tax credit may not be as important as its presence (39).

The Federal Government also funds several subsidy programs. Four State and local assistance Programs (SLAP), administered by DOE provide States with Federal technical assistance as well as money for specific energy conservation programs, including low-income home weatherization, matching grants to schools and hospitals for energy conservation projects, energy education, and various other State and local conservation programs. The SLAP programs are funded through both direct congressional appropriations and the States' use of Petroleum Overcharge Funds. ${ }^{36}$ Congress has maintained funding for these programs throughout the 1980s despite administration recommendations that these programs be terminated. The Institutional Conservation Program (ICP) pays for audits and half of any conservation investments in schools and hospitals. State and Federal officials rate this program successful, with over 32,000 buildings participating since 1977 and a cumulative energy bill

\footnotetext{
${ }^{34} \mathrm{~A}$ price elasticity measures the change in energy demand in response to a change in price of energy.

${ }^{35}$ Congress has implemented this idea with the "Gas Guzzler Tax" on inefficient cars (see ch. 5).

${ }^{36}$ Funds delegated to the States as a result of pricing violations by oil companies.
} 
savings of $\$ 1.9$ billion .37 The Weatherization Assistance Program funds States to retrofit low-income housing with insulation to conserve energy .38 The State Energy Conservation Program (SECP) provides financial assistance to the State Energy offices to promote energy efficiency and conservation in the commercial and residential sectors. The Energy Extension Service (EES) is a Federal/State effort to provide small scale energy users with individually tailored technical assistance for energy conservation and increased use of renewable. The SECP and the EES have been consolidated under the State Energy Conservation Programs Improvement Act (Public Law 101-440), signed into law October 18, 1990.

Other federally funded programs include the Low Income Home Energy Assistance Program (LIHEAP), the Residential Conservation Service (RCS), and the Solar Energy and Energy Conservation Bank (SEECB); the RCS and SEECB have recently expired. RCS is discussed under "Home Energy Audits" below. SEECB helped finance energy conservation and solar measures in low- and moderate-income housing and in commercial buildings owned by nonprofit organizations. LIHEAP (a Department of Health and Human Services program) gives grants to States to subsidize energy bills in low-income housing; 15 percent of the funding can be used for retrofits. The 1990 amendments to the Housing and Community Development Act of 1974 also included low-income housing conservation and efficiency grants to be administered by the Department of Housing and Urban Development.

\section{Demand-Side Management (DSM)}

DSM refers to utility programs designed to encourage customers to modify their pattern of electricity usage (17a). Particularly promisingfrom a global warming perspective-are those situations where utilities allow energy conservation to compete with traditional supply technologies (e.g., powerplants) to balance energy supply and demand .39 Because demand-side investments can be less expensive than new supply, and because utilities traditionally have longer time horizons than consumers, DSM can result in greater investments in energy efficiency than would be made by consumers alone. Utility programs can capture the potential in both the new and retrofit markets, for both equipment efficiency and building shell improvements. The ability to reach retrofit markets is particularly attractive because they are difficult to reach through building codes. Another attractive feature of DSM is that there is already considerable support for it by many State energy offices, State legislatures, and public utility commissions (34) (also see app. B, and box 3-C in ch. 3). Recalling figures 4-10 and 4-11, the biggest $\mathrm{CO}_{2}$ savings from the buildings sector as a whole came from increased thermal integrity of building shells and from raising the efficiency of space conditioning equipment. Therefore, DSM could play an important role in reducing greenhouse gas emissions from the buildings sector.

For DSM to stimulate significant investment in conservation, incentive structures must be changed so that utilities are equally willing to make supplyand demand-side investments. Currently, there can be a disincentive for investment in conservation, because utility revenues and profits depend on the amount of electricity sold. Methods used by some States to address this problem include:

1. a volume-of-sales adjustment that adjusts retail prices when the level of forecasted sales differs from actual sales; thus, sales drop due to conservation efforts, but a utility's return on investment will not drop;

2. a higher rate of return on conservation investments;

3. shared savings between customers and shareholders;

4. a contract bonus based on energy conservation performance in the form of increased rate of return, or an expanded concept of the rate base (i.e., adding conservation investments to the rate base); and

5. comparative bill earnings in which the performance of a utility is compared to that of other utilities in the region, with a higher rate of return available to utilities that achieve above average energy savings. ${ }^{40}$

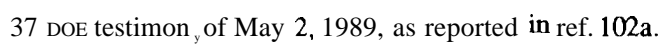

${ }^{38}$ Recently Public Law $101-440$ expanded the original focus of this program to include cooling efficiency modifications in an effort to emphasize annual energy efficiency.

${ }^{39} \mathrm{O}$ TA references to DSM in this chapter include measures improving efficiency as well as innovative programs to reduce total demand.

${ }^{40}$ For a discussion of the comparative bill earnings scheme, see ref. 58. For discussion of all of these options, see ref. 13.
} 
Federal and State governments share the regulation of electric utilities. The Federal Energy Regulatory Commission (FERC) has jurisdiction over wholesale transactions, both inter- and intra-state. This gives FERC jurisdiction over inter-utility sales for interstate holding companies and power pools and over many transactions within a State. ${ }^{41}$ Congress can play a leadership role in directing utility planning through the legislation that guides FERC. This ability is most apparent in the Public Utility Regulatory Policies Act of 1978 (PURPA), which required utilities to purchase electricity from qualifying facilities at avoided cost. Qualifying facilities include cogeneration and those using renewable energy sources. Recently Congress amended PURPA (Public Law 101-508) to eliminate the 80-megawatt capacity limitation for qualifying facilities fueled by wind, geothermal, solar, or waste energy.

The Federal Government also maintains a Least Cost Utility Planning Program at DOE; appropriations for 1991 were increased from $\$ 1$ to $\$ 3$ million. Its limited budget had allowed it to play only a catalytic role, working closely with the national laboratories and industry research institutes to provide utilities with data and analysis on a variety of DSM issues. ${ }^{42}$

There has been considerable activity in demandside planning by State commissions, trade associations, and utilities themselves. Different approaches may be most appropriate to different utilities, States, or regions. As DSM implementation is still nascent, it may be useful to let diversity flourish. Thus, any Federal legislation would ideally be general enough to allow States flexibility in implementation and specific enough to have a truly positive impact on conservation.

To promote demand-side planning, Congress could:

1. require Federal electric utilities (like the Tennessee Valley Authority) to expand DSM programs and set rates for their distributors based on achievement of DSM goals;

2. require States to formally consider demandside resources in their planning;

3. require least-cost planning for utilities whose projects fall under the jurisdiction of Federal Energy Regulatory Commission; and
4. require all utilities to use least-cost planning.

Congress could also encourage public utility commissions to formally assess the various incentive rate schemes and determine if any were applicable to their utility. This step would be analogous to the one taken in 1978, when PURPA directed the States to review a wide range of strategies to promote pricing. To increase the possibility of useful findings from the process, funding could be included so that nonprofit groups could participate in these proceedings.

Congress has already mandated, in the 1980 Pacific Northwest Electric Power Planning and Conservation Act (Public Law 96-501), that the Northwest Power Planning Council adopt rate structures that give conservation measures a cost break over other, more traditional supply-side measures.

To move beyond the above measures, Congress could also direct the Federal Government to establish a cost for the environmental externalities of supply-side options. The New York Public Service Commission, for one, requires explicit consideration of environmental factors (with a weight that amounts to 15 percent of the total score or up to 1.4 cents per $\mathrm{kWh}$ for the most polluting sources; see app. B) in utility assessment of bids for supply and demand resources (82). Or, Congress could require all States to develop a method for making demand-side investments as attractive as supply-side investments.

\section{Appliance Standards}

Appliance standards overcome the problem of emphasis on first cost by fiat, by removing inefficient appliances from the market. Properly set, standards can also be 'technology forcing. A DOE study comparing various policy alternatives concluded that standards result in more savings than other methods, including tax credits, rebates, and consumer education (101).

The National Appliance Energy Conservation Act (NAECA), approved by Congress in 1987, set minimum-efficiency standards for many appliances (see "Space Conditioning" above). The NAECA Amendments in 1988 extended the standard to some commercial building lighting ballasts. NAECA re-

\footnotetext{
${ }^{41}$ There is a history of tension over the sharing of jurisdiction for electricity planning (93a).

${ }^{42}$ Congress has considered expanding PURPA to include DSM as a new form Of qualifying facility.
} 
quires that the standards be reviewed twice during the 1990s, which provides an opportunity to obtain additional energy reductions through new or more stringent standards. Congress could consider extending standards to other equipment such as commercial HVAC equipment, light bulbs, and building components such as windows.

When Congress set the current standards, a payback period of 3 years was termed ' 'economically justifiable. ${ }^{43}$ Alternatively, a longer payback or a lifecycle costing rule could be used to set the standard. ${ }^{44}$ Because current economic analyses do not include the costs of environmental externalities, more stringent standards could be justified as a way of reflecting these environmental costs.

Congress could make standards even more effective by using them in conjunction with other incentives. For example, standards can be used to set a regulatory 'flloor,' removing the least efficient equipment and buildings from the market, while policies such as utility programs, appliance labeling, and tax schemes can provide incentives to exceed the standards.

One problem with standards is that they may drive up the purchase price so that a prohibitively large upfront payment is required. This problem could be remedied with loans, purchase credits, or some other form of initial purchase cost defrayment.

\section{Building Energy Codes}

Building energy codes serve a function analogous to that of appliance standards in that they keep the least efficient buildings from being constructed. Similarly, they can be used in conjunction with other policies such as utility programs, building rating systems, and tax schemes. Since most of the $\mathrm{CO}_{2}$ savings in 2015 in the Moderate case come from improved space conditioning equipment and better thermal integrity, codes could play an important role in controlling $\mathrm{CO}_{2}$ emissions.

Building codes have traditionally been under the jurisdiction of States and localities. Mandatory national building codes are finding little support from the States or the construction industry (61).

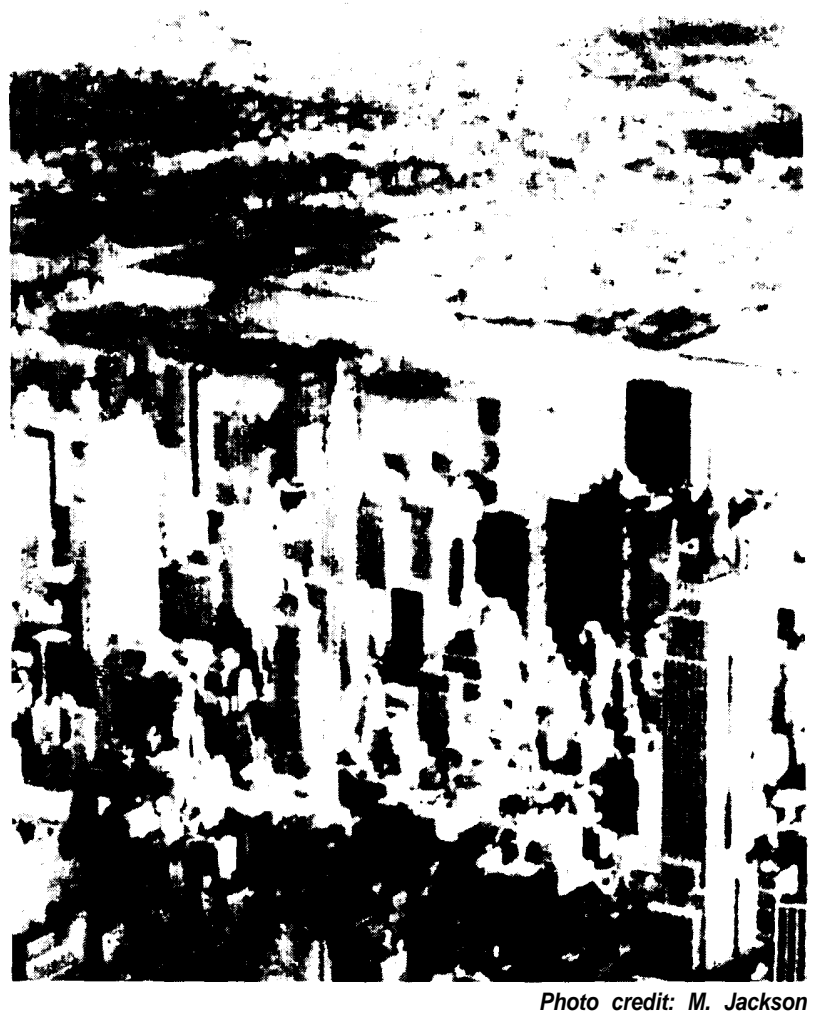

The Manhattan skyline: Commercial buildings harbor tremendous potential for energy savings. Replacing the lights and the heating, ventilating and air-conditioning (HVAC) systems with new equipment can cut a building's energy costs by 30 percent.

During the 1970s, however, there was some interest in a national code as a response to the patchwork of codes passed at the State level. ${ }^{45}$ In 1973, the National Council of States Building Codes Standards asked the National Bureau of Standards (now the National Institute for Science and Technology, or NIST) to provide the technical basis for a performance-type standard for energy conservation in buildings. ${ }^{46}$ By the time of the oil embargo, the Bureau of Standards, in cooperation with consultants from design professions and industry, had prepared a document defining energy budgets based on the specific functional requirements of buildings

\footnotetext{
${ }^{43}$ Additionally, factors such as impact on consumers and impact on manufacturerscan be used to determine what is economically justified.

44 Electric supply projects typically have paybacks of well over one decade

${ }^{45}$ Some States, notably California, have instituted mandatory building standards for both residential and commercial buildings.

${ }^{46}$ This chronology supplied by ref 113.
} 
and providing energy- and cost-effective choices for components of energy systems in buildings. The document and the energy budgets were turned over to the American Society of Heating, Refrigerating, and Air-Conditioning Engineers (ASHRAE) as bases for developing a national consensus standard. ASHRAE released standards in 1975 and updated them in 1980. According to an independent evaluation (53a), energy savings would range from 10 to 60 percent, compared to then-conventional practices, at reduced construction costs. Extra costs for higher performance envelopes were more than offset by savings in the space conditioning equipment required.

In addition to NIST, DOE also plays a role in developing building standards. In 1976, Congress enacted legislation that required the development of the Building Energy Performance Standards (BEPS), a national code based on performance standards. In 1981, prior to DOE releasing a final version of BEPS, the law was modified so that the standards were mandatory only for Federal buildings. (It is voluntary for non-Federal buildings, although DOE is mandated to encourage its adoption by States and localities.) DOE's proposed standards became effective 6 months after they were placed in the January 1989 Federal Register (102). Since then DOE has initiated demonstration grants.

DOE shares its role in building energy code development with the ASHRAE ${ }^{47}$ The proposed Federal building code is nearly identical to the recently released ASHRAE; standards (3). All 50 States have adopted all or a portion of the ASHRAE standards. The 1980 standard was estimated to result in reduced energy use in commercial buildings of 5 to 25 percent compared to buildings constructed in the late 1970s (15). The new standard is expected to provide 20 to 25 percent energy savings in commercial buildings over the existing code (27). However, the average energy efficiency of new homes in most States now exceeds the existing (i.e., 1980) ASHRAE standards (39).

Recently, the National Affordable Housing Act of 1990 (Public Law 101-922) required the Department of Housing and Urban Development (HUD) to develop energy-efficiency standards for new public housing, and housing subject to mortgages under the
National Housing Act (i.e., mortgages that include a loan for financing energy-conserving improvements or adding solar energy systems).

Changes in Federal building code policy that could achieve greater energy savings by changing the investment decisions of builders and buyers include:

1. the establishment of a uniform code by either mandating compliance or creating incentives for States to adopt the national code;

2. the development of a more stringent national code;

3. the development of energy standards for all existing buildings, with compliance taking the form of a mandatory performance test upon sale (an option that could also quickly affect O\&M practices detailed in our model); and

4. increased funding for implementation and enforcement.

Adequate enforcement is difficult, but necessary, for a building code to achieve significant savings.

\section{Consumer Information and Marketing Programs}

Lack of information is a key obstacle to greater investment in energy conservation. It adversely affects O\&M practices, investment decisions, and incentives to develop new energy-efficient technologies. The Federal Government can play a role in overcoming this barrier by providing information about opportunities to increase energy efficiency. Information dissemination is a key element of several of the policy options discussed above, including appliance standards, building codes, and utility planning.

In the past, the Federal Government has played a role in several consumer information and marketing programs. These include:

Energy rating systems. Energy rating systems tell buyers how efficient their prospective home or office is. One national survey found energy savings from a home energy rating system (HERS) to be 15 to 50 percent $(110,111)$. (No study has been done on a newer rating program for the commercial sector.) The Federal Government has helped to legitimize the use of HERS through its involvement in the

${ }^{47}$ The Department of Housing and Urban Development (HUD) also plays a role in building codes through its regulation Of manufactured housing (mobile homes). For a discussion of regulation of manufactured housing, see ref. 92. HUD is currently contemplating significant changes to its codes. 


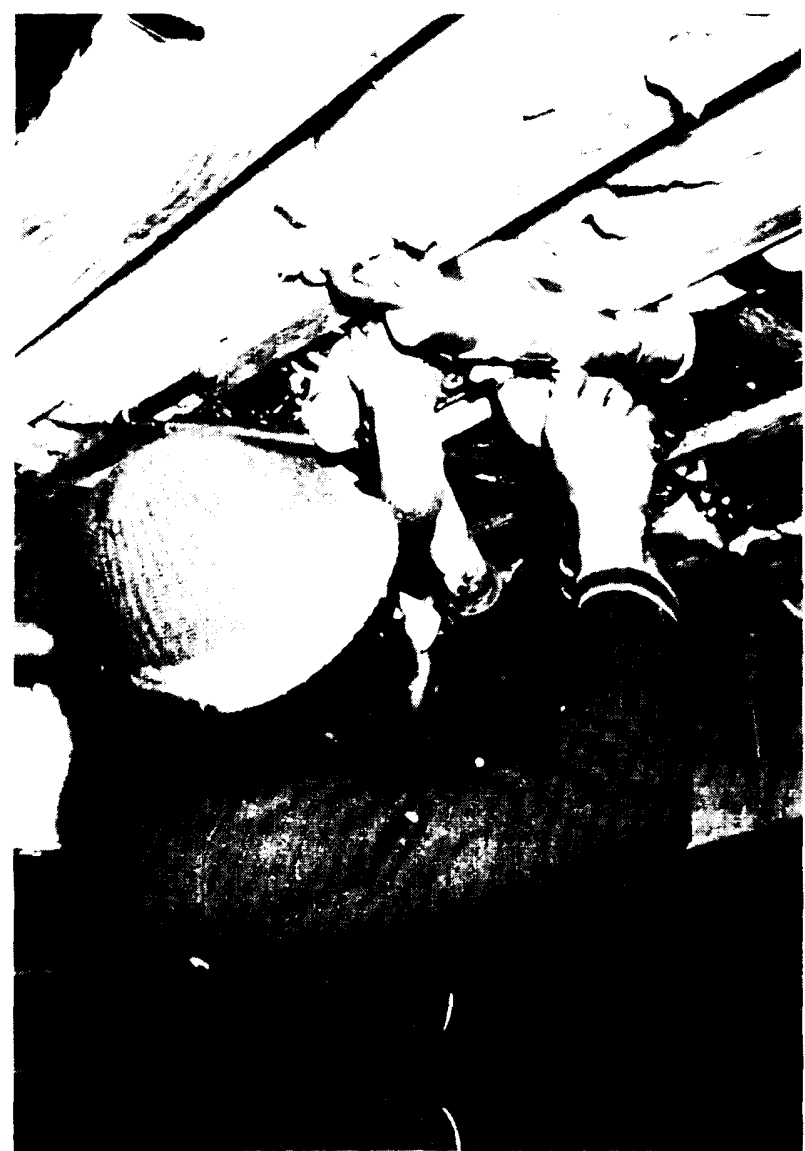

Photo credit: Dr. J. Hill, U.S. Department of Commerce, National Institute of Standards and Technology, Building Environment Division

Caulking joints and increasing insulation can be relatively inexpensive ways to reduce energy use in old buildings.

mortgage market. ${ }^{48}$ Currently many successful rating systems are funded through State offices and run via third-party, nonprofit organizations. The Federal Government could play a further role in expanding these partnerships by establishing a uniform energy rating system and a national housing databank for both residential and commercial buildings. ${ }^{49}$ If ratings are not standardized, the added overhead expenses for lending agencies to include the energy costs in their evaluation of mortgages may be unacceptably high. A national databank of all rated homes would allow profiling of the energy efficiency of housing stock in any part of the country. More importantly, typical energy costs for different house types with different fuel mixes could be generated. This would allow lenders and buyers to better evaluate the savings of more efficient houses .50 As a first step in this direction, the National Affordable Housing Act of 1990 requires HUD to develop a plan to make housing more affordable through mortgage financing incentives for energy efficiency.

Home energy audits. The Federal Residential Conservation Service (RCS) was created in 1978 to provide consumers with information on energy conservation for their homes. It mandated that gas and electric utilities provide their customers with on-site energy audits. The program was implemented in 1981 and recently expired. There has been very little evaluation of the program, and little reliable information has been kept on its success in reducing energy consumption. ${ }^{51}$

Any future Federal initiatives in the utility sector to provide energy audits should require the audits to generate a uniform energy rating with regular reporting of all audited/rated houses. This would make the data collected from the utility-audited/ rated houses available for future analysis.

Appliance labels. Energy users often have very little knowledge about appliance energy use and energy costs (46a). Appliance labels to supply this information for selected appliances were required by the National Energy Policy and Conservation Act of 1975. These labels were required on refrigeratorfreezers, freezers, room air conditioners, clothes washers, dishwashers, and electric and gas water heaters. These labels provide information on energy use and costs, and also indicate the highest and lower energy costs for models with similar features.

Evaluations of the effectiveness of these labels have been inconclusive. Some have argued that information, such as appliance labels, are necessary

${ }^{48}$ The Federal National Mortgage Association and the Federal Home Loan Mortgage Corp. have endorsed this concept and approve HERS for qualification in the secondary mortgage market. The Federal Housing Administration and the Veterans Administration have their own set of qualified HERS.

${ }^{49}$ For a discussion of the technical considerations in developing HERS, see ref. 69.

${ }^{50}$ For example, if an energy-efficient home is being purchased, mortgages could be approved for a higher percentage of a home buyer's income based on anticipated lower monthly energy expenses.

${ }^{51}$ One study (37) concluded that the programs' contribution t. national energy savings was small. However, some of the State programs worked well, suggesting that home energy audits could be a successful part of a home energy conservation policy. 
but not sufficient for improving efficiency-that such information programs, when combined with financial incentives and other programs, will be most effective (1 la).

General information campaigns. As mentioned above, the Federal Government funds a Stateimplemented information service called the Energy Extension Service (EES). It serves as a local source of information on energy use and efficiency. Discussions with State Energy Officers indicate that generalized advertising was their least effective tool. They found onsite workshops, auditor training, and campaigns targeted to a specific group to be their most effective activities (39). The Federal Government has also supported consumer information and outreach activities by State energy offices (e.g., New York), trade associations, and national laboratories.

\section{Research, Development, and Demonstration}

There are major barriers to private investment in $\mathrm{R} \& \mathrm{D}$ in the building shell, prefabrication, construction, and design industries. These barriers include the fragmented industry structure and the short-term perspective of many of the decisionmakers. Thus, the Federal Government has a key role to play in funding $R \& D$ for this sector.

The U.S. Government currently spends a negligible amount on housing research. In contrast, Sweden, with a population of only 9 million, spends more on research for home construction than the United States (93). In countries such as Sweden and Japan, R\&D spending has been part of the trend toward prefabricated housing, which has contributed to the energy efficiency of homes through standardization of energy saving features and quality control in the design and manufacture of building components.

Areas that could benefit from more governmental $R \& D$ efforts include:

Building shell systems. Items of potential energysaving value include wall materials that are highly insulating and load-bearing, inovative window systems, and insulating foams that do not need CFCs.

Energy-efficient field practices, In order to fully realize the advantages of the new, standardized building components, it will be necessary to evaluate and improve current construction (on and offsite) techniques and technologies (e.g., joint sealants and structural support units).
Manufacturing and design tools. In order to maximize the energy savings possible with new techniques and technologies, designers need to have design tools that enable them to factor in energy efficiency. As was mentioned earlier, the lack of design tools is a significant barrier to the diffusion of energy-efficient technologies and techniques. Similarly, better manufacturing techniques are needed that will allow builders to cut the costs (and energy requirements) of producing new construction components.

Technology performance, Energy requirements can be minimized through better prediction of building performance (66). In many instances the estimates of how much energy will actually be saved by certain measures prove incorrect, yet little effort goes into studies of why this is so. For example, the Hood River Conservation Project achieved 40 percent of predicted savings (38). Evaluation programs should be aimed at boosting measured performance and developing more accurate estimates of savings. Equally important is evaluation aimed at anticipating future problems caused by energy efficiency measures. For example, as houses are tightened to decrease infiltration, moisture buildup and indoor air quality problems can ensue.

Demonstration. As a first step, Congress has required HUD, in the National Affordable Housing Act of 1990, to develop a plan to improve energy efficiency in newly constructed, rehabilitated, and existing housing; and demonstrate various methods of improving the energy efficiency of existing housing. Such projects should encourage the development of 'energy-efficiency businesses' that can bridge the gap between owners, builders, and occupants of buildings.

The Federal Energy Management Program (FEMP), administered by the Department of Energy, works with government agencies to implement costeffective, energy-efficiency improvements. Congress could authorize FEMP to test and demonstrate performance, acceptance, and cost-effectiveness of new technologies in Federal buildings.

\section{CHAPTER 4 REFERENCES}

1. Akbari, H. et al., "The Impact of S ummer Heat Islands on Cooling Energy Consumption and $\mathrm{CO}_{2}$ Emissions, " paper presented at ACEEE Summer Study on Energy Efficiency in Buildings (Asilomar, CA: August 1988).

2. American Council for an Energy-Efficient Economy, The Most Energy-Efficient Appliances (Washington DC: 1987). 
3. American Society of Heating, Refrigerating, and AirConditioning Engineers (ASHRAE), "Energy Efficient Design of New Buildings Except Low Rise Residential Buildings, ASHRAE-IES Standard 90.1-1989 (Atlanta, GA:1989).

4. American Yazaki Corp., "'Yazaki Gas and Solar Air Conditioning Equipment" (Farmers Branch, TX: 1987).

5. Andrews, J.W.et al., "Modular Cogeneration in District Heating and Cooling Systems, ' BNL 52133 (Washington, DC: U.S. Department of Energy, December 1987).

6. Association of Home Appliance Manufacturers, 1990 Directory of Certified Refrigerators and Freezers (Chicago, IL: January 1990).

7. Bashmakov, I. A., "Comparative Analysis of Energy Develop ment in the USSR, USA, and Western Europe: 19702000," paper presented at International Energy Workshop (Laxenburg, Austria: International Institute for Applied System Analysis, June 20-22, 1989).

8. Bevington, R. and A.H. Rosenfeld, "Energy for Buildings and Homes, "Scientific American 263(3):76-86, September 1990.

9. Brody, H., ' 'Companies Struggle to Automate Homes," High Technology Business 8(3):34-38, March 1988.

10. Brookhaven National Laboratory, "Analysis and Technology Transfer Annual Report-1987,' prepared for U.S. Department of Energy, Office of Buildings and Community Systems (Upton NY: July 1988)

11. Calm, J, M., ' 'District Heating and Cooling with Heat Pumps Outside the United Stat\&s, ' preprint DA-8845, for inclusion in ASHRAE Transactions 1988 94(l), 1988.

1 la. Cantor, R.A. and D.A. Trumble, Gas Furnance Purchases, A Study of Consumer Decisionmaking and Conservation Investments, ORNL/TM- 10727 (Oak Ridge, TN: Oak Ridge National Laboratory, 1988)

12. Chandler, W. U., "Assessing the Carbon Emission Control Strategies: The Case of China," Climatic Change, Feb. 4, 1988

13. Cicchetti, C.J., "Incentive Regulation: Some Conceptual and Policy Thoughts" (Cambridge, MA: Energy and Environmental Policy Center, Kennedy School of Government, Harvard University, May 1, 1989).

14. Cochran, J., “Daylighting Cuts Commercial Peaks, ” Public Power, pp. 16-21, March-April 1988.

15. Crawley, D., "Energy Conservation Standards: Promoting Energy Efficient New Non-Residential Buildings in the U.S., " General Problems of Energy Refrigeration Components and Systems Proceedings, CLIMA 2000, Second World Congress on Heating, Ventdating, Refrigerating, and Air Conditioning, vol. 5 , pp. 133-138, sponsored by REHVA-ZIB-ASHRAE, Sarejavo, Yugoslavia, August 1989 (Amersfoort, The Netherlands: REHVA, 1989).

16. Data Resources, Inc. and McGraw-Hill, Energy Review, Autumn 1989.

17. Electric Power Research Institute, Proceedings: Buildings and Their Energy Systems-Technologies and Planning Strategies, EPRI EA/EM-4197 (Palo Alto, CA: September 1985).

17a. Electric Power Research Institute, Impact of Demand-Side Management on Future Customer Electricity Demand: An Update, EPRI CU-6953s (Palo Alto, CA: September 1990).

18. Fathy, H., Natural Energy and Vernacular Architecture (Chicago, IL: University of Chicago Press, 1986).

19. Ferree, B., ' 'Climatic Influences in Primitive Architecture,' The American Anthropologist, pp. 147-158, April 1890.

20. Fitch, J. M., and D.P. Branch, "Primitive Architecture and Climate," Scientific American 203(6):40, December 1960,

21. Flavin, C., Energy and Architecture: The Solar and Conservation Potential (Washington, DC: Worldwatch Institute, November 1980).

22. Gas Energy Inc., "The Hitachi Paraflow Direct Fired ChillerHeater' (Brooklyn, NY: 1985).
23. Geller, H. S., "The Potential for Electricity Conservation in Brazil' (Sao Paulo, Brazil: Companhia Energetic de Sao Paulo, 1984)

24. Geller, H. S., "ImprovingEnd-Use Electrical Efficiency: Options for Developing Countries" (Washington, DC: World Bank Energy Department, June 1986).

25. Geller, H. S., "The Role of Federal Research and Development in Advancing Energy Efficiency: A $\$ 50$ Billion Contribution to the U.S. Economy, " Annual Review of Energy 12:357-395,1987.

26. Geller, H. S., "Energy and Economical Savings from National Appliance Energy Standards' (Washington DC: American Council for an Energy-Efficient Economy, 1987)

27. Geller, H. S., "Commercial Building Equipment Efficiency: A State-of-the-Art Review, contract prepared for U.S. Congress, Office of Technology Assessment (Washington, DC: American Council for an Energy-Efficient Economy, February 1988).

28. Geller, H. S., "Residential Equipment Efficiency: A State-of-theArt Review," contract prepared for U.S. Congress, Office of Technology Assessment (Washington, DC: American Council for an Energy-Efficient Economy, 1988).

29. Giov annini, J., "Whole-House Automation to Raise the I.Q. of the Home," New York Times, p. Cl, Feb. 18, 1988.

30. Goldemberg, J. et al., "An End-Use Oriented Global Energy Strategy, "Annual Review of Energy 10:613-688, 1985.

31. Goldemberg, J. et al, Energy for a Sustainable World (Washington, DC: World Resources Institute, September 1987).

32. Goldemberg, J. et al, Energy for a Sustainable World (New Delhi, India: Wiley Eastern Ltd., 1988).

33. Goldman, C. A., "Measured Results of Energy Conservation Retrofits in Residential Buildings, " paper presented at 1986 ASHRAE Winter Meeting, LBL-20950 (San Francisco, CA: Jan. 19-22, 1986).

34. Goldman, C., Least-Cost Planning in the Utility Sector: Progress and Challenges, LBL-27 130, ORNL/CON-284 (Springfield, VA: National Technical Information Service, 1989).

35. Hammitt, J.K. et al., Product Uses and Market Trends for Potential Ozone-Depleting Substances, 1985-2000 (Santa Monica, CA: RAND Corp., 1986).

36. Herendeen, R.A., "Notes and Comment on the Energy Cost of Building Construction" Energy and Buildings 1:95-96, 1977.

37. Hirst, E., "Improving Energy Efficiency of Existing Homes: The Residential Conservation Service," State Energy Policy: Current Issues, Future Directions (Boulder, CO: Westview Press, 1985).

38. Hirst, E., "The Hood River Conservation Project, Cooperation and Community Conservation, Comprehensive Report," DOIYBP11287-18 (Oak Ridge, TN: Oak Ridge National Laboratory, 1987).

39. Hirst, E. et al., Energy Efficiency in Buildings, Progress and Prom"se (Washington, DC: American Council for an EnergyEfficient Economy. 1986).

40. Hirst, E. et al., "Assessing Integrated Resource Plans Prepared by Electric Utilities, ” ORNL/CON-298 (Springfield, VA: National Technical Information Service, 1990).

41. Holtberg, P.D., Woods, T.J., Ashby, A.B., and Lynn, M.L., 1988 GRI Baseline Projection of U.S, Energy Supply and Demand to 2010 (Chicago, IL: Gas Research Institute, 1988).

42. Hough, M., City Form and Natural Process (New York, NY: Van Nostrand Reinhold Co., 1984).

43. Ingersoll, J.G. and B. Givoni, ' 'Passive Cooling Systems in Residential Buildings," pp. 209-228 in D. Hafemeister et aI. (eds.), Energy Sources: Conservation and Renewable, AIP Conference Proceedings, Number 135 (New York, NY: American Institute of Physics, 1985).

44. International Energy Agency, Energy Balances of OECD Countries, 1970-1985 (Paris: 1986).

45. Jorgenson, D. and P. Wilcoxen, "Global Change, Energy Prices, and U.S. Economic Growth," paper presented at the Workshop on Economic/Energy/Environmental Modeling for Climate Policy Analysis, Washington, DC, Oct. 22-23, 1990. 
46. Kolar, S. and W.U. Chandler, "Energy and Energy Conservation in Eastern Europe,' report prepared for U.S. Agency for International Development (Washington DC: Battelle Memorial Institute, Pacific Northwest Laboratories, 1990).

46a. Komor, P. and R. Katzev, "Behavioral Determinants of Energy Use in Small Commercial Buildings: Implications for Energy Efficiency," Energy Systems and Policy, vol. 12, pp. 233-242. 1988.

47. Krause, C., ' "The Smart House Project," Oak Ridge National Laboratory Review 20(3):62-64, 1987.

48. Lane, J., Energy-Efficient Housing Design (New York, NY: Van Nostrand Reinhold Co., 1986).

49. Laquatra, J., "Energy Efficiency in Rental Housing, " Energy Policy 15:549-558, December 1987

50. Lawrence Berkeley Laboratory, "Buildings Energy Use Compilation and Analysis Project" (Berkeley, CA: Mar. 6, 1986).

51, Leach, G. et al., Energy and Growth, A Comparison of 13 Industrial and Developing Countries (Guildford, England: Butterworth Scientific, 1986).

52. Leach, G., Household Energy in South Asia ('London: International Institute for Environment and Development, May 1986).

53, Levine, M.D. et al., "Economics of Efficiency Improvements in Residential Appliances and Space conditioning Equipment, "D. Hafemeister et al. (eds.),Energy Sources: Conservation and Renewable, AIP Conference Proceedings, Number 135 (New York, NY: American Institute of Physics, 1985).

53a. Little, A. D., Federal Energy Commission, "Energy, Conservation in New Building Design, An Impact Assessment of ASHRAE 90-75, "Conservation Paper \# 43B, 1975.

54. MacDonald, J. M., "A Research Plan for Commercial Sector Retrofits,' Proceedings from ACEEE 1986 Summer Study on Energy Efficiency in Buildings, Volume 3, Large Building Technologies (Washington, DC: American Council for an Energy-Efficient Economy, 1986).

55. Marine, AS. and R.G. Richels, Global $\mathrm{CO}_{2}$ Emission Reductions--The Impacts of Rising Energy Costs (Palo Alto, CA: Electric Power Research Institute, 1990).

56, Meckler, M., "Off-Peak Desiccant Cooling and Cogeneration Combine to Maximize Gas Utilization," preprint DA-88-1-5, for inclusion in ASHRAE Transactions 1988 94(1), 1988.

57. Meyers, S., "Energy Consumption and Structure of the U.S. Residential Sector: Changes Between 1970 and 1984," LBL21190, UC-95c (Berkeley, CA: Energy Analysis Program, Lawrence Berkeley Laboratory, March 1986).

58. Moscovitz, D., "Will Least-Cost Planning Work Without Significant Regulatory Reform?' paper presented at Least-Cost Planning Seminar, National Association of Regulatory Utility Commissioners (Aspen, CO: Apr. 12, 1988).

59. Myers, R. J., "Energy Management Market Continues to Heat Up," High Technology, p. 40, February 1987.

60, Nisson, J.D.N. and G. Dutt, The Superinsulated Home Book (New York, NY: John Wiley \& Sons, 1985)

61. Norberg-Bohm, V., "Potential for Carbon Dioxide Emission Reductions in Buildings, " background paper prepared for U.S. Congress, Office of Technology Assessment (Washington DC: June 9, 1989).

62. Norberg-Bohm, V., "Potential for Carbon Dioxide Emission Reductions in Buildings, "Global Environmental Policy Project Discussion Paper (Cambridge, MA: Harvard University, John F. Kennedy School of Government, March 1990).

63. Nerd.haus, W., "An Intertemporal General-Equilibrium Model of Economic Growth and Climate Change," paper presented at the Workshop on Economic/Energy/Environmental Modeling for Climate Policy Analysis, Washington, DC, Oct. 22-23, 1990.

64. Northwest Power Planning Council, Northwest Conservation and Electric Power Plan (Portland, OR: 1986).

65. Northwest Power Planning Council, 1989 Supplement to the 1986 Northwest Conservation and Electric Power Plan (Portland, OR: 1989). 65a. Northwest Power Planning Council, Technical Appendix to Conservation Supply for the 1990 Power Plan (Portland, OR: 1989).

66. Oak Ridge National Laboratory, Energy Technology R\&D: What Could Make a Difference?, draft (Oak Ridge, TN: December 1988).

67. Organization for Economic Cooperation and Development, Energy Balances of OECD Countries (Paris: 1987).

68. Prindle,W.R. and M.W. Reid, "Energy Efficiency: A Key to Affordable Housing, paper presented at Conference on Preparing for the Energy Challenges of the 1990s (Washington, DC: The Alliance to Save Energy, Jan. 28, 1988).

69. Rosenfeld, A.H. and B.S. Wagner, Technical Issues for Building Energy Ratings, LBL-14914 Rev. (Berkeley, CA: Lawrence Berkeley Laboratory, 1983).

70. Rosenfeld, A.H. and D. Hafemeister, "Energy-Efficient Buildings," Scientific American 258(4):78-85, April 1988.

71. Sagers, M.J. and A. Tretyakova, USSR: Energy Consumption in the Housing and Municipal Sector, Center for International Research, U.S. Bureau of the Census, CIR Staff Paper No. 30 (Washington, DC: September 1987).

72. Sathaye, J. et al., "Energy Demand in Developing Countries: A Sectoral Analysis of Recent Trends, 'Annual Review of Energy 12:253-281, 1987

73. Sathaye, J. and S. Meyers, "Energy Use in Cities of the Developing Countries," Annual Review of Energy 10:109-133, 1985.

74. Schipper, L. and R.C. Cooper, "Energy Conservation in the USSR: Realistic of Mirage? Prospects for More Efficient Energy Use, ' presentation to the U.S. Environmental Protection Agency (Berkeley, CA: Lawrence Berkeley Laboratory, International Energy Studies, June 29, 1989).

75. Schipper, L., A. Ketoff, and A. Kahane, "Explaining Residential Energy Use by International Bottom-Up Comparisons," Аnпиal Review of Energy 10:341 -406, 1985,

76. Schipper, L., A. Ketoff, et al., "Residential Electricity Consumption in Industrialized Countries: Changes Since 1973, " Energy 12(12): 1197-1208, 1987.

77. Schipper, L., S. Meyers, and H. Kelly, Coming in From the Cold, Energy-Wise Housing in Sweden (Cabin John, MD: Seven Locks Press, 1985)

78. Schipper, L., S. Meyers, and A. Ketoff, "Energy Use in the Service Sector: An International Perspective, " Energy Policy 14:210-218, June 1986

79. Serrato-Combe, A., Housing Within Different Contexts (Salt Lake City, UT: Assist Inc., 1982).

80. Sitrin, T.W., "Windows for the '90s," Public Power, pp. 40-43, May-June 1990.

81. Solar Energy Research Institute, et al., A New Prosperity, Building a Sustainable Energy Future, The SERI Solar/ Conservation Study (Andover, MA: Brick House Publishing, 1981).

82. State of New York Department of Public Service, "Consideration of Environmental Externalities in New York State Utilities' Bidding Programs for Acquiring Future Electric Capacity" (Albany, NY: 1989).

83. Statt, T. G., "The Use of Chlorofluorocarbons in Refrigeration, Insulation and Mobile Air Conditioning in the United States," paper prepared for EPA Conference on Substitutes and Alternatives to CFCS and Halons (Washington, DC: Jan. 13-15, 1988),

84. Stein, R. G., "Energy Cost of Building Construction, " Energy and Buildings 1:27-29, 1977.

85. Stoiaken, L. N., "Modular Cogeneration: Full Steam Ahead," Alternative Sources of Energy 93:8-13, September 1987.

86. Thompson, R (cd.), Do-It-Yourself Energy Saving Projects (Menlo Park, CA: Lane Publishing Co., 1981).

87, Turiel, I., D. Berman, et al., "U.S. Residential Appliance Energy Efficiency: Present Status and Future Directions, ' in Proceedings of the ACEEE 1990 Summer Study on Energy Efficiency in 
Buildings (Washington, DC: ACEEE, 1990), pp. 213-234.

88 United Nations Environment Program, Technical Progress on Protecting the Ozone Layer (Nairobi, Kenya: July 30, 1989).

89 U.S. Agency for International Development, Power Shortages in Developing Countries: Magnitude, Impacts, Solutions, and the Role of the Private Sector, A Report to Congress (Washington, DC: March 1988).

90. U.S. Congress, Congressional Budget Office, Carbon Charges as a Response to Global Warming: The Effects of Taxing Fossil Fuels (Washington, DC: U.S. Government Printing Office, August 1990).

91. U.S. Congress, Office of Technology Assessment New Electric Power Technologies: Problems and Prospects for the 1990s, OTA-E-246 (Washington, DC: U.S. Government Printing Office, July 1985).

92. U.S. Congress, Office of Technology Assessment, Technology, Trade, and the U.S Residential Construction Industry, OTA-TET315 (Springfield, VA: National Technical Information Service, September 1986).

93. U.S. Congress, Office of Technology Assessment, Technology and the American Economic Transition, Choices for the Future, OTA-TET-283 (Springfield, VA: National Technical Information Service, May 1988),

93a. U.S. Congress, Office of Technology Assessment, Electric Power-Wheeling and Dealing: Technological Considerations for Increasing Competition, OTA-E-409 (Washington, DC: U.S. Government Printing Office, May 1989).

94. U.S. Congress, Office of Technology Assessment, Energy in Developing Countries, OTA-E-486 (Washington, DC: U.S. Government Printing Office, January 1991).

95. U.S. Department of Energy, DOE Assistant Secretary's Review of Office of Buildings and Community Systems (Berkeley, CA: Lawrence Berkeley Laboratory, October 1986).

96. U.S. Department of Energy, Energy Information Administration, Annual Energy Review, DOE/EIA-0384 (Washington, DC: 1986).

97. US, Department of Energy, Energy Efficient Lighting, DOE/CE0162 (Washington, DC: 1986).

98. U.S. Department of Energy, Assistant Secretary, Conservation and Renewable Energy, "Amual Report on Federal Government Energy Management, Fiscal Year 1987” (Washington DC: 1987).

98a. US, Department of Energy, Office of Conservation and Renewables, Annual Report on Federal Energy Conservation Programs Fiscal Year 1988 (Washington, DC: 1988).

99. U.S. Department of Energy, Office of Scientific and Technical Information, Buildings Energy Technology (Oak Ridge, TN: 1988).

100. U.S. Department of Energy, Energy Information Administration, International Energy Annual 1987, DOE/EIA-0219(87) (Washington, DC: October 1988)

101. U.S. Department of Energy, Assistant Secretary, Conservation and Renewable Energy Building Equipment Division, Technical Support Document. Energy Conservation Standards for Consumer Products. Refrigerators, Furnaces, and Television Sets, including Environmental A ssessment (DOE/EA-0372) and Regu latory Impact Analysis, COE/CE-0239 (Washington, DC: November 1988)
102. U.S. Department of Energy, Office of Conservation and Renewable Resources, "Energy Conservation Voluntary Performance Standards for Commercial and Multi-Family High-Rise Residential Buildings; Mandatory for New Federal Buildings; Interim Rule," Federal Register 54(18), Jan. 30, 1989.

102a. U.S. Congress, State Energy Efficiency Programs Improvement Act of 1989, Calendar No. 433, Report 101-235, Jan. 10, 1988, report submitted by Mr. Johnston, Committee on Energy and Natural Resources to accompany S. 247.

103. U.S. Department of Energy, Office of Policy, Planning \& Analysis, Energy Conservation Trends: Understanding the Factors that Affect Conservation Gains in the U.S. Economy, DOE/PE-0092 (Washington DC: September 1989).

104. U.S. Department of Energy, Energy Information Administration, Indicators of Energy Efficiency: An International Comparison, EIA Service Report, SR/EMEU/90-02 (Washington, DC: July 1990).

105. U.S. Department of Energy, Annual Energy Review, 1989, DOE/EIA-0384(89) (Washington, DC: Energy Information Administration May 1990).

105a. U.S. Department of Energy, Office of Conservation and Renewables, Annual Report to Congress on Federal Government Energy Management and Conservation Programs Fiscal Year 1989 (Washington DC: October 1990).

106. U.S. Environmental Protection Agency, Costs and Benefits of Phasing Out Production of CFCS and Halons in the United States, draft (Washington DC: Nov. 3, 1989).

107. U.S. Environmental Protection Agency, "Protection of Stratospheric Ozone, Advanced Notice of Proposed Rulemaking," Federal Register 55(84):18256-18273, May 1, 1990.

108. U.S. Environmental Protection Agency, Policy Options for Stabilizing Global Climate, Draft, Report to Congress (Washington, DC: June 1990).

108a. U.S. Government Accounting Office, Report to the Congressional Requesters on Federal Shared Energy Savings Contracting, GAO/RCED/89-99 (Washington, DC: April 1989).

109. Van der Ryn, S. and P. Calthorpe (eds. ), Sustainable Communities (San Francisco, CA: Sierra Club, 1986).

110. Vine, E., B.K. Barnes, and R. Ritschard, Evaluation of the [implementation of Home Energy Rating System, National Technical Information Service No. PC A02/MF AO1 (Berkeley, CA: Lawrence Berkeley Laboratory, 1987).

111. Vine, E., B.K. Barnes, and R. Ritschard, Home Energy Rating Systems: Program Descriptions, LBL-229 19, UC-95d (Berkeley, CA: Lawrence Berkeley Laboratory, 1987).

112. Wilson, D. et al., "Policies and Programs for Promoting Energy Conservation in the Residential Sector: Lessons From Five OECD Countries, ' LBL-27289 (Berkeley, CA: Lawrence Berkeley Laboratory, June 1989).

113. Wright, R., Director, Center for Building Technology, National Institute for Standards and Technology, written comments to OTA, Jan. 29, 1990.

114. Yuan, L.J., "Traditional Housing: A Solution to Hopelessness in the Third World-The Malaysian Example, "The Ecologist 18(1): 16-23, 1988 . 


\section{Chapter 5}

\section{The Transportation Sector}

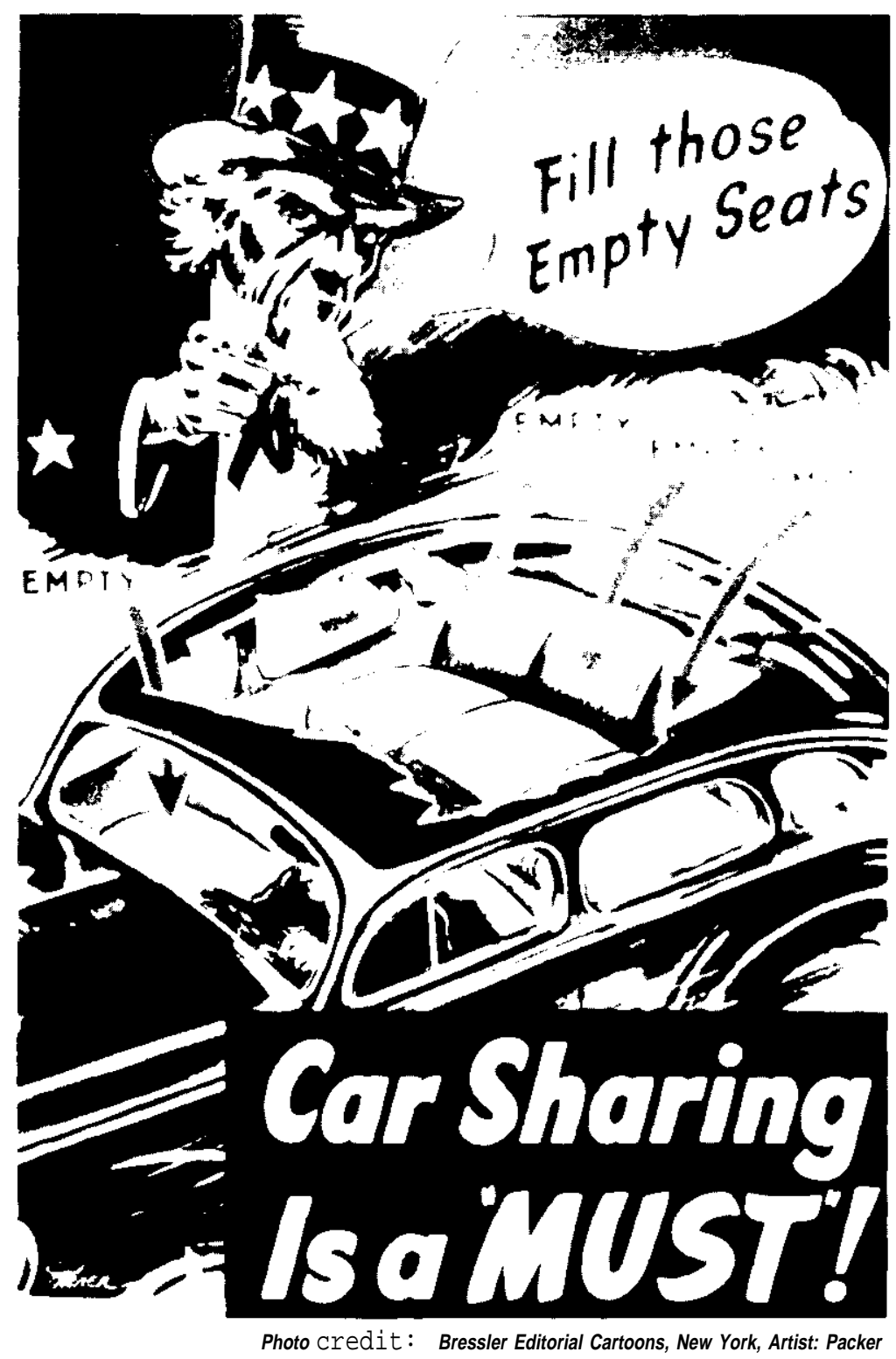

A World War II poster encouraging carpooling. Today, urban commuters average 1.2 passengers per vehicle to and from work. 


\section{CONTENTS}

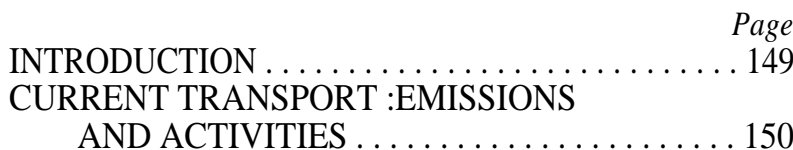

Source of Emissions . . . . . . . . . . . . . . . 150

Trends in Passenger Travel . . . . . . . . . . . . . 150

Trends in Freight ....................... 152

Trends inefficiency . . . . . . . . . . . . . . . 153

TECHNOLOGICAL AND INSTITUTIONAL

INFLUENCES ON EMISSIONS . . . . . . . . . . 154

Reducing Vehicle Miles Traveled . . . . . . . . . . . . 154

The Role of Land-Use Planning . . . . . . . . . . . 155

Factors Affecting Carbon Dioxide Emissions

Per Mile .............................. 157

OTA EMISSION REDUCTION SCENARIOS . . . 160

The Base Case ......................... 160

Moderate Control Measures . . . . . . . . . . . . . . . . . 160

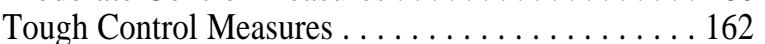

Summary of the OTA Scenarios . . . . . . . . . . . 163

Costs of the Tough Scenario . . . . . . . . . . . . . . 163

Alternatively Fueled Vehicles, . . . . . . . . . . . . . . . 164

POLICY OPTIONS . . . . . . . . . . . . . . . . . . . . . . . . . 164

Fuel Taxes $\ldots \ldots \ldots \ldots \ldots \ldots \ldots \ldots \ldots \ldots . \ldots 165$

Fuel Economy Standards. . . . . . . . . . . . . . 166

Vehicle Taxes and Rebates . . . . . . . . . . . . . . . . 167

Incentives for Manufacturers . . . . . . . . . . . . . . . . 167

Policy Directed at Operation and Maintenance.. 168

Transportation Control Measures . . . . . . . . . . . . 168

Controlling Settlement Patterns . . . . . . . . . . . . . 169

Research and Development . . . . . . . . . . . . . . . . 171

CHAPTER PREFERENCES . . . . . . . . . . . . . . 172

\section{Boxes}

Box

5-A. Chlorofluorocarbons in the Transportation

Sector .............................. 151

5-B. Transportation Energy Use in Eastern Europe and the U.S.S.R. ................. 154

5-C. Successful Urban Bus Systems . . . . . . . . . 156

5-D. Congestion . . . . . . . . . . . . . . . . . . . . . . . . . 158

5-E. Safety v. Efficiency . . . . . . . . . . . . . . . . . . . . 159

5-F. The Los Angeles Air Quality Plan . . . . . . . . . . 170

\section{Figures}

Figure Page

5-1. Contribution of the Transportation Sector to $\mathrm{CO}_{2}$ Emissions

5-2. Vehicle Travel per Year per

Driving-Age Adult . ................. 150

5-3. Trends in New Passenger Car Fuel Economy, 1978-90

5-4.The Effect of Vehicle Speed on

Fuel Consumption ....................... 157

5-5. CO Emissions Reductions in 2000 and 2015 Expressed as a Percentage of 1987 Transport Sector Emissions, by Control Method, Under the Moderate Scenario . . . . . . . . . . . . . . . 162

5-6. $\mathrm{CO}_{2}$ Emissions Reductions in 2000 and 2015 Expressed as a Percentage of 1987 Transport Sector Emissions by Control Method, Under the Tough Scenario . . . . . . . . . . . . . . . . . 162

5-7. Summary of $\mathrm{CO}_{2}$ Emissions Under the Base Case, Moderate, and Tough Scenarios, by Year ........................... 163

5-8. Summary of $\mathrm{CO}_{2}$ Emissions by 2015 , by Transportation Mode ............... 163

5-9. International Gasoline Prices and Taxes, 1989

\section{Tables}

Table Page

5-1. Carbon Emissions From Transportation . . . . . . 150

5-2. Trends in Passenger Travel for

Six Selected Countries ................... . 152

5-3. World Auto Registrations, 1987 . . . . . . . . . . 153

5-4. Projected Fuel Economy Impacts of Auto Technical Changes ................. 158

5-5. Greenhouse Gas Emissions From Alternatively Fueled Vehicles

5-6. Transportation Sector Conservation

Measures 161 


\section{INTRODUCTION}

This chapter examines the relationship between activity in the transportation sector and global warming. It looks at both the technology and the economics of passenger travel and freight within the United States and, to a lesser extent, the rest of the world. In 1987, transport contributed about one-third of the U.S. total carbon dioxide $\left(\mathrm{CO}_{2}\right)$ emissions (figure 5-1 ). Worldwide, transportation is responsible for about 20 to 25 percent of total $\mathrm{CO}_{2}$ emissions from fossil fuels $(27,73)$.

Assuming current trends and regulations, we estimate that U.S. transportation-related $\mathrm{CO}_{2}$ emissions will grow by about 25 percent by 2010 . The Energy information Administration (69) forecasts growth of between 16 and 32 percent, depending on oil prices. in the developing world, transportation fuel consumption could nearly triple over the next 20 to 30 years (27), These forecasts imply that the transport sector will continue to be a major source of $\mathrm{CO}_{2}$ emissions throughout and well beyond this study timeframe.

A number of measures could be initiated to reduce $\mathrm{CO}_{2}$ emissions from transport, but OTA's analysis reveals that it will be very difficult to reduce U.S. emissions much below 1987 levels through changes in technology alone. Reducing emissions below 1987 levels by 2015 would require, in addition, some behavioral compromise such as the acceptance of smaller cars, carpooling or increased use of mass

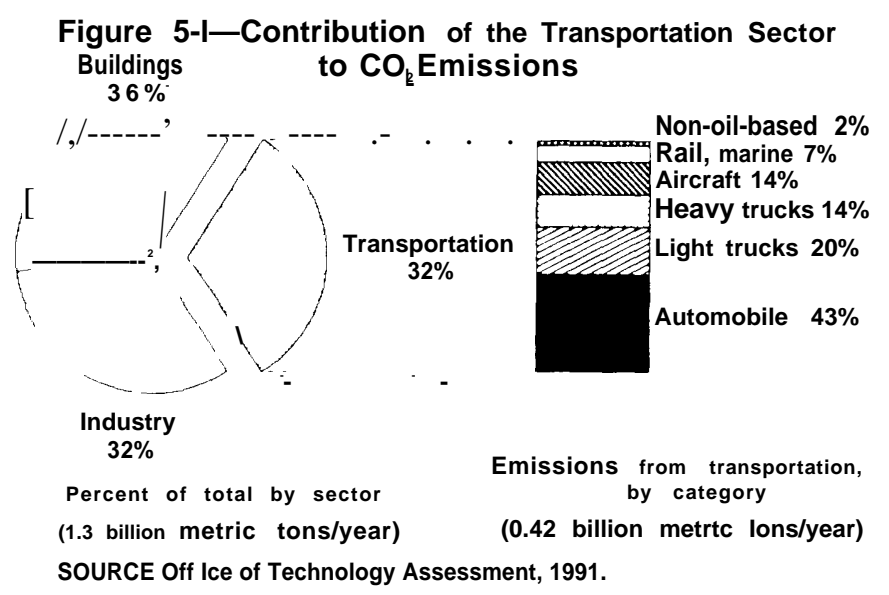

transit, or lower growth in the expected increase in demand for highway or air travel.

The difficulty of holding emissions low will be compounded even further past the 25-year time horizon of this assessment if population and demand for travel per person continue to grow, The gains possible over the next few decades can be easily lost. Lunger term progress will depend on either lowering the need for travel (e.g., through innovations in urban design or telecommunications) or drastically cutting emissions per mile through use of lower emitting fuels (e. g., methanol derived from sustainably harvested wood).

To be most effective, any program to promote more efficient modes of transport and discourage less efficient ones should incorporate both " regulatory push" and "market pull" mechanisms. One obvious tool is government standards, particularly for passenger car and light-truck fuel economy. Fuel economy standards appear to have been an effective instrument for raising efficiency levels over the past decade, though some believe that much of the improvement was due to higher fuel prices. Another obvious tool is fuel taxes. Though effective, taxes are more severely felt by low income segments of the population. Other financially oriented policies, such as rebates on high efficiency vehicles, do not have the same near-term potential as fuel taxes alone. Nevertheless, they could bean important element in a diversified strategy to reduce $\mathrm{CO}_{2}$.

To help ensure success, a reduction program could incorporate an extensive group of policies, some of which may be worth implementing because they will lay the groundwork for future progress; because, when taken as a package, they can achieve larger gains; or even for their symbolic value. Support of R\&D in new technologies (e.g., novel engine and transmission designs and lightweight materials) may result in longer term gains. A package of strategies to encourage people to change travel patterns (i.e., parking controls, vanpools or cat-pools, expanded mass transit, and increased 'telecommuting' can achieve large gains. Stepped up support for innovation in the above activities could have significant impacts on the U.S. ability to control its $\mathrm{CO}_{2}$ emissions. 


\section{CURRENT TRANSPORT EMISSIONS AND ACTIVITIES}

\section{Source of Emissions}

About 80 percent of transport's contribution to global warming comes from the carbon dioxide released by burning fuel. The remaining 20 percent comes from chlorofluorocarbons (CFCs) used in vehicle fabrication and for transport air-conditioning (see box 5-A).'

The United States is the single largest emitter of transport $\mathrm{CO}_{2}$ emissions, with Western Europe and Eastern Europe following at some distance. The developing world presently adds about 20 percent of the $\mathrm{CO}_{2}$ from this sector (see table 5-1).

\section{Trends in Passenger Travel}

Total vehicular travel per person ranges from an average of several thousand miles per year in the industrial countries to several hundred miles per year in the developing world. Table 5-2 shows trends in passenger travel for six countries and the primary means of transportation--private car, buses, rail water, air. Values for the poorest countries are biased downward because they omit walking, cycling, and animal transport (37).

Total travel, car ownership, and travel by car have all increased steadily throughout the world over the past two decades, gradually in the industrial countries and rapidly in the developing countries. Currently, car ownership ranges from one car per 1.8 people in the United States (in 1987) to one car per 1,075 in the People's Republic of China (see table 5-3). In many of the developing countries, travel and car ownership have been growing faster than income (49). Recent political changes and hoped for economic progress in Eastern Europe and the U.S.S.R. could lead to especially large increases in transportrelated emissions in these countries (see box 5-B).

In the United States, travel per person (all modes) increased from 10,400 miles in 1970 to 13,300 in 1985 , an average annual increase of 1.7 percent $(11$, 40). About 90 percent of travel was by car and light trucks, 9 percent by air, and 2 percent by bus and rail. Figure 5-2 illustrates the increase in annual auto travel per driving-age adult from 1960 to the present.
Table 5-I-Carbon Emissions From Transportation

\begin{tabular}{|c|c|c|}
\hline $\begin{array}{c}\text { Transport } \\
\text { CO* }^{*}\end{array}$ & $\begin{array}{l}\text { Share } \\
\text { of world }\end{array}$ & $\begin{array}{l}\text { Transport } \\
\text { share of } \\
\text { region's } \\
\text { fossil } \mathrm{CO}_{2}\end{array}$ \\
\hline $\begin{array}{l}\text { U.S.A. } \ldots \ldots \ldots \ldots \ldots \ldots \\
\text { Canada and Western }\end{array}$ & $36 \%$ & $30 \%$ \\
\hline $\begin{array}{l}\text { Europe } \ldots \ldots \ldots \ldots 266 \\
\text { Japan, Australia and }\end{array}$ & 23 & 31 \\
\hline $\begin{array}{l}\text { New Zealand . . . . . . } 90 \\
\text { U.S.S.R. and E. Europe . } 171\end{array}$ & $\begin{array}{r}8 \\
15\end{array}$ & $\begin{array}{l}30 \\
12\end{array}$ \\
\hline S. and E. Asia . . . . . 50 & 4 & 19 \\
\hline China . . . . . . . . . . 19 & 2 & 4 \\
\hline Africa $\ldots \ldots \ldots \ldots \ldots \ldots 40$ & 4 & 26 \\
\hline Latin America . . . . . . . . 83 & 7 & 36 \\
\hline Middle East $\ldots \ldots \ldots \ldots 21$ & 2 & 14 \\
\hline World total. . . . . . . 1,153 & & $22 \%$ \\
\hline
\end{tabular}

${ }^{2}$ Transport share of world's fossil-fuel $\mathrm{CO}_{2}$ emissions.

SOURCES: U.S. Environmental Protection Agency, Policy Options for Stabilizing Global Climate, draft report (Washington, DC: 1989), app. B; and ICF Inc., background tables to EPA stabilization report, personal communication to OTA, 1989.

Figure 5-2-Vehicle Travel per Year per
Driving-Age Adult

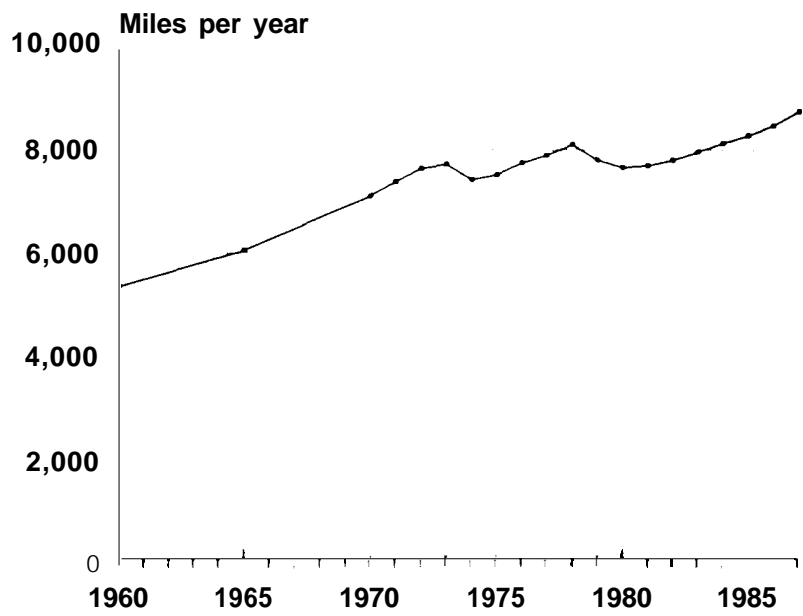

SOURCES: Motor Vehicle Manufacturers Association, Facts and Figures '89 (Detroit, MI: 1990). U.S. Department of Commerce, The Statistical Abstract of the United States (Washington, DC: 1989).

These trends reflect changing economics, demographics, and settlement patterns. As the large post-war "baby boom" generation and unprecedented numbers of women moved into the workforce, employment increased much faster than the total population-it grew even in metropolitan

\footnotetext{
'As detailed in box 5-A, U.S.CFC emissions total about 53,000 metric tons of CFC-12 and 15,000 metric tons of CFC-11 annually. U.S.CO emissions from transportation amount to about 420 million metric tons of carbon per year. One ton of CFC-12 has a global warming potential equal to about 2,000 tons of carbon (28). The corresponding figure for CFC-11 is about 950 .
} 


\section{Box 5-A-Chlorofluorocarbons in the Transportation Sector}

Chlorofluorocarbons (CFCs) are used in transport as working fluids for air-conditioning, and in smaller quantities in foam seats, padding, and insulation. Because of their destructive effect on the stratospheric ozone layer, they have been restricted by an international agreement, the recently ratified Montreal Protocol (see box 2-C in ch. 2). These compounds are also major contributors to global warming.

Three CFCs are used in transport: CFC-12,CFC-11, and CFC-113, all controlled under the Montreal Protocol. CFC-12 is the working fluid in auto air conditioners, and is also used for blowing rigid foam insulation. CFC-11 is used in vehicle manufacture for blowing flexible foam seat cushions and interior padding, and for blowing rigid foam insulation in refrigerated trucks and rail cars. CFC-113 is a solvent used for cleaning electronic components in vehicle manufacture. Table 5A-1 shows estimated 1985 CFC use in American transport. The largest component, CFC-12 in mobile air-conditioning, represents about 20 percent of total U.S. CFC use.

All three of the CFCs currently used in transport will have to be cut back under the terms of the Montreal Protocol. For each of them, there are new techniques or substitute materials under development to reduce emissions. Just as the CFCs differ in their ozone depletion potential, they also differ in their relative greenhouse effect. Chapter 2 discusses both the ozone depletion and greenhouse potential for the three CFCs used in transport and some possible substitutes,

Although emissions of CFCs are much smaller than emissions of $\mathrm{CO}_{2}$, the greenhouse potential per ton of CFC-12 is roughly 2,000 times greater than that of $\mathrm{CO}_{2}$ (measured in tons of carbon) (28), so the CFC contribution to human-induced warming is significant. CFC emissions from all sources (not just transportation) are estimated to account for about one-quarter of the current effect from all greenhouse gases (28).

The United States dominates the world mobile air-conditioning market, and mobile air-conditioning dominates U.S. CFC use in transport. In the 1986 model year, 80 percent of new U.S. domestic cars and light trucks, and 50 percent of imports, were air-conditioned. About 65 percent of the total U.S. vehicle fleet was air-conditioned in 1985 (45). In contrast, only 20 percent of new vehicles-sold in the rest of the world are air-conditioned (24); because air-conditioning is growing, the fraction in the fleet would be lower still.

Of the 115 million pounds of CFC-12 produced for U.S. mobile air-conditioning in 1985,35 percent went to charging new systems, 25 percent to recharging after leaks, 35 percent to recharging after service venting, and 7 percent to recharging after accidents.

New compounds are being developed to replace CFC-12 in air-conditioning systems. HCFC-134a is a promising replacement candidate because it resembles CFC-12 closely enough to be used in existing systems. It will require development of new lubricants, though, because it is not soluble in present mineral oil lubricants, and still requires several years of toxicity testing. Other possible substitutes include HCFC-22, mixtures, and hydrocarbons, but these presently require substantial system redesign and retooling. DuPont has recently announced a promising new blend requiring minimal retooling (2).

For blowing flexible foams, several alternative blowing agents are available. Carbon dioxide and methylene chloride are both used at present (58), and a new water-blown process is under development (38a). For cleaning electronic components, methyl chloroform can replace CFC-113 in many but not all applications. Nearly complete capture and recycling of CFC-113 will be possible, though (38a).

In summary, CFCs are a significant contribution to total transport greenhouse emissions, especially through leaks from mobile air-conditioning systems. Control of CFCs in transport will likely continue to be driven by concern over ozone depletion. Greenhouse considerations, though, should preclude a strategy based on replacing present CFCs with new ones that are less damaging to stratospheric ozone but just as active as greenhouse gases.

Table 5A-1-1985 U.S. Transport CFC Use, Millions of Pounds

\begin{tabular}{llcc}
\hline \multicolumn{5}{c}{ CFC-11 } & CFC-12 & CFC-113 \\
\hline Air-conditioning $\ldots \ldots \ldots \ldots$ & \multicolumn{2}{c}{113.1} \\
Foam seats and padding $\ldots \ldots$ & $24 a$ & & \\
Rigid foam insulation $\ldots \ldots$ & 7.8 & 2.5 & \\
Solvents $\ldots \ldots \ldots \ldots \ldots \ldots$ & & & b $\ldots$ \\
\hline
\end{tabular}

aUse of CFC- 11 for flexible foams is about 33 million pounds, which includes furniture, bedding, packaging, and carpet underlay as well as vehicles. Unestimated 24 million pounds is the transport share, based on roughly 2 pounds for each of the $\mathbf{1 2 . 2}$ million light vehicles manufactured in the United States in the 1986 model year (38a). $\%$ otalCFC-113 use for solvents was 164 million pounds. Transport share not available,

SOURCE: T.G. Statt, "The Use of CFCs in Refrigeration, Insulation, and Mobile AC in the U.S.," paper prepared for the EPA Conference on Substitutes ancAlternatives to CFCs and $\mathrm{Ha}$ /ens, Washington, DC, Jan. 13-15, 198S. 
Table 5-2-Trends in Passenger Travel for Six Selected Countries

\begin{tabular}{|c|c|c|c|c|c|c|c|c|}
\hline & & \multirow{3}{*}{$\begin{array}{c}\text { Passenger miles } \\
\text { per person }\end{array}$} & \multirow{3}{*}{$\begin{array}{l}\text { People } \\
\text { per car }\end{array}$} & \multicolumn{5}{|c|}{ Mode shares (percent) } \\
\hline & & & & \multicolumn{2}{|c|}{ Road } & \multirow[b]{2}{*}{ Rail } & \multirow[b]{2}{*}{ Water } & \multirow[b]{2}{*}{ Air } \\
\hline & & & & (private) & (public) & & & \\
\hline Brazil . ............ & $\begin{array}{l}197 \mathrm{Cl} \\
198 \mathrm{Cl}\end{array}$ & $\begin{array}{r}752 \\
2,270\end{array}$ & $\begin{array}{l}34 \\
15\end{array}$ & $\begin{array}{l}28 \\
33\end{array}$ & $\begin{array}{l}66 \\
62\end{array}$ & $\begin{array}{l}5 \\
3\end{array}$ & $\begin{array}{l}0 \\
0\end{array}$ & $\begin{array}{l}2 \\
2\end{array}$ \\
\hline China ........... & $\begin{array}{l}197 C^{\prime} \\
1980\end{array}$ & $\begin{array}{r}76 \\
145\end{array}$ & 27,700 & - & $\begin{array}{l}23 \\
32\end{array}$ & $\begin{array}{l}70 \\
61\end{array}$ & $\begin{array}{l}7 \\
6\end{array}$ & $\begin{array}{l}0.2 \\
1.8\end{array}$ \\
\hline India $\ldots, \ldots \ldots \ldots$ & $\begin{array}{l}1970 \\
1980\end{array}$ & $\begin{array}{l}263 \\
487\end{array}$ & $\begin{array}{l}902 \\
718\end{array}$ & $\begin{array}{l}7 \\
7\end{array}$ & $\begin{array}{l}52 \\
52\end{array}$ & $\begin{array}{l}41 \\
41\end{array}$ & & $\begin{array}{l}0.5 \\
0.9\end{array}$ \\
\hline Japan $\ldots \ldots \ldots \ldots$ & $\begin{array}{l}1970 \\
1980\end{array}$ & $\begin{array}{l}2,700 \\
3,366\end{array}$ & $\begin{array}{r}12.0 \\
4.9\end{array}$ & $\begin{array}{l}51 \\
57\end{array}$ & $\begin{array}{l}12 \\
11\end{array}$ & $\begin{array}{l}34 \\
26\end{array}$ & $\begin{array}{l}1 \\
1\end{array}$ & $\begin{array}{l}2 \\
5\end{array}$ \\
\hline United Kingdom . . . . . & $\begin{array}{l}1971 \\
1981\end{array}$ & $\begin{array}{l}4,817 \\
5,643\end{array}$ & -3.6 & $\begin{array}{l}79 \\
85\end{array}$ & $\begin{array}{r}12 \\
8\end{array}$ & $\begin{array}{l}9 \\
7\end{array}$ & & $\begin{array}{l}0.4 \\
0.6\end{array}$ \\
\hline U.S.S.R. $\ldots \ldots \ldots$ & $\begin{array}{l}1970 \\
1980\end{array}$ & $\begin{array}{l}1,624 \\
2,976\end{array}$ & $\begin{array}{r}147 \\
32\end{array}$ & $\begin{array}{r}6 \\
19\end{array}$ & $\begin{array}{l}38 \\
41\end{array}$ & $\begin{array}{l}43 \\
27\end{array}$ & $\begin{array}{l}1 \\
1\end{array}$ & $\begin{array}{l}12 \\
13\end{array}$ \\
\hline
\end{tabular}

NOTES: 1. The division of road transport into private and public for Japan, Brazil, China, and India is estimated based on other studies.

2. Walking and cycling, large modes in China and India, are excluded.

aFor Japan, a 1968 Tokyo study on trip split has been used for 1965 and 1970 (81 percent private, 19 percent public; Moavenzadeh and Geltner, table 4-14), and aggregated mode splits for Japan, Australia and New Zealand in 1979 used for 1980 (84 percent private; Ang, table 6.6). For Brazil, a 1867 Sao Paolo trip survey has been used for 1965 and 1970 (30 percent private; Moavenzadeh and Geltner, table 4-14), and a 1977 trip survey of all metropolitan areas for 1980 (Poole, table 3.2). For China, because of extremely low auto ownership, all road travel has been called public. For India, a crude estimate was derived from registration data presented in Dunkerley et al. It was assumed that annual miles per bus were triple the value for autos, and that buses averaged 30 occupants versus 2 for automobiles. These assumptions yielded estimates of 89 percent private in 1965, 88 percent in 1970 and 1980.

SOURCES: B.W.Ang, "Modelling World Energy Demand for Transport," Discussion Paper EDP 28 (Cambridge: Cambridge University, Energy Research Group, Aug. 25, 1983); J. Dunkerley et al., "Energy and Transport: The Indian Experience," Pacific and Asian Journal of Energy, 1987; G. Leach, L. Jarass, G. Obermair, and L. Ho ffmann, Energy and Growth: A Comparison of 13 Industrial and Developing Countries (London: Butterworth Scientific, 1986); F. Maavenzadeh and D. Geltner, "Transportation, Energy, and Economic Development: A Dilemma in the Developing World," Energy Research, Volume 5 (Amsterdam: Elsevier, 1984); Motor Vehicle Manufacturer's Association, Facts and Figures (Detroit, MI: various years); A. Poole, "Energy and Transport in Brazil," report to U.S. Agency for International Development (Washington, DC: Resources for the Future, January 1983) ;A. Tretyakovaand B. Kostinsky, USSR: MotorFuel Use and Conservation in Transportation and Agriculture, 1970 to 1984, Center for International Research, U.S. Bureau of the Census, CIR Staff Paper No. 32 (Washington, DC: December 1987); J. Yenny and L.V. Uy, "Transport in China," World Bank Staff Working Paper No. 723 (Washington DC: 1985).

areas that lost population between 1960 and 1980. The accompanying increase in work travel accounts for much of the growth in per-capita car ownership and travel. Also during this period, low-density suburbs grew more rapidly than central cities. Although data are ambiguous on whether or not average trip length has increased, it seems plausible that it increased through the 1960s, and has leveled off or declined since the 1970s. ${ }^{2}$

The large increase in air travel since 1960 can be attributed both to rising personal incomes and to the declining real cost of air travel brought about by technological advance and, in the 1980s, deregulation. Events of the last few years suggest, though, that industry consolidation may bring higher real prices, moderating current growth trends.

In 1985, passenger travel accounted for two-thirds of the energy consumed in U.S. transport. The other major energy user was freight, which consumed roughly one-quarter of the total transport energy. (11).

\section{Trends in Freight}

Freight has been growing worldwide at roughly the same rate as gross domestic product (GDP) in OECD countries and faster than GDP elsewhere (32, $44,60,77$ ). Freight intensity (ton-miles of freight per dollar of GDP) varies greatly among countries, generally as a function of country size, population density, and economic structure. Intensity increases as an economy moves from agriculture into primary industry, then declines slowly as an economy shifts toward secondary manufacturing and services. U.S. freight statistics have followed this trend.

In 1987, U.S. freight activity amounted to about 11,000 ton-miles per person. About 37 percent was by rail, 25 percent by road, 22 percent by pipeline, 16 percent by water and less than 1 percent by air. These shares have been roughly constant since the

'See discussions in table 3.26 of ref. 43 and refs. 30 and 34. 
Table 5-3--World Auto Registrations, 1987

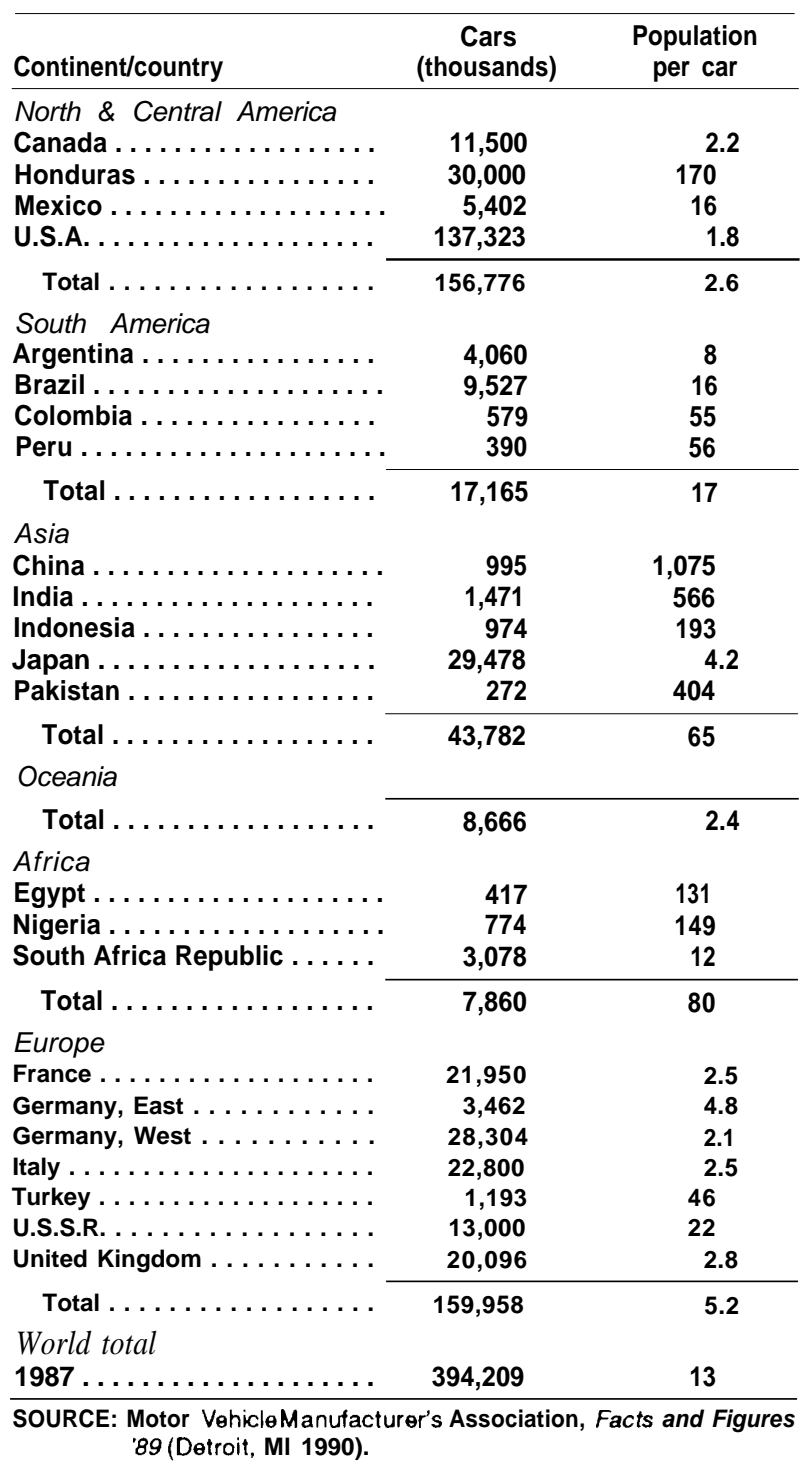

mid-1970s, while over a longer period freight has shifted gradually from rail to truck and pipeline. Continued movement of producers to suburbs, often far from rail spurs, and increased use of sophisticated inventory management (e.g., just-in-time delivery systems) is likely to provide a continuing advantage to trucking or novel combinations of road, rail, and other modes. ${ }^{3}$ Worldwide, continuing industrialization in the developing countries will likely offset reductions in U.S. freight intensity. For
Figure 5-3-Trends in New Passenger Car Fuel Economy, 1978-90

35

Miles per gallon (EPA test combined city-highway)

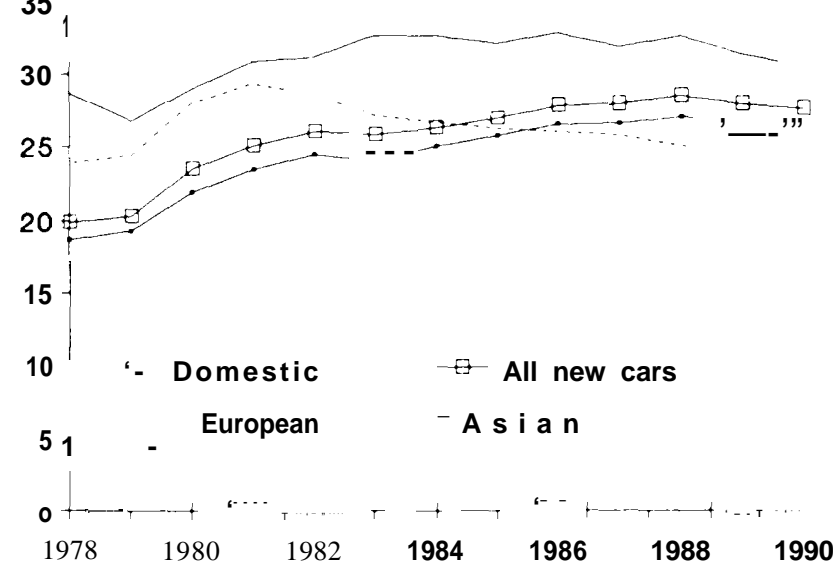

SOURCE: R.M.Heavenrich and J.D.Murrell, "Light-Duty Automotive Technology and Fuel Economy Trends Through 1988," U.S. Environmental Protection Agency, Office of Mobile Sources, EPAAACTAB-88-07 (Ann Arbor, MI: June 1988).

example, between 1960 and 1980, the freight intensity of Korea increased by more than 40 percent, that of Brazil by over 25 percent (77).

\section{Trends in Efficiency}

The energy efficiency of transport has increased both in the United States and worldwide. The largest gains have been in American light vehicles (see figure 5-3). New-vehicle average fuel economy almost doubled (from 13 to 24 miles per gallon (mpg)) between 1973 and 1985 through the combined effects of technical progress, oil price shocks, and regulation (29). During the same period, new-car efficiencies in the United Kingdom increased from 21 to $31 \mathrm{mpg}$; in Japan, from 23 to $30 \mathrm{mpg}$; and in West Germany, from 23 to $31 \mathrm{mpg}$. Almost no efficiency gains have been made in new vehicles since 1985 , however $(11,25)$.

In freight, the broad trend worldwide is towards energy-intensive modes, but with substantial efficiency improvements within each mode. For example, in the United States, truck freight efficiency improved by 20 percent between 1970 and 1985 (66). Less dramatic but nevertheless substantial efficiency gains have been made in other modes worldwide.

\footnotetext{
${ }^{3}$ An uncertain factor in future freight demand and structure, at least in the OECD, is recycling. As total material demands become smaller, a larger fraction can be met by recycled materials. This fact changes the basic path of material travel through the economy from a once-through trip to a circular one. The overall effect on total freight requirements could be an increase or decrease. (For more on recycling, see ch. 6.)
} 


\section{Box 5-B-Transportation Energy Use in Eastern Europe and the U.S.S.R.}

Eastern Europe--The transportation sector currently accounts for about 13 percent of energy demand in Eastern Europe. Railroads account for 30 to 55 percent of total passenger miles, depending on the country, and for a greater share of freight transport (31). While railroads are expected to remain important, passenger and freight transport are expected to increasingly shift to private cars and large trucks, especially as per-capita car ownership increases. Air travel also is expected to increase rapidly.

Kolar and Chandler (31) projected that if only minimal improvements occur in automobile fuel economy, primary energy demand in the sector will more than double by 2025. In contrast, significant increases in vehicle fuel economy (e.g., from the current East European average for passenger cars of 27 miles per gallon to 47 miles per gallon) and conversion of the truck fleet from predominantly gasoline-powered to predominantly diesel-powered engines, could limit energy demand growth in this sector to about 50 percent.

U.S.S.R.- - In the U. S.S.R., transportation is responsible for about 12 percent of total fossil fuel carbon emissions (60). The most prevalent modes of passenger travel are public transportation (40 percent) and rail (25 percent). ${ }^{1}$ The U.S.S.R. has about 45 personal cars per 1,000 people, roughly one-tenth the ratio in Western Europe and the United States. This situation is likely to change as more automobiles become available and as per-capita incomes rise. U.S.S.R. passenger car production increased dramatically during the 1970s; while growth plateaued during the early 1980s, at least three new auto assembly plants are planned and production is expected to increase again in the 1990s.

Freight transportation accounts for a much larger sham of transport fuel consumption in the U.S.S.R. than passenger transportation. In 1982,66 percent of freight transportation was by rail, 22 percent by river or ocean, and 9 percent by truck (60). Truck transportation traditionally has been based on gasoline engines, rather than diesel engines, which are more energy-efficient. ${ }^{2}$ However, the portion of diesel-powered trucks is slowly increasing, which partly explains why total freight turnover increased by 40 percent between 1975 and 1985 even though total fuel consumption remained unchanged (60).

There is little doubt that energy use in passenger transportation will increase, but how fast demand will grow, how fast it will be satisfied by domestic production of passenger automobiles, and what type of fuel will be used are unknown. Soviet vehicles tend to be inefficient and highly polluting, so opportunities exist to reduce emissions by producing new cars using more modern technologies and new car designs. The U.S.S.R. also could attempt to strengthen and improve its well-developed urban transportation system, which would partially offset growth of passenger automobile use.

IPrivate cars account for 19 percent and air travel accounts for 13 percent.

2In 1984 diesel-engine trucks comprised only 19 percent of Soviet truck freight haulage, compared with over 80 percent $\mathrm{m}$ Western Europe, and more than 40 percent in the United States (60).

\section{TECHNOLOGICAL AND INSTITUTIONAL INFLUENCES ON EMISSIONS}

Three factors-population growth (especially in developing countries), miles traveled per person, and greenhouse gas emissions per unit of travelwill determine future world transport greenhouse emissions and the trajectory of emissions growth. These factors will in turn be influenced by the economic development of different countries or groups of countries and by a number of technological and institutional forces, many, but not all, of which are amenable to policy intervention (see last section of this chapter).

\section{Reducing Vehicle Miles Traveled}

Very little travel is done for intrinsic pleasure; people travel in order to get somewhere they want to be. In the United States, travel for work, travel for family business, and travel for recreation each account for roughly one-third of passenger vehicle miles traveled (VMT) (38). Existing settlement patterns, economic activity, and available transportation infrastructure determine both how much travel is needed and how it is accomplished.

Americans exhibit a strong preference for traveling in cars and light trucks, primarily alone. Since passenger travel consumed two-thirds of U.S. transport energy in 1985 and nearly 90 percent of that was in light vehicles (i.e., cars and light trucks), control- 
ling light vehicle VMT would have a large effect on transport $\mathrm{CO}_{2}$ emissions (11). However, the only ways to reduce light vehicle VMT are to displace single-occupancy driving with other transportation modes, reduce the need for trips through altered work scheduling (e.g., 4-day workweeks) or by combining errands, or to shorten each trip through better urban design.

The primary alternatives to single-occupancy driving are carpools and mass transit. American ridership shares of public transit remain low, in contrast to some non-U.S. cities (see box 5-C). Strategies to reduce the number of single-occupancy car trips include: improved mass transit, employer rideshare and mass transit incentives, parking management (higher parking meter fees, eliminating employer-subsidized parking, etc.), vanpool purchase incentives, auto use restrictions, and highoccupancy vehicle (HOV) lanes. Collectively such measures are referred to as transportation control measures (TCMs)

Several key generalizations about TCMs can be drawn from past programs to reduce air pollution in various cities (63). First, TCMs will be most effective if implemented as a package of several measures simultaneously. For example, ridesharing programs and mass transit are likely to be more successful if some highway lanes are restricted to buses and carpools, or if parking in business districts is restricted or expensive. A recent comparison of the business districts of San Francisco, Portland, Seattle and Denver found that transit shares were highest in the cities with the highest parking prices and most limited parking (26). In general, larger reductions in emissions are likely to be achieved if TCM programs are coordinated throughout an area and over an extended time horizon, than if measures are developed on a piecemeal or sporadic basis. Major capitol projects such as development of mass transit obviously require long lead times and sustained efforts.

TCM programs have to be tailored to each individual area, and thus must be implemented locally. Critical local characteristics that need to be considered in developing TCM programs include: population and employment distributions and densities, city layout and transportation routes, highway system capacity and level of congestion, access to mass transit, and parking availability and costs.
Finally, the success of many transportation control measures depends to a large degree on public acceptance and participation. In the absence of widespread support, past experience indicates that political resistance to involuntary restrictions on peoples' modes or amount of travel can be insurmountable.

\section{The Role of Land-Use Planning}

Land-use patterns play an important role in either tying people to their cars or facilitating other modes of transportation. As an illustration, people who live within a few miles of work might choose to walk or bike. But where urban areas consist of sprawling residential suburbs and separate business districts or industrial parks, few people have these options. A recent comparison of 10 U.S. cities found that per capita gasoline consumption is relatively low in cities with high population and job density, and relatively high in cities with abundant roads and parking. Per capita gasoline consumption is 10 times higher for residents of suburbs outside of Denver than for residents of Manhattan (39).

Between 1980 and 1986, about 85 percent of the population growth in the United States was in metropolitan areas. About three-fourths of that growth occurred in the suburbs of those areas. According to a task force formed to advise the

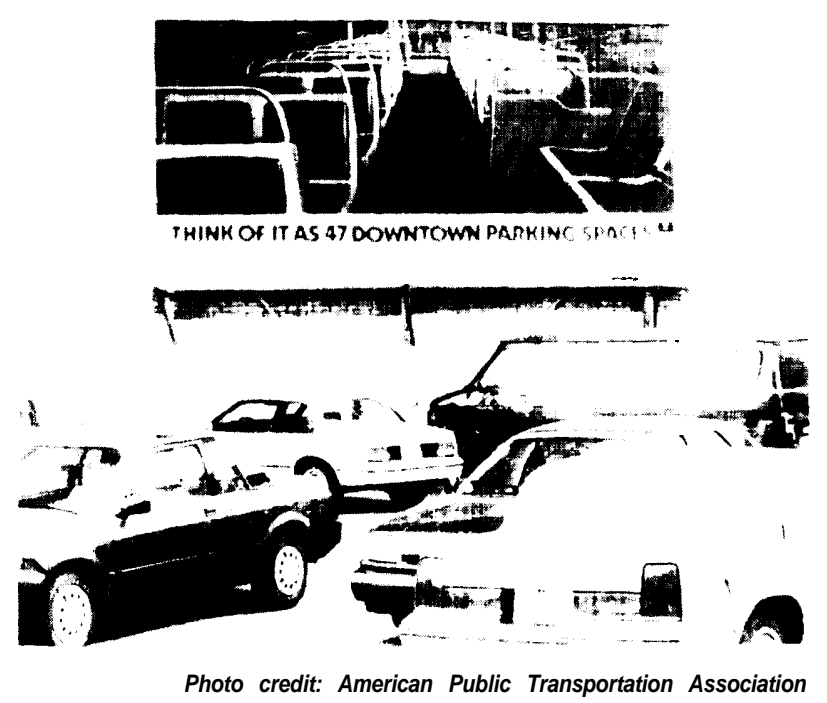

The Southwest Ohio Regional Transit Authority promotes public transportation with billboards like this one in Cincinnati, $\mathrm{OH}$. 


\section{Box 5-C-Successful Urban Bus Systems}

Every author who looks at public transit concludes that Americans just don't like it. This could change. Many cities in other industrial countries have efficient, heavily used public transit systems; some cities similar in many ways to American ones have attracted large numbers of motorists to public transit through service improvements.

Ottawa, Canada a metropolitan area of about 600,000, began a major transit improvement in the mid-1970s (coupled with the abolition of free parking downtown for Federal public servants). ${ }^{\text {T }}$ The cornerstone of the program was construction of a 20-mile dedicated busway, separated from other traffic but with ramps feeding into arterial roads at major stations, spaced at about 1-mile intervals. The program also included premium-priced express service between outlying suburbs and major employment centers, expanded connections to intercity terminals, mom buses, and many operating innovations.

The program 's success has been impressive. A greater percentage of people ride the bus in Ottawa than in any other medium-sized city in North America. Along major suburban corridors, 23 to 45 percent of ail trips are taken in buses. That is up from 2 to 20 percent in 1971. The system covers a steady 60 percent of operating costs from revenue.

Curitiba, Brazil, is a prosperous and rapidly growing metropolitan area with a population of about 1.5 milliom ${ }^{2}$ Faced with bad traffic congestion in the early 1970s, the city developed a comprehensive public transport plan based on a 35-mile network of separated bus lanes along the medians of radial arterial roads. The lanes are not grade separated at intersections, but have signal priority. The system is operated by several private companies with coordinating management committees to oversee such matters as intercompany reimbursementfor transferring passengers. Fares are low, and the companies are profitable.

In 1970, about 40 percent of trips in Curitiba were made by private auto, indicative of the higher incomes here than in other Brazilian cities. (The nationwide average for metropolitan areas was 30 percent.) The remarkable success of the transport system is that between 1970 and 1980, while Curitiba's auto fleet grew by more than 10 percent per year, the fraction of metropolitan trips made by auto declined to 30 percent

The experiences of both Ottawa and Curitiba suggest that attracting riders from cars to public transit depends on comprehensive attention to details of service convenience and quality. Major gains can be made when, because of priority treatment on congested roads, public transit is faster and more convenient than driving.

\footnotetext{
${ }^{1}$ This section is drawn from ref. 36.

2This section is drawn from ref. 44.
}

Federal Highway Administration (FHWA), this pattern of growth is expected to continue (20). However, growth in the suburbs does not necessarily have to mean more and longer commutes in private cars. The FHWA's task force anticipates that the density of residential development in the suburbs will increase as rising housing costs and declining household sizes necessitate construction of apartments and compact townhouses rather than expansive subdivisions (20). This increase in density could facilitate transit service. And, some analysts have suggested, land-use policies could guide development to limit reliance on driving.

Land-use planning and regulation are traditionally activities carried out by local governments, whereas transportation planning is more apt to be a State or regional responsibility. Land-use policies are implemented through local zoning laws and permit requirements for subdivision and commercial site development. Permit reviews typically ensure that public works (e.g., water, sewers, roads, interchanges, and parking) are adequate to support the development. Interaction between transportation and land-use planning agencies usually takes the form of assessing the impacts of new developments. The number of trips that would be generated by a proposed development is estimated and compared with the capacity of nearby roads and intersections.

If a transportation system is inadequate to support new development, it maybe expanded, sometimes at a developer's expense. Increasingly, where funds are limited or congestion is already an issue, developers are being required to take steps such as providing convenience stores on site or providing transit shelters or bike paths, in order to reduce potential transportation impacts. Downtown developers in several cities have been faced with caps on the number of parking spaces they can provide. In Los 
Angeles, area-wide land-use regulations are being developed to help reduce traffic congestion and air pollution. The guiding principles include: promoting development in areas with existing mass transit services; encouraging development within developed areas to increase population density and thus make transit services easier to provide; and promoting housing construction in job-rich areas or employment opportunities in residential areas. Due to the links between land-use policies, jobs, and tax revenues, local political resistance is apt to be the major problem in trying to modify land-use regulations (12).

\section{Factors Affecting Carbon Dioxide Emissions Per Mile}

Carbon dioxide emissions per unit of travel are largely determined by two types of factors: operation and maintenance practices (including occupancy level, the speed at which vehicles are operated, and vehicle tuning) and vehicle efficiency technology (including such market-determined factors as the average size and power of vehicles in the fleet),

Vehicle speed has a significant effect on fuel use (figure 5-4). The lowest fuel use per mile (and thus lowest $\mathrm{CO}_{2}$ emissions per mile) occurs in the range of 35 to $45 \mathrm{mph}$. Traveling at $65 \mathrm{mph}$ typically results in 20 to 25 percent higher $\mathrm{CO}_{2}$ emissions per mile than traveling at $55 \mathrm{mph}$. Traveling at $75 \mathrm{mph}$ results in about 50 percent higher emissions. Speeds lower than $35 \mathrm{mph}$, often a result of highway congestion, result in higher emissions, as well. Increasing urban highway congestion has, and will continue to, cut overall on-road efficiency (see box 5-D).

Even if revived public transit reduces projected VMT growth, cars and light trucks (pickup trucks, minivans and four-wheel drive ' 'sport' vehicles) will continue to dominate U.S. transport. Assuming the mix of types and sizes of vehicles remains about the same, the single most important factor determining future transport energy use and $\mathrm{CO}_{2}$ emissions will be the rate of light vehicle efficiency gains. Today's best production models and prototypes surpass $50 \mathrm{mpg}$ and $80 \mathrm{mpg}$ respectively, indicating that cars can be much more efficient than they are, on average, today (see table 5-4). More efficient cars make some sacrifices in performance and size, but, with further development, significant efficiency gains should be possible even with today's vehicle
Figure 5-4-The Effect of Vehicle Speed on Fuel Consumption

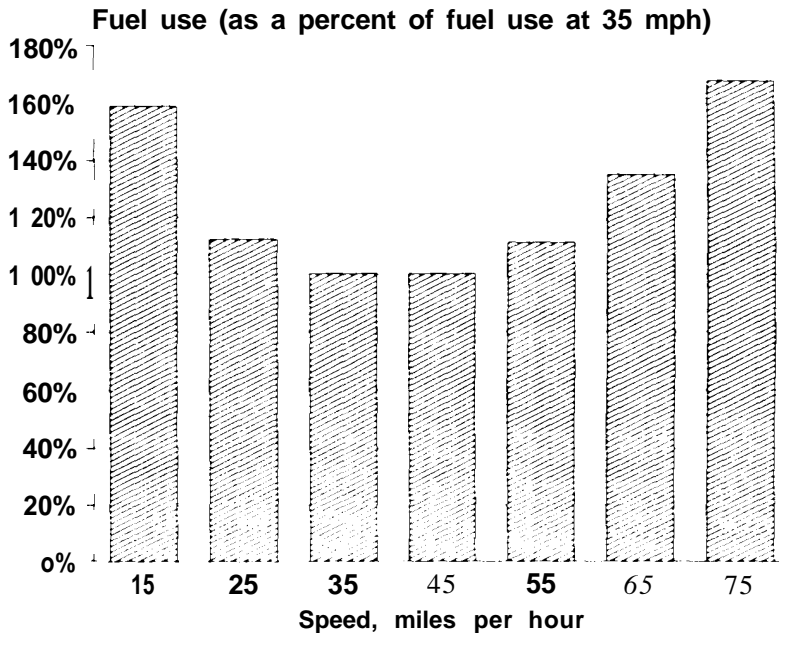

SOURCE: S.C. Davis, D.B. Shonka, and P.S. Hu, Automated Transportation Energy Data Book (Oak Ridge, TN: Oak Ridge National Laboratory, May 31,1988$)$, table 3.35 .

size and performance. The rate of improvement possible for the entire fleet is discussed in detail in "OTA Emission Reduction Scenarios," below.

In addition to efficiency gains from new technologies, additional improvement can be had by shifting sales to smaller cars. Difiglio et al, (14) estimate that by 2000 , a new-vehicle fleet-average efficiency of about $39 \mathrm{mpg}$ is the maximum technologically achievable without changing the size mix of the fleet. An additional 5 to $7 \mathrm{mpg}$ average is possible if between 75 and 95 percent of car purchases are from the smaller, most fuel-efficient car lines. However, not all consumers would be satisfied with these vehicles. Moreover, shifting to smaller vehicles raises safety concerns (see box 5 -E).

Large efficiency gains can be achieved if consumers will accept much smaller, lighter, and less powerful cars as second vehicles. While limited in applications, very small cars are suitable for some purposes such as urban commuting. If a substantial fraction of mileage was driven in cars sized for the number of passengers traveling and the purpose of the trip-say, 20 percent of vehicle miles in halfwidth cars getting $120 \mathrm{mpg}$ and the remainder at 34 mpg (the average we forecast for the year 2010)-then fleet average efficiency would increase by about $6 \mathrm{mpg}$. Whether such vehicles could meet safety requirements is unknown, however. 


\section{Box 5-D-Congestion}

Traffic is increasing in many cities. Average automobile speeds in London are reportedly as low as 8 miles per hour (mph), and in Tokyo speeds are even lower (46). In Los Angeles, average speeds are expected to decline from about 35 to 19 mph between 1984 and 2010 (55). A drop in average speed in the range expected in Los Angeles could result in a one-quarter reduction in average automobile fuel economy for these vehicles. ${ }^{1}$

According to the Federal Highway Administration, in 1987, congestion on U.S. freeways alone created about 2 billion hours of delay and wasted about 2.2 billion gallons of fuel due to the negative effects of stop-and-go driving on automobile fuel economy (33). This amounted to about 2 percent of total gasoline consumption in the United States in 1987. The cost of this loss in productivity (i.e., time lost sitting in traffic) and excess fuel consumption totaled about $\$ 16$ billion in 1987. If no further improvements are made to our transportation system, by 2005 , congestion-induced gasoline use on freeways is expected to contribute about 12 percent of the total consumption (68).

To mitigate the congestion wrought by the projected growth outlined above, we can choose to either improve the highway system or take steps to reduce the rate of growth in vehicle miles traveled (VMT). Increasing the capacity of, and the traffic flow on, existing highways could ease congestion, but the benefits may only be temporary since VMT growth could eventually meet and surpass future capacity. Reducing the rate of VMT growth, or demand through the adoption of transportation control measures can also help ease congestion, but such measures require region-wide cooperation among municipalities as well as public acceptance and participation. In a strategy that targets both transportation supply and demand, the Los Angeles area estimates that traffic delays in 2010 can be reduced by 50 percent over what they would have been without any further improvements.

${ }^{1}$ This estimate assumes thal the relationship between fuel cconomy and speed is linear between 20 and 35 mph (soe ref. 33), and that the average automobile fuel economy of late-model-year automobiles is about 25 miles per gallon at $20 \mathrm{mph}$ and about 34 miles per gallon at 35 mph (see ref. 11).

Table 5-4:-Projected Fuel Economy Impacts of Auto Technical Changes

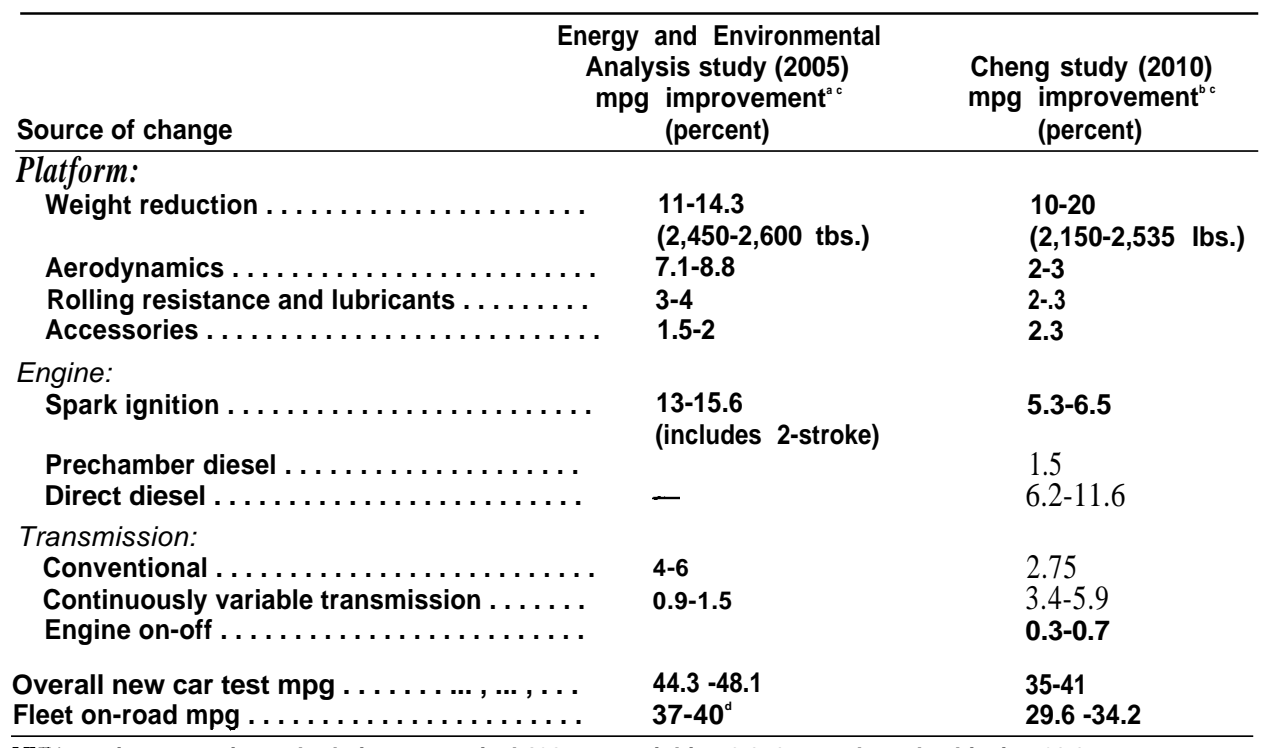

aEEA's gains are estimated relative to a typical 1987 car weighing 3,070 pounds and achieving $28.0 \mathrm{mpg}$. bCheng's gains are estimated relative to a typical 1985 car weighing 2,900 pounds and achieving $27.0 \mathrm{mpg}$. 'Gains shown here wight each author's estimated technical effect by his estimated market penetration. dEEA does not present fleet on-road mileages. This figure is calculated assuming the same ratio between newandfleet figures as in Cheng.

SOURCES: Derived from H.C.Cheng, "Potential Reductions in U.S. $\mathrm{CO}_{2}$ Emissions in 1995 and 2010 by Technology Improvements in Electricity Generation and Transportation Sectors" (Upton, NY: Brookhaven National Laboratory, Process Sciences Division, April 1988); Energy and Environmental Analysis, Inc.Developments in the Fuel Economy of Light-Duty Highway Vehicles, draft final report for U.S. Congress, Office of Technology Assessment (Arlington, VA: June 1988). 
Efficiency improvements are more readily adopted in other modes than in private vehicles for two reasons. First, commercial operators pay more

\section{Box 5-E-Safety v. Efficiency}

Are efficient cars necessarily more dangerous? Other things being equal, a larger and heavier car is both safer and less fuel-efficient (9). Any factor that shifts the vehicle fleet toward smaller and lighter cars-with other factors held constant-will increase fatalities; the National Highway Traffic Safety Administration (NHTSA) states that major downsizing of vehicles to increase fuel economy above $27.5 \mathrm{mpg}$ would result in increased fatalities and injuries (72). This argument applies not just to standards, but also to any market or regulatory effect that pushes toward lighter cars.

NHTSA analyzed single-vehicle crashes involving passenger cars (through model year 1986) for the years 1970 to 1989 (72a). In nonrollover crashes, reduced car weight had little or no effect on the risk of fatality but was related to a small increase in the risk of nonfatal injury. In rollover crashes, however, smaller cars had art increased risk of fatal injury of about one-third; under the same crash conditions, narrow, light, short cars had higher rollover rates than wide, heavy, long cars.

The Insurance Institute for Highway Safety (IIHS) examined actual death rates in car crashes, by car size, body style, and age and sex of driver (27a). Only 1 small car was among the 10 with the lowest death rates, while 12 small- and 3 mid-sized cars were among the 15 with the highest death rates. Cars with high percentages of young and/or male drivers tended to have higher death rates.

However, good design and safety features can offset the effect of decreasing vehicle weight, as the steady decline in fatalities per mile traveled since the mid-1970s illustrates. ${ }^{1}$ Moreover, the IIHS analysis reveals that some small cars in several of the body style categories exhibited actual fatality rates that are just as low as those of the best mid-sized and large cars.

Nevertheless, a substantial move to smaller and lighter cars while maintaining or improving occupant safety will continue to be a major engineering challenge.

\footnotetext{
IBetween 1975 and 1988 new-ear fuel economy doubled and average weight declined by 1,000 pounds, but deaths dropped from 3.6 to 2.4 per hundred million vehicle miles. This decline represents a combination of technical advances, increased seatbelt use, and crackdowns on drunk driving.
}

attention to life-cycle costs. Second, each vehicle typically is operated more often so that fuel is a larger fraction of total life-cycle cost. As mentioned, the trend in freight is towards more energy-intensive modes (i.e., trucks) but also greater efficiency within those modes.

Air efficiencies are also improving thanks to technological advancements and changed routing (which increases the number of passengers per trip). The next generation of aircraft, which could start to appear in the mid- 1990s, could make use of advances in engines, wings and general aerodynamics, and lightweight structural materials that would yield significant savings in energy per seat-mile. For example, current airplanes such as the Boeing 757 and 767 achieve 70 seat-miles per gallon (with a full airplane). Boeing forecasts that the $7 \mathrm{~J} 7$ will achieve 130 to 150 seat-miles per gallon and that it might be possible to have an airplane operating at 200 seat-miles per gallon early in the 21 st century (59). Similarly, innovations in nonrail freight (e.g., trailers that double as railroad cars and the use of wingsails to help power ships) can further reduce transport energy intensity.

This assessment assumes petroleum will remain the fuel of choice in both passenger and freight modes through 2015. However, other fuels are under development, including methanol derived from natural gas (and, past the timefrarne of this study, possibly from coal), ethanol derived from corn or wood, and natural gas in compressed or liquefied form.

These alternative fuels are being considered for reducing urban air pollution but not all are good candidates for lowering emissions of greenhouse gases (see table 5-5). Methanol made from natural gas will have a negligible to modest effect on reducing greenhouse gas emissions. Natural gas systems can leak and since methane-the prime constituent in natural gas-is a powerful greenhouse gas, even low leak rates can offset much of the at best modest gains achieved by switching from oil to compressed natural gas. Gas or methanol made from woody biomass offers considerable reduction potential, but only if emissions are offset with additional biomass growth. (Wood emits a high amount of $\mathrm{CO}_{2}$ for every useful unit of energy it provides. See ch. 7.)

Electric vehicles will produce more $\mathrm{CO}_{2}$ emissions than gasoline vehicles if recharged with electricity from coal-fired plants but almost no 
Table 5-5-Greenhouse Gas Emissions From Alternatively Fueled Vehicles

\begin{tabular}{|c|c|}
\hline Fuel and feedstock & $\begin{array}{l}\text { Percent change } \\
\text { from present }\end{array}$ \\
\hline \multicolumn{2}{|l|}{ Methanol: } \\
\hline $\begin{array}{l}\text { M85, current natural gas conversion } \\
\text { technology . . . . . . . . . . . . . . . . . . . } \\
\text { M100, improved vehicle and gas }\end{array}$ & -2 \\
\hline $\begin{array}{l}\text { conversion technology .............. } \\
\text { M100, improved vehicle and best coal }\end{array}$ & -17 \\
\hline conversion technology . . . . . . . . . & +25 to +30 \\
\hline \multicolumn{2}{|l|}{ Natural gas: } \\
\hline Compressed, from domestic sources. . . . . & -14 to o \\
\hline \multicolumn{2}{|l|}{ Biomass fuels: } \\
\hline Ethanol from corn using coal for & -10 to +30 \\
\hline \multirow{2}{*}{\multicolumn{2}{|c|}{$\begin{array}{c}\text { biomass } \ldots \ldots \ldots \ldots \ldots \ldots \ldots \\
\text { Methanol from woody biomass } \ldots \ldots \ldots \ldots\end{array}$}} \\
\hline & -70 \\
\hline \multicolumn{2}{|l|}{ Electricity: } \\
\hline Recharging from coal-fired plant. . . . . . . & +5 \\
\hline Recharging from current electricity mix. . . . & -23 \\
\hline Recharging from best gas turbines . . . . . & -45 \\
\hline Recharging from nuclear plants......... & -80 \\
\hline Recharging from solar or hydropower .... & -85 \\
\hline \multicolumn{2}{|l|}{ Hydrogen: } \\
\hline \multicolumn{2}{|l|}{ Hydride vehicle, nuclear electrolytic } \\
\hline hydrogen $\ldots \ldots \ldots \ldots \ldots \ldots \ldots \ldots$ & -55 \\
\hline Liquid hydrogen, all solar hydrogen . . . . . . & -85 \\
\hline \multicolumn{2}{|c|}{$\begin{array}{l}\text { SOURCE: Modified from M.A.DeLuchi, State-of-the-art Assessment of } \\
\text { Emissions of Greenhouse Gases From the Use of Fossil and } \\
\text { Nonfossil Fuels, With Emphasis on Alternative Transportation } \\
\text { Fuels, draft report (Davis, CA: University of California, June 3, } \\
\text { 1990), table 10. Estimates rocalculated by M.A.DeLuchi, Dee. } \\
\text { 11, 1990. }\end{array}$} \\
\hline
\end{tabular}

emissions if renewable or nuclear sources are used. Improved vehicles recharged with electricity from the current U.S. mix of powerplants might lower emissions per mile by about 25 percent. Hydrogen (if generated from renewable or nuclear energy) offers significant long-term potential, but is the least technically advanced of any of the options. Table 5-5 compares greenhouse gas emissions from alternative fuel and gasoline vehicles. For more information on the status of alternative fuel vehicles, see a recent OTA report, Replacing Gasoline: Alternative Fuels for Light-Duty Vehicles (64).

\section{OTA EMISSION REDUCTION SCENARIOS}

OTA developed a general energy accounting model to track the effects of various policy measures on U.S. $\mathrm{CO}_{2}$ emissions ${ }^{4}$ (see app. A). Within the transportation sector, we forecast about a 35-percent increase from 1987 emission levels by 2015 as our "Base case" scenario. By simulating a series of Moderate control measures in the model, $\mathrm{CO}_{2}$ emissions were held to about a 20 percent increase by 2015. Only under our Tough scenario did $\mathrm{CO}_{2}$ emissions fall below current levels, to about 10 percent below 1987 emissions. Table 5-6 includes details about the control measures in the Moderate and Tough scenarios. We assume that gasoline prices rise to about $\$ 2.00$ per gallon (1987 dollars) by 2015 .

\section{The Base Case}

A basic assumption of the OTA Base case is that people will continue to place a high value on performance and vehicle size and continue to prefer single-occupancy driving to any other mode of transportation. The model projects combined auto and light truck VMT to grow at an average annual rate of 2.6 percent through 2000 and about 1.5 percent from 2000 to 2015. Thus, much of the growth in $\mathrm{CO}_{2}$ emissions in the OTA Base case comes from a steady rise in VMT. This growth more than offsets the $\mathrm{CO}_{2}$ reduction from a 25-percent improvement in auto fuel efficiency (to a new-car fleet average of about $37 \mathrm{mpg}$ by 2010).

\section{Moderate Control Measures}

$\mathrm{CO}_{2}$ emissions growth could be slowed but not reversed by implementing policies that would encourage measures that we classify as Moderate. If adopted by 1995, all of the Moderate measures together (see table 5-6) would lower transportation emissions by about 10 percent of 1987 levels by 2000 and by 13 percent by 2015 (see figure 5-5). However, emissions increases more than offset these savings: by $2015, \mathrm{CO}_{2}$ emissions still rise 20 percent relative to 1987 levels.

Before the year 2000, the greatest savings come from those measures OTA categorized as "Operation and Maintenance of Existing Stock" (O\&M). These measures include improving truck maintenance, reducing VMT through rideshare programs and parking controls, and enforcing a 55-mph speed limit.

\footnotetext{
${ }^{4}$ For the transportation sector the Oak Ridge National Laboratory's "Alternative Motor Fuel Use Model" was used as the modeling framework for highway vehicles (41).
} 
Table 5-6-Transportation Sector Conservation Measures

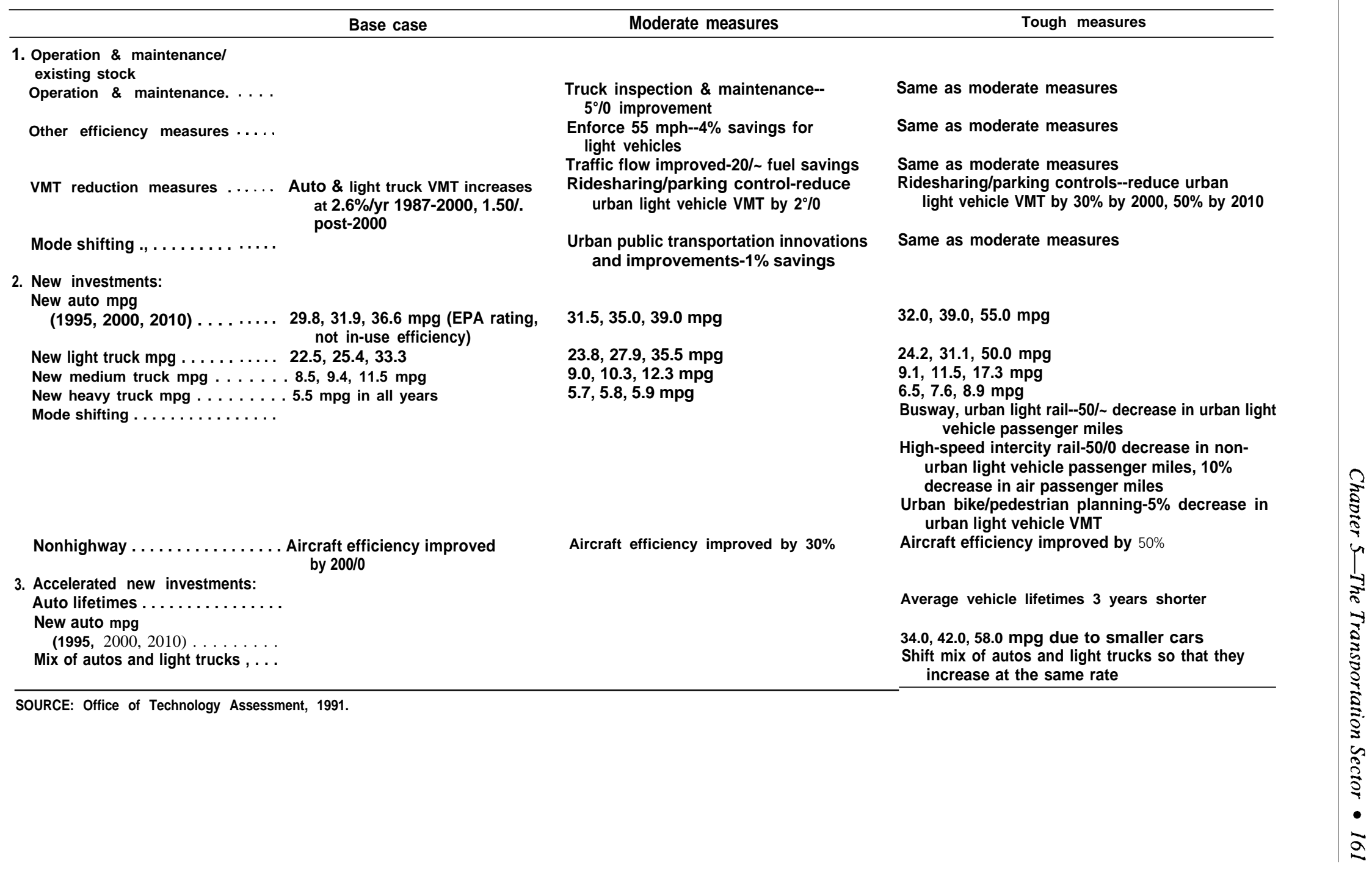


Figure 5-5- $\mathrm{CO}_{2}$ Emissions Reductions in 2000 and 2015 Expressed as a Percentage of 1987 Transport Sector Emissions, by Control Method, Under the Moderate Scenario

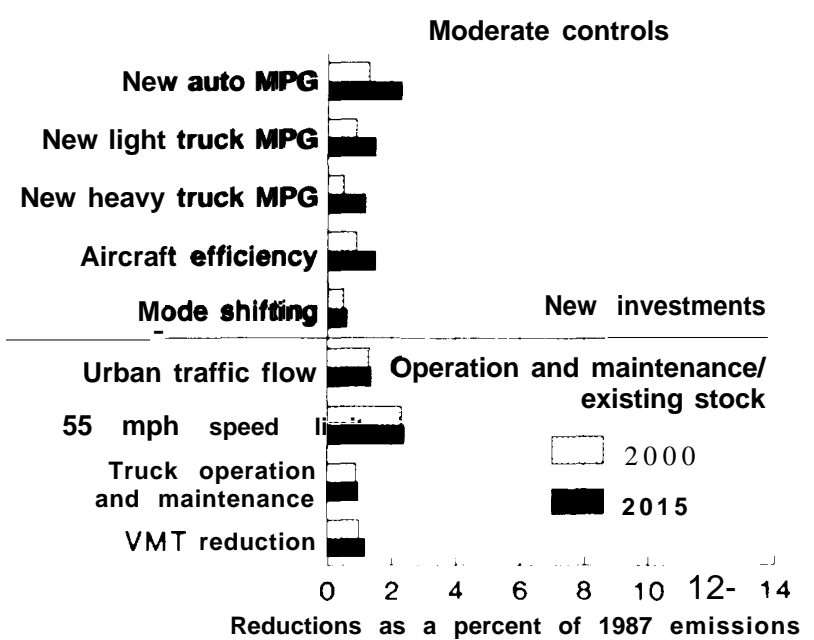

NOTE: The data presented above should be interpreted as the emissions reductions achievable in some future year expressed as a percentage of 1987 emissions from the transportation sector, not as a percentage decrease in emissions below 1987 levels.

SOURCE: Office of Technology Assessment, 1991.

Though the contribution from these measures grows very little with time under the Moderate scenario, O\&M still accounts for about half the total annual reductions by 2015 . Over half of the total savings from Moderate O\&M measures comes from returning the speed limit to $55 \mathrm{mph}$ and improving traffic flow. The balance comes from better truck maintenance and reductions in VMT through carpooling and vanpooling and parking controls. In this scenario no additional funds are devoted to mass transit infrastructure.

Improving fuel efficiency starts out as an important but modest part of the saving and increases over time. Measures to increase vehicle fuel efficiency can reduce transport emissions by about 2 percent of 1987 levels by 2000 and 7 percent by 2015 . Autos and light trucks account for the greatest proportion of savings.

In our Base case, we assume that new cars will average about $32 \mathrm{mpg}$ by 2000 and $36.5 \mathrm{mpg}$ by 2010. Under the Moderate scenario, new car efficiency averages $35 \mathrm{mpg}$ by 2000 ( 15 ) and $39 \mathrm{mpg}$ by 2010.
Figure 5-6-- $\mathrm{CO}_{2}$ Emissions Reductions in 2000 and 2015 Expressed as a Percentage of 1987 Transport Sector Emissions, By Control Method, Under the Tough Scenario

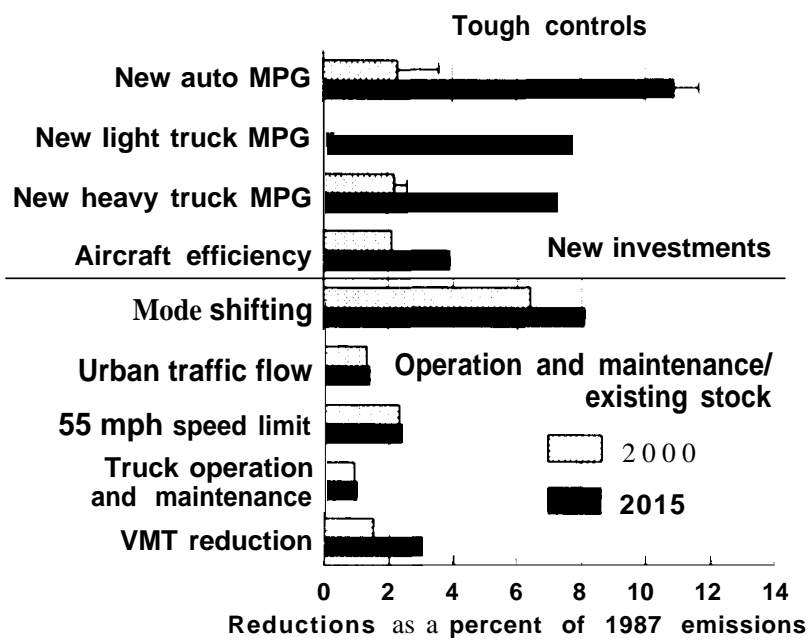

NOTE: The data presented above should be interpreted as the emissions reductions achievable in some future year expressed as a percentage of 1987 emissions from the transportation sector, not as a percentage decrease in emissions below 1987 levels. The thin horizontal bars show additional reductions possible if existing vehicles are replaced sooner than expected.

SOURCE: Office of Technology Assessment, 1991.

\section{Tough Control Measures}

In OTA's Tough scenario, $\mathrm{CO}_{2}$ emissions from the transport sector fall to about 5 percent below 1987 emissions by 2015 even with light vehicle size and performance more or less at current levels. If some consumers can be moved into smaller or less powerful cars and old cars are retired somewhat more rapidly, then emissions could fall to 10 percent below 1987 levels.

Reductions from the O\&M component are similar under the Moderate and Tough scenarios (see figure 5-6). Note, however, that O\&M plays a smaller role under the Tough scenario (about one-fifth of the total saving) than it does in the Moderate one (one-half of the savings).

New-car efficiencies of $34 \mathrm{mpg}$ by 2000 and 55 mpg by 2010 might be possible with an aggressive introduction of technical improvements, including a shift to diesel engines. This assumes that consumers buy cars of the same size and performance as today's (14), If the majority of consumers are willing to purchase smaller cars, new car fleet average efficiencies of $42 \mathrm{mpg}$ by 2000 and $58 \mathrm{mpg}$ by $2010 \mathrm{might}$ be achievable (14). Assuming such efficiencies (and policies that encourage people to buy fewer light 
trucks and buy new cars an average of 3 years earlier than they would otherwise) car emissions might be reduced by about 12 percent of 1987 levels by 2015 . In addition, 8 percent reductions from light trucks and 7 percent from medium- and heavy-duty trucks are achievable under our Tough scenario,

Measures to move people out of their cars and into mass transit under the Tough scenario would yield reductions of about 11 percent of 1987 levels, To achieve this, however, urban auto traffic would have to be reduced by 10 percent through urban light rail, subways, and urban bike paths. High-speed intercity rail would have to lower interurban car travel by 5 percent and air traffic by 10 percent.

\section{Summary of the OTA Scenarios}

Figure 5-7 summarizes the aggregated results for the Moderate and Tough scenarios through 2015. Figure 5-8 summarizes the results by mode of travel. As shown, all of the Moderate measures together are able to reduce the growth of emissions but not eliminate all growth above 1987 levels. Under the Tough scenario, emissions drop to about 10 percent below current levels. If future VMT growth turns out to be lower than we forecast, then greater reductions are possible. However, if vehicle miles traveled keep increasing at the rates we assumed and if those miles continue to be dominated by private cars of currentor increasing-size and performance, it will be difficult to hold down $\mathrm{CO}_{2}$ emissions. The critical factors are how fast society is willing to adopt more

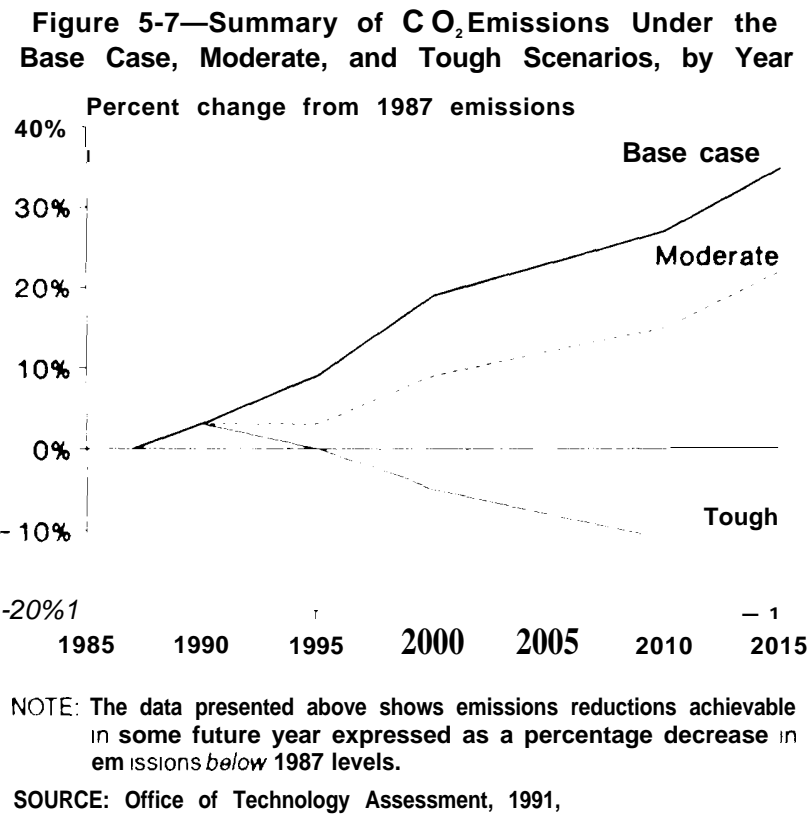

efficient technologies and the extent to which society will accept changes in how it moves people and goods.

\section{Costs of the Tough Scenario}

We estimate that the net costs (increased cost of the measures minus fuel savings) of the Tough scenario range between savings of about $\$ 35$ billion per year to costs of about $\$ 38$ billion per year $(1987 \$)$ in 2015 . The range is quite large because cost data exist for only some of the measures. For others, we assumed that costs were comparable to similar measures (e.g., truck efficiency improvements cost about the same as car efficiency improvements). Details on the calculations are presented in appendix A.

Overall, we estimate that the Tough new-vehicle efficiency measures will save money by 2015 , given the expected rise in the price of gasoline (to about $\$ 2.00$ per gallon). They are considered "Tough" primarily because they are technically challenging goals. We assume that the additional cost of fuel efficiency improvements to achieve a $55 \mathrm{mpg}$ new-car fleet average by 2010 will be in the range of $\$ 500$ to $\$ 750$ per car (1987\$) (14). Achieving a 58 mpg car fleet by encouraging consumers to buy smaller cars might require a subsidy of about $\$ 250$ to $\$ 500$ per vehicle (1 5). Thus we use $\$ 750$ to $\$ 1,250$ as our range of new car costs, Assuming light-duty truck efficiency improvements under the Tough scenario will also cost $\$ 500$ to $\$ 750$ per vehicle, we

Figure 5-\&Summary of $\mathrm{CO}_{2}$ Emissions by 2015, by Transportation Mode

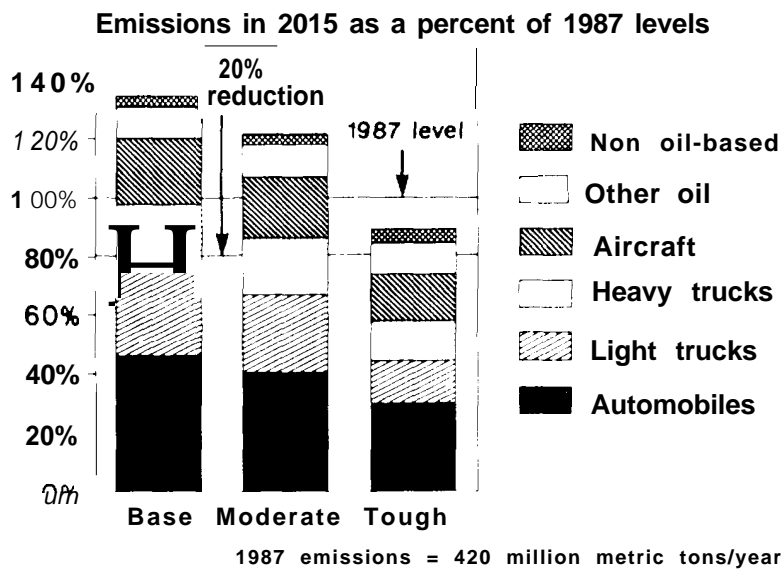

NOTE: The data presented above should be interpreted as the emissions reductions achievable in $\mathbf{2 0 1 5}$ expressed as a percentage of 1987 emissions from transportation, not as a percentage decrease in emissions below 1987 levels.

SOURCE: Office of Technology Assessment, 1991. 
estimate total passenger vehicle costs will be about $\$ 30$ to $\$ 50$ billion per year.

However, the higher efficiency under the Tough scenario saves about $\$ 58$ billion in fuel costs. Thus, net costs for improved light-duty vehicle efficiency are in the range of savings of $\$ 8$ to $\$ 28$ billion per year. The cost effectiveness of these measures is in the range of $-\$ 340$ to $-\$ 100$ per ton of carbon.

Lacking estimates for the costs of heavy-duty truck improvements, we assume similar dollar per ton costs as for light-duty vehicles. Savings amount to between $\$ 7$ and $\$ 15$ billion per year. For lack of a better estimate, we assume that cost of the aircraft efficiency improvements will equal fuel savings.

The cost of the O\&M measures in figure 5-6 varies widely. We estimate that using mass transit costs about $\$ 0.13$ to $\$ 0.21$ per passenger mile more than using cars. Mass transit and intercity rail costs under our Tough scenario total $\$ 26$ billion to $\$ 55$ billion per year, or about $\$ 1,200$ to $\$ 2,500$ per ton of carbon. Urban traffic flow improvements, truck inspection and maintenance programs, and improved urban planning are all probably low cost measures. Fuel savings from these programs amount to about $\$ 15$ billion per year. The remaining measures-55 mph speed limit, ridesharing, parking controls, etc.-all have associated inconvenience costs. Depending on what we assume for the value of these inconvenience costs, we estimate net costs in the range of savings of $\$ 9$ billion to costs of $\$ 9$ billion per year.

\section{Alternatively Fueled Vehicles}

Though discussed in an earlier section, we do not include use of alternative fuels as one of our near-term Tough control measures. Two of these fuels, however, offer considerable potential for lowering emissions past the 25-year time horizon of this assessment: methanol made from sustainably harvested wood and electricity generated from nonfossil fuels. Thus Congress may choose to adopt an alternative fuel program that will serve as a demonstration program for possible wide scale use of alternatively fueled vehicles after 2015 .
Table 5-5 included comparisons of greenhouse gas emissions between current gasoline and alternatively fueled vehicles. Under our Tough scenario, the ultimate effectiveness of alternatively fueled vehicles will depend on:

1. how rapidly the efficiency of alternatively fueled vehicles can be improved in comparison to efficiency improvements possible with gasoline and diesel fuels; and

2. whether these fuels (methanol and electricity) will be made from low emitting primary sources, i.e., sustainably grown biomass fuels for methanol and nonfossil sources to generate electricity.

To provide insight into the near-term gains from a large-scale, alternative fuel demonstration program, we estimated the emission reductions assuming that 15 percent of new passenger cars purchased between 2000 and 2015 use alternative fuels, evenly split between electricity and biomass methanol. By 2015 , about 1 out of every 10 vehicles would be alternatively fueled.

In our scenario, electricity is generated according to our Tough supply scenario discussed in chapter 3 . The potential for biomass fuels is sufficient to supply the feedstock for all of the methanol vehicles in the program (about 1 quad of biomass, see ch. 7). We assume that both electric and methanol vehicles improve through time, faster than under our base case but not as rapidly as gasoline or diesel vehicles under our Tough scenario.

Ass uming that the alternatively fueled vehicles substitute for those under our Tough scenario, such a program would achieve reductions equal to about 3 percent of $1987 \mathrm{CO}_{2}$ emissions. The program would also lower petroleum consumption by the transportation sector by about 5 percent.

\section{POLICY OPTIONS}

Urban passenger travel in cars and light trucks (i.e., light vehicles) consumes the largest share of transport energy in the United States. It is also in light vehicles that the market for fuel efficiency seems to operate least effectively. Consequently, policy to lower transport's $\mathrm{CO}_{2}$ emissions could be directed, first, at measures to increase the energy

\footnotetext{
${ }^{5}$ We assume that in 2000 the efficiency of methanol vehicles is 15 percent higher than our Moderate scenario vehicle and that efficiency will improve by another 15 percent between 2000 and 2015. We assume that the efficiency of electric vehicles will improve by 25 percent between 2000 and 2015 . These estimates are consistent with the ranges presented in ref. 13.
} 
efficiency of light vehicles, and second, at measures to encourage urban passengers to drive less by ride-sharing, switching to more energy-efficient modes, or reducing travel.

To increase efficiency and reduce VMT, a combination of several policy initiatives would seem to be best. These might include:

1. taxes on fuel and/or sales or registration taxes based on efficiency,

2 fuel efficiency standards,

3 , rebates on new fuel-efficient automobiles,

4. programs to change the way people meet their transportation needs, and

5, government support for research, development, and demonstration of new technologies and fuels.

\section{Fuel Taxes}

The United States has relatively inexpensive fuel prices relative to other industrialized countries, primarily due to low fuel taxes (see figure 5-9). A higher fuel tax would create incentives for increased efficiency and travel reduction for all modes. Its theoretical attractiveness is that it allows consumers to choose how they adjust their behavior to use less fuel: spend money on fuel economy technologies, use mass transit, carpool, or simply travel less. In practice, taxes do send powerful signals throughout the economy and can enhance the effectiveness of other policies such as fuel economy standards (see below). But there are several problems with fuel taxes. First, they are regressive-that is, they affect the poor relatively more than they affect the rich. For example, in 1985, households with incomes greater than $\$ 35,000$ per year spent about 4 percent of their income on gasoline. Those with incomes in the range of $\$ 10,000$ to $\$ 15,000$ per year spent about 9 percent and those households between $\$ 5,000$ and $\$ 10,000$ per year spent about 11 percent of their income on gasoline (23).

Second, the effectiveness of taxes is hard to predict, hence it is difficult to set a tax to achieve a desired result. Studies document a wide range of past consumer response to gasoline price increases. Over the short term, one might expect a 10-percent gas hike to yield a 2-percent drop in gas consumption
Figure 5-9-international Gasoline Prices and Taxes,
1989

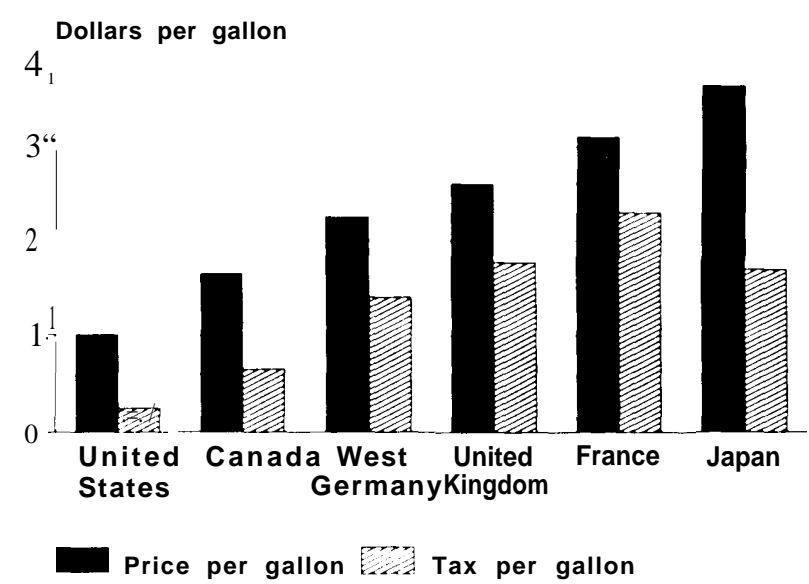

SOURCE: Business Week, Jan. 30, 1989, p. 20.

(though some studies indicate a 6-percent drop; others, less than 1 Percent). ${ }^{6}$ A 50-percent increase in the price of gasoline might yield about an 8-percent drop (between 5 and 20 percent). Assuming one can extrapolate in this fashion, a doubling or tripling in price-similar to prices in Europe and Japan-might yield a 13- to 20-percent drop in gasoline consumption.

Over the long term (i.e., allowing enough time for consumers not only to change their driving habits but also the efficiency of the cars they buy), the response is likely to be greater. A 10-percent gas hike might yield about a 7-percent drop in gas consumption in the long run. However, uncertainty with respect to the long-term response is even greater than uncertainty as to the short-term response, and it grows as prices increase. About half of the long-term response might be attributable to driving less and the rest to more efficient vehicles. Unfortunately, the data on which these estimates rest are from the 1970s. Fuel efficiency improvements may be more expensive today, hence consumer response to gasoline price increases may be lower. Thus, the long-term response one might expect from a relatively large price hike might be stifled by a lack of cost-effective technology. Still, one would expect that a doubling of gasoline price would elicit a long-term response somewhat greater than the short-

\footnotetext{
${ }^{6}$ Two recent studies (refs. 4 and 10) reviewed the relationship between gasoline price and consumption, based on dozens of published papers that have estimated the "elasticity" of gasoline consumption to price, i.e., the ratio of the percentage change in consumption to the percentage change in price. We use 0.2 as a best guess of short-term elasticity and 0.4 to 0.8 as a range for long-term elasticity (with the lower end of the range applying when technology changes are constraining).
} 


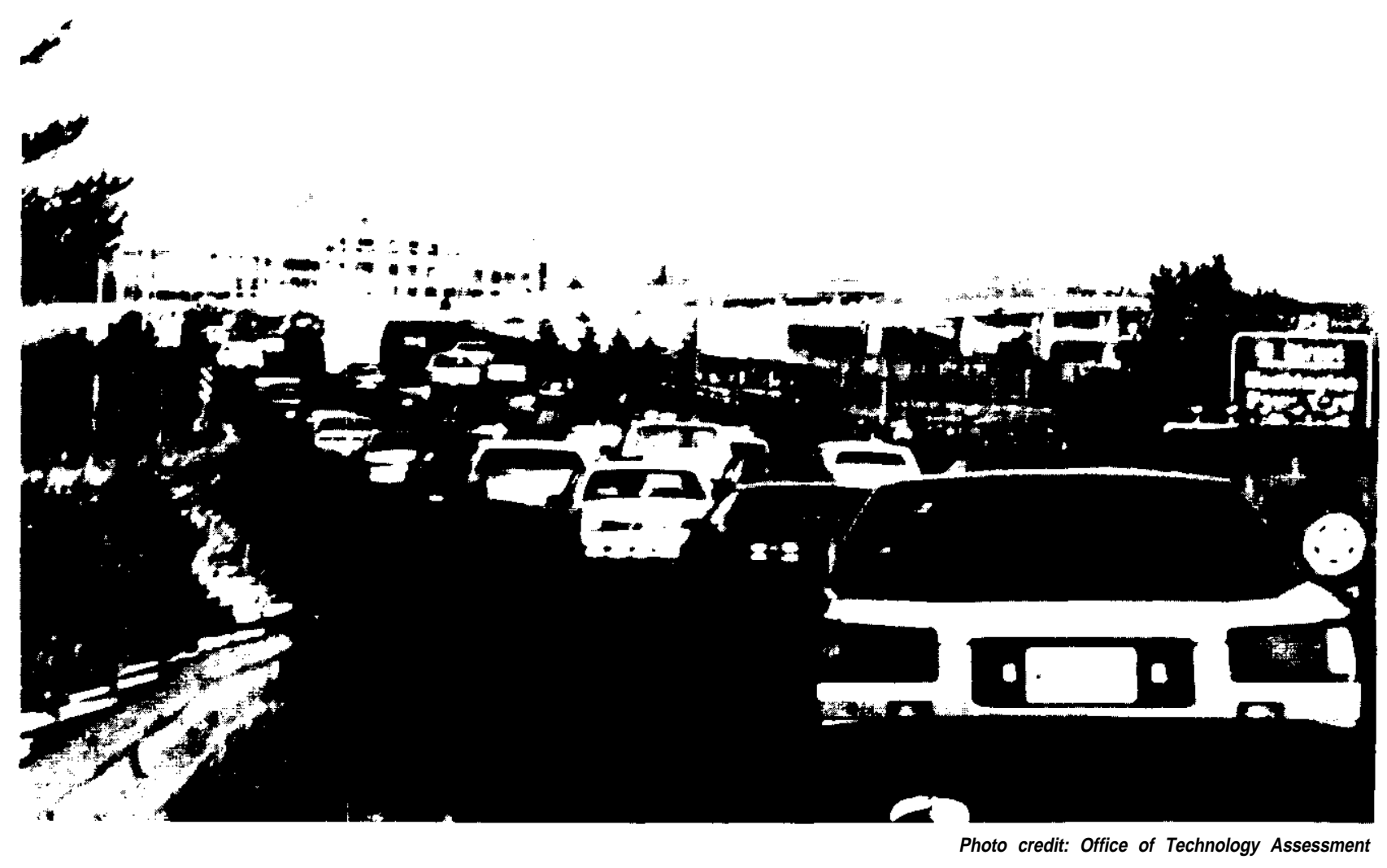

Highway congestion leads to greater fuel consumption and $\mathrm{CO}_{2}$ emissions. When traffic slows to speeds below about $35 \mathrm{mph}$, fuel use per mile increases.

term response, possibly as high as a 25- to 30percent drop in gasoline consumption. A tripling of gasoline price might lower consumption by as much as 35 to 40 percent.

If Congress deems that a fuel taxis a desirable part of a program to reduce $\mathrm{CO}_{2}$ emissions, it might also pursue policies to minimize the problems described above. To make the tax program less regressive, it could, for example, provide lump-sum rebates to low-income households. Congress could also phase in the tax to give consumers time to adjust their purchasing decisions and operation and management practices.

\section{Fuel Economy Standards}

Fuel economy standards influence tradeoffs among cost, performance, size, and efficiency that underlie new model design and introduction decisions. The current fuel economy standards for light vehicles, in place since 1978, have helped to increase auto fuel economy. Renewed and possibly redesigned standards offer significant benefits as a component of a fuel economy policy.

New standards must take account of engineering time scales and thus are somewhat slower to take effect than fuel taxes. Typically a vehicle reaches market 4 years after manufacturers make initial design decisions pertinent to its fuel economy; manufacturers need adequate lead time to respond to new standards.

Redesigned standards might compensate for differences in manufacturers' size mixes. The present Corporate Average Fuel Efficiency (CAFE) scheme imposes unequal burdens on different automakersfull-line manufacturers get hit harder than those specializing in small cars. An efficiency regime that varies with vehicle volume could meet these concerns, One such regime is the proposed Volume

\footnotetext{
${ }^{7}$ The pros and cons of fuel economy standards are still the subject of some debate. For a summary, see ref. 19.
} 
Average Fuel Economy (VAFE), which sets fuel efficiency standards based on the interior space of a car (35). Further, by using load capacity instead of interior room, light trucks could be pushed to the same level of technical effort as automobiles. ${ }^{8}$

The VAFE approach is not without problems, however. First, it does not recognize efforts some manufacturers have already taken to downsize their fleet to achieve higher corporate average fuel economy (Chrysler Corp. has frequently pointed this out). Second, since there is no minimum fuel economy standard for a manufacturer's overall fleet, shifts from small to large cars could occur, reducing the net improvement in fleet average fuel efficiency. Finally, a large potential for fuel economy performance resides with downsizing to lighter vehicles. The VAFE approach does not inherently include this downsizing incentive (whereas CAFE does).

As with taxes, the 'right level for new standards is difficult to define. It will depend to a large degree on the intent of the standards. If Congress desires standards that are cost-effective (i.e., fuel cost savings about equal to increased vehicle costs), the Department of Energy (DOE) estimates that standards by 2000 should be set at between 32 and $36 \mathrm{mpg}$ (12a). In 2000 (assuming unchanged real gasoline prices), a fleet economy of $32 \mathrm{mpg}$ would be cost-effective for a car's first owner (4-year ownership); over the car's 10-year life, $36 \mathrm{mpg}$ would be cost-effective.

If Congress wanted to push consumers to conserve even further, standards would have to be higher. DOE calculated that the toughest standard that is technically achievable (without requiring significant size shifts, disrupting the orderly development of new models, or unduly disrupting the required flow of earnings) would be $39 \mathrm{mpg}$ by 2000 . The 39-mpg car would be cost-effective at $\$ 1.70$ per gallon (1989 dollars) or more (assuming consumers are willing to accept the technology changes necessary to achieve this level of fuel efficiency) (15). The corresponding maximum-technology figure for 2010 was 40 to $55 \mathrm{mpg}$, depending on the assumed penetration of diesels or other new engines (15). ${ }^{9}$ These estimates assume that size, luxury, and performance of the fleet is frozen at 1987 levels (though the recent trend has been toward larger or more powerful vehicles).

\section{J'chicle Taxes and Rebates}

Taxes and rebates on vehicles can create incentives to sacrifice some size and performance for economy. Taxes on inefficient vehicles would be most effective if accompanied by rebates for highly efficient cars. The program could be designed so that it was 'revenue neutral' '- all the money taken in from the taxes would be recycled through the rebates. To achieve this over an extended period, the thresholds for both tax and rebate will have to increase over time as average fuel economy increases.

The Federal Gas Guzzler Tax, ${ }^{10}$ already applies to cars whose economy is below certain thresholds. Until recently, the tax started at $\$ 500$ for cars below $22.5 \mathrm{mpg}$, increasing to $\$ 3,850$ for those below 12.5 mpg, Legislation passed in the 101st Congress doubled the tax to between $\$ 1,000$ and $\$ 7,700$ per vehicle. ${ }^{11}$ The tax was originally intended to be coupled with a rebate for extremely efficient cars, but the rebate was never enacted.

An expanded program of vehicle taxes and rebates could complement fuel economy standards and taxes, but it could pose serious trade difficulties as long as the high-efficiency end of the auto market is dominated by imports. Such measures would discriminate against domestic manufacturers. And, any such measure that set out to protect domestic manufacturers might conflict with General Agreement on Tariffs and Trade (GATT) rules.

\section{Incentives for Manufacturers}

Government-sponsored competitions could be used as incentives to induce manufacturers to develop high-efficiency cars. A bill proposing this was introduced in Congress in $1982 .{ }^{12}$ However, it

\footnotetext{
${ }^{8}$ For further discussion of size-class standards, see ref. 61.

'Forty mpg with no additional diesel penetration, 55 mpg with 100 percent penetration. Note that representatives of Ford and General Motors at OTA'S workshop disputed these figures. They asserted that economy gains achievable from the technologies listed were smaller, and their costs were larger.

${ }^{10}$ Public Law 95-618, the Energy Tax Act of 1978.

1'Public Law 101-508, the Ominibus Reconciliation Act Of 1990.

${ }^{12}$ The Shamansky bill would have sponsored a competition to produce an 80-mpg gasoline car or a 100-mpg diesel car meeting minimum performance, safety, and emissions criteria To win, the car would have to be put into limited production.
} 
is unlikely that the government would pay enough in prize money to induce major manufacturers to participate (3).

A variant of the incentive scheme injects competitive elements into a high-efficiency rebate program (48). The government could identify a few classes of vehicles most in need of economy improvement and offer a competitive reward in the form of large (e.g., $\$ 500)$ consumer rebates on a large production run (e.g., 200,000 units) of a new vehicle achieving the best fuel economy above a specified threshold.

\section{Policy Directed at Operation and Maintenance}

Government action targeting the way vehicles are maintained and operated can help lower transport $\mathrm{CO}_{2}$ emissions. These offer smaller potential reductions-typically ranging from less than 1 up to 5 percent each in the OTA model. Still, they may be important because they move in the right direction, may bring other benefits, or may be reminders of a commitment to energy efficiency. More significantly, most of the measures that these polices promote have short start-up times and do not require large, up-front capital investment. They include reimposing (and enforcing) the 55-mph speed limit; requiring fairings for trucks to lower wind resistance, enforced through efficiency inspections; requiring high-efficiency tires and oils on Federal vehicles; preferential use of rail and intermodal freight (i.e., freight that can travel on both roads and railroad tracks) for Federal shipping; and charging efficiency-promoting parking fees at Federal offices and contractors.

\section{Transportation Control Measures}

Several American cities are now experimenting with policy measures intended to reduce travel in private automobiles. While many cities have experimented with a few of these, the most ambitious program is just beginning in Los Angeles (see box 5-F). The advantage of these measures, collectively called Transportation Control Measures or TCMs, is that they directly address urban passenger miles traveled. They also share some of the characteristics of the operation and maintenance steps described above: individually, they only slightly reduce $\mathrm{CO}_{2}$ emissions but have short startup times, low capital costs, and can reduce energy use and $\mathrm{CO}_{2}$ emissions even within existing settlement and employment patterns.
However, TCMs are in a very early stage of adoption. Moreover, the range of possibilities and the complexity of interactions among different measures means that any major TCM initiative must proceed by trial and error.

A recent study summarizing U.S. experience with several major categories of TCMs (5) concluded that information on TCMs was incomplete and quantitative data was lacking on the effects of several promising categories. Some of the TCMs evaluated by the authors, Cambridge Systematic, include:

- Areawide Ridesharing: Promotion and matching services achieved areawide reductions of 0.1 to 3.6 percent in VMT (average 0.3 percent) in 32 programs now in place.

- Employer-based Transportation Management: Comprehensive programs are run at the workplace to get people out of single-occupancy cars and into any alternative--carpools, vanpools, bike, or transit, The programs combine high parking charges for solo drivers with transit or vanpool subsidies and expedited transactions-e. g., bus passes, van leasing, and insurance are all on sale at work. Such programs have achieved movements of 30 to 80 percent of all workers into nonsolo modes at large workplaces, with reductions of commuting VMT from 10 to 50 percent. Feasible areawide VMT reduction depends on the concentration of workplaces, but is estimated around 1 percent.

- High-Occupancy Vehicle (HOV) Lanes: Restricting lanes on freeways to cars with three or four occupants or to buses can reduce congestion and give time incentives for ridesharing. The 14 examples operating in the United States as of 1985 showed reductions of 5 to 10 percent in peak corridor VMT during peak commuting times. (Some of this reduction comes from commuting at a different time rather than finding different ways to commute.)

- Bicycling Promotion: Comprehensive programs including bike lanes or paths, secure locking facilities and showers, and public education and promotion can reduce areawide VMT by 0.05 to 0.1 percent. The data are very weak, though, and American experience with bicycling promotion programs is very limited.

- Parking Management: This includes parking taxes or development surcharges, restricting street parking, and mandating high parking 
charges at workplaces (usually with special rates for carpools). American data are very weak, but the experience of Ottawa suggests that the impact can be large, especially if coordinated with improvement of alternatives to driving.

- Park-and-Ride: There are two approaches. Remote park-and-ride tries to reduce VMT by intercepting drivers near to their origins, but the remote lots pose theft problems; peripheral park-and-ride seeks principally to reduce downtown congestion and has little effect on total VMT. Cambridge Systematics estimates a potential of 2- to 4-percent VMT reduction within specific corridors.

- Transit Improvements: Even large investments in rail systems have achieved at most 3-to 5-percent reduction in areawide VMT. Short-range improvements including bus service expansion, operational changes, and fare changes have been much more successful. Cambridge Systematic cites experience in nine cities showing increases in transit ridership from 8 to 50 percent and reductions in VMT from 0.1 to 0.5 percent.

- Travel Substitution (telecommunications, workat-home, and flexible hours): Views are still mixed on the potential for telecommunications and work-at-home to reduce travel. The Los Angeles plan takes an ambitious stance and projects 20-percent reduction in worktrips due to telecommuting and 10 percent due to alternative work schedules, for a net decrease in areawide VMT of 6.8 percent. Cambridge Systematic estimates the total impact of flexible schedules as only 0.1- to 1. O-percent reduction in areawide VMT.

- Traffic Flow Improvements (sophisticated signals, ramp metering, intersection improvement): These measures are principally intended to reduce congestion, but secondarily reduce energy and greenhouse emissions because less fuel is burnt idling in stopped traffic and average speeds increase. Reductions in fuel consumption up to 6 percent have occurred on particular routes, but areawide impacts have not been measured in American cities. If faster traffic induces people to drive more, such measures can increase fuel consumption, though. A recent study in Perth, Australia found just this unintended effect (39).
In aggregate, transportation control measures appear to hold modest promise for reducing VMT, but much more experimentation and data are needed before their potential impact can be assessed. However, even modest VMT reductions in congested areas can improve traffic flow, thereby reducing both miles traveled and fuel consumption per mile.

\section{Controlling Settlement Patterns}

Emissions can be reduced in the long run by changing patterns of settlement to reduce the need for travel or to increase the utility of mass transit. This can be accomplished through higher densities, or through mixing uses so that residences, jobs, and services are roughly balanced at a local scale. When more destinations are close to home, more trips can be made by foot, and public transit can serve more trips effectively.

In the United States, except possibly for some high-growth areas in the South and West, efforts to change the shape of settlement in major cities is likely to have limited impact in the near term. Because we are entering a period of slower population growth, the shape of cities might not change as drastically as it did in the 1950s and 1960s. In a period of slow population growth, change in urban shape proceeds only marginally faster than the replacement of the standing building stock, which takes 50 to 100 years.

Nevertheless, some changes are feasible, particularly in the balancing of homes and workplaces in the suburbs. The Los Angeles air quality plan, for example, includes measures to balance jobs and housing through a combination of market and regulatory measures. It projects that 12 percent of jobs and 6 percent of housing in the region will be affected by the measures, and reductions of about 10 percent in VMT will be achieved (55).

Changes in density are also possible in the United States through changed zoning and infilling. The difficulty will be that urban residents often strenuously resist increasing densities. Paradoxically, traffic congestion is often cited as one of the reasons to oppose higher density development, although with fixed travel needs, congestion is often higher in lower density areas. 


\section{Box 5-F-The Los Angeles Air Quality Plan}

The Los Angeles area is notorious for its air pollution problems. Despite numerous control measures, the region still exceeds Federal standards for ozone, carbon monoxide, nitrogen oxides, and suspended particulates--giving it the worst air quality in the Nation. The South Coast Air Quality Management District and the Southern California Association of Governments have recently completed a comprehensive Air Quality Management Plan (AQMP) designed to bring the region into compliance with all standards except the strict State standards for ozone and particulate by the year 2007 and hold total vehicle miles traveled (VMT) to a 30-percent increase (rather than the projected 72 percent) by $2010(22,54)$.

Although the AQMP does not directly address the problem of global climate change, it contains many transportation control measures that may serve as models for other local, State, and national governments in their attempts to reduce $\mathrm{CO}_{2}$ emissions.

The Plan's control methods are divided into three sections, or "tiers," depending upon their readiness for implementation. Since cars and trucks contribute the majority of carbon monoxide, reactive organic compounds, and nitrogen oxides emissions in the Los Angeles Basin (53), each of the tiers contains a number of measures designed to modify transportation methods and behaviors.

Tier I-The first phase of the Plan provides controls on motor vehicles, transportation systems, and land use that can be implemented within the next 5 years and that will encourage alternative fuel use, improve efficiency, and lead to reductions in congestion and VMT $(54,55)$.

New buses in the region will be fueled by methanol and current transit buses will be retrofitted to accommodate other alternative fuels such as ethanol, propane, and compressed or liquefied natural gas. Owners of commercial and public fleets (15 or more vehicles) will also be required to purchase vehicles capable of operating on an alternative fuel when replacing units or expanding operations. Conversion to such fuels can be positive or negative in terms of global warming depending 011 what type of feedstock is used to produce the fuel.'

Transportation control measures focus on trip reduction programs (to ease the congestion and associated emissions; see box 5-D) and strategies to shift use toward more efficient modes. They promote the use of alternative work schedules, telecommuting, ridesharing, public transit, and vanpool-purchase incentives and better parking management in addition to the current Los Angeles trip reduction ordinance. Tier I measures also require merchants to provide incentives for public transit and facilities for nonmotorized transportation users (e.g., advertised bus passes and bicycle lockers).

Local ordinances would require special-event centers (stadiums, amphitheaters, etc.) to establish and operate park-and-ride programs and provide incentives for public transportation use. The plan also calls for designating auto-free zones in areas with dense pedestrian activity in conjunction with park-and-ride services. The transportation infrastructure will be improved through the construction of more high-occupancy-vehicle (HOV) facilities and at least 80 miles of light rail service. Finally, truck traffic patterns will be modified through rerouting, changing delivery times, and diverting port-related truck traffic to rail to increase efficiency and ease congestion at peak hours.

Land use is to be modified through growth management designed to attain job/housing balances in local jurisdictions. Implementation methods include modified zoning, development fees, density bonuses, and fast-track permit processing for those developments beneficial to the job/housing balance targets. The plan also calls for new job- or residence creating public facilities to be located in strategic areas to minimize commuting.

Tier II-Unlike Tier I, the second phase of the AQMP will require significant advances in current applications of existing technology and strong regulatory action for successful implementation by the year $2007(54,55)$.

To further encourage trip reduction through telecommuting, Tier II calls for implementation of tax incentives for telecommunications development and local ordinances requiring employers with multiple facilities to devote five percent of the building space to satellite work centers.

To ensure progress in alternative fuels technology, research and development will be funded by a $\$ 30$ million alternative fuels program, which also contains provisions for demonstration projects and fuel infrastructure enhancement. In addition, Tier II contains supplemental measures for imposing technology-forcing standards and limitations on the number of gasoline- and diesel-powered vehicles registered in the L.A. Basin. 
Tier III-The final tier of the AQMP depends on “. . . commitments to research, development, and widespread commercial application of technologies that may not exist yet, but maybe reasonably expected given the rapid technological advances experienced over the past 20 years" (54). These technologies may include improved fuel cells, solar cells, storage batteries, and superconductors for use in private and public transportation. Short-term actions to be taken by air-quality management agencies to promote RD\&D in these areas area part of the current Plan and will be updated regularly.

Tier III also anticipates extensive electrification of transportation modes, which, although eliminating the mobile sources of pollution, does not necessarily reduce overall carbon emissions and will increase demand for power generation. To mitigate these effects, the Plan contains proposals for energy conservation and noncarbon fuel promotion.

Finally, Tier III presents a number of contingency measures of last resort (including emission charges on vehicles, parking lots, and gasoline) that will be imposed if the control measures previously enumerated are not implemented or fail to perform as well as expected.

1For example, if coal is used as the feedstock to make methanol, greenhouse gas emissions can increase by 30 percent compared to gasoline; if woody biomass is the feedstock, greenhouse gas emissions can decrease by about 70 percent (see table 5-5).

2The 1987 ordinance applies to all employers of 100 or more people (about 8,000 businesses). Employers are required to prepare comprehensive trip reduction plans, with the goal of reducing the number of private motor vehicle trips by 10 percent. While falling short of this goal does not violate the ordinance, failure to submit a plan or annual update or to provide any stipulated incentives exposes the employer to possible civil penalties (63).

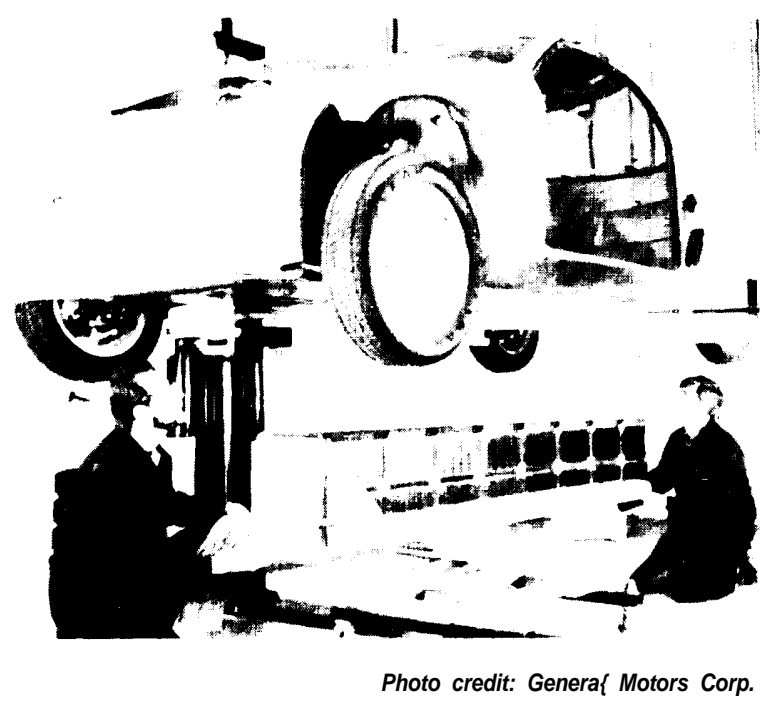

General Motors' prototype electric vehicle, the Impact. The Impact's battery pack, shown being installed, takes up the center portion of the vehicle. The current range of the vehicle is over 100 miles between charges. If recharged with electricity generated from natural gas or nonfossil sources, $\mathrm{CO}_{2}$ emissions per mile are much lower than from gasoline vehicles. With improved batteries- key hurdle facing this technology-both range and efficiency would increase.

Traffic congestion is already prompting some remarkably stringent suburban restrictions on development-some apply only to commercial and industrial development, some apply to new residential development as well (16). However, these measures will have little effect on congestion unless coordinated over entire metropolitan areas, and may even increase congestion if they reduce opportunities for people to live near work.

\section{Research and Development}

Large R\&D efforts will be essential for further technical efficiency advances beyond the turn of the century. A recent study of the state of fuel efficiency research and development in the auto industry found that American automakers lag far behind their Japanese and, to a lesser extent, European, counter parts---especially in moving research results to the market (3). During the late 1970s, the Department of Transportation funded the Cooperative Automotive Research Program (CARP) to support more aggressive research and development in the American auto industry. Unfortunately, it foundered in the prevailing atmosphere of mistrust between the industry and government and was cut back under the Reagan administration (3).

For such a program to be successful, domestic automakers, their suppliers, and innovative research companies all need to be key players. The program could target medium-term technologies such as continuously variable transmissions and energystorage systems. Other areas where federally supported $R \& D$ could have substantial impact include new engine design for heavy trucks, improved safety 
for lighter vehicles, and innovations to permit increased intermodal freight.

One area of longer term research that deserves special attention is development of truly clean, cost-effective, alternative fuels. Those fuels with the greatest potential-hydrogen or electricity from nonfossil sources (e.g., solar or nuclear power) and woody biomass fuels grown on a sustainable basisare the furthest from large-scale technical viability. Expanded research programs are needed to envision and expand the range of options available. At the same time, demonstration programs can assess the actual performance of a variety of fuels.

\section{CHAPTER 5 REFERENCES}

1. Ang, B. W., "Modelling World Energy Demand for Transport," Discussion Paper EDP 28 (Cambridge: Cambridge University, Energy Research Group, Aug. 25, 1983).

2. Automotive News, "Dupont Non-CFC Refrigerant May Solve Auto-Air Problem," p. 3, Feb. 6, 1989.

3. Bleviss, D. L., The New Oil Crisis and Fuel Economy Technologies (New York, NY: Quorum Books, 1988).

4. Bohi, D. R., and M.B. Zimmerman, "An Update on Econometric Studies of Energy Demand Behavior," Ann. Rev. Energy 9: 105$154,1984$.

5. Business Week, Jan. 30, 1989, p. 20.

6. Cambridge Systematics, Ltd., Improved Air Quality in Maricopa and Pima Counties, report to U.S. Environmental Protection Agency Region IX, November 1986.

7. Cheng, H.C., "Potential Reductions in U.S. $\mathrm{CO}_{2}$ Emissions in 1995 and 2010 by Technology Improvements in Electricity Generation and Transportation Sectors' (Upton, NY: Brookhaven National Laboratory, Process Sciences Division, April 1988).

8. Crandall, R. W., H.K. Gruenspecht, T.E. Keeler, and L.B.Lave, Regulating the Automobile (Washington, DC: Brookings Institution, 1986).

9. Crandall, R.W. and J.D. Graham, "The Effect of Fuel Economy Standards on Automobile Safety," The Journal of Law and Economics 32(1) :97-118, April 1989.

10. Dahl, C. A., *'Gasoline Demand Survey," The Energy Journal 7(1):67-82, 1986.

11. Davis, S.C., D.B. Shonka, and P.S. Hu, Transportation Energy Data Book (Oak Ridge, TN: Oak Ridge National Laboratory, May 31, 1988).

12. Deakin, E., "Land Use and Transportation Planningin Response to Congestion: A Review and Critique,'* paper No. 880586, presented at the 68th Annual Meeting of the Transportation Research Board (Washington, DC: Jan. 22-26, 1989).

12a. DiFiglio, C., Department of Energy, presentation at OTA Workshop on Transport and Global Warming, Apr. 6, 1989.

13. DeLuchi, M.A., State-of-the-art Assessment of Emissions of Greenhouse Gases From the Use of Fossil and Nonfossil Fuels, With Emphasis on Alternative Transportation Fuels, draft report (Davis, CA: University of California, June 3, 1990).

14. Difiglio, C., presentation at OTA Workshop on Transport and Global Warming (Washington, DC: Apr. 6, 1989).

15. Difiglio, C., K.G. Duleep, and D.L Greene, 'Cost Effectiveness of Future Fuel Economy Improvements,' Energy Journal 11 (1):65(22), January 1990

16. Downs, A., "The Real Problem With Suburban Anti-Growth Policies," Brookings Review, pp. 23-29, Spring 1988.
17! Dunkerley, J., I. Hoch, C. Gadhok, and K. Thukral, "Energy and Transport: The Indian Experience, ' Pacific and Asian Journal of Energy, 1987.

18. Edmonds, J. et al., A Preliminary Analysis of U.S. $\mathrm{CO}_{2}$ Emissions Reduction Potential From Energy Conservation and the Substitution of Natural Gas for Coal in the Period to 2010, TR045, DOENBB-0085 (Washington DC: U.S. Department of Energy, 1989).

19. Energy and Environmental Analysis, Inc., Developments in the Fuel Economy of Light-Duty Highway Vehicles, draft final report for U.S. Congress, Office of Technology Assessment (Arlington, VA: June 1988).

20. Federal Highway Administration, America's Challenge for Highway Transportation in the 21st Century, interim report of the Future National Highway Program Task Force, FHWA-PL-89-020 HPP-1-11-88(2M)E (Washington, DC: U.S. Department of Transportation, November 1988).

21. Flinger, D. and J.R. Kuzmyak, Personal Travel in the U.S. Washington, DC: U.S. Department of Transportation\% Federal Highway Administration 1986), vol. 2.

22. Green, C., South Coast Air Ouality Management District, personat communication Sept. 11, 1990.

23. Greene, D.L., "Technology and Fuel Efficiency," Forum for Applied Research and Public Policy 5(1):23, Spring 1990.

24. Hammitt, J.K. et al, Product Uses and Market Trends for Potential Ozone-Depleting Substances, 1985-2000, R-3386-EPA (Santa Monica, CA: Rand Corp., 1986), xvii(107):11,23.

25. Heavenrich, R.M. and J.D. Murrell, "Light-Duty Automotive Technology and Fuel Economy Trends Through 1988," U.S. Environmental Protection Agency, Office of Mobile Sources, EPA/AA/CTAB-88-07 (Ann Arbor, MI: June 1988).

26. Higgins, T., "Parking Management and Traffic Mitigation in Six Cities: Implications for Local Policy, " paper No. 8803\%, presented at the 68th Annual Meeting of the Transportation Research Board (Washington, DC: Jan. 22-26, 1989).

27. ICF Inc., background tables to EPA Stabilization Report, personal communication to OTA, 1989

27a. Insurance Institute for Highway Safety, "Occupant Death Rates by Car Series," Status Report 24(1 1), Nov. 25, 1989.

28. Intergovernmental Panel on Climate Change, Climate Change: The IPCC Scientific Assessment (Cambridge, MA: Cambridge University Press, 1990).

29, International Energy Agency, Fuel Efficiency of Passenger Cars (Paris: 1987)

30. Klinger, D. and J.R.Kuzmyak, Personal Travel in the U.S., 1983-1984 Nationwide Personal Transportation Study (Washington DC: U.S. Department of Transportation August 1986).

31. Kolar, S. and W.U. Chandler, "Energy and Energy Conservation in Eastern Europe, ' report prepared for U.S. Agency for International Development (Washington DC: Battelle Memorial Institute, Pacific Northwest Laboratories, 1990).

32. Leach, G., L. Jarass, G. Obermair, and L. Hoffmann, Energy and Growth: A Comparison of 13 Industrial and Developing Countries (London: Butterworth Scientific, 1986).

33. Lindley, J. A., "Urban Freeway Congestion Problems and Solutions: An Update," ITE Journal 59(12):21-23, December 1989.

34. Lowry, 1.s., "Planning for Urban Sprawl," presented to TRB Conference on Long-Range Trends and Requirements for the Nation's Highways and Public Transit Systems (Washington DC: June 22-24, 1988).

35. McNutt, B. and P. Patterson, "CAFE Standards-Isa Change of Form Needed?" SAE 861424 (1986).

36. Mintzer, I., Projecting Future Energy Demand in Industrialized Countries, draft of World Resources Institute report for U.S. Environmental Protection Agency (Washington, DC: October 1988).

37. Moavenzadeh, F. and D. Geltner, "Transportation Energy, and Economic Development: A Dilemma in the Developing World," Energy Research, Volume 5 (Amsterdam: Elsevier, 1984). 
38. Motor Vehicle Manufacturer's Association, Facts and Figures' 89 (Detroit, MI: 1990).

39. Newman, P.W.G. and J.R. Kenworthy, "The Transport Energy Tradeoff: Fuel-Efficient Traffic or Fuel-Efficient Cities, 'Transportation Researih 22 A:3,163-174, 1988.

40. Oak Ridge National Laboratory, Transportation Energy Conservation Data Book (Oak Ridge, TN: 1977).

41. Oak Ridge National Laboratory, Alternative Motor Fuel Use Model (Oak Ridge, TN: 1988).

42. Ottawa-Carleton Regional Transit Commission, Strategic Plan and Financial Forecast (Ottawa: 1986), p. 42.

43. Pisarski, A. E., Commuting in America (Westport, CT: Eno Foundation for Transportation, 1987).

44 Poole, A, "Energy and Transport in Brazil," report to U.S. Agency for International Development (Washington, DC: Resources for the Future, January 1983).

45, Poole, J. E., ICI General Chemicals Group, "Alternatives to CFC-12 in Mobile Air Conditioning, " presentation to Substitutes and Alternatives to CFCs and Halons Trade Fair (Washington DC: January 1988)

46. Renner, M., Rethinking the Role of the Automobile, Worldwatch Paper 84 (Washington, DC. Worldwatch Institute, 1988).

47. Roberts, P.O. and Fauth, G. W., ' 'The Outlook for Commercial Freight Transportation," prepared for presentation at the Conference on Long-Range Trends and Requirement for the Nan"on Highway and Public Transportation Systems, "A Lookat the Future--Year 2020,' June 22-24, 1988.

48. Ross, M., Light Duty Vehicles and Petroleum Use in the United States, contractor report prepared for U.S. Congress, Office of Technology Assessment, July 15, 1988.

49. Sathaye, J., A. Ghirardi, and L. Schipper, "Energy Demand in Developing Countries: A Sectoral Analysis of Recent Trends,' Annual Review of Energy 12:253-281, 1987.

50, Sathaye, J., B. Atkinson, and S. Meyers, Alternative Fuels Assessment: The International Experience, LBL-24736 (Berkeley, CA: Lawrence Berkeley Laboratory, March 1988).

51, Sathaye, J., L. Schipper, A. Ketoff, and S. Lele, An End-Use Approach to Development of Long-Term Energy Demand Scenarios for Developing Countries (Berkeley: International Energy Studies Group, Lawrence Berkeley Laboratory, September 1988).

52. South Coast Air Quality Management District, Draft Appendix IV-A: Tier I and Tier II Control Measures (Los Angeles, CA: June 1988).

53. South Coast Air Quality Management District and Southern California Association of Governments, Draft 1988 Air Quality Management Plan, (Los Angeles, CA: September 1988).

54. South Coast Air Quality Management District and Southern California Association of Governments, The Path to Clean Air: Attainment Strategies, (Los Angeles, CA: May 1989).

55, Southern California Association of Governments, Draft Air Quality Management Plan Appendix IV-G. Transportation Land Use and Energy Conservation Measures (Los Angeles, CA: September 1988).

56. Southern California Association of Governments, Draft Regional Mobility Plan (Los Angeles, CA: October 1988),

57, Sperling D., and M.A. DeLuchi, Alternative Transportation Fuels and Air Pollution, report prepared for Environment Directorate (Paris: March 1990).

58. Statt, T, G., "The Use of CFCs in Refrigeration Insulation, and Mobile AC in the U S.," paper prepared for the EPA Conference on Substitutes and Alternatives to CFCs and Halons (Washington DC: Jan. 13-15, 1988).
59. Swihart, J. M., "Aeronautical Developments for the 21 st Cenq,' paper presented at AIAA, AHS, and ASEE, Aircraft Design, Systems and Operations Meeting (St. Louis, MO: AIAA, 1987).

60. Tretyakova, A., and B. Kostinsky, USSR: Motor Fuel Use and Conservation in Transportation and Agriculture, 1970 to 1984, Center for International Research, U.S. Bureau of the Census, CIR Staff Paper No. 32 (Washington, DC: December 1987).

61. U.S. Congress, Office of Technology Assessment, "Increasing the Efficiency of Automobiles and Light Trucks-A Component of a Strategy to Combat Global Warming and Growing U.S. Oil Dependence,' Testimony of Steven E. Plotkin to Consumer Subcommittee, Committee on Commerce, Science and Transportation, U.S. Senate, May 2, 1989.

62. U.S. Congress, Office of Technology Assessment, "Increased Efficiency Potential for the U.S. Fleet of Highway Passenger Vehicles, 'Testimony of Steven E. Plotkin to Subcommittee on Oversight and Investigations, Committee on Energy and Commerce, U.S. House of Representatives, Apr. 10, 1989

63. U.S. Congress, Office of Technology Assessment, Catching Our Breath: Next Steps for Reducing Urban Ozone, OTA-O-412 (Washington, DC: U.S. Government Printing Office, July 1989).

64. U.S. Congress, Office of Technology Assessment, Replacing Gasoline: Alternative Fuels for Light Duty Vehicles, OTA-E-364 (Washington, DC: U.S. Government Printing Office, September 1990).

65. U.S. Department of Commerce, The Statistical Abstract of the United States (Washington DC: 1989).

66. U.S. Department of Energy, Assessment of Costs and Benefits of Flexible and Alternative Fuel Use in the U.S. Transportation Sector, Progress Report One: Context and Analytic Framework (Washington, DC: January 1988).

67. U.S. Department of Energy, Energy Information Administration, Annual Energy Outlook: 1987, DOE/ELA-1383(87)(Washington, DC: Mar. 28, 1988)

68. U.S. Department of Energy, Long Range Energy Projections to 2010,DOE/PE-0082, Office of Policy, Planning and Analysis (Washington, DC: July 1988).

69. U.S. Department of Energy, Energy Information Administration. Annual Energy Outlook: 1990, DOE/ELA-0383(90) (Washington, DC: January 1990)

70. U.S. Department of Transportation\% "The Safe Fuel-Efficient Car: A Report on Its Feasibility and Marketability, " HS 805-644 (Washington, DC: 1980)

71. U.S. Department of Transportation Office of Environment and Safety, The Costs and Effectiveness of Transportation Control Measures in Achieving Air Quality Goals (Washington, DC: August 1981).

72. U.S. Department of Transportation, Effect of Car Size on Fatality and Injury Risk in Single-Vehicle Crashes, HS 805-729 (Washington, DC: National Highway Traffice Safety Administration: August 1990).

73. U.S. Environmental Protection Agency, Policy Options for Stabilizing Global Climate, draft report (Washington, DC: 1989).

74. U.S. Environmental Protection Agency, 1989 Fuel Economy Guide (Washington DC: 1989).

75. Walsh, M. B., review comments submitted to OTA (Arlington, VA: December 1989).

76. World Meteorological Organization and United Nations Environment Programme, Scientific Assessment of Stratospheric Ozone: 1989, July 1989.

77. Yenny, J., and L.V. Uy, "Transport in China," World Bank Staff Working Paper No. 723 (Washington DC:1985). 
Chapter 6

\section{The Manufacturing Sector}

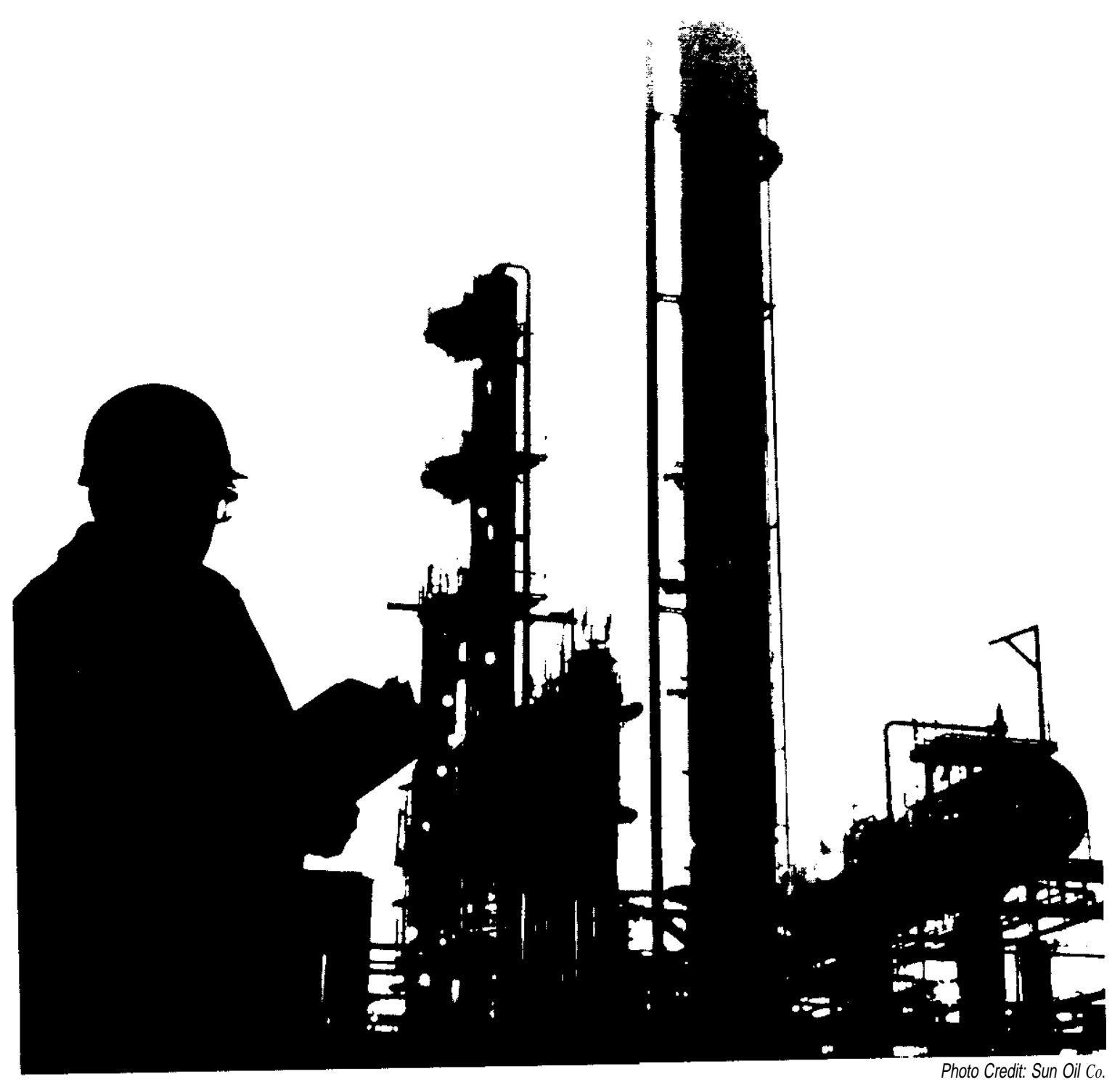




\section{CONTENTS}

INTRODUCTION $\ldots \ldots \ldots \ldots \ldots \ldots \ldots \ldots \ldots \ldots 177$
OVERVIEW $\ldots \ldots \ldots \ldots \ldots \ldots \ldots \ldots \ldots \ldots 177$
PAST AND PRESENT EMISSIONS

AND ENERGY USE . . . . . . . . . . . . . . . . . 177

Recent Changes in Energy Use.. . . . . . . . . 179

ANATOMY OF ENERGY USE IN

MANUFACTURING . . . . . . . . . . . 180

Services Provided by Energy in the

Manufacturing Sector .............. 180

The Largest Users of Energy in the

Manufacturing Sector... . . . . . . . . . . . 182

Energy-Efficiency Improvement

Techniques ..................... 185

OTA EMISSION REDUCTION

SCENARIOS . . . . . . . . . . . . . . . . . . . 187

Base Case ......................... 190

Moderate Controls . . . . . . . . . . . . . . . . . . 190

Tough Controls .................... 190

Costs of the Tough Control Scenario . . . . . 192

POLICIES FOR REDUCING $\mathrm{CO}_{2}$

EMISSIONS FROM THE

INDUSTRIAL SECTOR . . . . . . . . . . . . 192

Policy Strategies . . . . . . . . . . . . . . . . . 192

Policy Options ...................... 194

CHAPTER PREFERENCES . . . . . . . . . . . . . 197

\section{Boxes}

Box Page

6-A. Potential for Industrial Energy Efficiency in the U.S.S.R. and Eastern Europe . . . . 187

\section{Figures}

Figure

6-1. Contribution of Industry $\mathrm{CO}_{2}$

Emissions in 1987 . . . . . . . . . . . . 178

6-2. U.S. Energy Intensity: Energy

Consumption Per Dollar of Gross

Domestic Product . . . . . . . . . . . . . . . 179

6-3. Manufacturing Consumption of Energy

for Heat and Power . . . . . . . . . . . . . . . . 179
Figure

Page

6-4. Direct and Indirect Energy Use

Associated With Imports and Exports . 180

6-5. 1987 Industrial Energy Use by

Function . . . . . . . . . . . . . . . . . 181

6-6. Consumption of Fossil Fuels and Electricity by Selected Manufacturing Industries $\ldots \ldots \ldots \ldots \ldots \ldots \ldots \ldots \ldots$. . . . 182

6-7. Emissions in 2015 Under the Base Case, Moderate, and Tough Scenarios, by Energy Service Category ............ 188

6-8. Summary ofC $0_{2}$ EmissiOns Under the Base Case, Moderate, and Tough Scenarios, by Year ............. 188

6-9. Fuel Use Under the Base Case, Moderate, and Tough Scenarios, by Fuel Type . . 188

6-10. $\mathrm{CO}_{2}$ Emissions Reductions in 2000 and 2015 Expressed as a Percentage of 1987 Manufacturing Sector Emissions, by Control Method,Under the Moderate Scenario . . . . . . . . . . . . . 191

6-11. $\mathrm{CO}_{2}$ Emissions Reductions in 2000 and 2015 Expressed as a Percentage of 1987 Manufacturing Sector Emissions, by Control Method, Under the Tough Scenario

6-12. Ranking of Manufacturing Industries by Direct and Indirect Primary

Energy Use

\section{Tables}

Table

6-1. Manufacturing's Use of Energy

Page in 1985 ......................... 177

6-2. Ranking of 1985 Manufacturing

Energy Intensities

6-3. Electricity Cogeneration by Industry, 1985

6-4. Industrial Sector Conservation

Measures 


\section{INTRODUCTION}

Manufacturing is a diverse sector of the U.S. economy, consisting of a heterogeneous group of industries that employ a wide array of technologies to produce everything from aircraft to toy dolls. Because of this diversity, a somewhat different set of policies is needed to address this economic sector than those discussed for other sectors such as transportation or buildings. This chapter explores manufacturings energy use and emissions, the major emissions-contributing industries, scenarios for the future, and policies that could effect the future.

\section{OVERVIEW}

Manufacturing accounts for about 30 percent of all energy consumed in the United States, and 80 percent of industrial energy use (51a). (Agriculture, mining, and construction account for the remaining 20 percent.) About one-third of U.S. carbon dioxide $\left(\mathrm{CO}_{2}\right)$ emissions result from all industrial activity. Due to data limitations, this chapter uses data for the broader category of industry as a proxy for that of the manufacturing sector.

Onsite combustion of fossil fuels and biomass for heat and power account for about half of industrial emissions, and purchased, fossil-fuel generated electricity accounts for most of the remainder. Some additional greenhouse gases are also released to the atmosphere as byproducts of manufacturing processes. For example, $\mathrm{CO}_{2}$ is released during cement manufacture; chlorofluorocarbons (CFCs) are emitted from industrial solvents used in the electronics industry. Such noncombustion processes probably account for about 2 percent of U.S. greenhouse gas emissions. This chapter is principally concerned with energy-related emissions and the potential for their reduction.

Energy use in manufacturing can be changed in three ways:

1. by reducing the amount of energy consumed,

2. by switching to energy sources that emit lessor no greenhouse gases, and

3. by changing the mix of industries and products within the manufacturing sector.
By and large, policies for reducing greenhouse gas emissions from manufacturing focus on the frost two strategies. Macroeconomic policies such as trade or monetary policies tend to affect the industrial makeup of the manufacturing sector.

\section{PAST AND PRESENT EMISSIONS AND ENERGY USE}

U.S. manufacturing consumed over 17.5 quadrillion Btu's (quads) of fossil fuel and electricity in 1985 (see table 6-1), about one-quarter of the economy-wide total. This total would be 24 percent higher if the energy consumed in electricity generation and transmission were included (56).

Industrial energy consumption and electricity generation losses accounted for about 32 percent of U.S. $\mathrm{CO}_{2}$ emissions. Nearly a third of these emissions came from electricity used to power machines and electrolytic processes. Over a quarter of the emissions came from process steam and a fifth came from process heat (see figure 6-1).

Although industry uses significant energy, its consumption relative to that of other sectors has diminished over time. In 1960, the industrial sector used 46 percent of all energy consumed in the United States (56). By 1980, industry's share of energy use had fallen to 40 percent, and in 1989 it had slipped to 36 percent (56). Some of this decline can be attributed to energy efficiency improvements within industry and to growth in the building and transportation sectors.

Table 6-I-Manufacturing's Use of Energy in 1985 (quadrillion Btu's)

\footnotetext{
Total fuel consumption . . . . . . . . . . . . . $\quad 13.6$

Total purchased fuels and electricity . . . . . . 9.7

Fuel byproduct (i.e., coke gas) . . . . . . . . . 1.1

Process byproducts (i.e., wood chips) . . . . . 2.8

Raw material (feedstock) inputs . . . . . . . . . $\quad 5.0$

Less fuel byproducts . . . . . . . . . . . . . . . .

Total primary energy consumption . . . . . . . 17.5

NOTE: The Department of Energy does not account for generation and distribution losses associated with the production of electricity in these estimates of energy use.

SOURCE: U.S. Department of Energy, Energy Information Administration, Manufacturing Energy Consumption Survey: Consumption of Energy, 1985, DOE/EIA-0512(85) (Washington, DC: 1985).
} 
Figure 6-I-Contribution of Industry $\mathrm{CO}_{2}$ Emissions in 1987

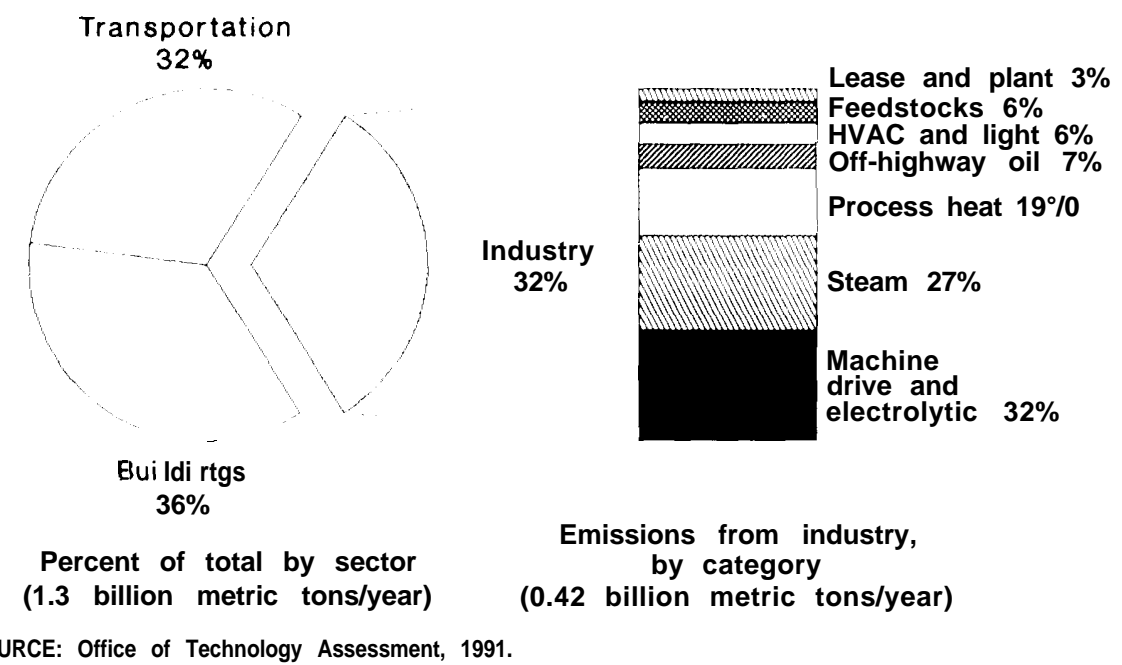

Within industry, the manufacturing sector also has changed significantly in the recent past. From the 1950s through about 1972, the energy intensity of manufacturing (the energy used to produce a dollar's worth of output) was relatively flat (see figure 6-2). Thus, growth in manufacturing seemed to be directly coupled to growth in energy use. ${ }^{1}$ Since 1972, however, the economy has suffered two unanticipated energy price shocks. In addition, legislation to control energy-related pollution was enforced and many of the biggest manufacturing firms experienced rapidly declining demand for their products (30). As a result of efficiency improvements and rising fuel prices, the energy intensity of manufacturing fell by more than a third from 1972 to 1985 , with coal and oil intensities falling by almost 40 and 50 percent, respectively (33) (see figure 6-3). Shortages of natural gas after 1972 contributed to a 50 percent drop in energy intensity in manufacturing between 1971 and 1985 (33).

The electricity intensity of manufacturing increased rapidly from 1958 to 1970 and then, partly because of a rise in the price of electricity, began to level out (33). At 1987 average prices, it cost almost five times as much to use electricity as natural gas to provide equivalent heating value. Manufacturers thus use electricity not as a simple substitute for fuel, but to perform functions that require electricity or in specific processes where the overall efficiency of electricity is much higher than that of fuel. This illustrates that while different forms of energy can be

discussed in terms of a common unit, Btu's, their utility for specific uses varies (20).

Because industries within the manufacturing sector differ in energy intensity by more than a factor of 10 (see table 6-2), a shift in output mix can have a significant effect on the energy intensity of the sector as a whole. In fact, roughly one-third to one-half of the decline in manufacturing's energy intensity between 1972 and 1985 can be attributed to a shift in the mix of output, with ' 'smokestack' industries like steel declining relative to lighter manufacturing industries like electronics $(7,27)$.

Our manufacturing sector's contribution to climate change is larger than these measures indicate. The United States now imports large amounts of energy-intensive manufactured products, including cars and steel. The energy embodied in these goods does not enter into U.S. energy intensity calculations, nor is it included in measures of our dependence on foreign energy (44). Nonenergy imports have doubled (as a percentage of GNP) since 1970, increasing the need to account for the energy they represent.

Such accounting can be done by assuming that all nonenergy imports can be made domestically at the same price using a similar mix of inputs as their domestic counterparts. When this is done for 1985 nonenergy imports, U.S. use of imported energy rises by over 50 percent, from 13 to 20 quads (see

${ }^{1}$ Some analysts argue that a strong link still exists (6). 
Figure 6-2-U.S. Energy Intensity: Energy Consumption Per Dollar of Gross Domestic Product 40

1,000 Btu's consumed per dollar of GDP

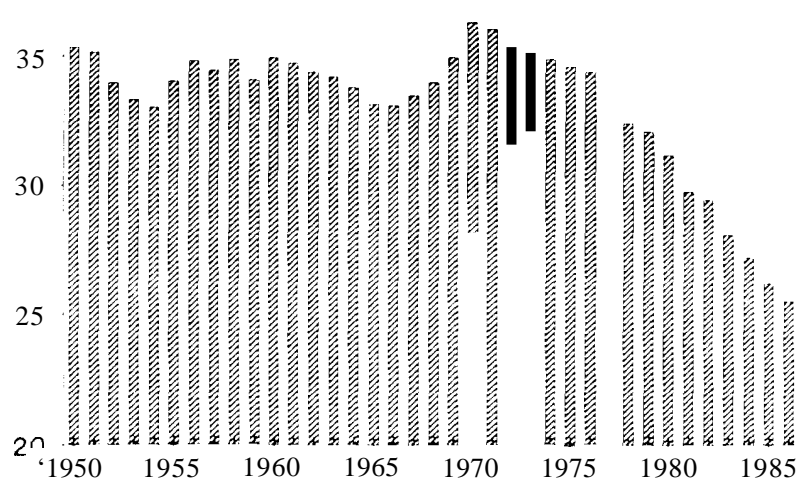

SOURCE: U.S. Congress, Office of Technology Assessment, Energy Use and the U S Economy, OTA-BP-E-57 (Washington, DC: U.S. Government Printing Off Ice, June 1990).

Table 6-2-Ranking of 1985 Manufacturing Energy Intensities (thousand Btu's per constant 1980 -dollar value of shipments)

\begin{tabular}{|c|c|}
\hline Stone, clay, and glass products $\ldots \ldots \ldots \ldots$ & 16.6 \\
\hline Primary metal industries $\ldots \ldots \ldots \ldots \ldots$ & 14.6 \\
\hline Paper and allied products $\ldots \ldots \ldots \ldots \ldots$ & 13.9 \\
\hline Chemicals and allied products $\ldots \ldots \ldots \ldots$ & 12.4 \\
\hline Textile mill products $\ldots \ldots \ldots \ldots \ldots \ldots$ & 4.8 \\
\hline Petroleum and coal products $\ldots \ldots \ldots \ldots \ldots$ & 4.4 \\
\hline Rubber and miscellaneous plastics,,$\ldots \ldots \ldots$ & 3.1 \\
\hline Food and kindred products $\ldots \ldots \ldots \ldots \ldots$ & 2.7 \\
\hline Fabricated metal products $\ldots \ldots \ldots \ldots \ldots$ & 2.3 \\
\hline Furniture and fixtures $\ldots \ldots \ldots \ldots \ldots$ & 1.6 \\
\hline Other manufacturing $\ldots \ldots \ldots \ldots \ldots \ldots$ & 1.4 \\
\hline Electrical and electronic equipment $\ldots \ldots \ldots$ & 1.2 \\
\hline Instruments and related equipment $\ldots \ldots \ldots$ & 1.2 \\
\hline Transportation equipment ., . . . . . . . . . & 1.1 \\
\hline Printing and publishing $\ldots \ldots \ldots \ldots \ldots$ & 0.9 \\
\hline Machinery, except electrical . . . . . . . . . & 0.9 \\
\hline All manufacturing. $\ldots \ldots \ldots \ldots \ldots$ & 4.4 \\
\hline
\end{tabular}

SOURCE: U.S. Department of Energy, Energy Information Agency, Manufacturing Energy Consumption Survey: Changes in Energy Efficiency 1980-1985, DOE/EIA-0516(85) (Washington, DC: January 1990), table ES1, p. viii.

figure 6-4). ${ }^{2}$ While the energy embodied in U.S. exported products stayed relatively steady in the early 1980s, the energy embodied in imported products increased as the U.S. trade deficit deepened

\section{Figure 6-3-Manufacturing Consumption of Energy for Heat and Power}

\section{5}

Quadrillion Btu's per billion $\$ 1982$

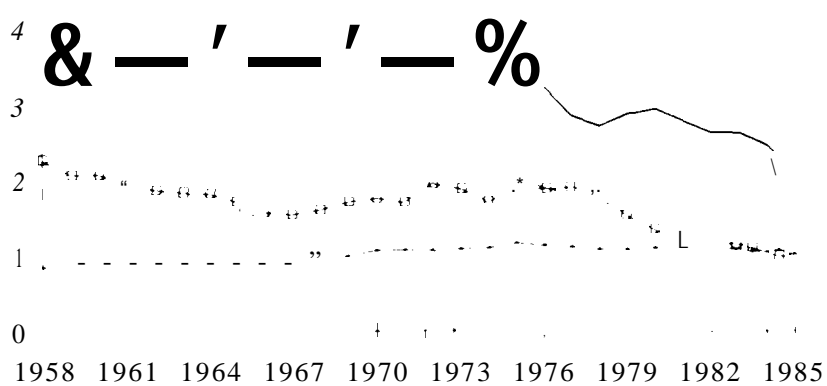

Coal

Purchased electricity

- Natural gas

Oil

SOURCE: M. Ross, "Industrial Energy Conservation,"Natural Resources Journa/24(2):369, April 1984.

(see figure 6-4). The trade balance has improved somewhat since 1985 and so presumably net imports of embodied energy have declined.

\section{Recent Changes in Energy Use}

Total energy use in the United States increased by an estimated 6 quads ( 8 percent) between 1985 and 1988. This gain breaks a 13-year trend, begun in 1972, of relatively level energy use (15). The energy intensity of the economy continued to decline from 1985 to 1988 , but by only -1.0 percent annually as opposed to -2.4 percent annually from 1972 to 1985.

Detailed data is lacking on how manufacturing fared during this 3-year period, but preliminary figures suggest a 6-percent increase in energy use. There is, however, no indication that the energy efficiency of production processes declined. In fact, the annual rate of investment in new plants and equipment from 1985 to 1988 was 7 percent, as opposed to 5 percent from 1972 to 1985 . It is likely that these new investments boosted energy efficiency (47).

Rather, a reduction in the cost of energy, coupled with increased spending and changes in what was being bought, favored a shift towards relatively

${ }^{2}$ This estimate matches the U.S. Department of Energy's 1984 estimate (48) and is roughly in line with the 8 quads estimated for the energy embodied in 1984 exports in another recent U.S. Department of Energy study (54).

${ }^{3}$ This section is based on ref 44.

${ }^{4}$ Preliminary data from U.S. Department of Energy's 1988 Manufacturing Energy Consumption Survey, 'supplied to OTA Apr. 5, 1990, by J L Preston. 
Figure 6-4-Direct and Indirect Energy Use Associated With Imports and Exports*

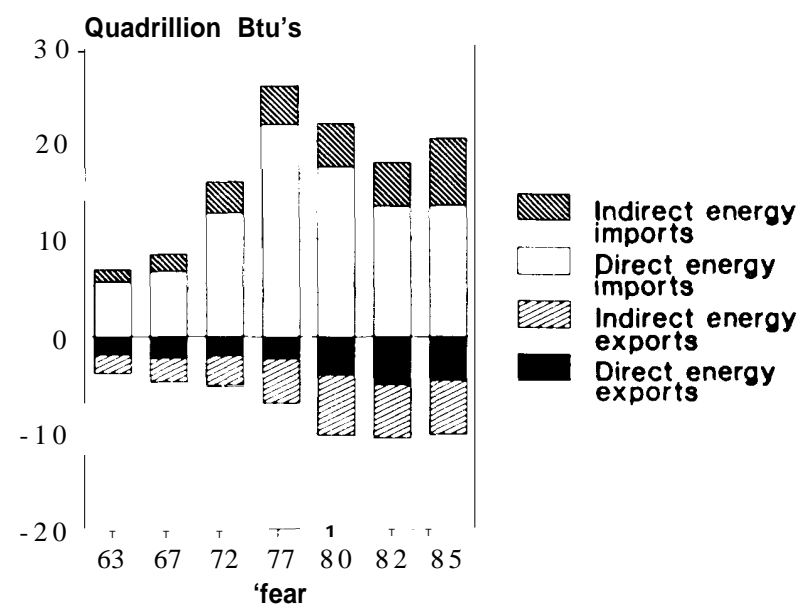

The United States directly imports and exports energy. Although direct exports have stayed relatively steady, imports rose dramatically between 1963 and 1977 and then declined from 1977 to 1985. The United States also uses energy indirectly in the form of energy embodied in nonenergy exports (e.g., grain) and imports (e.g., autos). Prior to the emergence of a trade deficit this indirect use of energy was in balance, but by 1985 the indirect use of energy associated with imports boosted our dependence on foreign sources of energy by 50 percent.

- Production recipe kept constant at 1985 level.

SOURCE: U.S. Congress, Office of Technology Assessment, Energy Use and the U.S. Economy, CTA-BP-E-57 (Washington, DC: U.S. Government Printing Office, June 1990).

energy-intensive industries from 1985 to $1988^{5}(44)$, which could account for the increased energy consumption by manufacturing. For example, nondefense purchases by the Federal Government fell in real terms by 16 percent over the 3-year period, and defense purchases, which are about one-and-a-half times as energy intensive, grew by 10 percent (47). The export sector also grew faster than other economic sectors over this period, increasing its real share of GNP from 10 to 13 percent. Since most exports are manufactured goods, such a shift tends to result in increased energy use. Contributing to the export surge were such energy-intensive products as aluminum (44-percent growth in exports) and steel mill products (121-percent growth in exports) (1).

The shift toward more energy-intensive industries might be a temporary one. Two potentially conflicting policy goals may interact to shape future manufacturing-the desire, on the one hand, to improve the sector and revive exports to lessen the trade deficit (44); and the need, on the other hand, to reduce $\mathrm{CO}_{2}$ emissions by shifting from more to less energy-intensive manufacturing activities.

\section{ANATOMY OF ENERGY USE IN MANUFACTURING}

The previous section provided abroad perspective on manufacturing's energy use, which is useful for a general understanding of the sector and its relationship to the economy. This section tracks how energy is specifically used in manufacturing, particularly by the four most energy-consumptive manufacturing industries: primary metals, paper and allied products, chemical and allied products, and petroleum refining.

\section{Services Provided bv Energy in the Manufacturing Sector}

About half of the fossil fuels and electricity used by industry provides process heat, steam, and cogenerated heat and steam (see figure 6-5). Energy in manufacturing is also used for feedstocks, mechanical drive, electrolysis, lighting, and space heat.

Boilers and Process Heaters

The basic materials industries (metals, chemicals, petroleum) rely on many high-temperature processes, hence large amounts of process heat. For example, steel is heated so that it can be shaped into specigic products such as sheet, tube, or wire. Process heat also accounts for most of the energy used for metals smelting, petroleum refining, and cement manufacture. Improved insulation around heaters, computer-controlled regulation of fuel combustion, and increased utilization of waste heat have led to major improvements in process-heat fuel efficiency since 1973 (37).

\section{Cogeneration of Electricity and Steam}

Cogeneration refers to the combined production of heat (usually steam) and electricity from the same energy source. Nationwide about 20 to 25 percent of the cogenerated energy output is electricity, the remainder is steam (14). Depending on the degree to which cogenerated steam is utilized, cogeneration technologies can almost double fuel efficiency (33) for user firms, reducing their need to purchase energy. Cogeneration is usually restricted by economic considerations to applications where heat of

\footnotetext{
${ }^{5}$ Data for 1985 and 1988 from refs. 47 and 46, respectively.
} 
Figure 6-5-1987 Industrial Energy Use by Function (percent)

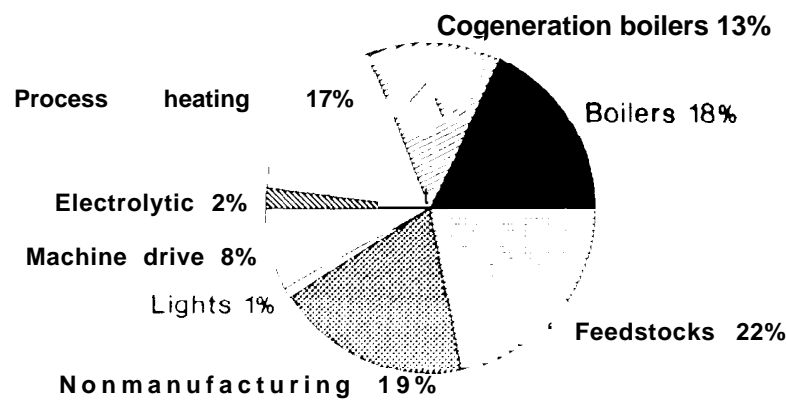

SOURCE: Gas Research Institute, Industrial Natural Gas Markets: Facts, Fallacies, and Forecasts (Washington, DC: 1989).

low-to-moderate temperature is needed on a regular basis. In 1958, more than one-fifth of the electricity manufacturers used was cogenerated. This dropped to 8 percent in 1981 , but rebounded to 10 percent in 1986 (33). This recovery trend is likely to continue; in fiscal year 1988, more than 300 cogeneration facilities with a planned capacity of 7,005 megawatts were registered for operations (12).

The four most energy-intensive manufacturing industries dominate use of cogeneration (see table 6-3). Industrial and commercial cogeneration capacity is currently about 23,000 megawatts, almost 4 percent of total U.S. electric generation capacity (19). An additional 60,000 megawatts may be technically and economically feasible (18).

Feedstocks

Unlike other energy services, feedstocks (i.e., petroleum feedstocks in chemicals and plastics manufacture) are raw material inputs to manufactured goods. Since feedstocks are generally not combusted (the notable exception is coke, used in steel manufacture), their consumption does not lead to emissions of greenhouse gases, except to the extent that heat is required to process them.

\section{Mechanical Drive}

Energy is used for mechanical drive equipment, conveyers, stamping presses, pumps, compressors, blowers, and fans (31). Diesel- and gasoline-driven engines provide a small amount of this energy service, but electric motors are by far the most prevalent machine-drive technology in manufacturing, accounting for two-thirds of industry's electricity use (9).
Table 6-3-Electricity Cogeneration by Industry, 1985

\begin{tabular}{|c|c|c|}
\hline Industry & $\begin{array}{c}\text { Million } \\
\text { kWh }\end{array}$ & Percent \\
\hline $\begin{array}{l}\text { Paper and allied products } \ldots \ldots \ldots \text {. } \\
\text { Chemicals and allied products . . . . }\end{array}$ & $\begin{array}{l}32,866 \\
19,827\end{array}$ & $\begin{array}{l}47 \\
28\end{array}$ \\
\hline Petroleum and coal products ...... & 5,507 & 8 \\
\hline Primary metal industries . . . . . . . & 4,556 & 7 \\
\hline Food and kindred products . . . . . . & 3,618 & 5 \\
\hline Transportation equipment. . . . . . . . . & 318 & $<0.5$ \\
\hline Textile mill products . . . . . . . . . . & 305 & $<0.5$ \\
\hline Stone, clay, and glass products . . . . & 207 & $<0.5$ \\
\hline Machinery, except electrical . . . . . . . & 194 & $<0.5$ \\
\hline $\begin{array}{l}\text { Rubber and miscellaneous } \\
\quad \text { plastics } \ldots \ldots \ldots \ldots \ldots \ldots \ldots\end{array}$ & 69 & $<0.5$ \\
\hline Fabricated metal products . . . . . . . & 65 & $<0.5$ \\
\hline Printing and publishing . . . . . . . . & 26 & $<0.5$ \\
\hline Other manufacturing $\ldots \ldots \ldots \ldots$ & 2,197 & 3 \\
\hline Total . . . . . . . . . . . . . . . & 69,755 & 100 \\
\hline
\end{tabular}

NOTE: Total does not add to 100 due to rounding.

SOURCE: U.S. Department of Energy, Energy Information Administration, Manufacturing Energy Consumption Survey: Consumption of Energy, 1985,DOE/EIA-0512(85) (Washington, DC: November 1988), table 9 , p. 39.

\section{Electrolysis}

Electrolytic processes use electricity, rather than heat and pressure, to change matter at the atomic level. Electrolytic processes account for 10 to 15 percent of all electricity used by manufacturing (9). Two industries, aluminum and chlorine manufacturing, dominate energy use for electrolysis (37). Gains in electrolysis efficiency can result in reductions of greenhouse gas emissions if the electricity is supplied by fossil fuels. In 1989, 70 percent of utility-generated electricity came from fossil fuel combustion (55).

Space Heat

Manufacturing, by and large, uses the same space heating and cooling technologies as does the buildings sector (see ch. 4), although waste heat from thermal processes is employed in some cases. Potential gains in energy efficiency can be made by improving heating and cooling technologies, and by utilizing waste heat more extensively.

\section{Nonmanufacturing Industry Uses}

Nonmanufacturing energy use is concentrated in four industries: mining, natural gas production, agriculture, and construction. About one-quarter of nonmanufacturing industrial energy use is used to prepare natural gas for pipeline delivery; another one-quarter is used in off-highway vehicles in agriculture, mining, and construction. Most of the remainder is used in boilers and process heaters (14). 
Figure 6-6-Consumption of Fossil Fuels and Electricity y by Selected Manufacturing Industries

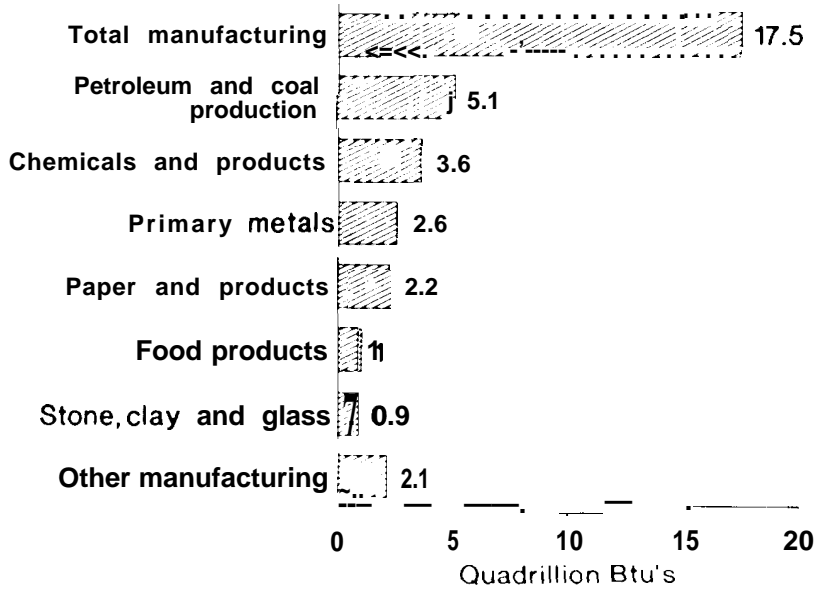

SOURCE: U.S. Department of Energy, Energy Information Administration, Manufacturing Energy Consumption Survey: Changes in Energy Efficiency 1980-1985, DOE/EIA-0516(85) (Washington, DC: January 1990).

\section{The Largest Users of Energy in the Manufacturing Sector}

The four biggest manufacturing energy consumers are paper and allied products, chemicals and allied products, petroleum and coal, and primary metals (see figure 6-6). Collectively these industries account for over three-quarters of manufacturing's energy use. Each of the four industries is responsible for between 14 and 19 percent of manufacturing's $\mathrm{CO}_{2}$ emissions, although their principal emission sources differ. The primary metals industry, for example, was third in terms of energy consumption but first in $\mathrm{CO}_{2}$ emissions because of its heavy use of coal.

Each of these industries is an important "upstream' producer that sells its output to industries 'downstream' for further processing into final goods. Given this interdependence, efforts to curtail emissions should focus on the potential for improving energy efficiency, rather than on limiting output. Reducing domestic output would probably result in these materials being imported, which would do little to affect the global generation of greenhouse gases.

Paper and Allied Products

The paper industry consumes more fuel oil for heat and power than any other manufacturing industry (53). Nevertheless, both energy and cost reduction activities at the mills have reduced energy intensity (energy consumed per ton of product). Most important among the changes affecting energy use are:

1. water is being recirculated more, instead of being discharged, reducing steam requirements;

2. recycling of post-consumer fibers is increasing, which reduces pulping energy requirements;

3. thermo-mechanical pulping (TMP) (an improved method for grinding the wood) is increasing, boosting electricity requirements; and

4. cogeneration of electricity and steam, historically very strong at pulp and paper mills, continues to expand.

In addition, the use of biomass byproducts (pulping liquor, bark, sawdust) for energy has increased significantly. In 1972, 40 percent of the energy used by the industry was obtained from biomass; in 1985 , 56 percent (33). As a result, the use of conventional fuels and electricity (including losses) for papermaking fell from 24.8 to 17.8 million Btu's per ton between 1972 and 1985, an average rate of decline of 2.5 percent per year.

Further gains in energy efficiency can be made in the paper industry by improved process optimization and pressing and drying, continued investment in cogeneration and other energy-efficient technologies, and increased paper recycling (41). Use of scrap paper, rather than virgin timber, permits the pulping process to be bypassed and reduces the

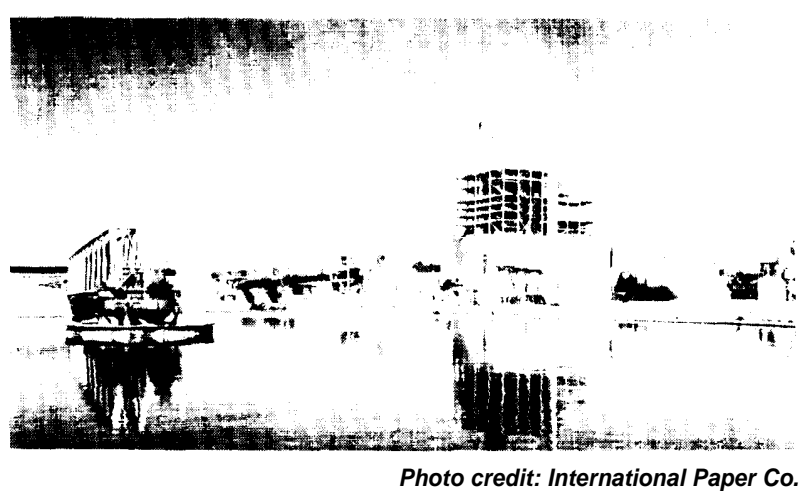

The settling pond in the foreground is part of the paper mill's environmental protection system. Behind looms the recovery boiler, which can meet a significant portion of a mill's energy needs by burning waste from the pulping process. 
amount of energy required for manufacturing some grades of paper products (42).

\section{Chemicals and Allied Products}

In 1985, the chemicals industry was the second largest manufacturing industry in terms of energy use, consuming almost 3.6 quads of energy (53). It is the most complex of the four main energyintensive industries. Instead of one specific product, it produces a wide range of intermediate and final goods, including agricultural chemicals, plastics, and paints. The purposes for which energy is used by the chemicals industry are correspondingly variedthe use of energy as feedstocks accounts for a large portion of consumption; large quantities of energy are also expended on process heat, steam heat, mechanical drive, and electrolysis. Natural gas is the dominant energy source in the industry, and is used both as a feedstock and as a source of heat and power.

From 1972 to 1985 the basic chemicals industry reduced its energy use per pound of product by 36 percent (32). This probably reflects the combined effects of initially high energy intensity, a high level of technical capability (e.g., the relatively large number of process engineers at chemical plants), and the modest thermodynamic requirement (e.g., low temperature) of many processes. A recent increase in cogeneration has provided a significant savings as well. The most substantial improvements in energy efficiency in the future will come as older equipment is replaced and as energy-inefficient processes are abandoned in favor of more efficient ones (33). The three main opportunities for increased energy efficiency through new technologies and/or process modifications are distillation, waste heat recovery, and product integration (i.e., whereby intermediate products such as ethylene are produced in petroleum refining complexes) (40).

\section{Petroleum and Coal}

The petroleum and coal industry is the largest energy user among manufacturing industries, consuming more than 5 quads of energy in 1985 (53). Petroleum refining dominates the industry's energy use, accounting for 90 to 98 percent of total annual energy consumption $(37,45,49)$.

Unlike the paper industry, which has a large resource base of domestic timber and relies mainly on self-generated energy, U.S. petroleum refineries depend on a foreign supply of crude oil for both

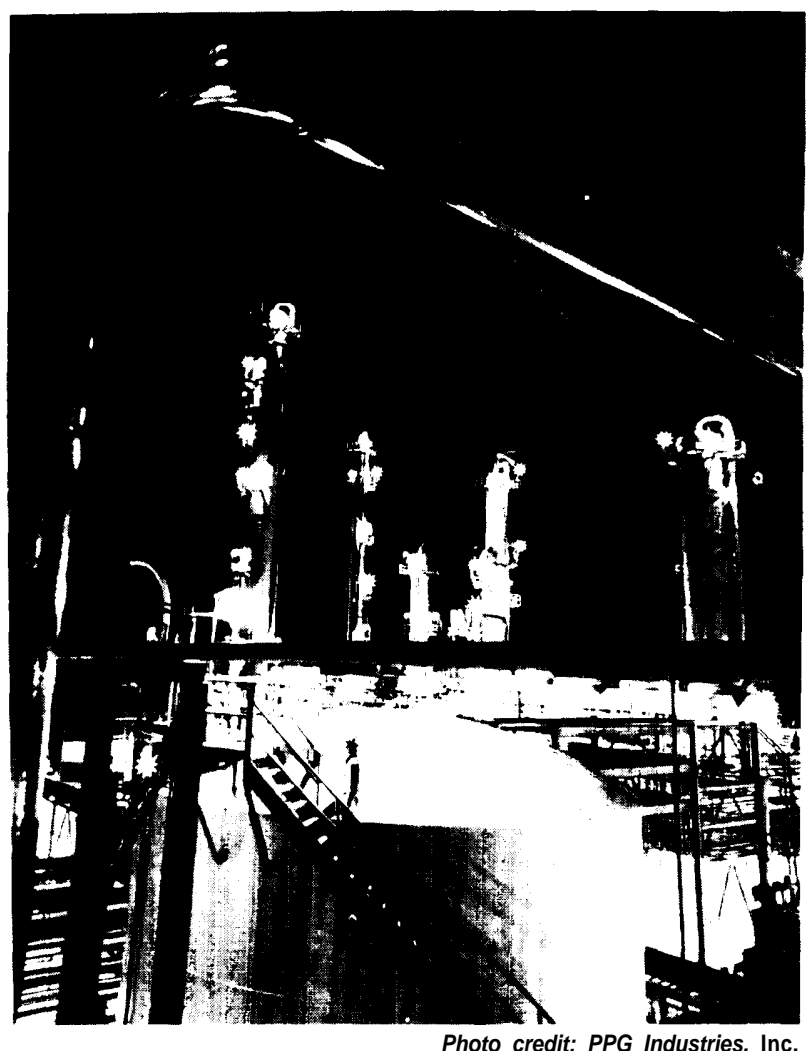

A plant for the production of ethylene glycol is shown above. Glycol is used for making polyester fibers, photo film, and plastic bottles.

feedstock and energy source. This supply is subject to sudden changes in the price, quantity, and type of crude imported, all of which can influence energy consumption by refineries. Recent trends toward use of ' 'heavy' crude oil, for example, have increased the energy needed for processing as compared to lighter crudes.

Two additional factors influencing energy use are shifting demand for different types of products and environmental regulations. Demand has decreased for most sulfurous fuels (such as residual fuel oil) and high-octane unleaded gasoline (40). Environmental regulations limiting sulfur and lead content in fuels have mandated extra processing of fuel, hence increased use of energy for refining.

Improvements in refinery equipment and operations and computer process controls have led to nearly a 13-percent drop in the energy required per barrel of output from 1972 to 1985 (32). Key improvements have been made in steam systems. Large savings have resulted from rationalizing these 
systems, reducing leaks, renovating steam traps, using low-pressure steam that used to be vented, etc. In addition, new installations of boilers that cogenerate electricity and steam are allowing refineries to meet their medium pressure steam needs more efficiently.

\section{Primary Metals}

Steel and aluminum manufacturing account for most energy used in primary metals, which totaled about 2.6 quads in 1985 (53). The primary metals industry is the biggest industrial user of both coal and electricity, and is a leading emitter of $\mathrm{CO}_{2}$, accounting for about 5 percent of total U.S. $\mathrm{CO}_{2}$ emissions in 1985.

Steel-Production of steel involves many energyintensive processes, most requiring large amounts of process heat to alter the chemical makeup of input materials and for shaping the steel into useful forms. Three types of steelmaking furnaces are currently used in the United States. Open hearth furnaces are the oldest and now least used type. Basic oxygen furnaces, which speed the steelmaking process by blowing oxygen into the furnace, are the most common type. Electric arc furnaces, which produce steel by electric arcing between carbon electrodes, are the most efficient type of furnace used today and are responsible for a growing share of U.S. steel production.

In the early and mid-1980s, U.S. producers reduced cost and improved energy efficiency by closing obsolete and unneeded mills and facilitiesunfortunately, though, over half the jobs in the industry have been lost as a result. Between 1972 and 1985 additional investments in modernization reduced energy use per ton of steel mill products by 21 percent, or 1.8 percent per year (33). Specifically, the electric arc furnace has resulted in increased substitution of scrap for iron ore, which allows steelmakers to bypass the beneficiation and smelting processes and reduce energy use by 30 to 40 percent (37). Continuous casting, which permits increased working of hot steel, reduces the energy spent on reheating metal at various stages of the production process by about 15 to 20 percent, while vastly increasing the production yield (37). The continuous casting of steel has risen from 9.1 percent of all steel production in 1975 to 61.3 percent in 1988 (1).

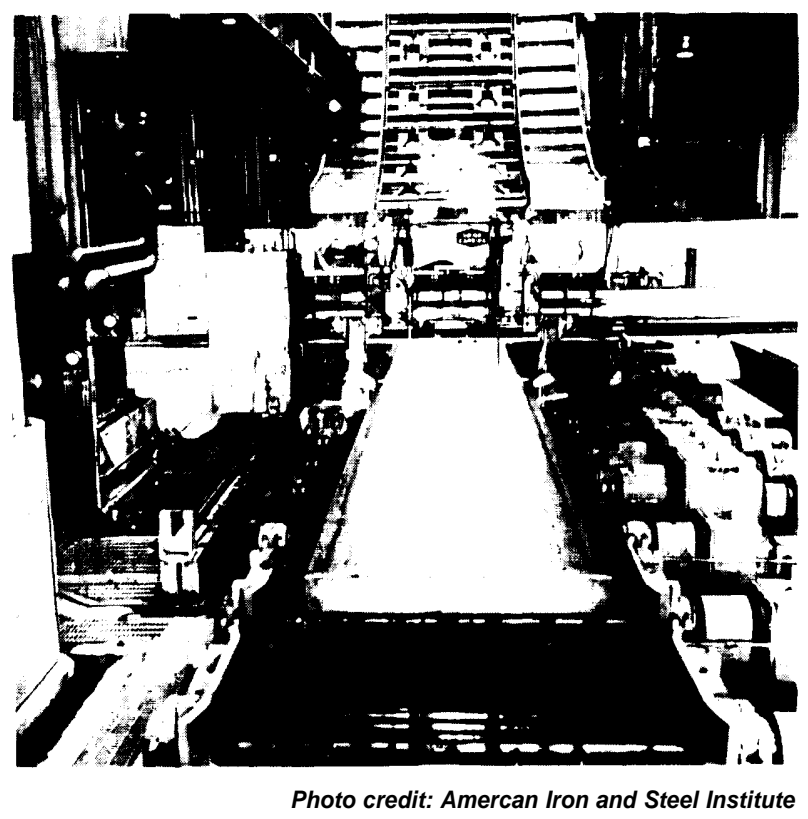

\begin{abstract}
The slab is being torch cut after emerging from the continuous slab caster. Continuous casting eliminates the need for ingot stripping, reheating, and primary rolling. Continuous casting is also more energy efficient because less metal must be returned to the steelmaking process in the form of waste.
\end{abstract}

Aluminum-The aluminum industry, like the steel industry, uses large quantities of energy to convert ore into metal and form the metal into finished goods. Manufacture of aluminum, however, involves somewhat different processes and a different mix of fuel types. Electricity accounts for most energy use in aluminum manufacture-77 percent in 1981 (45). Hydroelectric power, which currently provides about 10 percent of electricity generation capacity in the United States, accounts for over one-third of electricity used by the aluminum industry (10). Thus, electricity used in the aluminum industry is significantly less $\mathrm{CO}_{2}$-intensive than the nationwide average. Production of aluminum has also become more energy-efficient in recent years due to the introduction of new technologies.

How quickly the energy efficiency of the primary metals industry improves in the future will largely depend on the rate of capital stock turnover. Because of slow growth in the primary metals industry and the long lifetimes of most capital equipment, accelerated replacement of energy-using equipment in the near future is unlikely without incentives. ${ }^{6}$

\footnotetext{
${ }^{6} \mathrm{Am}$ example of such an incentive is the Department of Energy's cooperative program with the steel companies to research new continuous steelmaking technologies.
} 
There is potential for significant reductions in energy use in the near future through recycling of primary metals. Production of aluminum from scrap requires about 90 percent less energy than production from bauxite ore. Production of steel from scrap consumes about 40 to 50 percent less energy than production from iron ore (8). As of 1987, the United States recycled about 43 percent of all aluminum in municipal solid waste and over 55 percent of used aluminum beverage cans (42).

\section{other Manufacturing Industries}

Aside from the four largest industries, and the stone, clay, glass, and food processing industries, most manufacturing involves the intermediate processing of raw materials. The intermediate processing or ' 'second-tier' industries together accounted for 30 percent of the manufacturing sector's total use of fossil fuels in 1985, and almost half the sector's electricity use (49). ${ }^{7}$ The heavy use of electricity reflects the extent to which these industries rely on mechanical drive. While second-tier industries do not require much process heat, they consume most of manufacturing's space heat energy, since they are generally more labor intensive than the basic materials industries. The stone, clay, glass and food processing industries also use significant natural gas for heating purposes.

In contrast to the four largest industries, secondtier manufacturers usually give low priority to improved energy efficiency and energy conservation. Hence, they offer a potentially significant target for reducing manufacturing's energy use (32).

\section{Energy-Efficiency Improvement Techniques}

Energy efficiency can be improved in manufacturing by changing operations and associated equipment to reduce energy use, and/or by significantly changing overall production processes (33). Equipment changes and energy conservation add-on technologies involve significant investment (typically $\$ 100,000$ to a few tens of million dollars), which are often justified by reduced energy costs. Changes in the major production processes often require a new facility, at costs which usually exceed $\$ 100$ million.

\section{Energy-Efficient Operations}

Energy-efficient operations are achieved, in part, by good housekeeping practices by well-qualified staff with leadership and support from top management. General energy conservation practices include: inspections to encourage conservation activity; training programs for operations of energyintensive equipment; scheduling of energy-intensive activities; better space heating/cooling controls; systematic maintenance programs; accounting procedures to charge energy costs to specific production departments; and low-level investments such as for inspection equipment. At some plants, employee suggestions for and participation in energy conservation have led to improved operations (32).

\section{Energy Management Systems}

Equipment can be turned off or down as appropriate by an energy management system, i.e., a microprocessor connected to major energy distribution lines and/or equipment, which records and partly controls energy use. For example, it is still common industrial practice to leave electrical equipment on between production shifts. Large energy savings can be achieved by turning off equipment at these times and by selectively turning off or down equipment when production is below capacity. However, costly installation of wiring and switching is often required for systematic shut-downs of process equipment, lights, and fans.

Extensive changes may be required to selectively turn off appropriate equipment in a major factory. The typical cost of an energy management system in an auto plant with a load of 100 million $\mathrm{kWh}$ per year is about $\$ 750,000$, with energy savings of about 10 percent. Exact costs and savings are, of course, site specific (33). Energy management systems have not yet been installed in most factories.

\section{Changes in Energy-Intensive Equipment}

Some of the major technologies that can reduce the energy intensity of a given process are more efficient burners, more efficient motors and lights, heat recovery, automatic controls, the capture and reuse of waste materials, cogeneration, and insulation. The following discussion expands on a few of these.

\footnotetext{
${ }^{7}$ These numbers include the stone, clay, glass, and food processing industries. Without these four industries, the manufacturing sector's use of fossil fuel and electricity would be 12 and 34 percent, respectively.
} 
Heat recovery refers to the capture of waste heat, its application, and, in some cases, the upgrading of heat quality (i.e., with a heat pump). The main sources of heat are burner stack gases, heated product, and other hot material streams. The main applications are production of steam for general use (e.g., in waste-heat boilers) and the preheating of materials, such as water destined for a boiler, a product stream destined for a heater, or fuel or air destined for combustion.

High-efficiency motors are now routinely ordered at many firms when a motor is being replaced. (Most larger motors, however, are not replaced when they malfunction but are rewound. ) High-efficiency motors typically cost about 20 percent more than standard motors (e.g., \$60/hp compared with $\$ 50 /$ hp) and save about 5 percent in electricity, depending on the size of the motor (2).

Motors can also be equipped with electronic variable-speed drives, allowing the motor to be run at a speed appropriate for the task at hand. Variablespeed drives typically replace conventional, constantspeed applications where:

1. motors provide more flow than is usually required,

2. motors work against variable-flow restriction devices, or

3. motors are turned on and off to regulate flow.

Typically, variable-speed drives reduce electricity use by about 20 percent (21).

Savings from more efficient lighting can be relatively large. If high-pressure sodium lamps replace mercury-vapor lamps for area lighting, energy savings of 50 to 60 percent can be achieved. Similarly, efficient high-frequency ballasts and specular reflectors can be installed in fluorescent lighting systems with electricity savings of 50 to 60 percent. With half as many bulbs this combination delivers about 90 percent as much light as the standard installation, Nonetheless, many improvements in lighting technology have yet to be widely adopted.

The importance of automatic controls is, of course, increasing as microelectronic technology improves. Such controls include:

1. process controls that sense characteristics such as temperature, chemical composition, and flow rate and immediately optimize them;
2. burner controls such as those that control the air-to-fuel ratio;

3. motor controls that, for example, adapt motor speed to the load; and

4. energy management control systems (discussed above).

While industry has made a start in applying some automatic controls (i.e., first generation burner controls and process controls), opportunities remain for further applications, particularly of more advanced models. Motor controls have not yet been extensively applied.

\section{Changes in the Production Process}

For this report, production activity is discussed at the level of an integrated mill or factory. The introduction of new processes in factories (i.e., new ways of transforming materials) and shifts in the relative use of competing processes are among the most important sources of declining energy intensity in materials manufacturing. The growing use of recycled material, both fabricators' scrap and postconsumer scrap, also has a major impact on energy savings. Only about one-tenth as much energy is required to melt scrap aluminum as to reduce aluminum ore to make the same amount of molten metal.

Many energy-saving opportunities relate to the capture and use of materials that have previously been disposed of, such as (flared) organic byproduct gases, organics in waste streams (e.g., in exhaust gases at a paint dryer), water, or steam condensate. Reducing material flows can also save energy.

Material recovery projects have been widely implemented since the first oil shock both to achieve energy savings and to meet pollution standards. Increased heat recovery equipment was widely installed where higher fuel prices made it very profitable; thus less retrofit activity can be expected in this area, unless fuel prices rise again.

\section{Energy Savings as a Byproduct of Adopting Other Technologies}

Potentially, the greatest decrease in emissions will not be the result of direct efforts to reduce energy consumption but of indirectly pursuing other economic goals like improved product quality, 


\section{Box 6-A-Potential for Industrial Energy Efficiency in the U.S.S.R. and Eastern Europe}

U.S.S.R.

The Soviet industrial base is similar to that of past decades in the United States and many other OECD countries, with a strong reliance on energy-intensive industries (e.g., primary metal, mineral, mining, and chemical works), along with the production of energy itself. These will continue to be needed in order to produce the housing, appliances, vehicles, and transportation infrastructure desired by Soviet citizens.

Industrial energy consumption currently represents more than 50 percent of total energy use in the U.S.S.R. Ferrous metallurgy, fuels and power, machine building, and chemicals, petrochemicals, and petroleum refining consume 70 percent of all industrial energy, or about 40 percent of total Soviet energy consumption (34). Improving end-use energy efficiency in these industries is possible, but it will require continued reforms in the Soviet economic system (see ch. 9).

One Soviet analyst (3) estimated that the industrial sector could reduce energy use by about 20 percent by using the most efficient, currently available technologies. This might require a substantial increase in Soviet foreign trade with OECD countries, though, because the majority of these technologies are presently used and produced only in those countries.

\section{Eastern Europe}

Industry is the largest energy-consuming sector in Eastern Europe, accounting for 59 percent on average of primary energy consumption in 1985 (26). Despite major growth in the residential and commercial sectors, industrial energy use is expected to continue to dominate the energy supply and demand picture in Eastern Europe well into the 21 st century.

Kolar and Chandler (26) projected that policies encouraging energy efficiency might reduce energy demand in the overall Eastern European industrial sector by about 6 quads by 2025. This does not reflect the effects of potential economic reform on structural changes and overall energy intensity. Some people in Czechoslovakia, for example, have called for reducing the production of steel to one-half of its present level, and even more dramatic changes have been recommended for nonferrous metallurgy and chemicals production.

lower product costs, or pursuing specialized markets. ${ }^{8}$ For example, the innovative float process of making glass was not adopted solely because of energy savings, but because of the production flexibility that the new system offered (22). The major impact of the continuous casting of steel is not energy saved, but improved product yield (60). The shift in the steel industry from large, very energyintensive open hearth furnaces to more energyefficient basic oxygen and electric furnaces has occur-red in a large part because of the demand for small, regular shipments of products with special metallurgical and dimensional characteristics (17, 36). Metal stamping plants have implemented new techniques for cushioning their presses not because of the 10 percent energy savings involved, but because of the desire for a more consistent product achieved with fewer maintenance costs (33).

Canada's National Energy Board concluded that most of the industrial energy-efficiency gains that the country achieved have ". . . resulted from the adoption of new processes, motivated by concerns for competitiveness and productivity, rather than energy costs' (28). Future industrial savings are also likely to be associated dividends of larger goals, given the increased competition from foreign fins, the advent of information technologies that allow production to be more closely monitored, and the movement towards high-value-added products. ${ }^{9}$

In the U.S.S.R. and Eastern Europe, the industrial sector consumes a much larger share of total energy than in the United States. Many opportunities exist for energy savings in the rapidly changing industrial economies of these nations (see box 6-A).

\section{OTA EMISSION REDUCTION SCENARIOS}

OTA developed an energy technology model to track the effects of various technical options to reduce $\mathrm{CO}_{2}$ emissions (see app. A). Figure 6-7 summarizes $\mathrm{CO}_{2}$ emissions from the manufacturing

\footnotetext{
${ }^{8}$ Thesteel industry is one example $(17,36)$.

${ }^{9}$ For more on this conclusion, see refs. $27,33$.
} 
Figure 6-7-Emissions in 2015 Under the Base Case, Moderate, and Tough Scenarios, by Energy Service Category

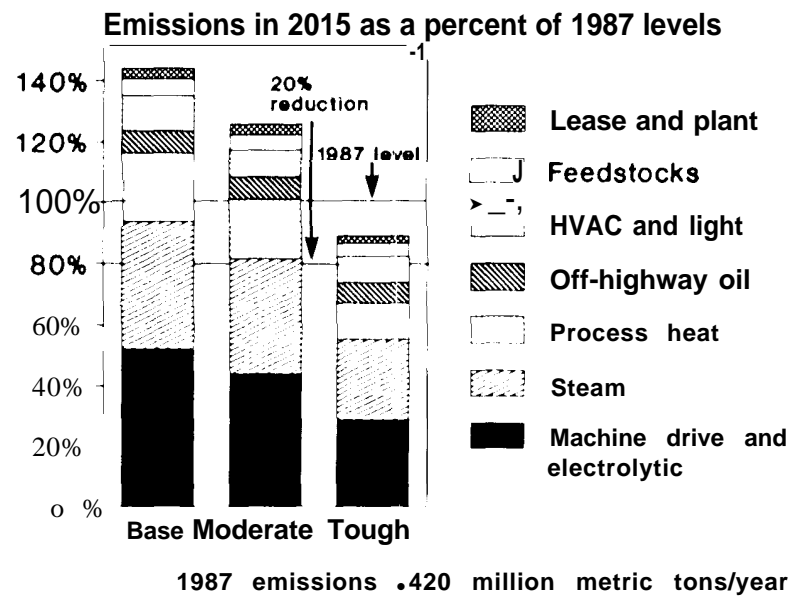

NOTE: The data presented above should be interpreted as the emissions reductions achievable in 2015 expressed as a percentage of 1987 emissions from industry, not as a percentage decrease in emissions below 1987 levels.

SOURCE: Office of Technology Assessment, 1991.

sector in 2015 as a percentage of 1987 levels, by type of energy service, for the Base, Moderate, and Tough scenarios. Figure 6-8 shows our projections of industrial emissions as a percentage change from 1987 industrial emissions under the Base, Moderate, and Tough scenarios up to the year 2015. In the Base case or "business-as-usual scenario, no new policies are adopted, resulting in about a 45 percent emissions increase, from about 420 million metric tons of carbon in 1987 to about 610 million metric tons in 2015. Over the same period, energy use is projected to increase by about one-third. Carbon emissions increase more rapidly because coal and purchased electricity both gain market share over the period (see figure 6-9).

Application of technologies that are currently available and cost-effective on a life-cycle basis (the Moderate scenario) still result in emission levels in 2015 that are about one-quarter above 1987 levels. Only in the Tough scenario, where technologies are employed that are either currently expensive or not expected to be commercially available in the next decade, do emission levels drop below the 1987 level by 2015, to about 10 percent below 1987 levels.
Figure 6-\&Summary of $\mathrm{CO}_{2}$ Emissions Under the Base Case, Moderate, and Tough Scenarios, by Year

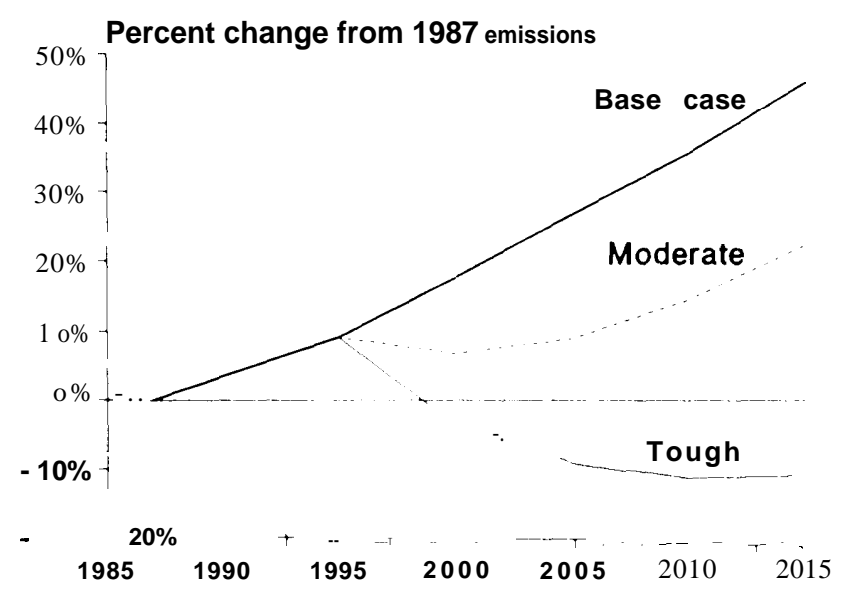

NOTE: The data presented above shows emissions reductions achievable in some future year expressed as a percentage decrease in emissions below 1987 levels.

SOURCE: Office of Technology Assessment, 1991.

Figure 6-9-Fuel Use Under the Base Case, Moderate, and Tough Scenarios, by Fuel Type $307^{\text {Fuel use (quadrillion Btu's) }}$

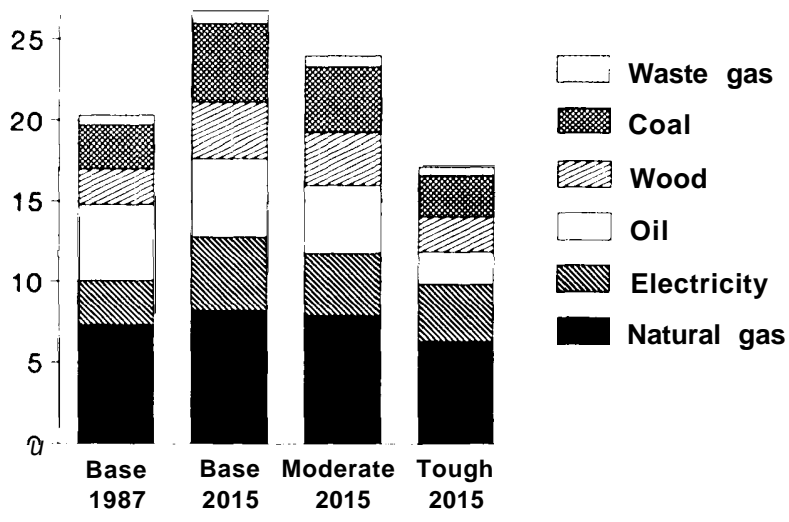

SOURCE: Office of Technology Assessment, 1991.

Table 6-4 lists the technical options considered in each of the above categories. The column headings (Base case, Moderate, and Tough) denote the three different levels of commitment. Listed underneath them are technological improvements and operational changes that could be expected to occur as a result of the implementation of the strategy. 
Table 6-4-industrial Sector Conservation Measures

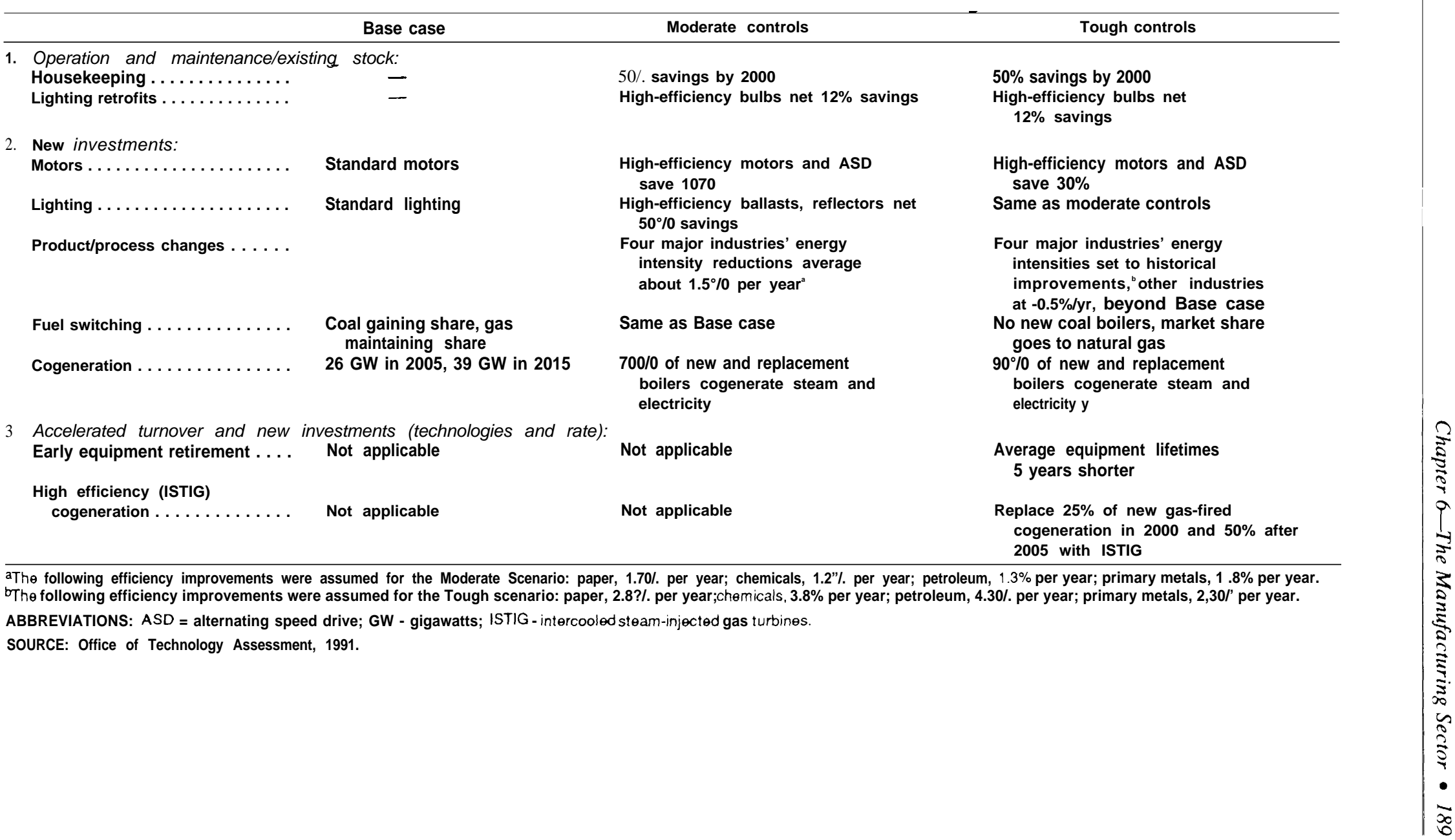


While the column headings characterize levels of commitment measured in terms of overall costs, the row headings (Operation \& Maintenance/Existing Stock, New Investments, Accelerated Turnover and New Technology) loosely reflect the lead times (going from short to long) associated with a particular group of changes. Operation \& Maintenance/ Existing Stock focuses on improving efficiency within the confines of the existing capital equipment stock. New Investment includes what might occur if policies were adopted that steer purchasing decisions towards high-efficiency equipment. Accelerated Turnover and New Technologies simulate what might be possible with policies that hasten the development of new technologies and the retirement of old equipment.

The energy conservation opportunities in the industrial sector are more difficult to analyze than in other sectors because the uses of energy are very heterogeneous and are often interrelated. Energy conservation can result from investment in individual pieces of equipment (e.g., a high-efficiency motor) or in changes to a whole manufacturing process (e.g., continuous casting steel). To deal with this problem, the analysis of the industrial sector examines efficiency in specific types of equipment that are used in many types of industrial processes and specifically focuses on likely process changes in the four biggest energy-consuming industriespaper and allied products, chemicals, petroleum refining, and primary metals.

Note that in this analysis, emissions reductions are not linked to major changes in the utility fuel mix that produces electricity for industry. Because over half of U.S. electricity is produced by burning coal (the most $\mathrm{CO}_{2}$-intensive fuel), the emissions reductions described in this chapter could be augmented by changing how electricity is made (see ch. 3 ).

\section{Base Case}

OTA's Base case projection of a 45 percent increase in emissions from 1987 to 2015 reflects the Gas Research Institute's 1988 baseline projections. Industrial production is projected to increase 2.7 percent per year, but energy use is estimated to grow more slowly. The result will be a continuing decline in the energy intensity of U.S. industry, including that of each of the four biggest energy using industries.
By 2015, we assume there will be about 39 gigawatts of industrial cogeneration capacity in the Base case. Most of the electricity is used internally by industrial fins, but about one-quarter is sold to utilities. Gas is projected to be the fuel most used for cogeneration, but coal's share increases significantly by 2015 .

\section{Moderate Controls}

Adopting Moderate control measures could reduce $\mathrm{CO}_{2}$ emissions by 77 million metric tons per year below Base case projections for 2015; emission levels would still exceed 1987 levels by 25 percent (see figure 6-7). Figure 6-10 shows the emissions reductions achievable in 2000 and 2015 by each of our Moderate control measures. Product and process changes that reduce the energy intensity of the four biggest energy-using industries achieve the greatest emissions reductions (about 9 percent of 1987 levels) (52), The impacts of other conservation measures (motors and lighting) may overlap with those of process and product changes; the scenario is adjusted to avoid double counting of the same emission reduction opportunities. Improvements in housekeeping and new, more efficient motors reduce emissions by 6 percent and 4 percent of 1987 , respectively, by 2015 .

Increased cogeneration based on gas and biomass achieves $\mathrm{CO}_{2}$ emission reductions equivalent to about 3 percent of 1987 levels by 2015, even though energy delivered and consumed increases. The OTA model assumes that cogeneration systems are designed to deliver both electricity and steam for internal use rather than to maximize electricity production. The assumed design maximizes the technical fuel efficiency and therefore minimizes carbon emissions, even though in some cases it may not be the least-cost alternative.

\section{Tough Controls}

By 2015, emissions under the Tough control scenario fall to about 10 percent below 1987 levels (see figure 6-7). Total emissions are about 40 percent lower than the Base case in 2015. Figure 6-11 shows the emissions reductions in 2000 and 2015 for each of the Tough measures as percentages 
Figure 6-10-- $\mathrm{CO}_{2}$ Emissions Reductions in 2000 and 2015 Expressed as a Percentage of 1987 Manufacturing Sector Emissions, by Control Method, Under the Moderate Scenario

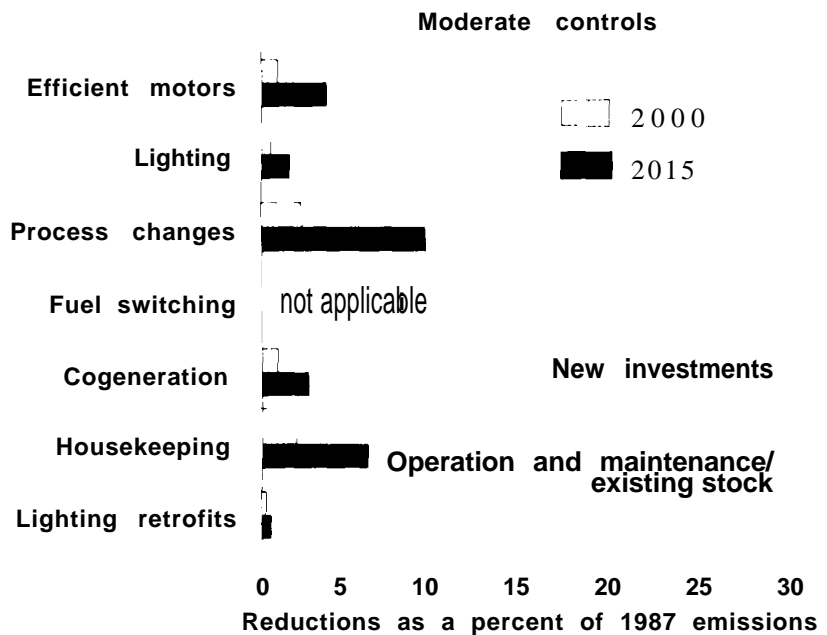

NOTE: The data presented above should be interpreted as the emissions reductions achievable in a future year expressed as a percentage of 1987 emissions from industry, not as a percentage decrease in emissions below 1987 levels.

SOURCE: Office of Technology Assessment, 1991.

of 1987 levels. *O Reductions from all Tough measures total about 210 million metric tons, roughly half of 1987 emissions. To achieve such reductions, equipment stocks (e.g., boilers, motors, etc. ) must be replaced 5 years sooner than they normally would be. Operation and Maintenance/Existing Stock measures are the same as in the Moderate scenario, but are introduced more quickly.

Process changes occurring in all industries achieve about a 26 percent reduction by 2015 , compared to 1987 emission levels, assuming the energy intensity of the four largest industrial energy users continues to decline at the 1980-85 rate. Other industries are assumed to experience an additional energy intensity reduction of 0.5 percent per year compared to the Base case.

High-efficiency motors, which use 30 percent less energy than standard motors, reduce emissions by 12 percent of 1987 levels by 2015. If existing motors are replaced 5 years sooner than scheduled, an additional 1 percent reduction can be achieved.
Figure 6-11- $\mathrm{CO}_{2}$ Emissions Reductions in 2000 and 2015 Expressed as a Percentage of 1987 Manufacturing Sector Emissions, by Control Method, Under the Tough Scenario

Tough controls

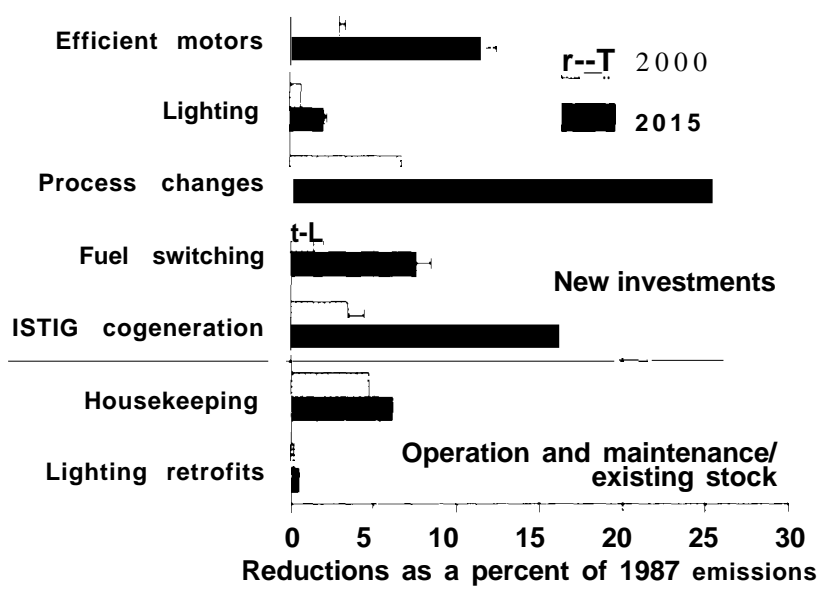

NOTE: The data presented above should be interpreted as the em issions reductions achievable in 2015 expressed as a percentage of 1987 emissions from industry, not as a percentage decrease in emissions below 1987 levels. The thin horizontal bars show the additional reductions possible if existing equipment is replaced sooner than scheduled.

SOURCE: Office of Technology Assessment, 1991.

If the building of new coal-fired boilers is stopped, and the entire market share for new coal shifts to natural gas (the fuel-switching measure), an 8-percent reduction in industrial $\mathrm{CO}_{2}$ emissions would be achieved by 2015 ( 9 percent if existing boilers are replaced 5 years sooner than scheduled).

New investments in cogeneration can achieve about a 7 percent reduction in $\mathrm{CO}_{2}$ emissions by 2015 , assuming that cogeneration provides 61 gigawatts $(\mathrm{GW})$ in 2015 and meets 90 percent of new industrial steam demand.11 New, more efficient cogeneration technologies, such as intercooled steaminjected gas turbines (ISTIG), should become widely available in the 1990s. We estimate that if ISTIG cogeneration replaces about half of the new gas-freed cogeneration after 2005, then industrial $\mathrm{CO}_{2}$ emissions can be reduced by about 16 percent in 2015 , relative to 1987 levels.

Because many of the Tough measures have overlapping effects, total reductions under the Tough scenario are lower than the sum of the reductions from each individual measure shown in figures 6-10

${ }^{10}$ This format should not be confused with the one presented in figure 6-8, which shows emissions as a percent change from 1987 levels

1 I Note that thiscategory is not included in figure 6-11. The more stringent ISTIGcogeneration technology is presented instead. 
and 6-11. For example, the potential reductions from cogeneration are lower if other conservation measures that lower the demand for steam energy are also assumed. On the other hand, other emissions reduction options may exist that were not included in this analysis. The potential savings calculated here should not, therefore, be taken as an absolute limit. In general, however, large emissions reductions may be very difficult to achieve by 2015 , in part because of continued growth in the manufacturing sector, and in part because industry has already invested in energy efficiency.

\section{Costs of the Tough Control Scenario}

We estimate that the cost of all the Tough industrial control measures falls in the range of $\$ 18$ billion to $\$ 55$ billion per year. The cost of individual measures are summarized below and presented in greater detail in appendix A.

Use of more efficient motors and lighting and general housekeeping improvements are all measures that are either low cost or save money due to large fuel savings. We estimate cost savings from these measures of about $\$ 9$ billion per year.

The extensive use of extremely efficient cogeneration technologies under our Tough scenario costs, on average, about an additional $\$ 0.02$ to $\$ 0.07$ per $\mathrm{kWh}$ of electricity generated. Costs for cogeneration total about $\$ 3$ billion to $\$ 7$ billion per year. The cost-effectiveness of these reductions is in the range of $\$ 55$ to $\$ 120$ per ton of carbon.

The moratorium on new coal industrial boilers (assuming natural gas is the fuel of choice) would increase natural gas use by about 2.3 quads over the Base case. At our 2015 prices, this costs about $\$ 14$ billion per year, with a cost effectiveness of about $\$ 520$ per ton of carbon reduced.

The largest share of the industrial reductions comes from process change;. We have no source of estimates for the cost of these reductions. We assumed a range of $\$ 120$ per ton to $\$ 520$ per ton (the upper bound of the cost-effectiveness of cogeneration to the cost-effectiveness of fuel switching from coal to natural gas). Total costs for process changes thus would fall in the range of about $\$ 10$ billion to $\$ 43$ billion,

\section{POLICIES FOR REDUCING $\mathrm{CO}_{2}$ EMISSIONS FROM THE INDUSTRIAL SECTOR}

Strategies for reducing emissions of greenhouse gases from the manufacturing sector fall into three categories: those meant to reduce overall energy use, those intended to shift the composition of industrial output, and those meant to encourage switching from greenhouse gas-intensive energy sources to sources that emit fewer or no greenhouse gases. These strategies are outlined in greater detail below. Policy options are presented in a following section.

\section{Policy Strategies}

\section{Changes in Energy Efficiency}

The energy efficiency of a manufacturing process can be improved by increased housekeeping, equipment retrofit, or construction of entirely new production facilities. Housekeeping essentially involves increased labor and management inputs to reduce energy inputs. Equipment retrofit is a relatively inexpensive alternative to actual equipment replacement. However, equipment replacement or construction of entirely new facilities, though costly, offer the largest overall energy savings.

Improving energy efficiency in manufacturing can be quite cost-effective. Between 1976 and 1988, about 2,500 energy audits were performed free of charge for small and medium-sized manufacturers (i.e., under 180 employees) through the Energy and Diagnostic Center (EADC) program sponsored by the Department of Energy's Office of Industrial Programs. The program is administered by the University City Science Center in Philadelphia and currently has auditing centers at 18 universities, During 1987-88, the audits performed contained recommendations for savings of about 5 percent of the total energy use by these manufacturers, equivalent to a financial savings of $\$ 13.6$ million. While these savings are certainly encouraging, much more potential for improvement exists: only half of the recommendations made by the energy auditors were implemented by the manufacturers. ${ }^{12}$ Most (73 percent) of the energy savings resulted from improved conservation and efficiency in production and energy-service technologies (i.e., mechanical

\footnotetext{
${ }^{12}$ Research bearing on the impediments t. adoption of energy-efficient technology will be presented in a forthcoming OTA study, U.S.Energy Efficiency. Past Trends and Future Opportunities.
} 
drive systems and boilers). The remainder was saved through housekeeping and in lighting and space conditioning systems.

Depending on assumptions made about investment interest rates, the manufacturers' annual rates of return from energy-conserving investments in 1987-88 were between 488 and 663 percent. The Federal Government, which paid for the audits, earned between 60 and 77 percent per year on its investment in increased taxes from manufacturers (25).

\section{Changes in Output}

The energy intensity of manufacturing industries is unevenly distributed (see figure 6-12). Of the 53 manufacturing industries, only 4 have a primary energy intensity of 100,000 Btu's or more per dollar output; 11 are between 50,000 and 99,999 Btu's; and 38 use less than 50,000 Btu's (roughly the average) per dollar of output (5). Thus, increased efficiency in a few industries or a realignment of the economy away from the most energy-intensive industries could have a significant effect on the overall energy intensity of manufacturing.

Indeed, decreased output of energy-intensive goods accounted for about one-third of the decline in energy use by the U.S. industrial sector between 1972 and 1982 (27). To the extent that consumers substitute less energy-intensive goods for more energy-intensive ones, $\mathrm{C}_{2}$ emissions from U.S. manufacturing can be reduced. However, the experience from 1985 to 1988 indicates that economic output can also swing in the opposite direction toward a more energy-intensive configuration. Moreover, imports of energy-intensive products increased in the period when U.S. manufacturing shifted from more to less energy-intensive goods. To calculate our total contribution to global problems like climate change, and to formulate effective energy reduction policies, it is important to include estimates of the energy associated with nonenergy imports. Failure to do so presents a false picture of U.S. energy use and of the potential for savings.

Advances in information technologies have made it possible to substitute information for materials, leading to changes in production that indirectly save energy. Instead of creating dozens of prototypes, for example, Levi Strauss Co. is using computers to test out new fabrics, patterns, and designs before ever cutting a piece of cloth (4). Thus, quality and
Figure 6-1 2-Ranking of Manufacturing Industries by Direct and Indirect Primary Energy Use

200 1,000 Btu's

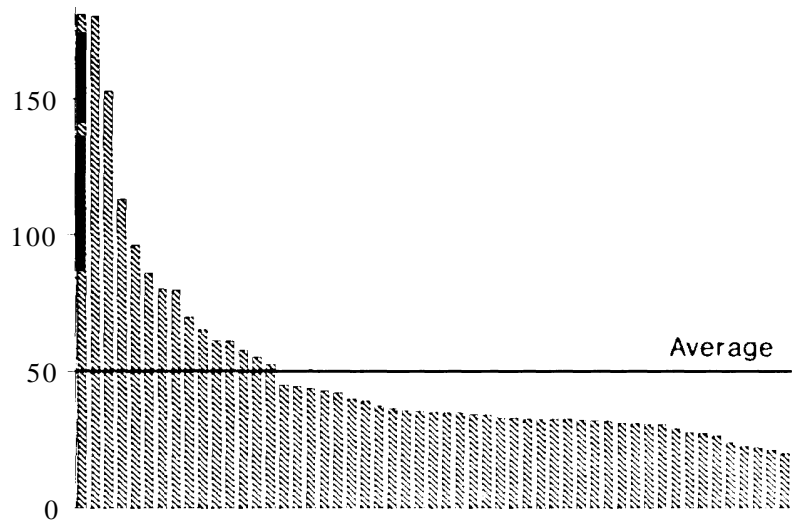

SOURCE: S. Casler and B. Hannon, "Readjustment Potentials in Industrial Energy Efficiency and Structure," Journal of Environmental Economics and Management 17:93-108, 1989.

flexibility are enhanced and the use of materials and associated energy is reduced. In essence, a shift in output has occurred, with the software and information technology industries gaining (43a).

\section{Fuel Switching}

Manufacturing industries can also reduce emissions of greenhouse gases by switching to 'cleaner' energy sources. Natural gas and oil emit less $\mathrm{CO}_{2}$ per unit of energy than does coal, and no greenhouse gases are directly emitted by generation of electricity at hydroelectric or nuclear powerplants. In one analysis, researchers found large-scale movement towards refined petroleum products and electricity from 1967 to 1972 and a movement away from natural gas from 1972 to 1977 , indicating that “. . . many industries are able to exercise a great deal of flexibility in their use of fuels over spans of time as short as five years' (5).

The decision to switch the type of energy used, however, may be influenced by technical, economic, environmental, and energy security factors. Any of these factors may constrain movement from one type of energy to another. Potential supply restraints also can limit opportunities for fuel switching. Nevertheless, energy switching could reduce $\mathrm{CO}_{2}$ emissions from manufacturing by as much as 5 to 10 percent; these reductions could be much higher in the long run if reliable, nonfossil energy sources are developed, without seriously conflicting with manufacturing interests. 


\section{Policy Options}

Several categories of policies can be used to implement the emission-reducing strategies outlined above. They include regulatory and financial policies; electric utility programs; and information and research and development policies. Unfortunately, no single policy is without flaws. Careful coordination of several types of policies is probably the best approach for achieving significant emission reductions from the manufacturing sector.

Opportunities for reducing $\mathrm{CO}_{2}$ emissions in this sector are more difficult to identify than in other sectors because of the wide variety of uses for energy. Thus, those policies that affect energy consumption in general, for example, carbon taxes or marketable permits for carbon emissions, are a logical choice for this sector. Moreover, because industrial decisionmakers are often both more knowledgeable and sensitive to prices than, for example, residential energy consumers, one would expect market-oriented options to be relatively more effective. Nonetheless, other types of policy approaches in concert with market-oriented approaches can help to ensure success.

Without any intervention, emissions may increase by about 45 percent by the year 2015. Federal policies to encourage energy efficiency, fuel switching, and $\mathrm{CO}_{2}$ offsets in the manufacturing sector have the potential to reduce the sector's $\mathrm{CO}_{2}$ emissions to about 10 percent below current levels in the next 25 years. Such changes will not come about by themselves. A coordinated policy effort at the Federal level is needed to ensure success.

\section{Regulatory Policies}

One possible means of regulating $\mathrm{CO}_{2}$ emissions from manufacturing is to require permits for $\mathrm{CO}_{2}$ emissions. Manufacturers could be issued permits to cover a prescribed level of emissions, for example a set percentage of 1990 emissions. Reductions can be accomplished by implementing energy -efficient technologies or fuel switching, or by supporting approved reforestation/afforestation projects to offset $\mathrm{CO}_{2}$ emissions from manufacturing activities (see ch. 7). It would be up to the manufacturer to choose the most cost-effective strategy, depending on costs of available resources. Firms could be allowed to trade their unused carbon permits to other firms whose emissions exceed permit levels, thereby creating a market for carbon emissions. Marketable permits are the basis of the U.S. regulatory approach for phasing out emissions of CFCs and for reducing sulfur dioxide emissions to control acid rain. Marketable carbon permits are likely to be more difficult to implement than permits for CFCs or sulfur dioxide; nevertheless, such a system may still be less intrusive to firms than mandated standards or equipment. Marketable permits are discussed in greater detail in chapter 3 .

Another more traditional regulatory policy is to require efficiency standards for common energyusing equipment, similar to those existing for automobiles and some appliances. Motors are prime candidates for such standards. Efficiency standards historically have been opposed by industry because standards can be inflexible (33). However, decisions such as motor purchases and recycling are made by professionals dealing with a wide variety of specific situations and are not immune to shortsightedness or mistakes. Even so, the rationale for mandating the use of a particular type of equipment is not as strong as it is for setting efficiency standards for cars or appliances; the consuming public might not be competent or willing to evaluate the technical details bearing on efficiency.

\section{Electric Utility Programs}

Some programs sponsored by electric utilitiesDemand Side Management (DSM)--offer another means of achieving reductions in greenhouse gas emissions from manufacturing. The cost to utilities of facilitating energy savings (especially in large energy users such as industry), may be competitive with the cost of adding new supply capacity: the utility interacts with the customer to conserve energy and maximize profits. Many of these programs are in their infancy and it is too early to judge their effectiveness. The major programs are:

1. rebates to customers who install agreed-on kinds of equipment;

2. payments (by the utility that solicits bids) for electricity savings resulting from installations;

3. low-interest loans to customers for conservation installations; and

4. installation, at utility cost, of conservation equipment (33).

See chapters 1 and 3 for more discussion of DSM.

Many large industrial customers of electric utilities receive special lower rates because they supply the utility with a large, dependable portion of 
electricity demand. Utility programs could be used to reduce greenhouse gas emissions by making these special rates contingent on improved use of electricity. This differs from least-cost planning in that the financial burden of improving energy use is placed on the manufacturer, not the utility.

Energy or Carbon Taxes

The price of energy is obviously a very important factor affecting its use. Prices can be affected through a carbon tax, energy taxes (e.g., an oilimport fee), or regulation of electricity prices, to name a few. These are discussed in greater detail in chapter 3 .

A carbon tax is a particularly effective way of levying the heaviest economic sanctions against the worst emitters of $\mathrm{CO}_{2}$. Under such an approach, the tax would be highest on coal, low for natural gas, and zero for noncarbon sources.

Using several econometric models, the Congressional Budget Office estimated that a carbon tax of $\$ 100$ per ton would hold $\mathrm{CO}_{2}$ emissions at from about current levels to as much as 25 percent below current levels by 2000 (38). Within the industrial sector, the tax is estimated to lower $\mathrm{CO}_{2}$ emissions in 2000 by between 10 and 35 percent below Base case emissions in that year. The higher reduction estimate is a result of a 70-percent reduction in coal use.

However, analyses of pricing policies such as carbon taxes may tend to overemphasize the role of price. The fact that the energy intensity of the economy began to decline before the first oil shock and continued to fall during periods of declining energy prices suggests that decisions about energy use are not solely contingent on price. Energy prices are important in decisionmaking, but are not the only consideration. For example, reliability of supplies is extremely important; facilities have been added at many factories so that both natural gas and residual oil can be burned and electricity generated.

Other very important considerations in energy decisionmaking are the connections between energyusing technology and product quality, yield of materials, maintenance of equipment, capacity of production, and so forth. Energy conservation measures are not undertaken if managers believe that the measures are at all likely to interfere with production or if the return on investment is not extremely high. In most industries, energy costs are not that impor- tant in the overall scheme of production. However, many projects undertaken primarily to boost product quality or to further automate production have side benefits including saving energy. Such energyconservation projects, once identified, can be readily undertaken.

Unlike other sectors, such as buildings or electricity generation, nearly every manufacturing industry faces increasingly intense foreign competition. Caution should be exercised in increasing costs to domestic manufacturers if there is not a commensurate increase in costs to foreign competitors, or some sort of equalizing export subsidy. Unless the costs of policies are relatively equal worldwide, domestic manufacturers could beat a unique disadvantage and demand would conceivably shift from domestic producers of a product to foreign firms, doing little to curb the global production of greenhouse gases.

\section{Tax Incentives}

Much of the energy-using equipment in industry is old and inefficient compared to the best available technology. In 1975, for example, more than 70 percent of equipment in manufacturing was at least 15 years old and more than half was over 25 years of age (40), Because in many cases replacing old equipment improves energy efficiency by 10 to 50 percent, financial policies (such as, tax credits or accelerated tax depreciation schedules aimed at stimulating rapid replacement of older equipment with more energy-efficient stock) have potential for achieving improvements in energy use. Newer equipment also generally improves the overall productivity and competitiveness of the company.

This strategy has been tried in the past. The National Energy Act (1978) provided a 10-percent added energy investment tax credit (EITC) for certain energy conservation investments (as well as tax credits for certain energy supply investments). The tax credits were available until 1985. They applied to a specific list of technologies such as heat recovery devices.

One study of the EITC concluded, based on interviews and scrutiny of records at 15 participating corporations, that the 10-percent EITC seldom affected investment decisionmaking even though the tax credit was almost always applied for (33). In effect, almost all of the identified investment projects relating to conservation provided excellent returns and probably would have been undertaken 

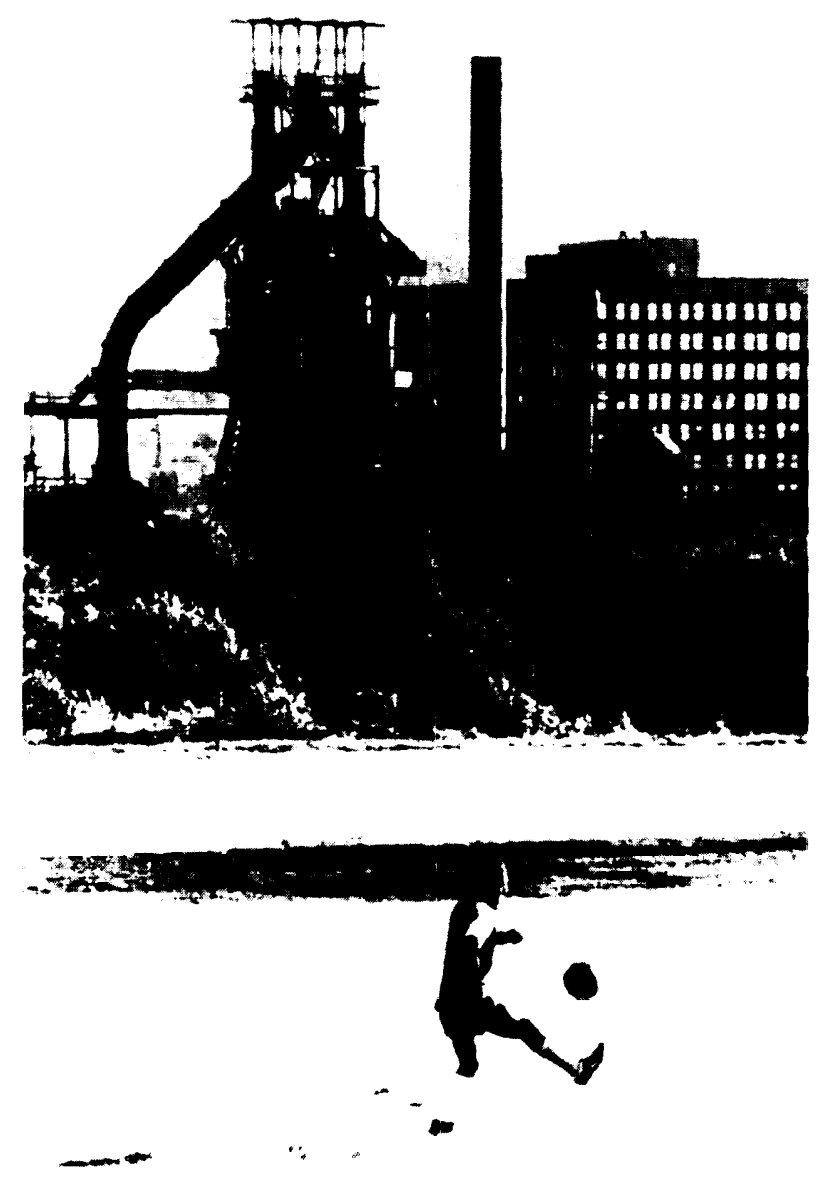

Photo credit: M. Procter

Bethlehem Steel main plant in Pennsylvania

even without the EITC. Many firms did not even factor the EITC into their financial evaluation. An additional objection to the EITC was that it specified technologies; it thus ran counter to the essence of technical change, which thrives on multiple new technologies and concepts and often involves multipurpose goals.

\section{Informational Policies}

A major barrier to reducing emissions from the manufacturing sector is a lack of information about how to improve energy use. Informational policies can include performance goals, the collection of performance data, energy performance labeling of equipment, training, or performance audits (32a). The Department of Energy's Office of Industrial Programs EADC program and its research and development information transfer program are ex- amples of successful Federal policy in this area. Initiated in 1976, the EADC serves to transfer state-of-the-art research information and energy analysis expertise to manufacturers, who are able to use the information for practical purposes. With EADC finding, faculty and students at 18 universities perform free energy audits for small and medium-sized manufacturers in more than 30 States. From 1976 to 1988, nearly 2,500 audits were undertaken, proposing a total of about 82 trillion Btu's of energy savings, mainly from efficiency improvements associated with cogeneration, space heating, lighting, and process equipment maintenance and replacement (in descending order of cost savings). These recommendations represented about $\$ 400$ million (nominal) in cost savings to industry. Actual implementation of EADC's recommendations yielded savings of 50 trillion Btu's of energy and \$247 million (nominal) over the 12-year period. The program has had a cumulative cost to the Federal Government of $\$ 11.25$ million through 1989 (25).

The success of programs such as EADC depends largely on the quality of work being performed; to expand the program would require a significant increase in the number of knowledgeable professionals involved. To the extent that increases are possible, the success of EADC seems to make an attempt worthwhile.

\section{Research and Development}

Research and development sponsored by OIP in waste energy reduction and industrial process efficiency is projected to save more than 3 quads of energy per year by the year 2000 , based on continued funding of $\$ 30$ million per year (1 1). Other federally sponsored research, such as that done at Oak Ridge National Laboratory (ORNL), will also contribute to improved energy technologies. Particularly promising research areas identified by ORNL are: improved use of catalysts in chemical production, intelligent sensors and controls, heat recovery and cogeneration, and separation techniques (29). Research and development in nonenergy areas, such as materials science, also holds promise for partial replacement of energy-intensive materials like steel and aluminum. Likewise, research and development into the quality of recycled goods could help reduce energy use by increasing demand for recycled materials such as paper, steel, and aluminum (32a). 


\section{CHAPTER 6 REFERENCES}

1. American Iron and Steel Institute, Annual Statistical Report, 1988 (Washington, DC: $19 \mathrm{~W}$ ).

2. Baldwin, S.F., "The Materials Revolution and Energy-Efficient Electrical Drive Systems, 'Annual Review of Energy 13:67-94, 1988

3. Bashmakov, I. A., ' 'Comparative Analysis of Energy Development in the USSR, USA, and Western Europe: 1970-2000,' paper presented at the International Energy Workshop (Laxenburg, Austria: International Institute for Applied System Analysis, June 20-22, 1989).

4. Business Week, "Computer Graphics Are Animating Another Market, 'Business Week, p. 92, Mar. 16, 1987.

5 Casler, S. and B Hannon, "Retijustment Potentials in Industrial Energy Efficiency and Structure,' Journal of Environmental Economics and Management 17:93-108,1989.

6. Cleveland, C. J., R.Stanza, C.A.S. Hall, and R. Kaufman, " 'Energy and the U.S. Economy: A B iophysical Perspective," Science 225:890-897, Aug. 31, 1984.

7.Doblin, C. P., "Dcclinmg Energy Intensity in the U.S. Manufacturing Sector," The Energy Journal 9(2): 109-135, 1988

8. Ehrlich, A H., P R. Ehrlich, and J P. Holdren, Ecoscience Population, Resources, Environment (San Francisco, CA:W.H Freeman \& Co., 1977)

9. Electric Power Research Institute, Efficient Electricity Use Estimates of Maximum Energy Savings (Palo Alto, CA: March 1990)

10. Electric Power Research Institute, Prospects for U.S. Basic Industries, 1986 -2000. Implications for Electricity Demand (Palo Alto, CA. March 1986)

11. Energetics, Inc., Non-Energy Impacts of industrial Energy Conservation, final task report, prepared for U S. Department of Energy (Columbia, MD: September 1985),

12. Flavin, C, R. Piltz, and C, Nichols, Sustainable Energy (Washington, DC: Renew America, 1989).

13 Gas Research Institute, Baseline Projection Data Book, 1988 GRI Baseline Projection of U S. Energy Supply and Demand to 2010 (Washington, DC: 1988).

14 Gas Research Institute, Industrial Natural Gas Markets: Facts, Fallacies, and Forecasts (Washington, DC: 1989).

15. Geller, H. S., "Testimony presented to the Subcommittee on Energy and Power, Committee on Energy and Commerce, U.S. House of Representatives, Feb. 7, 1989."

16. General Energy Associates, 'Industrial Cogeneration Potential: Targeting of Opportunities at the Plant Site" (Washington, DC: U S. Department of Energy, 1982).

17 Gold, B., "Technological Change and Vertical Integration, Managerial and Decision Economics, vol. 7, 1986.

18. Gross, T., Office of Industrial Programs, U.S. Department of Energy, personal communication, May 11, 1989.

19. Hagler, Bailly, Inc., Cogenerationand Small Power Generation Data Base (Washington, DC. RCG/Hagler, Bailly, Inc., December 1988).

20 Huntington, G.H. and J G. Myers, "'Sectoral Shift and Industrial Energy Demand: What Have We Learned?" unpublished paper for Energy Modeling Forum 8.3 (Palo Alto, CA: Stanford University, May 1986).

21. Kahane, A and R. Squitieri, "Electricity Use in Manufacturing,' Annual Review of Energy 12:223-252, 1987.

22. Kelly, H.C et al., "Energy Use and Productivity: Current Trends and Policy Implications," Annual Review of Energy 14:321-352, 1989.

23. Kelly, W.J. et al., "Opportunities for Improvement in the Energy Efficiency of Soviet Blast Furnaces: A Demographic Approach," paper presented at 51st Annual Conference of the Southern Economic Association (New Orleans, LA: Nov. 6, 1981),
24, Kelly, W.J. and T.P. Spengler, "Application of Soviet Technology in Japanese Ferrous Metallurgy," paper presented at 20th National Convention of the Amen"can Association for the Advancement of Slavic Studies (Honolulu, HI: November 1988).

25. Kirsch, F. W., Energy Conserved and Costs Saved by Small and Medium-Sized Manufacturers: 1987-88 EADC Program Period (Philadelphia, PA: University City Science Center, June 1990).

26. Kolar, S. and W.U. Chandler, "Energy and Energy Conservation in Eastern Europe, report prepared for U.S. Agency for International Development (Washington, DC:Battelle Memorial Institute, Pacific Northwest Laboratories, 1990).

27. Marlay, R.C., "Trends in Industrial Use of Energy, "Science 226: $1277-1283,1984$

28. National Energy Board, Canadian Energy: Supplyand Demand, 1987-2005, Canada, September 1988

29. Oak Ridge National Laboratory, Energy Technology R\&D:What Could Make a Difference? (Oak Ridge, TN: December 1988).

30. Roop, J. M., "Energy Implications of Structural Change in the United States Economy, paper presented at IEA-Energy Demand Analysis Symposium (Paris: Oct. 12-14, 1987).

31. Ross, M., "Energy Consumption by Industry," Annual Review of Energy 6:379-416, 1981.

3 la. Ross, M., "Industrial Energy Conservation,' Natural Resources Journal 24(2):369, April 1984

32. Ross, M., "Energy Use in Manufacturing," contractor report prepared for U.S. Congress, Office of Technology Assessment, October 1988

32a. Ross, M., "The Potential for Reducing the Energy Intensity and Carbon Dioxide Emissions in U.S. Manufacturing" (Ann Arbor, MI: University of Michigan, unpublished paper, 1990).

33. Ross, M., "Improving the Energy Efficiency of Electricity Usc in Manufacturing," Science 244:31 1-317, Apr. 21, 1989

34. Sagers, MJ. and A. Tretyakova, Fuel and EnergyUse in the Sof'let Metallurgy Industries, Center for International Research, U.S. Bureau of the Census, CIR staff paper No.28 (Washington, DC: July 1987).

35. Sagers, M.J. and A. Tretyakova, USSR: Energy Consumption in the Chemical, Petrochemical, and Petroleum Refining Industries, Center for International Research, U.S. Bureau of the Census, CIR staff paper No. 29 (Washington, DC: September 1987).

36. Szekely, J., "Can Advanced Technology Save the U.S. Stœel Industry?" Scientific American 237(1):40, 1987,

37. Thoreson, R. et al., ' 'Industrial Fuel Use: Structure and Trends, ' Annual Review of Energy 10: 165-200, 1985.

38. U.S. Congress, Congressional Budget Office, Carbon Charges as a Response to Global Warming: The Effects of Taxing Fossil Fuels (Washington, DC: U.S. Government Printing Office, August 1990).

39. U.S. Congress, Office of Technology Assessment, Industrial and Commercial Cogeneration, OTA-E-192 (Springfield, VA: National Technical Information Service, 1983).

40. U.S. Congress, Office of Technology Assessment, Industrial Energy Use, OTA-E-198 (Springfield, VA: National Technical Information Service, June 1983).

41. U.S. Congress, Office of Technology Assessment, WoodUse:U.S Competitiveness and Technology, OTE-E-21O (Springfield, VA: National Technical Information Service, August 1983).

42. U.S. Congress, Office of Technology Assessment, Facing America's Trash: What Next for Municipal Solid Waste?, OTA-O-424 (Washington, DC: U.S. Government Printing Office, October 1989).

43. U.S. Congress, Office of Technology Assessment, Making Things Better: Competing in Manufacturing, OTA-ITE-443 (Washington, DC: U.S. Government Printing Office, March 1990).

43a. U.S. Congress, Office of Technology Assessment, The U.S. Textile and Apparel Industry: A Revolution in Progress, OTA-TET-332 (Washington, DC: U.S. Government Printing Office, April 1987). 
44. U.S. Congress, Office of Technology Assessment, Energy Use and the U.S. Economy, OTA-BP-E-57 (Washington, DC: U.S. Government Printing Office, June 1990).

45. U.S. Department of Commerce, Bureau of the Census, Census of Manufactures: Fuels and Electric Energy Consumed (Washington, DC: 1972, 1977, 1981, 1982).

46. U.S. Department of Commerce, Bureau of Economic Analysis, Survey of Current Business 69(9) :s1-s2, 1988.

47. U.S. Department of Commerce, Bureau of Census, Statistical Abstract of the United States, 1989 (Washington, DC: 1989).

48. U.S. Department of Energy, Office of Policy Planning and Analysis, Energy Use Trends in the United States 1972-1984 (Washington, DC: May 1985).

49. U.S. Department of Energy, Energy Information Administration Manufacturing Energy Consumption Survey: Consumption of Energy, 1985, DOE/EIA-0512(85) (Washington DC: 1985).

50. U.S. Department of Energy, Energy Information Administration Monthly Energy Review (Washington DC: January 1987).

51. U.S. Department of Energy, Energy Information Administration Annual Review of Energy, 1987, 1988, DOE/EIA-0384(87) (Washington, DC: May 1988).

51a. U.S. Department of Energy, Energy Information Administration Annual Review of Energy, 1989, DOE/EIA-0384(89) (Washington, DC: May 1989).
52. U.S. Department of Energy, Energy Information Administration Monthly Energy Review (Washington, DC: June 1988).

53. U.S. Department of Energy, Energy Conservation Multi-Year Plan: 1990-1994 (Washington, DC: August 1988).

54. U.S. Department of Energy, Office of Policy Planning and Analysis, Energy's Role in International Trade: Structural Change and Competitiveness (Washington, DC: July 1989).

55. U.S. Department of Energy, Energy Information Administration Manufacturing Energy Consumption Survey: Changes in Energy Efficiency 1980-1985, DOE/EIA-0516(85) (Washington DC: January 1990).

56. U.S. Department of Energy, Energy Information Administration Annual Review of Energy, 1990, DOE/ELA-0384(89) (Washington DC: May 1990).

57. U.S. Department of the Interior, Minerals Yearbook 1985 (Washington, DC: U.S. Government Printing Office, 1986).

58. U.S. Federal Reserve Bank, Federal Reserve Bulletin (Washington, DC: Board of Governors of the Federal Reserve System, November 1989).

59. walker, w., ' 'Information Technology and The Use of Energy, ' Energy Supply, pp. 460461, October 1985.

60. Young, E., American Iron and Steel Institute, remarks at OTA Energy Use in Industry Workshop, Washington, DC, May 11, 1989. 


\section{Chapter 7}

\section{The Forestry Sector}

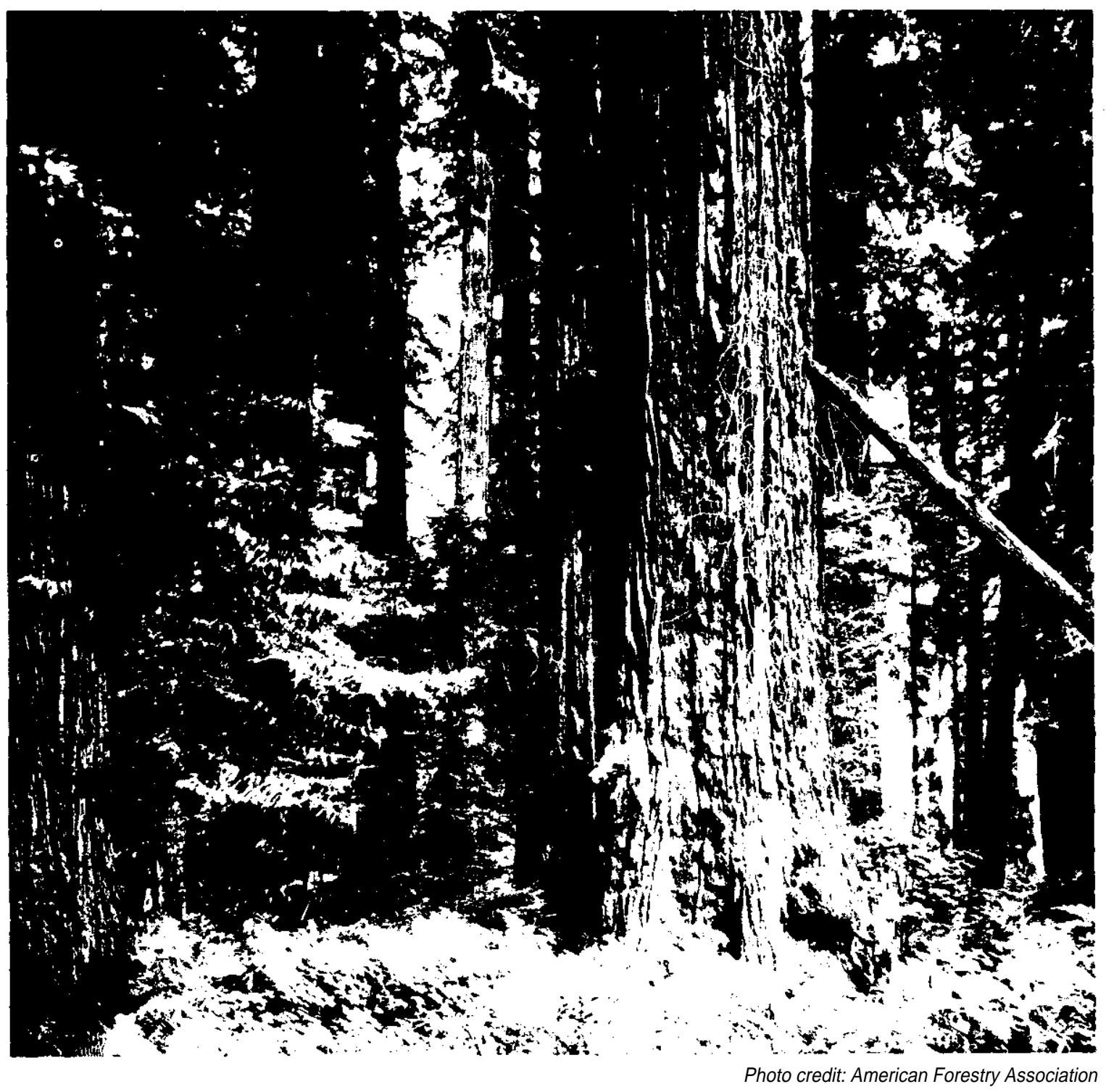




\section{CONTENTS}

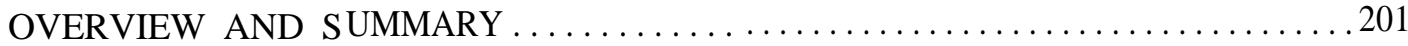

SETTING THE STAGE: FOREST AREA AND EMISSIONS $\ldots \ldots \ldots \ldots \ldots \ldots \ldots \ldots 203$

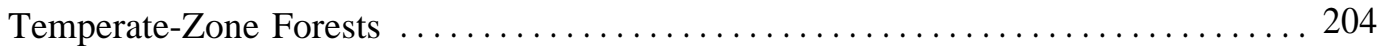

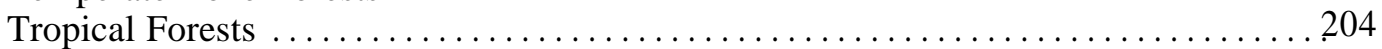

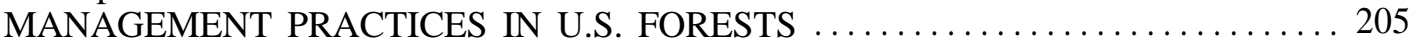

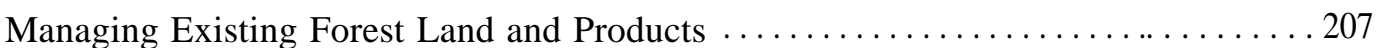

New Forests and Trees .......................................... 211

MANAGEMENT PRACTICES IN TROPICAL FORESTS $\ldots \ldots \ldots \ldots \ldots \ldots \ldots \ldots . \ldots 216$

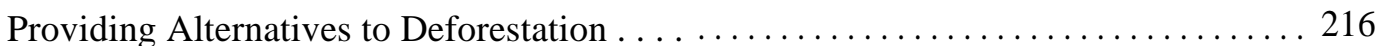

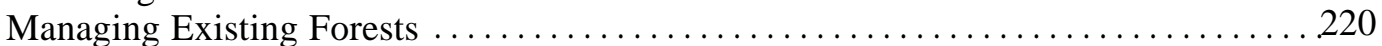

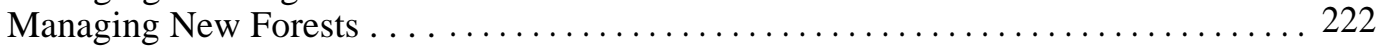

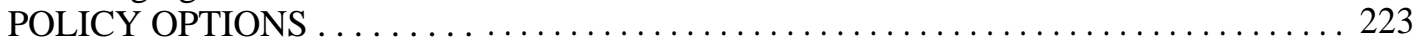

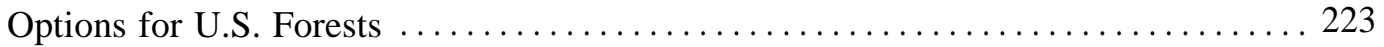

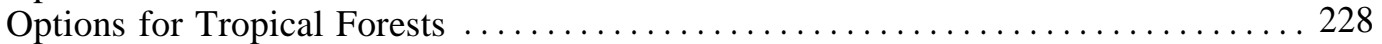

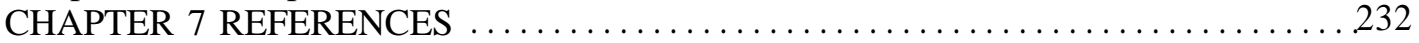

\section{Boxes}

Box Page

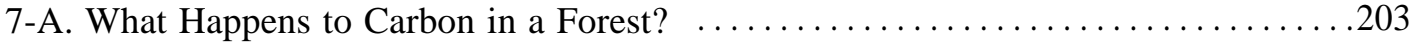

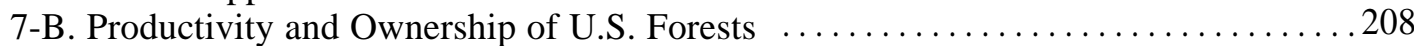

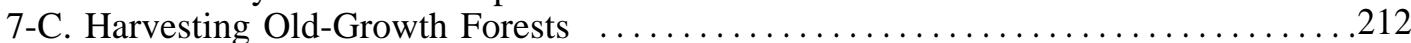

7-D. Forests and Future Global Climate Change ....................... 224

7-E. USDA: Forest Service and Agricultural Stabilization and Conservation Service . . 225

7-F. Multilateral and Bilateral Institutions and Programs .................... 229

Figure

Figures

7-1. Estimates of Relative Carbon Emissions From Fossil Fuel Use and Tropical

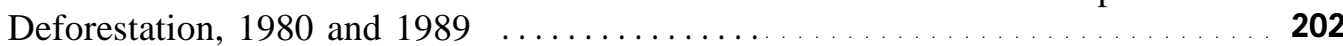

7-2. Potential for Forestry Practices To Offset U.S. Carbon Emissions, Relative to 1987 Emissions Levels ....,...****.*...***,.,.,**..,.,,,...,.*.. 202

7-3. Commercial Status of All U.S. Forests and Distribution of Timberland

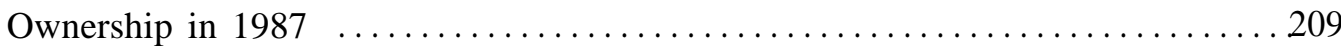

7-4. Reforestation of U.S. Timberlands by Ownership Category, Fiscal Year 1989 . . 210

7-5. Funding Levels for the U.S. Forest Service's State and Private

Forestry Programs, 1988-91 226

\section{Tables}

Table

7-1. U.S. Forest Management: Potential Carbon Storage/Savings and Percent Offset of 1987 Carbon Emissions From U.S. Fossil Fuel Use, for 2000 and 2015 . . . . . . 206

7-2. Tropical Forest Management: Potential Percent Offset of Estimated 1989 Carbon Emissions From Deforestation, for 2000 and 2015

7-3. FAO Estimates of Plantations Established by End of 1980 and During 1981-85 in 111 Developing Countries and Territories, by Region 


\section{OVERVIEW AND SUMMARY}

Humans have long altered forests and, in the process, affected the flow of greenhouse gasesparticularly carbon dioxide $\left(\mathrm{CO}_{2}\right)$--between forest lands and the atmosphere. In recent decades, the net flow to the atmosphere appears to have accelerated. Opportunities exist to moderate this trend through practices such as increasing forest productivity and tree planting in the United States, and agroforestry, better timber harvest management, use of nontimber forest products, and reforestation in the tropics. Most of these also will provide other benefits such as protection of watersheds, riparian habitats, and biodiversity; provision of food; reduced soil erosion; and stability in nutrient and hydrologic cycles.

Most current forest-related emissions come from tropical forests. These forests, located almost exclusively in developing countries, are being deforested and degraded on a widespread, unprecedented scale. Estimates indicate that tropical deforestation accounts for 7 to as much as 31 percent of worldwide $\mathrm{CO}_{2}$ emissions from all sources (see figure 7-1). Temperate-zone deforestation, mostly in industrialized countries, contributes comparatively little $\mathrm{CO}_{2}$ emissions; however, temperate-zone forests underwent massive alterations in the past. ${ }^{2}$

Since industrialized countries contribute the vast majority of global $\mathrm{CO}_{2}$ emissions through their use of fossil fuels (see figure 7-1), halting tropical deforestation will not stop the accumulation of greenhouse gases in the atmosphere. Nor is reforestation feasible on a large enough scale to totally offset $\mathrm{CO}_{2}$ emissions from fossil fuel use. ${ }^{3}$ To reduce greenhouse gas emissions, industrialized countries must first reduce fossil fuel use in their building, energy, manufacturing, and transportation sectors (see chs. 3 through 6).
At the same time, temperate-zone forestry management practices might offset---+ver the short term-some emissions from industrialized countries. Although difficult, this can be achieved by:

- increasing carbon storage in existing forests;

- growing tree crops on unforested land for use as fuel; and

- planting and maintaining trees in urban areas and marginal crop and pasturelands.

OTA estimates that forestry-related practices in the United States might be able to offset about 2 percent of U.S. 1987 carbon emissions from fossil fuel combustion in the year 2000 and 7.5 percent in 2015 (see figure 7-2), at an annualized cost in 2015 of $\$ 10$ to $\$ 13$ billion per year (see app. A for cost estimates). Congress could promote such practices by enhancing or augmenting existing forest management and tree planting programs of the U.S. Forest Service and the Agricultural Stabilization and Conservation Service, and by enhancing the biomass energy research program of the Department of Energy. Congress also could consider using financial incentives (e.g., tax policies to make investments in forest management more attractive; tax on fossil fuels to make biomass fuels more competitive).

There are several caveats to this potential for offsetting emissions. Trees planted today can continue to store carbon beyond this report's 25-year timeframe. But this carbon eventually will be released to the atmosphere, either when trees die and decompose naturally, when they are harvested and burned, or when products made from wood eventually decompose. But unless the wood is used to displace fossil fuel or is permanently stored under conditions that will not allow decomposition, the carbon offsets in later years will dwindle. In addition, current estimates of forestry-related offsets assume that increasing the carbon storage rate in a

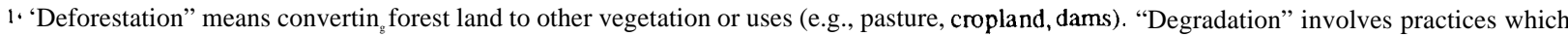
leave trees as the predominant vegetation but which degrade overall forest quality (e.g., soil erosion, damages to trees and streams from selective logging).

\footnotetext{
${ }^{2}$ In this report, the term 'temperate-zone forests' refers to temperate and boreal coniferous forests and temperate deciduous forests.

${ }^{3}$ For example, estimates of how much tree planting would be needed to offset global $\mathrm{CO}_{2}$ emissions range from 500 to almost ${ }^{1}$ billion hectares of new plantations exhibiting moderately high growth rates $(1.55,239,240)$. The lower end of this range represents over 1.5 times the total area of U.S. forest and more than 15 percent of the world's total closed forest area,
} 
Figure 7-1 -Estimates of Relative Carbon Emissions From Fossil Fuel Use arid Tropical Deforestation, 1980 and 1989

Carbon emissions (billion metric tons)

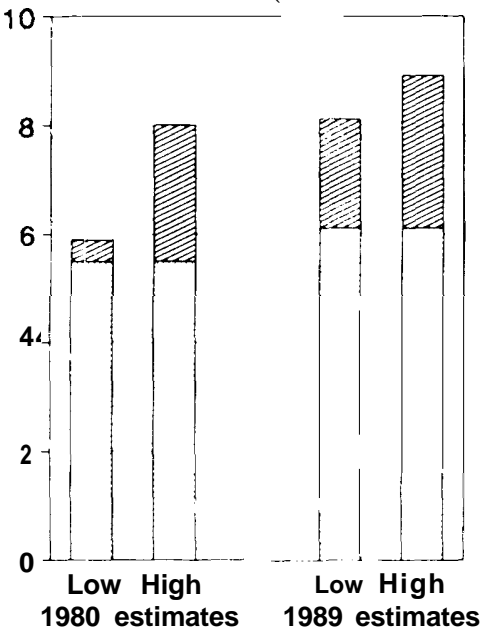

"Low" and "High" represent the range of estimates for carbon emissions during that year.

SOURCES: 1980 deforestation estimates from R.K. Detwiler and C.A.S. Hall, "Tropical Forests and the Global Carbon Cycle," Science 239:42-47, Jan 1, 1988; and from R.A. Houghton et al., "The Flux of Carbon From Terrestrial Ecosystems to the Atmosphere in 1980 Due to Changes in Land Use: Geographic Distribution of the Global Flux," Tellus 39B:122-139, 1987. 1989 deforestation esthetes from R.A. Houghton, "Emissions of Greenhouse Gases," Part 4 (pp. 53-62) in N. Myers, Deforestation Rates in Tropical Forests and Their Climatic Implications (London: Friends of the Earth Ltd., 1989); and from N. Myers, Deforestation Rates in Tropical Forests and The/r Climatic Implications (London: Friends of the Earth Ltd., 1989). 1980 and 1989 fossil fuel use from U.S. Department of Energy, International Energy Annual, DOEEEIA-0219(88) (Washington, DC: Energy Information Administration, November 1989) (using estimated 1988 emissions, the latest year for which estimates are available, as a surrogate for 1989 emissions).

forest's commercial timber component will also increase the total storage rate in the entire forest ecosystem. Finally, forests-and the feasibility of using forestry practices to offset emissions-are likely to be affected by future climate changes. Therefore, forestry options in industrialized countries cannot be considered a substitute for reducing total energy use or developing non-fossil fuel alternatives, but rather as a way of "buying" time while developing alternative sources and improving the efficiency of their energy use in general.

To reduce their current $\mathrm{CO}_{2}$ emissions, developing countries need to stop tropical deforestation and degradation, which occur as forests are converted to temporary agriculture ('shifting" cultivation) and permanent agriculture (including cattle ranching) and as a result of poor timber harvesting practices.
Figure 7-2-Potential for Forestry Practices To Offset U.S. Carbon Emissions, Relative to 1987 Emissions Levels

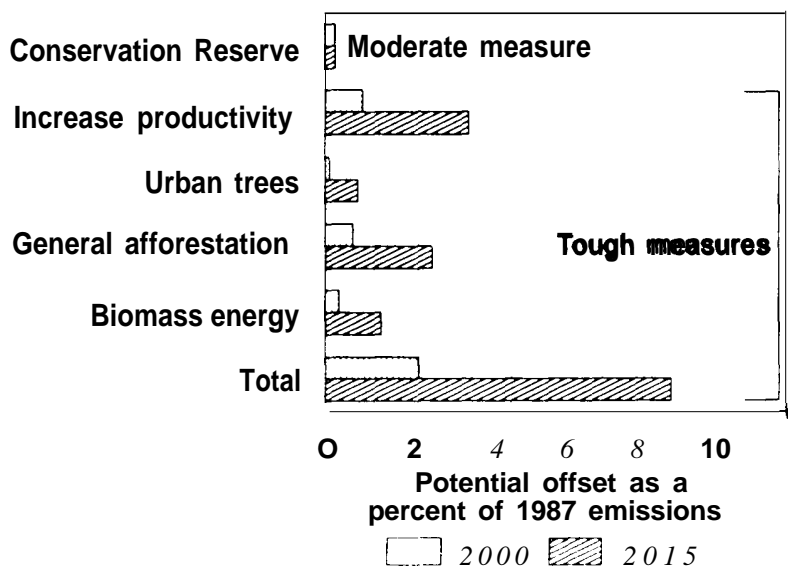

For comparison with the energy model (see app A), OTA considers the Conservation Reserve Program to be a "moderate" measure, primarily because it is already being implemented. The other forestry measures are considered "tough" measures because they will require greater efforts and investments to be fully achieved. These estimates all depend on assumptions discussed in the text.

SOURCE: Office of Technology Assessment (from table 7-1).

However, these activities are driven by underlying social, economic, and political factors-poverty and lack of land tenure for most people, national development policies, and foreign debts-that are exacerbated by rapid population growth (337). Emissions from fossil fuel use are relatively less important now but are likely to increase significantly as these countries develop (ch. 9).

The primary needs in developing countries, then, are to remove incentives for deforestation; provide for population planning, land reform, and debt reduction; and provide alternative livelihoods for millions of shifting cultivators and thousands of rural communities. The suitability of alternatives such as agroforestry and "sustainable' agriculture, improved forest management, increased use of nontimber forest products, and reforestation depends on site-specific conditions and, in most cases, giving local people a vested interest in seeing them implemented.

The United States can ensure that its foreign aid assistance programs (primarily of the U.S. Agency for International Development), and those of multilateral lending and international assistance organizations (e.g., World Bank, U.N. Food and Agriculture Organization), address developing country social 


\section{Box 7-A-What Happens to Carbon in a Forest?}

During the day, plants take carbon dioxide $\left(\mathrm{CO}_{2}\right)$ from the atmosphere and convert it into organic compounds such as carbohydrates by using solar energy and water (i.e., photosynthesis). Plants emit $\mathrm{CO}_{2}$ during respiration, when they use the energy stored in these compounds. The balance favors the net accumulation of carbon in trees, shrubs, herbs, and roots. Much of the carbon in forests, however, is "hidden' '-almost 60 percent on average in U.S. forests is stored below ground in organic matter (including roots) and organisms in the soil $(18,19)$.

The rate of carbon storage in an ecosystem is known as "net growth' or "net productivity. "Young, vigorous forest stands tend to exhibit the greatest net growth rates. The total carbon stored at any time is greatest in older, mature forests, even though they have a net growth rate near or sometimes less than zero $(156,288)$.

Unmanaged forests normally change over time as individual trees die and as new species move in during succession (178). When trees die and decompose, they emit $\mathrm{CO}_{2}$ (although generally over a longer period and at a slower rate than if harvested). The rate at which changes occur is determined by factors such as competition with other plants for light, nutrients, and water, as well as by pest outbreaks and fire.

When forests are cut, the effect on atmospheric $\mathrm{CO}_{2}$ depends on how much carbon was stored (i.e., total biomass), what happens to the cut wood, and how the lands are managed. If the time scale is long enough and the land is used for a series of harvests, then the flux of carbon can be cyclic.

When cut wood is left on a site, microorganisms (e.g., fungi, bacteria) "decompose" it, along with leaf and branch litter. Through their metabolic activities, microorganisms convert carbon in the wood into $\mathrm{CO}_{2}$ and other compounds such as methane that are emitted to the atmosphere. Decomposition rates depend on factors such as oxygen availability, temperature, and moisture.

If wood is burned, $\mathrm{CO}_{2}$, methane, nitrous oxide, particulate matter, and other chemicals are emitted. In some cases, though, using wood as a fuel can replace the use of fossil fuels; over one-half of the wood removed from U.S. forests in the early 1980s was burned for energy, either by the forest products industry or in households (274). The net effect on $\mathrm{CO}_{2}$ depends on combustion efficiency, whether fossil fuel use is actually replaced, and the rate of carbon storage in vegetation that replaces the harvested wood.

When wood is converted into products, some carbon is stored until the products begin to decompose. Relatively durable products such as construction lumber can retain carbon for decades or centuries; about one-fourth of U.S. stemwood harvested during the last 35 years has been converted to such products (241). Relatively short-lived products such as paper may decompose and release $\mathrm{CO}_{2}$ or methane after being discarded, depending on conditions at the discard site; recent research, though, indicates that decomposition of organic materials in landfills proceeds slowly $(209,281,327)$.

After harvesting, $\mathrm{CO}_{2}$ is again taken in by new vegetation growing on the site, assuming the land is not converted to a highway, reservoir, or other nonvegetative state. The net effect in offsetting $\mathrm{CO}_{2}$ emissions from the harvesting depends on the type of vegetation (e.g., crops, pasture, or trees), the rate at which it stores carbon, the rate at which carbon reaccumulates in the soil, availability of nutrients, and how long the vegetation grows before being harvested again.

and economic needs and promote alternative landuse practices. The United States also could work to make the Tropical Forestry Action Plan and the international Tropical Timber Organization more effective vehicles for promoting forest conservation and improved commercial forest management. In addition, the United States could support a global forestry conservation protocol, as recommended by the intergovernmental Panel on Climate Change (1 14, 1 14a).

\section{SETTING THE STAGE: FOREST AREA AND EMISSIONS}

Carbon is stored in forests as they grow and is released when vegetation is removed or disturbed (see box 7-A). The net global flux of carbon from forests to the atmosphere has not been measured directly, but it has been estimated using data on changes in forest cover and on the amount of carbon held in vegetation and soils (105). ${ }^{4}$

4 Other gases besides $\mathrm{CO}_{2}$ are emitted when forests are cleared or burned. Fires, for example, release methane, carbon monoxide, nitric and nitrous oxide, methyl chloride, and other compounds, as well as particulate matter (7, 8, 44a, 48, 124, 126, 137, 145, 206.219). 


\section{Temperate-Zone Forests}

Temperate-zone forests (i.e., boreal and temperate conifer forests, and temperate deciduous forests) cover about 2.2 billion hectares, or 8.5 million square miles (338). They are the source of most wood and paper products used by industrialized nations. About 42 percent are in the U. S. S. R., 20 percent in Canada, and 14 percent in the United States.

\section{Changes in Forest Cover}

Current changes in temperate-zone forest cover are small. Large-scale deforestation occurred mostly in the past (e.g., 50 to 200 years ago in North America and up to 5,000 years ago in the Far East). During this century, forest cover has increased in many areas of North America and Europe $(9,288)$ through natural regeneration and planting of trees in areas that have lacked forests for centuries, although it has decreased recently in the United States.

Nevertheless, changes do occur. For example, wooded areas near many U.S. cities are undergoing rapid conversion for real estate development, which often exacerbates runoff into nearby freshwater and marine habitats (277). The U.S. Forest Service (299) estimated that U.S. forest land declined by almost 6.6 percent (21 million hectares) from 1953 to 1987 and will decline another 2.2 percent $(7$ million hectares) by 2010 , mainly through conversion to reservoirs, urban developments, highways, airports, and surface mines. Losses in forest cover and composition also are possible from airborne pollutants $(80,178,276,280)$.

\section{Carbon Emissions}

The magnitude of carbon reservoirs and emissions in the Northern Hemisphere are Uncertain. ${ }^{\text {SP }}$ ublished estimates suggest that $\mathrm{CO}_{2}$ emissions from temperate-zone deforestation are relatively low, around 25 to 130 million metric tons per year; emissions are thought to be greatest from China and the U. S. S.R., less significant from the United States and Canada (103, 107, 161).

Extensive burning (from natural and human causes) of forests and other biomass occurs in temperate latitudes, but the magnitude of associated emissions is Uncertain. ${ }^{6}$ While the amount burned in both the United States and Canada generally declined from the 1920s through the 1970s, this trend reversed during the $1980 \mathrm{~s}$ and increased to a post-war high. ${ }^{7}$ Large fires also affected other temperate areas, including over 1 million hectares of boreal forest in China and over 4 million hectares in the U.S.S.R. in 1987 (34, 81, 138, 229, 256). Fires also affect albedo (the Earth's reflectivity) and thus can have feedback effects on local climate. Crutzen and Andreae (44a) estimated that biomass burning in the temperate and boreal zone releases 150 to 300 million metric tons $\mathrm{C}$ yearly.

\section{Tropical Forests}

\section{Changes in Forest Cover}

Tropical forests cover about 2.1 billion hectares. ${ }^{8}$ Almost all are located in developing countries, where they make up two-thirds of woody vegetation. ${ }^{9}$ They are home to some of the last huntergatherer tribes, harbor at least half of the world's organisms, and are the source of many products (e.g., wood, medicines, fibers, fruits, nuts) (275).

\footnotetext{
${ }^{5}$ For example, one analysis $(23,24)$ concluded that previous estimates of carbon content in borealforests are too high. Another (257), though, suggests that the Northern Hemisphere may be a larger terrestrial carbon sink than previously thought; whether this would involve boreal forests or other ecosystems such as tundra is unknown.

6Other catastrophic incidents also affect forests. In 1989, for example, Hurricane Hugo darnaged at least 1 million hectares of forest in North and south Carolina $(33,199)$.

${ }^{7}$ In the United States, over 1 million hectares burned yearl from 1985 to 1989, including over 2 million hectares in 1988 (205). However, fires consumed over 10 million hectares annually during 16 years from 1926 to 1943 (287, 297). In Canada, over 24 million hectares burned during the 1980 s, including over 6 million in 1989, more than repotted in any other decade $(55,56,189,313)$. These estimates, however, also include some fires on nonforest lands (e.g., grasslands, marshlands).

${ }^{8}$ They occur in many forms, under moisture conditions that range from wet (Amazonian "rain' forest) to seasonally moist (Asian monsoon forest) to dry (Sahelian open savanna).

9The United States has jurisdiction over about 0.5 percent of tropical forests, mostly in Puerto Rico, the Virgin Islands, Hawaii, American Samoa, and Micronesia $(275,278)$. Other developed countries, such as France, also have small areas of tropical forest under their jurisdiction.
} 


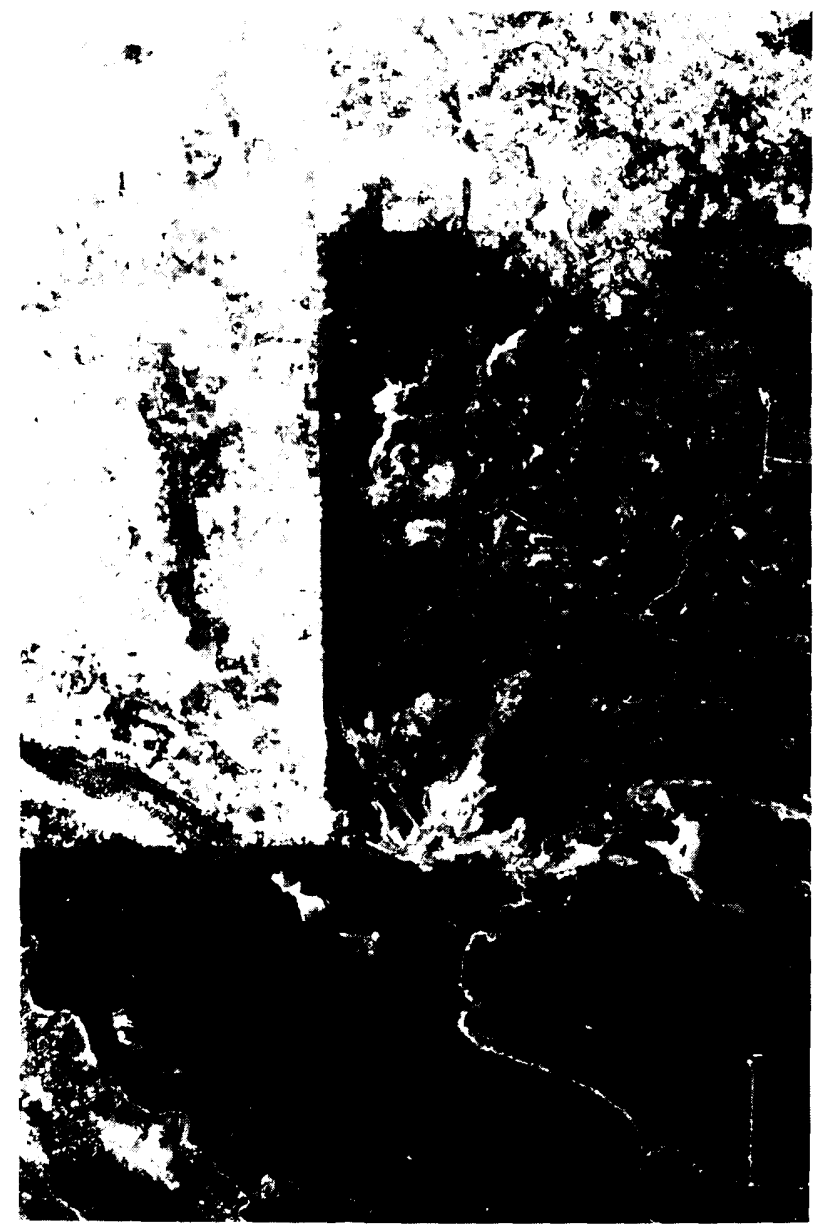

Photo credit NASA/Courtesy Earth Resources Laboratory, John C. Stennis Space Center, Mississippi

This Landsat image shows an area in southern Mexico where a large rural population has converted most tropical forest there into agricultural fields. In the adjacent area in Guatemala, the rural population is sparse and the forest is still mostly intact.

Deforestation of tropical forests (including fa.1$10 \mathrm{~W}$ ) is occurring at an unprecedented rate..$^{10}$ Aside from carbon emissions, other effects of deforestation and degradation-soil erosion, increased downstream flooding, desertification, decreased biodiversity, and effects on local microclimates-are enormous.
The overall rate of deforestation appears to have increased in the last decade. As of 1980, the Food and Agriculture Organization (FAO) estimated that 11.3 million hectares of closed and open forests were being cleared annually (70). " For 1989, however, a preliminary report from FAO's 1990 Forest Resources Assessment estimates that deforestation rates have increased by over 50 percent, to around 17.1 million hectares (or 1.2 percent of tropical forests) per year $(76,77,264) .^{12}$

\section{Carbon Emissions}

The level of carbon emissions from tropical deforestation is uncertain. Estimates for 1980 range from 0.4 to 2.5 billion metric tons $\mathrm{C}$ per year $(50,51$, $103,105,106,107,108)$. Since these estimates do not include degradation of forests, and deforestation rates appear to be greater now, current emissions might be higher, Indeed, Houghton (104, 105) estimated that emissions in 1989 were between 2.0 and 2.8 billion metric tons, roughly 25 to 31 percent of all carbon emissions (see figure 7-1).13

\section{MANAGEMENT PRACTICES IN U.S. FORESTS}

Forestry-related management practices can store carbon and/or offset some $\mathrm{CO}_{2}$ emissions in temperatezone areas. For the United States, OTA estimates that by 2015 a combination of practices might offset approximately 7.5 percent of current (i.e., 1987) U.S. $\mathrm{CO}_{2}$ emissions from fossil fuel use (see table 7-1). Some observers contend that higher rates are possible for individual practices (e.g., 230, 343). Regardless, the practices also could provide other benefits, many of which are goals of existing U.S. legislation-e. g., reduced soil erosion, improved water quality, and increased biodiversity, aesthetic qualities, and recreational opportunities.

\footnotetext{
10The term "fallow' or "secondary" refers to forests cleared for agriculture but now in the process of regenerating

${ }^{11}$ While this estimate has been debated or modified by others $(25,27,50,51,70,75,107,108,155,162,172,174,288)$, it is based on the largest and most systematic database available. No estimates exist regarding overall rates of forest degradation, but it is important in many areas, for example in South and Southeast Asia (26).

${ }^{12}$ The annual rate of deforestation as of 1989 was an estimated 1.7 percent in Africa, 1.4 percent in Asia, and 0.9 percent in Latin America (where over 60 percent of global deforestation was occurring). Myers (174) estimated that deforestation in 1989 was 90 percent higher than a decade earlier, although this has not been confirmed (114).

${ }^{13}$ These estimates do not necessarily account for the fact that disturbed or degraded soils and vegetation can still slowly sequester carbon over time $(28,15 \mathrm{G})$, nor that deforested lands also typically support vegetation (e.g., grassland, annual crops).
} 
Table 7-1-U.S. Forest Management: Potential Carbon Storage/Savings and Percent Offset of 1987 Carbon Emissions From U.S. Fossil Fuel Use, for 2000 and 2015

\begin{tabular}{|c|c|c|c|c|c|c|}
\hline Management practice & Assumptions ${ }^{a}$ & $\begin{array}{l}\text { Million } \\
\text { metric tons C } \\
\text { in } 2000^{\mathrm{b}}\end{array}$ & $\begin{array}{l}\text { Percent of } 1987 \\
\text { carbon offset } \\
\text { in } 2000^{c}\end{array}$ & $\begin{array}{l}\text { Million } \\
\text { metric tons C } \\
\text { in 2015b }\end{array}$ & $\begin{array}{l}\text { Percent of } 1987 \\
\text { carbon offset } \\
\text { in } 2015 \mathrm{C}\end{array}$ & $\begin{array}{l}\text { Examples of } \\
\text { other benefits }\end{array}$ \\
\hline Moderate measures? & & & & & & \\
\hline $\begin{array}{l}\text { Conservation Reserve } \\
\text { Program (CRP) }\end{array}$ & $\begin{array}{l}\text { Total enrollment } 2.3 \text { million ha } 1995, \\
\text { growth rate of } 1 \text { metric ton } \mathrm{C} / \mathrm{ha}\end{array}$ & 2.3 & $0.2 \%$ & 2.3 & $0.2 \%$ & $\begin{array}{l}\text { Soil and watershed } \\
\text { protection }\end{array}$ \\
\hline $\begin{array}{l}\text { Tough measures! } \\
\text { Increase productivity }\end{array}$ & $\begin{array}{l}\text { Programs begin } 1995 \text {. Nonindustry: } \\
37 \text { million ha, additional storage } \\
0.5 \text { metric tons C/ha/yr. Timber } \\
\text { industry: } 20 \text { million ha, storage } \\
\text { increment } 1 \text { metric ton C/ha/yr. }\end{array}$ & 10 & $0.80 / 0$ & 40 & $3.10 / 0$ & Increased timber revenues \\
\hline $\begin{array}{l}\text { General afforestation } \\
\text { (excluding CRP) }\end{array}$ & $\begin{array}{l}\text { Programs begin } 1995 \text {. Total } 30 \text { million ha, } \\
\text { storage increment } 1 \text { metric ton } \\
\text { C/ha/yr }\end{array}$ & 7.5 & $0.6 \%$ & 30 & $2.30 / 0$ & $\begin{array}{l}\text { Biodiversity, soil, and } \\
\text { watershed protection }\end{array}$ \\
\hline Biomass energy crops & $\begin{array}{l}\text { Program begins } 1995.0 .5 \text { million ha } \\
\text { planted/year, storage increment } \\
3 \text { metric tons } \mathrm{C} / \mathrm{ha} / \mathrm{yr}\end{array}$ & 4 & $0.3 \%$ & 15 & $1.2 \%$ & $\begin{array}{l}\text { Less dependence on other } \\
\text { energy sources }\end{array}$ \\
\hline Urban trees & $\begin{array}{l}\text { Program begins } 1995.100 \text { million trees/ } \\
\text { yr, no savings from shading until } 2005\end{array}$ & 1 & $0.1 \%$ & 9 & $0.7 \%$ & $\begin{array}{l}\text { Less heat island effect, } \\
\text { aesthetics }\end{array}$ \\
\hline Total & & & $2.0 \%$ & & $7.5 \%$ & \\
\hline
\end{tabular}

aSee text for greater detail; in general, assumptions do not directly reflect oconomic feasibility.

or other management occurs in year 1 , but some does not occur untilyear 25.

cPercent of estimated 1.3 billion metric tons $C$ from fossil fuel use. Individual percentage offsets not additive.
dFor comparison with the energy model (se日 app. A), OTA considers the Conservation ReserveProgram to be a "moderate" measure, primarily because it is already being implemented. The other, "tough" measures will require greater efforts and investments to be fully achieved.

SOURCE: Office of Technology Assessment, 1991. 


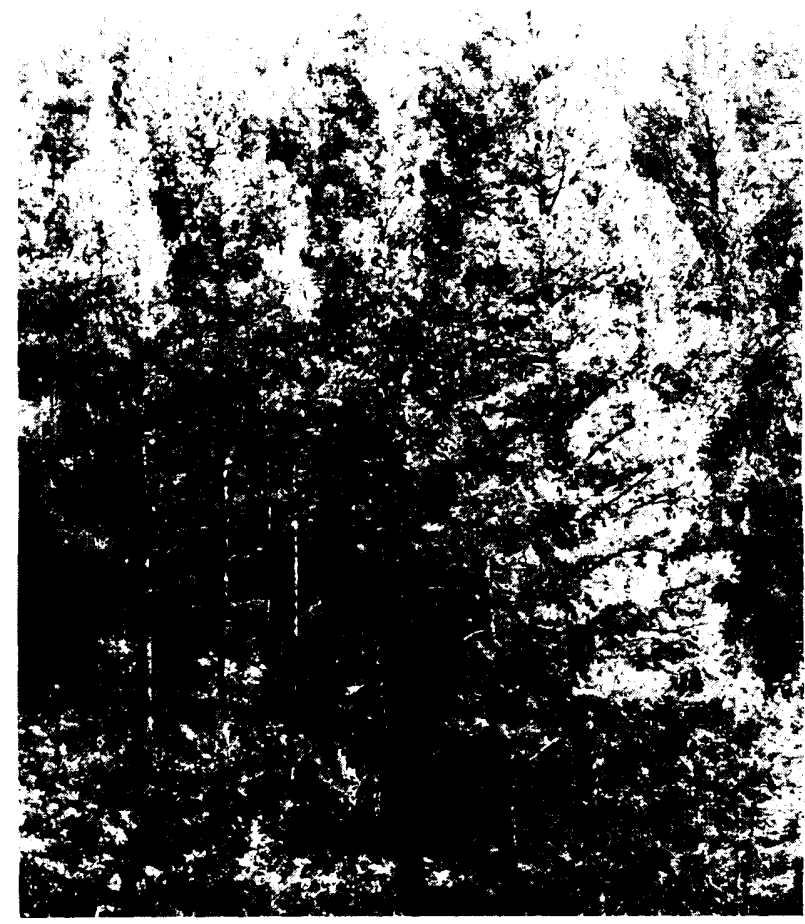

Photo credit: Forest Service/USDA photo

Douglas-fir is the most abundant and important commercial timber tree in the West. It is found in the Rocky Mountains (as shown here on a steep slope in Colorado), Pacific Northwest, and Pacific Southwest. Douglas-fir forests on the Pacific slope in the Northwest are among the most productive softwood forests in the United States.

\section{Managing Existing Forest Land and Products}

\section{Increasing Productivity}

In principle, forests can be managed to increase the rate at which they store carbon (i.e., increase productivity). Most people are concerned with increasing the productivity of the "industrial' portion (i.e., excluding branches, leaves, litter, etc.) of commercially available timber, because investments in such management offer a chance for increased economic returns (as opposed to trying to increase productivity in wilderness areas and parks). Whether increasing the rate of carbon storage in commercial timber means that the rate of total carbon storage in the entire forest ecosystem also increases, however, is a critical, generally un- tested, assumption. The discussion here assumes that total carbon storage also increases, but this requires testing.

"Conventional' management often is used to enhance productivity of commercial species. For example, "thinning' involves removing some young trees or temporarily suppressing other vegetation to lessen competition (for water, light, and nutrients) and to adjust the number of trees per hectare. 'Stocking' refers to obtaining the desired number of trees, by thinning or additional planting, Growth rates for the commercial portion of existing U.S. forests are estimated to be 60 percent on average of their fully stocked potential (155).

More "intensive management might increase growth rates for the commercial portion beyond this potential, at least for short periods $(60,156,239$, 274). This includes site preparation (e.g., minor drainage, fertilization), genetic selection of superior strains, improved nursery practices, and protection from fire, insects, and disease. In one study, drainage, fertilization, and genetic selection resulted in two- to four-fold increases in Douglas fir and loblolly pine growth rates (60). Similar results have been obtained with sycamore, eucalyptus, and other pines $(156,177)$.

Intensive management is generally more suitable for newly planted forests than for existing forests. Its long-term feasibility is uncertain, however, partly because research on this practice only began intensifying in the late 1970s. High growth rates have been attained only for young individuals of selected species and have not yet been sustained over extended periods (155); again, whether total productivity of affected areas increases is unclear. Increased use of fertilizers and herbicides could have other environmental effects (e.g., $\mathrm{N}_{2} \mathrm{O}$ emissions and groundwater contamination from fertilizer application, $\mathrm{CO}_{2}$ emissions from fertilizer manufacturing), and preferences for monoculture would reduce biological diversity. ${ }^{14}$ Research is needed on how repeated harvesting of intensively managed forests would affect soil structure and erosion, wood y debris, nutrient availability, and below-ground carbon storage (over one-half on average of the carbon

\footnotetext{
${ }^{14} \mathrm{One}$ study in red pine and oak/maple forests in Massachusetts concluded that fertilization also reduced methane consumption by soil microorganisms by about one-third compared to control plots (255) (bacteria in forest soils produce and consume methane; methane-producing bacteria live in deeper and wetter portions of soil where oxygen is absent, while methane-eonsuming bacteria live in surface layers of soil where oxygen is present). How this might affect atmospheric concentrations of methane is unknown, The potential significance of this effect deserves more research.
} 


\section{Box 7-B-Productivity and Ownership of U.S. Forests}

U.S. forests cover about 295 million hectares, or 32 percent of total land area, roughly one-quarter less than in colonial times $(155,299)$. Overall forest area declined by about 6.6 percent (or 21 million hectares) between 1953 and 1987. However, commercial timber volume has increased, at least during the last two decades. From 1970 to 1987, overall area declined by 3.5 percent but commercial volume increased by an estimated 4 percent $(299,300)$. Forest area is expected to decline by an additional 2.2 percent from 1987 to 2010 (about 0.3 million hectares per year), due to construction of reservoirs, highways, and airports; urban development; surface mining; and other activities (300).

Timberland Ownership--Two-thirds of all U.S. forests are considered timberland--i.e., producing or capable of producing industrial wood (which does not include roots, bark, branches, and leaves) at a rate of 20 cubic feet or more per acre (or 1.4 cubic meters per hectare) per year (300). Some timberland is in parks and wilderness areas and thus is protected from harvest (14 million hectares), but most is commercially available (1\% million hectares). Almost three-fourths of commercial timberland is in the East.

Of commercial timberland, governments own only 28 percent, including 18 percent in National Forests (see figure 7-3) and 5 percent in State forests; the Federal portion is mostly in the West. Most commercial timberland is owned by the timber industry, farmers, and other private entities. Over one-half of timber industry holdings are in the South. Nonindustry landowners number in the millions, and their holdings often are small; most farmer-owned timberland is east of the Mississippi River (300).

Timberland Productivity-Xn ecological terms, productivity is the rate at which solar energy is converted during photosynthesis into living biomass. For timberland productivity, the U.S. Forest Service uses a more restricted measure-the amount of industrial wood that can be grown per year in fully stocked natural stands (300). It estimates that the overall average for U.S. timberland is around 3.2 cubic meters of woody biomass per hectare per year.

About one-third of U.S. timberland (i.e., less than one-fourth of all U.S. forests) exhibits average productivity rates of over 5.6 cubic meters per hectare per year. The timberlands with the very highest rates are primarily in the South and West: 1) pine, oak, hickory, and cypress in the Southeast and Mississippi River delta; 2) Douglas fir, hemlock-spruce, and red alder in the Northwest; and 3) redwood, spruce-fir, western hardwood, and ponderosa pine in California $(299,300)$. High productivity timberland also occurs in the oak-hickory, maple-beech-birch, and aspen-birch forests of the North.

Two-thirds of timberlands exhibit only moderate or low productivity, but their abundance makes them commercially important; national forests tend to be located in these areas. Other forests that are not considered timberland can be harvested, but generally not for industrial wood (300). Two areas account for almost three-fifths of this "nontimberland"- the spruce-fir forests of interior Alaska and the pinyon-juniper forests of the Rockies.

in U.S. forests is below ground) $(44,60,93,253$, 295).

Use of these techniques will vary with land ownership and forest size. Private nontimber industry owners, generally with smaller holdings, seem likely to use less intensive techniques, while timber industry landowners seem likely to use a combination of techniques. Together, implementing these practices on private lands might increase carbon storage by 10 million metric tons per year in 2000 (0.8 percent of U.S. $\mathrm{CO}_{2}$ emissions) and by 40 million metric tons per year in 2015 (3.1 percent of U.S. $\mathrm{CO}_{2}$ emissions) (see table 7-1), at an annualized cost in 2015 of around $\$ 150$ to $\$ 200$ per ton C (based on data in app. A). Intensive management on public lands seems-less likely because it would involve government expenditures at a time when budgets in general are being reduced, some expenditures on public lands are being criticized (e.g., roads for below-cost timber sales), and resources for maintenance are not always sufficient.

Nontimber Industry-About 112 million hectares (57 percent) of U.S. commercial timberland consists of relatively small parcels held by private nontimber-industry owners, including farmers (see box 7-B and figure 7-3). Full stocking on these lands might increase growth rates for commercially valuable wood by an average of about 0.5 metric ton $C$ per 
Figure 7-3--Commercial Status of All U.S. Forests (by hectares) and Distribution of Timberland Ownership in 1987
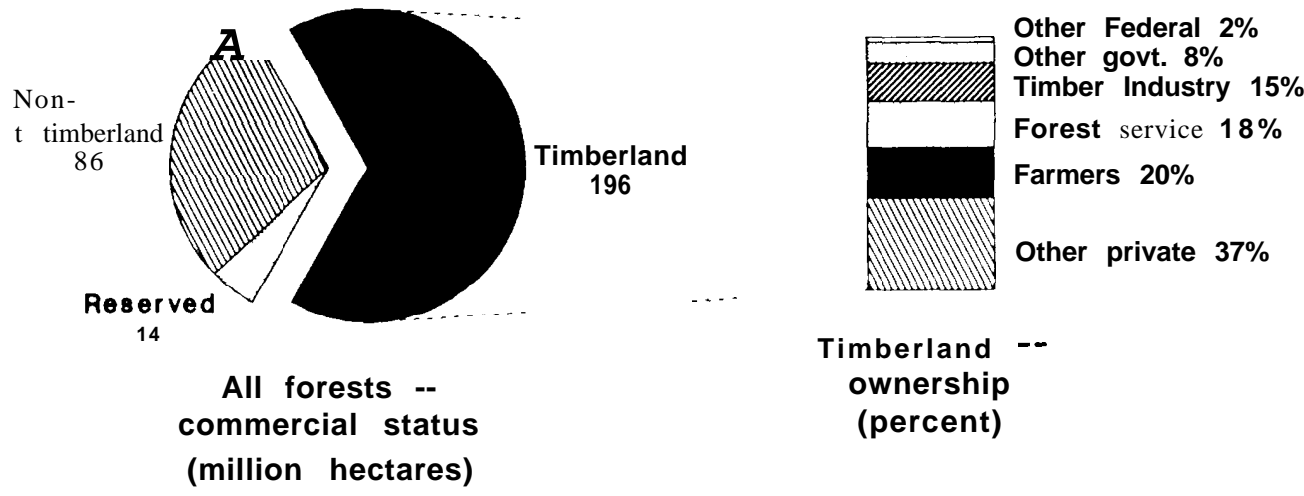

Two-thirds of all U.S. forests are considered timberland (i.e., forest producing or capable of producing "industrial" wood at a rate of 1.4 cubic meters or more per hectare per year). Most of this is commercially available for harvesting, but some is in parks and wilderness areas and is "reserved" from commercial harvest. Of commercially available timberland, the private sector owns 72 percent and the public sector owns 28 percent. ("Other govt." refers to Bureau of Land Management, Native American, and State and local government lands.) The remaining one-third of U.S. forests is considered nontimberland.

SOURCE: U.S. Forest Service, An Analysis of the Land Situation in the United States: 1989-2040, A Technical Document Supporting the 1989 RPA Assessment, General Technical Report RM-181 (Fort Collins, CO: U.S. Department of Agriculture, 1989); U.S. Forest Service,An Analysis of the Timber Situation in the United States: 1989-2040, Part/: The Current Resource and Use Situation, Draft (Washington, DC: U.S. Department of Agriculture, 1989).

hectare per year. 15 If a program encouraging the 'se of additional management techniques on one-third of nonindustry timberland (i.e., 37 million hectares) began in 1995 and was carried through 2015, then additional carbon storage could amount to about 4,6 million metric tons in 2000 and 20 million metric tons in $2015 .{ }^{16}$ However, this does not account for carbon emissions from the removed vegetation, some of which may be burned onsite or left to decompose.

Timber Industry-The timber industry owns 29 million hectares (15 percent) of commercial timberland (see figure 7-3). This land should be amenable to intensive management because it often is on more productive sites and because large holdings should provide economies of scale for such management. Intensive management on a large scale, though, will require that planting, site preparation, maintenance, and other practices be conducted on an unprecedented scale. Since some research indicates that large increases in timber growth rates are possible in some circumstances (see above), OTA assumes that the average productivity of affected systems might double, i.e., increase by $y_{7}$ an average of 1 metric ton $\mathrm{C}$ per hectare per year. If a program to encourage intensive management on two-thirds of industry timberlands (i.e., 20 million hectares) began in 1995 and was fully realized by 2015 , then additional carbon storage could amount to 5 million metric tons in 2000 and 20 million metric tons in $2015 .^{18}$

${ }^{15}$ Marland(155) estimated, based on 1977 data, that the average carbon storage rate for all U.S. timberland was 0.82 metric ton $C$ per hectare per year, and that the potential average rate for fully stocked forests was an additional 0.53 metric ton $\mathrm{C}$ per hectare per year. Average growth rates have not changed significantly since then, and the average growth rate in 1986 for nontimber industry private lands was essentially the same as the average rate for all U.S. timberland (300).

${ }^{16} \mathrm{~A}$ program of such magnitude seems reasonable, since about 2 percent of the volume of commercial timber on nonindustry lands is harvested annually (based on data in ref. 300).

${ }^{17}$ Higher growth rates occur under experimental conditions; e.g., the average total growth rate of genetically improved loblolly pine on one igh productivity site was 3 metric tom C/ha/yr over a 35-year period (based on data in refs. 18, 19). OTA assumes that average increases might be 1 metric ton $\mathrm{C} / \mathrm{ha} / \mathrm{yr}$ because of questions about maintaining high growth rates over long periods, and because the net effect depends on the extent of $\mathrm{CO}_{2}$ emissions from harvesting and the disposition of harvested wood (box 7-A).

${ }^{18} \mathrm{~A}$ program of such magnitude seems reasonable, since about 5 percent of the volume of commercial timber on timber industry lands is harvested annually (based on data in ref. 300). 
Bringing 1 million hectares yearly under intensive management would require dedicating all current replanting efforts to such management (since planting seedlings or young trees on prepared sites usually is required). Most forest regeneration in the United States occurs naturally, but about 1.22 million hectares were intentionally planted in fiscal year 1989, compared with 1.37 million hectares in fiscal year 1988 and 1.23 million hectares in fiscal year 1987 (301, 302, 303). ${ }^{19}$ In general, 80 percent of the planting has been in the South and 85 percent has been on private land (see figure 7-4).

"New Forestry" Practices-Planners also need to consider how forests might be affected by future climate changes, however uncertain these changes might be (see box 7-Din 'Policy Options' below). For example. monoculture may be more susceptible to damage from increased pest outbreaks than are natural forests with a mosaic of species and ages, although some pests require a mixture of age classes $(220,236,237,246,275)$. Some evidence suggests that harvesting practices that fragment Douglas fir forests into smaller parcels can increase pest problems (200). Caution is needed, though, in making generalizations $(200,237)$. For example, virulent diseases such as chestnut blight and insects such as gypsy moths have devastated natural, heterogeneous forests.

Some ecologists suggest that making commercial timberland more adaptable to future climate changes, preserving biological diversity, and allowing timber commodity production will require "new forestry' management based on harvest patterns that maintain the characteristics of old-growth forest ecosystems $(79,83,200,236)$. For forests under multiple-use management, for example, this would entail leaving standing dead trees, fallen logs, and other woody debris $^{20}$; developing stands of mixed composition and structure; using harvesting patterns that do not fragment forests into numerous small parcels; and using harvesting and reforestation methods that do not greatly disturb the soil. This approach has been tried on a small scale in the Pacific Northwest; more
Figure 7-4-Reforestation of U.S. Timberlands by Ownership Category, Fiscal Year 1989

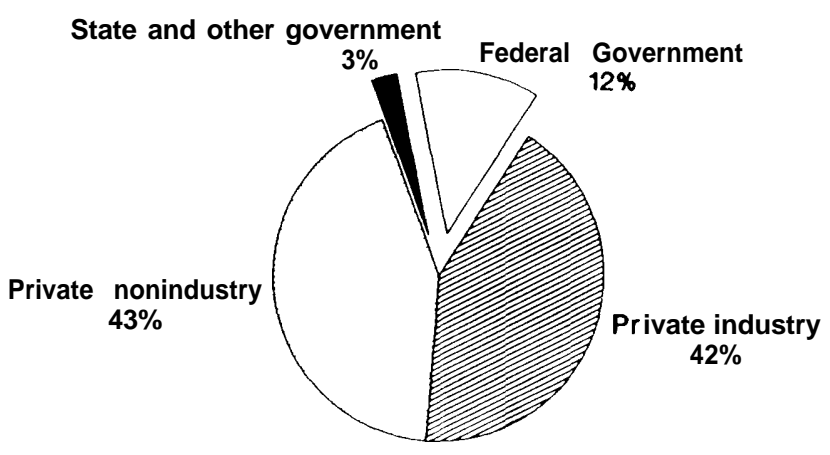

SOURCE: U.S. Forest Service, Report of the Forest Service, Fiscal Year 1989 (Washington, DC: U.S. Department of Agriculture, February 1990$)$.

research is needed to determine whether its timber production and resource conservation goals can be meshed successfully in different situations.

\section{Restrictions on Commercial Harvests-One un-} resolved issue is whether it is better to harvest forests, sequester some of the carbon in products, and replant the harvested area, or to leave forests alone over the short term. Restricting commercial harvesting to avoid releasing $\mathrm{CO}_{2}$ has been suggested. However, demand for wood and paper products will continue to be high-so if harvesting is restricted on a large scale, wood will have to come from elsewhere and be used more efficiently, or energy will have to be used to extract other materials and manufacture substitutes for wood products. Moreover, even unharvested forests change over time and can emit $\mathrm{CO}_{2}$ (see box 7-A). ${ }^{21} \mathrm{~A} \mathrm{n}$ alternative to large restrictions in general could be to assess the feasibility of "new forestry' practices (see above) that might allow some accommodation between timber production and natural resource conservation goals.

\footnotetext{
${ }^{19}$ These reforestation rates refer to the number of hectares planted, not the number of surviving trees. The 1988 plantings involved nursery production of 2.3 billion seedlings (over one-half from private nurseries).

${ }^{20}$ Although this could increase fire risks, $\mathrm{o}_{\mathrm{r}}$ increase $\mathrm{CO}_{2}$ emissions from subsequent decomposition, compared, for example, with burning the WOOd in place of fossil fuels.

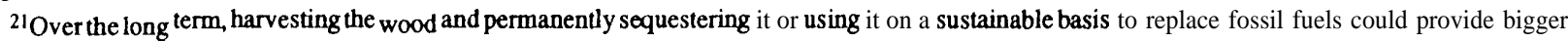
reductions in carbon emissions.
} 
Another possibility is smaller scale restrictions. For example, restricting the harvesting of "oldgrowth" forests can be justfiled for a variety of reasons, including the opportunity for the United States to demonstrate leadership in global efforts to preserve biodiversity and halt deforestation of virgin forests. Its effect on carbon emissions, however, would probably be relatively small (see box 7-C).

Increasing End-Use Efficiency and RecyclingOther practices involve increasing end-use efficiency and conservation in the forest products industry and its products (similar to increasing efficiency in other sectors; see chs. 3 through 6). OTA (274) discussed how the forest products industry could use wood more efficiently to make products and how end-use efficiencies of wood products could be increased (e.g., improving building construction designs, using efficient fuelwood burners).

Recycling of paper and paperboard products (e.g., newsprint, printing and packaging paper, cardboard) has received great attention because of municipal solid waste problems (281). Recycling these products can reduce the use of both virgin fibers and energy in making some new paper products, and help divert some municipal solid waste away from landfills $(91,281,296)$. If other demands for wood fibers remain constant, then some trees might be left unharvested because of recycling efforts; they would continue to store carbon for some time.

Whether recycling offsets carbon emissions, however, depends on what happens to paper in landfills. Some research suggests that landfilled paper may not decompose into either $\mathrm{CO}_{2}$ or methane for decades (see box 7-A). If true, then sequestering paper in landfills might be better than recycling in terms of avoiding greenhouse gas emissions, at least in the short-term. However, since methane is a potent greenhouse gas (see ch. 2), then recycling might be preferred if landfilled paper does contribute to methane emissions. But whether the methane emitted from landfills is derived from paper or from yard and food wastes is unknown. Regardless, methane from landfills can be collected and used as an energy source (see box 3-A in ch. 3), and recycling itself involves emissions of $\mathrm{CO}_{2}$ from transporting and processing recovered paper.

\section{New Forests and Trees}

\section{General Afforestation and Conservation Reserve Program}

Afforestation-planting trees on land that has never supported forests or where forests have been cleared for decades or more--offers opportunities to store carbon in new trees and help stabilize soil in many areas. The extent of carbon storage depends on factors such as soil conditions, rainfall, types of trees, whether or not trees are harvested. and maintenance. ${ }^{22}$ Most U.S. cropland being taken out of production (see below) is highly erodible, and some of it may exhibit soil degradation from mineral depletion, so not all is suitable for tree planting.

In general, trees planted on unforested lands are unlikely to be intensively managed (except for biomass fuel crops; see "Planting for Biomass Energy" below), in contrast to plantations established to reforest harvested timberlands. A cautious assumption is that average growth rates for the woody portion might be similar to those on unmanaged timberland, about 1 metric ton $\mathrm{C}$, per hectare per years. ${ }^{23}$ As noted above (see "Increasing Productivity' '), whether this means that total productivity increases is unclear. And, as with intensive management techniques, tradeoffs can include $\mathrm{N}_{2} 0$ emissions from fertilization and $\mathrm{CO}_{2}$ emissions from soil disturbance.

To estimate potential carbon savings, it is reasonable to examine current tree planting in the Conservation Reserve Program (CRP) and the potential for planting on non-CRP lands. Through 10-year contracts with farmers, the CRP aims to plant trees on 2.3 million hectares of cropland (as part of its overall goal of removing 16 to 18 million hectares of cropland from production; see box 7-E in "Options for U.S. Forests" below). If this goal is met by 1995 and trees are retained through 2015, and if annual growth rates average 1 metric ton $\mathrm{C}$ per hectare, then about 2.3 million metric tons $\mathrm{C}$ would be stored per year, including both 2000 and 2015. For non-CRP lands,

\footnotetext{
${ }^{22}$ The drought of 1988, for example, killed about 250 million tree seedlings on 140,000 hectares of forest plantations (205).

${ }^{23}$ The average growth rate for the commercial wood on existing U.S. timberland is 1 to 2 short tons $C$ per hectare per year (300). Similarly, the average growth rate exhibited by spruce-fir forests with natural regeneration on an average site was 1.4 short tons $\mathrm{C}$ per hectare per year over a 65 -year rotation (1 8). However, growth rates could be higher in some areas, particularly where croplands are more productive than average timberland.
} 


\section{Box 7-C--Harvesting Old-Growth Forests}

The Debate About Old-Growth Forests-"Old-growth" forests generally have a mixture of large old trees (including dead "snags"), layers of small-and medium-sized trees, and fallen logs and other woody debris on the ground $(250,326)$. However, disagreements exist about exact definitions for different regions and a result, about the extent and location of remaining old-growth forests. Probably less than 2 percent of all U.S. forest land is still old-growth. Almost all old-growth on private land has been cut. Ramaining stands are primarily in western national forests, particularly Douglas-fir stands in the Pacific Northwest and spruce-hemlock stands in Alaska's panhandle (mostly in Tongass National Forest). Douglas-fir is the predominant commercial species in the Pacific Northwest.

Environmental groups support restrictions on future harvesting because most old-growth has already been cut and the remainder, mostly on public lands, affords nontimber values such as biological diversity, watershed protection, fisheries, and wilderness. They feel these values arc inadequately protected by national forest planning processes. 'Much of the debate has centered around the northern spotted owl, an "indicator" species that is now listed by the U.S. Fish and Wildlife Service as threatened throughout its range.

The timber industry contends that sufficient old-growth (over 0.4 million hectares of stands over 200 years old) is already protected in wilderness areas, national monuments, and national parks; that some old-growth must be harvested to meet demands for products such as special veneers and decking; and that restrictions will cause losses of jobs and of revenues to counties from sales on Federal lands ( 25 percent of gross receipts from timber sales on Federal lands is allocated to counties for road construction and education). Along with the USFS, it believes current planning processes should not be interrupted $(250,251,309)$.

Carbon Dioxide and Old-Growth---Old-growth forests contain large amounts of carbon (over 400 tons per hectare in some areas of the Pacific Northwest) but exhibit little or no net growth or additional carbon storage. In contrast second-growth forests contain less carbon but continue to take up and store carbon.

One model (93) projected that carbon storage m second-growth forests in the Pacific Northwest would not approach the level of carbon stored in old-growth forests for at least two centuries, and that converting old-growth to second-growth reduced net carbon storage on a forest site by a total of 305 metric tons per hectare over a 60 -year rotation. ${ }^{3}$ Current harvesting rates for old-growth maybe around 10,000 to 25,000 hectares per year. ${ }^{4}$ Using the model's projections and assuming that harvesting is not increased elsewhere, the net effect of not clearing this land would be to hold about 3 to 8 million metric tons of carbon that would have otherwise been released and not resequestered during the course of a 60 -year rotations

\footnotetext{
INational Forest planning processes are outlined in the Multiple-use Sustained-Yield Act of 1960, Forest and Rangeland Renewable Resources Planning Act of 1974, ad National Forest Management Act of 1976. Bureau of Land Management planning is addressed in the Pederal Land Policy and Management Act of 1976.

2While the Fish and Wildlife Service was undertakingits listing determination, the U.S. Forest Service and the Bureau of Land Management were sued to halt harvesting in spotted owl habitat. Ensuing court actions would have halted timber sales of more than 2 billion bored feet of timber $(\mathbf{1 4 4}, \mathbf{3 0 9})$. In the fiscal year 1990 appropriations for the Interior Department (Public Law 101-121), Congress modified the court actions so that some old-growth is protected and some sales can be offered, although sates still are expected to decline by about 0.7 billion board feet per year.

${ }^{3}$ Assumptions in the model include: 1) 42 percent of the boles are converted to building structural components (with 2 percent annual replacement of structures); 2) repeated harvesting does not reduce long-term site productivity; 3) net productivity of second-growth bole wood and bark peaks at 30 years, at 8.5 metric tons of $C$ per hectare per year, and 4) changinglimatic condition do not affect processing rates. The model also assumes that old-growth forests stay relatively constant, but old-growth trees eventually die and release carbon; even so, this would primarily affect the timing of emissions-i.e., commencial rotations would have "pukes" every 60 or so years, whereas old-growth stands might not exhibit significantrethissons for centuries.

4The Wilderness society (320) estimated that 25,000 hectares are harvested yearly. However, using a more restrictod ecological definition, as the society did elsewhere (324), leads to the assumption that perhaps 10,000 to 15,000 hectares are harvested yearly.

5other factors also win influence these estimates. For example, if harvested wood is used in place of fossil fuels for energy production, then the net effect would be lower. Whether nutrient availability is sufficient to maintain carbon storage rates during a serics of harvest rotations is unknown; fertilization might belp, but it would result in $\mathrm{N}_{2} \mathrm{O}$ and $\mathrm{CO}_{2}$ emissions ( $\mathrm{sce} \mathrm{ch}$. 8). Whether higher average temperatures (from climate change) might decrease the rate of microbial decomposition (and associated emissions) of debris $\mathrm{m}$ them forests, or whether drier conditions might counter this, also is unknown
} 
Economic Effects of Restrictions-Estimates about how restrictions would affect local economies in the Pacific Northwest and in Alaska are controversial and vary widely $(57,144)$. From a historical perspective, though, the Pacific Northwest timber industry generally has been declining since the early 1970s, and employment is expected to continue to fall because of improvements in mill automation (272). The Wilderness Society (325) considers mill automation and a general decline in the availability of timber in general to be the most important factors in overall job losses in the Northwest.

The decline in domestic timber availability is partly related to exports of unprocessed logs, harvested mostly from second-growth stands on private and State lands. ${ }^{6}$ These exports are attractive to companies because of higher overseas market prices and accounted for 39 percent by value of U.S. wood exports from 1980 to 1988; 42 percent by value went to Japan (143). According to industry representatives, Japanese trade barriers discriminate against value-added U.S. wood products $(49,148)$.

Linkages-The likely outcome of the debates and negotiations that have taken place over the last few years-particularly since the U.S. Fish and Wildlife Service must still decide how much critical habitat is needed to support viable spotted owl populations-is a plan that provides for conservation of some additional old-growth forests and for some harvesting. Although this would not preserve all remaining U.S. old-growth forests, it still could enhance U.S. efforts to reduce tropical deforestation, provide for better tropical forest management, and conserve biological diversity, particularly if international forestry protocols (see ch. 1) are negotiated. This also could be linked with efforts to change U.S. harvesting patterns so that more old-growth characteristics are retained (see "New Forestry Practices" above), as well as with efforts to ensure that the most valuable timber is used for relatively long-lived products.

One way to stem domestic job losses might be to ban or tax exports of unprocessed logs from private and State lands, to encourage domestic processing of these logs to obtain the added value of finished products (see "Options for U.S. Forests"); we also can continue to improve the end-use efficiency of processing to obtain more from each $\log$ (see "Increasing End-Use Efficiency and Recycling" above). Plans to set aside additional old-growth stands on Federal lands also should consider provisions to help compensate loggers and communities for economic impacts (e.g., see 86,143$)$.

${ }^{6}$ Congress has prohibited, in the annual Interior Department appropriations, exports from Federal lands. Some loopholes allow "substitution' (i.e., when private landowners export timber from their lands and then purchase Federal timber for use in their mills).

economic opportunities for tree planting may exist on around 30 million hectares. ${ }^{24}$ If a program to plant trees on 30 million hectares began in 1995 and was maintained through 2015, then additional carbon storage (assuming the same growth rates) would amount to 7.5 million metric tons in 2000 and 30 million metric tons in 2015. OTA estimates that the CRP and General Afforestation together might offset 0.8 percent of 1987 emissions in 2000 and 2,3 percent in 2015 (see table 7-1), at an annualized cost in 2015 of around $\$ 35$ per ton C (based on data in app. A).
This would require planting 1.4 million hectares of unforested land per year, slightly more than current rates on previously forested lands (see 'Increasing Productivity' above) .25 For unforested lands, the highest planting rate under previous Federal programs was 0.2 million hectares per year, from 1957 to 1961 in the Soil Bank Program (which, like the CRP, paid farmers to retire land from crop production) $(40,168,301){ }^{26}$ Under the CRP, current tree planting rates average 0.25 million hectares per year, with a total of 0.9 million hectares planted as of March 1990 (286).

${ }^{24}$ The USFS estimates that opportunities exist on up to 33 million hectares of crop and pastureland (170, 305). After accounting for the CRP, the total would be around 30 million hectares. For comparison, about 350 million hectares might be available in the entire temperate zone, including over 250 million hectares in the U.S.S.R. and much smaller amounts in Canada, Europe, and China (54, 102). In the U. S. S.R., however, only 5 million hectares had been set aside as of 1984 for silvicultural treatment and much of the remainder was considered relatively inaccessible (102, 288), and whether current management can be maintained has been questioned (12),

${ }^{25}$ In 1989, approximately 225 million trees were planted on Federal lands (305). The President's proposed "America the Beautiful” tree-planting program (see "Options for U.S. Forests" below) called for planting 1 billion trees on 0.6 million hectares of rural land per year and 30 million trees per year in communities $(191,304)$.

${ }^{26}$ Under the Shelterbelt Project, run by the USFS from 1935 to 1942 , about 100,000 hectares were planted, including 18,000 miles Of shelterbelts, and a chain of tree nurseries was developed from Texas to Canada (52). 
CRP enrollment varies regionally, depending on markets for food crops, promotion by State agencies, and potential economic returns from trees $(59,169$, 271).27 Timber becomes more valuable after its first decade or so of growth, which could enhance retention of trees for a few years. ${ }^{28}$ The 1985 Food Security Act (which established the CRP) could make it more difficult to reconvert to cropland, through its swampbuster, sodbuster, and conservation compliance provisions (168) (also see ch. 8).

\section{Planting for Biomass Energy}

Unforested lands or even some previously forested lands also could be planted with quickgrowing tree crops that are harvested and used as a renewable "biomass energy' fuel. ${ }^{29}$ During the late 1980 s, forest residues and wood wastes supplied about 3 to 4 percent (2.5 to 3.0 quads) of U.S. energy use, with one-third used at residences and two-thirds by industry. Biomass crops might eventually supply double this amount $(273,342)$; however, only about 3.7 quads were considered economically recoverable from biomass crops in the late 1980s (100).

The U.S. Department of Energy has sponsored research since 1978 on producing "short-rotation' woody crops that could be economically competitive with fossil fuels $(290,342)$. The research involves intensive management (e. g., genetic selection, site preparation, fertilization) of fast-growing species, and harvesting on a 3- to 10-year cycle. Average growth rates of about 4 to 7 metric tons $\mathrm{C}$ per hectare per year have been attained in trials, and plots of hybrid cottonwoods have exceeded the goal of around 9 metric tons $C$ per hectare $(99,208,343)$. Current research is addressing genetic improvements in disease resistance and energy qualities, species adaptability, and economics $(46,187,343)$,

Questions about short-rotation crops bear on:

. maintenance of productivity over long periods; . long-term effects of repeated harvesting on soil debris, nutrients, and erosion;
- effects on monoculture of pest and disease outbreaks; and

. availability of advanced propagation and harvesting technologies $(44,112,343)$.

More fertilizer use would lead to $\mathrm{CO}_{2}$ emissions from its manufacture and possibly $\mathrm{N}_{2} \mathrm{O}$ emissions after application (see ch. 8). Other tradeoffs include $\mathrm{CO}_{2}$ emissions from soil disturbances (e.g., during harvesting) and from energy use in planting, harvesting, transporting, and processing.

OTA assumes that growth rates for the harvestable biomass in large, long-term operations might be 3 metric tons $\mathrm{C}$ per hectare per year. ${ }^{30}$ How much land might be dedicated to biomass crops is unclear; only 7,500 hectares were in full-scale production or research trials in North America in 1989 (342). ${ }^{31}$ The amount of unforested U.S. land economically available for planting in general might be 33 million hectares (see "General Afforestation" above), but this could be higher if biomass becomes competitive with other energy sources. However, the infrastructure for a large biomass industry (e.g., plantations, equipment suppliers, processing plants, etc.) needs to be developed (1 12). Whether landowners would opt for biomass crops with unproven market performance, as opposed to subsidized tree planting programs (e.g., the Conservation Reserve Program; see 'General Afforestation' above) is unknown.

As a moderate estimate, if a program to plant 0.5 million hectares per year for biomass energy crops began in 1995 and was carried through to 2015 without affecting other planting efforts, then additional carbon storage in the harvestable biomass would amount to 7.5 million metric tons per year in 2000 and 30 million metric tons per year in 2015. The energy content of this biomass would equal about 1.2 quads per year in 2015. This would require doubling cur-rent rates for all planting on unforested lands, to about one-third the current rate on forested lands. Not all of this storage would actually offset $\mathrm{CO}_{2}$ emissions. The net effect would depend on:

\footnotetext{
${ }^{27}$ About 85 percent of the planting has been in the Mississippi Delta and the Southeast; most re maining eligible (i.e., highly erodible) cropland is concentrated in arid regions of the Plains and Rocky Mountains that are less amenable to trees $(169,299)$.

${ }^{28}$ Over 85 percent of the acreage planted in the Soil Bank program retained trees two decades later $(4,129)$, but many trees planted during the Shelterbelt program have been cut as trees aged and marginal cropland was cultivated.

${ }^{29}$ Nonwood vegetation (e.g., grass and legume herbs, crop residues, ethanol feedstocks)also is suitable for biomass energy.

${ }^{30}$ This assumption is lower than what has been achieved experimentally, but it is three times greater than average growth rates on unmanaged lands. It accounts for uncertainties discussed above and for nonproductive areas (e.g., roads, fences, streams) that typically are not present in test plots but that would be in larger operations; it also includes carbon storage in the soil and in nonindustrial wood components (e.g., roots, twigs).

${ }^{31}$ Trials also are being conducted in at least seven European countries (92).
} 
- relative emissions of $\mathrm{CO}_{2}$ (and methane) from energy-equivalent units of biomass and fossil fuel;

- $\mathrm{CO}_{2}$ emissions during harvest and transport of crops;

- what and how much fossil fuel is actually supplanted by biomass; and

- whether new crops are grown to replace those used for fuel.

For example, using biomass to replace coal in boilers would offset more emissions than using it (with an additional conversion step) to replace transportation fuels such as gasoline (which have less carbon and fewer emissions per unit of energy than coal). Given these uncertainties, OTA assumes that biomass fuels can offset carbon emissions from an energyequivalent amount of fossil fuel by, on average, one-half of the amount of carbon stored in the harvestable portion of the crops. For the planting program described above, this would amount to about an offset of 4 million metric tons in 2000 (0.3 percent of 1987 emissions) and 15 million metric tons in 2015 (1.2 percent of 1987 emissions) (see table 7-1) at an annualized cost in 2015 of around $\$ 67$ to $\$ 133$ per ton $\mathrm{C}$ (based on data in app. A). ${ }^{32}$

By 2015, much of the additional wood grown through intensive management (as described in "Increasing Productivity" above) will be available for use as biomass fuel as well. Over the 20 years, the management practices described earlier will have yielded additional wood storage containing about 25 quads of energy. To continue to gain carbon benefits from the increased productivity, the wood must either be used as biomass fuel (on a sustainable basis) or cut and permanently sequestered in some way.

\section{Urban Tree Planting}

Trees and shrubs in urban areas store some carbon and, once they are large enough, can reduce some of the heat load on adjacent buildings in the summer and shelter them from wind in the winter $(1,2,110$, $160,197)$. Trees also help reduce the "heat island" effect (i.e., increases in average ambient air temperatures) common in cities.

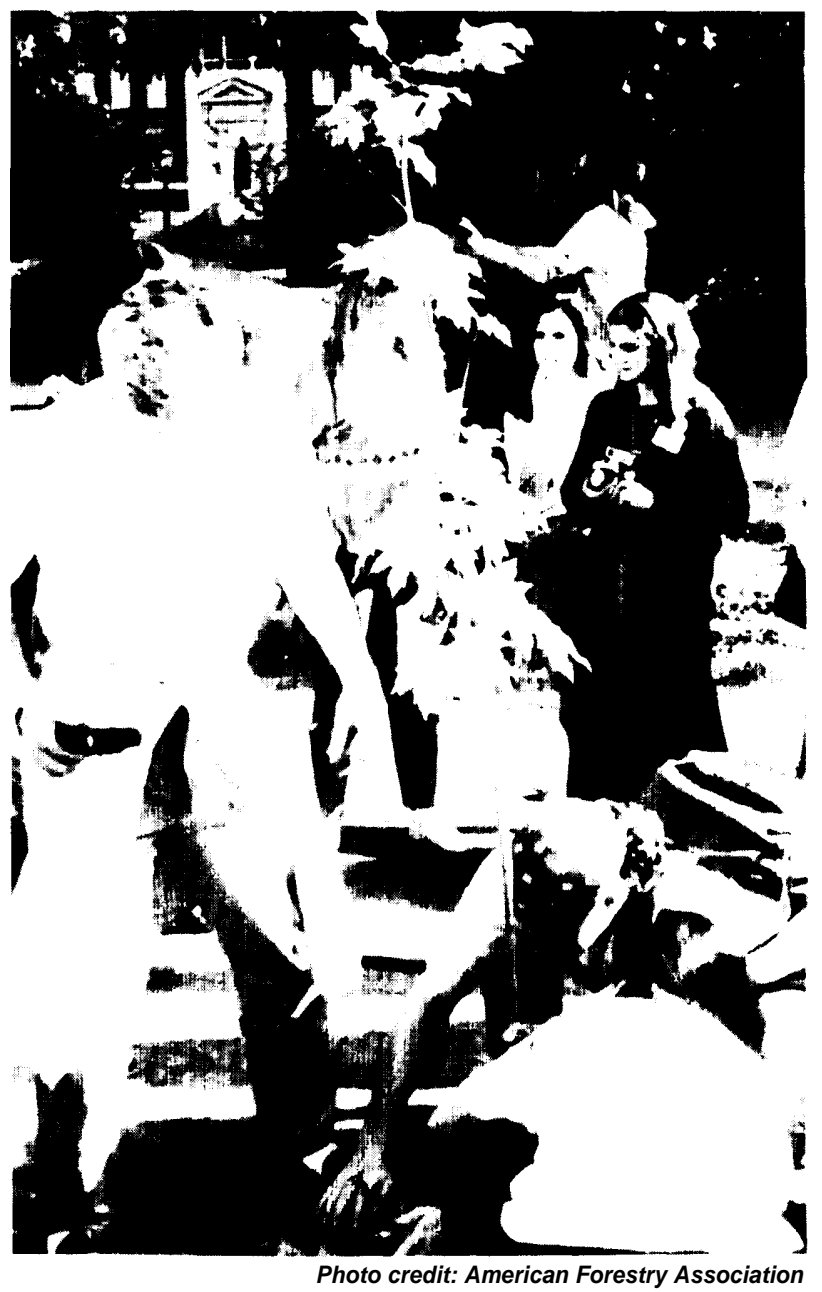

Many groups around the country sponsor tree-planting efforts in their communities. Urban trees provide numerous benefits, including beauty, carbon storage, shading of buildings, and reduced "heat island" effects.

One modeling exercise estimated that planting 100 million trees around air-conditioned homes and small commercial buildings in the United States might save 8.2 million metric tons $C$ per year in avoided fossil fuel use for cooling; carbon storage in the trees might increase this by 5 to 10 percent (1). ${ }^{33}$ However, these estimates are subject to uncertainties such as feasibility of field application, potential for feedbacks on local climate (e.g., evapotranspiration from trees, changes in albedo), and potential for $\mathrm{CO}_{2}$ or methane emissions from the decomposition of additional leaves.

${ }^{32}$ The Department of Energy estimates that short-rotation woody crops could offset 3 to 5 percent of current annual U.S. CO 2 emissions, assuming current production and conversion technologies, and up to 35 percent assuming technology advancements (e.g., higher conversion efficiencies and higher growth rates) and using a high estimate of land availability (343).

${ }^{33}$ Assuming that one-half of peak demand (i.e., when energy is most often used for cooling) is supplied by coal and one-half by oil and gas. 
If a program to plant 100 million trees near buildings begins in 1995, and it takes trees about 10 years to reach a large enough size to provide sufficient shade for reducing heat loads, and if energy savings are as estimated by the model, then carbon savings might amount to about 1 million metric tons in 2000 (i.e., from carbon stored in growing trees, but no energy savings yet from shade because the trees are too small) and about 9 million metric tons in 2015. This would offset about 0.1 percent of 1987 U.S. emissions in 2000 and 0.7 percent in 2015 (see table 7-1), at an annualized cost in 2015 of around $\$ 180$ per ton C (based on data in app. A).

A critical issue in any tree-planting program (whether the CRP or an urban tree program) is proper planting and maintenance. Many urban trees, particularly along roadsides but also in parks, suffer from inadequate root space, mechanical stresses, air pollution, and poor maintenance $(5,22,115,127$, $166,167)$. Unfortunately, budgets for urban tree maintenance have declined in most cities, and trees are being lost faster than they are being replaced $(166,167){ }^{34}$ Maintenance and other costs can include damages from falling trees; destruction of pipes; and labor costs of pruning trees, removing trees that reach the end of their useful lives, finding and marking underground power lines in highly urbanized areas, and removing leaves from roadsides or parks.

\section{MANAGEMENT PRACTICES IN TROPICAL FORESTS}

Several management and land-use practices could help reduce $\mathrm{CO}_{2}$ emissions associated with tropical deforestation (see table 7-2), and provide other benefits such as protection of soils, watersheds, and biodiversity. While the theoretical potential for reducing deforestation and $\mathrm{CO}_{2}$ emissions seems relatively high, each practice faces obstacles in the form of social attitudes, counterproductive development policies, and population pressures, not to mention costs; these are discussed below in "Options for Tropical Forests."

\section{Providing Alternatives to Deforestation}

Agroforestry and "Sustainable" Agriculture

Traditionally, shifting cultivation involved clearing forests (typically on upland soils), producing crops for a couple of years, abandoning the land for a 'fallow' period that allowed nutrient levels to rebuild, and then recultivating it two to three decades later $(72,164,207,232,275,292) .{ }^{35}$ This did not greatly affect tropical forests until recently. In the last few decades, however, many people have migrated from long-established farming areas into forest areas, often along logging access roads, and they have tended to use shorter fallow periods. Population pressures, lack of land tenure, agricultural mechanization in some areas, and/or largescale colonization schemes have contributed to this migration $(62,68,107,131,174,207,231,275)$. As a result, shifting cultivation accounted for perhaps 45 percent of deforestation in 1980 (264).

Land-use practices such as agroforestry or "sustainable' agriculture, which tend to be small-scale and adaptable to variable conditions and traditional farming systems, might lessen some of these pressures. More research is needed, though, to evaluate their effects on forest conversion rates; it is unclear how readily they will be adopted (especially without financial and technical assistance) and how many people they can support in a given area $(6,61,151$, $176,295)$.

Agroforestry--Agroforestry means growing trees and shrubs along with annual crops and/or livestock (e.g., in windbreaks, along perimeters, intercropped in fields), at the same time or sequentially. In principle, it can help store carbon, improve soil quality and reduce nutrient losses, provide food and other nonwood products and shade, and increase fuelwood supplies. While it has been practiced for centuries or millenia, most formal research has been conducted only in the last decade or so. ${ }^{36}$

Some projects initiated by local farmers and peasants (with and without outside assistance) have been successful and have been copied by others; other projects are in early stages $(43,335)$. In

\footnotetext{
${ }^{34}$ In 1986, City budgets for planting and maintenance totaled about $\$ 425$ million, with average expenditures of $\$ 11$ per tree, but this was nOt adequate for proper maintenance (115). Cities may contain over 600 million trees (167); while some may not need yearly maintenance, these data suggest that proper planting and maintenance might require several billion dollars per year nationwide.

35 Conversion of forests t. permanent cropland has occured more often in nonmountainous, lowland areas; it may be a more important cause Of deforestation in some areas, for example in much of Africa.

${ }^{36}$ E.g., see refs. 6, 14, 72, 85, 133,151,176, 180, 181, 182, 185, 186, 192, 207, 211,243, 254, 260,279,314,319,329, 339, 3@.
} 
Table 7-2-Tropical Forest Management: Potential Percent Offset of Estimated 1989 Carbon Emissions From Deforestation, for 2000 and 2015

\begin{tabular}{|c|c|c|c|c|c|c|}
\hline Management practice & Assumptions $^{\mathrm{a}}$ & $\begin{array}{l}\text { Million } \\
\text { metric tons C } \\
\text { in } 2000^{\circ}\end{array}$ & $\begin{array}{l}\text { Percent offset } \\
\text { from } 1989 \\
\text { deforestation } \\
\text { levels by } 2000^{\circ}\end{array}$ & $\begin{array}{l}\text { Million } \\
\text { metric tons C } \\
\text { in 2015b }\end{array}$ & $\begin{array}{l}\text { Percent offset } \\
\text { from } 1989 \\
\text { deforestation } \\
\text { levels by } 2015 \mathrm{C}\end{array}$ & $\begin{array}{l}\text { Examples of } \\
\text { other benefits }\end{array}$ \\
\hline \multicolumn{7}{|c|}{ Alternatives to deforestation: } \\
\hline Agroforestry & $\begin{array}{l}50 \text { million ha by } 2000,200 \text { million ha by } \\
2015 \text {; net storage } 0.1-1 \text { metric ton } \\
\mathrm{C} / \mathrm{ha} / \mathrm{yr}\end{array}$ & $5-50$ & $<1-2 \%$ & $20-200$ & $1-7 \%$ & $\begin{array}{l}\text { Soil and watershed } \\
\text { protection, biodiversity }\end{array}$ \\
\hline "Sustainable" agriculture & 0.5 million ha/yr; see text & 100 & $4 \%$ & 100 & $4 \%$ & $\begin{array}{l}\text { Soil and watershed } \\
\text { protection, biodiversity }\end{array}$ \\
\hline Reduced cattle ranching & $\begin{array}{l}\text { Reduce conversion by } 1 \text { million ha/yr by } \\
2000 \text {; by } 2 \text { million ha/yr by } 2015\end{array}$ & 100 & $3-4 \%$ & 200 & $7 \%$ & $\begin{array}{l}\text { Soil protection, biodiversity, } \\
\text { local climate effects }\end{array}$ \\
\hline Improved cookstoves & $\begin{array}{l}300 \text { million people by } 2000,1 \text { billion } \\
\text { people by } 2015 ; 40 \% \text { less fuelstove }\end{array}$ & $15-30$ & $1 \%$. & $50-100$ & $2-4 \%$ & $\begin{array}{l}\text { Increase time for social, } \\
\text { educational activities }\end{array}$ \\
\hline Managing existing forests: & (see text) & $\mathrm{NE}^{\mathrm{d}}$ & NE & NE & NE & Soil and watershed \\
\hline $\begin{array}{l}\text { Improved timber } \\
\text { harvesting }\end{array}$ & (see text) & NE & NE & NE & NE & $\begin{array}{l}\text { Biodiversity, soil and } \\
\text { watershed protection, } \\
\text { local climate benefits }\end{array}$ \\
\hline \multicolumn{7}{|l|}{ Managing new forests: } \\
\hline Reforestation & $\begin{array}{l}\text { Double rate to } 2 \text { million ha/yr; storage } \\
5 \text { metric tons } \mathrm{C} / \mathrm{ha} / \mathrm{yr}\end{array}$ & 50 & $2 \%$ & 200 & $7 \%$ & $\begin{array}{l}\text { Increase economic } \\
\text { productivity, restore } \\
\text { topsoil }\end{array}$ \\
\hline
\end{tabular}

aee text for greater detail; in general, assumptions do not directly reflect economic feasibility.
bAccounting for gradual implementation over a 25 -year period; ;.e., some planting and growth or other management occurs in year 1 , but some does not occur until year 25 .

bAccounting for gradual implementation over a 25 -year period; $1 . \theta$., some planting and growth or other management occurs in year 1, but some does not
cPercent of high estimate of 2.8 billion metric tons $\mathrm{C} / \mathrm{yr}$ from tropical deforestation (see text and figure 7-1); individual percentage offsets are not additive.

'NE = No estimate.

SOURCE: Office of Technology Assessment, 1991. 


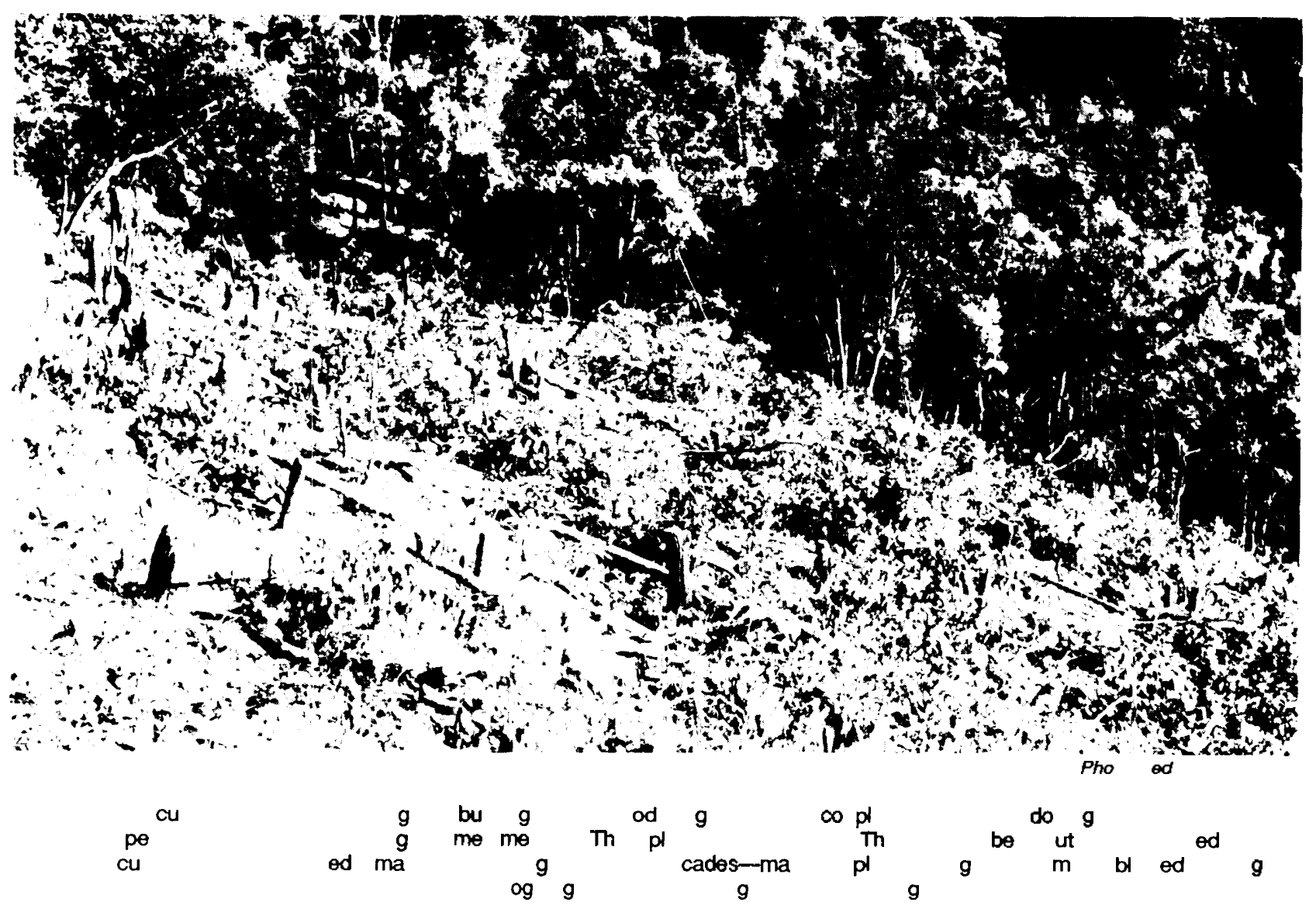

Guatemala, for example, thousands of farm families are planting a mix of tree species to produce poles, fodder, fuelwood, and fruits and other crops, and to stabilize slopes $(260,339){ }^{37}$

While agroforestry is promising, more and broader research is needed $(6,14,130)$. Relatively few projects have been conducted in wet lowland tropical forests, on degraded forest lands, or on most major soil types. Leguminous trees such as acacias and leucaena have justly received attention, but research is needed on other trees $(116,151,315,317)$. Other constraints include lack of: land tenure for peasants, local involvement in planning, markets for products, and incentives to sustain projects once official assistance ends $(6,14,37,43,89,151,157,176)$.
Published measurements of carbon storage in the woody biomass of trees in agroforestry systems range from 0.3 to 4 metric tons $C$ per hectare per year (54) ${ }^{38}$ Most systems have short rotations, and harvested crops generally are used in ways that quickly lead to $\mathrm{CO}_{2}$ emissions, but some carbon is stored in durable wood products that may last for decades and some trees are retained as "live" fencing. The net effect thus might be carbon storage ranging from 0.1 to 1 metric ton $\mathrm{C}$ per hectare per year. ${ }^{39}$ If a very ambitious program were begun in 1995 to have 200 million hectares (one-fourth the estimated cropland in tropical developing countries; see ref. 338) in agroforestry by 2015, carbon storage would be about 5 to 50 million metric tons in 2000 ( 1 to 2 percent of 1989 emissions) and 20 to 200

\footnotetext{
${ }^{37}$ The impetus and some funding i $\mathbf{\$ 2}$ million) for this is from Applied Energy Services, an American firm aiming to offset $\mathbf{C O} \mathbf{O}_{2}$ emissions from a new coal-fired power plant in Connecticut. This is the first forestry-related project designed to offset emissions from a particular industrial source. In April 1990, the Netherlands budgeted a similar project in Bolivia, Peru, and Colombia, to offset emissions from two planned coal-fired plants.

${ }^{38}$ These would be higher if foliage, fine branches, and below-ground carbon were included.

${ }^{39}$ Assuming that: 1) two-thirds of harvested wood is stemwood and one-fourth of this is stored in durable products; 2) some trees are retained as live fencing; but 3) the majority, perhaps three-fourths or more, of trees and harvested wood is used in ways that quickly lead to $\mathrm{CO}_{2}$ emissions.
} 


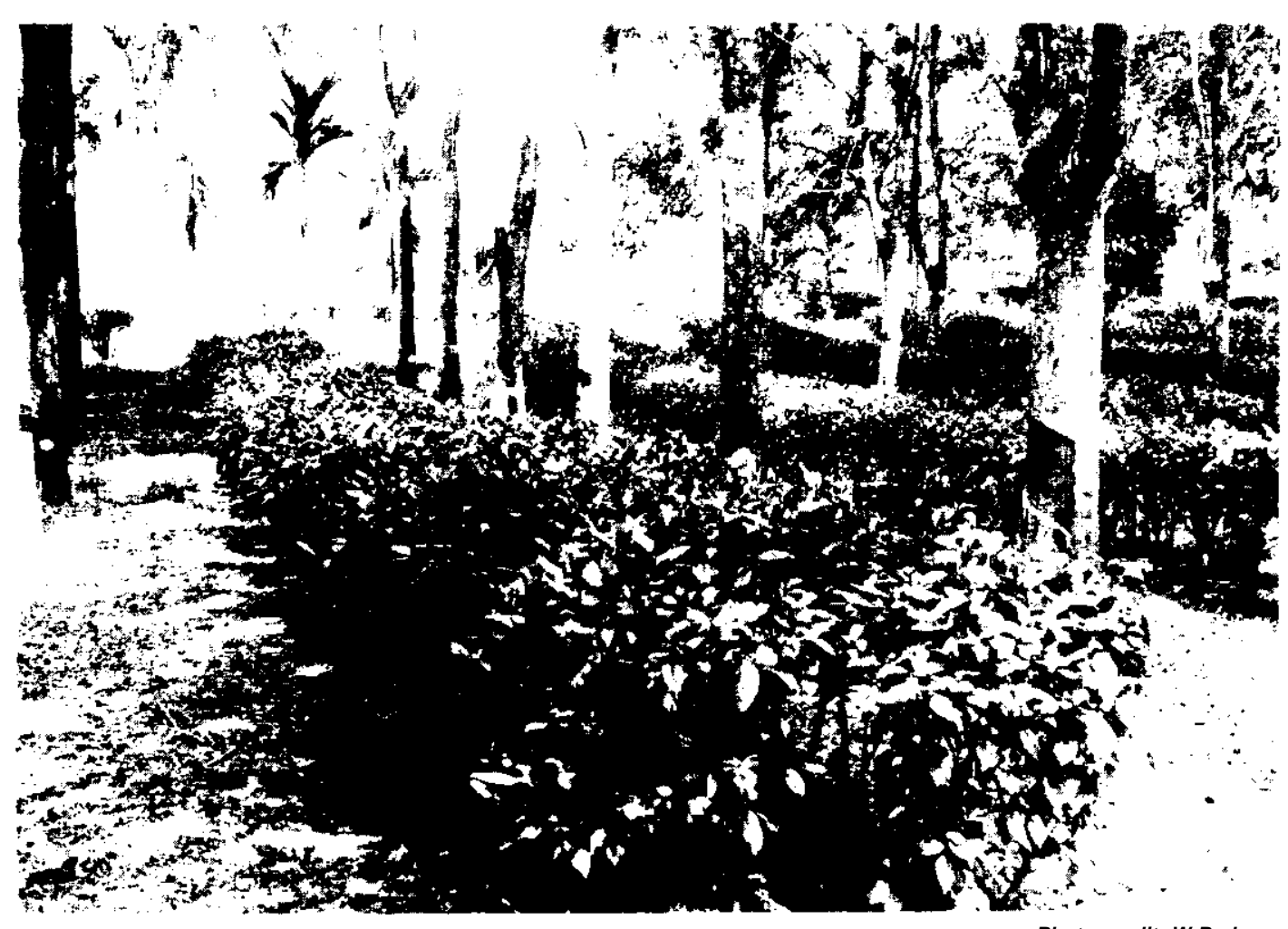

Photo credit: W Parham

\begin{abstract}
Agroforestry can take many forms, including interspersing various crops. This shows a field in China's southern Yunnan Province planted with rubber trees and tea plants. The government's Xishuangbanna Tropical Botanic Garden is experimenting with agroforestry in this area to restore degraded lands and provide crops that can be sold or used directly by local people. Other crops include peanuts, pomelos, coffee, cocoa vanilla, pineapple, sugar cane, medicinal plants, and various nitrogen-fixing cover crops and firewood crops.
\end{abstract}

million metric tons in 2015 ( 1 to 7 percent of 1989 emissions) (see table 7-2), excluding savings from avoided deforestation.

"Sustainable" Agriculture-in an agricultural context, "sustainable' generally refers to maintaining yields without impairing the land's long-term productivity. "High-input" agricultural systems involve relatively high use of fertilizers and pest controls. Research in a few tropical forest areas has shown that such systems can produce high yields for several years, but they also require extensive sampling to determine appropriate fertilizer applications; this in turn requires technical assistance or training of local people $(61,64,132,232,321,322)$. Most shifting cultivators and small rural farmers lack capital for such practices and access to assistance and training.

One alternative, ' 'low-input' ' agriculture, is designed to minimize use of purchased fertilizers and pest controls; emphasis is placed on locally adapted crops and on recycling nutrients (e.g., crop residues, manure). In the Peruvian Amazon, a 1-hectare experiment yielded seven continuous crops in a 3 -year period and replaced an estimated 5 hectares of shifting cultivation before yields declined and the area was left fallow $(231,233) .^{41}$

The long-term utility of such systems remains unproven. Nevertheless, if low-input systems could be initiated on 0.5 million hectares each year, they might save about 2 million hectares from shifting

\footnotetext{
4"In a broader context, the U.N. general definition is to "meet the needs of the present without compromising the ability of future generation to meet their own needs' (337).

${ }^{4 !}$ The experiment featured maximum residue return, no tillage, and minimal fertilizer use, but use of commercial herbicides andmanual labor tocontrol weeds.
} 
cultivation each year. Perhaps 100 tons $\mathrm{C}$ are initially released from each hectare cleared by shifting cultivation. ${ }^{42}$ If the land is allowed a fallow period, some $\mathrm{CO}_{2}$ will be stored in regrowing forest vegetation, If this amounts to, for example, an average of 50 tons $C$ per hectare over the next two decades, then the net effect-over the 25-year timeframe of this report-of leaving 2 million hectares of forest standing would be to avoid around 100 million metric tons of emissions per year (about 4 percent of 1989 emissions from deforestation) (see table 7-2).

\section{Reduced Cattle Ranching}

Large areas of tropical forest have been converted to pasture since the $1950 \mathrm{~s}$, particularly in Latin America $(98,204)$; globally, an estimated 3 to 7 million hectares have been converted to pasture per year (50). While some productive pastures have been maintained for decades in countries such as Costa Rica and Venezuela (29). some tropical forest soils are not well suited for livestock and only support a meager grass cover for a short period before weeds and inedible grasses invade $(88,98,263)$. This has occurred in Southeast Asia and Latin America (264).

Reducing the annual forest-to-pasture conversion rate by 1 million hectares by 2000 and 2 million hectares by 2015 would avoid 100 million metric tons of carbon emissions in 2000 (3 to 4 percent of 1989 emissions) and 200 million metric tons in 2015 (about 7 percent of 1989 emissions) (assuming around 100 metric tons $\mathrm{C}$ are released per hectare cleared) (see table 7-2). Another benefit might also be a reduction in future methane emissions from livestock (see ch. 8). However, the economic costs of slowing conversion are unknown and the institutional and social barriers are likely to be enormous (see "Policy Options" below). At the same time, though, efforts also could be made to improve existing cattle ranching (e.g., by using better forage and grazing management) (242),

\section{Use of Improved Cookstoves}

The importance of fuelwood consumption as a cause of deforestation is unclear $(114,134)$. Cutting trees directly for fuel (especially to make charcoal) can cause local deforestation, for example in drier regions with open tree formations, in high montane areas, and near urban areas and along roadways (123, $134,155)$. In many areas, though, cutting trees for fuelwood may be a more important cause of forest degradation than of deforestation.

End-use demand for fuelwood can be reduced by using better cookstoves. During the 1980s, some improved charcoal cookstoves with higher heat transfer efficiency than traditional stoves gained consumer acceptance in many countries (1 1), In Kenya, for example, an improved version of the traditional ' 'jiko' ceramic stove can reduce fuel use by 15 to 40 percent and pay for itself within a few months $(11,94,192,211,268)$.

Annual fuelwood use for cooking might be on the order of 0.2 to 0.4 metric ton per capita. ${ }^{43}$ If improved cookstoves reduced fuelwood consumption by 25 percent, a savings of 0.05 to 0.1 metric ton $\mathrm{C}$ per year per capita might be achieved. If 50 million additional households with 6 people per household (300 million people) used such stoves by 2000 , then carbon savings would be around 15 to 30 million metric tons (1 percent of 1989 emissions) (see table 7-2). If 175 million additional households ( 1 billion people) used them by 2015 , then carbon savings would be around 50 to 100 million metric tons ( 2 to 4 percent of 1989 emissions) (see table 7-2). ${ }^{44}$

\section{Managing Existing Forests}

\section{Harvesting Nontimber Forest Products}

Many nontimber forest products provide services and revenues to local people-e. g., nuts, herbal medicines, fibers, latex, fruits, oils, spices, fodder, palm thatch, bamboo, cork, tannin-but little has been done to estimate their value or to identify new products $(47,65,70,84,87,316,317)$. In Indonesia, the minimum export value of such products in 1987

\footnotetext{
${ }^{42}$ The amount of above-ground carbon varies with location and forest type, Closed tropical forests contain an estimated 138 to 192 metric tons $\mathrm{C}$ per hectare in aboveground biomass (25), but open forests contain considerably less (27). Fearnside (68a) estimated that Brazilian Amazon forests contain 106 to 124 metric tons $\mathrm{C}$ per hectare,

${ }^{43}$ Based on estimates for some developing countries that fuelwood used for cooking ranges from 8 to 18 Gigajoules per person ( 11 ), and on conversion factors of 1,054 joules per Btu and 55 pounds of carbon per million Btu (ch.3).

${ }^{44}$ These estimates assume less fuelwood use rather than a shift of fuelwood to noncooking uses. Whether this is a fair assumption is unknown. Another question is whether any relationship exists between emissions from improved cookstoves and respiratory infections and chronic lung diseases, as has been suggested for older cookstoves $(11,134,171,247,248,268)$.
} 
was estimated at $\$ 238$ million, more than 10 percent of the value of all $\log$ exports (47). In the Peruvian Amazon, net revenues from nontimber products on 1 hectare were estimated to be two to three times higher than revenues from harvesting commercial timber on a similar-sized plot $(201,202) .{ }^{45}$

However, because nontimber products tend to be marketed locally and in a decentralized manner, their value is generally hard to recognize and assess. In contrast, timber products receive greater government support, partly because they generate foreign exchange. High discount rates also enable entrepreneurs to obtain quick profits from intense timber harvesting $(66,135,201)$.

Nontimber products have been promoted in a few cases by establishing '"extractive reserves' '—areas of standing forest in which products are extracted, usually with traditional methods. Such reserves have been established in Brazil for nuts and rubber, for example (211). ${ }^{46}$ Their potential effect on $\mathrm{CO}_{2}$ emissions cannot be estimated, however, without knowing how many people can be supported, establishment and maintenance costs, and transport and market opportunities for products. Today, rubbertapping in the Amazon supports only a sparse population and already is heavily subsidized by the Brazilian government (65). In some cases, harvesting may even be nonrenewable (e.g., cutting palm trees to more easily obtain their fruits) (22). Nevertheless, extractive reserves can play a role in more integrated systems (e.g., with concurrent agroforestry in adjacent areas) .47

\section{Improving Commercial Forest Management}

Commercial logging, mostly in humid forests, affected an estimated 4.4 million hectares annually in $1980(114,264)$. Usually no more than 10 percent of tree species are commercially favored, and these typically are harvested by selective logging (i.e., "high-grading' '). Exports of these trees have generated major revenues during the last few decades, particularly in Southeast Asia and Western Africa; roughly one-half of the exports have been to developed countries $(175,292)$.

How much commercial harvesting is conducted on a "sustainable' basis is controversial. ${ }^{48}$ In many areas, high-grading and lack of long-term management have depleted the most valuable trees, and harvesting has shifted elsewhere $(214,263)$. Highgrading also often degrades forests by damaging or destroying noncommercial species and greatly reducing canopy cover $(214,215,216,263,275)$. Thus, many developing countries have lost or are losing this revenue source. ${ }^{49}$ In addition, logging roads open up new areas to migrating cultivators and ranchers.

Harvesting will continue, though, and research is needed on how to improve it. Research has been conducted in Southeast Asia and elsewhere on harvest techniques that minimize damage to remaining trees and on management techniques that enhance growth rates of favored species $(66,121,154)$. In Costa Rica, a door manufacturer is trying different harvest techniques to assure a sustainable supply of mahogany in a project insured by the Overseas Private Investment Council (see ch. 9). ${ }^{50}$

Opportunities also exist to increase the use of lesser known species and of each harvested log (e.g., using residues for particleboard) (282). These efforts might increase returns from a given area and reduce pressures for harvesting other areas, but they also would encourage clearcutting. The history of commercial logging and reforestation in the tropics

\footnotetext{
${ }^{45}$ This $\mathrm{ma}_{\mathrm{y}}$ be a special situation because a large, nearby market for perishable fruits and the infrastructure for transporting and marketing the fruits already exist.

46 In asimilar manner, som wildlife species threatened with extinction are being "farmed' to provide revenues for local villagers, conserve habitats, and increase species population=. g., butterflies in Papua New Guinea and crocodiles in several Asian and African countries ( 183, 184). Others, for example some large African mammals, are managed in native habitats to provide revenues from tourism, hunting, and meat production for community-based projects (336). By providing income, these projects can lessen pressures to clear forests for planting of cash crops.

${ }^{47}$ Other efforts t. preserve tropical forests and biodiversity in general also will help protect sources of nontimber products. One initiative,for example, aims to develop conservation programs in collaboration with local organizations and national governments in 12 countries that contain an estimated 60 percent of the world's species and much of the remaining primary tropical forest (41; also see 159).

${ }^{48}$ Some investigators conclude that very little "sustaimble' commercial harvesting actually occurs in tropical moist forests $(39,203)$. Also sec "Tropical Forestry Action Plan" below.

${ }^{49}$ The World Bank estimated that only 10 of the 33 countries that were net exporters of tropical forest products in 1985 would be net exporters by 2000 (215).

${ }^{50}$ Instead of establishing plantations, the company buys natural forest tracts or marginal farmland where the tree is found and hires local farmers as guardians ( 194, 228).
} 
Table 7-3--FAO Estimates of Plantations Established by End of 1980 and During 1981-85 in 111 Developing Countries and Territories, by Region (number of countries in parentheses) (in millions of hectares)'

\begin{tabular}{|c|c|c|c|c|c|}
\hline \multirow[b]{2}{*}{ Region } & \multicolumn{2}{|c|}{ Established } & \multirow[b]{2}{*}{ Total } & \multirow{2}{*}{$\begin{array}{l}\text { Annual } \\
\text { rate }\end{array}$} & \multirow{2}{*}{$\begin{array}{l}\text { Estimated percent of annual } \\
\text { deforestation replaced } \\
\text { with plantations }\end{array}$} \\
\hline & by 1980 & $1981-85$ & & & \\
\hline \multicolumn{6}{|l|}{ Tropical: } \\
\hline Africa (42) . . . . . . . . . . . & 1.8 & 0.6 & 2.5 & 0.1 & $3 \%$ \\
\hline Asia $(15) \ldots \ldots \ldots \ldots$ & 5.2 & 2.2 & 7.4 & 0.4 & $21 \%$ \\
\hline C. \& S. America (27) . . . . & 4.6 & 2.7 & 7.3 & 0.5 & $9 \%$ \\
\hline Oceania (6) . . . . . . . . . & 0.1 & 0.1 & 0.1 & $<0.1$ & $34 \%$ \\
\hline Total $(90) \ldots \ldots \ldots \ldots$ & 11.7 & 5.5 & 17.3 & 1.1 & $10 \%$ \\
\hline \multicolumn{6}{|l|}{ Nontropical: } \\
\hline Africa (7) . . . . . . . . . & 1.2 & 0.5 & 1.7 & 0.1 & $\mathbf{N ~ E}^{\mathrm{b}}$ \\
\hline Asia (11) . . . . . . . . & 14.5 & $0.3^{c}$ & 14.9 & $0.1^{\mathrm{c}}$ & NE \\
\hline America (3) . . . . . . . . . . & 1.6 & 0.6 & 2.2 & 0.1 & NE \\
\hline Total $(21) \ldots \ldots \ldots \ldots$ & 17.2 & 1.5 & 18.7 & 0.3 & NE \\
\hline
\end{tabular}

aBased on official government responses to FAO survey; does not include trees planted on small landowner plots (e.g., agroforestry, windbreaks) or plantations of nontimber trees such as rubber, oil palm, coconut, and shade trees.

bNE = not estimated.

'Does not include value for China.

SOURCE: Food and Agriculture Organization, 1988.

suggests that clearcutting should not be allowed on a large scale unless acceptable management plans and stringent enforcement mechanisms are in place.

Another practice, ' 'natural' forest management, combines natural regeneration with small clearcuts to allow sustainable harvesting with little damage to remaining trees. Natural regeneration typically involves the growth of volunteer seedlings and saplings; for some species, a small ' 'gap' in the canopy is needed for seeds to germinate and grow initially. In one project in Peru, this gap is simulated by clearcutting long narrow strips from a mature forest, on a 30 - to 40 -year rotation $(96,97)$. Native trees regenerate naturally in the small, open strips. Oxen remove felled logs, and the timber is processed at a local cooperative run by villagers. In late 1989, the cooperative shipped its first exports to U.S. buyers (53).

Considerable research is needed on this and other practices. In general, though, the major problems associated with commercial logging are economic, political, and institutional. To ensure that logging in the tropics is conducted in accordance with accepted management norms, national governments and international organizations must develop rational management plans, enforcement mechanisms, and trading systems (see ' 'Options for Tropical Forests' below).

\section{Managing New Forests}

\section{Reforestation}

Reforestation consists of establishing forests on previously harvested lands, often in the form of monoculture plantations, sometimes in more heterogeneous stands; it can be of great use in improving watershed management and erosion control.

The potential for tropical reforestation varies widely. On degraded lands, barriers include competition with invading grasses that support periodic fires; hotter and drier microclimates in cleared areas; lack of appropriate seed sources; and poor soil characteristics (e.g., low nutrient and water-holding capacity, compaction from overgrazing) $(188,245)$. Reforestation is possible on degraded lands if proper techniques and ecologically suitable species are chosen $(147,149,188)$, but it is likely to be difficult.

Many large reforestation projects involve establishing plantations on relatively less degraded land. As of 1985, about 17 million hectares of plantations had been established in tropical forest areas (see table 7-3). ${ }^{51}$ Successful plantations have been established in countries as diverse as India, Malaysia, the Philippines, and Trinidad and Tobago $(71,235)$. However, the overall rate of establishing new plantations is relatively low-about 1 million hec-

\footnotetext{
${ }^{51}$ These data do not include trees planted around farm fields, as windbreaks, or along roadways (204).

${ }^{52}$ However, Palmberg (196) estimated higher rates for 1981 to 1985-2.9 million hectares per year of industrial timber plantations, 2.6 million hectares per year for nonindustrial purposes.
} 
tares per year in the early 1980 s, or one-tenth the estimated rate of deforestation (see table 7-3). ${ }^{52}$

Estimated growth rates for tropical plantations in the early 1980s ranged between 2 and 10 metric tons $\mathrm{C}$ per hectare per year (based on data in refs. 30, 71). OTA assumes that an average annual growth rate of 5 metric tons $\mathrm{C}$ per hectare might be maintained on plantations; this may be optimistic, given lower rates on degraded lands, problems associated with plantations, and a lower net effect when plantations replace previously forested land. How much land might be available is unclear. ${ }^{53}$ If a program to double the current establishment rate were to begin in 1995, then carbon storage attributable to reforestation might amount to 50 million metric tons in 2000 (2 percent of 1989 emissions) and 200 million metric tons in 2015 (7 percent of 1989 emissions) (see table $7-2)$.

Problems with plantations include poor site and species selection, faulty management, fire, and disease (71). One of the largest projects, in Jari, Brazil, has been more expensive and less productive than anticipated (63), Some monoculture plantations in Southeast Asia have lost thousands of hectares due to pest infestations (204). Monoculture have other opportunity costs such as reduced biodiversity and less access to medicinal plants and other products.

Any reforestation effort must also contend with social issues such as land ownership and local needs. Reforestation projects could be designed to provide local people with products and services (e.g., medicines, food, etc. ) from different forest successional stages, which would mean planting and managing more heterogeneous forests $(26,116,316,318)$ (also see 'Harvesting Nontimber Forest Products' above). Mixed-species forests might also reduce the likelihood and intensity of infestations (310),

Attempts also could be made to restore degraded lands to something resembling original conditions (84, 120), Although relatively little is known about how to do this, a pioneering effort to restore crop and range land back into dry tropical forest is taking place in northwest Costa Rica, on what will be over 70,000 hectares in Guanacaste National Park (158).
It is designed to benefit local residents through watershed protection, employment, income from tourism, and educational programs (21 1). Another possibility is to restore damaged or cutover mangrove forests, which are important as sediment filters and as habitat for many marine species (258, 275). Several Southeast Asian countries (e.g., Malaysia, Vietnam) are attempting to restore mangroves and other coastal vegetation $(243 \mathrm{a}, 258)$.

\section{POLICY OPTIONS}

This section describes policy options for influencing forestry management and land use practices in the United States and in tropical areas. Policy makers should recognize that the management practices described above might be affected by future climate changes, the impacts of which are difficult to predict for specific forest areas (see box 7-D).

\section{Options for U.S. Forests}

Policies to offset carbon emissions in the United States fall into three general categories: those encouraging increased carbon storage in existing wooded areas; those promoting biomass energy; and those for growing new trees in unforested rural areas and in urban communities. Several U.S. Department of Agriculture agencies, particularly the U.S. Forest Service (USFS) and the Agricultural Conservation and Stabilization Service (see box 7-E), could be instrumental in carrying out these policies.

\section{Incentives for Increasing Carbon Storage in Forested Areas}

Increasing carbon storage in forested areas as a means of offsetting $\mathrm{CO}_{2}$ emissions actually means increasing the rate at which an entire forest ecosystem removes $\mathrm{CO}_{2}$ from the atmosphere and stores it in wood, leaves, roots, soil and soil organisms, etc. While this carbon ultimately will be released back to the atmosphere (see box 7-A) unless it is permanently stored under conditions that do not allow decomposition, increasing total productivity still is an appropriate goal for the 25-year timeframe of this report. Most people are concerned with increasing the productivity of a forest's commercial timber component, because of possible capital returns from harvesting the timber. Whether an increase in timber

\footnotetext{
${ }^{53} \mathrm{Of}$ formerly forested lands not currently used extensively for agriculture or settlement, Houghton (10S) concluded that 500 million hectares of mostly degraded land were available, including large areas of savanna in west Africa. In addition, he concluded that 365 million hectares of fallow areas could be reforested if shifting cultivation were replaced with permanent agriculture. Grainger (88) estimated that over 700 million hectares might be available for reforestation.
} 


\section{Box 7-D-Forests and Future Global Climate Change}

The General Circulation Models (GCMs) currently used to make predictions about climate change have only limited regional resolution and cannot predict how individual trees might respond to local climate changes (see ch. 2). Nevertheless, they can be used to indicate, as a first approximation, how potential climate changes might affect forests.

First, changes in average temperature and moisture can affect the physiology and competitive regimes (i.e., with other plants), and hence survival and reproduction, of individual trees. These effects could be positive or negative. For example, warmer conditions might enhance growth rates in boreal forests $(16,125)$ but decrease survivorship of some species' seedlings elsewhere $(31,35,79,205)$.

Second, the frequency and intensity of episodic disturbances (e.g., fires, windstorms, pest and disease outbreaks) might increase in some areas, although they might decrease elsewhere. Little attention has been given to this issue, even though such events could hinder efforts to reduce deforestation or increase carbon storage. Where they occur, changes in episodic events may have greater effects on forest biomass and composition than would changes in average conditions $(79,117,193)$. Changes in average conditions such as warmer winter temperatures also could allow some pathogens, parasites, and insects to expand into unaffected forests (79, '190), although currently affected forests might experience reductions in such problems.

Several reports summarize projections of how North American forests might respond to changes in average global climate $(79,117,122,136,165,210,223,294)$. The projections generally indicate that forests will not shift as units, but that some species would migrate to higher elevations (e.g., in the Northwest) and latitudes (e.g., in the East). For some species, however, shifts in suitable conditions may outpace natural dispersal rates $(31,261)$ ). Some areas, such as the southern part of the Southeast United States, might convert to scrub, savanna, or sparse forest. Shifts also could lead to competition with existing land uses (e.g., cropland).

Effects of these changes on $\mathrm{CO}_{2}$ levels are difficult to predict. If existing forests suffer diebacks, then carbon emissions from decomposing trees could increase (223). Stressed trees that die also could increase fuel loads and hence fire intensity. On the other hand, overall productivity of Northeastern forests could increase if slow-growing spruces and firs are replaced by faster growing hardwoods.

Less is known about potential effects on tropical forests. Some consider it unlikely that higher temperatures will be directly detrimental (e.g., ref. 95). Warmer temperatures could even lead to boundary expansions, depending on factors such as changes in daily temperature regimes, how far polar air masses penetrate into the tropics, and cloud cover. However, increased seasonality of rainfall in humid tropical forests might greatly affect the fruiting of trees such as figs and palms that are important for humans and numerous birds and mammals (78).

$\mathrm{CO}_{2}$ "Fertilization"- - Laboratory and greenhouse experiments on crops and a few trees show that increases in $\mathrm{CO}_{2}$ concentrations can result in $\mathrm{CO}_{2}$ "fertilization" or "enhancement' '-increases in growth rates, efficiency of water and nitrogen use, and ability to withstand water stress $(128,136,222,289)$.

This raises the possibility that increasing atmospheric concentrations of $\mathrm{CO}_{2}$ might stimulate growth rates and associated carbon storage in natural forests. There is no evidence yet that this has happened, however, and debate about its likelihood continues $(16,125,238,289,330)$. The experimental findings ca.nnmot be easily generalized. Virtually all the experiments have been short-term, conducted under conditions unlike those encountered by plants in natural conditions $(13,82,128,136,190,330)$. In the field, plant growth may be limited by other factors (e.g., water, nutrients) that interact with plant physiology, by competition with other plants, and by pathogens.

Moreover, higher temperatures also might increase plant respiration rates, thereby increasing $\mathrm{CO}_{2}$ emissions and partially or entirely offsetting carbon storage resulting from increased photosynthesis (109, 136,330, 331). Higher temperatures also could increase oxidation and emissions of soil carbon (125) and the production of methane in anaerobic environments (109).

${ }^{1}$ Changes also might occur in soil conditions and affect the microorg anisms that help make soils amenable for plants (323). 


\section{Box 7-E-USDA: Forest Service and Agricultural Stabilization and Conservation Service}

U.S. Forest Service (USFS)-The USFS administers timber sales and other activities on national forest land, under the National Forest Management Act of 1976 and the Forest and Rangeland Renewable Resources Planning Act of 1974. It also administers programs to stimulate investments by private nonindustry landowners in forestry practices. Under the Cooperative Forest Assistance Act of 1978, the State and Private Forestry program provides assistance to State forestry organizations, which then offer direct assistance to landowners for pest and fire protection and forest management; this totaled $\$ 87$ million in fiscal year 1989, including \$2.5 million for urban forestry $(306,309)$. Under the Renewable Resources Extension Act of 1978, the agency provides assistance for forest management through extension service programs.

The International Forestry program assists international organizations such as the United Nations Food and Agriculture Organization and the World Bank in evaluating and implementing projects (309). One of its units, the Forestry Support Program, is managed with funding from A.I.D. and provides technical assistance to A. I.D., the Peace Corps, and NGOs (283). The USFS also operates two tropical forest research centers (in Puerto Rico and Hawaii) that conduct some research on agroforestry and reforestation $(113,278)$; the Forestry Private Enterprise Initiative, which helps small forest-based businesses (including ecotourism) in the tropics; and the Forest Products Laboratory, which conducts research on the use of temperate and tropical woods.

The USFS spent over $\$ 138$ million on forest research in fiscal year 1989, including \$14 million on global change. The proposed fiscal year 1991 budget for global change research is $\$ 23$ million (306).'

Agricultural Stabilization and Conservation Service (ASCS)-The ASCS administers several programs with technical assistance from USFS, Soil Conservation Service, and State agencies (45). The Forestry Incentives Program (FIP) provides cost-sharing (up to 65 percent) for reforestation, timber management, and firebreaks, on private forest lands of less than 400 hectares. The Agricultural Conservation Program (ACP) provides cost-sharing to farmers for soil and water conservation practices, including tree planting and timber improvement. These programs treated over 140,000 hectares annually during the last few years, mostly (over 80 percent) for reforestation; in 1986, the FIP provided over $\$ 11$ million, over 75 percent in the South, while the ACP provided over $\$ 6$ million.

The ASCS also administers the Conservation Reserve Program (CRP), with assistance from the Soil Conservation Service and USFS. Established under the Food Security Act of 1985, the CRP is designed to improve soil, water, and wildlife resources by paying landowners to remove highly erodible land from production $(284,285)$ (also see ch. 8). Its goal is to have 16 to 18 million hectares enrolled by 1990, with one-eighth to be reforested. The Federal Government enters into 10-year contracts with farmers, makes rental payments, and pays one-half the costs of establishing protective vegetation. As of March 1990, about 0.9 million hectares were enrolled for tree planting (40 percent of the reforestation goal), over 90 percent in the South $(45,170 \mathrm{a})$.

${ }^{1}$ The Forest/Atmosphere Interaction Priority Research Program is designed to research the effects Of climate change on forests and related ecosystems (298). It builds on the Forest Response Program, which conducted (through 1990) research on acidic deposition. The Forest Ecosystems and Atmospheric Pollution Research Act of 1988 (Public Law 100-521) designated the USFS as the lead agency to continue research begun under the National Acid Precipitation Assessment Program and carried out by the Forest Response Program.

productivity represents a similar increase in total productivity, however, is an issue that requires esting. Assuming that it does, then incentives could be provided to increase timber productivity; incantives will differ for publicly and privately owned forests, but all should account for potential tradeoffs such as increased $\mathrm{N}_{2} \mathrm{O}$ emissions from fertilization, increased erosion, or decreased biological diversity.
For public lands, Congress could direct the USFS and Bureau of Land Management to increase reforestation activities (including more stringent reforestation requirements in contracts with the private sector) and to consider using carbon storage as a criterion in forest planning processes $(127) \cdot{ }^{54} \mathrm{To}$ assess the extent to which ' 'new forestry' practices (see 'Increasing Productivity' can maintain higher

\footnotetext{
${ }^{54}$ Management objectives for National Forests, for example, are determined in accordance with provisions in the Forest and Rangeland Renewable Resources Planning Act and National Forest Management Act, within the overall framework set forth in the Multiple-Use and Sustained-Yield Act of 1960 (274).
} 
Figure 7-5-Funding Levels for the U.S. Forest Servicers State and Private Forestry Programs, 200 Million dollars $198 \$-91$

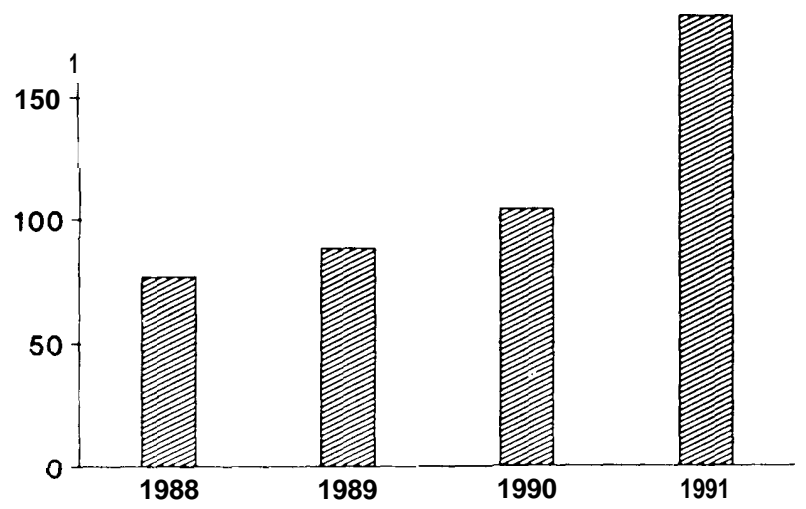

Levels for fiscal years 1988 and 1989 are actual spending; level for fiscal year 1990 is estimated spending; and level for fiscal year 1991 is appropriated funding. (All amounts are in real dollars.) SOURCES: Office of Management and Budget, Executive Office of the President, Budget of the United States Government, Fiscal Year 1991 (Washington, DC: U.S. Government Printing Off ice, 1990); U.S. Congress, "Continuing Appropriations for the Fiscal Year Ending September, 1988," Conference Report 100-498 (Washington, DC: Dec. 21, 1987); Congressional Record, 136(1 50): H-12409, Oct. 27, 1990.

levels of diversity and allow commodity production, Congress could direct the USFS to increase research on these practices in the National Forests.

For nonindustry private forests, Congress could continue to increase assistance to States and private landowners. In the Interior and Related Agencies Appropriations Bill for fiscal year 1991, for example, Congress increased funding for USFS State and private forestry programs (see box 7-E) from $\$ 104$ million in 1990 to $\$ 183$ million in fiscal year 1991, continuing the trend seen in the late 1980s (see figure 7-5). In addition, the 1990 Food Agriculture, Conservation, and Trade Act (Public Law 101-624) authorized a forestry stewardship program, in which the USFS would work with State and local governments, land grant universities, and the private sector to improve resource management on privately owned forest land. Congress could also consider increasing funding for programs administered by the Agricultural Conservation and Stabilization Service, such as the Forestry Incentives Program (FIP) and the Agricultural Conservation Program (ACP) (see box 7-E) (also see 111,179 ). These programs currently reach only about 2 percent of nonindustry private owners, although as a group these owners are responsible for over 40 percent of all reforestation (see figure 7-4). The fiscal year 1991 appropriation for the Forestry Incentives Program was \$12.5 million, the same as in fiscal year 1990 .

For industry-owned timberland, investments might also be stimulated through changes in capital gains provisions. Congress could consider restoring preferential tax rates or providing a partial exclusion from taxable income, for timber held longer than 20 years, and allowing full annual deductions for expenses, as well as increasing funding for Federal assistance programs. 55 Analysts at the Natural Resources Defense Council (15) suggested that tax and program benefits be made available only to owners who comply with relevant forest management guidelines.

To increase Federal funding of assistance programs, one possibility is to use funds that would be saved if "below-cost" timber sales in national forests were eliminated, ${ }^{56}$ Timber sales in general, along with USFS assistance in surveying and road construction, are used to promote the U.S. forest products industry .57 For all 122 national forests, net revenues to the government from fiscal year 1989 sales amounted to $\$ 403$ million (307). However, 66 forests exhibited net losses totaling $\$ 45$ million. ${ }^{58}$

Some local job losses in the timber industry are likely if below-cost sales are eliminated. In addition, 25 percent of gross revenues from all Federal timber sales (including below-cost sales) are paid to States, to be distributed to counties for roads and schools,

${ }^{55}$ Tax provisions that have been favorable for forestry investments include: capital gains; annual expensing Of some costs; and a reforestation tax credit $(15,139,226,301)$. The 1986 Tax Reform Act eliminated differential rates for long-term capital gains.

${ }^{56}$ Assuming that demand for wood remains the same, eliminating such sales would not effect carbon emissions because harvesting would shift elsewhere.

${ }^{57}$ Repetto andPezzeY(218) suggest " ${ }^{1}$ iminating, over time, all Federal appropriations for forest management, other than for protecting biodiversity and other nonmarketable services. They propose financing management expenses out of net receipts from forest operations, and establishing user fees based on market values for nontimber values (which could increase pressure for more roads and other forms of access into old-growth and wilderness areas).

${ }^{58}$ Timber harvested from such sales accounted for about one-fifth of the total harvest fromnational forests. The only western forest to ShOW a net monetary loss was the Chatham unit of Tongass National Forest in Alaska (270, 303, 307). GAO (270) provide-s slightly different estimates of net losses. 
and some of this would be lost as well. ${ }^{59}$ Some rural towns and timber operators would probably need training, development, m-relocation assistance. Banning exports of unprocessed logs also might offset some 'job losses (see box 7-C). Indeed, the current ban on exports of logs from Federal lands, previously enacted annually in the appropriations process, has now been made permanent. ${ }^{60}$ Congress also could make cost-sharing assistance under the FIP and ACP available only to States that ban exports from private and State lands, Potential disadvantages of export bans (90) include countering freetrade policies (although Japanese trade policies discourage imports of processed wood products); adding to the U.S. trade deficit; and job losses among longshoremen (possibly offset by new sawmill jobs).

\section{Incentives for Biomass Energy To offset $\mathrm{CO}_{2}$ Emissions}

The Department of Energy's research program on short-rotation woody crops could be increased ${ }^{61}$ and focused to reduce uncertainties regarding long-term productivity and costs. Increasing taxes on fossil fuel use (see ch, 1 ) will make biomass fuels more competitive, although it also could increase pressures to cut trees for fuel wood on lands not dedicated to biomass crops. 62 Also, farmers wishing to invest in biomass crops may be limited by loss of base acreage in commodity support programs (see ch. 8) and by lack of revenues for the first 5 years or so; this suggests that changes in support programs or provision of subsidies may be needed to stimulate investments in biomass crops on current cropland. Chapter 3 discusses other options for increasing the use of biomass fuels in electric utilities; chapter 5 discusses biomass use in vehicles. All of these options assume that the infrastructure to support cultivation and use of such crops is in place.

\section{Incentives for Growing New Trees}

Afforestation can be promoted through programs such as the Conservation Reserve Program (CRP) and the proposed America the Beautiful program and through financial mechanisms such as tax incentives or credits. Any program must consider the financial and technical resources needed to maintain trees in a healthy state once planted, a factor that will be even more critical if climate changes occur (see box 7-D).

Congress could expand the CRP's tree-planting goals and its incentives for enrolling land for tree planting (e.g., greater share of reforestation costs, longer contracts) ${ }^{63} \mathrm{~A}$ variation might be to encourage new shelterbelts, perhaps through tax credits or by conservation compliance requirements tied to price support programs (see ch. 8) ${ }^{64}$

The Food Agriculture, Conservation, and Trade Act of 1990 also authorized startup funds for a new America the Beautiful tree-planting program (initiated by President Bush), as well as funds for urban and community tree planting and maintenance. The Interior and Related Agencies Appropriations Bill for fiscal year 1991 did not contain funding for the America the Beautiful program, but it almost doubled funding for the USFS's State and private forestry programs, which include tree planting and management (figure 7-5). However, infrastructure for increased planting also may need to be developed, since current planting is near the historical peak of about 1.4 million hectares per year; funding for long-term maintenance also will be needed.

\footnotetext{
${ }^{59}$ The USFS budget request for fiscal year 1991 proposed phasing out below-cost sales on 12 forests, and testing whether increased funding for recreation would result in increased recreational usage to offset revenue losses to local economies caused by eliminating the sales. This proposal is opposed by many States with targeted forests because of fears about revenue losses (58).

${ }^{60}$ The Customs and Trade Act of 1990 (Public Law 101-382) permanently bans exports of unprocessed logs from Federal lands in the West, bans exports of at least 75 percent of the annual sales volumes of unprocessed timber from State lands, and bars mills from 'substituting' unprocessed timber from public lands for exported unprocessed timber originating from private lands.

${ }^{61}$ Federal support for research on energy from biomass and municipal waste dropped from $\$ 58$ million in fiscal year 1981 to $\$ 13$ million in fiscal year 1989 (187)

$62 \mathrm{H}_{\text {owever }}$, a tax on "carbon' 'per se could have the opposite effect because the carbon content of wood is about the same as that "coal.

$631_{n}$ the Food Agriculture, Conservation, and Trade Act of 1990(Public Law 101-624), Congress expanded CRP eligibility criteria to include, for example, marginal pasture lands previously converted to wetlands or wildlife habitat, marginal pasture lands to be converted to trees in or near riparian areas, and croplands that contribute to water quality degradation.

${ }^{64}$ Options more readily implemented at the State and local levels include requiring developers to grow trees (onSite or elsewhere) or contribute to a reforestation fund if they clear a certain portion of trees on a development site; and giving property tax breaks to landowners that agree not to convert or degrade forest lands (e.g., as in North Dakota; see ref. 32).
} 
Congress also could consider providing tax incentives (similar to ones for energy conservation) for planting and maintaining urban trees (especially near buildings, to save energy used for cooling).$^{65}$

\section{Options for Tropical Forests}

\section{Introduction}

Policy makers must recognize that changes in tropical forests are driven by underlying factors such as national and multilateral economic development policies, foreign debt, lack of land tenure, and population growth.

Some governments favor development of tropical forest areas because of concerns about national security, population pressures, and foreign debt (17, $174,215,216,235,275,340)$. Transmigration, highway and dam construction, and other projects undertaken in response to these concerns have greatly increased deforestation $(10,66,67,153,174$, 216, 249). Many projects have been partially funded by multilateral development banks, which have only recently begun to consider long-term environmental costs in their decisions about projects. In addition, forest products are exported to obtain foreign exchange and service debts (225), but frequently at a pace that cannot be sustained for long periods.

Some agricultural policies have promoted converting forests into large cattle ranches, particularly in Latin America. In Brazil, for example, previous tax laws penalized owners of "unimproved" forest land but virtually exempted agriculture and ranching from taxation $(17,66)$. The government suspended most of these provisions (38), but ranches still are an attractive hedge against inflation (17, 98). Many countries also maintain low food prices to help urban populations, which lessens incentives for better agricultural practices.

Timber policies often enable forest industries to generate profits by rapidly depleting timber stocks $(213,214,215,216,340)$. Such policies include short-term concessions (e.g., less than 30 years), tax holidays, low "rents," and negative interest rates. Industrialized nations, by erecting tariffs on processed tropical imports (to protect their own indus- tries), encourage inefficient harvesting in tropical forests because full market values for the resources cannot be obtained.

Population growth exacerbates all of these factors. Populations in developing nations are expected to almost double to 7 billion by the year 2025 (see ch. 9). This growth, coupled with high poverty rates and inequitable land distribution, increases pressures to clear forests for agriculture. In many developing countries, most arable land is owned by a small upper class or by middle-class land speculators $(98,173,275)$. Without access and tenure to productive farmland or access to alternative livelihoods, subsistence farmers often migrate into forest frontiers $(98,101,275)$.

Given this background, potential U.S. policies to influence what happens in tropical forests can be geared to:

* encourage continued change in multilateral development bank policies;

- address population planning, land reform, and debt reduction;

- build host country institutions and increase research;

- provide assistance for nontimber alternatives; and

- promote improved commercial forest management.

A number of U.S. and international agencies and programs could be instrumental in pursuing such policies (see boxes 7-E and 7-F). The United States also could support development of an international forestry convention or protocol that sets global standards for conserving and managing forest resources, perhaps within the context of a global climate change convention. ${ }^{66}$

Encourage Continued Change in Multilateral Development Bank Policies

The International Development and Finance Act of 1989 (Public Law 101-240) directed the U.S. Executive Directors of each Multilateral Development Bank (MDB) (see box 7-F) not to vote in favor of proposed actions that would have significant

\footnotetext{
${ }^{65}$ The American Forestry Association has launched a ' G1oLMI Releaf' project, the objective of which is to plant 100 million young trees (larger than seedlings) around U.S. homes and buildings by $1992(166,167,230)$; this would increase the number of trees in urban areas by an estimated 15 to 20 percent.

66As recommended $\mathrm{b}_{y}$ the FAO $(76,77)$, IPCC $(114,114 \mathrm{a})$, and Ullsten et al. (264), which differ somewhat, however, on the potential relationship between a forestry convention and a climate change convention.
} 


\section{Box 7-F-Multilateral and Bilateral Institutions and Programs}

Multilateral development banks (MDBs) include the World Bank and its affiliate, the International Development Association, and the Inter-American, Asian, and African Development Banks. World Bank lending for forestry-related projects is expected to be about $\$ 1$ billion by 1992 (334). Many MDB projects have led directly or indirectly to deforestation, but recently the banks have begun to address these issues. U.S. Executive Directors to the MDBs are directed through the Department of Treasury's Office of Multilateral Development Banks (275).

International assistance agencies such as the United Nations Development Program (UNDP), Food and Agriculture Organization (FAO), UN Environment Program (UNEP), and more regional agencies (e.g., Commission of European Communities) provide funding for tropical forestry. The FAO is the largest organization addressing forestry; it inventories forest resources, conducts research on forest management practices, and coordinates the Tropical Forestry Action Plan. Even so, less than 5 percent of FAO's budget is allocated to forestry (264).

The Tropical Forestry Action Plan (TFAP) was initiated in 1986 under the sponsorship of the World Bank, UNDP, FAO, and World Resources Institute to provide a framework for enhancing donor cooperation and funding in: integrating forestry into improved land use practices, improving forest-based industries, restoring fuelwood supplies, conserving forest ecosystems, and building developing country institutions $(73,89,142,328,340)$. Coordinated by FAO, the TFAP initially involves a review of the forestry sector in requesting countries; to date, over 50 countries have requested reviews. A national forestry action plan then is prepared that identifies potential projects amenable to financing from donors. TFAP's implementation, however, has been severely criticized (see "Options for Tropical Forests").

The International Tropical Timber Organization (ITTO) was established under the International Tropical Timber Agreement (265), which came into force in 1985. Its goal is to provide a framework for coordination and cooperation between tropical timber producing and consuming countries regarding tropical timber economies. Operational since 1987, it has 43 member countries representing 95 percent of world tropical timber trade and over 75 percent of remaining tropical rain forests. It uses voluntary member contributions to support projects for improved forest management and reforestation, increased domestic processing, market analyses, and better pricing structures. Japan has been the largest supporter among industrialized nations that have made voluntary contributions.

The U.S. Agency for International Development (A.I.D.) provides bilateral support for agroforestry, natural forest management, and reforestation projects through its own programs, the USPS Forestry Support Program (see box 7-E), the ITTO and TFAP, and international research organizations. It spent $\$ 72$ million in fiscal year 1989 on about 160 tropical forest projects in 40 countries. It also provides support through the Food for Peace program, for example by distributing food to villagers engaged in forestry activities (267), and through projects for distributing more efficient cookstoves (268). The Foreign Assistance Act (amended by Public Law 99-529) requires A.I.D. to conduct environmental assessments for projects that significantly affect natural resources in developing countries, places priority on conservation and sustainable management of tropical forests and on practices such as agroforestry, and requires that NGOs be used to manage relevant projects when feasible. A.I.D. has had environmental review procedures for its projects since 1978; its Early Project Notification System requests information (submitted to Congress semi-annually) from field missions and embassies, NGOs, and MDBs about potential environmental problems associated with upcoming MDB loans (31 1).

environmental effects, unless an environmental impact assessment of the action and its alternatives had been conducted. The World Bank (332, 333), for example, recently outlined procedures for assessing the environmental consequences of its proposed projects. This is a critical step, but it is too early to ascertain its effect. ${ }^{67}$ Bank procedures also do not provide for cross-compliance among different loans to a country.

Congress could continue to review MDB progress in implementing environmental impact assessment procedures, particularly to learn how these proce-

\footnotetext{
${ }^{67}$ For example, some observers question whether sufficient staff will be hired or whether the public will have substantive input in decisionmaking $(3,20,101,262)$. Nor is it clear how to account for previous projects that lead to new ones with environmental consequences (e.g., Brazil's pig-iron smelter project will use railways and mines built with previous Bank funding).
} 
dures actually affect tropical forests. ${ }^{68}$ It also could direct the U.S. Executive Directors to promote cross-compliance, so that even when all funds from a loan have been distributed to the recipient country, noncompliance with its environmental provisions would result in loss of funds from other loans. In addition, it can continue encouraging MDBs to:

- make loans contingent on changes in host country policies (e.g., elimination of subsidies for ranching and poor logging);

- increase loan provisions designed to strengthen environmental ministries, extension services, and monitoring capabilities of developing countries; and

- increase involvement and capabilities of local non-governmental organizations (NGOs) and communities in planning and implementing projects.

Address Population Growth, Land Tenure, Foreign Debt

Support Population Planning and Land Reform - The United States could increase its assistance through the Agency for International Development (A. I.D.) for family planning services in developing countries and for international organizations such as the U.N. Fund for Population Activities and the International Planned Parenthood Federation. This critical issue is discussed in chapter 9, The United States also could support both agrarian land reforms initiated by developing countries (especially those focused on large, unproductive landholdings in regions where small farmers are leaving due to mechanization and other factors) and urban projects that increase employment opportunities for rural migrants.

Debt Reduction and Debt-for-Nature SwapsOne option to reduce foreign debts and promote natural resources conservation is "debt-for-nature swaps.' Private, nonprofit groups can purchase debt sold by commercial banks at discounted rates in the secondary debt market, and then exchange or "swap' the debt note with a developing country for an obligation by that government to create some type of conservation program. As of 1989, Bolivia, Ecuador, Costa Rica, Madagascar, and the Philippines had participated in such swaps, with a reduction in external debt of $\$ 100$ million (340).

Although only 1 percent of developing country debt is traded on the secondary market, reorienting even a small percentage of current debts to natural resource conservation and management is helpful, especially given the lack of funds generally available for such purposes in many developing countries $(141,212,320) .{ }^{69}$ Congress could direct the Internal Revenue Service to publicize a 1987 ruling (and clarifications) that allows creditors, including U.S. banks, to receive full-value tax deductions when part of a debt is donated to eligible NGOs for use in the debtor country (293). ${ }^{70}$ Congress also could continue trying to have MDBs evaluate ways to facilitate swaps.

\section{Provide Assistance for Institutions and Research}

Environmental Ministries and NGOs-Few developing countries have adequate programs for forestry management or agroforestry $(84,329)$. Congress could direct A.I.D. to devote more resources to improving the abilities of environmental ministries and extension services to collect data and analyze environmental effects, monitor forest practices, improve planning, and enforce regulations. Congress also could increase direct funding and technical support through A.I.D. for U.S. and foreign NGOs that work on forestry-related issues. ${ }^{72}$ These groups often can quickly implement small-scale, innovative projects; for example, CARE (Cooperative for American Relief Everywhere) and the Pan

\footnotetext{
${ }^{68}$ In a related vein, the United States could promote revision of the U.N. 'S accounting systern fOr national economic performan ce, which places little value on forest services such as watershed protection and nontimber products $(92,152,215,216,217)$ (see ch. 9).

${ }^{69}$ Swaps have been criticized, though, for refocusin ${ }_{8}$ domestic priorities away from infrastructure, housing, and food supplies and for 'giving' awaY resources, and in some cases for ignoring the needs and rights of tribal people living in affected areas. However, the debtor country retains ownership of the resources in question and can decide for itself whether a proposed swap is worthwhile $(141,195)$.

${ }^{70}$ Todate,largerbankshave not found trading debt at discounted rates attractive. Most swaps have involved the purchase of secondary debt by NGOs, using funds from foundations and individual donors (341). As of 1988, onfy one bank had made a debt donation, to the amount of $\$ 250,000$ (340).

${ }^{71}$ Currently, MDBloans cannot\& used for swaps because they are not salable on secondary markets and cannot be rescheduled (269, 293). In 1987, Congress instructed the Department of Treasury to analyze potential ways in which MDBs could facilitate swaps. The 1989 International Development and Finance Act directed the U.S. Executive Directors to promote protection of sensitive ecosystems through swaps.

72The 1989 International Developrnent and Finance Actalso requires the. U.S. Executive Directors to MDBs to promote increased assistance and support for non-U. S. NGOs.
} 
American Development Foundation have been instrumental in agroforestry projects $(89,275,335)$.

International Research Organizations-Congress could increase support for international research organizations that address forestry-related issues, such as the International Council for Research in Agroforestry and the Consultative Group on International Agricultural Research (CGIAR). ${ }^{73}$ No central body, however, coordinates tropical forestry research or offers help to donors and national governments $(119,221,252)$. The United States could support development of an applied research system that both focuses on issues not currently covered adequately (e.g., nontimber forest products, natural forest management) and coordinates existing efforts. Congress also could increase support for U.S. university and Peace Corps programs to train U.S. professionals in tropical forestry $(54,164,266)$ and direct A.I.D. to expand its support of research and training in forestry.

\section{Provide Assistance for Nontimber Alternatives}

Direct A.I.D. funding for tropical forestry projects was $\$ 72$ million in 1989 (see box 7-F), about 1 percent of total A.I.D. economic assistance. Congress could increase funding for A.I.D. projects on agroforestry, sustainable agriculture, and nontimber forest products (without reducing other programs). Congress also could ensure that A.I.D. systematically assesses the potential for its projects to decrease deforestation. ${ }^{74}$ USFS tropical research centers and the Forest Products Laboratory (see box 7-E) could be expanded to include more research and training on nontimber forest products.

Internationally, the United States could promote alternative land use practices through its influence on MDB policies, and it could promote sustainable harvesting of nontimber products through its potential influence on the International Tropical Timber Organization (ITTO) and Tropical Forestry Action Plan (TFAP) (see next section).

\section{Promote Improved Commercial Forest Management}

Where commercial timber harvesting occurs, existing incentives for short-term use and mismanagement need to be replaced with incentives for better practices (1 14a), For example, the United States can work through international organizations and programs to promote:

- longer terms for timber concession licenses;

- increased ability of government ministries to oversee harvesting;

- increased research on natural forest management;

- more plantations and agroforestry on degraded lands; and

- importing forest products only from areas managed on a sustainable basis.

Some of this can be done through the MDBs and UN agencies such as the FAO. Congress also could direct U.S. agencies such as A.I.D. and USFS to expand activities in these areas, as well as to work together more often (e.g., as they did in Honduras on a project contracted by USFS and funded by A.I.D. in 1989). ${ }^{75}$

It may be even more important for the United States to help make the TFAP and ITTO more effective vehicles for promoting forest conservation and improved commercial forest management (114a).

Tropical Forestry Action Plan-The TFAP was designed to improve forestry practices in developing countries through cooperative efforts between donors and host countries (see box 7-F). However, its implementation has been criticized for stressing export-oriented commercial forestry instead of conservation; failing to address issues such as land tenure; perpetuating "top-down" planning; and failing to develop the capabilities of host countries $(3,36,39,101,146,224,234,259,262)$. Some groups oppose increased lending by MDBs for

$73 \mathrm{~F}_{\text {or }}$ descriptions, see refs. $42,89,151,275$; but also see criticisms in ref. 244 . CGLAR recently expanded its mandate, to address tropic\&d deforestation through research on sustainable agriculture (42).

${ }^{74} \mathrm{Public}$ Law 101.167 and A.I.D. regulations require the agency to issue guidance to its missions and bureaus on the need to reduce greenhouse gas emissions associated with its projects, and to identify key developing countries in which forest conservation along with energy efficiency and renewable energy, could significantly reduce emissions.

${ }^{75}$ The USFS historically has had no direct mandate fo its international programs. Congress could provide such authority, as well as provide stable funding to the Forestry Support Program to directly serve NGOs and additional funding to the Forest Products Laboratory to develop new products (including nontimber ones) from tropical resources and to transfer technologies to developing countries. The United States also could demonstrate leadership by increasing research on reforestation of degraded tropical forest lands on its insular territories (278), through the USFS tropical forest research centers (see box 7-E). 
commercial logging projects until these issues are resolved.

Two recent reviews, commissioned by the FAO and the World Resources Institute (both original cosponsors), confirmed many of these problems and also noted that project quality control, public access to information, and criteria for monitoring performance at the national and international levels are lacking $(264,328)$. While the United States could withdraw its support for and participation in the TFAP, it probably is the only international vehicle that could address these problems in a comprehensive manner.

The reviews recommended that TFAP be substantially restructured and redirected.$^{76}$ Congress could ask A. I.D., EPA, USFS, and the State and Treasury Departments to assess progress in reforming TFAP. Assuming the major problems are being resolved, Congress could direct the agencies to increase support for the new TFAP. ${ }^{77}$ This support can, for example, include increased training for host institutions and NGOs, technical! assistance in assessing needed policy reforms, and financial assistance in carrying out new national Forestry Action Plans.

International Tropical Timber Organization (ITTO) and Trade--Some people have called for banning imports of tropical timber products in order to reduce harvesting of tropical forests. Indiscriminate bans, however, might remove the few existing incentives for improved management of those forests, which will continue to be cut for domestic purposes and for foreign markets that do not impose bans.

Alternatively, and along with improving the TFAP, the United States could work through the ITTO to link trade in tropical timber products with improved forest management. The United States could support ITTO efforts to have timberproducing countries adopt and implement guidelines on sustainable forest management (1 18). It also could support ITTO and other projects that explore pricing reforms within host countries (e.g., increased rents or fees from timber companies for the resources they harvest) and labeling mechanisms in international trade. If labeling mechanisms could be developed internationally, then imports (including nontimber products) might be allowed only from areas managed according to internationally acceptable forest management practices and labeled as such. Improvements in internal pricing policies, labeling mechanisms, and international guidelines for acceptable forest management could be incorporated into new national Forestry Action Plans developed under a revised TFAP. Moreover, ITTO and a revised TFAP also might encourage harvesting only in secondary forests, or at least reducing harvests of low-value products in primary tropical forests. U.S. influence in the ITTO currently is undermined, however, because it is in arrears of dues (slightly over \$200,000). Congress could authorize payment of dues and additional funding for financing ITTO projects. $^{78}$

The United States and other developed countries also could use ITTO and other forums to discuss, with producer countries, lowering the high tariffs that developed countries impose on imports of processed tropical wood products. These tariffs are enacted primarily to protect domestic processing industries, but they lead to increased imports of unprocessed tropical $\operatorname{logs}$ and reduce incentives for better harvesting in tropical forests. ${ }^{79}$ Reducing them would allow developing countries to obtain the full market value for their resources, which might stimulate development of more efficient processing industries in these countries and allow them to compete in world markets without subsidies from their own governments $(84,204,215,216)$.

\section{CHAPTER 7 REFERENCES}

1. Akbari, $\mathbf{H}$. et al., "The Impact of Summer Heat Islands on Cooling
Energy Consumption and $\mathrm{CO}_{2}$ Emissions," paper presented at
ACEEE Summer Study on Energy Efficiency in Buildings (Asilo-

\footnotetext{
${ }^{76}$ In particular, ${ }_{\mathrm{o}}$ 1) change from a project. specific, donor-driven plan to a systematic, host-driven program, with a new internationalmanagement structure;2) focus more on people who live in or use forests, forest degradation and conservation and sustainable economic use (including land use in surrounding areas); 3) increase institutional capacities of host countries; 4) stimulate policy reforms in host countries (e.g., tax policies, timber concessions) and in development assistance institutions (e.g., criteria for funding projects); and 5) revise guidelines to delineate responsibilities of donors and host countries and to lay out criteria on preparation of national plans, monitoring of and reporting on plan implementation, and other issues.

77 The fiscal year 1991 budget requested $\$ 0.5$ million for the TFAP Trust Fund (312).

${ }^{78}$ Congress appropriated payment of full dues in fiscal year 1990, but not payment of arrears. The proposed fiscal year 1991 budget requests full dues for fiscal year 1991, plus funds for some arrearages and \$1 million for ITTO special projects (36a ,312).

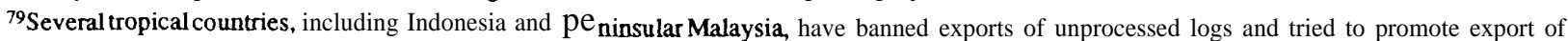
processed products (143).
} 
mar, CA: August, 1988).

2. Akbari, H., A.H. Rosenfeld, and H. Taha, "Summer Heat Islands, Urban Trees, and White Surfaces, " paper AT-924-1 presented at ASHRAE January 1990 Meeting (Atlanta, GA: American Society of Heating, Refrigerating and Air-Conditioning Engineers, 1990).

3. Alexander, N., Friends Committee on National Legislation, "Testimony on the International Development Association," testimony before the Subcommittee on International Development, Finance, Trade and Monetary Policy, Committee on Banking, Finance and Urban Affairs, U.S. House of Representatives, Mar. 28, 1990.

4. Alig, R.J., T.J. Mills, and R.L.Shackelford, "Most Soil Bank Plantings in the South Have Been Retained; Some Need FollowUp Treatments," Southern J. of Applied Forestry 4(1):60-64, 1980.

5. American Forestry Association, "Making Spaces for Trees," Urban Forest Forum 8(4):7-8, September/October 1988.

6. Anderson, D., The Economics of Afforestation: A Case Study in Africa (Baltimore, MD: Johns Hopkins University Press, 1987).

7. Anderson, I. et al., " Enhanced Biogenic Emissions of Nitric Oxide and Nitrous Oxide Following Surface Biomass Burning, ' J, of Geophysical Research 93:3893-3898, 1988.

8. Andreae, M. O., "Consequences of Biomass Burning for Tropical Atmospheric Chemistry: Results from Amazonia and Equatorial Africa,' ' paper presented at Chapman Conference on Global Biomass Burning Atmospheric, Climatic and Biospheric Implications (Williamsburg, VA: Mar. 19-23, 1990).

9. Armentano, T. and C. Ralston, "The Role of Temperate Zone Forests in the World Carbon Cycle, " Can. J. Forest Research 10: 53-60, 1980.

10. Aufderheide, P. and B. Rich, "Environmental Reform and the Multinational Banks, " World Policy Journal, pp. 301-321, spring 1988

11. Baldwin, S., H. Geller, G. Dutt, and N.H. Ravindranath, "Improved Woodburning Stoves: Signs of Success,' Ambio 14(4/5):280287, 1985.

12. Barr, B.M. and K.E. Braden, The Disappearing Russian Forest: A Dilemma in Soviet Resource Management (London: Rowman \& Littlefield, 1988)

13. Bazzaz, F. A., K. Garbutt, and W.E. Williams, "Effect of Increased Atmospheric Carbon Dioxide Concentration on Plant Communities, in U.S. Department of Energy, Direct Effects of Increasing Carbon Dioxide on Vegetation, B.R. Strain and J.D. Cure (eds.), DOE/ER-0238 (Washington, DC: Office of Energy Research, December 1985), pp. 155-170.

14. Beets, W. C., Agroforestry in African Farming Systems, U.S. Agency for International Development Project 698-0424 (Washington, DC: Energy/Development International, 1985).

15. Benfield, F, K., A.E. Kinsinger, and J.R. Ward, "Taxing the Tree Farm: Sensible Policies for Sensible Private Forestry" (Washington, DC: Natural Resources Defense Council, May 1988).

16. Binkley, C. S., "Climatic Change and Forests," Science 243:991, Feb. 24, 1989.

17. Binswanger, H. P., "Brazilian Policies That Encourage Deforestation in the Amazon," Environment Department working paper No. 16 (Washington, DC: The World Bank, April 1989).

18. Birdsey, R. A., ' Estimation of Regional Carbon Yields for Forest Types in the United States, " draft manuscript (Washington, DC: Feb. 13, 1990).

19. Birdsey, R. A., "Potentd Changes in Carbon Storage Through Conversion of Lands to Plantation Forests, " paper presented at North American Conference on Forestry Responses to Climate Change (Washington, DC: May 15-17, 1990).

20. Blackwelder, B., ' Testimony Before the House and Senate Appropriation Subcommittees on Foreign Operations for the FY 1989 Appropriations" (Washington, DC: Environmental Policy Institute, Apr. 27, 1988).
21. Bodmer, R.E., T.G. Fang, and L. Moya, "Fruits of the Forest," Nature 343:109, Jan. 11, 1990,

22. Boerner, D.A., "Tree Angel of Santo Domingo," American Forests 95(9/10):61-64, September/October 1989

23. Botkin, D.B. and L.G.Simpson, "Biomass of the North American Boreal Forest: A Step Toward Accurate Global Measures, ' Biogeochemistry, 9:161-174, 1990.

24. Botkin, D.B. and L.G. Simpson, "The Distribution of Biomass in the North American Boreal Forest," in Proceedings of Global Natural Resource Monitoring and Assessment: Preparing for the 21st Century, Volume 3 (Bethesda, MD: American Society of Photogrammetry and Remote Sensing, 1989).

25. Brown, S., A.J.R. Gillespie, and A.E. Lugo, "Biomass Estimation Methods for Tropical Forests With Applications to Forest Inventory Data," Forest Science 35(4):881-902, 1989.

26. Brown, S., A.J.R. Gillespie, and A.E. Lugo, "Biomass of Tropical Forests of South and Southeast Asia," Canadian J, Forestry Research, in press.

27. Brown, S. and A.E. Lugo, "Biomass of Tropical Forests: A New Estimate Based on Forest Volumes," Science 223:1290-1293, March 1984.

28. Brown, S. and A.E. Lugo, "Effects of Forest Clearing and Succession on the Carbon and Nitrogen Content of Soils in Puerto Rico and US Virgin Islands," Plant and Soil 124:53-64, 1990.

29. Brown, S., University of Illinois, personal communication, August 1990

30. Brown, S., A.E. Lugo, and J. Chapman, "Biomass of Tropical Tree Plantations and Its Implications for the Global Carbon Budget, Can. J. For. Res. 16(2) :390-394, 1986.

31. Brubaker, L.B., ' 'Responses of Tree Populations to Climatic Change," Vegetatio 67: 119-130, 1986.

32. Brumbaugh, C., ' 'North Dakota's Woodland Tax Law, ' NDFS 0300-3 (Walhalla, ND: January 1990).

33. Burnett, H., “In Hugo's Wake," American Forests 96(1/2): 17-20, January/February 1990.

34. Cahoon, D.R. et al., "The Great Chinese Fire of 1987: The View From Space, ' paper presented at Chapman Conference on Global Biomass Burning: Atmospheric, Climatic and Biospheric Implications (Williamsburg, VA: Mar. 19-23, 1990).

35. California Energy Commission "The Impacts of Global Warming on California, Interim Report," Committee Report P500-89-004 (Sacramento, CA: June 1989).

36. Carothers, A., "Defenders of the Forest," Greenpeace 15(4):8-12, July/August 1990.

36a. Caswell, S., Department of State, personal communication Sept. 4, 1990.

37. Chapin, M., "Ecodevelopment and Wishful Thinking," The Ecologist 19(6):259-261, November/December 1989.

38. Climate Institute, "Climate News Around the Globe," Climate Alert 2(3):8, Fall 1989.

39. Colchester, M. and L. Lohmann, The Tropical Forestry Action Plan: What Progress? (Penang, Malaysia: World Rainforest Movement, 1990).

40. Conrad, J., "The Conservation Reserve: Tree-Planting Windfall or Tilting at Windmills?" American Forests 92:12-14,50-52,54, September 1986.

41. Conservation International, 'The Rain Forest Imperative' (Washington, DC: 1990).

42. Consultative Group on International Agricultural Research, " Annex 1, Declaration of Intent on the Future Work of the CGIAR' (Canberra, Australia: May 1989).

43. Cook, C.C. and M. Grut, Agroforestry in Sub-Saharan Africa: A Farmer's Perspective, World Bank technical paper No.112 (Washington, DC: The World Bank, 1989).

44. Cropper, W.P. and K.C.Ewel, "A Regional Carbon Storage Simulation for Large-Scale Biomass Plantations, "Ecological Modelling 36:171-180, 1987. 
44a. Crutzen, P.J. and M.O. Andreae, "Biomass Burning in the Tropics: Impact on Atmospheric Chemistry and Biogeochemical Cycles,' Science 250:1669-1678, Dec. 21, 1990

45. Cubbage, F. W., "Current Federal Land Conversion Programs: Accomplishments, Effectiveness, and Efficiency," paper prepared for American Forestry Association Document and Conference on Forests and Climate Change, draft manuscript (Athens, GA: Feb. 12, 1990).

46. Cushman, J.H. "Short Rotation Woody Crops," Trees for America, draft (Oak Ridge, TN: Oak Ridge National Laboratory, 1989).

47. de Beer, J.H. and M.J. McDermott, The Economic Value of Non-timber Forest Products in Southeast Asia (Amsterdam, The Netherlands: Netherlands Committee for IUCN, July 1989).

48. Dehnas, R.A. et al., "Methane Emission from Combustion in Equatorial Africa," paper presented at Chapman Conference on Global Biomass Burning: Atmospheric, Climatic and Biospheric Implications (Williamsburg, VA: Mar. 19-23, 1990).

49. Dennison, S. S., "Prepared Statement of Stanley S. Dennison," Japanese Trade Barriers to Forest Products, Hearing before the Subcommittee on International Trade of the Committee on Finance, United States Senate, S. Hearing 101-526, Part 2 (Washington, DC: U.S. Government Printing Office, 1990).

50. Detwiler, R.K. and C.A.S. Hall " "Tropical Forests and the Global Carbon Cycle," Science 239:42-47, Jan. I, 1988

51. Detwiler, R.K. and C.A.S. Hall, "The Global Carbon Cycle," Science 241:1738-1739, Sept. 30, 1988.

52. Droze, W. H., Trees, Prairies, and People, A History of Tree Planting in the Plains States (Denton, TX: Texas Woman's University, 1977)

53. Earhart, J.J., ' 'Peruvian Indians Work To Save Forest Home,' FOCUS 12(4):5, July/August, 1990.

54. E.DI, Forestry Sector of the Climate Change Assessment, contract prepared for U.S. Congress, Office of Technology Assessment (Washington, DC: July 1989)

55. Environment Canada, "Record Heat-Wave in North-western Canada," Climatic Perspectives, Monthly Review 11:1,8, August 1989.

56. Environment Canada, "The $1980 \mathrm{~S}$-A Warmer Decade," Climatic Perspectives, Monthly Review 11:1, December 1989.

57. Environmental and Energy Study Conference, "Tongass Timber Reform Act," Floor Brief (Washington, DC: Juiy 11, 1989).

58. Environmental and Energy Study Conference, "Tongass, Howls Over Owls Dominate Second Session," Special Report (Washington, DC: Aug. 7, 1990)

59. Esseks, J. D., S.E.Kraft, and R.]". Moulton, "A Survey Research Perspective on the Forestry Component of the Conservation Reserve Program," draft manuscript (Washington, DC: American Forestry Association, 1990).

60. Farnum, P., R. Timmis, and J.L. Kulp, "Biotechnology of Forest Yield, "Science 219:694-702, 1983.

61. Fearnside, P. M., "Rekíinking Continuous Cultivation in Amazonia," Bioscience 37(3):209-214, March 1987.

62. Fearnside, P. M., ${ }^{4}$ 'Deforestation and International Economic Development Projects in Brazilian Amazonia," Conservation Biology 1(3):214-221, October 1987.

63. Fearnside, P. M., "Jari at Age 19: Lessons for Brazil's Silvicultural Plans at Caracas," Interciencia 13(1):12-24, January-February 1988.

64. Fearnside, P. M., "Yurimaguas Reply," Bioscience 38(8):525527, September 1988

65. Fearnside, P. M., "Extractive Reserves in Brazilian Amazonia," Bioscience 39(6):387-393, June 1989.

66. Fearnside, P. M., "Forest Management in Amazonia: The Need for New Criteria in Evaluating Development Options, "Forest Ecology and Management 27:61-79, 1989.

67. Fearnside, P. M., "The Charcoal of Caracas: A Threat to the Forests of Brazil's Eastern Amazon Region," Ambio 18(2): 141-143, 1989.
68. Fearnside, P. M., "Practical Targets for Sustainable Development in Amazonia," J. Burnett and N. Polunin (eds.), Maintenance of the Biosphere: Proceedings of the Third International Conference on the Environmental Future (Edinburgh, Scotland: Edinburgh University Press, 1990), pp. 167-174.

68a. Fearnside, P. M., National Institute for Research in the Amazon, personal communication, Mar. 10, 1990.

69. Food and Agriculture Organization Forest Resources in the European Region (Rome: 1976).

70. Food arid Agriculture Organization Tropical Forest Resources, Forestry Paper No. 30 (Rome: 1982).

71. Food and Agriculture Organization Intensive Multiple-Use Forest Management in the Tropics, Forestry Paper No. 55 (Rome: 1985).

72. Food and Agriculture Organization, Forestry Department, "Changes in Shifting Cultivation in Africa,' Unasylva 37(150):40-50, 1985

73. Food and Agriculture Organization, World Resources Institute, World Bank, and United Nations Development Programme, The Tropical Forestry Action Plan (Rome: 1985).

74. Food and Agriculture Organization "The Outlook for Pulp and Paper to 1995, Executive Summary “ ('Rome: 1986).

75. Food and Agriculture Organization "An Interim Report on the State of Forest Resources in the Developing Countries, "Forest Resources Division, Forestry Department, FO:MISC/88/6 (Rome, Italy: 1988).

76. Food and Agriculture Organization, "Proposal for an International Convention on Conservation and Development of Forests," Committee on Forestry, Tenth Session, COFO-90/3(a) (Rome September 1990).

77. Food and Agriculture Organization, "FAO Director-General Proposes International Convention to Save the World's Forests, News Release PR 90/52 (Rome: Sept. 24, 1990).

78. Foster, R.B., "Famine on Barro Colorado Island, ' pp. 201-212 in E.G. Leigh, Jr. et al. (eds.), The Ecology of a Tropical Forest, Seasonal Rhythms and Long-Term Changes (Washington DC: Smithsonian Institution Press, 1982), pp. 201-212.

79. Franklin, J.F., D.A. Perry, and T.D. Schowalter, "The Importance of Ecological Diversity," D.A. Perry et al.(eds.), Maintaining the Long-Term Productivity of Pacific Northwest Forest Ecosystems (Portland, OR: Timber Press, 1989).

80. French, H.A., "'Clearing the Air: A Global Agenda, ' Worldwatch Paper 94 (Washington, DC: Worldwatch Institute, January 1990).

81. Gammon, R.H. and K. Kelly, "Biomass Burning Trace Signature of the Great China Fire of May, 1987,' paper presented at Chapman Conference on Global Biomass Burning: Atmospheric, Climatic and Biospheric Implications (Williamsburg, VA: Mar. 19-23, 1990)

82. Gates, D. M., "Global Biospheric Response to Increasing Atmospheric Carbon Dioxide Concentration, " U.S. Department of Energy, Direct Effects of Increasing Carbon Dioxide on Vegetation, B.R. Strain and J.D. Cure (eds.), DOE/ER-0238 (Washington DC: Office of Energy Research, December 1985), pp. 171-184.

83. Gillis, A., "The New Forestry, An Ecosystem Approach to Land Management," Bioscience 40(8): 558-562, September 1990.

84. Gillis, M. and R. Repetto, "Conclusion: Findings and Policy Implications, ' chapter 9 in R. Repetto and M. Gillis (eds.), Public Policies and the Misuse of Forest Resources (Washington DC: World Resources Institute, 1988),

85. Goodman, G.T., "Biomass Energy in Developing Countries: Problems and Challenges, "Ambio 16 (2-3):1 11-119, 1987.

86. Gorte, J.K. and R.W. Gorte, "Employment and Community Stability in the Forest Products Industries, " D.C. LeMaster and J.H. Benter (eds.), Community Stability in Forest-Based Economies (Portland, OR: Timber Press, 1989).

87. Gradwohl, J. and R. Greenberg, Saving the Tropical Forests (London: Earthscan Publishing, Ltd., 1988).

88. Grainger, A., "Estimating Areas of Degraded Tropical Lands Requiring Replenishment of Forest Cover," Int. Tree Crops $J$. 5(1/2):31-61, 1988 . 
89 Gregersen, H, M., ' 'People, Trees, and Rural Development: The Role of Social Forestry," J Forestry 86(10):22-30, October 1988.

90 Gruenfeld, J. and B. Flynn, "Log Exports: An Update," American Forests 96(9-10):50-53,74-76, September/October 1990.

91. Gunn, T.L. and B. Hannon, "Energy Conservation and Recycling in the Paper Industry," Resources and Energy, pp. 243-260, May 1983,

92. Hail, C. A, S., "Sanctiomng Resource Depletion: Economic Development and Neo-Classsical Economics,' The Ecologist 20(3):99104, May/June 1990.

93. Harmon, M.E., W.K. Ferrell, and J.F. Franklin, "Effects on Carbon Storage of Conversion of Old-Growth Forests to Young Forests, "Science 247:699-702, Feb. 9, 1990.

94. Harrison, P., The Greening of Africa (New York, NY: Viking/ Penguin, Inc., 1987).

95. Hartshorn, G. S., "Possible Effects of Global Warming on the Biological Diversity in Tropical Forests, " paper presented at Consequences of the Greenhouse Effect for Biological Diversity (Washington, DC: World Wildlife Fund, Oct. 4-6, 1988),

96. Hartshorn, G. S., ' 'Application of Gap Theory to Tropical Forest Management: Natural Regeneration on Strip Clear-Cuts in the Peruvian Amazon," Ecology 70(3):567-569, June 1989,

97. Hartshorn, G. S., R. Simeone, and J.A. Tosi, Jr., "Sustained Yield Management of Tropical Forests: A Synopsis of the Palcazu Development Project in the Central Selva of the Peruvian Amazon,' J.C. Figueroa C., F.H. Wadsworth, and S. Branham (eds.), Management of the Forests of Tropical America: Prospects and Technologies (Rio Piedras, Puerto Rico: Institute of Tropical Forestry, 1987), pp. 235-243,

98. Hecht, S. B., "The Sacred Cow in the Green Hell: Livestock and Forest Conversion in the Brazilian Amaze\%' The Ecologist 19(6):229-234, November/December 1989.

99. Heilman,P.E. and R.F.Stettler, "Genetic Variation and Productivity of Populus Trichocarpa T and G and Its Hybrids, II: Biomass Production in a 4-Year Plantation, " Canadian J. For, Res. $15: 384-388,1985$

100. High, C. and K. Skog, "Current and Projected Wood Energy Consumption in the United States, " paper presented at $I G T$ Symposium on Energy from Biomass and Wastes XIII (New Orleans, LA: Feb. 13-17, 1989).

101. Hildyard, N., "Amazonia: The Future in the Balance," The Ecologist 19(6):207-210, November/December 1989

102. Holowacz, R. A., "Forests of the U. S. S.R., " The Forestry Chronicle 61(5):366-373, 1985.

103. Houghton, R.A. "The Global Carbon Cycle, " Science 241 :1736, Sept. 30, 1988

104. Houghton, R. A., ' 'Emissions of Greenhouse Gases, ' Part 4 (pp. 53-62) in N. Myers, Deforestation Rates in Tropical Forests and Their Climatic Implications (London: Friends of the Earth Ltd., 1989).

105, Houghton, R. A., “The Global Effects of Tropical Deforestation' Environ. Sci.Technol.24(4):414-421, 1990.

106. Houghton, R.A., "The Future Role of Tropical Forests in Affecting the Carbon Dioxide Concentration of the Atmosphere, ' Ambio 19(4):204-209, July 1990

107. Houghton, R.A. et al., "The Flux of Carbon From Terrestrial Ecosystems to the Atmosphere in 1980 Due to Changes in Land Use: Geographic Distribution of the Global Flux, ' Tel/us 39B: 122139, 1987.

108, Houghton, R.A. et al., "Net Flux of Carbon Dioxide from Tropical Forests in 1980," Nature 316:617-620, Aug. 15, 1985.

109. Houghton, R.A. and G.M.Woodwell, "Global Climate Change," Scientific American 260(4):36-44, April 1989

110, Huang, Y.J., H. Akbari, and H. Taha, "The Wind-Shielding and Shading Effects of Trees on Residential Heating and Cooling Requirements,' paper AT-90-24-4 presented at ASHRAE January 1990 Meeting (Atlanta, GA: American Society of Heating, Refrigerating and Air-Conditioning Engineers, 1990).
111. Hyde, W. F., R.G. Boyd, and B .L. Daniels, " The Impacts of Public Interventions: An Examination of the Forestry Sector, 'Journal of Policy Analysis and Management 7(1):40-61, 1987.

112. Idaho National Engineering Laboratory, Los Alamos National Laboratory, Oak Ridge National Laboratory, Sandia National Laboratories, Solar Energy Research Institute, The Potential of Renewable Energy, An Interlaboratory Analytic Paper, draft prepared for U.S. Department of Energy, Office of Policy, Planning and Analysis (January 1990).

113. Institute of Tropical Forestry, "Annual Letter, 1987-88" (Rio Piedras, Puerto Rico: September 1988),

114. Intergovernmental Panel on Climate Change, "Report of the Subgroup on Agriculture, Forestry, and Other Human Activities" (Geneva, Switzerland: World Meteorological Organization and UN Environment Program, March 1990).

1 14a. Intergovernmental Panel on Climate Change, The IPPC Response Strategies, working draft (Geneva, Switzerland: World Meteorological Organization and UN Environment program, October 1990).

115. International City Management Association Trends in Urban Forestry Management 20(1): 1-17, January/February 1988.

116. International Fund for Agricultural Research, "A program to Accelerate the Survey, Collection, Conservation and Use of the Diversity of Selected Tree Species of the Tropics" (Arlington, VA: April 1990).

117. International Institute for Applied Systems Analysis, "Envisaged Climate Changes Could Kill Boreal Forests, Options, September 1989, pp. 8-9.

118. International Tropical Timber Organization, "ITTO Guidelines for the Sustainable Management of Natural Tropical Forests, " Permanent Committee on Reforestation and Forest Management, Sixth Session, PCF(VJ)/16 (Denpasar, Bali, Indonesia: May 21, 1990).

119. International Union of Forestry Research Organizations, "INCAFORE: A Research and Extension System for Tropical Forestry" (Vienna, Austria: January 1989).

120. Janzen, D. H., "Tropical Ecological and Biocultural Restoration" Science 239:243-244, Jan. 15, 1988.

121. Jonkers, W.B.J. and P. Schmidt, "Ecology and Timber Production in Tropical Rainforest in Suriname, 'Interciencia 9(5):290-297. 1984.

122, Joyce, L. A., M.A. Fosberg, and J.M.Comanor, Climate Change and America's Forests, Rocky Mountain Forest and Range Experimental Station General Technical Report RM-187(Fort Collins, CO: U.S. Department of Agriculture, Forest Service, February 1990).

123. Kalapula, E. S., "'Woodfuel Situation and Deforestation in Zambia," Ambio 18(5):293-294, 1989.

124. Kaufman, Y.J., CJ. Tucker, and I. Pung, "Remote Sensing of Biomass Burning in the Tropics," J.Geophysical Research 95(D7):9927-9939, June 20, 1990.

125. Kauppi, P. and M. Posch, "Boreal Forests and the Global Carbon Cycle," Science 243:1535-1536, Mar. 24, 1989.

126. Keller, M., W.A. Kaplan, and S.C. Wofsy, "Emissions of $\mathrm{N}_{2} \mathrm{O}$, $\mathrm{CH}_{4}$ and $\mathrm{CO}_{2}$ From Tropical Forest Soils, "Journ.Geophysical Research 91(D11): 1 1,791-11,802, Oct. 20, 1986.

127. Kinsman, J.D. and G. Marland, "Contribution of Deforestation to Atmospheric $\mathrm{CO}_{2}$ and Reforestation as an Option to Control CO, , paper 89-148.5 presented at 82nd Annual Meeting \& Exhibition, Air \& Waste Management Association (Anaheim, CA: June 25-30, 1989).

128. Kramer, P.J. and N. Sionit, "Effects of Increasing Carbon Dioxide Concentration on the Physiology and Growth of Forest Trees, " W.E. Shands and J.S. Hoffman (eds.), The Greenhouse Effect, Climate Change, and U.S. Forests (Washington DC: The Conservation Foundation, 1987), pp. 219-246.

129. Kurtz, W.B., R.J.Alig, and T.J. Mills, "Retention and Condition of Agricultural Conservation Program Conifer Plantings, ' $J$. Forestry 78(5):273-276, May 1980. 
130. Lal, R., "Potential of Agroforestry as a Sustainable Alternative to Shifting Cultivation: Concluding Remarks, "Agroforestry Systems 8:239-242,1989.

131. Lanly, J.P., "Defining and Measuring Shifting Cultivation" Unasylva 37(147): 17-21, 1985

132. Lavelle, P., “Yurimaguas Technology, ” Bioscience 37(9):638639, October 1987.

133. Leach, G., “Woodfuels (and Smallholder Molestation), ” paper presented at IPCC Tropical Forestry Response Options Workshop (Sao Paulo, Brazil: Jan. 9-12, 1990).

134. Leach, G. and R. Mearns, Beyond the Woodfuel Crisis-People, Land and Trees in Africa (London: Earthscan Publishing, Ltd., 1988)

135. Leslie, A. J., "A Second Look at the Economics of Natural Management Systems in Tropical Mixed Forests, "Unasylva 39(1):46-58, 1987

136. Leverenz, J.W. and D.J. Lev, "Effects of Carbon Dioxide-Induced Climate Changes on the Natural Ranges of Six Major Commercia Species in the Western United States," W.E. Shands and J.S Hoffman (eds.), The Greenhouse Effect, Climate Change, and U.S Forests (Washington, DC: The Conservation Foundation 1987), pp. 123-155.

137. Levine, J.S. et al., "Enhanced Biogenic Emission of $\mathbf{C H}_{4}, \mathrm{~N}_{2} \mathbf{O}$, and NO Following Burning," paper presented at Chapman Conference on Global Biomass Burning: Atmospheric, Climatic and Biospheric Implications (Williamsburg, VA: Mar. 19-23, 1990).

138. Levine, J.S. et al., "The Great Chinese Fire of 1987: Emission of Trace Gases to the Atmosphere," paper presented at Chapman Conference on Global Biomass Burning: Atmospheric, Climatic and Biospheric Implications (Williamsburg, VA: Mar. 19-23, 1990).

139. Library of Congress, Congressional Research Service, "Timber Industry Possible Effects of Various Tax Reform Proposals," Issue Brief IB86009 (Washington DC: Dec. 1, 1986).

140. Library of Congress, Congressional Research Service, "Canadian Lumber Imports: Impacts of the U.S. Lumber Industry," Report No. IB85178 (Washington DC: Feb. 9, 1987).

141. Library of Congress, Congressional Research Service, "Debt-forNature Swaps in Developing Countries: An Overview of Recent Conservation Efforts," 88-647 ENR (Washington DC: Sept. 26, 1988).

142. Library of Congress, Congressional Research Service, "Tropical Deforestation: International Implications,' IB8901O (Washington DC: May 25, 1989).

143. Library of Congress, Congressional Research Service, "Wood Export Promotion,' 90-94 ENR(Washington, DC: Feb. 15, 1990).

144. Library of Congress, Congressional Research Service, "Economic Impacts of protecting the Northern Spotted Owl," 90-74 ENR (Washington, DC: Mar. 5, 1990).

145. Lobert, J.M. et al., "Importance of Biomass Burning in the Atmospheric Budgets of Nitrogen-Containing Gases," Nature 346:552-554, Aug. 9, 1990.

146. Lohmann, L. and M. Colchester, "Paved With Good Intentions: TFAP's Road to Oblivion," The Ecologist 20(3):91-98, May/June 1990

147. Lovejoy, T. E., "Rehabilitation of Degraded Tropical Forest Lands," The Environmentalist 5(1):13-20,1985.

148. Lovett, S. M., "Prepared Statement of Stephen M. Lovett," Iapanese Trade Barriers to Forest Products, Hearing before the Subcommittee on International Trade of the Committee on Finance, United States Senate, S. Hearing 101-526, Part 2 (Washington, DC: U.S. Government Printing Office, 1990).

149. Lugo, A, E., "Ecosystem Rehabilitation in the Tropics," Environment 30(7): $17-20,41=45,1988$.

150, Lugo, A.E. and S. Brown, "Steady State Terrestrial Ecosystems and the Global Carbon Cycle," Vegetatio 68:83-90, 1986.
151. Lundgren, B. and P.K.R. Nair, "Agroforestry for Soil Conservation," pp. 703-717 in S.A. El-Swaify, W.C.Moldenhauer, and A. Lo (eds.), Soil Erosion and Conservation (Ankeny, IA: Soil Conservation Society of America, 1985).

152. MacNeill, J., P. Winsemius, and T. Yakushiji, Beyond Interdependence, The Meshing of the World's Economy and the Earth's Ecology, A Report to the Trilateral Commission (Institute for Research on Public Policy, 1990).

153. Mahar, D., Governmental Policies and Deforestation in Brazil's Amazon Region (Washington DC: The World Bank, 1989).

154. Maitre, H.F., "Natural Forest Management in Cote d'Ivoire," Unasylva 39 (3/4):53-60, 1987.

155. Marland, G., ' 'The Prospect of Solving the $\mathrm{CO}_{2}$ Problem Through Global Reforestation," DOE/NBB-0082 (Washington DC: U.S. Department of Energy, Office of Energy Research, February 1988).

156. Marland, G., "Reforestation: Pulling Greenhouse Gases Out of Thin Air," pp. 14-18, Biologue, 6(2):14-18, April/May 1989.

157. McGahuey, M., "Impacts of Forestry Initiatives in the Sahel" (Washington, DC: Chemonics, undated).

158. McLarney, W.O., 'Guanacaste: The Dawn of a Park," The Nature Conservancy Magazine 38(l): 11-15, January/February 1988.

159. McNeely, J.A. et al., Conserving the World's Biological Diversity (Philadelphia, PA: International Union for Conservation of Nature and Natural Resources, World Resources Institute, Conservation International, World Wildlife Fund-US, and World Bank, 1990).

160. McPherson, E. G., "Vegetation To Conserve Water and Mitigate Urban Heat Islands, " pp. 54-69 in Controlling Summer Heat Islands, LBL-27872 (Berkeley, CA: Lawrence Berkeley Laboratory, Feb. 23-24, 1989).

161. Melillo, J.M. et al., "Land-use Change in the Soviet Union Between 1850 and 1980: Causes of a Net Release of $\mathbf{C O}_{2}$ to the Atmosphere," Tellus 40B:116-128, 1988.

162. Melillo, J.M. et al., "A Comparison of Two Recent Estimates of Disturbance in Tropical Forests, " Environmental Conservation 12(1):37-40, 1985

163. Meyers, S. and G. Leach, "Biomass Fuels in the Developing Countries: An Overview," LBL-27222 (Berkeley, CA: Lawrence Berkeley Laboratory, May 1989).

164. Miller, R.H. and P. Sanchez, 'Testimony Before the United States Senate, Senate Appropriations Subcommittee on Foreign Operations, Agriculture Committee" (Washington, DC: May 10, 1989).

165. Miller, W. F., P.M. Dougherty, and G.L.Switzer, "Effect of Rising Carbon Dioxide and Potential climate Change on Loblolly Pine Distribution, Growth, Survival, and productivity, "W.E. Shands and J.S. Hoffman (eds.), The Greenhouse Effect, Climate Change, and U.S. Forests (Washington, DC: The Conservation Foundation 1987), pp. 157-187.

166. Moll, G., "The State of Our City Forests,' American Forests, pp. 6-8, May/June 1989

167. Moll, G., “'The State of Our Urban Forests, " American Forests, pp. 61-64, November/December 1989

168. :Moulton, R-J. and M.R. Dicks, "Implications of the 1985 Farm Act for Forestry," paper presented at 1987 Joint Annual Meeting of the Southern and Midwest Forest Economists (Asheville, NC: Apr. 8-10, 1987).

169. 1Moulton, R.J. et al., "The Timberland in Conservation Reserve IProgram and Its Effect on Southern Rural Economies,' proceedings, 1989 Annual Meeting of the Southern Forest Economists (San Antonio, TX: March 1989), pp. 145-159.

170. 1Moulton, R.J. and K.R. Richards, "Costs of Sequestering Carbon 'Through Tree Planting and Forest Management in the United States," draft General Technical Report (Washington DC: U.S Forest Service, June 19, 1990).

170a. Moulton, R.J., U.S. Forest Service, personal communication, Mar. 2, 1990 .

171. Mumford, J.L. et al., "Lung Cancer and Indoor Air Pollution in Xuan Wei, China," Science 235:217-220, Jan. 9, 1987. 
172 Myers, N., Conversion of Tropical Moist Forests (Washington, DC: National Academy of Sciences, 1980).

173 Myers, N., The Primary Source: Tropical Forests and Our Future Earth (New York, NY: W.W. Norton\& Co., 1984).

174 Myers, N., Deforestation Rates in Tropical Forests and Their Climatic Implications (London: Friends of the Earth Ltd., 1989).

175. Myers, N., "The World's Forests and Human Populations: The Environmental Interconnections," paper in K. Davis and M.S. Bernstam (eds.) Population and Development Review (1990 in press),

176 Nair,P. K. R., ' 'Multiple Land-Use and Agroforestry,' Better Crops for Food: Ciba Foundation Symposium 97 (London: Pitman Books, Ltd., 1983), pp. 101-115.

177. Nambiar, E, K, S., ' 'Plantation Forests: Their Scope and a Perspective on Plantation Nutrition.' G.D. Bowen and E.K.S. Nambiar (eds.), Nutrition of Plantation Forests (London: Academic Press, 1984), pp. $1-15$

178, National Acid Precipitation Assessment Program, Changes in Forest Health and Productivity in the United States of America, State-of-SciencelTechnology Report 16, draft manuscript (December 1989)

179, National Association of State Foresters, "Global Warming and Forestry in the United States, " Background Paper (Washington, DC: April 1990).

180. National Research Council, Tropical Legumes: Resources for the Future (Washington, DC: National Academy of Sciences Press, 1979).

181. National Research Council, Firewood Crops, Shrub and Tree Species for Energy Production, Volume 2 (Washington DC: National Academy of Sciences Press, 1983).

182. National Research Council, Calliandra A Versatile Small Tree for the Humid Tropics (Washington, DC: National Academy of Sciences Press, 1983)

183. National Research Council, Butte fly Farming in Papua New Guinea (Washington, DC: National Academy of Sciences Press, 1983),

184, National Research Council, Crocodiles as a Resource for the Tropics (Washington, DC: National Academy of Sciences Press, 1983).

185, National Research Council, Casuarinas: Nitrogen-Fixing Trees for Adverse Sires ('Washington, DC: National Academy of Sciences Press, 1984).

186. National Research Council, Leucaena: Promising Forage and Tree Crop for the Tropics (Washington, DC: National Academy of Sciences Press, 1984)

187. National Wood Energy Association, Federal Programs for Research and Development of Biomass and Municipal Waste Technology, Industry Analysis and Recommendations for Funding for FY 1990 (Arlington, VA: 1990).

188. Nepstad, D., C. Uhl, and E.A.Serrao, "Surmounting Barriers to Forest Regeneration m Abandoned, Highly Degraded Pastures (Parogominas, Para, Brazil), ' A.B. Anderson (cd.), Alternativesto Deforestation Steps Toward Sustainable Utilization of Amazon Forests (New York, NY: Columbia University Press, 1990).

189. Nixon, D , "Canada Blazing,' American Forests 96(5\&6):33-35, May/June 1990,

190. Oechel, W.C. and B.R. Strain, ' 'Native Species Responses to Increased Atmospheric Carbon Dioxide Concentration" in U.S. Department of Energy, Direct Effects of Increasing Carbon Dioxide on Vegetation, B.R.Strain and J.D. Cure (eds.), DOE/ER0238 (Washington, DC: Office of Energy Research, December 1985), pp. 117-154,

191. Office of Management and Budget, Executive Office of the President, Budget of the United States Government, Fiscal Year 1991 (Washington, DC: U.S. Government Printing Office, 1990).

192. O'Keefe, P. and B. Munslow, "Understanding Fuelwood, 1: A Critique of Existing Intervention in Southern Africa, Natural Resources Forum, pp. 2-10, February 1989.
193. Overpeck, J.T., D. Rind, and R. Goldberg, "Climate-induced Changes in Forest Disturbance and Vegetation," Nature 343:5153, Jan. 4, 1990.

194. Overseas Private Investment Corp., Fiscal 1988 Development Report (Washington, DC: 1989).

195, Painter, J., "Unpaid Debt to Nature, "South August, pp. 108-109, 1989.

196. Palmberg, c., "Research Needs in Forest Tree Breeding and Improvement in Developing Countries, "Agroforestry Systems 9:29-35, 1989.

197. Parker, J. H., "The Use of Shrubs in Energy Conservation Plantings," Landscape Journal 6:1 32-139, 1987.

198, Pasca, T. M., "The Politics of Tropical Deforestation\%" American Forests 94(1 1/12):21-24, November/December 1988.

199. Patterson, D., "Hugo Leaves Serious Fire Threat Behind," Associated Press, newswire, Jan. 18, 1990.

200. Perry, D. A., 'Landscape Pattern and Forest Pests, The Northwest Environmental Journal 4:213-228, 1988.

201, Peters, C. M., "Rain Forest Economics," The World \& I 5:324331, August 1990.

202. Peters, C. M., A.H. Gentry, and R.O. Mendelssohn, "Valuation of an Amazonian Rainforest," Nature 339:655-656, June 29, 1989

203. Poore, D. et al., No Timber Without Trees: Sustainability in the Tropical Forest (London: Earthscan Publishing, Ltd., 1989).

204, Postel, S. and L. Heise, Reforesting the Earth, Worldwatch Paper 83 (Washington, DC: Worldwatch Institute, 1988).

205. President's Interagency Drought Policy Committee, The Drought of 1988, Final Report of the President's Interagency Drought Policy Committee (Washington, DC: Dec. 30, 1988)

206. Quay, P.D. et al., "Methane Release Rate From Biomass Burning: Estimates Derived From ${ }^{13} \mathrm{C}$ Composition of Atmospheric Methane,' paper presented at Chapman Conference on Global Biomass Burning: Atmospheric, Climatic and Biospheric Implications (Williamsburg, VA: Mar. 19-23, 1990).

207. Raintree, J.B. and K. Warner, "Agroforestry Pathways for the Intensification of Shifting Cultivation,' Agroforestry Systems 4:39-54, 1986

208. Ranney, J.W. et al., "Hardwood Energy Crops: The Technology of Intensive Culture, ' J. Forestry 85: 17-28. September 1987.

209, Rathje, W.L. et al., "Source Reduction and Landfill Myths," paper presented at ASTSWMO National Solid Waste Forum on Integrated Municipal Waste Management (Lake Buena Vista, FL: July $17-20,1988)$,

210. Regens, J.L., F.W.Cubbage, and D.G. Hodges, "Greenhouse Gases, Climate Change, and U.S. Forest Markets, "Environment 31(4):4-5,41, May 1989

211, Reid, W., "Sustainable Development; Lessons From Success," Environment 31(4):7-35, May 1989.

212. Reilly, W.K., "Debt-for-Nature Swaps: The Time Has Come, ' International Environmental Affairs 2(2): 134-139, Spring 1990.

213. Repetto, R., "Creating Incentives for Sustainable Forest Developmerit, " Ambio 16(2-3):94-99, 1987.

214. Repetto, R., "Needed: New Policy Goals," American Forests 94(1 1/12):59,82-86, November/December 1988

215. Repetto, R., "The Forest for the Trees? Government Policy and the Misuse of Forest Resources' (Washington, DC: World Resources Institute, 1988).

216. Repetto, R., "Overview, " chapter 1 in R. Repetto and M. Gillis (eds), Public Policies and the Misuse of Forest Resources (Washington, DC: World Resources Institute, 1988).

217. Repetto, R. et al., Wasting Assets: Natural Resources in the National Income Accounts (Washington DC: World Resources Institute: June 1989).

218, Repetto, R. and J. Pezzey, "The Economics of Sustainable Development,' overview paper prepared for UNECE/USEPA Workshop on the Economics of Sustainable Development (Washington, DC: Jan. 23-26, 1990). 
219 Robertson, G.P. and J.M. Tiedje, "Deforestation Alters Denitrification in a Lowland Tropical Rain Forest, "Nature 336:756-759, Dec. 22 and 29, 1988.

220 Robinson, G., The Forest and the Trees (Washington DC: Island Press, 1988).

221 Rockefeller Foundation United Nations Development Pro-e, World Bank, and Food and Agriculture Organization of the United Nations, A Global Research Strategy for Tropical Forestry, Report of an International Task Force on Forestry Research, September 1988.

222. Rogers, H.H., J.F. Thomas, and G.E. Bingham, "Response of Agronomic and Forest Species to Elevated Atmospheric Carbon Dioxide," Science 220:428-429, Apr. 22, 1983.

223. Rosenfeld, A.H. and D.B. Botkin, "Trees Can Sequester Carbon, Or Die and Amplify Global Warming: Possible Feedback Between Rising Temperature, Stressed Forests, and $\mathrm{CO}_{2}$, Physics and Society 19(2):5-8, April 1990.

224. Ross, M.S. and D.G. Donovan, "The World Tropical Forestry Action Plan: Can It Save the Tropical Forests?" J. World Forest Resource Management 2:1 19-136, 1986.

225. Ross-Sheriff, B. and P. Cough, "Background Paper, Intergovernmental Parel on Climate Change (IPCC) Tropical Forestry Response Options Workshop," prepared for U.S. Environmental Protection Agency (Washington, DC: International Resources Group, Ltd., January 1989).

226. Royer, J.P. and R.J. Moulton, "Reforestation Incentives, " $J$. Forestry 85(8):45-47, August 1987.

227. Row, C., ' 'Global Warming and Pacific Northwest Forest Management: An Environmental Issue, ' unpublished manuscript (Phoenix, AZ: h\&y 1989).

228. Ryan, J. C., "Timber's Last Stand, ” World Watch 3(4):27-34, July/August 1990.

229.Salisbury, H.E., The Great Black Dragon Fire, A Chinese Inferno (Boston, MA: Little, Brown and Co., 1989).

230. Sampson, R. N., “ReLeaf for Global warming," American Forests 94 (11/12):9-14, November/December 1988.

231. Sanchez, P., "Deforestation Reduction Initiative: An Imperative for World Sustainability in the Twenty-First Century," paper presented at the Bureau of Science and Technology, U.S. Agency for International Development (Washington, DC: 1988),

232. Sanchez, P.A. et al., "Amazon Basin Soils: Management for Continuous Crop Production," Science 216:821-827, May 21, 1982.

233. Sanchez, P. and J.R. Benites, "Imw Input Cropping for Acid Soils of the Humid Tropics," Science 238:1521-1527, 1987.

234. Sattaur, O., ' 'Forest 'Preservation' Plan Comes Under Fire From Third World Group, "New Scientist125(1710):25, Mar. 31, 1990.

235. Schmidt, R., "Tropical Rairı Forest Management,"Unasylva 39(2):2-17, 1987.

236. Schowalter, T.D., "Forest Pest Management: A Synopsis," The Northwest Environmental Journal 4:313-318, 1988.

237. Schowalter, T. D., W.W. Hargrove, and D.A. Crossley, Jr., "Herbivory in Forested Ecosystems," Annual Rev. Entomology $31: 177-196,1986$

238. Sedjo, R. A., "Climate and Forests, " Science 244:631, May 12, 1989.

239. Sedjo, R.A., "Forests To Offset the Greenhouse Effect," J. Forestry 87(7): 12-15, July 1989.

240. Sedjo, R.A., "Forests, A Tool To Moderate Global Warming?" Environment 31(1):14-20, January/February 1990.

241. Sedjo, R.A. and A. Solomon, "Climate and Forests," N.J. Rosenberg et al. (eds.), Greenhouse Warming: Abatement and Adaption (Washington, DC: Resources for the Future, 1989).

242. Serrao, E, A., "Pasture Development and Carbon Emission/ Accumulation in the Amazon, "Contribution to the IPCC Meeting on Gas Emission from Conversion of Tropical Forests (Sao Paulo, Brazil: January 1990).
243. Shaikh, A. et al., Opportunities for Sustained Development, Successful Natural Resources Management in the Sahel (Washington, DC: E/DI, October 1988).

243a. Shen, S., World Bank, personal communication Aug. 23, 1990.

244. Shiva, V., "Biodiversity, Biotechnology and Profit: The Need for a Peoples' Plan to Protect Biological Diversity," The Ecologist 20(3):44-47, March/April 1990.

245. Shukla, J., C. Nobre, and P. Sellers, "Amazon Deforestation and Climate Change," Science 247: 1322-1325, Mar. 16, 1990.

246. Smith, D., The Practice of Silviculture (New York, NY: John Wiley \& Sons, 1986).

247. Smith, K.R., Biomass Fuels, Air Pollution, and Health: A Global Review (New York, NY: Plenum Publishing Co., 1987).

248. Smith, K.R., A.L. Aggarwal, and R.M. Dave, "Air Pollution and Rural Biomass Fuels in Developing Countries: A Pilot Village Study in India and Implications for Research and Policy," Atmospheric Environment 17(1 1):2343-2362, 1983.

249. Smith, N., "Colonization Lessons From a Tropical Forest," Science 214:755-761, Nov. 13, 1981.

250. Society of American Foresters, "Scheduling the Harvest of Old Growth,"SAF Resources Policy Series (Bethesda, MD: 1984).

251. Society of AmericanForesters, "O1d-Growth Forests in the Pacific Northwest," Professional View (Bethesda, MD: July 6, 1989).

252. Spears, J., "Containing Tropical Deforestation: A Review of Priority Areas for Technological and Policy Research,"'L.R Meyers (cd.), Innovation in Resource Management, Proceedings of the Ninth Agriculture Sector Symposium (Washington DC: The World Bank, October 1989), pp. 135-150.

253. Spies, T.A., J.F. Franklin, and T.B. Thomas, "Coarse Woody Debris in Douglas-fir Forests of Western Oregon and WashingIon," Ecology 69(6): 1689-1702, 1988.

254. Steiner, F. "Agroforestry's Coming of Age, " Journal of Soil and Water Conservation 43(2):157-158, March-April 1988.

255. Steudler, P.A. et al., "Influence of Nitrogen Fertilization on Methane Uptake in Temperate Forest Soils,' Nature 341:314-316, Sept. 28, 1989.

256. Stocks, B.J., "The Extent and Impact of Forest Fires in Northern Circumpolar Countries,' paper presented at Chapman Conference on Global Biomass Burning. Atmospheric, Climatic and Biospheric Implications (Williamsburg, VA: Mar. 19-23, 1990).

257. Tans, P.P., I.Y. Fung, and T, Takahashi, "Observational Constraints on the Global Atmospheric $\mathrm{CO}_{2}$ Budget, "Science 247:1431-1438, Mar. 23, 1990.

258. Thaman, R.R., "Coastal Reforestation and Agroforestry as Immediate Ameliorative Measures To Address Global Warming and To Promote Sustainable Habitation of Low-Lying and Coastal Areas, "D.G. Streets and T.A. Siddiqi (eds.), Responding to the Threat of Global Warming: Options for the Pacific and Asia, ANL/EAIS/TM-17 (Argonne, IL: Argonne National Laboratory, 1989), pp. 4-33457.

259. The Economist, "The Vanishing Jungle," The Economist, pp. 25-28, Oct. 15, 1988

260. Trexler, M. C., P.E. Faeth, and J.M. Kramer, "Forestry as a Response to Global Warming: An Analysis of the Guatemala Agroforestry and Carbon Sequestration Project" (Washington, DC: World Resources Institute, June 1989).

261. Tsukada, M., "Pseudotsuga menziesii (Mirb.) France: Its Pollen Dispersal and Late Quarternary History in the Pacific Northwest' Japanese Jour. Ecology 32:159-187, 1982.

262. Udall, L., Environmental Defense Fund, "The Environmental and Social Performance of the International Development Association," Testimony before the Subcommittee on international Development, Finance, Trade and Monetary Policy, Committee on Banking, Finance and Urban Affairs, U.S. House of Representatives, Mar. 28, 1990.

263. Uhl, C. and I.C.G. Vieira, "Ecological Impacts of Selective Logging in the Brazilian Amazon: A Case Study From the Paragominas Region of the State of Para, "Biotropica 21(2):98[06, 1989. 
264, Ullsten, O., S. Mohd. Nor, and M. Yudelman, Tropical Forestry Action Plan, Report of the Independent Review, report to the U.N. Food and Agriculture Organization (Kuala Lumpur, Malaysia: May 1990).

265, United Nations, "International Tropical Timber Agreement, 1983" (New York: 1984).

266. U.S. Agency for International Development, Environment and Natural Resources: Strategies for Sustainable Agriculture, A Task Force Report of the Board for International Food and Agricultural Development (Washington, DC: February 1988).

267. U.S. Agency for International Development, Progress in Conserving Tropical Forests and Biological Diversity in Developing Countries (Washington DC: June 1988).

268. U.S. Agency for International Development, Energy Efficient Stoves in East Africa: An Assessment of the Kenya Ceramic Jiko (Stove) Program, prepared by Oak Ridge National Laboratory for the Office of Energy, Bureau for Science and Technology, Report No. 89-01 (Washington, DC: Jan, 31, 1989).

269, U.S. Congress, "Continuing Appropriations for the Fiscal Year Ending September, 1988, ' Conference Report 100-498 (WashingIon, DC: Dec. 21, 1987).

270. U.S. Congress, General Accounting Office, "Tongass National Forest, Timber Provision of the Alaska Lands Act Needs Clarification,' GAO/RCED-88-54 (Washington DC: U.S. Government Printing Office, April 1988).

271. U.S. Congress, General Accounting Office, "Conservation Reserve Program Could Be Less Costly and More Effective,' GAO/RCED-90-13 (Washington, DC: November 1989),

272. U.S. Congress, General Accounting Office, "Forest Service Timber Harvesting, Planting, Assistance Programs and Tax Provisions, " GAO/RCED-90-107BR (Washington, DC: April 1990).

273. U.S. Congress, Office of Technology Assessment, Energy From Biological Processes, OTA-E-124 (Springfield, VA: National Technical Information Service, July 1980).

274. U.S. Congress, Office of Technology Assessment, Wood Use: US. Competitiveness and Technology, OTE-E-21O (Springfield, VA: National Technical Information Service, August 1983).

275. U.S. Congress, Office of Technology Assessment, Technologies to Sustain Tropical Forest Resources, OTA-F-214 (Springfield, VA: National Technical Information Service, March 1984).

276. U.S. Congress, Office of Technology Assessment, Acid Rain and Transported Air Pollutants: implications for Public Policy, OTA-O-204 (Springfield, VA: National Technical Information Service, June 1984)

277. U.S. Congress, Office of Technology Assessment, Wastes in Marine Environments, OTA-O-334 (Springfield, VA: National Technical Information Service, April 1987).

278. U.S. Congress, Office of Technology Assessment, Integrated Renewable Resource Management for US, Insular Areas, OTA-F325 (Springfield, VA: National Technical Information Service, June 1987).

279. U.S. Congress, Office of Technology Assessment, Enhancing Agriculture in Africa: A Role for U.S. Development Assistance, OTA-F-356 (Washington, DC: U.S. Government Printing Office, September 1988).

280. U.S. Congress, Office of Technology Assessment, Catching Our Breath: Next Steps for Reducing Urban Ozone, OTA-O-412 (Washington, DC: U.S. Government Printing Office, July 1989).

281, U.S. Congress, Office of Technology Assessment, Facing America's Trash: What Next for Municipal Solid Waste? OTA-O-424 (Washington, DC: U.S. Government Printing Office, October 1989).

282. U.S. Department of Agriculture and U.S. Agency for International Development, Proceedings of Conference on Improved Utilization of Tropical Forests (Madison, WI: 1978).

283. U.S. Department of Agriculture, Progress Report of the Forestry Support Program (FSP) 1988 (Washington, DC: Forest Service and Office of International Cooperation and Development, 1988),
284. U.S. Department of Agriculture, Conservation Reserve Program Work Group, Progress Report and Preliminary Evacuation of the First Two Years (Washington, DC: January 1989).

285. U.S. Department of Agriculture, Economic Research Service, Water Quality Benefits From the Conservation Reserve Program, Agricultural Economic Report No. 606 (Washington, DC: February 1989).

286. U.S. Department of Agriculture, Agricultural Stabilization and Conservation Service, "Supplement I to 'The Conservation Reserve Program: Progress Report and preliminary Evaluation of the First Two Years (Signups 1-7),, " Draft Report (Washington. DC: Feb. 13, 1990).

287. U.S. Department of Commerce, Bureau of the Census, Historical Statistics of the United States, Colonial Times to 1970, Part I (Washington, DC: U.S. Government Printing Office, September 1975).

288, U.S. Department of Energy, The Role of Temperate Zone Forests in the World Carbon Cycle-Problem Definition and Research Needs, CONF-79O31O5 (Washington, DC: Office of Health and Environmental Research, February 1980).

289. U.S. Department of Energy, Direct Effects of Increasing Carbon Dioxide on Vegetation, B.R. Strain and J.D. Cure (eds.), DOE/ER0238 (Washington DC: Office of Energy Research, December 1985).

290. U.S. Department of Energy, Five Year Research Plan, 1988-1992, Biofuels: Renewable Fuels for the Future, Biofuels and Municipal Waste Technology Division, DOE/CH10093-25 (Washington DC: July 1988)

291. U.S. Department of Energy, International Energy Annual, DOE/EIA-0219(88) (Washington, DC: Energy Information Administration, November 1989).

292. U.S. Department of State, The World's Tropical Forests: A Policy, Strategy, and Program for the United States, Report to the President by a U.S. Interagency Task Force on Tropical Forests, Publication 9117 (Washington, DC: U.S. Government Printing Office, May 1980).

293. U.S. Department of Treasury, “U.S. Treasury Department Report to Congress on Debt-for-Nature Swaps" (Washington, DC: April 1988).

294. U.S. Environmental Protection Agency, The Potential Effects of Global Climatic Change on the United States, Draft, Report to Congress (Washington DC: October 1988).

295. U.S. Environmental Protection Agency, Policy Options for Stabilizing Global Climate, Drafi, Report to Congress, Volume I: Chapters I-V (Washington DC: June 1990).

296. U.S. Environmental protection Agency, Office of Solid Waste, The Solid Waste Dilemma: AnAgendafor Action, EPA/530-SW-89019 (Washington DC: February 1989).

297. U.S. Forest Service, 1966 Forest Fire Statistics (Washington DC: U.S. Department of Agriculture, 1966).

298. U.S. Forest Service, Forest Health and Productivity in a Changing Atmospheric Environment, A Priority Research Program (Washington, DC: U.S. Department of Agriculture, 1988).

299. U.S. Forest Service, An Analysis of the Land Situation in the United States: 1989-2040, A Technical Document Supporting the 1989 RPA Assessment, General Technical Report RM-181 (Fort Collins, CO: U.S. Department of Agriculture, 1989).

300. U.S. Forest Service, An Analysis of the Timber Situation in the United States: 1989-2040, Part I: The Current Resource and Use Situation, Draft (Washington DC: U.S. Department of Agriculture, 1989),

301. U.S. Forest Service, An Analysis of the Timber Situation in the United States: 1989-2040, Part II: The Future Resource Situation, Draft (Washington, DC: U.S. Department of Agriculture, 1989).

302. U.S. Forest Service, 4. 1988 U.S. Forest Planting Report" (Washington, DC: U.S. Department of Agriculture, March 1989).

303. U.S. Forest Service, Timber Sale Program Annual Report, Fiscal Year 1988 Test, Forest Level Information (Washington, DC: U.S. Department of Agriculture, March 1989). 
304 U.S. Forest Service, "America the Beautiful, National Tree Planting Initiative" (Washington DC: U.S. Department of Agriculture, 1990).

305 U.S. Forest Service, "National Tree Planting Initiative, Questions and Answers About Trees' ('Washington DC: U.S. Department of Agriculture, Feb. 1, 1990).

306. U.S. Forest Service, “ 1991 Budget Explanatory Notes for Committee on Appropriations" (Washington DC: U.S. Department of Agriculture, 1990)

307. U.S. Forest Service, Timber Sale Program Annual Report, Fiscal Year 1989, National Summary (Washington DC: U.S. Department of Agriculture, March 1990).

308. U.S. Forest Service, "FY 1989 U.S. Forest Planting Report" (Washington, DC: U.S. Department of Agriculture, March 1990).

309. U.S. Forest Service, Report of the Forest Service, Fiscal Year 1989 (Washington, DC: U.S. Department of Agriculture, February 1990).

310. U.S. Forest Service, "Global Neighbors Growing Together, A Tropical Forestry Program" (Washington DC: U.S. Department of Agriculture, undated).

311. U.S. International Development Cooperation Agency, Interna tional Organ izations and programs, Congressional presentation, Fiscal Year 1991 (Washington, DC: February 1990).

312. U.S. International Development Cooperation Agency, Congressional Presentation, Fiscal Year 1991 (Washington, DC: February 1990),

313. van Wagner, C. E., "The Historical Pattern of Annual Burned Area in Canada," The Forestry Chronicle 64(3): 182-185, June 1988.

314, Vergara, N. T., “Agroforestry Systems, A Primer, " Unasylva 37(147):22-28, 1985.

315. Vietmeyer, N., "Urban Forestry," Summary Concept Paper (Washington, DC: National Academy of Sciences, 1988).

316. Vietmeyer, N., "Bamboo: The Poor People's Friend," Summary Concept Paper (Washington DC: National Academy of Sciences, 1989).

317. Vietmeyer, N., "Little-Known Palms: Multi-Purpose Resources for the Future, ' Summary Concept Paper (Washington DC: National Academy of Sciences, 1989).

318. Vietmeyer, N., "Imovations in Tropical Reforestation Increasing the Options: Future Species, " Concept Paper (Washington DC: National Academy of Sciences, 1989).

319. von Maydell, H. J., "The Contribution of Agroforestry to World Forestry Development,' Agroforestry Systems 3:83-90, 1985.

320. Wagner, R. B., ' 'Doing More With Debt-for-Nature Swaps, " international Environmental Affairs 2(2): 160-165, Spring 1990

321. Walker, B.H., 'Yurimaguas Technology,' Bioscience 37(9):638, October 1987.

322. Weischet, W., "Yurimaguas Technology, ' Bioscience 37(9):639640, October 1987.

323. Whitford, W. G., "Effects of Climate Change on Soil Biotic Communities and Soil Processes," paper presented at Consequences of the Greenhouse Effect for Biological Diversity (Washington, DC: World Wildlife Fund, Oct. 4-6, 1988).

324. Wilderness Society, End of the Ancient Forests, Special Report on Vational Forest Plans in the Pacific Northwest (Washington, DC: lane 1988).

325, Wilderness Society and National Wildlife Federation, National Forests: Policies for the Future, Volume 4, Pacific Northwest Lumber and Wood Products: An Industry in Transition (Washing- ton, DC: September 1988).

326. Wilderness Society, Old Growth in the Pacific Northwest, A Status Report (Washington DC: November 1988).

327. Wilson, D.C., "Ancient Trash, Modern Solid Wastes: An Archaeologist's Perspective on Reuse, Recycling, Waste, and Landfill Degradation' paper presented at National Solid Waste Management Symposium (Prescott, AZ: Apr. 10, 1989).

328. Winterbottom, R., Taking Stock: The Tropical Forestry Action Plan After Five Years (Washington, DC: World Resources Institute, June 1990).

329. Winterbottom, R. and P. Hazelwood, "Agroforestry and Sustainable Development: Making the Connection," Ambio 16(2-3): 100110.1987.

330. Woodwell, G, M., "Biotic Effects on the Concentration of Atmospheric Carbon Dioxide: A Review and Projection' Changing Climate (Washington, DC: National Academy Press, 1983).

331. Woodwell, G., "Forests and Climate: Surprises in Store," Oceanus 29(4): 71-75, Winter 1986/87.

332. World Bank, "Striking a Balance, The Environmental Challenge of Development' (Washington, DC: September 1989).

333. World Bank, "Operational Directive 4.00, Annex A: Environmental Assessment" (Washington DC: Sept. 21, 1989).

334, World Bank, "World Bank Support for the Environment: A Progress Report," Development Committee Pamphlet No. 22 (Washington, DC: September 1989).

335. World Bank, People and Trees, The Role of Social Forestry in Sustainable Development, EDI Seminar Series (Washington DC: 1989).

336. World Bank, Living With Wildlife: Wildlife Resource Management With Local Participation in Africa (Washington DC: 1990).

337. World Commission on Environment and Development, Our Common Future (Oxford: Oxford University Press, 1987)

338. World Resources Institute and International Institute for Environment and Development World Resources 1988-89 (New York. NY: Basic Books, Inc., 1988).

339. World Resources Institute, "Power Company To Fund Reforestation To Offset Carbon Dioxide Emissions, Slow Greenhouse Effect," Press Release (Washington DC: Oct. 11, 1988),

340. World Resources Institute, Natural Endowments: Financing Resource Conservation for Development (Washington DC: Sep tember 1989).

341. World Wildlife Fund, "Debt-for-Nature Swaps: A New Conservation Tool, "World Wildlife Fund Letter No. 1 (Washington DC: 1988)

342. Wright, L. L., J.H.Cushman, and P.A. Layton, ' 'Dedicated Energy Crops, Expanding the Market by Improving the Resource, Biologue 6(3): 12-19, June/July/August 1989.

343. Wright, L. L., R.L. Graham, and A.F. Turhollow, "Short-Rotation Woody Crop Opportunities To Mitigate Carbon Dioxide Buildup," paper presented at North American Conference on Forestry Responses to Climate Change (Washington, DC: Climate Institute, May 15-17, 1990).

344. Young, A., "Hypotheses for Soil-Agroforestry Research," Agroforestry Today 1(1):13-16, January-March 1989. 
Chapter 8

\section{The Food System}

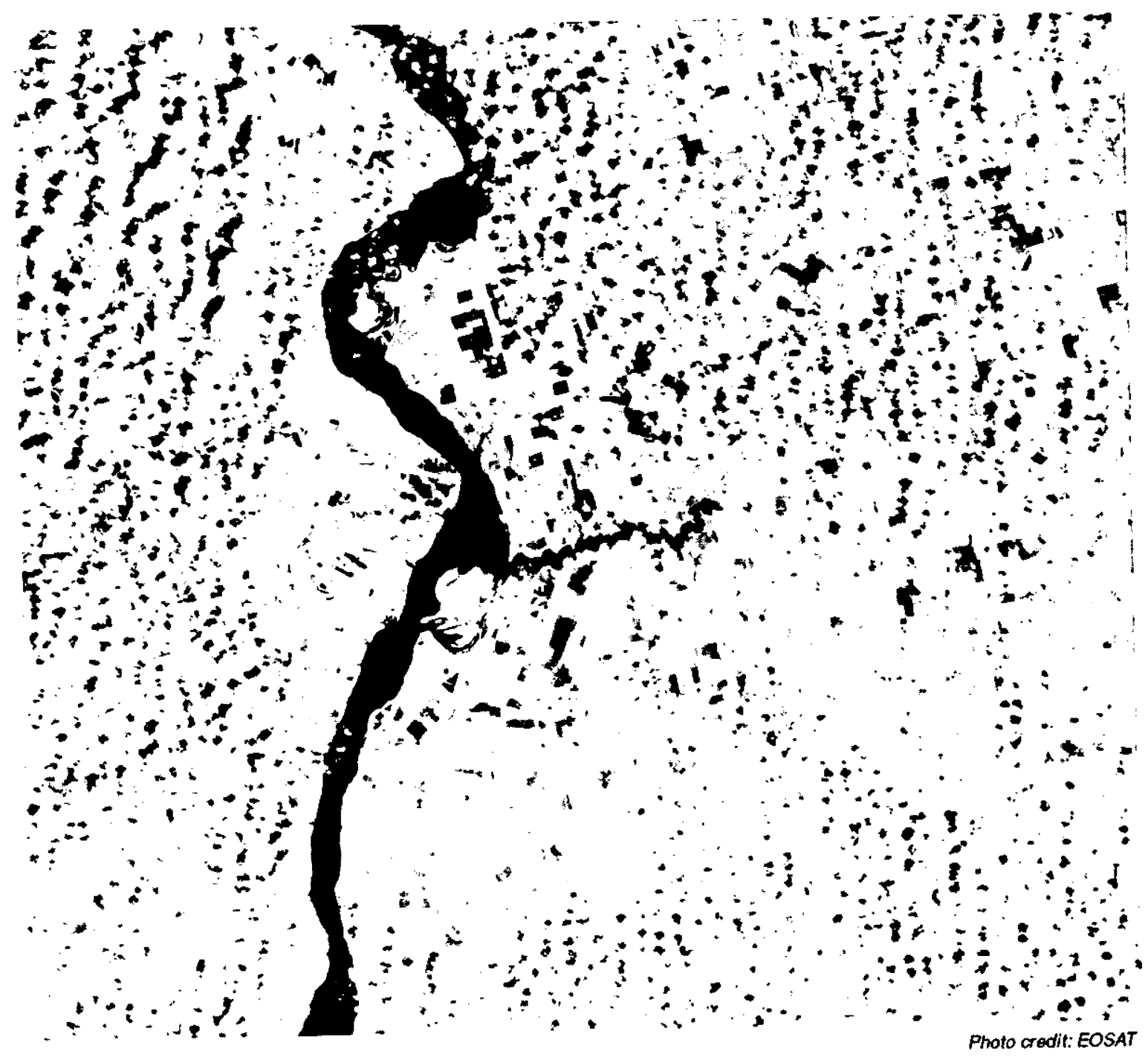




\section{CONTENTS}

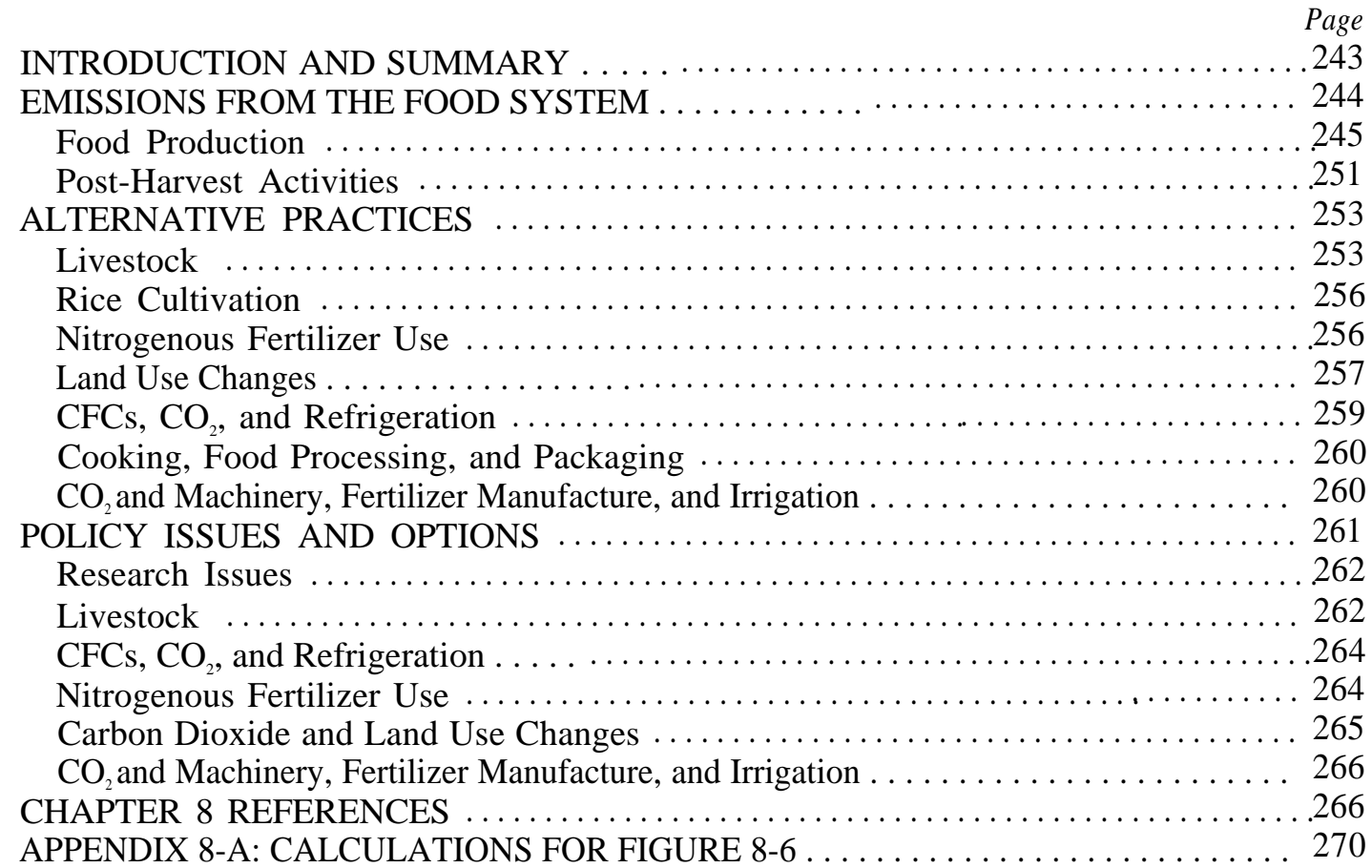

\section{Boxes}

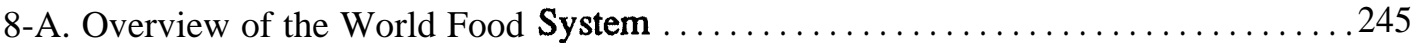

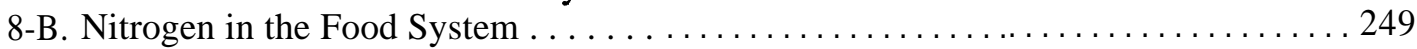

8-C. Post-Harvest Food Losses and Waste .................................... 259

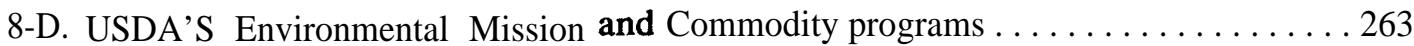

8-2. Contribution of Selected Food-Related Sources to Global Warming in the 1980s . 246

8-3. Estimated Global Emissions of Methane . . . . . . . . . . . . . . . . . . . . . . 246

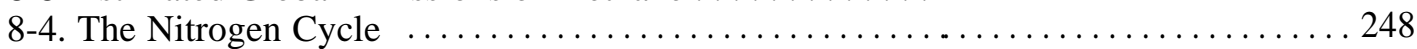

8-5. Effect of Nitrogen Fertilizer Application Rate on Maize Yield and

Soil Nitrogen ............................................... 250

8-6. The U.S. Food System: $\mathrm{CO}_{2}$ Emissions From Selected Fossil Fuel Uses . ....... 251

8-7. Consumption of CFC-11 Plus CFC-12 for Food-Related Refrigeration and Other Uses in 1985, by Region 


\section{INTRODUCTION AND SUMMARY}

The food system (see figure 8-1 and box 8-A) encompasses all the activities associated with providing food to consumers. These include food production (e.g., onsite clearing, cultivation, and harvesting, and off site production of fertilizer and other agricultural inputs) and post-harvest activities (e.g., food processing, transport, cooking) (see figure 8-1).

Congress has become increasingly aware of the environmental impacts of the food system and has begun to address some of these through legislation. ${ }^{1}$ In addition to previously identified environmental impacts of agriculture (pollution of surface and groundwater by nitrate and pesticides, soil erosion, depletion of aquifers to meet irrigation needs, loss of natural habitat), the food system is now also recognized as a potential contributor to global climate change.

Figure 8-2 below shows the global food system's contribution to global warming in the $1980 \mathrm{~s}^{2}$ Although estimates are uncertain, the food sector may account for one-third of global methane $\left(\mathrm{CH}_{4}\right)$ emissions; one-fifth of net global carbon dioxide $\left.(\mathrm{C})_{2}\right)_{\text {e emissions }}^{3}$; up to 15 percent of chlorofluorocarbon (CFC) emissions; and anywhere from onetenth to one-fifth of current global nitrous oxide $\left(\mathrm{N}_{2} \mathrm{O}\right)$ emissions. Food sector emissions of all these gases will grow, barring efforts to contain them, as efforts to provide food for the world's growing population intensify.

Uncertainty in agricultural emissions data currently makes it difficult to predict the efficacy of any of the control methods available to reduce this sector's contribution to global warming, yet many of these controls deserve consideration in their own right as a means to combat other agriculture-related environmental problems. Indeed, many have been or are being considered by Congress for reasons other than climate change,

In the United States and the industrialized world in general, several options are available to reduce food sector emissions in the near term. Methane emissions from livestock could be reduced by improving nutrient and manure management (and, possibly, by increasing productivity) or by reducing demand for livestock products. ${ }^{4}$ Fertilizers and other sources of applied nitrogen, such as crop residues and animal wastes, could be used more efficiently; this may reduce $\mathrm{N}_{2} \mathrm{O}$ emissions, as well as surface and groundwater contamination, and would help conserve soil organic matter. Nitrogen fertilizer manufacturing and onsite farm machinery and cultivation practices could be more energy efficient; while reductions in $\mathrm{CO}_{2}$ emissions would be relatively small, other benefits such as decreased local air pollution from fossil fuel combustion would accrue. Land transformations that help remove carbon from the atmosphere (such as converting cropland to forest land) could be encouraged, while those that increase $\mathrm{CO}_{2}$ emissions could be discouraged. In food refrigeration, emissions can be curbed by preventing the release of CFCs from existing refrigerators and eliminating their future use; and by improving energy efficiencies. Further $\mathrm{CO}_{2}$ reductions could be achieved by designing stoves and ovens that use energy more efficiently and by increasing fuel efficiency in vehicles used in food transport (see chs. 4 and 5).

In developing countries, slowing deforestation, maintaining or increasing crop yields, and reducing emissions associated with cooking can be more effective, in the short term, than changing current

\footnotetext{
I such as the FoodSecurity Act of 1985 (Public Law 99-198) and the Food, Agriculture, Conservation and Trade Act of 1990 (Public Law 101-624).

${ }^{2}$ These and other estimates throughout the chapter arc rough and should be considered as order-of-magnitude estimates.

${ }^{3}$ This estimate refers primarily t. emissions from food production activities, including the clearing and burning of forests. Note that these emissions are already included in deforestation estimates presented in $\mathrm{ch} .7$ but are discussed here to provide a more systematic understanding of the food sector. In contrast, estimates of globalCO $\mathrm{C}_{2}$ emissions from post-harvest activities (including processing, transportation, and cooking) are not included because data on which to derive such estimates arc lacking; however, cmissions from these activities in the United States arc discussed below. Accurate estimates of globalemissions from cooking with biomass fuels arc also not available.

${ }^{4}$ By increasing productivity (i.e., the output of meat or dairy products per unit of feed), the same amount of output could be obtained from a smaller herd size, thereby reducing total methane emissions. This assumes that the rate of output (e.g., milk, beef,) per animal due 10 productivity enhancements increases faster than emissions of methane per animal and that the level of demand remains relatively unchanged.
} 
Figure 8-I-The Food System

\section{Food Production}

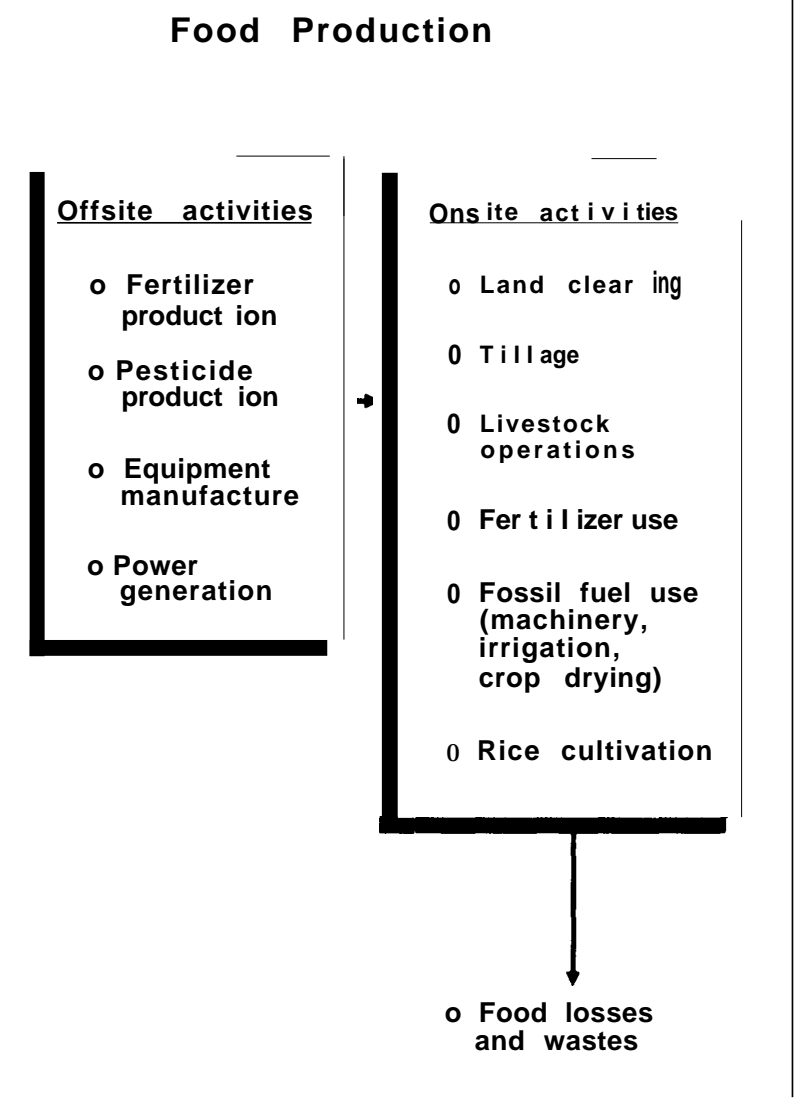

Post-Harvest Activities

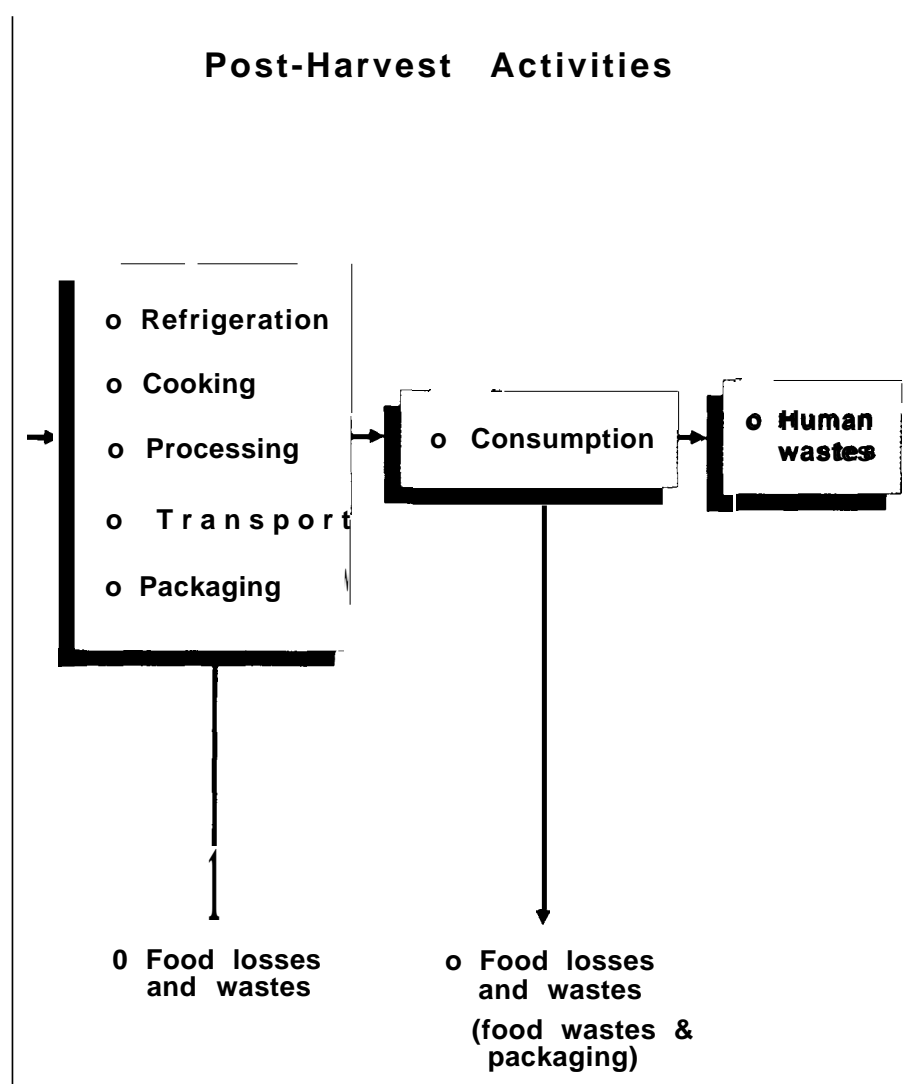

SOURCE: Office of Technology Assessment, 1991.

patterns of fossil fuel use, ${ }^{5}$ Alternatives to clearing of tropical forests include increased use of agroforestry and "sustainable" agriculture, and decreased subsidies for cattle ranching on lands that cannot support livestock for more than a few years (see ch. 7). Crop yields maybe improved on existing agricultural land with increased agricultural inputs (e.g., fertilizers, irrigation, etc.), but this may increase greenhouse gas emissions per acre. Opportunities exist to reduce methane emissions from livestock through technololgy transfer to developing countries, but the relevant technologies may not be readily applicable in most developing countries. In general, direct U.S. Government influence in these areas tends to be through the U.S. Agency for International Development (A. I.D.), research pro- grams, multinational corporations, and participation in multilateral lending institutions.

\section{EMISSIONS FROM THE FOOD SYSTEM}

Activities in the food system affect the flows of many substances to and from the atmosphere, including small particles (aerosols) and numerous trace gases. The system itself and key trends in global food production and consumption are summarized in box 8-A. In some developing countries, food production (i.e., activities up to and including harvest) is the dominant source of greenhouse gases, primarily because of $\mathrm{CO}_{2}$ emitted through land transformations (e.g., land clearing and field burn-

\footnotetext{
${ }^{5}$ Fossil fuel use in the food sectors of developing countries might rise in the future if farm mechanization and refrigeration increase; an important opportunity for industrialized countries is to help developing countries increase the use of technologies that reduce costs of and emissions from such increases.
} 


\section{Box 8-A-Overview of the World Food System}

Food production involves activities up to and including harvest-cultivation, manufacture and application of fertilizers and pesticides, irrigation, and other practices (see figure 8-1). In 1985, the world's production of plant crops exceeded 3 billion metric tons, 60 percent of which was grains; meat, fish, and dairy products amounted to an additional 0.75 billion metric tons $(114,133)$. In developed countries, agriculture represents about 3 percent of the gross domestic product (GDP) output, whereas in some developing countries it contributes as much as 48 percent of GDP (109).

World food production has increased rapidly during the last 40 years, although per-capita production leveled off in the mid-1980s $(114,133)$. For example, grain yields per hectare more than doubled between 1950 and 1984 (12). To achieve this, existing agricultural lands and marine fisheries have been exploited more intensively, with heavy dependence on fossil fuel, commercial fertilizers and pesticides, and water-worldwide fertilizer use increased ninefold, irrigated acreage tripled, and farm tractor fleets quadrupled. Worldwide consumption of nitrogen fertilizers increased by 60 percent from 1975-76 to 1985-86 alone, to about 70 million metric tons of nitrogen (111). Water use for agriculture also has grown rapidly; more water is consumed in global agriculture than in all other applications combined $(2,62){ }^{1}$

Agriculture also has expanded (and continues to expand) into previously uncultivated areas that are only marginality suited for farming or ranching, including many mountainous and tropical forest areas. Varied environmental stresses such as water pollution, soil erosion, downstream flooding, and loss of biodiversity have come with this expansion.

A substantial portion of world crops is fed to animals. Nearly 50 percent of world coarse grain (i.e., barley, corn, oats, rye, sorghum) production, and over two-thirds in the United States, as well as over 30 percent of the world's fisheries catch, is used for animal feed $(89,115)$. Livestock populations have increased rapidly since 1950 and exceeded 4 billion in $1988^{2}$, with India having the largest share (152). About one-third were cattle, and 8 percent of these were in the United States. Chicken populations are also quite large, totaling about 9.7 billion worldwide and about 1.3 billion in the United States alone (152).

Post-harvest activities take food once harvested or killed, through a varying series of steps (i.e., transportation, processing, packaging, marketing, storage, and cooking) (see figure 8-1). In industrialized countries such as the United States, most of the fossil fuel-related and CFC emissions associated with the food system result from post-harvest activities. Cooking accounts for a relatively small portion of post-harvest emissions in industrialized countries. In developing countries, however, cooking (mostly with coal or biomass) is probably the most important post-harvest source of emissions.

\footnotetext{
1As used here, "consumed" refers to water withdrawn from surface or groundwater supplies and not promptly returned. Water that evaporates during use is considered consumed.

Includes cattle, sheep, goats, pigs, horses, buffaloes, and camels.

SOURCE: Office of Technology Assessment, 1991.
}

ing) and $\mathrm{CH}_{4}$ emitted through rice cultivation. ${ }^{6}$ Although global data on emissions from postharvest activities are poor, these activities are likely the most important source of emissions in industrialized countries.

\section{Food Production}

Greenhouse gas sources from food production activities include:

1. flooded rice fields, which are significant sources of $\mathrm{CH}_{4}$, particularly in the developing countries of Asia;

2. livestock, a significant source of $\mathrm{CH}_{4}$ in many industrialized and developing countries, through direct emissions from animals as well as their manure;

3. nitrogenous fertilizers, the use of which results in $\mathrm{N}_{2} \mathrm{O}$;

4. large-scale land transformations (e.g., clearing tropical forests) in many developing countries

\footnotetext{
${ }^{6}$ Previousland transformations still play a large role in overall emissions. For example, rice paddies located on lands cleared thousands of years ago arc a major source of current methane emissions.
} 
Figure 8-2-Contribution of Selected Food-Related Sources to Global Warming in the 1980s

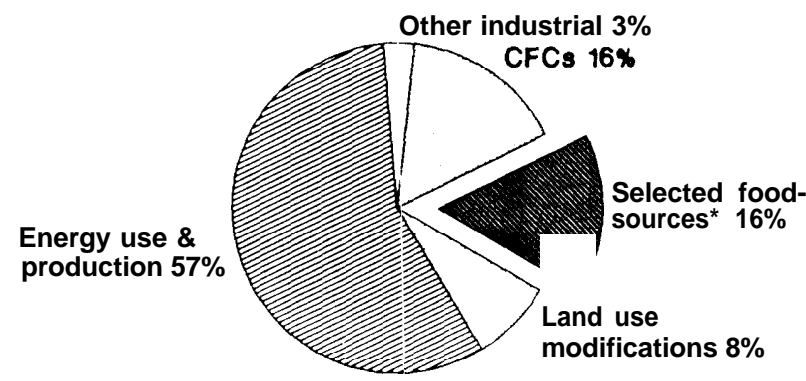

Food-related sources include rice cultivation, enteric fermentation from domestic animals, nitrogenous fertilizers, biomass burning, and CFCs from refrigeration; half of the emissions from biomass burning are assumed to be food-related (143) (emissions from biomass burning may be greater; see ref. 19a.) his would increase the food related contribution by a few percent. The "CFC" slice includes CFCs not used in the food system. We assume that $\mathrm{CO}_{2}$ from fossil fuels used in cooking, food processing, packaging, and transportation are included in the energy-use slice. The use of biomass for cooking is not included.

SOURCE: Office of Technoloay Assessment, 1991, adapted from U.S. Environmental Protection Agency, Policy Options for Stabilizing Global Climate, Draft, Report to Congress (Washington DC: June 1990).

(see ch. 7); and, to a lesser extent, land use changes in industrialized countries (e.g., urbanization), both of which result in $\mathrm{COs}$ emissions; and

5. burning of vegetation to clear and/or prepare land for agriculture (especially in developing countries), which adds to atmospheric concentrations of several gases, including $\mathrm{CO}_{2}, \mathrm{CH}_{4}, \mathrm{~N}_{2} \mathrm{O}$, and carbon monoxide.

In general, emissions from food production and their contributions to climate change are difficult to quantify because of the complex interactions of biological and chemical processes in soils, water, plants, animals, and the atmosphere, and because studies are lacking for many topics and areas. ${ }^{7}$ Nevertheless, some approximations and projections are possible. For example, EPA (143) estimates that if current agricultural practices continue, $\mathrm{CH}_{\mathrm{A}}$ emissions from rice will increase by about 35 percent by 2025 , those from livestock will rise by about 65 percent, and $\mathrm{N}_{4} \mathrm{O}$ emissions from fertilizers could more than double.
Figure 8-3-Estimated Global Emissions of Methane

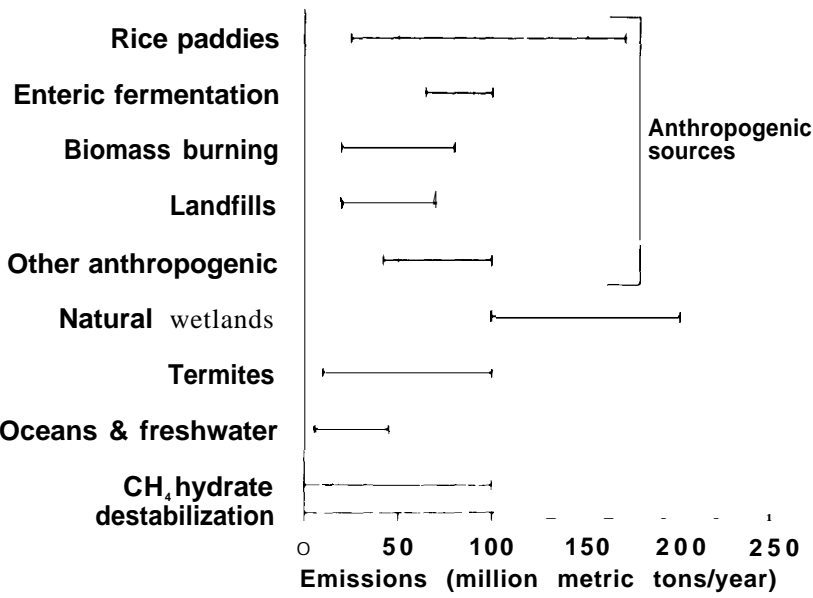

Total methane emissions are about 290 to 960 million metric tons per year; about 50 to 60 percent are from anthropogenic sources. About 60 percent of the anthropogenic emissions are from selected food-related emissions including rice cultivation, enteric fermentation from domestic animals, and roughly half of the emissions from biomass burning; we assume that about one-half of the biomass burning emissions are agricultural-related deforestation (143). The estimate for food-related emissions does not include animal wastes or post-harvest emissions from food losses and wastes (although landfills include some emissions from the latter category). Other anthropogenic sources include coal mining, and gas drilling, venting, and transmission.

SOURCES: Intergovernmental Panel on Climate Change, Scientific Assessment of Climate Change, Summary and Report (Geneva: World Meteorological Organization/U.N. Environmental Program, 1990); R.J. Cicerone and R.S. Oremland, "Biogeochemical Aspects of Atmospheric Methane," Global Biogeochemical Cycles 2(4):299-327, 1988,

\section{Methane $\left(\mathrm{CH}_{4}\right.$}

Methane is produced when bacteria decompose organic material in oxygen-deficient (i.e., anaerobic) environments, such as sediments at the bottom of flooded or rainfed rice paddies, landfills, and the digestive tract of ruminant animals and termites; $\mathrm{CH}_{4}$ is also emitted as a byproduct when wood and other biomass are burned. Emissions from these and other $\mathrm{CH}_{4}$ sources are very poorly characterized, partly because they vary enormously on geographic scales and over time. Available evidence indicates that about one-third of total global $\mathrm{CH}_{4}$ emissions comes from the food sector $(16,50)$; this represents about 60 percent of total emissions from anthropogenic sources, or roughly 10 percent of global warming in the 1980s. ${ }^{8}$

\footnotetext{
${ }^{7}$ Although the focus in this discussion is on $\mathrm{CH}_{4}, \mathrm{~N}_{2} \mathrm{O}, \mathrm{CO}_{2}$, and $\mathrm{CFCs}$, large quantities of particulate are also emitted when forests and grasslands are burned for agricultural purposes. These particulates are an important global source of cloud condensation nuclei, and clouds themselves are important climatic variables (see ch. 2; also see ref. 19a for more extensive discussion).

${ }^{8}$ This assumes global $\mathrm{CH}_{4}$ emissions contributed about 19 percent of the global $\mathrm{w}_{\text {arming }}$ in the $1980 \mathrm{~s}$ (143).
} 


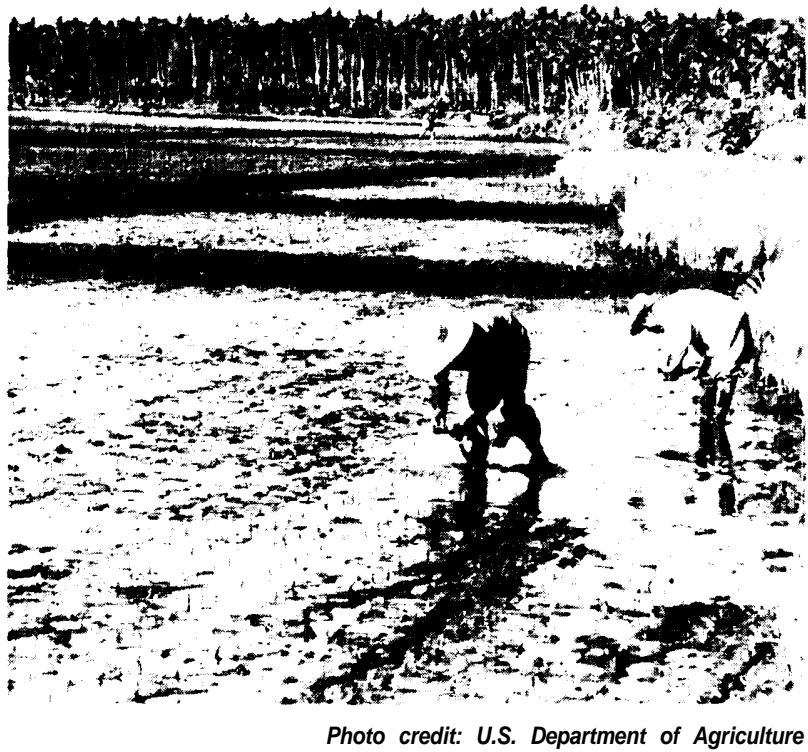

Over 90 percent of the world's rice is grown in the developing countries of Asia. Global rice production has tripled between the late 1940s and 1985. Methane is produced when bacteria anaerobically decompose organic matter in sediments at the bottom of paddies.

Rice Paddies-Rice provided about one-fourth of the world's cereal grains in 1985. China and India produced well over half of the total, the United States only 1 percent. Global rice production increased by nearly 200 percent between the late 1940 s and 1985, while acreage grew by 43 percent (1 14).

Estimates of $\mathrm{CH}_{4}$ released from rice paddies in the mid-1980s range from roughly 25 to 170 million metric tons, or about 15 to 30 percent of world methane emissions from anthropogenic sources (16, 50) (see figure 8-3). Rice paddies thus accounted for about 3 to 6 percent of the contribution to global warming in the 1980s. These emissions estimates are based on a few studies conducted in temperate regions (California, Italy, and Spain), but because $\mathrm{CH}_{4}$ emissions are likely to be highly site-specific, the extrapolation of these data to other regions (including tropical areas, where most of the world's rice is grown) is problematic. However, new data from Japan, China, and the Philippines are now becoming available $(56,78,94,154)$. Recent field tests, for example, have shown that during the growing season, rice fields in China emit up to 10 times more $\mathrm{CH}_{4}$ per hectare per hour than rice fields in Europe and the United States (56). If new data from China are representative of conditions in the Far East (over 90 percent of the world's rice is produced in Asia), then $\mathrm{CH}_{4}$ emissions from rice cultivation are higher than the estimates presented above, although it is difficult to estimate by how much.

Ruminants-Much of the world's livestock consists of ruminant animals-sheep, goats, camels, cattle, and buffalo (see box 8-A). One of the unique features of ruminants is their four-chambered stomach, including one chamber called the rumen in which bacteria break down food and generate $\mathrm{CH}_{4}$ as a byproduct. Ruminants emitted an estimated 65 to 100 million metric tons of $\mathrm{CH}_{4}$ per year in the mid-1980s, perhaps 10 to 20 percent of global $\mathrm{CH}_{4}$ emissions from all sources (16), or about 20 to 40 percent of total anthropogenic emissions. ${ }^{9}$ Therefore, ruminant digestion accounted for about 4 to 7 percent of the global warming in the 1980s, given that all anthropogenic $\mathrm{CH}_{4}$ sources accounted for a total of about 19 percent (143). Globally, cattle account for about three-fourths of livestock $\mathrm{CH}_{4}$ emissions (58), or about 7 to 15 percent of total global $\mathrm{CH}_{4}$ emissions from all sources. Beef and dairy cattle in the United States account for about 1 percent of total global $\mathrm{CH}_{4}$ emissions (145).

The above estimates do not include $\mathrm{CH}_{4}$ emissions from animal manure. If manure decomposes anaerobically, some of its organic matter is converted to $\mathrm{CH}_{4}$. In industrialized countries, manure handling practices at feedlots, dairies, and swine and poultry farms may release significant methane. In developing countries, however, most manure is spread as fertilizer, burned for fuel, or left in pastures; the magnitude of $\mathrm{CH}_{4}$ emissions from these practices is poorly quantified but likely is low since most decomposition takes place aerobically (however, this leads to more $\mathrm{CO}_{2}$ emissions). Preliminary estimates suggest global $\mathrm{CH}_{4}$ emissions from manure are on the order of about 20 to 40 million metric tons per year $(91,141)$.

Biomass Burning-Burning vegetation contributes 20 to 80 million metric tons of methane per year, or roughly 7 to 8 percent of global emissions from

\footnotetext{
${ }^{9}$ The amounts emitted per animal vary widely among species. A typical goat may emit $5 \mathrm{~kg}$ of methane per year, whereas a U.S. dairy cow might average $84 \mathrm{~kg}$ over the same period (20), These averages mask variability arising from other factors such as diets.
} 
Figure 8-4-The Nitrogen Cycle

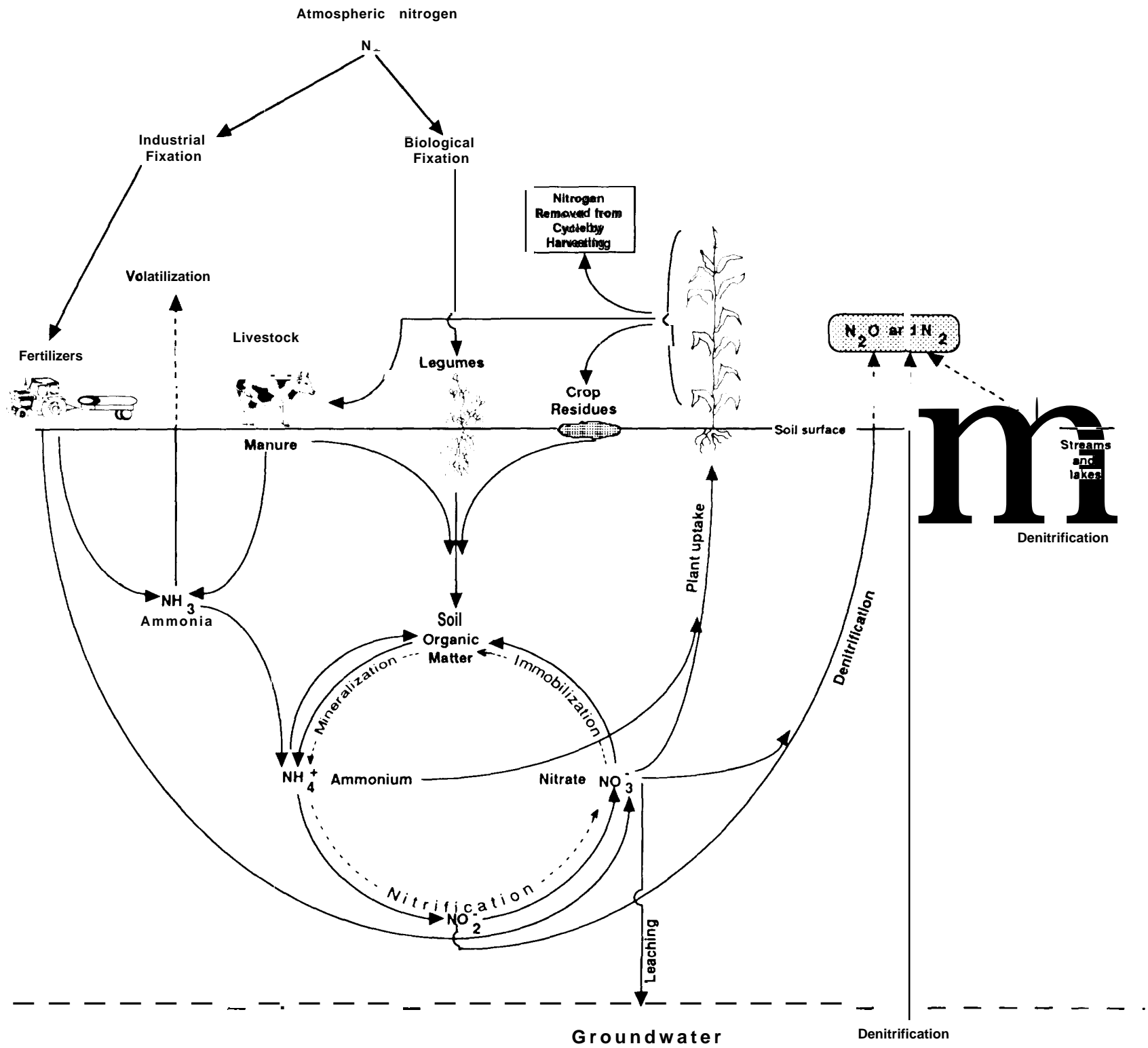

The cycling of nitrogen compounds from lightning and fires is not shown.

SOURCE: Office of Technology Assessment, 1991; F.J. Stevenson, "Soil Nitrogen," fertilizer Nitrogen, Its Chemistry and Technology, V. Sauchelli (ad.) (New York, NY: Reinhold Publishing Co., 1964), pp. 18-39.

anthropogenic sources and natural sources such as lightning-induced forest frees $(16,19 \mathrm{a}, 50,87$, 143). ${ }^{10}$ This portion may be higher if recent data indicating higher deforestation rates are correct (72; see ch. 7). Substantial but unquantified $\mathrm{CH}_{4}$ emissions result from fires ignited deliberately-forests burned to produce rangeland or cropland; grasslands burned to enhance forage; and crop residues burned

10We distinguish in-situ burning of vegetation to clear land for agricultural purposes from burning of "traditional biomass fuels" such as wood, crop residues, and manure for cooking and heating. 


\section{Box 8-B-Nitrogen in the Food System}

Figure 8-4 shows how nitrogen flows through the environment Molecular nitrogen $\mathbf{~}_{\mathbf{N}} \mathbf{0}$--an element essential to all plant and animal life--makes up 78 percent of the atmosphere, but few organisms can use it until it has been "fixed" (i.e., made into usable compounds or ions). Much of the nitrogen stored in soil also is not readily available to plants. Therefore, even though nitrogen is contained in relatively large amounts in the atmosphere and soil, it is often the limiting nutrient in agricultural systems.

Some microorganisms take molecular nitrogen from the atmosphere (or the air spaces in soil) and convert (or fix) it into ammonium and related nitrogen-containing compounds. Many microorganisms can do this, but the most famous are bacteria that live $\mathrm{m}$ the root nodules of many legumes (e.g., peas, beans). Bacteria and fungi also decompose organic materials (e.g., manure, crop residues) in the soil and release ammonia or ammonium as part of their metabolic processes. Other bacteria then oxidize the ammonia or ammonium to nitrite, and another group of bacteria then oxidizes nitrite to nitrate. This process is called nitrification. Nitrate and ammonium ions can be directly taken up from the soil and used by plants. Animals then obtain nitrogen in the form of mom complex organic compounds manufactured by plants.

Conversely, nitrogen compounds can be lost from the soil by leaching into ground and surface waters, and by soil erosion. Moreover, yet another group of bacteria can convert nitrate, in the absence of oxygen, into gaseous nitrogen compounds, including $\mathrm{N}_{\mathrm{z}} \mathrm{O}$, that are emitted into the atmosphere. This process is known as denitrification. Other nitrogen-based gases, such as nitrogen oxide (NO) and nitrogen dioxide (NO in the formation of tropospheric ozone smog), are also emitted by these microbial processes. In fact, recent evidence indicates that in some soils the emission of $\mathrm{NO}$ far exceeds that of $\mathrm{N}_{\mathrm{z}} \mathrm{O}(106)$.

SOURCE: Office of Technology Assessment, 1991.

to return nutrients to the soil. These emissions are heavily concentrated in tropical countries, where large areas of savanna and forest are burned or cleared each year for agriculture (see ch. 7).

Nitrous Oxide $\left(\mathrm{N}_{2} \mathrm{O}\right)$

Agriculture introduces nitrogenous compounds to the environment in the form of commercial fertilizers, legumes, and crop residues. $\mathrm{N}_{2} \mathrm{O}$ emissions from soil and water occur through vitrification and denitrification of these compounds (see figure 8-4 and box 8-B) and also result when vegetation is cleared through burning (4, 19a, 27, 59, 146).

The magnitude of $\mathrm{N}_{2} \mathrm{O}$ emissions from terrestrial and aquatic sources is very poorly characterized. Based on annual increases in $\mathrm{N}_{2} \mathrm{O}$ atmospheric concentrations, the Intergovernmental Panel on Climate Change (50) estimates that total global $\mathrm{N}_{2} \mathrm{O}$ emissions should be around 10 to 17.5 million metric tons per year; however, only 4.4 to 10 million metric tons can be accounted for from known sources (see ch. 2).

$\mathrm{N}_{2} \mathrm{O}$ emissions associated with fertilizer use are not well understood and probably vary with factors such as fertilizer type, method of application, and amount applied. Worldwide nitrogen fertilizer con-

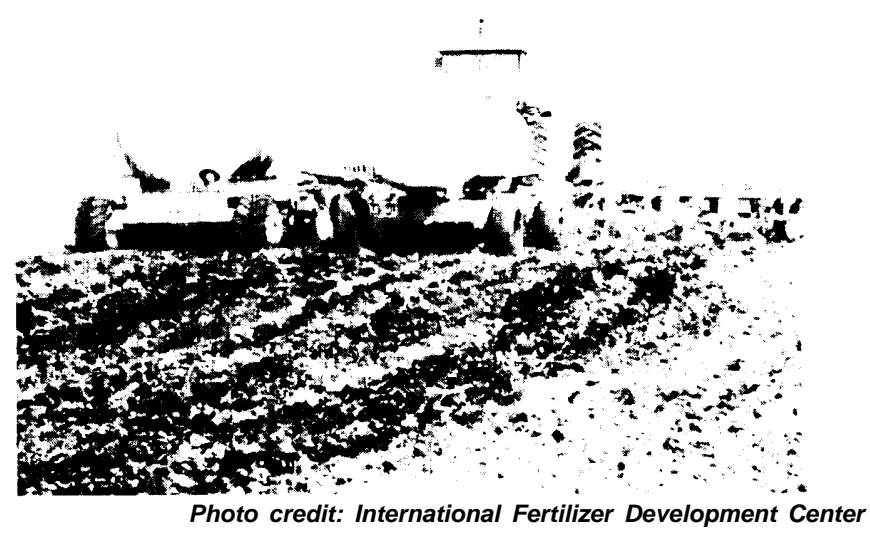

Nitrogen from agricultural sources such as nitrogenous fertilizers (e.g., anhydrous ammonia), crop residues, and leguminous plants, can be converted to $\mathrm{N}_{2} \mathrm{O}$ through chemical processes called vitrification and denitrification which occur in both soils and water.

sumption is about 74 million metric tons per year. China accounted for nearly 20 percent of this consumption in 1987, the United States for about 13 percent (30). Current fertilizer-derived emissions are on the order of 0.01 to 2.2 million metric tons per year, about 0.2 to 20 percent of global emissions

${ }_{1}^{1}$ Large areas of temperate-zone vegetation are burned annually from forest and grassland fires (ch. 7 ). 
Figure 8-5-Effect of Nitrogen Fertilizer Application Rate on Maize Yield and Soil Nitrogen

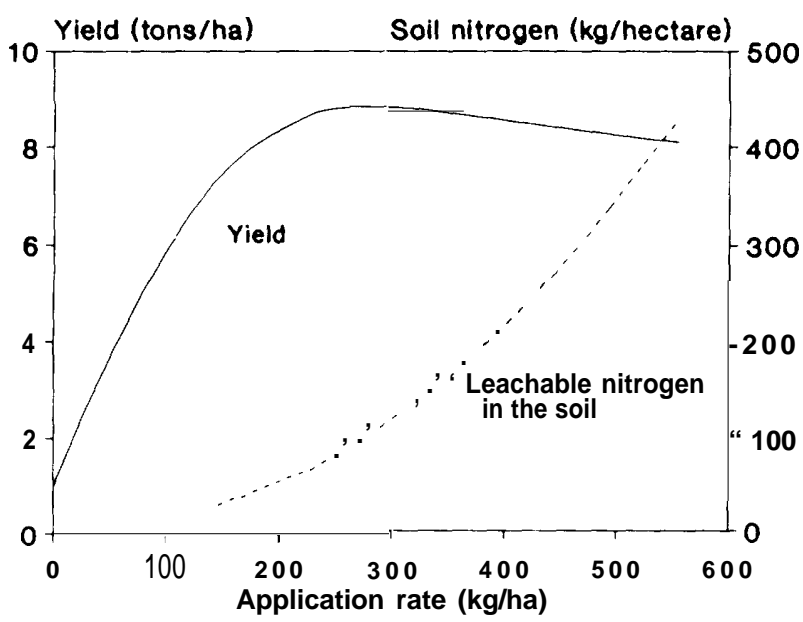

NOTE: Leachable nitrogen in the soil can be a significant source of $\mathrm{N}_{2} \mathrm{O}$ emissions.

SOURCE: R.D.Hauck, "Agronomic and Public Aspects of Soil Nitrogen Research," Soil Use and Management 6(2) :66-70, June 1990.

from all sources, or about 10 to 80 percent of all anthropogenic emissions (50).

The general relationship between nitrogen application rate and maize yields (see figure 8-5) illustrates that yields are highest at a certain optimal nitrogen application rate; further additions result in either stable or even lower yields (because nitrogen is no longer used as effectively by plants), and nitrogen concentrations build up in the soil. The potential for nitrogen losses through leaching, volatilization, or denitrification grows.

Nitrogen application rates are generally higher in developed countries. Although U.S. application rates for wheat are comparatively lower than those for many countries, U.S. rates for other crops (e.g., corn, rice) are among the highest in the world (64, 65). Although global fertilizer application data provide a picture of overall intensity of fertilizer use, they do not reveal whether nitrogen fertilizers generally are being over- or under-applied for specific crops and countries.

Leguminous crops (e.g., soybeans, peas, alfalfa) also add nitrogen to agricultural soils; legumes use atmospheric nitrogen directly and require much less nitrogenous fertilizers than non-leguminous $\mathrm{crops}$ (see pp. 121-122 in ref. 128; see also box 8-B above and "Alternative Practices" section below). Worldwide production of legumes increased by roughly 85 percent from the late 1940s to 1985 . Two-thirds of the world's legume production is in developing countries; only 2 percent is in the United States (1 14).

\section{Carbon Dioxide $\left(\mathrm{CO}_{2}\right)$}

The flow of $\mathrm{CO}_{2}$ to and from the atmosphere is influenced by food production in two ways:

1. changes in terrestrial carbon stocks associated with land transformations, and

2. emissions from fossil fuel use. (See figure 2-9 inch. 2 for an illustration of the carbon cycle.)

Land Use Changes and Terresti'al CarbonLand transformations have characterized the entire 10,000-year history of agricultural development and continue on a large scale today. Although concern over deforestation now focuses on tropical areas, many temperate forests have also been cleared at least once during the last few hundred years. $\mathrm{CO}_{2}$ is emitted in this process, and also when grasslands and savannas are burned to enhance grazing conditions and when carbon contained in soil organic matter is carried off by erosion or converted into $\mathrm{CO}_{2}$ by microorganisms. Urbanization claims additional forest and agricultural land each year. These land transformations greatly affect how carbon is distributed in organisms, soils, and sediments, and how it flows to and from the atmosphere. The net result has increased atmospheric carbon concentrations, mostly as $\mathrm{CO}_{2}$ but also in the form of other carbon compounds such as methane.

Today, up to one-fifth of net global $\mathrm{CO}_{2}$ emissions may be attributed to clearing and burning tropical forests for food production (see ch. 7). Additional $\mathrm{CO}_{2}$ emissions result from burning savannas and agricultural wastes, and using biomass fuels for cooking (19a). Therefore, these activities might have accounted for roughly 8 to 10 percent of the global warming in the 1980s. As population and economic pressures increase, the rate of deforestation could accelerate. $\mathrm{CO}_{2}$ emissions from soil erosion may account for about 1 to 2 percent of global emissions (85), but data on this pathway are sparse and very uncertain.

Fossil Fuel Combustion-Most food-related $\mathrm{CO}_{2}$ emissions in the U.S. occur in the post-harvest phase (see "Post-Harvest Activities' below). However, fossil fuels are also used for food production, for example to drive farm machinery such as tractors and irrigation pumps and to produce, offsite, inputs such as fertilizers and pesticides. Collectively, these 
uses account for a relatively small share of world fossil fuel use and for about 2 percent of U.S. $\mathrm{CO}_{2}$ emissions. $^{12}$

Onsite Fossil Fuel Use---Global data are relatively poor but suggest that farms released perhaps 76 million metric tons of carbon annually during the mid- 1980s through on site fossil fuel use (not including emissions from fertilizer and pesticide manufacture). ${ }^{13}$ This represents about 1 percent of global carbon emissions from fossil fuel use and accounted for only about one-half percent of global warming in the 1980s. Similarly, $\mathrm{CO}_{2}$ emissions from fossil fuel use on U.S. farms during this period (about 14 million metric tons per year) represented about 1 percent of U.S. $\mathrm{CO}_{2}$ emissions from fossil fuels (see figure 8-6). However, both total and per-hectare energy use in the United States have declined sharply since the mid- 1970 s. ${ }^{14}$

Offsite Nitrogen Fertilizer ManufacturingAnother 1 percent of world $\mathrm{CO}_{2}$ emissions from fossil fuel use, or about 0.5 percent of the global warming in the $1980 \mathrm{~s},{ }^{15}$ results from commercial fertilizer manufacture. ${ }^{16}$ Nitrogen fertilizers account for most of these emissions because they are produced in large amounts and their manufacture (often with natural gas as a feedstock) is very energy intensive. ${ }^{17}$ In the United States, nitrogen fertilizer production accounted for about 0.8 percent of U.S. $\mathrm{CO}_{2}$ emissions from fossil fuel use (see figure 8-6). World fertilizer production increased at a rate of 6.2 percent annually from 1965 to 1985 , and the outlook is for continued growth, especially in developing countries (1 13).

\section{Post-Harvest Activities}

Once harvested, some food is consumed directly by livestock and humans. The bulk, however, is processed, preserved (often though cooking), stored,

\section{Figure 8-6-The U.S. Food System: $\mathrm{CO}_{2}$ Emissions From Selected Fossil Fuel Uses}

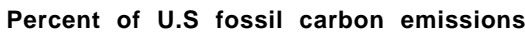

1

2

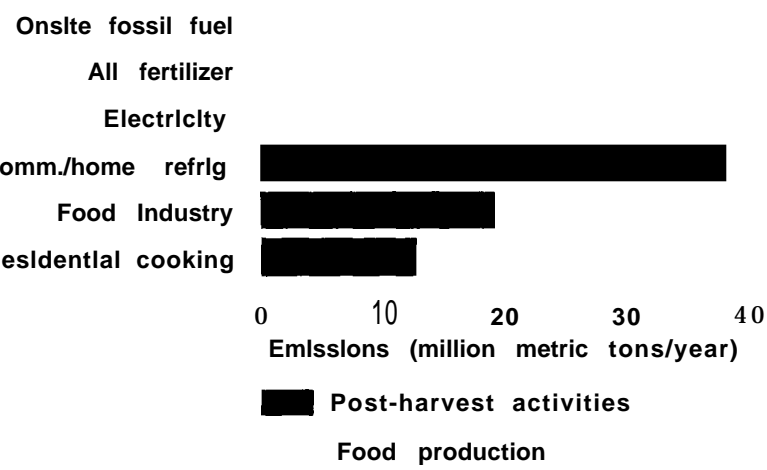

SOURCE: Office of Technology Assessment, 1991.

and distributed with a certain amount of loss and waste during transport. The major emissions from these post-harvest activities include:

1, CFCs from refrigeration;

2. $\mathrm{CO}_{2}$ from fossil fuels used in food processing, refrigeration, transport, and cooking, and from biomass fuels used for cooking; and

3. $\mathrm{CH}_{4}$ from decomposition of food-related wastes (including packaging).

Some of these post-harvest activities (e.g., food transport, refrigeration) fall within sectors examined elsewhere in the report but are highlighted here.

\section{Chlorofluorocarbons (CFCs)}

CFCs used in refrigeration are emitted through refrigerant leaks, intentional venting (during manufacture, disposal, or repair), and deterioration of insulation. Worldwide, about 47,000 metric tons of CFC-11 and 85,000 metric tons of CFC-12roughly 15 percent of total consumption-are used

\footnotetext{
${ }^{12}$ In 1987,1.6 quads of energy were used in agriculture (103) (including direct use and energy used to manufacture fertilizers and pesticides), out Of about 79 quads (137), This does not include energy used in post-harvest activities such as processing and transportation nor biomass energy used for cooking.

${ }^{13}$ The U.N.Food and Agriculture Organization (101)projected that theamount of energy to be used in 1985/86 for operating farm machinery and for irrigation would be 3.6 quads ( 95 percent for machinery and 5 percent for irrigation). If all is assumed to be petroleum, then projected emissions would have been about 76 million metric tons ( 3.6 quads x $21 \mathrm{mg} / \mathrm{Btu}$ ).

${ }^{14} \mathrm{Per}$-hectare usage of diesel, gasoline, and liquid petroleum gas fell by 30 percent between 1977 and 1986(103).

${ }^{15}$ This estimate assumestotal $\mathrm{CO}_{2}$ emissions from fossil fuel combustion of about 5.5 billion metric tons/year, total production of nitrogen fertilizers of about 73 million metric tons (1986 estimate, from ref. 113); all fertilizer is produced with natural gas as a feedstock, which emits about $14.5 \mathrm{~kg}$ of carbon per million Btu; and a nitrogen production efficiency of between 54 and 76 million Btu/metric ton of nutrient (based on ammonia and prilled urea production, respectively) (8). This figure may be an underestimate since some production uses coal and other fossil fuel feedstocks.

${ }^{16}$ These emissions are included in the manufacturing sector (see ch. 6).

${ }^{17}$ Most commercial nitrogen fertilizers combine hydrogen from methane with nitrogen from the atmosphere to produce anhydrous ammonia.
} 
Figure 8-7--Consumption of CFC-11 Plus CFC-12 for Food-Related Refrigeration and Other Uses in 1985, by Region

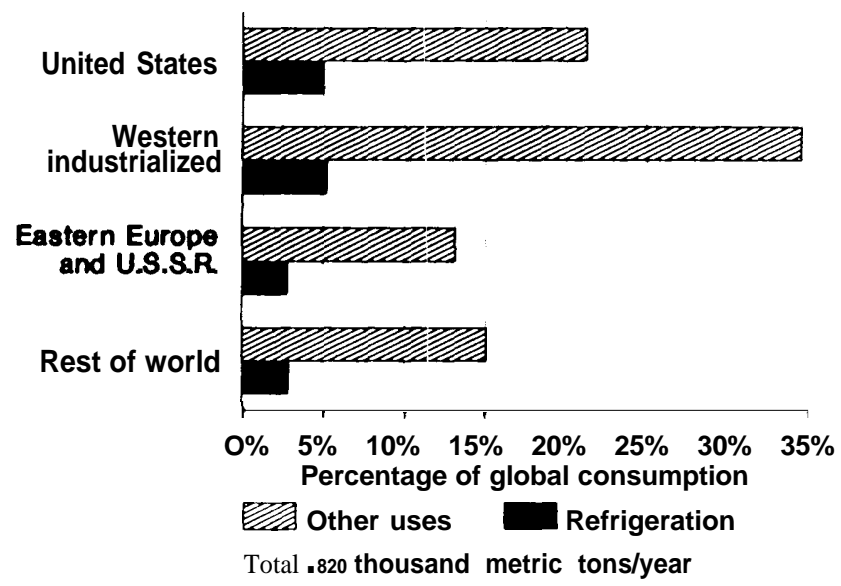

SOURCE: Derived from U.S. Environmental Protection Agency, Office of Air and Radiation, Analysis of the Environmental Implications of the Future Growth in Demand for Partially-Halogenated Chlorinated compounds, draft report (Washington, DC: 1989).

for food-related refrigeration (see figure 8-7) (142). ${ }^{18}$ CFCs used in the food system accounted for about 2 percent of the global warming in the 1980s, assuming that all are eventually emitted to the atmosphere and that total CFC-11 and -12 uses accounted for about 14 percent (143). Most CFC use in refrigeration occurs in cold storage warehouses, retail refrigeration, and refrigerated transport. Lesser, but still substantial, amounts are used in residential refrigerators and freezers.

Global use of CFCs has increased dramatically during the 60 years they have been commercially produced. From 1976 to 1986, despite mounting evidence of the ozone-depleting properties of CFCs, CFC-12 refrigerant sales increased by over 50 percent. ${ }^{19}$ The United States used 41,000 metric tons of CFC-11 and CFC-12 for food refrigeration in 1985. This represents one-third of world use for food-related refrigeration and about 19 percent of total U.S. use of the compounds (142).

CFC use is expected to rise rapidly in developing countries. With the promise of funding from the industrialized world, however, key countries such as China and India are expected to join the Montreal Protocol and pledge to reduce and eventually phase out CFC use (97). (See box 2-C in ch. 2 for more details on the Montreal Protocol.)

\section{Carbon Dioxide $\left(\mathrm{CO}_{2}\right)$}

In developing countries, residential cooking is by far the most significant source of post-harvest $\mathrm{CO}_{2}$ emissions. In industrialized countries, the most significant post-harvest activities are processing in the food industry, residential cooking, and refrigeration (i.e., powerplant emissions attributed to the energy needs of refrigeration). In the United States, energy used for residential and supermarket refrigeration, residential cooking, and food processing and packaging accounted for about 5 percent of U.S. $\mathrm{CO}_{2}$ emissions from fossil fuel use (see figure 8-6), or roughly 1 percent of global emissions from fossil fuels. Additional $\mathrm{CO}_{2}$ emissions arise from other activities (e.g., energy use in food wholesaling, restaurants, and food transport).

In general, more fossil fuel is used in industrialized countries for post-harvest activities than during food production. Even so, $\mathrm{CO}_{2}$ emissions from post-harvest activities are relatively small compared with those from the energy, building, transportation, and manufacturing sectors (chs. 3 through 6).

Food Refrigeration-Accurate estimates of worldwide $\mathrm{CO}_{2}$ emissions from refrigeration are not readily available, although estimates for specific countries suggest they are important within the food sector but small relative to other sectors.

In the United States, energy use for household and supermarket refrigeration accounted for about 3 percent of total U.S. $\mathrm{CO}_{2}$ emissions in 1985 (see figure $8-6) .{ }^{20}$ Of this, two-thirds (24 million metric tons) can be attributed to domestic refrigeration, and about one-third to refrigeration at supermarkets. As refrigerators have "saturated" the market in industrialized countries and average energy efficiencies have improved $(1,107)$, growth in energy use for refrigeration in these countries has slowed.

By contrast, refrigeration in China accounts for only a small fraction of national energy use (only 0.4 percent of which goes to generate all electricity), but this is rapidly changing. Between 1979 and 1987, for example, China's production of refrigerators in-

\footnotetext{
ISCFC-11 is used to produce foam insulation; CFC- 12 is used primari ly as a refrigerant, although it also is used to produce insulation.

${ }^{19}$ This includes only reporting companies of the Chemical Manufacturers Association which includes most producers incountries with market economies at that time (15).
}

${ }^{20}$ This estimate does not include emissions from food transportation or from commercial refrigeration other than in supermarkets. 
creased by a factor of 125 , and many of the several hundred million households that still do not have one may acquire one in the next decade.

Processing, Transportation, and Cooking-h the United States, post-harvest activities accounted for over 19 million metric tons of emissions in 1985, or about 1.5 percent of U.S. fossil fuel $\mathrm{CO}_{2}$ emissions (see figure 8-6); over 40 percent of this came from purchased electric power (136). Cooking in residences contributed approximately 12 million metric tons of emissions, roughly 1 percent of total U.S. carbon emissions. Emissions also result from transporting food, but they are poorly quantified. (See ch. 5 for details on transportation sources in general.) The overall magnitude of emissions from other sources-such as cooking in commercial establishments and heating of hot water for dishwashing--cannot be readily calculated, In the United States, these emissions could be important given that about half of all meals are prepared outside the home.

In developing countries, cooking is the major source of $\mathrm{CO}_{2}$ emissions from post-harvest activities and accounts for most household energy use (92). Energy use in transportation and processing is relatively small. Although $\mathrm{CO}_{2}$ emissions from cooking have not been quantified, the most common cooking fuels (e.g., biomass, coal) have high carbon content. Traditional biomass fuels (animal dung, crop residues, wood, etc.), which may account for as much as 15 percent of world energy use, are used extensively for cooking (44) and food processing (e.g., for drying). Coal also is very important in some regions. Over one-fourth of coal use in China, the world's largest coal consumer, is for domestic purposes, primarily for cooking (45; also see ch. 9).

\section{Methane $\left(\mathrm{CH}_{4}\right)$}

Following preparation and consumption of food, solid wastes (e.g., food residues, packaging) and sewage are generated. Under some disposal conditions, these wastes result in the emission of $\mathrm{CH}_{4}$ to the atmosphere. In landfills, for example, carboncontaining compounds decompose in two stagesfrost aerobically, producing $\mathrm{CO}_{2}$ emissions; then, once oxygen is used up, anaerobically (i.e., without oxygen) by methane-producing bacteria. Landfills may emit about 30 to 70 million metric tons of $\mathrm{CH}_{4}$ annually worldwide (see figure 8-3), about one-half of what livestock emit $(7,16)$. In the United States, about 6,000 municipal solid waste landfills were operating in 1986 (127).

\section{ALTERNATIVE PRACTICES}

This section discusses alternative practices that could be pursued to reduce future greenhouse gas emissions from the food sector. While the overall costs and benefits of these practices are not clearly defined, collectively they could substantially reduce some emissions. Many would carry other environmental benefits as well----e. g., reducing water pollution from croplands, reducing soil erosion, conserving water supplies, preserving biological diversity, and reducing waste generation in food processing. However, tradeoffs may be associated with some alternatives. For example, some tillage practices used to conserve soils require more pesticides. Also, to reduce the pressure to open new lands to agriculture, crop yields must be increased on existing acreage, which may require greater use of fertilizer and other inputs.

\section{Livestock}

Livestock directly produce about 10 to 20 percent of the world's $\mathrm{CH}_{4}$ emissions through digestive processes, and indirectly produce additional emissions from anaerobic decomposition of manure (see figure 8-3). They also indirectly account for emissions of $\mathrm{CO}_{2}$ and $\mathrm{N}_{2} \mathrm{O}$ by virtue of the land and agricultural inputs required to sustain them.

\section{Decrease Methane Emissions Per Unit of Output}

Opportunities exist for reducing, or at least limiting, the growth rate of $\mathrm{CH}_{4}$ emissions from livestock by increasing digestion efficiency and/or animal productivity (i.e., the amount of animal product produced per unit of feed). Emissions reductions on the order of 25 to 75 percent per unit of product are thought to be possible ${ }^{21}(141)$, with most potential for change in developing countries (industrialized countries have already made strides in raising more productive animals). This range of possible emission reductions roughly corresponds to

\footnotetext{
${ }^{21}$ The upper end of this range assumes that: techniques to improve the diet of animals can be successfully introduced into developing countries; these improvements will result in a twofold to threefold increase in productivity; and the number of livestock will decline as productivity increases, assuming demand for animal products remains constant.
} 


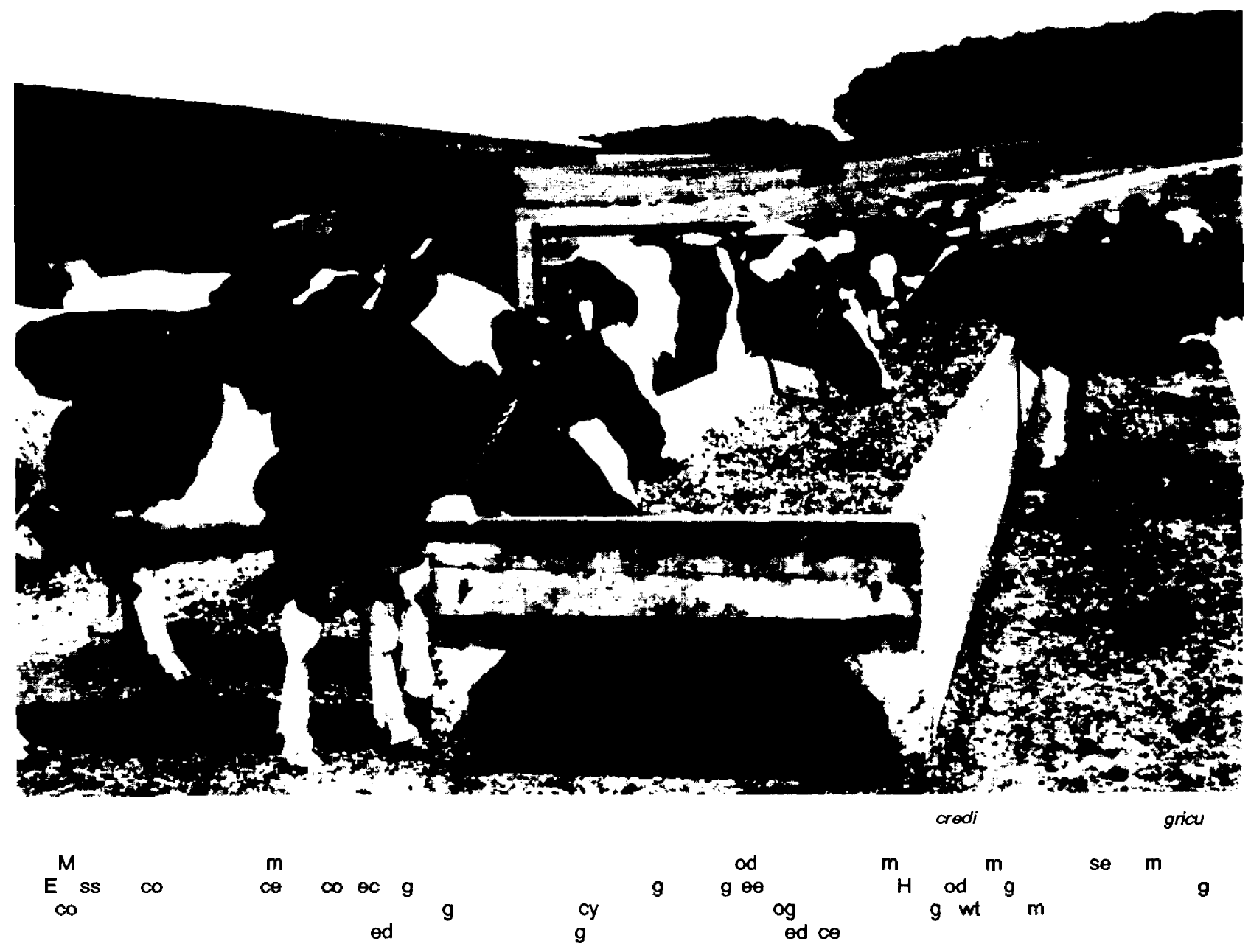

a 2- to 5-percent reduction in global $\mathrm{CH}_{4}$ emissions (29). ${ }^{22}$

Specific options include (141):

1. supplement the diets of grazing animals to correct nutrient deficiencies often found in lower quality forage;

2. substitute feeds with low $\mathrm{CH}_{4}$-producing potential for feeds with higher $\mathrm{CH}_{4}$-producing potential in the diets of animals in confined (as opposed to free-ranging livestock);

3. develop feed additives that increase digestion efficiency and reduce methanogenesis in the rumen;

4. use growth promotants (e.g., bovine somatotropin); and

\section{5. improve reproductive efficiency.}

Enhancing animal productivity can reduce $\mathrm{CH}_{4}$ emissions given the following assumptions: that by increasing productivity, the same amount of output could be obtained from a smaller herd size; that the rate of output (e.g., milk, beef) per animal increases faster than emissions of $\mathrm{CH}_{4}$ per animal; and that consumer demand for these products remains relatively stable. It is also assumed that more productive cattle could be brought to market sooner, decreasing the total lifetime $\mathrm{CH}_{4}$ emissions per animal. The assumption that increased productivity could lead to fewer livestock (and, thus, lower total $\mathrm{CH}_{4}$ emissions) could be challenged, though. In fact, a large unmet demand for cattle products in developing

\footnotetext{
${ }^{22}$ Excluding possible reductions from animal wastes; and assuming little penetration of technologies to improve livestock productivity indeveloping
} countries. 
countries could lead to greater livestock populations even if productivity increases.

Many productivity-enhancing/methane-reducing strategies have been used with great success in the United States and could be transferred to other countries, However, for some countries, especially in the developing world where most cattle graze in unconfined situations, it is difficult to determine how effective some of these options would be.

For example, feed additives called 'ionophores,' which can increase digestion efficiency, currently are feasible only for confined cattle and therefore may not be of immediate utility in developing countries. ${ }^{23}$ Growth hormones, such as bovine somatotropin, have been used in nondairy cattle to increase productivity per animal.

Another option, increasing the reproductive efficiency of animals, could help reduce $\mathrm{CH}_{4}$ emissions by decreasing the number of cattle needed to produce calves. This could be accomplished by increasing nutrient-use efficiency, as described above, as well as by improving breeding techniques. ${ }^{24}$ However, some highly productive breeds developed in industrialized countries may not adapt well to the different environmental and feeding conditions of some developing countries.

\section{Reduce Methane From Animal Wastes}

Manure storage piles, pits, and lagoons are commonly used to reduce runoff from feedlots into surface water and groundwater (e.g., 19, 32). Methane could be collected from these sources for later use as a fuel, with technologies such as specially designed biogas generators (141). About 50 to 90 percent of $\mathrm{CH}_{4}$ generated from waste lagoons could potentially be recovered (28), achieving reductions of up to 1 percent of total $\mathrm{CH}_{4}$ emissions (29). This option is applicable where animals are kept in confined situations, that is, primarily in industrialized countries.
In many developing countries, dried animal manure is an important fuel for cooking and heating; that not used for cooking generally remains in unconfined, pasture/forage systems. However, if manure were collected and processed in anaerobic digesters (see box 3-A in ch. 3), the $\mathrm{CH}_{4}$ generated from this process could offset some of the demand for wood fuels. ${ }^{25}$

\section{Reduce Demand for Livestock Products}

Finally, $\mathrm{CH}_{4}$ emissions might be reduced by shifting meat production and consumption from ruminants to non-ruminant animals, such as fish, hogs, or broiler chickens, or to more vegetarian diets. ${ }^{26}$ For example, to produce a given amount of protein, feedlot beef require nearly five times as much feed as catfish raised in intensive aquiculture systems (82). Lowering livestock numbers could also help reduce: nitrogenous fertilizer used in growing feed for livestock (and associated $\mathrm{N}_{2} \mathrm{O}$ emissions); pressures to expand agricultural acreage in some countries; declines in soil productivity from overgrazing; water pollution from erosion and from runoff of wastes; and health costs of high cholesterol diets, depending on what other foods are substituted in diets (104). ${ }^{27}$

However, because animal products are also good sources of calcium, iron, zinc, and high-quality protein, reducing their consumption in developing countries may put further nutritional stress on people in some of these areas. In these countries, increased demand for vegetable protein substitutes may also create additional burdens on already stressed grain supplies and have adverse environmental impacts. For example, increased demand for poultry and hogs would require increased amounts of feed and expanded manure handling. Moreover, reducing livestock numbers in developing countries may be especially difficult because of the multifaceted economic and cultural role they play. In many developing countries where livestock are used

\footnotetext{
${ }^{23}$ It also may $b_{c}$ possible t. pretreat feeds with geneticall engineered bacteria designed to inhibit methanogenesis (i.e., to decrease $\mathrm{CH}_{4}$ ). However, this is seen as a more long-term option and would apply mostly to confined cattle (141).

${ }^{24}$ For example, selection for increased productivity in the dairy industry has enabled milk production to increase over the last several decades, even as the number of dairy cows has fallen.

${ }^{25}$ In the 1970s, China encouraged the building of family-sized biogas digesters and also built hundreds of "biogas stations" for motor vehicle fuels as well as small biogas-fueled electricity generators. However, because of poor construction and maintenance, and in some cases, inadequate supplies of fermentable materials, the number of family-sized digesters declined from about 7 million in the 1970s to about 3 to 4.5 million by 1984 (149).

${ }^{26}$ This is already occurring to some extent in the United States, mainly because of greater health consciousness and because non-ruminant protein sources are becoming more economical.

${ }^{27}$ The Surgeon General's report (104) noted that the major dietary sources of fat for Americans are animal products and recommended " '[r]educe[d] consumption of fat (especially saturated fat) and cholesterol. '
} 
primarily for draft power and are kept as religious or status symbols, opportunities for emissions reductions may be limited.

\section{Rice Cultivation}

In the near term, our ability to reduce $\mathrm{CH}_{4}$ emissions from rice appears very limited. However, according to a panel of experts convened by the IPCC, a long-term research effort begun today and focusing on new irrigation techniques, more efficient fertilizer use, and developing new high-yield rice species may someday (e.g., two decades) enable global emissions reductions on the order of 10 to 30 percent (29).

High-yield varieties grow more quickly, permitting more than one crop to be grown per year. In theory, increasing rice yields per hectare might reduce the need to expand production onto uncultivated lands, thus reducing total $\mathrm{CH}_{4}$ emissions. However, annual $\mathrm{CH}_{4}$ emissions per acre will also increase with double harvesting. It is unclear whether increasing harvests on existing lands would result in higher or lower net annual greenhouse gas emissions than clearing new lands for production. ${ }^{28}$

Average yields have not increased significantly since high-yield rice varieties were introduced in the mid-1960s, however, and are not expected to increase dramatically without new technological breakthroughs (12), for example, genetic engineering to enhance resistance to viruses $(37,67)$. Although existing high-yield varieties produce less methane than traditional varieties (because of a higher grain-to-straw ratio), ${ }^{29}$ no new technologies to reduce per unit $\mathrm{CH}_{4}$ emissions are anticipated in the near term (143).

Better flood control might help increase the production efficiency of high-yield varieties, which tend to show lower and more variable yields under flooded conditions than under controlled irrigation. Fertilizer losses from intermittent flooding would also decline. More research is needed to develop varieties that consistently produce high yields under different conditions (e.g., dry upland environments, rain-fed conditions); and to eliminate the need to flood rice fields where flooding is not natural (e.g.,
California, South American savannas). Although rice grown under dry-land conditions emits much less methane than rain-fed or flooded rice paddies, dry-land rice accumulates more soil cadmium (a potentially toxic trace metal) than paddy rice. This is a problem in some major rice-producing countries where soil cadmium levels are already high (55).

\section{Nitrogenous Fertilizer Use}

If current trends continue, world fertilizer use will double over the next few decades, rising 1.3 percent per year in industrialized countries and 4 percent per year in developing countries (150). Fertilizers often are used very inefficiently; in parts of Asia, for example, fertilizer losses are estimated to be about 50 to 60 percent of the amount applied (100). ${ }^{30}$ Inefficient fertilization practices result in losses of soil nitrogen through several pathways. Denitrification is the predominant mechanism of loss, through $\mathrm{N}_{2} 0$ formation (see box 8-B). The level of $\mathrm{N}_{2} 0$ emissions from fertilized soils depends on many factors: fertilizer type and amount, application technique and timing, tillage and irrigation practices, use of pesticides, soil and crop type, and amount of residual nitrogen in the soil. $\mathrm{N}_{2} \mathrm{O}$ emissions rates per hectare of cropland can vary by three orders of magnitude depending on how the above factors interact (9).

Several options are available to increase fertilizer efficiency or reduce the need for fertilizers and thereby reduce $\mathrm{N}_{2} \mathrm{O}$ emissions, although the extent to which emissions can be reduced is not known. Nonetheless, other environmental benefits such as reduced nitrate contamination of groundwater and surface waters can also be achieved. These options include:

1. efficient fertilizer application,

2. low $\mathrm{N}_{2} 0$-emitting fertilizers,

3. slow-release fertilizers,

4. vitrification inhibitors, and

5 , leguminous sources of nitrogen.

\section{More Efficient Fertilizer Application}

The efficiency of fertilizer use can be increased by determining: how much nitrogen is already available in the root zone as well as how much crops can

\footnotetext{
${ }^{28}$ In addition, high-yield varieties often require greater amounts Of organic and chemical fertilizers.

${ }^{29}$ In addition to organic material at the bottom of rice paddies, straw or the stalk of the rice plant itself is an additional source of organic material that can also decompose to form methane.

${ }^{30}$ Fertilizer use efficiency refers to the amount of nitrogen in fertilizer applied to the soil that is ultimately taken up by plants.
} 
optimally use; when during the growing cycle fertilizers are most needed; and at what depth they should be placed for various tillage systems. Under certain conditions, for example, fertilizers applied in the spring emit less $\mathrm{N}_{2} \mathrm{O}$ than those applied during the fall (143). Efficiency also can be doubled under some conditions by placing fertilizers deep in the soil, rather than 'broadcasting' them on the surface (loo, 143).

\section{Low $\mathrm{N}_{2} \mathrm{O}$-Emitting Fertilizers}

The $\mathrm{N}_{2} \mathrm{O}$ emission potential of various fertilizers has been studied only under highly site-specific conditions $(10,11,35,96)$, limiting generalizations about emissions reduction potential of particular fertilizers. Research is needed on emission levels under a variety of field and cropping conditions. Studies suggest, however, that emission rates may vary by one or two orders of magnitude, with generally higher emissions for anhydrous ammonia than for other nitrogenous fertilizers (143). ${ }^{31}$

Slow-Release Fertilizers and Vitrification Inhibitors

Greenhouse studies with flood-irrigated rice suggest that slow-release fertilizers can considerably reduce denitrification (46) and allow for more efficient plant uptake. Under certain conditions this can double fertilizer efficiency (100); whether $\mathrm{N}_{2} \mathrm{O}$ emissions are simultaneously reduced is unclear. Also, slow-release fertilizers may continue releasing nitrogen after plants have been harvested, thereby creating the potential for nitrate production and leaching as well as additional $\mathrm{N}_{2} \mathrm{O}$ emissions during the winter and early spring (48). Slow-release fertilizers are not likely to become a viable technology until production costs drop.

Chemical additives in fertilizers can limit soil vitrification processes and, in turn, reduce the amount of nitrate available for denitrification. A wide range of chemicals has been registered and sold in the United States for use as nitrification inhibitors, and under certain conditions these can reduce nitrogen losses and increase fertilizer efficiency by 30 percent (47). Like slow-release fertilizers, these compounds may only delay the emissions of $\mathrm{N}_{2} \mathrm{O}$. After the plants have been taken out of the ground at harvest and nutrient uptake ceases, more soil nitro- gen becomes available for nitrification, which then can lead to further emissions.

\section{Leguminous Sources of Nitrogen}

Nitrogen can be added to the soil by growing ' "nitrogen-ftig' legume crops such as peas or beans (see box 8-B) in rotation with grains. A few studies suggest that $\mathrm{N}_{2} \mathrm{O}$ emission rates from legume-based systems are similar to those Ii-em fertilized crop systems, and possibly higher if no-till practices are used (43). If increased use of legumes reduces demand for nitrogenous fertilizers, then $\mathrm{CO}_{2}$ emissions from fertilizer manufacturing might be lowered. However, the lack of data on $\mathrm{N}_{2} \mathrm{O}$ emissions from legume cultivation and on the degree to which legumes could offset fertilizer use makes it difficult to determine the net effect on emissions. Regardless of their effect on $\mathrm{N}_{2} \mathrm{O}$ emissions, the planting of legumes makes sense from a soil conservation standpoint (76).

\section{Land Use Changes}

As mentioned earlier, the food system's single largest contributor to global warming is deforestation (roughly 10 percent of the warming effect; see ref. 143 and ch. 7). In developing countries as a whole, deforestation is the dominant source of $\mathrm{CO}_{2}$ emissions; techniques to discourage tropical deforestation are discussed in chapter 7. In this section we discuss other ways to encourage land use practices that store more carbon, techniques to maintain or increase yields on existing agricultural lands, and ways to cut production-related food losses and wastes.

\section{Encouraging Transformations That Increase Carbon Storage}

In developing countries a great deal of attention has been given to agroforestry--growing trees along with annual crops and livestock. The trees sequester carbon and generate products and revenues for small-scale farmers. (See ch. 7 regarding agroforestry's potential to reduce deforestation.)

Replacing annual crops on existing agricultural lands with perennial tree crops or woody plants could provide a long-term ' sink' for atmospheric carbon as well as produce desirable food products. Examples are hazelnuts and chestnuts in temperate

\footnotetext{
${ }^{31}$ In the United States, anhydrous ammonia accounts for about 38 percent of nitrogenous fertilizer use; ammonium nitrate, 21 percent; and urea, 11 percent. In Asia, urea accounts for about 60 to 65 percent of fertilizer use (100).
} 
regions and palms in tropical regions. Whereas most of the $\mathrm{CO}_{2}$ taken from the atmosphere during the growth cycle of annual crops is released again during post-harvest tillage, the roots of woody perennial plants reach much deeper and lock carbon out of the atmosphere for much longer periods (90). However, woody crops still require fertilizer and pesticides. Also, new varieties will have to be developed for various cropping systems, and economic and cultural obstacles (e.g., development of sufficient market demand, convincing farmers to switch farming practices) must be overcome.

With further research and development, several wild, non-tree perennials, such as eastern gama grass, giant wild rye, and Illinois bundleflower, may provide the germ for future perennial agricultural grains $(26,52,84)$. Like their woody counterparts, perennial grains would conserve soil and water resources. However, the development of perennial grain crops into widely used agricultural staples still may be decades away.

Finally, taking highly erodible agricultural lands out of production and converting them (or allowing them to revert) to perennial grasslands or forests helps conserve soil organic matter, a major carbon reservoir. ${ }^{32}$ This practice also helps protect surface waters from agricultural runoff $(124,129,138,139$, 140). $\mathrm{N}_{2} \mathrm{O}$ and $\mathrm{CO}_{2}$ emissions may also be reduced through avoided fertilizer and fossil fuel use. Setasides can also increase or help maintain biological diversity (129).

\section{Maintaining or Increasing Yields}

The rate of food production depends on crop acreage and crop yields which, in turn, are determined by a complex set of variables, ranging from soil and plant characteristics to pest outbreaks and varying weather conditions. If per-acre yields are limited or decline, food production can be maintained or increased only by expanding the area of land exploited. In tropical forest areas, for example, peasant farmers commonly respond to declining yields by converting additional forest areas into temporary croplands or by recultivating formerly abandoned areas that have regrown a "secondary" forest. Such transformations are likely to continue unless efforts are made to redistribute land, slow population growth, and stabilize or even increase yields.

Several techniques can be pursued in both industrialized and developing countries to maintain yields while limiting greenhouse gas emissions and limiting area of land used. More efficient fertilization practices and techniques to maintain or increase yields for rice were discussed above. It is important to note that the push to increase yields may require additional fertilizer inputs. As maximum yields are reached, nitrogen efficiencies begin to drop (see figure 8-5), which could lead to greater $\mathrm{N}_{2} \mathrm{O}$ emissions and other adverse environmental impacts.

\section{Reducing Food Losses}

Food losses from pest damage may cut world food production by one-third and rice production by up to 50 percent (74). Adverse weather conditions account for the largest annual variations in food production (74), which is ominous in view of possible future climate change. Yields also can be unintentionally reduced by human activities. ${ }^{33}$

Efforts could be increased to reduce various wastes and losses in the food system. Techniques for reducing erosion (e.g., conservation tillage, streamside tree plantings) would help maintain productivity (e.g., see 5,76, 120, 122). Post-harvest losses and wastes from pests, spoilage, and other factors could be reduced in several ways (see box 8-C). Nutrients from human wastes (e.g., food residues, sewage) can be recycled back into the food production system, rather than relegated to landfills or discharged into surface waters. Treated wastewater from sewage treatment plants is now being used for aquiculture (124) and for irrigation water in countries like Israel (95). Recycling food wastes and sewage wastewater can help improve soil quality, thereby reducing the need for supplemental fertilizer and other energy inputs. However, the costs of processing and transporting wastes and the problems associated with chemical and biological contaminants in the wastes $(124,127)$ pose disadvantages.

\footnotetext{
${ }^{32}$ The U.S. Department of Agriculture's Conservation Reserve Program is designed to do just this (see ch. 7 and "Policy Options" below). Note that this option is viable onty in areas that have excess amounts of land in production.

${ }^{33}$ For example, crop productivity can decline if soils become more saline as a result of excessive irrigation or are lost due to erosion. Soilerosion removed over 2.7 billion metric tons of soil in the United States in 1982 (131). Air pollution from nearby urban areas also carI undermine crop yields. For example, ozone from localized air pollution in the United States reportedly reduces yields of key crops by 1 to 20 percent in various crop-growing regions $(63,126)$.
} 


\section{Box 8-C-Post-Harvest Food Losses and Waste}

From the moment of harvest to the time food reaches the consumer's mouth, food losses and waste occur; these range from deterioration in food quality to consumption by rodents or disposal as household garbage. Worldwide losses and wastes appear to be substantial. For example, the Food and Agriculture Organization estimated that about 5 to 16 million metric tons of fish are caught and subsequently discarded by fishing vessels each year; this represents 6 to 20 percent of the amount that is retained (115). Additionally, about 10 percent of fresh fish supplies may be lost because of post-harvest problems such as inadequate refrigeration. A study in the early 1980s suggested that individual American households may waste 6 to 25 percent, or more, of their food-perhaps $\$ 30$ billion of food (34). Despite these and other examples, though, the magnitude of total losses and wastes remains very poorly defined at all levels, from the local to the global scale.

In industrialized countries, post-harvest food losses up to and including the storage, processing, and packaging steps (see figure 8-1) were relatively minor in the 1970s (1 to 2 percent) compared to developing countries, where such losses totaled at least 10 percent and often were higher (25a). However, for secondary food processing, marketing, and consumption, the situation is reversed. In industrialized countries, large amounts of food from eating establishments outside the home (e.g., restaurants, cafeterias, airlines, carry-out fast food outlets) are wasted on the plate and generally are discarded as garbage. In developing countries little food is wasted in this manner.

Cutting such losses and wastes offers an opportunity to increase food supplies without expanding food production. This would help alleviate pressures on land crops and on fisheries, thereby facilitating efforts to slow land transformations, and it also could help reduce the use of commercial fertilizers and fossil fuel inputs. Largely motivated by a desire to improve diets around the world, a variety of national and international organizations have called for efforts to reduce post-harvest losses and wastes $(110,117)$.

Serious obstacles impede progress in reducing losses, however. Even where losses can be quantified, solutions may not be cheap or easy. Where losses and wastes are large and they can be reduced in a cost-effective manner, a variety of opportunities are available. These range from encouraging education, training, and alternative technologies, to supporting economic and social changes and financing a broad spectrum of local, national, and international institutions $(69,75)$.

SOURCE: Office of Technology Assessment, 1991.

\section{CFCs, $\mathrm{CO}_{v}$ and Refrigeration}

New refrigeration systems are significantly more energy efficient than older systems and, hence, emit less $\mathrm{CO}_{2}$ from electricity requirements. However, efficiency improvements have not led to comparable reductions in CFC emissions; indeed, these improvements are partially attributable to greater use of CFCs in insulation. Political pressure, however, is building to reduce both $\mathrm{CO}_{2}$ and $\mathrm{CFC}$ emissions, and some new systems and components can reduce or eliminate CFC use (both as a refrigerant and as insulation) and reduce $\mathrm{CO}_{2}$ emissions. Some promising systems involve highly effective CFC-free insulation that improves energy efficiency (155, 156). Using smaller refrigerators also can reduce CFC and $\mathrm{CO}_{2}$ emissions. ${ }^{34}$
Other opportunities include using different working fluids $(41,68,142)$ and energy sources. For example, refrigerators can operate on energy sources such as natural gas, solar energy, and heat generated from waste materials $(14,79,105)$, all of which would reduce $\mathrm{CO}_{2}$ emissions and energy costs. The major drawback is the capital cost of shifting to new technologies.

Emissions from CFCs already in use as refrigerants could be limited by minimizing accidental emissions during repair (e.g., from leaks) and by sequestering and/or destroying CFCs instead of venting them during repairs or prior to final disposal of refrigeration systems $(33,51,77) .{ }^{35}$ The primary drawbacks are the costs of recovery and disposal and the costs of purifying CFCs for reuse (e.g., 73).

\footnotetext{
${ }^{34}$ U.S. refrigerators require more CFCs and energy to operate than units in most other industrialized countries. In 1983, the typical U.S. refrigerator consumed roughly $1,290 \mathrm{kWh}$, as compared to $480 \mathrm{kWh}$ for the typical German unit (93), principally because of the much larger size of U.S. units.

${ }^{35}$ Some countries (e.g., West Germany) (80) and States (see app. B) have programs in place to encourage the use of repair equipment that prevents CFC 10ss (80). This technology can be implemented quickly.
} 
Existing inefficient equipment also could be retired early in order to accelerate deployment of better technologies. The advantages include the possibility of rapid implementation, reduced fuel costs for new equipment, and, in some cases, reduced costs for electric utilities, which may be spared building additional generating capacity (39, 40). The primary disadvantages are the costs of collection and disposal and of purchasing a replacement unit.

\section{Cooking, Food Processing, and Packaging}

Emissions from cooking can be reduced, in theory, by changing the types of energy used or by improving fuel-use efficiency. Any strategy that promotes these changes, though, must consider fuel costs and availability, how cooking is normally conducted, and dietary and social preferences. In addition, improved cooking efficiencies may simply allow more cooking with the same amount of fuel, with no substantive change in emissions. Because these considerations have not been fully explored in different parts of the world, assessments of the global potential for limiting emissions from cooking cannot be made readily.

The United States and other industrialized countries emit far less $\mathrm{CO}_{2}$ from cooking than from other activities (see chs. 3 through 6). Even so, emissions can be reduced by using more efficient ovens and stoves. In developing countries significant $\mathrm{CO}_{2}$ and other emissions result from cooking with coal and biomass (see ch. 7). Shifts to other fuels have occurred fairly quickly in some cases. ${ }^{36}$ Increases in cooking efficiency also have occurred-often through improved cookstove designs $(53,66,112)$ (see ch. 7)--and can significantly reduce emissions per unit of delivered energy; however, they do not necessarily reduce total emissions. Where fuel availability is already constrained, improved efficiencies may allow people to cook more or to shift fuels to other end-uses such as heating (147). ${ }^{37}$

There are also opportunities in the areas of food processing and packaging to improve energy efficiencies and switch to low-emission energy sources. Options range from gas-fired cogeneration of elec- tricity and process heat to more fundamental process modifications (3).

\section{$\mathrm{CO}_{2}$ and Machinery, Fertilizer Manufacture, and Irrigation}

Although the impact of reducing emissions from farm machinery (e.g., engines, pumps) and fertilizer manufacture would be relatively small (see figure 8-6), technologies to improve energy efficiency could help reduce reliance on fossil fuels and hence save farmers considerable expense. Promising options to reduce fossil fuel use during food production involve changes in the character and efficiency of field operations (e.g., more efficient farm vehicles and irrigation, use of ethanol fuels, and innovative tillage practices and crop drying techniques) and improved efficiency in fertilizer manufacturing. Alternative energy sources such as wind and solar could be used for some operations (e.g., 38, 61).

\section{Efficiency Improvements for Farm Vehicles}

Over the next 10 to 15 years, for example, farm-tractor fuel efficiencies could be improved by 5 to 15 percent with new technologies such as adiabatic engines equipped with turbochargers, electronic controls, and onboard system diagnostics (6). However, these technologies require upfront capital expenditures and their long-term reliability is unknown. In developing countries their potential impact is unclear. In addition to costs, some analysts suggest that mechanization will be slow because tremendous labor supplies exist (85).

\section{Fertilizer Manufacture}

Energy efficiency in fertilizer manufacturing has improved substantially. By the mid-1980s, new plants were using about 20 percent less energy than in the early 1980 s primarily due to energy recovery equipment (21). Several new urea processes could decrease energy requirements by another 25 to 50 percent relative to the U.S. plant average (24). $\mathrm{CO}_{2}$ emissions reductions gained by improving energy efficiency could be negated, however, if more coal replaces gas as a primary feedstock in the production process.

${ }^{36}$ For example, one study of urban households in India (cited in 66) fourid that from 1979 to 1984 , woodfuel use for heating and cooking fell from 42 to 27 percent of total energy use for those purposes, kerosene increased from 19 to 36 percent, and liquefied petroleum gas grew from 7 to 12 percent.

${ }^{37}$ In one region of China, for example, over $\mathbf{8 0}$ percent of rural households lack enough coal and biomass for cooking and heating; improving cooking efficiency may result in increasing fuel use for heating, with the result being higher comfort levels rather than reduced consumption or emissions (147). 


\section{Efficient Irrigation}

The energy intensity of irrigation in the United States continues to rise, primarily because of increased pumping of groundwater (49); the same is true for some developing countries such as India and China (12). For U.S. food production activities, energy use for irrigation ranks third (behind pesticide and fertilizer manufacturing and use, and farm machinery use) (13). Worldwide, more than 60 percent of irrigation water, on average, is lost due to inefficient practices $(86,151)$. Technologies available to reduce water and energy use in irrigation include: Low Energy Precision Application (LEPA) designed to apply irrigation water and agrichemicals in small amounts and in precise locations (128); sprinkler and drip-irrigation systems to reduce evaporation; monitoring of soil moisture so water can be applied when needed; liners in canals to prevent seepage; and lasers to measure field levels so that water can be evenly distributed ${ }^{38}$ Recycling of agricultural runoff and municipal wastewater can also reduce demands for irrigation water, but energy requirements for pumping may be high. ${ }^{39}$

\section{Ethanol Fuels}

As discussed in the transportation sector (see ch. 5), corn-based ethanol emits from 10 percent less to 30 percent more $\mathrm{CO}_{2}$ than gasoline (23a). In 1987, about 3.2 billion liters of ethanol were sold in the United States, making this country the world's second largest ethanol consumer after Brazil (98, 153). Over 80 percent of U.S. ethanol plant capacity in 1986 was dedicated to corn feedstocks (134). ${ }^{40}$ Although the above estimates do account for the additional $\mathrm{CO}_{2}$ emissions associated with the manufacture of fertilizers, pesticides, and other energyintensive inputs needed for increased corn production, other impacts-such as additional $\mathrm{N}_{2} \mathrm{O}$ emissions from fertilizer breakdown, increased soil erosion, and other environmental problems associated with corn crops grown in monoculture must also be recognized.

\section{Innovative Tillage Practices}

By simultaneously laying seed and herbicides onto unplowed soil, a farmer can limit tractor tips to just one per crop cycle. This can reduce fuel use and attendant emissions, as well as enhance the soil's ability to retain organically bound carbon and water. This and other "conservation tillage" practices are primarily used to control soil erosion. However, they tend to require more herbicides for weed control than conventional tillage and therefore may result in greater $\mathrm{N}_{2} \mathrm{O}$ emissions (43). They also require more seed.

\section{Crop Drying}

In the United States, most crops sun-dry in the field. Some mops are dried with heated air, though; this accounted for about 3 percent of total on-farm energy use in 1978, mostly for corn and tobacco (102). Liquefied petroleum gas and natural gas are the most common energy sources. Alternative sources such as solar energy can reduce fuel use by as much as 20 percent (148). At present, 2 percent of U.S. crops are dried using active solar energy systems (123). Many passive solar crop drying systems (i.e., systems that rely on natural air convection) are in use in developing countries.

\section{POLICY ISSUES AND OPTIONS}

Most options discussed in the preceding section individually provide relatively small potential for reducing greenhouse gas emissions. But the sum of such efforts may someday provide substantial emissions reductions. In the case of livestock and CFCs for refrigeration-two categories that together accounted for about 6 to 9 percent of the global warming in the 1980s-promising, substantial opportunities may exist in the near term. While reductions in $\mathrm{CH}_{4}$ emissions from rice cultivation are theoretically possible, technologies to achieve this are much farther off and will require significant research and development. Techniques to increase fertilizer-use efficiency are currently available and

38 Reducing water use alsowould alleviate pressures on existing water supplies, possibly reduce the costs of making water available (e.g., government costs of water projects, farmer costs for water rights), and cause fewer environmental problems (e.g., increased salt levels in soil), Sprinkler irrigation techniques can reduce water use but require more energy for water distribution compared with gravity-flow systems (49), On the other hand, pressurized irrigation systems may help reduce fertilizer requirements (49).

${ }^{39}$ Energy from photovoltaic solar cells and wind power can be competitive with traditional diesel engines, particularly where fuel supplies and maintenance services are expensive and unreliable and where only a few thousand people are served (116; also see ch. 9).

40Most ethanol is us@ for 10 percent blends with gasoline (i.e., "gasohol"). One study estimated that relying on ethanol for 10 percent of U.S. automotive fuel demands might require about 40 percent of the corn harvest (88). Another study estimated that 20 to 25 percent of the U.S. corn crop would be needed to completely replace gasoline use on farms (6). 
will help reduce localized water pollution problems, but their effect on $\mathrm{N}_{2} \mathrm{O}$ emissions is inconclusive and will require more study. Improvements in fuel efficiencies of farm equipment and fertilizer manufacturing are likely to result in minor $\mathrm{CO}_{2}$ emissions reductions in developed countries, even less in developing countries where the level of mechanization is low and is likely to remain so in the near future.

This discussion focuses on policy mechanisms that Congress could use both to implement some of the technical options discussed above for the U.S. food system and to influence international emission reduction efforts. Policy considerations extend beyond technological factors to include many social, political, and economic issues. In the United States, for example, choices will be greatly influenced by farm support programs (see box 8-D). In many developing countries, efforts to limit food sector emissions and to gain associated environmental benefits will have to be linked with efforts to combat poverty, inadequate nutritional levels, inequitable land distribution, and rapid population growth (see chs. 7 and 9).

\section{Research Issues}

One of the most important research priorities for understanding the relationship between the food system and global climate change is the development of an emissions database representative of agricultural systems and growing conditions throughout the world. For example,

- better $\mathrm{CH}_{4}$ emissions data are needed from the large rice-producing areas in Asia and the Pacific; the general biogeochemistry of $\mathrm{CH}_{4}$ production in flooded rice paddies also needs to be established;

- factors affecting $\mathrm{CH}_{4}$ emissions from rice cultivation, such as climate, soil and water, species type, use of fertilizers, cultural practices, site, seasonal and diurnal variations, and relationship to other greenhouse gas emissions (e.g., $\left.\mathbf{N}_{2} \mathbf{O}\right)(\mathbf{1 4 5})$, need to be studied to establish representative emission factors;

- the relationships between $\mathrm{N}_{2} \mathrm{O}$ emissions and natural factors; fertilizer type, application rate, and placement; residual soil nitrogen; cropspecific nitrogen uptake; soil and water conditions; and timing need to be established;
- uniform, simple, and inexpensive techniques for measuring $\mathrm{CH}_{4}$ emissions from rice paddies and $\mathrm{N}_{2} \mathrm{O}$ emissions from all types of fertilized soils must be established so that comparable data can be collected worldwide; and

- how $\mathrm{CH}_{4}$ emissions from livestock vary by type and age of the animal and by type of management system (e.g., how and what animals are fed; manure handling) needs to be enumerated for the many regions throughout the world with large livestock populations.

- the relationship between biomass burning and emissions of trace gases (including $\mathrm{CH}_{4}, \mathrm{~N}_{2} \mathrm{O}$, $\mathrm{NO}$, and others) and the effects of such burning on the atmospheric and terrestrial environments.

Many international organizations already fund or coordinate agricultural research (e.g., International Fertilizer Development Center, International Board for Soil Research and Management, International Council for Research in Agroforestry, InterAmerican Institute for Cooperation on Agriculture) $(23,125)$. However, there is no overall promotion or coordination of research on the relationship between agriculture and global climate change. The United States could promote an international program to focus greater attention on this issue and to develop research protocols so that results can be meaningfully compared on a global scale. The Consultative Group for International Agricultural Research (CGIAR), an association of 13 regional and international agricultural research centers, might appropriately house such an effort.

\section{Livestock}

\section{U.S. Practices}

On the domestic front, Congress could direct the U.S. Department of Agriculture (USDA) to determine the extent to which methane-reducing techniques, such as feed additives, ionophores, and other nutrient management techniques, as well as animal waste management, are currently used in the United States. Such a program could also identify both institutional and technical barriers that hinder more widespread development and use of such techniques. Congress could provide additional support (e.g., through the USDA Agricultural Research Service and the National Science Foundation) for research on these techniques. 


\section{Box 8-D-USDA's Environmental Mission and Commodity Programs}

The USDA's mandate under the 1985 Food Security Act (Public Law 99-198), the Food, Agriculture, Conservation, and Trade Act of 1990 (Public Law 101-624) and other statutes includes considering agriculture's effects on water quality, and the agency has established programs that seek to lessen these effects. For example, through provisions such as the Conservation Compliance Program run by the Soil Conservation Service, about 800,000 farms were required to submit plans by 1990 to reduce erosion and to implement these plans by 1995 . If this is enforced, failure to comply with these plans will preclude eligibility for various commodity price supports and other Federal programs.

However, other environmental effects are not explicitly included as part of USDA's statutory mission. Including a broader definition of environmental protection as a part of the agency's mission could ensure that issues such as the food sector's effects on climate change are factored dirctly into national farm policies.

This could be particularly important with respect to USDA commodity programs, which are maintained to stabilize and support crop prices and farmers' incomes, as authorized in the Food Security Act. About two-thirds of all U.S. cropland is enrolled in programs that support such crops as wheat, feed grains (e.g., corn, sorghum, barley, oats), cotton, and rice. The cost to the Federal Government was about $\$ 11.6$ billion in fiscal year 1990 (76).

Price and income supports are based on the amount of acreage devoted to a given crop (called "base" acreage) and the average yield of that crop over the past 5 years (crop yields are currently frozen at the 1981-to-1985 average). Farmers who plant any other crop besides the one designated for that base acreage not only lose payments for that year, but also lower their base acreage for that crop and therefore lower future payments. This encourages farmers to grow the same crop on the same plot of land, year after year, in order to maximize their Federal subsidies. Furthermore, to comply with "cross-compliance" provisions (i.e., eligibility for a benefit depends on compliance with other provisions), farmers may not plant any other crop unless it is within their allotted base. Therefore, a farmer who wants to rotate crops using a crop in which he/she has little or no base acreage will lose all entitlements for that year.

All of this encourages a tendency to overuse fertilizers and other inputs, because maintaining yields on lands devoted to monoculture often requires significant amounts of these inputs. Excess fertilizer use, however, can cause groundwater contamination (128), surface water eutrophication, $\mathrm{N}_{2} \mathrm{O}$ emissions from denitrification, and loss of soil organic carbon.

Decoupling the rigid connection between Federal subsidies and production decisions would allow farmers flexibility to plant crops based on market demand, without risking the loss of all income supports, and reduce Federal expenditures on crops already in surplus $(60,118,128)$. ${ }^{\text {P }}$ Proposals to achieve this include allowing farmers to: 1) obtain payments for an enrolled crop, even if a portion of base acreage is planted with other crops; 2) temporarily switch a portion of their base-acreage crop to another crop without losing the original base; and 3) plant any combination of crops (allowed by USDA) within a designated "normal" acreage, if a certain portion of other acreage on which these crops are grown is taken out of production. In fact, the 1990 farm bill (Public Law 101-624) now allows farmers to plant a limited amount of selected crops on lands designated for other crops, without losing commodity program benefits.

\footnotetext{
1These options assume that the Federal Government will continue providing financial assistance to farmers to compensate for droughts and other poor growing conditions.
}

SOURCE: Office of Technology Assessment, 1991.

To limit future growth in, or even reduce, livestock populations in the United States, Congress could reduce or remove price supports (see box 8-D) for feed grains, which might make beef and dairy products more expensive (although it is unclear if the costs would rise or fall in the long term). About two-thirds of the total Federal grain subsidies apply to livestock feed (76; also see box 8-D). Feed grain farmers might grow other crops that make more money and, if feed grain prices rose sufficiently, livestock producers might raise less meat. However, this could cause large near-term economic disruptions for some farmers and portions of the food industry.

Congress could also modify eligibility criteria in the Conservation Reserve Program so that farmers can choose to put more land now used to grow feed grains into reserve; this also would reduce $\mathrm{CO}_{2}$ emissions from onfarm fossil fuel use and fertilizer manufacture and $\mathrm{N}_{2} \mathrm{O}$ emissions from fertilizer use. 


\section{Developing-Country Practices}

In developing countries, programs to increase productivity through improved breeding techniques or to enhance animal waste management systems must meet the special needs of livestock management systems in these countries, where livestock are primarily pasture-fed and are used for many purposes other than provision of food. With this in mind, Congress could contribute funds, through U.S. bilateral aid programs and through multilateral organizations (see ch. 9), to expand research programs in developing countries so that methane reductions become an additional research priority. For example, research institutes such as the International Livestock Centre for Africa and the International Laboratory for Research on Animal Diseases are part of the CGIAR system, which receives U.S. funding through A.I.D.

However, promoting technologies that lower per-animal emissions or policies that reduce livestock numbers will probably be difficult. Many of the technologies designed to reduce methane from individual animals are geared toward controlling the diets of animals in feedlot management systems, which are less common in developing countries. Also, efforts to introduce more productive livestock breeds into developing countries must first recognize that the unique genetic qualities of indigenous breeds that have evolved over thousands of years in adaptation to different ecological conditions.

Because livestock in developing countries are used for many purposes other than food production-as symbols of social status and wealth, for their religious values, for draft (construction) activities, for the energy value of their manure, and as alternative sources for income in the event of crop failures-convincing peasants to change their livestock management habits or to reduce their livestock numbers will probably be difficult.

Also, it may be difficult to decrease the lure of cattle ranching to middle- and upper-class landowners and investors. In many countries (particularly in Latin America), ranching is encouraged by national development policies, land ownership patterns, and land speculation (see ch. 7). Indirect opportunities exist for Congress to influence this particular situation, through its control of funding for bilateral aid programs and influence on multilateral lending institutions, but many obstacles must be overcome (see ch. 7).

\section{$\mathrm{CFCs}, \mathrm{CO}_{v}$ and Refrigeration}

In industrialized countries, obstacles to implementing energy efficiency options and other refrigeration improvements include consumer attitudes, regulatory barriers, and technical problems (e.g., lack of equipment that can directly use replacements for CFCs) $(31,108)$. The basic issues, though, are not whether refrigeration can be accomplished more efficiently and without CFCs, but how best to do this and at what costs compared with the benefits of emissions reductions.

Steering developing countries away from CFC production, CFC-based refrigerators, and lowefficiency equipment will be more problematic. Policy alternatives include encouraging these countries to sign and ratify the Montreal protocol, and transfer-ring information, technologies, and capital to enable them to pursue alternative and acceptable refrigeration practices economically. Box $2-\mathrm{C}$ in chapter 2 discusses recent changes to the Montreal Protocol, including funding mechanisms to help developing countries.

\section{Nitrogenous Fertilizer Use}

Congress could promote more efficient fertilizer use in the United States by changing commodity programs so as not to encourage excessive production (see box 8-D) and to allow farmers to grow crops and adopt practices that rely less on commercial fertilizers and other energy-intensive inputs, without loss of program base acreage (41).

Best Management Practices (BMPs) are designed by the Soil Conservation Service (SCS) to reduce soil degradation and water contamination from agricultural activities. ${ }^{42}$ At present, the SCS does not have statutory authority to promulgate enforceable regulations. Congress could require implementation of BMPs through cross-compliance, i.e., make implementation a prerequisite for receiving Federal

\footnotetext{
${ }^{41}$ Congress could provide this cropping flexibility only to farmers who adopt environmentally sound alternatives. Congress could also provide incentives to adopt these alternative practices by linking crop decisions to support payments and by giving tax credits to ease the potentially negative financial impacts of adopting "low-input" practices.

${ }^{42}$ They include, for example, improved fertilizer USe, water impoundments, $\mathrm{P}$ ermanent vegetative cover, and manure storage.
} 
price and income supports. ${ }^{43}$ However, such a policy would not apply to the one-third of U.S. croplands that are not enrolled in Federal farm support programs. Congress also could provide incentives (i.e., special services from USDA extension agents) to farmers who voluntarily adopt BMPs.

\section{Carbon Dioxide and Land Use Changes}

\section{Encouraging Land Use Changes That Increase Carbon Storage}

The goal of the USDA's Conservation Reserve Program (CRP) is to take 40 percent (16 to 18 million hectares) of highly erodible croplands (about 10 percent of all cropland) out of production, and in some cases to plant trees or grasses on the land (see ch. 7). Farmers who take lands out of production for 10 years receive annual rental payments from the Federal Government. By the end of 1989, about 14 million hectares had been enrolled at a cost of over $\$ 1$ billion annually $(71,130,132)^{44}$; the Food, Agriculture, Conservation, and Trade Act of 1990 (Public Law 101-624) extended the sign-up period through 1995. The USDA (130) estimates that the CRP could reduce U.S. fertilizer use by as much as 3 percent.

Congress could modify the CRP by:

- increasing the acreage goal;

- including croplands eroding at moderate levels;

- including other environmental objectives such as groundwater protection;

- increasing incentives for enrollment (e.g., provide options to extend leases, lengthen lease periods, and/or increase rental payments); and providing incentives for managing existing croplands in an environmentally sound manner.

All of these options will require additional program appropriations. An expanded CRP could also have detrimental economic effects on communities that depend on local farm business (e.g., farm equipment dealers, repair shops, agrichemical dealers, etc.) (130), and consumers would likely protest if food costs went up substantially.

\section{Discouraging Land Use Changes That Increase Emissions}

Within the United States, limiting land transformations is primarily a local or State zoning issue. However, some Federal benefits (e.g., housing and infrastructure grants) and regulatory permits (e.g., for industrial facilities) affect the disposition of agricultural land (25). Efforts to consider long-term environmental issues in land-use decisions could be important symbolically for international attempts to influence land use decisions in developing countries. ${ }^{45}$ Efforts to slow urbanization can also reduce urban infrastructure costs, limit automobile travel (see ch. 5), and otherwise contribute to more livable and affordable communities $(18,22,81,119)$.

\section{Maintaining or Increasing Yields}

Congress could require USDA to expand existing programs (i.e., "Low-Input Sustainable Agriculture") and develop new ones that focus on alternative practices, including techniques that maintain or increase crop yields and reduce emissions per unit of food output. Congress could also increase research funding to define relationships among agricultural practices, crop yields, and emissions (see 'Research Issues" above), and change existing U.S. domestic agricultural commodities programs that discourage farmers from pursuing alternative technologies and methods such as crop rotation and integrated pest management (76).

Congress also could promote alternative practices overseas, particularly in developing countries, by increasing support for:

- A.I.D. assistance programs in sustainable agriculture (e.g., technical assistance, research and development); and

- multilateral programs such as those of the Food and Agriculture Organization, CGIAR, and numerous other international agricultural research institutions.

Projects funded through these sources must recognize, however, that alternative agricultural practices developed by, and for, the industrialized world may not be the most appropriate for the developing

${ }^{43}$ Such a program could be extended to other energy-intensive inputs such as pesticides and irrigation water. For example, the SCS could establish guidelines on how, and in what quantities, various inputs should be applied to crops in specific regions of the country.

${ }^{44}$ Critics point to this price tag, while supporters argue that by reducing production of price-supported commodities, the CRP reduces prim-depressing crop surpluses and provides a net savings to the Federal Government. Estimates of the net effect of these factors are discussed briefly in ch. 7.

${ }^{45} \mathrm{Ch} .7$ discusses options for reducing deforestation in developing countries. 
world. For example, in the humid areas of the developing world, significant amounts of harvested crops are lost due to inadequate storage, while in other countries post-harvest losses may occur for different reasons.

\section{$\mathrm{CO}_{2}$ and Machinery, Fertilizer Manufacture, and Irrigation}

Federal options for promoting efficiency in the production and use of energy for agriculture are numerous. They include increasing the cost of energy; setting efficiency standards; supporting research, development and! demonstration projects; and providing incentives to retire old equipment and deploy low-emission alternatives. Key issues range from concerns about the magnitude and distribution of costs and benefits to problems associated with altering energy usage in complex, integrated industrial systems. Chapters 5 and 6 discuss options for motor vehicles and manufacturing in general.

\section{CHAPTER 8 REFERENCES}

1. Abbate, G. P., "Trends in Home Appliances in Europe," Energy Efficiency and Structural Change: Implications for the Greenhouse Problem (Oakland, CA: Lawrence Berkeley Laboratory, May 1-3, 1988), pp. 25-27.

2. Ambroggi, R.P., "Water," Scientific American 243 (3):101-116, September 1980

3. American Consulting Engineers Council, Industrial Market and Energy Management Guide: Food and Kindred Products, \#541 (Washington, DC: 1987).

4. Andreae, M.O., "Consequences of Biomass B urning for Tropical Atmospheric Chemistry: Results from Amazonia and Equatorial Africa,' ' paper presented at Chapman Conference on Global BiomassBurning: Atmospheric, Climatic and Biospheric Implications (Williamsburg, VA: Mar. 19-23, 1990).

5. Barker, R., "Impact of Prospective New Technologies on Crop Productivity: Implications for Domestic and World Agriculture," Technology and Agricultural Policy (Washington DC: National Academy Press, 1990), pp. 47-61.

6. Battelle Columbus Laboratories, "Engine and Fuels," Technology, Public Policy, and the Changing Structure of American Agriculture, Volume II-Background Papers, Part A, prepared for U.S. Congress, Office of Technology Assessment, NTIS \#PB86210390 (Springfield, VA: National Technical Information Service, May 1986).

7. Bingemer, H. and P. Crutzen, "'The Production of Methane From Solid Wastes, " J. Geophysical Research 92(D2):2181-2187, February 1987.

8. Boswell, F. C., J.J. Meisinger, and N.L. Case, "Production Marketing, and Use of Nitrogen Fertilizers,' Fertilizer Technology and Use, O.P. Engelstad (cd.) (Madison, WT: Soil Science Society of Amercia, Inc., 1985), pp. 229-292.

9. Bouwman, A.F. (cd.) Soils and the Greenhouse Effect (New York, NY: John Wiley \& Sons, 1990), pp. 113-114.

10. Breitenbeck, G. A., A.M. Blackmer, and J.M.Bremner, "Effects of Different Nitrogenous Fertilizers on Emissions of Nitrous Oxide From Soils," Geophysical Research Letters 7(1):85-88, 1980.

11. Bremner, J.M. and A.M. Blackmer, "Nitrous Oxide: Emission From Soils During Nitrification of Fertilizer Nitrogen," Science 199:295-296, 1978.
12. Brown, L.R. "The World Food Prospect: The Nineties and Beyond," Worldwatch Paper 85 (Washington, DC: Worldwatch Institute, October 1988).

13. Burwell, C.C., Roles of Electricity. Agriculture (Palo Alto, CA: Electric Power Research Institute, 1987).

14. Carlock, M., "Super-fridge Can Run on Sunshine," Popular Science, p. 64, November 1985.

15. Chemical Manufacturers Association 1986 Production and Soles of Chlorofluorocarbons CFC-11 and CFC-12, October 1987 (Washington, DC: 1987).

16. Cicerone, R.J. and R.S. Oremland, "Biogeochemical Aspects of Atmospheric Methane,' Global Biogeochemical Cycles 2(4):299327, 1988.

17. Cohen, J., "Putting the Freeze on Refrigeration Costs," EPRI Journal 13(8):16-21, December 1988.

18. Council on Development Choices for the ' $80 \mathrm{~s}$, The Affordable Community (Washington DC: Urban Land Institute, 1981)

19. Crowder, B.M. and C.E. Young, "Modeling Agricultural Nonpoint Source Pollution for Economic Evaluation of the Conestoga Headwaters RCWP Project,' ERS Staff Report No. AGES850614 (Washington, DC: U.S. Department of Agriculture, Economic Research Service, September 1985).

19a. Crutzen, P.J. and M.O. Andreae, ' 'Biomass Burning in the Tropics: Impact on Atmospheric Chemistry and Biogeochemical Cycles, " Science 250:1669-1678, 1990.

20. Crutzen, P.J., I. Aselmann, and W. Seiler, "Methane Production by Domestic Animals, Wild Ruminants, Other Herbivorous Fauna, and Humans," Tellus 38:271-284, 1986.

21. Davis, C. H., "Chemical Fertilizers, " in: U.S. Congress, Office of Technology Assessment, Technology, Public Policy, and the Changing Structure of American Agriculture, Volume IIBackground Papers, Part A, NTIS \#PB86-210390(Springfield, VA: National Technical Information Service, May 1986).

22. Davis, S. (ed.), The Form of Housing (New York, NY: Van Nostrand Reinhold, 1977).

23. Development Alternatives, Inc., "Elements of a Sustainable Agriculture Strategy for the Inter-American Institute for Cooperation on Agriculture" (Washington DC: June 1989).

23a.DeLuchi, M., University of California, personal communication, December 11, 1990. Revision of data in: DeLuchi, M., State-ofthe-Art Assessment of Greenhouse Gases From the Use of Fossil and Nonfossil Fuels, With Emphasis on Transportation Fuels (Davis, CA: University of California, June 3, 1990), table 10.

24. Dooyeweerd, E. and J. Meessen, "Comparison of the Energy Consumptions of Low-Energy Urea Technologies, " Nitrogen 143:32-38, May-June 1983.

25. Dowall, D.E., "Land Policy in the United States," Land Use Policy 6(1):11-30, 1989.

25a.Dow, Michael McD., National Research Council, personal communicaiton, May 7, 1990.

26. Eisenberg, E., "Back to Eden," Atlantic Monthly, pp. 57-89, November 1989

27. Elkins, J.W. et al., "Laboratory and Field Investigations of the Emissions of Nitrous Oxide From Biomass Burning," paper presented at Chapman Conference on Global Biomass Burning: Atmospheric, Climatic and Biospheric Implications (Williamsburg, VA: Mar. 19-23, 1990).

28. Environment Agency of Japan, U.S. Agency for International Development and the U.S. Environmental Protection Agency, Proceedings of the International Workshop on Methane Emissions from Natural Gas Systems, Coal Mining, and Waste Management Systems (Washington, DC: Apr. 9-13, 1990).

29. Environment Agency of Japan and the U.S. Environmental Protection Agency, Methane Emissions and Opportunities for Control, Workshop Results of the Intergovernmental Panel on Climate Change, Response Strategies Working Group (Washington, DC: September 1990).

30. Fertilizer Institute, 1989 Fertilizer Facts and Figures (Washington DC: 1989). 
31. Fischer, S.K. and F.A.Creswick, Energy-Use Impact of Chlorofluorocarbon Alternatives, ORNL/CON-273 (Springfield, VA: National Technical information Service, 1989).

32. Frevert, K. and B.M. Crowder, "Analysis of Agricultural Nonpoint Pollution Control Options in the St. Albans Bay Watershed," ERS Staff Report No. AGES870423 (Washington, DC: U.S. Department of Agriculture, Economic Research Service, June 1987).

33. Friends of the Earth International, "Activists Move Industry to Recycle CFC Foam," Atmosphere 2(4): 4, Winter 1990.

34. Fung, E.E. and W.L.Rathje, "How We Waste \$31 Billion in Food a Year, " in U.S. Department of Agriculture, Food-From Farm to Table (Washington DC: U.S. Government Printing Office, 1982), pp. 352-357.

35. Fung, L, E. Matthews, and J. Lerner, "Trace Gas Emissions Associated With Agricultural Activities," paper presented at U.S. Environmental Protection Agency, Workshop on Agriculture and Climate Change (Washington DC: Feb. 29-Mar. 1, 1988).

36. Gardner, P.D., Research on Economic Post-Harvest Loss (Washington, DC: U.S. Department of Agriculture, Economic Research Service, 1987).

37. Gasser, C.S. and R.T.Fraley, "Genetically Engineering Plants for Crop Improvement' Science 244: 1293-1299, 1989.

38. Gipe, P., "Windmills: Still Primed for Pumping Water, "Independent Energy, pp. 62-64, July/August 1989.

39. Goldstein, D.B., "Refrigerator Reform: Guideline-s for Energy Gluttons," Technology Review 86(2): 36-46, March 1983.

40. Goldstein, D. B., "Reduced CFC Emissions and Energy Conservation: A Linkage of Solutions," paper presented at Conference on Substitutes and Alternatives to CFCs and Halons (Washington DC: Jan. 13-15, 1988).

41. Gosney, W., "Alternatives to Fluorocarbons," paper presented at Conference on Refrigerants and the Environment, Consequences of the Montreal Protocol, May 18, 1988 (London: Institute of Refrigeration and U.K. National Development Office, 1988).

42. Grinnel, G., Economic Research Service, U.S. Department of Agriculture, personal communication Jan. 20, 1990.

43. Groffman, P., P. Hendrix, and D. Crossley, "Nitrogen Dynamics in Conventional and No-Tillage Agroecosystems With Inorganic Fertilizer or Legume Nitrogen Inputs," Plant and Soil (97):315332, 1987

44. Hall, D. O., "Biomass, Bioenergy and Agriculture in Europe," Biologue 6(4): 17-22,35, September/October 1989.

45. Hanchen, W. and Z. Dianwu, "Air Pollution Control and Energy Use in China,' S. Meyers (cd.), Energy Markets and the Future of Energy Demand (Berkeley, CA: Lawrence Berkeley Laboratory, 1988), pp. 9-1 to 9-7.

46. Hauck, R. D., "Agronomic and Technological Approaches to Minimizing Gaseous Nitrogen Losses From Croplands, ” J.R. Freney and J.R. Simpson (eds.), Developments in Plant and Soil Sciences, Volume 9 (Boston, MA: Martinus Nijhoff and W. Junk Publishers, 1983), pp. 284-312.

47. Hauck, R. D., "Slow-Release and Bioinhibitor-Amended Fertilizers," Fertilizer Technology and Use (Madison, WI: Soil Science Society of America, Inc., 1985), pp. 293-322.

48, Hauck, R. D., "'Agronomic and Public Aspects of Soil Nitrogen Research," Soil Use and Management 6(2):66-70, June 1990

49. Hostetler, J. and G. Sloggett, "Energy and Irrigation' Inputs, Report No. 10S-8 (Washington, DC: U.S. Department of Agriculture, Economic Research Service, August 1985).

50. Intergovernmental Panel on Climate Change, Scientific Assessment of Climate Change, Summary and Report, (Geneva: World Meteorological Organization/U.N. Environmental Program, 1990).

51. Issues Review and Tracking, "Refrigerant Recycling," Issues Review and Tracking 5(l): 1, Jan. 18, 1990

52, Jackson, W., New Roofs for Agriculture (Lincoln, NE: University of Nebraska Press, 1985)
53. Jones, M.H. et al., Energy Efficient Stoves in East Africa: An Assessment of the Kenya Ceramic Jiko (Stove) Program, Report No. 89-01, prepared by Oak Ridge National Laboratory and Kenya Energy and Environmental Organization (Washington DC: U.S. Agency for International Development, 1989).

54. Kafka, J., "Cattle Business Good in South Dakota," Associated Press, Jan. 10, 1990, Pierre, South Dakota.

55. Kaufman, D., Soil-Microbial Laboratory, U.S. Department of Agriculture, personal communication May 24, 1990.

56. Khalil, M.A.K., R.A. Rasmussen, M.-X. Wang, and L. Ren, "Sources of Methane in China: Rice Fields, Biogas Fits, Cattle, Urban Areas, and Wetlands, paper No. 9139.5, Proceedings of the 83rd Meeting andExhibition of the Air and Waste Management Association (Pittsburgh, PA: Air and Waste Management Association, 1990).

57. Klinger, D. and J.R.Kuzmyak, Personal Travel in the U.S., Volume 1, 1983-84 Nationwide Personal Transportation Study (Washington, DC: U.S. Department of Transportation, 1986).

58. Lerner, J., E. Matthews, and I. Fung, "Methane Emissions From Animals: A Global Resolution Data Base, "Global Biogeochemical Cycles 2(2):139-156, June 1988.

59. Levine, J. S., W.R. Cofer, and R.P. Rhinehart, "Enhanced Biogenic Emission of $\mathrm{CH}_{4}, \mathrm{~N}_{2} \mathrm{O}$, and NO Following Burning, " paper presented at Chapman Conference on Global Biomass Burning: Atmospheric, Climatic and Biospheric Implications (Williamsburg, VA: Mar. 19-23, 1990).

60. Library of Congress, Congressional Research Service, "The 1990 Farm Bill Notebook,' Report Number 89-540 ENR (Washington DC: Sept. 25, 1989).

61. Little, R. G., Board Chairman, U.S. Export Council for Renewable Energy, Testimony before House Energy \& Commerce Committee, Subcommittee on Energy and Power, Hearing on the Renewable Energy And Energy Efficiency Technology Competitiveness Act (Washington, DC: Apr. 26, 1989).

62. Lvovitch, M.I., "World Water Resources Present and Future," Ambio 6(1):13-21, 1977.

63. MacKenzie, J.J. and M.T.El-Ashry, Air Pollution's Toll on Forests and Crops (New Haven, CT: Yale University Press, 1989),

64. Martinez, A. and R.B.Diamond, Fertilizer Use Statistics in Crop Production (Muscle Shoals, AL: International Fertilizer Develop ment Center, 1982)

65. Martinez, A., Fertilizer Use Statistics and Crop Yields (Muscle Shoals, AL: International Fertilizer Development Center, 1990).

66. Meyers, S. and G. Leach, Biomass Fuels in the Developing Countries: An Overview, LBL-2722 (Berkeley, CA: Lawrence Berkeley Laboratory, 1989).

67. Moffat, A. S., "Engineering Useful Plants," Mosaic 21(1):34-43, spMg 1990.

68. Moore, T., "The Challenge of Doing Without, 'EPRI Journal 14(6):4-13, September 1989.

69. Morrissey, M.T., Postharvest Fishery Losses (Kingston, RI: International Center for Marine Resource Development University of Rhode Island, 1988).

70. Motor Vehicle Manufacturers Association Motor Vehicle Facts and Figures '89 (Detroit, MI: 1989).

71. Moulton, R., U.S. Forest Service, personal communication, Mm. 2,1990 .

72. Myers, N., Deforestation Rates in Tropical Forests and Their Climatic Implications (London: Friends of the Earth Ltd., 1989).

73. Naj, A. K., "Plan to Release CFC Coolants Produces Heat," Wall Street Journal, page Bl, Sept. 6, 1989.

74. National Research Council, Commission on International Relations, World Food and Nutrition Study. The Potential Contributions of Research (Washington, DC: National Academy of Sciences, 1977).

75 National Research Council, Board on Science and Technology for International Development, Postharvest Food Losses in Developing Countries (Washington DC: National Academy of Sciences, 1978). 
76. National Research Council, Board on Agriculture, Alternative Agriculture (Washington DC: National Academy Press, 1989).

77. National Environmental Protection Board, CFCs/Freons (Sweden: Swedish National Environmental Protection Board, 1987), Report 3410.

78. Neue, H. U., P. Becker-Heidmann, and H.W.Scharpenseel, "Organic Matter Dynamics, Soil Properties and Cultural Practices in Rice Lands and Their Relationship to Methane Production" A.F. Bouwman (cd.), Soils and the Greenhouse Effect (Chichester-New York-Brisbane-Toronto-Singapore: John Wiley, 1990), pp. 457466

79. New Scientist "Sun Drives CooI Compartments for the Third World," New Scientist 116:30, Dec. 10, 1987.

80. New Scientist, "'Gemany to Collect Fridges for Recycling,' New Scientist 121:26, Mar. 11, 1989.

81. Owens, S.E., Energy, Planning, and Urban Form (London:Pion, 1986).

82. Pimentel, D. and M. Pimentel, Food, Energy, and Society (New York, NY: Wiley, 1979).

83. Pimentel, D., T.W. Culliney, I.W. Buttler, D.J. Reinemann, and K.B. Beckman, "Low-Input Sustainable Agriculture Using Ecological Management Practices," Agriculture, Ecosystems and Environment (27):3-24, 1989

84. Pimentel, D., W. Jackson, M. Bender, and W. Pickett, "Perennial Grains, an Ecology of New Crops," Interdisciplinary Science Reviews 1 1(1): 42-49, 1986.

85. Pimentel, D., Cornell University, personal communication May 11 and Aug. 10, 1990.

86. Postel, S., "Water for Agriculture: Facing the Limits," Worldwatch Paper 93 (Washington, DC: Worldwatch Institute, December 1989).

87. Quay, P.D., S.L. King, J. Stutsman, J.M. Lansdown, and D.O. Wilbur, 'Methane Release Rate From Biomass Burning: Estimates Derived from ${ }^{13} \mathrm{C}$ Composition of Atmospheric Methane," paper presented at Chapman Conference on Global Biomass Burning: Atmospheric, Climatic and Biospheric Implications (Williamsburg, VA: Mar. 19-23, 1990),

88. Renner, M. "Rethinking the Role of the Automobile," Worldwatch Paper 84 (Washington DC: Worldwatch Institute, June 1988).

89. Rifkin, A., U.S. Department of Agriculture, personal communication, December 29, 1989.

90. Rutter, P. A., "Woody Agriculture: Increased Carbon Fixation and Co-Production of Food and Fuel, " Proceeding of the World Conference on Preparing for Climate Change, Cairo, Egypt, Dec. 17-21, 1989 (Washington DC: The Climate Institute).

91. Safley, L. M., and M.E.Casada, "Global Estimates of Methane Emissions From Animal Waste s-Preliminary Estimates," Proceedings of the International Workshop on Methane Emissions From Natural Gas Systems, Coal Mining, and Waste Management Systems (Washington, DC: Environment Agency of Japan, U.S. Agency for International Development and U.S. Environmental Protection Agency, Apr. 9-13, 1990).

92. Sathaye, J. A., "Urbanization and Modem Lifestyles: Implications for Fuel Use," pp. 15-1 to 15-11 in S. Meyers (cd.), Energy Markets and the Future of Energy Demand (Berkeley, CA: Lawrence Berkeley Laboratory, 1988).

93. Schipper, L. et al., Electricity and the Home: An International Overview of Trends (Berkeley, CA: Lawrence Berkeley Laboratory, 1986).

94. Schutz, H., W. Seiler, and H. Rennenberg, "Soil and Land-Use Related Sources and Sinks of Methane in the Context of the Global Methane Budget, A.F. Bouwman (cd.), Soils and the Greenhouse Effect (Chichester-New York-Brisbane-Toronto-Singapore: John Wiley, 1990), pp. 269-285,

95. Shuval, H.I., 'The Development of Water Reuse in Israel,' Ambio 16:(4), 1987.

$\%$. Slemr, F. and W. Seder, "Field Measurements of $\mathrm{NO}$ and $\mathrm{N}_{2} \mathrm{O}$ Emissions from Fertilized and Unfertilized Soils, "Journal of
Atmospheric Chemistry 2:1-24, 1984.

97. Smith, Richard J., U.S. Department of State, Testimony presented before the U.S. House of Representatives, Committee on Science, Space, and Technology, Subcommittee on International Scientific Cooperation and the Subcommittee on Natural Resources, Agricultural Research and Environment Joint Hearing on "CFC Reduction-Technology Transfer to the Developing World, Part 1: Review of Amendments to the Montreal Protocol, "July 11, 1990.

98. Sperling, D., New Transportation Fuels (Berkeley, CA: University of California Press, 1988)

99. Sperling D. and M.A. DeLuchi, Alternative Transportation Fuels and Air Pollution, report prepared for Environment Directorate, Organisation for Economic Cooperation and Development, Paris, France, March 1990.

100. Stangel, P., "Technological Options Affecting Emissions," paper presented at U.S. Environmental Protection Agency Workshop on Agriculture and Climate Change (Washington, DC: Feb. 28-Mar. 1, 1988).

101. Stout, B.A., Energy for World Agriculture, FAO Agriculture Series No. 7 (Rome: Food and Agriculture Organization of the United Nations, 1979).

102. Stout, B.A., Energy Use and Management in Agriculture (North Scituate, MA: Breton Publishers, 1984).

103. Stout, B.A., and R.F. Nehring, "Agricultural Energy: 1988 and the Future," National Forum 68(3):32-36, Summer 1988.

104. Surgeon General, Surgeon General's Report on Nutrition and Health (Washington, DC: U.S. Government Printing Office, 1988).

105. Tchernev, D.I., "Use of Natural Zeolites in Solar Refrigeration, 'W.G. Pond and F.A. Mumpton (eds.), Zeo-Agriculture: The Use of Natural Zeolites in Agriculture \& Aquiculture (Boulder, CO: WestView Press, 1984), pp. 273-280.

106. Tortoso, A.C. and G.L.Hutchinson, "Contributions of Autotrophic Nitrifiers to Soil $\mathrm{NO}$ and $\mathrm{N}_{2} \mathrm{O}, '$ Appl.Environ. Microbiol.56, June 1990.

107. Turiel, I., "Energy Efficiency in Residential Appliances, " Energy Efficiency and Structural Change: Implications for the Greenhouse Problem (Oakland, CA: Lawrence Berkeley Laboratory, May 1-3, 1988), pp. 28-30

108. Turiel, I. and M.D. Levine, "Energy Efficient Refrigeration and the Reduction of Chlorofluorocarbon Use, "Annual Review of Energy 14:173-204, 1989.

109. United Nations, Overall Socio-Economic Perspectives of the World Economy to the Year 2000 ST/ESA/215 (New York, NY: United Nations, 1990).

110. United Nations Committee of the Whole, Food and Agriculture in Global Perspective (New York, NY: Pergamon, 1980).

111. United Nations Department of International Economic and Social Affairs, Statistical Office, 1985/86 Statistical Yearbook (New York, $N Y:$ 1988).

112. United Nations Development Program and World Energy Sector Management Assistance Program, Niger Improved Stoves Project, Activity Completion Report No. 080/87 (Washington, DC: World Bank, 1987).

113. United Nations Food and Agriculture Organization Current World Fertilizer Situation and Outlook 1985/86-1991192 (Rome, Italy: 1987).

114. United Nations Food and Agriculture Organization, 1948-1985 World Crop and Livestock Statistics (Rome: 1987).

115. United Nations Food and Agriculture Organization Agriculture: Toward 2000, C87/27 (Rome: 1987).

116. U.S. Agency for International Development "Renewable Energy for Agriculture and Health" (Washington DC: May 1988).

117. U.S. Congress, General Accounting Office, "Hungq Nations Need to Reduce Food Losses Caused by Storage, Spillage, and Spoilage," ID-7665 (Washington DC: 1976).

118. U.S. Congress, General Accounting Office, " 1990 Farm Bill, Opportunities for Change," GAO/RCED-90-142 (Washington 
DC: April, 1990)

119. U.S. Congress, House of Representatives, Committee on Banking, Finance and Urban Affairs, Subcommittee on the City, Hearing on Energy and the City (Washington, DC: U.S. Government Printing Office, 1977).

120. U.S. Congress, Office of Technology Assessment, Impacts of Technology on U.S. Cropland and Rangeland Productivity, OTA-F-166 (Springfield, VA: National Technical Information Service, 1982).

121. U.S. Congress, Office of Technology Assessment, Technologies to Sustain Tropical Forest Resources, OTA-F-214 (Springfield, VA: National Technical Information Service, March 1984).

122. U.S. Congress, Office of Technology Assessment, Technology, Public Policy, and the Changing Structure of American Agriculture, OTA-F-285 (Springfield, VA: National Technical Information Service, March 1986).

123, U.S. Congress, Office of Technology Assessment, Technology, Public Policy, and the Changing Structure of American Agriculture, Volume II-Background Papers, Part A, NTIS \#PB86210390 (Springfield, VA: National Technical Information Service, May 1986).

124. U.S. Congress, Office of Technology Assessment, Wastes in Marine Environments, OTA-O-334 (Springfield, VA: National Technical Information Service, April 1987).

125. U.S. Congress, Office of Technology Assessment, Enhancing Agriculture in Africa, A Role for U.S. Development Assistance, OTA-F-356 (Washington+ DC: U.S. Government Printing Office, September 1988)

126. U.S. Congress, Office of Technology Assessment, Catching Our Breath, Next Steps for Reducing Urban Ozone, OTA-O-412 (Washington, DC: U.S. Government Printing Office, July 1989).

127. U.S. Congress, Office of Technology Assessment, Facing America's Trash, What Next for Municipal Solid Waste? OTA-O-424 (Washington, DC: U.S. Government Printing Office, 1989).

128. U.S. Congress, Office of Technology Assessment Beneath the Bottom Line: Agricultural Approaches to Reduce Agrichemical Contamination of GroundWater, OTA-F 418 (Washington DC: U.S. Government Printing Office, November 1990).

129, U.S. Department of Agriculture, Economic Research Service, Water Quality Benefits From the Conservation Reserve Program, Agricultural Economic Report No. 606 (Washington, DC: February 1989).

130. U.S. Department of Agriculture, Conservation Reserve Program, Progress Report and Preliminary Evaluation of the First Two Years (Washington, DC: 1989).

131. U.S. Department of Agriculture, The Second RCA Appraisal. Soil, Water, and Related Resources on Non-Federal Land in the United States, Analyses of Conditions and Trends (Washington DC: June 1989).

132. U.S. Department of Agriculture, Agricultural Stabilization and Conservation Service, "Supplement I to 'The Conservation Reserve Program: Progress Report and Preliminary Evaluation of the First Two Years(Signups 1-7) '," Draft Report(Washington, DC: Feb. 13, 1990)

133. U.S. Department of Commerce, National Oceanic andAtmospheric Administration National Marine Fisheries Service, Fisheries of the United States, 1988, Current Fishery Statistics No. 8800 (Washington, DC: 1989).

134. U.S. Department of Energy, Assessment of Costs and Benefits of Flexible and Alternative Fuel Use in the U.S. Transportation Sector, DOE/PE-0080 (Washington, DC: U.S. Government Printing Office, January 1988).

135. U.S. Department of Energy, Analysis and Technology Transfer, Annual Report-1987, Buildings and Community Systems (Upton, NY: Brookhaven National Laboratory, 1988).

136, U.S. Department of Energy, Energy Information Administration Office of Energy Markets and End-Use, Manufacturing Energy Consumption Survey: Consumption of Energy, 1985 (Washington DC: 1989).
137. U.S. Department of Energy, Energy Information Administration, Annual Energy Review, 1989, DOE/EIA 0384(89) (Washington, DC: U.S. Government Printing Office, May 1990).

138. U.S. Environmental protection Agency, Office of Water program Operations, Nonpoint Source Pollution in the U.S. (Washington, DC: January 1984).

139. U.S. Environmental Protection Agency, Final Report on the Federal/StatelLocal Nonpoint Source Task Force and Recommended National Nonpoint Source Policy (Washington DC: 1985).

140. U.S. Environmental Protection Agency, Office of Water, National Water Quality Inventory, 1986 Report to Congress, EPA440-87008 (Washington, DC: 1987).

141. U.S. Environmental Protection Agency, Office of Air and Radiation, Reducing Methane Emissions From Livestock: Opportunities and Issues, EPA 4(X)/1-89/002 (Washington, DC: August 1989).

142. U.S. Environmental Protection Agency, Office of Air and Radiation, Analysis of the Environmental Implications of the Future Growth in Demand For Partially-Halog enated Chlorinated Compounds, draft report (Washington DC: 1989).

143. U.S. Environmental Protection Agency, Policy Options for Stabilizing Global Climate, Draft, Report to Congress (Washington DC: June 1990).

144. U.S. Environmental Protection Agency, Policy Options for Stabilizing Global Climate, Draft, Report to Congress, Appendices (Washington DC: June 1990).

145. U.S. Environmental Protection Agency, Greenhouse Gas Emissions from Agricultural Systems, 20P-2005, Intergovernmental Panel on Climate Change (Washington DC: September 1990).

146. Winstead, E.L. et al., "Nitrous Oxide Emissions from Burning Biomass," paper presented at Chapman Conference on Global Biomass Burning: Atmospheric, Climatic and Biospheric Implications (Williamsburg, VA: Mar. 19-23, 1990).

147. Wirtshafter, R. M., A. Sorrentino, and C. Song-ying, "Improving Energy Efficiency in Chinese Housing, "Proceedings from the ACEEE 1986 Summer Study on Energy Efficiency in Buildings, Volume 8, Planning and Forecasting (Washington, DC: American Council for an Energy-Efficient Economy, 1986), pp.8.224-8.236.

148. Wittmus, H.L.O. and D. Lane, "Energy Requirements for Conventional vs. Minimum Tillage," Journ. Soil and Water Conservation 30:72-75, 1975

149. World Bank, China, the Energy Sector, Annex 3 to China, Long-Term Development Issues and Options, A World Bank Country Study (Washington, DC: World Bank, 1985).

150. World Bank, World Bank, FAO, UNIDO Fertilizer Working Group Nitrogen Supply, Demand and Balances for 1986/87 to 1992/93 (Washington, DC: World Bank, 1988).

151. World Resources Institute and International Institute for Environment and Development World Resources 1988-89 (New York, NY: Basic Books, Inc., 1988).

152. World Resources Institute, World Resources 1990-91 (New York, NY: Oxford University Press, 1990).

153. Wyman, C.E and N.D. Hinman, "Ethanol: Fundamentals of Production From Renewable Feedstocks and Use as a Transportation Fuel" (Golden, CO: Solar Energy Research Institute, undated).

154. Yagi, K. and K. Minami;, "Effects of Organic Matter Applications on Methane Emission From Japanese Paddy Fields, " A.F. Bouwman (cd.), Soils and the Greenhouse Effect (Chichester-New York-Brisbane-Toronto-Singapore: John Wiley, 1990), pp. 467473

155. Yarbrough, D.W. et al., The Thermal Resistance of Perlite-Based Evacuated Insulations for Refrigerators, ORNL/CON-215 (Oak Ridge, TN: Oak Ridge National Laboratory, September 1986).

156, Yarbrough, D.W. et al., Development of Advanced Thermal Insulation for Appliances, Progress Report for the Period July 1984 through June 1985, ORNL/CON-199 (Oak Ridge, TN: Oak Ridge National Laboratory, May 1986). 


\section{Appendix 6-A: Calculations for Figure 8-6}

\section{General}

Total U.S. $\mathrm{CO}_{2}$ emissions from fossil fuels in $1985: 1,300 \times 10^{12} \mathrm{~g}$, SOURCE: USEPA (143).

Carbon emissions attributed to electricity use: $0.4 \mathrm{lb} / \mathrm{kWh}$.

SOURCE: Office of Technology Assessment, based on national mix of energy sources used to produce electrical energy (see ch. 3).

Fertilizer

\section{Food Production}

All fertilizer: $\left(707,000 \times 10^{\prime}>B t u\right) X\left(14 \times 10^{3} \mathrm{~g} C / B t u\right)=9.9 \times 1012 \mathrm{~g}$. Assumes all energy consists of direct consumption of natural gas used as feedstock. While this is not the case, nitrogen fertilizer production accounts for the majority of energy used in fertilizer production, and natural gas supplies most of that energy.

Share of total US. $\mathrm{CO}_{2}$ emissions: $\left(9.9 \times 10^{12} \mathrm{~g}\right) /\left(1,300 \times 10^{12} \mathrm{~g}\right)=0.8 \%$ SOURCE: Btu figure provided by ref. 42.

Elect riclt y

Electricity y consumed in "traditional" agricultural sector: $\left(31,816 \mathrm{X} 1 \mathrm{O}^{6} \mathrm{kWh}\right) \mathrm{X}(0.4 \mathrm{lb} \mathrm{C} / \mathrm{kWh})=12,726.4 \mathrm{X} 1 \mathrm{O}^{6} \mathrm{lb}=5.8 \mathrm{X} 10^{12}$ g. This does not include electricity consumed in producing inputs (e.g., fertilizer) for the agricultural sector.

Share of total U.S. $\mathrm{CO}_{2}$ emissions: $\left(5.8 \times 10^{12} \mathrm{~g}\right) /(1,300 \times 1012 \mathrm{~g})=0.4^{\circ} \mathrm{A}$ SOURCE: kWh figure provided by ref. 42.

Onsite Fossil Fuel Use

Gasoline: $\left(1,900,000 \times 10^{3} \mathrm{gal}\right) \times(5.48 \mathrm{lb} \mathrm{C} / \mathrm{gal}) \times(1 \mathrm{~kg} / 2.25 \mathrm{lbs})=4.6 \times 10^{12} \mathrm{~g}$

Diesel: $\left(2,870,000 \times 10^{3} \mathrm{gal}\right) \times(6 \mathrm{lb} / \mathrm{gal}) \times(1 \mathrm{~kg} / 2.25 \mathrm{lb})=7.65 \times 10^{12} \mathrm{~g}$

Fuel oil: $\left(78,400 \times 10^{3} \mathrm{gal}\right) \times(6 \mathrm{lb} / \mathrm{gal}) \times(1 \mathrm{~kg} / 2.25 \mathrm{lb})=0.2 \times 1012 \mathrm{~g}$

LP gas: $\left(955,000 \times 10^{3}\right.$ gal) $X\left(13.6 \mathrm{~kg} \mathrm{C} / 10^{9}\right.$ Joules $) X\left(97 \times 10^{6} \mathrm{Joules} / \mathrm{gal}\right)=0.01 \times 1012 \mathrm{~g}$ (Assumes LPG is $100 \%$ propane, $92,000 \mathrm{Btu} / \mathrm{gal}$ )

Natural gas: $\left(48,800 \times 10^{6} \mathrm{cf}\right) X\left(16.3 \mathrm{~kg} C / / \mathrm{O}^{9}\right.$ Joules $) X(37.3 \times 106$ Joules $/ 35.3 \mathrm{cf})=0.8 \times 1012 \mathrm{~g}$

Coal: $(42,500$ tons $) \times\left(22 \times 10^{6} \mathrm{Btu} /\right.$ ton $) \times(26 \mathrm{mg} / \mathrm{Btu})=0.243 \times 10^{12} \mathrm{~g}$

Share of total U.S. $\mathrm{CO}_{2}$ emissions: $\left(13.5 \times 10^{12} \mathrm{~g}\right) /(1,300 \times 1012 \mathrm{~g})=1.0 \%$ SOURCE: Initial figure (i.e., quantity of fuel) in each calculation from ref. 103.

Food Industry

\section{Post-Harvest}

Electricity: $(44,400$ million $\mathrm{kWh}) X(0.18 \mathrm{~kg} / \mathrm{kWh})=8 \times 10^{12} \mathrm{~g}$

Residual fuel oil: $(6,290,000$ barrels $) X\left(6.289 \times 10^{6}\right.$ Btu/barrel $) X(20 \mathrm{mg} / \mathrm{Btu})=0.8 \times 1012 \mathrm{~g}$

Distillate fuel oil: $(4,360,000$ barrels $) X\left(5.82 \times 10^{6}\right.$ Btu/barrel $) X(20 \mathrm{mg} / \mathrm{Btu})=0.5 \times 1012 \mathrm{~g}$

Natural gas: (464 billion cubic feet) $X(1,020$ Btu/cubic foot $) X(14 \mathrm{mg} / \mathrm{Btu})=6.6 \times 10^{12} \mathrm{~g}$

LPG: (89 million gal) $X\left(13.6 \mathrm{~kg} \mathrm{C} / 10^{9}\right.$ Joules) $X\left(97 \times 10^{6} \mathrm{Joules} / \mathrm{gal}\right)=0.1 \times 1012 \mathrm{~g}$

(Assumes LPG is $100 \%$ propane, $92,000 \mathrm{Btu} / \mathrm{gal}$ )

Coal: $(5,570,000$ short tons $) \times\left(22 \times 10^{6} \mathrm{Btu} /\right.$ ton $) \times(26 \mathrm{mg} / \mathrm{Btu})=3.2 \times 10^{12} \mathrm{~g}$

Other: 121 trillion Btu

Total: $19.2 \times 10^{12} \mathrm{~g}$

Share of total U.S. $\mathrm{CO}_{2}$ emissions: $\left(19 \times 10^{12} \mathrm{~g}\right) /\left(1,300 \times 10^{12} \mathrm{~g}\right)=1.5 \%$ SOURCE: See ref. 136.

Residential Cooking Energy

Electric ranges/ovens: $(0.63 \times 1015 \mathrm{Btu}) \mathrm{X}(1 \mathrm{kWh} / 11,500 \mathrm{Btu}) \mathrm{X}(181 \mathrm{~g} / \mathrm{kWh})=9.9 \times 10^{12} \mathrm{~g}$

Gas ranges/ovens: $\left(0.21 \times 10^{15} \mathrm{Btu}\right) \mathrm{X}(14 \mathrm{mg} / \mathrm{Btu})=2.94 \times 1012 \mathrm{~g}$

Total, excluding small electric appliances: $12.8 \times 1012 \mathrm{~g}$ of $\mathrm{C}$

Share of total U.S. $\mathrm{CO}_{2}$ emissions: $\left(12.8 \times 10^{12} \mathrm{~g}\right) /\left(1,300 \times 10^{12} \mathrm{~g}\right)=1.0 \%$ SOURCE: Initial figures (i.e., Btu use) from ref. 135.

Supermarket/Domestic Refrigeration

Residential refrigeration: $(1,850 \times 1012 \mathrm{Btu}) \mathrm{X}(1 \mathrm{kWh} / 1 \quad 1,500 \mathrm{Btu}) \mathrm{X}(181 \mathrm{~g} / \mathrm{kWh})=29 \times 10^{12} \mathrm{~g} \mathrm{C}$ Based on total electricity use in 1985 of 1.85 quads (refrigerators: 1.41 quads; freezers: 0.44 quads)

Supermarkets: $9.5 \times 10^{12} \mathrm{~g}$. Based on: 1) 35,000 supermarkets in operation account for about $4 \%$ of all electric energy used, and approximately one-half of that (i.e., $2^{\circ} \mathrm{A}$ of all electric energy used) is attributable to refrigeration equipment (ref. 17); 2) emissions of $\mathrm{CO}_{2}$ from utilities amounted to about 460 teragrams in 1985 (based on data in ref. 144); and 3) $(460 \mathrm{Tg}) \times(0.02)=9.2 \times 10^{12} \mathrm{~g}$.

Total supermarkets and residential: $(29+9.2) \times 10^{12} \mathrm{~g} \mathrm{C}=38.2 \times 1012 \mathrm{~g} \mathrm{C}$

Share of total U.S. $\mathrm{CO}_{2}$ emissions: $\left(38.2 \times 10^{12} \mathrm{~g}\right) /(1,300 \times 1012 \mathrm{~g})=2.9 \%$ SOURCES: Ref. 17,135,144.

1 Totals may not add up due to rounding. 
Chapter 9

\section{International Dimensions: \\ U.S. Influence and Regional Trends}

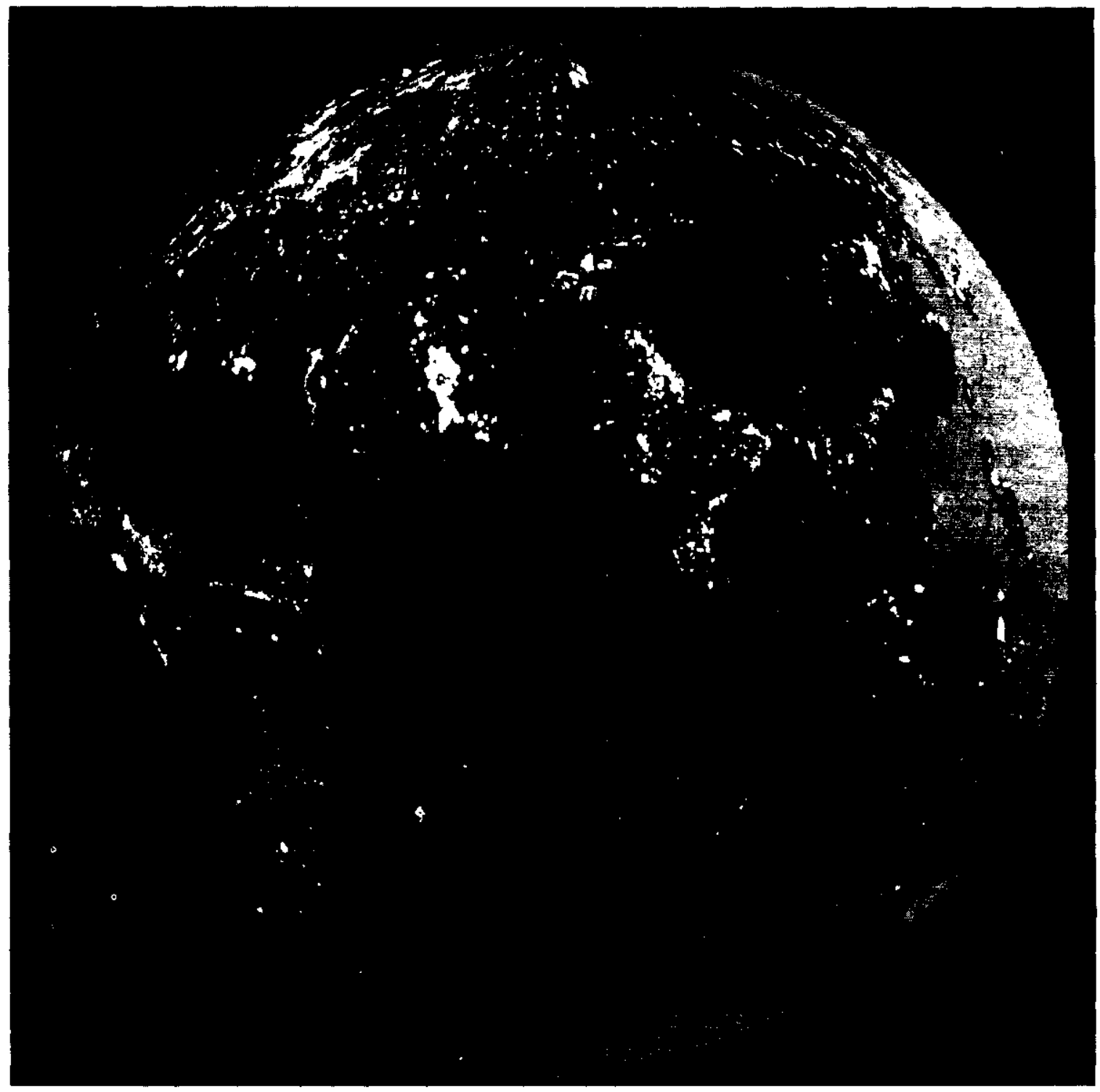

Photo credit: Gene Carl Feldman, NASA, from "The Earth at Night" (S 1985) of W.T. Sullivan II, University of Washington 


\section{CONTENTS}

INTRODUCTION .................. Page

Relative Greenhouse Gas Emissions . . . . . . 273

Population Projections . . . . . . . . . . . . . 275

GENERAL AVENUES FOR U.S.

INFLUENCE . . . . . . . . . . . . . . . 278

U.S. Bilateral Organizations and Involvement in Multilateral organizations .......... 279

Technology Transfer and Trade With

Other Countries .................281

Non-Governmental Organizations (NGOs). 286

DEVELOPING COUNTRIES .. ...........287

Contribution to Greenhouse Gas Emissions. 287

General Areas for Improvements . . . . . . . . 288

Policy Directions for the United States . . . . 290

EASTERN EUROPE AND THE U.S.S.R. . . . 294

Trends in Eastern Europe . . . . . . . . . . . . 295

Trends in the U.S.S.R. .............295

Options for Possible U.S. Influence . . . . . . 2\%

OECD COUNTRIES ................300

Trends and Projections in Energy Use and

Carbon Emissions . . . . . . . . . . . . 300

Policies Regarding Energy and

Greenhouse Gases ..................301

CHAPTER PREFERENCES ............. 306

\section{Boxes}

Box

9-A. Global Population Growth . . . . . . . . . . 277

9-B. Agencies and Organizations That Can Influence Greenhouse Gas Emissions . . . 282

9-C. U.S. Trade in Renewable and Efficient Energy Technologies 285

Figures

Figure Page

9-1. Regional Trends in $\mathrm{CO}_{2}$ Emissions From Fossil Fuels, 1950-86 . . . . . . . . . . . 273

9-2. World Primary Energy Consumption, 1988
Figure

9-3. Per-Capita Consumption of

Primary Energy ............*...*

Page

9-4. Projected Primary En ergy Consumption by Region for "High Emissions" Scenario, 1985 to 2025 ... . . . ..............* .. . 276

9-5, World Population Growth, 1750 to 2100.277

9-6. The World's 15 Largest Cities, 1970 (actual) and 2000 (projected) .... 279

9-7. Projected $\mathrm{CO}_{2}$ Emissions in Selected Developing Countries ..............288

9-8. Projected Carbon Emissions in the U.S.S.R. . *..**..**.**,,.,.....*.. $2 \%$

9-9. Projected Carbon Emissions in the European Community

\section{Tables}

Table Page

9-1. Fossil Fuel Use, by Region .. ***+**,.. 274

9-2. Countries Ranked by Population Size for 1950, 1989, and 2020 ...***..*.*..***. 278

9-3. Examples of Avenues for U.S. Influence . 280

9-4. Funding for Major Energy Assistance to Developing Countries, 1988-89 ...... 292

9-5. Total Foreign Trade as a Percentage of GNP, 1988, for Selected Countries . . . . 297

9-6. Policies Enacted for Energy Efficiency by OECD Countries, 1970s and 1980s . . 303

9-7. Official Greenhouse Gas Emission Stabilization and Reduction Policies of OECD Countries . . . . . . . . . . . . . . . . . . 304

9-8. New Plans and Programs in OECD Countries, Specifically Designed To Reduce Greenhouse Gas Emissions, as of 1990 


\section{International Dimensions: U.S. Influence and Regional Trends}

\section{INTRODUCTION}

Greenhouse gas emissions are a function of many factors, including level and rate of technological development, rate of energy use (and types of fuels used), rates of land conversion and resource depletion (e.g., deforestation), agricultural practices (e.g., wet v. dry rice farming), and population growth and urbanization. These factors, their cumulative impact on emissions, and the problems faced in attempting to slow the growth rate in emissions vary greatly from one region or nation to another. These variations will be of paramount importance in any international negotiations regarding climate change and reductions in greenhouse gas emissions.

This chapter discusses three groups of countries:

- developing countries, most with market economies, some with centrally planned economies;

- Eastern Europe and the U. S. S. R.--countries with centrally planned economies, many of which are changing to market economies; and

- the Organization for Economic Cooperation and Development (OECD)---developed countries with market economies (18 countries in Western Europe plus Australia, Canada, Japan, New Zealand, Turkey, and the United States).

Since energy use is likely to increase as material living standards rise in developing countries, an appropriate goal for the United States and other OECD countries is to help developing countries adopt technologies and practices that minimize emissions yet still enhance economic growth. This can be done by promoting efficient energy and materials use; renewable, nonfossil fuels (e.g., solar, nuclear, geothermal, biomass); and more sustainable use of forestry and agricultural resources. The same goal also is appropriate for U.S. and OECD policies regarding Eastern Europe and the U.S.S.R. In these countries, though, systemic obstacles to more efficient energy use (particularly rigid, centralized economic planning and highly subsidized energy resources) must be overcome.
Clearly our impact in these spheres will depend on our own domestic policies. The United States and other OECD countries face the daunting task of implementing technologies and practices to reduce their own energy use without major economic disruptions.

\section{Relative Greenhouse Gas Emissions}

Worldwide carbon emissions from primary energy use account for an estimated 55 percent of the current 'radiative forcing effect' (see ch. 2) associated with all greenhouse gas emissions from anthropogenic sources (32). Overall estimated carbon emissions have risen in all regions since 1950 and have been highest in OECD countries, the U. S. S. R., and Eastern Europe (see figure 9-1). Since the early 1970s, however, carbon emissions have been relatively stable in OECD countries while continuing to rise elsewhere.

The OECD countries, U. S. S. R., and Eastern Europe currently contribute one-half to two-thirds of

Figure 9-I-Regional Trends in $\mathrm{CO}_{2}$ Emissions From Fossil Fuels, 1950-86

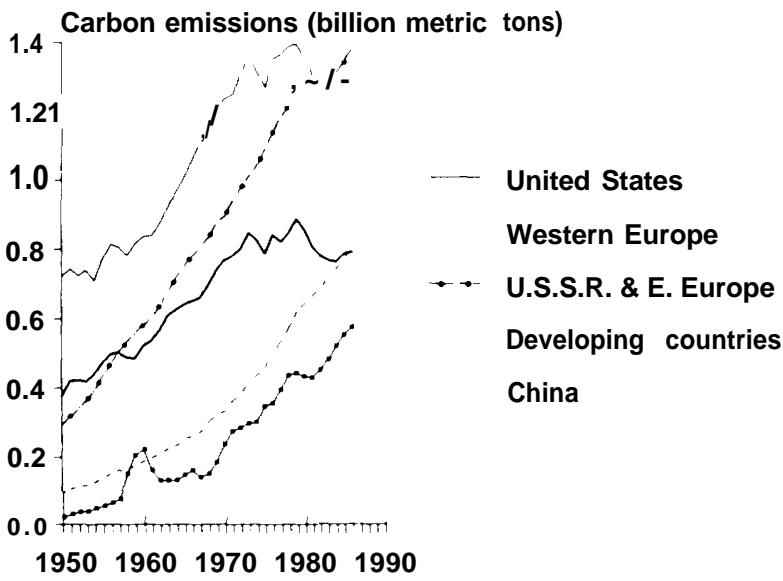

SOURCE: G. Marland et al., Estimates of $\mathrm{CO}_{2}$ Emissions From Fossil Fuel Burning and Cement Manufacturing Using theUnited Nations Energy Statistics and the U.S. Bureau of Mines Cement Manufacturing Data, ORNLCDIAC-25,NDP-030 (Oak Ridge, TN: Oak Ridge National Laboratory, Carbon Dioxide Information Analysis Center, October 1988).

'The World Bank defines "developing countries"' as low-income (e.g., China, India, Pakistan, Kenya) and middle-income (e.g., Indonesia, Philippines, Mexico, Brazil) (132). Also see ref. 104 for additional details. 
Table 9-I-Fossil Fuel Use, by Region

\begin{tabular}{|c|c|c|c|c|c|}
\hline & \multicolumn{2}{|c|}{$\begin{array}{l}\text { Average annual growth in fossil } \\
\text { fuel use, } 1950-95\end{array}$} & \multicolumn{3}{|c|}{ Energy use by sector, late 1980 s } \\
\hline & Total & Per capita & Industry & Buildings & Transportation \\
\hline $\begin{array}{l}\text { Developed market economies } \ldots \ldots \ldots \ldots \\
\text { Eastern Europe and U.S.S.R. . } \ldots \ldots \ldots \ldots \\
\text { Centrally planned Asia......... } \\
\text { Developing market economies } \ldots \ldots \ldots \ldots \\
\end{array}$ & $\begin{array}{l}4.0 \% \\
5.2 \% \\
9.5 \% \\
6.4 \%\end{array}$ & $\begin{array}{l}1.1 \% \\
3.4 \% \\
7.8 \% \\
3.7 \%\end{array}$ & $\begin{array}{l}35 \% \\
60 \% \\
45 \% \\
49 \%\end{array}$ & $\begin{array}{l}32 \% \\
27 \% \\
50 \% \\
24 \%\end{array}$ & $\begin{array}{r}33 \% \\
13 \% \\
5 \% \\
27 \% \\
\end{array}$ \\
\hline
\end{tabular}

SOURCE: Intergovernmental Panel on Climate Change, Energy and Industry Sub Group Report (Geneva: May 31, 1990).

all greenhouse gas emissions, mostly from combustion of fossil fuels to power their economies. In 1986, the United States and other OECD countries accounted for over 40 percent of estimated emissions (1 10), although they are home to only 16 percent of the world's population (66). The U.S.S.R. and Eastern Europe, with 8 percent of the world's population, accounted for over 20 percent of estimated emissions.

The rest of the world-in essence the developing countries--contributed at least one-third of global emissions. Among developing countries the most important emitters are China, Brazil, Indonesia, India, Mexico, Thailand, and Ivory Coast (56). ${ }^{2}$ China and India had the highest emissions from fossil fuel use, while Brazil and Indonesia had the highest estimated emissions from deforestation. The developing world could be contributing as much as one-half of global $\mathrm{CO}_{2}$ emissions if the highest estimates of emissions from tropical deforestation (see ch. 7) are accurate.

Most developing country emissions currently stem from deforestation and other land use practices (e.g., methane from cultivation of rice and raising of livestock). Population growth probably will lead to further increases of emissions from these activities. Fossil fuel emissions are expected to grow very rapidly, paralleling growth in population and in energy consumption in all sectors $(18,31,32,56,76$, 110). Chlorofluorocarbon (CFC) emissions also are likely to increase, because not all developing coun- tries are signatories to the Montreal Protocol; the Protocol, moreover, permits those that did sign to increase their use of CFCs for 10 years before cutbacks are required (see box 2-C in ch. 2).

Emissions from OECD countries are expected to remain relatively stable, while emissions in Eastern Europe and the U.S.S.R. are expected to rise moderately as more services become available and as per-capita incomes rise (33). ${ }^{3}$ As a result, total emissions from developing countries may equal or exceed those from the developed world within a few decades.

\section{Energy Use}

Globally, fossil fuel use has nearly quadrupled since 1950, growing fastest in the developing countries (see table 9-1). The OECD countries, including the United States, still account for slightly over half of global primary energy consumption, while the U.S.S.R. and Eastern Europe account for 24 percent (see figure 9-2). ${ }^{4}$ Developing countries account for about 25 percent of the total. When estimates of traditional fuel usage are included, the developing countries account for a greater share of energy use, but such usage is not well quantified.s

Greater use of fossil fuels in OECD countries and in Eastern Europe and the U.S.S.R. reflects much higher levels of per-capita energy consumption than in developing countries (see figure 9-3). Per-capita rates in OECD countries could drop if energyefficient technologies are more widely implemented,

${ }^{2}$ This report is part of a U.S. Agency for International Developmenteffort, mandated by the fiscal year 1990 Foreign Operations Appropriations Act (Public Law 101-167), to identify key developing countries contributing greenhouse gas emissions.

${ }^{3}$ Projections of future greenhouse gas emissions depend on assumptions about future energy supply and use, rates of economic and population growth, changes in land use practices, and emissions control policies.

4"Primary" or "primary commercial" energy refers to energy commodities that are widely traded in organized markets (e.g., coal, oil, gas, and electricity; see ref. 104). "Traditional" or "biomass" fuels refers to firewood, charcoal, animal wastes, and crop residues. Some biomass fuels, particularly firewood and charcoal, are traded in organized markets.

${ }^{5}$ Populations that live in rural areas in developing countries tend to have little access to commercial fuels and technologies. In these areas, traditional fuels satisfy most heating and cooking needs, and manual labor is used for most agricultural, transportation and industrial needs (104). 
Figure 9-2-World Primary Energy Consumption, 1988

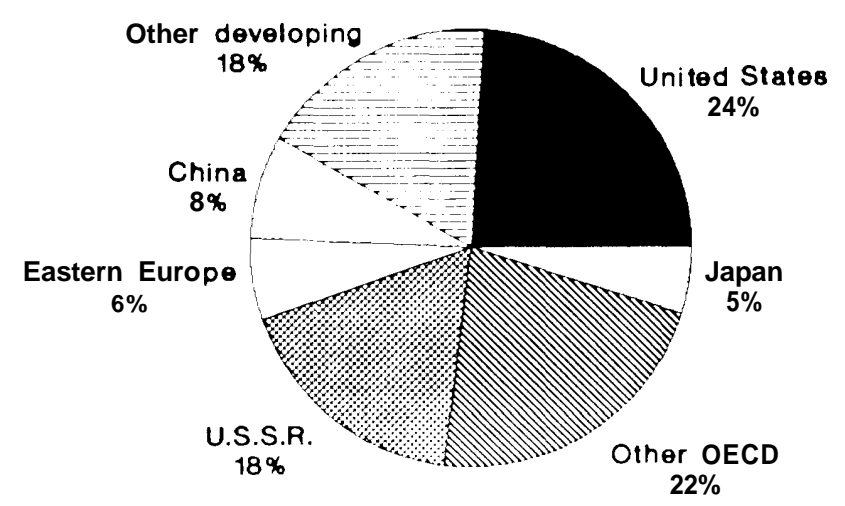

SOURCE: U.s. Department of Energy, International Energy. Annual, DOEJEIA-0219(88)(Washington, DC: Energy Information Administration, November 1989).

Figure 9-3-Per-Capita Consumption of Primary Energy (excluding biomass)

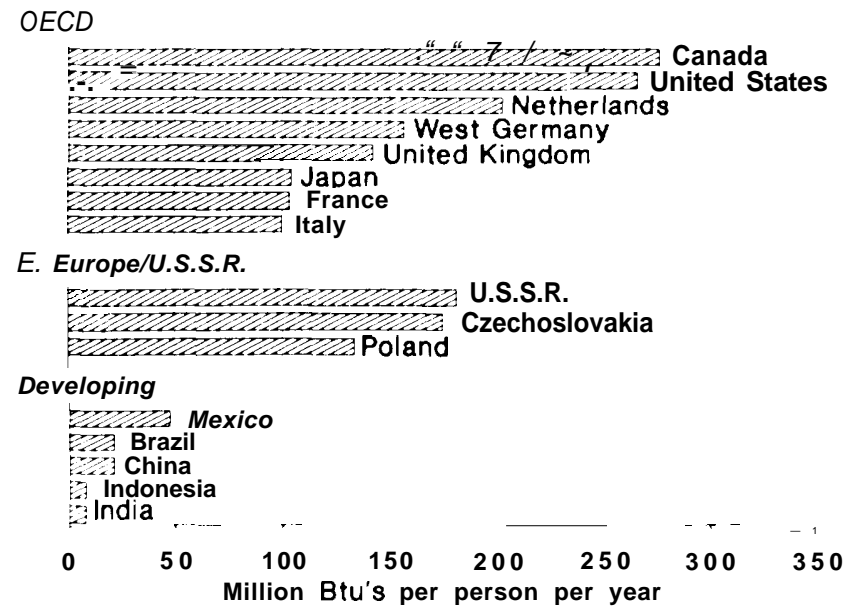

SOURCE: U.S. Congress, Office of Technology Assessment, Energy in Developing Countries, OTA-E-486 (Washington, DC: U.S. Government Printing Office, January 1991 ).

since population levels are relatively stable and economic growth is likely to be moderate. In contrast, per-capita rates in developing countries are likely to increase as development measures (especially for electricity generation, direct industrial use, and transportation) are implemented, even if energy efficiency measures are included.

Hence, the developing countries' primary energy consumption is expected to grow much more rapidly than that of the OECD countries, with Eastern Europe and the U.S.S.R. exhibiting intermediate growth (see figure 9-4). Various projections (31, 32,
$34,76,110)$ indicate that the absolute portion of primary energy use in developing nations will overtake that of developed countries early in the next century, even though the per-capita difference between developed and developing countries is likely to persist well into the next century.

\section{Deforestation}

Tropical forests, located almost exclusively in developing countries, are rapidly being deforested and degraded (see ch. 7). Between 7 and 31 percent of worldwide $\mathrm{CO}_{2}$ emissions may result from deforestation. Temperate-zone forests, located mostly in developed countries, currently contribute comparatively little to $\mathrm{CO}_{2}$ emissions from deforestation, although they have undergone massive alterations, in some cases complete deforestation, in the past.

The major causes of tropical deforestation and degradation are the conversion of forests to temporary (e. g., "'shifting' cultivation) and permanent agriculture (including cattle ranching) and unsustainable timber harvesting practices. These practices are driven by rapid population growth, poverty and lack of land tenure for many people, national and international development policies that favor conversion of forests to agricultural and grazing land, massive foreign debts, and accounting systems that do not recognize many nontimber forest values.

\section{Population Projections}

Rapid population growth, in combination with economic growth, will fuel increased global demands for energy and land resources long beyond the time frame of this study, particularly in the developing countries. While decreases in current population growth rates would not greatly affect total emissions during the next two decades, they could have major implications for emissions levels during the remainder of the 21 st century, depending partly on how rapidly renewable fuels and/or nuclear power replace fossil fuels.

For most of human history, the number of people was probably no more than 5 to 10 million, and even by 1750 it was still less than 1 billion. Since 1750 , however, population growth has been extremely rapid (box 9-A). Now the world's population stands at 5.3 billion (figure 9-5), and it is growing at a rate of over 10,000 people per hour. The relationships among growth rates, birth and death rates, replace- 
Figure 9-4-Projected Primary Energy Consumption by Region, for "High Emissions" (I.e., Base case) Scenario, 1985 to 2025

Lower economic growth rate

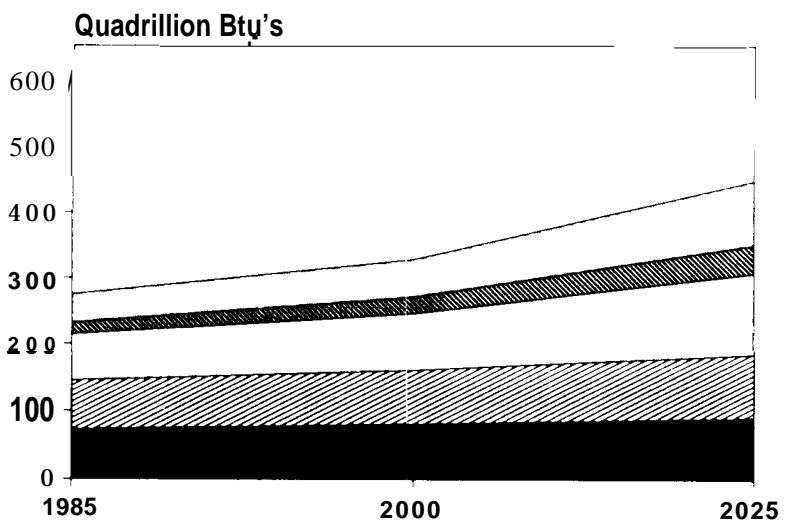

United States

Other OECD countries
Higher economic growth rate

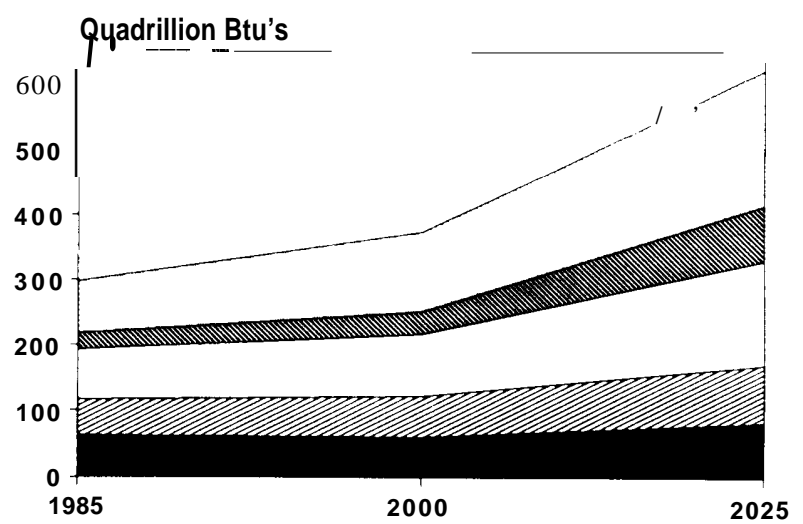

China and centrally planned Asia

Other developing countries

U.S.S.R. and centrally planned Europe

This figure shows projections of primary energy consumption under a "High Emissions" scenario--a base-case situation in which few or no steps are taken to reduce greenhouse gas emissions. Continued population and economic growth result in increased energy use and tropical deforestation; fossil fuels continue to dominate energy supply; and the share of coal increases. The figure on the left shows the projection for a low economic growth case; i.e., the average annual rate of global GNP growth decreases from 2.2 percent per year for 1985 through 2000, to 2.1 percent per year for 2000 to 2025, and to 1.3 percent per year for 2025 to 2100 . The figure on the right shows the projection for a higher economic growth case; i.e., the average annual rate of global GNP growth decreases from 3.6 percent per year for 1985 through 2000, to 3.3 percent per year for 2000 to 2005, and to 2.6 percent per year for 2025 to2100.

SOURCE: Intergovernmental Panel on Climate Change, Emissions Scenarios, Report of the Expert Group on Emissions Scenarios (RSWG Steering Committee, Task A) (Geneva: Response Strategies Working Group, April 1990).

ment fertility rates, and population age structure are examined in box 9-A.

World Bank and United Nations projections suggest that the world population will increase to over 8 billion by 2025 and over 11 billion by 2100 (the U.N. projection discussed here is its "medium" scenario, one of three scenarios modeled). ${ }^{6}$ The Bank projects that population will stabilize at 11.5 billion some years later $(2,71)$. Projected growth rates also portend major rerankings of countries by population size (see table 9-2).

Over 90 percent of population growth is projected to occur in the developing countries of Africa, Asia, and Latin America (see figure 9-5). Unless current trends change dramatically, the proportion of the world's population living in Africa, the continent with the highest growth rate, would increase from 12 percent today to 26 percent in 2100 . China's and India's growth rates (1.4 and 2.1 percent, respectively), while far from the highest in the world, are adding sizable numbers of people each year because of built-in population "momentum" (see box 9-A) and large population bases (21 and 16 percent, respectively, of the global population) (66). The proportion of people living in the developed countries is projected to fall from 23 percent today to about 12 percent in 2100 (2). Growth rates in the U.S.S.R. and most European and North American countries are low, and three countries (Denmark,

\footnotetext{
${ }^{6}$ Population Projections are not Prediction, but rather are estimates of future population levels given assumptions (e.g., declining birth rates throughout the developing world), models, and collections of base data that vary in accuracy. Projections are increasingly subject to error the they reach into the future.
} 


\section{Box 9-A-Global Population Growth}

About 10,000 years ago, humans began to shift from a hunting and gathering lifestyle to a more settled existence based on agriculture and domestication of animals. This shift permitted populations to increase, and by 1750 the world's population had grown slowly to probably around 750 million $(50,67)$. Over the next two centuries, the world's population tripled to 2.5 billion (see figure 9-5). Between 1950 and 1987, it doubled again, to more than 5 billion. 'At current rates, the world adds almost a billion people every decade (66).

The first major increase, after 1750, occurred in the more developed countries as death rates began to decline slowly, probably due to improvements in nutrition and sanitation, and birth rates remained relatively high. The net increase was gradual (about 1.5 percent per year) (101). Eventually, though, birth rates also declined, and today the developed countries are growing by only 0.5 percent annually (71). The shift from high birth and death rates and low population growth to low birth and death rates with low or no population growth is called the demographic transition. This transition in the developed countries took place over a relatively long period.

The second major increase in world population began after World War II in the developing countries of Africa, Asia, and Latin America (101). It has been much more rapid than the first major increase for two reasons. First, death rates declined very rapidly, because of the transfer of medical and agricultural improvements from developed countries. Second, although lower birth rates followed rapidly in some countries (e.g., China, Mexico), in general they have not yet begun to parallel the decline in death rates. As a result, net growth rates have been high ( 2.5 to 3.5 percent and even higher per year) and remain explosive in many countries. The demographic transition in these countries is incomplete. Annual growth rates between 1990 and 1995, for example, are projected to be 6.7 percent in Afghanistan (which will double its population in about 10 years), 4.1 percent in Kenya, and between 3 and 4 percent in many African and Middle Eastern countries (71).

The developing countries exhibit tremendous "population momentum" and will continue to grow for one or more generations even after the average fertility rate drops to replacement levels. The degree of momentum depends on the population's age structure. When the majority of the population is still in or entering the reproductive years, even replacement rates $(2.1$ children per couple, which accounts for the death of some women during their child-bearing years) result in a net population increase. Many developing countries exhibit this age structure. In contrast, the age structure in developed countries is such that births roughly balance deaths.

\footnotetext{
${ }^{1}$ A population's doubling time can be closely estimated by dividing 70 by the growth rate. For example, a population growing at 3 P@ per year will double in about 23 years (and increase by a factor of about $10 \mathrm{~m}$ a century).
}

Germany, and Hungary) exhibit zero or even negative growth.

Figure 9-S-World Population Growth 1750 to 2100

Most developing countries support family planning, and over the past several decades many have reduced their birth rates, resulting in improvements in maternal health and per-capita economic growth. However, while international support for family planning programs has remained relatively stable 6 since 1972, it has declined as a percentage of official 4 development assistance (92).

Urbanization-The world also is becoming increasingly urban. In 1950, 29 percent of the world's people lived in urban areas and today 48 percent do; by 2010,56 percent of the world's population is projected to live in cities $(89,105)$. Great variations

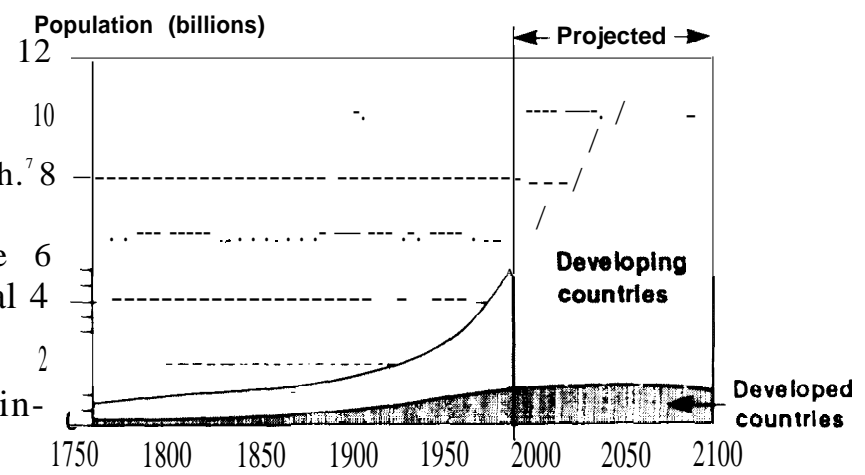

SOURCE: Population Reference Bureau, 199(7 Workd Population Data Sheet (Washington, DC: 1990).

'In China, for example, since Chou En Lai's "Directive 51" in 1971 (101), fertility dropped from 5.8 births per woman in 1970 to the replacement level of 2.1 in 1984 (50). In Thailand, Colombia, and South Korea, it took 15 years or less to reduce average fertility from 6 to 3.5 births per woman (105). Mexico's fertility rate dropped from 6.8 births per woman in the early 1970 s to 4.3 in 1982 and 3.8 in 1989, and it is projected to approach replacement level by $2010(50,65)$. 
Table 9-2-Countries Ranked by Population Size for 1950,1989, and 2020 (population size In millions In parentheses)

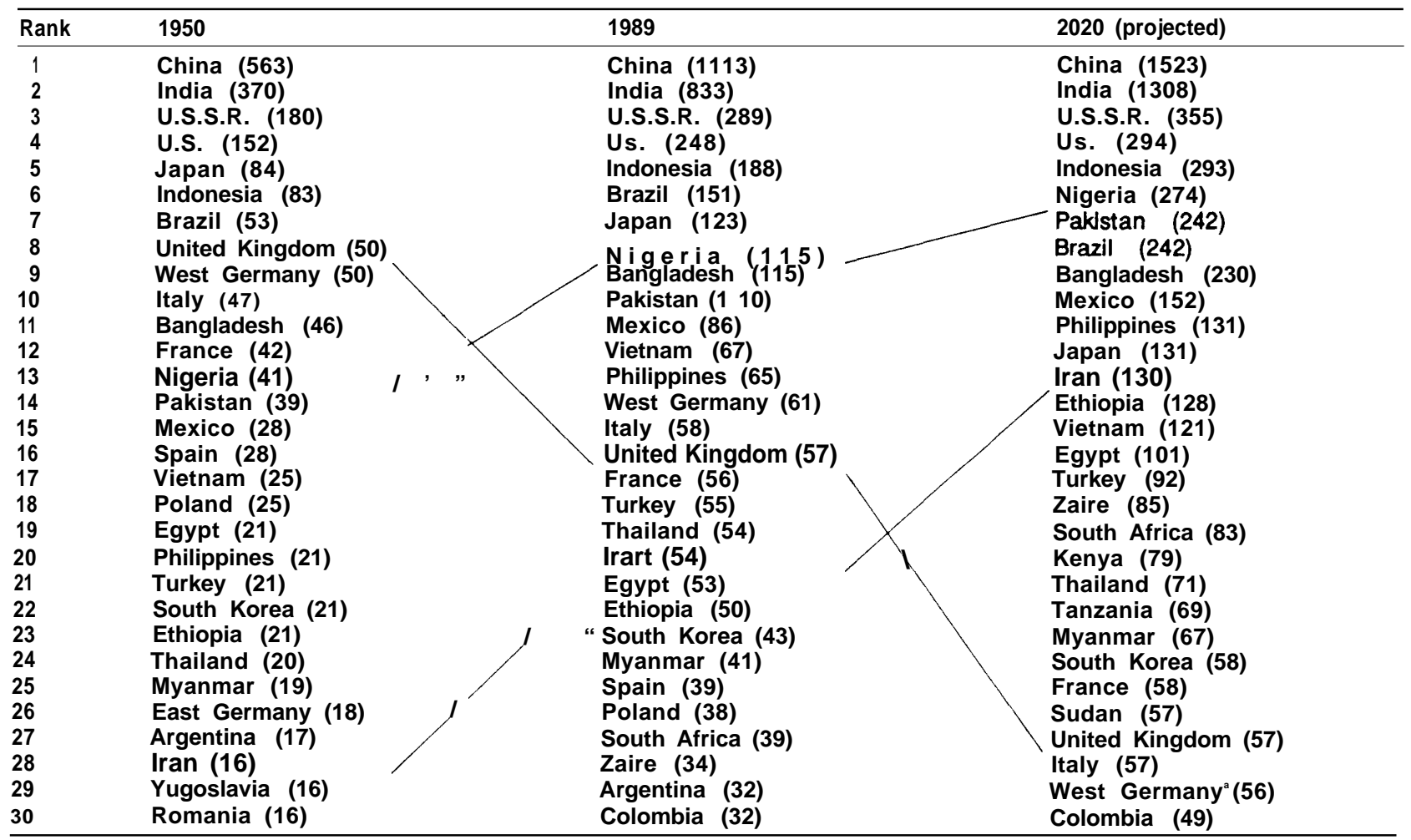

axcluding East Germany.

NOTE: This table shows that the relative population ranking of some countries will change through time. For example, the United Kingdom is projected to drop from 8th largest in 1950 to 27th largest in 2020, while Iran is projected to move from 27th to 13th position in the same period. The top four countries are expected to retain their current rankings, although Indonesia and Nigeria will approach the size of the United States.

SOURCE: Office of Technology Assessment, 1991, based on U.S. Department of Commerce, Bureau of the Census, World Population Profile:1989, WP-89 (Washington, Dc: U.S. Government Printing Office, September 19S9).

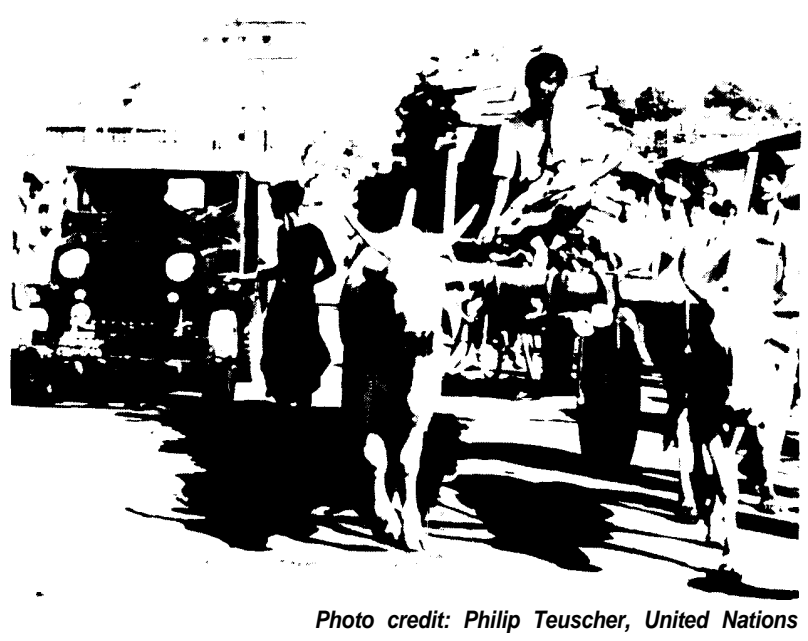

Urbanization is proceeding rapidly in most parts of the developing world, following past trends in the developed world; by 2010, 56 percent of the world's population is projected to live in cities. exist among different countries and regions-for example, over 70 percent of today's population in the developed world and Latin America is urban, compared to 35 percent in Africa and 30 percent in Asia. Urbanization is proceeding rapidly in most parts of the developing world, though, following past trends in the developed world. Rapid urban growth in the developing world is reflected in the shift in location of the world's 10 largest cities away from the developed world (figure 9-6).

\section{GENERAL AVENUES FOR U.S. INFLUENCE}

Chapters 1 and 3 through 8 set out specific policy options in various sectors (i.e., energy, buildings, transportation, manufacturing, forestry, and food) which the United States could pursue in order to reduce or offset its own greenhouse gas emissions. There are many compelling reasons to do so (see ch. 
Figure 9-6---The World's 15 Largest Cities, 1970 (actual) and 2000 \{projected)

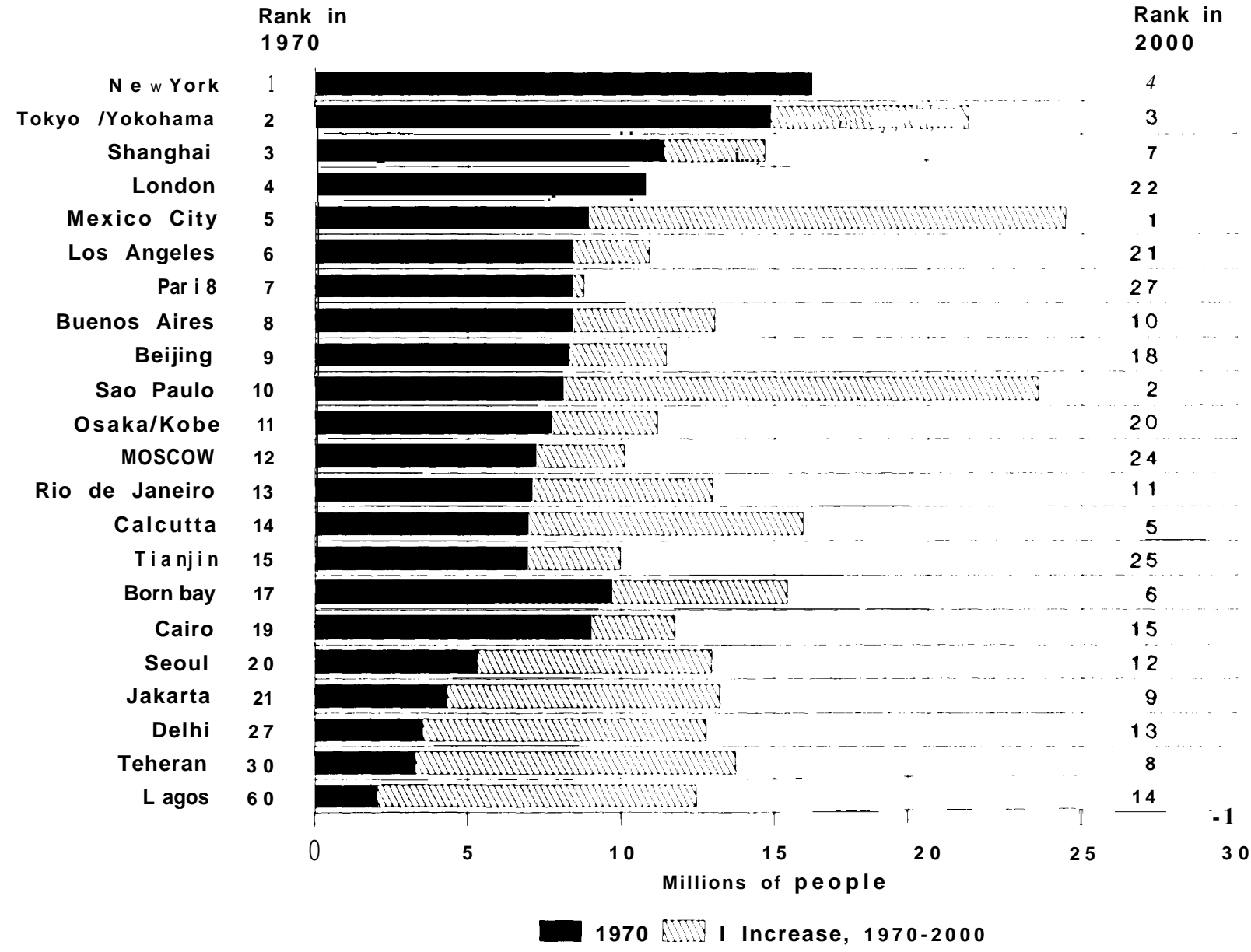

SOURCE: U.N. Department of International Economic and Social Affairs, Prospects of World Urbanization, 1988, Population Studies No. 112, ST/ESANSER.A1 12 (New York: 1989).

1), and by taking such actions to reduce its own emissions the United States could provide leadership through example.

The United States also could encourage other countries to follow suit. ${ }^{8}$ This section summarizes how the United States can, in general, potentially influence other countries' policies and practices: through bilateral and multilateral assistance organizations, trade with other nations, and nongovernmental organizations (see table 9-3). The United States also could participate in negotiations on an international framework convention on green- house gas emissions. Such negotiations are expected to begin early this year.'

\section{U.S. Bilateral Organizations and Involvement in Multilateral Organizations}

The United States provides direct bilateral assistance to developing countries through the U.S. Agency for International Development (A. I.D.) and other government agencies, and it contributes to multilateral assistance through its participation in various international organizations (box 9-B).

${ }^{8}$ The section on the OECD (see،'OECDCountries" 'below) describes actions that several industrialized Countries have taken without waiting ' 0 r the United States. As of December 1990, the United States was the only G-7 country without a $\mathrm{CO}_{2}$ target goal. The G-7 (Group of 7) countries consist of Canada, France, Germany, Italy, Japan, United Kingdom, and the United States.

In July 1989, the G-7 countries agreed at their Economic S ummit that a U.N. framework convention on climate change setting out global principles was needed and that protocols containing concrete commitments could be fit into the framework as scientific evidence permitted. Several precedents exist for negotiating such agreements, most notably the Montreal Protocol on Substances that Deplete the Ozone Layer (see box 2-C). 


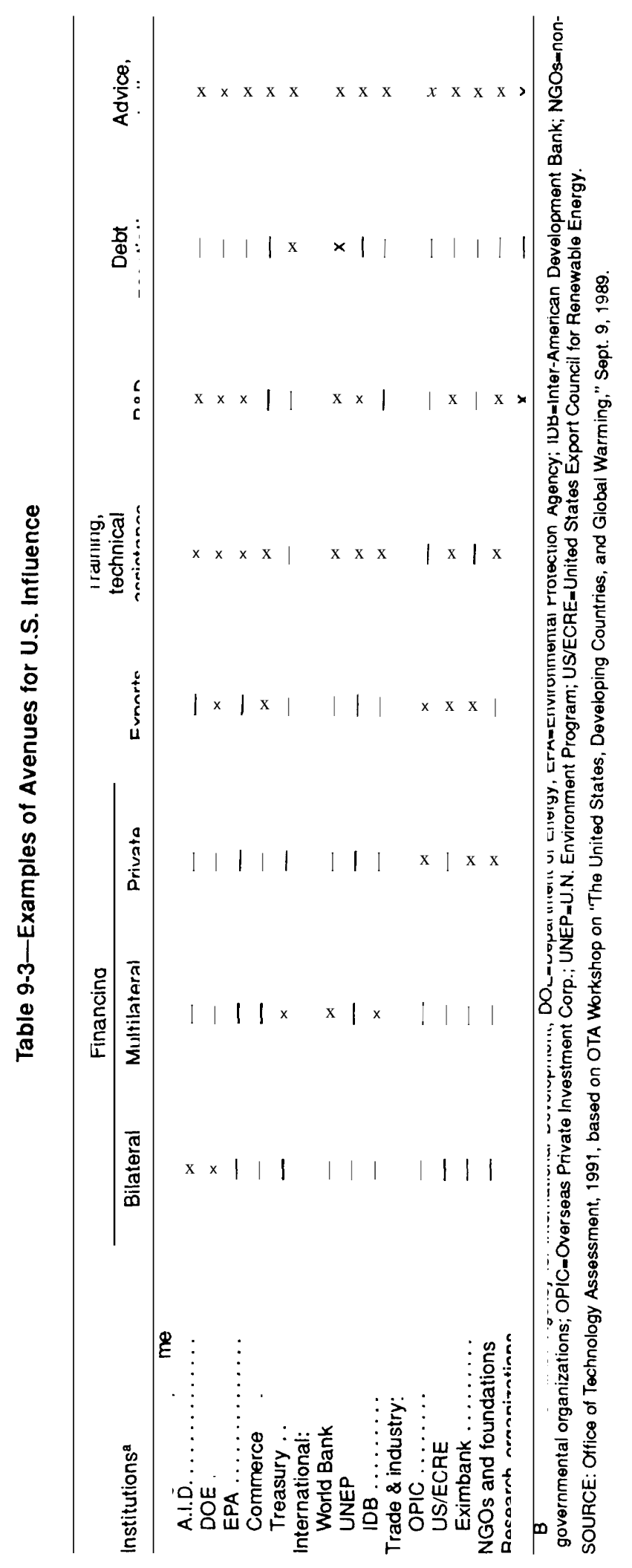


Total U.S. foreign aid assistance to developing countries is about $\$ 9$ billion annually. 10 This represents about 20 percent of all such assistance globally and makes the United States the second largest donor in the world, after Japan. Compared to other countries, however, U.S. assistance is a small percentage of its Gross National Product (GNP) (83, 113). The U.S. portion was 0.19 percent in 1987 and 0.21 percent in 1988 . In 1987 , the larger Western European countries provided an average of 0.42 percent and Japan provided 0.31 percent; Norway topped the list at 1.10 percent.

\section{Technology Transfer and Trade With Other Countries}

More efficient energy production and use, renewable and/or nuclear energy sources, and CFC-free technologies could help reduce, or at least slow the rate of increase in, future greenhouse gas emissions in Eastern Europe, the U. S. S. R., and developing countries without necessarily impeding economic development. Improvements in energy efficiency are possible with available, commercialized technologies and services (see chs. 3 through 6). ${ }^{11}$ Nonfossil fuel energy generation is possible with available technologies and services, including photovoltaic, wind turbine, geothermal, biomass, and nuclear systems.

The opportunity seems ripe for U.S. businesses to increase exports of energy-related technologies to developing countries, since much of the energy infrastructure needed to fulfill development aspirations is yet to be built, This is occurring to some extent-for example, U.S. electric power equipment manufacturers have entered into several energyrelated agreements with China (55), and U.S. renewable energy companies have products installed in 150 countries (94). Exports of photovoltaics increased by 37 percent from 1987 to 1988, primarily in developing counties (82). The market in developing countries for electric power equipment over the next 20 years might be between $\$ 370$ and $\$ 900$ billion (93).

Even so, U.S. businesses often have difficulty competing in foreign markets $(20,37,43)$. Several
U.S. Government and private sector programs exist to facilitate U.S. trade in renewable and efficient energy technologies (box 9-C), although some analyses conclude they may not be as effective in helping the U.S. private sector as are programs of other OECD countries that provide similar assistance to their private sectors $(94,121)$.

Congress could facilitate U.S. trade in efficient energy and renewable energy technologies in several ways. First, it could expand the financial resources of independent agencies that finance technology exports, such as Eximbank and the Overseas Private Investment Corp. (OPIC), or those that fund project preparation work, such as A. I.D., as well as direct these agencies to focus resources on specific technology areas. For example, the FY 1990 Foreign Operations Appropriations Act (Public Law 101167) directs Eximbank to set aside 5 percent of its energy industry export funds for renewable energy projects, and directs A.I.D. to focus on energy efficiency, renewable energy, and least-cost energy planning in the development of national energy plans. 12 Congress also could consider directing agencies such as A. I.D., Commerce, Environmental Protection Agency, and others to set up multiagency committees to promote trade in given technology areas, perhaps using the Committee on Renewable Energy Commerce and Trade (CORECT) (see box 9-C) as a model for such efforts, and tofacilitate better matches between U.S. goods and services and market conditions in host countries. EPA's National Advisory Council for Environmental Policy and Technology also might play a role, for example through its International Cooperation Committee.

Second, Congress could consider further use of "tied-aid" financing (i.e., linking foreign aid to the financing of foreign purchases of U.S products)-a practice that runs counter to free market policies, but one that is used by other OECD countries. Congress appropriated some resources for tied-aid financing to Eximbank, which joined with A.I.D. in creating a $\$ 500$ million tied-aid pool to leverage financing for exports of U.S. products in developing countries (21,

Including bilateral and multilateral aid, food aid, and security-related economic support funds.

1'Including reducing electricity transmission losses and methane leaks from natural gas production and distribution. The latter will be particularly important if national and international policies encourage fuel-switching from other fossil fuels to natural gas (122).

12The Act also appropriated $\$ 15$ million for greater development and use of renewable energy and for initiatives to reverse tropical deforestation. 


\section{Box 9-B-Agencies and Organizations That Can Influence Greenhouse Gas Emissions}

Many U.S. and United Nations agencies, multilateral lending institutions, and international science and natural resource organizations have programs that can potentially influence greenhouse gas missions in different parts of the world.

U.S. Government Agencies-The Agency for International Development (A.I.D.) is the lead government agency for administering foreign economic assistance, through training and institution building, education and research, policy advice, technical assistance, and technology transfer (115,1 16). In 1989, it spent \$2.4 billion on bilateral development assistance, 18 percent of total U.S. foreign operations appropriations (including Economic Support Funds, military aid, and assistance channeled through multilateral organizations) (97). ${ }^{1}$ About $\$ 245$ million was authorized for family planning programs, slightly over one-third of all such international efforts. The Foreign Operations Appropriations Act of Fiscal Year 1990 (Public Law 101-167) directed A.I.D. to concentrate more of its resources on helping to reduce greenhouse gas emissions from deforestation and fossil fuel use in "key" developing countries. A.I.D. administers numerous programs related to forestry and agricultural resources (see ch. 7), the sale and donation of agricultural commodities under Public Law 480, and the Foreign Disaster Assistance program. In the energy sector, A.I.D. has provided around $\$ 200$ million annually over the last 5 years, about two-thirds for the power sector. ${ }^{2}$ Current programs in this sector are emphasizing end-use energy efficiency and renewable energy resources and increased attention to natural gas and coalbed methane fuels.

The Department of Agriculture (USDA) promotes and finances U.S. agricultural products, collects data on foreign production and consumption, and coordinates U.S. agricultural trade policy with other U.S. agencies (95). The agency's Foreign Agricultural Service works in over 40 countries. The U.S. Forest Service plays an increasing role in international forestry issues (see ch. 7).

The Department of Commerce helps U.S. manufacturers and businesses pursue overseas export opportunities, collects and disseminates commercial information, and supports other U.S. overseas programs, including the Eximbank and Overseas Private Investment Corp. (see box 9-C). For example, the department's International Trade Administration provides marketing assistance.

The Department of Energy (DOE) is examining how U.S. energy programs contribute to climate change problems, as a part of the forthcoming National Energy Strategy. It also runs several programs, such as the Committee on Renewable Energy Commerce and Trade (CORECT), to identify and promote energy technologies that can mitigate greenhouse gas emissions (see box 9-C). The department-run National Laboratories spend about $\$ 10$ million annually (mostly from outside funding sources) to provide energy assistance to developing countries (43). The department also has over 30 bilateral R\&D agreements with developing countries (primarily newly industrialized countries).

The Department of State is responsible for overall conduct of U.S. foreign policy, including U.S. representation in the Intergovernmental Panel on Climate Change (IPCC). U.S. Ambassadors are responsible for foreign aid and all other U.S. policy in their assigned countries. In a given country, the mission director for A.I.D. and any in-country representatives of other U.S. departments all report to the Ambassador (95).

The Department of Treasury is responsible for U.S. financial policies affecting other countries and for U.S. participation in international financial institutions such as the World Bank. The Office of Multilateral Development Banks directs the U.S. Executive Directors that sit on the boards of the MDBs; through the directors, the United States has been active in scrutinizing MDB environmental policies.

The Environmental Protection Agency (EPA) is examining global climate change issues-particularly energy use, deforestation, methane from agriculture, chlorofluorocarbons (CFCs), and sea-level rise--in the United States, Eastern Europe, U. S.S.R., and developing countries. It provides technical support for U.S. involvement in the IPCC.

\footnotetext{
${ }^{1}$ About 80 percent of bilateral development assistance was allocated by Congress to functional sectors (e.g., health, population agriculture). About 20 percent ( $\$ 5(\mathrm{~N})$ million) was allocated to the Development Fund for Africa without reference to functional sectors.

In fiscal years 1985 and 1986, over 80 percent of power sector assistance was for Egypt and Pakistan, with the remaing distributed among two dozen or so countries (93).
} 
The U.S. Trade Representative is a cabinet-level agency charged with formulating overall trade policy and with conducting bilateral and multilateral trade negotiations.

Multilateral Development Banks (MDBs)-The MDBs--the World Bank and the three regional banks (Inter-American, Asian, and African Development Banks)-loaned developing countries over \$25 billion in 1986 (69). Although this represents less than 20 percent of all development investments by developing countries themselves, it provides a more favorable atmosphere for other lenders $(83,88,118)$. Many MDB projects have led to tropical deforestation or inefficient energy use, but recently the banks have begun to address these issues. ${ }^{3}$

The World Bank, the largest MDB, spent approximately $\$ 15$ billion in 1989 (128). ${ }^{4}$ Approximately $\$ 3.3$ billion was in the energy sector; about two-thirds of this was for electric power generation. Bank funding for free-standing environmental projects during the period 1990 through 1992 is expected to be about $\$ 1.3$ billion (13). The Bank recently issued an operational directive outlining procedures for assessing the environmental consequences of proposed Bank projects (see ch. 7). Environmental issues papers and action plans are being drawn up for borrowing countries, and the Bank expects these to have a growing influence on lending activities (128). These are important steps, but it is too early to ascertain their effect. In the energy sector, most projects now contain loan conditions, where necessary, to improve fuel pricing and the efficiency of energy consumption. The Energy Sector Management Assistance Program (ESMAP), established by the Bank and the UN Development Program in 1983 and funded at a level of $\$ 12.5$ million in 1988, conducts assessments in the energy sector and facilitates energy policy recommendations and investments $(43,131)$.

The three regional development banks have a larger role than does the World Bank in many countries, for example in Central America. The African Development Bank and Inter-American Development Bank (IDB) provided about $\$ 1$ billion for energy sector projects in 1988 (43). The IDB has sponsored projects on watershed management, and meetings to coordinate activities with NGOs. With UNDP, it helped compile an agenda of environmental topics in Latin America and the Caribbean to serve as a vehicle for donor cooperation. In 1990, the IDB established an Environmental Protection Division to provide increased attention to environmental issues in project design, and it established procedures for evaluating environmental impacts (30). The division expands previous IDB efforts (including a 1979 policy statement and the establishment in 1983 of an Environmental Management Committee) to address environmental issues.

United Nations Agencies-The family of United Nations agencies provides assistance for a multitude of projects related in some way to climate change. Some of the better known agencies are briefly described here.

The U.N. Development Program (UNDP) allocated about $\mathbf{\$ 0 . 5}$ billion of its $\$ 3.8$ billion portfolio to environmental activities in 1989 (90). It provides funds and advisory services to developing countries for trade in development technology $(43,108)$. It also helps finance over 50 of the national plans being developed under the Tropical Forestry Action Plan (ch. 7). UNDP also is developing Environmental Management Guidelines to identify environmental issues as early as possible in its project design activities.

The U.N. Environment Program (UNEP) reviews global environmental trends and coordinates environmental activities and provides policy guidance within the United Nations. It led the development of the Vienna Convention and Montreal Protocol to Protect the Ozone Layer and along with the World Meteorological Organization, jointly manages the World Climate Program and jointly coordinated the IPCC (see below).

The U.N. Food and Agriculture Organization (FAO) is active in energy assessments, planning for rural and agricultural development, fuelwood and charcoal projects, and tropical forestry issues (see ch. 7).

\footnotetext{
${ }^{3}$ In contrast, the International Monetary Fund-which affects economic practices in developing countries through, fOr example, the conditions of its structural reform packages-has not taken steps to incorporate environmental concerns in ita decisions (45).

4The World Bank includes the International Bank for Reconstruction and Development the International Development Association and the International Finance Corp. 'l'he IBRD provides loans at interest rates related to the Bank's cost of borrowing the IDA provides interest-tie credits with long grace periods to poorer developing countries; and the IFC raises financing, generally in line with commercial lending rates, for private companies and joint ventures (43).
} 


\section{Box 9-B-Agencies and Organizations That Can Influence Greenhouse Gas Emissions--Continued}

The U,N. Population Fund (UNFPA) promotes strategies and provides assistance to developing countries to deal with national and international population problems. It provided about \$169 million in 1988 for programs in 141 countries.

The UN. Industrial Development Organization (UNIDO) promotes industrialization in developing countries and provides assistance to improve industrial use of energy.

The World Meteorological Organization (WMO) monitors overall climate trends, provides a framework for cooperative research on models of global climate, facilitates the exchange of meteorological information between countries and, with UNEP, jointly sponsors the IPCC. It also jointly manages, with UNEP and the International Council of Scientific Unions (see below), the World Climate Research Program

Regional Organizations--The developed countries are served by many regional organizations, including the Organization for Economic Cooperation and Development (OECD), International Energy Agency (IEA), and European Economic Commission (EEC). The OECD's Environment Committee, for example, is assessing energy options related to climate change and socioeconomic implications of such change; its Development Assistance Committee provides a forum to coordinate donor efforts in addressing environmentalproblems in developing countries (109). The IEA provides a framework for promoting energy diversification, energy efficiency and conservation, and alternative energy sources; it also runs information and data exchange centers dealing with energy technologies.

Developing nations have some regional bodies that are beginning to provide similar services--for example, tie South Asian Association forRegional Cooperation (SAARC), Association of South East Asian States (ASEAN), Gulf Cooperation Council, Southern Africa Development Coordination Conference (SAD(X), and Organization of American States (OAS) (45).

Intergovernmental Panel on Climate Change (IPCC)--The IPCC was set up in 1988 under the auspices of UNEP and WMO to serve as the primary international forum for addressing climate change. It has three working groups charged with:

- assessing scientific evidence on climate change;

. assessing likely impacts resulting from such change; and

- considering possible response strategies for limiting or adapting to climate change.

The groups are chaired by the United Kingdom, U.S.S.R., and United States, respectively. To encourage representation of developing country viewpoints, the IPCC established a trust fund to support the participation of developing countries; as a result, developing countries have comprised about one-third of the national delegations at recent IPCC meetings. On the other hand, no formal links have been established with the private sector or NGOs. The WCC'S final report was presented to the Second World Climate Conference and the U.N. General Assembly in late 1990. The findings from the scientific assessment working group are summarized in chapter 2.

International Science and Natural Resource Organizations-The International Council of Scientific Unions (ICSU) coordinates worldwide scientific projects and works with NGOs and intergovernmental agencies in project implementation. The ICSU runs the International Geosphere-Biosphere Programme, which conducts research on basic global processes, and is a joint manager of the World Climate Research Program

Numerous other research and management organizations and plans address natural resource issues, primarily in agriculture and forestry. For example, the International Fund for Agricultural Development (WAD), funded by OPEC and OECD members, makes financial resources available on concessional terms for agricultural development in developing countries (109). The Consultative Group on International Agricultural Research (CGIAR) is a network of regional and international organizations that conduct agricultural research in developing countries (CGIAR and Other agricultural institutions are described in ch. 8). The International Tropical Timber Organization provides a framework for coordination between tropical timber producing and consuming countries, and the Tropical Forestry Action Plan attempts to enhance donor cooperation and funding in sustainable forestry management. Both of these entities have come under severe criticism recently (see ch. 7). 


\section{Box 9-C-U.S. Trade in Renewable and Efficient Energy Technologies}

Various programs to help U.S. businesses overcome obstacles in exporting efficient and renewable energy technologies to non-OECD countries have been established by the U.S. Government, independent government agencies, and the private sector.

Agency for International Development (A. I.D.) Programs-A.I.D. promotes energy-related technology development and transfer by supporting prefeasibility funding studies and by leveraging private, multilateral, and other bilateral resources for projects. Some of the leveraging is accomplished through the MDBs, using the Multi-Agency Group on Power Sector Innovation (MAGPI). The agency sponsors reverse trade missions and an energy and environmental training program for host country nationals. A.I.D. has established a Private Enterprise Fund for Eastern Europe to assist the export of U.S. technologies, including energy-related ones. It also is collaborating with India on a 6-year Program for the Acceleration of Commercial Energy Research (PACER) that promotes the commercialization of indigenous energy technologies and improvement of transmission and distribution planning and technologies; PACER has helped establish consortia that link the industrial, commercial, $\mathrm{R} \& \mathrm{D}$, and government sectors.

Department of Energy and CORECT_The Committee on Renewable Energy Commerce and Trade (CORE $(\mathrm{X})$ is a multiagency committee led by the Department of Energy and involving 12 other Federal agencies. Established in 1984, it promotes trade of U.S. renewable energy technologies (and is expanding its efforts to energy efficiency), brings government and business personnel from other countries to the United States for trade conferences and missions, provides technical assistance, and funds the Renewable Energy Design Assistance Center (REDAC) at Sandia National Laboratories to provide technical assessments, prefeasibility and feasibility studies, financing, and other forms of project support.

Export-Import Bank (Eximbank,)--Eximbank is an independent U.S. Government agency, chartered under the Export-Import Bank Act of 1945, that helps finance and facilitate the sale of U.S. goods and services to foreign buyers, particularly in developing countries $(95,123)$. Its main programs are direct loans, guarantees, and insurance. The 1990 Foreign Operations Appropriations Act (Public Law 101-167) directed Eximbank to direct not less than 5 percent of its financial assistance in the energy sector to renewable energy projects. In FY 1990, Eximbank provided support for over $\$ 6$ billion in exports. In the energy sector, it provided final commitments to support $\$ 2.1$ million, and had pending final commitments for an additional $\$ 11.8$ million, in renewable energy projects (i.e., hydroelectric, photovoltaics). Assuming pending commitments are fried, Eximbank's fiscal year 1990 support for renewable energy projects would represent 7.4 percent of its total energy sector support (21).

Overseas Private Investment Corp. (OPIC)-The Overseas Private Investment Corp. (OPIC) is an independent corporation created by Congress. It directly finances projects sponsored by U.S. private investors in over 100 developing countries and provides insurance against political risks for U.S. private investments in those countries. It can provide direct loans of up to $\$ 6$ million to small- and medium-sized firms and investment guarantees for up to $\$ 50$ million. In fiscal year 1989, OPIC provided project insurance totaling over $\$ 1.5$ billion and direct loans and loan guarantees totaling \$208 million (59). OPIC is developing a privately owned and managed Environmental Investment Fund for business enterprises in developing countries and Eastern Europe that involve renewable energy, ecotourism, sustainable agriculture, forest management, and pollution prevention $(59,60,61)$. OPIC hopes to capitalize the fund with $\$ 60$ million of equity raised from U.S. businesses and institutional investors and $\$ 40$ million in OPIC-guaranteed long-term debt,

Private Export Funding Corporation-The Private Export Funding Corp. (PEFCO) is a governmentsponsored commercial corporation that raises funds for export financing in the private market, using unconditional Eximbank guarantees.

U.S. Trade and Development Program-The U.S. Trade and Development Program (TDP), in the U.S. International Development Cooperation Agency. funds feasibility studies, consultancies, training programs, and other planning services for projects involving export markets for U.S. goods and services. Its focus is primarily on large public sector projects $(43,93)$. 


\section{Box 9-C-U..\% Trade in Renewable and Efficient Energy Technologies-Continued}

United States Export Council for Renewable Energy (US/ECRE)-US/ECRE is an umbrella organization composed of eight national trade associations that represent manufacturers of renewable energy technologies. It promotes exports of these technologies, specifically for alcohol fuels, biomass, geothermal, hydropower, photovoltaics, solar thermal, wind and wood. It engages in country studies and market analyses; advises members on overseas projects, procurement opportunities, and trade shows; and serves as a clearinghouse for inquiries regarding renewable energy. It has collaborated with DOE and Volunteers in Technical Assistance on a low-orbit satellite system that will allow NGOs to communicate with each other and obtain technical information on renewable and other energy technologies.

Other Industry-Sponsored Efforts--The International Environmental Bureau (IEB) is a nonprofit educational division of the International Chamber of Commerce, funded independently by its member companies (19 from North America, 9 from Europe, and 1 from South America including such giants as ALCOA, Monsanto, and ARCO). Its principal purpose is to make available know-how and expertise on environmental problems to companies in developing countries and to medium- and small-sized companies everywhere, free of charge (36). It was established in 1984 and by July 1989 had received about 80 requests for assistance.

The Foreign Credit Insurance Corp. (FCIC), an association of 50 or so private insurance companies, insures against commercial risk in short-term transactions with repayment terms of up to 100 days.

The Industry Cooperative for Ozone Layer Protection was set up by nine major companies (including AT\& Northern Telecom, Boeing, Ford Motor Corp.) in October 1989 to promote cooperation in ending the use of chlorofluorocarbons (CFCs) as cleaning agents. CFC-113, for example, is widely used as a degreaser in the manufacture of computer and electronic parts. The cooperative intends to act as a clearinghouse for information on new, safe substitute solvents and to encourage their adoption. Its formation followed a 1989 announcement by Petrofirm that it had developed a citrus-based substitute for CFC-113.

22). ${ }^{13}$ The extent to which this will be used for renewable and efficient energy technologies remains to be seen, but Eximbank also is working through CORECT to assist U.S. renewable energy businesses.

Third, Congress could continue to change restrictions on technology exports to Eastern Europe and the U.S.S.R. This could be done as part of the reauthorization of the Export Administration Act and/or by providing new directions on U.S. participation in the Coordinating Committee on Multilateral Export Controls (COCOM) (see section on "Eastern Europe and the U. S. S. R." for more discussion).

In addition, Congress could consider establishing, with the cooperation of host countries, technology research and/or assistance centers in Eastern Europe and developing countries, For example, EPA is coordinating the establishment of a center in $\mathrm{Bu}-$ dapest that will function as an environmental information clearinghouse for Eastern Europe (111). ${ }^{14}$
A.I.D. has proposed a Global Energy Efficiency Initiative, to be supported in part by developed countries and multilateral institutions, for promoting pricing reform, end-use energy efficiency, cogeneration, and private sector activities in other countries (99, 119). The National Laboratories could be directed to increase $\mathrm{R} \& \mathrm{D}$ on technologies for developing countries, as is being done for renewable energy at the CORECT-sponsored Sandia Renewable Energy Design Assistance Center.

\section{Non-Governmental Organizations (NGOs)}

Private agencies and organizations, or NGOs, have succeeded in mobilizing support from and participation by local communities in development and environmental projects around the world (129). More than 1,000 are represented at the UNDP's Nongovernmental Environmental Liaison Office, and over 240 were registered with A.I.D. as of 1989. Some are multinational (e.g., Greenpeace, Friends of the Earth). The U.S. funds foreign NGOs in developing countries through the Inter-American Founda-

\footnotetext{
${ }_{13}^{13}$ Projects would be in the telecommunications, electric power (including renewable energy), construction, and transportation sectors, with an initial focus on Indonesia, Pakistan, the Philippines, and Thailand (22).

${ }^{14}$ In 1990, the Senate Foreign Relations Committee approved the Support for East European Democracy Act (SEED II). The act would have included technical assistance for establishing business centers to provide information and logistical support for U.S. businesses operating in Eastern Europe and the U.S.S.R. (15).
} 
tion and the African Development Foundation, through direct grants, and through hundreds of American NGOs that receive A.I.D. funding. Foreign and U.S. NGOs registered with A.I.D. received $\$ 456$ million in development assistance funds in fiscal year 1989 (1 13) and an estimated \$399 million in fiscal year 1990 (97).

Congress has attempted to expand and strengthen the role of U.S. and foreign NGOs in a number of ways. ${ }^{15}$ Many NGOs, however, still lack the resources (financial, technical, managerial) and experience to implement plans and projects $(45,136)$. By building the capacities of NGOs, particularly in developing countries, it may be possible to foster more effective energy and natural resource policies and programs.

\section{DEVELOPING COUNTRIES}

Tropical deforestation is the major source of current carbon emissions in developing countries (ch. 7), while rice cultivation and livestock operations are the main sources of methane (ch. 8). Emissions from fossil fuel use are relatively low but are likely to increase as developing countries become more industrialized and their citizens use more modern methods for cooking, heating, and transportation. Indeed, total and per-capita energy consumption is rising more rapidly in developing countries than in developed countries.

The decisions that developing countries make in the next decade about how to pursue economic growth will affect emissions for decades to come. Economic growth could require dramatic expansions in energy services and infrastructure (e.g., industrial bases, electric generation). Opportunities exist today to implement efficient technologies and services to help meet these demands. Opportunities also exist to reverse or slow tropical deforestation.
However, massive foreign debts make it difficult for developing countries to invest in energy-efficient infrastructures and also provide an incentive for rapid depletion of natural resources (in order to service the debts). ${ }^{16}$ Some developing countries may not sign international agreements on climate change unless their concerns about debt and other development issues are addressed $(63,134){ }^{17}$

\section{Contribution to Greenhouse Gas Emissions}

\section{$\mathrm{CO}_{2}$ From Deforestation}

Deforestation in developing countries accounts for between 7 and 31 percent of global $\mathrm{CO}_{2}$ emissions, as well as unknown amounts of methane, $\mathrm{N}_{2} \mathrm{O}$, and other gases (ch. 7). While some deforestation occurs because of hydroelectric development and fuelwood consumption, the major direct causes are land use changes for agriculture (including cattle ranching) and timber harvesting. Perhaps 17 million hectares are deforested yearly.

\section{$\mathrm{CO}_{2}$ From Energy Use}

The developing countries' share of world commercial energy use increased from 16 to about 25 percent between 1970 and 1988 (1, 31,43, 75, 76, 106, 127). China, India, and Brazil accounted for about 45 percent of developing countries' consumption of commercial and traditional fuels in 1988, with China alone accounting for 30 percent (104, 106; also see ch. 3).

Commercial energy use will increase as developing countries expand industrial and transportation infrastructures, continue to fully electrify cities, and begin or continue rural electrification programs $(71$, 104). New electrical power generation is likely to be based largely on domestic energy sources, primarily coal and hydroelectric facilities (93). ${ }^{18}$ one-half of planned electricity generation in China and India, for example, is to be based on coal (56).

${ }^{15}$ For example, Public Law 101.167 directed agencies such as A.I.D. to make increased use of U.S. and foreign NGOs and to provide technical assistance in increasing the institutional capacities of foreign NGOs. The 1989 International Development and Finance Act (Public Law 101-240) requires the U.S, Executive Directors to multilateral development banks to promote increased assistance and support for foreign NGOs. Congress also appropriated \$1 million in fiscal year 1991 for a project to launch a low-orbit satellite linking NGOs in an information network (see US/ECRE in box 9-C) (82).

16 Much of the hardcurrency generated $b_{y}$ developing countries flows back to lenders to service debts; annual interest payments on developing country foreign debt are over $\$ 60$ billion (4 S). Debt service and austerity measures required under IMF structural adjustment agreements have led to government cutbacks in operating expenditures, often in natural resource management programs (56).

${ }^{17}$ The U.N. resolution toconvenethe U.N.Conference on Environment and Development (91), to be held in Brazil in 1992, includes the objectives of devising agreements regarding climate change and addressing theoncerns of developing countries about debt and development issues.

${ }^{18}$ Power generation in developing countries rose by 8.6 percent annually between 1971 and 1987, compared with an average of 3.6 percent annually in developed countries (93). Most added capacity in developing countries has been fossil fuel plants, while much new capacity in OECD countries has been non- $\mathrm{CO}_{2}$ emitting nuclear plants (34). 


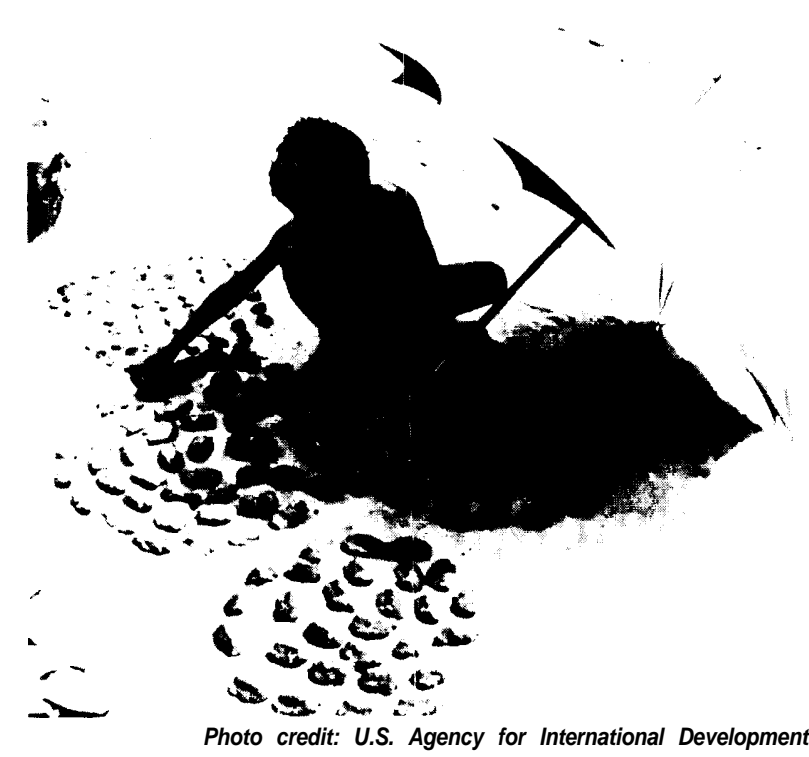

Animal wastes are a "traditional" energy source for cooking and heating in many countries.

One analysis (76) developed two scenarios for $\mathrm{CO}_{2}$ emissions related to energy use in nine developing countries (four Asian, four Latin American, and one African). One scenario assumed high emission rates (i.e., no constraints on economic and energy growth) and the other assumed lower rates (i.e., because of energy efficiency and fuel substitution measures). The projected $\mathrm{CO}_{2}$ emissions rise significantly, even in the low emissions, energy-efficiency scenario (figure 9-7),

\section{CFC Use}

The main CFC producers among developing countries are China, Brazil, Indonesia, and Mexico. In 1985 their total production was 19 percent of U.S. production (1 10), but refrigeration, air-conditioning, and other CFC applications are expanding rapidly $(26,51,76)$. For example, China has a goal of one refrigerator per household by the year 2000(71), and its population is growing by several million households per year. Its consumption of $\mathrm{CFC}_{\mathrm{s}}$ and halons is projected to increase 12 percent annually between 1990 and 1996 (38). Future CFC use in these countries thus will be significant if better technologies and substitutes are not widely and economically available (see discussion of refrigeration in ch. 8) or if limits on CFC use cannot be implemented (see box 2-C in ch. 2).
Figure 9-7-Projected $\mathrm{CO}_{2}$ Emissions in Selected Developing Countries (including use of biomass)

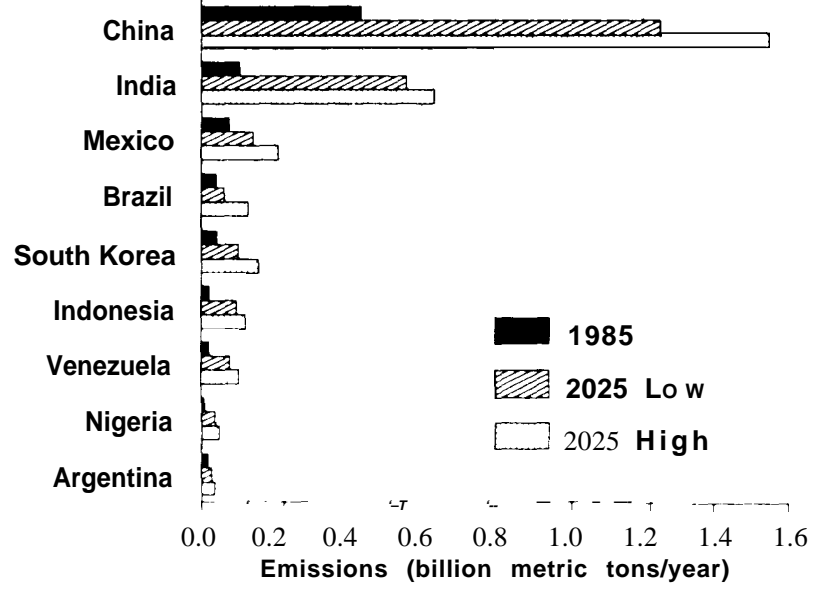

$\mathrm{CO}_{2}$ emissions in developing countries are projected to rise significantly by 2025 , as shown here for four countries in Asia, four in Latin America, and one in Africa. The "High" scenario assumed no constraints on economic and energy growth. The "Low" scenario assumed that policies are enacted to improve energy efficiency and change the fuel mix.

SOURCE: J. Sathaye and A. Ketoff, $\mathrm{CO}_{2}$ Emissions from Major Developing Countries: Better Understanding the Role of Energy in the Long Term, Interim Report, LBL-29507 (Berkeley, CA: Lawrence Livermore Laboratory, August 1990).

\section{Methane}

While there is great uncertainty regarding emissions levels, the main anthropogenic sources of methane are rice production under irrigated or flood conditions, livestock operations, fossil fuel production (including leaks from coal mines and natural gas pipelines and flaring), and landfills. ${ }^{19}$ Rice cultivation and livestock operations account for an estimated 20 to 50 percent of global methane emissions. Developing countries are the major contributors of methane from rice production and, along with developed countries, major sources of methane from livestock (see ch. 8).

\section{General Areas for Improvements}

Important technical opportunities for stabilizing or reducing future emissions from developing countries include:

- increasing efficiency of energy use;

. moving toward natural gas and nonfossil fuels;

. developing and disseminating CFC substitutes; and

- slowing deforestation.

\footnotetext{
${ }^{19} \mathrm{Ch} .2$ describes these sources in more detail; box $3-\mathrm{A}$ in ch. 3 discusses landfills.
} 


\section{Increased Energy Efficiency}

Developing countries tend to have inefficient energy production, transmission and distribution, and consumption systems $(16,43)$. For example, steam powerplants in many developing countries may use 20 to 45 percent more fuel per $\mathrm{kWh}$ of electricity than typical U.S. steam plants; many plants are operational only 50 to 60 percent of the time, compared with over 80 percent in developed countries, because of frequent power shortages and lack of proper maintenance (93). Electricity losses during transmission and distribution also are high (e.g., over 30 percent in the Dominican Republic and Bangladesh, and over 20 percent in Pakistan, India, and Egypt) $(62,93)$.

Many opportunities will exist over the next few decades to invest in improved, cost-effective technologies (93). ${ }^{20}$ These technologies could include, for example, variable speed drives for industrial motors; electric arc furnaces for steel production; energy-efficient lighting, water pumping, heating, and refrigeration systems; and capacitors in electricity lines to reduce transmission and distribution losses (see chs. 3 to 6). Cogeneration might also increase effective electricity generation, primarily in the industrial sector (27). One study, for example, estimated that implementing energy-efficient technologies and practices in Brazil might reduce the total electricity demand projected for the year 2000 by almost 20 percent, at a cost far lower than the investments in new electrical generating capacity that would otherwise be needed (124),

However, technical and institutional obstacles to increased energy efficiency exist in developing countries. For example, many developing countries cannot use efficient motor-compressors in refrigerators because of problems with voltage fluctuations (104). Moreover, almost all developing countries grant monopolies to government-owned utilities for electricity generation and distribution, and many subsidize the price of energy supplied to consumers. As a result, utilities often operate inefficiently and end-users have little incentive to conserve.

\section{Switching Fuels}

Switching from coal to natural gas would reduce carbon emissions by 15 to 50 percent per unit of delivered energy, depending on the end product (steam or electricity) and the technology used (ch. 3). Switching to natural gas, however, might require retrofitting old facilities or building new ones (including the distribution infrastructure) and ensuring that methane leaks from production and distribution systems are minimized $(96,122)$. Natural gas also is not readily available everywhere; for example, China and India each contain less than 1 percent of total world natural gas reserves $(1,106)$.

Nuclear and renewable energy sources have fewer greenhouse gas emissions (and in some cases no emissions at all) per unit of delivered energy. Nuclear power currently plays a minimal role in most developing countries, however, and is unlikely to increase substantially in the near future (see ch. 3). Issues of concern include lead times to develop plants, safety and environmental risks, costs, and nuclear weapons proliferation. Some renewable energy supplies are modular, hence adaptable to local situations and to decentralized power systems, relatively easily maintained, and often costeffective, particularly in remote areas $(94,112)$. Thousands of photovoltaic (PV) and wind systems exist in rural areas for water pumping, drip irrigation, electric power, and lighting. PV modules often are used to refrigerate vaccine supplies in rural areas. Small hydropower systems (e.g., less than 10 megawatts) have been used for milling grains, providing local electric power, and other applications. Biomass systems based on agricultural residues are used to produce electricity, process heat, and/or liquid fuels.

However, various factors still limit the role of renewable energy sources in developing countries. Of the many renewable energy projects funded over the past two decades by A.I.D. and other donors, few have resulted in subsequent commercialization. This is partly because donor agencies and host government institutions have rarely established appropriate mechanisms for financing (including provision of hard currency), business development, or consumer credit; in addition, the private sector in most developing countries plays a limited role in the

\footnotetext{
${ }^{20}$ A.I.D. (96) reviewed 1,500 energy projects in 11 developing countries (involving measures such as waste reduction, fuel switching, Process optimization, and cogeneration) and concluded that investments of \$46 million were yielding actual annual savings of \$26 million, with an average payback period of 1.8 years,
} 


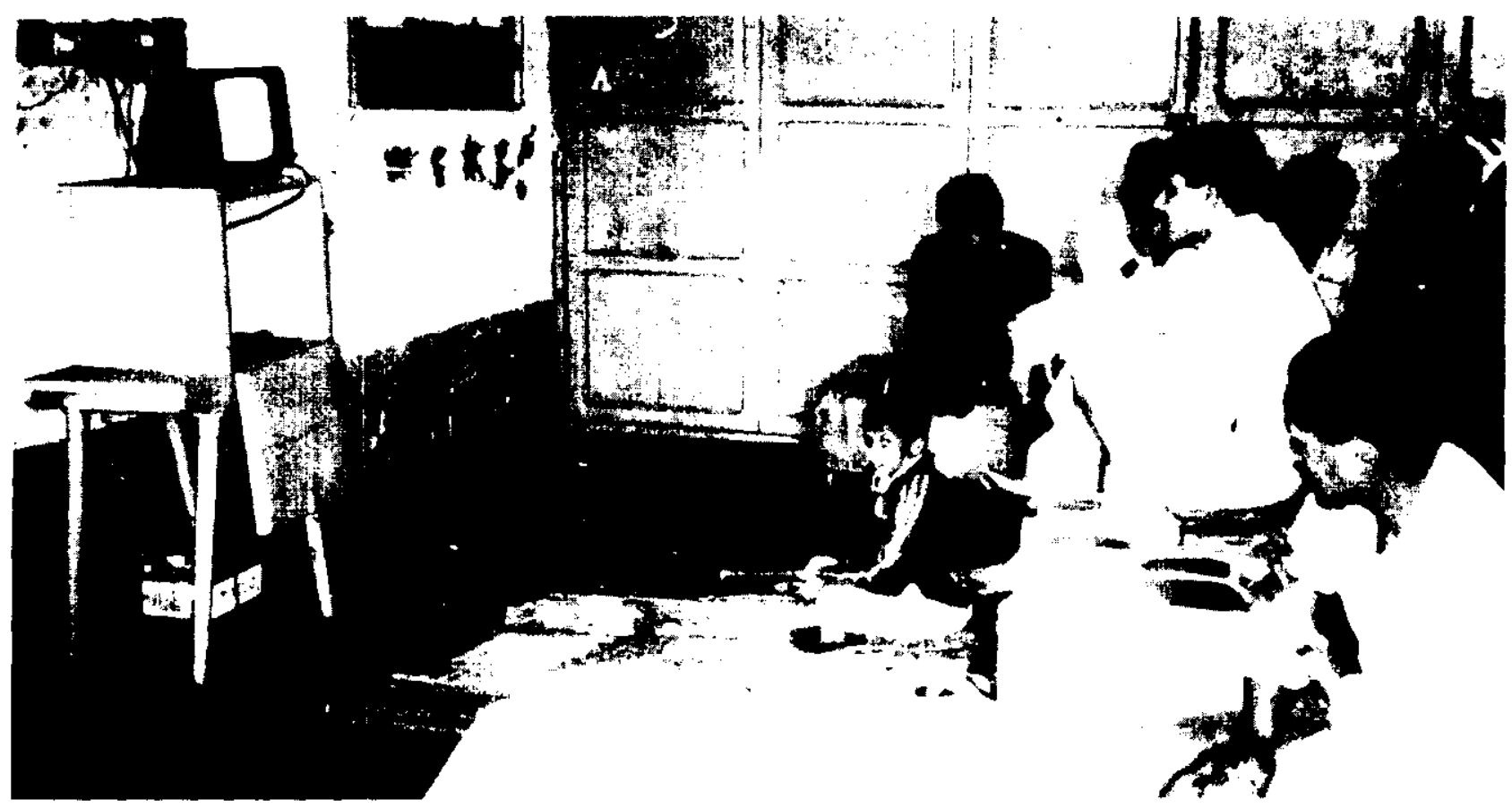

Photo credit: African Development Foundation

Thousands of photovoltaic and wind systems exist in rural areas for water pumping, drip irrigation, electric power, and lighting systems. Here, people in an Egyptian village are viewing a solar-powered television at their community center.

development and operation of electric power systems (93). ${ }^{21}$

\section{CFC Reductions and Substitutes}

Research into CFC substitutes is extremely active and some substitutes may be mass-produced within a few years. Proposed substitutes such as hydrochlorofluorocarbons (HCFCs) and hydrofluorocarbons (HFCs) have much lower ozone depletion potentials than do CFCs; some have 30 to 70 percent of the global warming potentials of the original CFCs (see ch. 2). However, new refrigeration systems with CFC-free (and more energy-efficient) insulation or with energy sources such as natural gas and solar energy show increasing promise (see ch. 8; also see 'Switching Fuels' above on PV systems).

\section{Slow or Decrease Deforestation}

Slowing or reversing tropical deforestation will require much local, national, and international effort. Important steps include debt relief from creditor nations, enhancement of environmental ministries, promotion of sustainable commercial forestry practices and of reforestation, land reform within developing countries, and increased use of practices such as agroforestry, sustainable agriculture, and harvesting of nontimber forest products. These are discussed in detail in chapter 7 .

\section{Policy Directions for the United States}

Since developing countries themselves finance 80 percent or more of their development activities (83), U.S. assistance to them might be best viewed as a catalyst for establishing cooperative programs to address development issues, including controlling greenhouse gas emissions $(56,83,134)$. Congress can gear U.S. assistance and influence toward building local institutional capacities, and toward redirecting energy, natural resource, and population policies. Relevant sector-specific options (e.g., for transportation, forestry) are discussed in chs. 3 through 8 .

\section{Building Local Institutional Capacities}

Building local institutional capacities can play a major role in redirecting natural resource, energy, and population policies in developing countries. Bilateral and multilateral lending and assistance

${ }^{21}$ A few countries, supported by A. I.D., have begun to open power production to the private sector, which should provide some incentive for more efficient production. 
agencies (e.g., World Bank, UNDP and UNEP, and A. I.D.) already provide some assistance in this area. Most large A.I.D. projects, for example, contain some training, education, and institutional development component, and many of its agricultural projects have assisted in the development of national agricultural universities and research institutions (56). Congress could direct A.I.D. to increase its emphasis on such activities. This would likely require increased funding for education and training; environmental information gathering and analysis; conservation planning and policy analysis; and coordination of regional authorities and communitybased organizations $(56,136)$.

\section{Redirecting Natural Resources Policy}

Most developing country economies are based on natural resources $(45,136)$, and many of these resources have been exploited rapidly during the past few decades. However, short-term revenue gains have come at the cost of reductions in the long-term and even immediate economic outlook for some countries. During the 1980 s, for example, some countries that once were net exporters of tropical hardwood products found that their forests could no longer maintain a positive export flow (ch. 7). Resource depletion in one area also can have unintended consequences elsewhere-for example, upland deforestation has increased silting of reservoirs and flooding in many downstream areas (129).

Many national and multilateral development policies foster resource exploitation, including subsidies for cattle ranching and short-term, low-rent licenses for timber harvesting (ch. 7). The effectiveness of plans and programs such as the Tropical Forestry Action Plan can be evaluated in light of these considerations. Fortunately, direct bilateral and multilateral assistance is beginning to be restructured to promote more environmentally sensitive economic development. A. I.D., the World Bank, the InterAmerican Development Bank, and UNDP, among others, are all developing or have recently adopted environmental assessment guidelines (ch. 7).
U. N.-endorsed procedures for estimating national economic performance (e.g., Gross Domestic Product, or GDP) do not account for values such as clean air and water, watershed protection, soil retention, and biodiversity $(45,70,135) .22$ To address this, the U.S. Ambassador to the United Nations and the U.S. Executive Directors to the multilateral development banks (MDBs) could promote economic accounting procedures that include natural resource values and services. For example, this could be included as part of the World Bank's environmental assessment procedure. Congress also could encourage A.I.D. to expand its activities in promoting such accounting. ${ }^{23}$

Financing for resource conservation projects could also be increased. A new multilateral fund-a Global Environmental Facility or "Green Fund"-was established in November 1990 to provide funding for projects on greenhouse gases (e.g., non- $\mathrm{CO}_{2}$ energy sources, energy efficiency, reforestation), biological diversity, marine pollution, and CFC substitutes $(29 \mathrm{a}, 130,133){ }^{24}$ The World Bank will administer the facility, UNEP will ensure its policies are consistent with U.N. environmental goals, and UNDP will conduct prefeasibility studies. In addition to U.S. participation in the facility, Congress could direct U.S. organizations such as OPIC and A.I.D. to expand their activities in financing similar resource conservation projects.

\section{Redirecting Energy Policies}

A. I.D., various U.N. agencies, and the World Bank's Energy Sector Management Assistance Program (ESMAP) provided over $\$ 200$ million in fiscal year 1988 for energy-related grants and assistance (table 9-4); in addition, over $\$ 6$ billion was provided for energy-related loans. Including technical assistance from other countries and technical support derived from portions of the loans, total technical assistance for energy may be on the order of $\$ 500$ million per year-less than 1 percent of total annual energy expenditures by developing countries (43).

Until recently, much of this assistance focused on conventional energy projects such as large hydro-

\footnotetext{
${ }^{22}$ These procedures measure the flow of economic activities rather than changes in resource stocks contributing to the activities; in essence, short-term economic gains represent interest being obtained from a shrinking capital/resource base, The U.N. Statistical Commission and Statistical Office currently is revising its guidelines on national accounting procedures, but provisions addressing the issue of natural resource depletion are not expected to be included (45),

${ }^{23}$ For example, A.I.D. is assisting Kenya and Niger in linking their current development assistance programs to such an accounting system (56).

${ }^{24}$ Similarly, the World Resources Institute suggested establishing a global International Environmental Facility, jointly financed by OECD bilateral development agencies and MDBs (136), Its purpose would be to promote coordination among UN agencies, developing country governments, and NGOS in identifying conservation needs and to help arrange financing from existing sources for projects.
} 
Table 9-4-Funding for Major Energy Assistance to Developing Countries, 1988-89

\begin{tabular}{|c|c|c|c|}
\hline Organization & Activity & \$ Million & Year $^{\mathrm{a}}$ \\
\hline 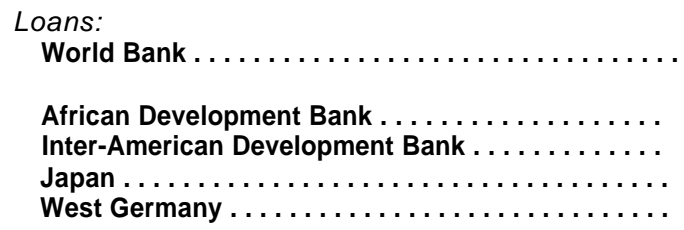 & $\begin{array}{l}\text { Power sector loans } \\
\text { Oil and gas loans } \\
\text { Energy project loans } \\
\text { Energy sector loans } \\
\text { Power and gas loans } \\
\text { Energy loans }\end{array}$ & $\begin{array}{r}3,282 \\
581 \\
567 \\
405 \\
1,100 \\
410\end{array}$ & $\begin{array}{l}\text { FY1989 } \\
\text { FY1989 } \\
1988 \\
\text { FY1988 } \\
\text { FY1988 } \\
1988\end{array}$ \\
\hline 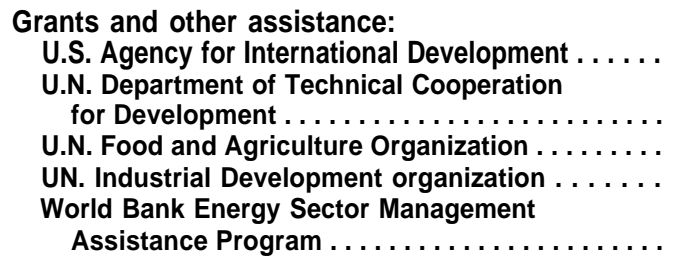 & $\begin{array}{l}\text { Energy projects } \\
\text { Technical assistance } \\
\text { Rural energy assistance } \\
\text { Industrial energy assistance } \\
\text { Preinvestment studies, training }\end{array}$ & $\begin{array}{r}130 \\
25-30 \\
20-30 \\
5-10\end{array}$ & $\begin{array}{r}\text { FY1988 } \\
1988 \\
1988 \\
1988 \\
1988\end{array}$ \\
\hline
\end{tabular}

electric darns and coal plants; only a few World Bank and Inter-American Development Bank energy projects from 1980 through 1988 involved renewable energy other than large hydroelectric projects (126). ${ }^{25}$ For fiscal year 1989, US/ECRE (1 12) estimated that World Bank lending for solar, geothermal, and wood-bassed energy projects amounted to less than 1 percent of its energy sector funding. Energy efficiency and renewable energy receive scant attention for many reasons, including:

- insufficient capital in developing countries to purchase technologies;

- lack of access in developing countries to relevant information on such systems;

- artificially low fossil fuel prices;

- reluctance by multilateral organizations to fund small projects, because of overhead and staffing demands; and

- lack of attention in assistance projects to disseminating commercial technologies and developing local infrastructures for their maintenance.
To address these problems, U.S. and multilateral policies could focus on several areas-improving energy institutions in developing countries; increasing energy efficiency; developing renewable energy sources (and facilitating their trade); and working with host governments to initiate reforms in pricing policies (e.g., subsidies for energy production) $(24,25,43,93,96,115,116,127,128){ }^{26}$

Several U.S. agencies (e.g., EPA, A. I.D., CORECT, and DOE) already provide technical assistance and grants for energy efficiency and renewable energy technologies, often linked to financing from MDBs and private investments. Recent U.S. legislation (Public Law 101-167) directed A.I.D. to focus on least-cost energy planning, energy pricing policy reform, end-use energy efficiency, and renewable energy. Congress could direct A.I.D. to initiate activities in countries not currently served by the agency (e.g., China and Mexico) .27 The legislation also instructed the Executive Directors to the MDBs to promote end-use energy efficiency and renewable energy as criteria in decisions about new projects. Congress could ensure

${ }^{25}$ Of all multilateral and bilateral energy assistance from 1972 to 1980, an estimated 91 percent was for large, conventional electrical Power systems (including nuclear), 5 percent was for fossil-fuel exploration and recovery, 3 percent was for renewable energy sources, and 1 percent was for technical assistance (including energy planning) (25).

${ }^{26}$ Note, however, that many developed countries, including the United States, also subsidize various aspects of the production, distribution, and $\mathrm{u}^{*}$ of fossil fuels.

${ }^{27}$ Public Law 101-167 directed A.I.D. to identify key middle- and low-income countries in which changes in energy and forestry policies @ @ significantly reduce greenhouse gas emissions. In a report to A.I.D., ORNL (56) concluded that four developing countries stood out - China, Brazil, Indonesia, and India (China and India because of cord use and rice cultivation, Brazil and Indonesia because of deforestation and all four because of possible impacts from sea-level rise). Other candidates for attention were Poland, Egypt, Mexico, East Germany, Thailand, Colombia, the Philippine, Bangladesh, Nigeria, and Zaire. 
that A.I.D. and the Department of Treasury have sufficient resources to comply with these provisions. A.I.D. also could review the effectiveness of the Multi-Agency Working Group for Power Sector Innovation (MAGPI), which was established in 1987 to coordinate activities among donors (including A.I.D. and the World Bank) in power sector lending, in achieving these objectives.

To overcome the reluctance of agencies and lending institutions to finance small projects, Congress could promote "bundling' '----combining several small projects (e.g., for renewable energy) into a large project that supplies a substantial amount of energy and involves financial scales more customarily handled by large development banks (e.g., \$5 million or more). Indeed, Public Law 101-167 instructed the Treasury Department to work with borrowing countries to develop loans for bundled projects on end-use energy efficiency and renewable energy. The "Green Fund" (see above) might be used to finance bundled projects. Congress also could promote greater funding by smaller development organizations. For example, the InterAmerican Foundation (IAF) and the African Development Foundation (ADF) work with the larger Inter-American and African Development Banks to fund (IAF) or implement (ADF) community-scale, grassroots development programs (102); to date, though, they have rarely been involved in energy projects.

\section{population Policies}

History of U.S. Population Policy-The United States has supported the right of couples worldwide to control the number and spacing of their children since the mid- 1960s. The Foreign Assistance Act, as amended in 1965 , considered family planning an important contributor to economic development and improved health and nutrition $(17,44)$. The Act also established A. I.D., which has been the major source of U.S. population assistance funds.

In the 1970s, as developing countries became increasingly worried about their ability to accommodate rising numbers, support for family planning programs grew rapidly. A U. N.-sponsored confer- ence in 1974, attended by 137 countries (including the United States), adopted a "World Population Plan of Action" that called for "socioeconomic development as well as health and family planning programs designed to reduce excess fertility" (63a). It asked that governments provide individuals and couples with the information and means to determine the number and spacing of their children. Today, about 84 percent of the people in developing countries live in countries with some type of governmental population policy (29).

Meanwhile, the United States grew increasingly conservative about family planning, primarily because of concern over abortion. At the 1984 world population conference in Mexico City, the United States reversed its earlier position by declaring that population growth was a 'neutral' factor and that economic development could compensate for any population level.

New restrictions on A.I.D. made organizations associated with abortion services in developing countries ineligible for funding. Thus, in the mid1980s, two of the most important international population assistance programs lost U.S. funds: the International Planned Parenthood Federation (IPPF) and the United Nations Population Fund (UNFPA).

Current Issues for U.S. Population PolicyWith respect to family planning assistance, Congress can now consider the appropriate level of funding, how funds should be distributed, and under what restrictions or sanctions. Arguments for and against attaching sanctions to funds, though, are beyond the scope of this report.

U.S. funding earmarked specifically for A. I.D. 's population account declined from $\$ 290$ million in fiscal year 1985 to $\$ 218$ million in fiscal year 1990 (97). ${ }^{28}$ Total funding for population-related projects is slightly higher in each year, though, because of funds allocated under the Economic Support Fund and the Development Fund for Africa. ${ }^{29}$ Among major donors, U.S. assistance is relatively high in terms of absolute amounts but relatively low in terms of its share of GDP (92).

\footnotetext{
${ }^{28}$ These are actual or estimated expenditures and vary slightly from official authorizations (e.g., $\$ 198$ million authorized in fiscal year $1989, \$ 202$ million expended).

${ }^{29}$ For example, total funding $i_{n}$ fiscal year 1989 was about $\$ 245$ million, Congress authorized $\$ 198$ million directly for A.I.D. 's population planning account, and population-related projects also received about $\$ 30$ million from the Development Fund for Africa (3) and an estimated \$18 million for projects in Pakistan and Egypt funded under the Economic Support Fund $(97,98)$.
} 
There is disagreement as to whether these levels are adequate and appropriate. Some people argue that family planning assistance should be reduced or eliminated as a part of international aid (17). However, the UNFPA ('71) concluded that more assistance is needed if the world's population is to stabilize at or near the UN's ' "medium' projection of 10 to 11 billion people. ${ }^{30}$ In particular, more assistance is needed to meet the "unmet need for contraception." ${ }^{31}$ The UNFPA estimates that the cost for direct contraceptive services and a range of backup activities (e.g., education, women's programs, research, and evaluation) would be several billion dollars per year.

U.S. funding prior to 1986 was distributed primarily through bilateral aid, U.S.-based NGOs, IPPF, and UNFPA. These pathways include a complex network of donors and recipients, making it easier to tailor assistance to the needs and conditions of specific areas. A broad array of agencies and channels can also be helpful when political factors make some sources of aid more acceptable than others. Loss of UNFPA and IPPF as channels, however, has removed much of this flexibility and reduced overall U.S. influence in family planning assistance.

\section{EASTERN EUROPE AND THE U.S.S.R.}

The U.S.S.R. and the Eastern European countries account for about one-fifth of current global greenhouse gas emissions, mostly from combustion of fossil fuels to provide energy. ${ }^{32}$ Their existing energy infrastructure is both massive and inefficient; thus, investments are needed both in new, more efficient facilities and in retrofitting existing facilities for better energy use. ${ }^{33}$

Efforts to promote energy conservation and efficiency and thereby reduce future growth in carbon emissions in these countries must overcome several systemic and institutional obstacles. Most resources, including energy, are priced at artificial values that do not reflect their true costs. Currencies convertible in Western markets, needed for purchasing modern, energy-efficient equipment, are lacking. Rigid quotas set by central economic planners for goods and services provide no incentives for efficient production. Finally, implementation of plans for alternative energy sources is hindered by a fragmentation of responsibilities among multiple government agencies. Thus, even when opportunities exist, there are strong disincentives to save energy and raw materials and to make efficient capital investments.

These obstacles have led to high industrial demand for energy, energy-inefficient production of goods and services, less electricity for nonindustrial consumers, and low standards of living. Energyinefficient industrialization also has led to severe environmental problems in the region. Many rivers and groundwater aquifers in Eastern Europe and the Soviet Union are seriously polluted from industrial wastes and agricultural runoff (e.g., 9, 19, 77, 87). Forests in the Black Triangle region (an area shared by Poland, Czechoslovakia, and Germany) and other areas exhibit severe effects from anthropogenic air pollutants (e.g., 49).

The political revolutions sweeping through Eastern Europe and the U.S.S.R, augur many changes in economic systems, energy-use patterns, and environmental protection. Eastern Europe is returning to the economic traditions of Central and Western Europe that prevailed in the region before World War II. Hungary, for example, has been active in introducing market mechanisms and decentralizing its economy (39), and other countries are following suit. Some Eastern European countries may become observers to the European Community in a few years, and some may even become members. Even so, they are likely to remain tied to the U.S.S.R. for decades, through trade and political agreements.

The United States can help Eastern Europe and the U.S.S.R. cope with inefficient energy use and greenhouse gas emissions, and at the same time benefit from increased trade opportunities with these countries. Opportunities exist to remove export restrictions, facilitate joint ventures, and increase

\footnotetext{
${ }^{30}$ To achieve this goal, 56 percent of women in developing countries would have to use family planning by the end of the century, compared to 45 percent today,

${ }^{3}$ I.e., the percentage of fertile married and/or sexually active women who do not want more children or who wish to increase the interval between births and are neither pregnant nor protected from pregnancy.

${ }^{32}$ Eastern Europe includes Bulgaria, Czechoslovakia, East Ge rmany (prior to unification with West Germany in October 1990), Hungary, Poland, and Romania.

${ }^{33}$ This differs from the situation in developing countries, which generally have less industrial infrastructure (see above).
} 
technical assistance (e.g., see 20, 27a). U.S. influence may be greatest in Eastern European countries, where trade represents a greater proportion of GNP than it does in the U.S.S.R. (albeit most of their trade is with the U.S.S.R.). Trade and joint ventures with Eastern Europe (particularly Poland, Hungary, and Czechoslovakia at this time) might, however. be an effective avenue for influencing energy use in the U.S.S.R. The success of U.S. policies ultimately will depend on the degree to which the U.S.S.R. and Eastern European countries can reform their own economies.

\section{Trends in Eastern Europe}

\section{Energy Use}

Eastern European countries accounted for 6 percent of world energy consumption in 1988 (see figure 9-2). Coal was the predominant energy source, accounting for 69 percent of primary energy consumption in East Germany, 84 percent in Poland, and 58 percent in the region as a whole in 1988 (see table 3-1 inch. 3). Oil was somewhat more important than coal in Bulgaria, Hungary, and Romania, while natural gas was the most important energy source in Romania.

The industrial sector accounted for 60 percent of primary energy demand in the six Eastern European countries combined $(32,41)$. Residential and commercial buildings accounted for 27 percent, while transportation accounted for only 13 percent, These sectoral percentages differ sharply from those of the United States and other OECD countries.

Per-capita energy consumption in at least some parts of the region is roughly equivalent to that of some OECD countries (see figure 9-3), although per-capita income is much lower. For example, Hungary's per-capita energy use is about the same as Japan's, but its per-capita income is one-third to one-fifth that of Japan (39). Poland and Austria compare in a similar way (81).

According to one projection (41), without special incentives for energy efficiency but with structural changes (i. e., the composition of goods and services making up the economy) that are likely to occur anyway, primary energy demand in Eastern Europe will increase by about 40 percent between 1985 and 2025. Over one-half of the increase would occur in the buildings sector. In contrast, if incentives for energy efficiency are enacted (e.g., standards requir- ing greater automobile fuel efficiency; price reforms allowing energy prices to escalate to world market levels), energy demand could remain at about today's levels. Demand would decline in the industrial sector and increase in the buildings and transportation sectors.

\section{Carbon Emissions}

Projections of future carbon emissions have been made for Hungary (39) and Poland (8 1). For Hungary, without structural changes or energy efficiency measures (i.e., a 'Base' case scenario), projected emissions in 2030 are about 30 percent greater than current levels. A combination of structural changes and energy efficiency measures result in projected emissions in 2030 that are 20 percent lower than current levels. For Poland, a combination of structural changes and energy efficiency measures lead to a projected 20 percent reduction from current levels by the year 2030 .

\section{Trends in the U.S.S.R.}

\section{Energy Use}

In 1988, the U.S.S.R. accounted for 18 percent of global primary energy consumption, second only to U.S. consumption (see figure 9-2 above). Per-capita energy consumption in the U.S.S.R. is comparable to that of some OECD countries (see figure 9-3), although per-capita income is much lower. In the 1960 s and 1970 s, the predominant fuel used in the U.S.S.R. shifted from coal to petroleum; since then natural gas has played an increasingly significant role. As of 1988, natural gas supplied the U.S.S.R. with 37 percent of its primary energy needs, petroleum 32 percent, coal 24 percent, and nuclear and hydroelectric power together 8 percent (see table $3-1)$. In the early 1980s, Soviet planners expected nuclear power to meet at least 30 percent of the U. S. S.R.'s electricity demand by the year 2000 . However, public opposition to nuclear power-e. g., reactions to Chernobyl, massive demonstrations at the Ignalina facility in Lithuania, opposition to construction of the Crimean plant in the Ukraine--problems at the Soviet reactor construction facility, and lack of capital have stalled the program.

The industrial sector accounts for over 50 percent of total energy consumption (47). The most energyconsuming branches are ferrous metallurgy; fuels and power; machine building; and chemicals, petrochemicals, and petroleum refining (72). The build- 
ings sector accounts for approximately 20 percent of energy use, transportation about 12 percent, and the energy sector about 16 percent $(47,73)$.

Between 1975 and 1988, Soviet investments in energy production increased almost fourfold, and in 1988 they represented 25 percent of all investments in the economy (42). Even greater investments in energy production may be needed if economic growth is to occur at a rate of 2 percent or more per year (47).

In light of such predications, Soviet authorities have directed all sectors to make more efficient use of energy. Goals for this were articulated in the 5-year plans for 1981-85 and for 1986-90. Soviet planners hoped to use conservation and efficiency measures to reduce projected energy demand by about one-half (47). This was to be achieved by restructuring the industrial sector (partly by reducing military expenditures) and adopting modern, more efficient technologies.

The extent to which these goals can be achieved is as yet unknown, particularly given the changes now taking place in the Soviet economic system. Energy savings are possible in the industrial, transportation, and buildings sectors (see chs. 4 to 6), but increased consumption of" products and services (e.g., automobiles, space heating, electric appliances, per-capita living space) and related energy use is likely. The net effect on total energy use thus is uncertain.

\section{Carbon Emissions}

The U.S.S.R. contributed an estimated 14 percent of global greenhouse gas emissions during the 1980s (1 10), primarily from fossil fuel combustion. If current trends in energy use continue (i.e., "Base' case), one model (47) projects that emissions will increase 45 to 100 percent by 2020, depending on rates of economic growth (see figure 9-8; the Base case assumes economic growth at 3 to 3.5 percent yearly through 2005 and 2.5 to 3 percent thereafter).

In an "Energy-Efficiency" scenario, projected emissions would rise about " 15 percent by 2020 . This assumes that energy intensity declines by an annual rate of about 2 percent between 1990 and 2020, as a result of measures such as regulated electric drive motors, better lighting, gas turbines and combinedcycle plants, and multifuel boilers as efficient as those in advanced capitalist countries. Projected
Figure 9-8-Projected Carbon Emissions in the U.S.S.R.

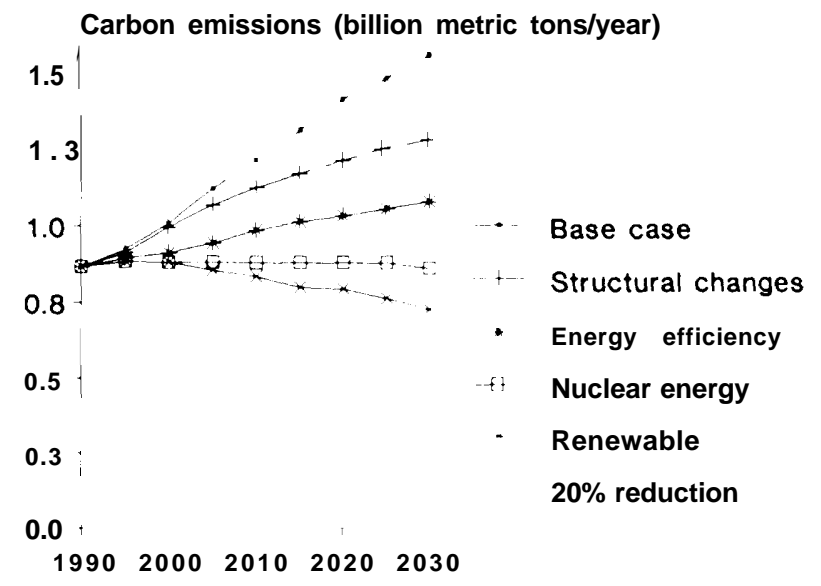

Soviet researchers modeled future carbon emissions from the U.S.S.R. In a "Base" case scenario, for example, current trends in energy use continue and emissions increase by over 50 percent by 2020 . In an "Energy Efficiency" scenario, projected emissions would rise about 15 percent by 2020 . Projected emissions decline from estimated 1990 levels only if concerted efforts are also made to expand the role of nuclear power and renewable energy.

SOURCE: A.A. Makarov and I.A. Bashmakov, The Soviet Union: $A$ Strategy of Energy Development with Minimum Emission of Greenhouse Gases, prepared for U.S. Environmental Protection Agency (Richland, WA: Battelle Pacific Northwest Laboratories, April 1990).

emissions actually decline from current (estimated) levels only if concerted efforts are also made to expand the role of nuclear power and renewable energy (47).

\section{Options for Possible U.S. Influence}

The United States might influence energy use and carbon emissions in Eastern Europe and the U.S.S.R. through technical assistance and expanded trade in energy-efficient technologies. Several U.S. Government and private sector groups already promote trade in energy-efficient and renewable energy technologies-including CORECT, OPIC, Eximbank, U.S. Trade and Development program (TDP), and the U.S. Export Council for Renewable Energy (US/ECRE) (see box 9-C above).

However, trade is likely to be limited until systemic changes occur in Eastern Europe and the U.S.S.R. $(9,41)$. Some financial constraints to trade result from the difficult economic transitions occurring in these countries. Eastern Europe faces additional trade constraints because of Soviet intentions to make its oil supplies available at prevailing world 
prices (paid in convertible currencies) and because of losses of scheduled oil shipments from Iraq (23). ${ }^{34}$

If these obstacles can be overcome, it might be easier to use trade to influence policies in Eastern Europe than in the U.S.S.R. Trade is a greater percentage of GNP in Eastern Europe than in the U.S.S.R. (see table 9-5), although much Eastern European trade is with the U.S.S.R. Many of these countries also have some tradition of Western industrial practices. This and the current economic and political changes occurring in Eastern Europe could create a more positive climate for trade with Western businesses.

Facilitating the use of energy-efficient technology in Eastern Europe, through trade and joint ventures, might also benefit the U. S. S. R.; almost 60 percent of all Soviet imports comes from Eastern Europe and technology comprises the bulk of the imports .35 U.S. companies could also attempt to set up energyrelated joint ventures in the U.S.S.R.

\section{Constraints in Centrally Planned Systems}

As noted earlier, several systemic and institutional constraints pose barriers to increasing energy efficiency and reducing energy use in Eastern Europe and the U.S.S.R. Energy subsidies, for example, substantially lower the cost of power to consumers, particularly industries. In Poland, subsidies accounted for 49 and 83 percent of the delivered prices of coal and natural gas, respectively, in 1987 (81); in Hungary, average consumer prices for energy were only about 30 percent of those in Western Europe (74). Rigid quotas for production of goods and services and use of energy destroy any incentive to save raw materials or energy. Enterprises must consume virtually all of the supplies allocated to them by central planners, even when not all are needed, in order to receive the same or a larger
Table 9-5--Total Foreign Trade as a Percentage of GNP, 1988, for Selected Countries

\begin{tabular}{|c|c|}
\hline Country & $\begin{array}{l}\text { Percent } \\
\text { of GNP }^{\mathrm{a}}\end{array}$ \\
\hline 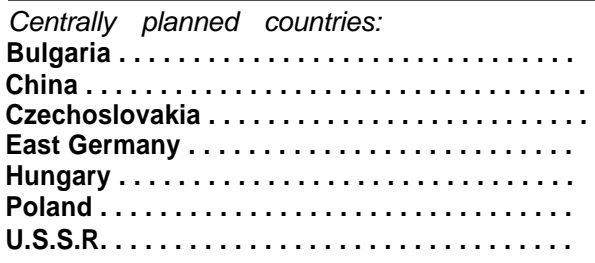 & $\begin{array}{l}61 \% \\
32 \% \\
33 \% \\
30 \% \\
41 \% \\
20 \% \\
9 \%\end{array}$ \\
\hline 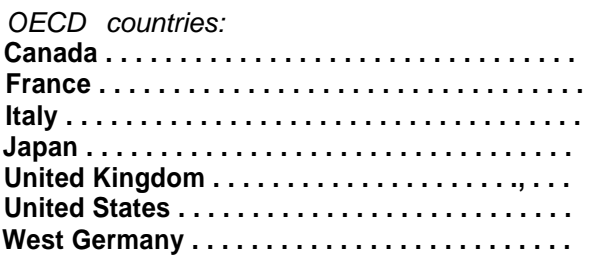 & $\begin{array}{l}45 \% \\
48 \% \\
35 \% \\
26 \% \\
44 \% \\
16 \% \\
66 \%\end{array}$ \\
\hline
\end{tabular}

afor centrally planned countries, data converted at U.S. purchasing power equivalents.

based on 1987 trade data.

SOURCE: Based on GNP and trade data in Central Intelligence Agency, Directorate of Intelligence, Handbook of Economic Statistics, 1989, CPAS 89-10002 (Washington, DC: September 1989).

amount the next year. ${ }^{36}$ Funding for maintenance (e.g., of pipelines; ref. 62a) often is inadequate. The production quotas also lead to greater investments in heavy industries (e.g., steel, aluminum, chemicals) at the expense of services and consumer goods. Trade with Western nations also is constrained by lack of convertible currencies.

Fragmented institutional responsibilities also limit governmental abilities to develop and implement new energy and environmental policies (40). In the U. S. S. R., six major ministries share the task of supplying energy. 37 Different ministries also direct the development and the use of specific energy sources. ${ }^{38}$ In 1988, the high-level State Committee for Environmental Protection, or Goskompriroda,

\footnotetext{
${ }^{34}$ Petroleum is the U.S.S.R.'s most important means of earning hard currency on western markets; in late 1987, Soviet oil and natural gas exports supplied approximately 15 percent of Western Europe's use of each fuel (57). The elimination of subsidized oil imports from the U.S.S.R. might result in Eastern European countries consuming even more "brown" coal, unless and until investments are made to develop alternative energy sources and promote energy efficiency.

${ }^{35}$ Trade accounts for only 9 percent of the U.S.S.R. 's GNP. Imports from OECD countries represent O@' one-tenth of this, and technology is only a small Portion of these imports $(6,114)$. Energy in all forms comprises over one-half of the value of all Soviet exports.

${ }^{36}$ Fuel deliveries, for example, are planned on a centralized basis in accordance with guidelines on enterprises' assigned priorities in the national economy and their technical specifications, but the potential for energy conservation generally is not considered by planners.

${ }^{37}$ The Ministries of Oil Industry, Gas Industry, Coal Industry, Electrification, Geology, and Atomic Energy. While the Council "Ministers coordinates their activities, its own membership is comprised of some 60 Soviet industrial ministries and committees. Research institutes, universities, and academies of sciences in each republic also conduct R\&D.

38 For example, identification of " proven stocks' ' of geothermal waters falls under the Ministry of Geology, but their use for hinting falls under the Ministry of Gas Industry. Likewise, development of solar power is entrusted to the Ministry of the Electrical Equipment Industry, but its $u s e$ is under the Ministry of Power and Electrification.
} 


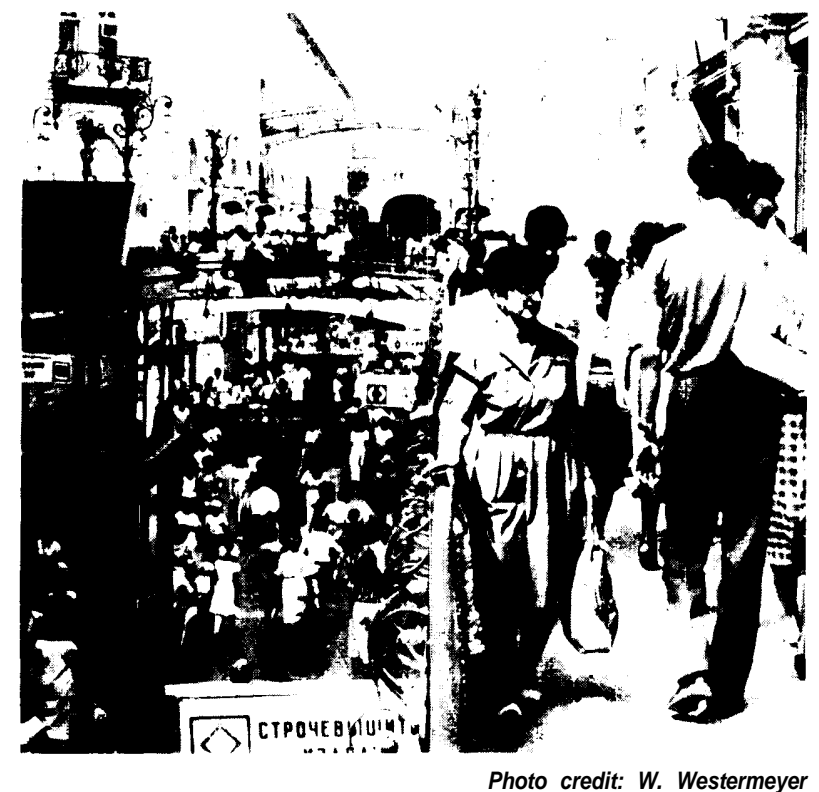

Gum's department store in Moscow. All over the U.S.S.R. and Eastern Europe, overcoming the obstacles typical of centrally planned economies-and ensuing economic and environmental problems-will be a formidable challenge.

was created to clean up harmful pollutants. Its powers were formerly distributed over numerous bodies; however, legislation formally defining its wide-ranging jurisdiction has not yet been enacted, and opposition has emerged from many of the ministries impinged on by Goskompriroda $(40,117)$. Movements by various Soviet republics to gain more autonomy will make jurisdictional questions even more complex.

Added to these systemic and institutional constraints to increasing energy efficiency and reducing energy use is the absence of global warming as a topic in domestic policy discussions. Although the U.S.S.R. has been significantly involved in the International Panel on Climate Change (IPCC) and chaired IPCC Working Group II on impacts (see box 9-B above), global warmingis unlikely to receive high priority in the current domestic policy agenda unless it overlaps and buttresses major domestic economic and environmental issues such as improving energy efficiency and local pollution control. ${ }^{39}$ This is partly because devastating air and water pollution problems are much more pressing in the
U.S.S.R. and Eastern Europe (77), particularly in the context of severe economic problems and changing political atmospheres.

\section{U.S. and OECD Policy Barriers}

The United States has erected many restrictions on technology exports to the U.S.S.R. and Eastern Europe for national security and other foreign policy reasons. U.S. restrictions were first codified in the Export Control Act of 1949 and now are codified primarily in the Export Administration Act (EAA) of 1979, which authorizes the President to prohibit or curtail the export of goods and technologies. ${ }^{40}$ The Byrd Amendment to the Trade Act of 1974 (Amendment 435) also limits credit to the U.S.S.R. to $\$ 300$ million in the aggregate without prior congressional approval (100). Moreover, for much of the 1970s and 1980s, U.S. trade with the U.S.S.R. took place within the context of "linkage' (i.e., using trade to moderate Soviet behavior). The Jackson-Vanik Amendments to the EAA linked the extension of most-favorednation trade status and eligibility for official export credits to increased emigration of Soviet Jews; the export of computers to the U.S.S.R. was linked to the treatment of dissidents.

These restrictions are made partly within the context of U.S. participation in the Coordinating Committee on Multilateral Export Controls (COCOM), a nontreaty agreement established in 1949 to harmonize export control policies among 17 OECD nations (1 14). By the end of 1989, COCOM had assembled a list of over 100,000 restricted items in 120 categories and developed guidelines for export licensing, with restrictions generally more stringent for the U.S.S.R. than for Eastern Europe.

Some bilateral and multilateral export restrictions have been reduced as Cold War tensions have eased (84). In June 1990, the United States agreed to remove 30 proscribed categories from the COCOM list, including advanced machine tools and computers, which are needed for modern automobile plants and other facilities $\left(\begin{array}{ll}1 & 14\end{array}\right)$ and for some pollution control equipment. The Administration also eased other restrictions imposed on the U.S.S.R. in response to the 1980 occupation of Afghanistan. Another indicator of liberalization in U.S. policies is

\footnotetext{
${ }^{39} \mathrm{~A}$ few Soviet scientists argue that future climate changes may benefit the U.S.S.R. (53), although this view does not appear to be generally held by Soviet officials.

${ }^{40}$ Public Law 96.72, as amended by the 1988 Omnibus Trade and Competitiveness Act (Public Law 100418); the latter allowed unlicensed exports of nonstrategic technical data to the U.S.S.R. and Eastern Europe (1 14).
} 
the Support for East European Democracy (SEED) Act of 1989 (Public Law 101-179). SEED authorized almost $\$ 1$ billion for Hungary and Poland for fiscal years 1990 to 1992 , made the two countries eligible for OPIC and Eximbank loans and for TDP assistance, and specified that environmental assistance be provided to them. ${ }^{41}$

\section{Policy Options}

Remove U.S. Barriers on Exports-Congress could continue to liberalize export controls. One possible venue is during reauthorization of the Export Administration Act (EAA), which expired in $1990 .{ }^{42}$ In this context, Congress could: specify removal from the COCOM control list of all items for which no specific justification for restriction exists; allow technologies that can be exported to China to also be exported to Eastern Europe and the U. S. S. R.; allow -reexports among these countries; and direct U.S. agencies (e. g., Commerce, Defense, Energy, U.S. Trade Representative) to review their procedures and policies to ensure that no unnecessary barriers exist on exports of energy-efficient or renewable energy technologies (1 14$)$.

To help foster trade, the United States can extend most-favored-nation (MFN) status to more Eastern European countries, making trade with those countries nondiscriminatory (primarily in the sense of tariff concessions) $(68) \cdot{ }^{43}$ The United States currently has granted unconditional MFN status to Poland (and Yugoslavia) and conditional status to Hungary $(68,114) .{ }^{44}$ After the President issued a Jackson-Vanik waiver, Czechoslovakia and the United
States signed a bilateral trade agreement in April 1990. The President also signed a trade agreement with the U.S.S.R. in June 1990 that, if approved by Congress, would confer unconditional MFN treatment to the U.S.S.R. and provide procedures for improving trade relations $(14) .^{45}$

Encourage Joint Ventures and Direct U.S. Agencies To Enhance Trade-U.S. companies could try to export more energy-related technologies directly to the U.S.S.R. and Eastern Europe and to establish more joint ventures with these countries. Joint ventures between U.S. companies and Eastern Europe and the U.S.S.R. increased in all fields in the late 1980s. While fewer than 10 were started in 1985 , 60 started in 1989, and over 140 may start in 1990 (20). ${ }^{46}$ However, known ventures in the energy sector declined from 14 in 1985, to between 5 and 9 per year from 1987 to $1989 .{ }^{47}$ Potential U. S.U.S.S.R. joint ventures for construction projects in developing countries are also being explored (5).

Lack of commercial financing by U.S. banks and inability to change profits into Western currencies still pose major obstacles to increasing trade in the U.S.S.R, and Eastern Europe for some companies (20). ${ }^{48}$ The latter constraint apparently does not apply to joint ventures that produce goods for export from the U.S.S.R. These earn hard currency that, under current Soviet law, the enterprises can keep.

U.S. business could be encouraged in the U.S.S.R. and Eastern Europe by increasing OPIC, Eximbank, and TDP resources and extending their activities to more countries. OPIC currently is authorized to

\footnotetext{
41 SEED authorized EPA to spend \$10 million on educational, research, and technical and financial assistance, for example in establishing an air quality monitoring network in Krakow and a regional environmental center (managed by an international board of trustees) in Budapest. It authorized the Department of Energy to spend \$30 million for retrofitting a coal-fired commercial powerplant in Krakow with clean coal technology; assessing Poland's capability to manufacture equipment enabling industries to use fossil fuels cleanly; and improving end-use energy efficiency in Poland and Hungary.

${ }^{42}$ The Export Facilitation Act of 1990, which would havereauthorized the EAA and liberalize some U.S.trade policies, was vetoed by the President in November 1990.

${ }^{43}$ MFN status also means that parties t. bilateral trade agreements or to the General Agreement on Tariffs and Trade (GATT) have reciprocal obligations.

44 Hungary has conditional status because it issubject to an annual approval of a Jackson-Vanik waiver. Romania received conditional MFN status m 1975 but declined to have it renewed in 1988.

${ }_{45}$ In December 1990 , the President waived the Jackson-Vanik provision and approved credit guarantees for Soviet purchases of up to \$1 billion in American commodities, making the U.S.S.R, eligible for loans to buy U.S. grain and for some Eximbank credits and guarantees. However, the June trade agreement will not be submitted to Congress for approval until Soviet emigration laws are revised, so MFN status cannot yet be conferred on the U.S.S.R. In addition, the continuing upheaval in the U.S.S.R. may make it difficult for the Soviets to take full advantage of this for some time.

${ }^{46}$ As of January 1989,191 joint stock Companies were registered in the U.S ,S .R., of which 164 were Soviet-Western or Soviet-Japanese companies. Of these, 10 were in the energy sector,

47@Dec.26,1990,the United States announced it willdoublethe number of joint trade-promotion programs in 1991; top priority will begiven to helping the Soviets increase their oil and gas exploration and production capabilities-a means of obtaining needed hard currency.

48 Estimated debts range as high as $\$ 50$ billion for the U, S.S.R. and $\$ 40$ billion for Poland; billions of dollars are spent in servicing loan obligations. Some European countries, such as Finland, have proposed forgiving portions of these debts in exchange for political and economic concessions.
} 
provide risk coverage to transactions in Hungary and Poland. ${ }^{49}$ Eximbank is authorized to provide insurance, loans, and guarantees to transactions in Hungary and Poland (and Yugoslavia) because these nations have MFN status, and in Czechoslovakia because that nation recently received a JacksonVanik waiver (46). As part of these efforts, the United States could target specific industries and sectors that exhibit Potential for energy savings (e.g., ferrous metallurgy, refining techniques, appliances, gas turbines, and building and automobile construction).

Congress could direct US. agencies and organizations such as CORECT to assess opportunities for enhancing trade with the U.S.S.R. and Eastern Europe in renewable and energy-efficient technologies, as discussed above in the context of developing nations (see "Redirecting Energy Policies"). Some agencies might be able to negotiate trade agreements; precedent exists, for example, in the form of a bilateral maritime shipping agreement signed by the United States and the U.S.S.R. (4). Congress could also direct Eximbank to allocate more funds for insuring exports of renewable energy technologies, beyond what is mandated in Public Law 101-167 (see "Technology Transfer and Trade With Other Countries" above).

The United States also could work through the IMF and World Bank to develop policy reforms and loans that promote energy-efficient or renewable energy technologies. Poland and Hungary already are eligible for IMF structural readjustment loans, and Czechoslovakia is being reviewed for such status. Congress could consider authorizing funds for the proposed new European Bank for Reconstruction and Development, which is scheduled to open in late $1990(46,52)$. It may also wish to consider a Czechoslovak proposal (known as the Dienstbier Plan, after the Czechoslovak Foreign Minister) that Western countries establish a special fund in the bank to finance exports from Czechoslovakia, Hungary, and Poland to the U.S.S.R, (85).

Support Institutes or Centers for Energy Efficiency-The United States could support, either unilaterally or with other OECD countries, the creation of institutes or academic and research centers in Eastern Europe or the U.S.S.R. that promote energy efficiency and conservation. Initiatives to this effect are discussed in "Technology Transfer and Trade With Other Countries" (also see footnote 41).

\section{OECD COUNTRIES}

The Organization for Economic Cooperation and Development (OECD) consists of the most industrialized countries in the world-18 Western European nations, plus Australia, Canada, Japan, New Zealand, Turkey, and the United States. ${ }^{50}$ These countries, though they are home to less than one-fourth of the world's population, account for one-half of all global primary energy consumption (see figure 9-2) and, by EPA (1 10) estimates, for over 40 percent of current greenhouse gas emissions. The vast majority of emissions is from energy use, specifically the combustion of fossil fuels such as coal and oil. The United States alone accounts for almost one-half of OECD emissions.

\section{Trends and Projections in Energy Use and Carbon Emissions}

\section{Energy Use}

Total fuel use by OECD countries between 1973 and 1987 grew relatively slowly, and even declined between 1980 and 1982; it increased between 1983 and 1987 by an average of 2.3 percent yearly (34). Growth in electricity use, particularly in the residential and commercial buildings sector (especially for appliances, also for space heating) has been strong, accounting for over three-fourths of the growth in energy consumption since 1973; nearly one-half of all primary energy consumption in OECD countries is for electricity generation. Energy consumption in the OECD industrial sector, which accounted for 37 percent of total OECD energy consumption in 1985, increased by 1.6 percent annually between 1983 and 1986.

Of total primary energy consumption in OECD nations, oil accounted for 44 percent; natural gas, 19 percent; coal, 21 percent; hydroelectric, 7 percent; and nuclear, 9 percent (see table 3-1). Over 60

\footnotetext{
${ }^{49} \mathrm{OPIC}$ recentl $\mathrm{y}_{\mathrm{y}}$ approved its first project in Eastern Europe (insur ance for a General Electric investment in a Hungarian electric lighting products company) and is establishing an Environmental Investment Fund (see ch. 7) and a European Growth Fund applicable to these countries (60, 61).

50The western European countries are Austria, Belgium, Denmark, Finland, France, Germany, Greece, Iceland, Ireland, Italy, Luxembourg, the Netherlands, Norway, Portugal, Spain, Sweden, Switzerland, and the United Kingdom, Established in 1\% 1, the OECD promotes increased economic growth and employment in its member countries and promotes the expansion of world trade in general.
} 
percent of the electricity is generated from coal and nuclear power, at least in the 21 OECD countries belonging to the International Energy Agency (IEA) (34).51

Total OECD primary energy requirements are projected to grow by about 1,3 percent annually through 2005, because of continued growth in the industrial sector and expected increases in the use of oil for transportation $(18,34)$. Even so, the OECD's overall share of total world energy demand is expected to decrease from 50 to 40 percent because of greater growth in developing countries, Eastern Europe, and the U.S.S.R. How these projections are affected by the Persian Gulf situation is unknown; any lasting rise in oil prices might stimulate more efficient use of oil, but it also could make coal more attractive.

Many observers claim that the United States uses more energy per unit of GDP (i.e., has a higher “'energy intensity' than other industrialized countries. Indeed, while our technologies are comparable to those of other OECD countries, our energy usage patterns often differ (107). ${ }^{52}$ For example, new car fuel economy in the United States is similar to that in Germany, Japan, and the United Kingdom (78, 107). However, the United States has more cars, higher vehicle miles traveled per capita, and an increasing penchant for less efficient light-duty trucks. Thus, transportation energy consumption per person is twice that of other G-7 countries (107). ${ }^{53}$ U.S. residential heating efficiency, on a per square foot basis, is about the same as that of many other industrialized countries, but U.S. homes tend to be bigger so energy use per house is greater. Energy intensity in the U.S. industrial sector is relatively high, at least partly because the United States has large, energy-intensive industries (petrochemical, chemical, and primary metals) that were developed to use abundant energy supplies.

\section{Carbon Emissions}

EPA (1 10) estimates that OECD countries contributed slightly over 40 percent of all greenhouse gas emissions in 1985. Emissions between 1973 and 1987 (see figure 9-1; also see ref. 8) were relatively stable, even while economies and overall energy consumption generally grew, because of structural changes in economies and energy efficiency measures stimulated by the 1973 oil embargo (35). Major structural changes included a continuing shift from energy-intensive industries (e.g., steel and cement manufacturing) to service-oriented industries and continuing modernization of energy-intensive industries $(35,78)$. Energy efficiency measures have been particularly important in end-use applications such as passenger vehicles and electric appliances (35).

Between 1987 and 1989, however, carbon emissions increased from some OECD countries, including the United States, primarily because of falling energy prices, above-average growth in industrial production, and a weakening of energy efficiency programs $(10,18,35,103)$,

The European Community (12) modeled three scenarios for projected carbon emissions between 1987 and 2010 from its 12 member States (see figure 9-9). ${ }^{54}$ The "Business As Usual' scenario (Scenario 1) projects emissions increasing 24 percent by 2010 , with power generation and transportation accounting for about 60 percent of total emissions. The "How Things Could Go Wrong' scenario (Scenario 2) projects emissions in 2010 about 40 percent above 1987 levels, In contrast, the "High Economic Growth in Clean Environment" scenario (Scenario 3) projects emissions in 2010 about 17 percent below 1987 levels.

\footnotetext{
${ }^{51}$ The IEA is an autonomous body established in 1974 within the framework of the OECD with the purpose of implementing an international energy program. It includes all OECD countries except for Finland, France, and Iceland.

${ }^{52}$ Energy intensity (i.e., amount of energy consumed per unit of production) is a common measure of changes in energy efficiency. However, this ratio does not give a good picture of the relative efficiency of energy use in any one country or a correct comparative picture between countries (see 79, 80). Moreover, it can provide a false indicator of changes in relative energy efficiency in a country if the changes reflect the movement of energy-intensive industries overseas to developing countries, but the former host country still receives the benefits of the production $(45,104)$.

${ }^{53}$ I.e., Canada, France, Ge rmany, Italy, Japan, and the United Kingdom.

${ }^{54}$ The "Business as Usual" scenario assumes economic growth of 2.7 percent per year and market-driven changes in energy use and conservation. The ' 'How Things Could Go Wrong' scenario assumes economic growth of 3.5 percent yearly until 2000 and 2.5 percent thereafter in addition, energy use in traditional heavy industries declines more slowly than expected, and transport congestion increases. The "High Economic Growth in Clean Environment scenario assumes economic growth of 3.5 percent yearly until 2000 and 3 percent thereafter however, strict government policies on energy conservation (e.g., changes in the fuel mix for power generation, including a doubling of nuclear power between 1987 and 2010 ) and environmental protection are rapidly implemented.
} 
Figure 9-9-Projected Carbon Emissions in the European Community

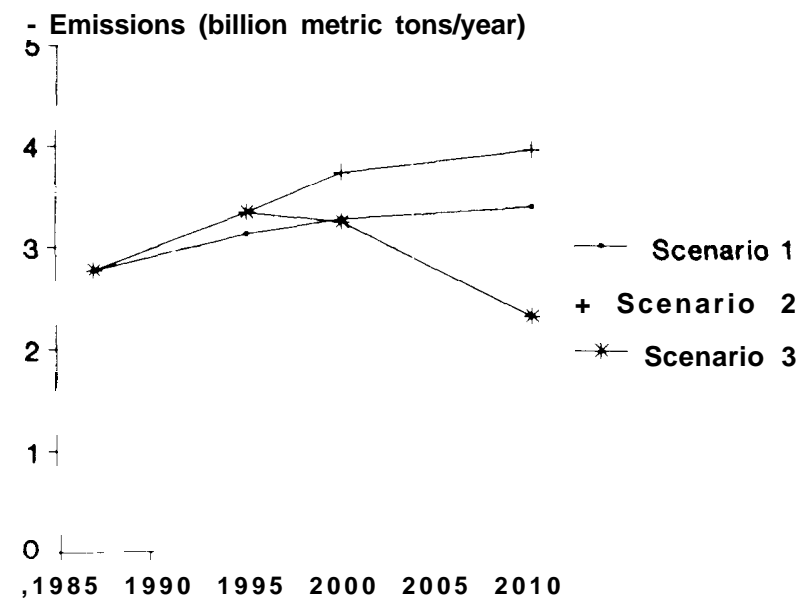

The Commission of the European Communities modeled future carbon emissions from its member nations under three scenarios: "Business As Usual" (Scenario 1 ), "How Things Could Go Wrong" (Scenario 2), and "High Economic Growth in Clean Environment" (Scenario 3) (see text for assumptions). In Scenario 3, rapid implementation of strict policies on energy conservation and changes in the fuel mix (including a doubling of nuclear power between 1987 and 2010) result in projected emissions in 2010 that are about 17 percent below ' 1987 levels.

SOURCE: Commission of the Europea n Communities, "Energy in Europe, Major Themes in Energy, 'r Special Issue (Brussels: September 1969).

\section{Policies Regarding Energy and Greenhouse Gases}

\section{Energy Use}

OECD countries have enacted many policies over the last two decades regarding energy supply and efficiency (see table 9-6) (U.S. policies are discussed in chs. 1 and 3 through 6). On the supply side, many policies have been oriented towards the development of indigenous energy sources-particularly oil, natural gas, and coal, as well as hydroelectric power to a lesser extent-and nuclear power.

Demand-side policies have focused on end-use efficiency in the commercial and residential sectors (e.g., appliance efficiency standards, conservation programs developed by utilities for consumers, and energy labeling for homes). Most countries also have an active renewable energy development and demonstration program; several countries, including Denmark, West Germany, and the Netherlands, have had subsidy programs for wind energy systems, with subsidies tied directly to electricity production (54). Overall government funding for the development of wind turbine technology is estimated to be around $\$ 80$ million annually in Europe.

However, the trend has been for less government involvement in energy policies (e.g., reduced subsidy programs, more deregulation, less emphasis on energy efficiency and renewable energy) $(10,35)$. Government energy research, development, and demonstration (RD\&D) budgets have declined in the 21 IEA countries, from a total of $\$ 12.5$ billion in 1980 to $\$ 6.9$ billion in 1988 (35) ${ }^{55}$ In 1988 , only 7 percent of this was devoted to energy efficiency and only 8 percent was for renewable energy; 56 percent was for nuclear power.

How this picture might change when the European Community becomes a more integrated economic entity in 1992 is unclear. In 1986, though, the Community adopted policy objectives on which to base national energy policies (10, 11). Energy objectives for 1995 include reducing dependence on imports of oil by diversifying the fuel supply and improving the energy efficiency of end use by at least 20 percent. However, attaining the 20 percent goal is considered unlikely without stronger actions (10), and any increases in the use of coal relative to natural gas and oil would lead to greater greenhouse gas emissions.

\section{Greenhouse Gas Policies}

Some OECD countries have announced plans to unilaterally reduce their greenhouse gas emissions (see table 9-7), and in October 1990 the European Community pledged to stabilize $\mathrm{CO}_{2}$ emissions from the community as a whole (although not necessarily from all member countries) in the year 2000 at 1990 levels (2a). It remains to be seen whether these countries can provide the regulatory and market incentives needed to achieve significant emission reductions. Nonetheless, their declarations indicate a willingness to accept responsibility to address global climate change.

\footnotetext{
${ }^{55}$ All figures in 1988 U.S. dollars. Energy RD\&D expenditures in 1988 were less than 1 percent of each country's GDP, ranging from 0.14 to 0.98 percent; excluding nuclear power, the range was 0.08 to 0.58 percent. The United States and Japan accounted for 61 percent of total RD\&D. See ch. 3 for information on U.S. RD\&D budgets during this period.
} 


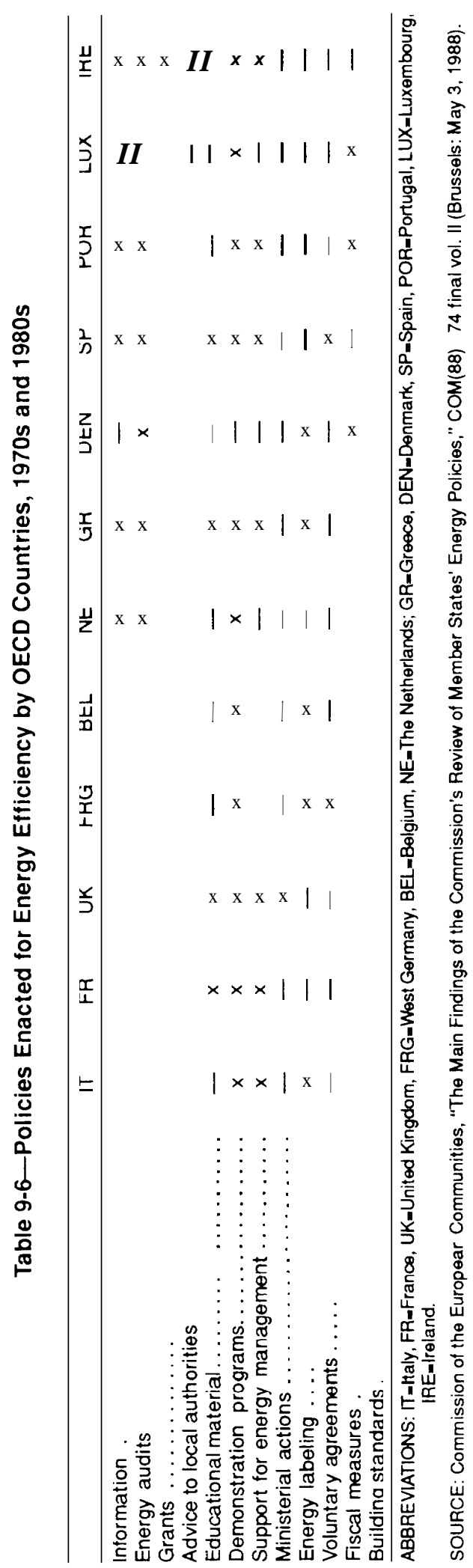


Table 9-7-Official Greenhouse Gas Emission Stabilization and Reduction Policies of OECD Countries

\begin{tabular}{|c|c|c|c|c|}
\hline Jurisdiction & $\begin{array}{c}\text { Base level } \\
\text { year }\end{array}$ & $\begin{array}{c}\text { Stabilization } \\
\text { year }\end{array}$ & $\begin{array}{l}\text { Percent reduction } \\
\text { target }\end{array}$ & Target year \\
\hline 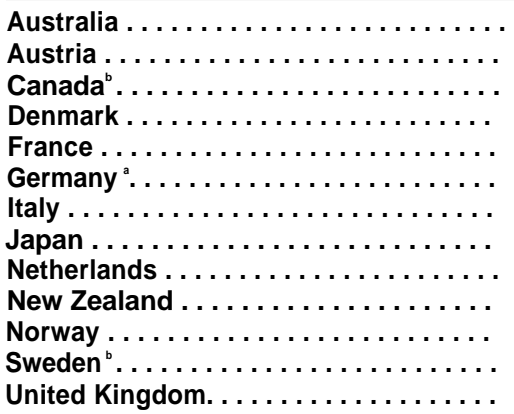 & $\begin{array}{c}1988 \\
1987 \\
1988 \\
1988 \\
1989 / 90 \\
1987 \\
1990 \\
1990 \\
1989 / 90 \\
1990 \\
1989 \\
1988 \\
1990\end{array}$ & $\begin{array}{l}2000 \\
\text { Not declared } \\
2005 \\
2005 \\
2000 \\
- \\
2000 \\
2000 \\
1995 \\
\text { Not declared } \\
2000 \\
\text { Not declared } \\
2005\end{array}$ & $\begin{array}{l}20 \% \text { of all gases } \\
20 \% \text { of } \mathrm{CO}^{*} \\
\mathrm{Not} \text { declared } \\
200 / 0 \text { of } \mathrm{CO}_{2} \\
\mathrm{Not} \text { declared } \\
25 \% \text { of } \mathrm{CO}_{2} \\
20 \% \text { of } \mathrm{CO}_{2} \\
\mathrm{Not} \text { declared } \\
5 \% \text { of } \mathrm{CO}_{2} \\
20 \% \text { of } \mathrm{CO}_{2} \\
\text { Not declared } \\
\text { Not declared } \\
\text { Not declared }\end{array}$ & $\begin{array}{c}2005 \\
2005 \\
\text { Not declared } \\
2000 \\
\text { Not declared } \\
2005 \\
2005 \\
\text { Not declared } \\
2000 \\
2005 \\
\text { Not declared } \\
\text { Not declared } \\
\text { Not declared }\end{array}$ \\
\hline
\end{tabular}

aExcluding eastern Germany. The German Bundestag's Enquete Commission (ref. 23a) has proposed a new target of 30 percent $\mathrm{CO}_{2}$ reduction by 2005 for the entire country.

bTentative.

SOURCE: OTA Survey of Embassies; Organization for Economic Cooperation and Development and International Energy Agency, "Summary of Actions in Member Countries To Deal With the Problem of Climate Change (Note by the Secretariat),"IEASLT(90)51(1 st Revision), draft (Paris: Standing Group on Long-Term Cooperation, Committee for Energy Research and Development, Oct. 24, 1990).

Several European nations, Australia, Japan, and New Zealand have taken the lead in declaring official greenhouse gas emission reduction schedules (see table 9-7). Australia has the most ambitious goal-a 20 percent reduction by 2005 in emissions of all greenhouse gases. Austria, Denmark, Germany, Italy, and New Zealand have $\mathrm{CO}_{2}$ reduction goals ranging from 20 to 2.5 percent by 2005 , while the Netherlands has a $\mathrm{CO}_{2}$ reduction goal of 5 percent by $2000 .{ }^{56}$ Japan, Norway, and the United Kingdom have thus far committed to a goal of stabilizing $\mathrm{CO}_{2}$ emissions at "current" (i.e., 1989 or 1990) levels within the next 10 to 15 years. ${ }^{57}$ Canada and Sweden have declared tentative $\mathrm{CO}_{2}$ emission goals to stabilize emissions at current levels by the year 2000. France has a goal of stabilizing $\mathrm{CO}_{2}$ emissions at a level about 10 percent over current levels by 2000 (7). The United States has no official goal-for either stabilization or reduction. However, it is scheduled to host the first formal negotiating session on a framework convention early this year.

Table 9-8 presents a more detailed summary of OECD national policies and programs, both proposed and enacted, specifically designed to reduce greenhouse gas emissions. Among countries with official stabilization or reduction targets, the Netherlands has one of the most complete sets of proposals for increasing energy efficiency and reducing emissions from transportation, including a tax on $\mathrm{CO}_{2}$ emissions. ${ }^{58}$ The Swedish parliament also considered a tax on $\mathrm{CO}_{2}$ emissions, initially in the energy production and transportation sectors (86), but it decided not to implement the tax until it coordinates its $\mathrm{CO}_{2}$ emissions policies with other European countries (18a).

\footnotetext{
56For Germany, this schedule will apply to West German emissions only, since attaining large reductions in the currently inefficient East German energy sector would be a relatively easy task.

${ }^{57}$ The United Kingdom chose 2005. Japan also established a goal of stabilizing $\mathbf{N}_{\mathbf{2}} \mathrm{O}, \mathbf{C H}_{\mathbf{4}}$, and other gases at today's levels.

${ }^{58} \mathrm{The}^{\mathrm{CO}_{2}}$ tax is an addition $\mathrm{t}$. the existing fossil fuel tax, which consists of a general fuel excise tax and an environmental levy; the $\mathrm{CO}_{2}$ tax adds an amount to the environmental levy.
} 
Table 9-8—New Plans and Programs in OECD Countries, Specifically Designed To Reduce Greenhouse Gas Emissions, as of 1990a

\begin{tabular}{|c|c|c|c|c|c|c|c|c|c|c|}
\hline Plan or program & CAN & DEN & GER $^{\mathrm{b}}$ & JAP & NET & NEZ & NOR & SWE & UK & us \\
\hline Carbon or $\mathrm{CO}_{2}$ emissions tax $\ldots \ldots \ldots$ & - - & $\mathbf{P}$ & $P$ & - & E & - & $\mathbf{P}$ & $E$ & - & - \\
\hline Modified utility planning/funding $\ldots \ldots \ldots$ & $\mathbf{P}-$ & $\mathrm{P}$ & - & -- & $\vec{P}$ & - & $\mathrm{P}$ & $\mathrm{P}$ & $\mathbf{P}$ & $\mathbf{P}$ \\
\hline Strengthened building or appliance standards. . . & $\mathbf{P}-$ & $P$ & - & - & P & $\mathbf{P}$ & $P$ & - & $\mathrm{E}$ & $\mathbf{p}$ \\
\hline Support for renewable and/or alternative fuels ${ }^{d}$. & $\mathbf{P}-$ & $\mathrm{P}$ & $\mathbf{P}$ & $\mathbf{P}$ & P & $\mathrm{P}$ & $\mathrm{P}$ & $\mathbf{P}$ & $\vec{P}$ & $\mathrm{P}$ \\
\hline TCMs or tightened fuel efficiency standards $\ldots \ldots \ldots$ & $P$ & - & - & $\mathbf{P}$ & $P$ & - & $\mathbf{P}$ & $\mathrm{P}$ & - & $\mathbf{P}$ \\
\hline Land use planning and/or reforestation .... & & $\mathbf{P}-$ & - & $\mathbf{P}$ & $\mathrm{P}$ & - & $\mathbf{P}$ & - & - & E \\
\hline Energy audits and/or public information programs & & $\mathbf{P}-$ & - & $\mathbf{P}$ & $\mathbf{P}$ & $E$ & - & - & - & - \\
\hline CFC reductions faster than Montreal Protocol'........E & $P$ & - & $E$ & - & - & $\mathrm{E}$ & $E$ & - & - & $\mathbf{P}$ \\
\hline
\end{tabular}

CFC reductions faster than Montreal Protocol'..........

a Note that some countries may already be implementing these measures in programs previously established for other purposes (e.g. Canada has programs

for utility planning and energy audits). This table refers only to new programs and plans that address greenhouse gas emissions as a top priority.

bWest Germany only.

Includes policies to encourage fuel switching and cogeneration.

Alternative fuels include ethanol, methanol, and other biofuels.

TCMs - transportation control measures (e.g., ride-sharing, public transit).

KEY: P. Proposed

E. Enacted
ABBREVIATIONS: AUS - Australia; CAN - Canada; DEN - Denmark; GER - Germany; JAP - Japan; NET. The Netherlands; NZ - New Zealand; NOR - Norway; SWE - Sweden; UK= United Kingdom; US = United States.

SOURCE: OTA Survey of Embassies; Organization for Economic Cooperation and Development and international Energy Agency, "Summary of Actions in Member Countries To Deal With the Problem of Climate Change (Note by the Secretariat)," IEASLT(90)51 (1 st Revision), draft (Pans: Standing Group on Long-Term Cooperation, Committee for Energy Research and Development, Oct. 24, 1990). 


\section{CHAPTER 9 REFERENCES}

1. British Petroleum Co., BP Statistical Review of World Energy 1988 (London: June 1988).

2. Bulatao, R.A.et al., Europe, Middle East, and Africa(EMN) Region Population Projection, 1989-90 Edition (Washington. DC: World Bank, 1989).

2a. Bureau of National Affairs, "European Ministers Reach Accord To Stabilize $\mathrm{C}_{2}$ Emissions By 2000, " International Environmental Reporter 13(13):457-458, Nov. 7, 1990.

3. Camp., S., Population Crisis Committee, personal communication July 16,1990

4. Canna, E., "U.S.-Soviet Maritime Agreement, Rules of the Game," Amen"can Shipper 32 (7):14-16, July 1990.

5. Carvounis, C.C. and B.Z. Carvounis, "Economic Competition and Cooperation Between the Soviet Union and the United States in Less-Developed Counties, "Business Economics 25:36-41, January 1990.

6. Central Intelligence Agency, Directorate of Intelligence, Handbook of Economic Statistics, 1989, CPAS 89-10002 (Washington DC: September 1989).

7. Central Intelligence Agency, "Positions on $\mathrm{CO}_{2}$ Emission $\mathrm{Tar}-$ gets," paper prepared for C.S. delegation to Second World Climate Conference (McLean, VA: October 1990).

8. Chandler, W.U. (cd.), Carbon Emissions Control Strategies, Executive Summary (Baltimore, MD: World Wildlife Fund and The Conservation Foundation, 1990).

9. Chandler, W.U. et al., "Energy for the Soviet Union, Eastern Europe and China, "Scientific American 262(9): 120127, September 1990 .

10. Commission of the European Communities, "The Main Findings of the Commission's Review of Member States' Energy Policies,' COM(88) 174 fii vol. II (Brussels: May 3, 1988).

11. Commission of the European Communities, "Energy in Europe, Energy Policies and Trends in the European Community, ' No. 13 (Brussels: May 1989).

12. Commission of the European Communities, "Energy in Europe, Major Themes in Energy," Special Issue (Brussels: September 1989).

13. Conable, B.B., "Remarks by Barber B. Conable, President, World Bank," Conference on Global Environment and Human Response Toward Sustainable Development (Tokyo: Sept. 11, 1989).

14. Congressional Quarterly, "U S.-Soviet Trade Accord: Highlights, " Congressional Quarterly, p. 1776, June 9, 1990.

15. Congressional Quarterly, "GOP Members Boycott Markup of Technical Aid Bill, ” CQ Wee/c/y Report 48(29):2334, July 21, 1990.

16. Cruver, P. C., "Greenhouse Effect Prods Global Legislative Initiatives," IEEE Technology and Society Magazine 9(l): 10-16, March/April 1990.

17. Donaldson, P.J. and C.B. Kc+, "Population and Family Planning: An International Perspective, ' Family Planning Perspectives 20(6):307-31 1,320, November/December 1988.

18. Dreyfus, D.A. and A.B.Ashby, "Fueling Our Global Future," Environment 32(4):16-20,36-41, May 1990.

18a. Embassy of Sweden, Office of Science and Technology, personal communication Jan. 22, 1991.

19. Ember, L. R., 'Pollution Chokes East-Bloc Nations,' Chemical \& Engineering News 68(16):7-16, Apr. 16, 1990.

20, Enterprise Development International, Inc., Energy \& the Environment in Eastern Europe \& the Son" et Union: Current Status \& Policy Recommendations, contract prepared for U.S. Congress, Office of Technology Assessment (Bethesda, MD: Sept. 17, 1990).

21. Export-Import Bank of the United States, "Report on Renewable Energy Support to the Committees on Appropriations Under Sec. 534(d) of the Fcreign Operations, Export Financing, and Related Programs Appropriations Act, 1990, P.L. 101-167" (Washington DC: Apr. 15, 1990).
22. Export-Import Bank of the United States, "Eximbank and A.I.D. Create $\$ 500$ Million Tied-Aid Pool” (Washington, DC: May 15, 1990).

23. Fallenbuchl, Z. M., "Foreign Trade Developments in 1990," Report on Eastern Europe 1(41):25-28, Oct. 12, 1990.

23a. German Bundestag, Protecting the Earth, A Status Report With Recommendations for a New Energy Policy (Bonn: Enquete Commission October 1990)

24. Goldemberg, J. et al., Energy for Development (Washington, DC World Resources Institute, September 1987).

25. Goldemberg, J. et al., Energyfor a Sustainable World (New Delhi: Wiley Eastern Ltd., 1988)

26. Goldemberg, J. "How To Stop Global Warming," Technology Review 93(8):25-31, November/December 1990.

27. Hagler, Bailly \& Co., "Cogeneration in Developing Countries: Prospects and problems," report prepared for U.S. Agency for International Development Bureau for Science and Technology (Washington, DC: May 1986).

27a. Harfield, L.A., "Selling to the B1oc," State Government News 33:14-17, August 1990.

28. Haub, C., *'Understanding Population Projections, "Population Bulletin 42(4): 1-41, December 1987.

29. Haub, C., Population Reference Bureau, personal communication July $17,1990$.

29a. Helland-Hansen, E., paper presented at Global Climate Change: The Economic Costs of Mitigation and Adaptation, Seventh Annual Conference of the Air Resources Information Clearinghouse (Washington DC: Dec. 4-5, 1990).

30. Inter-American Development Bank, "Inter-American Develop ment Bank, Development and the Environment in the 1990s' (Washington, DC: 1990).

31. Intergovernmental Panel on climate Change, Emissions Scenarios, Report of the Expert Group on Emissions Scenarios (RSWG Steering Committee, Task A)(Geneva: Response Strategies Working Group, April 1990).

32. Intergovernmental Panel on Climate Change, Energy and Industry Sub Group Report (Geneva: May 31, 1990).

33. Intergovernmental Panel on Climate Change, Policymakers Summary of the Formulation of Response Strategies (Geneva: Working Group III, June 1990).

34. International Energy Agency, World Energy Statistics and Balances (Paris: OECD, 1989).

35. International Energy Agency, Energy Policies and Programmed of IEA Countries: 1988 Review (Paris: OECD, 1989).

36. International Environmental Bureau, "Presentation to the International Media" (Geneva: July 5, 1989).

37. International Environmental Technology TransferAdvisory Board, Interim Report of the International Environmental Technology Transfer Advisory Board (Washington, DC: May 1990).

38. Isaksen, I. et al., "Report of a United Nations Development Programme Mission to Investigate Ozone Layer Protection in China," CPR/89/029 (Beijing: People's Republic of China, National Environmental Protection Agency, May 28, 1990).

39. Jaszay, T., Carbon Dioxide Emissions Control in Hungary: Case Study to the Year 20.?0, prepared for U.S. Environmental Protection Agency (Richland, WA: Battelle Pacific Northwest Laboratories, May 1990),

40. Khabibullov, M.R. et al., "New Trends in Soviet Environmental Policy," Field Staff Reports, Europe, No. 1, 1990/91.

41. Kolar, S. and W.U. Chandler, "Energy and Energy Conservation in Eastern Europe, ' report prepared for U.S. Agency for International Development (Washington, DC: Battelle Memorial Institute, Pacific Northwest Laboratories, 1990).

42. Korchemkin, M.B., "Energy Aspects of Perestroika," Center for International Energy Studies, Erasmus University (Rotterdam, Netherlands: April 1989).

43. Lawrence Berkeley Laboratory, Argonne National Laboratory, Oak Ridge National Laboratory, Sandia National Laboratory, Solar Energy Research Institute, Los Alamos National Laboratory, 
Pacific Northwest Laboratory, Energy Technology for Developing Countries: Issues for the U.S. National Energy Strategy, prepared for U.S. Department of Energy (Berkeley, CA: Lawrence Berkeley Laboratory, December 1989).

44. Library of Congress, Congressional Research Service, "International Population and Family Planning programs: Issues for Congress," IB85 187 (Washington, DC: Mar. 30, 1990).

45. MacNeil], J. et al., Beyond Interdependence, The Meshing of the World's Economy and the Earth's Ecology, A Report to the Trilateral Commission (Halifax, Canada: Institute for Research on Public Policy, 1990).

46. Macomber, J., "Capitalizing Eastern Europe," The International Economy 4(3):78-80, June/July 1990.

47. Makarov, A.A. and I.A.Bashmakov, The Soviet Union: A Strategy of Energy Development with Minimum Emission of Greenhouse Gases, prepared for U.S. Environmental Protection Agency (Richland, WA: Battelle Pacific Northwest Laboratories, April 1990)

48. Marland, G. et al., Estimates of $\mathrm{CO}_{2}$ Emissions From Fossil Fuel Burning and Cement Manufacturing Using the United Nations Energy Statistics and the US, Bureau of Mines Cement Manufacturing Data, ORNL/CDIAC-25,NDP-030 (Oak Ridge, TN: Oak Ridge National Laboratory, Carbon Dioxide Information Analysis Center, October 1988).

49, Mazurski, K. R., "Industrial Pollution: The Threat to Polish Forests," Ambio 19(2):70-74, April 1990.

50. Merrick, T. W., "World Population in Transition, ' Population Bulletin 41(2): 1-51, January 1988.

51. Meyers, S. and Sathaye, J., "Electricity Use in the Developing Countries: Changes Since 1970, " Energy 14:435-441, 1989.

52. Mike, F. T., "U.S. Assistance to Eastern Europe, " CRS Review 11 (5-6):28-30, May-June 1990,

53. Miller, J. and F. Pearce, ' 'Soviet Climatologist Predicts Greenhouse 'Paradise '," New Scientist 123:24, Aug. 26, 1989.

54. Moore, T., 'Excellent Forecast for Wind,' EPRI Journal 15(4): 14-25, June 1990.

55. Morgan, M.G. and Xiao-lin Xi, ' 'Energizing China: First Itself, Next the World," IEEE Spectrum 26(3):59-63, March 1989,

56. Oak Ridge National Laboratory, Sustained Development and the Global Climate Change Issue, A Preliminary Assessment of Connections with the Programs of the US. Agency for Internarional Development, prepared for the U.S. Agency of International Development, Draft Report (Oak Ridge, TN: June 1990),

57. Oil and Gas Journal, ' 'Study Sees New Flap Over Soviet Gas to Europe," Oil and Gas Journal 85(49):89, Dec. 7,1987.

58. Organization for Economic Co-operation and Development and International Energy Agency, "Summary of Actions in Member Countries to Deal with the Problem of Climate Change (Note by the Secretariat), IEA/SLT(90)5I(1st Revision), draft (Paris: Standing Group on Long-Term Co-operation, Committee for Energy Research and Development Oct. 24, 1990),

59 overseas private Investment Corp., Overseas Private Investment Corporation 1989 Report (Washington, DC: 1989).

60. Overseas Private Investment Corp., "The OPIC Environmental Investment Fund, Executive Summary" (Washington, DC: 1990).

61. overseas Private Investment Corp., "OPIC in Eastern Europe" (Washington, DC: 1990),

62. Pachauri, R. K., "Global Warming: Perspectives on India's Energy Policies and Responses to Climate Change, "pp. 6-1 to 6-11 in D.G. Streets and T.A. Siddiqi (eds.), Responding to the Threat of Global Warming Options for the Pacific andAsia, ANLJEAIS/TM17 (Argonne, IL: Argonne National Laboratory, 1989).

62a. Peterson, D. J., "Bleeding Arteries: Pipelines in the Soviet Union," Radio Liberty Report on the U.S.S.R.2(24):1-3, June 15, 1990.

63. Piddington, K. W., "Sovereignty and the Environment, Part of the Solution or Part of the Problem?" Environment 31(7):18-20,3539, September 1989 , 63a. Piet-Pelon, N., "The finding Controversy, " Foreign Service Journal, pp. 40-44, January 1989.

64. Population Crisis Committee, '4 1990 Report on Progress Towards Population Stabilization," Briefing Paper No. 23 (Washington, DC: 1990).

65. Population Reference Bureau, 1989 World Population Data Sheet (Washington, DC: 1989).

66. Population Reference Bureau, 1990 World Population Data Sheet (Washington, DC: 1990).

67. Population Resource Center, "Population Facts in Brief (Washington, DC: 1989).

68. Pregelj, V. N., “"Most-Favored-Nation Treatment," CRS Review 11(5-6):24-25, May-June 1990.

69. Reid, W., "Sustainable Development Lessons From Success," Environment 31(4):7-35, May 1989.

70. Repetto, R. et al., Wasting Assets: Natural Resources in the National Income Accounts (Washington, DC: World Resources Institute, June 1989).

71. Sadik N., "The State of World Population, 1990" (New York, NY: UN Population Fund, 1990).

72. Sagers, M.J. and A. Tretyakova, Fuel and Energy Use in the Soviet Metallurgy Industries, Center for International Research, U.S. Bureau of the Census, CIR Staff Paper No. 28 (Washington, DC: July 1987).

73. Sagers, M.J. and A. Tretyakova, USSR: Energy Consumption in the Housing and Municipal Sector, C'enter for International Research, U.S. Bureau of the Census, CIR staff paper No. 30 (Washington, DC: September 1987),

74. Salay, J., "Restructuring the Energy System, ' Report on Eastern Europe 1(35): 16-21, Aug. 31, 1990

75. Sathaye, J. et al., "Energy Demand in Developing Countries: A Sectoral Analysis of Recent Trends," Annual Review of Energy 12:253-281, 1987.

76. Sathaye, J. and A. Ketoff, $\mathrm{CO}_{2}$ Emissions from Major Developing Countries: Better Understanding the Role of Energy in the Long Term, Interim Report, LBL-29507 (Berkeley, CA: Lawrence Livermore Laboratory, August 1990).

77. Savinskaya, I., ' 'Threat to the Biosphere,' Sovietskaya Kultura,p 2, Mar, 25, 1989 (reprinted in Joint Publications Research Service-USSR Economic Affairs, May 22, 1989).

78. Schipper, L., "Energy Savings in the U.S. and Other Wealthy Countries: Can the Momentum Be Maintained? " in Energy and the Environment in the 21st Century, conference proceedings (Cambridge, MA: Massachusetts Institute of Technology, Mar 26-28, 1990).

79. Schipper, L. et al., "United States Energy Use From 1973 to 1987: The Impacts of Improved Efficiency,' Annual Review of Energy $15: 455-504,1990$

80. Schipper, L. and A. Lichtenberg, "Efficient Energy Use and Well Being: The Swedish Example, " Science 197: 1001-1013, Dec. 3, 1976.

81. Sitnicki, S. et al., Poland: Opportunities for Carbon Emissions Control, prepared for U.S. Environmental Protection Agency (Richland, WA: Battelle Pacific Northwest Laboratories, May 1990).

82. Sklar, S., U.S. Export Council for Renewable Energy, personal communication July 26, 1990.

83. Smuckler, R.H. et al., New Challenges, New Opportunities, U.S Cooperation for International Growth and Development in the 1990s (East Lansing, MI: Michigan State University, Center for Advanced Study of International Development, August 1988).

84. Sobell, v., "CoCorn Agrees on Significant Liberalization," Report on Eastern Europe 1:53-57, July 27, 1990.

85. Solomon, A.M. and J.E. Mroz, "Prague's Plan to Aid Moscow," New York Times, p. 19, July 10, 1990.

86. Swedish Ministry of the Environment, "Swedish Parliament Decides to Introduce Carbon-Dioxide 'I\%" (Stockholm: June 25, 1990) 
87. Tarnoff, C., "Eastern Europe and the Environment," CRS Review 11(3-4):29-31, March-April 1990.

88. Tugwell, F., Pacific Gas \& Electric Enterprises, remarks at OTA Workshop on "The U. S., Developing Countries, and Global warming" (Washington, DC: Sept. 13, 1989),

89. U.N. Department of International Economic and Social Affairs, Prospects of World Urbanization, 1988, Population Studies No. 112, ST/ESA/SER.A/112 (New York: 1989).

90. U.N. Development Programme, "Environmental Dimensions of Development: Commitment and Progress in 1989, Report of the Administrator," DP/1990/27 (Geneva: April 1990).

91. U.N. General Assembly, "Resolution 44/228, United Nations Conference on Environment and Development" (New York, NY: Dec. 22, 1989).

92. U.N. Population Fund, Glotral Population Assistance Report, 1982 -1988 (New York, NY: 1989).

93. U.S. Agency for International Development, Power Shortages in Developing Countries: Magnitude, Impacts, Solutions, and the Role of the Private Sector, A Report to Congress (Washington DC: March 1988).

94. U.S. Agency for International Development, Renewable Energy for Agriculture and Health (Washington DC: May 1988).

95. U.S. Agency for International Development Development and the National Interest: U.S. Economic Assistance into the 21st Century (Washington, DC: February 1989).

96. U.S. Agency for International Development, Energy Conservation Investment Decisionmaking in Developing Countries: A Review of Project Implementation in Industry, report no. 89-16, prepared by RCB/Hagler, Bailly, Inc. (Washington, DC: Bureau for Science and Technology, December 1989).

97. U.S. Agency for International Development, Congressional Presentation, FY 1991, Main Volume (Washington, DC: U.S. Government printing Office, February 1990).

98. U.S. Agency for International Development Congressional Presentation, FY 1991, Annex 11, Asia, Near East and Europe (Washington, DC: U.S. Government printing Office, February 1990).

99. U.S. Agency for International Development "Initiative on the Environment' (Washington, DC: Working Group on the Environment, May 1990).

100. U.S. Congress, House Committee on Ways and Means and Senate Committee on Finance, Summary of Senate Amendments to H.R 10710, Trade Act of 1974, Conference Committee Report (Washington, DC: U.S. Government Printing Office, Dec. 16, 1974).

101. U.S. Congress, Office of Technology Assessment, World Population and Fertility Planning Technologies: The Next 20 Years, OTA-HR-157(Springfield, VA: National Technical Information Service, February 1982).

102. U.S. Congress, Office of Technology Assessment, Grassroots Development: The African Development Foundation, OTA-F-378 (Springfield, VA: National Technical Information Service, June 1988).

103. U.S. Congress, Office of Technology Assessment, Energy Use and the U.S. Economy, Background Paper, OTA-BP-E-57 (Washington, DC: U.S. Government Printing Office, June 1990).

104. U.S. Congress, Office of Technology Assessment, Energy in Developing Countries, OTA-E 486 (Washington DC: U.S. Government Printing Office, January 1991).

105. U.S. Department of Commerce, Bureau of the Census, World Population Profile: 1989, WP-89 (Washington DC:U.S.Government Printing Office, September 1989).

106. U.S. Department of Energy, International EnergyAnnual, DOWEIA)219(88) (Washington DC: Energy Information Administration November 1989).

107. IU.S. Department of Energy, Indicators of Energy Efficiency: An linternational Comparison, ELA Service Report, SR/EMEU/90-02 (Washington, DC: Energy Information Adminstration, July 1990).

108. IJ.S. Department of State, "U.S. Concept Paper on Technology Assistance, Development, and Transfer Measures,' paper pre- pared for Intergovernmental Panel on Climate Change Response Strategies Working Group Meeting, Oct. 2-6, 1989 (Washington, DC: Aug. 15, 1989)

109. U.S. Department of State, 'Legal/Institutional Mechanisms Paper,' paper prepared for Intergovernmental Panel on Climate Change Response Strategies Working Group Meeting, Oct. 2-6, 1989 (Washington, DC: Aug. 15, 1989).

110. U.S. Environmental Protection Agency, Office of Policy, Planning and Evaluation, Policy Options for Stabilizing Global Climate, Executive Summary, Draft Report to Congress (Washington, DC: February 1989).

111. U.S. Environmental Protection Agency, "International Technology Transfer Activities' (Washington DC: Office of International Activities, July 1990).

112. U.S. Export Council for Renewable Energy, Energy Lending at The World Bank and Inter-Amen"can Development Bank (Arlington, VA: January 1990).

113. U.S. International Development Cooperation Agency, Congressional Presentation, FY 1991 (Washington DC: U.S. Government Printing Office, February 1990).

114. U.S. International Trade Commission, Trade Between the United States and the Nonmarket Economy Countries During JanuaryMarch 1990, USITC Publication 2302 (Washington DC: August 1990).

115. Vanderryn, J., "U.S. Agency for International Development: Renewable Energy Programs and Other Responses to Climate Change Concerns," paper presented at Forum on Renewable Energy and Climate Change (Washington DC: U.S. A.I.D., June 14-15, 1989).

116. Vanderryn, J., U.S. Agency for International Development, remarks at OTA Workshop on "The U. S., Developing Countries, and Global Warming" (Washington, DC: Sept. 13, 1989).

117. Vorontsov, N., Director, U.S.S.R. State Committee for the Protection of Nature, interview with OTA (Washington DC: Aug. $18,1989)$

118. Vukmani'c, F., U.S. Department of Treasury, remarks at OTA Workshop on "The U.S., Developing Countries, and Global Warming" (Washington, DC: Sept. 13, 1989).

119. Wilbanks, TJ., "The Outlook for Electricity Efficiency Improvements in Developing Countries, ' manuscript (Oak Ridge, TN Oak Ridge National Laboratory, May 1990).

120. Wilbanks, T.J., "Implementing Environmentally Sound Power Sector Strategies in Developing Countries, " manuscript (Oak Ridge, TN: Oak Ridge National Laboratory, 1990).

121. Wilbanks, T.J., Oak Ridge National Laboratory, personal communication, July 25, 1990.

122. Wilson, D., 'Quantifying and Comparing Fuel-Cycle GreenhouseGas Emissions: Coal, Oil and Natural Gas Consumption' Energy Policy 18(6):550-562, July/August 1990.

123, Wisniewski, J., Export-Import Bank, Remarks at OTA Workshop on "The U. S., Developing Countries, and Global Warming" (Washington, DC: Sept. 13, 1989).

124. World Bank, End-Use Electricity Conservation: Options for Developing Countries, Energy Department Paper No. 32 (Washington, DC: October 1986).

125. World Bank, World Development Report 1987 (Washington, DC: 1987).

126. World Bank, Recent WorldBank Activities in Energy, Industry and Energy Department Working Paper, Energy Series Paper No. 7, revised edition (Washington, DC: September 1988).

27. World Bank, World Development Report 1989 (Washington, DC: 1989).

28. World Bank, "World Bank Support for the Environment: A Progress Report," Development Committee Pamphlet No. 22 (Washington, DC: September 1989).

29. World Bank, People and Trees, The Role of Social Forestry in Sustainable Development, EDI Seminar Series (Washington, DC: 1989). 
130. World Bank, "Funding for the Global Environment" discussion paper (Washington DC: February 1990).

131. World Bank, Energy Sector Management Assistance Program, ESMAP Information and Status Report (Washington DC: March 1990).

132. World Bank, World Development Report 1990 (Washington, DC: 1990).

133 World Bank, "Funding for the Global Environment, 1. Framework for Program Design and Allocation Criteria, Discussion Notes"
(Washington, DC: May 1990).

134. World Commission on Environment and Development, Our Common Future (Oxford: Oxford University Press, 1987).

135. World Resources Institute, Wasting Assets: Natural Resources in the National Income Accounts (Washington, DC: June 1989).

136. World Resources Institute, Natural Endowments: Financing Resource Conservation for Development (Washington DC: Sep tember 1989). 


\section{Appendixes}




\section{Introduction to the OTA $\mathrm{CO}_{2}$ Emissions Model}

OTA developed a simple energy accounting model that allows us to estimate the effectiveness of various technical options for lowering $\mathrm{CO}_{2}$ emissions. The model is based on a much larger system of energy and economic models used by the Gas Research Institute (GRI) to forecast energy use through 2010 (19).

Of all the integrated energy/economic forecasting models that we reviewed, GRI's includes the greatest detail on energy demand by specific technologies. Estimates of total residential electricity demand, for example, include breakdowns by heating, cooling, refrigerators, freezers, clothes dryers, etc. Thus, we are able to simulate the potential for lowering $\mathrm{CO}_{2}$ emissions through specific changes in technology.

To do this, we first built a very much simplified set of models based on detailed output from GRI model simulations of energy use through 2010. For example, to estimate the energy demand for heating homes, GRI estimated the number of existing furnaces, heat pumps, and electric heaters and forecast the number that must be replaced through time (with more efficient technology) based on typical equipment lifetimes. The number of new homes to be heated is forecast based on economic conditions. Whether consumers buy gas, oil, or electric heaters is forecast in part based on economics and in part on historical buying habits.

OTA's simplified models simulate the number and energy efficiency of each technology type (e.g., gas furnaces) through time, based only on the GRI detailed output data, not on the economic decisions that influence the forecast. For two categories--highway vehicles and electric utilities-we felt that the GRI model did not have adequate detail for our needs. For highway vehicles, we used Oak Ridge National Laboratory's “Alternative Motor Fuel Use Model" (27), but used GRI's oil price assumptions for consistency. For electric utilities, we built our own model using detailed data from the Energy Information Administration.

We total all the energy use and $\mathrm{CO}_{2}$ emissions from each technology category in all sectors, which yields our Base case forecast of emissions approximately 50 percent above today's level by 2015. For our Base case, OTA implicitly assumes GRI's forecast of Gross National Product (GNP) growth (averaging 2.3 percent per year) and energy price increases (averaging 1.7 percent per year for coal, 3.7 percent per year for oil, and 4.8 percent per year for natural gas) over the next two decades. These estimates are reasonable, barring major changes in energy supply, economic, or regulatory conditions. We specify two alternatives to the Base case-the "Moderate' and "Tough" scenarios, discussed in later sections. These incorporate the effect that changes in technology or policy could have on future energy use and $\mathrm{CO}_{2}$ emissions.

Our model, for the most part, assumes the same level of ' 'services' as the GRI base case. In the alternative scenarios, $\mathrm{CO}_{2}$ emissions are reduced, for example, by using more efficient furnaces, by switching fuel, or by insulating houses but not by assuming people keep their homes at lower temperatures in the winter or air-condition less in the summer than they currently do. In a few cases, most notably the transportation options, all "services' are not identical. For example, we consider the effect of reinstating a $55 \mathrm{mph}$ speed limit. Under our most aggressive scenario, we assume that cars will be somewhat smaller than they are today (due to either economic incentives or fuel economy regulations). Both changes include some loss of amenity to consumers; however, the "service" (number of miles traveled in reasonably similar cars at highway speeds) remains quite similar.

\section{U.S. Energy Consumption and $\mathrm{CO}_{2}$ Emissions}

Total U.S. energy consumption in 1989 was about 84 quads. As discussed in detail in chapter 3, oil provided about 40 percent of this, coal and gas about 23 percent each, nuclear power 7 percent, and hydroelectric power and biomass about 3 percent each. ${ }^{2}$

Currently about 20 percent of $\mathrm{CO}_{2}$ emissions result from activities within our homes and apartments; 16 percent come from commercial buildings. About onethird of these emissions are from fossil fuels burned within residential and commercial buildings; two-thirds comes from electricity use within them. About 32 percent of emissions are transportation related and 32 percent come from industry (table A-1).

1 The GRI modeling system has as its core the DRI U.S. Energy Model, developed by Data Resources, Inc. (DRI) The model includes four submodels: the industrial sector, residential buildings sector, commercial buildings sector, and electric utilities. Economic projections, which drive the Energy Model, come from the DRI Macroeconomic Model of the U.S. economy. Additional inputs are generated from the Industrial Sector Technology Use Model, developed by Energy and Environmental Anatysis, Inc.; the GRI Hydrocarbon Supply Model; and the RDI Coal Model, developed by Resource Data International.

${ }^{2}$ Data for 1989 energy consumption, except for biomass fuels, is from ref. 33a. 
Table A-I-Carbon Emissions by Activity (percent of 1987 emissions)

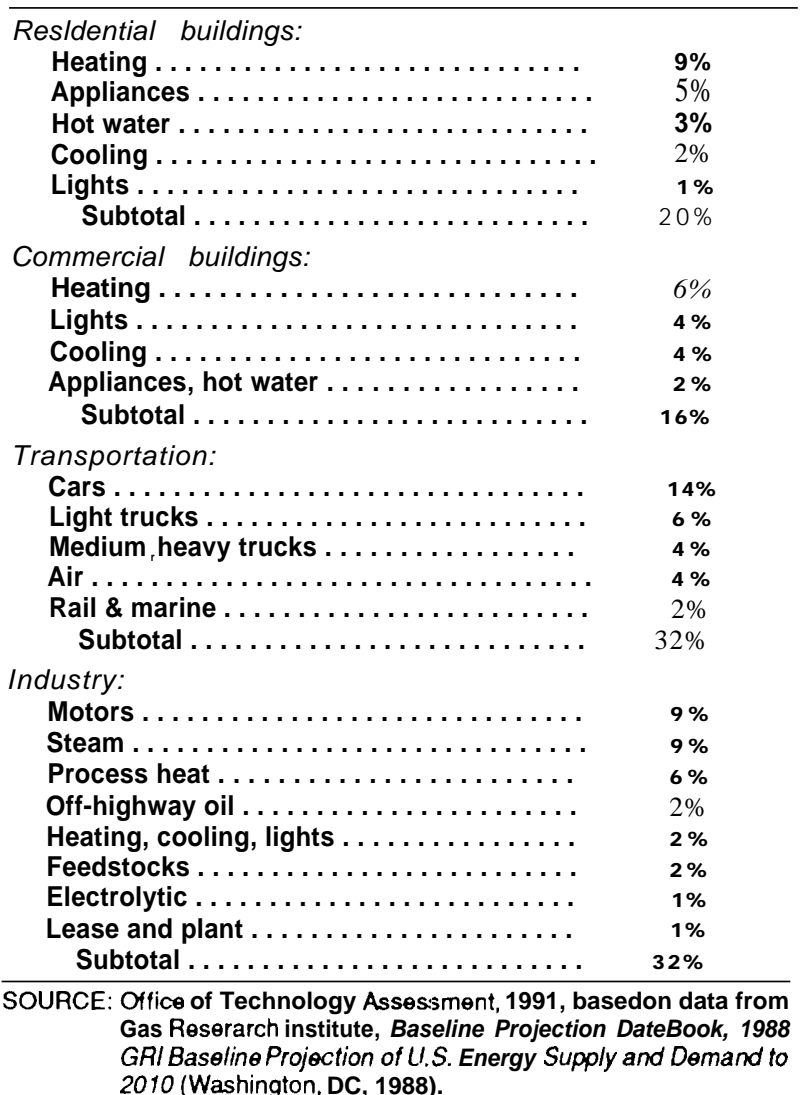

About 9 percent of total U.S. $\mathrm{CO}_{2}$ emissions comes from heating our homes and another 6 percent from heating our stores and offices. About 5 percent comes from cooling buildings and another 5 percent from lighting them. Such major home appliances as refrigerators, stoves, washing machines, dryers, freezers, and dishwashers each contribute close to a percent, totaling about 5 percent occurrent emissions.

About 20 percent of emissions comes from passenger cars and light-duty trucks. Freight (truck, rail, and ship) accounts for about 10 percent of U.S. $\mathrm{CO}_{2}$ emissions. Within industry, steam and process heat used in the basic materials industries (e.g., metals, chemicals, and petro- leum refining) account for about 15 percent of $\mathrm{CO}_{2}$ emissions. Electric motors on pumps, fans, and compressors are responsible for another 9 percent.

Carbon emissions can also be categorized by consumer purchases (table A-2). ${ }^{3}$ About half of $\mathrm{CO}_{2}$ emissions originate from the energy we purchase and use directly to heat our homes, run our appliances and lights, fill the gas tanks of our cars, and so on. The remainder originate from the products and services that we buy-the energy to manufacture cars, furniture, electronic equipment; to process food items; and to heat and light the stores in which we shop. As an example of the carbon emissions associated with consumer purchases, consider 100 dollars' worth of clothing. About half this amount goes for the retailers' markup, the other half goes to various manufacturers primarily within the apparel industry. Using the carbon intensities in table A-2, we can estimate that about $60 \mathrm{lbs}$ of carbon were associated with the purchase of those clothes: $35 \mathrm{lbs}$ to manufacture them ${ }^{4}$ and $25 \mathrm{lbs}$ to operate the store in which they are sold.

\section{Emissions Scenarios}

\section{The OTA Base Case}

OTA's Base case can be compared to several other recent forecasts (figure A-1). These include a high- and low-growth scenario developed by the Environmental Protection Agency (EPA) (34), high- and low-growth scenarios developed by the Energy Information Administration (EIA) (33), and a base case forecast developed by GRI (from which the OTA scenario was developed) (14). We generated estimates of $\mathrm{CO}_{2}$ emissions from EIA and GRI forecasts of fuel consumption.

Note that our Base case predicts higher emissions than the GRI model, which forecasts the demand for energy from current goods and services. However, just as 10 years ago such a "bottom up" forecast would have missed the demand for electricity from personal computers and FAX machines, so too is the GRI forecast likely to miss demand from new products by 2010 . Thus for our Base case we added an increment of demand for electricity to the GRI forecast. ${ }^{5}$ Our demand growth forecast is similar to others (i.e., EIA's) that use a statistical (' 'top down' approach based on recent economic and energy use trends.

\footnotetext{
${ }^{3}$ Carbon emissions from consumer purchases account for about two-thirds of total U.S. emissions in the accounting scheme that we used. Of the remainder, about one-quarter was associated with exports, onequarter with government purchases, and half with private investment in capital goods and structures. See the manufacturing chapter (ch. 6) for details on the analytical methods used to derive these estimates.

${ }^{4}$ The carbon $(\mathrm{C})$ intensity of the apparel industry is about ()$, 7 \mathrm{lbs} \mathrm{C} / \$$ and that of retail trade is about $0.5 \mathrm{lbs} \mathrm{C} / \$$. Thus, $\$ 50 \times 0.7 \mathrm{lbs} \mathrm{C} / \$$ for the garment plus $\$ 50 \times 0.5 \mathrm{lbs} \mathrm{C} / \$$ for operating the store totals $60 \mathrm{lbs}$ of carbon.

${ }^{5}$ The GRI model forecasts that electricity demand will increase at about 1.5 percent per year through 2010 . In our analysis, we added an extra increment of unspecified demand- 0,75 percent per year in the base case - for a total growth in electricity demand of about 2.25 percent per year. Under our Moderate demand scenario, we add an extra 0.56 percent per year increment of unspecified electricity dernand and under our Tough scenario we add 0,38 percent per year.
} 
Table A-2-Carbon Emissions From Goods and Services: Household Purchases Only

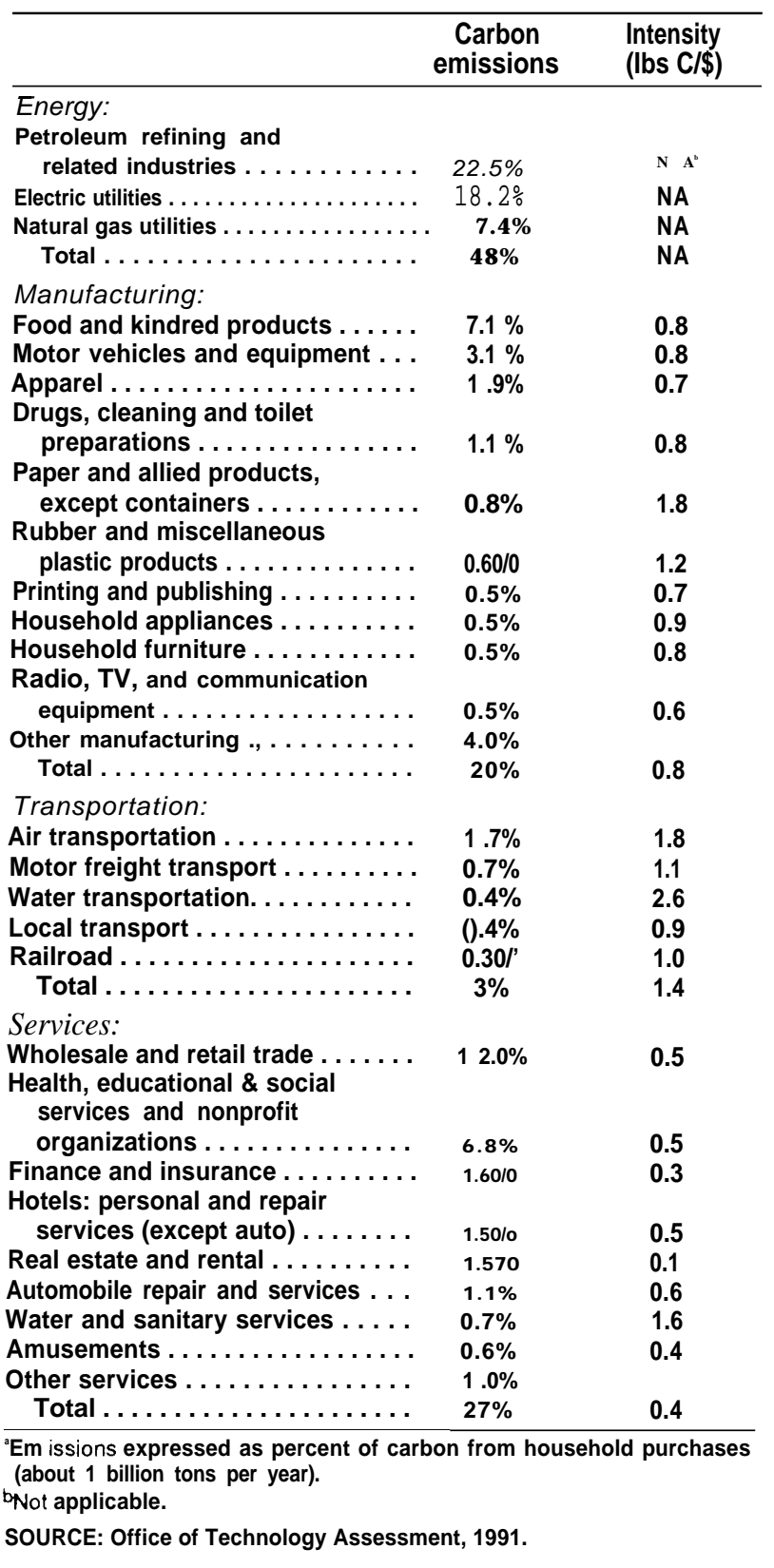

\section{Alternative Emission Scenarios}

Under our Moderate scenario of energy demand, technical measures are adopted that initially require some additional capital investment but save money on fuel. Over the life of the investment, these measures typically save money or, in some cases, are of modest cost. None of the measures are technically difficult to achieve, though getting people to use them may not be easy.

\section{Figure A-I-Comparison of Base Case Forecasts of U.S. Carbon Emissions}

\section{6}

Billion metric tons/year

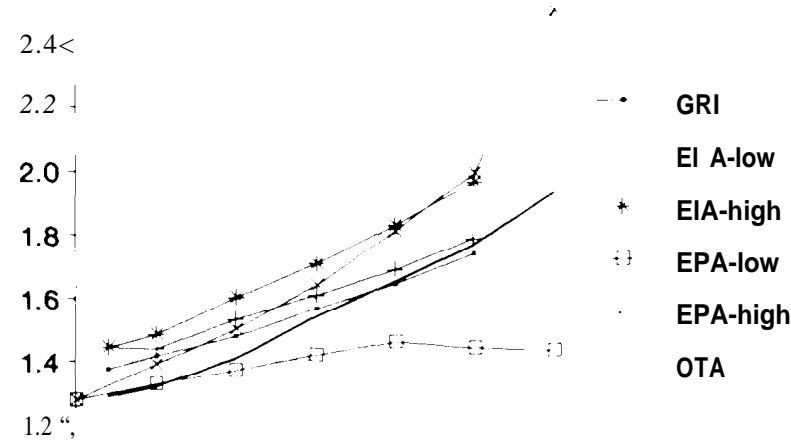

1.0

1985199019952000200520102015

SOURCE: Office of Technology Assessment, 1991, calculated using energy demand forecasts in: Holtberg.P.D. et al., 1988 GRI Baseline Projection of U. S. Energy Supply and Demand to20 10 (Chicago, IL: Gas Research Institute, 1988); U.S. Department of Energy, Annual Energy Outiook 1990, DOE/EIA-0383(90) (Washington, DC: Energy Information Administration, January 1990); and U.S. Environmental Protection Agency, Office of Policy, Planning and Evaluation, Policy Options for Stabilizing Global Climate, Draft Report to Congress (Washington, DC: June 1990).

The Tough scenario measures can lower energy demand even further, but they are either technically difficult or will cost more for the same or similar service. We feel that all of the measures are technically feasible, though many will be challenging to implement. In most cases, the performance of the technology is less than that achievable by the best available prototypes, because we attempt to make judgments about what will be feasible in widespread use.

\section{Overall Modeling Results}

Figure A-2 presents the results of our energy modeling analysis. Under our Base case (upper line), by 2015 emissions are forecast to increase by close to 50 percent above today's level of about 1.5 billion metric tons of carbon per year. A series of Moderate control measures imposed on both the demand side and the supply side (utilities) can lower emissions to about 15 percent above today's levels by 2015 .

Moderate demand-side measures along with Tough supply-side measures results in holding emissions to just about current levels by 2015 . Tough demand-side measures along with Moderate supply-side measures can lower emissions to about 20 percent below current levels by 2015. Finally our most stringent scenario--Tough demandside and Tough supply-side measures--can lower emissions to 29 percent below today's levels by 2015 . Note that under this scenario, $\mathrm{CO}_{2}$ emissions are about half of 
Figure A-2-Carbon Emissions Under the OTA Scenarios, Energy Measures Only

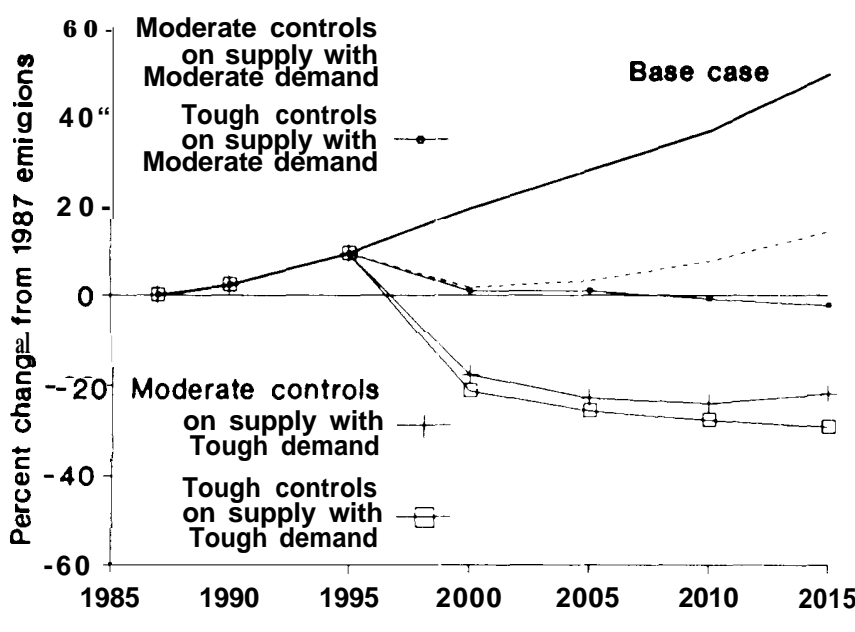

SOURCE: Office of Technology Assussment, 1991.

our Base case forecast for 2015 (i.e., 0.9 billion v. 1.9 billion metric tons of carbon per year).

Figure A-2 incorporates only those measures that lower emissions of $\mathrm{CO}_{2}$ and does not include options for removing additional $\mathrm{CO}_{2}$ from the atmosphere and storing it in biomass. Figure A-3 includes all the energy-related measures discussed above and adds forestry measures that can remove $\mathrm{CO}_{2}$ (and in some cases lower fossil fuel use as well). On this graph, we show three scenarios: 1) Base case emissions, 2) emissions assuming all Moderate energy measures minus the carbon offset by Moderate forestry measures, and 3) emissions after all Tough energy measures minus the carbon offset by Tough forestry measures. Under the most stringent scenario, effective 2015 "emissions" (after accounting for the offset from forestry practices) are 37 percent below current levels. This is about 55 to 60 percent below our Base case forecast for 2015.

Figure A-4 displays the effect of these measures as a percentage of all the major greenhouse gas emissions $\left(\mathrm{CO}_{2}\right.$, chlorofluorocarbons (CFCs), nitrous oxide, and methane). ${ }^{6}$ The decline in emissions other than $\mathrm{CO}_{2}$ is primarily due to banning CFCs under the Montreal protocol and the Clean Air Act (see ch. 2).

\section{Results by Sector}

Figures A-5, A-6, and A-7 show the change in energy-related in carbon emissions under each of our scenarios by sector: residential and commercial buildings, transportation, and industry. As noted, current emissions from the three sectors are roughly equal: 36
Figure A-3-Carbon Emissions Under the OTA Scenarios, Including Uptake From Forestry Measures

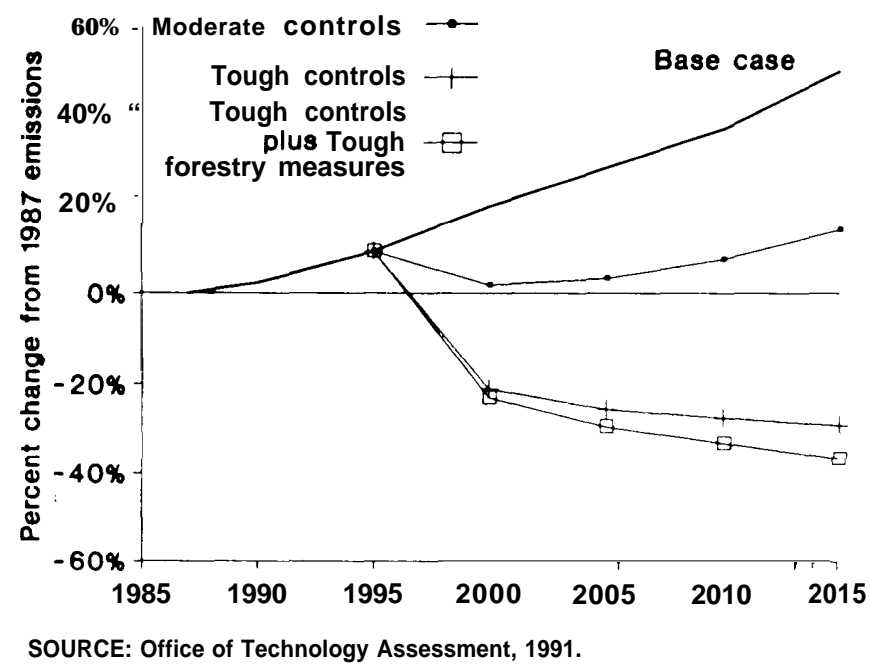

Figure A-4-Greenhouse Gas Emissions Under the OTA Scenarios, Including Carbon Dioxide, Chlorofluorocarbons, Methane, and Nitrous Oxide

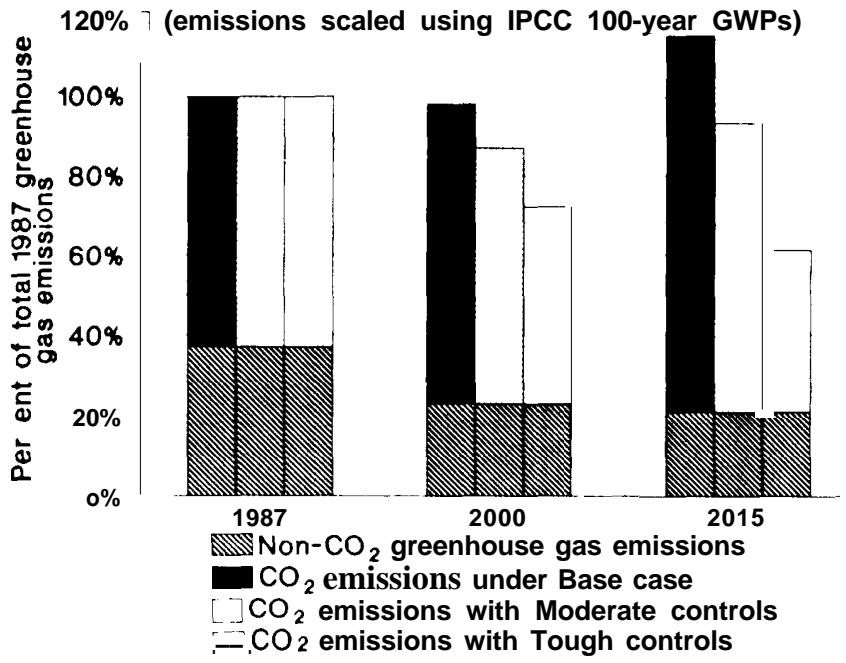

SOURCE: Office of Technology Assessment, 1991. Estimates of CFC emissions from J. Wasson, ICF Inc., personal communication, Aug. 30, 1990. Estimates of methane and nitrous oxide emissions from A. Cristofaro, Air and Energy Policy Division, "The Cost of Reducing Greenhouse Gas Emissions in the United States" (Washington, DC: U.S. Environmental Protection Agency, 1990).

\footnotetext{
${ }^{6}$ To compare the effects of the various greenhouse gases, we have used the 100 year "global warming potential" (GWP) discussed in ch. 2.
} 
Figure A-5-Carbon Emissions From Buildings Under the OTA Scenarios

\section{Buildings}

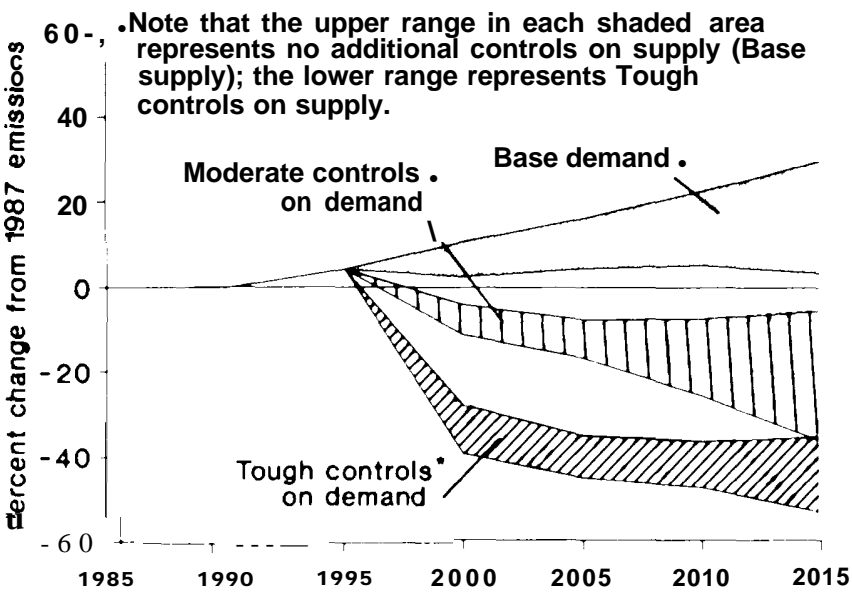

SOURCE: Off Ice of Technology Assessment, 1991.

Figure A-6-Carbon Emissions From Transportation Under the OTA Scenarios

Transportation

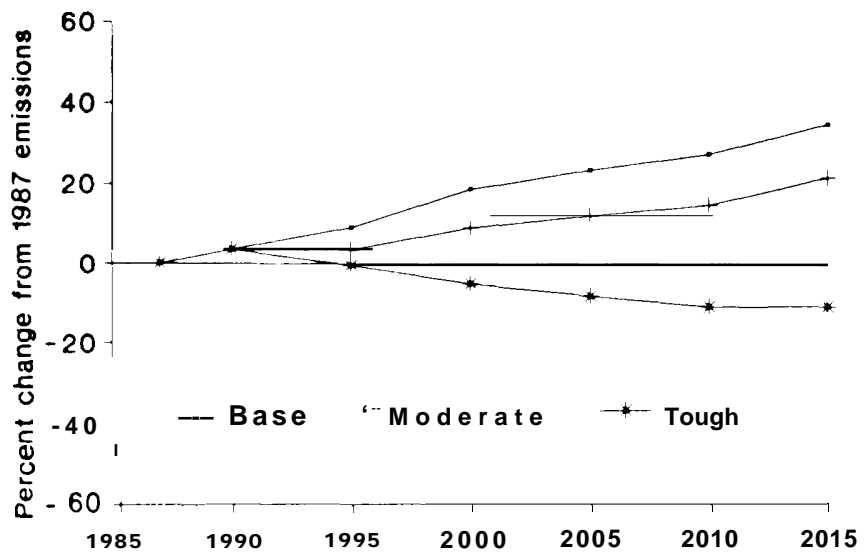

SOURCE: Office of Technology Assessment, 1991

percent from buildings, 32 percent from transportation, and 32 percent from industry. Each of the figures includes three bands illustrating the effect of demand-side changes within each sector. The top band is the Base case, the middle band shows the effect of the Moderate measures, and the lower band displays emissions with implementation of all the Tough measures within the sector. Within each band, the upper end assumes that utilities will continue to generate electricity as they do under the Base case; the lower end of the range assumes that utilities will adopt a series of Tough measures to lower COs emissions per kilowatt-hour of electricity generated.

\section{Figure A-7-Carbon Emissions From Industry Under the OTA Scenarios \\ Industry}

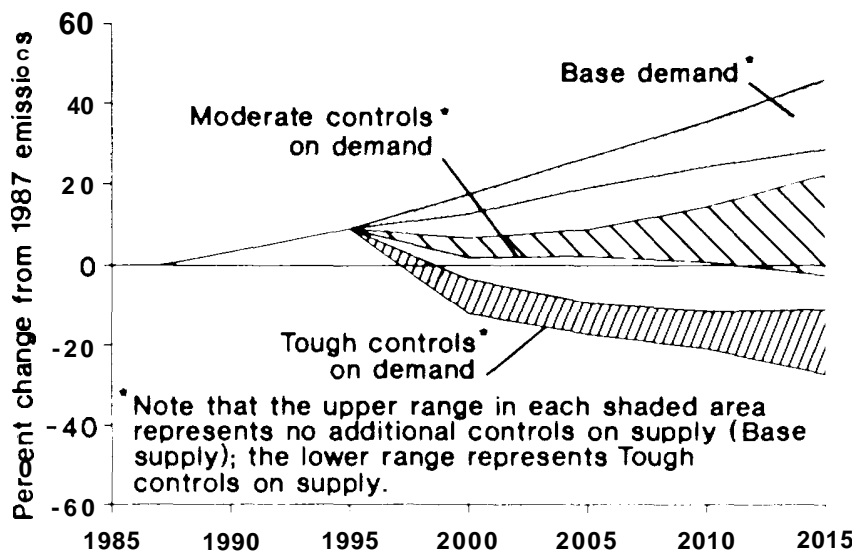

SOURCE: Office of Technology Assessment, 1991.

Under the Base case demand for energy in residential and commercial buildings (figure A-5), emissions will increase by 5 to 30 percent by 2015 (depending on what actions are taken by electric utilities). By adopting all of our Moderate scenario measures for buildings, emissions by 2015 might decline by 5 to 35 percent below their current levels. The Tough measures might lower emissions to 35 to 55 percent below their current levels. Utility measures have such a large impact on this sector because about two-thirds of the carbon emitted as a result of energy use within buildings comes from powerplant stacks.

Transportation emissions (figure A-6) are the most difficult to control. Under our Base case, emissions go up by about 35 percent. After applying all Tough measures, emissions drop to about 10 percent below current levels. Because such a small fraction of our transportation system uses electricity, we have not shown the effect of utility measures.

Industrial emissions (figure A-7) range from a 45percent increase by 2015 under the Base case to a 25-percent drop after applying all the Tough measures.

\section{Reductions by Technical Option}

In this report we express all reductions as a percent of current (1987) emissions. One "percent of current emissions' is equal to 13 million metric tons of carbon. To hold emissions at current levels, we must achieve reductions by 2015 equal to 50 percent of current emissions; this means reducing emissions expected under Base-case forecasts by about 650 million tons per year. To lower emissions to 20 percent below current levels by 
Table A-3-Measures to Lower U.S. Carbon Emissions

(expressed as percentage of 1987 total emissions)

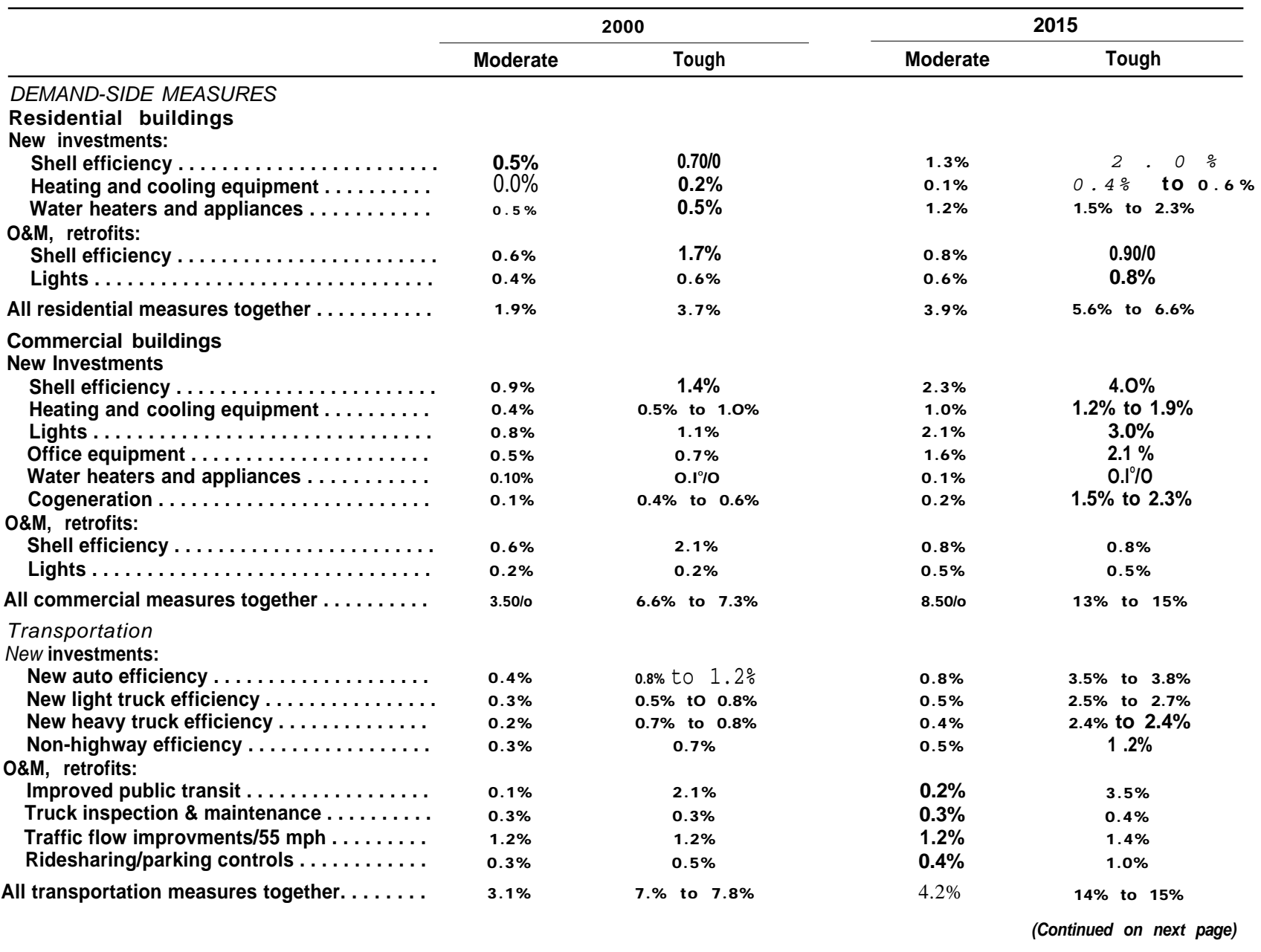

2015 , we must achieve reductions equal to 70 percent of current emissions.

Measures were identified through technical reviews by OTA staff and contractors and through a series of workshops.

\section{Buildings}

For buildings (ch. 4), improved shell efficiency and lighting are two of the largest measures (see table A-3). Under the Base case, we assume that by 2015, new homes and apartments will be designed such that they need about 15 percent less heat and 8 percent less air-conditioning than current new homes. By adopting Moderate shell efficiency measures, such as thicker insulation and better windows, we estimate that new homes will require 50 percent less heat and 25 percent less air-conditioning than today's average new home (23). With Tough measures, we estimate that homes can be built to require 85 percent less heat and 45 percent less air-conditioning (17). Moderate shell improvements in new residential buildings can reduce carbon emissions by 1.3 percent of current levels by 2015. Adopting Tough measures in the North (and Moderate ones in the South) might achieve reductions of 2.0 percent. Tough measures for new commercial buildings can achieve reductions equal to 4 percent of 1987 levels by 2015 .

Existing homes can also be made more efficient by installing insulation, new windows, and so forth. Under our Base case, we assume that existing homes will require 10 percent less heating and cooling by 2015 because of replacements and improvements that will happen in any case. Moderate measures boost this to 20 percent by 2015 and Tough measures boost it to 30 percent by 2000 (18). Tough measures in the North and Moderate ones in the South would reduce carbon emissions by 1.7 percent by 2000; this would drop to about half that amount by 2015 as many older homes are replaced by new ones. 
Table A-3-Measures to Lower U.S. Carbon Emissions-Continued (expressed as percentage of 1987 total emissions)

\begin{tabular}{|c|c|c|c|c|}
\hline & \multicolumn{2}{|c|}{2000} & \multicolumn{2}{|c|}{2015} \\
\hline & Moderate & Tough & Moderate & Tough \\
\hline \multicolumn{5}{|l|}{ DEMAND-SIDE MEASURES } \\
\hline \multicolumn{5}{|l|}{$\begin{array}{l}\text { Industry } \\
\text { New investments: }\end{array}$} \\
\hline 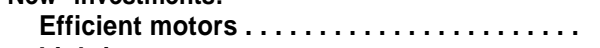 & $0.3 \%$ & $1.0 \%$ to $1.1 \%$ & $1.2 \%$ & $3.7 \%$ to $4.0 \%$ \\
\hline Lighting $\ldots \ldots \ldots \ldots \ldots \ldots \ldots \ldots \ldots$ & $0.1 \%$ & $0.2 \%$ & $0.5 \%$ & $0.7 \%$ to $0.8 \%$ \\
\hline Process change, top 4 industries . . . . . . & $0.7 \%$ & $2.2 \%$ & $3.0 \%$ & $8.2 \%$ \\
\hline Fuel switch to gas $\ldots \ldots \ldots \ldots \ldots \ldots \ldots \ldots$ & $0.0 \%$ & $0.5 \%$ to $0.7 \%$ & $0.0 \%$ & $2.4 \%$ to $2.7 \%$ \\
\hline Cogeneration $\ldots \ldots \ldots \ldots \ldots \ldots \ldots \ldots$ & $0.3 \%$ & $1.1 \%$ to $1.4 \%$ & $0.8 \%$ & $5.2 \%$ to $5.8 \%$ \\
\hline O\&M, retrofits: & & & & \\
\hline Housekeeping $\ldots \ldots \ldots \ldots \ldots \ldots \ldots$ & $0.6 \%$ & $1.5 \%$ & $1.9 \%$ & $2.0 \%$ \\
\hline Lighting $\ldots \ldots \ldots \ldots \ldots \ldots \ldots \ldots$ & $0.1 \%$ & $0.1 \%$ & $0.1 \%$ & $0.2 \%$ \\
\hline All industry measures together $\ldots \ldots \ldots \ldots$ & $2.2 \%$ & $6.1 \%$ to $6.7 \%$ & $7.6 \%$ & $17 \%$ to $18 \%$ \\
\hline \multicolumn{5}{|l|}{$\begin{array}{l}\text { UTILITY SUPPLY-SIDE MEASURES } \\
\text { Existing plant measures: }\end{array}$} \\
\hline Improved nuclear utilization $\ldots \ldots \ldots \ldots \ldots$ & $1.3 \%$ & $1.3 \%$ & $4.1 \%$ & $4.1 \%$ \\
\hline Fossil efficiency improvements . . . . . . . . & $1.7 \%$ & $1.7 \%$ & $1.7 \%$ & $1.7 \%$ \\
\hline Upgraded hydroelectric plants . . . . . . . . . & $0.6 \%$ & $0.6 \%$ & $0.5 \%$ & $0.5 \%$ \\
\hline Natural gas co-firing $\ldots \ldots \ldots \ldots \ldots \ldots$ & 一 & $3.7 \%$ & - & $3.7 \%$ \\
\hline \multicolumn{5}{|l|}{ New plant measures: } \\
\hline $\begin{array}{l}\text { No new coal higher fraction of new } \\
\text { nonfossil sources } \ldots \ldots \ldots \ldots \ldots \ldots\end{array}$ & - & $0.0 \%$ & - & $0.0 \%$ to $4.7 \%$ \\
\hline $\mathrm{CO}_{2}$ emission rate standards $\ldots \ldots \ldots \ldots \ldots$ & $0.0 \%$ & $0.0 \%$ & $0.4 \%$ & $0.0 \%$ to $0.1 \%$ \\
\hline All utility measures together $\ldots \ldots \ldots \ldots \ldots$ & $3.4 \%$ & $6.50 / 0$ & $6.6 \%$ & $9.9 \%$ to $14 \%$ \\
\hline \multicolumn{5}{|l|}{$\begin{array}{l}\text { FORESTRY MEASURES } \\
\text { Afforestation: }\end{array}$} \\
\hline Conservation Reserve Program . . . . . . . . & $0.2 \%$ & $0.2 \%$ & $0.2 \%$ & $0.2 \%$ \\
\hline Urban trees... $\ldots \ldots \ldots \ldots \ldots \ldots \ldots \ldots$ & 一 & $0.1 \%$ & - & $0.7 \%$ \\
\hline Additional tree planting $\ldots \ldots \ldots \ldots \ldots$ & - & $0.6 \%$ & - & $2.3 \%$ \\
\hline Increased tree productivity $\ldots \ldots \ldots \ldots \ldots \ldots$ & - & $0.8 \%$ & - & $3.1 \%$ \\
\hline Increased use of biomass fuels.... . . . . . . & . & $0.3 \%$ & - & $1.2 \%$ \\
\hline All forestry measures together $\ldots \ldots \ldots \ldots$ & $0.2 \% 0$ & $2.0 \%$ & $0.2 \%$ & $7.5 \%$ \\
\hline
\end{tabular}

SOURCE: Office of Technology Assessment, 1991

Improving the efficiency of lighting in commercial buildings is another technical option that can yield substantial reductions. Our Tough measures-a combination of high-efficiency fluorescent bulbs and ballasts, improved reflectors, and better use of daylight--can lower lighting energy needs by 60 percent in new buildings and 50 percent in existing ones (15). This translates to a 3-percent reduction in emissions by 2015 .

Replacing heavily used bulbs in homes with compact fluorescent (16) and using high-efficiency fluorescent in existing fixtures in commercial buildings (15) can lower emissions by 1.3 percent.

\section{Transportation}

For transportation (ch. 5), the major reductions come from higher auto and truck efficiency, better control of traffic speed, and, under the Tough scenario, improved public transit (see table A-3). Our Base case assumes that new cars will average about 32 miles per gallon (mpg) by
2000 and $36.5 \mathrm{mpg}$ by 2010. Under the Moderate scenario, new car efficiency averages $35 \mathrm{mpg}$ by 2000 (7) and 39 mpg by 2010 (8). By 2015, reductions of about 0.8 percent of current U.S. carbon emissions are possible.

We have constructed a range of Tough new car efficiencies. Efficiencies of $39 \mathrm{mpg}$ by 2000 and $55 \mathrm{mpg}$ by 2010 might be possible assuming that consumers maintain their current size class preferences (8). By 2015, reductions amount to 3.5 percent of current emissions. If consumers are willing to purchase smaller cars, new car fleet average efficiencies of $42 \mathrm{mpg}$ by 2000 and $58 \mathrm{mpg}$ by 2010 might be achievable (8). Assuming such efficiencies, and policies that encourage people to scrap their old cars an average of 3 years earlier than they would otherwise, reductions of about 3.8 percent might be achieved by 2015 . Reductions of about 2.7 percent from light trucks and another 2.4 percent from medium- and heavy-duty trucks are achievable under our Tough scenario as well. 
Traffic speed affects fuel consumption, too. By reinstating the $55 \mathrm{mph}$ speed limit to slow down travel on highways and by improving traffic congestion in urban areas to speed up travel, reductions of 1.2 percent by 2000 are possible. We consider both of these to be Moderate measures.

Measures to move people out of their cars and into mass transit under the Tough scenario would yield reductions of about 3.5 percent. To achieve this, however, urban auto traffic would have to be reduced by 10 percent through urban light rail, busways, and improved urban design. High-speed intercity rail would lower interurban car travel by 5 percent.

\section{Industry}

For industry (ch. 6), three types of technical improvements offer the greatest promise (see table A-3). Cogenerating electricity and steam for industrial processes is one. About two-thirds of the energy from burning fuel for electricity is released as heat. If electricity is generated at industrial sites where the heat can be used, the efficiency of fossil fuel use can be increased dramatically. Under our Tough scenario, we assume that 90 percent of new industrial steam boilers will cogenerate electricity. Such measures can lead to reductions equivalent to about 5.5 percent of current emissions. More efficient motors are another technical improvement that can lead to substantial improvements. Moderate improvements might improve motor efficiencies by 10 percent and Tough ones by 20 percent (3), yielding reductions of about 1.2 percent by 2015 under the Moderate scenario and 4 percent under the Tough one,

The four top manufacturing energy consumers are the paper industry, chemicals, petroleum, and primary metals, Between 1980 and 1985, these industries managed to improve their energy efficiency by between 2.3 and 4.3 percent per year (10). If this pace can be maintained, reductions equal to about 8 percent of current emissions will result.

\section{Electricity Generation}

Measures that lower the rate of carbon emissions per kilowatt-hour of electricity generated can achieve substantial reductions. All of the Moderate utility supply-side measures can lower emissions by about 6.6 percent (see table A-3). The two with the greatest reduction potential are: 1) increasing the efficiency of fossil-fuel-fired plants (by about 5 percent) through improved maintenance (9) and 2) operating existing nuclear powerplants 70 percent of the time (similar to Western Europe and Japan) (13) and extending their useful life to 45 years.
A series of Tough measures eliminate coal use wherever possible. A combination of renewable energy sources, improved nuclear designs that may be available after 2005, and high-efficiency gas turbines are the only technologies allowed for new utility plants built after 2000. However, if all the Tough demand-side measures are implemented, demand for electricity is so low that very few new plants are needed through 2015 . Thus, to lower emissions from electricity generation (beyond the Moderate measures) one must either cofire existing coal plants with 50-percent natural gas or retire existing fossil-fuel plants after 40 years of operation (rather than the typical 60 years), replacing them with renewable, nuclear, or high-efficiency natural gas. The former measure would yield reductions of about 3.7 percent of current levels by 2015 and the latter would yield reductions of about 4.7 percent.

\section{Forestry}

The forestry measures (ch. 7) with the greatest potential include increasing the productivity of existing forests and planting trees in new areas (afforestation) (see table A-3). Genetically selected seedlings, fertilization, and improved management might double forest productivity on timber industry lands and increase productivity by 50 percent on other private holdings. ${ }^{8}$ The increased carbon uptake would be equivalent to emissions reductions of about 3.1 percent of current levels by 2015 . Planting 33 million hectares (ha) $(125,000$ square miles) of new forests and wood lots (35) as well as additional urban trees (1) would be equivalent to emissions reductions of about 3 percent of current levels by 2015 .

\section{Estimating the Costs of OTA's Tough Scenario}

This section includes rough estimates of the costs of control measures included under OTA's "Tough" scenario. Table A-3 listed the emissions reductions associated with each of the control measures. Detailed descriptions of each of the measures are documented in tables 3-6, 4-2, 5-6, 6-4, and 7-1 in the energy, buildings, transportation, industry, and forestry chapters, respectively. Table A-4 lists fuel savings from the demand-side measures (in trillion Btus and billions of dollars) for both the Moderate and Tough scenarios, Projected fuel prices are listed in table A-5.

All costs presented in this section are in 1987 dollars. A 7-percent discount rate is used to annualize capital costs (typically over 30 years unless noted otherwise). 
Table A-4-Changes in Fuel and Power Use and Costs

\begin{tabular}{|c|c|c|c|c|c|c|c|}
\hline & \multirow[b]{3}{*}{1987} & \multicolumn{3}{|c|}{ Energy (trillion Btu) } & \multicolumn{3}{|c|}{ Cost (billion 1987\$, 2015 prices) } \\
\hline & & \multirow[b]{2}{*}{$\begin{array}{l}\text { Base } \\
2015\end{array}$} & \multicolumn{2}{|c|}{ Change: } & \multirow[b]{2}{*}{$\begin{array}{l}\text { Base } \\
2015\end{array}$} & \multicolumn{2}{|c|}{ Change: } \\
\hline & & & $\begin{array}{c}\text { Moderate } \\
2015 \\
\end{array}$ & $\begin{array}{c}\text { Tough } \\
2015 \\
\end{array}$ & & $\begin{array}{c}\text { Moderate } \\
2015 \\
\end{array}$ & $\begin{array}{c}\text { Tough } \\
2015 \\
\end{array}$ \\
\hline \multicolumn{8}{|l|}{ Residential buildings: } \\
\hline Natural gas . ................ & 4,462 & 4,198 & -639 & $-1,320$ & $\$ 48$ & $-\$ 7$ & $-\$ 15$ \\
\hline Electricity . . . . . . . . . . . & 2,854 & 3,323 & -597 & $-1,067$ & $\$ 110$ & $-\$ 20$ & $-\$ 35$ \\
\hline Oil $\ldots \ldots \ldots \ldots \ldots \ldots \ldots$ & 1,590 & 1,124 & -174 & -374 & $\$ 11$ & $-\$ 2$ & $-\$ 4$ \\
\hline 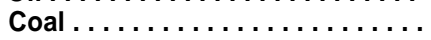 & 74 & 62 & -8 & -13 & $\$ 0$ & $-\$ 0$ & $-\$ 0$ \\
\hline Wood $\ldots \ldots \ldots \ldots \ldots \ldots \ldots$ & 837 & 1,516 & -353 & -897 & & & \\
\hline Total $\ldots \ldots \ldots \ldots \ldots \ldots$ & 8,980 & 8,707 & $-1,418$ & $-2,774$ & $\$ 169$ & $-\$ 29$ & $-\$ 54$ \\
\hline \multicolumn{8}{|l|}{ Commercial buildings: } \\
\hline Natural gas $\ldots \ldots \ldots \ldots \ldots \ldots$ & 2,421 & 3,387 & 416 & 387 & $\$ 36$ & & $\$ 4$ \\
\hline Electricity $\ldots \ldots \ldots \ldots \ldots \ldots$ & 2,525 & 4,264 & $-1,572$ & $-2,922$ & $\$ 119$ & $-\$ 44$ & $-\$ 81$ \\
\hline Oil $\ldots \ldots \ldots \ldots \ldots \ldots \ldots$ & 1,086 & 922 & -259 & -649 & $\$ 9$ & $-\$ 3$ & $-\$ 6$ \\
\hline 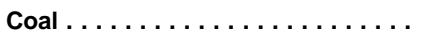 & 107 & 114 & -23 & -43 & $\$ 0$ & & $-\$ 0$ \\
\hline Total $\ldots \ldots \ldots \ldots \ldots \ldots \ldots$ & 6,139 & 8,687 & $-2,270$ & $-3,226$ & $\$ 164$ & $-\$ 51$ & $-\$ 84$ \\
\hline \multicolumn{8}{|l|}{ industry: } \\
\hline Coal ...... & 2,678 & 4,598 & $-1,299$ & $-3,088$ & $\$ 13$ & $-\$ 4$ & $-\$ 9$ \\
\hline Natural gas $\ldots \ldots \ldots \ldots \ldots \ldots \ldots$ & 7,044 & 7,685 & -227 & -24 & $\$ 69$ & $-\$ 2$ & $-\$ 0$ \\
\hline oil $\ldots \ldots \ldots \ldots \ldots \ldots \ldots \ldots$ & 4,725 & 5,041 & -627 & $-1,742$ & $\$ 40$ & $-\$ 5$ & $-\$ 14$ \\
\hline 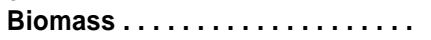 & 2,230 & 3,520 & -298 & $-1,370$ & & & \\
\hline Electric . . . . . . . . . . . & 2,679 & 4,398 & -685 & $-1,686$ & $\$ 97$ & $-\$ 15$ & $-\$ 37$ \\
\hline Total $\ldots \ldots \ldots \ldots \ldots \ldots$ & 19,355 & 25,242 & $-3,136$ & $-7,909$ & $\$ 219$ & $-\$ 26$ & $-\$ 60$ \\
\hline \multicolumn{8}{|l|}{ Transportation: } \\
\hline Gasoline ................ & 13,393 & 16,380 & $-2,008$ & $-6,927$ & $\$ 244$ & $-\$ 30$ & $-\$ 103$ \\
\hline Distillate oil . . . . . . . . . . & 3,338 & 5,140 & -420 & $-1,586$ & $\$ 51$ & $-\$ 4$ & $-\$ 16$ \\
\hline Jet fuel $\ldots \ldots \ldots \ldots \ldots \ldots \ldots$ & 2,872 & 4,686 & -317 & $-1,327$ & $\$ 70$ & $-\$ 5$ & $-\$ 20$ \\
\hline Aviation gas... $\ldots \ldots \ldots \ldots \ldots$ & 45 & 48 & 0 & 0 & $\$ 1$ & $\$ 0$ & \\
\hline Residual oil . . . . . . . . . . . & 817 & 1207 & 0 & 0 & $\$ 10$ & $\$ 0$ & $\$ 0$ \\
\hline Natural gas.... . . $\ldots \ldots \ldots \ldots$ & 571 & 724 & 0 & 0 & $\$ 8$ & $\$ 0$ & $\$ 0$ \\
\hline Electricity $\ldots \ldots \ldots \ldots \ldots \ldots$ & 17 & 28 & 0 & 104 & & & $\$ 3$ \\
\hline Total $\ldots \ldots \ldots \ldots \ldots \ldots \ldots$ & 21,053 & 28,213 & $-2,745$ & $-9,736$ & $\$ 39$ & $-\$ 136$ & $-\$ 136$ \\
\hline Exogenous electricity ........ & 0 & 2,527 & -632 & $-1,263$ & $\$ 69$ & $-\$ 17$ & $-\$ 35$ \\
\hline \multicolumn{8}{|l|}{ All sectors: } \\
\hline Natural gas..... . . . . . . . & 14,497 & 15,994 & $-1,282$ & -957 & $\$ 160$ & $-\$ 14$ & $-\$ 11$ \\
\hline Electricity $\ldots \ldots \ldots \ldots \ldots$ & 8,074 & 12,013 & $-2,855$ & $-5,571$ & $\$ 396$ & $-\$ 96$ & $-\$ 186$ \\
\hline יו & 27,866 & 34,548 & $-3,805$ & $-12,605$ & $\$ 436$ & $-\$ 48$ & $\$ 163$ \\
\hline Coal $\ldots \ldots \ldots \ldots \ldots \ldots \ldots$ & 2,859 & 4,774 & $-1,330$ & $-3,143$ & $\$ 14$ & $-\$ 4$ & $-\$ 9$ \\
\hline Biomass . . . . . . . . . . . & 3,067 & 5,036 & -651 & $-2,267$ & & & \\
\hline Total $\ldots \ldots \ldots \ldots \ldots \ldots$ & 56.364 & 72,365 & $-9,923$ & $-24,543$ & $\$ 1,006$ & $-\$ 162$ & $-\$ 369$ \\
\hline
\end{tabular}

\section{Total Costs}

Adding results documented below by sector yields the following net annual costs (i.e., annualized capital and operating costs minus fuel savings):

\section{Utilities: $+\$ 35$ billion}

Residential buildings: $-\$ 25$ to- $\$ 15$ billion

Commercial buildings: $-\$ 28$ to $+\$ 22$ billion

Transportation: $-\$ 35$ to $+\$ 38$ billion

Industry: $+\$ 21$ to $+\$ 58$ billion

Forestry: $+\$ 10$ to $+\$ 13$ billion

Total: $-\$ 22$ to $+\$ 150$ billion
GNP in 2015 is forecast to be about $\$ 8.4$ trillion (1987 dollars). ${ }^{9}$ Thus, our Tough scenario may entail net savings of a few tenths of a percent of GNP upwards to costs equal to about 1.8 percent of GNP.

Again, note these are net costs. The fuel savings for the Tough scenario are about $\$ 370$ billion in 2015 assuming our projected 2015 fuel prices. Thus, annualized capital and operating costs fall in the range of about $\$ 350$ to $\$ 520$ billion per year--somewhere between 5 percent less than and 40 percent more than expected fuel savings.

The fuel savings for the Moderate scenario are about $\$ 160$ billion in 2015 assuming 2015 prices. Thus, even

\footnotetext{
${ }^{9}$ We obtain this estimate by extrapolating GRI's 2010 GNP forecast using their estimate of GNP growth between 2005 and 2010.
} 
Table A-5--Projections of Future Fuel Prices (1987 dollars per million Btu)

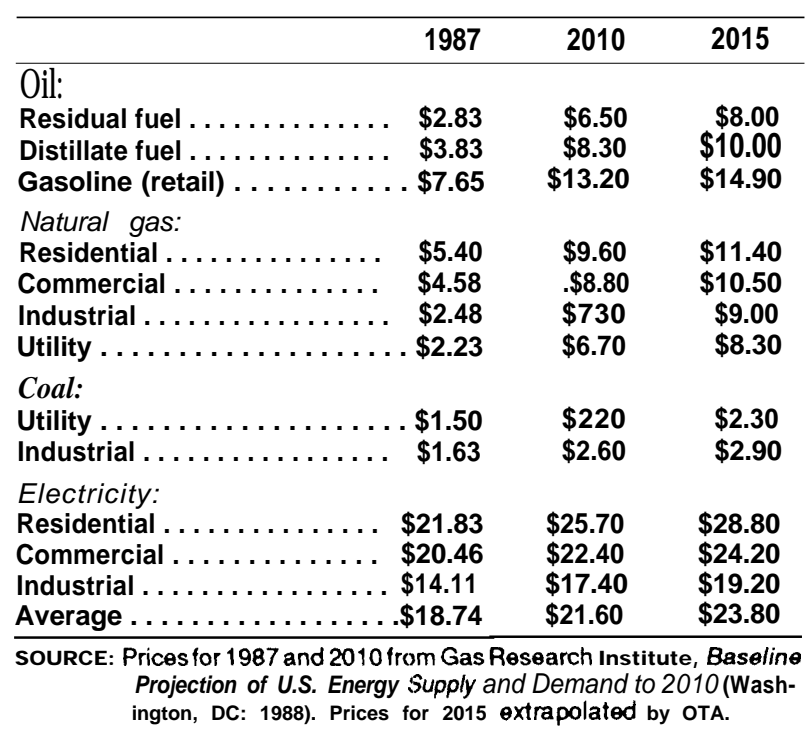

under the Moderate scenario, very large sums of money change hands.

The cost effectiveness of these measures (i.e., tons of carbon avoided per dollar of net costs) varies widely (see figure A-8). Between about one-third to one-half of the reductions either save money or are of very low cost. About one-quarter of the reductions have costs exceeding $\$ 200$ per ton of carbon avoided. The costs and cost effectiveness of the individual measures are discussed below.

Other groups have tried to estimate the costs of $\mathrm{CO}_{2}$ reductions, but with different control scenarios. For example, the Congressional Budget Office (CBO) estimated the reductions and economic impacts from a carbon tax (28a), CBO looked at two economic models that forecast energy use past 2000, one used by EPA and the other by the Electric Power Research Institute (EPRI). Although they widely diverge by 2100 , primarily due to assumptions about Base case growth, at 2015 they are reasonably similar to each other and to our own Base case and thus offer a useful comparison of the costs of reductions. The EPA model forecasts that holding emissions to 10 to 15 percent below current levels would lower GNP by about 1 to 1.3 percent by the year 2015. The EPRI model forecasts that holding emissions to 20 percent below current levels would lower GNP by about 3 percent by that year. Results from the EPA model seem consistent with our own cost estimates; the EPRI economic estimates appear to be somewhat higher than our own. Note, however, that we estimate compliance costs (annual capital and operating costs minus fuel savings) while the CBO results are estimates of changes in GNP. The two are
Figure A-\$-Cost Effectiveness of Control Measures Under the Tough Scenario

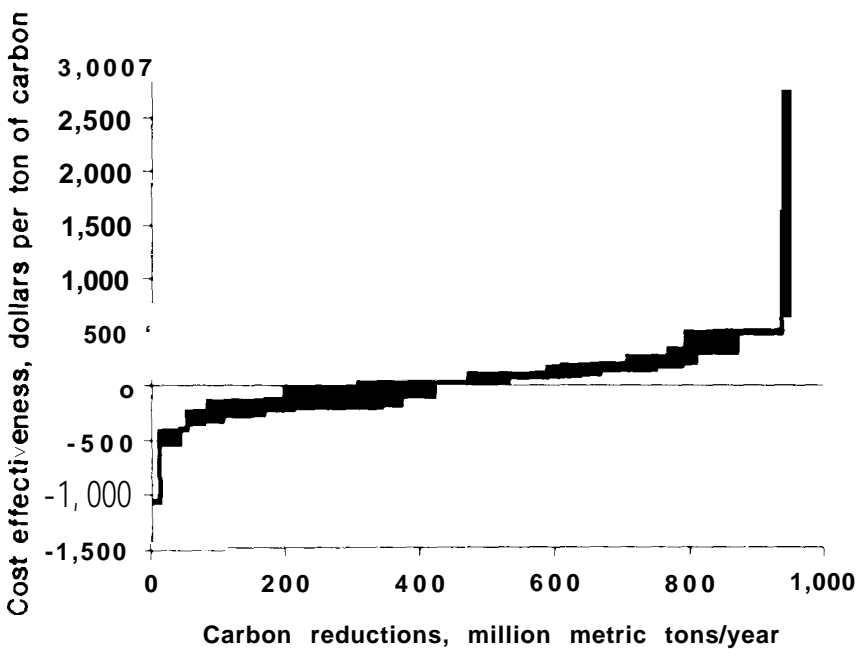

SOURCE: Office of Technology Assessment, 1991.

not directly comparable, but studies of the effect of other environmental control costs on the economy indicate that the estimates should fall within a factor of two of each other. All of the analyses of the costs of controlling $\mathrm{CO}_{2}$ attempted to date should be considered as only rough estimates and in need of considerable refinement.

\section{Electricity Supply}

We estimate that the Tough electricity supply-side scenario will cost about $\$ 35$ billion per year $(1987 \$)$ by the year 2015, assuming it is implemented along with all Tough demand-side measures. This is the cost of the Tough supply-side measures alone and does not include the costs of lowering electricity demand (which are discussed in the following three sections).

Low Cost Measures That Apply to Existing PlantsOur Tough scenario includes the following measures that we estimate are low cost (or save money):

1. modestly improving the efficiency of existing fossilfuel-fired plants (9),

2. increasing the output of existing hydroelectric plants by adding additional generating units to capture energy from water currently bypassing the plants $(6)_{s}$ and

3. increasing utilization of existing nuclear power plants and lengthening their useful life to 45 years (13).

We assign no net costs for these measures.

Cofiring Coal Boilers With Natural Gas-About half of this sector's total costs come from cofiring existing coal plants with natural gas. By 2015, we estimate that 
natural gas will cost about $\$ 6$ per million British thermal units (Btu's) more than coal. Cofiring coal boilers with 50-percent natural gas will increase generation costs by about $\$ 0.03$ per kilowatthour $(\mathrm{kWh})$. In 2015 , costs would total about $\$ 18$ billion per year, at a cost effectiveness of about' $\$ 510$ per ton of carbon avoided.

Early Retirement of Existing Facilities With a Moratorium on New Coal Plants-Most of the remaining costs for this sector come from forcing existing fossil-fuelfired plants to retire after 40 years of operation and replacing them with natural gas and nonfossil sources. Forcing coal-fired plants to retire early and replacing them with highly efficient natural gas-fired combined cycle turbines could increase electricity costs at affected plants by $\$ 0.04$ to $\$ 0.05$ per $\mathrm{kWh}$. Forcing existing oil and natural gas plants to retire early saves money-about $\$ 0.01$ to $\$ 0.02$ per $\mathrm{kWh}$--because the replacement facilities are so much more efficient, Costs are based on the projected 2015 fuel prices presented in table A-5; efficiencies and capital and operation and maintenance costs are from the Electric Power Research Institute (EPRI) (12). Because existing facilities are fully depreciated after 30 years, no capital charges are applied to electricity generated from existing plants.

Note, however, that once these existing facilities retire, costs must be compared to replacement coal or natural gas plants. Electricity from new natural-gas-fired combined cycle turbines (assuming our 2015 fuel prices) would cost about $\$ 0.02$ per $\mathrm{kWh}$ more than electricity from a new coal-fired powerplant, less than half the cost premium over existing plants. Note, too, that costs are sensitive to fuel prices. Costs are about $\$ 0.01$ per $\mathrm{kWh}$ lower assuming 2010 prices.

We have assumed that the cost of electricity from nonfossil sources (either renewable sources or nuclear power) will be about comparable to natural-gas-fired combined cycle turbines. The cost of early retirement of existing fossil-fuel-fired sources and replacement with natural gas and nonfossil sources is about $\$ 17$ billion per year, at a cost effectiveness of $\$ 280$ per ton of carbon eliminated.

\section{Buildings}

Costs for all Tough measures that are applicable to buildings in both the residential and commercial sectors fall in a range between net savings (i.e., equipment costs minus fuel savings) of $\$ 53$ billion per year to net costs of $\$ 7$ billion per year (1987\$).

Residential Buildings-Costs for the residential sector are best estimated by household. By 2015, there will be about 115 million households, 35 million built after 1995 and 80 million built before. We estimate that shell improvements to pre-1995 houses under our Tough scenario will cost about $\$ 2,300$ per single family house in northern climates and $\$ 1,000$ per single family houses in southern ones. ${ }^{10}$ Costs for shell improvements to pre1995 multifamily dwellings (about one-quarter of households) will average about $\$ 1,200$ per dwelling in northern climates and $\$ 600$ in southern climates. All costs are incremental costs for improvements over our assumed Base case efficiencies. Northern climates include the New England, Mid-Atlantic, North Central, and northern Mountain Census regions.

The costs of shell improvements in post- 1995 houses under our Tough scenario are somewhat higher. In northern climates, costs might be in the range of $\$ 6,000$ to $\$ 8,000$ per house; in the South, costs might be about $\$ 2,500$ per house. Shell improvements in new multifamily dwellings might cost $\$ 2,000$ to $\$ 3,000$ in northern climates and \$1,200 in southern ones.

Costs for more efficient furnaces and appliances might total about $\$ 1,000$ to $\$ 1,500$ per household, based on the following estimates of additional costs: furnace (\$750), water heater $(\$ 45)$, refrigerator ( $\$ 185)$, air conditioner $(\$ 300)$, freezer $(\$ 50)$, washer $(\$ 28)$, dryer $(\$ 70)$, dishwasher $(\$ 18),{ }^{11}$

Assuming the shell improvements have a 30-year life and the more efficient appliances average a 15-year life, total costs for the residential sector will be in the range of $\$ 30$ to $\$ 40$ billion per year. However, fuel savings from these measures are about $\$ 55$ billion per year assuming 2015 fuel prices. Thus, the net costs for the residential sector fall in the range of savings of $\$ 15$ billion to $\$ 25$ billion per year. The cost effectiveness of these reductions is in the range of $-\$ 175$ to $-\$ 300$ per ton of carbon (i.e., savings of $\$ 175$ to $\$ 300$ per ton of carbon).

Commercial Buildings-By 2015, we anticipate the United States having about 72 billion square feet of commercial building space (up from about 45 billion today). Though costs of energy efficiency improvements vary by building type, they appear to cluster in the range of $\$ 5$ to $\$ 11$ per square foot for a package similar to our Tough measures. ${ }^{12}$ These are the most aggressive measures considered by the Northwest Power Planning Council and include somewhat better lighting improvements than we assumed, reasonably equivalent shell improvements and heating and cooling efficiencies for several building types, but lower improvements for others than we assumed for other building types.

\footnotetext{
${ }^{10}$ The costs of our Tough scenario are estimated primarily from data in ref. 26, tables 3-13, 3-14, and 3-36.

${ }^{11}$ All appliance estimates from ref. 26; except for furnaces from ref. 12.

${ }^{12}$ Costs are derived from ref. 26 , tables $54 \mathrm{~A}$ through $54 \mathrm{H}$.
} 
Costs for these improvements total about $\$ 30$ to $\$ 65$ billion per year but fuel savings are approximately $\$ 55$ billion per year at 2015 fuel prices. Thus net costs for these measures fall between savings of $\$ 25$ billion per year and costs of $\$ 10$ billion per year. The cost effectiveness of these reductions ranges between $-\$ 190$ per ton and $\$ 75$ per ton of carbon avoided.

By 2015, we assume the commercial sector will be able to install $25 \mathrm{GW}$ of cogeneration systems. We assign a cost premium of $\$ 0,02$ to $\$ 0.05$ per $\mathrm{kWh}$ to cogenerated electricity, the same cost we derive for cogeneration within industry (see below). Costs total about $\$ 2.5$ to $\$ 6$ billion per year, at a cost effectiveness of $\$ 85$ to $\$ 210$ per ton of carbon.

For the remaining reductions (from office equipment and water heaters and appliances), we assume a range of costs equal to the range of commercial measures discussed above: $-\$ 200$ to $\$ 200$ per ton of carbon. Net costs for the remainder total between $-\$ 5.5$ to $\$ 5.5$ billion per year.

Total costs for the commercial sector are between savings of $\$ 28$ billion per year to costs of $\$ 22$ billion per year. The cost effectiveness of these reductions falls in the range of $-\$ 150$ to $\$ 120$ per ton of carbon avoided.

\section{Transportation}

We estimate that the net costs of the Tough transportation measures fall in a range between savings of about $\$ 35$ billion per year to costs of about $\$ 38$ billion per year (1987\$) in 2015 ,

Highway Vehicle Efficiency--The new-vehicle efficiency measures will save money by 2015 , assuming the expected rise in the price of gasoline (about $\$ 1.85$ per gallon in 1987\$). They are considered "Tough" primarily because they are technically challenging goals. We assume that the additional cost of fuel-efficiency improvements to achieve a $55 \mathrm{mpg}$ new car fleet average by 2010 will be in the range of $\$ .500$ to $\$ 750$ per car (1987\$) (8). Achieving a $58 \mathrm{mpg}$ car fleet by encouraging consumers to buy smaller can; might require a subsidy of about $\$ 250$ to $\$ 500$ per vehicle (7). Thus we use $\$ 750$ to $\$ 1,250$ as our range of new car costs. We assume light-duty truck efficiency improvements under the Tough scenario will cost $\$ 500$ to $\$ 750$ per vehicle (i.e., the same as new cars without subsidies for smaller cars). Assuming 168 million cars and 74 million light trucks and amortizing the costs over 7 years, we estimate the increase in passenger vehicle costs will be about $\$ 30$ to $\$ 50$ billion per year,
However, the higher efficiency under the Tough scenario saves about $\$ 58$ billion in fuel costs per year. Thus, net costs for improved light-duty vehicle efficiency are in the range of savings of $\$ 8$ to $\$ 28$ billion per year. The cost effectiveness of the Tough fuel efficiency measure for cars is in the range of $-\$ 220$ to $-\$ 110$ per ton of carbon avoided; for light trucks, the range is $-\$ 510$ to $-\$ 410$ per ton.

Lacking estimates for the costs of heavy-duty truck improvements, we assume similar dollar per ton costs as light-duty vehicles. Savings amount to between $\$ 3$ billion and $\$ 9$ billion per year. For lack of a better estimate, we assume that the cost of the aircraft efficiency improvements will equal fuel savings.

Mass Transit-We estimate that travel by mass transit costs about $\$ 0.13$ to $\$ 0.21$ per passenger mile more than travel in cars. Mass transit costs were in the range of $\$ 0.45$ per passenger mile for $1988 .{ }^{13}$ Passenger car operating costs were about $\$ 0.382$ per vehicle mile in 1989 (25). Using a range of 1.6 passengers per vehicle (a 1983 urban average from ref. 36 for all travel) to 1.2 passengers per vehicle (urban work commuting average) yields costs of $\$ 0.24$ per passenger mile for all urban car travel and \$0.32 per passenger mile for work commuting by car. Assuming the per-mile travel premium derived above, mass transit and intercity rail costs under our Tough scenario total \$26 to $\$ 55$ billion per year, or about $\$ 1,150$ to $\$ 2,300$ per ton of carbon.

Other Measures-Urban traffic flow improvements, truck inspection and maintenance programs, and improved urban planning are all probably low cost measures. Fuel savings from these programs amount to about $\$ 15$ billion per year, which we use as our estimate of the net cost of these measures.

The remaining measures-55 mph speed limit, ridesharing, parking controls, etc.-all lead to fuel savings but have associated inconvenience costs as well. We assume that these fall somewhere in the range between 50 percent less than and 50 percent greater than fuel savings. Because fuel savings from these measures are about $\$ 18$ billion per year, net costs fall in the range of savings of $\$ 9$ billion per year to costs of $\$ 9$ billion per year.

\section{Industry}

We estimate that the cost of all the Tough industrial control measures falls in the range of $\$ 18$ billion to $\$ 55$ billion per year.

Motors and Lights-Use of more efficient motors, lighting, and general housekeeping improvements are all measures that are either low cost or save money due to

\footnotetext{
${ }^{13}$ Assumes a 5-year average capital cost from ref. 2, table 38 (Federal contribution is assumed to be $7 \mathrm{~S}$ percent of total). Operating costs and passenger miles traveled from ref. 37 , tables 2.09 and 2.13 .
} 
large electricity savings. The Electric Power Research Institute estimates that more efficient motors can save $\$ 0.03$ per $\mathrm{kWh}$ and more efficient lighting can save $\$ 0.04$ per $\mathrm{kWh}$ over the life of the equipment (22). We have simply assumed that these two measures cost half of the amount they save in electricity costs. We assume that general housekeeping costs as much as it saves in energy. Net cost savings from these measures total about $\$ 6$ billion per year. The cost effectiveness of the reductions from motors and lights is about $-\$ 130$ per ton of carbon avoided.

Lower Emitting Fuels--A moratorium on new coal industrial boilers (assuming natural gas is the fuel of choice) would increase natural gas use by about 2.3 quads over the Base case. At our 2015 prices, this costs about $\$ 14$ billion per year, with a cost effectiveness of about $\$ 520$ per ton.

Cogeneration--While in many situations industrial cogeneration will save money, assuming that 90 percent of all new and replacement boilers would cogenerate might add a cost penalty, on average, of $\$ 0.02$ to $\$ 0.05$ per $\mathrm{kWh}$. The higher cost is an EPA-contractor estimate assuming that all noncogenerating industrial boilers (existing and new) that burn oil or natural gas will cogenerate; the lower estimate assumes that the most expensive 7 percent of such boilers are exempt from the requirement. Requiring in addition that all cogeneration systems use equipment equal in efficiency to Intercooled Steam Injected Gas Turbines might add another \$0.01 to $\$ 0.02$ per $\mathrm{kWh}$. We add the $\$ 0.01$ to $\$ 0.02$ per $\mathrm{kWh}$ premium to all cogenerated electricity, including the amount assumed to occur under our Base case, Costs for cogeneration total about $\$ 3$ to $\$ 7$ billion per year. The cost effectiveness of these reductions is in the range of $\$ 55$ to $\$ 120$ per ton of carbon.

Process Change--The largest share of the industrial reductions comes from process change. We have no source of estimates for the cost of these reductions. We assumed a range of $\$ 120$ per ton to $\$ 520$ per ton (the upper bound of the cost effectiveness of cogeneration to the cost effectiveness of fuel switching from coal to natural gas). Total costs for process changes thus would fall in the range of about $\$ 10$ to $\$ 43$ billion.

\section{Forestry}

We estimate that implementing our Tough forestryrelated measures would cost in the range of $\$ 10$ to $\$ 13$ billion per year. The cost effectiveness of these measures averages $\$ 105$ to $\$ 135$ per ton of carbon sequestered.

Afforestation-Afforestation is estimated to cost about $\$ 2.7$ billion per year (about $\$ 1.6$ billion for urban trees, $\$ 0.3$ billion for the Conservation Reserve Program (CRP), and $\$ 0.8$ billion for general afforestation). The cost effectiveness of the CRP and general afforestation averages about $\$ 35$ per ton of carbon sequestered; the cost effectiveness for urban tree planting averages about $\$ 180$ per ton.

For urban trees, we estimate maintenance at $\$ 10$ per tree per year (based on ref. 21), and planting of saplings at $\$ 75$ per tree (including time, transportation, and labor). Planting and maintaining 100 million trees then would cost $\$ 1.6$ billion per year.

For the CRP, the total cost for a 10-year contract is an estimated $\$ 1,420$ per hectare (based on data in ref. 31). Assuming that the current legislative goal of planting trees on 2.3 million hectares is met, then costs would be $\$ 0.3$ billion per year.

For general afforestation, we estimate costs for land, seedling and soil preparation, and labor at about $\$ 325$ per hectare (based on refs, 31, 32). Planting 30 million hectares would cost $\$ 0.8$ billion per year.

Increased Productivity-We estimate maintenance costs in programs to increase productivity at about $\$ 10$ per hectare per year, exclusive of credits for sales or taxes (based, for example, on ref. 28); and site preparation and planting costs at about $\$ 420$ to $\$ 600$ per ha (based on ref. 39). Given this range in site preparation and planting costs, increasing productivity on 140 million hectares of already forested lands would cost between $\$ 6$ and $\$ 8$ billion per year. The cost effectiveness of these reductions is in the range of $\$ 150$ to $\$ 200$ per ton of carbon sequestered.

Biomass Fuels-We estimate biomass fuel to cost \$2 to $\$ 3$ per million Btu; this assumes that fuel costs $\$ 68$ to $\$ 102$ per ton carbon (40) and that biomass fuels contain 55 to $60 \mathrm{lb}$ of carbon per million Btu. We assign biomass fuels a premium over coal (for use in utility or industrial boilers) of roughly $\$ 1$ to $\$ 2$ per million Btu, including a penalty for drop in efficiency. Given this premium, 1 quad of biomass fuel would cost $\$ 1$ to $\$ 2$ billion per year. The cost effectiveness of these reductions is in the range of $\$ 67$ to $\$ 133$ per ton of carbon sequestered.

\section{Appendix A References}

1. Akbari, H. et al., "The Impact of Summer Heat Islands on Cooling Energy Consumption and $\mathrm{CO}_{2}$ Emissions, " paper presented at ACEEE Summer Study on Energy Efficiency in Buildings (Asilomar CA: August 1988).

2. American Public Transit Association, 1989Transit Fact Book (Washington, DC: 1989)

3. Baldwin, S., 'Energy-efficient Electric Motor Drive Systems, ' in T.B. Johansson et al. (eds.), Efficient End Use and New Generation Technologies, and Their Planning Implications (Lund, Sweden: Lund University Press, 1989)

\footnotetext{
${ }^{14}$ We have derived these estimates using the capital costs and fuel savings from ref, 20 and our ownestimates of 2015 fuel prices.
} 
4. Birdsey, R.A., "Estimation of Regional Carbon Yields for Forest Types in the United States," draft manuscript (Washington, DC: Feb. 13, 1990).

5. Cambridge Systematic, Inc., Improved Air Quality in Maricopa and Pima Counties - The Application of Transportation Measures (Cambridge, MA: November 1986)

6. Davis, D.W. and J.J. Buckley, National Hydroelectric Power Resources Study, Volume IX. Potential for Increasing the Output of Existing Hydroelectric Plants (Fort Belvoir, VA: Institute for Water Resources, 1981).

7. DiFiglio, C. et al., "Cost Effectiveness of Future Fuel Economy Improvements," Energy Journal 11(1):65(87), January 1990.

8. DiFiglio, C., presentation at OTA workshop on transport and global warming, Apr. 6, 1989.

9. Electric Power Research Institute, Power Plant Performance Monitoring and Improvement, EPRI report CS/EL-4415, vol. 3 (Palo Alto, CA: February 1986).

10. Energy Information Administration, Manufacturing Energy Consumption Survey: Consumption of Energy, 1985, DOE/EIA0512(85) (Washington, DC: 1990).

11. Electric Power Research Institute, TAG Technical Assessment Guide. Volume 1: Electricity Supply_1989, EPRI report P-6587L, vol. 1 (Palo Alto, CA: September 1989).

12. Electric Power Research Institute, TAG Technical Assessment Guide. Volume 2: Electriciry End Use. Part I: Residential Electricity Use-1987 (Palo Alto, CA:1987).

13. Fulkerson, W. et al., Energy Technology $\boldsymbol{R} \& D$ : What Can Make A Difference?, Volume 2, Suppiy Technology, ORNL-6541/V2/P2 (Oak Ridge, TN: Oak Ridge National Laboratory, 1989).

14. Gas Research Institute, Baseline Projection Data Book, 1988 GRI Baseline Projection of U.S. Energy Supply and Demand to 2010 (Washington, DC: 1988)

15. Geller, H., "Commercial Building Efficiency: A-State-of-the-Art Review," contractor report prepared for U.S. Congress, Office of Technology Assessment, 1988.

16. Geller, H., "Residential Building Efficiency: A-State-of-the-Art Review, " contractor report prepared for U.S. Congress, Office of Technology Assessment 1988.

17. Goldemberg, J. et al., Energy for a Sustainable World (New Delhi, India: Wiley Eastern Ltd., 1988)

18. Goldman, C. A., "Measured Results of Energy Conservation Retrofits in Residential Buildings," presented at 1986 ASHRAE Winter Meeting, San Francisco, CA, Jan. 19-22,1986, LBL-20950.

19. Holtberg, P.D. et al., 1988 GRI Baseline Projection of U. S, Energy Supply and Demand to 2010 (Chicago, IL: Gas Research institute, 1988).

20. ICF Incorporated, Preliminary Technology Cost Estimates of Measures Available to Reduce U.S. Greenhouse Gas Emissions by 2010, report submitted to U.S. Environmental Protection Agency, August 1990.

21. International City Management Association Trends in Urban Forestry Management 20(1):1-17, January/February 1988

22. Lammare, L., "New Push for Energy Efficiency, " $E_{?}^{\prime} R I$ Journal 15(3):4-17, April 1990.

23. Lawrence Berkeley Laboratory, Buildings Energy Use Compilation and Analysis Project (Berkeley, CA: Mar. 6, 1986).

24. Marland, G., "The Prospect of Solving the $\mathrm{CO}_{2}$ Problem Through Global Reforestation," DOE/NBB-0082 (Washington DC: U.S. Department of Energy, Office of Energy Research, February 1988)

25. Motor Vehicle Manufacturer's Association, Facts and Figures ' 89 (Detroit, MI: 1990).
26. Northwest Power Planning Council, Technical Appendix to Conservation Supply for the 1990 Power Plan (Portland, OR: 1989).

27. Oak Ridge National Laboratory, Alternative Motor Fuel Use Model (Oak Ridge, TN: 1988).

28. Sedjo, R. A., The Comparative Economics of Plantation Forestry, A Global Assessment (Washington, DC: Resources for the Future, 1983),

28a. U.S. Congress, Congressional Budget Office, Carbon Charges as a Response to Global Warming: The Effects of Taxing Fossil Fuels (Washington, DC: U.S. Government Printing Office, August 1990).

29. U.S. Congress, General Accounting Office, "Conservation Reserve Program Could Be Less Costly and More Effective," GAO/RCED-90-13(Washington, DC: November 1989).

30. U.S. Congress, Office of Technology Assessment, Wood Use, U.S. Competitiveness and Technology, OTE-E-21O (Springfield, VA: National Technical Information Service, August 1983).

31. U.S. Department of Agriculture, Conservation Reserve program Work Group, Progress Report and Preliminary Evaluation of the First Two Years (Washington DC: January 1989).

32. U.S. Department of Agriculture, Agricultural Stabilization and Conservation Service, "Supplement I to 'The Conservation Reserve Program: Progress Report and Preliminary Evacuation of the First Two Years (Signups 1-7)'," draft report (Washington, DC: Feb. 13, 1990).

33. U.S. Department of Energy, Energy Information Administration, Annual Energy Outlook With Projections to 2010, DOwIA0383(90) (Washington, DC: January 1990).

33a. U.S. Department of Energy, Energy Information Administration, Annual Energy Review, 1989, DOE/EIA-0384(89) (Washington DC: May 1990).

34. U.S. Environmental Protection Agency, Office of Policy, Planning and Evaluation Policy Options for Stabilizing Global Climate, Executive Summary, draft report to Congress (Washington, DC: June 1990).

35. U.S. Forest Service, "National Tree Planting Initiative, Questions and Answers About Trees' (Washington, DC: U.S. Department of Agriculture, Feb. 1, 1990).

36. U.S. Department of Transportation, Personal Travel in the US. Volume II (Washington, DC: November, 1986)

37. U.S. Department of Transportation, National Urban Mass Transportation Statistics. 1988 Section 15 Annual Report (Washington, DC: December, 1989)

38. Westbrook, F. and P. Patterson, "Changing Driving Patterns and Their Effect on Fuel Economy," paper presented at the 1989 SAE Government/Industry Meeting, Washington-q DC, May 2, 1989.

39. Winjum, J.K., "Forest Regeneration Cost for PNW and Southeast, ' U.S. Environmental Protection Agency, Environmental Research Laboratory, memorandum to D.A. Tirpak (Corvallis, OR: June 14, 1988)

40. Wright, L.L., R.L. Graham, and A.F. Turhollow, "Short-Rotation Woody Crop Opportunities to Mitigate Carbon Dioxide Buildup," paper presented at North American Conference on Forestry Responses to Climate Change (Washington DC: Climate Institute, May 15-17, 1990)

41. Young, C.E. and C.T.Osborn, The Conservation Reserve Program, An Economic Assessment, Agricultural Economic Report Number 626 (Washington, DC: U.S. Department of Agriculture, Economic Research Service, February 1990). 
In the last 2 years, some States have taken an active role in addressing greenhouse gas emissions without waiting for the Federal Government to act-usually through legislation or executive orders, most often with respect to energy efficiency and use of chlorofluorocarbons. Table B-1 provides titles, dates enacted, and general substance of several legislative and executive actions.

A few States have developed quantitative reduction goals for greenhouse gas emissions. For example, Vermont's policy calls for greenhouse gases to be reduced at least 15 percent below current levels by the year 2000; it promotes measures to reduce per-capita nonrenewable energy use, increase alternative fuel use, and develop renewable energy sources (table B-1; ref. 15). Oregon's goal is to reduce greenhouse gas emissions 20 percent below 1988 levels by the year 2005 (20).

Other States, while not formulating specific reduction targets, have established relatively broad goals related to global warming. New Jersey is seeking to reduce emissions by decreasing energy consumption and encouraging energy conservation, public education, and tree planting (table B-1; ref. 22). Its educational initiative is unique in calling for improved public education about the causes and effects of climate change; it asks colleges and universities that train teachers to integrate environmental education activities into course material. Connecticut's 1990 global warming act includes a range of energyefficiency goals, requirements for transportation (e. g., passenger vehicle occupancy levels, telecommuting), buildings standards, State vehicle fuel efficiency, recycling, and long-term energy use (table B-1; refs. 7 and 30). A 1990 Iowa bill contains provisions addressing energy efficiency in buildings, alternative fuels demonstration grants, an Iowa Energy Center, and energy-efficiency planning by utilities (table B-1; ref. 4).

Many State programs are specifically designed to address $\mathrm{CO}_{2}$ emissions from individual sectors. Most involve energy use and efficiency in the buildings, transportation, and energy supply sectors. Many States also developed programs during the 1970s and 1980s that, although not designed to address concerns about global warming, nonetheless can help reduce emissions. Most of these programs have focused on energy supply (e.g., least-cost utility planning) and buildings (e.g., efficiency standards) (16).

Table B-I-State Legislation and Orders Addressing Greenhouse Gas Emissions

\begin{tabular}{|c|c|c|c|}
\hline State & Document & Date enacted & Subjects emphasized \\
\hline $\begin{array}{l}\text { Arizona . . . . . . . . . } \\
\text { Connecticut . . . . }\end{array}$ & $\begin{array}{l}\text { House Bill } 2206 \\
\text { Public Act } 219\end{array}$ & $\begin{array}{l}1988 \\
1990\end{array}$ & $\begin{array}{l}\text { Air quality, natural gas, transportation control measures } \\
\text { Transportation control measures, building codes, State } \\
\text { vehicles, tree planting, State energy plan, recycling }\end{array}$ \\
\hline $\begin{array}{l}\text { Hawaii . . . . . . . } \\
\text { lowa . . . . . }\end{array}$ & $\begin{array}{l}\text { Senate Bill } 1344 \\
\text { Senate File } 2403\end{array}$ & $\begin{array}{l}\text { May 11, } 1989 \\
1990\end{array}$ & $\begin{array}{l}\text { CFCs } \\
\text { Building energy efficiency, alternative fuels demonstration } \\
\text { grants, utility energy-efficiency planning }\end{array}$ \\
\hline Maine . . . . . . . . . & Public Law 622 & Feb. 23, 1990 & CFCs \\
\hline New Jersey . . . . . & Executive Order 219 & Oct. 23, 1989 & $\begin{array}{l}\mathrm{CO}_{2} \text { emissions, State equipment purchases, energy use, } \\
\text { CFCs, tree planting }\end{array}$ \\
\hline $\begin{array}{l}\text { New York . . . . . . . } \\
\text { Oregon . . . . . . }\end{array}$ & $\begin{array}{l}\text { Executive Order } 118 \\
\text { Senate Bill } 576\end{array}$ & $\begin{array}{l}\text { Dec. 28, } 1988 \\
1989\end{array}$ & $\begin{array}{l}\text { State Energy Plan, energy use, } \mathrm{CO}_{2} \text { emissions } \\
\text { Greenhouse gas emissions, energy conservation, } \\
\text { renewable resources, alternative fuels }\end{array}$ \\
\hline Texas . . . . . . . . . & $\begin{array}{l}\text { Senate Bill } 740 \\
\text { Senate Bill } 760\end{array}$ & $\begin{array}{l}1989 \\
1989\end{array}$ & $\begin{array}{l}\text { State vehicles } \\
\text { Natural gas, alternative fuels, technologies }\end{array}$ \\
\hline $\begin{array}{l}\text { Washington . . . . . } \\
\text { Wisconsin . . . . }\end{array}$ & $\begin{array}{l}\text { House Bill } 2198 \\
\text { Act } 284 \\
\text { Public Service Commission } \\
\quad \text { Order 05-EP-5 }\end{array}$ & $\begin{array}{l}\text { Feb. 5, } 1990 \\
\text { Apr. 21, } 1990 \\
\text { Apr. 7, } 1989\end{array}$ & $\begin{array}{l}\text { Residential buildings } \\
\text { CFCs } \\
\text { Utilities, cost of reducing } \mathrm{CO}_{2} \text { emissions }\end{array}$ \\
\hline
\end{tabular}

SOURCE: Of fice of Technology Assessment, 1991. 
Most of the specific greenhouse gas-related actions have occurred in the last year or two and some are not yet legally effective, so the extent to which they will be implemented and enforced remains to be seen. This appendix presents examples of these actions, based primarily on responses to an OTA survey of different regions of the country; it is not intended to be an exhaustive list.

\section{Chlorofluorocarbons (CFCs) and Halons}

Of all the greenhouse gases, CFCs have been the most widely addressed by State legislatures. In 1989, Hawaii became the first State to enact legislation restricting the use of CFCs (table B-1; ref. 33). The statute, which goes into effect on January 1, 1991, requires mandatory recycling of CFCs and prohibits the sale of CFC coolants for air conditioners in containers smaller than 15 pounds (the latter as a means of deterring inexperienced installers).

Soon after Hawaii's action, Vermont enacted a statute that bans the sale of cleaning sprays, containers of CFCs smaller than 15 pounds, and halon fire extinguishers for home use (table B-1; ref. 15). The law also prohibits the sale of cars with CFC-using air conditioners, beginning with model year 1993, and requires service stations that repair automobile air conditioners to recycle CFCs.

Under Maine's CFC-related statute, new cars using CFCs may not be registered in the State after 1994, automobile CFCs must be recycled, and the sale of small quantities of CFCs is restricted (table B-1; ref. 17). The legislation bans the use of CFC foam board for household insulation, effective when alternative blowing agents are available.

In Wisconsin, beginning in 1991, motor vehicle air conditioner refrigerant in containers holding less than 15 pounds will be banned (table B-1; ref. 31). Beginning in 1992 , anyone servicing or installing refrigeration equipment containing at least 5 pounds of CFC refrigerant must use proper recycling procedures. In 1996, the distribution or registration of new motor vehicles using air conditioners that contain over a specified amount of CFCs will be prohibited.

Other States with legislation or directives that address CFC emissions include California (see box 5-A in ch. 5), Connecticut, Florida, Illinois, Iowa, Louisiana, Maryland,

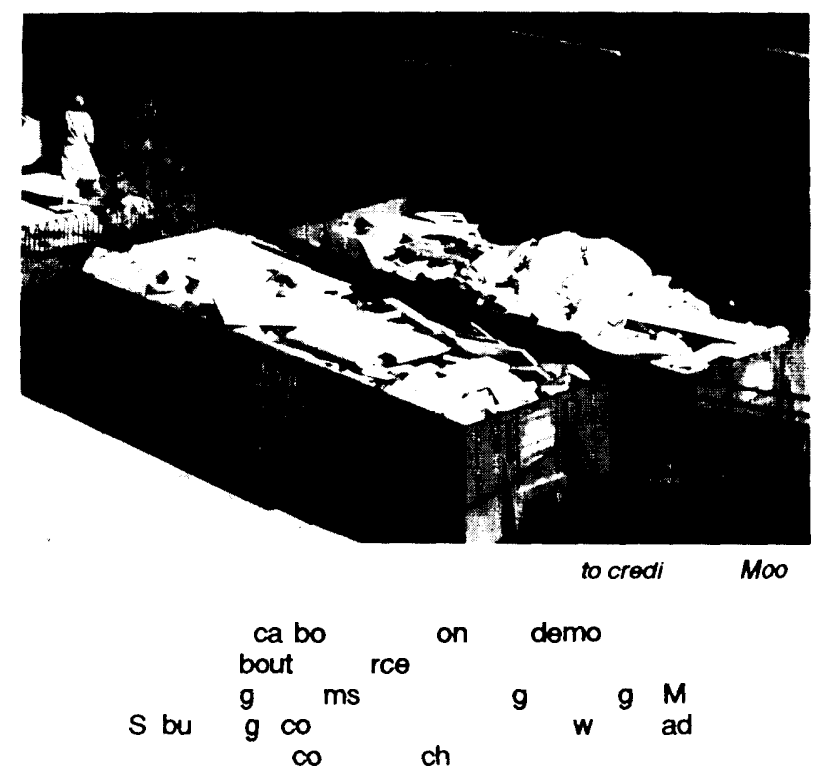

Minnesota, Missouri, New Jersey, New York, Rhode Island, and Oregon. ${ }^{2}$ Legislation has been introduced in at least 7 other States (17).

\section{Energy}

Marty States have had energy planning and assistance programs since the early 1970s and 1980s, largely in response to the 1973 oil embargo. As of 1988, for example, 24 States had collaborative energy-efflciency projects with utilities, and 15 had State energy tax credits for renewable energy sources (e.g., photovoltaics, wind, biomass) $(1,16)$. Since the mid-1970s, many utilities and State regulators have increased their interest in least-cost planning (LCP), which aims to balance supply- and demand-side management alternatives to meet energy needs at the least possible cost (8a) (see box 3-C in ch. 3 for more discussion of demand-side management). As of 1990, 23 States had LCP strategies. ${ }^{3}$ Almost all States also received funding from the Oil Overcharge fund, to be used in energy conservation grants administered by the U.S. Department of Energy. ${ }^{4}$ More recently, several States have enacted energy policies that directly address greenhouse gas emissions.

I we previously passed a law prohibiting the use of polystyrene foam food packaging made with CFCs; Minnesota and Rhode Island also passed similar laws (25).

${ }^{2}$ In addition, some municipalities have passed comprehensive ordinances regulating CFCs-including Irvine, California, in August 1989; and Denver, Colorado (refs. 6, 12) in April 1990.

${ }^{3}$ According t. ref. 8a, legislatures have passed LCP laws or given authority to utility commission to establish and enforce regulations in at least 16 States. Utilities also use LCP without legislative or regulatory mandates in a few other States.

${ }^{4}$ These funds are granted by the Department to the States for previously authorized conservation projects; they are derived from a 1986 U.S. District Court decision on alleged pricing violations by oil companies. The DOE grant programs are the Energy Extension Service, the State Energy Conservation Program, the Institutional Conservation Program, and the Weatherization Assistance program (these are discussed inch. 4). 
As of September 1990, six State utility commissions had modified the selection procedures of their electric utility companies to account for residual environmental damages (32). ${ }^{5}$ New York's Public Service Commission introduced guidelines for a competitive bidding process for new electricity supply that includes the estimated cost of environmental pollution, including $\mathrm{CO}_{2}$ emissions; the cost is added to bids in order to make energy-efficient and environmentally cleaner technologies more competitive with traditional fossil fuel-fired generation technologies $(21,23,24) .{ }^{6}$ New York also has issued an Executive Order (table B-1; ref. 21) establishing a statewide energy planning process involving the State Energy Office, Department of Public Service, and Department of Environmental Conservation.

In Vermont, an Executive Order (table B-1) calls for increasing the effectiveness of energy-efficiency services provided by utilities, private businesses, and State agencies, and for increasing Vermont reliance on renewable energy supplies. The State Agency Task Force on Energy was created to oversee the implementation of energy efficiency and emission reduction strategies.

New Jersey's goal of reducing greenhouse gas emissions includes directives to State agencies to foster energy conservation-for example, by purchasing and using efficient heating, ventilation, air-conditioning, and lighting equipment; increasing reliance on lower emitting fuels; and using alternatives to CFC- and haloncontaining equipment (22). New Jersey's initiative is distinguished from other State plans by its emphasis on public education, as noted above.

In Wisconsin, the Public Service Commission issued an order in 1989 that requires the Wisconsin Utilities to assess the cost of using existing technologies to reduce $\mathrm{CO}_{2}$ emissions by 20 percent below 1985 levels (31).

Some States are using Oil Overcharge funds to establish energy-related programs. In Arizona, funds are being used to construct a solar village on State Trust Land (1 1). In New Mexico, some funds are being used for municipal solid waste reduction and recycling projects that result in net energy savings (10).

\section{Transportation}

As of 1988, a number of States had programs dealing with public transportation, ridesharing, vehicle inspection and maintenance, and high-occupancy lanes (16). For example, at least 15 States provided some funding for ridesharing. In the last few years, States such as Arizona, California, Connecticut, and Texas have enacted legislation specifically designed to reduce $\mathrm{CO}_{2}$ emissions in the transportation sector.

California probably has the most comprehensive plan in the country regarding transportation policies, In particular, the South Coast Air Quality Management plan sets forth an ambitious and far-reaching program of control measures that could greatly affect transportation emissions (see box 5-F in ch. 5 for details).

Arizona's 1988 air legislation (table B-1) includes a tax break for use of compressed natural gas (CNG) and funding for pilot projects on oxygenated fuels (29). ${ }^{7} \mathrm{It}$ also includes a variety of transportation control measures, such as travel reduction programs, compensation for vanpool costs, and prohibition of parking in certain areas.

Connecticut 1990 legislation (table B-1) requires that new cars and trucks purchased by the State have an average MPG rating of 45 and 35, respectively, by 2000 (30) and that alternative fuel vehicles be considered in purchasing decisions. It also establishes a range of other transportation goals, including increasing average car occupancy levels, increasing use of public transportation, providing disincentives for free parking, and eventually, telecommuting for State agencies. The Department of Transportation must provide the State with an analysis of public transportation, paratransit (carpooling), and traffic management.

Two Texas acts are designed to reduce transportation $\mathrm{CO}_{2}$ emissions (table B-1; ref. 26). One prohibits State agencies with 15 or more vehicles from purchasing or leasing vehicles (after September 1991) not capable of using CNG or other alternative fuels with lower emissions. By September 1994, 30 percent of a State agency's fleet must be capable of operating on CNG or other alternative fuels; the percentage will increase to 50 percent by 1996, The second act requires the Air Control Board to encourage use of natural gas, alternative fuels, and more efficient technologies. Some Oil Overcharge funds also have been allocated for transportation programs (e.g., traffic signal synchronization, traffic management, fleet management, alternative fuels).

\footnotetext{
${ }^{5}$ Massachusetts and New York are assigning specific costs to environmental damages, as described in this paragraph for New York; Colorado, New Jersey, and Vermont are using a point system that achieves a similar result without quantifying damages in monetary terms; and Wisconsin is assigning a penalty to account for environmental damages (32),

${ }^{6}$ The State(ref. 25) has estimated the additional cost of mitigating environmental impacts from coal-fired plants to be up to 1.405 cents/kWh; costs for specific damages were estimated at 0.10 cents $/ \mathrm{kWh}$ for $\mathrm{CO}_{2}, 0.25$ cents/kWh for $\mathrm{SO}_{2}, 0.55$ cents/kWh for $\mathrm{NO}$, 0.005 cents/kWh for particulate, 0.10 cents $/ \mathrm{kWh}$ for water impacts, and 0.40 cents $/ \mathrm{kWh}$ for land use (e.g., terrestrial impacts, fuel delivery, noise, transmission, solid waste, aesthetics).

${ }^{7}$ Use of unconventional automotive fuels for vehicles, such as natural gas or electricity, do not necessarily result in lesser climatic impacts. This depends on many variables, ranging from the type of energy source used, to leakage rates (in the case of natural gas) and efficiency levels (see ch. 5).
} 


\section{Buildings}

Connecticut has several legislative provisions addressing energy use in buildings (table B-1). It requires stricter codes for commercial buildings; standards for State buildings that would reduce energy use per square foot by 30 percent by 2000 and 50 percent by 2010 ; and State purchases of energy-efficient appliances (30). It also requires that preference be given to energy-efficient projects in State housing grant and loan programs, and calls for utilities to charge higher rates for new energywasting buildings beginning in 1993.

Many States have started loan programs for retrofitting State, public school, and local government facilities, often using funds from the Oil Overcharge fund. The LoanSTAR program in Texas, which commenced in 1988, consists of a $\$ 98$ million revolving loan program for energy conservation retrofits in Texas State, local government, and public school buildings (27). ${ }^{8}$ The Governor's Energy Management Center expects that retrofits funded through November 1, 1990, will generate annual utility savings of $\$ 4.8$ million and that retrofits now being funded will generate an additional savings of $\$ 4$ million annually (26).

Both the California Energy Commission and the Northwest Power Planning Council (NPPC) have established model energy-efficient building codes for residential and commercial buildings (1 1), The California Legislature directed the California Energy Commission to prescribe, through regulations, various building design and construction standards (e.g., lighting, insulation, automatic control systems) that will increase energy efficiency in new buildings (8). ${ }^{9}$ In 1990, the State of Washington enacted legislation adopting standards equivalent to the NPPC's Model Conservation Standards for residential buildings, requiring increased efficiency in new homes and apartments (table B-1; ref. 28). ${ }^{10}$ The State estimates that resultant savings will beat least 200 megawatts of electrical power and 21 million annual therms of natural gas by 2010 (28). A State-utility collaborative program established by the act includes a public awareness and education element, as well as utility rebates.

\section{Food and Forestry}

We are unaware of any States with agricultural programs specifically designed to reduce greenhouse gas emissions. However, Minnesota has legislation address- ing the use of nitrogen fertilizers (table B-1; ref. 5). A Nitrogen Fertilizer Task Force was established to study the effects of nitrogen fertilizer use on water resources so that the State can develop best management practices, a fertilizer management plan, and nitrogen fertilizer use regulations (14).

In Georgia, the State Office of Energy Resources has a program funded by Oil Overcharge funds to increase energy efficiency in the crop processing sector (19). The Agricultural Processor Energy Conservation Service provides technical know-how and audits to processing plants. For example, Georgia Tech University has noted that the energy used in processing peanuts, at a cost of around $\$ 11$ million per year, could potentially be reduced by 10 to 20 percent if cost-effective technologies are used.

Many States have long had forest management programs of one sort or another and some are now establishing tree-planting programs in response to global warming and other concerns $(11,13,16)$. For example, New Jersey's 1990 Executive Order (table B-1; ref. 9) calls for maximizing the number of trees in the State; a program requiring replacement of trees lost as result of State construction activities has been instituted through the order.

\section{Appendix B References}

1. Alliance to Save Energy, Profiles of Energy Efficiency Projects Jointly Operated by States and Utilities (Washington, DC: November 1988).

2. American Council for an Energy-Efficient Economy, ACEEE 1990 Summer Study on Energy Efficiency in Buildings, Proceedings (Washington DC: 1990).

3. Arkansas Forestry Commission, ' 'Arkansas' Reforestation Program" (Little Rock, AR: January 1990).

4. Bean, L., Iowa Department of Natural Resources, personal communication, Nov. 5, 1990.

4a. Boyle, J., Fleishman/Hillard Inc., personal communication, Jan. 14, 1991.

5. Buzicky, G., Nitrogen Fertilizer Task Force, Minnesota Department of Agriculture, personal communication, Oct. 30, 1990.

6. Carnahan, A., "Ozone-protection Bill OK'd," Rocky Mountain News, p. 7, Apr. 17, 1990

7. Connecticut Office of Policy and Management, Energy Division, Connecticut's Energy Future, Making the Right Choices (Hartford, CT: October 1990).

8. Deller, N. J., California Energy Commission, personal communicaion, Nov. 14, 1990.

8a. Electric Power Research Institute, Least-Cost Planning in the United States: 1990, EPRI CU-6966, Project 2982-2, Final Report (Palo Alto, CA: September 1990).

9. Keene, M.L., "Leading States' Policy Responses to Global Climate Change, " paper presented to The Massachusetts Task Force on Global Climate Change (Medford, MA: Tufts University, Center

\footnotetext{
${ }^{8}$ Loans at a rate of 4.04 percent APR (Average Percentage Rate) are available for installation of energy-efficient lighting; heat@, ventilation, and air-conditioning systems; building shell improvements; computerized energy management systems; boiler efficiency improvements; energy recovery systems; and load management hardware.

${ }^{9}$ The Commission also is studying specific measures and policy options to reduce greenhouse gases, in response to Assembly Bill 4420 of 1988.

10 To offset any added costs to consumers because of the requirements, the law requires electric utilities to provide $\$ 900$ for new homes under 2,000 square feet; these payments will be available from July 1, 1991 through June 30, 1995.
} 
for Environmental Management, July 6, 1990).

10. Kowalski, J., New Mexico Department of Energy, Minerals, and Natural Resources, personal communication, Dec. 19, 1990.

11. Lashof, D.A. and E.L. Washburn, The Statehouse Effect: State Policies To Cool the Greenhouse (Washington DC: Natural Resources Defense Council, July 26, 1990).

12. Lipsher, S., "Council Bans Sale of Ozone-harming Chemicals," The Denver Post, Apr. 17, 1990.

13. National Governors' Association, Consensus for Change, A World of Difference, Report of the Task Force on Global Climate Change (Washington, DC: 1990).

14. Nitrogen Fertilizer Task Force, Recommendations of the Nitrogen Fertilizer Task Force on The Nitrogen Fertilizer Management Plan, to the Minnesota Commissioner of Agriculture (St. Paul, MN: Minnesota Department of Agriculture, August 1990).

15. Parker, S., Vermont Public Services Department, Conservation and Renewable Energy Unit, personal communication Oct. 30, 1990.

16. Renew America, Reducing the Rate of Global Warming, The States' Role (Washington, DC: November 1988).

17. Rice, B., Center for Policy Alternatives, personal communication, Nov. 13, 1990.

18. Riggs, R. W., "State Responses to the Threat of Global Warming: A Review of Policy and Legislation," paper 90-141.4 presented at 83rd Annual Meeting \& Exhibition, Air \& Waste Management Association (Pittsburgh, PA: June 24-29, 1990).

19. Robertson, E, S., Georgia Office of Energy Resources, personal communication, Nov. 6, 1990.

20. Sadler, S., Oregon Department of Energy, personal communication Oct. 31, 1990,

21. Smith, P. R., New York State Energy Office, personal communication, Dec. 4, 1990.

22. State of New Jersey Executive Department, ' Executive Order No. 219" (Trenton, NJ: Oct. 23, 1989).
23. State of New York Department of Public Service, "Consideration of Environmental Externalities in New York State Utilities' Bidding Programs for Acquiring Future Electric Capacity" (Albany, NY: 1989).

24. State of New York Public Service Commission, "Opinion and Order Establishing Guidelines for Bidding Program, " Opinion No. 89-7 (Albany, NY: Apr. 13, 1989).

25. U.S. Congress, Office of Technology Assessment, Facing America's Trash: What Next for Municipal Solid Waste? OTA-O-424 (Washington DC: U.S. Government Printing Office, October 1989).

26. Verdict, M., Governor's Energy Management Center, State of Texas, personal communication Nov. 6, 1990.

27. Verdict, M. et al., "Monitoring $\$ 98$ Million in Energy Efficiency Retrofits: The Texas LoanSTAR Program" (Austin, TX: 1989).

28. Washington State Energy Office, "Governor Gardner Signs Energy Code Bill," WSEO Dispatch, March-April 1990.

29. Weaver, R., American Public Transit Association, personal communication, Nov. 7, 1990.

30, West, C., Connecticut Office of Policy and Management, Energy Division, personal communication Dec. 11, 1990.

31. Wichert, D., Wisconsin Division of Energy and Intergovernmental Relations, personal communication, Nov. 16, 1990.

32. Wiel, S., "Facing Up to the True Environmental Costs of Electric Power Generation," preprint of paper presented at GermanAmerican Workshop on Analysis and Internalization of External Environmental Costs of Electric Power Production and Utility Acquisition (Oct. 24, 1990).

33. Zane, L., Hawaii Department of Planning and Economic Development, Energy Division, personal communication, Nov. 30, 1990. 


\section{Conversion Factors, Abbreviations, and Glossary}

\section{Conversion Factors}

1 square kilometer $\left(\mathrm{km}^{2}\right)=$ 0.386 square mile

247 acres

100 hectares

1 square mile $=$

2.59 square kilometers $\left(\mathrm{km}^{2}\right)$

$6.4 \times 10$ acres

$2.59 \times 10^{2}$ hectares

1 kilogram $(\mathrm{kg})=$

2.20 pounds $(\mathrm{lb})$

1 pound $(l b)=$

0.454 kilogram $(\mathrm{kg})$

1 quad (quadrillion Btu)=

$1.05 \times 10^{18}$ Joules $(\mathrm{J})$

1.05 exajoules (EJ)

$3.60 \times 10^{5}$ metric tons, coal

$1,72 \times 10^{6}$ barrels, Oil

$2.36 \times 10^{5}$ metric tons, oil

$2.83 \times 101^{\circ}$ cubic meters, gas

$1.07 \times 10^{12}$ cubic feet, gas

$2.93 \times 10^{2}$ terawatt hours

1 liter $(1)=$

$2.64 \times 10^{-1}$ gallons (liquid, U. S.)

$6.29 \times 10^{-3}$ barrels (petroleum, U. S.)

$1 \times 10^{-3}$ cubic meters $\left(\mathrm{m}^{3}\right)$

3.53x $10^{-2}$ cubic feet $\left(\mathrm{ft}^{3}\right)$

1 gallon (liquid, U.S. $)=$

3.78 liters (1)

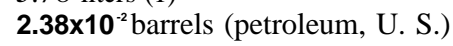

$3.78 \times 10^{-3}$ cubic meter $\left(\mathrm{m}^{3}\right)$

$1.33 \times 10^{-1}$ cubic feet $\left(\mathrm{ft}^{3}\right)$

1 barrel (bbl) (petroleum, U.S., $)=$

$1.59 \times 10^{2}$ liters (1)

42 gallons (liquid, U. S.)

$1.5 \% 10$-' cubic meters $\left(\mathrm{m}^{3}\right)$

5.61 cubic feet $\left(\mathrm{ft}^{3}\right)$

From Centigrade to Fahrenheit:

$((9 / 5) X(" C))+32={ }^{\circ} \mathrm{F}$
Area

1 acre $=$

0.405 hectare (ha)

$1.56 \times 10^{-3}$ square miles

4.05 square kilometers $\left(\mathrm{km}^{2}\right)$

1 hectare $=$

0.01 square kilometer $\left(\mathrm{km}^{2}\right)$

$3.86 \times 10^{-3}$ square miles

2.47 acres

Weight

I metric ton (ret) (or "long ton' ')= 1,000 kilograms or $\mathbf{2 , 2 0 0 ~} \mathrm{lbs}$

1 short ton=

2,000 pounds or $907 \mathrm{~kg}$

Energy

1 kilowatthour=

$3.41 \times 10^{3}$ British thermal units (Btu)

$3.6 \times 10^{6}$ Joules $(\mathrm{J})$

1 Joule $=$

$9.48 \times 10^{4}$ British thermal unit (Btu)

$2.78 \times 10^{-7}$ kilowatthours (kWh)

$I$ British thermal unit $($ Btu $)=$ $2.93 \times 10^{4}$ kilowatthours $(\mathrm{kWh})$ $1.05 \times 10^{3}$ Joules (J)

Volume

1 cubic meter $(\#)=$

$1 \times 10^{3}$ liters (1)

$2.64 \times 10^{2}$ gallons (liquid, U. S.)

6.29 barrels (petroleum, U. S.)

35.3 cubic feet $\left(\mathrm{ft}^{3}\right)$

1 cubic foot $\left(\mathrm{ft}^{3}\right)=$

2.83x 101 liters (1)

7.48 gallons (liquid, U. S.)

$1.78 \times 10^{-1}$ barrels (petroleum, U. S.)

$2.83 \times 10^{-2}$ cubic meters $\left(\mathrm{m}^{3}\right)$

1 cord wood $=$

128 cubic feet $\left(\mathrm{ft}^{3}\right)$ stacked wood

3.62 cubic meters $\left(\mathrm{m}^{3}\right)$ stacked wood

1 dry (i.e., no moisture) ton of wood

\section{Temperature}

Temperature changes:

From Fahrenheit to Centigrade. $(5 / 9) \times(\mathrm{oF}-32)={ }^{\circ} \mathrm{C}$

- To convert a Centigrade change to a Fahrenheit change: $9 / 5 \times$ (change in $\mathrm{C}$ ) = change in $\mathrm{OF}$

-To convert a Fahrenheit change to a Centigrade change: $5 / 9 \times$ (change in ${ }^{\prime} \mathrm{F}$ ) $=$ change in ${ }^{\circ} \mathrm{C}$

-Example: a $3.0^{\circ} \mathrm{C}$ rise in temperature $=$ a $5.4 \mathrm{OF}$ rise in temperature 
Carbon Contents of Various Fuel

\begin{tabular}{|c|c|c|c|}
\hline Fuel & $\begin{array}{l}\text { Pounds of carbon } \\
\text { per common unit } \\
\text { of measure }\end{array}$ & $\stackrel{\mathrm{kg}}{\mathrm{C} / 10^{9} \mathrm{~J}}$ & $\begin{array}{c}\mathrm{mg} \\
\mathrm{C} / \text { Btu }\end{array}$ \\
\hline Wood (dry poplar) . . . & $1,032 \mathrm{lbs} C /$ cord & 24.9 & 26 \\
\hline Bituminous coal (dry) & $1,300 \mathrm{lbs} \mathrm{C} / \mathrm{sh}$ ort ton & 24.4 & 26 \\
\hline Heating oil ........ & $6.4 \mathrm{lbs} \mathrm{C} / \mathrm{gal}$ & 20.0 & 21 \\
\hline Diesel fuel & $6.0 \mathrm{lbs} \mathrm{C} / \mathrm{gal}$. & 19.7 & 21 \\
\hline Crude oil. . & $255 \mathrm{lbs} \mathrm{C} / \mathrm{bbl}$ & 18.9 & 20 \\
\hline Gasoline . . . . . . . . & $5.5 \mathrm{lbs} \mathrm{C} / \mathrm{gal}$. & 18.9 & 20 \\
\hline No. 2 diesel fuel . . . & $6.0 \mathrm{lbs} \mathrm{C} / \mathrm{gal}$. & 18.8 & 20 \\
\hline Gasohol ......... & $5.3 \mathrm{lbs} \mathrm{C} / \mathrm{gal}$. & 18.8 & 20 \\
\hline Ethanot. & $3.5 \mathrm{lbs} \mathrm{C} / \mathrm{gal}$. & 17.6 & 19 \\
\hline Methanol ........ & $2.5 \mathrm{lbs} \mathrm{C} / \mathrm{gal}$ & 16.6 & 18 \\
\hline Propane ......... & $\begin{array}{l}9.5 \text { lbs Chundred cubic } \\
\mathrm{ft} \text {. }\end{array}$ & 16.3 & 17 \\
\hline Natural gas ...... & $\begin{array}{l}3.3 \text { lbs Chundred cubic } \\
\mathrm{ft}\end{array}$ & 13.6 & 14 \\
\hline Natural gas . . . . . . & $3.3 \mathrm{lbs} \mathrm{C} /$ therm & 13.6 & 14 \\
\hline Electricity (U.S. avg) & $0.4 \mathrm{lbs} \mathrm{C} / \mathrm{kWh}$ & 50.5 & 53 \\
\hline
\end{tabular}

International System of Units (S1): Prefixes

\begin{tabular}{|c|c|c|}
\hline Prefix & SI symbol & Multiplication factor \\
\hline exa & $E$ & $10^{18}(1,000,000,000,000,000,000)$ \\
\hline peta & $P$ & $10^{15}(1,000,000,000,000,000)$ \\
\hline tera & $\mathrm{T}$ & $10^{12}(1,000,000,000,000)$ \\
\hline giga & G & $10^{\circ}(1,000,000,000)$ \\
\hline mega & M & $10^{6}(1,000,000)$ \\
\hline kilo & k & $10^{3}(1,000)$ \\
\hline hecto & $\mathrm{h}$ & $10^{2}(100)$ \\
\hline deca & da & 10 \\
\hline \multicolumn{3}{|c|}{$\begin{array}{l}\text { EXAMPLES: } 1 \text { Teragram or } \mathrm{Tg}\left(10^{12} \text { or } 1,000,000,000,000 \text { or } 1 \text { trillion }\right. \\
\text { grams); } 1 \text { megawatt-electric or } \mathrm{MWe}\left(10^{6} \text { or } 1,000,000 \text { or } 1\right. \\
\text { million watts-electric). }\end{array}$} \\
\hline \multicolumn{3}{|c|}{$\begin{array}{c}\text { EXCEPTION: } 10^{15}(1,000,000,000,000,000) \text { British thermal units }(B t u) \text { is } \\
\text { not generally referred to as a PBtu. Instead it is known as a } \\
\text { quad, or one quadrillion Btu's. }\end{array}$} \\
\hline
\end{tabular}

\section{Abbreviations}

\begin{tabular}{|c|c|c|c|}
\hline $\mathrm{ACP}$ & -Agricultural Conservation Program & DOE & —U.S. Department of Energy \\
\hline ADF & -African Development Foundation & DSM & —Demand-side management \\
\hline A.I.D. & -Agency for International Development & EAA & —Export Administration Act \\
\hline AQMP & -Air Quality Management Plan & EADC & -Energy Analysis and Diagnostic Center \\
\hline ASCS & $\begin{array}{l}\text {-Agricultural Stabilization and Conservation } \\
\text { Service }\end{array}$ & $\begin{array}{l}\text { EES } \\
\text { EIA }\end{array}$ & $\begin{array}{l}\text {-Energy Extension Service } \\
\text { —Energy Information Administration }\end{array}$ \\
\hline ASD & —Adjustable speed drive & EITC & -Energy investment tax credit \\
\hline ASHRAE & $\begin{array}{l}\text {-American Society of Heating, Refrigeration } \\
\text { and Air-Conditioning Engineers }\end{array}$ & $\begin{array}{l}\text { EPA } \\
\text { EPRI }\end{array}$ & $\begin{array}{l}\text { —Environmental Protection Agency } \\
\text { —Electric Power Research Institute }\end{array}$ \\
\hline ATNT & $\begin{array}{l}\text { —Accelerated Turnover and New } \\
\text { Technologies }\end{array}$ & ESMAP & $\begin{array}{l}\text {-Energy Sector Management Assistance } \\
\text { Program }\end{array}$ \\
\hline BEPS & —Building Energy Performance Standards & FAO & -Food and Agriculture Organization \\
\hline BLS & —Bureau of Labor Statistics & FBC & —Fluidized-bed combustor \\
\hline BMPs & —Best management practices & FEMIA & —Federal Energy Management Improvement \\
\hline Btu & —British thermal unit & & Act \\
\hline CAFE & -Corporate Average Fuel Efficiency & FEMP & —Federal Energy Management Program \\
\hline CARE & $\begin{array}{l}\text { - Cooperative for American Relief } \\
\text { Everywhere }\end{array}$ & $\begin{array}{l}\text { FERC } \\
\text { FIP }\end{array}$ & $\begin{array}{l}\text {-Federal Energy Regulatory Commission } \\
\text {-Forestry Incentives Program }\end{array}$ \\
\hline CARP & -Cooperative Automotive Research Program & GAO & -General Accounting Office \\
\hline CBO & -Congressional Budget Office & GATT & -General Agreement on Tariffs and Trade \\
\hline CFCs & —Chlorofluorocarbons & GCM & -General circulation model \\
\hline CGIAR & $\begin{array}{l}\text {-Consultative Group on International } \\
\text { Agricultural Research }\end{array}$ & $\begin{array}{l}\text { GDP } \\
\text { GNP }\end{array}$ & $\begin{array}{l}\text { —Gross Domestic Product } \\
\text { —Gross National Product }\end{array}$ \\
\hline $\mathrm{CH}_{9}$ & --Methane & GRI & —Gas Research Institute \\
\hline & —Compressed natural gas & HCFC & —Hydrochlorofluorocarbon \\
\hline & -Carbon dioxide & HERS & -Home Energy Rating System \\
\hline & $\begin{array}{l}\text {-Comprehensive Omnibus Budget } \\
\text { Reconciliation Act }\end{array}$ & $\begin{array}{l}\text { HFC } \\
\text { HUD }\end{array}$ & $\begin{array}{l}\text {-Hydrofluorocarbon } \\
\text {-U.S. Department of Housing and Urban }\end{array}$ \\
\hline COCOM & $\begin{array}{l}\text {-Coordinating Committee on Multilateral } \\
\text { Export Controls } \\
\text {-Committee on Renewable Energy }\end{array}$ & HVAC & $\begin{array}{l}\text { Development } \\
\text { - Heating, ventilation, air-conditioning } \\
\text { equipment }\end{array}$ \\
\hline & Commerce and Trade & IAF & -Inter-American Foundation \\
\hline CRP & —Conservation Reserve Program & ICP & -Institutional Conservation Program \\
\hline CRS & -Congressional Research Service & IDB & -Inter-American Development Bank \\
\hline
\end{tabular}




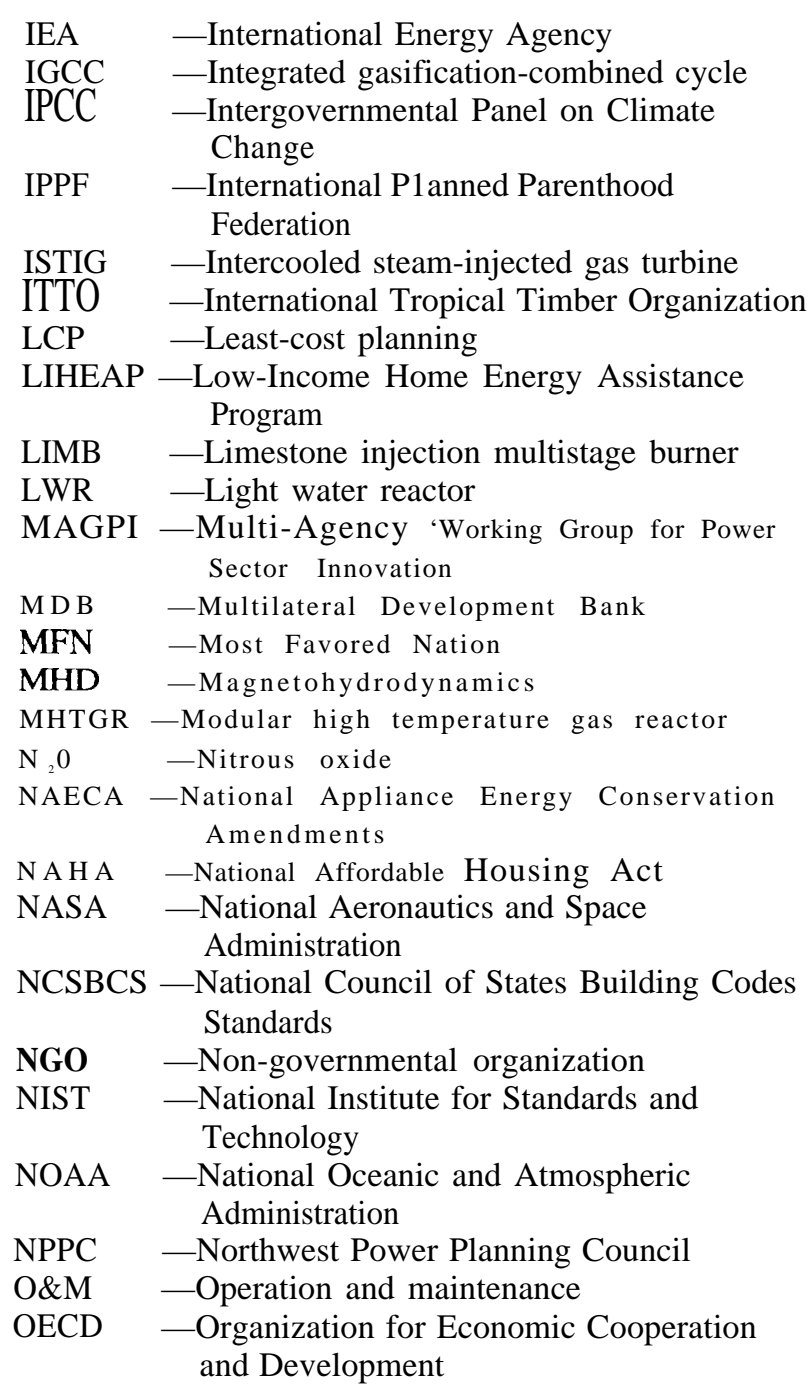

OIP -Office of Industrial Programs

OPIC -Overseas Private Investment Corp.

ORNL -Oak Ridge National Laboratory

PACER - Program for the Acceleration of Commercial Energy Research

PURPA —Public Utility Regulatory Policies Act

PV -Photovoltaic

RCS - Residential Conservation Service

RD\&D -Research, Development, and Demonstration

REDAC - Renewable Energy Design Assistance Center

SCS - Soil Conservation Service

SECP - State Energy Conservation Program

SEECB - Solar Energy and Energy Conservation Bank

SEED - Support for Eastern European Democracy

SERI - Solar Energy Research Institute

SES - Shared Energy Savings

SLAP - State and local assistance programs

TCM - Transportation control measure

TDP - Trade and Development Program

TFAP - Tropical Forestry Action Plan

UNDP - United Nations Development Program

UNEP -United Nations Environment program

UNFPA -United Nations Fund for Population

Activities (UN Population Fund)

USDA -U.S. Department of Agriculture

USECRE - U.S. Export Council for Renewable Energy

USFS -U.S. Forest Service

UV - Ultraviolet radiation

VAFE - Volume Average Fuel Economy

VMT - Vehicle miles traveled

WAP - Weatherization Assistance Program

WMO — World Meteorological Organization

\section{Glossary}

Aerosols: Microscopic particles suspended in the atmosphere, originating from both natural sources (e.g., volcanoes) and human activities (e.g., coal burning).

Al bedo: The reflectivity of the Earth.

Appliance: Any household energy-using device.

Biodiversity: Biological diversity, i.e., the variety of species in a given area.

Biomass: Technically, the total dry organic matter or stored energy content of living organisms in a given area. As used by OTA, biomass refers to forms of living matter (e.g., grasses, trees) or their derivatives (e.g., ethanol, timber, charcoal) that can be used as a fuel.

Btu (British thermal unit): The amount of heat needed to raise the temperature of 1 pound of water by 1 'Fat a specified temperature.
Carbon budget: The sum of the flows of carbon to and from a carbon reservoir. See also Carbon cycle.

Carbon cycle: General term used in reference to the sum of all reservoirs and flows of carbon on Earth. The flows tend to be cyclic in nature; for example, carbon removed from the atmosphere (one reservoir) and converted into plant tissue (another reservoir) is returned back into the atmosphere when the plant is burned.

Carbon dioxide fertilization: The enhancement of plant growth in response to an increase in the concentration of atmospheric $\mathrm{CO}_{2}$.

Carbon reservoir or sink: Within the carbon cycle, the physical site at which carbon is stored (e.g., atmosphere, oceans, Earth's vegetation and soils, and fossil fuel deposits), 
Chlorocarbon: A compound containing chlorine and carbon; examples include carbon tetrachloride and methyl chloroform, both of which are ozone depleters.

Cloroflourocarbons: Compounds containing chlorine, fluorine, and carbon; they generally are used as propellants, refrigerants, blowing agents (for producing foam), and solvents. They are identified with numbered suffixes (e. g., CFC-11, CFC-12) which identify the ratio of these elements in each compound. They are known to deplete stratospheric ozone and also are ' greenhouse' gases in that they effectively absorb certain types of radiation in the atmosphere.

Climate: The statistical collection and representation of the weather conditions for a specified area during a specified time interval (usually decades).

Climate anomaly: The "significant" deviation of a particular climate variable from its long-term average.

Cogeneration: The simultaneous generation of both electric power and heat; the heat, instead of being discharged without further use. is used in some fashion (e.g., in district heating systems).

Deforestation: Converting forest land to other vegetation or uses (e. g., cropland, pasture, dams).

Demand-side management. The planning, implementation, and monitoring of utility activities designed to encourage customers to modify their pattern of electricity usage.

Discount rate: The rate at which money grows in value (relative to inflation) if it is invested.

Emissions: Flows of gases, liquid droplets, or solid particles into the atmosphere. Gross emissions from a specific source are the total quantity released. Net emissions are gross emissions minus flows back to the original source. Plants, for example, take carbon from the atmosphere and store it as biomass during photosynthesis, and they release it during respiration, when they decompose, or when they are burned.

Energy intensity: The amount of energy required per unit of a particular product or activity. Often used interchangeably with ' 'energy per dollar of GNP.'

Energy services: The service or end use ultimately provided by energy. For example, in a home with an electric heat pump, the service provided by electricity is not to drive the heat pump's electric motor but rather to provide comfortable conditions inside the house.

Feedback: When one variable in a system (e.g., increasing temperature) triggers changes in a second variable (e.g., cloud cover) which in turn ultimately affect the original variable (i. e., augmenting or diminishing the warming). A positive feedback intensifies the effect. A negative feedback reduces the effect.

Fluorocarbon: A compound containing fluorine and carbon; among these are chlorinated fluorocarbons (CFCs) and brominated fluorocarbons (haIons).
Fossil fuel: Coal, petroleum, or natural gas or any fuel derived from them.

Generating capacity: The capacity of a powerplant to generate electricity, typically expressed in wattselectric (e.g., kWe or MWe).

Greenhouse effect: The effect produced as certain atmospheric gases allow incoming solar radiation to pass through to the Earth's surface, but prevent the (infrared) radiation, which is reradiated from the Earth from escaping into outer space. The effect responsible for warming the planet.

Greenhouse gas: Any gas that absorbs infrared radiation in the atmosphere.

Halocarbon: A compound containing carbon and at least one halogen.

Halogen: Any one of the following chemical elements: bromine, chlorine, fluorine, iodine, or astatine.

Halogenated: A compound containing a halogen. A fully halogenated $\mathrm{CFC}$ is one in which all hydrogen has been replaced with chlorine and/or fluorine. A partially halogenated $\mathrm{CFC}$ is one in which some hydrogen remains.

HaIon: Compounds containing bromine, commonly used as fire extinguishing agents.

Heat-island effect: The tendency of large urbanized areas to increase local temperatures, creating 'heat islands' surrounded by cooler countrysides.

Hydrochlorofluorocarbon: A chlorofluorocarbon that contains some hydrogen (i.e., a "partially halogenated" chlorofluorocarbon); an example is HCFC-22.

Hydrofluorocarbon: Compounds containing hydrogen, fluorine, and carbon. Unlike CFCs, they do not contain chlorine.

Infrared radiation: Radiation with wavelengths roughly between 700 and 1000 nanometers; these wavelengths are longer than those of visible light.

Least-cost planning: In energy planning, the practice of basing investment decisions on the least costly option for providing energy services. It is distinguished from the more traditional approach taken by utilities, which focuses on the least costly way to provide specific types of energy, with little or no consideration of less costly alternatives that provide the same energy service at lower costs.

Life cycle cost: The cost of a good or service over its entire life cycle.

Methane: A compound consisting of one carbon atom and four hydrogen atoms; it occurs naturally, often in association with coal and petroleum (see Natural gas below) and as a byproduct of the metabolic activities of some microorganisms; it also can be synthesized artificially. 
Monoculture: The exclusive cultivation of single species (e.g., corn or soybeans), a common practice in modern agriculture.

Montreal Protocol: The principal international agreement under which ozone-depleting compounds are regulated.

Natural gas: A naturally occurring mixture of hydrocarbons (principally methane) and small quantities of other gases found in porous geological formations, often in association with petroleum.

OECD: Organization for Economic Cooperation and Development, an organization that includes most of the world's industrialized, market economies. Members include Australia, Austria, Belgium, Canada, Denmark, Finland, France, Germany, Greece, Iceland, Ireland, Italy, Japan, Luxembourg, Netherlands, New Zealand, Norway, Portugal, Spain, Sweden, Switzerland, Turkey, United Kingdom, and United States.

Ozone: A molecule consisting of three oxygen atoms; in the atmosphere, it is found in both the stratosphere and the troposphere. Ozone effectively absorbs certain forms of solar ultraviolet radiation known to damage living organisms. It also absorbs certain wavelengths of infrared radiation and therefore is a 'greenhouse' gas.

Ozone layer: Ozone found throughout the stratosphere.

Particulate: Airborne particles.

Photochemical reaction: A chemical reaction triggered by sunlight.

Primary productivity: The rate at which radiant energy is stored by the photosynthetic and chemosynthetic activities of producer organisms (e.g., green plants) in the form of organic substances which can be used as food materials,

Radiation: See Infrared radiation and Ultraviolet radiation.

Radiative forcing: The degree to which changes in the radiative balance of the atmosphere cause changes in temperatures.

Retrofit: To update an existing structure or technology by modifying it, as opposed to creating something entirely new from scratch. For example, an old house can be retrofitted with advanced windows to slow the flow of energy into or from the house.

Sequester: To isolate and remove something. As used here, the processes by which carbon dioxide is removed from the atmosphere and retained for some period in a carbon reservoir (e.g., trees).

Stratosphere: The upper portion of the atmosphere, between 11 and $50 \mathrm{~km}$ above the surface of the Earth; in contrast to the troposphere, temperatures change little with changing altitude, clouds are rare, and convection is minimal. The stratosphere also holds relatively higher concentrations of ozone, resulting in what is known as the 'ozone layer'

Sustainable: A term used to characterize human activities that can be undertaken in such a manner as to not adversely affect the environmental conditions (e.g., soil, water quality, climate) necessary to support those same activities in the future.

Temperate: Relating to the region between the tropics and the polar circles (between $23.5^{\circ}$ and 66.5 o) in both hemispheres.

Trace gas: Atmospheric gases that exist in relatively small or ' 'trace' concentrations.

Tropical: Relating to the region between the Tropic of Cancer and the Tropic of Capricorn $\left(23.5^{\circ}\right.$ North and $23.5^{\circ}$ South, respectively).

Troposphere: The portion of the atmosphere which extends outward from the Earth's surface to about 16 $\mathrm{km}$, directly below the stratosphere; temperatures generally decrease rapidly with altitude, clouds form, and convection is active.

Ultraviolet radiation: Radiation with wavelengths roughly between 200 and 400 nanometers; these wavelengths are shorter than those of visible light and longer than those of X-rays.

Watt (W): A common unit used in measuring power (i.e., as the flow of energy overtime), equivalent to $3.41 \mathrm{Btu}$ per hour. Where an ' $\mathrm{e}$ ' follows the unit (as in $\mathrm{kWe}$ or $\mathrm{MWe}$ ), the watt is in the form of electrical energy. Where a " $\mathrm{t}$ " follows the unit (as in $\mathrm{kWt}$ or MWt), the watt is in the form of thermal energy, 
Five separate Advisory Panels are listed at the front of the report. The 106 members of the Advisory Panels participated in the workshops listed below and reviewed drafts of the relevant chapters.

\title{
Energy Use in Buildings and Greenhouse Gas Emissions March 29, 1989 \\ William U. Chandler, Chairman
}

\author{
Workshop on Innovation in the U.S. Construction Industry \\ March 30, 1989 \\ Henry Kelly, Chairman
}

Energy Use in Transportation and Greenhouse Gas Emissions April 6, 1989

William U. Chandler, Chairman

Energy Use in Industry May 11, 1989

William U, Chandler, Chairman

Energy Supply and Greenhouse Gas Emissions May 16, 1989

William U. Chandler, Chairman

The U. S., Developing Countries, and Global Warming September 13, 1989

Michael Greene, Chairman

Additionally, we had special review groups for the forestry and food chapters (listed below). Finally, many other people contributed information and/or participated in several layers of external review over the past 2 years.

\section{Forest Review Group}

H. Akbari

Lawrence Berkeley Laboratory

Samuel Baldwin

Office of Technology Assessment

Scott Berg

American Forest Council

Clark Binkley

Yale University

Richard Birdsey

U.S. Forest Service

Daniel Botkin

University of California, Santa Barbara

Sandra Brown

University of Illinois

Stephanie Caswell

U.S. Department of State

Paul Cough

U.S. Environmental Protection Agency

Janet Cushman

Oak Ridge National Laboratory

John Ewel

University of Florida
Philip M. Fearnside

National Institute for Research in the Amazon (INPA) Brazil

Jerry Franklin

University of Washington

Jane Freeman

National Association of State Foresters

B.C,Y. Freezailah

International Tropical Timber Organization

Carl Gallegos

U.S. Agency for International Development

Ross Gorte

Office of Technology Assessment

Judy Gradwohl

Smithsonian Institution

Dwight Hair

American Forest Association

David Harcharik

U.S. Forest Service

Gary Hartshorn

World Wildlife Fund
Kate Heaton

Bruce Co.

Alison Hess

Office of Technology Assessment

Colin High

Dartmouth College

R.A. Houghton

Woods Hole Research Center

Twig Johnson

U.S. Agency for International Development

Agnes Kiss

World Bank

John Michael Kramer

International Resource Group

Jean-Paul Lanly

U.N. Food and Agriculture Organization

Gerald Leach

Stockholm Environment Institute

Ariel Lugo

Institute of Tropical Forestry

Edward MacDonald

U.S. Environmental Protection Agency 
Gregg Marland

Oak Ridge National Laboratory

Gary A. Moll

American Forestry Association

Robert Moulton

U.S. Forest Service

Norman Myers

Oxford University

Phil O'Keefe

\section{ETC (U)}

Keith Openshaw

World Bank

Walter E. Parham

Office of Technology Assessment

John Potter

Consultant

David C. Rinebolt

National Wood Energy Association

Frank Baker

Winrock International Institute for Agricultural Development

Janet Brown

World Resources Institute

Lauretta Burke

U.S. Environmental Protection Agency

Michael Dow

National Academy of Sciences

Patricia Durana

Office of Technology Assessment

James Dyer

Rocky Mountain Institute

Debbie Fesser

National Corn Growers Association

Kirk Gadzia

Center for Holistic Resource Management

Earle Gavett

U.S. Department of Agriculture

Peter Groffman

University of Rhode Island

Thurman Grove

U.S. Agency for International

Development
Bruce Ross

International Resource Group

R. Neil Sampson

American Forestry Association

Jeff Schweitzer

U.S. Agency for International Development

Roger Sedjo

Resources for the Future

Susan Shen

World Bank

P. Gregory Smith

Society of American Foresters

William Sommers

U.S. Forest Service

Benjamin stout

National Council of the Paper Industry for Air and Stream Improvement, Inc.

\section{Food Review Group}

Kathleen Hartnett

National Cattlemen's Association

Roland Hauck

Tennessee Valley Authority

National Fertilizer Development and Environmental Research Center

Brian Holmes

University of Wisconsin

Gordon Hutchinson

USDA Agricultural Research Service

Donald Johnson

Colorado State University

Donald Kaufman

USDA Agricultural Research Service

Clyde Kiker

University of Florida

Elaine Matthews

Goddard Institute for Space Studies

National Aeronautics and Space

$$
\text { Administration }
$$

John Nickel

Centro Internacional de Agricultural Tropical

Colombia
Tim Sullivan

Smithsonian International Center

Mark Trexler

World Resources Institute

Christopher Uhl

Pennsylvania State University

R.I. Van Hook

Oak Ridge National Laboratory

Noel Vietmeyer

National Academy of Sciences

Jack Winjum

U.S. Environmental Protection Ageney
Calvin Parnell

Texas A\&M University

David Pimentel

Cornell University

Norman Rosenberg

Resources for the Future

Philip Rutter

Badgersett Research Farm

Richard Straub

University of Wisconsin

Henry Tyrrell

USDA Ruminant Nutrition Lab

Richard Wiles

National Research Council

Richard Wheeler

Rodale Institute

Garth Youngberg

Institute for Alternative Agriculture

\section{Other Reviewers and Contributors}

Rick Adcock

Tufts University

Daniel Albritton

National Oceanic and Atmospheric Administration
John Alic

Office of Technology Assessment

Ken Andrasko

U.S. Environmental Protection Agency
Jim Angell

National Oceanic and Atmospheric Administration

Bradford Ashton

Battelle, Pacific Northwest Laboratories 
Adela Backiel

Congressional Research Service

Tim Barnett

University of California, San Diego

David W. Barns

Battelle, Pacific Northwest Laboratories

Larry Bean

Iowa Department of Natural Resources

Richard Benedict

Conservation Foundation

Fred Bernthal

National Science Foundation

Peter Blair

Office of Technology Assessment

Stewart Boyle

Association for the Conservation of Energy, U.K.

Richard Bradley

U.S. Department of Energy

Marilyn Brown

Oak Ridge National Laboratory

Rodolfo Bulatao

World Bank

Sharon Burke

Office of Technology Assessment

Greg Buzicky

Minnesota Department of Agriculture

Sharon Camp

Population Crisis Committee

Ray Cantrell

Bureau of Mines

U.S. Department of the Interior

Robert Cess

State University of New York at Stony Brook

Bill Clark

Howard University

Melvin Conant

Melvin Conant \& Associates, Ltd.

Kenneth A. Cook

Center For Resource Economics

Ruth Caron Cooper

Lawrence Berkeley Laboratory

Alan Crane

Office of Technology Assessment

Ann Cronin-Cossette

Embassy of Canada

Charlie Curtis

Van Ness, Feldman, Curtis and Levenberg

Nancy Deller

California Energy Commission

Mark DeLuchi

Princeton University
Denis Dewez

Embassy of Belgium

Henry Diaz

National Oceanic and Atmospheric Administration

Roger Dower

World Resources Institute

Alford Drinkwater

Arkansas Industrial Development

Commission

V. Duleep

Energy and Environmental Analysis, Inc.

Joy Dunkerley

Office of Technology Assessment

Jim Durana

EOSAT

Gautum Dutt

Princeton University

Jae Edmonds

Battelle, Pacific Northwest Laboratories

Michael Faser

Oxford University

Jay Fein

National Science Foundation

Tom Foley

Northwest Power Planning Council

Doug Foy

Conservation Law Foundation

Robert Fri

Resources for the Future

Ken Friedman

U.S. Department of Energy

R.M. Fujita

Environmental Defense Fund

Inez Fung

National Aeronautics and Space Administration

John Garber

National Geographic

E. Norbert Garrett

Central Intelligence Agency

Clark W. Gellings

Electric Power Research Institute

Michael Gibbs

ICF Consulting Associates

Lev Ginzburg

Applied Biomathematics

Thomas Gleason

International District Heating and Cooling Association

Peter H. Gleick

Pacific Institute for Studies in Development, Environment, and Security
Ronnie L. Goldberg

U.S. Council for International Business

Marshall Goldman

Harvard University

Norman Gomm

Embassy of Australia

Thomas O. Gray

Council for Renewable Energy Education

Eric Green

American Council on U.S.-Soviet

Relations

David L. Greene

Oak Ridge National Laboratory

Paul Gromer

Massachusetts Division of Energy Resources

Daniel Guttman

Spiegel \& McDiarmid

David Hafemeister

Lawrence Berkeley Laboratory

Jeff Harris

U.S. Department of Energy

John Harte

Congressional Research Service

Barbara Harwood

Consultant

Carl Haub

Population Reference Bureau

Alan Hecht

U.S. Environmental Protection Agency

Susanna Hecht

University of California, Los Angeles

Karl Hellman

U.S. Environmental Protection Agency

Ed Hewett

The Brookings Institution

George Hidy

Electric Power Research Institute

Richard Hilt

Gas Research Institute

Eric Hirst

Oak Ridge National Laboratory

John Hoffman

U.S. Environmental Protection Agency

Sverker Hogberg

Embassy of Sweden

Paul Holtberg

Gas Research Institute

Mary Horn

World Bank

Ron Hughes

Energy Rated Homes of America

Peter Hunt

Peter Hunt Associates 
Edward Hutabarat

Embassy of Endonesia

Peter Impara

International Resources Group

Wes Jackson

The Land Institute

Barbara Jancar

State University of New York, Brockport

Kempton Jenkins

ARMCO

Roger Jennings

British Embassy

Skip Johns

Office of Technology Assessment

Eric Johnson

Georgetown University

Dennis Johnson

Tropical Research and Development, Inc.

Evy Jordan

Embassy of Denmark

John Justus

Congressional Research Service

Tom Karl

National Oceanic and Atmospheric Administration

Maurice Kaya

Hawaii Department of Planning and Economic Development

Michelle L. Keene

Tufts University

Bill Keepin

Consultant

Dale Kellogg

University Corporation for Atmospheric Research

William J. Kelly

Battelle Columbus Laboratory

Greta Kieman

New Jersey Board of Public Utilities

Andreas Klassen

Embassy of the Federal Republic of Germany

Pat Koshel

U.S. Agency for International

Development

Paul Komor

Office of Technology Assessment

Jon Kramer

University of Maryland

John Kutzbach

University of Wisconsin-Madison

Karen Larsen

Office of Technology Assessment

Richard Lawson

National Coal Association
Marc Ledbetter

American Council for an Energy-Efficient Economy

Henry Lee

Cambridge University

Henry R. Linden

Gas Research Institute

Ronnie D. Lipschutz

Pacific Institute for Studies in

Development, Environment, and Security

Phil Liu

U.S. Environmental Protection Agency

Manuel Lorenzo

Embassy of Spain

J.E. Loveland

University of Washington

Nancy Lubin

Carnegie-Mellon University

James MacNeill

Institute for Research on Public Policy

John Martin

Moss Landing Marine Laboratories

Roger McKeska

National Cattlemen's Association

Jim McMahon

Lawrence Berkeley Laboratory

A. Meier

Lawrence Berkeley Laboratory

Jerry Meehl

National Center for Atmospheric Research

Bert Metz

Embassy of the Netherlands

Steve Meyers

Massachusetts Institute of Technology

Russell Mittermeier

Conservation International

David Montgomery

Congressional Budget Office

William Moomaw

Tufts University

Mary Lou Muntz

Wisconsin Public Service Commission

Roger Naill

Applied Energy Services, Inc.

Shinkichi Nakamura

Toyota Motors

John Newman

Office of Technology Assessment

Flo Ormond

National Aeronautics and Space Administration

Erik Ovesen

Embassy of Denmark
Edith Page

Office of Technology Assessment

Garth W. Paltridge

National Oceanic and Atmospheric Administration

S. Parker

Vermont Public Service Department

Bruce Pasternak

Booz Allen

Ralph Perhac

Electric Power Research Institute

Loretta Platt

Massachusetts Division of Energy Resources

Steve Plotkin

Office of Technology Assessment

Philip R. Pryde

San Diego State University

Dave Publicover

Yale University

Lucio Reca

Enter-American Development Bank

Bill Rice

Center for Policy Alternatives

Lisa Ritter

National Geographic

Joseph Riva

Congressional Research Service

Walter Orr Roberts

University Corporation for Atmospheric Research

Elizabeth Sparrow Robertson

Georgia Office of Energy Resources

Sherwood Rowland

University of California, Irvine

Chet Ropelewski

National Oceanic and Atmospheric Administration

John Ross

Debt-for-Development Coalition

Dick Rowberg

Congressional Research Service

Regine Roy

Commission of the European Communities

Robin Roy

Office of Technology Assessment

Nafis Sadik

United Nations Fund for Population Activities

Sam Sadler

Oregon Department of Energy

Pedro Sanchez

North Carolina State University 
Roger Sant

Applied Energy Systems

J.L. Sarmiento

Princeton University

Maxine Savitz

Garrett Engineering Corp.

Gerson Scher

National Science Foundation

Lee Schipper

Lawrence Berkeley Laboratory

Michael Schlesinger

University of Illinois at Urbana-Champaign

Steve Schneider

National Center for Atmospheric Research

Tom Secrest

Battelle, Pacific Northwest Laboratories

Joanne Seder

Office of Technology Assessment

Stephen Seidel

U.S. Environmental Protection Agency

Eileen Shea

National Oceanic and Atmospheric Administration

Ed Sheets

Northwest Power Planning Council

Yasuhiro Shimizu

Embassy of Japan

Christine Shirley

Pacific Institute for Studies in Development, Environment, and Security

Marshall Shulman

Columbia University

Scott Sklar

U.S, Export Council for Renewable Energy

John E. Smith

New York State Energy Office
Peter Smith

New York State Energy Office

Ralph Smuckler

Michigan State University

Robert Socolow

Princeton University

Bruce Strain

Enron Corp.

Joel Swisher

Stanford University

David Tarbell

International Economics and Energy Affairs

The Pentagon

David Taylor

Embassy of New Zealand

Helene Kirwan-Taylor

Office of Technology Assessment

Dennis Tirpak

U.S. Environmental Protection Agency

Barbara Torrey

Bureau of the Census

Jim Tripp

Consultant

Comptom Tucker

National Aeronautics and Space Administration

Malcolm Verdict

State of Texas Governor's Energy Management Center

Peter Vitousek

Stanford University

C. Waeterloos

Directorate-General for Energy

Commission of the European Communities

Thomas F. Walton

General Motors Corp.
Thomas Waltz

World Bank

Robert Watson

National Aeronautics and Space Administration

\section{Rich Weaver}

American Public Transit Association

Carolyn West

Connecticut Office of Policy and Management

Bill Westermeyer

Office of Technology Assessment

Leif Westgaard

Embassy of Norway

Don Wichert

Wisconsin Division of Energy and Intergovernmental Relations

Jonathan Wiener

U.S. Department of Justice

Jack W. Wilkinson

Sun Company Inc.

Richard S. Williams, Jr.

U.S. Geological Survey

Robert Winterbottom

International Institute for Environment and Development

George M. Woodwell

Woods Hole Research Center

Mark Worwick

Oregon Energy Commission

Oskar Zaborsky

National Research Council

Lynn Zane

Hawaii Department of Planning and Economic Development 


\section{Index}


acid rain: 7

afforestation: see tree planting

African Development Bank: 39, 283, 292, 293

African Development Foundation: 39,287, 293

Agency for International Development

bilateral aid: $34,35,37-40,87,202,229-231,244,264,265$, $279-282,284,286,287,289-293$

congressional directives: 34, 39, 229, 274, 281, 282, 292

energy-related projects: $34,35,38,39,281,282, \quad 284,291,292$

"key" countries: 39, 282

natural resources projects: 34, 38, 229-232, 282

Office of Energy: 39

Agricultural Conservation Program: 28, 225-227

Agricultural Research Service: 262

Agricultural Stabilization and Conservation Service: 28, 35, $201,223,225,226$

agriculture: see crops, commodity support, food, forests agroforestry: 201, 202, 216-219, 230, 231, 257, 290 air-conditioning: $3,17,33,61,63,116-121,124,126,127,131$, $134,151,215,288,318,328$

Air Quality Management Plan: 169-171, 329

albedo: 215

aluminum: see primary metals

American Society of Heating,

Refrigeration and Air-Conditioning Engineers: 140

America the Beautiful Program: 29, 30, 227

Antarctica, Antarctic Ocean: 52,53, 58, 65,72,73

appliances: 8, 107, 116-119, 121, 124, 125, 128, 130, 132-136, $138-142,302,314,315,318,323,324,330$

also see regulations

Applied Energy Services: 218

Asian Development Bank: 36, 283

audits, energy: 14, 17, 20, 25, 107, 141, 192, 195, 196

Australia: 7,81, 82, 150, 300, 304, 305

automobiles and trucks

also see fuels, transportation, transportation control measures

Cooperative Automotive Research Program: 171

Eastern Europe: 150, 154

electric vehicles: $159,160,164,171-172$

emissions: $8,149,157,158,162-164,314$

energy use: $20,150,154-157$

fuel economy standards: 22, 149, 165-167, 305, 327

fuel efficiency: $11,17,21,149,153,154,157-166,301,318$, $319,324,327,329$

fuel prices: $149,159,160,165,166$

Gas Guzzler Tax: 167

hydrogen vehicles: 160,172

manufacturers' incentives: 167,168

O\&M: 157, 161, 162, 168,318, 324

ownership patterns: $150,152-154$

rebates: $149,165-167$

safety: 159,171

size: $21,149,157,159,161,162,166,167,319,324$

speed limits: $160-162,168,320,324$

U. S. S. R.: 150,154

vehicle miles travelled: $149,150,157,158,161-163,165$, $168-170,324$ best management practices: $31,264,265,330$

bicycles: 160, 161, 163, 168

biodiversity: 38,201,204-206,212,213, 217,221,225,253,291

biomass burning

agriculture: $85,246-248,250-253,262$

cooking: $38,85,86,127,128,250-255,260$

forests: $60,86,203,204,248,250$

biomass energy: $13,77,78,80,85-89,97,99,109,126,227$, $273,287-289,321,325$

competitiveness: $28,86,103,201,202,214,227,325$

crops for energy: $27,28,85,86,89,201,202,206,214,215$, $227,319,325$

emissions: $38,79,85,214,215,319$

in manufacturing: $182,188,190$

traditional fuels: $38,85,86,127-129,248,253,260,274,288$

Bonneville Power Authority: 26, 107

Brazil: 33,39,68, 78,80, 87, 89,91, 152, 153, 156, 221,223, $228,274,275,278,287-289$

brominated compounds: $61,62,64$

buildings

also see heating, insulation, lighting, shells, windows

Building Energy Performance Standards: 19, 144

CFCs: $115,119,126,127$

codes: 14, 16, 19, 115, 119, 120,124, 135, 137, 139, 140, 330

cogeneration: $126,131-134,138,318,324$

commercial: $115,118,122,128,131-134,318,319,323-324$

cooking: $116,124,127,128$

developing countries: 127,128

Eastern Europe: 119, 121, 295

emissions: 7, 8, 58, 115-117, 129-133, 314, 317-319

energy efficiency: $11,17,90,119-134,137,323,324,330$

energy management systems: $119,124,125$

energy use: 115-133, 135, 140, 274, 300, 301, 313

home energy rating systems: 140,141

mortgage incentives: 141

policies: $134-142$

R\&D: 20, 125, 133, 135, 142

residential: 115-118, 122, 128-130, 132-134, 301, 318, 323, 327

retrofitting: 118-120, 130-134, 136, 330

"smart' homes: 124,125

U. S. S. R.: 119, 121,295

Bureau of Land Management: 28, 209, 212,225

buses: $150,156,161,169,170,320$

California Energy Commission: 330

Canada: 7,33,81-83,87,117, 150,153,156, 165,187,204,275, $279,297,300,301,304,305$

carbon: see carbon dioxide emissions, taxes; individual fuels, sectors, countries

cycle: 201, 203, 204

carbon dioxide, atmospheric

concentrations: $45,54,56,58$

contribution to radiative forcing: $54-57$

doubling of: $49,50,52$

global warming potential: $3,55,56$

ice core measurements: 56,57

lifetime in atmosphere: 55,58

Mauna Loa record: 56,58 
stabilization of atmospheric concentrations: 46,58

carbon dioxide emissions: $3-41,56-58,80,92-110,116,117$, $129-133,149,151,155-164,171,177,181-195,201-223$, $273,274,313-320$

also see biomass burning, deforestation, emissions; individual sectors, countries

carbon dioxide sinks: 58, 72, 73, 250

also see emissions (forestry offsets), forestry

carbon sequestration: see emissions (forestry offsets), forestry

carbon tetrachloride: $62,65,68$

cattle: see livestock, tropical forests

cement manufacturing: 57, 177, 181

centrally -planned economies: see China, Eastern Europe, U.S.S.R.

CFCs: see chlorofluorocarbons

chemical industry

cogeneration: 181,183

efficiency: 183,189

energy use, emissions: 179-183, 314

waste heat recovery: 183

Chemical Manufacturers Association: 63, 127, 252

China: $5,33,39,58,68,78,80-82,84-87,91,128,150,152,153$, $204,219,247,249,252,253,255,260,261,273-278,281$, 287-289, 292, 299

chlorocarbons: 67

chlorofluorocarbons: 3-5, 30, 61-68, 194, 282, 286, 316

also see Montreal Protocol, ozone

air-conditioning: $61,63,126,127,150,151,328$

atmospheric concentrations: $45,46,48,53,54,61-63$

consumption: $67,68,127,177,251,252$

emissions: $115,119,126,127,150,151,177$

global Warming potential: $55,56,62,290$

insulation: 3, 61, 63, 64, 126, 127, 151, 259

in transportation: 150,151

lifetimes: 55, 61, 62, 66

other uses: 3,252

ozone depletion potential: $62-66,290$

radiative forcing: 54-56, 64

recycling: $127,151,259,327,328$

refrigeration: $61,63,126,127, ' 243,245,251,252,259,260$, 264

State initiatives: $327-329$

substitutes: 162, 259, 286, 290, 291

Clean Air Act Amendments: 3, 16, 316

clean coal technologies: 299

climate and climate change: $3,45-68$

also see individual gases

albedo: 215

“benchmark' warrning: 49

clouds: 46, 48-50, 52, 65, 240

equilibrium w arming: 48,49, 52.-55, 57, 64

factors driving: $46,47,49$

feedback processes: 48-53,58, 60

general circulation models: 45,46,49-52,224

greenhouse effect: $3,45-53$

historical trends: 47,50,51, 56

ice ages: 47

natural variability: $46-48,50-53$

precipitation: $45,47,52$

predicted changes: $45,46,49,50,224$

radiative forcing (heat trapping): $4,48-57$

role of oceans: $45-53,58,60,61,72,73$ sea level: $46,53,282$

seasonality: $47,57,58$

snow and ice: 46-49, 52

solar radiation: $46-48,51,52,65$

temperature: $45-53,57$

volcanoes: 47,51

climate convention/protocol: 34,279

clouds: $46,48-50,52,65,240$

$\mathrm{CO}_{2}$ : see carbon dioxide

coal

also see electricity (generation)

carbon content: $8,79,84,333$

carbon emissions: 8, 57, 58, 77, 79, 81, 86, 92-94, 97, 108

consumption: $7,8,77,78,81,82,93,115,127,287,295,321$

efficiency of use: 178,179

methane emissions: 80, 81, 84, 106, 246

production: 82,183

reserves: 81,82

trade: 81,82

use in industry: $183,188,190$

cogeneration: $11,12,17,23,25,88,104,126,131-134,138$, 180-182,184,189-192, 196,260,289,305,318-320, 324, 325

combined-cycle turbines: 26, 92, 93, 95, 108, 109, 323

commercial buildings: see buildings

commercial timberland: 28, 29, 208-210, 212, 213, 223

Commission of European Communities: 229,302

Committee on Renewable Energy Commerce and Trade: 34,35, $37,281,285,286,292,296,299$

commodity support: $31,227,262-265$

Congressional Budget Office: 11,24, 103, 104, 195,322

Conservation Compliance Program: 263

Conservation Reserve Program: 11,27-30, 201,202,206,211, $213,214,216,225,227,319,325$

Consultative Group on International Agricultural Research: 36, $38,231,262,264,265,294$

conversion factors: 332

cooking: $116,127,128,220$

cookstoves: $217,220,260$

Cooperative Automotive Research Program: 23, 171

Cooperative for American Relief Everywhere: 230

Cooperative Forest Assistance Act: 225

Coordinating Committee on Multilateral Export Controls: 37, 286, 298,299

Corporate Average Fuel Efficiency: 166

costs of reducing emissions

OTA estimates: 9-12, 102, 133, 134, 163, 164, 191, 192,208, $212,213,215,216,320-325$

other estimates: 11-12, 24, 103, 104, 195, 322

crops

also see commodity support, food

annual vs. perennial: 257,258

drying: 260,261

for energy: $27,28,85,86,89,201,202,206,214,215,227$, 319,325

yields: $243,244,250,253,256-258,263$

Customs and Trade Act: 227

Czechoslovakia: $33,78,82,83,187,275 ， \quad 294,295,297,299,300$

dam construction: 228

debt: $32,38,202,228,230,275, \quad 280,287,291,299$

debt-for-nature swaps: 230

effect on natural resource policies: 32, 202, 228, 275 
deforestation

$\mathrm{CO}_{2}$ emissions: $32,57,201,202,205,274,275$

government policies: 32, 38, 202,216, 228, 275, 290, 291

reasons: 32, 38, 202, 216, 220, 221, 228, 275, 287, 291

temperate zone: $32,201,204,246,275$

tropical: .32, 38, 201, 202, 205, 216, 220, 221, 228, 243-245, 275, 287, 290, 291

demand-side management: 18, 24, 107, 115, 137, 138, 194

Federal Energy Regulatory Commission: 18, 138

Northwest Power Planning Commission: 18, 107, 138

State policies: $18,137,138$

utility programs: 18,24, 107, 137, 138, 141, 194

denitrification: see nitrogen cycle

Denmark: 7, 78, 82, 276, 300, 302, 305

Department of Agriculture: 34, 35, 282

Agricultural Conservation Program: 28, 225-227

Agricultural Research Service: 262

Agricultural Stabilization and Conservation Service: 28, 35, 201, 223, 225, 226

commodity support programs: $31,227,262-265$

Conservation Compliance Program: 263

Conservation Reserve Program: 11, 27-30, 201,202,206, $211,213,214,216,225,227,319,325$

environmental mission: 263

Forestry Incentives Program: 28, 225-227

Forest Service: see U.S. Forest Service

Low Input/Sustainable Agriculture Program: 265

Soil Conservation Service: 31, 263-265

Department of Commerce: 34, 35, 280-282, 285, 286, 299

Department of Energy: 10, 20, 25, 27,34,35,86, 95, 107, 108, $110,135,138,140,184,281,292,299,328$

biomass energy: 28, 30, 86, 201, 214, 215, 227

CORECT: $34,35,37,281,285,286,292,296,299$

Energy Analysis and Diagnostic Center: 25, 192, 196 energy audits: 192, 196

energy efficiency centers: 37

Energy Extension Service: 20, 137, 142, 328

Energy Information Administration: 10, 12, 149, 313, 314

Federal Energy Management Program: 20, 135, 142

Institutional Conservation Program: 19, 136, 137, 328

Least Cost Utility Planning Program: 138

Office of Industrial Programs: 25, 192, 196

State Energy Conservation Program: 20, 137, 328

Weatherization Assistance Program: 19, 137, 328

Department of Health and Human Services: 137

Department of Housing and Urban Development 19, 20, 137, 140-142

Department of State: 34, 35, 38,282

Department of Transportation: 23,171

Department of Treasury: 34, 35, 39, 229, 280, 282, 293

developing countries:

also see deforestation, livestock, population, tropical forests; individual sectors, fuels

agriculture: 38, 243-245, 247-250, 253, 255-258, 260, 262, 264

buildings: $115,116,127,128$

CFCs: 288

development needs: $31-34,81,128,202,230,287$

electrification: $32,33,116,128,275,281,287,289$

energy policies: $38,39,289-292$

energy use: $7,31-33,78,81,84-86,106,115,127,128,202$, 273-275, 287, 288 forestry policies: $38,202,216,228-232$

infrastructure: $32,33,287$

institutional capacities: 37, 230-232, 290, 291

Montreal Protocol: 67, 68, 252, 274

natural resource policies: 32, 38, 202, 216, 228-232, 291

population growth: $31-33,39,40,274-278,293-294$

refrigerators: $128,252,253,264$

transportation: $150,152,153$

development assistance

multilateral: 36, 38, 39, 219, 279, 283, 291, 292

percentage of Gross National Product: 34, 281

U.S. bilateral: $34,35,37-40,87,202,229-23$ 1,244,264,265, $279,281,282$

diesel fuel: 154

doubling time: see carbon dioxide

Eastern Europe

emissions: 5, 273, 274, 295

energy efficiency efforts: 121, 187, 284

energy use: 32, 94, 121, 154, 187, 273-276, 282, 294, 295

environmental problems: 33, 294, 298

institutional constraints: 33, 37, 39, 273, 294, 296, 297, 299

joint ventures: $37,294,295,297,299,300$

trade: $34,37,281,286,295-300$

education programs: see information

efficiency, energy: see individual end-uses and sectors

electricity

also see cogeneration, demand-side management; individual fuels, technologies, and countries

capacity: $80,87,90,96,98-100,289$

developing countries: $32,33,80,90,91,94,116,127,128$, $275,281,287,289$

efficiency of use: 92-96, 178, 179, 184-186, 320, 322, 328, 329

electrification: $32,33,80,116,117,118,128,275,281,287$, 289

emissions: $25,26,57,80,92-94,96-110,129,317$

energy sources: 79, 80, 87, 90, 92-94

production technologies: 92-94, 96-99, 115, 190, 289, 323

transmission and distribution losses: 84,92,94, 106, 177,281, 289

use: $115,116,177-184,188,321$

utilities: 7, 18, 23-27, 99, 106-110, 115, 132, 135, 137, 138, $141,194,218,319,320,327-330$

Electric Power Research Institute: 11, 90, 103-105, 107, 322, 323,325

electrolysis: $177,178,181,183$

emissions, current and historic: $3-8,25,56-58,77-80, \$ 12-94$, $115-116,159,201-205,243,253,273-275,295,296$, 313-315

also see individual sectors and countries

emissions, projected: 4-7, 149, 295, 296, 301, 302

forestry offsets: 5,9, 11,27-30,202,206,208-211, 213,223, $316,319,320$

OTA model: 4-6,8-11, 17, 18,21,23-28,94-102, 117, $129-133,160-163,188-191,315-320$

Endangered Species Act: 212

energy use: $3,7,8,20,77,115-127,150,154-157,177-185,194$, $195,201,273-275,294-296,300,301,313,314$

also see emissions; individual countries, fuels, sectors, technologies

efficiency centers: 37, 286, 299, 300

intensity: 117, 178-184, 189-191, 193, 301 
management systems: 118,185

per-capita: 3,31-33, 115, 11'7, 127,274, 275,287,295

prices: $6,10,12,21,81,102-104,108,109,129,136,149$,

$160,165,166,178,179, \quad 183,195,301,313,320-324,325$ rating systems: 140,141

research needs: $105,106,109,110$

supply: $77-110$

taxes: see taxes

Energy Analysis and Diagnostic Center: 25, 192, 196

Energy Extension Service: 20, 137, 142, 328

Energy Information Administration: 10, 12, 149, 313,314

energy investment tax credit: 25, 195

Energy Sector Management Assistance Program: 38, 283, 291, 292

Energy Tax Act: 22,25, 167

environmental assessments: 36, 38, 228-230, 283, 291

Environmental Protection Agency: 4,5, 11,34, 35,50,59,65, $67,104,232,280-282,292,299,300,322$

emissions projections: 246, 314, 301, 322

energy efficiency centers: 37, 286, 299

ethanol: 89, 159, 160, 164, 261

Europe: see Eastern Europe, European Community, OECD

European Bank for Reconstruction and Development: 300

European Community: 301-303

emission projections: 301,302

greenhouse gas policies: 302

European Economic Commission: 284

Export Administration Act: 37, '286, 298, 299

Export Control Act: 298

Export Facilitation Act: 299

Export-Import Bank (Eximbank): 34,35,37,280,281,285, 286, 296, 299,300

exports: see trade

extractive reserves: 221

family plarming: 38-40,202, 228, 230, 277, 282, 293, 294 also see population

Farm Bill: see Food Agriculture, Conservation, and Trade Act farms: see crops, food

Federal Energy Management Program: 20, 135, 142

Federal Energy Regulatory Commission: 18, 27, 108, 138

Federal Highway Administration: 156, 158

Federal Home Loan Mortgage Corporation: 141

Federal Housing Administration 141

Federal National Mortgage Association: 141

feedback, climate: $48-53,58,60$

feedstocks, fossil fuel: $8,86,181,183,314$

fertilization

also see crops, fertilizers, food

$\mathrm{CO}_{2}$ fertilization of plants: 58., 224

fertilizing oceans with iron: 58,72, 73

fertilizers: 3, 244-246,248-251

also see commodity support, crops, nitrogen cycle, nitrous oxide

application: $31,60,207,249,250,256-258,263,330$

consumption: $245,256,265$

forest management: $207,211,212,214,225$

manufacturing: $30,31,207,214,243,250, \quad 251,260,262,270$

Minnesota Nitrogen Fertilizer Task Force: 330

nitrogen: 245, 246, 248, 249, 256, 257

financial mechanisms

bundling: 39, 293

incentives: 7, 13-16, 19, 20, 103, 104, 107, 149, 165-167, 194,
195, 201

marketable permits: $13,14,16,24,26,103,104,108,109$, 193, 194

taxes: see taxes

tied-aid financing: 37, 281, 286

fires: 204,248

also see biomass

fluidized bed combustion: 92, 97

fluorescent bulbs: 17, 18, 119, 121, 130, 186,319

food (and agriculture)

also see crops, Department of Agriculture, fertilizers, livestock, methane, rice

CFCs: $30,243,245,251,252,259-261$

commodity support: $31,262-265$

consumption: $244,245,259$

cooking: 30, 243-245, 250-254, 260, 270

developing countries: 38, 243-245, 247-250, 253,255-258, 260, 262,264

emissions: $30,38,243-253$

energy use: 181, 243, 244, 246, 250-253, 259-261, 266, 270

ethanol fuels: 261

forest clearing for agriculture: 30, 243-245,250, 257

grains and subsidies: $245,262,263$

irrigation: $30,107,244,245,251,256,258,261$

land use changes: $30,243,244,257,258,265$

machinery: $30,243,244,250,260,261,266$

methane: $30,38,243,245-249,253-256$

nitrous oxide: $30,243,248-250,255,261$

post-harvest activities: $247-244,251-253,270$

processing and packaging: 244, 251-253, 259,260

production: $243-252,258,270$

research needs: $31,247,256-258,262,265$

soil erosion: 201, 205, 243, 250, 253, 255, 258, 261

sustainable agriculture: $38,202,244$

tillage practices: $253,256,258,261$

wastes flosses: 251, 253, 258, 259, 266

Food Agriculture, Conservation, and Trade Act: 28-30,226, $227,243,263,265$

Food and Agriculture Organization: 36, 259,265

Food Security Act: 30, 214, 243, 263

Foreign Assistance Act: 39, 229,293

Foreign Credit Insurance Corp.: 286

Foreign Operations Appropriations Act: 34, 39, 274, 281,282, 285

Forest and Rangeland Renewable Resources Planning Act: 28, 212,224

forestry: see forests

Forestry Incentives Program: 28,225-227

forests and forestry

also see deforestation, tree planting, tropical forests, U.S. Forest Service

biomass energy: $11,13,27,28,30$

commercial timberland, U. S.: 28, 29, 208-210, 212, 213, 223

effects of climate change: $210,223,228$

efficiency of end use: 211,213

emissions, offsets: 5, 9, 11, 27-30, 201-223, 316, 319, 320

fires: 204, 224

increased productivity: 11, 13, 27-29,202,206-210,223, 319 , 320,325

log exports: 213,227

"new forestry' $210,213,225$

old-growth: $210-217$ 
policies: $223,225-232$

restrictions on harvesting: $210-213$

timber industry, U. S.: 209-213

fossil fuels: $81-86$

see also coal, emissions, natural gas, petroleum, taxes

emissions: $3,5-8,56-58,77-80,86,92-94$

prices: see energy use (prices)

use: $177,182,188,189,250,251,270,274,275$

France: $7,33,78,82,83,91,117,131,153,165,275,278,279$, $297,300,301,303,304$

freight travel: see travel

fuel cell: 26, 27, 92,93, 105, 109, 171

fuels

also see energy, ethanol, gasoline, methanol, renewable energy

alternative fuels: $23,89,149,159,160,164,170,261,305$, 327,330

economy standards: $149,165-167$

traditional: $38,85,86,127-129,248,253,260$

fuel switching: $11,12,17,24,77,84,92-94,96-99,104,108$, $119,128,129,134,177,189,191-194,260,261,289,290$, $305,319,325$

fuelwood

contribution to deforestation: 220

cookstoves: $217,220,260$

gasoline

mileage standards: $149,166-167$

prices: $6,21,149,160,165-167$

tax: 165-167

Gas Research Institute: 10, 94,99, 105, 129, 190, 313, 314

gas turbine: $25,92,93,103,320$

General Agreement on Trade and Tariffs: 22, 167, 299

general circulation models: 45,46,49-52, 224

geothermal power: 18,39, 77,80,87,97,105,138, 273,281,292

Germany: 7,33,68,78,82-84,91, 117, 153, 165,259,275,276, $278,279,292,294,297,300-305$

Global Environmental Facility: 38, 291

Global Releaf Program: 228

global warming: see climate

global warming potential: see individual gases

grains: see food

Green Fund: 291, 293

greenhouse effect: $3,45-53$

also see climate

greenhouse gases: 3,45-68

also see climate, emissions; individual gases

Gross Domestic Product: 152,245, 302

Gross National Product: 6, 10,11,31,34,35.103, 104, 178-180, $281,291,301,313,321$

groundwater contamination: 7, 207, 243, 263

Group of 7:279, 301

Guanacaste National Park: 223

halons: $3,45,61,62,65,66,68,126,288,328,329$

also see Montreal Protocol

fire extinguishers: $61,127,328$

global warming potential: 62

ozone depletion potential: 62,65

harvesting of timber: see forests

heating: 3 , 17, 117, 118, 120-122, 124, 130, 131, 133, 138, 181, $185,188,192,196,323,324$

also see space conditioning

heating, ventilation, air-conditioning equipment: $8,11,17,19$,
$118,122,124,130,131,133,138,139,318,329$

heat island effect: $45,50,124,215$

heat pumps: $117,130,131$

heat recovery: 25, 186, 196

High Occupancy Vehicle lanes: 22, 155, 168, 170, 329

Home Energy Rating Systems: 140, 141

Hood River Conservation Project: 142

Housing and Community Development Act: 137

hydrochlorofluorocarbons: 55,56,62-64,68, 127, 151, 290

global Warming potential: 55,56, 62-64, 290

ozone depletion potential: 62-64, 290

hydroelectric power: $7,11,13,25,39,77,78,80,87,97-100$, $107,109,184,287,289,291,295,303,319,322$

hydrofluorocarbons: 55, 56,63,64, 290

ice ages: 47

incandescent bulbs: see lighting

India: $33,39,68,78,80-82,86,87,90,91,94,152,153,222,245$, $252,260,261,274-276,278,284,287-289$

Indonesia: $33,39,68,83,87, \quad 153,221,222,232,274, \quad 275,278$, 286, 288

industry: see manufacturing

Industry Cooperative for Ozone Layer Protection: 286

information programs: $13-15,17,20,25,115,135,140-142,286$, $302,303,305,327$

audits: 14, 17, 20, 25, 107, 115, 141, 192, 195, 302, 303, 305

Home Energy Rating System: 20, 140, 141

labels: $14,17,141,142,302,303$

Institutional Conservation Program: 19, 136, 137,328

insulation: $11,17,18,61,63,118-121,123,127,318,327$

Insurance Institute for Highway Safety: 159

integrated gasification combined cycle: $26,92,93,95,108,323$

Inter-American Development Bank: 36, 38, 39, 280, 283,291, 293

Inter-American Foundation: 39, 286,287,293

Inter-American Institute for Cooperation on Agriculture: 262

intercity rail: $21,161,163,164,170,320,324$

intercooled steam-injected gas turbines: 17, 92, 93, 189, 191, 325

Intergovernmental Panel on Climate Change: 4, 5, 36,4547, 282-284, 298

findings: $45-47,50,51,53,55,58,60,61,66,67,249$

structure, working groups: $36,283,284,298$

Interior and Related Agencies Appropriations Act: 28,30, 226, 227

Internal Revenue Service: 230

International Board for Soil Research and Development: 262

International Council for Research in Agroforestry: 231, 262

International Council of Scientific Unions: 36, 284

International Development and Finance Act: 228, 230, 287

International Energy Agency: 284, 301, 302

International Environmental Bureau: 286

International Fertilizer Development Center: 262

International Fund for Agricultural Development: 36, 284

International Laboratory for Research on Animal Diseases: 264

International Livestock Centre for Africa: 264

International Monetary Fund: 283, 287, 300

international Planned Parenthood Federation: 40,230, 293,294

International Tropical Timber Organization: 36, 38, 203, 229, $231,232,284$

ionophores: 255,262

irrigation: $30,244,245,256,258$

energy use: 251 
technologies to reduce: 261

Italy: 7,33,82,83,87, 117, 153,247,275,278,279, 297, 300, $301,303,304$

Jackson-Vanik Amendment: 2'98-300

Japan: 7,20,21, 23,25, 33, 35, 36,78,80-85,87, 91,97, 108, $117,125,150,153,156,213,227,229,247,275,278$, 279, 292, 295, 297, 300, 301, 304, 305

joint ventures: see trade

labels: 232

landfills: 59, 60, 86, 88, 211, 246, 253

land tenure, reform: 32, 38, 202, 216, 218, 228, 230, 275

land use changes: see deforestation, urbanization

land-use planning: 22, 155-157, 169-171, 265, 305

least-cost utility planning: $137,138,194,292,327,328$

legumes: $218,249,250,257$

lifecycle cost: 15, 17, 134, 136, 139, 159

lighting

also see regulations (appliance standards)

automatic controls: $119-121,186$

energy efficiency: $11,17,118-121,124,128,131-134,185$, 186, 189-192, 196, 318

energy use, emissions: $3,115-117,119,181,185,186,314$, 318,319

fluorescent bulbs: 17, 18, 119, 121, 130, 186, 319

livestock: 31, 38,59,60, 220, 248, 261, 262, 287, 288

also see methane, tropical forests

and grain subsidies: 263

developing countries: 220,244,245,253,255, 256,264,287, 288

manure: $31,243,247,255,262$

productivity enhancements: $31,243,244,253,264$

reduced demand for: $31,243,255,256,264$

ruminants: $31,246,247,253$

United States: 31, 245,255, 262, 263

loans, low-interest: 14-16,24, 194

logging: see deforestation, forests

Los Angeles

Air Quality Management Plan: 169-171, 329

traffic: $157,158,168$

Low Income Home Energy Assistance Program: 19, 137

magnetohydrodynarnics

manufacturing

automatic controls: 185,186

boilers: $180,181,185,189-192,325$

CFCs: 177

cogeneration: $11,17,23,25,180-184,189-192,196,319,320$, 325

Eastern Europe: 187,295

efficiency: 11, 177-192

electrolysis: $177,178,181,183,314$

emissions: 7,8,58, 177, 181-184, 187-195,314,317,319, 320

energy in imports: $178-180,193$

energy use: $177-186,188,190-193,274,300,313,320$

fuel switching: 11, 17, 177, 189, 191-194, 319, 325

heat recovery: $25,186,196$

housekeeping: $11,17,185,18^{\prime} 9-192,319,325$

intercooled steam-injected gas turbines: 17, 189, 191, 325

lighting: 181, 185, 186, 188-192, 196,319

major industries: see chemical, paper, petroleum, primary metals

mechanical drive: $8,181,183,185,188,192$

motors: 11, 17, 23, 24, 186, 189-192, 194, 314, 319, 320, 325 policies: $192-196$

process heat: $8,180,181,183,185,188,314,325$

product and process changes: $17,23,186,187,189-192,319$

recycling: $182-186$

research: 25,185

"second-tier" industries: 179, 181, 185

space heat: $181,185,188,192,196$

structural changes: $177,178,192,301$

U.S.S.R: $187,295,2 \%$

variable-speed drives: 186

manure: see livestock

marketable permits: $13,14,16,24,26,103,104,108,109,193$, 194

also see financial mechanisms

mass transit: 11, 17, 21, 22, 149, 155-157, 161, 163, 164, 169, $170,318-320,324$

Mauna Loa $\mathrm{CO}_{2}$ record: 56, 58

methane

also see landfills, livestock, natural gas

atmospheric concentrations: $45,46,54,58-60$

control methods: $31,86,88,106,211,220,253-256,262-264$

emissions, sources: $3,5,30,38,45,48,59,60,79,80,84-86$, $88,106,203,207,211,220,243,245-249,253,282,285$, $287-289,316$

global warming potential: 55,56

lifetime in atmosphere: 55,59

methane-hydrates: 60

radiative forcing: $54-56,59$

methanol: $89,159,160,164$

methyl chloroform: 62, 65, 68, 151

also see Montreal Protocol

Mexico: 33,39,68,82-84,87,91, 153,274,275,277,278, 288, 292

microorganisms: 203, 207, 248, 249

model, OTA

also see costs

Base case: 5,6, 8,9, 12, 17, 21, 22, 25, 26, 94-102, 117, $129-133,160-163,188-190,313-320$

basic structure: 10,313

buildings: 129-134

energy supply: $94-102$

manufacturing: $187-192$

Moderate: 5,6,8-11, 17,21-25,94-102, 115, 117, 129-133, $160-163,188-190,313,315-320$

Tough: 5,6,8-12, 17, 21-26,94-102, 115, 117, 129-134, $161-163,188-191,313,315-320$

transportation: $160-164$

monoculture: 210,263

Montreal Protocol: 3,5, 16,45, 64,66-68, 127, 151,252, 264, 274, 305,316

1990 revisions: 5,45,64,68

and Clean Air Act Amendments: 16, 68, 316

developing countries: $67,68,252,274$

initial agreement: 67

Multilateral Fund: 68

Most Favored Nation: see trade

motors, electric: $23,24,107,186,189-192,194,314,319,320$, 325

Multi-Agency Working Group for Power Sector Innovation: 284, 293

multilateral development banks: 35, 36, 38, 39, 228, 229, 280, 283 
African Development Bank: 36, 39, 283,292

Asian Development Bank: 36, 283

development assistance: 36, 38, 39,229,283, 291, 292

environmental assessments: 36, 38, 228, 229, 283, 291

Inter-American Development Bank: 36,38,39,280,282,291, 292

role in deforestation: $38,228,283$

U.S. Executive Directors: 35, 228-230, 282,287,291, 296

World Bank: see World Bank

Multilateral Fund: 68

Multiple-Use and Sustained-Yield Act: 28, 212, 225

municipal solid waste: $86,88,211,329$

methane from landfills: 88, 211, 253

paper recycling: 211

national accounting procedures: 230, 291

natural resource values: 291

U.N. Statistical Commission: 291

National Advisory Council for Environmental Policy and Technology: 281

National Affordable Housing Act: 19,20, 140-142

National Appliance Energy Conservation Amendments: 19, $124,125,129,138,139$

National Council of States Building Codes Standards: 139

National Energy Act: 195

National Energy Policy and Conservation Act: 141

National Forest Management Act: 28, 212, 225

National Forests: 28, 29, 208, 226

National Highway Traffic Safety Administration: 159

National Housing Act: 19, 140

National Institute for Science and Technology: 139, 140

National Research Council: 72

National Science Foundation: 262

natural gas

also see electricity (generation)

carbon content: $8,79,333$

carbon emissions: $8,77,79,84,85,92-94,108$

co-firing: 11, 25, 26,57,58, 93,94,97-99, 101, 102, 108, 319, 320,323

consumption: $7,8,77,78,81,83,84,93,99,115,127,159$, $160,179,183,185,188,190,289,295,321$

efficiency of use: $85,178,179$

methane emissions: 59, 80, 84, 85, 94, 104, 106, 159, 246, $281,288,289$

production: $30,81,83,84,181$

reserves: 81,83

trade: $81,83,84$

transmission and distribution: 30, 45, 84, 94, 159

Natural Resources Defense Council: 226

Netherlands: 7, 33, 82, 83,95, 300, 302-304

New York Public Service Commission: 137

New Zealand: 7, 87, 300, 304,305

vitrification: see nitrogen cycle

nitrogen cycle: $248,250,256$

also see fertilizers, food

denitrification: $248,249,256$

legumes: $249,250,257$

vitrification: $248,249,256$

role of microorganisms: $60,248,249$

nitrous oxide

also see fertilizers, food

atmospheric concentrations: 45, 46, 54, 60

emissions, sources: $3,5,30,31,48,60,203,207,211,212$,
$214,225,243,245,246, \quad 249,250,256,257,261-263,316$ global warming potential: 55,56, 60

lifetime in atmosphere: 55,61

vitrification inhibitors: 256,257

radiative forcing: $54-56,60$

non-governmental organizations: 35, 37, 230-232, 280, 286, 287, 294

nontimber products: 38, 201, 202, 204, 217, 220, 221, 231

Northwest Power Planning Commission: 18, 107, 138,323,330

Norway: 7, 35, 83, 300, 304, 305

nuclear power

electricity generation: $7,11,25,26,77,78,80,91,92,97,98$, $100,108,109,289$

emissions: 80,91

Europe: 91,108

improved utilization: $25,27,97,98,100,107,108,319,320$, 322

light water reactor: 13,110

modular high temperature gas reactor: 109,110

opposition: 13, 91, 295

proliferation: $91,92,289$

U. S. S. R.: 295

waste: 92,105

Nuclear Regulatory Commission: 27, 108

Oak Ridge National Laboratory: 10, 25, 105, 160, 196, 313

oceans

effects on global climate: $45-53,58,60,61,72,73$

fertilization with iron: $58,72,73$

role in carbon cycle: $45,58,72,73$

Office of Industrial Programs: 25, 192, 196

Official Development Assistance: 35

see Agency for International Development, multilateral development banks

offsets, carbon: see emissions, forestry

oil: see petroleum

old-growth forests: $214-217$

Organization for Economic Cooperation and Development: 37, $152,153,187,276,284,291$

emissions: 5, 273, 274, 301, 302

energy efficiency programs: $117,119,302,303$

energy use: $32,85,115-118,273-275,287,300,301$

European Community: 301-303

greenhouse gas policies: 7, 302-305

member countries: $115,273,300$

OTA model: see costs, scenarios

Overseas Private Investment Corp.: 34,35,221,280,281,285, 291, 296,299, 300

Environmental Investment Fund: 285, 300

ozone, stratospheric

depletion: 3,4,7,48,61, 64-67, 127, 252

also see chlorofluorocarbons, halons, Montreal Protocol

ozone, tropospheric: 249

Pacific Northwest Electric Power Planning and Conservation Act: 138

Pan-American Development Foundation: 231

paper industry

cogeneration: 181,182

efficiency: 182,189

energy use, emissions: $179,182,315$

recycling: 182,183

parking: $11,22,149,155,156,160-162,164,168-170,318,324$ 329 
particulate: 115

passenger travel: see travel

permits: see marketable permits, regulations

petroleum

carbon content: $8,79,333$

cogeneration: 181

consumption: $7,15,77,78,81,82,84,85,115,127,295,301$, 321

efficiency of use: $85,178,179,183,189$

emissions: $8,57,58,77,79,80,84$

Petroleum Overcharge Fund: 136, 328-330

production: $15,81,82,85,183$

refining industry: 179-183, 189, 314, 315

reserves: $81,82,85$

trade: $81,82,85$

photosynthesis: $56,58,85,203,224$

photovoltaics: $91,105,281,289,290$

phytoplankton: 47

fertilizing with iron: 72,73

pipeline leaks: $80,84,106,281,289$

plantations: 201, 222

Poland: $33,39,68,78,82,83,275,278,294,295,297,299,300$

polar ice sheets: 46

population

age structure: 277

country, city rankings: 278,279

family planning programs: $38-40,202,228,230,277,282$, 293, 294

global: 31-33,40, 278,293, 294

growth, projections: 31-33,39,40,274-278, 294

International Planned Parenthood Federation: 40, 293, 294

momentum: 276, 277

policies: $40,202,293,294$

UN Population Fund: 36,40,230,284, 293, 294

urbanization: $115,128,155,250,265,277-279$

U.S. funding: 40,282, 293, 294

world population conference: 39, 293

potential global warming: see individual gases

powerplant retirement: $98-102,110$

precipitation: $45,47,52$

prices, energy: see energy, gasoline

primary metals

aluminum: $180,181,184-186$

cogeneration: 181

energy use, emissions: 179-180, 182, 184, 185, 189, 314

recycling: 185,186

steel: $180,181,184,187$

Private Export Funding Corp.: 285

process heat: $180,181,183,185,188$

productivity, increasing

livestock: $31,243,244,253,264$

timber: 11, 13, 27-29, 202, 206-210, 223, 319, 320, 325

Program for the Acceleration of Commercial Energy Research: 285

proliferation, nuclear: 91,92, 289

Public Utility Commissions: 27., 107, 108, 137, 138

Public Utility Regulatory Policies Act: 18, 138

radiation

solar radiation: $46-48,51,52,65$

ultraviolet: 65

radiative forcing: $4,48-57,59,60,64$

rebates: 20-22, 24, 149, 165-167, 194 recycling

aluminum: 184-186

paper: $182,183,211$

steel: 184,185

water: 261

refining: 179-183, 189, 314, 315

reforestation: see tree planting

refrigeration

alternative working fluids: 259,290

CFCs: $61,63,115,126,127,243,245,251,259,260,264$, 288,328

$\mathrm{CO}_{2}$ emissions: $115,243,251,252,259,314$

in developed countries: 252,264

in developing countries: $33,128,252,253,264,288$

use of electricity: $252,259,260,270$

regulations: $12-14,16,18,19,24,183$

appliance standards: 16, 19, 115, 124,125, 135, 138, 139,302, 305

building codes: 14, 16, 19, 115, 119, 120, 124, 135, 137, 139, $140,303,305,330$

emissions standards: 26, 27, 108, 109, 194, 305, 319

fuel economy standards: 22, 149, 165-167,305

performance standards: 14,16

renewable energy: $4,5,12,13,25,26,77,80,87-92,97-102$, $105,109,117,126,202,260,273,281,285,289,292$, $305,327-329$

also see individual sources, technologies

R\&D funding: $6,16,27,105,110,302$

trade, technology transfer: 281,285,286,292,299, 300

Renewable Energy Design Assistance Center: 285,286

Renewable Resources Extension Act: 225

research and development: 3,6,7, 13-16,27, 115, 120, 142, 196, 214,280,286,302, 303

residences: see buildings

Residential Conservation Service: 20, 137, 141

retrofitting: 11, 17, 118-120, 130-134, 136, 189, 192, 330

rice

also see methane

methane emissions: 59, 60, 245-247, 256, 262, 287, 288

production: $246,247,256$

yields: 256

ridesharing: $11,22,149,155,161,162,164,168,170,324,329$

rubber tapping: 221

ruminants: see livestock

safety issues: 159,171

scenarios, OTA model: see model

scrubbers: $77,92,93,95$

sea level: $46,53,282$

seasonality: $47,57,58$

sequestration, carbon: see emissions (forestry offsets), forestry shells, building: 11, 17, 18, 118, 130-134, 137, 142, 318, 323

Shelterbelt Program: 213

shifting cultivation: 202, 216, 217, 219, 275

short-rotation woody crops: $27,28,85,86,89$

"smart" house: 124,125

snow: $46-49,52$

Soil Bank: 214

Soil Conservation Service: $31,225,263-265$

soil erosion: 201, 205, 207, 211, 225, 243, 250, 253, 255, 258, 261

solar energy: 5,6, 11, 18, 39, 77, 80,87,90,97, 122, 126, 138, $261,273,289,292$ 


\section{electricity: $27,90,105$}

photovoltaics: $91,105,281,289,290$

Solar Energy and Energy Conservation Bank: 137

Solar Energy Research Institute: 105, 109, 110, 126

solid waste disposal: $86,88,253,329$

South Coast Air Quality Management Plan: 169-171,329

Soviet Union: see U.S.S.R.

space conditioning: 8,85, 115-118, 120-122, 124, 139, 181, 185, 188, 192, 196

also see air-conditioning, heating

spotted owl: 212,213

standards: 7, 14, 16, 18, 19, 22, 24-27, 108, 109, 115, 119, 120, $124,135,137-140,149,165-167,194,302,303,305,319$

also see regulations

State activities: $142,327-330$

Public Utility Commissions: 27, 107, 108, 137, 138,329

State and private forestry: 28-30,225-227

State Energy Conservation Program: 20, 137, 328

steel: see primary metals

storms: 46

stratosphere: see ozone

structural changes: $6,177,178,192$

subsidies: 26,38

see commodity support; individual fuels and sectors

Support for Eastern European Democracy Act: 286,299

Surgeon General: 255

sustainable agriculture: $38,202,244$

Sweden: 7, 20, 78, 117, 119, 120, 124, 300, 304,305

taxes

capital gains: 29,226

carbon: $11,14-16,18,24,26,85,103,104,108,109,194,195$, 304,305

energy-use: $3,7,14,15,26,103,104,115,135,136,195$

fuel taxes: $21,28,85,149,165,166,201$

Gas Guzzler: 21, 136, 167

initial purchase: $14,15,19,20,22,115,135,136$

tax credits: 19, 24, 25, 29, 136, 195, 227, 230, 328, 329

tax incentives: 14, 15, 29, 30, 103, 104, 136, 195, 201, 226-228

Tax Reform Act: 19, 136, 226

technology transfer: see trade

telecommuting: $22,149,169,170$

temperate zone forests: 201-216, 275

also see forests

temperatures: $45-53$

Tennessee Valley Authority: 26, 107, 138

termites: 60, 246

thermo-mechanical pulping: 182

till age practices: see food

timber: see forests

trade: $35,37,178-180,281,285-287$

bundling: 39,293

COCOM: 37, 286, 298, 299

CORECT: $34,35,37,281,285,286,292,296,299$

Export Administration Act: 37, 286, 298, 299

Export Control Act: 298

Export Facilitation Act: 299

Export-Import Bank: 34,35,37,280,281,285, 286,296,299, 300

General Agreement on Trade and Tariffs: 22, 167,299

Jackson-Vanik Amendment: 298-300

joint ventures: 37, 294,297, 299,300
Most Favored Nation status: 37,299

Omnibus Trade and Competitiveness Act: 298

Overseas Private Investment Corp.: 34,35,221, 280,281, 285, 291, 296,299, 300

percent of GNP: 301

renewable energy: 34, 281, 285, 286, 292, 299, 300

Support for Eastern European Democracy Act: 286,299

tied-aid financing: $37,281,286$

trade restrictions: $37,213,227,228,232,298-300$

tropical timber: $38,221,228,232$

US/ECRE: 280, 286, 287, 291, 296

U.S. Trade Development Program: 34, 35, 285, 296.299

with developing countries: 34, 38, 281, 285, 286

with Eastern Europe, U. S. S. R.: 34, 37, 187, 281, 286, 294

Trade Act: 298

traffic flow: 11, 17, 22, 155, 164, 169, 170, 318

transmission and distribution: see electricity

transportation

also see automobiles, fuels, transportation control measures aircraft: $159,161-163$

bicycling: $156,161,163,168$

buses: $150,156,161,169,170,320$

CFCs: 150,151

congestion: 156-158, 168-171

Eastem Europe: 295

emissions: 7, 8, 20, 57, 149-151, 155-164, 171, 314, 315, 317

energy use: $20,150,154-157,274,301,313$

intercity rail: $21,161,163,164,170,320,324$

land use plarming: $155-157,169-171$

O\&M: 22, 161, 162, 164, 168, 318, 324

rebates: $149,165-167$

R\&D: $23,149,165,170-172$

taxes: see taxes

travel: see travel

U. S. S. R.: 295

vehicle miles traveled: $149,150,154,155,157,158,160-163$, $168-170$

transportation control measures: 22,23, 158, 168-170,305,327, 329

bicycling: 168,170

High Occupancy Vehicle lanes: 22, 155, 168, 170, 329

mass transit: $11,17,21,22,149,155-157,161,163,164,169$, $170,318,319,320,324$

parking management: $11,22,149,155,156,160-162,164$, $168-170,318,324,329$

ridesharing, vanpools: $11,22,149,155,161,162,164,168$, 170, 324,329

telecommuting: $22,149,169,170,327,329$

trafficflow: $11,17,22,155,164,169,170,318,319,324$

travel

air: $149,150,152,154,159,315$

freight: $149,152-154,159,315$

marine: $149,152-154,315$

passenger: $149,150,152,154$

rail: $149,152-154,315$

tree planting, U.S.

also see forests

afforestation: 11, 27-29, 194, 202, 206, 211, 213, 214, 215, $227,319,320,325,327,330$

America the Beautiful Program: 29, 30, 227

$\mathrm{CO}_{2}$ offset, sequestration: 201,202, 205-209,211-216,223, 319 
Conservation Reserve Program: 11,27-30, 201,202,206, $211,213,214,216,225,227,319,325$

Global Releaf Program: 228

reforestation: 28, 38, 194, 201, 202, 210, 226, 305

Shelterbelt Program: 213

Soil Bank: 214

urban trees: 11,27,29,30, 201, 202,206,215,216,227, 228, $319,320,325$

tropical forests

also see cookstoves, deforestation, forests, shifting cultivation, trade

agroforestry: 201, 202, 216-219, 221, 230, 231, 290

cattle ranching: 32, 38, 202, 217, 220, 228, 244, 264, 275

commercial logging: $38,202,217,221,222,231,232,290$, 291

emissions: 202, 205, 217-220, 223, 287

extent: 204

management: 38, 221, 230-232, 290, 291

"natural" management: 222, 231

nontimber products: 38, 201, 202, 204, 217, 220, 221, 231

plantations: 201,222

policies: $228-232$

reforestation: $217,222,223$

sustainable agriculture: $216,217,219,220,290$

Tropical Forestry Action Plan: 36, 38,203,229,231, 232, 283, 284

troposphere: 249

trucks: see automobiles and trucks

turbines: 12, 25-27, 90, 92, 93, 95, 105, 108, 109, 320, 323

United Kingdom: 7,36,82-83,117,152,153, 165,275,278,279, 284, 297, 300, 301, 303, 305

United Nations

Conference on Environment and Development: 287

Development Program: 36-38,229,283,286,291

Environment Program: 36-38,229,280,283,284, 291

Food and Agriculture Organization: 36, 202, 205, 229,231, 232, 243,263, 265, 283, 292

Industrial Development Organization: 36, 284, 292

Population Fund: 36,40,230, 284, 293, 294

Statistical Commission: 291

World Meteorological Organization: 36

U.S. Department of: see Department of

U.S. Export Council for Renewable Energy: 280,286,287,291, 296

U.S. Fish and Wildlife Service: 212, 213

U.S. Forest Service: 28, 35, 201, 204, 212, 223, 225, 231, 232, 282

below-cost sales: 29,226, 227

Forest Products Lab: 235

research: $28,225,226,231$
State and private forestry: $28-30,225-227$

tropical research centers: 225,231

U.S. Geological Survey: 87

U.S. Trade and Development Program: 34,35, 285,296, 299

U.S. Trade Representative: 34, 35, 87,282,299

U. S. S. R.: 5, 34, 36,68, 81-84,87, 91,94, 119, 121, 127, 150, $152,153,187,204,273-276,282,284,298$

also see individual sectors

emissions: 5, 32, 33, 58, 273, 274, 296

energy efficiency efforts: $121,187,296$

energy use: $32,33,121,154,187,273-276,294-296$

environmental problems: 33, 294, 298

institutional constraints: $33,39,121,294,296-299$

joint ventures: $37,294,297,299-300$

trade: $34,37,187,281,286,294-300$

urbanization: $115,128,155,250,265,277-279$

urban trees: 11, 27, 29, 30, 201, 202, 206, 215, 216, 227, 228, $319,320,325$

utilities: 7, 18,23-27,99, 106-110, 115, 132, 135, 137, 138, 141, $194,218,289,305,319,320,327-330$

also see demand-side management, electricity

powerplant retirement: $98-102,110,320,323$

vanpools, ridesharing: $11,22,149,155,161,162,164,168,170$ variability, climate: $46-48,50-53$

vehicle tax: 167

Veterans Administration: 141

Vienna Convention for the Protection of the Ozone Layer: 283

volcanoes: 47, 51

Volume Average Fuel Economy: 167

water heating: $8,11,17,107,115-117,124,130-134,314,318$, 323,324

Weatherization Assistance Program: 19, 136,328

wetlands: 60

Wilderness Society: 212, 213

windows: $17,107,118-121,123,139,318$

wind power: $18,27,77,80,87,90,99,105,109,126,138,281$, 289, 290,302

World Bank: 37,202,221,229, 276,280,283,291-293

also see multilateral development banks

Energy Sector Management Assistance Program: 38, 283, 291, 292

environmental assessment guidelines: 36, 38, 229, 283, 291

funding: $36,38,39,229,283,291,292,300$

Green Fund: 291, 293

World Climate Research Program: 283,284

World Meteorological Organization: 36,283, 284

World Resources Institute: 232,291

zoning ordinances: $22,135,169,170,265$ 


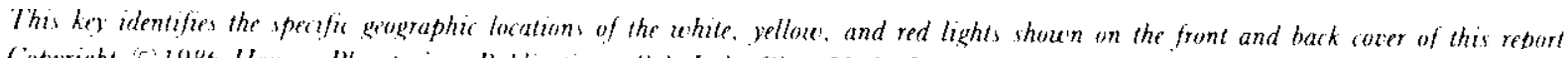

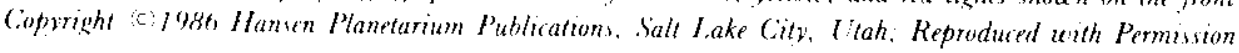

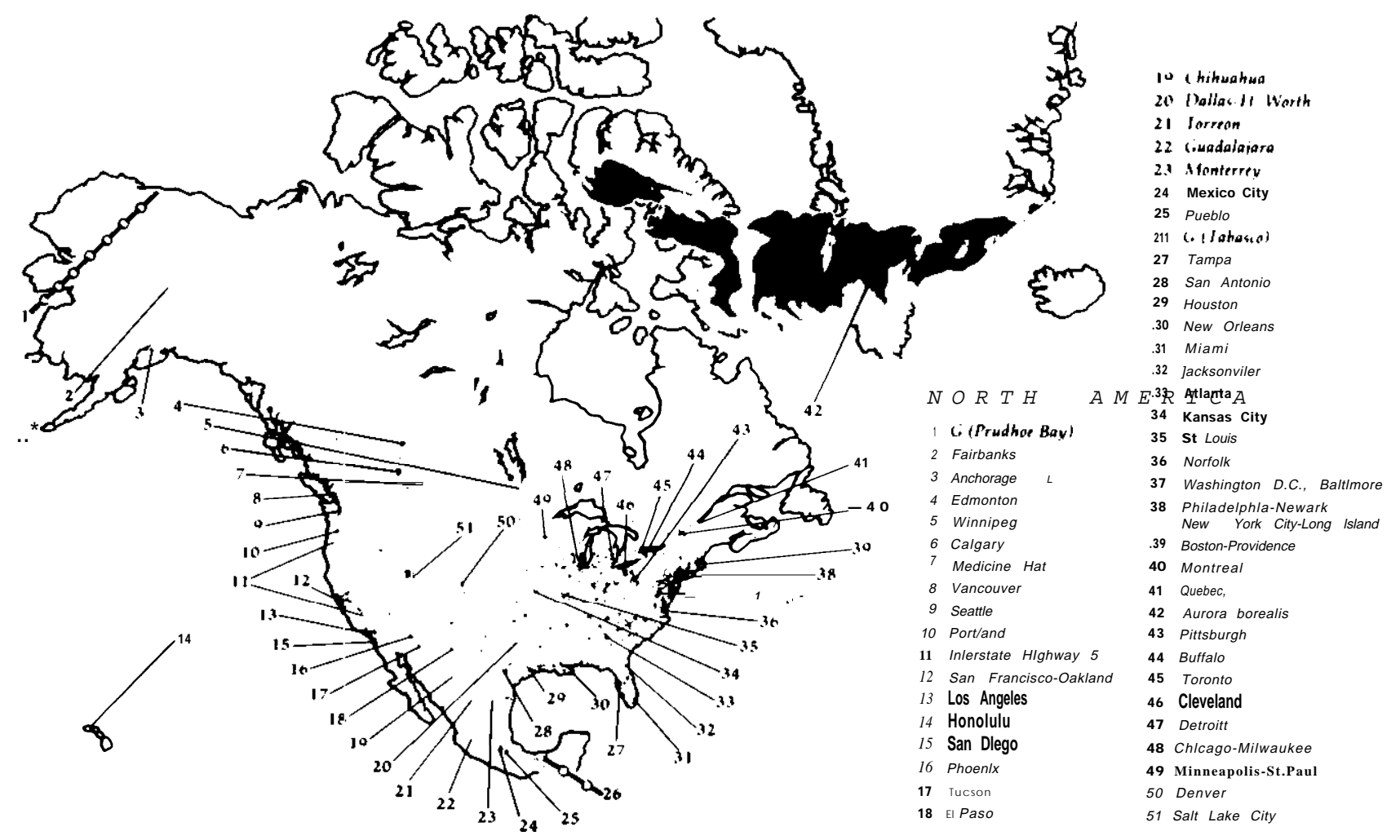

(LNIRAL E SOUIIH AMERICA
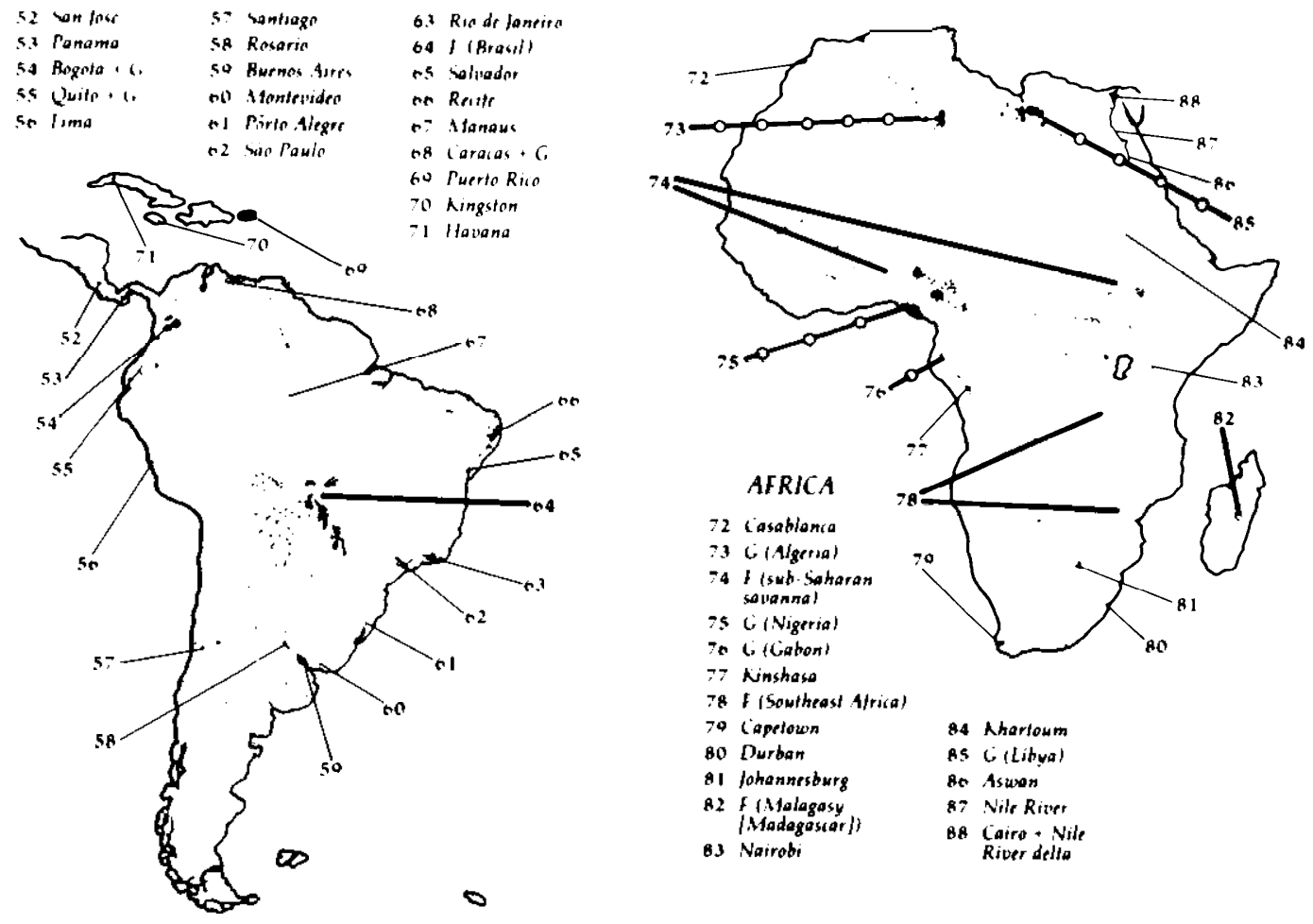

7o 6 (Gabion

7g I (Sowtheast A/rica)

79 capelown

84 Ahartoum

Bo Durban

As 6 (Libya)

1 Iohannesburg

B2 F Malagasy

Bo Asuren

63 Nairobi

87 Nile River

B8 Caira + Nile

$\infty$ 

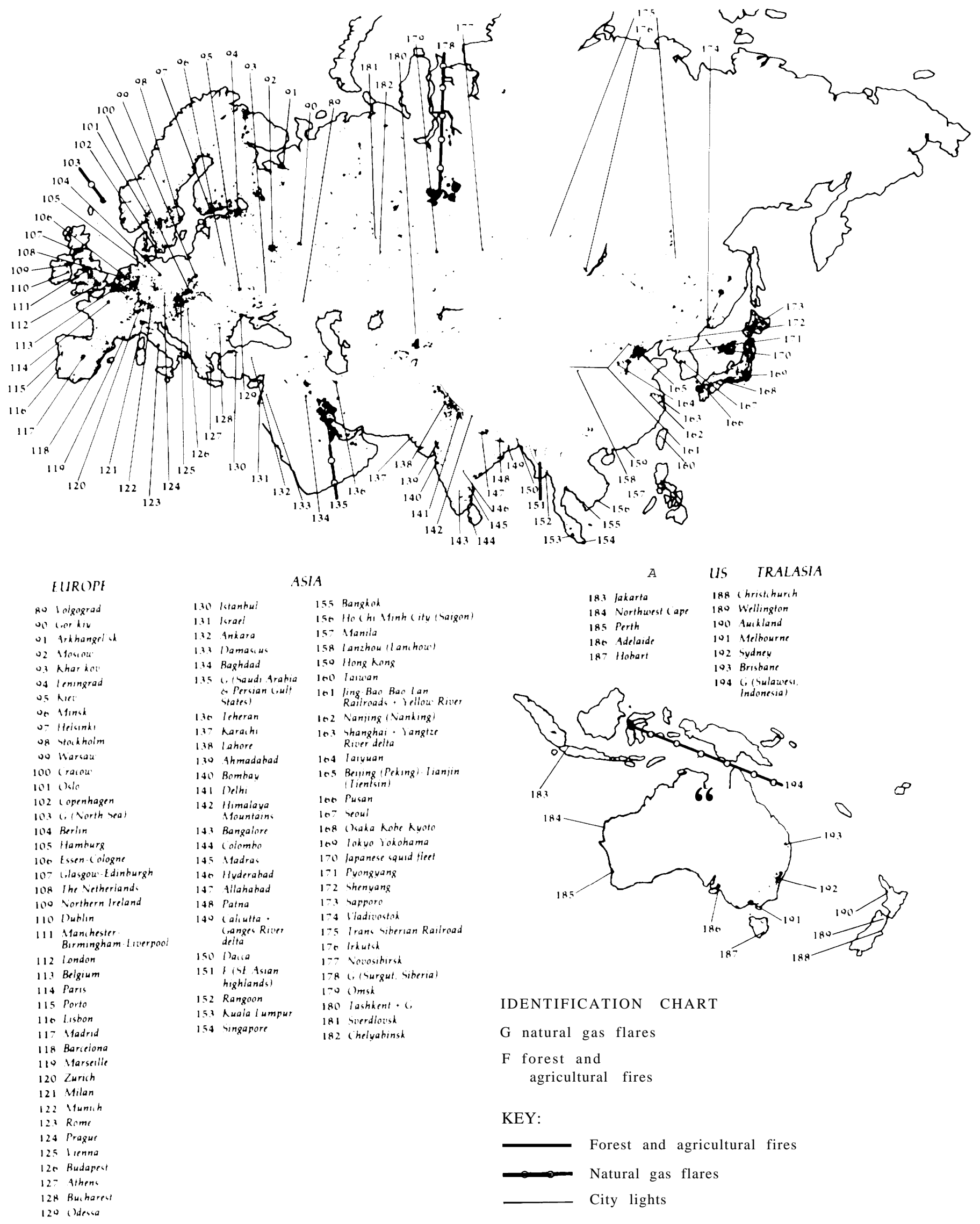

\section{HIIROPE}

go iniggrad

D) Arkhangel at

02 Mosiou

0.3 Khar hos

os lemengrad

05 kiet

0 - Helsink

og rtokhoim

40 Warsas

Manchester.

12 Iondion

13 Belgium

114 Parrs

21 Milan

120 (1)desia

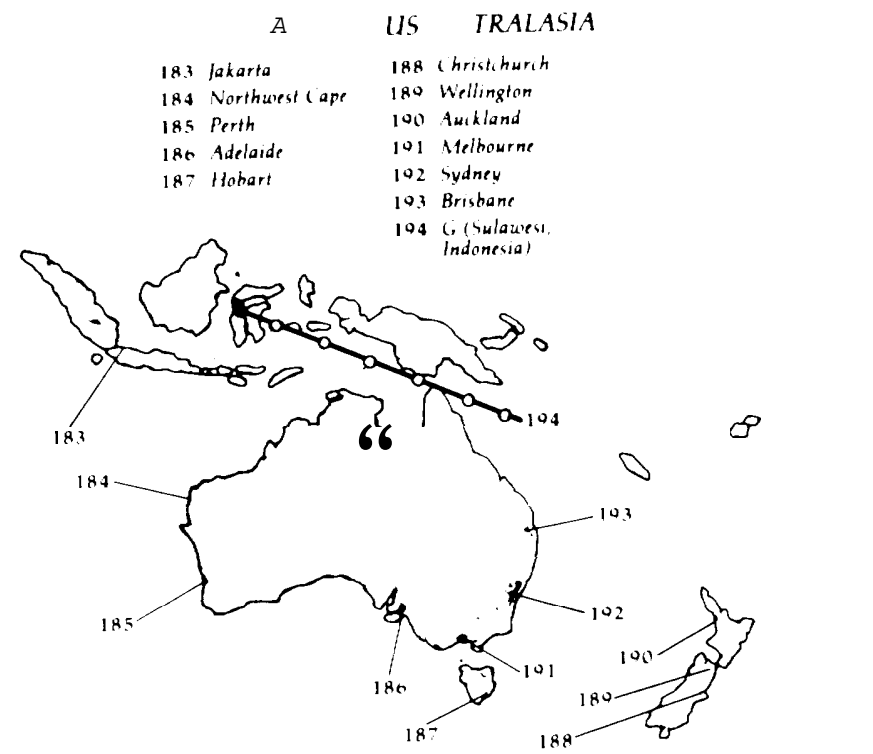

IDENTIFICATION CHART

$G$ natural gas flares

$F$ forest and

agricultural fires

KEY:

Forest and agricultural fires

Natural gas flares

City lights 